\title{
Apollonia du Pont (Sozopol)
}

La nécropole de Kalfata ( $V^{e}-I I I^{e}$ s. av. J.-C.)

\section{Antoine Hermary (dir.)}

DOI : 10.4000/books.pccj. 158

Éditeur : Publications du Centre Camille Jullian, Éditions Errance

Lieu d'édition : Aix-en-Provence

Année d'édition : 2010

Date de mise en ligne : 13 février 2020

Collection : Bibliothèque d'archéologie méditerranéenne et africaine

ISBN électronique : 9782957155743

\section{Qboooks}

http://books.openedition.org

Édition imprimée

ISBN : 9782877724241

Nombre de pages : 300

Référence électronique

HERMARY, Antoine (dir.). Apollonia du Pont (Sozopol) : La nécropole de Kalfata (Ve-IIle s. av. J.-C.). Nouvelle édition [en ligne]. Aix-en-Provence : Publications du Centre Camille Jullian, 2010 (généré le 21

décembre 2020). Disponible sur Internet : <http://books.openedition.org/pccj/158>. ISBN

9782957155743. DOI : https://doi.org/10.4000/books.pccj.158.

(C) Publications du Centre Camille Jullian, 2010

Conditions d'utilisation:

http://www.openedition.org/6540 


\section{$\mathrm{B}$ ibliothèque d'Archéologie \\ Méditerranéenne et Africaine 5}


Dans la lignée des anciens Travaux du Centre Camille Jullian, la Bibliothèque d'Archéologie Méditerranéenne et Africaine (BiAMA) regroupe des travaux (monographie, actes de colloques, ouvrages collectifs) en relation avec les programmes scientifiques du Centre Camille Jullian, sur l'histoire et l'archéologie de la Gaule méridionale, de l'Afrique du Nord et du bassin méditerranéen. La BiAMA peut comprendre des sous-séries, comme la collection Études massaliètes (EtMassa).

\section{Responsable légal :}

Dominique Garcia, Directeur du CCJ

Directeur de la publication :

Henri Tréziny

Comité de pilotage :

Xavier Delestre, Dominique Garcia, Henri Tréziny

Conception graphique et mise en page :

Véronique Gémonet

\section{Comité de lecture :}

Ph. Borgard (CCJ, CNRS), M.-Br. Carre (CCJ, CNRS), X. Delestre (DRAC PACA), D. Garcia (CCJ, Université de Provence), M. Griesheimer (CCJ, Université de Provence), A. Hermary (CCJ, Université de Provence), Ph. Jockey (CCJ, Université de Provence), M. Lombardo (Professeur à l'Université de Lecce), T. S. Loseby (Professeur à l'Université de Sheffield), J.-M. Mignon (Service archéologique départemental du Vaucluse), P. Pomey (CCJ, CNRS), L. Rivet (CCJ, CNRS), J. Sanmarti (Professeur à l'Université de Barcelone), H. Tréziny (CCJ, CNRS), C. Virlouvet (CCJ, Université de Provence), E. Voutiras (Professeur à l'Université de Thessalonique).

(C) 2010 pour tous pays,

Édition Errance, éditeur du groupe Actes Sud,

7 , rue Jean Du Bellay 75004 Paris

Tél. : 0443268582

Fax : 0143293488

Courriel : contact@editions-errance.fr

http://www.libairie-epona.fr

Centre Camille Jullian

Maison Méditerranéenne des Sciences de l'Homme

5 rue du Château de l'Horloge. BP 647, 13094 Aix-en-Provence Cedex 2

ISBN : 978-2-87772-424-1

Illustrations de couverture :

Vue de la côte près d'Apollonia/Sozopol (cl. L. Damelet - CCJ)

En encadré : la tombe SP 340 (cl. K. Panayotova)

Illustration 4ème de couverture :

Hydrie attique à figures rouges, tombe SP 345 (cl. L. Damelet - CCJ)

\section{Publications du Centre Camille Jullian}
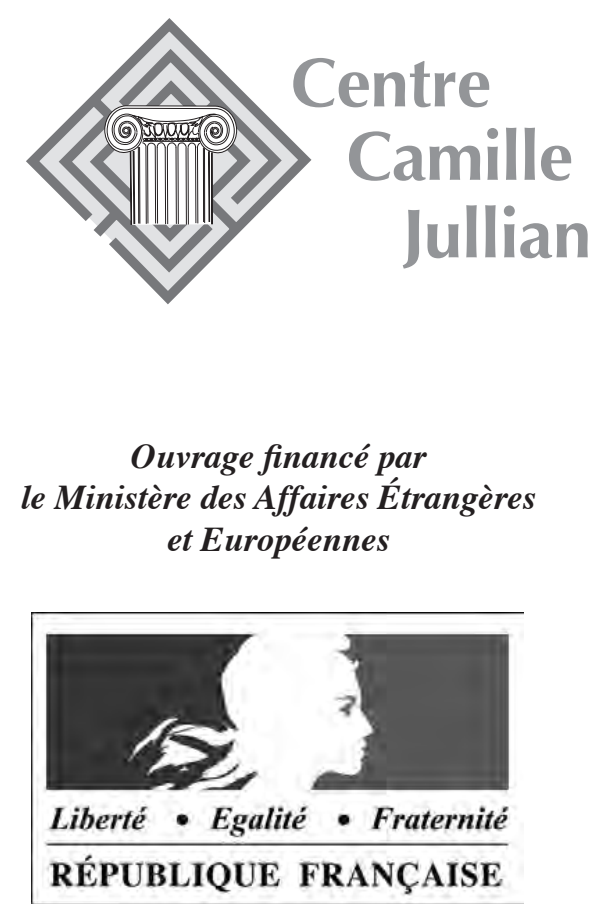

MINISTÈRE DES AFFAIRES
ÉTRANGĖRES

Avec le concours de l'ANR «Pont-Euxin» Géoarchéologie des sites grecs du sud et de l'ouest de la mer Noire

Envoyer les manuscrits à :

Henri Tréziny

Bibliothèque d'Archéologie Méditerranéenne et Africaine

Centre Camille Jullian

Maison Méditerranéenne des Sciences de l'Homme

5 rue du Château de l'Horloge. BP 647,

13094 Aix-en-Provence Cedex 2 


\section{APOLLONIA DU PONT (SOZOPOL) LA NÉCROPOLE DE KALFATA (Ve - III s. av. J.-C.)}

\section{Fouilles franco-bulgares (2002-2004)}

Textes réunis et édités par Antoine HERMARY

\section{Antoine HERMARY, Krastina PANAYOTOVA, Alexandre BARALIS, Margarit DAMYANOV, Atila RIAPOV}

Avec des contributions de Philippe Columeau, Benoît Devillers, Martin Gyuzelev, Anne Keenleyside, Anne-Sophie Koeller, Nick Marriner, Christophe Morhange, Dimitar Nedev, Anne Richier 


\section{Sommaire}

Introduction : (A. Hermary, K. Panayotova)

\section{PREMIÈRE PARTIE : LA TOPOGRAPHIE D'APOLLONIA ET LA NÉCROPOLE DE KALFATA}

Chapitre 1 : Présentation générale de l'histoire et de la topographie d'Apollonia

(A. Baralis, A. Hermary)

Chapitre 2 : Histoire de la recherche archéologique à Apollonia

(K. Panayotova)

Chapitre 3 : Étude géomorphologique des rivages d'Apollonia

(Chr. Morhange, B. Devillers, N. Marriner)

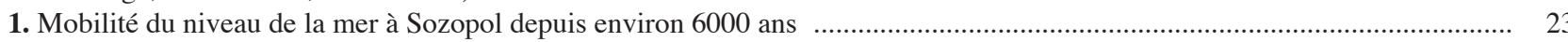

2. Mobilité des lignes de rivage

3. Essai de localisation du port antique protégé d'Apollonia

4. Étude géomorphologique de la nécropole de Kalfata, baie de Harmanité

Chapitre 4 : Présentation de l'espace urbain et du territoire

(D. Nedev, M. Gyuzelev)

\section{Chapitre 5 : Kalfata dans l'ensemble des nécropoles d'Apollonia}

(K. Panayotova)

1. Topographie générale

2. La nécropole de Kalfata, remarques générales

\section{DEUXIÈME PARTIE : LES FOUILLES DE 2002-2004}

Introduction : (A. Hermary)

Chapitre 1 : Stratigraphie et évolution architecturale de l'ensemble du secteur

(A. Riapov, A. Baralis, M. Damyanov, A. Hermary)

1. Phase 1 : Deuxième moitié du $\mathrm{V}^{\mathrm{e}} \mathrm{s}$. av. J.-C.

2. Phase 2 : Premier quart du $\mathrm{IV}^{\mathrm{e}} \mathrm{s}$. av. J.-C

3. Phase 3 : Du deuxième quart à la fin du $\mathrm{IV}^{\mathrm{e}} \mathrm{s}$. av. J.-C.

3.1. Deuxième quart du IV ${ }^{\mathrm{e}} \mathrm{s}$. av. J.-C.

3.2. Deuxième moitié du $\operatorname{IV}^{\mathrm{e}} \mathrm{s}$. av. J.-C.

4. Phase 4 : Première moitié du III ${ }^{\mathrm{e}} \mathrm{s}$. av. J.-C.

5. Remarques générales

Chapitre 2 : Descriptions des tombes, dépôts et foyers

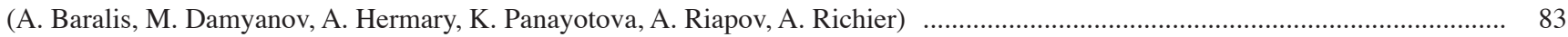

1. Description des tombes

1.1. Sépultures à crémation

1.2. Sépultures à inhumation

2. Inventaire des dépôts (DP 1 à 20 et 35 fouilles bulgares; DP 21 à 34, fouilles françaises)

3. Inventaire des objets trouvés dans les foyers (F 1 à $\mathrm{F} 11)$ 


\section{TROISIÈME PARTIE : SYNTHÈSES}

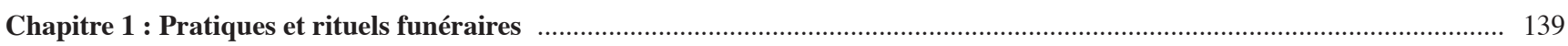

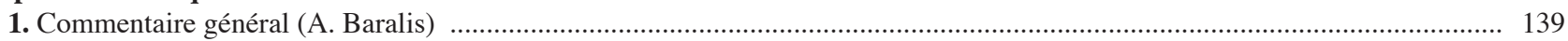

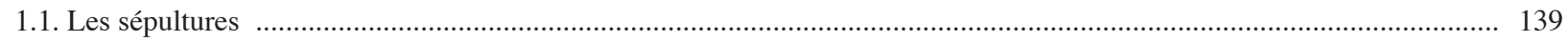

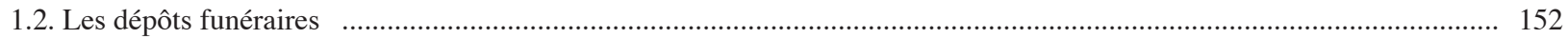

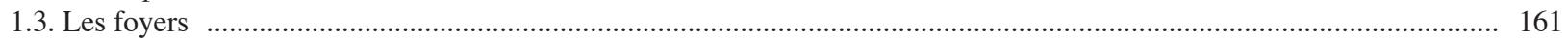

2. Remarques complémentaires sur certains aspects des rituels funéraires (A. Hermary), avec un rapport de Ph. Columeau

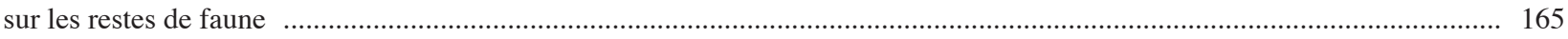

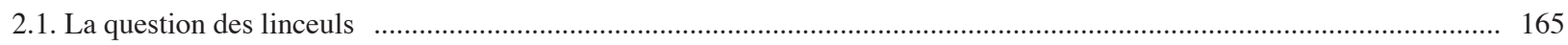

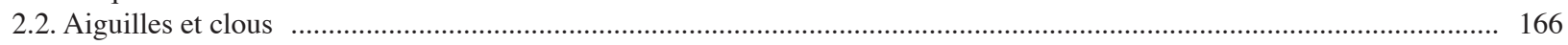

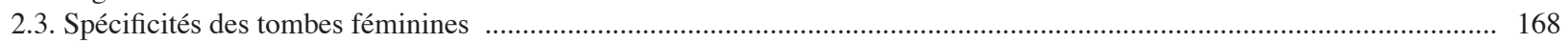

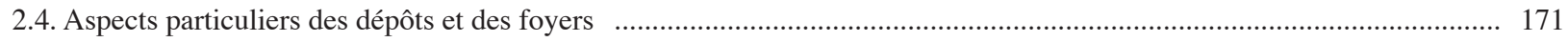

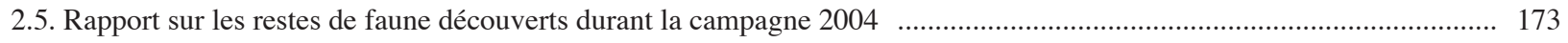

3. Les sépultures d'enfants étudiées dans un contexte plus large (A.-S. Koeller) …........................................................... 173

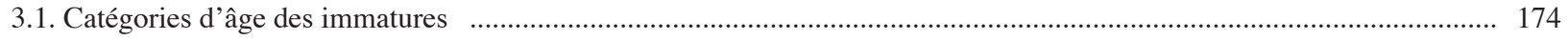

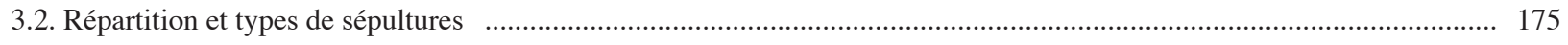

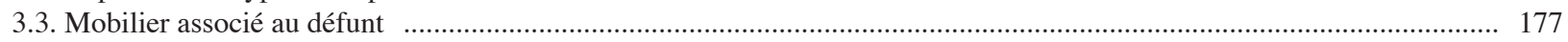

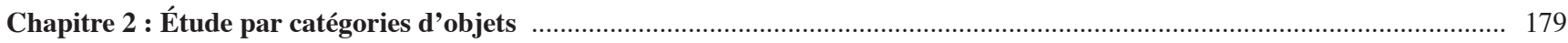

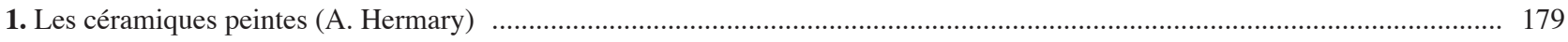

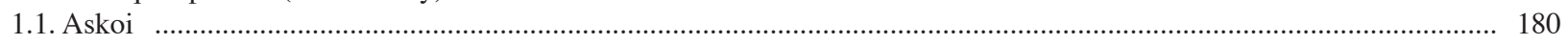

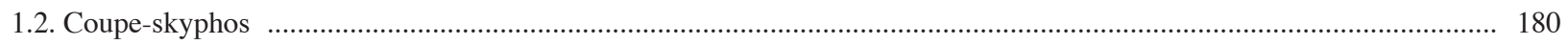

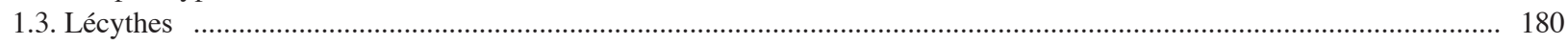

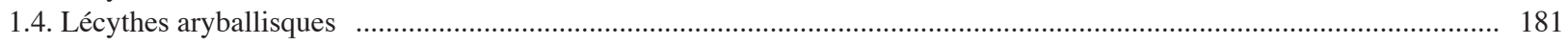

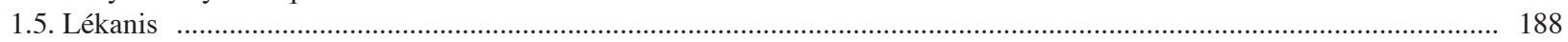

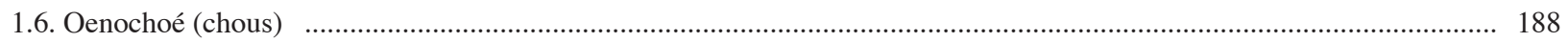

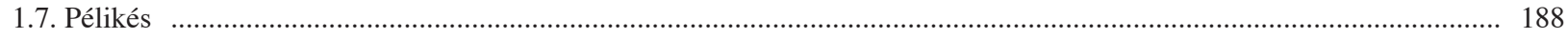

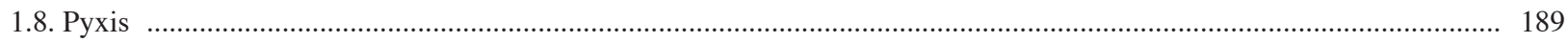

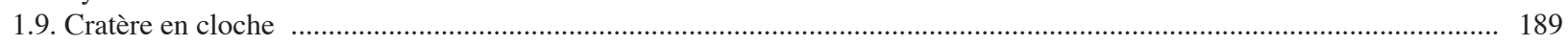

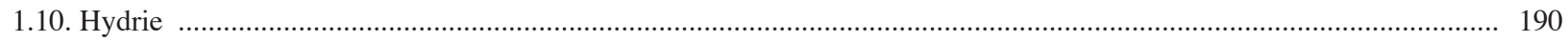

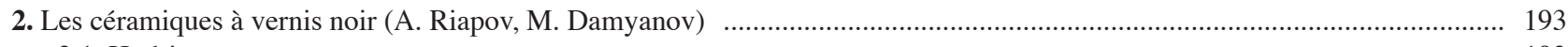

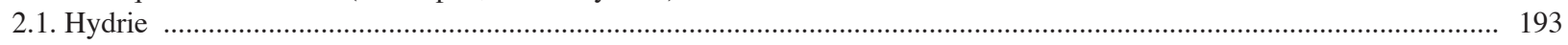

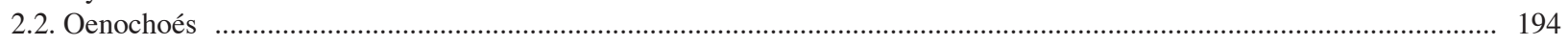

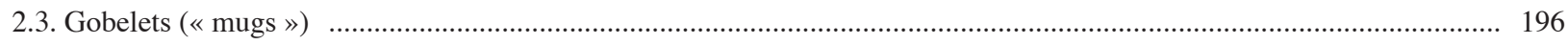

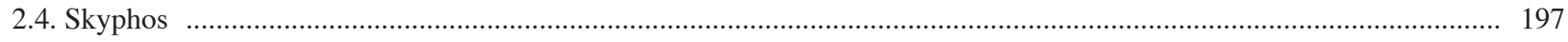

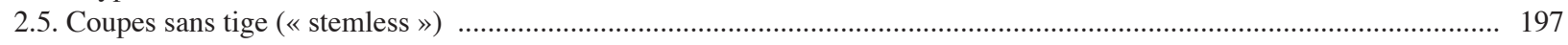

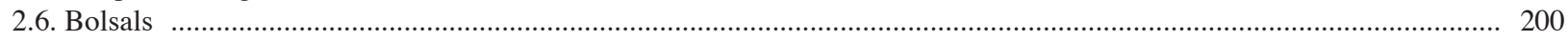

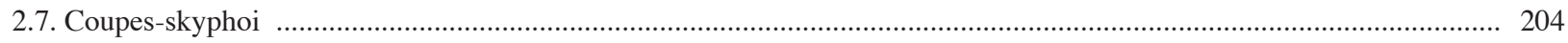

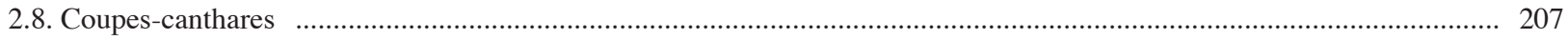

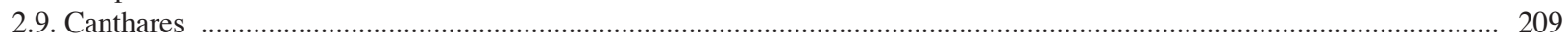

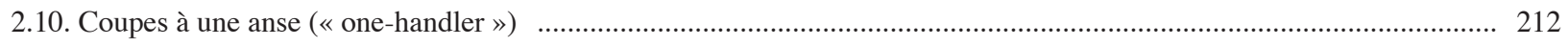

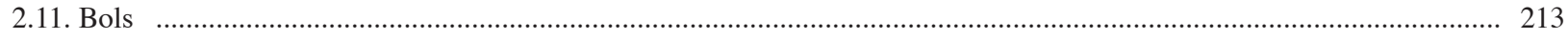

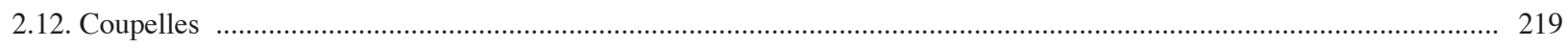

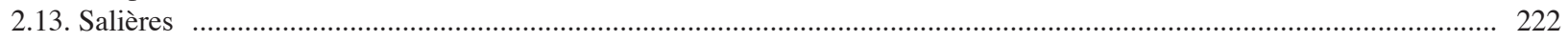

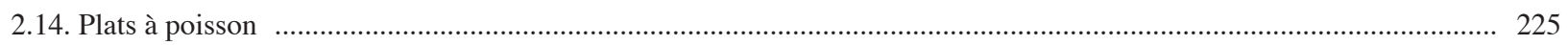

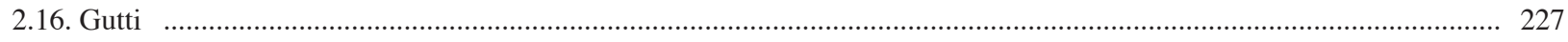

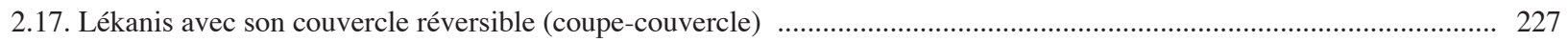

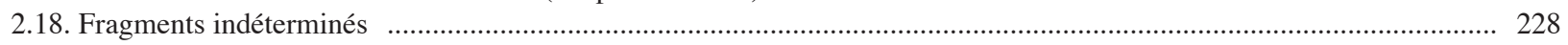

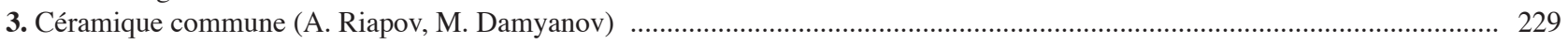

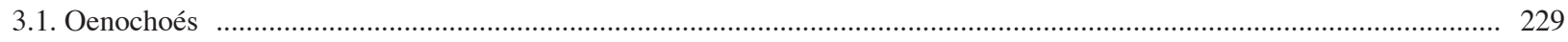

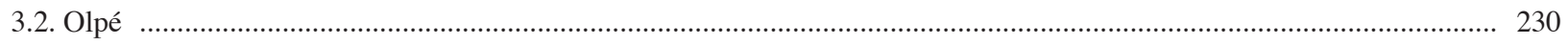

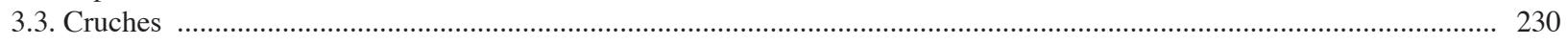

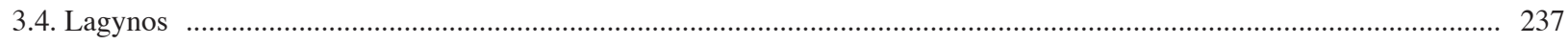

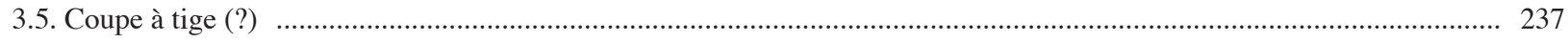

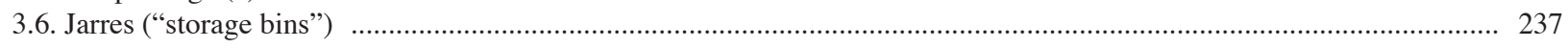

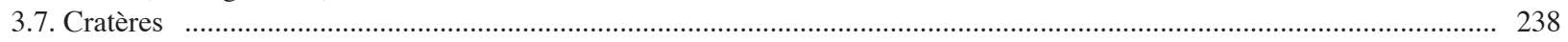

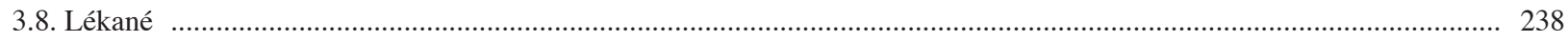

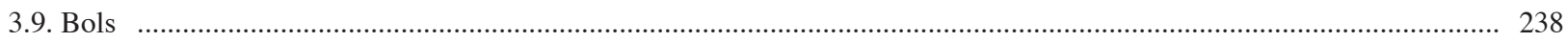

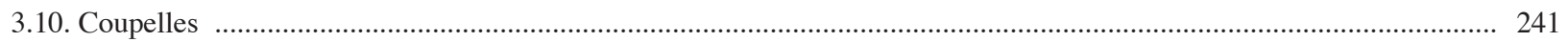


3.11. Plats à poisson

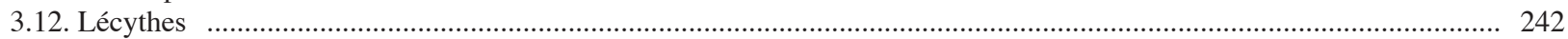

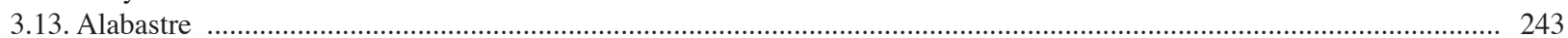

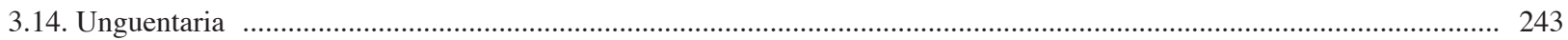

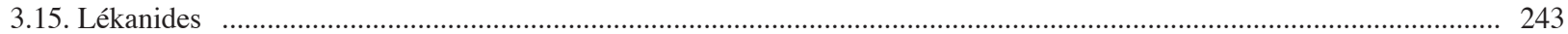

3.16. Couvercles

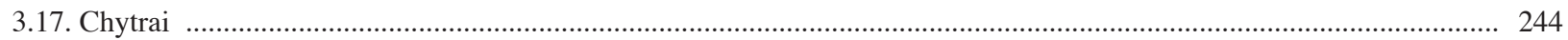

4. Figurines et objets divers en terre cuite, vase plastique (K. Panayotova, A. Hermary) …............................................ 247

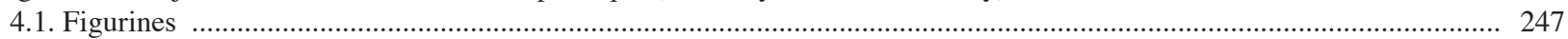

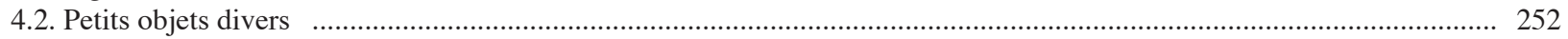

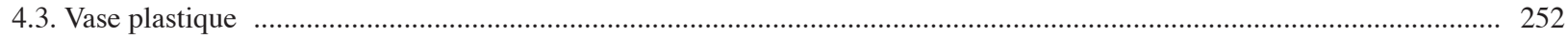

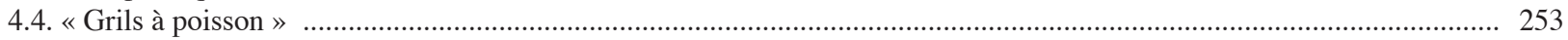

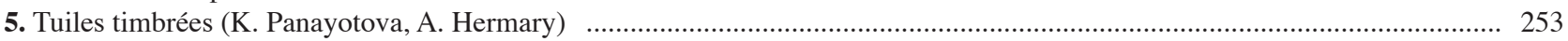

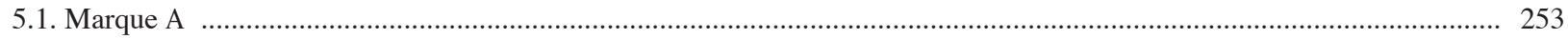

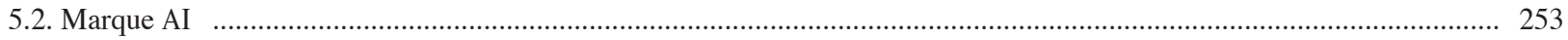

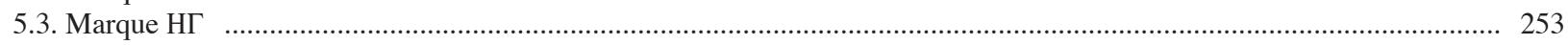

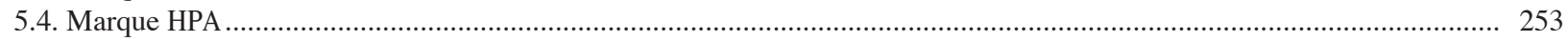

5.5. Marque $\mathrm{OEO}$

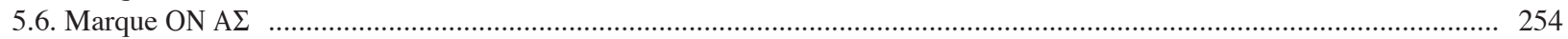

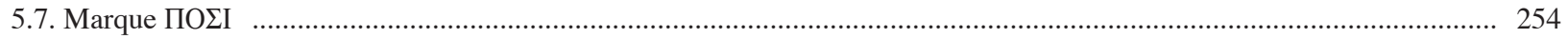

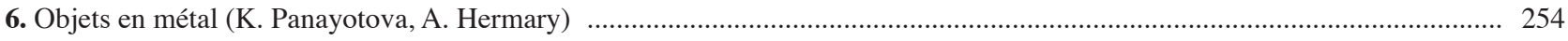

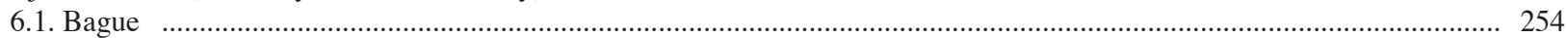

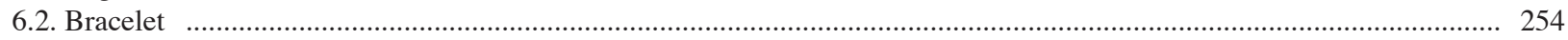

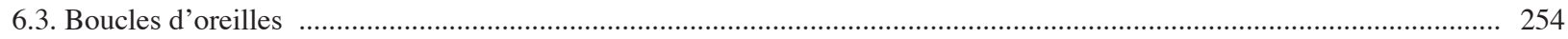

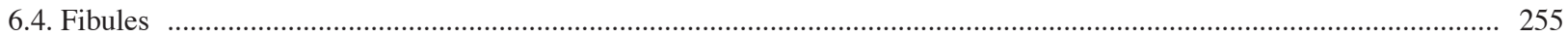

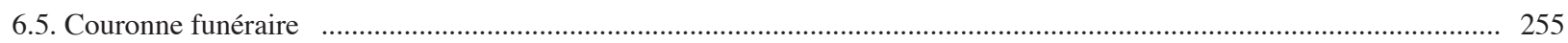

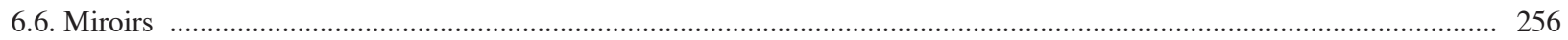

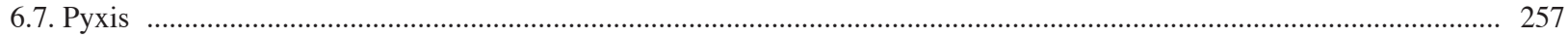

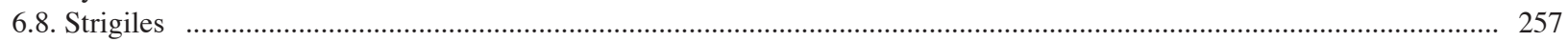

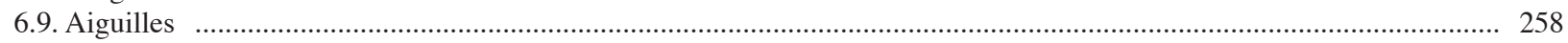

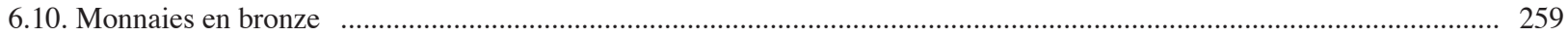

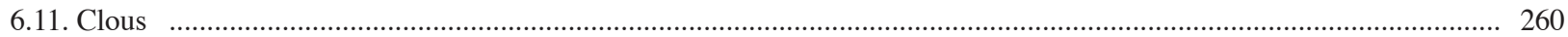

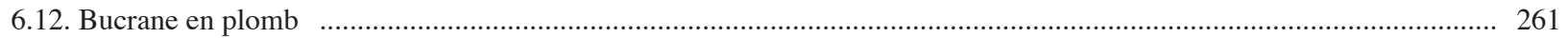

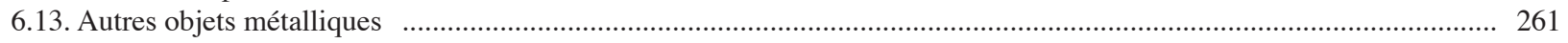

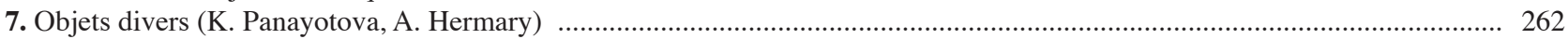

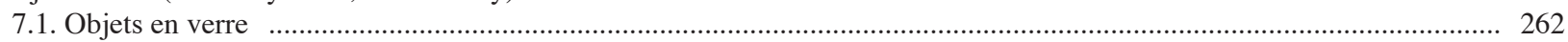

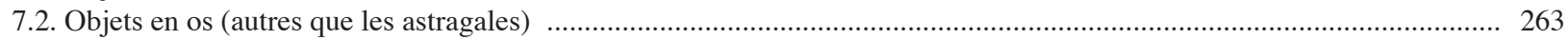

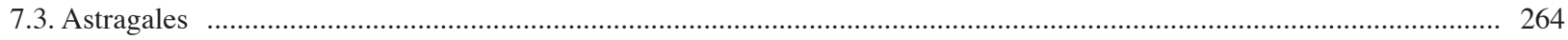

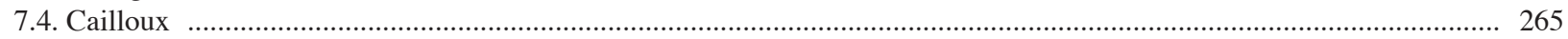

Appendice : A Bioarchaeological Study of the Kalfata Necropolis (A. Keenleyside) ............................................................ 267

Bibliographie

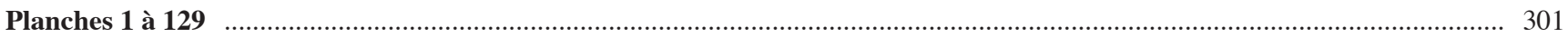




\section{Introduction}

Le projet de ces recherches communes dans la nécropole de Kalfata, la plus étendue de la cité d'Apollonia du Pont et, pour l'époque classique et le début de l'époque hellénistique, une des plus importantes de toutes les colonies grecques de mer Noire, remonte à l'année 2001. Il est dû à Alexandre Baralis et Atila Riapov, alors jeunes doctorants à l'université d'Aix-Marseille I et au Centre Camille Jullian, qui avaient participé cette année-là aux fouilles dirigées par Krastina Panayotova et Dimitar Nedev dans la nécropole de Kalfata ${ }^{1}$, après avoir travaillé précédemment avec la mission de l'École française d'Athènes, dirigée par Véronique Chankowski, sur le site de Pistiros. Antoine Hermary, directeur des thèses de Baralis et Riapov, fut rapidement convaincu de l'intérêt du projet - malgré son inexpérience de l'archéologie en mer Noire - et une première convention fut mise en place entre le CNRS et l'Académie Bulgare des Sciences pour un début des recherches communes en $2002^{2}$. Les institutions directement responsables étaient, en Bulgarie 1'Institut Archéologique de Sofia, en France le Centre Camille Jullian d'Aix-en-Provence (UMR 6573 du CNRS) : K. Panayotova assurait la direction du chantier du côté bulgare, en collaboration avec D. Nedev, directeur du musée archéologique de Sozopol ${ }^{3}$, et A. Hermary du côté français, assisté par A. Baralis et A. Riapov. Un secteur consacré aux fouilles communes, d'environ $300 \mathrm{~m}^{2}$, fut défini au sein de la vaste nécropole qui s'étend en bord de mer, au Sud de la ville moderne de Sozopol, zone dans laquelle des fouilles avaient été reprises par l'Institut archéologique bulgare en 1992 (dir. K. Panayotova), soit une trentaine d'années après la publication de celles menées dans la nécropole de Kalfata, après la deuxième guerre mondiale, sous la direction d'Ivan Venedikov.

Pour la première campagne, le financement de la mission française a été dû principalement au CNRS et au Centre Camille Jullian/Université de Provence, avec une aide du Centre Culturel français à Sofia. Ces moyens relativement limités n'ont pas permis de constituer une équipe étendue : seuls deux autres étudiants d'Aix, Stéphane Abellon et Anne-Sophie Koeller, ont participé aux fouilles qui ont duré du 26 août au 17 septembre 2002. Les bons résultats de ces premières recherches ont permis d'obtenir, pour l'année 2003 (fouilles du 18 août au 13 septembre), un important financement complémentaire de la part de la Commission des Fouilles auprès du ministère français des Affaires Étrangères : cette aide financière a été renouvelée jusqu'en 2007. Il a donc été possible de constituer une équipe plus importante, dont faisaient partie, en plus des jeunes chercheurs déjà mentionnés et de deux autres étudiants aixois (Lise Damotte et Assia Veleva), Anne Richier, archéo-anthropologue à l'INRAP, et Bruno Baudoin, topographe et infographiste. Par ses observations de terrain, A. Richier a complété les études anthropologiques de laboratoire que menait déjà Anne Keenleyside, anthropologue à l'université de Trent (Canada), au sein de l'équipe bulgare. De son côté, B. Baudoin a levé un plan de la zone fouillée qui est à la base de l'ensemble des relevés présentés dans la publication ${ }^{4}$. Les recherches de terrain ont été poursuivies en 2004 (fouilles du 9 août au 4 septembre), elles ont permis de terminer la fouille de la zone réservée dans le cadre du projet franco-bulgare. La démarche et l'apport scientifiques de ces recherches ont été récompensés, en 2004, par l'obtention du premier prix Clio pour la recherche archéologique française à l'étranger.

1 Atila Riapov avait déjà fouillé sur le site au cours de campagnes précédentes.

2 Cette convention, renouvelée jusqu'en 2005, a permis la venue en France, pour un séjour de recherche annuel d'un mois, de plusieurs collègues bulgares en plus de Krastina Panayotova : Margarit Damyanov, Martin Gyuzelev et Dimitar Nedev.

3 Nous tenons à lui adresser tous nos remerciements pour l'aide qu'il nous a apportée lors des études dans le musée. Sur le terrain, M. Damyanov a joué un rôle prépondérant, à la fois dans la fouille (équipe bulgare) et dans les relevés pour l'ensemble de la mission. Nous remercions aussi Rositza Pencheva, assistante de K. Panayotova dans l'équipe bulgare.

4 Cette mission a été réalisée avec l'aide du Laboratoire d'Archéologie Médiévale Méditerranéenne (LAMM) d'Aix-en-Provence. Vanessa Py, doctorante rattachée au même laboratoire, a d'autre part réalisé les analyses anthracologiques d'échantillons de charbons de bois trouvés en 2003 et 2004. Ont également participé aux fouilles, de façon plus limitée, Frédéric Barbero, Vincent Bignani, Vincent Cuche et Denitza Svilenova. Andréi Mladenov a réalisé un certain nombre de dessins sur le terrain. 
Ce sont principalement les résultats de ces fouilles des campagnes 2002-2004 qui sont publiés ici, portant sur 56 tombes s'échelonnant sur deux siècles environ, de la deuxième moitié du $\mathrm{V}^{\mathrm{e}} \mathrm{s}$. au milieu du $\mathrm{III}^{\mathrm{e}} \mathrm{s}$. av. J.-C., avec les foyers et les dépôts extérieurs qui leur sont associés. Cet ensemble, représentatif des pratiques funéraires des Apolloniates à cette époque, s'inscrit dans un cadre architectural intéressant, qui marque la limite Nord des périboles mis au jour lors des fouilles précédentes. La préparation de la publication a suscité plusieurs missions d'études en 2005-2007 5 , auxquelles se sont joints Loïc Damelet, photographe du Centre Camille Jullian - dont il faut souligner ici le rôle essentiel pour notre ouvrage - et une équipe de géographes et géomorphologues du CEREGE/Université de Provence, sous la direction de Christophe Morhange : il nous a paru important de l'associer à nos recherches pour mieux placer la nécropole de Kalfata dans le cadre de l'évolution géomorphologique du site antique d'Apollonia. Cette ouverture vers une histoire plus générale de l'ancienne colonie milésienne s'exprime également, dans la première partie de notre ouvrage, par une présentation des découvertes récentes dans l'espace urbain - recouvert par la moderne Sozopol - et le territoire d'Apollonia, par D. Nedev et Martin Gyuzelev (conservateur au musée de Bourgas). La présentation des recherches sur le terrain et l'inventaire des sépultures, dépôts et foyers constituent la partie centrale de l'ouvrage : il nous a été possible de déterminer, de façon relativement précise, l'évolution de ce secteur au cours des deux siècles de son occupation et de tirer, dans la troisième partie, un certain nombre de conclusions sur les pratiques funéraires des Apolloniates. Le dernier chapitre regroupe des études synthétiques sur les principales catégories de matériel, dont l'ampleur est différente d'un ensemble à l'autre. Il nous a paru préférable de placer en appendice l'étude bio-archéologique d'A. Keenleyside, qui dépasse assez largement les limites des fouilles effectuées en commun.

Notre publication a pour but de rendre compte, dans les meilleurs délais possibles, d'un type de collaboration dont les exemples sont peu nombreux dans notre domaine de recherche et, malgré le caractère limité de nos recherches sur le terrain, de présenter une documentation et des commentaires qui pourront servir de base à des études plus approfondies sur les colonies grecques de Thrace pontique.

Nous souhaitons adresser tous nos remerciements aux institutions qui, en France et en Bulgarie, ont permis la réalisation de ce projet commun de recherche, en premier lieu le Centre Camille Jullian et le Ministère des Affaires Étrangères dont le rôle a été essentiel pour les fouilles, la préparation de la publication et la publication elle-même, co-financée par les deux institutions. Il faut ajouter la part importante prise par le CNRS, non seulement à l'origine et dans les premières années du projet, mais par l'attribution à K. Panayotova, en 2008, d'un contrat d'étude de six mois à Aix-en-Provence, destiné à la rédaction de la publication.

Une publication qui associe une quinzaine de chercheurs répartis entre Aix, Sofia, Sozopol et Trent, et qui ont écrit dans des langues différentes, pose des problèmes qu'il n'est pas nécessaire de détailler: si nous avons conservé en anglais le texte d'A. Keenleyside, nous voudrions remercier, pour leur travail de traduction du bulgare en français, Iva Chirpanlieva et A. Riapov. La réalisation technique de cet ouvrage est due à Véronique Gémonet (CCJ) que nous remercions pour sa disponibilité et son efficacité dans des conditions de travail difficiles, ainsi que Guergana Guionova pour la vérification de la bibliographie bulgare. Le travail préparatoire sur l'illustration a été effectué par A.-S. Koeller et V. Gémonet, la mise au point finale est due à Vincent Dumas aidé par A. Baralis qui a également joué un rôle essentiel d'intermédiaire entre A. Hermary, responsable de l'édition, et les chercheurs résidant à Sofia, et qui a pris en charge sur les crédits de son ANR «Pont-Euxin » la partie en couleur des planches.

\section{A. Hermary, K. Panayotova}

5 Pour des raisons administratives, il n'a malheureusement pas été possible de faire revenir Anne Richier à Sozopol. 
Première Partie

\section{LA TOPOGRAPHIE D'APOLLONIA ET LA NÉCROPOLE DE KALFATA}

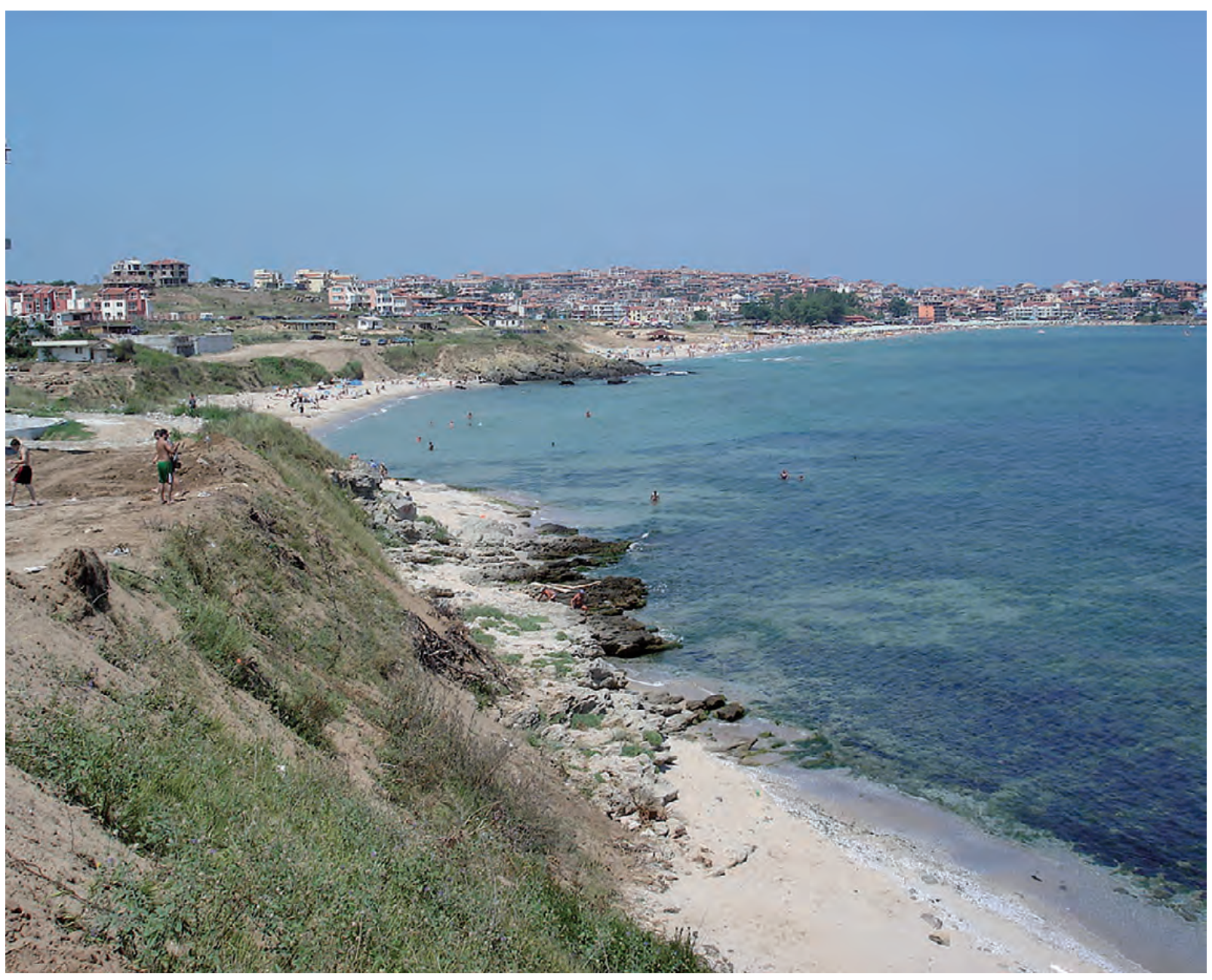

Vue, depuis Boudjaka, sur Kalfata, le quartier de Harmanité et la ville de Sozopol (Photo L. Damelet). 



\section{Chapitre 1}

\section{Présentation générale de l'histoire et de la topographie d'Apollonia}

$\mathrm{S}$ elon le Périple du Pseudo-Skylax (§ 67), Apollonia était la première cité grecque que rencontrait le voyageur le long du littoral occidental de la mer Noire (fig. 1). Cette situation privilégiée était la conséquence du caractère inhospitalier que présente la côte, de l'embouchure du Bosphore jusqu'aux environs de la ville moderne de Kiten : falaises abruptes et hauts-fonds rocheux se succèdent, favorisant les naufrages dans le cadre d'une navigation alors essentiellement côtière. Ces accidents représentaient pour les tribus thraces une manne économique inespérée qu'elles exploitaient grâce à un système de bornage original dont Xénophon (Anabase, VII, 5, 12-14) est le témoin lors de son séjour à Salmydessos ${ }^{1}$. Apollonia n'était pourtant pas, à proprement parler, le seul port que croisaient les vaisseaux au cours d'une navigation estimée par Arrien (Périple du Pont-Euxin, 24) à 1.440 stades $^{2}$. Cette dernière source, de même que Ptolémée (Géographie, III, 11, 3), nous renseigne sur l'existence d'une série d'autres établissements (Chersonésos, Tonzos, Peronticon, Aulaiou Teichos) qui jalonnaient, au II ${ }^{\mathrm{e}}$ s. ap. J.-C., la côte comprise entre Apollonia et le cap Thynias (aujourd'hui Ineada). Bien que l'histoire et, souvent, l'identification de ces différents établissements demeurent encore incertaines, les données archéologiques confirment la fréquentation par des marchands grecs, dès l'époque archaïque, de l'embouchure du fleuve Ropotamo, ainsi que des baies de Kiten et d'Ahtopol ${ }^{3}$. Plus que des mouillages destinés à une navigation au long cours, les sites portuaires localisés à ces endroits devaient constituer des lieux d'échanges avec les populations locales, chacun étant inscrit dans des réseaux régionaux de commerce.

1 Strabon (VII, 6, 1) insiste également sur l'aspect hostile de cette portion du littoral, qu'il qualifie de rocheuse et de déserte, et précise, non sans un certain décalage chronologique, que ces populations thraces appartiennent au groupe des Astes.

2 Soit environ $225 \mathrm{~km}$, si la valeur retenue du stade est de $177 \mathrm{~m}$ : De Boer, Stronk 2000-2001, p. 233.

3 Dimitrov, Porojanov, Orachev 1982, p. 450-454; Karayotov 1990 et 1992 ; Karayotov 2002, p. 558-564 ; De Boer, Stronk 20002001, p. 235-236 ; Gyuzelev, in Nedev, Panayotova 2003, p. 110-113.
À une toute autre échelle, Apollonia, distante d'une journée et une nuit de navigation de Byzance ${ }^{4}$, semble idéalement placée sur les routes maritimes conduisant aux colonies du littoral septentrional de la mer Noire. Le site de la ville antique, couvert par les vestiges de l'agglomération médiévale et ottomane de Sozopol, est situé à environ trente kilomètres au Sud-Est de Bourgas. Il se présente de nos jours sous les traits d'une longue péninsule connue sous le nom de Skamni (fig. 2). Dotée d'un des meilleurs ports de la toute la côte occidentale de la mer Noire, Apollonia contrôlait l'entrée méridionale du vaste golfe de Bourgas, dont les profondes articulations, abritant de nombreux mouillages, les plaines fertiles, les collines boisées et les riches gisements miniers devaient constituer un attrait majeur pour les premiers colons ioniens ${ }^{5}$.

Les circonstances qui entourent la fondation de la cité demeurent encore mal connues. Le Pseudo-Skymnos (§ 730-733), qui puise ses informations dans l'œuvre de Démétrios de Callatis, place cet événement 50 ans avant l'arrivée au pouvoir de Cyrus, soit autour de 610-609 av. J.-C., mais Elien (Histoires variées, III, 17) précise, à une date plus tardive, qu'Anaximandre a participé luimême à cette aventure. Or la naissance du philosophe est datée par Diogène Laërce (II, 2) à peu près dans ces mêmes années. Cette seconde tradition, si elle était acceptée, reviendrait à abaisser d'une génération la fondation de la cité, ce que les fouilles archéologiques conduites dans la ville permettent désormais d'infirmer ${ }^{6}$. Malgré la chronologie haute de sa fondation et en dépit de sa position géographique, il est à présent certain qu'Apollonia n'appartient pas au premier groupe de fondations grecques en mer Noire, qui rassemble quatre

4 Estimation avancée par J. De Boer et J. P. Stronk sur la base des distances contenues dans le Périple d'Arrien, ainsi que sur les indications fournies par Hérodote sur le temps de parcours des navires : De Boer, Stronk 2000-2001, p. 233.

5 Au sujet des avantages que présentait la situation géographique d'Apollonia, voir Danov 1947, p. 122-123 ; Isaac 1986, p. 242-243.

6 Cf. Nedev, Panayotova 2003, p. 99 ; Nedev, Giuzelev, sous presse. 


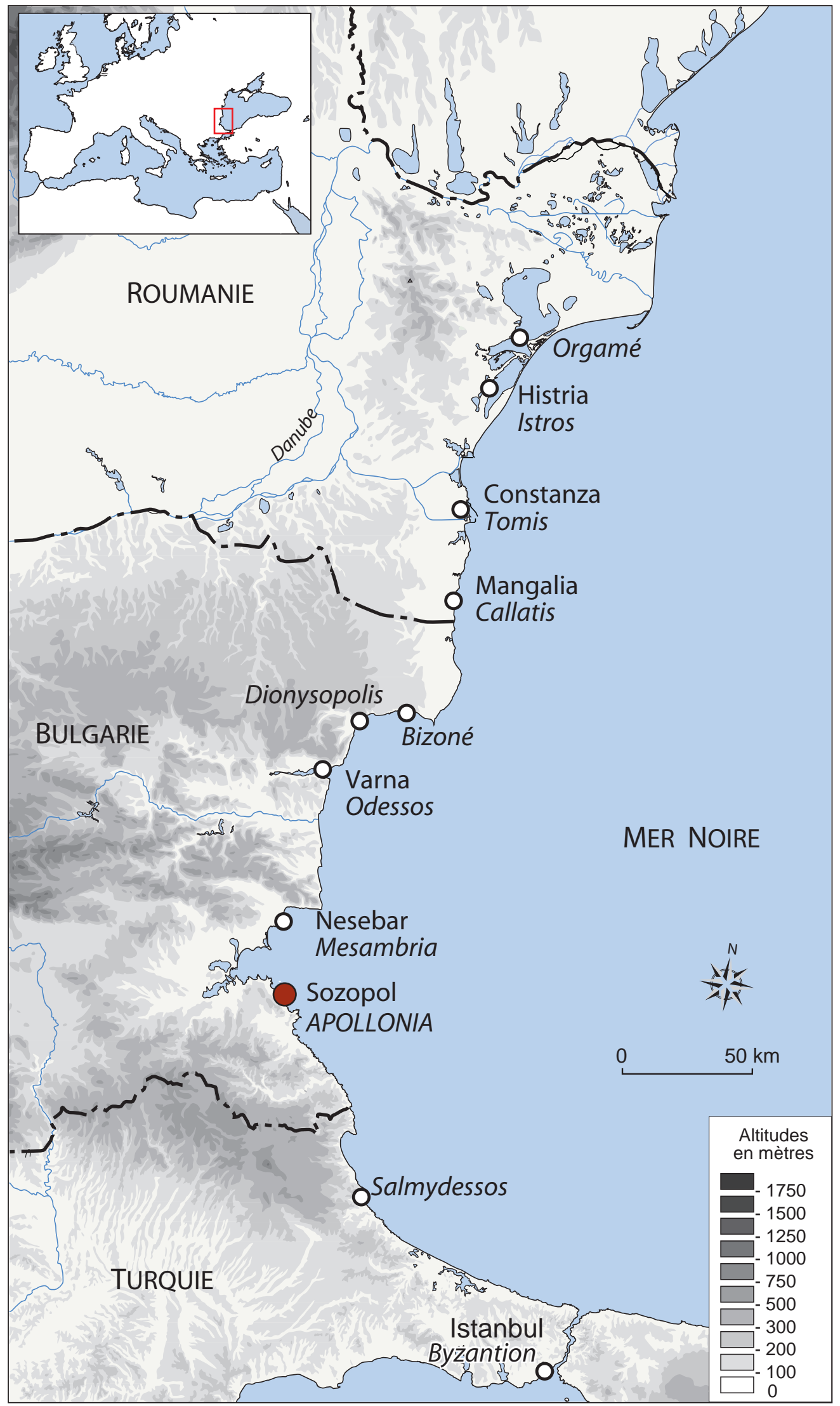

Fig. 1. Les colonies grecques du littoral occidental de la mer Noire. Les noms antiques sont en italiques (DAO P. Pentsch). 


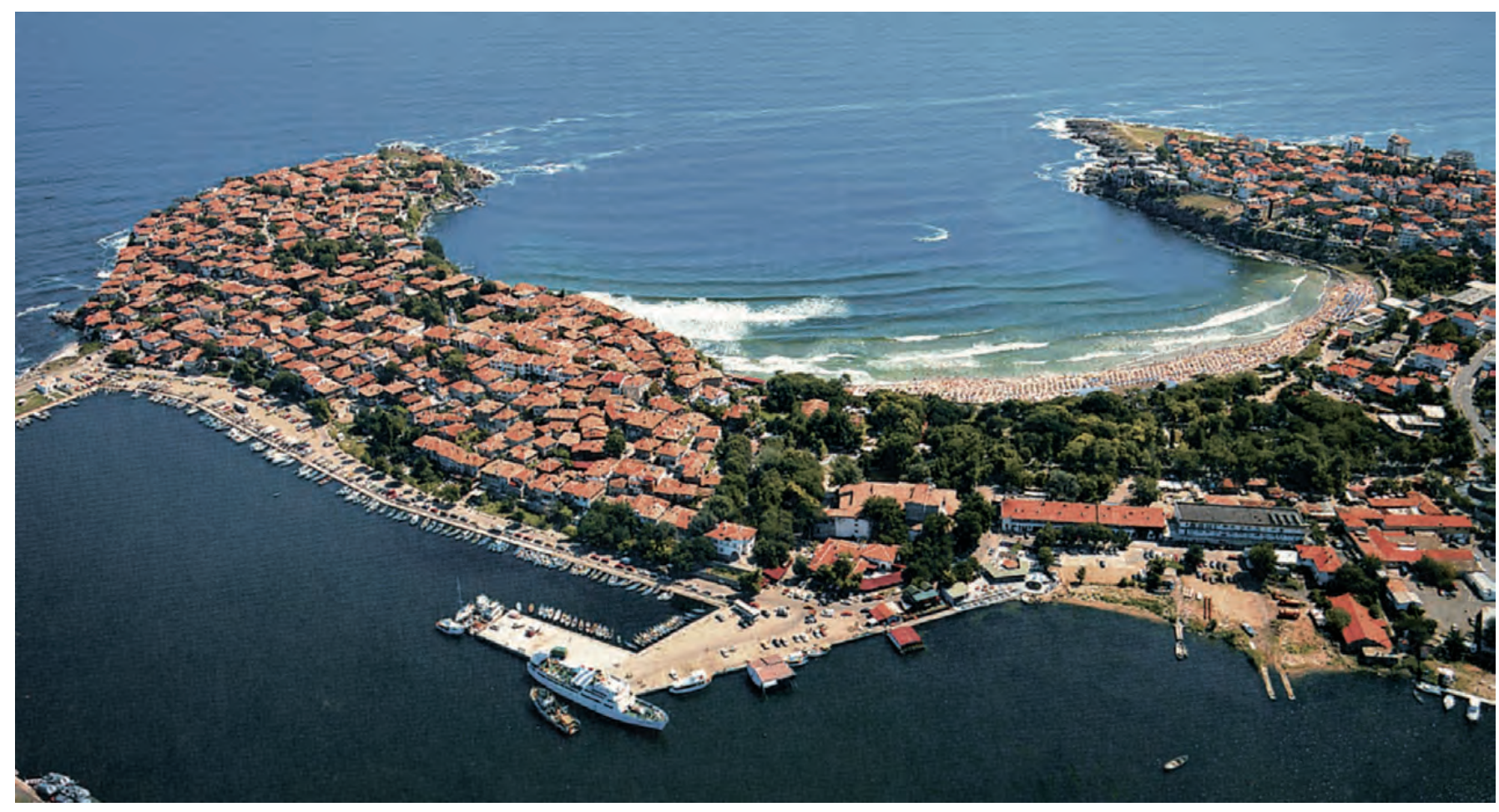

Fig. 2. La péninsule de Skamni, site principal de la ville antique (๑ Larus Ltd.).

établissements des côtes Nord et Nord-Ouest (Istros, Orgamé, Berezan et Olbia) ${ }^{7}$.

Strabon (VII, 6, 1), le Pseudo-Skymnos et Élien présentent Apollonia comme une colonie de Milet, confortant ainsi l'image de « lac milésien» de la mer Noire, mais Étienne de Byzance (s. v. 'A $\pi 0 \lambda \lambda \omega v i ́ \alpha)$ indique que la ville fut fondée conjointement par Rhodes et Milet $^{8}$. Même si l'origine milésienne de plusieurs cultes de la cité ne fait pas de doute ${ }^{9}$ et si l'onomastique est fortement marquée par celle de la métropole ${ }^{\mathbf{1 0}}$, cette

7 Dupont 2007, p. 29-31; Koshelenko 2007, p. 23. Plusieurs traditions s'affrontent en revanche autour de Sinope, et l'absence de fouilles ne permet pas de trancher : Hind 1995, p. 30.

8 Selon le même auteur (s. v.'Av $\theta \varepsilon i ́ \alpha)$, sa voisine Antheia aurait été fondée sur une initiative commune des Phocéens et des Milésiens. L'association de plusieurs cités, sous l'impulsion de l'une d'entre elles, dans la fondation d'une colonie constitue un phénomène relativement commun dont on commence désormais à mieux saisir l'étendue. Ainsi une participation éphésienne à la fondation de Marseille paraît maintenant vraisemblable (Hermary 2003, p. 64) et, d'après J. M. Fossey (Fossey 1999, p. 36-40), l'expansion coloniale mégarienne comporte sans doute la participation de cités du centre, du Sud et de l'Ouest de la Béotie, celles de l'Est s'associant plus volontiers aux entreprises des villes d'Eubée.

9 Ainsi pour Artémis Pythié, Hécate et, probablement, Apollon Iétros, le grand dieu de la cité : voir ci-dessous et, pour Apollon, Ehrhardt 1989.

10 Voir principalement Robert 1959, p. 232-233 ; Mihailov 1970, p. 373-393. tradition peut être mise en relation avec une indication d'Aristote (voir ci-dessous).

La ville était établie en grande partie sur l'actuelle péninsule de Skamni, orientée N.-E./S.-O., qui s'inscrit dans le prolongement d'un affleurement du substrat

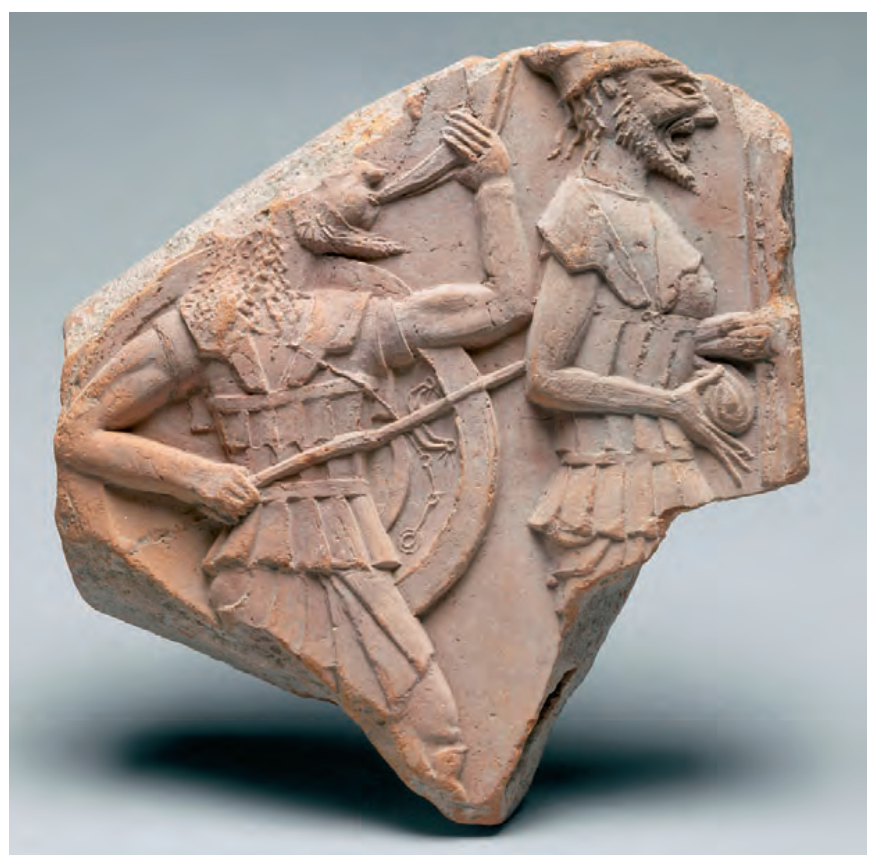

Fig. 3. Relief architectural en terre cuite provenant des fouilles de Degrand à Sv. Kirik. Paris, Louvre, CA 1748

(Photo RMN, Hervé Lewandowski). 
rocheux, émergeant à l'extrémité sud-orientale de la plaine littorale qui borde la chaîne du Meden Rid. Elle est entourée de trois îles : Sveti Kirik (Saint-Cyriaque), la plus proche, qui n'est séparée de Skamni que par un mince bras de mer, Sveti Ivan (Saint-Jean) et Sveti Peter (Saint-Pierre) qui, plus au Nord, prolongent la péninsule. Une difficulté majeure pour l'étude de la topographie d'Apollonia réside dans l'interprétation du passage de Strabon dans lequel le géographe grec indique que «la majeure partie de l'agglomération se trouve sur une petite île qui contient le sanctuaire d'Apollon d'où Marcus Lucullus a enlevé la statue colossale d'Apollon, œuvre de Calamis, qu'il a dédiée dans le Capitole » ${ }^{11}$. D. Nedev et M. Gyuzelev reviennent plus loin sur les hypothèses formulées sur l'identification de l'île et la localisation du sanctuaire ${ }^{12}$, mais l'étude géomorphologique dirigée par Ch. Morhange paraît bien confirmer que l'actuelle péninsule de Skamni ne peut guère avoir été l'île dont parle Strabon, qui pourrait donc être identifiée avec Sveti Kirik. Cette hypothèse, relativement fragile, justifie les fouilles qui ont débuté en 2009 sur cette île sous la direction de K. Panayotova. Les premiers résultats montrent qu'une zone sacrée a existé à cet endroit, mais ne permettent pas de dire si elle comprenait le sanctuaire d'Apollon En attendant d'autres informations, on peut dire que cette localisation expliquerait assez bien que, lors de l'attaque de Mésambria contre Apollonia au début du II ${ }^{\mathrm{e}}$ s. av. J.-C., seul le sanctuaire d'Apollon ait subi des dégâts sans que la ville elle-même soit prise (voir ci-dessous). On notera également qu'une dédicace fragmentaire à Apollon Iétros (aujourd'hui perdue) avait été trouvée dans l'île de Sveti Kirik ${ }^{13}$, où le consul français Degrand ${ }^{14}$ avait mis au jour un fond de jarre portant les lettres -HTPO- dans lesquelles on est tenté de reconnaître l'épithète du dieu ${ }^{15}$. Il faut rappeler d'autre part la découverte par le même Degrand de plusieurs fragments de reliefs en terre cuite qui peuvent être

11 Strabon VII, 6, 1, 14-17. R. Baladié, dont nous reprenons ici la traduction, rappelle que M. Licinius Lucullus, gouverneur de Macédoine, est le frère du vainqueur de Mithridate. L'indication sur la situation insulaire de la ville est reprise par Pline (IV, 27, 13) et Étienne de Byzance, s. v. Voir la discussion dans Mihailov 1970, p. 353-356.

12 Notons qu'il existe un petit problème d'établissement du texte pour le passage en question (Baladié 1989, apparat critique p. 128), mais le sens général paraît clair: Strabon associe le sanctuaire d'Apollon à « la petite île ».

13 Mikov 1925, p. 236-237 ; Mihailov 1970, p. 373, n 403.

14 Sur ses activités à Apollonia, voir ci-dessous, p. 19-20 Cf. également Gyuzelev 2008, p. 123 qui publie la photographie d'une coupe-skyphos attique à vernis noir portant les graffites « $\mathrm{A}$ » et «IH » (Apollon Iétros). Le vase a été trouvé lors du dragage du port de Sozopol en 1927.

15 Seure 1924, p. 346 ( ${ }^{\circ} 4$ r), avec une autre interprétation. datées, par leur style, vers la fin de l'époque archaïque et paraissent se rapporter à trois plaques tirées d'une même matrice. Le plus important d'entre eux, conservé au Louvre (CA 1748), montre deux guerriers marchant vers la droite (fig. 3) ${ }^{16}$ : le premier, qui a la bouche grande ouverte, tient dans la main droite un objet difficile à identifier (fronde ?) ${ }^{17}$, l'autre sonne du cor. Le bâtiment d'où proviennent ces plaques était-il un temple et, plus précisément, celui d'Apollon mentionné par Strabon? Les nombreux fragments de figurines en terre cuite du $\mathrm{VI}^{\mathrm{e}} \mathrm{s}$. trouvés sur l'île pourraient attester l'existence d'un lieu de culte à cet endroit dès l'époque archaïque, mais beaucoup sont de type féminin, comme une figurine tenant un oiseau, également conservée au Louvre ${ }^{18}$.

La prospérité d'Apollonia vers la fin de l'époque archaïque est indiquée de façon plus ponctuelle par la stèle funéraire en marbre d'un certain Deinès fils d'Anaxandros, portant une épigramme dans laquelle le personnage se présente comme «le plus renommé des citoyens ${ }^{19}$. Seule une face de cette stèle « amphiglyphe » (sculptée des deux côtés) est bien conservée : on y voit, selon le mode de représentation traditionnel pour les membres des classes sociales supérieures, le personnage drapé dans un himation, appuyé sur un long bâton et tendant un objet au chien de race qui l'accompagne; l'autre face, qui montrait un homme barbu de profil, a été ravalée dans l'Antiquité. Ce relief de grande qualité, qui provient peut-être de la nécropole d'Harmanité, a été attribué par H. Hiller à un artiste milésien. Une petite statue acéphale en marbre d'un personnage masculin drapé, découverte sur la péninsule d'Atiya et conservée au musée de Bourgas ${ }^{20}$, a été rapprochée à juste titre de kouroi ioniens drapés de la fin du $\mathrm{VI}^{\mathrm{e}} \mathrm{s} .{ }^{\mathbf{2 1}}$ : elle est attribuée par Hiller au même atelier que la stèle de Deinès ${ }^{22}$. Elle constitue un des rares témoignages provenant de l'ancien établissement d'Antheia. Étant donné l'extrême rareté des sculptures en marbre de la fin de l'archaïsme découvertes dans les cités grecques

16 Seure 1924, p. 307-316, fig. 86 ; Mollard-Besques 1954, p. 42, $n^{\circ}$ B 251, pl. XXX ; Frel 1960, p. 246, n 31 ; Åkerström 1966, p. 4, pl. 2,1 .

17 C'est l'interprétation proposée par G. Seure et reprise par MarieFrançoise Billot dans une étude encore inédite sur les terres cuites architecturales grecques du Louvre.

18 Mollard-Besques 1954, n B 244, pl. XXX ; Frel 1960, p. 246$247, n^{\circ} 33$.

19 Mihailov 1970, p. 373-375, n 405 (d'après Peek). Cf. également Dimitrov $1942-1943$ p. $1-16$, fig. 4 ; Hiller 1975 , p. $40-44$ et $152-$ $154, \mathrm{n}^{\circ}$ O 8, pl. 5, 1-3.

20 Galabov 1952, p. 93-102. Du même site provient un trésor de monnaies-pointes de flèches. Il s'agissait peut-être d'un sanctuaire de frontière de la cité d'Apollonia.

21 Langlotz 1975, p. 114, pl. 32, 4 et 7 : vers 500.

22 Hiller 1975, p. 43-44, pl. 27, 3-4. 
de mer Noire, ces œuvres donnent une bonne indication sur la prospérité des fondations grecques sur les rives du golfe de Bourgas au tournant des $\mathrm{VI}^{\mathrm{e}}-\mathrm{V}^{\mathrm{e}} \mathrm{s}$., attestée aussi par la construction de l'édifice auquel appartenaient les reliefs en terre cuite mentionnés plus haut et, vers 480470, par l'instauration d'un monnayage en argent qui dure jusque vers 300 av. J.-C. ${ }^{23}$.

Le témoignage le plus important sur la richesse d'Apollonia dans la première moitié $d u V^{\mathrm{e}} \mathrm{s}$. réside cependant dans la consécration dans le sanctuaire d'Apollon d'une statue en bronze du dieu, mentionnée par Strabon et qui, d'après Pline (Hist. Nat., XXXIV, 18, 39), mesurait 30 coudées (environ 13 mètres) et avait coûté 50 talents. Les Apolloniates en avaient confié la réalisation à Calamis, un des maîtres de l'époque du style sévère, actif dans les années 470-450 av. J.-C. (Moreno 2001). Cette statue colossale, reproduite sur le monnayage de la cité à l'époque hellénistique avec l'inscription $\mathrm{A} O \Lambda \Lambda \Omega N O \Sigma$ IATPOY, figurait le dieu entièrement nu, en appui sur la jambe droite, la tête tournée vers sa droite, tenant dans sa main gauche un arc et des flèches et, dans la droite, une grande branche de laurier sur laquelle est posé un oiseau (fig. 4) ${ }^{24}$. L'attitude d'ensemble est celle de statues en marbre appartenant aux types dits de l'Apollon à l'omphalos et de l'Apollon Choiseul-Gouffier ${ }^{25}$, répliques d'un original du style sévère qui, s'il ne s'agit pas de la statue d'Apollonia, devait en être très proche. L'offrande spectaculaire de l'Apollon de Calamis marque en tout cas l'aboutissement d'une évolution politique et économique très favorable que les découvertes archéologiques ne laissent actuellement qu'entrevoir.

23 Stefanova 1980 ; Hind 1985. Il convient toutefois de signaler que la date traditionnelle du début du monnayage d'Apollonia a été contestée par A. Stefanova qui propose une date plus basse, vers la fin $\mathrm{du} \mathrm{V}^{\mathrm{e}} \mathrm{s}$. av. J.-C.

24 Lacroix 1949, p. 248-249, pl. XX, fig. 6-10 ; Gerasimov 1965 ; Stefanova 1985, p. 276-279. Nous avons eu connaissance de l'exemplaire reproduit ici (tétradrachme en argent, 16,70 g, daté de la première moitié du $\mathrm{II}^{\mathrm{e}} \mathrm{s}$. av. J.-C.) grâce à M. Stavri Topalov, à qui nous adressons tous nos remerciements ; il fournit la description suivante du revers de cette monnaie (au droit, tête d'Apollon lauré à droite) : «Between the words of the inscription naked Apollo, fullface, standing on a pedestal and holding a laurel tree with his right hand and a bow with two arrows with his left hand. A bird, probably an eagle, in the branches of the laurel tree. Letters, probably initials of a magistrate's name at both sides under Apollo's knees. $\Theta$ at the left and $\mathrm{H}$ at the right, i. e. an initial that should be deciphered as $\mathrm{\Theta H}$, but traces of the letter A touching the lower end of the laurel tree are noticed in front of the letter $\Theta$ thus allowing to decipher the initial as $\mathrm{A} \Theta \mathrm{H}$ ». Cette monnaie est passée en vente en 1991, puis en 2009 : voir le catalogue de vente Triton XII, Lot 128, du 5 janvier 2009. 25 Rolley 1994, p. 342, fig. 353-354 ; cf. Moreno 2001, p. 381.

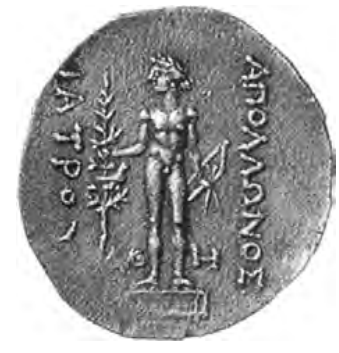

Fig. 4. Tétradrachme en argent d'Apollonia avec l'Apollon de Calamis (d'après cat. vente Triton, 5 janvier 2009).

Cette prospérité est-elle à l'origine de l'arrivée de nouveaux colons qui, d'après Aristote (Politique, V, $3,13)$, aurait provoqué une stasis, c'est-à-dire des tensions sociales? Il serait tentant de lier cet accroissement de la population à la soudaine extension de la superficie des nécropoles à partir de la deuxième moitié $d u \mathrm{~V}^{\mathrm{e}} \mathrm{s}$. Il demeure toutefois difficile de situer dans le temps cet événement, et d'autres hypothèses ont été avancées ${ }^{\mathbf{2 6}}$, y compris celle selon laquelle les indications d'Aristote concernent deux périodes différentes, en particulier l'arrivée de nouveaux colons peu après la fondation, suivie bien plus tard de troubles civiques (Avram, Hind, Tsetskhladze 2004, p. 931). Le passage d'Aristote indique cependant clairement que ces troubles civils sont provoqués par l'arrivée d'étrangers, qui pourraient être éventuellement les Rhodiens donnés par Étienne de Byzance comme les co-fondateurs de la colonie. En tout cas, l'activité croissante de la cité ne devait pas dépendre uniquement de son rôle d'escale, mais s'explique bien si on considère le contexte régional. Le choix de la péninsule de Skamni apparaît en effet particulièrement judicieux. Apollonia est installée à l'embouchure d'un golfe profond ouvrant sur la plaine supérieure de Thrace, à laquelle elle lie très tôt son destin (fig. 5). Par sa situation stratégique, elle contrôle l'accès de ce vaste espace maritime dont elle constitue parallèlement

26 L'invasion de l'Ionie sur l'initiative du général Harpage, vers 545-540 av. J.-C., entraîne la migration de nombreux groupes de population au sein du monde grec. L'exil choisi par les Phocéens, tout comme la refondation d'Abdère par des habitants de Téos, illustrent à eux seuls l'impact de cet événement. L'installation des Téiens à Phanagoria, sur les rives du Bosphore Cimmérien, démontre que la mer Noire a elle aussi été concernée, soulevant en retour la question de la présence éventuelle de réfugiés à Apollonia: Graham 1992, p. 48 ; Dominguez 2000, p. 512. L'ampleur de ces mouvements de population a suscité toutefois quelques interrogations. Ch. VeligianniTerzi défend l'idée d'un abandon total de Téos. En se basant sur le parallèle offert par les Phocéens, elle considère que seule une infime partie de la population téienne serait restée sur place. La participation de Téos à la révolte ionienne, puis à la bataille de Ladé, prouve en revanche l'existence de cette cité au début du V ${ }^{\mathrm{e}} \mathrm{s}$. av. J.-C., amenant Ch. Veligianni-Terzi à supposer que certains réfugiés sont revenus par la suite à Téos, vraisemblablement au moment même où Mégabaze soumet les colonies de Thrace égéenne, soit selon elle vers 510 av. J.-C. : Veligianni-Terzi 1997, p. 692-695. 


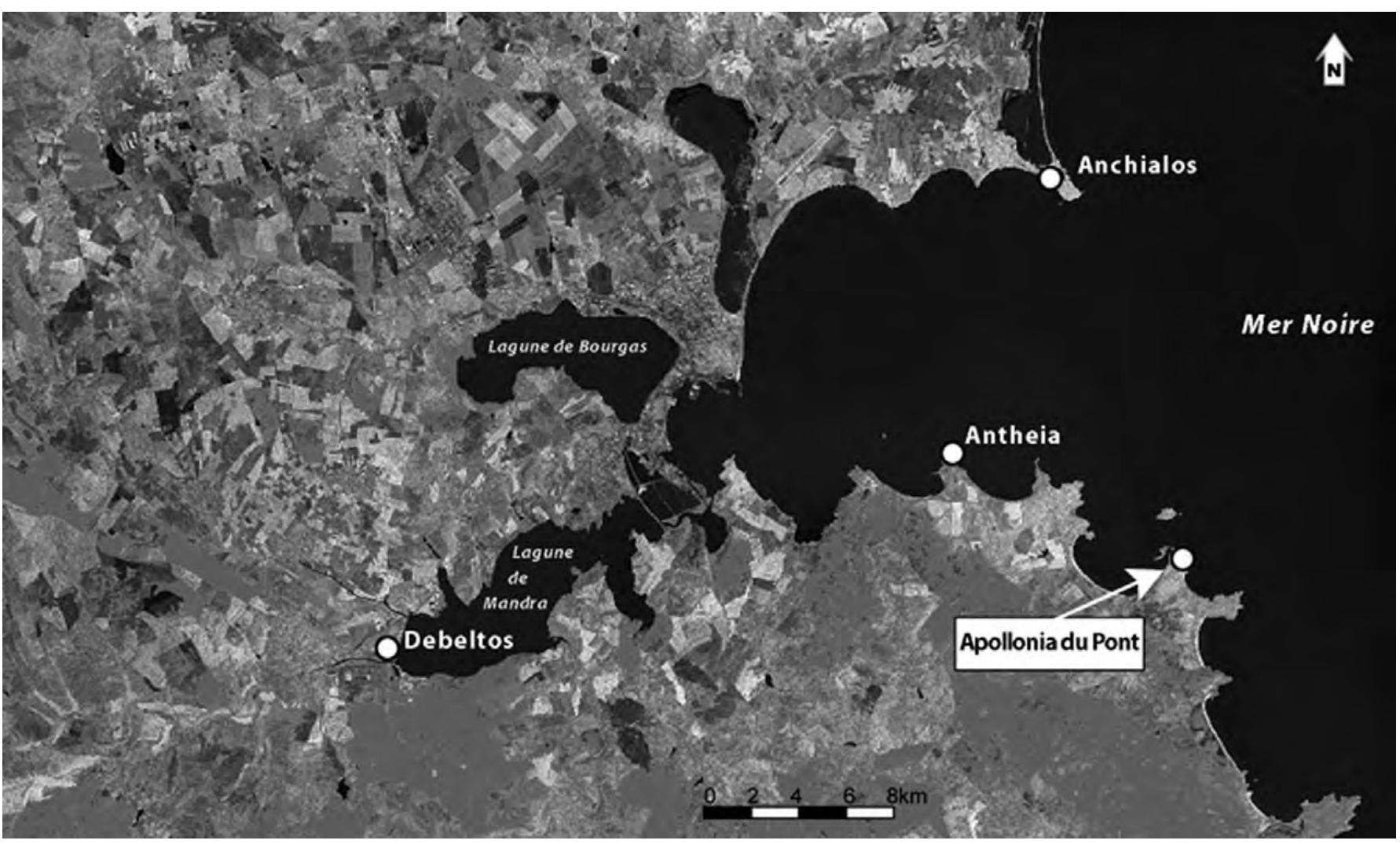

Fig. 5. Les établissements grecs dans le golfe de Bourgas (@ CCJ).

le meilleur mouillage ${ }^{27}$. La présence de matériel grec dès la période archaïque sur plusieurs sites autrefois côtiers, comme Debelt ${ }^{28}$, aujourd'hui situé au fond de la lagune de Mandra, et plus tard Sladkite Kladentsi ${ }^{29}$, au Sud de Bourgas, témoignent de l'importance des habitats locaux comme interfaces avec l'arrière-pays thrace, sans qu'il soit possible de déterminer à quelle date ces derniers furent intégrés dans son territoire.

Apollonia jouit ainsi, durant l'époque archaïque, d'une suprématie relative sur les rivages pontiques de la Thrace sans avoir à affronter de véritable concurrence. L'établissement voisin d'Antheia, situé à une quinzaine de kilomètres au Nord-Ouest, ne semble pas avoir représenté une véritable menace : il est en fait probablement intégré avant la fin de l'époque archaïque au territoire d'Apollonia. Seule la fondation de Mésambria, vers la fin du VI e s. av. J.-C., à l'initiative de Mégare et de Byzance, vient rompre ce fragile équilibre (Avram,

27 Quatre autres mouillages sont régulièrement cités par les pilotes maritimes : la péninsule d'Atiya, $15 \mathrm{~km}$ plus à l'Ouest, le golfe de Pharos qui lui succède, Bourgas et enfin Anchialos/Pomorié (Isaac 1986, p. 241, n. 176).

28 Balabanov 1986 ; Balabanov 1999 ; Gyuzelev 2008, p. 103-104. 29 Galabov 1950b; Balabanov, Drajeva 1985 ; Gyuzelev 2008, p. $98-100$.
Hind, Tsetskhladze 2004, p. 934-935, n 687), car cette nouvelle colonie, établie sur une péninsule qui fait face directement à Apollonia, remet en cause le contrôle que cette dernière exerce sur le golfe; la rivalité entre les deux villes n'est cependant attestée qu'à l'époque hellénistique. Si les nécropoles, en particulier celle de Kalfata, apportent des témoignages essentiels pour l'époque classique, il n'en va pas de même pour les textes littéraires ou épigraphiques ${ }^{30}$. Le nom d'Apollonia peut être restitué dans la liste des tributs versés à Athènes en 425/424 (IG $\left.\mathrm{I}^{3} 71, \mathrm{IV}, 126\right)$, mais il est difficile de dire si ce rattachement de la ville à la confédération maritime athénienne date de l'expédition menée par Périclès dans le Pont vers $436^{31}$. Par la suite, on sait simplement qu'Apollonia avait conclu en 341 un traité avec Philippe II de Macédoine au moment de son expédition contre les Scythes d'Athéas, traité qui indique sans doute une situation de dépendance (Justin, Epitomé, IX, 2, 1), et qu'en 313 elle avait probablement passé une alliance

30 Notons cependant l'intérêt des témoignages numismatiques : la diffusion durant la période classique de monnaies d'Apollonia à l'Est de Stara Zagora, entre Rhodopes et Balkans, permet en effet de délimiter approximativement l'étendue de la zone d'influence de la colonie.

31 Voir la discussion dans Avram 1995, p. 195-196, et Avram 2003, p. 307, ainsi qu'Angelescu 1992 et Braund 2005. 
contre Lysimaque avec Callatis, Istros et d'autres cités ouest-pontiques (Diodore, XIX, 73). Du point de vue épigraphique, la question de l'identification de l'Apollonia mentionnée dans l'inscription relative à l'emporion Pistiros, découverte à Vetren, reste très discutée, nous ne faisons que la signaler ici ${ }^{32}$.

Pour l'époque hellénistique les témoignages littéraires et épigraphiques sont restreints, mais la cité semble entretenir des relations avec les dynastes thraces, comme l'indique une inscription relative à Kotys, fils de Taroulas ${ }^{33}$, et une autre à Raiskouporis, fils de Kotys ${ }^{34}$. L'inscription concernant Sadalas, découverte à Nessebar, montre d'ailleurs qu'au cours de la haute époque hellénistique une partie du littoral thrace pontique échappait au contrôle des cités grecques et dépendait, en particulier à proximité de Mésambria, de souverains locaux thraces ${ }^{35}$.

32 Une ville d'Apollonia est citée aux lignes 23 et 32-33 de l'inscription publiée par V. Velkov et L. Domaradzka, BCH, 118, 1994, p. 1-2. Ces derniers résument les trois candidates potentielles sur les rivages nord-égéens : Apollonia de Chalcidique, dont la localisation n'est pas encore assurée, mais que certains situent près de Polygyros ; Apollonia de Mygdônie, datée par les sources de la période romaine ; enfin Apollonia, située entre le Nestos et le Strymon, sur le territoire de la pérée de Samothrace. Apollonia du Pont constitue naturellement la quatrième possibilité. J. Bouzek pense que toutes les cités présentes dans cette inscription appartiennent au littoral nordégéen et conclut qu'il ne peut s'agir que de la ville d'Apollonia située entre le Nestos et le Strymon, point de vue que rejoignent B. Bravo et A. Chankowski. Z. Archibald rappelle à ce sujet la découverte d'une inscription à la périphérie du site d'Adjiyska Vodenitsa se rapportant à un Apolloniate répondant au nom de Dionysios, fils de Diotréphès, et elle souligne que Diotréphès est attesté à la fois à Kéos et à Athènes, et donc se réfère plutôt au domaine égéen. Cette identification ne fait toutefois pas l'unanimité. F. Salviat, O. Picard et L. Loukopoulou pensent en effet que seule Apollonia du Pont peut être comparée, par son importance, à Maronée et Thasos. Voir V. Velkov, L. Domaradzka, BCH, 118, 1994, p. 13 ; Bouzek 1999, p. 189 ; F. Salviat, B. Bravo et L. Domaradzka, BCH, 123, 1999, p. 260-261, 286 et 352 ; V. Chankowski et L. Domaradzka, ibid., p. 252 ; Archibald 2001.

33 Mihailov 1970 , p. 397, $\mathrm{n}^{\circ} 469$ bis : fin du $\mathrm{III}^{\mathrm{e}}$ ou II ${ }^{\mathrm{e}}$ s. av. J.-C. ; Balabanov 2003, p. 27-28.

34 Kazarow 1917, p. 97-101; Mihailov 1970, p. 359, n 389 : milieu du III' s. av. J.-C. ; Balabanov 2003, p. 26-27.

35 Galabov 1950a, p. 7-20 : fin du IV e ou début du III e s. av. J.-C. ; Danov 1952, p. 110-140 : milieu ou deuxième moitié du $\mathrm{III}^{\mathrm{e}} \mathrm{s}$. av. J.-C. ; Mihailov 1955 ; Mihailov 1970, p. 257-262, n 307 : vers 281277 av. J.-C. ; Balabanov 2003, p. 23-26.
Pour Strabon (VII, 6, 1), le territoire d'Apollonia débutait au Nord à Anchialos/Anchialé et s'étendait au Sud jusqu'au cap Thynias. L'installation des Apolloniates sur la péninsule d'Anchialos, sans doute au cours de l'époque classique ${ }^{36}$, a exacerbé la rivalité entre Apollonia et Mésambria ${ }^{37}$, car ce nouvel établissement, qui bordait immédiatement à l'Ouest le territoire de la cité mégarienne, consacrait l'emprise d'Apollonia sur les deux rives du golfe. Une inscription trouvée à Istros/ Histria apporte un témoignage très important sur la guerre qui eut lieu entre Apollonia et Mésambria au début du $\mathrm{II}^{\mathrm{e}}$ s. av. J.-C. ${ }^{38} \mathrm{Il}$ s'agit d'un décret des Apolloniates en faveur de la cité d'Istros, « amie, parente et alliée », et du navarque autokratôr Hégésagoras, fils de Monimos, qui était venu défendre Apollonia, attaquée sans déclaration de guerre par les gens de Mésambria : ceux-ci ont commis des actes sacrilèges «nombreux et graves » dans le sanctuaire d'Apollon et ont fait courir les plus grands dangers à la cité ; ils s'étaient d'autre part emparés de la forteresse d'Anchialos, située dans la chôra d'Apollonia. Ainsi, Hégésagoras a défendu la ville, le territoire et les ports. Bien que, grâce à l'aide d'Istros, Apollonia soit sortie vainqueur de cette guerre, elle ne paraît pas avoir connu, dans la deuxième partie de l'époque hellénistique, une prospérité comparable à celle des siècles précédents. Un décret honorifique mentionne l'envoi par le roi Mithridate Eupatôr, au début du ${ }^{\text {er }}$ s. av. J.-C., d'un contingent militaire commandé par Epitynchanôn fils de Ménékratès, de Tarse (Danov 1937 ; Mihailov 1970, p. 361-362, n 392). Cette alliance avec le roi du Pont entraîne les représailles de Rome et la prise de la ville par Lucullus, qui la dépouille de sa grande statue d'Apollon Iétros (Appien, Illyr. 30). La cité ne joue plus, à l'époque impériale, qu'un rôle régional mineur, bien qu'une inscription mentionne des reconstructions financées par le Thrace Métokos, fils de Taroulas (Mihailov 1970 , p. $368-370$, n$\left.^{\circ} 400\right)$.

36 Voir la synthèse de M. Gyuzelev dans Nedev, Panayotova 2003, p. $107-108$.

37 Toutefois, une inscription très fragmentaire fait état des honneurs qu'un Apolloniate avait reçus, probablement, de la part de la cité de Mésambria, en tant que chef d'une petite troupe qui lui avait porté secours : Robert 1959, p. 217-218 ; Mihailov 1970, p. $348-351, \mathrm{n}^{\circ} 388$.

38 Pippidi, Popescu 1959 ; Robert 1961, p. 187-201; SEG XIX, $\mathrm{n}^{\circ} 468$; Mihailov 1970, p. 351-358, n³ 388bis. 



\section{Chapitre 2}

\section{Histoire de la recherche archéologique à Apollonia}

B ien que le nom d'Apollonia Pontique apparaisse souvent dans les sources antiques, les témoignages des auteurs anciens sur cette ville s'avèrent assez laconiques. Ils concernent essentiellement la fondation et le caractère ethnique de l'apoikia. Les études archéologiques de la ville et de ses nécropoles fournissent, en fait, l'essentiel des informations dont nous disposons sur le développement de la plus ancienne colonie grecque du littoral bulgare de la mer Noire.

L'intérêt envers les antiquités de la colonie milésienne d'Apollonia remonte à l'époque de la guerre russo-turque de 1828-1829. Durant ces événements, le poète et voyageur russe V. Teplyakov a visité Sozopol et acquis « deux vases de terre de grosseur moyenne » qu'il a envoyés au musée d'Odessa ${ }^{39}$. Il rapporte que les vases faisaient partie du mobilier d'une tombe à ciste découverte par les soldats russes à l'occasion de travaux exécutés sur les redoutes qui occupaient les hauteurs à proximité de la ville. Il a également assisté à la découverte dans cette même zone de deux tombeaux voûtés en briques, sans doute romains, qui ont livré des ossements humains, des unguentaria en verre et des objets en argile dont nous n'avons pas la description.

K. Jireček, qui s'est rendu dans la ville en 1884, nous apprend que des chercheurs de trésors sont tombés sur la nécropole d'Apollonia, qu'il situe à trois quarts d'heure de route au Sud-Est de la ville (Jireček 1886, p. 165). Plusieurs amphores timbrées, des fragments de vases à vernis noir et de fabrication locale, d'un vase en bronze et d'un autre en verre, des lampes et des restes d'une couronne funéraire ont été découverts à cette occasion. Il est fort probable que ces activités ont eu lieu dans le secteur exploré l'année suivante par le consul grec P. Goffas.

Les fouilles de Goffas sur le cap Kolokita en 1885 marquent le début de l'exploration archéologique des nécropoles de l'antique colonie milésienne. Elles ont concerné quatre tumuli qui semblent avoir livré plusieurs sépultures et un riche mobilier datant du $\mathrm{IV}^{\mathrm{e}} \mathrm{s}$. av. J.-C.

39 Teplyakov 1833, p. VIII ; Vajarova 1960, p. 59.
Malheureusement, le consul grec n'a laissé aucun témoignage écrit de ses travaux, qui ne nous sont connus que par quelques renseignements transmis quarante ans plus tard par l'archéologue français G. Seure ${ }^{40}$ et les indications sommaires des frères Škorpil qui ont visité l'emplacement des fouilles en $1889^{41}$. Les objets découverts ont été dispersés ou vendus à l'étranger ${ }^{42}$.

La découverte fortuite en 1895 du relief funéraire en marbre de Deinès, fils d'Anaxandros, daté du début du $\mathrm{V}^{\mathrm{e}}$ s. av. J.-C. (Dobruski 1896, p. 430-432, fig. 4, et cidessus p. 14), a donné une nouvelle impulsion à l'intérêt pour les antiquités d'Apollonia. En 1904, le consul de France à Plovdiv, A. Degrand, a exploré une quinzaine de tumuli sur le cap Kolokita, ainsi que dans le secteur de la baie de Kavatsité, aux lieux-dits Mapité, Sinetudes, Draku Saya, Kara Agach (fig. 6). Les sépultures découvertes ne sont pas nombreuses, mais appartiennent à des types variés qui peuvent être datés par leur mobilier des $\mathrm{IV}^{\mathrm{e}}$-III ${ }^{\mathrm{e}}$ s. av. J.-C. En parallèle à ces travaux, Degrand a effectué également plusieurs sondages sur l'île de Sveti Kirik, afin de localiser le célèbre sanctuaire d'Apollon Iétros mentionné par les sources anciennes. Ses recherches ont fait l'objet d'une analyse détaillée par G. Seure, qui a pu utiliser les rapports que le consul lui avait personnellement adressés (Collignon 1905 ; Seure 1924, p. 328-341). Une partie du matériel provenant de ces fouilles a été transporté au Louvre et plus tard publié par J. Frel (1960, p. 239-251). Le reste est conservé au Musée National d'Archéologie de Sofia. Certaines trouvailles ont été répertoriées dans la monographie

40 Seure 1924, p. 328-330. Ces renseignements étaient contenus dans les rapports qui lui ont été adressés par le consul Degrand et par A. Tacchella, chargé par les autorités bulgares de surveiller les travaux exécutés par le prince Chahovskoy. Les deux hommes les ont obtenus auprès d'un ancien employé de Goffas qui leur a également permis de dessiner, photographier ou acquérir quelques objets dérobés.

41 Škorpil 1891, p. 125-126, et 1999, p. 48, qui situent ces travaux sur le cap Baglar Alti, qui n'est probablement que le nom turc du cap Kolokita ou de la péninsule de Boudjaka dont il fait partie.

42 Il semble que plusieurs vases provenant d'Apollonia, qui se trouvent aujourd'hui dans de grands musées européens, soient issus des fouilles de Goffas. Ce sont notamment deux lécythes du « Groupe d'Apollonia » conservés à Berlin et à l'Ermitage de SaintPétersbourg : voir ci-dessous, p. 181, et Hermary, sous presse. 


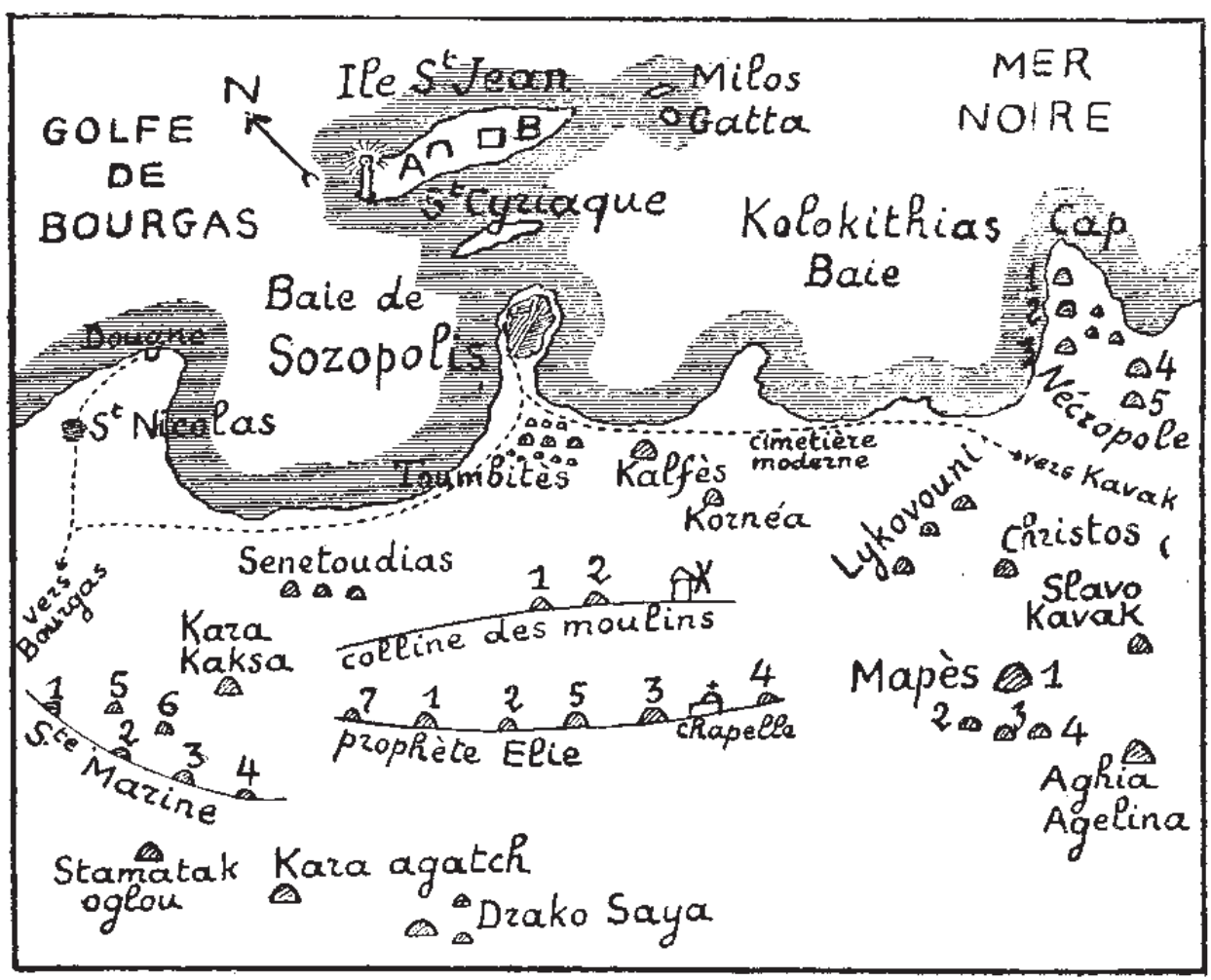

Fig. 6. Croquis de la région de Sozopol avec l'emplacement des nécropoles tumulaires (Degrand 1904, reproduit d'après Seure 1924, fig. 87).

de D. Robinson sur les figurines en terre cuite d'Olynthe (Robinson 1952, p. 27-30) et le catalogue des terres cuites du Louvre (Mollard-Besques 1954, p. 41-42, pl. XXX).

Un peu plus tard dans la même année, le prince B. Chahovskoy, consul de Russie à Bourgas, a fouillé cinq tumuli sur les collines de Sveti Iliya et Sveta Marina, où il a dégagé six sépultures attribuables au $\mathrm{IV}^{\mathrm{e}} \mathrm{s}$. av. J.-C. et à l'époque romaine. Dans ce cas encore, les seules données dont nous disposons nous sont fournies par G. Seure ${ }^{43}$, qui s'est servi d'un rapport sommaire et de quelques croquis que l'assistant de Chahovskoy, A. Tacchella, lui avait envoyés. Le devenir des objets découverts est incertain : quelques-uns sont probablement entrés dans les fonds du Musée National d'Archéologie de Sofia ${ }^{44}$, mais les plus intéressants semblent avoir été exportés et vendus à l'étranger.

En 1911, en guise de préparation à des travaux qui n'ont jamais eu lieu, B. Filov a effectué de petits sondages sur les tumuli de Sveti Iliya et Sveta Marina, dans

43 Seure 1924, p. 341-344. Une erreur de date peut être corrigée grâce à une lettre de Chahovskoy publiée dans Vajarova 1960, p. 277. Celle-ci établit de façon incontestable que les fouilles du consul de Russie ont eu lieu en 1904 et non pas en 1908, comme l'affirme Seure.

44 Cf. Reho 1992, p. 39, nº 39 et p. 104, nos 237-239. Cependant, ces vases ne figurent pas parmi les trouvailles mentionnées par Seure et, dès lors, leur provenance des fouilles de Chahovskoy doit être considérée comme douteuse. la zone explorée auparavant par le prince Chahovskoy ${ }^{45}$. Ces sondages n'ont pas donné de résultats significatifs, si ce n'est la découverte dans un tumulus de Sveti Iliya d'une tombe à ciste (probablement hellénistique) qui a livré une petite «bouteille» en argile et des éléments en terre cuite provenant sans doute d'une couronne funéraire.

En 1924, à l'occasion de la construction du bâtiment de l'École de pêche, V. Mikov a eu l'opportunité de faire des fouilles de sauvetage sur l'île de Sveti Kirik (Mikov 1925). Il a dégagé des restes d'édifices de l'Antiquité tardive, quelques tombes de date incertaine, des fragments de céramique de différentes époques, des monnaies en bronze, etc. L'auteur a également publié, avec les résultats de ses recherches, quelques inscriptions inédites de Sozopol.

Trois ans plus tard, en 1927, le dragage du port de Sozopol a livré un riche ensemble de vases, stèles et autres objets, dont l'origine, la date et la fonction sont extrêmement variées (Pandaleev 1928-1929, p. 328). Les vases de la période pré-romaine, publiés par I. Galabov (1952, p. 102-117, et 1965), présentent les caractéristiques d'un mobilier funéraire, posant en retour la question de l'existence éventuelle d'une partie des nécropoles d'Apollonia dans ce secteur (Panayotova 1994, p. 126-129).

45 Filov 1912-1913. Cf. aussi Seure 1924, p. 343 : tumulus IV. 
Lors de la construction d'une route le long de la rive Sud-Est de l'île de Sveti Kirik, on a découvert en 1935 «quelques tombes antiques construites en plaques de pierre ». Dans une de ces tombes a été mise au jour une petite tête en marbre blanc d'époque archaïque (Gerasimov 1938 ; Mansova 1972).

H. Danov a indiqué la découverte, au mois de mars 1937, d'une tombe au lieu-dit Kavatsité, le long de la baie du même nom, au Sud de Sozopol (Danov 1937). La sépulture proprement dite a été détruite, mais quelques objets de son mobilier ont été conservés et plus tard transmis au musée de Bourgas. Il s'agit d'un lécythe à figures rouges, de trois lécythes à palmette et d'un miroir en bronze qui permettent de proposer une date dans la première moitié du IV ${ }^{\mathrm{e}} \mathrm{s}$. av. J.-C. (cf. Reho 1990, p. 138-139, nos 395-398). Dans le même secteur, à l'emplacement d'une carrière de sable, ont été découverts à diverses occasions de nombreux vases, ainsi que des tombes à ciste datant de l'époque hellénistique. Dans le livre d'inventaire du musée archéologique de Sozopol figurent dix-huit numéros correspondant à des objets provenant de la «carrière de sable». Parmi eux, on dénombre deux stèles funéraires et un peson en argile. Les autres trouvailles (lécythes, coupes, coupelles à vernis noir, cruches, plat à poisson, gril, etc.) font partie de la vaisselle caractéristique du mobilier funéraire des nécropoles d'Apollonia. V. Mikov indique par ailleurs que, dans la même localité, on trouve fréquemment des monnaies autonomes en bronze d'Apollonia, en particulier les types frappés entre le $\mathrm{IV}^{\mathrm{e}}$ et le $\mathrm{II}^{\mathrm{e}} \mathrm{s}$. av. J.-C. (Mikov 1925, p. 239).

Durant la période 1946-1949, une équipe de l'Institut d'archéologie de Sofia, sous la direction d'Ivan Venedikov, a réalisé des fouilles à grande échelle sur une superficie d'environ $2500 \mathrm{~m}^{2}$ au lieu-dit Kalfata, le long de la plage de Harmanité. 801 tombes ont été étudiées à cette occasion, s'échelonnant stratigraphiquement jusqu'à une profondeur de cinq mètres. Elles se rattachent chronologiquement à une période allant de la deuxième moitié du $\mathrm{V}^{\mathrm{e}} \mathrm{s}$. à la fin du $\mathrm{III}^{\mathrm{e}} \mathrm{s}$. av. J.-C. (Venedikov 1948, p. 11-27, et 1963, p. 17-59). La même équipe a également réalisé des sondages dans le «jardin maritime » de Sozopol, sur une superficie d'environ $267 \mathrm{~m}^{2}$. On y a découvert 89 tombes, la plupart datées des $\mathrm{III}^{\mathrm{e}}-\mathrm{II}^{\mathrm{e}}$ s. av. J.-C. ; huit sont attribuées à l'époque romaine, une seule est définie comme paléochrétienne, une dernière n'est pas datée (Venedikov 1963a,p. 60-64). L'ensemble des sépultures, les objets du mobilier et les contextes rituels mis au jour ont plus tard fait l'objet de deux importantes monographies, comportant les contributions de plusieurs savants, qui demeurent aujourd'hui encore notre principale source de connaissance sur les nécropoles d'Apollonia (Venedikov et al. 1948 et 1963).
En relation avec le développement des activités de construction dans les années 1960-1970, plusieurs fouilles de sauvetage ont eu lieu dans la zone du quartier Harmanité, où a été localisée une nécropole des $\mathrm{VI}^{\mathrm{e}}$ $\mathrm{III}^{\mathrm{e}}$ s. av. J.-C. Les nombreuses sépultures découvertes lors de ces travaux ne nous sont malheureusement connues que par quelques communications préliminaires de M. Lazarov (1969, p. 7) et M. Tsaneva (1976, 1977, 1980), qui ont également publié certains des objets les plus intéressants ${ }^{46}$. Dans des circonstances similaires, quelques tumuli ont été explorés sur le cap Kolokita et les collines de Sveti Iliya et Sveta Marina au cours des années 1970-1980 ${ }^{47}$, ainsi que tout récemment, en $2006^{48}$.

Les travaux de construction plus récents à Kalfata et sur la péninsule de Boudjaka ont nécessité, en 1992, la reprise des fouilles dans cette partie de la nécropole d'Apollonia. Le site étudié se situe au lieu-dit Kalfata, à 500 m environ au Sud du secteur exploré en 19461949. Les fouilles de sauvetage se sont poursuivies sans interruption à cet endroit jusqu'en 2008, entrấnant la découverte d'environ 1.200 tombes des $\mathrm{V}^{\mathrm{e}}-\mathrm{III}^{\mathrm{e}} \mathrm{s}$. av. J.-C., de centaines de vestiges de rites post-funéraires et de milliers d'objets ${ }^{49}$. Au cours des campagnes 20022004, une partie de ces recherches a été effectuée en collaboration avec les archéologues du Centre Camille Jullian : plusieurs articles préliminaires ont déjà paru avant la présente publication ${ }^{\mathbf{5 0}}$.

Parallèlement à l'étude de la nécropole de Kalfata, des fouilles de sauvetage ont également été menées à l'emplacement de la nécropole hellénistique et romaine dans le Jardin maritime ${ }^{51}$, ainsi que dans le périmètre du noyau urbain d'Apollonia sur la péninsule de Skamni ${ }^{52}$. La multiplication des activités de construction dans le centre historique de Sozopol au cours de ces dernières décennies a abouti à la découverte d'une grande quantité de céramique archaïque dans des niveaux de construction plus ou moins perturbés, en particulier dans la

46 Tsaneva 1975 et 1982 ; Lazarov $2003, \mathrm{n}^{\text {os }} 3,5-6,16,18,20$, 23-25, 29, 36-38, 51, 53-59, 62. Voir également Reho 1985, p. 32-33, $\mathrm{n}^{\text {os }} 2-9$; Reho $1990, \mathrm{n}^{\text {os }} 84,86,134-136,138-144,146-147,157,185$, 187, 190, 192, 332

47 Tsaneva, Dimitrov 1976; Tsaneva 1983, 1985a-b, 1986a-b. Pour le matériel découvert, cf. aussi Dimitrov 1973; Reho 1990, p. 136-137, nos 388-389, 392 ; Damyanov 2005, p. 214-216, fig. 2.

48 Bojkova, Petrova 2007 ; Katsarova 2007 ; Mikov 2007.

49 Pour un aperçu d'ensemble des recherches récentes à Kalfata, voir Panayotova 1998a-b ; Nedev, Panayotova 2003, p. 125-140.

50 Hermary, Panayotova 2006 ; Panayotova, Riapov, Baralis 2006 ; Baralis, Riapov 2006 ; Hermary 2007 ; Baralis, Riapov, sous presse.

51 Tsaneva, Panayotova 1991 ; Panayotova, Penkova, Nedev 1994.

52 Les fouilles dans l'espace urbain d'Apollonia sont commentées plus loin par D. Nedev et M. Gyuzelev. Voir aussi Nedev, Panayotova 2003, p. 95-106, 120-123. 
partie Sud-Est et centrale de la péninsule. On a également étudié des restes d'édifices à caractère privé, public et religieux de l'époque classique et hellénistique, des vestiges de voirie et du système d'approvisionnement en eau de la ville.

Les résultats des dernières fouilles à Apollonia ont été synthétisés dans une série d'études qui comprennent également la publication préliminaire de certains types de monuments ${ }^{53}$.

53 Bojkova 1997 et 2000 ; Docter et al. 2008 ; Giuzelev 2002 ; Keenleyside, Panayotova 2005 ; Keenleyside, Schwarcz, Panayotova
Les recherches archéologiques représentent une source fondamentale pour l'étude de l'histoire et de l'urbanisme d'Apollonia, ses fortifications et son système d'approvisionnement en eau, son développement économique et ses relations commerciales et culturelles. L'exploration exhaustive des nécropoles offre la possibilité de définir les éléments principaux des croyances de ses citoyens. Elle fournit une information précieuse sur l'identité culturelle de cette ville et sur la place qu'elle occupe dans le monde classique.

2006 ; Konova 1997; Nedyalkov 2008; Panayotova 2003a-b, 2005a-b, 2006, 2007, 2008a-c ; Panayotova, Drajeva 2003. 


\section{Chapitre 3}

\section{Étude géomorphologique des rivages d'Apollonia}

$\mathrm{D}$ ans le cadre des fouilles archéologiques de la nécropole classique et hellénistique d'Apollonia, au lieu-dit Kalfata, nous avons eu l'opportunité de travailler sur la mobilité des paysages littoraux depuis environ 6000 ans. Nous avions plusieurs objectifs géomorphologiques à l'échelle de la région de Sozopol :

- Préciser la mobilité du niveau relatif de la mer;

- Mesurer les variations des lignes de rivage par rapport aux sites d'occupation humaine ;

- Estimer les potentialités et la vulnérabilité des milieux (ports antiques et tombolo d'Apollonia, lagunes marginales, cordons dunaires...) ;

- Caractériser les impacts d'origine anthropique sur l'environnement (dont le détritisme...).

À l'échelle urbaine et à celle du site des fouilles de la nécropole (baie de Harmanité), au Sud de la cité antique, il fallait reconstituer les paléoenvironnements, afin de préciser les relations spatiales entre l'occupation du territoire et les milieux physiques. Nous devions donc répondre à deux questions principales :

- Quel est l'environnement physique de la nécropole classique et hellénistique d'Apollonia ?

- Où étaient localisés les ports de la cité grecque ?

Le contexte géomorphologique actuel de Sozopol se caractérise par la présence d'une ancienne île (le promontoire de Skamni) reliée au continent par un isthme sableux constituant un tombolo (fig. 7). Deux façades maritimes s'opposent clairement. La côte Sud-Est est particulièrement exposée aux houles du large alors que les côtes Nord et Ouest sont relativement plus protégées par la présence de l'île de Sveti Kirik. C'est ce dernier secteur qui a abrité les ports antiques d'Apollonia.

\section{Mobilité du niveau de la mer à Sozopol depuis environ 6000 ans}

La bibliographie concernant cette question est abondante, du fait de l'héritage scientifique soviétique et de la controverse scientifique récente à propos de l'hypothèse émise par l'équipe de Ryan concernant le «déluge» de la Méditerranée en direction de la mer Noire vers
7000 ans BP (Ryan et al., 1997). Cette hypothèse catastrophiste semble de nos jours largement nuancée et remise en cause (Major et al. 2002; Kerey et al. 2004). Quel que soit le scénario proposé, la communication entre la Méditerranée et la mer Noire est établie dès 5000 ans BP. Concernant la Bulgarie, deux écoles s'opposent encore à propos des variations holocènes les plus récentes du niveau marin. Certains chercheurs privilégient la mise en évidence d'oscillations assez importantes et récentes du niveau marin, alors que d'autres proposent des reconstitutions plus lissées de la montée du niveau de la mer durant l'Holocène.

Shilik (1997) a publié une courbe des oscillations du niveau de la mer depuis 6000 ans en intégrant des données très disparates provenant de secteurs tectoniquement différents. Concernant la Bulgarie, il fait état de la présence dans les lacs de Varna de deux couches de tourbe à 8,5 $\mathrm{m}$ de profondeur (Lilienberg en 1970, références dans Shilik 1997), vers 4500 ans BP. Plus au Sud, les secteurs de Sozopol et Kiten sont caractérisés par des niveaux d'occupation du Chalcolithique final et du Bronze ancien jusqu'à $8 \mathrm{~m}$ sous le niveau actuel de la mer (Draganov 1995). Shilik (1997) a proposé de nommer ce bas niveau marin (- 9,5 m vers 4500 ans BP) la « régression varnienne». Il identifie aussi deux hauts niveaux marins supérieurs à l'actuel (dont un haut niveau «flandrien » vers $+2 \mathrm{~m}$ ca. 1800-1700 BC). Ce niveau serait suivi d'une « régression phanagorienne » d'une dizaine de mètres d'amplitude, puis d'une «transgression nymphéenne » vers un mètre au-dessus du niveau de la mer aux $\mathrm{VII}^{\mathrm{e}}$ et $\mathrm{VIII}^{\mathrm{e}}$ s. ap. J.-C. Finalement, une « régression korsunienne » vers - $3 \mathrm{~m}$ clôt cette reconstitution « de type yo-yo » de la mobilité du niveau marin de la mer Noire. Cette reconstitution apparaît fragile et spéculative. Elle s'apparente à un «collage » de nombreux indicateurs paléo-bathymétriques peu fiables et imprécis dans des secteurs géologiques très différents (Gergov 2000-2001; Chepalyga 1984).

Des travaux plus récents ont montré que le niveau marin s'est stabilisé depuis au moins 5000 ans en Bulgarie (Preisinger, Aslanian 2003 et 2004). Les données de terrain montrent en effet qu'il n'y a aucune trace de rivage holocène supérieur au niveau marin actuel. 
De la frontière turque à la frontière roumaine, nous n'avons retrouvé aucun indice géomorphologique (platier ou encoche soulevée) ni biologique (bioconstruction, biodéposition) en position supérieure à l'actuel. Le niveau marin actuel est donc le plus haut de l'Holocène. Les travaux d'archéologie sous-marine montrent à Sozopol la présence de pieux et de fragments de bois entre 6 et $5 \mathrm{~m}$ sous le niveau actuel, correspondant à des occupations humaines du Chalcolithique final et du Bronze ancien (Angelova, Draganov, Dimitrov 1994 ; Draganov 1995 ; Angelova, Draganov 2003). La mer Noire, connectée à l'océan mondial, a logiquement transgressé ces couches archéologiques depuis environ 3000 ans.

\section{Mobilité des lignes de rivage}

Dans un contexte de stabilisation généralisée du niveau de la mer (Laborel et al. 1994 ; Fairbanks 1989; Fleming et al. 1998), la variable la plus importante afin d'expliquer la mobilité des rivages est le budget sédimentaire au niveau de base depuis 5000 ans (Morhange 2001 ; Devillers 2008 ; Marriner, Morhange 2007).

L'étude de la variation du trait de côte à Sozopol est malheureusement à l'origine de plusieurs publications géomorphologiques qui «polluent» toute tentative de synthèse sur les rapports entre occupation du territoire depuis la fondation d'Apollonia, vers 610 av. J.-C., et dynamique paléo-géographique des milieux littoraux. Preisinger et Aslanian (2003 et 2004) ont en effet publié des cartes d'évolution des différents rivages depuis 7500 ans. Ils restituent sans aucun argument précis un môle thrace puis un môle grec au large de l'île de Sveti Kirik (fig. 8). Pour la période vers 3000 ans BP, ces auteurs proposent sans fondement de restituer une ligne de rivage vers $-5 \mathrm{~m}$ sous le niveau actuel de la mer, ce qui revient à supprimer la dépression entre le promontoire de Skamni qui porte la colonie grecque et l'île de Sveti Kirik. Le port romain se trouverait à l'extrémité orientale de l'île de Sveti Kirik, dans un secteur particulièrement exposé et battu par les houles du large (fig. 9). Ces spéculations non argumentées sont irrecevables.

Deux variables ont principalement influé sur la mobilité des rivages :

- Une mobilité verticale du niveau de la mer, très modeste depuis l'Antiquité. Par comparaison, dans un contexte tectonique stable, la montée du niveau de la mer est d'environ $70 \mathrm{~cm}$ depuis la fondation de Marseille (Morhange, Laborel, Hesnard 2001). L'analyse des données marégraphiques à Varna, Nessebar et Bourgas ne montre pas de mobilité significative du niveau de base depuis 1948 (Belyashki 1985; Becker et al. 2002;

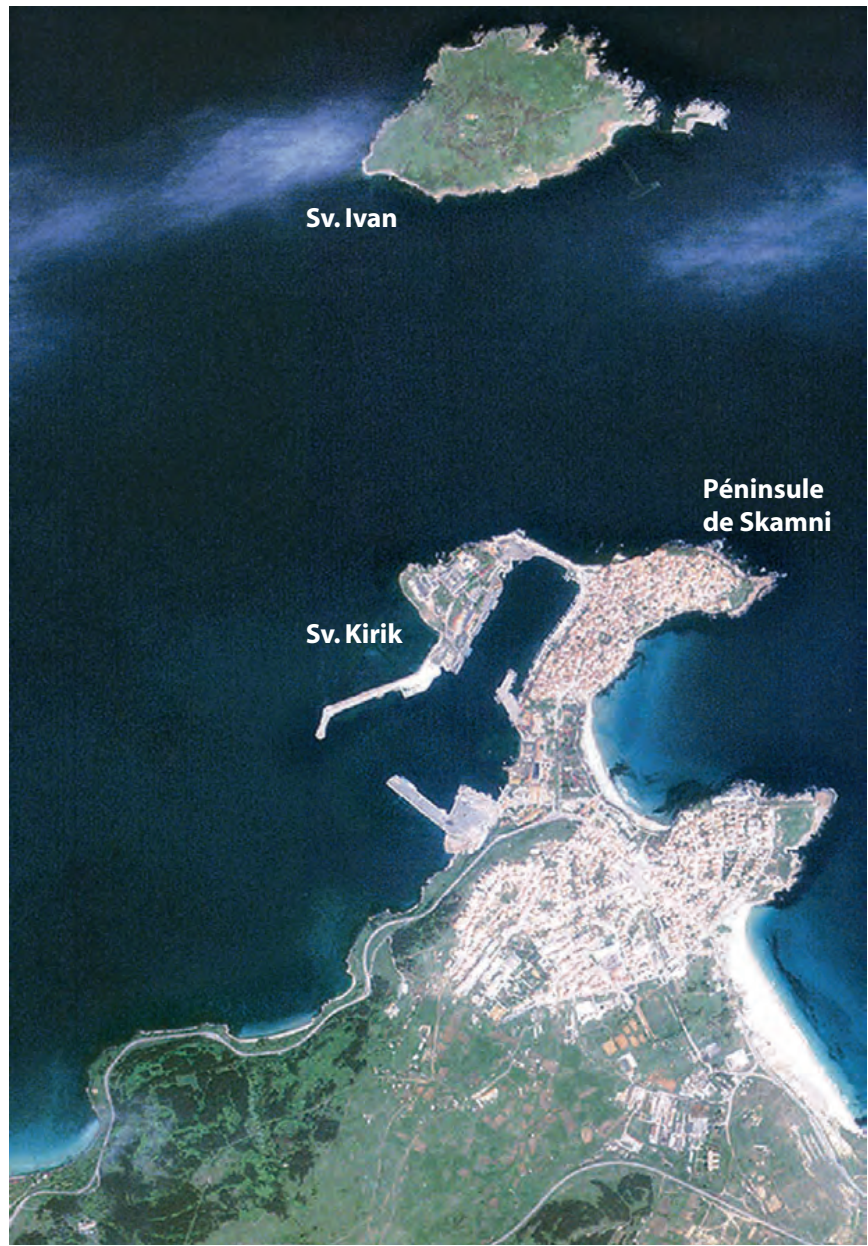

Fig. 7. Image satellite de la région de Sozopol (d'après Dimitrov 2004, modifié)

Cazenave et al. 2002). Sur la plage de Kalfata à Sozopol, des couches de sédiments biodétritiques supralittoraux actuels scellent par exemple des tombes du $\mathrm{V}^{\mathrm{e}} \mathrm{s}$. av. J.-C., suggérant la proximité immédiate du trait de côte et une mobilité du niveau de la mer très modeste depuis 2500 ans.

- En revanche, les apports sédimentaires à la côte ont grandement contribué à la régularisation du rivage. Les photographies anciennes présentent clairement l'isthme qui relie l'île-promontoire de Skamni au continent (fig. 10). Il s'agit d'un tombolo, d'une flèche sableuse reliant l'île de Skamni à la côte par diffraction des houles et accumulation préférentielle des sédiments dans la zone d'abri. Cette accumulation est antérieure à la période hellénistique, puisque des tombes de cette époque ont été découvertes et fouillées au sommet du tombolo. Dimitrov (2004) précise aussi que le tombolo est postérieur au $\mathrm{V}^{\mathrm{e}} \mathrm{s}$. avant J.-C., du fait de la construction d'une chaussée pavée qui a accéléré les processus de sédimentation. Un carottage réalisé dans le secteur de la chapelle Sveti Zosim présente deux faciès sédimentaires 

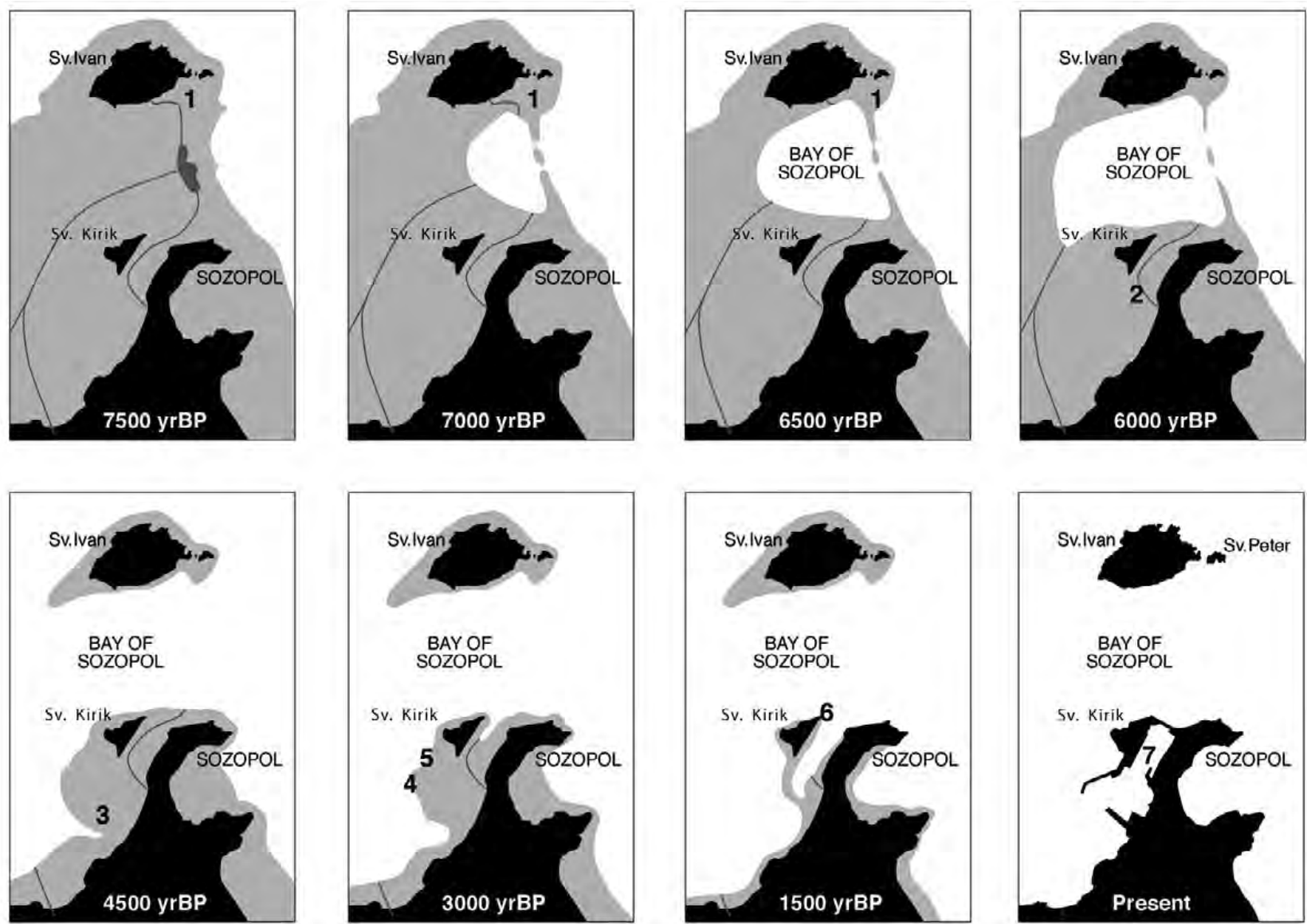

Fig. 8. Reconstitution des rivages et localisation hypothétiques des ports à Sozopol depuis 7500 ans (d'après Preisinger et al. 2000-2001, modifié).

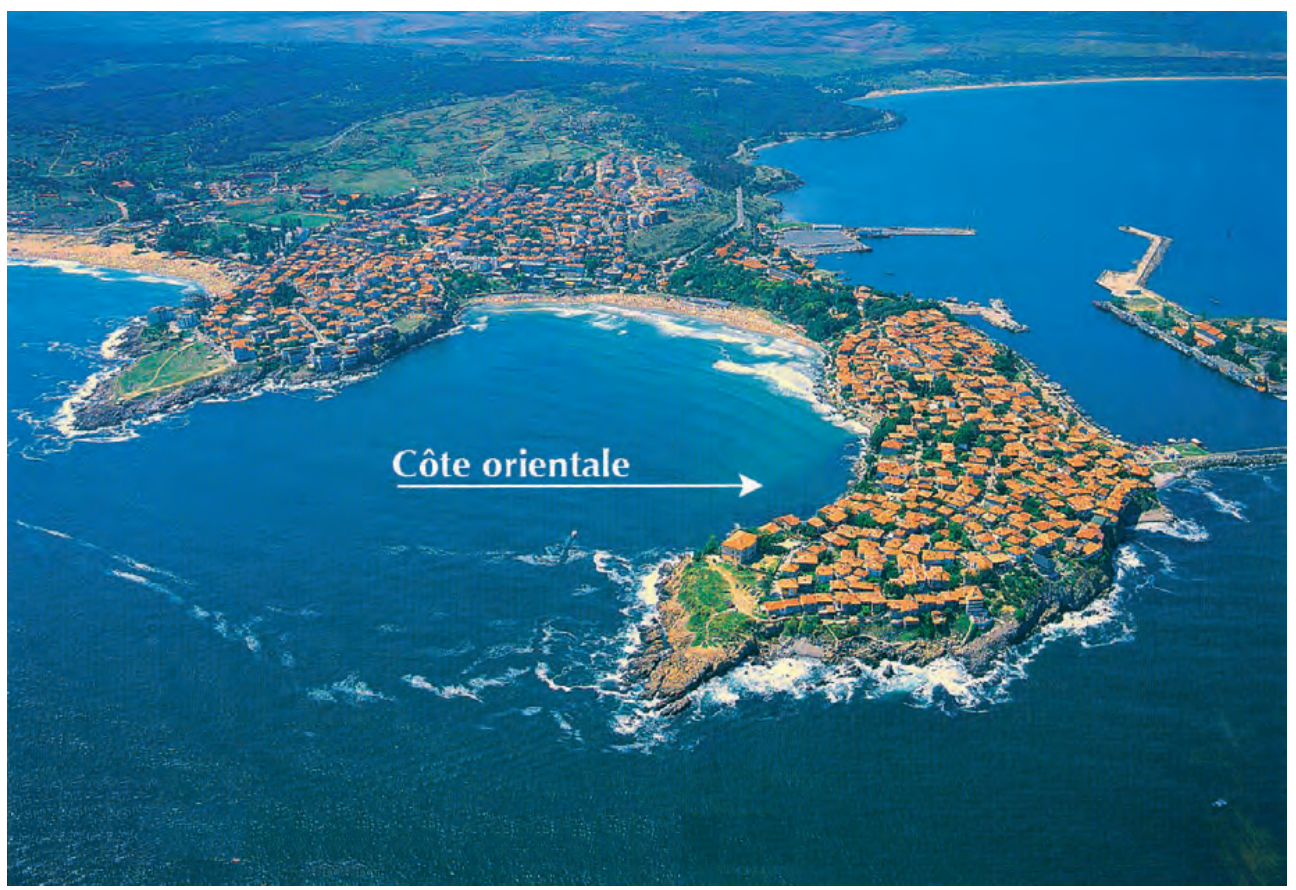

Fig. 9. La côte orientale du promontoire de Skamni est particulièrement exposée aux vents et aux houles du large. Le seul secteur littoral protégé correspond à la côte Nord-Ouest où se localise de nos jours le port de Sozopol (d'après une photographie aérienne Larus, modifiée). 


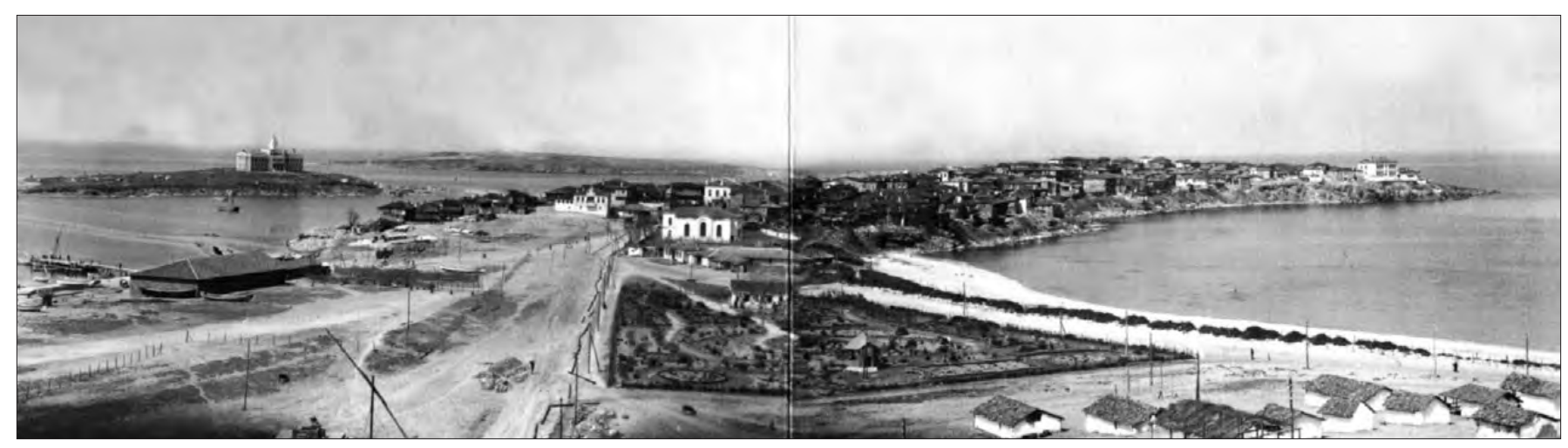

Fig. 10. Photographie du tombolo de Sozopol au début du XXe s. (d'après un cliché Laskaridis, Sozopol, modifié).

bien différents. Le substrat volcanique affleure vers $8 \mathrm{~m}$ sous le niveau du sol. Il est scellé par une couche de sables biodétritiques puis par deux mètres de remblais (Preisinger, communication personnelle). En l'absence de datation radiocarbone de cette carotte, et par comparaison avec d'autres tombolos beaucoup plus importants en taille et reliant des îles beaucoup plus éloignées du continent, comme Pharos d'Alexandrie (Goiran et al. 2005) ou Tyr (Marriner, Morhange, Meule 2007; Marriner, Goiran, Morhange 2008), nous pouvons faire l'hypothèse que le tombolo d'Apollonia est vraisemblablement pré-grec et date du début de la période de stabilisation du niveau marin, très antérieurement à la période de la colonisation grecque, vraisemblablement vers 6000 ans BP.

À plus grande échelle, la ville de Sozopol est entourée de vastes plaines de niveau de base qui correspondent à d'anciennes baies transformées en lagunes barrées par un cordon littoral (fig. 11). Au Nord-Ouest, la plaine de Gerena-Blatoto correspond à ce type de paléo-baie. Au Sud de Sozopol, les plaines de Kalfata et Kavatsité présentent une morphologie similaire qui évoque les mêmes processus de colmatage depuis environ 5000 ans. Des carottages dans la lagune proche d'Arkutino permettent d'évoquer quelques comparaisons (Bojilova, Beug 1992). Trois carottages ont déjà été effectués dans cette lagune. Onze datations radiocarbone ont été obtenues, indiquant que la sédimentation a commencé il y a environ 6000 ans, ce qui est un argument supplémentaire de ralentissement du niveau de la mer à cette période dans le secteur de Sozopol. Aucune influence d'eau saumâtre ou marine n'a pu être décelée du fait de la proximité immédiate de l'embouchure fluviale du Ropotamo. En 1989, un site de l'âge du Bronze a d'ailleurs été découvert sous le niveau de la mer à côté de l'embouchure du Ropotamo (Bojilova, Beug 1992). Cet indice est un argument complémentaire qui témoigne d'une stabilisation relative du niveau de la mer depuis l'âge du Bronze. La figure 11 montre la métamorphose des littoraux de la région de Sozopol depuis 5000 ans. La régularisation importante du littoral par colmatage des baies et l'édification d'un tombolo, comme à Sozopol, traduit donc à la fois la montée très modeste du niveau de la mer et l'importance du budget sédimentaire au niveau de base.

\section{Essai de localisation du port antique protégé d'Apollonia}

Un des objectifs principaux qui a guidé notre recherche était la localisation du port antique d'Apollonia au moment de la colonisation ionienne. L'importance de la situation maritime de la ville et son évolution historique ont été présentées ci-dessus.

Nous avons donc carotté dans deux secteurs littoraux de la ville antique susceptibles d'avoir abrité un port protégé :

1) sur la marge Nord-Ouest du promontoire de Skamni ;

2) le long de la rive Ouest du tombolo qui relie le centre ville de Sozopol à sa périphérie.

Comme les vents dominant soufflent du Nord-Est et de l'Est (Popov, Mishev 1974), nous avons carotté sur le quai du bassin portuaire actuel, protégé à la fois par le promontoire de Skamni et l'île de Sveti Kirik. Cette carotte fait plus de deux mètres de profondeur, avant de butter sur le substrat. Elle est composée de remblais hétérométriques au sommet, puis de sédiments sableux marins et terrigènes assez grossiers qui n'évoquent pas un faciès de décantation vaseuse typique des bassins portuaires protégés. Il s'agit donc de rivages relativement battus au pied de la falaise morte de Skamni. Une chaussée ne semble pas avoir été construite entre Skamni et l'île de Sveti Kirik, car le milieu de sédimentation serait alors beaucoup plus confiné. L'espace côtier disponible était à l'époque antique, comme de nos jours, particulièrement limité à une étroite frange littorale au pied de la 


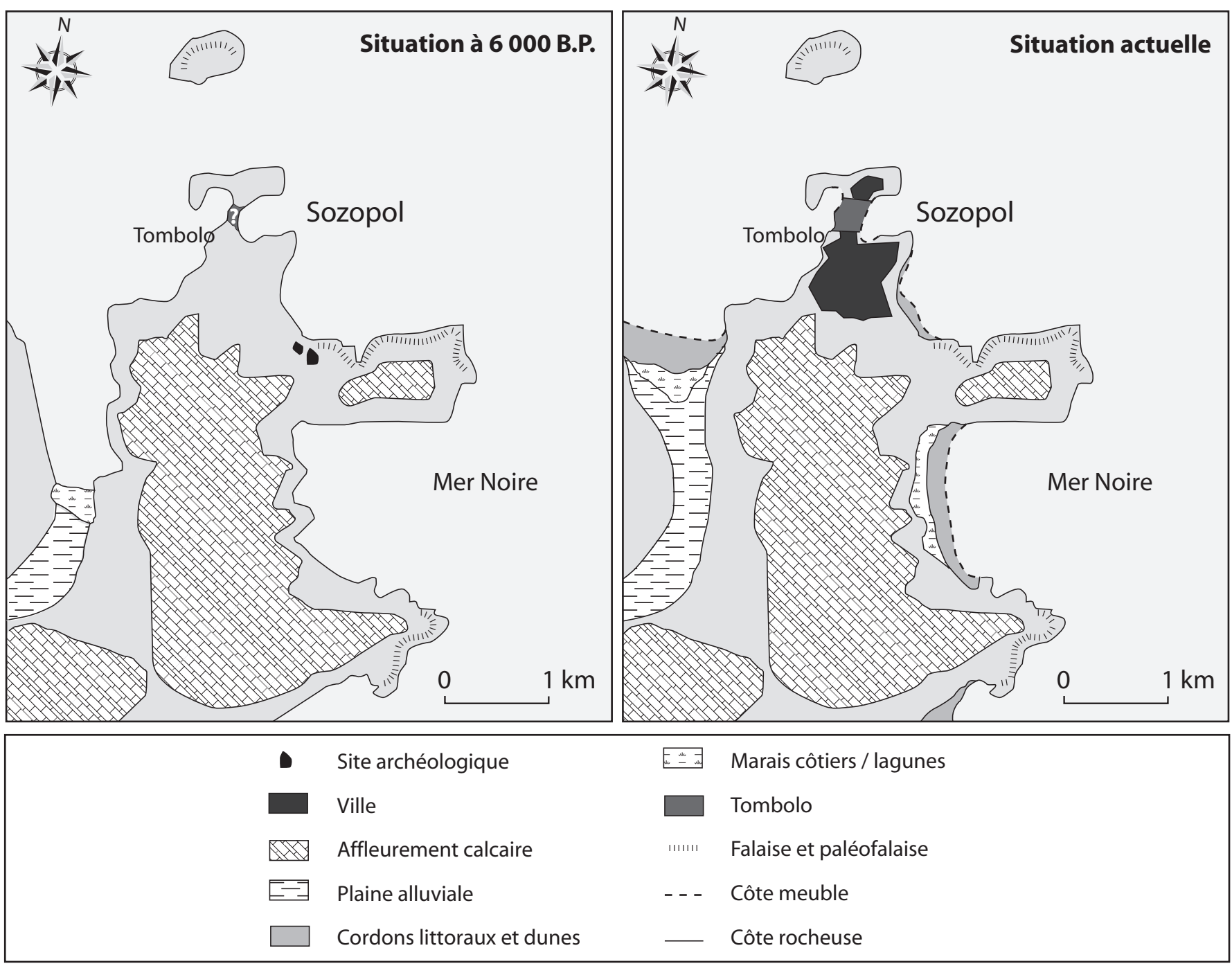

Fig. 11. Contexte géomorphologique de la région de Sozopol. A, Situation il y a environ 6000 ans - B, Situation actuelle. (B. Devillers).

falaise. On peut restituer un espace linéaire caractérisé par des navires tirés à sec à l'échouage. Le port antique protégé ne se situe pas dans ce secteur du promontoire.

Le secteur le plus propice à l'établissement d'un abri côtier est la façade Ouest du tombolo, protégée des houles d'Est et de Sud-Est à la fois par le cordon dunaire et le promontoire de Skamni, ainsi que par l'île de Sveti Kirik. De plus, la péninsule de Chernomorets protège assez efficacement ce secteur des houles de Nord-Ouest. Un carottage réalisé dans ce secteur a livré trois faciès sédimentaires différents (fig. 12-13 et tableau 1). La carotte fait $13 \mathrm{~m}$ de profondeur et n'a pas atteint le substrat volcanique. Les deux unités basales, datées entre 5000 et 4000 ans BP, sont constituées de sables marins assez grossiers. Deux espèces malacologiques dominent (Bittium reticulatum et Rissoa lineolata). Elles caractérisent les milieux infralittoraux sableux et rocheux. À partir d'environ sept mètres de profondeur et jusqu'à la surface du sol, le sédiment sableux devient plus grossier et plus coquillier. Il traduit une zone de déferlement des vagues au sommet de l'étage infralittoral entre 4000 et 2000 ans BP. Cette carotte démontre que la date d'édification du tombolo reliant la paléo-île de Skamni au continent est bien antérieure au VII ${ }^{\mathrm{e}} \mathrm{s}$. av. J.-C. Cette flèche sableuse a permis de faciliter l'accès continental à la cité et de délimiter un plan d'eau protégé au NordOuest. Ce secteur littoral protégé correspond au port antique d'Apollonia. Il s'agit d'un port « ouvert» qui prend la forme d'une plage aménagée au Nord-Ouest du tombolo. Dans l'état actuel de nos recherches, nous n'avons pas mis en évidence de bassin artificiellement protégé par un môle ou une digue, ce qui aurait inévitablement entraîné le dépôt de sédiments plus fins. Il semble que cette plage au Nord-Ouest du tombolo et le pied de falaise du promontoire de Skamni suffisaient pour accueillir les activités portuaires dans l'Antiquité, 


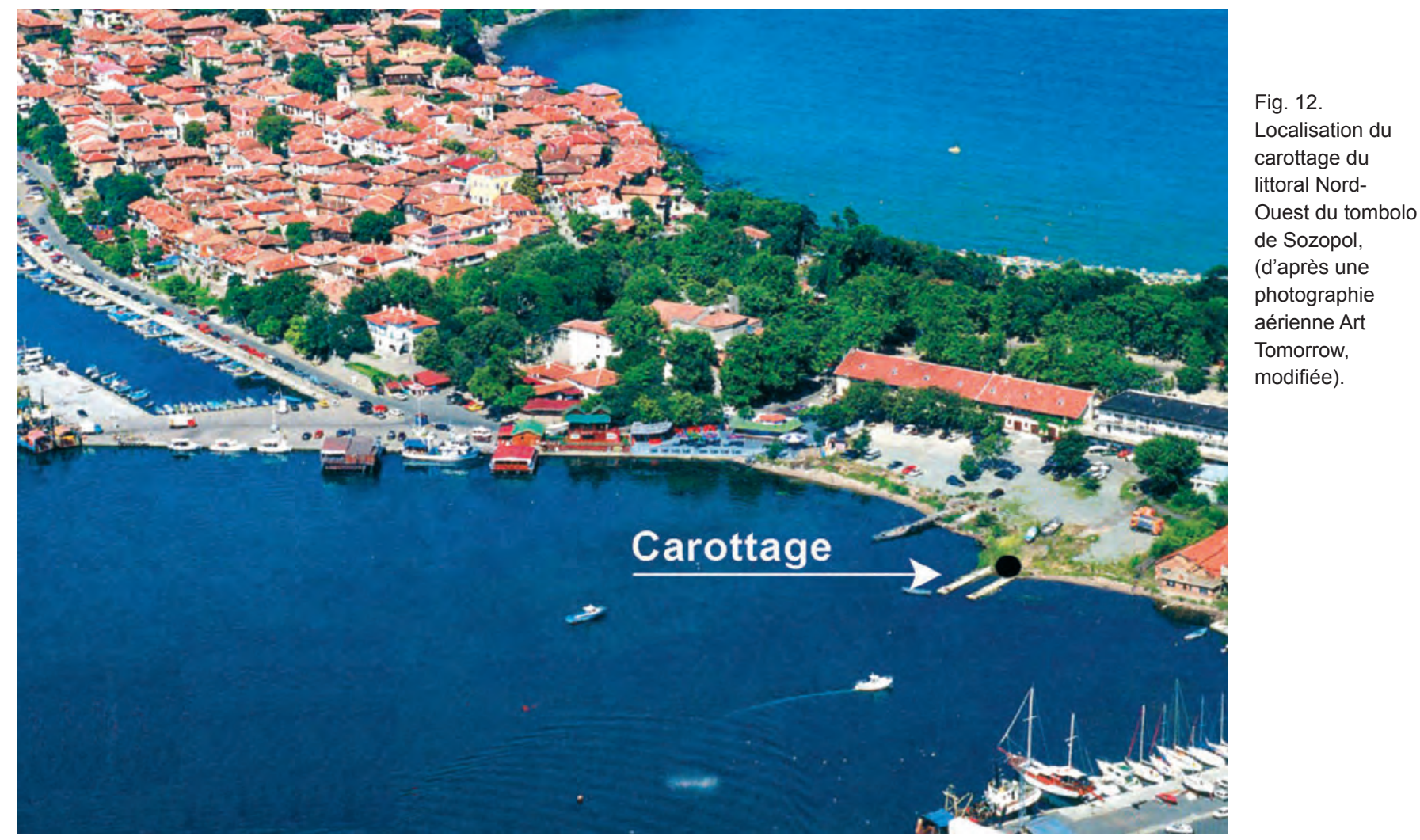

et même jusqu'à une époque très récente comme le montrent les photographies anciennes (fig. 10).

Deux mille cinq cents ans plus tard, le port de Sozopol est toujours localisé dans ce secteur. Cette permanence géographique traduit bien la très longue durée d'évolution des potentialités des interfaces littoraux.

\section{4. Étude géomorphologique de la nécropole de Kalfata, baie de Harmanité}

Les enjeux d'une recherche géoarchéologique et paléogéographique s'avèrent sensibles à Apollonia, en raison de la forte mobilité des milieux dans un espace littoral fortement impacté par la variation du niveau marin et par l'érosion des sols durant l'Holocène récent. La ville moderne, qui se superpose à la ville antique, occupe de nos jours une péninsule orientée Nord-Sud. Elle est reliée au continent par un tombolo où se développe, à l'époque hellénistique avancée et durant la période romaine, la principale nécropole d'Apollonia. Plus au Sud, le littoral présente une succession de caps rocheux séparés d'anciennes baies colmatées au cours de l'Holocène. Ces baies sont isolées de la mer par d'épais cordons sableux armés de dunes parfois imposantes. C'est dans ce vaste espace que la cité éparpille, durant les quatre premiers siècles de son existence, ses nécropoles plus anciennes.
Le site de Kalfata, en position littorale, est localisé sous le cordon dunaire actuel. Les observations croisées, archéologiques et géomorphologiques, démontrent que ce site présentait au moment de son installation un aspect très différent de l'actuel.

Nous avons pu effectuer une coupe complète de la nécropole qui présente deux milieux sédimentaires très différents (Gergov 2000-2001).

À la base, on distingue un sol sombre, les agrégats sont très bien développés. La texture est limonoargileuse, sans trace d'oxydation. Cette unité sombre découverte lors de la fouille correspond à un horizon A1 important. Aucun horizon A0 n'a été retrouvé. Les tranchées disponibles, peu profondes, n'ont pas permis de diagnostiquer d'autres horizons. Il est fort probable que ce sol corresponde à un Tchernozem ou à un Brunizem. La pédologie traduit la présence d'une steppe associée à des précipitations faibles, de l'ordre de $400 \mathrm{~mm}$.

La partie supérieure de la stratigraphie est composée exclusivement de sable homogène principalement détritique (faible proportion d'éléments bioclastiques). Ces couches sont reliées aux dunes actuellement visibles sur la plage de Kalfata. Les particules présentent un tri granulométrique très important. Ces sables sont disposés en lits millimétriques entrecroisés, de pendage uniforme vers le Nord. On observe aussi quelques lentilles de sable biodétritique, légèrement plus grossier et moins bien trié. Il s'agit de hauts de plage. 


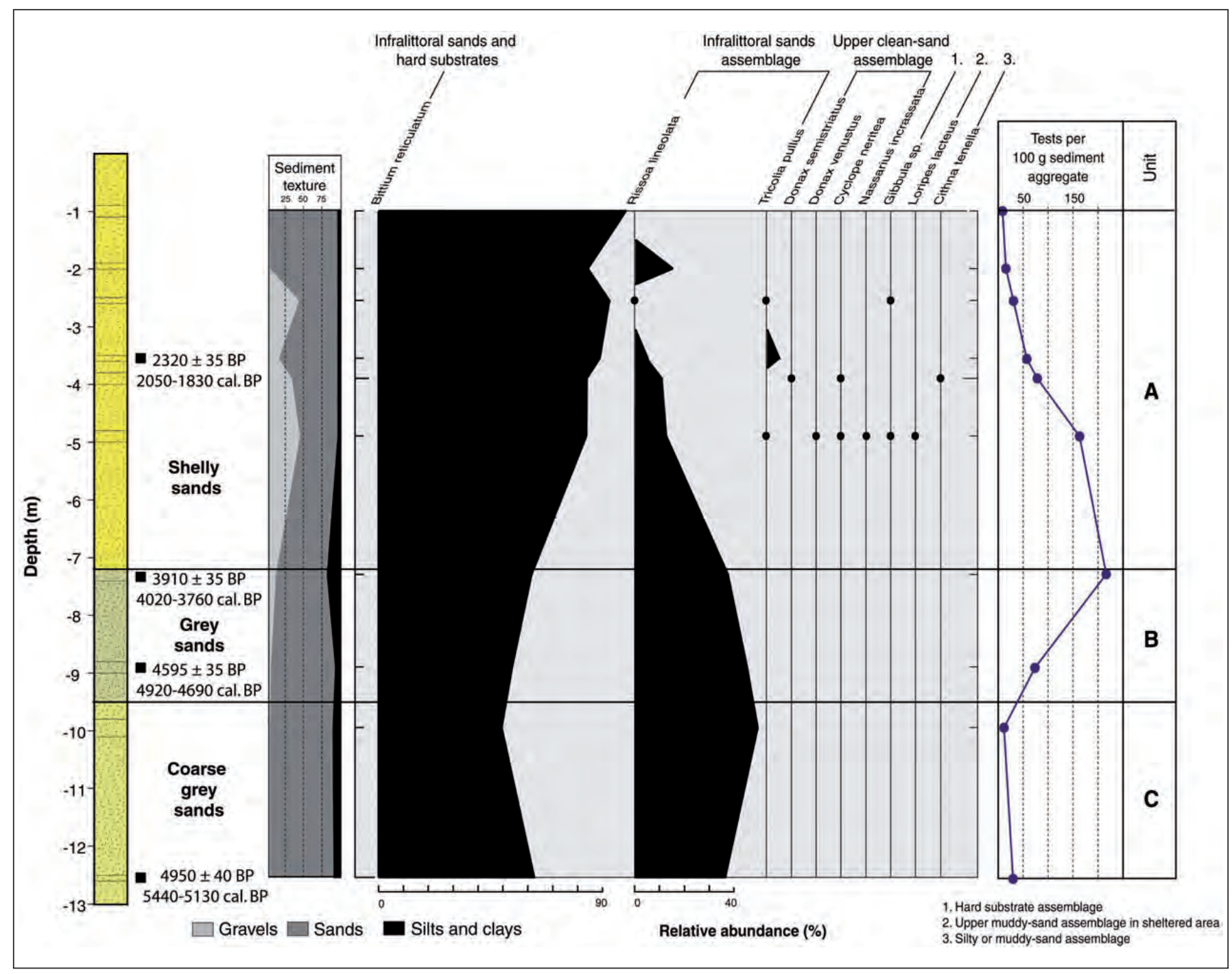

Fig. 13. Carotte du littoral Nord-Ouest du tombolo de Sozopol (analyses N. Marriner, 2008 ; datations radiocarbone par le laboratoire de Poznan).

\begin{tabular}{|l|l|l|l|l|}
\hline Echantillon & $\begin{array}{l}\text { Code } \\
\text { laboratoire }\end{array}$ & Type de matériel & $\begin{array}{l}\text { Datation radiocarbone } \\
\text { (BP) }\end{array}$ & Cal. BP \\
\hline Soz III 4 & Poz-25482 & $\begin{array}{l}\text { 2 Bittium reticulatum; } \\
\text { 2 Rissoa sp. }\end{array}$ & $2320 \pm 35 \mathrm{BP}$ & $2050-1830$ \\
\hline Soz III 7 & Poz-25483 & 4 Bittium reticulatum & $3910 \pm 35 \mathrm{BP}$ & $4020-3760$ \\
\hline Soz III 8 & Poz-25484 & 10 Rissoa sp. & $4595 \pm 35 \mathrm{BP}$ & $4920-4690$ \\
\hline Soz III 10 & Poz-25485 & 6 Bittium reticulatum & $4950 \pm 40 \mathrm{BP}$ & $5440-5130$ \\
\hline
\end{tabular}

Tableau 1. Datations radiocarbone de la carotte du tombolo de Sozopol. 
Ces différents éléments permettent donc de caractériser une accumulation continue de sables éoliens sous la forme de dunes et de placages. La présence des lentilles biodétriques à la base suggère la proximité du littoral. Des tombes du $\mathrm{IV}^{\mathrm{e}} \mathrm{s}$. av. J.-C. sont creusées à partir de ces niveaux sableux et en sont aussi totalement recouvertes. Le paysage sur le lieu du site à partir de cette époque est donc constitué d'un haut de plage dans un système littoral à tendance progradante.
La stratigraphie du site de Kalfata n'offre qu'une vision fragmentaire de la dynamique des paysages littoraux de la région de Sozopol. Elle met en évidence la formation d'un cordon littoral peut avant le IV ${ }^{\mathrm{e}} \mathrm{s}$. av. J.-C. qui traduit l'importance du détritisme à l'amont et vraisemblablement des mises en valeur agricoles à l'origine d'une érosion accélérée et de dégradations des couvertures pédologiques et des formations superficielles. 


\section{Chapitre 4}

\section{Présentation de l'espace urbain* et du territoire}

$\mathrm{L}$ es vestiges de l'antique Apollonia sont situés sur la péninsule de Skamni, sous l'actuel centre ancien de Sozopol. Sur cette péninsule et dans son voisinage immédiat, les témoignages d'occupation s'étalent sur plus de 6.000 ans, les premiers habitats apparaissant vers la fin du Chalcolithique et le début de l'âge du Bronze. Il s'agit de deux sites submergés, découverts dans le port de Sozopol à une profondeur de 5-6 m sous le niveau de la mer, qui ont fait l'objet de fouilles systématiques et d'un programme suivi de prospections géophysiques durant la période 1987-1995 ${ }^{54}$. Les résultats combinés de ces recherches ont montré qu'au moment de leur existence les habitats en question étaient installés dans un environnement paléolittoral fort différent de l'actuel : le site du Chalcolithique final était situé sur le rivage même de la mer, dans l'ancienne vallée (aujourd'hui submergée) de la rivière Patovska; après son abandon suite à un incendie, la zone s'était progressivement transformée en lagune d'eau douce au cours des siècles suivants avant qu'une occupation palafitte ait repris place durant le Bronze ancien (Angelova, Draganov, Dimitrov 1994, p. 18-19 ; Draganov 1995, p. 234-235).

Les derniers rapports parus sur l'exploration de ces sites font état également de la découverte sur le fond marin au Sud-Ouest, dans la zone de l'actuel port de plaisance, des restes d'un habitat de l'âge du Fer ancien (Angelova, Draganov, Dimitrov 1994, p. 19 ; Lazarov 2000, p. 28). Ce dernier est interprété à son tour comme un site submergé, détruit à la suite d'une montée du niveau de la mer. À la différence des sites mentionnés ci-dessus, il ne s'agit pas de vestiges qui sont en place, ce qui nous empêche pour l'instant d'accepter cette hypothèse. Néanmoins, une occupation de la période en question à l'extrémité méridionale de l'isthme sableux reliant la péninsule de Skamni au continent, à proximité de l'emplacement probable d'une source d'eau potable (Papaïoannidis 2004, p. 15 et 24), ne peut être exclue.

\footnotetext{
* Voir la Pl. 1 pour la localisation des sites.

54 Lazarov 1974, p. 107-108, fig. 1-6; Lazarov 1993, p. 9 ; Angelova, Draganov, Dimitrov 1994 ; Draganov 1995, p. 233-239; Angelova, Draganov 2003, p. 20-22.
}

Pour la même époque, il existe quelques indices concernant une occupation sur la péninsule proprement dite. Lors de fouilles réalisées en 1971 à son angle Sud-Est, près des fortifications de l'Antiquité tardive et du Moyen Âge, on a découvert dans la couche la plus profonde deux tasses en argile du Bronze récent (XV ${ }^{\mathrm{e}}-\mathrm{XII}{ }^{\mathrm{e}}$ s. av. J.-C.) (Lazarov 1974, p. 109, et 2000, p. 28). En se basant sur cette découverte et la présence de fragments datés de la fin du $\mathrm{II}^{\mathrm{e}}$ et du début du $\mathrm{I}^{\mathrm{er}}$ millénaire av. J.-C. dans le matériel provenant du dragage du port de Sozopol en $1927^{55}$, les auteurs du chapitre consacré aux habitats et fortifications thraces de la Strandja dans le premier volume des Mégalithes en Thrace ont formulé un peu plus tard l'hypothèse d'un établissement indigène à Skamni durant les quelques siècles précédant la colonisation grecque, selon le modèle attesté plus au Nord à Mésambria (Venedikov et al. 1976, p. 156 ; Venedikov 1980). Quelques découvertes ultérieures ${ }^{56}$, ainsi que les résultats des dernières recherches sur le site, montrent que cette hypothèse n'est pas dénuée de fondement. Des fragments céramiques au décor caractéristique du début de l'âge du Fer ont été mis au jour sous des niveaux archaïques (fin du VII'/début du VI ${ }^{\mathrm{e}}$ s. av. J.-C.) dans la partie Sud-Est de la péninsule, au $n^{\circ} 2$ rue Milet - site «Krepostni steni i saorajeniya »-, ainsi que dans sa partie centrale - site «Antichen jilishten kompleks » (Nedev, Panayotova 2003, p. 95-96; Gyuzelev 2008, p. 119-120). Néanmoins, leur quantité restreinte ne permet pour l'instant d'avoir aucune certitude quant à l'intensité et au caractère de l'occupation de la péninsule durant cette période, ni d'ailleurs de comprendre le lien qui existait entre cet éventuel établissement et les vestiges découverts dans la zone du port de plaisance au Sud.

Vers la fin du VII ${ }^{e}$ s. av. J.-C. s'installent à cet endroit les colons grecs fondateurs d'Apollonia, la plus ancienne apoikia de la côte Sud-Ouest du Pont-Euxin

55 Les fragments en question n'ont pas été publiés. Pour le matériel découvert lors du dragage du port, voir les références ci-dessous.

56 Voir Dimitrov 1987, p. 11, où il est fait état de la découverte, lors de travaux de construction dans le centre ancien de Sozopol, d'un vase décoré de mamelons («Buckelkeramik ») et d'une tasse à une anse du type connu à Troie VIIb2. 
selon le Pseudo-Skymnos. Il s'agit vraisemblablement de groupes originaires de Milet et de plusieurs autres villes d'Ionie du Sud. Cet événement est bien établi par les sources écrites et les monuments épigraphiques, ainsi que par les résultats des recherches archéologiques conduites sur l'île de Sveti Kirik et dans le centre ancien de Sozopol (Nedev, Panayotova 2003, p. 96 ; Gyuzelev 2008, p. 120-122).

La localisation du noyau primitif de la colonie ionienne, et celle du célèbre temple d'Apollon Iétros qui lui est souvent étroitement associée, sont l'objet d'importantes controverses qui durent maintenant depuis plus de 100 ans. À la base de ces discussions se trouve le passage de Strabon (VII, 6, 1) indiquant que la plus grande partie de la ville et le sanctuaire d'Apollon se trouvaient sur une petite île, ainsi que les interprétations du célèbre décret en l'honneur du navarque Hégésagoras découvert à Histria, mais provenant d'Apollonia. Le problème a déjà été examiné ci-dessus, dans le chapitre consacré à l'histoire et la topographie d'Apollonia. Nous nous bornerons ici à rappeler que la majorité des chercheurs semble s'accorder pour situer le temple abritant la statue colossale de Calamis sur l'actuelle île de Sveti Kirik, dans laquelle certains reconnaissent le premier établissement des colons grecs ${ }^{57}$, alors que d'autres considèrent qu'elle ne formait au début qu'une partie de la péninsule de Skamni, dont elle aurait été séparée par une montée du niveau marin vers la fin de l'époque hellénistique ${ }^{58}$, hypothèse contredite par le résultat des récentes recherches géomorphologiques (voir le chapitre précédent). Il existe d'autre part un groupe non négligeable de spécialistes qui, en suivant les indications de G. Seure, suppose que l'île de Sveti Kirik n'a eu qu'un usage strictement funéraire et que la ville antique s'est toujours développée sur la péninsule de Skamni, qui devait abriter également le temple d'Apollon ${ }^{59}$.

Pour le moment, les arguments archéologiques permettant d'étayer l'une ou l'autre de ces hypothèses sont assez rares. En ce qui concerne l'île de Sveti Kirik, les fouilles du consul Degrand en 1904 (Collignon 1905, p. 303-306 ; Seure 1924, p. 320-322 et 344-349) et les découvertes faites à l'occasion de la construction du bâtiment de l'ancienne École de pêche en 1924 (Mikov 1925, p. 236-239; Škorpil 1930/1931, p. 82), bien qu'ayant livré un matériel fort intéressant remontant

57 Collignon 1905, p. 303 et 306 ; Škorpil 1930/1931, p. 81-82; Papaïoannidis 2004, p. 41 ; Blavatskaya 1952, p. 26-27 ; Frel 1960, p. 251 ; Robert 1961, p. 191-192.

58 Dimitrov 1975b, p. 15-16; Dimitrov, Porojanov, Orachev 1982, p. 442 ; Lazarov 2000, p. 26-27 ; Oppermann 2004, p. 29 ; Gyuzelev 2008, p. 60-61.

59 Seure 1924, p. 320-325 ; Venedikov 1948, p. 9 ; Mihailov 1970, p. $353-356, n^{\circ} 388$ bis ; Panayotova 1994, p. 126-129.

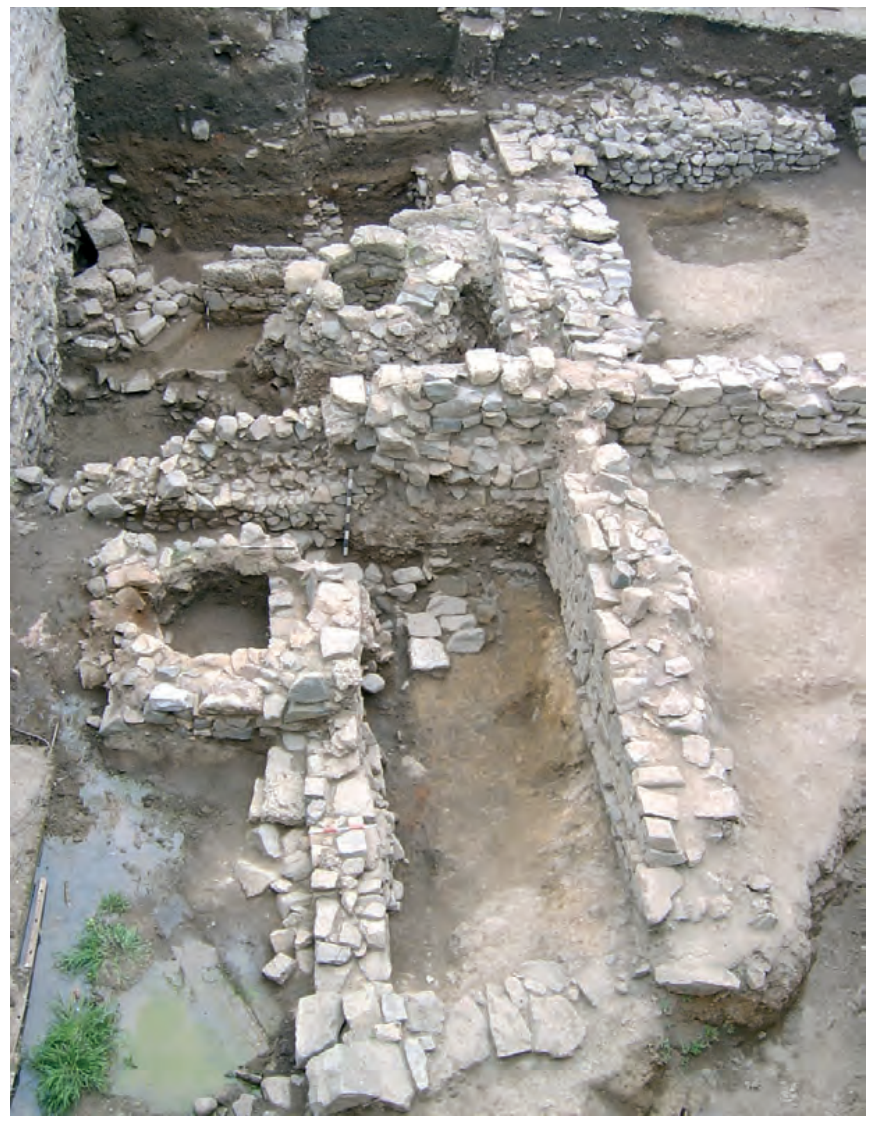

Fig. 14. Vestiges architecturaux d'époque hellénistique, rue Milet $n^{\circ} 16$ (UPI XI-XII-515) (Photo D. Nedev).

aux premières décennies de l'existence de la colonie ionienne, n'ont pas réussi à résoudre le problème de l'utilisation de cet espace dans l'Antiquité. Les riches trouvailles du dragage du port de Sozopol en 1927 posent également d'importants problèmes d'interprétation ${ }^{60}$. Il reste à espérer que les nouvelles fouilles débutées il y a quelques mois à peine par K. Panayotova sur la partie la plus élevée de l'île, à proximité immédiate du bâtiment de l'ancienne École de pêche, permettront d'apporter des éléments de réponse supplémentaires. Cependant, dans l'attente de la publication des premiers résultats, les informations les plus récentes dont nous disposons proviennent de la péninsule. Entièrement recouverte par le centre ancien de Sozopol (datant pour l'essentiel de la fin de l'époque ottomane), celle-ci est restée pendant très longtemps à l'écart des recherches archéologiques ${ }^{61}$, avant que la restitution des biens nationalisés

60 Voir Pandaleev 1928-29, p. 328 ; Galabov 1952, p. 102-117; Galabov 1965 ; Panayotova 1994.

61 On notera ainsi, avant le début des travaux dont il sera question plus loin, une seule publication consacrée à une oenochoé du style des Chèvres sauvages découverte par hasard lors du creusement d'un canal dans le centre ancien de Sozopol (Dimitrov 1975a). 


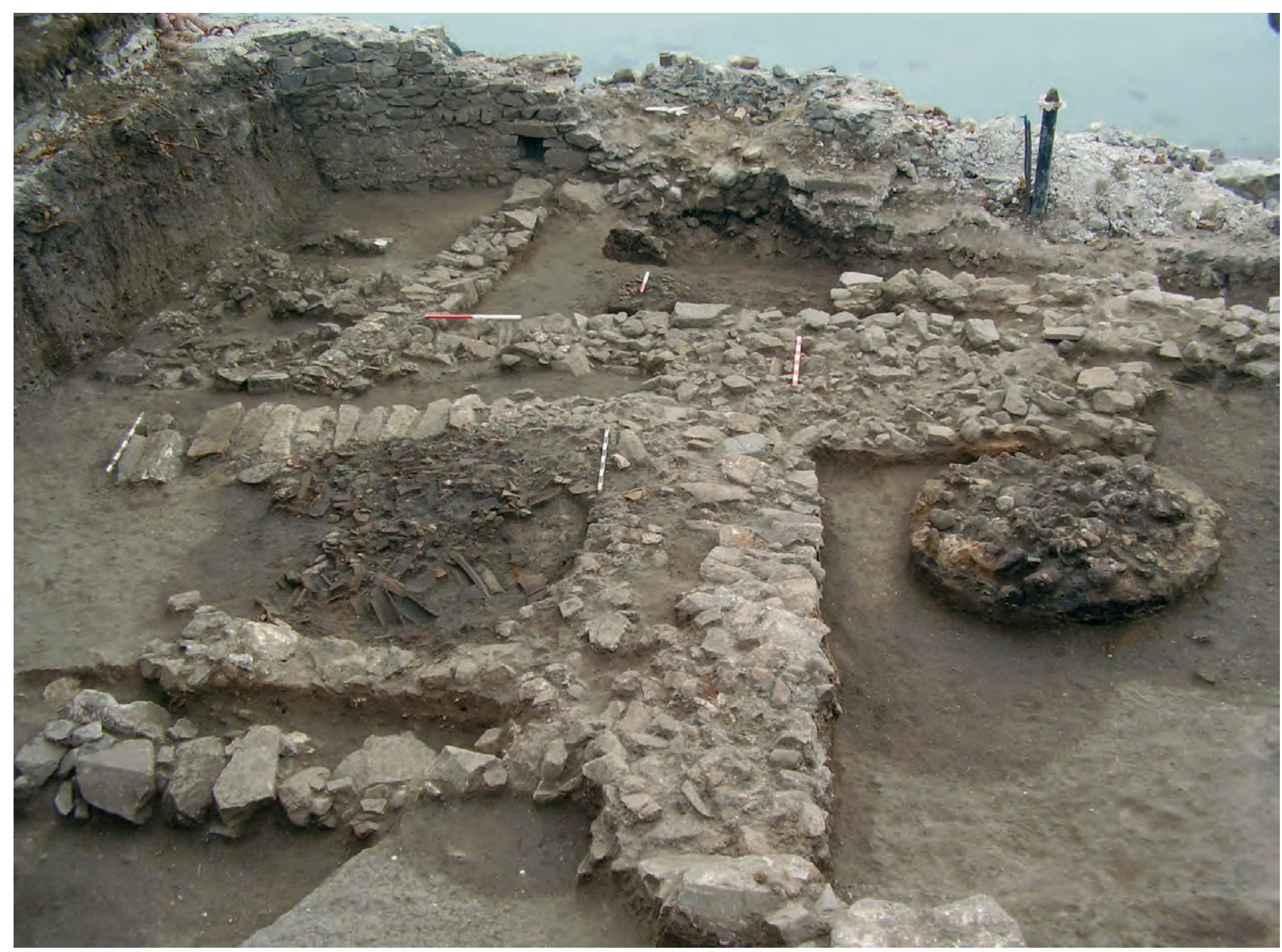

Fig. 15. Fosses d'époque archaïque, rue Sveti Kiril i Metody n³6 (Photo D. Nedev).

par le régime communiste et les travaux de construction durant ces quinze dernières années aient fourni l'occasion tant attendue d'étudier un nombre important de parcelles et d'effectuer des observations importantes sur l'urbanisme et l'architecture de la ville antique. Bien que la localisation du temple d'Apollon Iétros reste toujours problématique, les récentes fouilles de sauvetage ont confirmé que, dès la fin du VII e s. av. J.-C., Skamni était déjà pleinement intégrée au noyau urbain de la cité, rejetant ainsi l'hypothèse d'un établissement initial des colons grecs sur l'île qui ne se serait étendu que dans un second temps à la péninsule. C'est à la présentation de ces données que nous consacrons les lignes suivantes.

Les principales étapes de l'occupation de la péninsule au cours de l'époque archaïque peuvent être retracées d'après la diffusion et la concentration des céramiques archaïques. Il convient de signaler que les fouilles récentes à Skamni ont livré l'ensemble le plus vaste et le plus varié de céramiques de cette époque, qui dépasse toutes les découvertes effectuées précédemment sur l'île de Sveti Kirik ou dans le port de Sozopol (Nedev, Giuzelev, sous presse ; Nedev, Panayotova 2003, p. 99). Toutefois, la répartition de ce matériel sur la surface de la péninsule n'est pas uniforme. On note une forte densité dans les parties sud-orientale et centrale, sur les sites dits «Antichen jilishten kompleks », « Starata obshtina » ( $\mathrm{n}^{\circ} 17$ rue Sveti Kiril i Metodiy), « Krepostni steni i saorajeniya » $\left(\mathrm{n}^{\circ} 2\right.$ rue Milet $)$, «UPI XI-XII-515» $\left(\mathrm{n}^{\circ} 16\right.$ rue Milet) (fig. 14), «Maison Sumilev» $\left(\mathrm{n}^{\circ} 36\right.$ rue Milet), restaurant Orfey $\left(\mathrm{n}^{\circ} 34\right.$ rue Sveti Kiril i Metodiy), «Starata darvodelna » $\left(\mathrm{n}^{\circ} 46\right.$ rue Sveti Kiril i Metodiy), ainsi que sur le site situé au $n^{\circ} 36$ rue Sveti Kiril i Metodiy (fig. 15) ${ }^{62}$. Dans la partie septentrionale de la péninsule, où la densité est moindre, des fragments de cette époque sont attestés sur les deux sites dits

62 Drajeva, Nedev 1994a et b ; Drajeva, Nedev 1995 ; Drajeva, Nedev 1996, p. 54 ; Drajeva, Nedev 2005 ; Nedev 2006, p. 241 ; Gyuzelev 2007, p. 274-275; Nedev, Gospodinov 2007, p. 354 ; Nedev, Drajeva 2007, p. 357-358. 
«Morski skali » (nº 27 et 29 rue Morski skali). Enfin, un nombre bien inférieur de céramiques archaïques a été découvert à l'Ouest de l'axe central de la péninsule. Ces différences dans l'intensité d'occupation restent pour l'instant difficiles à expliquer, mais sont probablement dues aux conditions climatiques moins favorables sur les faces Ouest et Nord de Skamni.

En règle générale, le matériel archaïque provient de couches perturbées ou de fosses de rebuts creusées dans le substrat rocheux. C'est le cas tout particulièrement pour la partie Ouest de la péninsule. Dans quelques cas seulement, des restes d'habitations ont pu être dégagés, sans qu'il ait été possible de fixer leur plan d'ensemble. Il a tout de même été établi qu'elles étaient construites en briques crues sur un socle de pierres et qu'elles suivaient une orientation générale Nord-Sud. Leur couverture était probablement constituée de tuiles (Nedev, Panayotova 2003, p. 99 ; Gyuzelev 2007, p. 274).

La répartition chronologique des trouvailles confirme les observations faites précédemment au sujet de la céramique archaïque découverte à Apollonia (Nedev, Giuzelev, sous presse). Les fragments les plus anciens appartiennent à des productions de la Grèce de l'Est : des vases de la deuxième phase du style moyen des Chèvres sauvages (Middle Wild Goat Style II) et des bols à oiseaux qui sont datés de la fin du VII ${ }^{\mathrm{e}} \mathrm{s}$. av. J.-C. Les importations de Grèce de l'Est se poursuivent tout au long du siècle suivant avec le style tardif des Chèvres sauvages et le style de Fikellura. Les productions attiques à figures noires apparaissent dès la première moitié du $\mathrm{VI}^{\mathrm{e}} \mathrm{s}$. av. J.-C. et deviennent progressivement dominantes dans le courant de la deuxième moitié de ce même siècle. Les importations corinthiennes sont rares et limitées essentiellement à la première moitié du $\mathrm{VI}^{\mathrm{e}} \mathrm{s}$. av. J.-C.

Durant l'époque classique et hellénistique, l'établissement grec de Skamni possédait tous les éléments qui le caractérisent comme un noyau urbain (asty). Il était probablement protégé par un mur barrant l'isthme. Enée le Tacticien $(20,4)$ mentionne l'importante fortification et la porte de la ville d'Apollonia. Bien que ce témoignage ne soit pas confirmé par les données archéologiques, il est généralement accepté que le rempart entourait la plus grande partie de la péninsule et que la porte mentionnée par Enée se trouvait à proximité du port, lequel avait une grande importance dans la vie économique de la cité ${ }^{63}$.

63 Dimitrov 1987, p. 29 ; Nedev, Panayotova 2003, p. 101-102 ; Gyuzelev 2008, p. 124-125. Les vestiges de remparts conservés à la périphérie Sud-Est de la péninsule datent de l'époque protobyzantine (fin du $\mathrm{V}^{\mathrm{e}}$ ou début du $\mathrm{VI}^{\mathrm{e}} \mathrm{s}$. ap. J.-C.), ils ont été remaniés au Moyen Âge (XII ${ }^{\mathrm{e}}$-XIV ${ }^{\mathrm{e}}$ s.) : voir Drajeva, Nedev 1994b ; Nedev, Gospodinov 2007, p. 353 ; Nedev 2007, p. 356.
Dans l'asty étaient concentrés tous les bâtiments publics. Les recherches archéologiques n'ont pas donné jusqu'à présent d'indications sur la localisation de l'acropole et de l'agora d'Apollonia, mais elles ont enrichi nos connaissances sur les édifices de culte. Les vestiges d'un sanctuaire sont attestés sur le site « Starata Darvodelna »; il était lié au culte de l'Aphrodite

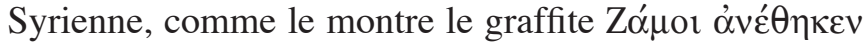

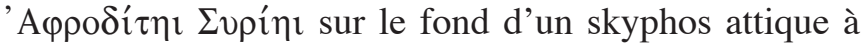
vernis noir retrouvé dans la pièce septentrionale, avec d'autres vases du troisième quart du $\mathrm{V}^{\mathrm{e}} \mathrm{s}$. (Nedev, Panayotova 2003, p. 102 ; Gyuzelev 2008, p. 125-126). Le bâtiment n'a pu être que partiellement exploré, car il a été incorporé dans le rempart de l'Antiquité tardive et du Moyen Âge, mais les restes de deux pièces orientées N.-E./ S.-O. dans l'axe longitudinal ont été dégagés. Contre la face interne du mur Ouest de la pièce septentrionale ont été découvertes trois plates-formes rituelles, dont deux présentaient des traces de feu à leur base; une quatrième plate-forme, de plus grandes dimensions et construite en pierres taillées sur un socle de moellons, se trouvait dans la pièce méridionale contre un mur de séparation. Celle-ci était malheureusement recoupée par le rempart médiéval et ses dimensions précises n'ont pu être établies. Les pièces conservées étaient recouvertes à leur tour par un bâtiment hellénistique ( $\mathrm{III}^{\mathrm{e}}-\mathrm{II}^{\mathrm{e}} \mathrm{s}$. av. J.-C.), qui fournit un terminus ante quem assuré pour la période de fonctionnement du sanctuaire. La largeur des fondations et la grande dimension des blocs utilisés pour la construction témoignent du caractère monumental de cet édifice de culte, mais rien de plus précis ne peut être dit au sujet de son plan d'ensemble.

Un autre sanctuaire a été localisé à l'extrémité méridionale de la première terrasse rocheuse qui se trouve au contact avec l'isthme (Nedev, Panayotova 2003, p. 121122 ; Gyuzelev 2008, p. 126). Ses vestiges étaient situés juste au-dessus du substrat, entre le rempart de l'Antiquité tardive et celui du Moyen Âge qui à cet endroit sont distincts. Une pièce à exèdre avec une entrée peu profonde qui permettait d'y accéder depuis le Sud a été dégagée. Au Sud de cette dernière ont été découvertes les fondations d'un autel construit en blocs de taille moyenne avec un emplecton constitué de mœllons non appareillés. À proximité a été mise au jour une base de

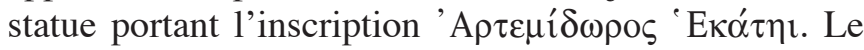
texte a un caractère votif, comme l'indique le nom au datif de la déesse Hécate. Le nom propre Artemidôros est théophore et doit probablement être mis en relation avec le syncrétisme des cultes d'Artémis et Hécate (Mihailov 1972, p. 229). L'espace sacré était limité à l'Ouest par un mur d'enceinte d'une longueur conservée de 18,50 m. Les objets découverts dans la pièce à exèdre et autour de l'autel datent approximativement de la fin du $\mathrm{III}^{\mathrm{e}}$ ou 
du II ${ }^{\mathrm{s}}$. av. J.-C. ; on notera, parmi eux, un médaillon à l'effigie d'Artémis, un kernos zoomorphe et des jetons en argile. La situation du sanctuaire à la périphérie méridionale de la ville s'explique par les fonctions d'Hécate comme protectrice des voyageurs ou son rôle chthonien, étant donné la proximité de la nécropole hellénistique.

Un troisième sanctuaire, datant également de l'époque hellénistique ( $2^{\mathrm{e}}$ moitié du $\mathrm{III}^{\mathrm{e}} \mathrm{s}$.), a été découvert au Nord de l'église Sveti Georgi (Saint-Georges), lors des fouilles du site «Antichen jilishten kompleks » (Nedev, Panayotova 2003, p. 122). En l'absence d'inscriptions permettant de l'identifier, il ne peut être lié à un culte précis. Il s'agit d'un édifice orienté Nord-Sud, composé d'une seule pièce précédée d'une petite antichambre sur son flanc méridional, dans laquelle avait été aménagée l'entrée. Les spécificités du plan et le grand nombre de terres cuites découvertes dans le comblement intérieur permettent de l'identifier comme un lieu de culte, probablement un sanctuaire domestique qui desservait l'ensemble résidentiel contemporain qui a été étudié à proximité ${ }^{64}$.

En plus de ces découvertes, les documents épigraphiques nous renseignent sur la présence d'autres cultes dans la ville. Ainsi, une inscription datée $d u V^{e}$ ou du $\mathrm{IV}^{\mathrm{e}} \mathrm{s}$. av. J.-C. mentionne l'existence d'un megaron de la déesse chthonienne Gaia (Kalinka 1905, col. 337, $\mathrm{n}^{\circ} 441$; Mihailov 1970, p. 365-366, $\mathrm{n}^{\circ}$ 398). Deux inscriptions plus tardives témoignent de l'existence d'organisations religieuses liées au culte et aux fêtes de Dionysos. La première d'entre elles représente une liste des membres du thiase du dieu, avec leurs fonctions (Mihailov 1970, p. 370-372, n 401). La deuxième - le décret en l'honneur du navarque histrien Hégésagoras de la première moitié du $\mathrm{II}^{\mathrm{e}} \mathrm{s}$. av. J.-C. - est d'une importance particulière pour l'étude de l'organisation sociale, politique et religieuse d'Apollonia (voir ci-dessus). Le fait même que le navarque soit honoré par les plus hauts magistrats de la cité lors des Dionysies témoigne du rôle très important joué par ce culte à Apollonia.

Parallèlement aux édifices de culte, les fouilles de sauvetage sur la péninsule de Skamni ont permis de révéler les restes de quelques bâtiments, dont le caractère monumental permet de supposer un usage public ou commercial. Un de ces édifices, datant de l'époque classique, a été découvert récemment au Sud de l'église Saint-Georges lors des fouilles du site «Starata obshtina » (Gyuzelev 2007, p. 275) (fig. 16). Il a malheureusement été en grande partie détruit par une maison hellénistique de la fin du $\mathrm{III}^{\mathrm{e}}$ ou du début du II ${ }^{\mathrm{e}}$ s. av. J.-C. qui s'est installée sur ses vestiges. Les

64 Nedev, Panayotova 2003, p. 122. Voir également Drajeva, Nedev 1994a, 1995, 1996 et 2003, p. 107-108. restes architecturaux comprennent un mur dont la façade est tournée au Sud-Est, construit en appareil régulier et associé à une plate-forme rectangulaire du côté Est. Onze éléments architecturaux appartenant à une corniche, un fragment de décret et un relief votif donnent une indication sur la probable fonction publique de l'édifice.

Un autre ensemble monumental, comprenant une vaste citerne de plan polygonal, creusée à une profondeur de 3,5 m dans le substrat rocheux, et les restes d'un bâtiment qui lui était associé à l'Ouest, a été mis au jour au n ${ }^{\circ} 35$ rue Sveti Kiril i Metodiy (Drajeva, Nedev 1995 ; Nedev, Panayotova 2003, p. 104 ; Gyuzelev 2008, p. 127). L'analyse quantitative des trouvailles a permis d'identifier quelque 2.000 vases, dont la plupart proviennent d'un ensemble clos (le remplissage de la citerne) qui peut être daté des années 380-330 av. J.-C. par une soixantaine de timbres amphoriques héracléotes et thasiens. Les fragments de vases à figures rouges sont d'une grande valeur artistique : on a répertorié des cratères, des lékanides, des askoi, un grand skyphos décoré de scènes du banquet d'Héraclès, un cratérisque, ainsi que plusieurs coupes-skyphoi appartenant à la production de l'atelier du «Peintre Q ». Le site est interprété par D. Nedev comme un bâtiment à vocation commerciale ou économique.

À proximité immédiate, au $n^{\circ} 34$ rue Sveti Kiril i Metodiy, un ensemble similaire datant de l'époque hellénistique (fin du $\mathrm{III}^{\mathrm{e}}$ ou première moitié du $\mathrm{II}^{\mathrm{e}} \mathrm{s}$. av. J.-C.) a été dégagé lors de sondages dans la cour du restaurant «Orfey » (Orphée) (Nedev, Panayotova 2003, p. 122 ; Gyuzelev 2008, p. 127). Ici encore, l'élément le mieux conservé était un puits de dimensions 2,45 x 2,5 m et d'une profondeur de 4,5 m. Il était construit en grands blocs de grès sans mortier et entièrement recouvert de deux couches d'enduit hydraulique à l'intérieur et au fond. Le remplissage comportait une grande quantité de tuiles (kalypters) à décor plastique, des antéfixes, des simas, des fragments d'une corniche en terre cuite à décor polychrome, ainsi que trois chapiteaux doriques. Ce puits a été interprété par D. Nedev comme un élément de fontaine ou de nymphée.

Dans l'espace de la péninsule a été localisé un certain nombre de maisons, à péristyle ou à pastas, construites sur une surface réduite (Nedev, Panayotova 2003, p. 106). Leurs fondations étaient établies sur un socle en pierres d'une largeur moyenne de 50 à $80 \mathrm{~cm}$. L'élévation était en briques crues avec une armature en bois, le tout enduit d'argile; le toit était probablement à double pente. L'état de conservation des murs ne permet pas de procéder à des reconstitutions précises des élévations, mais les fragments de tuiles de type laconien et corinthien découverts dans le remblai donnent des indications sur la couverture. Les nombreux objets découverts attestent 


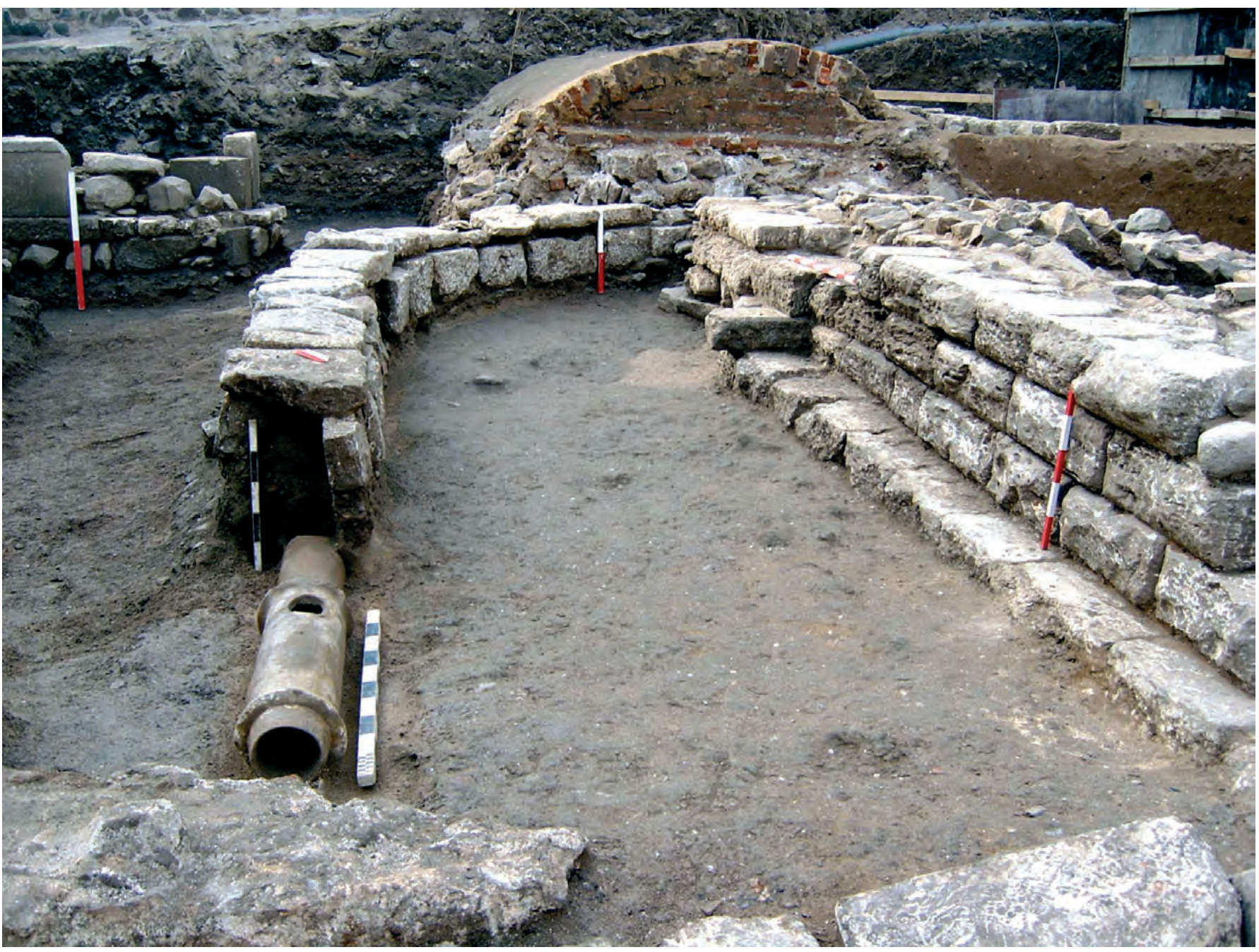

Fig. 16. Vestiges d'un bâtiment public d'époque classique, site «Starata obshtina (Ancienne mairie) », rue Sveti Kiril i Metody ${ }^{\circ} 17$ ( Photo D. Nedev).

la répartition interne des pièces en espaces à fonction économique ou domestique, auxquels s'ajoutaient parfois d'autres aménagements, telles des citernes ou des canalisations. En règle générale, il manque les éléments architecturaux permettant de supposer une dimension monumentale pour ces habitations.

Les vestiges étudiés dans les différents secteurs du noyau urbain d'Apollonia montrent une grande densité d'occupation et de construction sur toute la surface disponible. L'urbanisme est soumis à des principes uniformisés pour l'orientation des édifices, en fonction des conditions topographiques. Cette tendance, perceptible dès la première moitié du VI ${ }^{\mathrm{e}} \mathrm{s}$., est attestée jusqu'à la fin de l'Antiquité (Nedev, Panayotova 2003, p. 104).

Une part importante des témoignages sur l'urbanisme d'Apollonia nous est fournie par le système d'approvisionnement en eau. Sa mise en place a été effectuée en fonction des conditions spécifiques de la péninsule de Skamni, où la pénurie d'eau se faisait encore sentir jusqu'à une époque très récente. Le système était basé sur la construction d'un réseau de citernes creusées dans le substrat rocheux et revêtues dans la plupart des cas d'une maçonnerie en pierre. Elles étaient disposées le long de l'axe central de la péninsule, où le terrain est le plus élevé, ainsi que sur les terrasses côtières plus basses au Sud, au Sud-Est et à l'Ouest. Leur fonction était de récolter et de conserver l'eau de pluie. Le puits découvert dans la cour du restaurant Orphée ( $\mathrm{n}^{\circ} 34$ rue Sveti Kiril i Metodiy) et celui connu depuis de longues années sur l'île de Sveti Kirik (Filov 1912-1913 ; Seure 1924, p. 321) constituent les seuls aménagements alimentés par des eaux souterraines. Les citernes étaient souvent situées dans la cour des maisons. Au $n^{\circ} 35$ de la rue Saints Cyrille et Méthode a été mis au jour le plus important aménagement de ce type, d'une capacité de $100 \mathrm{~m}^{3}$, situé au Nord-Ouest du tracé probable d'une rue antique. 


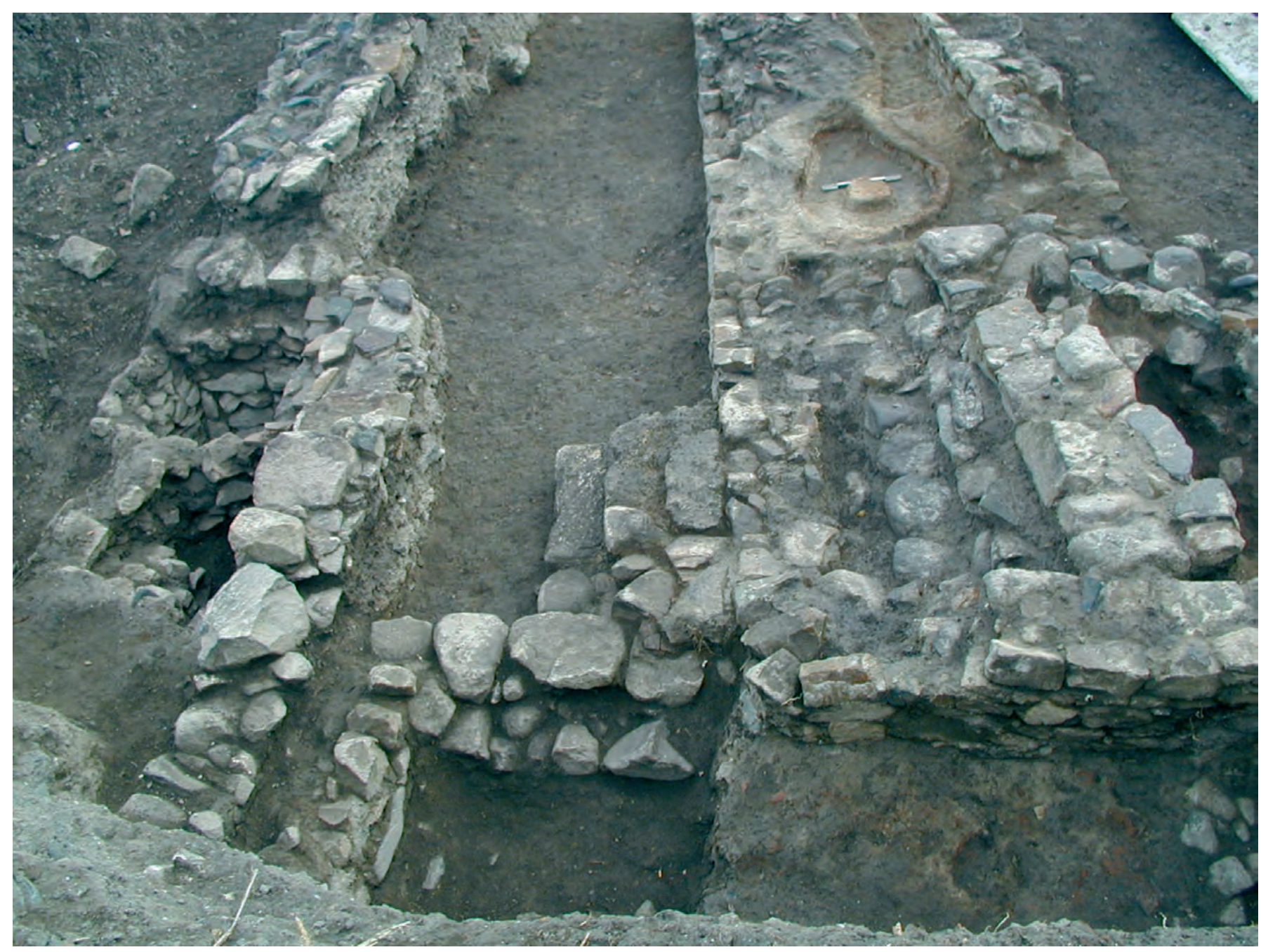

Fig. 17. Vestiges d'un complexe de production céramique, site « Morski Skali (Roches marines) », rue Morski skali n² 27-29 (Photo D. Nedev).

Un autre élément important du système d'approvisionnement en eau de la ville est la canalisation en terre cuite (datée entre la fin du $\mathrm{V}^{\mathrm{e}} \mathrm{s}$. et le début du troisième quart du IV ${ }^{\mathrm{e}}$ s. av. J.-C.) découverte lors des fouilles de la nécropole classique et hellénistique au lieu-dit Kalfata, qui part de la baie de Rayski zaliv et longe la plage de Harmanité. Elle était destinée à apporter de l'eau depuis une source à haut débit située à $1,5 \mathrm{~km}$ de la ville ${ }^{65}$.

Les dernières recherches en milieu urbain apportent également des données sur la vie artisanale de la population. Dans la partie septentrionale de la péninsule - sites « Morski skali » (fig. 17) et «Vyatarna melnitsa »- ont été mis au jour les vestiges de deux fours de potiers (Drajeva, Nedev 1994a; Nedev, Panayotova 2003,

65 Concernant cette source, qui était un lieu de promenade privilégié pour les habitants de Sozopol au début du $\mathrm{XX}^{\mathrm{e}}$ s., voir Papaioannidis 2004, p. 23-24. p. 105 ; Gyuzelev 2008, p. 127-128). Les trouvailles provenant de l'intérieur de ces structures - restes d'enduit rubéfié et de sole, fragments de vases à vernis noir et de productions communes - permettent de les dater de la deuxième moitié du IV ${ }^{\mathrm{e}} \mathrm{s}$. av. J.-C. Nous pouvons donc supposer qu'un quartier d'artisans, aux limites encore incertaines, avait existé dans cette partie de la ville.

Les larges accumulations de scories que l'on a retrouvées à divers endroits lors des fouilles de sauvetage témoignent par ailleurs d'une production métallurgique développée à Apollonia: il s'agit principalement de scories de bronze que l'on trouve surtout dans les couches des VI ${ }^{e}-I^{\text {e }}$ s. av. J.-C. (Nedev, Panayotova 2003, p. 106 ; Drajeva, Nedev 2003, p. 107 ; Gyuzelev 2007, p. 274). De même, les restes de deux fours métallurgiques ont été découverts en 2006 lors de fouilles dans la parcelle UPI 226, carré 18 (Nedev, Drajeva 2007, p. 358). Un seul de ces fours était relativement bien conservé. Il avait 
une forme tronconique, était enduit d'argile à l'intérieur et revêtu de moellons à l'extérieur. Le praefurnium était situé au Nord-Est. Les deux structures peuvent être datées du troisième quart du $\mathrm{VI}^{\mathrm{e}} \mathrm{s}$. av. J.-C. La production métallurgique à Apollonia était probablement destinée essentiellement à l'exportation, car ni les fouilles sur la péninsule de Skamni, ni celles des différentes nécropoles de la cité antique n'ont livré jusqu'à présent des quantités significatives d'objets en bronze.

Un processus d'appropriation des territoires extraurbains se développe parallèlement au développement urbain. La chôra d'Apollonia connaît à chaque période une dynamique de développement particulière ${ }^{66}$. Durant l'époque archaïque ses limites probables sont, au Nord, la péninsule d'Atiya et, au Sud, la baie de Kavatsité. La découverte d'une statue archaïque et d'un important trésor de monnaies-pointes de flèches (Pandaleev 1928-1929, p. 328 ; Galabov 1952, p. 93-102), étayée par la tradition littéraire, témoigne de l'intérêt d'Apollonia pour la péninsule d'Atiya qui devait lui procurer l'accès aux riches gisements de cuivre des collines de Rosen bair et Medni Rid. La cité devait contrôler également l'ensemble du réseau portuaire entre la baie de Sozopol et celle d'Atiya, au sein duquel le port d'Atiya devait avoir une importance particulière. La zone d'activité commerciale la plus ancienne entre les Thraces et les Grecs semble avoir été la région des lacs de Bourgas, dotée de terres fertiles et de riches gisements miniers. La céramique archaïque provenant des fosses rituelles découvertes au lieu-dit Kostadin Tchechma, près du village de Debelt, souligne le rôle du lac de Mandra, accessible par le cap Phoros (Balabanov 1986, p. 222223 et 228-230 ; Balabanov 1999).

Le remarquable développement économique d'Apollonia à l'époque classique s'exprime par la mise en place définitive du territoire de la cité. La ville élargit

66 Pour un aperçu détaillé de l'évolution du territoire d'Apollonia, se reporter en particulier au chapitre de M. Gyuzelev dans Nedev, Panayotova 2003, p. 107-119. Pour un inventaire complet et un commentaire des sites archéologiques qui y ont été repérés, voir Gyuzelev 2008, p. 95-119 et 142-150. son activité commerciale vers le Nord, dans la région des lacs de Bourgas qu'elle contrôle désormais, comme en témoignent les découvertes d'un habitat antique situé au lieu-dit «Sladkite kladentsi », dans l'actuel quartier «Pobeda » de Bourgas (Galabov 1950b; Balabanov, Drajeva 1985). Cette prospérité économique et le contrôle des routes maritimes dans ce secteur du PontEuxin aboutissent à la création d'un nouveau territoire côtier, dont les limites atteignent au Nord l'établissement d'Anchialos (sur la péninsule de Pomorié), qui a probablement été fondé à cette époque. Au voisinage de ce dernier, au lieu-dit Gerena, a été mis au jour du matériel d'époque classique (Stoyanov 1993). D'après Strabon (VII, 6, 1), le territoire de la cité s'étendait au Nord jusqu'à Anchialos et au Sud jusqu'au cap Thynias. La prospérité d'Apollonia a eu une influence positive sur les habitats thraces situés dans son territoire et à ses franges, sur les sommets des collines de Meden Rid. La cité dispose alors de nouvelles zones de contact au Sud, dans la région de la lagune d'Alepou et de Malkoto Kale, dans celle de l'embouchure du Ropotamo et le long de la frange littorale qui s'étend au Sud de la péninsule de Buruna. Dans l'ensemble de ces zones, on voit se multiplier au $\mathrm{IV}^{\mathrm{e}} \mathrm{s}$. av. J.-C. les trouvailles de céramique grecque importée et de tuiles timbrées produites à Apollonia.

Durant l'époque hellénistique, on ne note pas de changements essentiels dans la structure de la cité : Apollonia protège bien son intégrité territoriale, comme en témoigne la guerre avec Mésambria, mentionnée dans le décret en l'honneur d'Hégésagoras découvert à Histria. Pour cette période, on dispose de quelques données nous renseignant sur la présence de structures extra-urbaines dans le territoire d'Apollonia, grâce à un décret du $\mathrm{III}^{\mathrm{e}}$ ou du $\mathrm{II}^{\mathrm{e}} \mathrm{s}$. av. J.-C. mis au jour sur l'île de Sveti Kirik, qui fait état des relations entre Apollonia et le gouverneur thrace Kotys, fils de Taroulas (Mihailov 1970, p. 397, n 469bis).

Apollonia garde son rôle dominant sur la côte occidentale de la mer Noire jusqu'aux premières décennies du Ir s. av. J.-C., quand elle est conquise et détruite par les Romains. 


\section{Chapitre 5}

\section{Kalfata dans l'ensemble des nécropoles d'Apollonia}

\section{Topographie générale}

Les nécropoles qui entourent la cité constituent notre principal fil conducteur (fig. 18) pour comprendre l'évolution de la ville, bien que l'emplacement des sépultures les plus anciennes reste encore inconnu. Il n'est pas exclu que les secteurs funéraires de la fin du VII et du début du $\mathrm{VI}^{\mathrm{e}}$ s. av. J.-C. soient installés sur la péninsule même de Skamni, dans le voisinage immédiat de l'habitat des premiers colons ioniens, ou sur l'île toute proche de Sveti Kirik. G. Seure, dans le compte rendu qu'il donne des fouilles du consul Degrand, rapporte en effet la présence sur cette île, en particulier dans la partie Sud, de tombes construites en plaques calcaires qu'il considère toutes comme antiques (Seure 1924, p. 321 et 348). V. Mikov, T. Gerasimov et I. Galabov ont, par la suite, complété ces informations (Mikov 1925, p. 237 239 ; Gerasimov 1938 ; Galabov 1965, p. 13-16). On mentionnera en particulier une petite tête en marbre, de style vaguement dédalique (Gerasimov 1938 ; Mansowa 1972), énigmatique à la fois pour sa fonction (la partie inférieure montre qu'elle n'était pas associée à un corps) et sa date : il pourrait s'agir d'un support de lampe ou de brûle-parfum imitant des modèles dédaliques. I. Galabov met d'autre part en relation les découvertes faites sur l'île avec le matériel retrouvé lors du dragage du port en 1927, qui a livré plusieurs stèles funéraires, ainsi qu'un intéressant matériel céramique, démontrant peut-être que les alentours de l'actuelle zone portuaire ont été utilisés très tôt comme nécropole (Panayotova 1994, p. 128-130).

À partir du milieu du VI ${ }^{\mathrm{e}}$ s. av. J.-C., les habitants de la colonie ionienne ont commencé à enterrer leurs morts à l'extérieur de la péninsule de Skamni, en particulier sur les pentes méridionales de la colline rocheuse qui accueille de nos jours le quartier moderne de Harmanité (Lazarov 1969, p. 3-20 ; Tsaneva 1976, 1977 et 1980). Ce secteur de la nécropole, situé immédiatement au Sud de la cité, demeure en fonction jusque dans les premières décennies du III ${ }^{\mathrm{e}}$ s. av. J.-C. Il constitue le noyau initial à partir duquel s'opère dans la seconde moitié du $\mathrm{V}^{\mathrm{e}} \mathrm{s}$. un remarquable développement des zones funéraires, le long du littoral, en direction du Sud. La nécropole classique et hellénistique occupe en effet la deuxième terrasse sableuse, au lieu-dit Kalfata, ainsi que les falaises constituant l'extrémité occidentale de la péninsule de Boudjaka. Les inhumations se poursuivent dans cette zone éloignée de la cité jusqu'au début du $\mathrm{II}^{\mathrm{e}} \mathrm{s}$. av. J.-C. (Venedikov 1963a, p. 7-59; Panayotova 1998a et b; Nedev, Panayotova 2003, p. 125-126). Des sépultures de la même époque ont également été signalées au-delà de la péninsule de Boujdaka, au lieu-dit Kavatsité, distant de $5 \mathrm{~km}$ d'Apollonia. Dans ce secteur, plusieurs sources font état de découvertes fortuites réalisées lors du fonctionnement, au cours du $\mathrm{XX}^{\mathrm{e}} \mathrm{s}$., d'une carrière de sable sur un terrain délimité par l'ancienne route littorale et la nouvelle route panoramique pour Tsarevo. Les fouilles de sauvetage conduites durant ces trois dernières années aux lieux-dits Kavatsité et Solinaria ont depuis confirmé ces observations (Panayotova et al. 2006, p. 243). Il n'est toutefois pas exclu que les habitants inhumés ici proviennent d'une agglomération secondaire installée sur le territoire de la cité.

Parallèlement, I. Venedikov rapporte la découverte, au Sud-Ouest de la péninsule de Skamni, le long de la route moderne conduisant à Bourgas, de plusieurs tombes datées des $\mathrm{V}^{\mathrm{e}}$ et $\mathrm{IV}^{\mathrm{e}} \mathrm{s}$. av. J.-C., dispersées sur les pentes rocheuses (Venedikov 1963a, p. 8). Plusieurs autres exemples, mis au jour accidentellement, sont venus s'ajouter récemment lors des travaux de construction des nouvelles infrastructures hôtelières ${ }^{67}$. Ces découvertes permettent de fixer la limite septentrionale de la nécropole classique et hellénistique, qui atteignait la petite rivière Patovska qui se jette dans la mer le long du terrain du camping « Gradina ».

L'extension remarquable des zones funéraires aux $\mathrm{V}^{\mathrm{e}}-\mathrm{III}{ }^{\mathrm{e}} \mathrm{s}$. av. J.-C. a de fortes chances de refléter une croissance parallèle du nombre des habitants : en s'appuyant sur le témoignage d'Enée le Tacticien $(20,4)$, Ch. Danov estimait à environ 3.000 citoyens la population d'Apollonia à cette époque (Danov 1969, p. 293).

Tout autour de ces secteurs funéraires, où est inhumé l'essentiel de la population de la colonie, se développe

67 Nous remercions chaleureusement D. Nedev, directeur du Musée archéologique de Sozopol, pour ces informations. 


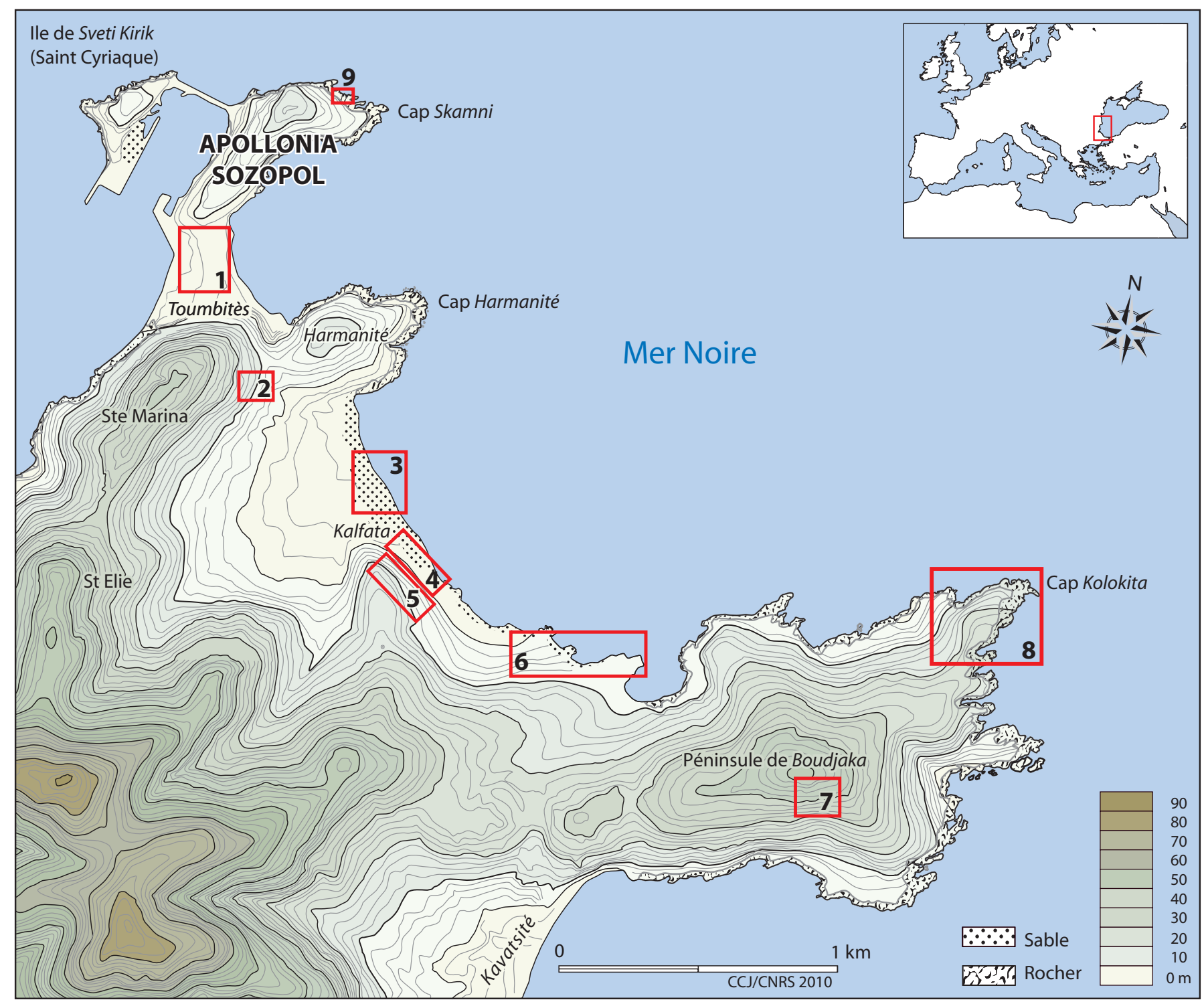

Fig. 18. Carte des nécropoles d'Apollonia (@ CCJ) :

1. Jardin maritime. Nécropole tardo-hellénistique et romaine. Fouilles d'I. Venedikov en 1949 (Institut et Musée archéologique de Sofia), de M. Tsaneva et de K. Panayotova, de 1987 à 1992 et en 1998 (Musée archéologique de Sozopol et Institut et Musée archéologique de Sofia).

2. Harmanité. Nécropole archaïque et classique. Fouilles de M. Lazarov de 1964 à 1966 et de M. Tsaneva dans les années 1970 (Musées archéologiques de Bourgas et de Sozopol).

3. Kalfata. Nécropole classique et hellénistique. Fouilles d'I. Venedikov de 1946 à 1949 (Institut et Musée archéologique de Sofia).

4. Kalfata. Nécropole classique et hellénistique. Fouilles de K. Panayotova, depuis 1992 (Institut et Musée archéologique de Sofia).

5. Kalfata. Nécropole classique et hellénistique. Fouilles de D. Nedev (Musée archéologique de Sozopol), K. Panayotova (Institut et Musée archéologique de Sofia), M. Gyuzelev (Musée archéologique de Bourgas) en 2001 et de 2005 à 2007.

6. Boudjaka. UPI 5040 à 5094. Nécropole classique et hellénistique. Fouilles de K. Panayotova de 2005 à 2009 (Institut et Musée archéologique de Sofia).

7. Boudjaka. Nécropole classique et hellénistique. Fouilles de D. Nedev en 2007 (Musée archéologique de Sozopol).

8. Kolokita. Nécropole tumulaire. Fouilles du consul de Grèce à Bourgas Goffas en 1885, du consul de France à Plovdiv Degrand en 1904 , ainsi que de M. Tsaneva de 1981 à 1985 (Musée archéologique de Sozopol), A. Boshkova, A. Petrova, V. Katsarova et R. Mikov en 2006 (fouilles de sauvetage de l'Institut et Musée archéologique de Sofia).

9. Morski Skali. Nécropole médio-byzantine. Fouilles de D. Nedev en 1993 (Musée archéologique de Sozopol). 
parallèlement une nécropole exclusivement tumulaire qui entoure les secteurs de Kalfata et de Boudjaka. Ces tumuli s'installent à partir du début du $\mathrm{IV}^{\mathrm{e}} \mathrm{s}$. av. J.-C. sur le cap Kolokita (à l'extrémité orientale de la péninsule de Boudjaka), au lieu-dit Mapité, près de la baie de Kavatsité, ainsi que sur la crête des collines de Sveti Ilia (Saint-Elie) et Sveta Marina, qui dominent au Sud/Sud-Ouest la ville antique. Un des plus grands tumuli de la région, celui de Mapité I, a livré une tombe à dromos, dans lequel ont été découvertes deux cistes : elles contenaient, selon les identifications proposées, un sujet de sexe masculin et un autre de sexe féminin, tous deux couronnés et accompagnés d'un mobilier datable de la fin du IV e ou du début du IIIe s. av. J.-C. (Seure 1924, p. 335-337 ; Ruseva 2002, n 32). Dans le secteur de la colline de Sveti Iliya, quelques tumuli protégeaient des urnes en pierre ou des cistes avec des restes de crémations. Les offrandes funéraires, similaires à celles attestées à Kalfata et Boudjaka, peuvent être datées pour la plupart vers le milieu du IV e s. av. J.-C. (Seure 1924, p. 341-344; Tsaneva, Dimitrov 1976).

Les fouilles de sauvetage effectuées ces dernières années sur le cap Kolokita ont confirmé le caractère particulier de cette nécropole tumulaire. Lors des premières fouilles dans ce secteur, réalisées en 1885 par le consul grec P. Goffas, un cercle de 50 amphores avait été mis au jour dans le tumulus IV, autour d'une tombe en pierre de contenu inconnu (Seure 1924, p. 330). Il est également probable que 62 autres amphores découvertes par le consul de France A. Degrand en 1904 proviennent du même complexe (ibid.). Dans le tumulus étudié par M. Tsaneva dans les années 1980, 120 amphores étaient disposées en demi-cercle (Tsaneva 1985b, p. 355356 ; Tsaneva 1986b, p. 170-171). En 2006, d'autres tumuli ont été fouillés à Kolokita, livrant des vestiges d'importantes structures funéraires du $\mathrm{IV}^{\mathrm{e}} \mathrm{s}$. av. J.-C. (Alexandrov 2007, p. 234 ; Katsarova 2007, p. 307310, fig. 1-3 ; Mikov 2007, p. 341-344, fig. 1-3). Sur la base des observations effectuées sur un des tumuli, qui a livré 75 timbres amphoriques datés des années 390-380 (Bojkova, Petrova 2007, p. 247), et en comparant ces données avec celles publiées par G. Seure, A. Bojkova et A. Petrova ont récemment formulé l'hypothèse que la nécropole établie sur le cap Kolokita exerçait, dans la première moitié du $\mathrm{IV}^{\mathrm{e}} \mathrm{s}$. av. J.-C., une fonction tout à fait spécifique. Elle aurait servi en effet à accueillir les sépultures, essentiellement symboliques, d'Apolloniates morts loin de leur patrie (Bojkova, Petrova 2007, p. 247). À l'appui de cette hypothèse, on peut citer le témoignage des frères Škorpil, qui rapportent la découverte dans ce secteur d'une boîte en cuivre argenté portant l'inscription $\triangle \mathrm{HMO} \Sigma$ АПО $\Lambda \Lambda \Omega$ NIA (Škorpil 1891 , p. 126, et 1999, p. 48). Cependant, comme me l'indiquent A. Baralis et A. Riapov, la probabilité que les tumuli étudiés en 2006, tous étrangement dépourvus de restes humains, correspondent non à des cénotaphes, mais plutôt aux dix tumuli fouillés par les consuls Goffas et Degrand au tournant des $\mathrm{XIX}^{\mathrm{e}}$ et $\mathrm{XX}^{\mathrm{e}}$ s., ne saurait être exclue ${ }^{68}$. Le caractère relativement luxueux des sépultures et des structures funéraires découvertes sur le cap Kolokita doit en revanche être souligné, suivant en cela la remarque formulée par M. Damyanov sur la base d'une comparaison des rites funéraires accomplis à cet endroit avec ceux attestés dans la zone de Kalfata ${ }^{69}$.

Entre les $\mathrm{III}^{\mathrm{e}}$ et $\mathrm{I}^{\mathrm{er}}$ S. av. J.-C., les zones funéraires connaissent une forte contraction, à l'issue de laquelle elles délaissent les secteurs de Kalfata et de Boudjaka pour se concentrer de nouveau à proximité des murs de la ville, dans le secteur de l'actuel Jardin maritime ${ }^{70}$, suivant une tradition qui s'est poursuivie durant l'époque moderne. Il est intéressant, sur ce point, de constater que cette évolution de la topographie funéraire intervient bien avant le sac de la ville perpétré en 72 av. J.-C. par Marcus Lucullus, auquel on attribue un déclin général de la cité (Pline, Hist. Nat., XXXIV, 39).

Par analogie avec d'autres nécropoles antiques, on peut supposer que le Jardin maritime avait initialement servi, durant l'époque hellénistique, comme lieu de sépulture pour des citoyens honorés par la cité (Winniczuk 1988, p. 9). La découverte à cet endroit d'objets de parure en or (Mladenova 1963a, p. 293-296, fig. 104, pl. 158-159) semble conforter cette hypothèse, tout comme la mise au jour de deux stèles funéraires de soldats, datées du $\mathrm{III}^{\mathrm{e}}$ s. av. J.-C., sur lesquelles on lit la formule O $\Delta \mathrm{HMO} \Sigma$ accompagnée de la représentation d'un autel couronné (Robert 1959, p. 220 ; Venedikov, Velkov 1963, p. 328 $\mathrm{n}^{\text {os }} 1159-1160$; Mihailov 1970, $\mathrm{n}^{\text {os }} 395$ bis et ter ). Elles témoignent des honneurs particuliers que les citoyens de la cité ont accordés aux défunts, selon une pratique connue par exemple à Athènes ou dans la nécropole de Métaponte-Pantanello où, à la fin du IV e et au début du III' s. av. J.-C., des membres de l'élite ont été inhumés dans les secteurs de la nécropole disposés à proximité immédiate de la ville (Carter 1998, p. 49).

68 Tous les fouilleurs rapportent en effet que les tumuli explorés avaient été fortement perturbés par des creusements récents. Il serait possible, par ailleurs, de rapprocher le matériel amphorique découvert par A. Bojkova et A. Petrova des trouvailles du tumulus IV fouillé par Goffas et Degrand (Seure 1924, p. 330), ou de comparer la tombe en fer à cheval dégagée par V. Katsarova à une structure très similaire mentionnée par les frères Škorpil, que l'on peut mettre en rapport avec les fouilles de Goffas (Škorpil 1999, p. 48).

69 Poster présenté à l'occasion du $\mathrm{III}^{\mathrm{e}}$ Congrès Pontique à Prague, 11-18 septembre 2005, «A burial mound in the vicinity of Apollonia Pontica ».

70 Venedikov 1963a, p. 60-64, et fouilles de sauvetage de M. Tsaneva, K. Panayotova, D. Nedev en 1997-1998. 
En 1980, lors de fouilles de sauvetage dirigées par M. Tsaneva et T. Stoyanov sur le site « Kulturen dom », dans la partie Nord-Ouest du Jardin maritime, ont été découvertes une dizaine de sépultures appartenant à la nécropole antique d'Apollonia. La plus ancienne est une ciste construite en dalles de calcaire à l'époque hellénistique, puis réutilisée à l'époque romaine $\left(\mathrm{III}^{\mathrm{e}}-\mathrm{IV}^{\mathrm{e}} \mathrm{s}\right.$. ap. J.-C.) (Tsaneva, Stoyanov 1981, p. 70-71). Parmi les trouvailles provenant de la zone voisine, on note une monnaie de Philippe II et cinq monnaies d'Apollonia datées de 350-306 av. J.-C., des fragments de tuiles et d'amphores, ainsi que de la céramique attique et ionienne importée. Parmi les vases importés, les coupes et les skyphoi prédominent, certains portant des graffiti. Il s'agit, jusqu'à présent, du secteur funéraire le plus proche de l'espace urbain.

Cette mobilité dans la topographie funéraire de la ville d'Apollonia/Sozopolis se poursuit au Moyen Âge. Au cours de l'époque médio-byzantine, les nécropoles occupent par exemple l'extrémité Nord de la péninsule de Skamni, tout comme, de façon éparse, celle de Harmanité. Elles se concentrent en revanche durant l'époque ottomane autour des églises extra-muros, notamment celles du Jardin maritime où elles demeurent en fonction tout au long du $\mathrm{XIX}^{\mathrm{e}} \mathrm{s}$., comme le rappellent les stèles encore visibles contre l'église de Sveti Zosim (Saint-Zosime).

\section{La nécropole de Kalfata, remarques générales}

La partie de la nécropole d'Apollonia du Pont découverte dans le secteur de Kalfata est localisée sur la deuxième terrasse sableuse qui borde la large baie de Harmanité (fig. 19). Le choix du lieu n'est pas fortuit et répondait probablement au désir d'utiliser les terres impropres à l'agriculture le long de la bande littorale. Cette pratique, consistant à inhumer les défunts sur la côte sableuse, est très largement diffusée parmi les premiers colons présents dans les cités grecques de Thrace égéenne ${ }^{71}$.

Les plus anciennes sépultures découvertes au lieu-dit Kalfata datent du milieu du $\mathrm{V}^{\mathrm{e}} \mathrm{s}$. av. J.-C. environ. Les données archéologiques laissent supposer que l'espace funéraire était initialement défini par l'intermédiaire

71 Les plus anciennes nécropoles de Mendé, d'Akanthos ou d'Abdère étaient situées sur la côte, non loin du premier lieu d'installation des colons. La nécropole d'Oisymè est également localisée au Sud de la ville sur la plage. D'après Ch. KoukouliChrysanthaki, la situation de cette nécropole, le long de la côte, révèle un choix conscient des colons qui ne désiraient pas perdre la terre propre à l'agriculture : Koukouli-Chrysanthaki 2006, p. 172. d'une rigole creusée dans le substrat argileux ou dans la roche meuble (fig. 20), selon un modèle également connu dans la nécropole de Nymphaion ${ }^{72}$. Son tracé, suivi actuellement sur plus de $120 \mathrm{~m}$, suit la ligne de côte selon une orientation N.-O./S.-E. De section trapézoïdale, elle est plus large en surface $(120$ à $130 \mathrm{~cm})$ et plus étroite dans sa partie inférieure (64 à $73 \mathrm{~cm}$ ); son comblement est constitué de sable pur.

En raison de l'accumulation de remblais au-dessus des structures funéraires, ainsi que de l'évolution naturelle du terrain (formation de dunes), la rigole a rapidement cessé de fonctionner et a été recoupée et recouverte par des sépultures postérieures.

Environ un siècle plus tard, l'espace funéraire a été réorganisé des deux côtés d'une voie littorale, baptisée parfois «via sacra » dans les rapports de fouilles (fig. 21). La portion étudiée de cette route sur le site de Kalfata est dépourvue de revêtement ; sa largeur varie de 6,50 à 7 m (fig. 22). Elle suit la même orientation N.-O./ S.-E. que la rigole, dont deux à trois mètres la séparent en direction de l'Est. Les observations réalisées plus au Sud, au lieu-dit Boudjaka, démontrent que, dans ce secteur également, la nécropole s'organisait des deux côtés d'une voie qui prolonge celle de Kalfata.

L'existence d'un lien entre les nécropoles et le réseau routier constitue une pratique habituelle dans le monde antique. Une organisation analogue de l'espace funéraire, des deux côtés des axes de circulation principaux, est attestée sur plusieurs sites de Grèce (Vokotopoulou 1994, p. 92) et dans le monde colonial ${ }^{73}$.

Des enclos familiaux, délimités par des murs en pierre, ont été implantés de part et d'autre de l'axe de circulation qui traverse le site de Kalfata. Les façades tournées vers la route présentent un travail plus soigné,

72 La rigole qui traverse durant l'époque hellénistique le secteur exploré de la nécropole de Nymphaion, selon une direction E./O., présente en coupe une forme triangulaire $(120 \mathrm{~cm}$ de large à la surface, $10 \mathrm{~cm}$ au fond). Sa profondeur varie entre 78 et $134 \mathrm{~cm}$. Elle est creusée dans le rocher. S.L. Solovyov considère qu'elle servait à établir les fondations d'une palissade en bois, ce qui expliquerait la présence de trous d'un diamètre de $18 \mathrm{~cm}$ et d'une profondeur de 10 à $16 \mathrm{~cm}$ au fond de cette rigole, tout comme son remplissage de terre, de pierres et de tessons de céramique : Solovyov 2003, p. 105-106, pl. 256-257.

$73 \mathrm{Au} \mathrm{V}$ e s. av. J.-C., l'organisation de la nécropole de Thasos suit la direction des routes reliant la ville à l'intérieur de l'île. La nécropole Nord de Galepsos se développe des deux côtés de la route antique par laquelle la ville fortifiée communiquait avec l'intérieur du pays. La situation des nécropoles le long des routes antiques, qui est courante dans les villes de Grèce méridionale, se retrouve également dans d'autres colonies grecques de la côte Nord de l'Egée : la nécropole d'Argilos est située le long d'une route qui correspondrait à celle suivie par Xerxès (Perreault, Bonias 1998, p. 37-48) ; celle de Tragilos suit également une voie antique et la nécropole S.-E. d'Amphipolis est localisée des deux côtés de la route moderne qui reprend le tracé de la route antique (Koukouli-Chrysanthaki 2006, p. 173). 


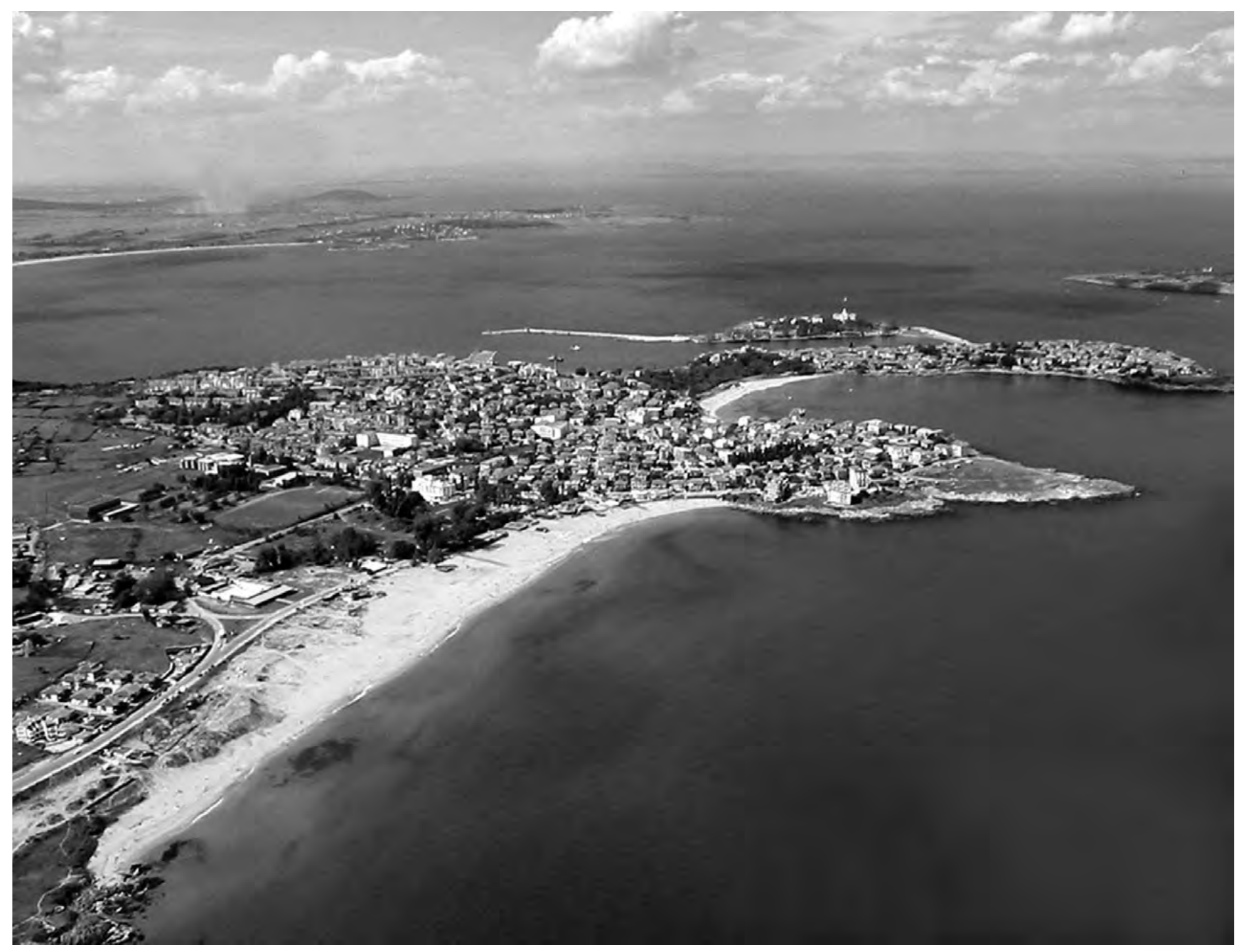

Fig. 19. Vue aérienne de Kalfata et de la péninsule de Harmanité depuis le S.-O. (๑ Larus Ltd.).

avec un enduit à base de chaux et de sable conservé par endroit; elles sont édifiées en moellons, ou en petits blocs de calcaire sur un soubassement de moellons. Les mêmes moellons sont également utilisés par endroit comme une sorte de superstructure, restes probables d'aménagements postérieurs. Les blocs de l'élévation sont agencés en deux ou trois assises disposées en retrait l'une par rapport à l'autre, de façon à former des sortes de gradins. La répartition interne de l'espace est effectuée au moyen de blocs de pierre disposés perpendiculairement aux murs de façade, ou d'alignements de moellons plus sommaires (Nedev, Panayotova 2003, p. 128, pl. 4, fig. 1-2). L'espace ainsi délimité, de plan carré ou rectangulaire, reste ouvert à l'arrière. Les murets peuvent entourer les petits tumuli qui recouvraient une ou plusieurs tombes.

Les différents enclos sont alignés, formant une suite continue le long de la route : l'ensemble le plus long est conservé sur environ 40 mètres (fig. 23). Leur juxtaposition précise montre que ces aménagements, qui dessinent des secteurs réguliers d'une longueur moyenne de six à sept mètres, ont été construits en plusieurs étapes, mais suivant une même logique et un plan préétabli (fig. 24). Il semble donc que le terrain de la nécropole ait été partagé en parcelles de dimensions identiques pour chaque famille, tout comme pouvait l'être, éventuellement, la terre labourable ${ }^{74}$.

Durant ces dernières années, les recherches ont confirmé les observations réalisées sur l'existence d'un parcellaire régulier à Kalfata, qui se prolonge à Boudjaka, dans les secteurs méridionaux de la nécropole (fig. 25).

74 Les données disponibles sur le territoire d'Apollonia ne nous permettent pas de définir son organisation. En revanche, nos connaissances sur les dispositions juridiques antiques révèlent que les colons recevaient lors de la fondation d'une nouvelle colonie des lots agricoles dont l'un avait le statut de lot principal et servait de garantie pour leur adhésion de plein droit à la communauté civique (Zubar 1993, p. 10). 


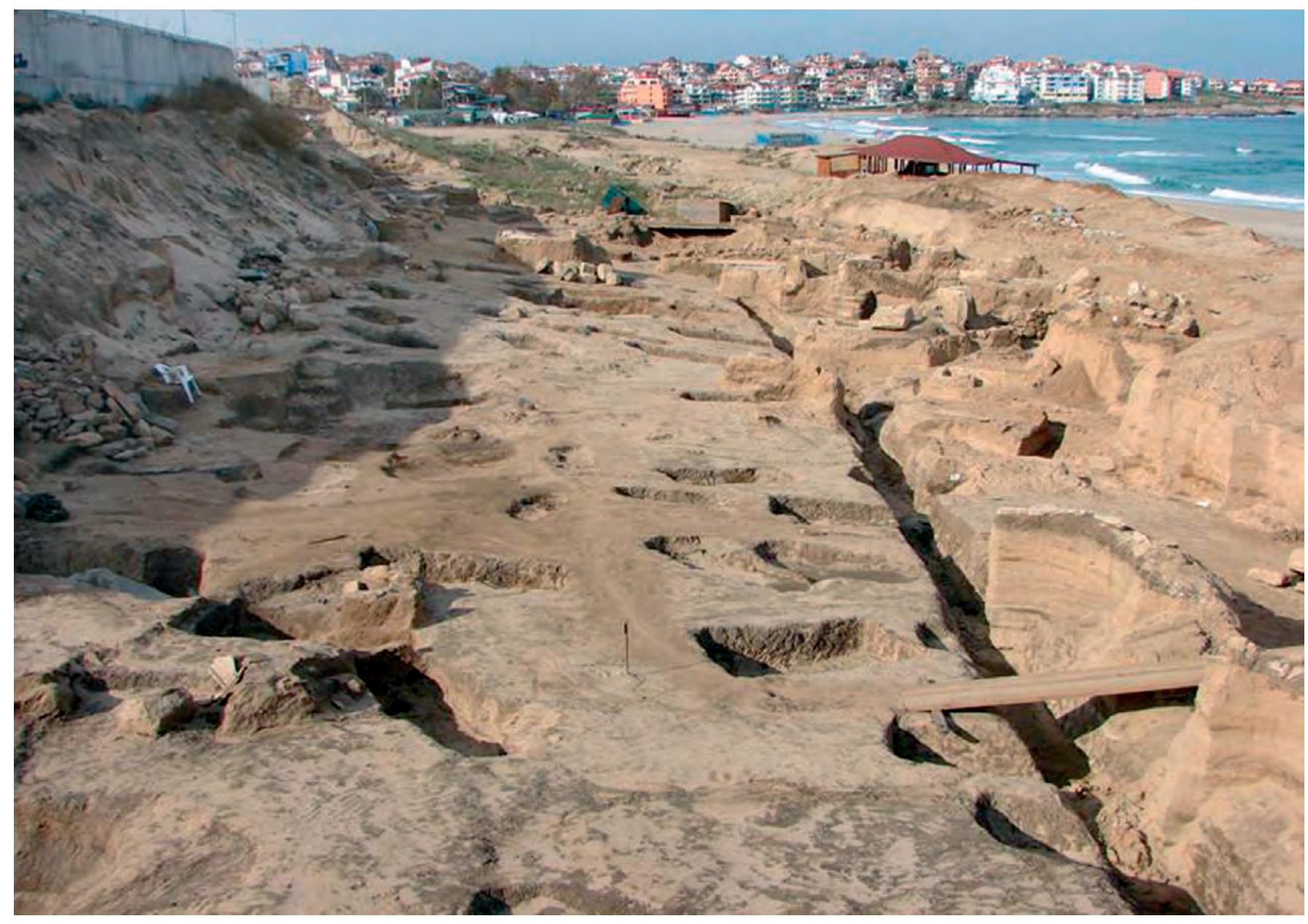

Fig. 20. Kalfata (phase 1). Rigole et tombes du troisième quart du Ve s. (parcelle cadastrale UPI 5518) (Photo K. Panayotova, 2007).

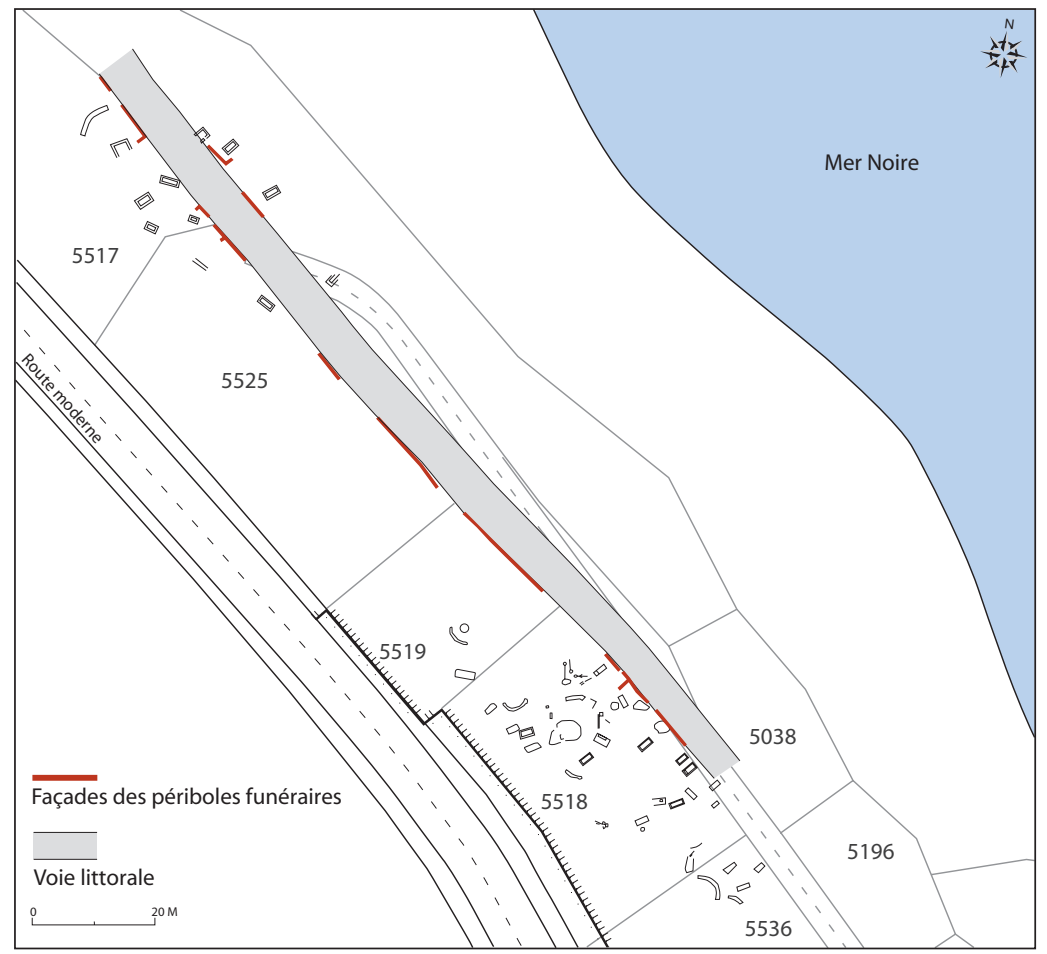

Fig. 21. Kalfata, plan schématique de la voie littorale Sud, dite parfois « via sacra » (Atanas Kameranov) 


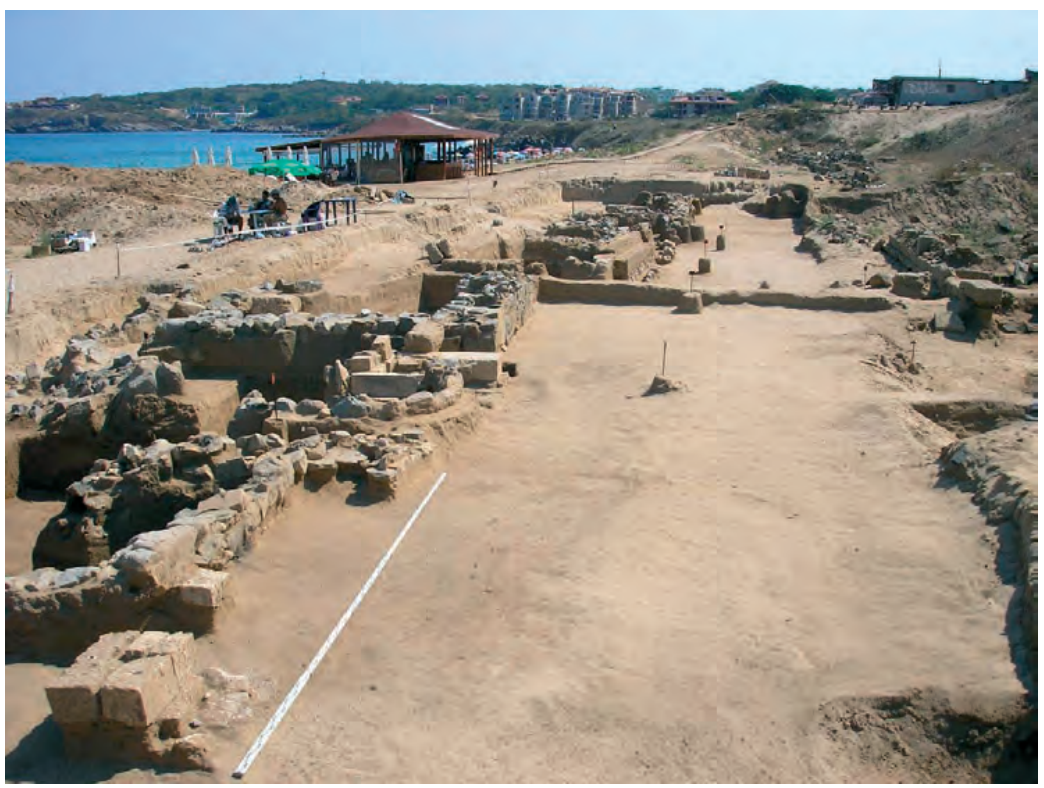

Fig. 22. La voie littorale vue du Nord (Kalfata, parcelle cadastrale UPI 5525) ; à droite, le secteur étudié durant les fouilles conjointes franco-bulgares, à gauche, les périboles funéraires mis au jour par K. Panayotova en 2005 (Photo K. Panayotova).

Fig. 24. Boudjaka (parcelle cadastrale UPI 5518), vue depuis l'Est sur les enclos funéraires du IV ${ }^{\text {e }} \mathrm{s}$. et la voie littorale. Photo K. Panayotova, 2007.

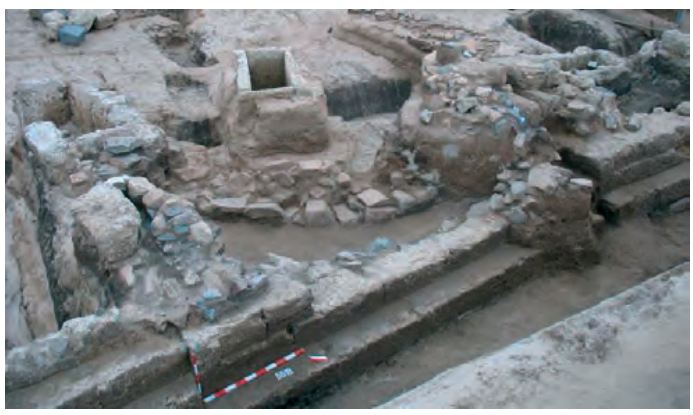

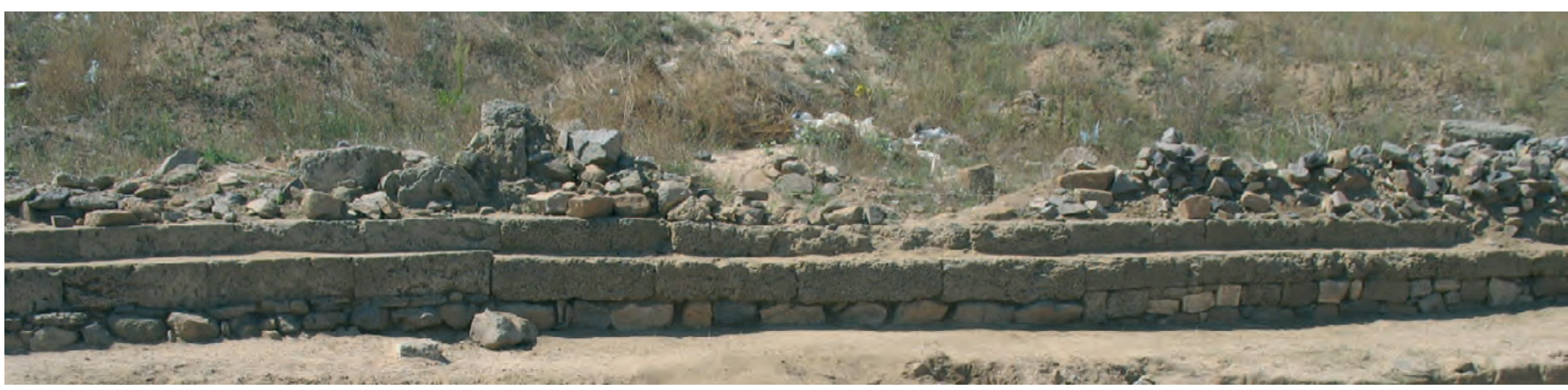

Fig. 23. Alignement de périboles funéraires du IVe s. à l'Ouest de la voie littorale (Kalfata, parcelle cadastrale UPI 5525-5518) (Photo K. Panayotova).

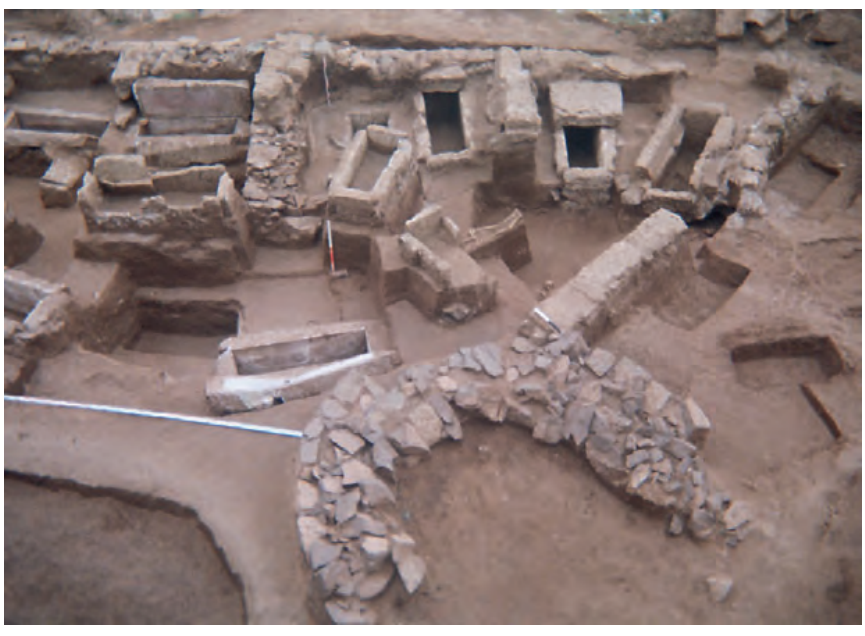

Fig. 25. Boudjaka (parcelle cadastrale UPI 5073), vue depuis le S.-O. sur les enclos funéraires du IV ${ }^{\text {s. }}$ (Photo D. Nedev, 2005).

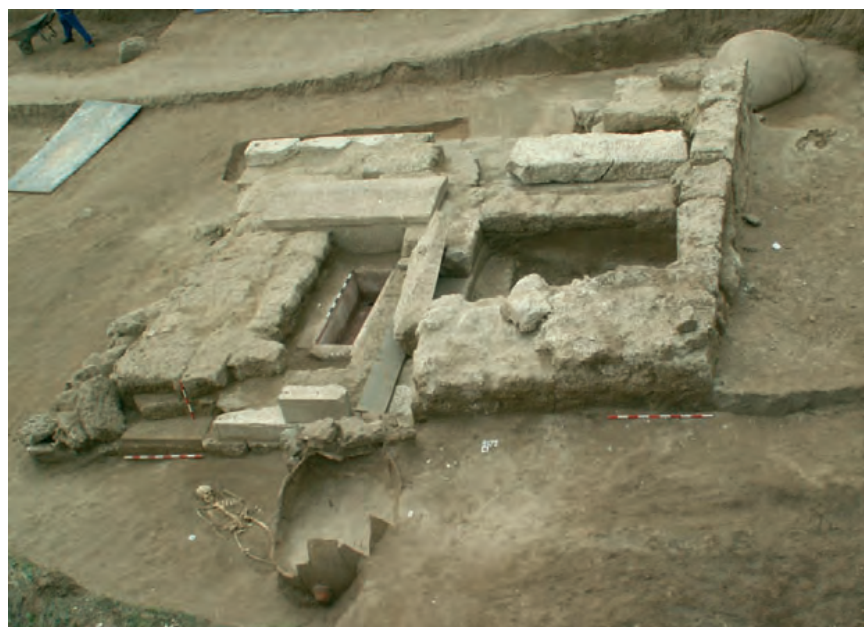

Fig. 26. Boudjaka (parcelle cadastrale UPI 5172). Terrasse funéraire du milieu du IVe s. (Photo K. Kostova, 2007). 
Deux structures monumentales en pierre, dont la face est constituée de trois rangées de blocs de calcaire métamorphique liés par des crampons en queue d'aronde, en fer et en plomb, ont récemment été mises au jour à cet endroit. L'intérieur de la première est constitué de quatre rangées de blocs de grès dunaire, matériau également employé pour le soubassement. On a découvert par ailleurs des fragments de marbre provenant probablement d'un décor monumental, ce qui permet d'identifier cette structure comme un monument commémoratif.

La deuxième structure représente un monument tripartite dans lequel, pour la première fois dans la nécropole d'Apollonia, a été découvert un sarcophage en marbre dont les parois internes sont peintes en rouge ; il était accompagné de deux cistes (fig. 26). A l'intérieur de cette structure, l'espace entre les tombes est comblé par des blocs de grès. La façade, tournée vers le tracé supposé de la voie, est constituée de blocs à bossage. Ces sépultures peuvent être datées vers le milieu du $\mathrm{IV}^{\mathrm{e}} \mathrm{s}$. av. J.-C. On trouve un parallèle proche dans une structure rectangulaire de la nécropole d'Aiani, en Macédoine, qui entoure quatre cistes (Karamitrou-Mentesidi 1995, p. 32-33). De tels aménagements, appelés «tombespériboles », sont apparus dans le monde grec dans la deuxième moitié du $\mathrm{V}^{\mathrm{e}} \mathrm{s}$. av. J.-C. (Triantaphyllos 2000).
En Attique, leur construction s'est poursuivie jusqu'en 317 av. J.-C., lorsque la loi promulguée par Démétrios de Phalère a interdit d'élever des monuments funéraires luxueux, mettant un terme à une pratique impliquant des dépenses parfois importantes ${ }^{75}$.

Parallèlement aux murs de façade, on trouve souvent entre les différents secteurs des bases de stèles funéraires; d'autres étaient vraisemblablement érigées sur les murs mêmes des enclos.

L'organisation de la nécropole de Pantanello, à Métaponte, offre un parallèle proche de celle d'Apollonia. Elle est divisée en espaces familiaux cloisonnés qui s'échelonnent le long des routes. Les parcelles de terre utilisées pour leur construction semblent avoir eu des dimensions standardisées qui, d'après J. Carter, sont similaires à celles des périboles du $\mathrm{IV}^{\mathrm{e}} \mathrm{s}$. av. J.-C. au Céramique, ainsi qu'à celles observées dans d'autres nécropoles des environs d'Athènes (Carter 1998, p. 161, fig. 5A.7).

75 Notons qu'un péribole du IV ${ }^{\text {e }}$ s. av. J.-C. a été découvert dans la nécropole Sud de Thasos (Koukouli-Chrysanthaki, Sgourou, Agelarakis 1996, p. 775, pl. 2). 


\section{Deuxième Partie}

\section{PRÉSENTATION DES FOUILLES 2002-2004}

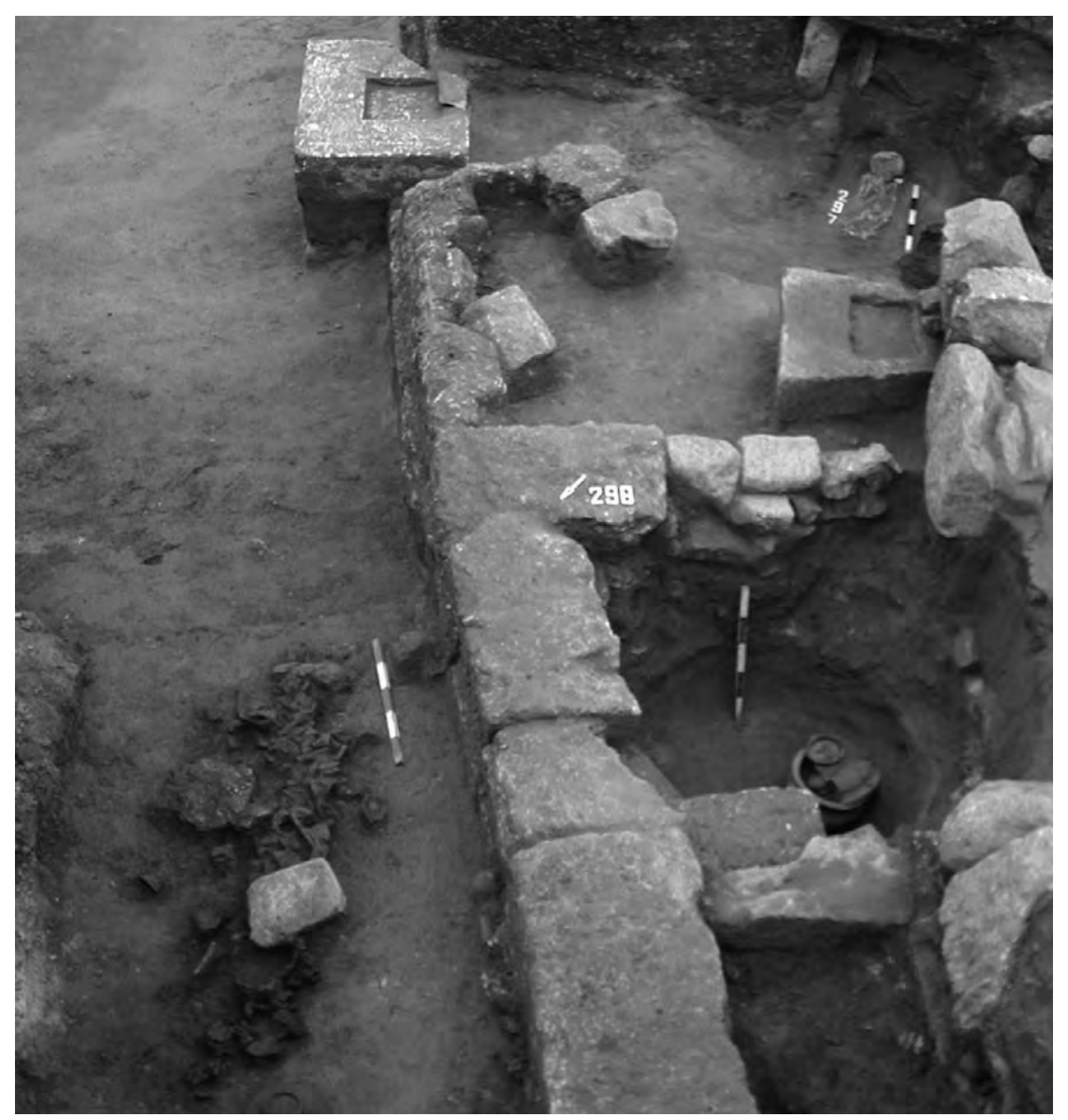

Le mur MR 1, avec à sa gauche le foyer F 1 et dans l'enclos l'urne SP 298 (Photo K. Panayotova). 



\section{Introduction}

$\mathrm{C}$

omme on l'a vu précédemment, le secteur fouillé en commun entre 2002 et 2004 ne représente qu'une toute petite partie de la nécropole qui occupe, sur plusieurs kilomètres de long, la frange littorale au Sud de la ville d'Apollonia, mais il est un bon témoin, durant toute la durée d'occupation de ce grand cimetière - du début de l'époque classique à la première partie de l'époque hellénistique - des pratiques funéraires des Apolloniates et des aménagements architecturaux dans lesquels elles s'insèrent. Cette recherche limitée constitue ainsi une contribution significative à l'histoire de la colonie milésienne, qui est plus difficile à percevoir à partir des fouilles de l'espace urbain et des autres zones de la nécropole, malgré le travail pionnier publié il y a près de 50 ans sous la direction d'Ivan Venedikov et les recherches récentes évoquées plus haut.

Les travaux de terrain se sont déroulés dans des conditions différentes selon les années et les ressources de chacune des deux équipes. Ainsi, en 2002, la mission française, faute de moyens financiers, n'a fonctionné que sur la base d'une équipe restreinte. Ses recherches se sont concentrées sur un secteur de $100 \mathrm{~m}^{2}$, situé au sein de la parcelle cadastrale UPI 5525, immédiatement au Nord des fouilles conduites par l'équipe bulgare. Cette dernière opérait alors sur une échelle plus large que celle retenue dans le cadre de cette étude. Elle a notamment achevé, au cours de cette campagne, l'étude de la zone comprise entre le mur MR 1 et la tombe SP 313, dans la partie méridionale du secteur Sud. Tous les relevés ont été assurés cette année-là par Margarit Damyanov.

En 2003, les fouilles françaises ont été étendues vers le Sud-Ouest, du côté de la route, ainsi que vers le NordEst, en direction du littoral, sur une zone correspondant au secteur Est. En parallèle, l'équipe bulgare s'est déplacée au Nord-Ouest du secteur français, mettant au jour le secteur Nord, ainsi que sur une zone étroite comprenant l'ensemble des sépultures présentes au Nord-Ouest de la ciste SP 300. Bruno Baudoin, topographe de la mission française, a réalisé un relevé détaillé du secteur fouillé, qu'il a replacé dans l'ensemble du site de Kalfata et, plus généralement, de l'espace occupé par la ville antique (pl. 2). De même, on a relevé la coupe stratigraphique de la berme restée en place, après les fouilles de 2002, à la limite Sud du secteur français (pl. 5). Le plan général établi en 2003 a été complété après la campagne de 2004, qui a livré un nombre nettement plus restreint de sépultures et n'a pas apporté de changement important dans la connaissance des structures architecturales, mais a permis d'atteindre, dans le secteur français et au Nord, le substrat naturel recouvert par une imposante paléodune. Les coupes et plans de détail ont été dessinés par Andrey Mladenov, alors étudiant à l'Université St Clément d'Ochrid à Sofia, et numérisés par Thomas Lorain (Institut Français d'Etudes Anatoliennes, Istanbul), ainsi que par l'architecte Yana Topalova à la fin de la campagne 2003. L'ensemble a été repris, pour la publication finale, par Vincent Dumas, infographiste du Centre Camille Jullian (pl. 3).

Malgré les variations d'une année sur l'autre et les difficultés rencontrées, le catalogue des sépultures, des dépôts et des foyers a pu être établi de façon suffisamment homogène, et la mise en commun de toute la documentation, à la suite de débats réguliers entre les principaux membres des deux missions, a permis la rédaction d'un chapitre sur la stratigraphie générale du secteur et la chronologie relative des sépultures et autres aménagements, aboutissant à la détermination de datations absolues qui sont reprises dans les différents catalogues et argumentées dans les chapitres de synthèse de la troisième partie à propos des principaux «marqueurs », essentiellement les céramiques attiques à vernis noir et à figures rouges. 


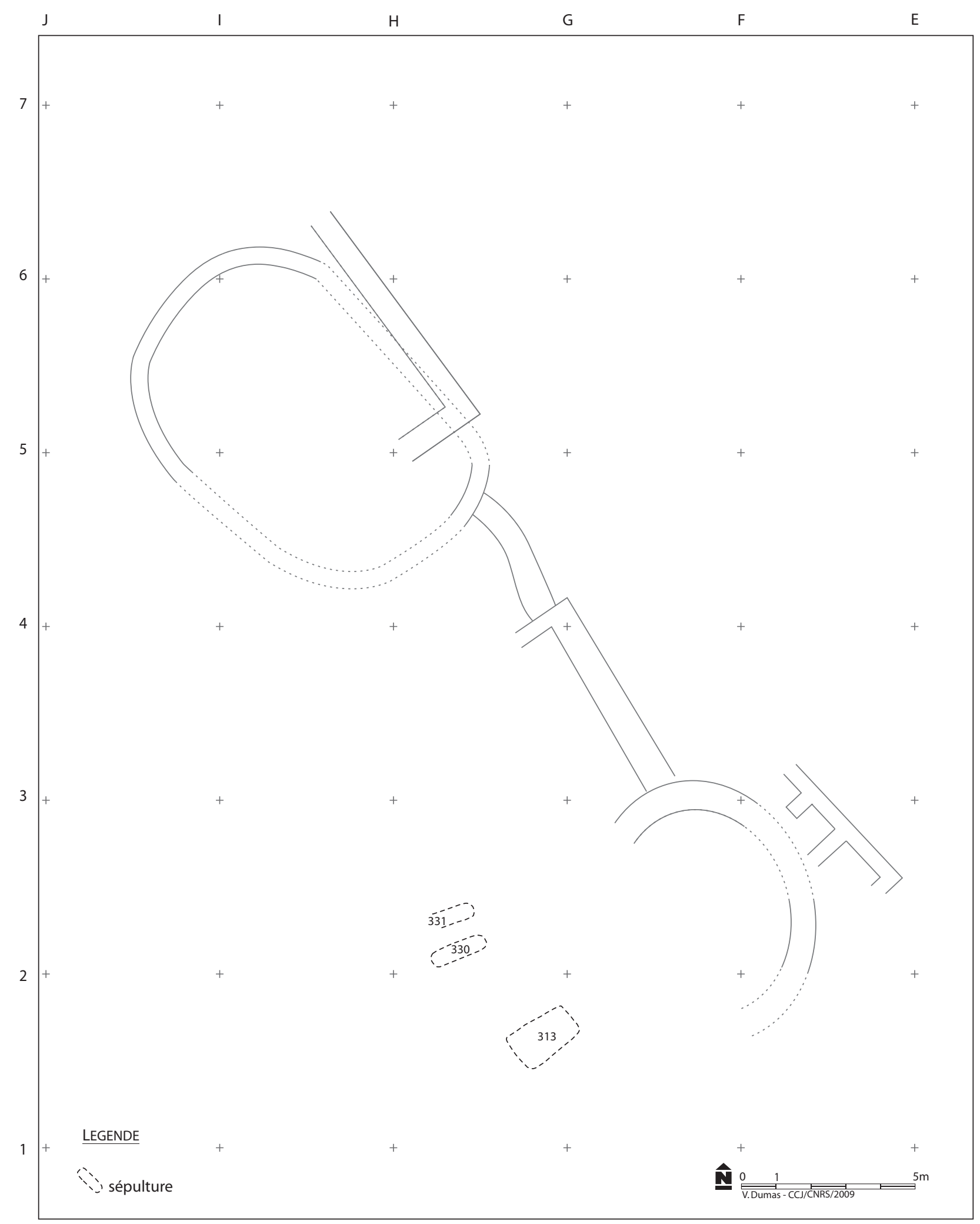

Fig. 27. Plan schématique de la phase 1 (๑ CCJ). 


\section{Chapitre 1}

\section{Stratigraphie et évolution architecturale de l'ensemble du secteur}

$\mathrm{L}$ a mise en évidence de la stratigraphie dans un espace occupé essentiellement par des remblais de sable est un exercice particulièrement difficile, rendu encore plus problématique par les variations qui ont eu lieu dans le déroulement des missions (voir ci-dessus p. 49): l'analyse stratigraphique telle qu'elle est présentée ici a été mise en place en 2002 par la mission française, il a fallu ensuite établir un lien entre les « unités stratigraphiques » (US) alors définies et la stratigraphie mise en évidence en 2002 et 2003 dans les secteurs fouillés par l'équipe bulgare.

Il nous a semblé que la meilleure façon de présenter l'évolution de l'occupation de ce petit espace de la nécropole, sur environ deux siècles, était de distinguer quatre phases principales et d'analyser la succession des sépultures, dépôts, foyers et aménagements architecturaux au sein de quatre secteurs qui se distinguent assez clairement (pl. 3) : le secteur central correspond pour l'essentiel à l'emprise de la zone fouillée par l'équipe française et celui qui se trouve immédiatement au Nord, fouillé par l'équipe bulgare, s'organise autour des murs MR 6, 7 et 8 ; le secteur Sud - dont seule la frange Nord a été fouillée par les Français - est assez bien défini topographiquement par le mur MR 2 ; enfin le secteur oriental est situé à l'extérieur des murs MR 2 et 3 (la zone Nord a été fouillée par les Français, le Sud par les Bulgares). Pour chaque phase on a mentionné les principales US, regroupées sous forme d'ensembles chronologiquement homogènes ou dans leur succession: certaines sont représentées sur les coupes stratigraphiques ou visibles sur les photographies, d'autres non.

Un bilan synthétique est présenté à la fin du chapitre, suivi par un tableau récapitulatif des sépultures avec la chronologique qui a été établie, et leur lien éventuel avec les dépôts et les foyers (p. 82).

\section{Phase 1 (deuxième moitié du $\mathrm{V}^{\mathrm{e}} \mathrm{s}$. av. J.-C.) : fig. 27}

L'horizon de base est constitué par une couche limono-argileuse particulièrement compacte, de couleur grise, qui accuse un léger pendage S.-O./N.-E. en direction de la mer (US 641). Il se double d'un second, plus important encore, orienté vers le Nord. Cette abaissement de l'altitude du terrain initial explique que ce niveau n'ait pu être atteint en secteur Est, ainsi qu'au Nord-Ouest du secteur Nord. On constate, à l'inverse, que le pendage change de direction en secteur Sud, au niveau de la tombe SP 330, et s'oriente vers le Sud-Ouest.

Une mince couche brune d'humus (US 640) recouvre ce premier horizon ${ }^{1}$. Ces deux unités représentent l'environnement du littoral avant l'installation des premières sépultures. Si l'emplacement de la ligne de côte ne semble pas avoir connu de changement sensible, l'aspect de la zone de Kalfata était cependant bien différent de celui qui est actuellement visible. En effet, au lieu d'un cordon littoral sableux, ce secteur abritait alors une végétation basse, de type steppique, nichée sous une paléo-falaise encore présente au Sud-Ouest, en surplomb de la route moderne.

Le creusement d'une longue rigole dans les US 641/640 constitue la première trace d'occupation dans l'espace concerné par les fouilles franco-bulgares. Son tracé a été suivi sur plus de $120 \mathrm{~m}$, de la parcelle UPI 5525 jusqu' au secteur Sud (Panayotova 2008c, p. 8).

Elle présente une orientation S.-E./N.-O. parallèle à la ligne de côte, avant d'obliquer vers l'Ouest au SudEst de nos fouilles, conformément à l'inflexion de la paléo-falaise située en surplomb. Cette structure a pu être étudiée en deux endroits du secteur Sud. Un premier tronçon, suivi sur $8,81 \mathrm{~m}$, passe entièrement sous la tombe SP 244, et arrive jusqu'à SP 300. Peu profond $(22 \mathrm{~cm})$, il est légèrement recourbé en forme de $S$ (fig. 28). Sa largeur à l'extrémité Sud-Est est de $75 \mathrm{~cm}$, mais elle s'élargit pour atteindre $1 \mathrm{~m}$ au centre, avant de se réduire à $90 \mathrm{~cm}$ à l'extrémité Nord-Ouest. Le deuxième tronçon a été mis au jour à l'Ouest de la tombe SP 300. Cette section, longue de 3,80 m, passe à côté des

1 Dans le secteur central, le niveau supérieur de l'US 640 est de 3,06 au S.-O. et de 2,57 près du mur MR 3. En secteur Sud, son altitude varie de 3,29 à 3,37 sous les tombes SP 375 et SP 300 ; elle n'est plus que de 2,78 et 2,88 sous les murs MR 3 et 2 . En raison du double pendage de l'US 641, notamment celui orienté vers le Nord, on constate que le niveau supérieur de l'US 640 est de 3,29 à l'angle Sud et de 2,57 près du mur MR 3. 
tombes SP 330 et 331 : elle est alors plus large (jusqu'à $1,35 \mathrm{~m})$ et plus profonde $(33 \mathrm{~cm})$. Son niveau varie en surface entre 3,54 et 3,59, et entre 3,33 et 3,20 au fond.

La fonction précise de cette structure pose problème, comme sa datation. Son creusement dans un horizon argileux parfaitement étanche et extrêmement compact laisserait penser à une canalisation d'eau. Cette hypothèse est renforcée par la présence à Boudjaka et à Kalfata, vers le milieu du $\mathrm{IV}^{\mathrm{e}} \mathrm{s}$., d'une canalisation en terre cuite au tracé similaire (Panayotova et al. 2007, p. 364). Toutefois, des rigoles comparables ont été découvertes dans d'autres nécropoles, notamment à Olbia, Pydna ${ }^{2}$ et Nymphaion (Solovyov 2003, p. 105-106, pl. 256257), où elles constituent un fossé peu profond destiné à abriter les fondations d'une palissade qui délimitait l'espace funéraire, comme le prouve la présence de trous de poteaux. Ces derniers sont toutefois absents dans la rigole de Kalfata, dont le comblement sableux n'a livré aucun matériel. Seule sa chronologie semble mieux assurée : on note en effet que la plupart des tombes du $\mathrm{V}^{\mathrm{e}} \mathrm{s}$. étaient situées au Sud-Ouest de cette structure, et que plusieurs d'entre elles se sont installées au cours du troisième quart $\mathrm{du} \mathrm{V}^{\mathrm{e}} \mathrm{s}$. dans sa partie supérieure et ont parfois recoupé son tracé, offrant un précieux terminus ante quem pour le creusement de la rigole.

La phase initiale du fonctionnement de cet espace en tant que nécropole est attestée dans le secteur Sud par trois tombes qui peuvent être datées par leur matériel, ainsi que par leur contexte stratigraphique, des années 430-420 av. J.-C. (SP 313, 330, 331). Il s'agit, comme pour les autres sépultures mises au jour au Sud-Est par K. Panayotova (Panayotova, Riapov, Baralis 2006, p. 101), de trois grandes fosses creusées dans l'US 641. En revanche, dans le secteur central, seuls quelques fragments de céramique épars, découverts au sommet de l'US 641, témoignent de la proximité des sépultures du troisième quart du $\mathrm{V}^{\mathrm{e}} \mathrm{s}$., sans qu'aucune tombe ait été mise au jour, pas plus qu'en secteur Nord.

Les nouveaux secteurs funéraires ne se trouvent donc pas dans la zone la plus proche du rivage, malgré la difficulté de creuser de grandes fosses dans l'horizon argileux US 641, particulièrement compact. Le comblement de ces sépultures par du sable jaune stérile permet de supposer la présence à peu de distance de zones

2 Les fouilles réalisées par M. Besios sur la parcelle 947 (propriété Lazaridis) de la nécropole Nord de Pydna ont livré plusieurs fossés dont deux (B et $\Gamma$ ) sont interprétés comme servant à délimiter des ensembles de tombes. En revanche, le fossé $\mathrm{A}$ se distingue par sa longueur et son tracé rectiligne, sa position indique qu'il est postérieur au troisième quart du $\mathrm{IV}^{\mathrm{e}} \mathrm{s}$. av. J.-C. et semble correspondre, pour M. Besios, au fossé creusé en 317-316 av. J.-C. par Cassandre autour de Pydna, lors du siège donné contre Olympias : Besios 1989, p. 158-159.

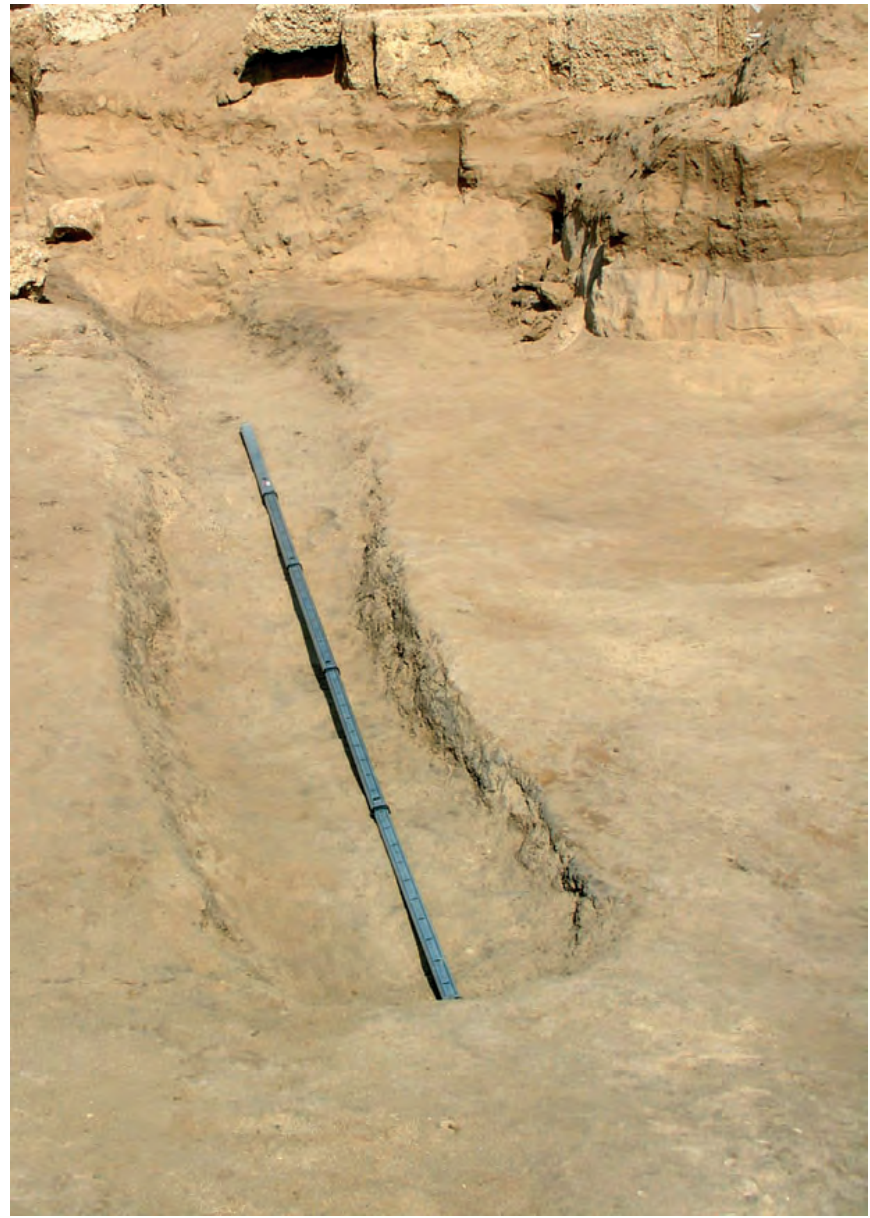

Fig. 28. Secteur Sud : section de la « rigole » qui passe sous la tombe SP 244 ; en haut à droite la ciste SP 300 (Photo K. Panayotova).

sableuses, notamment à proximité immédiate de la ligne de côte. Toutefois, dans le cas des tombes SP 330 et 331, la faible profondeur du creusement dans le substrat compact US 641 suggère une explication différente : leur installation semble en effet contemporaine des premiers temps de la forte phase d'ensablement qui affecte Kalfata durant le dernier quart $\mathrm{du} \mathrm{V}^{\mathrm{e}} \mathrm{s}$. Ce phénomène, qui modifie profondément la topographie de la zone étudiée, se matérialise tout d'abord par le dépôt d'une première couche de sable induré, épaisse de 2 à $5 \mathrm{~cm}$ (US 638), marquée par des traces actives d'écoulement pluvial à la surface de l'US 640 (fig. 29).

Elle est suivie de près par la mise en place d'une longue barre dunaire (US 218/627) qui occupe l'essentiel des secteurs Sud, central et Nord (fig. 30). Cette accumulation sableuse suit une orientation générale S.-E./N.-O, mais s'infléchit vers l'Est dans le secteur Sud, à partir des tombes SP 339 et 375 . Elle atteint, à la limite entre les secteurs central et Sud, une épaisseur variant entre 28 et $87 \mathrm{~cm}$, son sommet se trouvant approximativement sous la tombe SP 375 (niveau 4,01), 


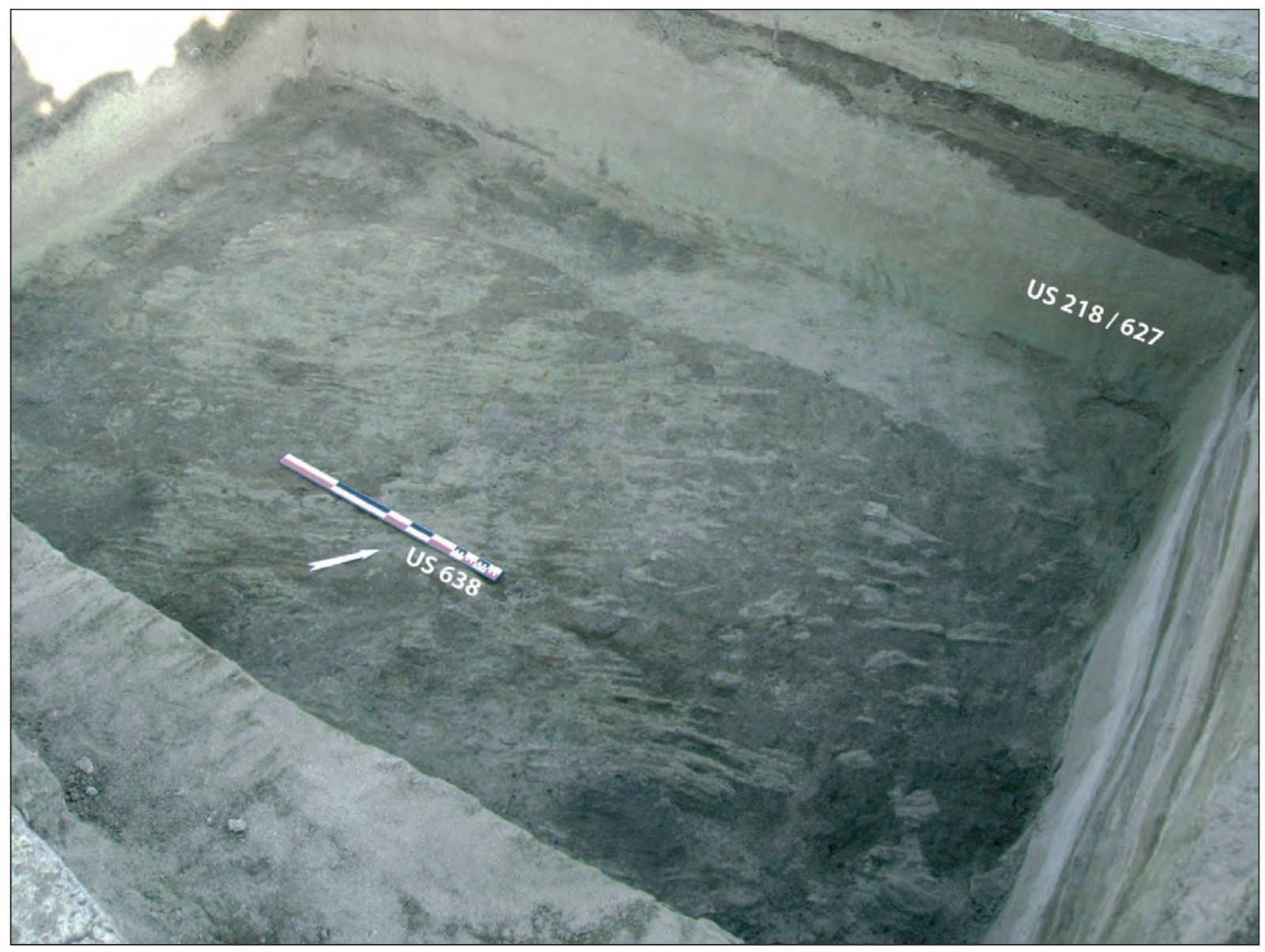

Fig. 29. Secteur central : surface de sable induré (US 638) surmonté de la dune de sable US 218/627 (Photo CCJ).

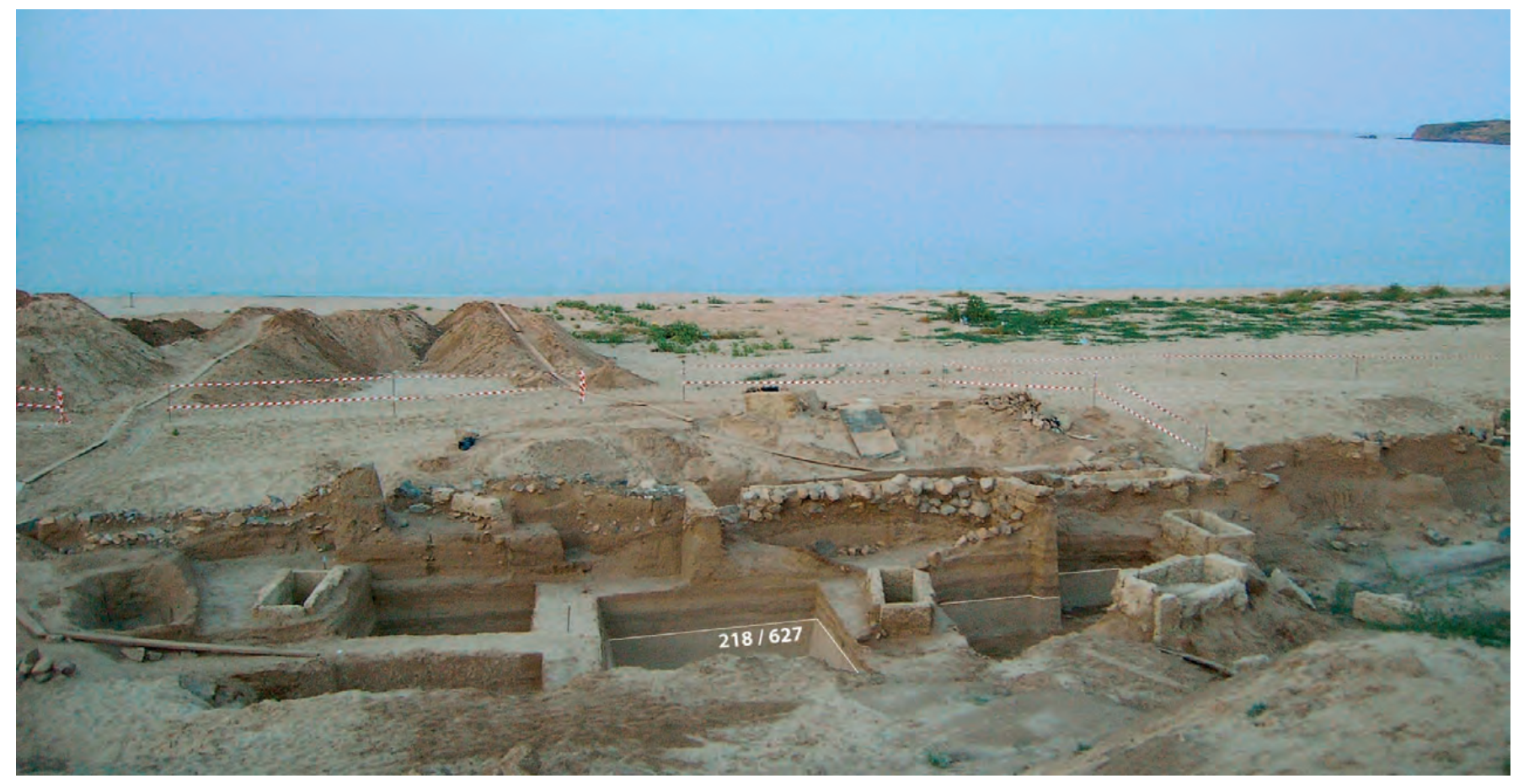

Fig. 30. Vue de la zone fouillée depuis le S.-O. On distingue la dune de sable US 218/267 sous le niveau des tombes de la phase 2 (Photo CCJ). 


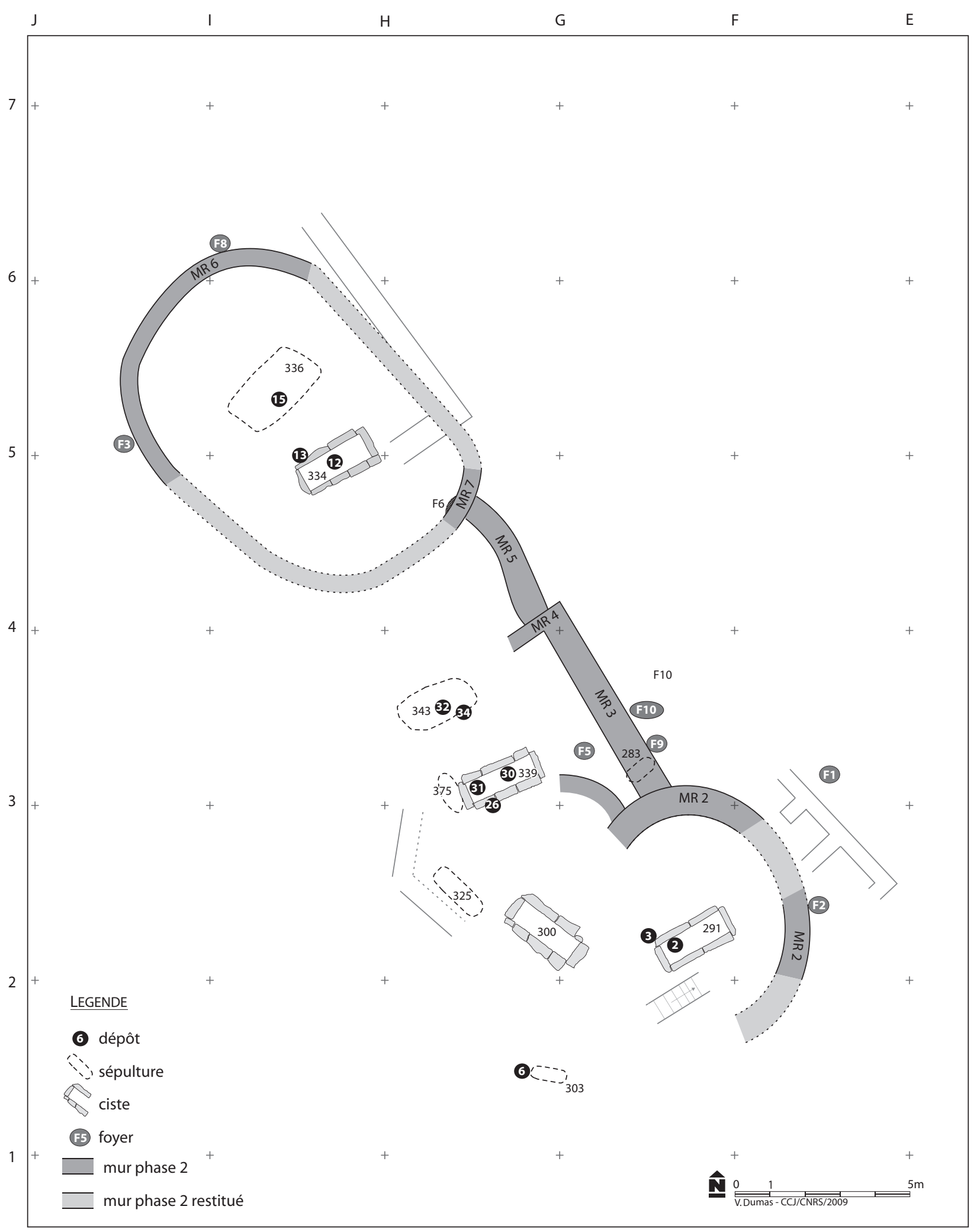

Fig. 31. Plan schématique de la phase 2 (๑ CCJ). 


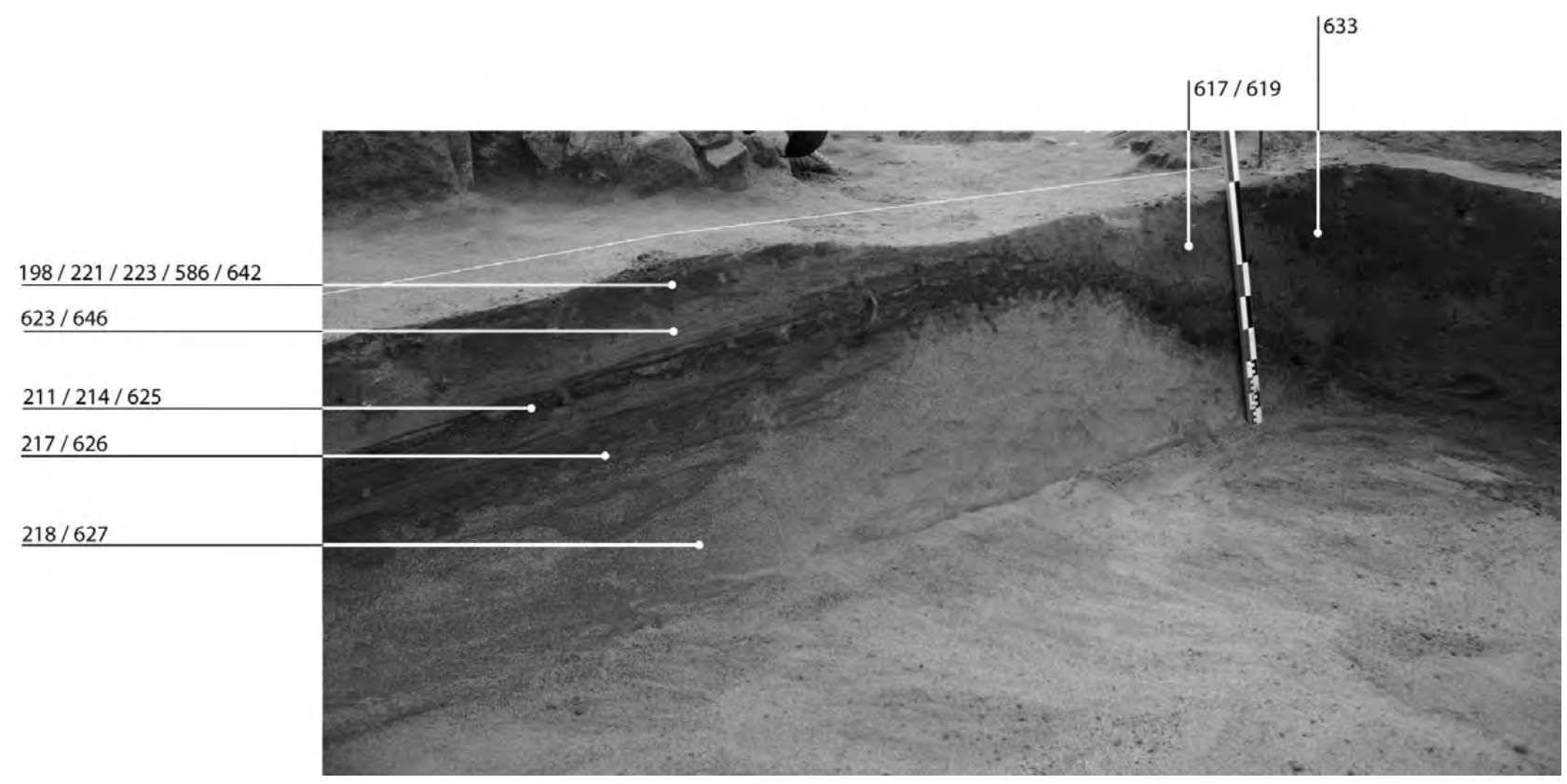

Fig. 32. Succession de couches d'origine anthropique et de couches de sable au-dessus de la dune US 218/627 (Photo CCJ).

ainsi qu'au Nord-Est de la tombe SP 300 (niveau 4,16, voir la pl. 4). Son épaisseur augmente en direction du Nord-Ouest, compensant partiellement dans cet espace la pente initiale du terrain ${ }^{3}$. Elle confère désormais aux trois secteurs une forme caractéristique en dos d'âne, isolant une importante dépression entre le sommet de la dune et la paléo-falaise.

Les facteurs à l'origine de ce changement spectaculaire dans les dynamiques paléo-environnementales sont difficiles à saisir à l'échelle de la nécropole. L'idée, avancée par B. Devillers, d'un apport alluvionnaire croissant entraîné par le réseau hydrographique local, en réponse à une ouverture de la végétation et une déstabilisation des sols de l'arrière-pays, demeure séduisante (voir p. 79). Elle traduirait ainsi une exploitation agricole plus intense du territoire de la colonie. Un tel schéma a le mérite d'expliquer le caractère soudain et limité de la phase la plus intense d'ensablement, tout en s'accordant avec l'extension contemporaine de la superficie des nécropoles, qui pourrait résulter d'un accroissement parallèle de la population de la ville. D'autres facteurs - modification des techniques agricoles, organisation plus lâche des secteurs funéraires - ne sont cependant pas à exclure et peuvent être à eux seuls à l'origine de chacun des deux phénomènes. L'absence de matériel dans l'horizon dunaire US 218/627 témoigne en revanche d'une interruption complète dans l'occupation de Kalfata

3 Niveau supérieur 3,78; épaisseur au S.-O. du mur MR 5 de 56 à $90 \mathrm{~cm}$. durant cette phase active d'ensablement. Ce processus est indirectement daté du dernier quart $\mathrm{du} \mathrm{V}^{\mathrm{e}} \mathrm{s}$., à la fois par les sépultures de la phase I recouvertes par les dunes et par les tombes du premier quart du IV e $s$. installées au sommet.

\section{Phase 2 (premier quart du $\mathrm{IV}^{\mathrm{e}}$ s. av. J.-C.) : fig. 31, pl. 4}

La phase 2 inaugure une nouvelle logique dans la succession stratigraphique de Kalfata. On constate en effet un apport répété de terre sur la pente nordorientale de la dune US 218/627, qui alterne avec un horizon sableux d'origine éolienne (fig. 32). Ce dernier témoigne de l'ensablement continu du littoral, qui s'exerce toutefois sur une échelle plus limitée ${ }^{4}$. C'est dans un tel contexte que s'opère la réoccupation de la zone funéraire de Kalfata, matérialisé dans le secteur central par l'installation de la tombe SP 343 qui constitue la sépulture la plus ancienne de la phase $2^{5}$. Sa mise en place peut être située, grâce aux observations

4 Horizon de terres: US 217/626, US 211/214/625/ US 198/ 221/223/586/642 ; horizon de sable : US 623/643. Dans les secteurs central et Nord, une couche supplémentaire de terre brune sableuse (US 624/644) vient s'ajouter au-dessus de l'US 211/214/625, entre l'horizon de terre sableuse US 217/626 et l'horizon de sable éolien US 623/643. Ces trois couches gagnent parallèlement en importance vers le N.-O., concourant ainsi à effacer le pendage initial du terrain. 5 Niveau d'installation (US 198/221/223/586/642) 4,36, au N.-E. de la tombe SP 300. 


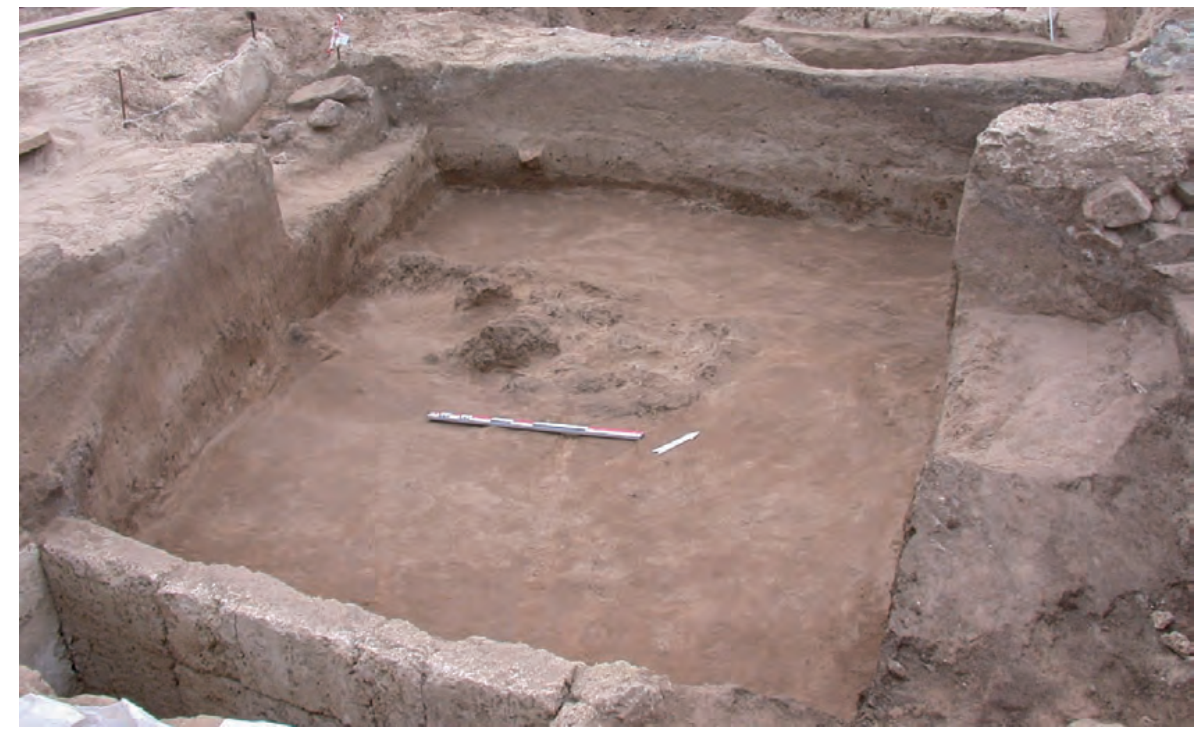

Fig. 33. Scellage de la fosse de SP 343 par une importante masse d'argile (US 579) ; en arrière-plan et sur un côté, contours de la couverture tumulaire (Photo CCJ). stratigraphiques et au matériel du dépôt DP 32 qui lui est associé, au tout début du IV e s. (vers 400-390). Par sa forme, la tombe reproduit le modèle des grandes fosses en usage durant le troisième quart $\mathrm{du} \mathrm{V}^{\mathrm{e}} \mathrm{s}$., mais elle est désormais surmontée, à l'image de l'ensemble des sépultures de la phase 2 découvertes lors des fouilles conjointes, d'une couverture tumu laire (fig. 33). Ce tertre, retenu par un scellage constitué de différents types de terre, est haut de $1,22 \mathrm{~m}$ (niveau supérieur 5,45) et d'un diamètre d'un peu plus de $5 \mathrm{~m}$ (pl. 7). La tombe SP 343 fixe, grâce à ce tumulus, l'élévation du terrain dans l'espace qu'elle occupe,

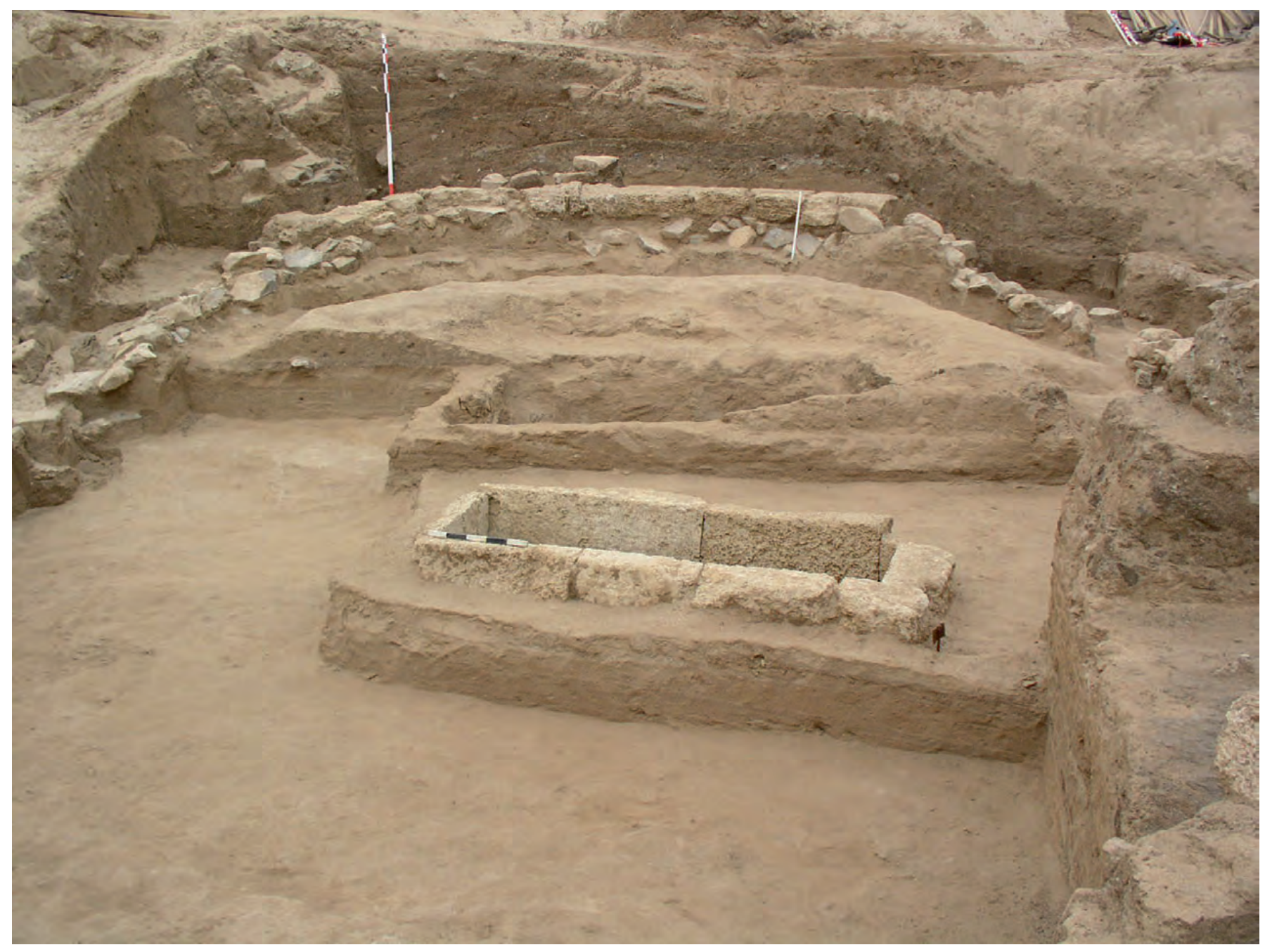

Fig. 34. Les tombes SP 334 et SP 336, avec le mur MR 6 en arrière-plan (Photo K. Panayotova). 


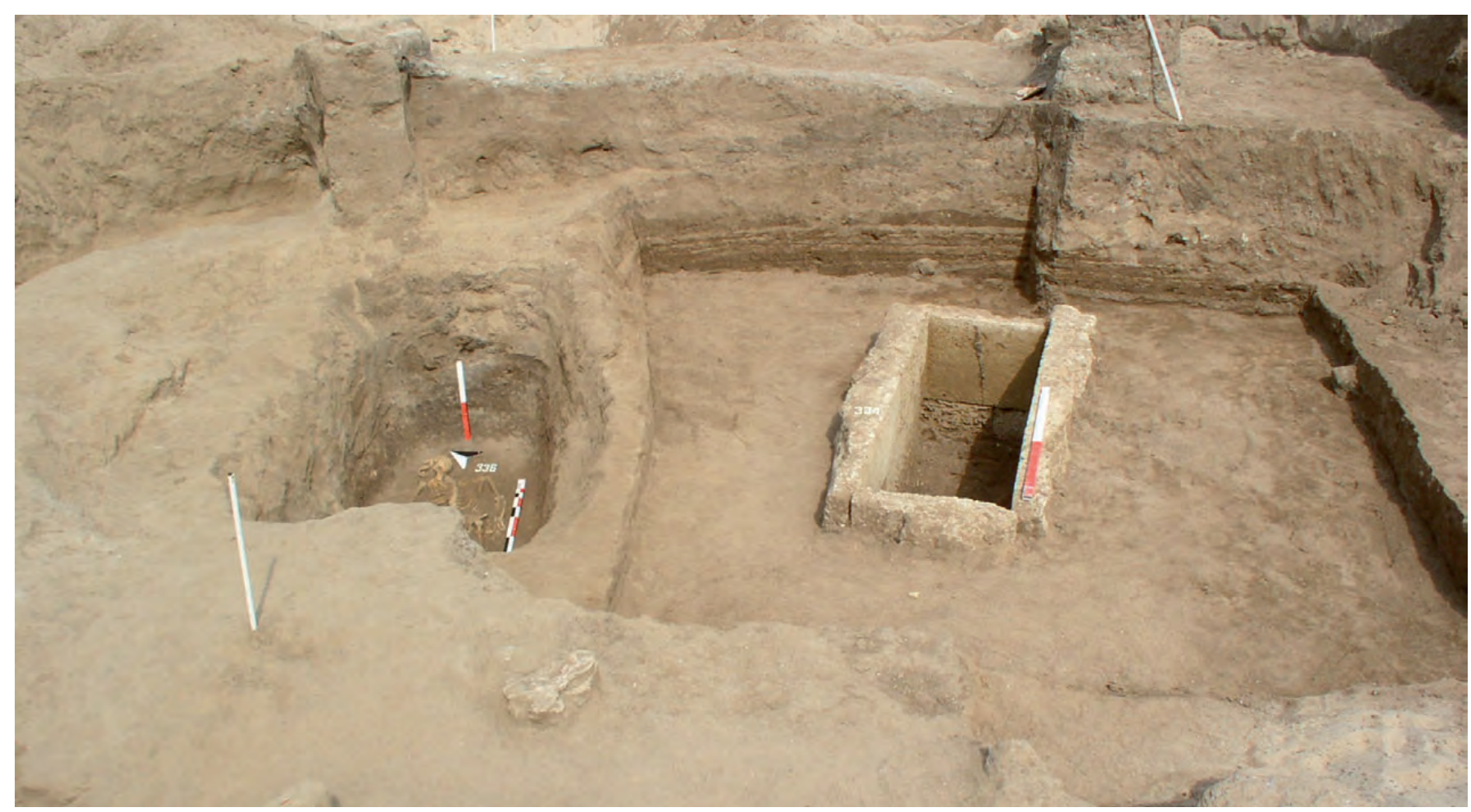

Fig. 35. Les tombes SP 334 (à droite) et SP 336 (à gauche) vues depuis le S.-O. (Photo K. Panayotova).

tandis que la succession d'horizons sableux et terreux se poursuit à ses abords, en particulier dans le secteur Sud où une seconde dune, recouverte elle aussi par une couche de terre noire argileuse ${ }^{6}$, se forme contre la pente occidentale de la dune US 218/627. Elle est recouverte à son tour par une dernière succession d'horizons de sable, scellés chacun par une couche de terre sableuse ${ }^{7}$.

L'origine de ces différents horizons de terre ne se laisse pas aisément deviner, car leur présence peut difficilement s'expliquer par le développement d'une quelconque végétation. Outre le caractère relativement épars des formations végétales en milieu sableux, le laps de temps concerné est en effet trop court pour avoir permis le développement d'une végétation assez abondante pour justifier une telle accumulation de matières organiques. De même, il paraît difficile d'évoquer un dépôt alluvionnaire depuis la colline qui surplombe le secteur littoral de Kalfata, en raison de la dépression située le long du flanc Sud-Ouest des dunes, qui agit comme un piège pour les écoulements. En revanche, les accumulations de terre traduisent un renouveau dans la fréquentation de Kalfata, comme en témoigne la présence de nombreux

6 Dune : US 617/619; scellage : US 633.

7 Horizons de sable: US 609/620/639 et US 109/212/215/637; scellages de terre sableuse : US 180/216/604/618/636 et US 108. fragments de céramique ${ }^{8}$. Ce matériel ne peut provenir d'ensembles funéraires détruits, car la plupart de ces couches de terre sont antérieures à la tombe SP 343. Les fragments de vases ont plus probablement été apportés avec les remblais de terre qui les contenaient, trahissant une volonté de stabiliser et de damer la surface des dunes en vue d'une réutilisation de ces espaces ${ }^{9}$.

8 L'US 624/644 a livré notamment un fond de coupe à vernis noir et la moitié d'un plat à pâte rouge comportant un graffito (fig. 64) : voir ci-dessous, p. 172. Tous deux sont attribués à la fin $\mathrm{du} \mathrm{V}^{\mathrm{e}} \mathrm{ou}$ au début du IV es. av. J.-C.

9 En ce sens, la présence d'ondulations parallèles et régulières découverte à la surface des US 198/221/223/586/642 et 633, entre les tombes SP 339 et SP 291, est pour le moins troublante (fig. 51-52). Ces formations ne sont pas sans évoquer des traces de mise en culture, ce que le contexte ici semble pourtant interdire. La dune US 617/619 et son scellage US 633, au sommet duquel se développent ces éventuelles traces d'exploitation agricole, se prolongent en effet au N.-O., où ils s'appuient tous deux sur le tertre qui recouvre la tombe SP 343 (US 554/571/573/590/592/612). Cette superposition stratigraphique confirme donc la formation de ces sillons au sommet de l'US 198/221/223/586/642 et de l'US 633, à un moment où le tumulus de SP 343 existait déjà, expliquant en retour que ces « rigoles » ne se retrouvent pas au N.-O., en secteur central. Le caractère contemporain de SP 343 et de ces sillons, tout comme leur proximité immédiate, rendent l'hypothèse d'un exploitation agricole de cet espace difficile à soutenir. La cohabitation entre activités agricoles et structures funéraires est attestée au $\mathrm{V}^{\mathrm{e}} \mathrm{s}$. av. J.-C. à Mégara Hyblaea, à un moment où la nécropole est déjà à l'abandon (Gras 1975, p. 43-47). L'origine de ces sillons demeure donc actuellement énigmatique. 


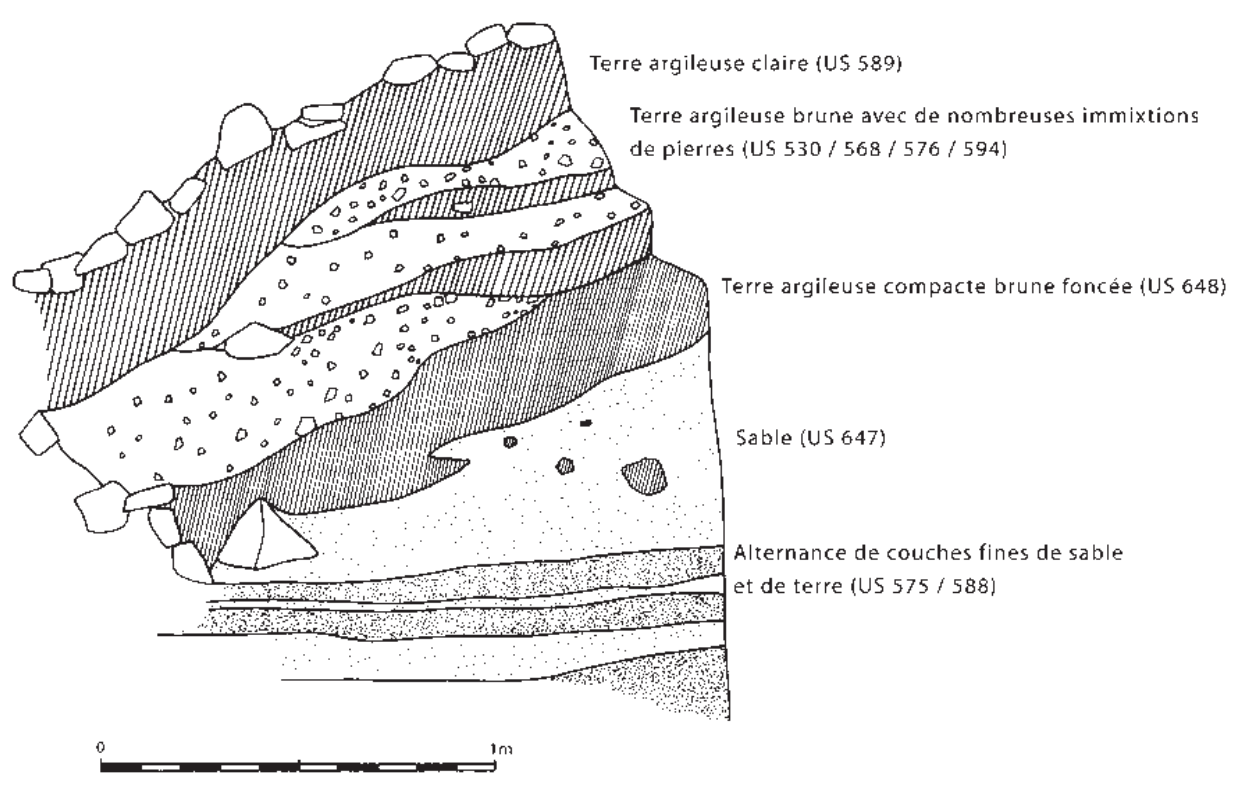

Fig. 36. Coupe sur la couverture tumulaire de SP 334 et les remblais liés à la construction du mur MR 8 (Dessin M. Damyanov).

C'est au sommet de ce vaste système, à un niveau donc bien supérieur à SP 343, que sont installées en secteur Sud les trois premières sépultures de la phase 2 (SP 325, 300, 303 et 291) (pl. 4). Leur chronologie relative se base essentiellement sur des critères stratigraphiques, aucune d'entre elles n'ayant livré un mobilier permettant une datation précise. Seuls les vases du dépôt DP 2, qui peut être mis en rapport avec la tombe SP 291, semblent confirmer une date assez haute, dans les années 390-380. La typologie de ces trois sépultures reprend celle connue dans les secteurs central et Nord, articulée entre de grandes fosses, similaires à celles $\mathrm{du} \mathrm{V}^{\mathrm{e}} \mathrm{s}$., et des cistes en calcaire ou en grès dunaire qui n'apparaissent à Kalfata qu'au début du IV ${ }^{\mathrm{e}} \mathrm{s}$. Cependant, les dimensions de SP 325 s'avèrent plus modestes que celles des fosses de SP 343 et SP 336, plus au Nord. La disposition des sépultures apparaît relativement lâche, en raison de leur couverture de type tumulaire. Il s'agit de petits tertres de sable, d'une hauteur moyenne de 60 à $80 \mathrm{~cm}$, recouverts chacun par un scellage de terre noire argileuse. La position de ces remblais, tout comme leur chevauchement, nous permet de définir la chronologie relative de l'installation des tombes. Il apparaît, sur la base de ces observations, que SP 325 constitue la sépulture la plus ancienne dans ce secteur. Son remblai tumulaire est recouvert par celui de SP 300, sur lequel s'appuie la couverture de SP 291. L'ensemble des tertres, par leur accumulation, rehausse l'altitude générale du secteur Sud et accentue la forme en dos d'âne qui le caractérise.

L'occupation du secteur Nord, qui se manifeste par l'installation des tombes SP 334 et SP 336, débute elle aussi à une date très proche, suivant le modèle offert par le secteur Sud. L'alternance de couches de sable et de terre présente sous ces deux sépultures est ici plus serrée (US 575/588) que celle observée en secteur Sud. Cette formation originale apparaît dans le secteur Est, au Nord-Ouest de la tombe SP 328, avant de passer en secteur central sous le mur MR 5 et de se poursuivre en direction du Nord-Ouest, où elle recouvre la majeure partie du secteur Nord. Par sa présence, cette succession de micro-couches apporte une indication chronologique précieuse, car elle vient s'appuyer dans le secteur central contre la couverture tumulaire de SP 343, confirmant une fois de plus l'antériorité de cette sépulture sur celles découvertes dans les secteurs adjacents.

Les tombes SP 334 et SP 336 sont caractéristiques des tombes attestées à Kalfata au cours la période 2 . La tombe SP 336 est en effet une fosse aux dimensions imposantes, similaire à SP 343, tandis que la ciste SP 334 illustre les innovations à l'œuvre à Apollonia au début du $\mathrm{IV}^{\mathrm{e}} \mathrm{s}$. (fig. 34-35). Toutes deux sont dotées de couvertures tumulaires dont le chevauchement nous permet de préciser, avec quelques réserves, leur chronologie relative. Contre toute attente, il semble bien que la ciste SP 334 soit la première à occuper cet espace. Elle est recouverte d'un remblai de sable (US 647) retenu par un épais scellage de terre argileuse (US 648) qui repose directement sur la surface de l'US 575/588 (fig. 36). La tombe SP 336 n'est en effet entourée que sur trois côtés (au N.-E., N.-O. et S.-O.) d'une couche relativement épaisse de terre argileuse de couleur brun foncé (US 649) qui suit dans ces trois directions un triple 


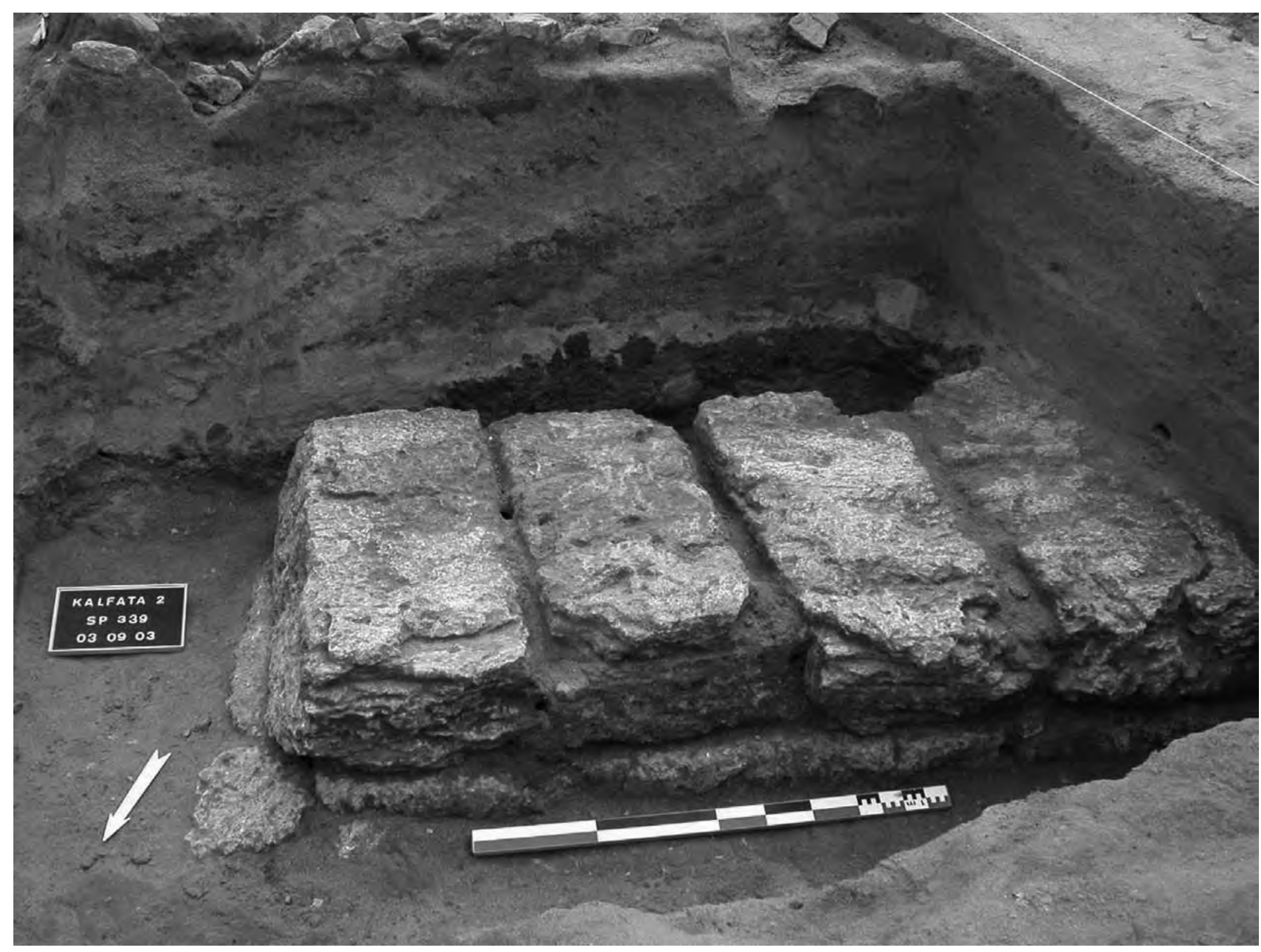

Fig. 37. La ciste SP 339 avant son ouverture, du N.-O. ; en arrière-plan, vue en coupe sur sa couverture tumulaire (Photo CCJ).

pendage, déterminé probablement par l'inclinaison du substrat argilo-sableux sous-jacent. Elle est en revanche absente le long du côté Sud-Est de la fosse de SP 336, où celle-ci semble avoir perturbé la couverture de SP 334. La chronologie haute de ces deux sépultures est confirmée par leur mobilier et par la présence, dans les remblais de couverture, de trois dépôts (DP 12, DP 13 et DP 15) qui peuvent leur être directement associés. De même, deux foyers ( $\mathbf{F} 6$ et $\mathbf{F ~ 8}$ ), datés par plusieurs vases autour de 390-380, représentent vraisemblablement la trace de rites commémoratifs pratiqués à proximité des couvertures tumulaires, selon l'exemple du foyer F 5 près de SP 343 et SP 339 en secteur central. Le foyer F 6, à l'extrémité Sud-Est du secteur Nord, doit en effet entretenir un rapport étroit avec le tumulus de SP 334, alors que $\mathrm{F} 8$ se situe à la périphérie Nord-Ouest de la couverture de SP 336.

Peu de temps après, ce premier ensemble de sépultures est complété par la mise en place dans le secteur central de la ciste SP 339 (fig. 37, pl. 8). Cette tombe utilise le seul espace alors disponible entre les couvertures tumulaires des SP 343 et 300, qu'elle perturbe par son creusement. Une seconde sépulture (SP 375) vient par la suite se coller contre son côté Sud-Ouest : il s'agit d'une inhumation en fosse dont les parois internes présentent sur trois côtés (le quatrième étant formé par la paroi de la ciste) un revêtement en moellons relativement soigné. Cette position singulière de SP 375 souligne l'existence d'un rapport de parenté direct entre le jeune garçon de la ciste SP 339 et la jeune fille inhumée ici. Il demeure en revanche difficile de déterminer si l'installation de SP 375 précède la mise en place d'une couverture tumulaire au-dessus de SP 339 ou lui est postérieure. L'impossibilité de définir, dans un contexte sableux extrêmement meuble et pur, une limite supérieure pour la fosse de SP 375 restreint la portée de nos observations. Indépendamment de cette question, les deux remblais de sable (US 566 et 515), auxquels se superpose une mince 

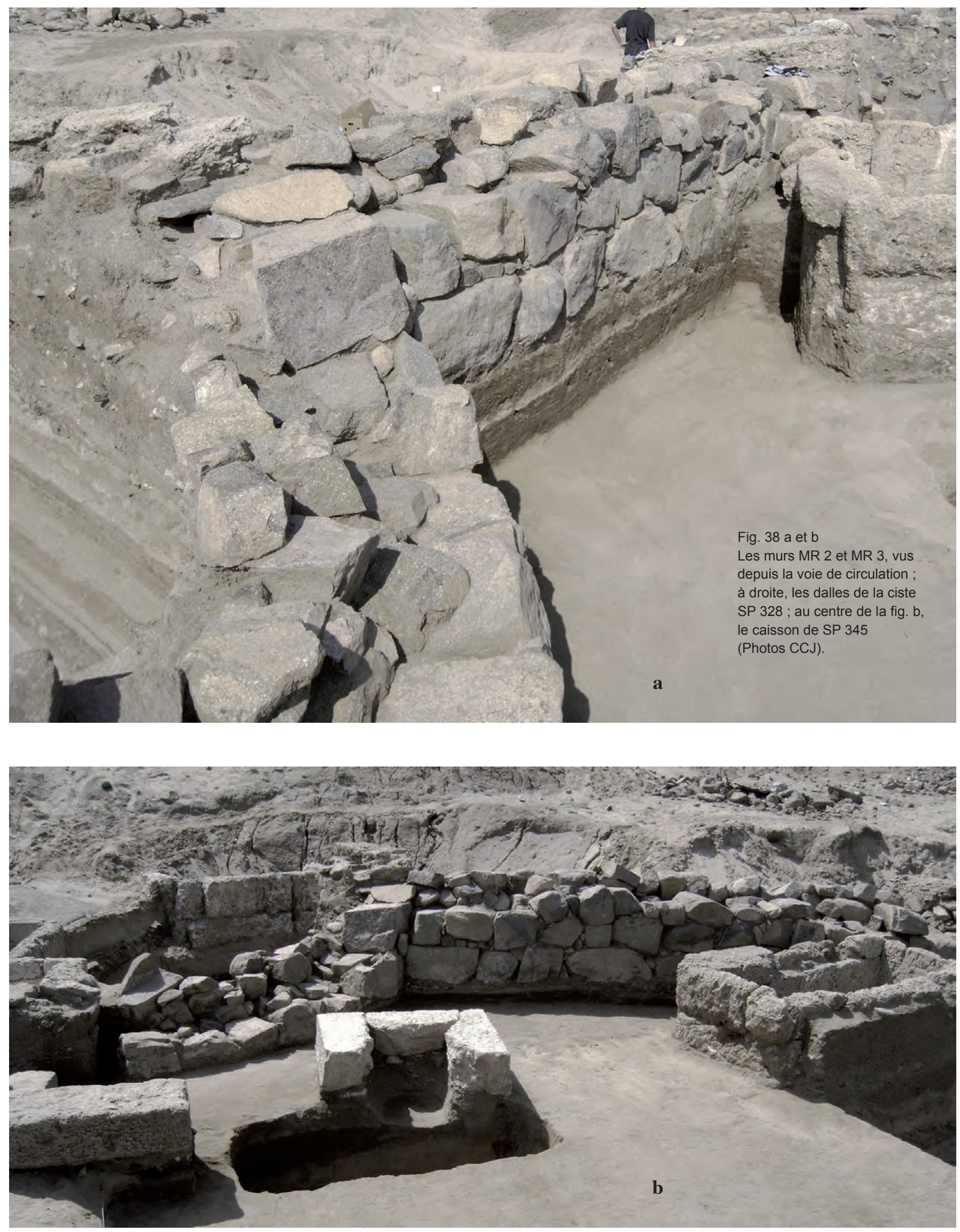


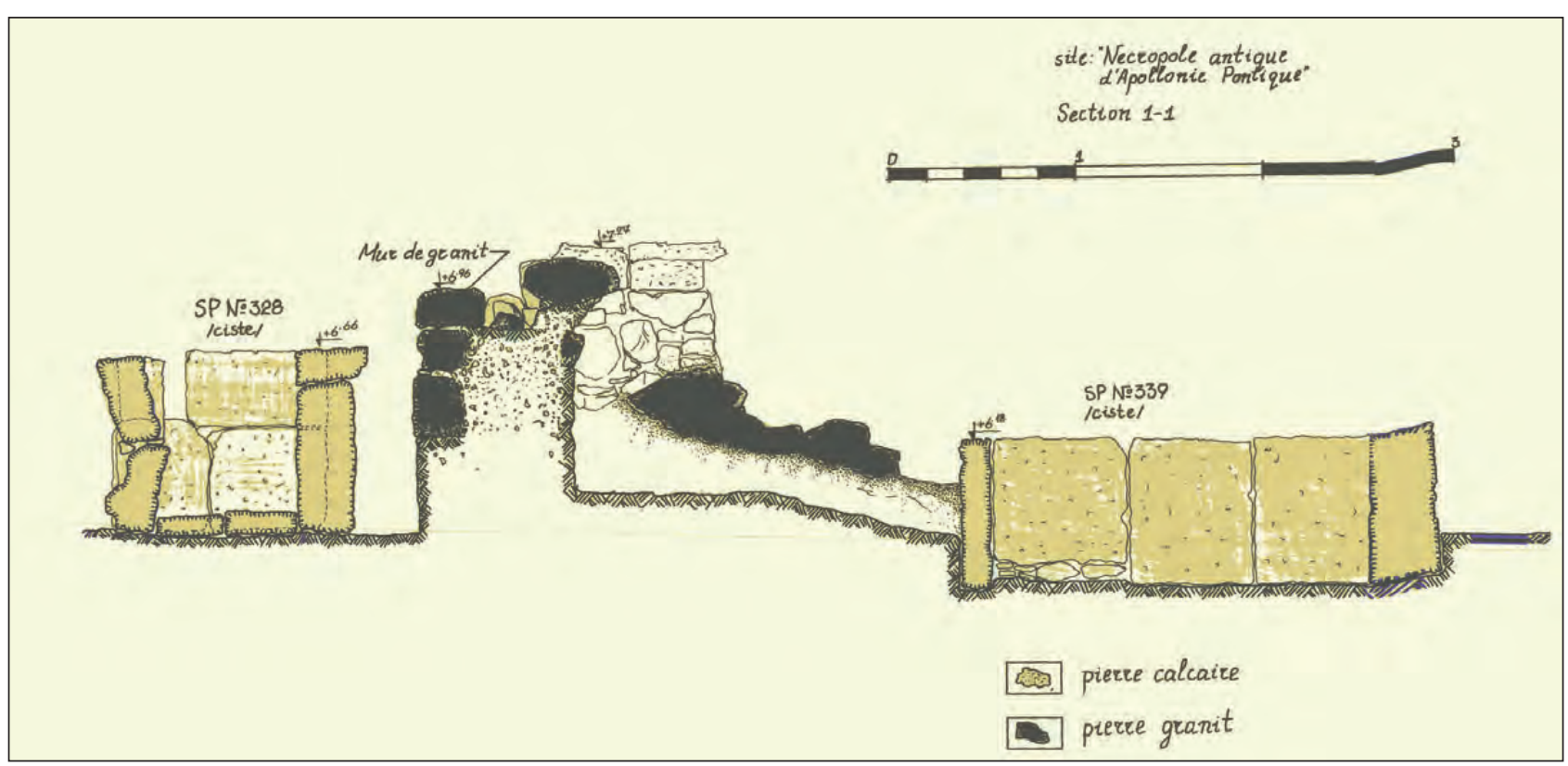

Fig. 39. Secteur central, coupe sur le mur MR 3 et les cistes SP 328 et SP 339 (Dessin Y. Topalova).

couche de terre sableuse (US 607), trop peu compacte cependant pour avoir formé un véritable scellage, constituent une couverture commune aux deux sépultures. Ces couches comblent définitivement l'espace laissé vacant entre les tumuli des tombes SP 300 et SP 343, déjà présents, et viennent buter au S./S.-O. contre le scellage de la couverture tumulaire de SP 325. La date d'installation du sable US 515, à la fin de la phase 2, est confirmée par deux dépôts (DP 26 et 30), auxquels on doit ajouter le foyer $\mathrm{F} 5$ découvert à proximité du tumulus de SP 343.

On note par ailleurs que les couvertures tumulaires qui recouvrent les sépultures de la phase 2 ont parfois été dotées à leur périphérie d'un alignement de pierres destiné à en protéger les abords et à retenir les terres. Ainsi, le tumulus de SP 300 disposait d'un petit muret dont seule une petite section subsiste entre l'angle Est de la ciste SP 339 et le mur MR 2. Il est perturbé à son tour, peu de temps après, par la construction d'un nouveau mur semi-circulaire (MR 2) qui protège, selon la même logique, l'extrémité orientale du tertre de SP 291 (fig. 38 a et b).

Ces deux structures témoignent par leur présence d'un souci nouveau d'isoler l'espace réservé à la sépulture du reste de l'espace funéraire. Cette analyse est directement confirmée par le fait que le mur MR 2 constitue également l'extrémité méridionale d'un alignement de plusieurs structures relativement contemporaines (MR 2/3/4/5/6/7) destinées à séparer l'espace funéraire de la voie qui le borde au Nord-Est. Il en représente également, avec l'enclos MR 6/7 en secteur Nord, un des éléments les plus anciens. Le mur MR 2, de forme semi-circulaire, dessine une structure de $6,20 \mathrm{~m}$ de diamètre et de $70 \mathrm{~cm}$ de largeur, conservée sur un espace qui va des points $\mathrm{F} / \mathrm{G} 3$ à E/F 2. Sa façade se compose de blocs de granit soigneusement équarris, assemblés sans mortier (niveau supérieur 5,65 à 5,70), tandis qu'un blocage de petites pierres constitue son parement interne. Il repose dans sa partie Nord-Ouest sur le scellage de la couverture tumulaire de SP $300{ }^{10}$. Sa datation nous est indirectement fournie par le foyer $\mathbf{F} 2$ qui s'étend plus au Sud, contre sa façade extérieure, et dont le contenu oriente au plus tard vers 380, offrant ainsi un terminus ante quem pour sa construction. En secteur central, la construction du mur MR 3 intervient probablement peu de temps après. Elle peut être datée, ici aussi, de façon assez précise grâce au foyer $\mathbf{F} \mathbf{9}$ découvert contre la façade du mur, en secteur Est. La date des différents vases à vernis noir provenant de ce foyer se situe, comme pour les vases du foyer $\mathbf{F} \mathbf{2}$ devant MR 2, autour de 380, ce qui confirme que le mur MR 3, bien que construit après MR 2, était presque contemporain. MR 3 présente un long tracé rectiligne, orienté S.-E./N.-O., qui vient se coller contre l'extrémité Nord-Ouest de la grande structure semi-circulaire. Comme celle-ci, il se compose de deux éléments nettement différenciés (fig. 38-39). Du côté de la mer, sa façade, relativement soignée,

10 Au S.-E., MR 2 est fondé directement sur l'horizon US 174/ 195/196/199/210/219/602/635, qui peut être identifié avec l'US 108. Il est édifié contre un remblai de terre argileuse contenant de nombreuses pierres (US 170), lequel est probablement mis en place au moment même de la construction du mur, afin de combler l'espace intermédiaire séparant ce dernier des couvertures tumulaires des tombes SP 300 et 291. 
est constituée de blocs de granit grossièrement équarris, alignés sur deux ou trois degrés et orientés vers la route ${ }^{11}$. La partie intérieure du mur est constituée d'une sorte de blocage de moellons granitiques (US 518) mélangés à de la terre argileuse (US 519). Sa mise en place est soigneusement préparée par l'accumulation de plusieurs remblais de sable ${ }^{12}$ entre les blocs de façade de MR 3 et les couvertures tumulaires de SP 343 et 339 , lesquels sont ensuite réunis sous un scellage commun de terre noire argileuse (US 610) avec les remblais antérieurs recouvrant SP 339 (pl. 6). Enfin, une ultime couche de terre argileuse compacte, comportant de nombreuses inclusions de petites pierres (US 531), est accumulée au-dessus de l'US 610, sur laquelle prend appui le parement interne de MR 3. Il est donc possible d'affirmer que l'accumulation de ces différents remblais va de pair avec la construction du mur, les couches de sable et de terre concourant à niveler un terrain rythmé par des couvertures tumulaires de diamètres variables et permettant ainsi d'assurer la stabilité globale de la structure.

Lors de la construction du mur MR 3 on a aménagé, à son extrémité Nord-Ouest, un passage étroit dont le seuil est formé par un grand bloc de granit structurellement lié aux blocs de la première assise de la façade, derrière lequel sont disposés quelques moellons identiques à ceux du parement interne. Ce passage est bordé au Nord-Ouest par un court muret transversal (MR 4), fondé comme une partie de MR 3 sur l'horizon d'installation des tombes SP 334 et 336 (US 575/588). Il est construit au moyen d'un blocage de pierres et d'un chaînage de trois blocs de granit en façade, avec au sommet un grand bloc de grès.

Plus au Nord-Ouest est entreprise à peu près au même moment la construction d'une vaste structure, MR 6 et 7, qui ferme sur trois côtés (au N.-E., au N.-O. et partiellement au S.-O.) l'espace occupé par les sépultures du premier quart du $\mathrm{IV}^{\mathrm{e}} \mathrm{s}$. Malheureusement, les destructions subies par l'enclos MR 6/7 durant la phase 3 sont trop importantes pour pouvoir restituer avec certitude le plan d'ensemble de la structure : il s'agissait vraisemblablement, à l'origine, d'un péribole de forme ovale qui entourait les couvertures tumulaires des tombes SP 334 et 336 (pl. 4). Il subsiste de cette structure un segment de mur en forme d'arc (MR 6), dessinant l'extrémité

11 Cette façade est fondée à cheval entre deux couches: la première, présente sous la plus grande partie du mur au S.-E., est l'horizon de terre US 174/195/196/199/210/219/602/635 qu'on retrouve également à la base de MR 2 ; la seconde, sous l'extrémité N.-O. de MR 3, représente une succession serrée de micro-horizons de sable et de terre (US 575/588) qui se prolonge sous le mur MR 5 et dans l'ensemble du secteur Nord.

12 US $172 / 605$, US $171 / 572$, US $173 / 542$ et US 8/516.
Nord-Ouest de l'enclos, suivi d'un deuxième segment beaucoup plus court (MR 7) à sa périphérie Sud-Est, à la limite avec le secteur central. Leur longueur conservée est respectivement de $6,5 \mathrm{~m}$ et $1,73 \mathrm{~m}$. Entre ces deux portions, qui ont conservé le parement de leur façade, il est possible de suivre le tracé de l'enclos sous les structures hellénistiques à la périphérie Nord-Est du secteur, où seule la première assise de moellons du parement extérieur est restée en place. Entre les points J 6 et I 6, contre la face extérieure du segment NordOuest du mur MR 6, est accolé un escalier constitué de six marches comportant entre une et trois pierres plates (fig. 40 a et b). Les quatre premières marches, du haut vers le bas, sont faites d'une pierre non appareillée posée horizontalement sur une couche de gravier, d'une épaisseur inégale. Cet escalier est bordé du côté extérieur par deux grandes pierres et d'autres plus petites qui forment un muret long de $57 \mathrm{~cm}$. Il permettait d'accéder directement au-delà du mur d'enclos à la surface des couvertures tumulaires depuis un espace de circulation situé au Nord-Ouest. Il est cependant difficile de déterminer s'il s'agit d'un aménagement contemporain de la construction du mur ou d'un ajout plus tardif.

Le foyer F 8, daté par plusieurs vases des années 390-380, s'engage sous ces murs et apporte ainsi un précieux terminus post quem pour leur édification. Cette chronologie est également confirmée par $\mathbf{F} 6$ (vers 380) qui s'avère contemporain de leur construction, comme l'indique sa position particulière sous la dernière assise du mur MR 7, mais à la surface du remblai l'US 530/568/576/594 dont la mise en place contre la couverture tumulaire de SP 334 est destinée à égaliser le terrain. La technique de construction reprend pour l'essentiel celle observée dans les secteurs Sud et central, bien que le traitement d'ensemble présente quelques différences. On retrouve ainsi deux éléments nettement différenciés : une façade relativement soignée et un blocage interne de moellons qui vient s'appuyer sur des remblais spécialement accumulés pour le soutenir et assurer la solidité de la structure ${ }^{13}$. La hauteur de la façade semble avoir varié en fonction du pendage suivi par le terrain : elle compte en effet quatre à cinq assises dans sa partie Nord-Ouest (MR 6) et deux assises seulement à l'extrémité Sud-Est de la structure (MR 7). Pour le reste, la technique de construction ne varie guère : une ou plusieurs assises de pierres de granit non appareillées forment un parement régulier sur la face extérieure, surmontées d'une assise de petits blocs taillés en grès, conférant ainsi à l'enclos un aspect plus fin,

13 Dans le cas du mur MR 7 : US 591, US 577/596, US 578, US 569/574, US 530/568/594/576. 
mais également moins monumental que celui des murs MR 2, 3 et 4. Le blocage mis en place à l'arrière de la façade ne comporte généralement qu'une ou deux assises de moellons et semble reposer partout sur une couche de terre argileuse contenant de nombreuses immixtions de pierres (US 530/568/576/594), posée directement sur le scellage des couvertures tumulaires de SP 334 et 336. Cette couche se retrouve dans l'ensemble du secteur Nord, au Nord-Est, au Nord-Ouest et au Sud-Ouest des tumuli préexistants, où elle fonctionne comme une couverture commune unissant l'espace funéraire du premier quart du $\mathrm{IV}^{\mathrm{e}} \mathrm{s}$. Elle se poursuit également en secteur central, où elle recouvre partiellement les pentes Nord-Est et Sud-Ouest du tumulus de SP 343 et sert d'appui, avec d'autres remblais antérieurs et postérieurs, à un dernier mur, MR 5, dont la fonction principale est d'assurer la fermeture de cette succession de murs.

Ce mur MR 5, légèrement convexe, vient s'appuyer plus au Sud contre le mur MR 4 (fig. 41). Malgré son apparence plus sommaire, il est construit d'une manière similaire à MR 2 et 3 . Ici encore, deux remblais de terre et de sable sont en effet ajoutés aux remblais précédents afin de niveler le terrain et servir d'appui à MR 5 contre le flanc Nord-Est du tumulus de SP $343^{14}$ (pl. 7a). Confirmant la chronologie de l'ensemble, on remarque que ces deux remblais s'appuient contre MR 7, tandis que la couche supérieure (US 20/507/514/593) est également en contact avec MR 4, démontrant ainsi que ces murs sont déjà en place au moment de la construction de MR 5. Le caractère plus tardif de MR 5 explique sa forme singulière adaptée au tracé des autres structures. Son élévation est constituée par un premier alignement de blocs de granit, posé en guise de semelle de fondation, sur lequel se développe un conglomérat épais de petits cailloutis et de blocs plus fins qui s'appuie contre la série des remblais présents au Sud-Ouest. L'ensemble est couronné par d'autres blocs de granit qui donnent à cette structure atypique sa forme définitive (niveau supérieur 5,72). L'alignement des murs MR 2 à 7 délimite ainsi, à l'extérieur, une étroite bande (appelée ici secteur Est) placée en contact direct avec la voie de circulation, et lui confère ainsi sa cohérence ${ }^{15}$. Cette zone a été, jusqu'alors, laissée libre de toute construction.

14 La terre argileuse US 20/507/514/593 et le sable US 595.

15 En raison de l'épaisseur des couches, le substrat de base (US 641) n'a pas été atteint à cet endroit. La profondeur maximale atteinte lors des fouilles varie dans les différentes parties de ce secteur. Ainsi, dans la zone située au N.-E. et au N.-O. de la tombe SP 328, les fouilles se sont arrêtées au niveau de l'horizon de terre sableuse US 624/644 (niveau 3,91), alors qu'au S.-E. de la ciste SP 328 les travaux n'ont pas avancé au-delà de l'horizon de terre compacte US 198/221/223/586/642 (niveau 4,29), qui correspond, en secteur central, au niveau d'installation de SP 343. La situation
Plusieurs interventions postérieures viennent clore la phase 2. Dans le secteur Sud, l'espace protégé par MR 2 est à son tour comblé par un important remblai de terre, particulièrement compact, qui comporte de nombreuses inclusions de pierre ${ }^{16}$. La fonction de ce remblai n'est pas clairement établie, mais il recouvre par sa position les couvertures tumulaires de SP 300 et SP 291 sous un seul ensemble et confère à cet espace une forte unité. De même, dans le secteur Est, on observe alors la mise en place de quatre foyers qui représentent vraisemblablement la trace de rites commémoratifs en rapport avec les sépultures creusées de l'autre côté des murs. Les foyers F 2, F 9 et F 10 sont, ainsi, situés contre la façade des murs MR 2 et 3. Le foyer F 10 (niveau 4,80) n'a livré que quelques fragments de céramique commune difficiles à dater, mais la chronologie de F 2 (niveau 4,68) et F 9 (niveau supérieur 4,91, inférieur 4,82) nous est en revanche donnée par plusieurs des vases qu'ils contiennent, attribuables aux années 380. Plus au SudEst, $\mathbf{F} 1$ est excentré et semble légèrement plus récent (vers 380) : il a livré en effet deux coupelles à vernis noir, dont la première trouve des parallèles exacts dans le matériel de $\mathrm{F} 2$, alors que la deuxième présente de nombreux traits communs avec quelques coupelles provenant de F 11. Or, ce dernier foyer peut être daté de la toute fin de la phase 2 .

étudiée semble en tout point conforme à celle observée au S.-O. de l'alignement de murs MR $2 / 3 / 4 / 5$, bien que l'on note quelques particularités, à savoir l'épaisseur plus importante de l'horizon US 198/221/223/586/642 (35 à $45 \mathrm{~cm}$ au N.-E. de SP 328), qui semble perdre son caractère compact et linéaire en progressant en direction de la mer, ainsi que les pendages uniformes suivis par toutes les couches de la partie inférieure de la séquence, à la fois vers le N.-E. et le S.-E.

Le secteur Est est, lui, à cheval sur deux logiques stratigraphiques. La première, au N.-O de SP 328, le rattache au secteur Nord par la succession serrée de micro-couches de sable et de terre (US 575/588), observée également sous l'extrémité N.-O. du mur MR 3 et à la base de MR 4 et 5 ; plus au S.-E., entre SP 328 et l'extrémité S.-E. du mur MR 2, la séquence stratigraphique comporte, à l'inverse, de fortes similitudes avec la situation observée en secteur Sud. Dans cette seconde zone, on constate la mise en place, au-dessus de l'US 198/221/223/586/642, de deux horizons de sable (US 609/620/639 et US 109/212/215/637) séparés par un horizon de terre (US 180/216/604/618/636), le tout scellé par un mince couche de terre compacte (US 174/195/196/199/210/219/602/635), sur laquelle reposent de larges portions de MR 2 et 3 . Par ailleurs, il est possible de distinguer également une troisième zone, périphérique par rapport au secteur étudié, qui présente de ce fait des caractéristiques moins claires. Celle-ci est confinée à l'espace immédiatement adjacent à la façade du petit enclos MR 1 et se caractérise par l'absence de toute accumulation contemporaine de couches au-dessus de l'horizon US 198/221/223/586/642, qui sert donc directement d'appui pour une grande partie du mur MR 1 et du foyer F 1 et correspond au niveau de circulation le long de la voie antique au N.-E.

16 US 102/138 : niveau supérieur près de SP 300, 6,57. 


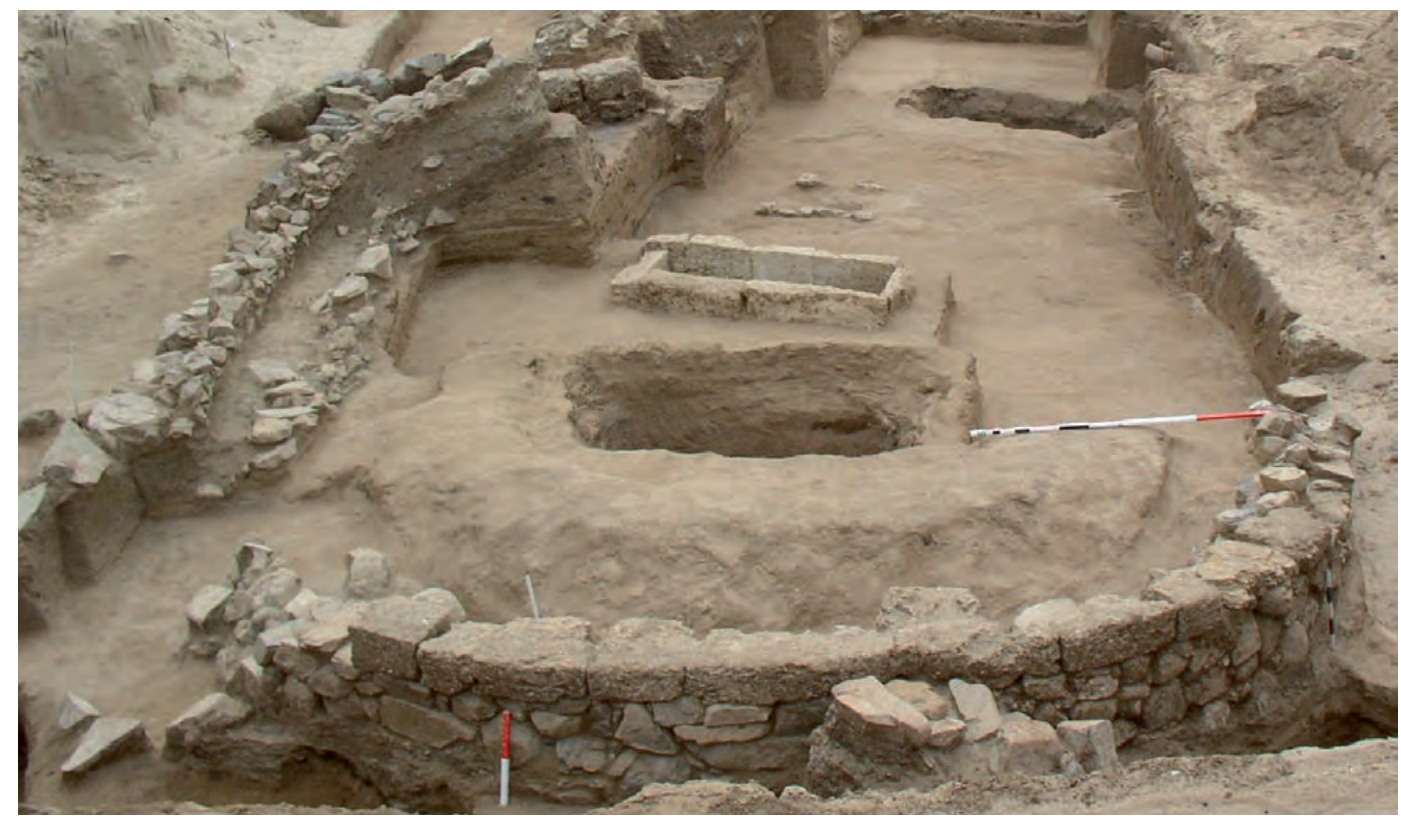

Fig. 40 a et b. Secteur Nord, le mur MR 6 et l'escalier accolé contre sa face N.-O. : ensemble et détail

(Photos K. Panayotova).

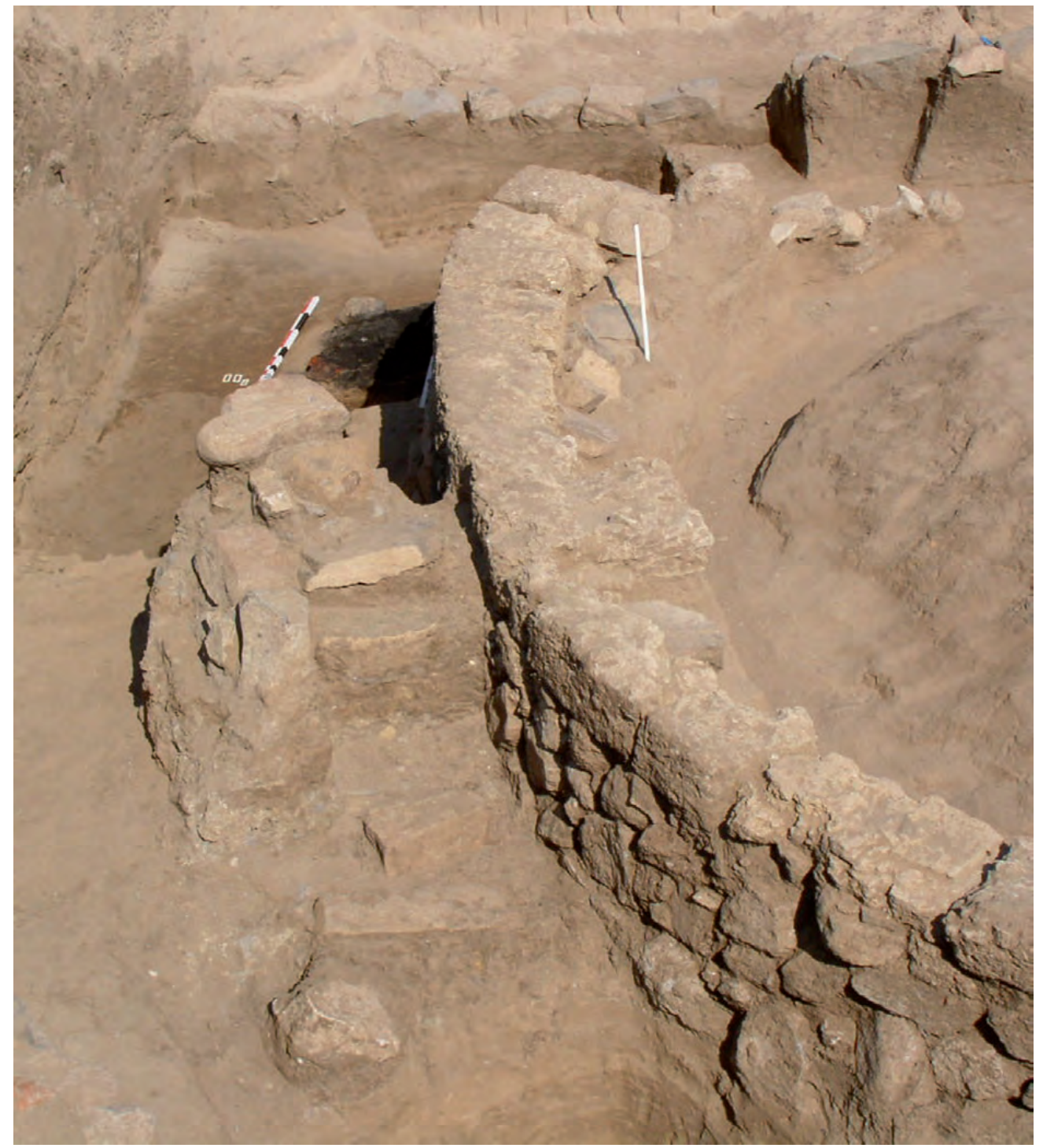




\section{Phase 3 (du deuxième quart à la fin du IV ${ }^{\mathrm{e}}$ s. av. J.-C.) : fig. 42, pl. 9}

Cette longue phase se caractérise par une transformation importante de l'organisation de l'espace funéraire : on passe d'une nécropole de type tumulaire à une nécropole plate au sein de laquelle l'occupation se fait plus dense. Cette transition n'affecte toutefois pas l'ensemble des secteurs dans la même proportion. Deux périodes peuvent être distinguées. La première, qui constitue une transition, voit l'effacement progressif des anciennes limites architecturales et des couvertures tumulaires de la phase 2 : les sépultures sont mises en funéraire et au dépôt DP 1 qui lui est associé, au début du second quart du IV ${ }^{\mathrm{e}} \mathrm{s}$. Suivant le modèle offert par les sépultures étudiées à Pydna ${ }^{17}$, une double fosse est aménagée dans l'US 102/138. Elle est dotée sur son flanc Sud-Est d'un escalier latéral (long. 2,55 m, larg. 1,20 à 1,30 m, dénivelé $1,95 \mathrm{~m}$ ) permettant d'atteindre la tombe située dans la fosse inférieure ${ }^{18}$. Deux dalles de calcaire de dimensions importantes $(119$ x 53 x $32 \mathrm{~cm}$ et $117 \times 43 \times 31 \mathrm{~cm}$ ), en situation de réemploi, sont placées en haut de la fosse supérieure et marquent la position de la tombe.

Peu après, à l'extrémité occidentale du secteur Sud, s'installe une sépulture à incinération secondaire (SP 316) qui constitue un des exemples les plus anciens

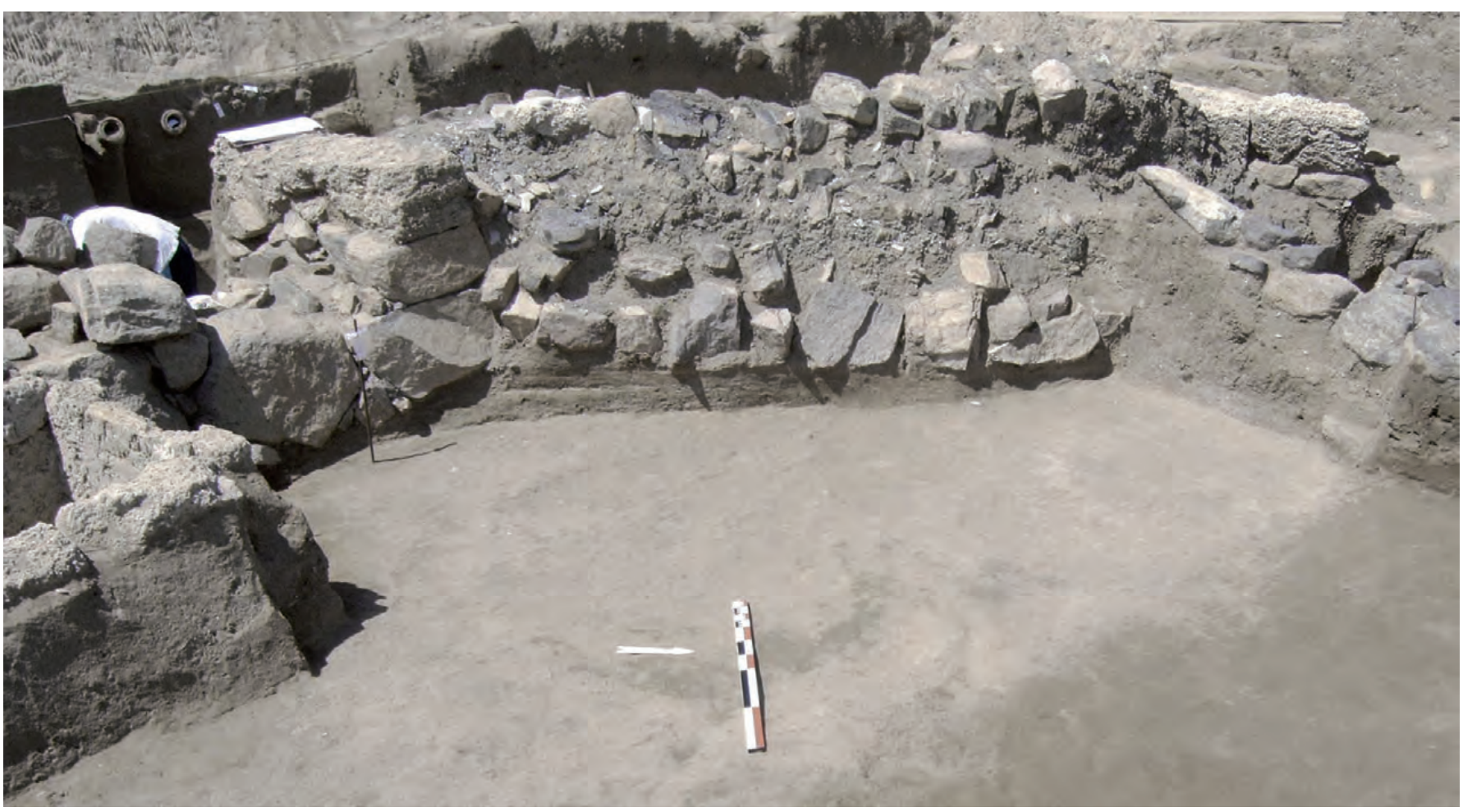

Fig. 41. Le mur MR 5 dans le secteur central ; à gauche, le passage ménagé entre MR 3 et 4 et la ciste SP 328 (Photo CCJ).

place dans le cadre d'une nécropole qui s'étend parallèlement aux secteurs proches de la voie de circulation. Dans la seconde, l'évolution aboutit à une organisation cohérente des sépultures, qui ignore désormais le tracé des murs de la phase 2.

\subsection{Deuxième quart du IV ${ }^{\mathrm{e}} \mathrm{s}$. av. J.-C.}

Dans le secteur Sud, une structure funéraire originale, liée à l'installation de la tombe SP 244, prend place au centre de la parcelle funéraire délimitée par le mur MR 2. Elle peut être attribuée, grâce à son mobilier
17 Le modèle de la double fosse avec escalier latéral, présent sur un des longs côtés de la fosse supérieure, apparaît à Pydna lors de la phase I du fonctionnement de la nécropole Nord, soit durant la seconde moitié du $\mathrm{V}^{\mathrm{e}} \mathrm{s}$., majoritairement pour des sujets de sexe masculin (Besios 1987, p. 209-210). Ce type de tombe devient prédominant à la fin du $\mathrm{IV}^{\mathrm{e}} \mathrm{s}$. et au début du $\mathrm{III}^{\mathrm{e}} \mathrm{s}$. av. J.-C., avec des dimensions plus monumentales (Besios 1990, p. 243, et 1991, p. 171-173). La présence de tombes à double fosse est attestée à Olbia, dans le domaine nord-pontique («niche tomb»), dès la fin du $\mathrm{VI}^{\mathrm{e}}$ s., mais, contrairement à Pydna, l'ajout d'un escalier n'apparaît pas systématique. L'introduction de ce type de sépulture est mise en relation avec une influence scythe, bien que ce lien soit contesté pour les exemples de la fin de l'archaïsme (Petersen 2007, p. 47-48).

18 Niveau supérieur du remplissage de la double fosse, $7 \mathrm{~m}$; du fond de la fosse de SP 244, 4,68 m. 


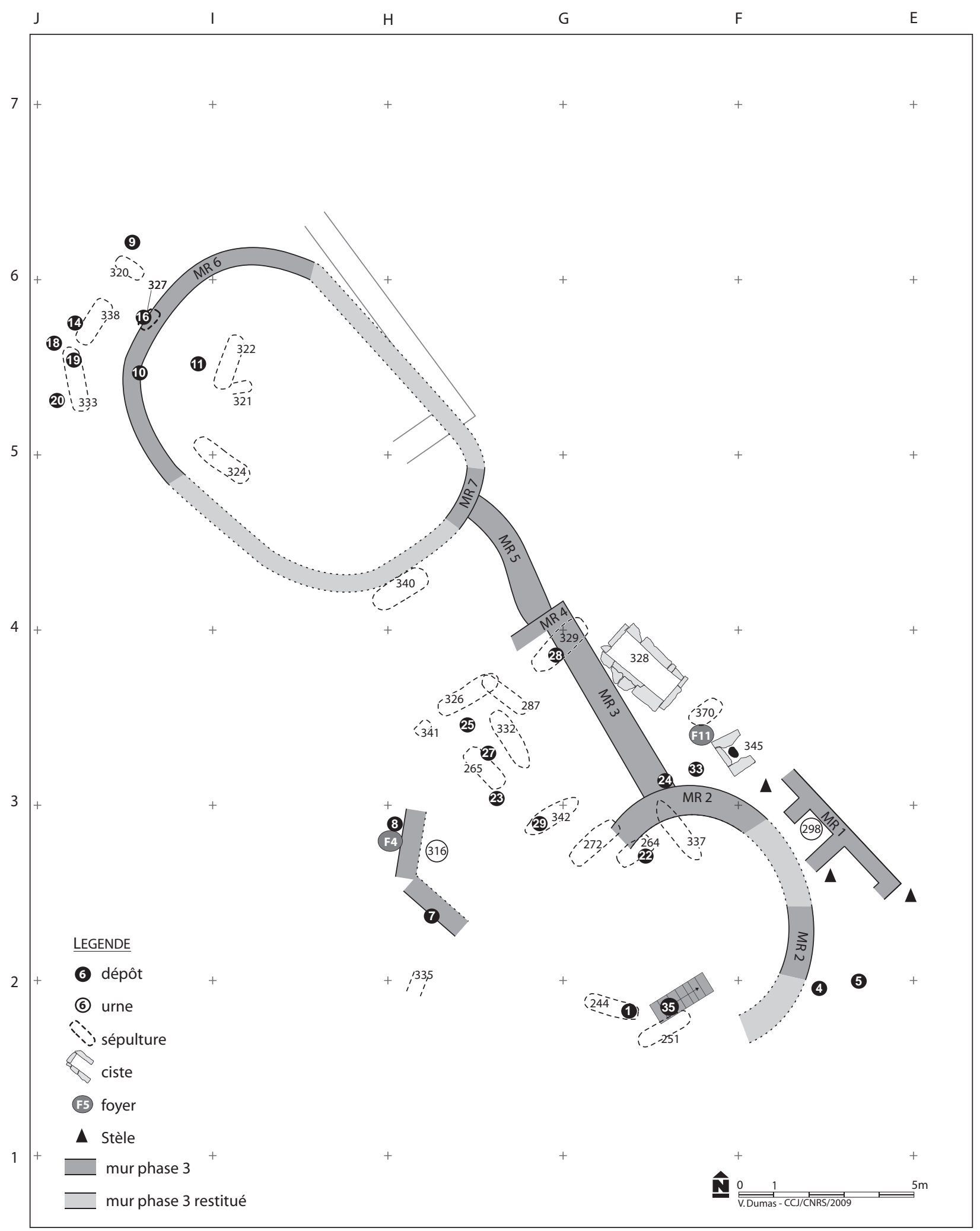

Fig. 42. Plan schématique de la phase 3 (๑ CCJ). 
de cette pratique dans la nécropole de Kalfata. Les restes incinérés du défunt sont recueillis dans un cratère attique à figures rouges daté du second quart du $\mathrm{IV}^{\mathrm{e}} \mathrm{s}$. Le vase est placé dans une fosse creusée dans la couverture tumulaire de SP 325.

On note surtout, durant ce même quart du siècle, que le mur MR 2 est gravement endommagé à plusieurs reprises et perd rapidement sa visibilité. Les premières traces de destruction semblent remonter au tout début de la phase 3 , probablement moins d'une décennie après la construction de la structure. Une grande partie de sa façade centrale est alors démontée, laissant seulement en place la première assise de pierres qu'une mince couche de terre vient rapidement recouvrir (US 143/537/598/634) : la mise en place de cette couche peut être fixée avec une relative précision grâce à la position du foyer $\mathbf{F} \mathbf{1 1}$ (secteur Est) qui suggère une date dans les années 380370. Quelques années plus tard, la construction du mur MR 1 sur cette même couche, contre MR 2 au NordEst, semble provoquer des dommages supplémentaires à cette dernière structure. Ce processus de destruction s'achève par un important décaissement réalisé à la jonction des MR 2 et 3 et dans la zone adjacente disposée plus à l'Ouest, auquel succède l'accumulation de deux remblais de terre ${ }^{19}$ qui recouvrent désormais définitivement les derniers vestiges de MR 2. Le remblai inférieur contient de nombreux blocs de pierre qui peuvent provenir du mur lui-même. Malgré sa datation relativement large, le dépôt $\mathbf{D P} \mathbf{3 3}$, situé à la surface du remblai l'US 19/114/129 en secteur Est, permet de placer leur installation avant 350 .

Cette disparition des anciennes limites attribuées à l'espace funéraire explique en retour l'installation vers le milieu du siècle, ou un peu avant, de plusieurs sépultures placées à proximité des anciens murs, voire au-dessus des derniers blocs conservés. Ainsi, une double fosse destinée à accueillir la tombe SP 337 est alors creusée à cheval sur plusieurs remblais (pl. 5). La sépulture n'a livré qu'un petit vase local sans date précise. Elle est accompagnée par l'installation dans cette même zone, au S./S.-O., de deux autres tombes. Grâce à son mobilier et au dépôt $\mathbf{D P} 22$ découvert à proximité, la première d'entre elles, SP 264, est très clairement datée autour de 350. La fosse accueillant la sépulture perturbe par son creusement celle de SP 337, démontrant l'antériorité de cette dernière. Un modeste remblai de sable (US 3) forme un petit tertre (niveau supérieur 6,29) audessus de SP 264. La seconde sépulture, SP 272, prend

19 US $115 / 120 / 130$ et US 19/114/129. place à proximité immédiate de cette dernière, à l'Ouest. Elle ne contenait aucun vase, mais doit être, du fait de sa position stratigraphique, strictement contemporaine de SP 264. Sa fosse, creusée dans plusieurs unités stratigraphiques, se superpose dans sa partie nord-orientale au dernier bloc du mur MR 2, tous deux n'étant séparés que de quelques centimètres.

Dans le secteur central, le second quart du IV ${ }^{\mathrm{e}} \mathrm{s}$. voit l'installation de plusieurs sépultures dans le tumulus de SP 343 ou dans les remblais accumulés contre lui lors de la construction des murs MR 3 et 5 . Ces sépultures sont dépourvues de la couverture tumulaire qui caractérisait les tombes de la phase 2. Deux tombes, SP 326 et SP 329, peuvent être attribuées avec une relative certitude à cette période. La tombe SP 326 est installée au sommet du tumulus de SP 343 (niveau 5,49). Elle doit dater des années 360-350, si on l'associe au dépôt DP 25 découvert à proximité. Aucun tertre ni marqueur ne lui est associé. Le mobilier livré par la tombe SP 329 (niveau 5,19) permet de la dater dans la même décennie. Elle occupe le passage aménagé entre les murs MR 3 et 4 : ce dernier, lors de l'installation de SP 329, est déjà partiellement comblé de terre et n'avait plus de fonction (fig. 43). Cette évolution explique l'effacement rapide de ces structures dans le secteur central, suivant le processus observé en secteur Sud à propos du mur MR 2. La fosse accueillant la nouvelle sépulture est recouverte d'une petite couverture de sable (US 10/527) et encadrée au Nord-Est d'un marqueur en forme de $\Pi$ construit en moellons granitiques et en blocs de calcaire (US 525). Ce dernier, à son tour, empiète partiellement sur l'amas de pierres (US 521), recouvrant les dalles de couverture de la ciste SP 328 dans le secteur Est et fournissant ainsi un premier indice pour déterminer la chronologie relative de cette sépulture.

Une autre sépulture peut être rattachée, avec quelques réserves, au même quart de siècle. À la limite du secteur Nord, la tombe SP 340 s'installe à partir de la surface du remblai US 530/568/576/594, associé à la construction du grand enclos MR 6/7. Du fait de sa profondeur importante, la fosse de la sépulture perturbe la périphérie Nord-Ouest du tumulus de SP 343 et les couches sousjacentes. La défunte était accompagnée d'un riche mobilier composé de plusieurs objets en métal et d'un grand lécythe polychrome montrant Aphrodite chevauchant un cygne. Le marquage de la tombe demeure incertain, bien qu'il soit tentant de lui attribuer l'accumulation de blocs de granit (US 509/613) découverte au-delà de ses limites au S./S.-E. Plus au Sud, la tombe SP 341 (niveau 4,72) est également installée dans une fosse creusée à partir du scellage de la couverture tumulaire de SP 343. Le matériel qui accompagne le sujet 


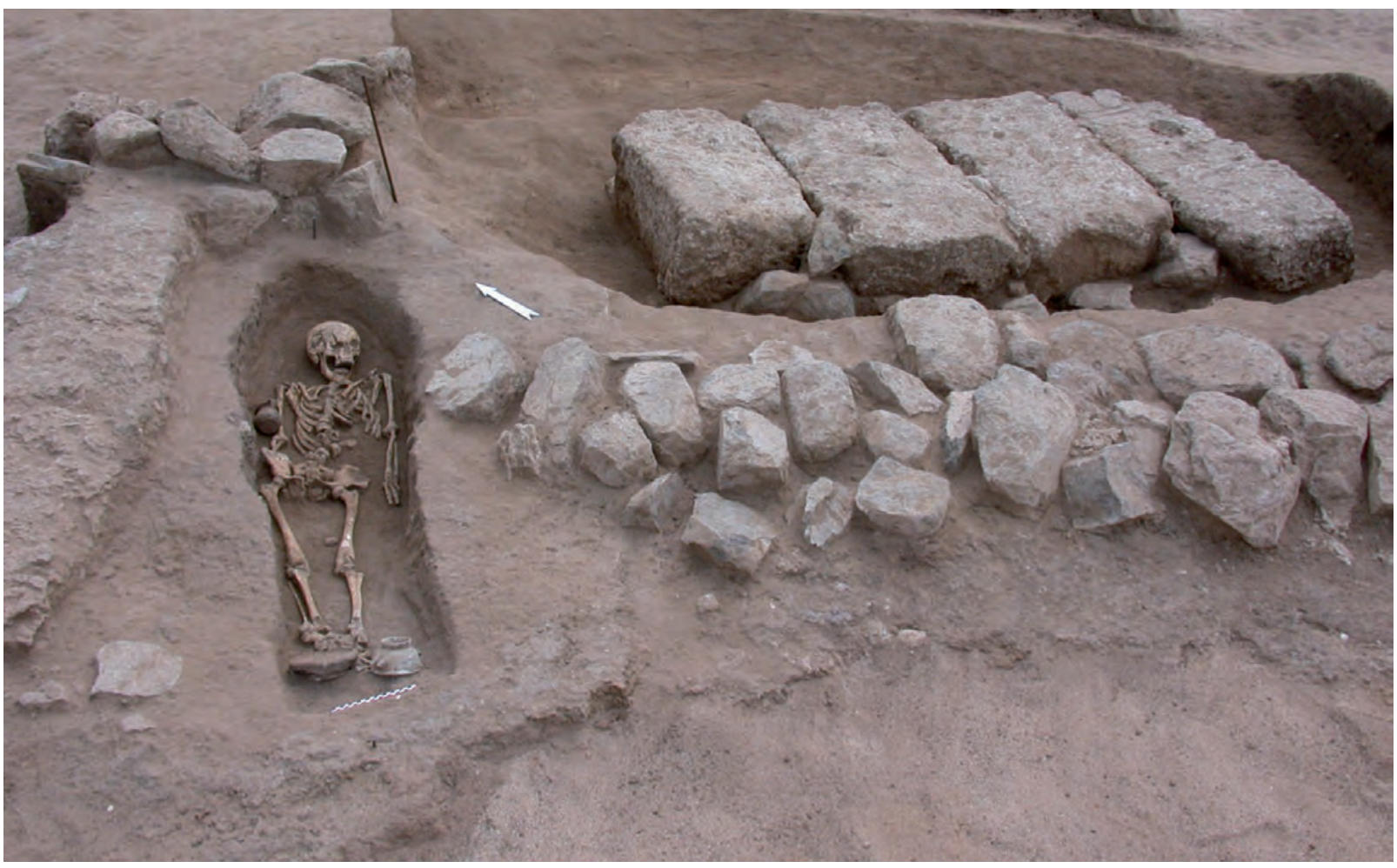

Fig. 43. Le passage entre les murs MR 3 (à dr.) et 4 (à g.); dans le comblement intervenu lors de la phase 3 , installation de la tombe SP 339 ; en arrière-plan à droite, la ciste SP 328 (Photo CCJ).

ne fournit cependant aucune indication chronologique claire. Ce jeune enfant de moins de deux ans ne disposait que d'une petite offrande alimentaire.

L'effacement du mur MR 3, comme celui de l'ensemble des murs de ce secteur, ne semble pas aussi avancé qu'en secteur Sud. S'ajoutant au comblement de l'ouverture qui sépare les murs MR 3 et 4, l'extrémité Sud-Est de cette première structure devient à son tour invisible à la suite de la destruction d'une grande partie de la façade du mur MR 2 et à la mise en place, déjà évoquée, de deux remblais de terre au-dessus de ses vestiges (US 19/114/129 et 115/120/130). Ces derniers viennent également recouvrir l'extrémité Sud-Est de MR 3, comme le démontre la situation du dépôt DP 33 en secteur Est, qui est situé à la surface de ces deux couches, dans la zone intermédiaire entre les deux structures. Il semble toutefois que la plus grande partie du mur MR 3, tout comme les murs MR 4-5, soit restée encore visible.

L'occupation de l'espace situé à l'Est des murs MR 2 à 7 débute durant cette même période par l'installation de la sépulture à crémation SP 345. La tranchée de fondation de la ciste (US 197) a en effet été creusée à partir de la surface de l'US 174/195/196/199/210/219/602/635. Les blocs ne sont travaillés que du côté extérieur. Ils sont dotés à mi-hauteur, exactement au niveau supérieur du comblement de la petite fosse, d'un léger ressaut. Ce dernier détail indique qu'une partie de la structure était restée visible après son installation. Au moment de la découverte, l'hydrie à figures rouges, utilisée comme urne cinéraire, était simplement dissimulée sous une couche de petites pierres. La base de stèle située immédiatement au Sud-Est a été mise en place ensuite, comme le montre le fait que l'extrémité Nord-Ouest de sa petite tranchée de fondation (US 205) recoupe la tranchée de fondation de SP 345 : il est très vraisemblable que les deux opérations ont été très rapprochées dans le temps, et que la stèle se rapportait à SP 345.

On assiste alors au remblaiement progressif de l'espace situé devant l'alignement MR 2/3/4/5. Ce processus débute par l'accumulation d'une couche argileuse d'une dizaine de centimètres d'épaisseur (US 143/537/598/634) contre la face occidentale de SP 345 et de la base de stèle à proximité. Sur cette nouvelle surface s'installe la tombe d'enfant SP 370 (niveau 4,77). Les ossements sont directement recouverts par une partie d'un vaste dépôt qui occupe la presque totalité de la zone comprise entre le mur MR 3 et les tombes SP 345 et 328 . Les charbons de bois mêlés à une grande quantité de tessons brûlés montrent qu'il s'agit de l'épandage d'un foyer (d'où sa désignation 


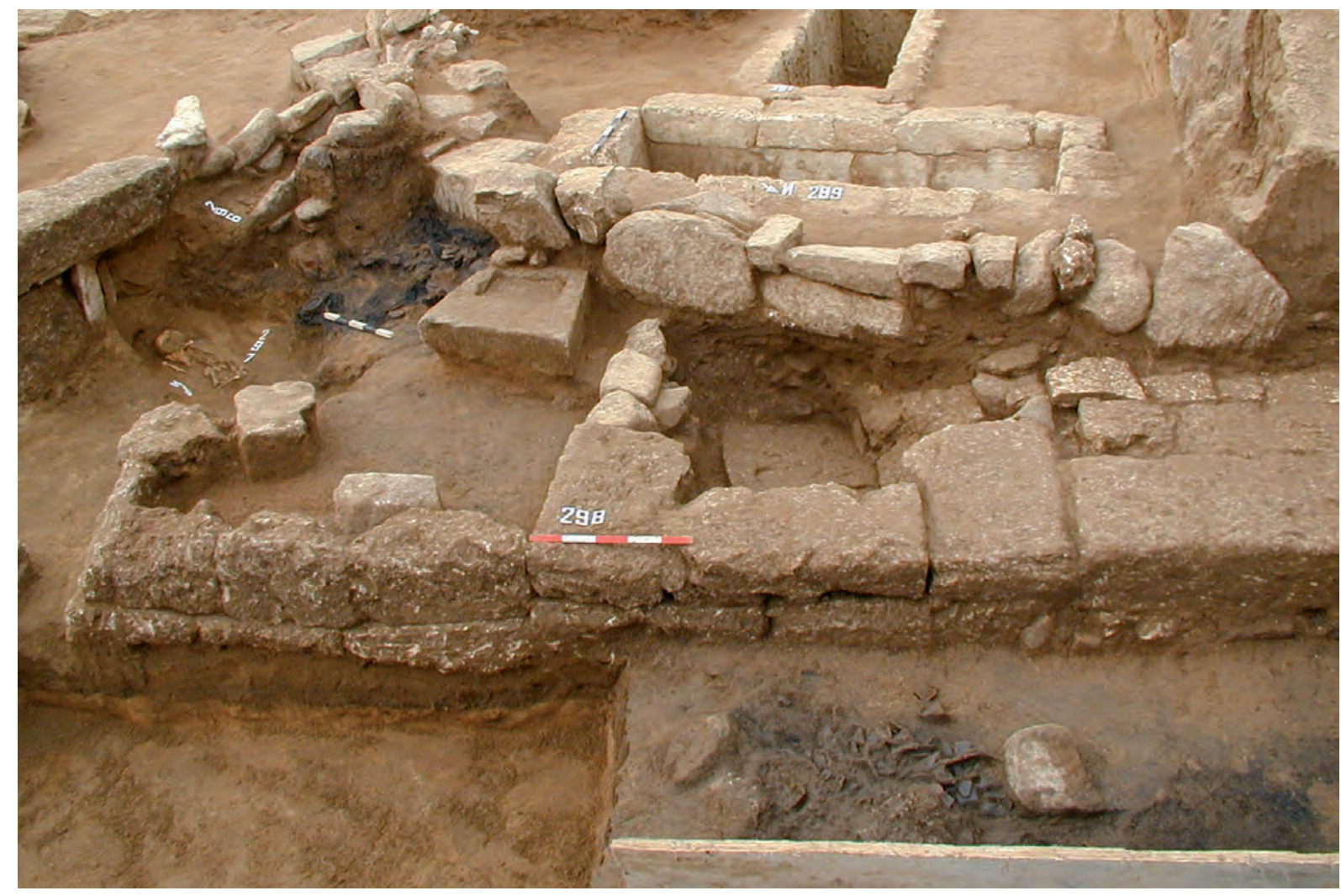

Fig. 44. Secteur Est, le mur MR 1 et l'emplacement aménagé pour l'urne SP 298, contre le mur MR 2 : à gauche les tombes SP 296 et 297

(Photo K. Panayotova).

Fig. 45. Le mur MR 1, avec à sa gauche le foyer $\mathrm{F} 1$ et dans l'enclos l'urne SP 298 (Photo K. Panayotova).

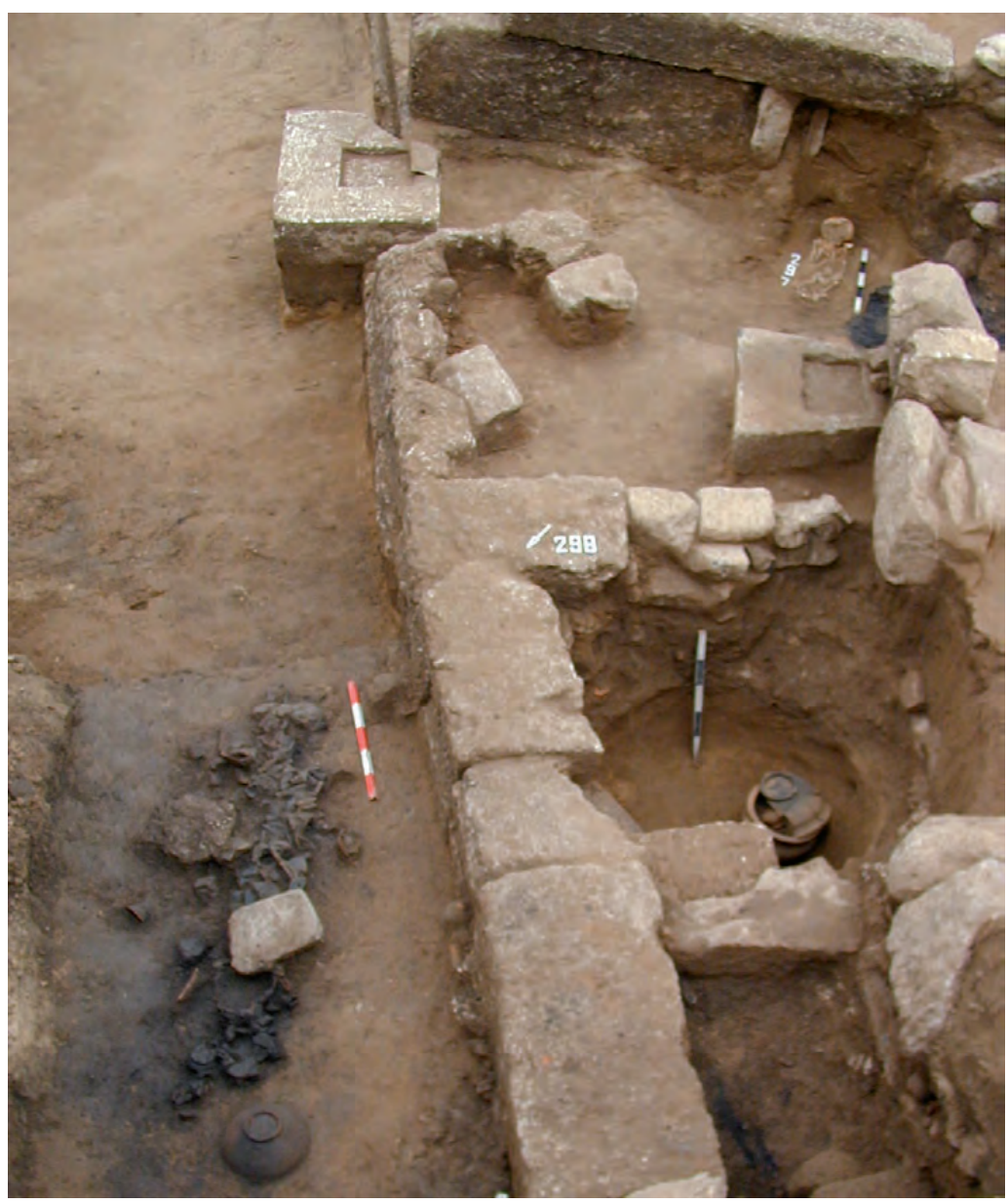


ici comme «foyer $\mathbf{F} \mathbf{1 1}{ }^{20}$ ), sans qu'il y ait de recollages avec des vases du foyer F $9^{21}$. La céramique qu'il contient permet de fixer des limites chronologiques assez précises, à la fois pour l'installation de SP 370 et pour l'accumulation préalable de l'US 143/537/598/634 : elle semble en effet légèrement plus récente que celle des foyers de la phase 2 (dont F 9), tout en s'inscrivant dans une continuité directe, ce qui suggère une date dans le début du second quart du $\mathrm{IV}^{\mathrm{e}}$ s., autour de 370. Ainsi, le laps de temps qui s'est écoulé entre la mise en place des foyers rituels à la fin de la phase 2, la destruction de la façade de MR 2, la mise en place de SP 345, l'accumulation de l'US 143/537/598/634, l'installation de SP 370 et son recouvrement par l'épandage $\mathrm{F} 11$ a été très court, de l'ordre à peu près d'une décennie. Cette précision est importante pour la datation de l'hydrie de SP 345 qui représente un des meilleurs exemples du style de Kertch ancien et, plus précisément, de ce que l'on appelle le « groupe d'Apollonia ».

C'est encore assez tôt, dans le second quart du $\mathrm{IV}^{\mathrm{e}} \mathrm{s}$., qu'il convient, semble-t-il, de placer la construction du mur MR 1 et la mise en place de l'incinération secondaire SP 298 qui lui est étroitement associé (fig. 44-45). Les observations stratigraphiques effectuées dans la partie Sud-Est du secteur apportent un éclairage précieux sur l'histoire de cet ensemble architectural ${ }^{22}$. L'enclos mis en place à l'arrière du mur MR 1 vient se coller à la structure semi-circulaire MR 2, sans qu'il y ait de véritable relation avec elle, ni avec les autres murs de la fin de la phase 2. Il peut être au contraire rattaché à une longue série d'enclos qui se développent au Sud-Est de la zone étudiée ici, le long de la voie antique, traduisant une volonté de réaménager au cours de la phase 3 cet axe de circulation ${ }^{23}$. Du fait de sa situation devant l'alignement MR 2/3/4/5, dans une zone restée inoccupée et dépourvue des grands remblais recouvrant les sépultures de la phase 2 dans les secteurs Sud et central, le mur MR 1 présente certaines particularités de construction. En effet, même s'il témoigne d'un même contraste assez net entre une façade relativement soignée, destinée à rester visible du côté de la route, et une structure intérieure

20 Niveau supérieur 5,10, inférieur 4,97.

21 Il n'y a pas plus de relations avec les autres foyers découverts dans le secteur (F 1 et 2). Il s'agit par conséquent d'un ensemble indépendant.

22 Si l'on excepte le dernier bloc au N.-O., MR 1 est fondé sur l'horizon US 198/221/223/586/642, qui est directement accessible dans cette zone périphérique du secteur et représente le niveau de circulation. Il vient buter, à son extrémité N.-O., contre l'US 143/537/598/634.

$23 \mathrm{Au}$ sujet de cet ensemble d'enclos, parfois accolés sur une longue distance et présentant des caractéristiques très similaires, voir en particulier Panayotova 1998b, p. 21-22 ; Nedev, Panayotova 2003, p. 127-128 ; Panayotova, Nedev, Hermary 2003, p. 107. plus sommaire qui vient s'appuyer sur les remblais préexistants, celle-ci ne consiste pas en un simple blocage de moellons, mais se caractérise par une division en compartiments destinés à accueillir de futures sépultures.

Le mur de la façade (niveau supérieur 4,88), d'orientation N.-O./S.-E., présente un appareil régulier. Sa longueur totale est de $4,40 \mathrm{~m}$, la hauteur moyenne de $40 \mathrm{~cm}$. Il est construit en deux assises de blocs de calcaire, sauf à son extrémité Nord-Ouest, où il ne comporte qu'un seul bloc, d'une taille plus imposante que les autres. À l'autre extrémité, il se termine par une dalle posée de chant qui marque un retour d'angle et permet d'isoler un passage étroit séparant l'enclos d'une structure similaire située au Sud-Est. On constate que l'installation des blocs de la façade a sérieusement perturbé le foyer F 1, dont une partie a alors disparu.

Au Sud-Ouest du mur de façade se développent deux alignements perpendiculaires, constitués d'une ou deux assises de pierres, qui devaient initialement rejoindre le mur MR 2, mais ont été coupés par l'installation postérieure de la ciste SP 289. Ils reposent directement à la surface de la même US 143/537/598/634 et isolent au centre un compartiment de forme presque carrée, dans lequel a été découverte l'incinération secondaire SP 298. Le cratère utilisé comme urne cinéraire était placé dans une fosse relativement profonde (niveau du fond 3,96), scellée par deux épaisseurs de dalles de calcaire ${ }^{24}$. Comme la lékané qui a servi de couvercle et le pot miniature qui accompagne les ossements, ce vase s'inscrit dans une série importante de productions locales qui a connu une longue période d'utilisation et ne permet pas de proposer une chronologie précise pour la mise en place de la sépulture. Un deuxième compartiment, de dimensions plus modestes, est aménagé immédiatement au Nord-Ouest. Il est occupé au Sud-Ouest par deux pierres plates dont l'une reposait partiellement sur la base de stèle proche de SP 345 . Un troisième compartiment, dépourvu de toute sépulture, a été aménagé au Sud-Est, jusqu'au retour marquant la fin de l'enclos ; il devait être originellement prévu pour un usage funéraire. Nous sommes donc en présence d'une structure qui traduit une toute autre logique dans ce secteur de la nécropole, puisqu'elle n'a pas été construite a posteriori pour isoler un groupe de tombes préexistantes, comme dans le cas du mur MR 2, mais a été conçue d'avance comme un ensemble funéraire commun, probablement pour les membres d'une même famille. Cette même volonté de parcellisation de l'espace funéraire semble être à l'origine de la construction du long enchaînement

24 Elle traverse l'US 143/537/598/634 et l'horizon 174/195/ 196/199/210/219/602/635 sous-jacent pour atteindre l'horizon de sable US 109/212/215/637, immédiatement inférieur. 


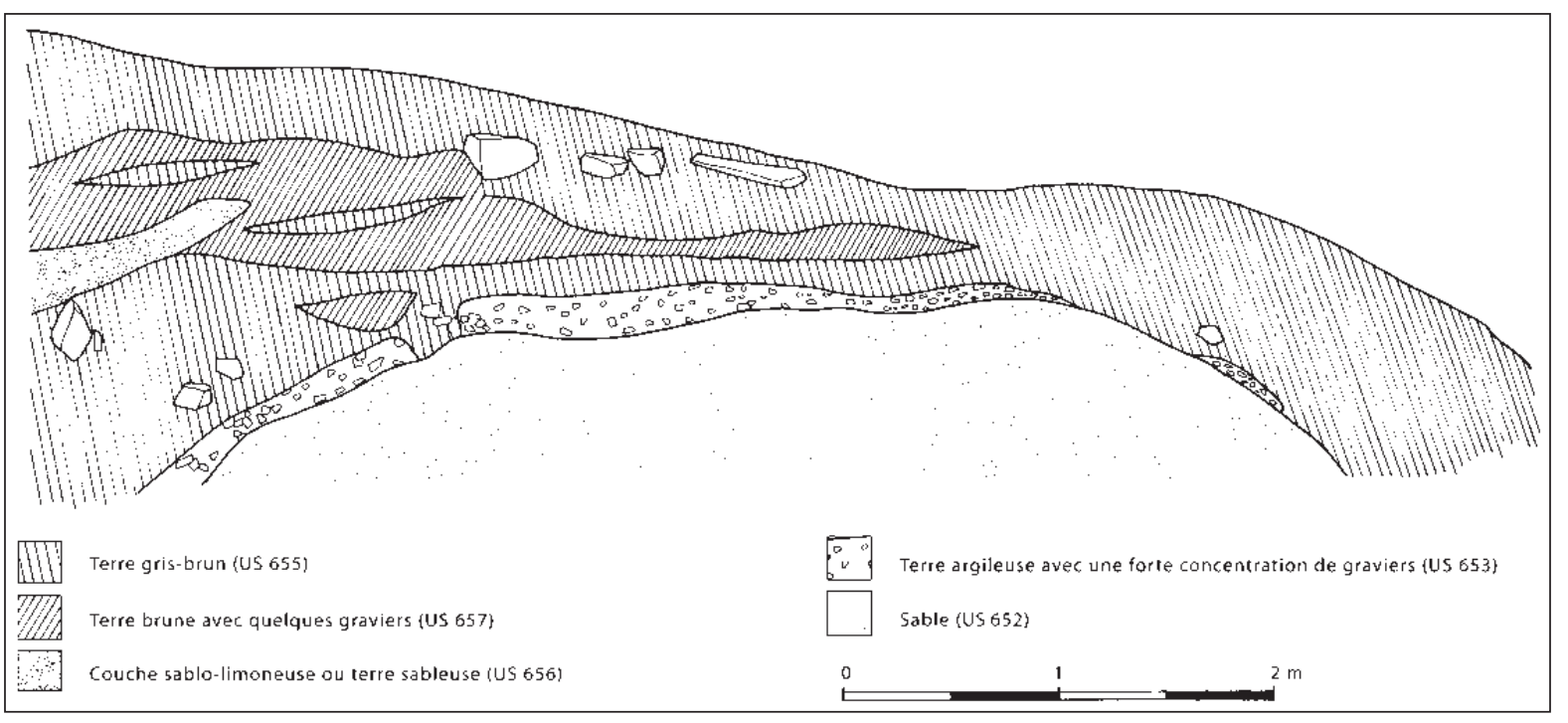

Fig. 46. Coupe sur les remblais au N.-O. du mur MR 6.

d'enclos similaires placé en bordure de la voie antique, dont MR 1 forme au Nord-Ouest le premier élément.

Peu après sa construction et la mise en place de SP 298, le mur MR 1 est successivement recouvert par deux remblais ${ }^{25}$ qui semblent soucieux de respecter la ligne de façade du nouvel enclos, tout en faisant disparaître au Sud-Ouest les derniers vestiges encore visibles de MR 2. Ce dernier subit alors de nouvelles destructions dont témoigne la présence de nombreux blocs de pierre dans l'US 115/120/130, ainsi que le vaste décaissement dont il a été question pour le secteur Sud, qui ne peut s'expliquer que par un désir de niveler le terrain pour faciliter les travaux de remblaiement de MR 1. Ces deux remblais débordent également au Nord-Ouest, où ils viennent recouvrir l'extrémité Sud-Est de MR 3 et le caisson de SP 345, qui n'est plus visible à partir de ce moment-là. Leur accumulation ne peut être précisément datée, mais la présence du dépôt DP 33 sur la surface du remblai supérieur (US 19/114/129) permet de supposer qu'elle est intervenue avant le troisième quart du $\mathrm{IV}^{\mathrm{e}} \mathrm{s}$. Cette limite chronologique constitue également un terminus ante quem pour la construction du MR 1 et l'installation de la tombe SP 298, pour lesquelles une date autour entre 370-360 av. J.-C. parait convenir.

Dans le secteur Nord, le deuxième quart du $\mathrm{IV}^{\mathrm{e}} \mathrm{s}$. témoigne à son tour du passage d'une nécropole tumulaire à une nécropole plate, selon un phénomène déjà étudié dans les secteurs Sud et central. En l'absence d'enregistrement précis des données stratigraphiques, il

25 US 115/120/130 et US 19/114/129, constituées respectivement d'une terre argileuse brune et d'une terre sableuse de couleur plus claire. est néanmoins très difficile de reconstituer une séquence chronologique détaillée de l'occupation pendant cette période. Seuls les objets du mobilier et, dans certains cas, les dépôts funéraires découverts à proximité des sépultures sont susceptibles de nous donner quelques indices concernant leur chronologie.

Les nouvelles sépultures se concentrent durant cette phase dans deux zones distinctes. Un premier groupe, constitué de trois sépultures (SP 321, 322 et 324), s'installe au sommet ou sur la pente des couvertures tumulaires de SP 334 et $336^{26}$. Les trois sujets sont logés à l'intérieur même des remblais de sable associés aux tombes du premier quart du $\mathrm{IV}^{\mathrm{e}} \mathrm{s}$., ce qui témoigne de la profondeur relativement importante des creusements. Les tombes SP 321 et SP 324 ne comportent pas de mobilier, seule SP 322 a livré un guttus et une œnochoé miniature à vernis noir qui donnent une date vers le milieu du $\mathrm{IV}^{\mathrm{e}} \mathrm{s}$. On constate cependant que, lors de son installation, cette dernière sépulture a perturbé SP 321, détruisant une grande partie du squelette, selon une situation qui n'est pas sans rappeler celle de SP 287 et 326 en secteur central. La tombe SP 321 est donc antérieure, bien qu'il soit impossible de déterminer l'intervalle chronologique qui les sépare.

Un deuxième groupe de sépultures, relativement compact, prend place le long de l'extrémité Nord-Ouest des murs MR 6/7. Elles sont associées à une série de remblais accumulés contre la face extérieure de l'enclos qui vient, à une date assez précoce au cours du second quart du $\mathrm{IV}^{\mathrm{e}} \mathrm{s}$., occuper un espace initialement réservé à la circulation (fig. 46). Toutes ces couches semblent

26 Probablement à partir de la surface de l'US 530/568/576/594 qui vient les recouvrir à la fin de la phase 2 . 
être en rapport avec des contextes funéraires situés en dehors du secteur concerné par les fouilles conjointes ${ }^{27}$. Deux d'entre elles (US 652 et US 654) recouvrent également la dernière assise du MR 6, selon un processus similaire à celui observable dans les secteurs Sud et central. Il apparaît ainsi que le vaste enclos entourant les sépultures de la phase 2 tombe lui aussi rapidement en désuétude, dès le début du deuxième quart du $\mathrm{IV}^{\mathrm{e}} \mathrm{s}$. La chronologie des tombes SP 327, SP 333 et SP 338 peut malgré tout être déterminée avec une relative précision. Elles semblent être les premières sépultures mises en place dans cette partie du secteur Nord. Leur mobilier, tout comme les dépôts DP 16, DP 18, DP 19 et DP 20 qui leur sont associés, comporte en effet plusieurs vases datables avant le milieu du IV ${ }^{\mathrm{e}} \mathrm{s}$. (vers 370-350).

\subsection{Deuxième moitié du IV e s. av. J.-C.}

Le secteur Sud n'est l'objet, dans l'ensemble de cette période, que d'interventions ponctuelles. Les années 350-340 voient la construction, à la périphérie Sud-Ouest de cette zone, de deux murets en pierre, orientés respectivement N.-O./S.-E et N./S., qui font probablement partie d'un seul et même ensemble. Bien qu'adossés à la couverture tumulaire de SP 325, ils n'entretiennent pas de rapport chronologique avec cette dernière, ni avec SP 316, et n'ont pas, semble-t-il, d'autre fonction que de protéger de tout glissement un terrain en pente dans cette zone ${ }^{28}$.

Enfin, l'ensemble de cette zone est scellée au cours $\mathrm{du}$ troisième quart du $\mathrm{IV}^{\mathrm{e}} \mathrm{s}$. par un épais remblai de terre argileuse foncée (US 2/501, niveau supérieur 6,95) dont la chronologie est bien établie grâce aux dépôts DP 23-24 et 29 découverts dans le secteur central : à cet

27 Ces contextes ont été fouillés par l'équipe bulgare en 2004 : voir Panayotova, Nedev, Hermary 2005, p. 238-240. Concernant les remblais, on distingue, au N.-O. du segment MR 6, une importante couverture de sable (US 652) retenue par un scellage de terre pierreuse (US 653) qui rejoint l'enclos au niveau de l'escalier extérieur que nous avons décrit plus haut. Elle est entamée par le creusement des tombes SP 320 et SP 338, ainsi que, probablement, par celui de SP 327, qui s'installe directement au-dessus de la dernière assise du mur MR 6. Contre cette première couverture se développe au S.-O. une deuxième couverture de sable (US 654) qui sert de niveau d'installation à la tombe SP 333.

28 La première de ces structures est fondée directement sur le scellage US 633 de la dune US 617/619, tandis que la seconde repose sur un remblai de terre sableuse US 616/628 qui recouvre partiellement au N.-O. l'horizon US 633. Cette dernière empiète sur le foyer F 4, qui fournit un terminus ante quem sûr pour sa mise en place.

Deux bases de stèle étaient réutilisées pour leur construction, l'une entière, l'autre fragmentaire. Contre une de ces bases a été retrouvée la partie supérieure d'un lécythe à vernis noir et, parmi les pierres, un astragale. endroit, les tombes s'étendent à partir des années 350340 vers la zone Sud-Est, où elles forment un niveau dense d'occupation. Il semble que leur mise en place soit précédée d'un nivellement des couches préexistantes, à mettre en rapport avec le décaissement contemporain observé en secteur Sud, dont il a été question précédemment à propos de SP $264^{29}$. C'est à partir du nouveau niveau ainsi obtenu que sont installées deux des cinq sépultures qu'on peut attribuer à la deuxième partie de la phase 3. La tombe SP 332 s'installe ainsi dans une fosse relativement profonde qui atteint la couverture de SP 339. Elle est liée au dépôt DP 27 qui fournit une date autour de 350. Quelques années plus tard, à partir du même horizon, une nouvelle fosse est creusée au SudEst, destinée à accueillir la tombe SP 342. Tout comme SP 332, cette sépulture atteint en profondeur la couverture de SP 339. La fosse est scellée au moyen d'une couche de pierres (US 133), bordée au Nord-Est et au Nord-Ouest par un alignement d'une rangée de moellons en forme de $\Gamma$. À proximité immédiate, dans le remblai US 2/501 dont nous reparlerons ci-dessous, est placé le dépôt DP 29 qui indique, grâce à son contexte stratigraphique et à l'amphore héracléote timbrée qu'il contient, une date vers 340 .

Parallèlement, la tombe SP 283 (niveau 5,42) est installée immédiatement au-dessus du mur MR 3, dans un des deux remblais (US 19/114/129) qui le recouvre. Ce mur n'est alors plus visible dans cette zone et semble avoir perdu tout rôle structurel. Comme SP 329, cette sépulture est dotée au Nord-Est d'un marqueur en forme de $\Pi$, construit en trois assises de blocs de granit grossièrement équarris. Autour de ce marqueur, dans l'US 2/501, s'étend au-dessus de SP 342 le dépôt DP 24 qui semble strictement contemporain de DP 29. Enfin, au Nord-Ouest, la tombe SP 287 est creusée, comme précédemment SP 326, au sommet du tumulus de SP 343. Elle recoupe d'ailleurs la tombe SP 326, dont elle perturbe l'occupant, ainsi qu'un petit remblai de sable (US 10/527) qui recouvre la fosse de SP 329. La sépulture n'a livré qu'un petit lécythe à décor réticulé sans date précise, mais sa position stratigraphique sous le remblai US 2/501 la rend contemporaine des tombes SP 332, 342 et 283. Aucun marqueur ni dépôt ne lui est associé.

Après la mise en place de l'ensemble des sépultures mentionnées ci-dessus, une dernière tombe vient compléter ce niveau d'installation et clore une période particulièrement active dans le secteur central. SP 265

29 Cette opération se manifeste par l'effacement de la partie supérieure du scellage US 610 retenant les remblais accumulés lors de la construction du mur MR 3 et la mise à nu de la couche de sable brun immédiatement inférieure (US 8/516). 


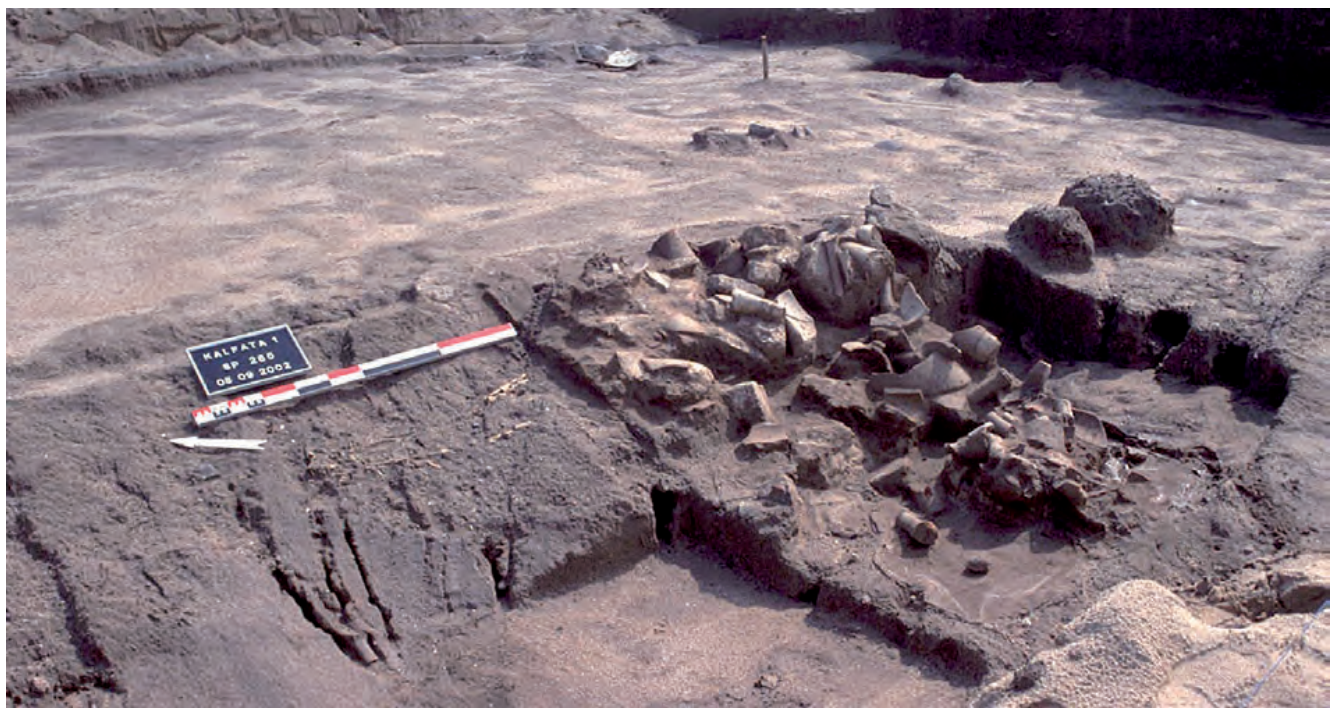

Fig. 47. Secteur central, le dépôt DP 23 et la tombe SP 265 en début de fouille (Photo CCJ).

(niveau 5,70), comme certaines tombes découvertes à Kalfata, n'a livré aucune trace d'un creusement de fosse, pourtant aisément identifiable dans un contexte terreux. Il semble, au contraire, que le sujet ait été déposé directement à la surface des couches sous-jacentes, dont il suit le pendage marqué vers le Sud-Ouest. La date nous est donnée par l'imposant dépôt DP 23, contenant plusieurs amphores et de nombreux fragments de céramique commune, dont les éléments les plus anciens sont en contact direct avec le squelette (fig. 47). Il s'agit notamment de deux cols d'amphores héracléotes portant des variantes d'un timbre rare à une lettre qui trouvent un parallèle précis dans une amphore timbrée de DP 27, un dépôt plus ancien que nous avons mis en rapport avec la tombe SP 332. Ce fait montre que l'accumulation du dépôt DP 23 commence peu après le milieu du siècle et que, bien que plus tardive, la tombe SP 265 ne peut être de beaucoup postérieure aux autres sépultures des années 350-340. L'accumulation du dépôt semble cependant se poursuivre pendant près de vingt ans, si l'on en croit un col d'amphore thasienne portant un timbre des années 320 , qui provient de la surface du dépôt. Au-delà des révisions dont les dates peuvent faire l'objet, il n'est pas impossible que ce vaste dépôt, initialement associé au défunt de la tombe SP 265, ait accueilli par la suite un matériel divers qui ne lui était pas destiné, venu s'ajouter à cette accumulation d'amphores et de vases brisés particulièrement visible au sein de la nécropole.

On observe que DP 23 est pris dans le vaste remblai US $2 / 501$, dont la présence a déjà été notée en secteur Sud. Cet horizon, relativement épais, vient recouvrir SP 265 et sceller l'ensemble de cette zone. La formation de cette couche n'apparaît pas homogène. Elle semble résulter de plusieurs interventions chronologiquement distinctes. Le début de son accumulation est en effet bien datée aux alentours de 340, à la fois par DP 23 et par deux autres contextes rituels (DP 24 et DP 29), liés respectivement à SP 283 et SP 342. Cette accumulation de terre se poursuit cependant bien au-delà de cette décennie, comme en témoignent les éléments les plus récents de DP 23. Ces derniers, bien qu'appartenant aux années 320 , sont à leur tour recouverts par le remblai US $2 / 501$.

Parallèlement, en secteur Est, d'autres processus de remblaiement, qui n'entretiennent pas un rapport direct avec la situation dans la zone du mur MR 1, se développent dans la partie Nord-Ouest, en particulier contre la façade de MR 3 et au niveau du passage aménagé entre les murs MR 3 et MR 4. Ils sont perturbés durant le second quart du siècle par l'installation de la ciste SP 328, dont il a déjà été question plus haut.

Un décaissement préalable du terrain au Nord-Ouest a été nécessaire à l'installation de cette sépulture, du fait de la différence de niveau. Conformément au modèle offert par les cistes des secteurs Sud, central et Nord, cette fosse n'est pas large, mais creusée profondément. Elle a coupé les foyers $\mathrm{F} 10$ et $\mathrm{F} 11$. On constate qu'à la différence des tombes du premier quart du IV ${ }^{\mathrm{e}} \mathrm{s}$., SP 328 n'est pas dotée d'une couverture tumulaire, mais simplement surmontée d'un amas de pierres de granit mêlées à une quantité importante de terre (US 521), qui devait servir à la fois à protéger les dalles de couverture et à marquer l'emplacement de la sépulture dans l'espace de la nécropole. Près de la zone de l'ancien passage entre les murs MR 3 et 4, l'amas de pierres US 521 a été partiellement recouvert par le marqueur en pierres de SP 329, située à la périphérie Nord-Est du secteur Central. Ce recouvrement n'implique cependant pas nécessairement 


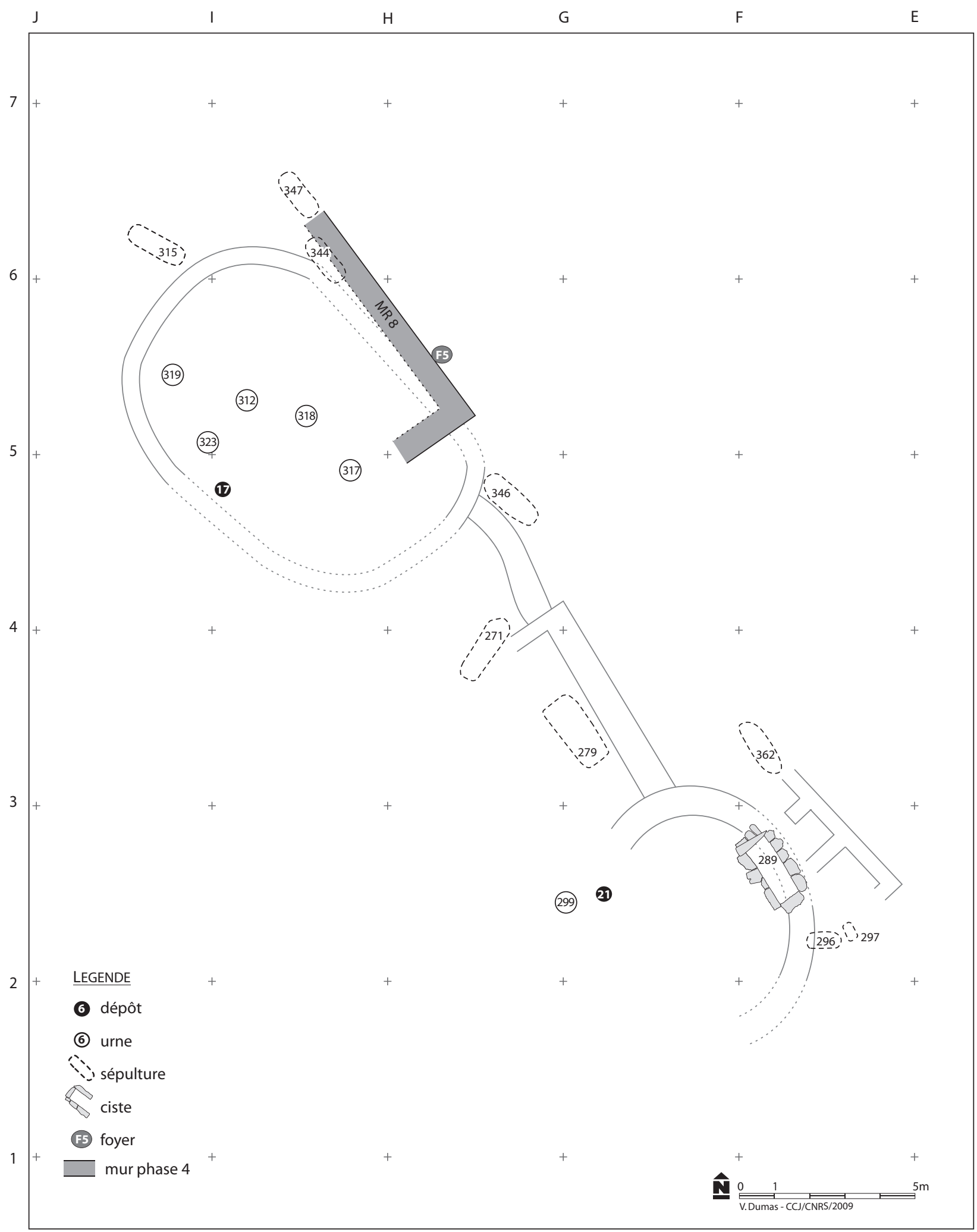

Fig. 48. Plan schématique de la phase 4 (๑ CCJ). 
une antériorité de SP 328 par rapport à SP 329 - sans doute elle-même antérieure au milieu du $\mathrm{IV}^{\mathrm{e}} \mathrm{s}$. -, le glissement des pierres ayant pu avoir lieu après la mise en place des deux sépultures.

Par la suite, au cours de la phase 3, le secteur Est n'accueille plus aucune sépulture. Le remblaiement des espaces situés devant les murs MR 2 et 3 semble, de même, avoir momentanément cessé jusqu'à ce que le grand remblai de terre argileuse US 2/501 vienne ici aussi combler, vers 340-330, l'ensemble de la zone située au Nord-Ouest de SP 345, recouvrant définitivement les parties encore visibles des murs MR 3, 4 et 5, ainsi que l'amas de pierres (US 521) situé au-dessus de SP 328. Cette unité s'étend jusqu'à la périphérie Nord-Ouest du secteur, en avant du mur MR 5, où elle repose directement sur la formation sablo-argileuse US 575/588, ce qui démontre que cet espace proche du secteur Nord est pendant longtemps resté inoccupé, sans être affecté par les différents remblais qui se mettent en place au SudEst durant la phase 3.

En secteur Nord, chacun des deux noyaux de sépultures identifiés continue d'accueillir de nouvelles tombes. À l'Ouest, une urne abritant une incinération secondaire (SP 323) a été découverte à $20 \mathrm{~cm}$ au-dessus des ossements de SP 324, mais, en l'absence d'autres indices chronologiques, la date de cette sépulture, et même son attribution à la phase 3 , restent sujettes à caution. La tombe SP 320 représente un cas tout aussi plus problématique, car elle n'a livré qu'un petit lécythe à palmette qui n'offre aucun repère chronologique. Cependant, l'installation de cette tombe, à l'image de SP 338, dans la couverture de sable US 652 et son recouvrement par le remblai de terre US 655 apportent deux arguments en faveur d'une datation dans la phase 3. Cette dernière couche de terre argileuse (US 655) représente en effet un horizon épais, relativement similaire au remblai US 2/501 découvert dans les secteurs Sud et central, qui scelle l'ensemble de cette zone après la mise en place des dernières sépultures de la phase 3 .

\section{Phase 4 (première moitié du III ${ }^{\mathrm{e}}$ S. av. J.-C.) : fig. 48, pl. 10}

La phase 4 constitue dans le secteur Sud une période de relative inactivité. Seules quelques interventions mineures sont à noter. Au Sud-Ouest de la tombe SP 272, une fosse est creusée afin d'accueillir les restes incinérés d'un sujet placé dans un fond d'amphore posé à l'envers (SP 299). Cette installation peut être datée de la toute fin du $\mathrm{IV}^{\mathrm{e}}$ ou du début du $\mathrm{III}^{\mathrm{e}} \mathrm{s}$. grâce au lécythe à vernis noir accompagnant les ossements. De même, à la périphérie Nord-Est du secteur Sud, non loin du mur MR 1, une grande fosse perturbe les remblais situés au-dessus du mur MR 2, dont une section est alors démontée afin de permettre l'installation de la ciste SP 289. On note cependant le souci manifeste de reconstituer cet alignement par la pose de plusieurs blocs de pierre immédiatement au Nord-Est de la ciste. L'unguentarium provenant de cette sépulture suggère que sa mise en place intervient elle aussi à la toute fin du $\mathrm{IV}^{\mathrm{e}}$ ou du début du $\mathrm{III}^{\mathrm{e}} \mathrm{s}$. L'ensemble du secteur Sud est, par la suite, recouvert par une couche de terre sableuse de couleur brun clair (US 1/101/117/194/500) qui marque l'abandon de la nécropole de Kalfata vers le milieu du $\mathrm{III}^{\mathrm{e}}$ s. av. J.-C.

Le secteur central suit une même tendance. Occupant les espaces laissés vacants au sein d'une nécropole désormais plate, la tombe SP $\mathbf{2 7 9}$ matérialise l'essor des tombes à tuiles durant cette période, dont elle présente une variante intéressante par son agencement en caisson. Son mobilier funéraire se compose d'un lécythe et d'une lampe qui peuvent être attribués au premier quart du $\mathrm{III}^{\mathrm{e}} \mathrm{s}$. Durant la première moitié de ce siècle, à une date difficile à préciser en raison de l'absence de toute offrande, la tombe SP 271 est installée dans une couche de terre argileuse très compacte, comportant de nombreuses immixtions de pierres (US 5/502), qui recouvre toute la partie Nord-Ouest du secteur (fig. 49). La fonction de cette couche n'est pas très claire, mais elle se prolonge en secteur Nord, où elle semble représenter une sorte de scellage mis en place au-dessus du groupe d'incinérations secondaires du premier quart du III' s. (SP 312, SP 317, SP 318, SP 319, SP 323), suggérant que cette tombe est postérieure à l'ensemble de ces sépultures. Elle est recouverte à son tour par la même US 1/101/117/194/500.

La situation apparaît toute autre en secteur Est. Durant la première moitié du $\mathrm{III}^{\mathrm{e}} \mathrm{s}$., plusieurs sépultures sont placées à proximité de la voie de circulation. La première, SP 362, s'installe immédiatement au Nord-Ouest de l'enclos MR 1, dont la façade demeure probablement encore visible. Il s'agit une tombe à tuiles qui semble se conformer au modèle offert par les tombes SP 344, 346 et 347 en secteur Nord. Elle est aménagée dans une fosse à la fois étroite et fort profonde ${ }^{30}$, dont le creusement détruit en partie le caisson en pierre de SP 345 et perturbe la partie Nord-Ouest du foyer F 1. La fosse est signalée en surface par une petite structure de forme rectangulaire, constituée d'une assise de pierres de granit non appareillées qui l'entoure sur trois côtés (au S.-E., au N.-E. et au N.-O.) et empiète partiellement sur son comblement. Le mobilier funéraire ne fournit aucun indice chronologique, mais la marque estampée

30 Niveau supérieur 5,10 à 4,90, niveau du fond 3,72 à 3,66. 
sur une des tuiles semble confirmer qu'elle n'est pas antérieure au III $\mathrm{s}$.

Deux sépultures d'enfants (SP 296 et SP 297) peuvent être également attribuées à cette phase. Du fait de leur situation à la périphérie Sud-Est du secteur, à l'intérieur même du passage aménagé au cours de la phase précédente entre le mur MR 1 et l'enclos voisin au SudEst, leur contexte stratigraphique est beaucoup moins clair. Il semble néanmoins qu'elles s'installent également à partir de la surface d'un des remblais recouvrant MR 1. La tombe SP 296 (niveau 4,90 à 4,94), accolée seulement que la périphérie Nord-Ouest est affectée par l'accumulation d'un remblai de terre sableuse (US 589) dont l'installation est en rapport avec la construction du mur MR 8 en secteur Nord. Dans la zone limitrophe du mur MR 5, ce remblai vient recouvrir l'US 2/501, qui comble pour la première fois cet espace au cours de la phase 3. Enfin, vers le milieu du III ${ }^{\mathrm{e}} \mathrm{s}$., l'ensemble du secteur est recouvert à son tour par l'US 1/101/117/194/500, qui marque, ici aussi, la fin de l'occupation du site.

Cette dynamique, observée le long de la voie de circulation dans le secteur Est, se prolonge également

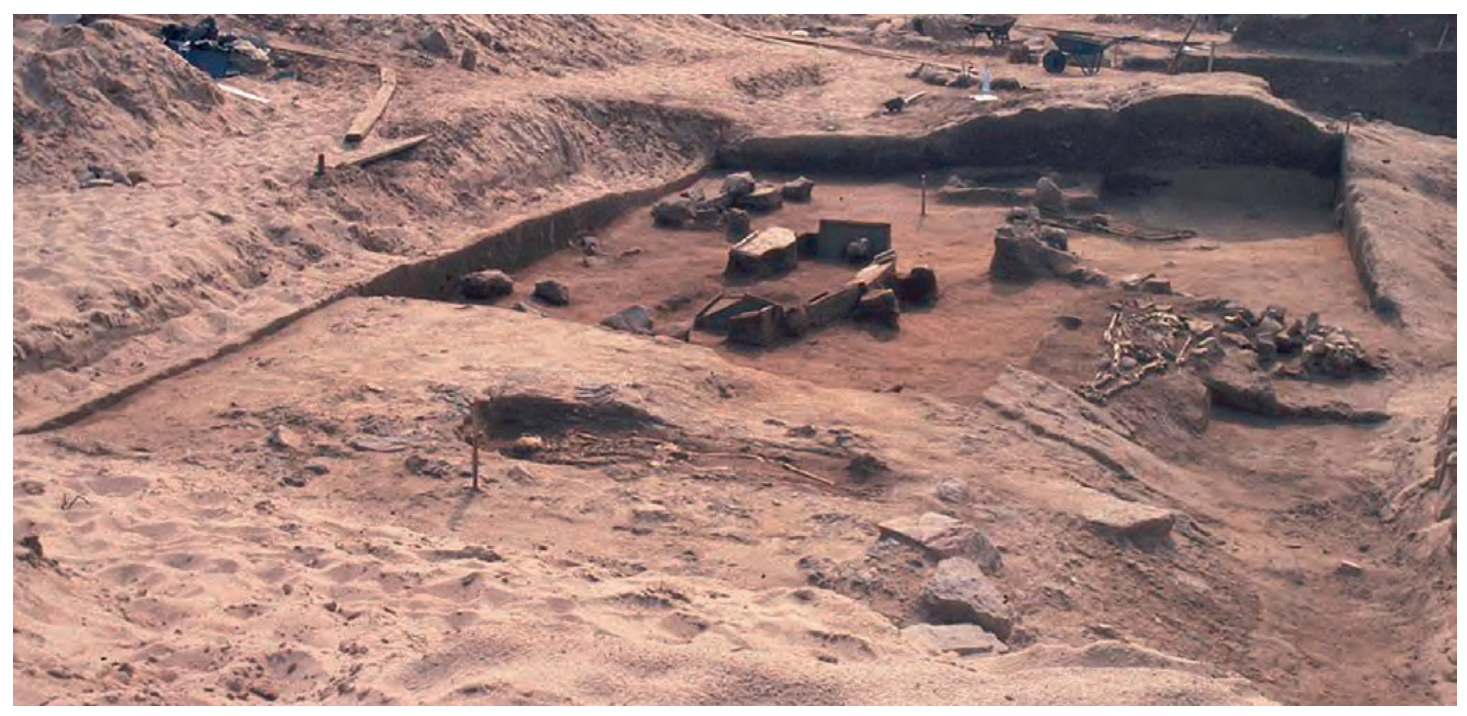

Fig. 49. Vue du secteur central et du Nord du secteur Sud au cours des fouilles 2002, avec les tombes de la phase 3. Au premier plan la tombe SP 271 entourée par l'US 5/502 (Photo CCJ).

contre la face extérieure de MR 2, reçoit un traitement similaire à SP 298. Elle occupe une petite fosse dont les parois Nord et Sud sont doublées de trois assises de pierres de granit assez grossières, qui forment avec MR 2 un caisson assez sommaire. Les quelques objets en métal qui accompagnent le sujet sont peu significatifs, et, en l'absence d'arguments stratigraphiques, seule la proximité de SP 297 peut justifier son attribution à la phase 4, sans exclure que cette tombe soit plus ancienne et puisse appartenir à la deuxième moitié de la phase 3 (troisième quart du $\mathrm{IV}^{\mathrm{e}} \mathrm{s}$.), lorsque l'ensemble de la zone est déjà remblayée. La tombe à tuiles SP 297, située à immédiatement à l'Est, s'installe pour sa part dans une fosse plus profonde (niveau du fond 4,36) qui vient se coller contre le mur correspondant au retour Nord-Ouest de l'enclos voisin de MR 1 et dont le creusement perturbe le foyer F 2. La sépulture peut être datée, grâce au lébès gamikos miniature à décor végétal, du début du $\mathrm{IIII}^{\mathrm{e}} \mathrm{s}$.

La mise en place de ces sépultures ne provoque pas de nouveaux remblaiements dans le secteur Est. On note en secteur Nord. Plusieurs sépultures à incinération secondaire (SP 312, SP 317, SP 318, SP 319, SP 323) occupent alors la partie centrale de cet espace, délimitée par l'enclos probablement formé par les murs MR 6/7, dont quelques vestiges restent encore visibles. Leur contexte stratigraphique n'est malheureusement pas clair. L'une d'entre elles (SP 323) a été découverte dans la couverture tumulaire de SP 336, près de la périphérie Sud-Ouest du secteur, où elle est placée à moins de $20 \mathrm{~cm}$ des genoux du défunt de SP 324, une tombe sans mobilier attribuée avec réserve à la phase 3 . La jarre qui a servi à recueillir les ossements incinérés et le plat à poisson utilisé en guise de couvercle ne permettent qu'une datation large dans la première moitié du III ${ }^{\mathrm{e}}$ s., une date qui semble s'accorder avec celle du dépôt DP 17 situé à peu distance au Sud, mais dont l'attribution n'est pas certaine en raison des incertitudes qui entourent également la tombe SP 324.

Les autres incinérations (SP 312, 317, 318, 319) s'installent à un niveau supérieur et dans un contexte 
stratigraphique différent ${ }^{31}$. La chronologie de ces sépultures pose des problèmes similaires à celle de la tombe SP 323, du fait de la variation importante des dates attribuées aux différents types de jarres utilisées comme urnes et aux plats locaux qui les ferment. Seuls les unguentaria accompagnant les ossements des tombes SP 317 et 318 indiquent une période plus précise qui, ici encore, semble être le premier quart du $\mathrm{III}^{\mathrm{e}} \mathrm{s}$. Cependant, compte tenu du fait que les tombes SP 312 et 319 sont installées dans la même couche et partagent une couverture commune avec ces deux sépultures, il est fort probable qu'elles soient à peu près contemporaines.

Vers la fin du premier quart du $\mathrm{III}^{\mathrm{e}}$ s., de vastes aménagements destinés à isoler le nouvel espace funéraire et à le rendre visible interviennent à la périphérie Nord-Est du secteur. On accumule alors, contre la pente NordEst des couvertures tumulaires de SP 334 et 336, un nouveau remblai de terre brune sableuse (US 589) qui vient recouvrir les derniers vestiges de l'enclos MR 6/7. Conformément à la tradition architecturale des périodes précédentes, ce remblai sert d'appui pour un nouveau mur (MR 8), orienté N.-O./S.-E., qui vient s'aligner sur la voie littorale. Le mur est fondé sur le même horizon stratigraphique (US 575/588) que l'enclos MR 6/7. Sa longueur conservée est de $9,78 \mathrm{~m}$, sa largeur de $75 \mathrm{~cm}$. Il est composé de deux ou trois assises de blocs de grande taille grossièrement travaillés en façade et d'autant d'assises de petits moellons à l'arrière. On constate également qu'à deux endroits des alignements de moellons non appareillés se détachent du parement interne du mur et s'avancent sur une distance de plus de deux mètres le long de la pente du remblai. Le premier part du milieu du mur, le deuxième se situe à son extrémité Sud-Est. Elles n'ont aucun rôle structurel et ne servent probablement qu'à matérialiser une volonté de diviser l'espace funéraire.

La construction du mur MR 8 est datée par la présence contre sa face externe du foyer F 7, qui fournit un précieux terminus ante quem autour de 280-260. Cette structure témoigne par sa présence de l'importance toujours vive de cet axe, tout comme du souci manifesté par les autorités locales d'éviter tout empiètement sur la voie, malgré l'ensablement permanent de Kalfata et l'élévation continue du niveau de la nécropole.

Durant les décennies suivantes, le mur MR 8 subit à son tour plusieurs interventions liées à l'installation de

31 Elles peuvent être associées à une couche sableuse (US 9/508) accumulée à la surface de l'US 530/568/576/594, au sommet des couvertures tumulaires des tombes du premier quart du $\mathrm{IV}^{\mathrm{e}} \mathrm{s}$.; cette couche est scellée plus tard par une couche de terre très argileuse et compacte, comportant une grande quantité de pierres (US 5/502) qui forment un manteau continu sur une partie importante de la zone. trois tombes à tuiles qui représentent les dernières sépultures de la phase 4 en secteur Nord. Toutes trois sont disposées à proximité de la route et occupent des fosses profondes. Celle de la tombe SP 344 recreuse un espace situé immédiatement en arrière de la façade du mur MR 8, en détruisant le parement interne du mur et en recoupant au Sud-Ouest le mur MR 6. Au Nord-Ouest, un enclos rectangulaire composé de grandes pierres non appareillées du côté de la route, plus petites à l'intérieur, est aménagé à l'extrémité du mur MR 8 pour abriter la tombe SP 347. On constate que la façade de cette construction respecte l'alignement de MR 8, selon une situation également observable au Sud-Est, à la limite avec le secteur central, où une structure similaire s'appuie contre les murs MR 5 et MR 7 et protège la tombe SP 346. Les mobiliers livrés par ces trois tombes n'autorisent pas de datation très précise, mais orientent vers le milieu du III $\mathrm{e}$. Tout comme dans les trois autres secteurs, elles sont recouvertes par l'US 1/101/117/194/500, puis par le sable dunaire moderne.

À ces structures associées aux quatre grandes phases d'occupation s'ajoutent quelques vestiges dont la chronologie n'a pas pu être déterminée (fig. 50).

\section{Remarques générales}

La zone littorale de Kalfata présentait au moment de l'installation des premières sépultures un aspect bien différent de celui que nous lui connaissons actuellement. En lieu et place d'une vaste étendue sableuse, le site accueillait une végétation basse de type steppique logée sous une paléo-falaise. Les premières sépultures apparaissent dans le secteur couvert par les fouilles conjointes $\mathrm{au}$ cours du troisième quart $\mathrm{du} \mathrm{V}^{\mathrm{e}} \mathrm{s}$. Elles consacrent une formidable extension des zones funéraires depuis le noyau archaïque et classique situé au Nord-Ouest, sous le quartier moderne de Harmanité. Cette implantation des nouveaux secteurs vers le Sud-Est, le long de la bande littorale, reproduit un modèle désormais bien connu dans le Nord de l'Egée. La présence d'un axe de circulation majeur peut expliquer ce phénomène, tout comme la faible valeur foncière de terrains difficilement valorisables sur le plan agricole.

La fonction de la longue rigole qui traverse l'ensemble du site de Kalfata demeure obscure. Aucune tombe du $\mathrm{V}^{\mathrm{e}} \mathrm{s}$. n'a été découverte au Nord-Est de cette structure, ce qui plaide en faveur d'un aménagement visant à délimiter l'espace funéraire, mais ce rapport pourrait n'être qu'indirect, comme le suggère le caractère plus ancien de son creusement, ainsi que l'implantation à son sommet de nombreuses sépultures qui recoupent son tracé, sans signe de respect particulier. L'idée que cette rigole 


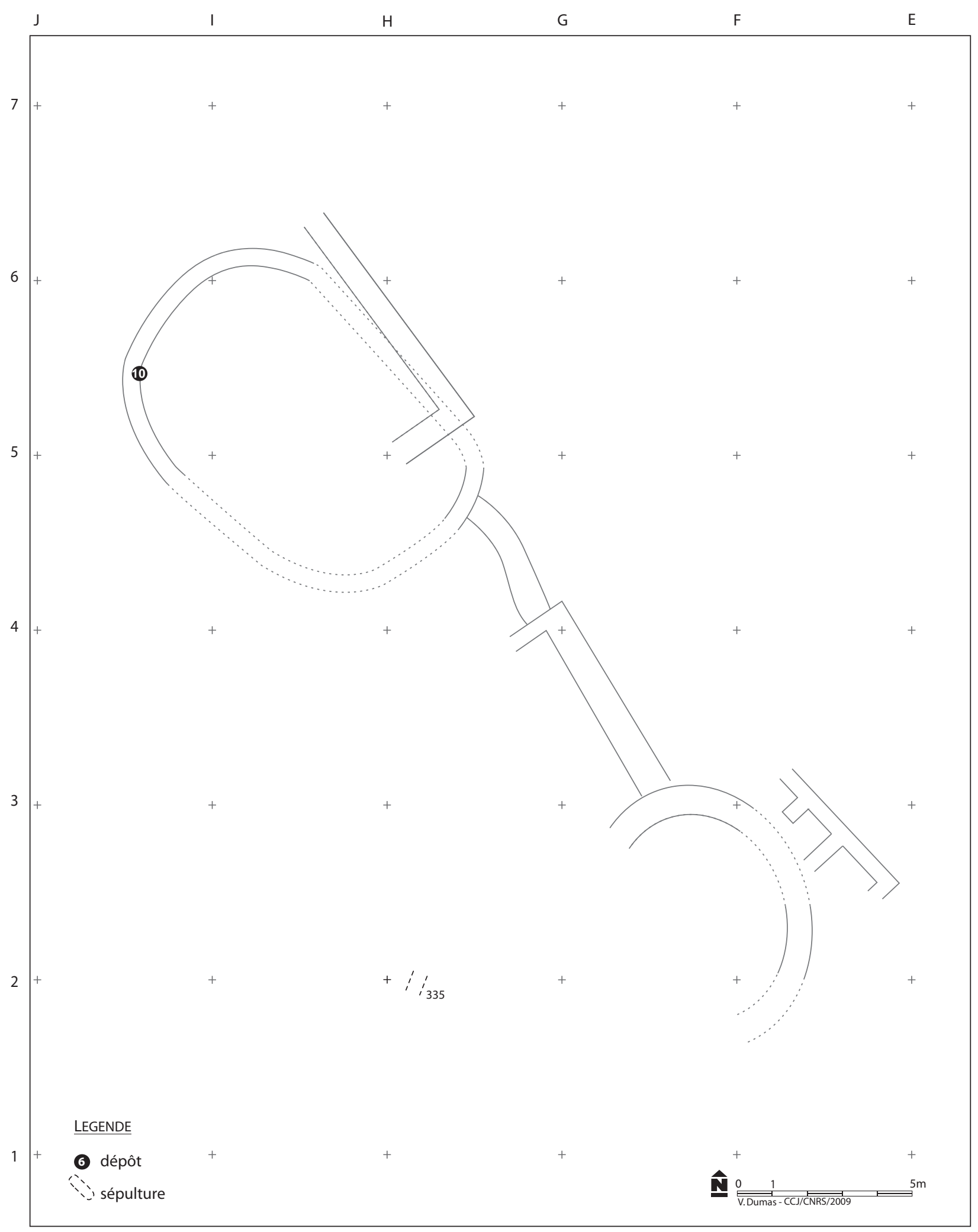

Fig. 50. Situation des vestiges d'époque indéterminée. (๑ CCJ). 
ne serve pas elle-même de limite, mais tienne compte comme les tombes d'un obstacle commun, comme un axe de circulation ou une séparation entre deux zones foncières, ne saurait être écartée.

La nécropole de Kalfata se caractérise durant la première phase de son fonctionnement par une disposition lâche des sépultures. Aucune orientation distincte, ni regroupement n'a pu être identifié, aussi bien dans le cadre des fouilles conjointes que dans les travaux plus anciens. L'absence de structure ou de marqueur est ici particulièrement remarquable, tout comme la typologie des sépultures qui reproduit le modèle unique de la grande fosse. L'implication des tombes de cette période dans la succession stratigraphique du site demeure donc relativement modeste.

Ce premier épisode dans la vie de la nécropole est rapidement interrompu par un ensablement accéléré du site qui accompagne un bouleversement radical dans les dynamiques paléo-environnementales de la zone littorale. B. Devillers suppose un défrichement du territoire qui exposerait les sols aux processus érosifs, engageant une crise alluvionnaire majeure dont la conséquence serait pour les espaces côtiers une déposition de ce matériel sous la forme de sables d'origine éolienne. Cette lecture pertinente concorde de façon troublante avec l'extension des nécropoles durant le troisième quart du $\mathrm{V}^{\mathrm{e}} \mathrm{s}$., qui pourrait témoigner d'une croissance parallèle de la population, selon la vision défendue par K. Panayotova. Toutefois, la faible densité des nouveaux secteurs funéraires et la méconnaissance des nécropoles apolloniates de la période archaïque et du début de la période classique rendent tout jugement difficile. Ce processus d'ensablement occupe en tout cas l'ensemble du dernier quart du $\mathrm{V}^{\mathrm{e}} \mathrm{s}$. : il interrompt de façon nette la fréquentation de Kalfata et modifie profondément sa topographie par l'installation d'une longue barre dunaire. En lieu et place d'un terrain accusant un double pendage, à la fois vers la mer, au Nord-Est, et de façon secondaire vers le Nord-Ouest, le secteur littoral présente désormais une morphologie en dos d'âne qui isole, entre sa pente Sud-Ouest et la paléo-falaise, une vaste dépression qui agit comme un piège pour les sédiments.

L'apport de sable éolien se poursuit durant les siècles suivants, mais présente dès la fin $\mathrm{du}^{\mathrm{e}} \mathrm{s}$. des signes évidents d'affaiblissement, ce qui renforce l'hypothèse d'une crise d'origine anthropique. La déposition de plusieurs couches de terre au sommet de la dune centrale traduit alors une volonté de réappropriation du site par les habitants de la colonie. Certains de ces nouveaux horizons contiennent un matériel varié (fragments de vases, petits objets en bronze, etc.) qui pose en retour la question de l'origine de la terre dont ils sont constitués. Ils alternent avec autant de strates de sable d'origine éolienne, ce qui permet de situer leur mise en place à un moment où le processus d'ensablement est encore relativement actif. La finalité de ces apports de terre n'est pas claire, mais les ondulations observées en secteur Sud à la surface des US 198/221/223/586/642 et 633 ne sont pas sans susciter quelques interrogations (fig. 51-52). Plus curieusement, comme le démontre l'enchaînement stratigraphique, ces formations prennent place à un moment où le secteur central a déjà retrouvé sa fonction funéraire, comme le démontre la présence contemporaine de SP 343. Cette dynamique sédimentaire se poursuit dans les secteurs qui entourent sa couverture tumulaire, et on observe dans le secteur Sud la déposition rapide de plusieurs remblais au sommet desquels viennent s'installer de nouvelles tombes selon un processus similaire à celui observé en secteur Nord.

La phase 2 de la nécropole connaît, à son tour, une mise en place relativement lâche des tombes selon une orientation désormais bien définie, majoritairement au Nord-Est et, de façon plus secondaire, suivant un axe perpendiculaire orienté au Sud-Est. L'alignement remarquable des sépultures, de même que l'absence de tombes contemporaines sous l'axe de circulation qui borde l'espace fouillé au Nord-Est, plaide pour l'existence contemporaine de cette route. Toutefois, la limite impartie au secteur funéraire est différente de celle observée au siècle précédent en raison d'une extension notable en direction de la mer.

La typologie des sépultures reprend le modèle de la grande fosse en usage au $\mathrm{V}^{\mathrm{e}} \mathrm{s}$. et s'enrichit d'une nouvelle structure, celle de la ciste édifiée en blocs de grès ou de calcaire. C'est cependant dans la couverture et le marquage des tombes que réside la particularité de la phase 2. L'ensemble des tombes sont dotées d'un tumulus durant le premier quart du $\mathrm{IV}^{\mathrm{e}} \mathrm{s}$., ce qui explique la forte contribution de cette période à l'élévation générale de l'altitude du site, tout comme le placement des sépultures légèrement en retrait de la route. Ces tumuli acquièrent parfois une valeur collective en isolant par leur chevauchement des groupes de tombes entre lesquelles l'existence d'un lien familial ou social ne saurait être exclue. La phase 2 s'achève sur la construction de plusieurs murs relativement contemporains, qui manifeste une volonté nouvelle de matérialiser les limites accordées à l'espace funéraire et à celles des différentes parcelles qui le composent. Deux constructions, l'enclos ovale MR 6/7 en secteur Nord et la structure semi-circulaire MR 2 en secteur Sud, confèrent aux parcelles qu'elles entourent une cohérence indéniable, chacune d'entre elles s'organisant autour d'un ensemble identifiable de tombes : SP 334-336 et SP 291, près de laquelle voisinent les SP 325, 300 et 339. Entre deux, les murs MR 3, 4 et 5 du secteur central isolent une sépulture 

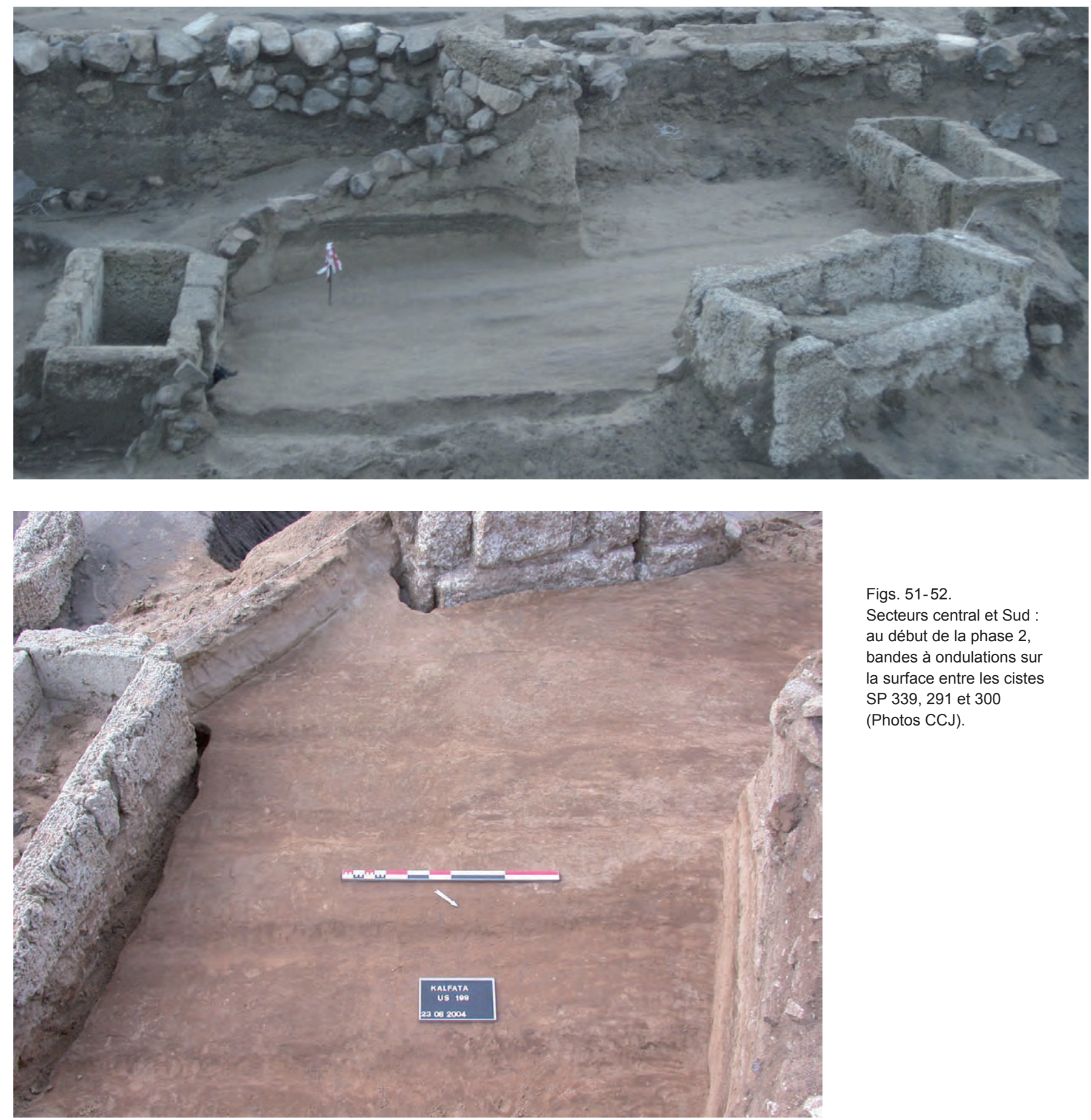

Figs. 51-52.

Secteurs central et Sud : au début de la phase 2 , bandes à ondulations sur la surface entre les cistes SP 339, 291 et 300 (Photos CCJ).

(SP 343) qui semble occuper une position intermédiaire. L'accès à l'espace funéraire s'opère soit directement depuis la route, notamment par l'intermédiaire du passage aménagé entre les MR 3 et 4, soit par le côté des périboles, comme l'illustre l'escalier situé au NordOuest du mur MR 6. Ce dernier aménagement témoigne à lui seul d'une volonté non seulement d'accéder à l'intérieur de chacune de ces parcelles, mais également de pouvoir circuler sur les couvertures tumulaires.
La phase 3 accompagne une transition nette entre deux modèles de nécropole. En lieu et place d'une nécropole tumulaire se développe désormais une nécropole plate. Cette évolution découle d'une densification sensible dans l'occupation de l'espace funéraire qui contribue à modifier l'organisation interne de la nécropole. Ce phénomène est favorisé par un effacement rapide, au cours du second quart du $\mathrm{IV}^{\mathrm{e}} \mathrm{s}$., de la plupart des murs et des anciennes limites parcellaires, favorisé 
par la destruction partielle, peu de temps après leur construction, de plusieurs structures. L'enclos ovale qui enserrait les sépultures SP 334 et 336 est ainsi en grande partie démonté, tout comme l'assise supérieure du mur MR 2 à proximité de SP 345. L'ensemble de ces murs est rapidement recouvert d'importants remblais de sable et de terre dont certains, comme en secteur Nord, sont liés à la couverture des nouvelles sépultures qui sont alors mises en place.

Parallèlement, la déposition continue de sable d'origine éolienne se fait sentir sur l'ensemble de la nécropole par la présence diffuse de poches qui comblent les espaces laissés vacants entre les anciennes couvertures tumulaires (notamment US 6). Le développement d'une nécropole plate durant les deuxième et troisième quarts du $\mathrm{IV}^{\mathrm{e}} \mathrm{s}$. engage un ralentissement sensible dans l'élévation de l'altitude générale de Kalfata. Ces nouvelles sépultures ne tiennent compte qu'incidemment des anciennes limites, en particulier quand ces dernières semblent encore visibles, comme dans le cas du voisinage de MR 3 et de SP 328. Ces tombes s'installent en particulier au sommet des anciennes couvertures tumulaires qu'elles contribuent à perturber, voire au-dessus des anciens murs. Elles obstruent enfin l'ancienne entrée aménagée entre les MR 3 et 4, devenue obsolète à la suite de l'élévation progressive du site.

Cette densification de l'espace funéraire s'accompagne d'une évolution notable dans la typologie des sépultures. Les grandes fosses cèdent la place à des unités plus modestes, tandis que les cistes se font plus rares. Le soin et l'investissement apportés aux structures funéraires semblent dans l'ensemble décliner, trahissant une évolution dans la sensibilité des habitants d'Apollonia. L'apparition ponctuelle d'une double fosse (SP 337 et SP 244), parfois dotée d'un escalier latéral (SP 244), auxquels s'ajoute dans le cas des cistes l'introduction de la kliné funéraire, témoignent, parallèlement, de la circulation le long de la côte occidentale de la mer Noire de pratiques issues d'autres régions du monde grec et connues notamment dans le Nord de l'Egée. Confirmant cette diversification à l'œuvre dans les rites funéraires, l'incinération fait son apparition (SP 316, 298, 345), sans que ces urnes funéraires soient associées, dans le secteur concerné par les fouilles conjointes, à des aires de crémation identifiables. La signalisation des sépultures n'est plus assurée durant la phase 3 par des couvertures tumulaires, mais par des amas de pierres ou par de petits murs en pierres sommairement construits à proximité de la tête du défunt. Cependant ce marquage des tombes n'est pas systématique, ce qui explique l'existence de recoupements ponctuels (SP 326/287 et SP 321/322).
Si le sens de circulation au sein de la nécropole ne semble plus obéir aux mêmes règles, la délimitation stricte de la voie de circulation est en revanche effective et comprise de tous, comme en témoigne l'absence de tout empiètement. Ce contraste matérialise un contrôle strict exercé par les autorités poliades sur cet espace et atteste l'existence d'un registre cadastral. La construction du mur MR 1 et le développement au Sud-Est et au Nord-Est d'un alignement de terrasses funéraires de part et d'autre de la voie, présentant toutes une même dimension en façade, confirment cette analyse.

Le dernier quart du $\mathrm{IV}^{\mathrm{e}} \mathrm{s}$. est étrangement peu représenté à Kalfata, confirmant les observations formulées autrefois par I. Venedikov à l'issue des fouilles de 19461949. Les vases attribuables à cette période découverts au sein de la nécropole demeurent peu nombreux, mais on ne peut exclure que certaines tombes appartenant à la fin de ce siècle aient été dépourvues de toute offrande ou que leur mobilier funéraire se limite à des productions locales. Ce hiatus est d'autant plus étrange que le fonctionnement de Kalfata se poursuit durant la première moitié du III ${ }^{\mathrm{s}} \mathrm{s}$, qui constitue ici la phase 4 de la nécropole, même si l'on note désormais une nette baisse de l'occupation. Seul le secteur Nord reçoit alors plusieurs urnes au sommet des anciens remblais tumulaires, alors que, paradoxalement, les secteurs central et Sud ne connaissent qu'une activité marginale. La proportion des incinérations augmente sensiblement, mais l'échantillon disponible est trop faible pour être considéré comme vraiment représentatif. On assiste durant cette dernière phase à un renouvellement de la typologie des structures funéraires. La simple fosse et la ciste, toujours en usage, s'enrichissent en effet de l'introduction de la tombe à tuile, entourée d'un coffrage en pierres. Ce modèle prédomine même parmi les tombes placées près de la route : l'une d'entre elles (SP 346) témoigne d'un soin particulier apporté au mobilier funéraire, notamment par la déposition de couronnes composées de feuilles dorées accompagnées de nombreux unguentaria. Ces sépultures témoignent de la forte valeur attribuée aux emplacements disposés au plus près de la route, sur laquelle cependant aucune n'empiète. Cette particularité illustre le maintien continu de règles cadastrales dans une période de déclin global de l'occupation de Kalfata.

La nécropole cesse de fonctionner au cours de la seconde moitié de ce siècle, comme en témoigne la déposition sur l'ensemble du site de la couche de scellage US 1/101/117/194/500, composée d'un mélange de sable d'origine éolienne et de terre d'origine diverse. Elle précède la déposition, dans les siècles suivants, d'une importante couche de sable stérile dépourvue de tout matériel. 


\begin{tabular}{|c|c|c|c|c|c|}
\hline SP 244 & Ph. $3: 375-350$ & DP $1+35$ & SP $323^{*}$ & Ph. 4 : 300-250 & DP $17(?)$ \\
\hline SP 250 & Ph. 4 : 300-290 & & SP 324 & Ph. 3 : 370-300 (?) & DP $17(?)$ \\
\hline SP 251 & Ph. $3: 375-300$ & & SP 325 & Ph. 2 : 390-380 & \\
\hline SP 264 & Ph. 3 : ca. 350 & DP 22 & SP 326 & Ph. $3: 375-350$ & DP 25 \\
\hline SP 265 & Ph. 3 : ca. 340 & DP 23 & SP 327 & Ph. $3: 370-350$ & DP 16 \\
\hline SP 271 & Ph. 4 : 300-250 & & SP 328 & Ph. $3: 360-350$ & \\
\hline SP 272 & Ph. 3 : ca. 350 & & SP 329 & Ph. $3: 360-350$ & DP 28 \\
\hline SP 279 & Ph. 4 : 300-290 & & SP 330 & Ph. 1 : ca. 420 & \\
\hline SP 283 & Ph. 3 : ca. 340 & DP 24 & SP 331 & Ph. 1 : ca. 420 & \\
\hline SP 287 & Ph. $3: 350-340$ & & SP 332 & Ph. 3 : ca. 350 & DP 27 \\
\hline SP 289 & Ph. $4: 300-290$ & & SP 333 & Ph. $3: 370-350$ & DP $18(?)+19+20$ \\
\hline SP 291 & Ph. 2 : 390-380 & DP $2+3$ & SP 334 & Ph. 2 : 390-380 & $\mathrm{DP} 12+13$ \\
\hline SP 296 & Ph. 4 : 300-250 (?) & & SP 335 & $(?)$ & \\
\hline SP 297 & Ph. 4 : 300-275 & & SP 336 & Ph. 2 : 390-380 & DP $11(?)+15$ \\
\hline SP 298* & Ph. $3: 370-360$ & & SP 337 & Ph. 3 : ca. 350 & \\
\hline SP 299* & Ph. 4 : 300-290 & DP 21 & SP 338 & Ph. $3: 375-350$ & DP $18(?)$ \\
\hline SP 300 & Ph. 2 : 390-380 & & SP 339 & Ph. 2 : ca. 380 & $\begin{array}{l}\text { DP } 26(?)+30(?) \\
+31(?)\end{array}$ \\
\hline SP 303 & Ph. 2 : 400-375 & DP 6 & SP 340 & Ph. $3: 360-350$ & \\
\hline SP $312^{*}$ & Ph. 4 : 300-275 & & SP 341 & Ph. $3: 375-300$ & \\
\hline SP 313 & Ph. $1: 430-420$ & & SP 342 & Ph. 3 : ca. 340 & DP 29 \\
\hline SP 315 & Ph. 4 : 300-250 & & SP 343 & Ph. 2 : 400-390 & DP $32+34$ \\
\hline SP $316^{*}$ & Ph. $3: 375-350$ & & SP 344 & Ph. 4 : ca. 250 & \\
\hline SP $317^{*}$ & Ph. 4 : 300-275 & & SP $345^{*}$ & Ph. 3 : ca. 375 & \\
\hline SP $318^{*}$ & Ph. 4 : 300-275 & & SP 346 & Ph. 4 : 260-250 & \\
\hline SP $319^{*}$ & Ph. 4 : 300-270 & & SP 347 & Ph. 4 : 260-250 & \\
\hline SP 320 & Ph. 3 : 370-300 (?) & & SP 362 & Ph. 4 : 300-250 & \\
\hline SP 321 & Ph. $3: 375-350$ & & SP 370 & Ph. 3 : ca. 370 & \\
\hline SP 322 & Ph. 3 : ca. 350 & & SP 375 & Ph. 2: $390-380$ & $\begin{array}{l}\text { DP } 26(?)+30(?) \\
+31(?)\end{array}$ \\
\hline
\end{tabular}

Tableau 2. Liste des sépultures (l'astérisque* indique une crémation), avec la répartition entre les phases et l'association aux dépôts et foyers. 


\section{Chapitre 2}

\section{Description des tombes, dépôts et foyers}

L a numérotation des sépultures (SP) a été établie en fonction de la date de la découverte. On a séparé ici les sépultures à incinération et à inhumation. Quand il a été décrit dans le chapitre précédent, le contexte stratigraphique n'est pas repris. Dans le catalogue des objets, le numéro entre parenthèses qui figure en tête renvoie aux synthèses de la troisième partie où sont décrits les objets ${ }^{32}$; les objets qui ne sont pas commentés dans la troisième partie, comme les amphores commerciales, ont donné lieu à une notice plus détaillée ici. Le numéro PIN correspond à l'inventaire établi au moment de la fouille, le numéro FR à celui de la mission française. Tous ces objets sont conservés au Musée Archéologique de Sozopol.

\section{Description des tombes}

\subsection{Sépultures à crémation}

\section{SP 298}

Sépulture à crémation secondaire découverte par l'équipe bulgare le 6 octobre 2002 dans le secteur Est, entre les points E 3 et F 3, à l'intérieur de l'enclos MR 1. Niveau supérieur 4,22, inférieur 3,96. Pl. 11

\section{Contexte stratigraphique et description archéologique}

L'urne était déposée dans une fosse $(110$ x $96 \mathrm{~cm})$ relativement profonde, incluse dans le compartiment central de l'enclos MR 1. La fosse était recouverte par deux assises de dalles de calcaire. Le niveau supérieur des blocs qui l'entourent est de 4,85-4,86 m. Des deux côtés de la fosse sont accolées deux autres «cellules » sans sépultures. Les murets latéraux du compartiment de SP 298 sont fondés $20 \mathrm{~cm}$ plus haut que l'assise inférieure du mur de façade. Le cratère 2 , utilisé comme urne cinéraire, était déposé au fond de la fosse (niveau inférieur 3,96 m) ; elle était couverte par la lékané 3 ; le pot $\mathbf{1}$ a été découvert à côté de l'urne.

$32 \mathrm{CC}=$ céramique commune $; \mathrm{CP}=$ céramique peinte $; \mathrm{D}=$ divers ; $\mathrm{M}=$ métal $; \mathrm{TC}=$ terre cuite $; \mathrm{TT}=$ tuiles timbrées $; \mathrm{VN}=$ vernis noir.

\section{Description anthropologique}

L'individu était un adulte, de sexe indéterminé.

\section{Inventaire des objets}

1 - (= CC 106) Cratère de fabrication locale. Inv. PIN 3250.

Pl. 11e (à g.)

2 - (= CC 201) Pot de fabrication locale. Inv. PIN 3252.

Pl. 11e (au centre)

3 - (= CC 109) Lékané de fabrication locale. Inv. PIN 3251.

Pl. 11e (à dr.)

\section{Datation, commentaire}

Le matériel de la tombe ne permet pas de datation précise, mais le contexte stratigraphique oriente vers le début du deuxième quart du $\mathrm{IV}^{\mathrm{e}} \mathrm{s}$.

\section{SP 299}

Sépulture à crémation secondaire découverte par l'équipe bulgare le 5 octobre 2002 dans le secteur Sud, entre les points $\mathrm{G} 2$ et $\mathrm{G}$ 3. Niveau 5,68. Pl. 12a-b

\section{Contexte stratigraphique et description archéologique}

Les ossements, déposés au fond d'une fosse, étaient recouverts par la partie inférieure d'une amphore, déposée à l'envers.

La fosse était creusée dans le remblai US 2/501 et atteignait en profondeur la lentille de sable US 6. Son remplissage était constitué d'un sable homogène jaune. Le lécythe $\mathbf{2}$ était posé à côté de l'amphore $\mathbf{1}$.

Association probable avec le dépôt DP 21.

\section{Inventaire des objets}

1 - Amphore de Chersonnèse Taurique, argile rouge micacée. Très fragmentaire, toute la partie supérieure manque. Ht conservée $41 \mathrm{~cm}$, diam. restitué $34 \mathrm{~cm}$. Inv. PIN 3255. Pl. 12b

Panse presque conique dans sa partie inférieure ; le sabot, bas et concave en dessous, à face extérieure convexe, est raccordé à la panse par une courte tige.

Variante I-B de S. Monahov : fin du IV e-III ${ }^{\mathrm{e}}$ s. Cf. Monahov 1989, p. 51-57 et annexe 2, pl. IV-XI. Parallèles : Monahov, Rogov 1990a, p. 137-138 n²9, pl. 4 et 7 : datée par le contexte de découverte vers la fin du IV e ou le premier quart du III ${ }^{\mathrm{e}}$ s. ; Monahov 1999, p. 481, 511, pl. 206, 5 et 
216, 1: le timbre de l'astynome Prytanios (groupe 2A de Kats 1994) permet de situer le premier des deux exemplaires autour de 280 .

2 - (= CC 155) Lécythe de fabrication locale. Inv. PIN 3256. Pl. 12a

\section{Datation, commentaire}

Le lécythe et l'amphore indiquent une date à la toute fin du $\mathrm{IV}^{\mathrm{e}} \mathrm{ou}$, plus probablement, au début du $\mathrm{III}^{\mathrm{e}}$ s., chronologie que confirme la stratigraphie du secteur.

\section{SP 312}

Sépulture à crémation secondaire découverte par l'équipe bulgare le 8 août 2003 dans le secteur Nord, entre les points H-I 5-6. Niveau 5,93. Pl. 12c-e

\section{Contexte stratigraphique et description archéologique}

Le cratère 1, utilisé comme urne cinéraire, était placé dans une fosse aux limites incertaines creusée dans l'horizon de sable US 9/508. Il était fermé par le plat à poisson 2.

\section{Description anthropologique}

Les restes sont ceux d'un adulte, de sexe indéterminé.

\section{Inventaire des objets}

1 - (= CC 107) Cratère de fabrication locale. Inv. PIN 3598.

Pl. 12e

2 - (= CC 146) Plat à poisson de fabrication locale.

Inv PIN 3599. Pl. 12d

\section{Datation, commentaire}

La tombe fait partie des sépultures les plus tardives du secteur. Le plat à poisson oriente vers le premier quart du III $^{\mathrm{e}} \mathrm{s}$.

\section{SP 316}

Sépulture à crémation secondaire, découverte par l'équipe bulgare le 13 août 2003 dans le secteur Sud, au S.-E. du point H3. Pl. 13a-d

\section{Contexte stratigraphique et description archéologique}

Le cratère à figures rouges, utilisé comme urne cinéraire, était placé dans une fosse aux limites incertaines, creusée dans la couverture tumulaire de SP 325. Au-dessus du cratère 1, peut-être dans le remplissage de la fosse, a été trouvée la monnaie en bronze 4. Le plat à poisson $\mathbf{2}$ servait de couvercle : au-dessus de lui se trouvait la partie inférieure d'un vase à vernis noir à panse cannelée. Le lécythe $\mathbf{3}$ était placé au milieu des os. Suite à l'affaissement du terrain, le cratère 1 s'était penché vers le S.-O. et s'était fissuré.

\section{Description anthropologique}

L'individu était un adulte, de sexe indéterminé.

\section{Inventaire des objets}

1 - (= CP 46) Cratère en cloche attique à figures rouges.

Inv. PIN 3628. Pl. 13d et 90

2 - (= VN 106) Plat à poisson à vernis noir. Inv. PIN 3629.

Pl. 13c

3 - (= CP 19) Lécythe aryballisque à figures rouges.

Inv. PIN 3631.

4 - (= M 40) Monnaie en bronze, illisible. Inv. PIN 3627.

\section{Datation, commentaire}

Le plat à poisson indique une date précoce, dans le premier quart du $\mathrm{IV}^{\mathrm{e}} \mathrm{s}$., mais le cratère et le contexte stratigraphique orientent vers une date plus basse, dans le second quart du même siècle.

\section{SP 317}

Sépulture à crémation secondaire, découverte par l'équipe bulgare le 13 août 2003 dans le secteur Nord, au S.-O. du point H 5. Pl. 13e-h

\section{Contexte stratigraphique et description archéologique}

La jarre 1, utilisée comme urne cinéraire, était placée dans une fosse aux limites incertaines creusée dans l'horizon de sable US 9/508. Elle était fermée par le couvercle 2, qui était tombé à l'intérieur. L'unguentarium 3 était placé au milieu des os.

\section{Description anthropologique}

L'individu était un adulte, de sexe indéterminé.

\section{Inventaire des objets}

1 - (= CC 103) Jarre de fabrication locale. Inv. PIN 3634a.

Pl. 13h

2 - (= CC 170) Couvercle de fabrication locale. Inv. PIN 3634b. Pl. 13g

3 - (= CC 161) Unguentarium de fabrication locale.

Inv. PIN 3635. Pl. $13 f$

\section{Datation, commentaire}

L'unguentarium oriente vers le premier quart du $\mathrm{III}^{\mathrm{e}}$ s., ce que confirme le contexte stratigraphique.

\section{SP 318}

Sépulture à crémation secondaire, découverte par l'équipe bulgare le 14 août 2003 dans le secteur Nord, entre les points H-I 5-6. Pl. 14a-c

\section{Contexte stratigraphique et description archéologique}

La jarre 1, utilisée comme urne cinéraire, était placée dans une fosse aux limites incertaines creusée dans l'horizon de sable US 9/508. Elle était fermée par le couvercle 2. Dans le sable autour de l'urne ont été trouvés les fragments de la figurine en terre cuite $\mathbf{5}$. 


\section{Description anthropologique}

L'individu était un adulte, de sexe indéterminé.

\section{Inventaire des objets}

1 - (= CC 105) Jarre de fabrication locale. Inv. PIN 3669a.

Pl. 14c

2 - (= CC 171) Couvercle de fabrication locale.

Inv. PIN 3669b. Pl. 14b

3 - (= CC 162) Unguentarium de fabrication locale.

Inv. PIN 3667. Pl. 14a (à g.)

4 - (= CC 13) Cruche (olpé) de fabrication locale.

Inv. PIN 3668. Pl. 14a (à dr.)

5 - (= TC 1) Figurine en terre cuite: personnage féminin trônant. Inv. PIN 3636 (?).

\section{Datation, commentaire}

L'unguentarium oriente vers le premier quart du $\mathrm{III}^{\mathrm{e}}$ s., ce que confirme le contexte stratigraphique.

\section{SP 319}

Sépulture à crémation secondaire, découverte par l'équipe bulgare le 14 août 2003 dans le secteur Nord, entre les points I-J 5-6. Pl. 14d

\section{Contexte stratigraphique et description archéologique}

Le cratère 1, utilisé comme urne cinéraire, était placé dans une fosse aux limites incertaines creusée dans l'horizon de sable US 9/508. Il était fermé par le bol 2. Aucune offrande n'était associée.

\section{Description anthropologique}

L'individu était un adulte, de sexe indéterminé.

\section{Inventaire des objets}

1 - (= CC 108) Cratère de fabrication locale. Inv. PIN 3672. Pl. 14d (à g.)

2 - (= CC 139) Bol de fabrication locale. Inv. PIN 3673.

Pl. 14d (à dr.)

\section{Datation, commentaire}

Le cratère et le bol ne donnent pas de date précise, mais le placement de la sépulture dans l'US 9/508, au même titre que les incinérations SP 312,317 et 318 , oriente dans les premières décennies du $\mathrm{III}^{\mathrm{e}} \mathrm{s}$.

\section{SP 323}

Sépulture à crémation secondaire, découverte par l'équipe bulgare le 20 août 2003 dans le secteur Nord, à côté du point I 5. Pl. 15

\section{Contexte stratigraphique et description archéologique}

La jarre 1, utilisée comme urne cinéraire, était placée $40 \mathrm{~cm}$ au-dessus des genoux du squelette de la tombe SP 324, dans une fosse aux limites incertaines. Les deux sépultures sont installées dans la couverture tumulaire de SP 336. La jarre 1, calée par deux petites pierres, était fermée par le couvercle 2. Aucune offrande n'est associée.

Association possible avec le dépôt DP 17.

\section{Description anthropologique}

L'individu était un adulte, de sexe indéterminé.

Inventaire des objets

1 - (= CC 104) Jarre de fabrication locale. Inv. PIN 3710a.

Pl. 15c-d

2 - (= CC 169) Couvercle de fabrication locale.

Inv. PIN 3710b. Pl. 15b-d

\section{Datation, commentaire}

La jarre ne donne pas de date précise, mais le plat oriente vers la première moitié du $\mathrm{III}^{\mathrm{e}} \mathrm{s}$.

\section{SP 345}

Sépulture à crémation secondaire trouvée par l'équipe française le 11 septembre 2003 dans le secteur Est, entre les points F 3 et F 4. Pl. 16

\section{Contexte stratigraphique}

Les blocs de la ciste/caisson qui contenait l'hydrie cinéraire étaient posés sur la couche de terre brune US 220 : niveaux 4,51 au Nord, 4,66 à l'Ouest, 4,65 à l'Est. Leur mise en place a nécessité la creusement d'une tranchée de fondation de 15 à $20 \mathrm{~cm}$ de large (US 197) qui a coupé à l'Ouest l'US 196, liée au foyer F 11. Le bloc oriental et, probablement, le couvercle ont ensuite été arrachés pour l'implantation de SP 362, les autres blocs et l'intérieur de la ciste étaient couverts par les US 120, 137 et 143. La base de stèle qui est en place au Sud lui est presque certainement associée. Voir plus haut pour la situation de SP 345 dans l'évolution stratigraphique du secteur.

\section{Description archéologique}

L'intérieur de la ciste n'était pas couvert. La lèvre de l'hydrie, bloquée par de petites pierres tirées du même calcaire que la ciste (US 154), se trouvait approximativement au centre de la ciste, au niveau 4,71, donc 16 à $18 \mathrm{~cm}$ plus bas que le sommet des blocs (4,87 au Nord et au Sud, 4,89 à l'Ouest).

Le vase était posé sur la couche compacte US 198/221/223/586/642, au niveau 4,28. Le remplissage de la petite fosse était constitué par une couche de sable (US 157) sous les pierres de blocage.

Aucune offrande n'était placée dans ce comblement, ni à l'intérieur de la ciste ; seul un petit fragment de fer a été trouvé dans l'US 154. L'hydrie était cassée en de très nombreux fragments. Aucune offrande n'a été placée dans le vase avec les ossements ${ }^{33}$.

33 Les quelques graines ou noyaux carbonisés signalés ci-dessous n'ont pas été identifiés. 
Description de la ciste - Les trois blocs conservés sont taillés dans un calcaire blanc à bleuté, en partie cristallisé, soigneusement travaillés sur leurs faces latérales et supérieures ; la face interne est irrégulièrement découpée.

Le bloc 1 (au Sud) a une longueur de $78 \mathrm{~cm}$, une largeur maximum de $33 \mathrm{~cm}$, une hauteur maximum de $29 \mathrm{~cm}$; sa face supérieure présente des traces d'outils, de gradine à dents fines vers l'extérieur (bandeau irrégulier, de $11 \mathrm{~cm}$ de large au maximum), de pointe vers le centre ; une petite pierre de calage est fixée aux angles Est et Ouest. Le bloc 2 (à l'Ouest) est long de $64 \mathrm{~cm}$, large de $21 \mathrm{~cm}$, haut de 26 à $27 \mathrm{~cm}$; sa surface est détériorée. Le bloc 3 (au Nord) est long de $85 \mathrm{~cm}$, sa largeur est très variable (34 $\mathrm{cm}$ au centre), il est haut de $32 \mathrm{~cm}$; sa surface est détériorée. Il présente sur son long côté, au niveau 4,73, un ressaut qui pourrait correspondre à la ligne de sol au moment de la mise en place.

\section{Description anthropologique}

Voir le commentaire détaillé ci-dessous.

\section{Inventaire des objets}

1 - (= CP 47) Hydrie attique à figures rouges. Inv. PIN 3664. Pl. 16d

\section{Datation, commentaire}

Le décor de l'hydrie, qui peut être attribué au «groupe d'Apollonia », rattache le vase au style de Kertch ancien : le contexte stratigraphique est en faveur d'une date relativement haute, vers le début du second quart du $\mathrm{IV}^{\mathrm{e}} \mathrm{s}$.

\section{Étude anthropologique de la sépulture à crémation SP 345}

La sépulture secondaire à crémation exhumée lors de la campagne 2003 a été prélevée en motte sur le terrain, après extraction des tessons appartenant au contenant. La fouille du dépôt de crémation a été effectuée en laboratoire, selon le protocole mis au point par Henri Duday ${ }^{34}$ et Gilles Grévin ${ }^{35}$. Celui-ci consiste à effectuer une micro-fouille du dépôt osseux, avec des décapages cotés de faible épaisseur et une reconnaissance des os en cours de fouille. Chaque niveau fait l'objet de relevés graphiques et photographiques permettant d'appréhender la répartition des ossements au sein de l'urne, leur densité, l'éventuelle présence de charbons de bois ou d'offrandes primaires (brûlées avec le défunt), la présence de sédiment intrusif ou de colmatage, etc. En outre, la reconnaissance des fragments osseux en cours de fouille améliore considérablement le score de détermination puisque les os brûlés sont extrêmement fragiles et fragmentés.

La fouille du dépôt osseux de SP 345 n'a pu être menée sur toute son épaisseur puisqu'une partie n'était plus en place, toutefois deux premiers niveaux (R1 et R2) ont pu être isolés. Les deux niveaux fouillés (R3 et R4), d'une épaisseur

34 UMR 5089, Laboratoire d'Anthropologie des populations du passé, Université Bordeaux I (Duday 1987).

35 CNRS - CRA, Unité d'Anthropologie physique, Laboratoire de Draguignan (Grévin 1990). moyenne de $5 \mathrm{~cm}$, correspondent au dépôt situé au fond de l'urne cinéraire. Les ossements crématisés étaient mêlés à du sédiment d'infiltration sableux, présent dans l'urne du fait de la fragmentation du contenant. Pratiquement aucun charbon de bois n'est présent, mais quelques graines ou noyaux carbonisés étaient mêlés aux ossements. Tout le sédiment a été conservé après tamisage sur une colonne de 0,4 et $0,2 \mathrm{~cm}$, permettant une identification et une étude future. Les ossements étaient répartis sur toute la largeur du dépôt (de 27 à $21 \mathrm{~cm}$ ), sans ordre apparent.

\section{Étude de la représentation du sujet}

Malgré la fragmentation du réceptacle, il semble que le dépôt cinéraire soit complet, ce qui permet de disposer de renseignements concernant le ramassage des ossements sur le bûcher et la représentation du sujet au sein de l'urne. Pour ce faire, une reconnaissance précise des fragments osseux est menée lors de l'étude et tous les fragments sont pesés par origine anatomique. L'étude pondérale des ossements crématisés donne de bien meilleurs résultats que l'étude quantitative, eu égard à l'extrême fragmentation des vestiges osseux. Aucun doublet ou différence de maturité n'ayant été rencontré, un seul sujet est présent dans l'urne.

Le poids total des ossements (1012,2 g) est important, il représente $62 \%$ du poids théorique moyen d'un individu complet incinéré selon J. I. MacKinley ${ }^{36}$, sachant que la variation admise est comprise entre 1001 g et 2422 g. L'étude anthropologique de nombreuses sépultures à incinération anciennes a cependant permis de ramener cette moyenne aux alentours d'un kilogramme (Richier 1997), ce qui indique que le sujet de SP 345 est sub-complet. Cette donnée n'est cependant pas la seule à prendre en considération dans l'étude de la représentation du sujet : il importe de la croiser avec la proportion des grandes régions anatomiques présentes.

Lawrence et Latimer (in Krogman 1978) ont travaillé sur le poids moyen des différentes parties anatomiques d'un individu. Il s'agit des seuls travaux actuellement disponibles et, bien que concernant des ossements secs et non brûlés, ils constituent une bonne référence quant à la représentativité proportionnelle des grandes régions anatomiques. En convertissant ces poids moyens en pourcentages, il est possible de comparer les données de référence à celles obtenues avec l'individu étudié. Les fragments indéterminés ont été systématiquement pris en compte dans cette comparaison puisqu'ils peuvent largement biaiser l'interprétation que l'on peut faire de sur-représentation ou sous-représentation de régions anatomiques pour un individu. Le taux d'identification (poids des os déterminés / poids total x 100) est pour SP 345 de $74 \%$, ce qui constitue un bon score permettant des interprétations.

Ainsi, la représentation des os par grandes régions anatomiques, comparée aux données de Lawrence et Latimer (Graphique 1), est intéressante : crâne et tronc sont

36 L'auteur propose un poids moyen de $1627 \mathrm{~g}$ selon une étude effectuée sur des crémations actuelles (Mac Kinley 1993). 
CHAPITRE 2 - DESCRIPTION DES TOMBES, DÉPÔTS ET FOYERS

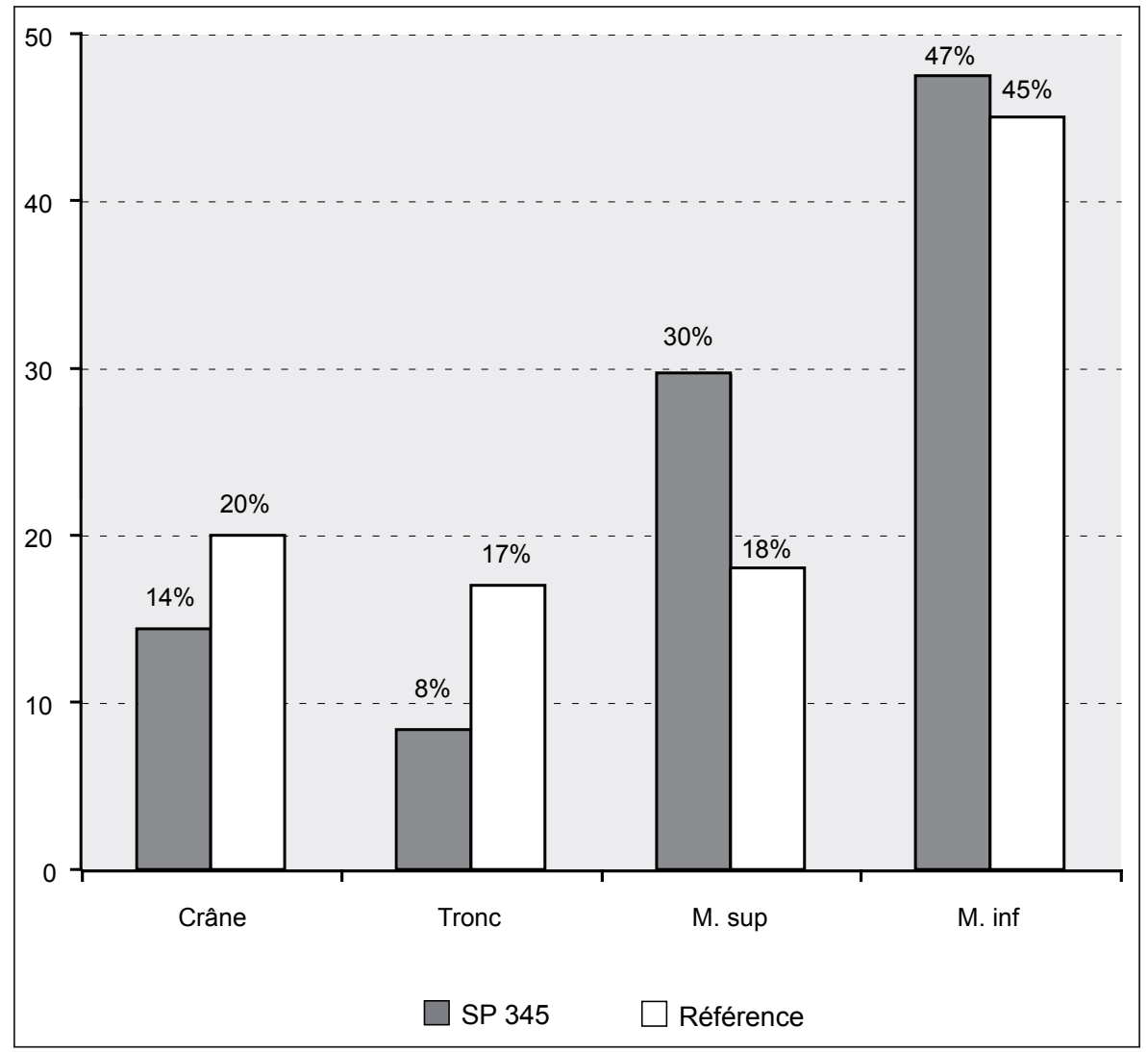

Graphique 1. Représentation par grandes régions anatomiques.

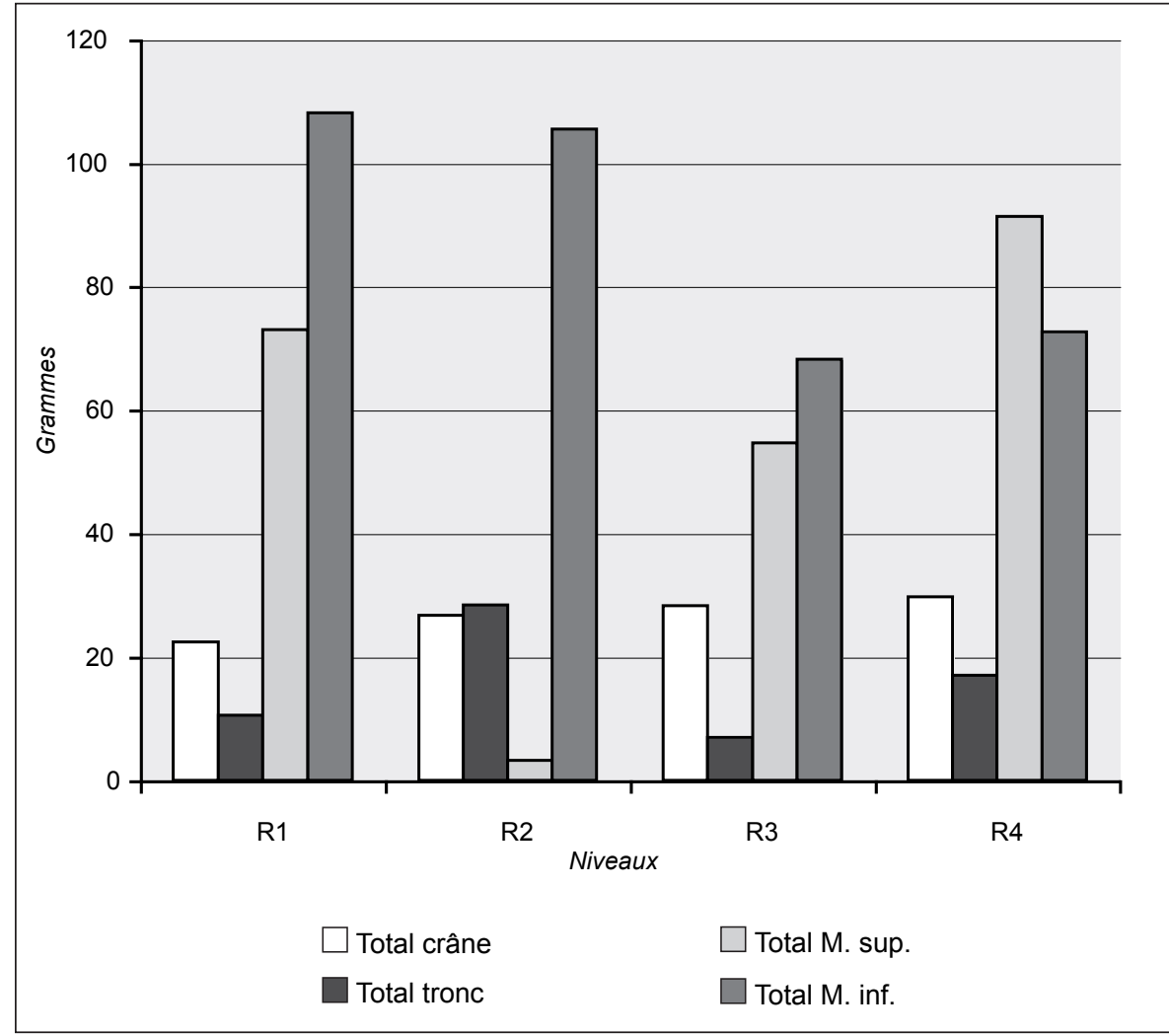

Graphique 2. Répartition des ossements par niveaux. 
largement sous-représentés alors que les membres sont en forte sur-représentation. Le crâne, dont les fragments sont pourtant très facilement identifiables et donc peu présents dans les ossements indéterminés, obtient un score (IPC) de 14,4. Comparé aux données de référence, soit un IPC de 20, ce score montre un déficit de presque un tiers. Malgré cette faible représentation, il est très étonnant de constater qu'aucune dent ou racine dentaire n'est présente. Le tronc indique une sous-représentation encore plus flagrante : 8,4 pour 17, soit un déficit de plus de la moitié. Ces importantes sous-représentations indiquent que le sujet est incomplet et que crâne et tronc ont été délaissés lors du ramassage sur le bûcher cinéraire. Le squelette appendiculaire, en revanche - surtout en ce qui concerne les membres supérieurs -, est très largement excédentaire. Cette sur-représentation, accentuée du fait de la présence de plus de 100 grammes de diaphyses indéterminées (ce type de fragments appartenant exclusivement aux membres), montre de manière évidente que le squelette appendiculaire a été préférentiellement prélevé sur le bûcher.

La distribution des ossements au sein de l'urne (Graphique 2) ne montre aucune stratigraphie particulière : toutes les grandes régions anatomiques sont présentes dans les quatre niveaux, dans des proportions équivalentes. Seuls les membres supérieurs montrent un très net déficit dans le niveau R2, mais, celui-ci n'étant pas en place, il est difficile d'en tirer quelque conclusion que ce soit. Le ramassage sur le bûcher et le remplissage de l'urne n'ont donc pas fait l'objet d'un tri sélectif.

\section{Étude des ossements crématisés}

L'individu est un adulte: aucune surface métaphysaire n'est présente, les sutures crâniennes sont complexes et la corticale des os longs est épaisse. Aucun signe de pathologie dégénérative n'est présent (arthrose, pertes dentaires, etc.), mais on note l'absence quasi-totale de corps vertébraux, et totale des dents. Cette dernière observation est étonnante : l'émail éclate au feu mais les racines se conservent très bien dans les incinérations. De plus, une partie de la mandibule a été identifiée, et il est possible de distinguer les alvéoles, non oblitérées, de PM2G à PM1D. Les deux patellas en revanche sont quasi-complètes et ne présentent aucune trace d'enthésopathies, ce qui peut indiquer un sujet d'un âge compris entre 25 et 40 ans.

Malgré la présence de gros fragments d'os coxaux (surtout situés aux alentours de la crête iliaque), il n'est pas possible de proposer une diagnose sexuelle. Il faut toutefois noter la gracilité des ossements conservés.

La température de crémation est inégale et hétérogène (Tableau 3) ; certains fragments sont bleus ou gris, indiquant une température inférieure ou égale à $500^{\circ} \mathrm{C}$ (Bonucci, Graziani 1975), tandis que d'autres sont d'un blanc crayeux, très fissurés et déformés, témoins d'une température supérieure

\begin{tabular}{|l|l|l|l|}
\hline SP 345 & Couleur & Température & Taille (cm) \\
\hline Crâne & Blanc/gris/bleu & $>500^{\circ} \mathrm{C}$ & $0,5-3,5$ \\
\hline Mandibule & Gris/bleu & $>500^{\circ} \mathrm{C}$ & $2-5$ \\
\hline Dents & - & - & - \\
\hline Vertèbres cervicales & Blanc/gris & $>500^{\circ} \mathrm{C}$ & 1,5 \\
\hline Vertèbres thoraciques & Blanc/gris & $>500^{\circ} \mathrm{C}$ & $0,5-2,5$ \\
\hline Vertèbres lombaires & Blanc/gris & $>500^{\circ} \mathrm{C}$ & $2-4,5$ \\
\hline Sacrum & Blanc & $\geq 660^{\circ} \mathrm{C}$ & $1-2$ \\
\hline Côtes & Blanc/gris & $>500^{\circ} \mathrm{C}$ & $0,5-3$ \\
\hline Clavicule & - & - & - \\
\hline Scapula & Blanc/gris & $>500^{\circ} \mathrm{C}$ & $1,5-2$ \\
\hline Humérus & Blanc & $\geq 660^{\circ} \mathrm{C}$ & $3,5-7,5$ \\
\hline Radius & Blanc & $\geq 660^{\circ} \mathrm{C}$ & $1-7$ \\
\hline Ulna & Blanc & $\geq 660^{\circ} \mathrm{C}$ & $3-7$ \\
\hline Main & Blanc & $\geq 660^{\circ} \mathrm{C}$ & $2-3,5$ \\
\hline Os coxal & Blanc & $\geq 660^{\circ} \mathrm{C}$ & $1,5-8$ \\
\hline Fémur & Blanc/gris & $>500^{\circ} \mathrm{C}$ & $0,5-5$ \\
\hline Tibia & Blanc & $\geq 660^{\circ} \mathrm{C}$ & $1-9$ \\
\hline Fibula & Blanc & $\geq 660^{\circ} \mathrm{C}$ & $2-10$ \\
\hline Patella & Blanc & $\geq 660^{\circ} \mathrm{C}$ & 4 \\
\hline Pied & Blanc & $\geq 660^{\circ} \mathrm{C}$ & $0,5-5$ \\
\hline
\end{tabular}

Tableau 3. Température de crémation et fragmentation par types d'ossements. 
CHAPITRE 2 - DESCRIPTION DES TOMBES, DÉPÔTS ET FOYERS

\begin{tabular}{|c|c|c|c|c|c|}
\hline Niveau & $\mathrm{R} 1$ & $\mathrm{R} 2$ & R3 & R4 & TOTAL \\
\hline Crâne & 22,4 & 25,9 & 28,3 & 20,2 & 96,7 \\
\hline Mandibule & & 0,9 & & 9,6 & 10,5 \\
\hline Dents sup. & & & & & 0,0 \\
\hline Dents inf. & & & & & 0,0 \\
\hline Dents indét. & & & & & 0,0 \\
\hline Os hyoïde & & & & & 0,0 \\
\hline Total crâne & 22,4 & 26,8 & 28,3 & 29,8 & 107,2 \\
\hline Atlas & & & & & 0,0 \\
\hline Axis & & & & & 0,0 \\
\hline C3-C7 & & 1,5 & & & 1,5 \\
\hline Thoraciques & 5,5 & 3,6 & & 2,8 & 11,9 \\
\hline Lombaires & & 5,9 & & 6,1 & 12,0 \\
\hline Vert. Indét. & & 5,7 & 2,9 & & 8,6 \\
\hline Sacrum & & 4,6 & & & 4,6 \\
\hline Coccyx & & & & & 0,0 \\
\hline Côtes & 5,1 & 7,2 & 4,1 & 4,0 & 20,4 \\
\hline Sternum & & & & 4,1 & 4,1 \\
\hline Total tronc & 10,6 & 28,4 & 7,0 & 17,1 & 63,1 \\
\hline Clavicule & & & & & 0,0 \\
\hline Scapula & 5,5 & & 3,9 & 1,0 & 10,4 \\
\hline Humérus & 34,4 & & 29,2 & 50,3 & 113,8 \\
\hline Radius & 7,4 & & & 9,7 & 17,1 \\
\hline Ulna & 22,8 & & 18,8 & 28,2 & 69,8 \\
\hline Carpe & & 0,9 & & & 0,9 \\
\hline Métacarpe & & 0,7 & & & 0,7 \\
\hline Phal. Main & 2,9 & 1,6 & 2,8 & 2,2 & 9,5 \\
\hline Total M. sup. & 73,0 & 3,2 & 54,7 & 91,4 & 222,2 \\
\hline Os coxal & 14,5 & 2,0 & 2,4 & 4,8 & 23,6 \\
\hline Fémur & 22,2 & 47,9 & 18,6 & 15,4 & 104,2 \\
\hline Patella & & & 6,8 & 5,1 & 12,0 \\
\hline Tibia & 48,2 & 33,7 & 33,5 & 37,2 & 152,7 \\
\hline Fibula & 12,1 & 10,7 & & 6,3 & 29,1 \\
\hline Tarse & 6,9 & & 2,0 & 1,4 & 10,3 \\
\hline Métatarse & & 11,2 & 4,9 & & 16,1 \\
\hline Phal. Pied & 4,4 & & & 2,5 & 6,8 \\
\hline Total M. inf. & 108,2 & 105,6 & 68,2 & 72,7 & 354,7 \\
\hline Total déterminé & 214,2 & 164,0 & 158,1 & 210,9 & 747,2 \\
\hline Diaph. indét. & 57,2 & 35,8 & 13,9 & 15,7 & 122,6 \\
\hline Os court-épiphyse & 14,0 & 12,5 & 7,1 & 7,8 & 41,4 \\
\hline Esquilles & 23,1 & 44,0 & 18,5 & 15,3 & 101,0 \\
\hline Total indéterminé & 94,3 & 92,3 & 39,5 & 38,9 & 265,0 \\
\hline TOTAL & 308,5 & 256,3 & 197,7 & 249,8 & 1012,2 \\
\hline
\end{tabular}

Tableau 4. Données pondérales de SP 345. 
ou égale à $660^{\circ} \mathrm{C}$. Il semble qu'une crémation différentielle selon les régions anatomiques en soit la cause : les os peu brûlés proviennent surtout de la partie supérieure du squelette axial. Cependant, la crémation est assez hétérogène également dans ces parties anatomiques : certains fragments sont à la fois bleus, gris et blancs, et les faces endo- et exo-crâniennes n'ont pas la même couleur. Tronc et crâne ont tout de même subi une ustion moindre par rapport aux membres, ce qui se constate assez rarement dans les crémations : si le crâne éclate assez rapidement sous l'action du feu, le tronc, en revanche, souvent situé au centre du foyer, est la partie anatomique connaissant les températures les plus fortes. Il semble donc que ce sont les zones périphériques du bûcher funéraire qui ont connu la plus forte crémation, dans un ensemble porté malgré tout à haute température (entre $500^{\circ} \mathrm{C}$ et $660^{\circ} \mathrm{C}$ ).

La fragmentation est peu importante (Tableau 4): de nombreux os sont entiers (patella, carpe, vertèbre lombaire) et de grandes longueurs diaphysaires sont conservées (jusqu'à $10 \mathrm{~cm}$ pour un fragment de fibula). De plus, les esquilles d'une longueur inférieure à $0,5 \mathrm{~cm}$ sont rares. Les os qui ont connu les plus fortes températures d'ustion ne sont pas ceux qui sont le plus fragmentés malgré leur fragilité et leur déformation due à l'action du feu (fissurations en ondes concentriques, rétrécissements conséquents). Ces constatations sont importantes, puisqu'elles indiquent d'une part une absence ou une très faible conduite du bûcher (action amenant à rabattre les membres et à entretenir le feu qui conduit à une grande fragmentation osseuse), d'autre part un certain soin pris lors du ramassage des ossements et de leur dépose dans l'urne.

\section{Interprétation et gestes funéraires}

Cette étude permet de conclure que l'urne cinéraire contient les restes d'un sujet unique, ce dernier étant un adulte assez jeune de sexe indéterminé. Aucun os de faune n'était mêlé aux restes humains, comme cela est parfois observé dans les sépultures grecques (Moliner et al. 2003). Seuls les quelques noyaux ou graines carbonisés présents dans l'urne peuvent peut-être donner des renseignements sur l'éventuelle présence d'offrandes alimentaires brûlées avec le défunt.

La crémation a été assez inégale suivant les régions anatomiques du sujet : crâne et tronc sont les parties qui ont été le moins exposées au feu, contrairement aux membres. De plus, la faible fragmentation osseuse conduit à restituer une absence quasi-totale d'entretien du foyer. Il est donc possible que le défunt ait été brûlé sur un bûcher en plein air ou dans un ustrinum sans conduite de la crémation, amenant à une combustion inégale, le feu n'étant pas entretenu par des crématistes.

Le prélèvement des ossements une fois la crémation achevée a été manifestement effectué avec soin, la conservation de grandes longueurs diaphysaires, pourtant bien brûlées, étant à ce sujet particulièrement éloquente. Celui-ci a intéressé toutes les régions anatomiques du défunt, avec toutefois une certaine préférence pour le squelette appendiculaire et surtout les deux membres supérieurs. De nombreux os du carpe (poignet) ainsi que des phalanges des mains et des pieds, pourtant de petite taille, sont présents dans l'urne, ce qui amène à restituer un prélèvement précis et soigné. L'absence presque totale de charbons de bois dans le réceptacle va également dans ce sens.

Le poids total de la masse osseuse est assez conséquent, et même si des lacunes existent dans la représentation du sujet, il est possible d'appréhender un souci d'exhaustivité dans le ramassage des restes osseux. Enfin, la dépose des ossements dans l'urne a été effectuée sans ordre apparent, toutes les régions anatomiques se retrouvant dans des proportions similaires au sein de chaque niveau individualisé.

\subsection{Sépultures à inhumation}

\section{SP 244}

Tombe à fosse découverte par l'équipe bulgare le 15 août 2002 dans le secteur Sud, au S.-E. du point G 2. Orientation E. Niveau du fond de fosse 4,68. Pl. 17

\section{Contexte stratigraphique}

La sépulture était installée au fond d'une double fosse, creusée à partir de la surface du remblai l'US 102/138. Parmi les pierres du marqueur ont été trouvés un gobelet attique à vernis noir et les fragments d'une lékanis à figures rouges (DP 1). Le comblement de la fosse supérieure était constitué de plusieurs unités stratigraphiques. Sous les plaques s'étendait une première US, constituée de terre sableuse, à laquelle succédait, sous l'amas de moellons, une couche de sable mêlé à du gravier et des cailloutis. Un escalier latéral de sept marches, situé dans l'angle oriental, conduisait à la tombe qu'il couvrait en partie (long. $255 \mathrm{~cm}$, larg. 120 à $130 \mathrm{~cm}$, prof. $195 \mathrm{~cm}$ ).

Tout autour de ce dernier ont été trouvés un nombre important de tessons appartenant probablement à deux amphores et à une coupe à vernis noir (DP 35). Dans l'angle Sud a été découverte une coupelle à vernis noir fragmentaire (Inv. PIN 2776), sous laquelle commençait une troisième couche de sable, d'où provient un fond d'amphore.

Au niveau de la dernière marche se trouvait un ensemble de pierres (long. $150 \mathrm{~cm}$ ) qui recouvrait la fosse de la sépulture proprement dite.

\section{Description archéologique}

La sépulture était signalée en surface par deux plaques en calcaire (dimensions 119 × 53 × $32 \mathrm{~cm}$ et 117 x 43,5 × $31 \mathrm{~cm}$; niveau moyen supérieur 7,00) et un amas de moellons (dimensions d'ensemble 100 x $104 \mathrm{~cm}$; niveau 6,84).

Les contours de la fosse n'ont pas été repérés, le squelette, trouvé sous les pierres évoquées précédemment, occupait un espace de 158 x $30 \mathrm{~cm}$. Le lécythe $\mathbf{1}$ était situé à côté du poignet droit, son embouchure sous le coude gauche. Près de l'abdomen était placée une fibule en bronze $\mathbf{2}$, du côté droit du crâne le lécythe $\mathbf{3}$.

L'association avec les dépôts DP 1 et 35 est assurée. 


\section{Description anthropologique}

Le squelette est en position allongée, sur le dos, membres supérieurs en extension. Le crâne est orienté vers l'Est. Les jambes sont repliées. La colonne vertébrale est déformée, en forme de $\mathrm{S}$, les vertèbres sont tordues au niveau du bassin.

L'individu est un adulte féminin, âgé de 21 à 35 ans.

\section{Inventaire des objets}

1 - (=CP 7) Lécythe aryballisque à figures rouges.

Inv. PIN 2731. PI. 17e (à dr.)

2 - (= M 6) Fibule en bronze. Inv. PIN 2732.

3 - (= CP 15) Lécythe aryballisque à figures rouges.

Inv. PIN 2733. Pl. 17e (à g.)

\section{Datation, commentaire}

Le contexte stratigraphique et le matériel de la tombe, en particulier le style du lécythe à figures rouges $\mathbf{1}$, permettent de la dater du deuxième quart du $\operatorname{IV}^{\mathrm{e}} \mathrm{s}$.

\section{SP 250}

Tombe à fosse découverte par l'équipe bulgare le 3 septembre 2002 dans le secteur Sud, à côté du point G 2 . Orientation N.-E. Niveau 5,66. PI. 18a-b

\section{Contexte stratigraphique et description archéologique}

La sépulture était installée à cheval entre le comblement de la fosse supérieure de la SP 244 et le remblai US 102/138.

Les contours de la fosse n'ont pas été repérés avec précision. Celle-ci accusait un pendage vers le S.-O. qui a entraîné la déformation du squelette. Le lécythe 1 était situé sur l'épaule gauche, le coquillage $\mathbf{2}$ près du fémur droit.

\section{Description anthropologique}

Squelette en décubitus dorsal, le crâne orienté au N.-O. Les jambes tombaient vers le bas.

L'individu est une femme âgée de 36 à 50 ans (pour ses pathologies osseuses, voir ci-dessous le diagnostic d'A. Keenleyside).

\section{Inventaire du matériel}

1 - (= CC 156) Lécythe de fabrication locale. Inv. PIN 2711.

2 - Coquillage (moule).

\section{Datation, commentaire}

La position de cette sépulture à cheval dans le comblement de la fosse supérieure de SP 244 et le remblai US 102/138 indique une date plus tardive, postérieure donc au second quart du $\mathrm{IV}^{\mathrm{e}} \mathrm{s}$. La forme du lécythe, similaire à l'exemplaire de SP 299, oriente vers une date à la toute fin du $\mathrm{IV}^{\mathrm{e}}$ ou au début du III' $\mathrm{s}$.

\section{SP 251}

Tombe à fosse découverte par l'équipe bulgare le 13 septembre 2002 dans le secteur Sud, entre les points F-G 1-2. Orientation N.-E. Niveau du crâne 6,64, des jambes 6,31. Pl. 18c-d

\section{Contexte stratigraphique et description archéologique}

La fosse était creusée dans le remblai US 102/138. Le lécythe 1 était situé près du crâne, du côté droit. Un clou était posé sur le tibia, un autre au-dessus du crâne. Des charbons se trouvaient dans la zone des jambes.

\section{Description anthropologique}

Le squelette était en décubitus dorsal, membres en extension, le crâne orienté vers le N.-E.

L'individu est un sujet adulte dont le sexe n'a pas pu être déterminé.

\section{Inventaire des objets}

1 - (= CP 27) Lécythe aryballisque à décor réticulé.

Inv. PIN 2717. Pl. 18c

2 - (= M 41) Deux clous en fer. Inv. PIN 2718.

\section{Datation, commentaire}

La situation stratigraphique de SP 251 est proche de celle de SP 250. Elle est creusée dans l'US 102/138 dont la mise en place date du début second quart du $\mathrm{IV}^{\mathrm{e}} \mathrm{s}$. Le lécythe à décor réticulé ne donne aucune datation précise, mais indique une fourchette chronologique qui pourrait descendre jusqu'au début du $\mathrm{III}^{\mathrm{e}} \mathrm{s}$.

\section{SP 264}

Tombe à fosse découverte par l'équipe française le 3 septembre 2002 dans le secteur Sud, entre les points F-G 2-3. Orientation N.-E $\left(60^{\circ}\right.$ E.). Dimensions $123 \mathrm{~cm}$ x $36 \mathrm{~cm}$. Niveau au centre de la fosse 5,88. Pl. 19a-b

\section{Contexte stratigraphique}

La sépulture était installée dans une fosse de plan rectangulaire $(123 \times 36 \mathrm{~cm})$, creusée dans une couche de terre partiellement sableuse (US 11). Les bords de la fosse étaient délimités par une rangée de petits moellons. Le remplissage était constitué de sable jaune très pur (US 12). Au-dessus de celui-ci se trouvait l'US 2/501 qui présentait à cet endroit une grande homogénéité et une épaisseur importante.

Par ailleurs, un petit foyer a été découvert aux abords de la fosse, contre sa paroi N.-O. Il ne contenait que des cendres mélangées à un peu de sable. L'analyse anthracologique des échantillons prélevés a montré la présence dominante de chêne à feuillage caduc $(86,4 \%)$, complétée par celle d'angiospermes dont l'espèce n'a pu être déterminée $(13,6 \%)$.

Enfin, dans la zone autour de la tombe SP 264 ont été mis au jour quelques vases fragmentaires qui sont probablement 
en rapport avec les rites effectués après la mise en place de la sépulture :

1 - (= CC 182) Au S.-O. de la fosse de SP 264, quatre fragments d'un pot de fabrication locale. Inv. FR 1.50.

2 - (= CC 123) Près de l'angle Nord de la fosse, un bol de fabrication locale. Inv. FR 1.48.

3 - Au N.-O. de la fosse, à proximité du petit foyer, quatre fragments d'un skyphos à figures rouges, appartenant au fond et au bord, avec le départ d'une anse ; décor avec silhouette d'un personnage. Diam. du pied 5,3 cm. Inv. FR 1.51.

\section{Description archéologique}

Le sable de l'US 3, qui contrastait assez nettement avec les remblais de terre US 2/501 et 11, a pu marquer l'emplacement de la sépulture : en tout cas les objets du DP 22 étaient posés à la surface de cette US et recouverts par l'US 2/501.

Les vases $\mathbf{1}$ et $\mathbf{2}$ étaient situés au-dessus de l'emplacement du bassin de l'individu (niveaux 6,13 et 5,96), 2 à l'envers, immédiatement au Nord-Ouest de $\mathbf{1}$; le lécythe $\mathbf{3}$ était déposé au S.-O., près de l'emplacement supposé du bas de la jambe gauche ; son col, cassé, a été trouvé à proximité.

L'association avec le dépôt DP 22 est assurée.

\section{Description anthropologique}

Le squelette était très mal conservé. Seule restait en place la jambe droite, ce qui permet de déterminer, avec réserve, un âge d'environ un an. Le sujet était vraisemblablement en position allongée, sur le dos, membres en extension. Le crâne devait être orienté vers la mer (N.-E.). Quelques ossements seulement ont pu être recueillis, éparpillés sur une zone d'environ $47 \mathrm{~cm}$ de long.

\section{Inventaire des objets}

1 - (= VN 40) Coupe-canthare à vernis noir. Inv. FR 1.8.1. Pl. 19b (à g.)

2 - (= VN 39) Coupe-canthare à vernis noir. Inv. FR 1.8.2.

Pl. 19b (à dr.)

3 - (= CP 8) Lécythe aryballisque à figures rouges.

Inv. FR 1.19. Pl. 19b (au centre.)

\section{Datation, commentaire}

Les deux coupes-canthares, ainsi que le lécythe, orientent vers le milieu du $\mathrm{IV}^{\mathrm{e}} \mathrm{s}$.

\section{SP 265}

Tombe à fosse découverte par l'équipe française le 6 septembre 2002 dans le secteur central, entre les points G-H 3-4. Orientation S.-E. $\left(140^{\circ}\right)$. Niveau supérieur du crâne 5,82, des pieds 5,70. Pl. 19c-e

\section{Contexte stratigraphique}

La sépulture était incluse dans le remblai de terre US 2/501, sous le dépôt DP 23, lequel recouvrait toute la partie supérieure du squelette jusqu'au bassin. Les limites de la fosse n'ont pas été mises en évidence.
Le défunt semble avoir été simplement posé à la surface des couches sous-jacentes, qui suivaient à cet endroit un pendage en direction du S.-O., et ensuite recouvert directement de terre, de pierres et des fragments du dépôt qui ont été trouvés mélangés avec les ossements et les objets qu'on peut rattacher au mobilier de la sépulture.

Ce mode de couverture de la sépulture par un dépôt céramique de l'importance du DP 23 est à notre connaissance une pratique inédite sur le site, sur laquelle il convient de s'interroger.

En tout cas, il ne fait pas de doute que le dépôt d'objets a commencé au moment même de l'installation de la sépulture, sans qu'il soit possible de déterminer avec exactitude la durée pendant laquelle on a continué à briser des vases à cet endroit.

\section{Description archéologique}

Le crâne et la partie supérieure du corps, jusqu'au bassin, étaient mélangés aux pierres et à certains éléments du dépôt DP 23, alors que les ossements des membres inférieurs étaient très abîmés, car non recouverts par les fragments du dépôt et affleurant pratiquement à la surface de 1'US 2/501 qui était moins épaisse à cet endroit. La coupelle 1 se trouvait entre les côtes et la partie supérieure du bassin, la fibule $\mathbf{2}$ sur les côtes, sous l'épaule droite, le strigile $\mathbf{3}$ sur le côté droit du thorax, l'aiguille $\mathbf{4}$ le long du bras droit, le clou 5 près des pieds.

\section{Description anthropologique}

Anthropologie de terrain (observations d'après photographies) - Le sujet se présentait en décubitus dorsal, tête au S.-E., membres supérieurs en extension le long du corps et membres inférieurs symétriquement en extension.

Le crâne, très fragmenté, apparaissait par sa face latérale droite, en connexion étroite avec la mandibule. Le thorax a subi une mise à plat partielle, avec une ouverture costale sur le côté gauche de l'individu et une relative conservation du volume costal à droite. Un léger effet de paroi est sensible sur le membre supérieur droit, sans toutefois qu'une compression transversale soit attestée. Les deux mains, posées sur les fémurs homolatéraux, présentent des connexions étroites et des positions de déséquilibre. Les deux os coxaux sont ouverts et aucune déconnexion n'est visible sur les membres inférieurs.

La majorité des connexions anatomiques sont étroites, seuls quelques déplacements osseux à l'intérieur du volume initial du corps sont à noter, ce qui indique une décomposition en espace colmaté, dans une fosse immédiatement remblayée.

Anthropologie biologique - L'individu est sub-complet mais l'état de conservation des ossements est moyen.

Le sujet est un adulte âgé de sexe plutôt féminin. Les sutures crâniennes sont en cours de synostose et l'état dentaire est particulièrement délabré : l'usure dentaire est très marquée, les troisièmes molaires sont absentes, un important abcès est visible au niveau de la première molaire supérieure gauche, ainsi qu'une carie sur une molaire. On note une anomalie sur le trou occipital du crâne.

\section{Inventaire des objets}

1 - (= CC 140) Coupelle de fabrication locale. Inv. FR 1.16. 
2 - (= M 7) Fibule en bronze, fragmentaire. Inv. FR 1.6.3. Pl. 19e (en bas à dr.)

3 - (= M 16) Fragment de strigile en bronze. Inv. FR 1.6.4.

Pl. 19e (en bas à g.)

4 - (= M 24) Aiguille à chas en bronze, fragmentaire.

Inv. FR 1.6.7.

5 - (= M 42) Clou en fer fragmentaire, fortement corrodé.

Inv. FR 1.5.3. Pl. 19e (en haut)

\section{Datation, commentaire}

Les objets ne donnent pas d'indication significative, mais l'emplacement de la sépulture sous le dépôt DP 23, dont la constitution est bien datée entre les années 340 et 320 grâce aux différents timbres amphoriques qu'il contient, permet d'attribuer cette sépulture au début du troisième quart du $\mathrm{IV}^{\mathrm{e}} \mathrm{s}$.

\section{SP 271}

Tombe à fosse découverte par l'équipe française le 6 septembre 2002 dans le secteur central, entre les points $\mathrm{G} 4$ et $\mathrm{H}$ 4. Orientation N.-E. $\left(30^{\circ}\right)$. Niveau supérieur du crâne 5,97, des pieds 5,95. Pl. 20a-b

\section{Contexte stratigraphique}

La fosse était creusée dans une couche de terre très compacte et argileuse (US 5/502), comportant de nombreux éclats de pierres de taille diverse et des tessons de céramique commune. Elle était recouverte par l'US 14, de consistance similaire à l'US 2/501, qui ne représentait qu'une fine pellicule de quelques centimètres d'épaisseur à cet endroit, puis par l'US 1/101/117/194/500 (terre sableuse de couleur brune claire), dernière couche de scellement du site, retrouvée sur l'ensemble de la zone fouillée par l'équipe française, directement au-dessous du sable dunaire stérile dégagé avant le début des fouilles.

\section{Description archéologique}

La sépulture était installée dans une fosse de faible profondeur et de plan irrégulier (dimensions : long. $210 \mathrm{~cm}$, larg. aux pieds $42 \mathrm{~cm}$, au centre $36 \mathrm{~cm}$, près de la tête $72 \mathrm{~cm}$, à l'extrémité supérieure $56 \mathrm{~cm}$ ), s'élargissant au niveau de la tête et de la partie supérieure du corps et se rétrécissant au niveau des jambes. Du fait du pendage suivi par les couches sous-jacentes en direction du S.-O., la fosse était plus profonde au niveau de la tête. Le remplissage était constitué de la même terre compacte et argileuse que l'US 5/502, mais sans l'empierrement important qui la caractérisait (US 13). Un fragment de cruche locale $\mathbf{1}$ en argile rouge a été retrouvé à droite du bassin.

\section{Description anthropologique}

Anthropologie de terrain (observations d'après photographies) - Le sujet se présentait en décubitus dorsal, tête au N.-E., membre supérieur gauche en extension le long du corps, membre supérieur droit en flexion à $160^{\circ}$ (main sur la ceinture scapulaire) et membres inférieurs asymétriquement en extension, avec une légère flexion du gauche. Le crâne apparaissait par sa face antéro-supérieure, en connexion apparemment lâche avec la mandibule. Le thorax a subi une mise à plat totale et les clavicules sont légèrement verticalisées, ce qui indique une compression transversale. Les deux os coxaux étaient largement ouverts, en connexion avec les fémurs. Le membre inférieur gauche a subi une éversion latérale, apparaissant dans sa totalité sur sa face médiale, en connexion étroite. Le membre inférieur droit était en extension, apparaissant par sa face antérieure.

Les pieds étaient apparemment en position primaire, mais leur état fragmentaire interdit d'autres observations. La majorité des connexions anatomiques étaient étroites, avec quelques déplacements osseux à l'intérieur du volume initial du corps, ce qui indique une décomposition en espace colmaté. Les effets de compression (tête et épaules), ainsi que la position du sujet peuvent, au vu des larges dimensions de la fosse, être mis en relation avec un port initial de linceul.

Anthropologie biologique - L'individu est sub-complet mais l'état de conservation des ossements est très médiocre. Il s'agit d'un adulte mature de sexe indéterminé. Les dents présentent une usure très marquée surtout au niveau des incisives. Le talus gauche comporte une éburnation (problème d'articulation).

\section{Inventaire des objets}

1 - Fragment de cruche, argile rouge-orangé. Sans numéro.

\section{Datation, commentaire}

La position de SP 271 dans l'US 5/502 oriente vers une date très tardive. Cette couche recouvre en effet l'US 9/508 dans laquelle ont été retrouvées les incinérations secondaires SP 312, 317, 318 et 319 en secteur Nord, elles-mêmes datées dans les premières décennies du $\mathrm{III}^{\mathrm{e}} \mathrm{s}$. Il est donc possible d'attribuer cette tombe au milieu du siècle.

\section{SP 272}

Tombe à fosse découverte par l'équipe française le 6 septembre 2002 dans le secteur Sud, au S.-E. du point G 3. Orientation N.-E. $\left(40^{\circ}\right)$. Niveau supérieur de la tête 5,80, des pieds 5,74. Pl. 20c-f

\section{Contexte stratigraphique}

Au S.-O., la fosse entamait le remblai de sable jaune US 6 qui occupait l'ensemble de l'angle Sud du secteur, alors qu'au N./N.-O. elle s'étendait partiellement dans la poche de sable de 1'US 7/126, laquelle occupait l'espace intermédiaire entre SP 272 et SP 279 (voir ci-dessous). Au S.-E. et au N.-E., la transition vers la couche de terre US 11 (qui s'étend sous SP 264) était beaucoup moins claire à cause de sa composition similaire à celle du remplissage de la fosse.

\section{Description archéologique}

La sépulture était installée dans une fosse de faible profondeur, de plan approximativement rectangulaire, dont le 
comblement était constitué d'un sédiment brun foncé similaire à l'US 2/501 des horizons supérieurs (US 15). Les limites de la fosse n'ont pu être que partiellement saisies.

L'individu était couché sur le dos, membres en extension, la tête tournée de trois quarts vers la droite. La main gauche passait sous l'os coxal du bassin. Les ossements étaient en bon état de conservation. Le miroir 1 était tenu dans la main droite et les « boutons » $\mathbf{2}$ placés par paires, entre les doigts et la base du miroir.

\section{Description anthropologique}

Anthropologie de terrain (observations d'après photographies) - Le sujet se présentait en décubitus dorsal, tête au N.-E., membres supérieurs en extension le long du corps avec les mains à côté du bassin et les membres inférieurs symétriquement en extension. Le crâne apparaissait par sa face antéro-supéro-latérale gauche, en connexion étroite avec la mandibule. Le thorax a subi une mise à plat partielle avec une petite conservation du volume costal, montrant une compression bilatérale. Les clavicules étaient légèrement verticalisées, mais les humérus ne montraient aucune marque de compression transversale. Les deux os coxaux étaient en position semi-fermée, le gauche étant même de chant, du fait de la disposition d'une offrande (miroir en bronze) qui provoquait un effet de paroi. Le membre inférieur droit présentait des connexions lâches au niveau de l'articulation coxo-fémorale et du genou. Le fémur témoignait d'une importante contrainte latérale, en se présentant sur sa face postéro-latérale alors que le tibia et la fibula étaient sur leur face latérale. Le membre inférieur gauche semble présenter des connexions strictes. Les deux pieds, assez bien conservés, étaient en position primaire avec de petites déconnexions métatarsiennes, les phalanges manquaient.

La majorité des connexions anatomiques étaient étroites, sauf pour le fémur droit dont la position pouvait être due à une contrainte, ce qui indique une décomposition en espace colmaté. Les effets de compression, à la fois importants et très localisés, sont difficilement interprétables : le port initial d'un linceul ou l'étroitesse d'une fosse aurait fatalement occasionné une compression au niveau des bras et avant-bras, ce qui n'est pas le cas. Il est en revanche probable que le fond de la fosse soit légèrement en cuvette : durant la décomposition, le thorax se serait affaissé dans cet espace vide, ainsi que les os coxaux, coincés dans cette petite dépression.

Anthropologie biologique - L'individu est sub-complet, mais l'état de conservation des ossements est très médiocre et ne permet que des observations très succinctes.

Le sujet est un adulte de sexe féminin. Le crâne comporte une suture métopique.

\section{Inventaire des objets}

1 - (= M 11) Miroir en bronze. Inv. FR 1.52. Pl. 20e

2 - (= D 5) Quatre « boutons » plano-convexes en os.

Inv. FR 1.23. Pl. 20f

\section{Datation, commentaire}

La situation stratigraphique de cette sépulture, sous le remblai US 2/501, au même niveau que SP 264, situe son installation autour du milieu du $\mathrm{IV}^{\mathrm{e}} \mathrm{s}$.

\section{SP 279}

Tombe à tuiles découverte par l'équipe française, les 7 et 11 septembre 2002 dans le secteur central, entre les points $G 3$ et G 4. Orientation N.-O. $\left(325^{\circ}\right)$. Niveau supérieur des tuiles 6,09 (Sud) à 5,96 (Nord), niveau supérieur du crâne et des pieds 5,64. Pl. 21

\section{Contexte stratigraphique}

La fosse était creusée dans le remblai US 2/501, apparaissant dès la surface de cette couche, sous l'US 1/101/117/194/500. Toutefois, du fait de sa profondeur relativement importante, elle entamait également des couches situées sous 1'US 2/501, en particulier l'US 10/527, qui a été identifiée comme un petit remblai de sable lié à SP 329.

\section{Description archéologique}

La sépulture était installée dans une fosse relativement profonde (plus de $50 \mathrm{~cm}$ ), plus large et de plan grossièrement ovale au niveau des tuiles de couverture, mais se rétrécissant et prenant une forme rectangulaire vers le fond (dimensions au niveau du squelette : 190 × $56 \mathrm{~cm}$ ).

L'individu se présentait couché sur le dos, membres en extension, la tête tournée de trois quarts vers la droite. Les deux mains passaient sous le bassin. À chaque extrémité de la fosse deux tuiles étaient plantées de chant et, à l'origine, trois tuiles placées en position horizontale servaient de couverture.

Toutefois, l'ensemble du dispositif de couverture semble avoir été perturbé : les tuiles étaient brisées, leurs fragments écartés de part et d'autre de la fosse ou effondrés à l'intérieur. Sur un fragment d'une des tuiles de couverture figure la marque estampée HГ, en écriture rétrograde (=TT 4). Après nettoyage, il s'est avéré qu'une partie des fragments manquait, ce qui peut expliquer la présence de quelques morceaux de tuiles (de toute évidence des rejets) dans la couche supérieure du DP 23 voisin qui appartient au même horizon stratigraphique et chronologique. Les raisons qui auraient provoqué cette perturbation du dispositif de couverture restent mystérieuses.

La découverte de deux tuiles qui étaient encore en place dans la fosse près de la tête et des pieds semble plaider en faveur de cette hypothèse, mais il est tout à fait possible également qu'il n'y en ait jamais eu plus et qu'on ait voulu faire l'économie de ce matériel.

En tout cas, il est certain que ce n'est qu'à un moment postérieur à la réouverture de la tombe que le squelette de SP 279, originellement déposé dans un espace vide, s'est trouvé recouvert d'un premier sédiment de terre (US 18).

Cette certitude vient en particulier du fait que le sédiment en question recouvrait le grand fragment d'une tuile de couverture qui était tombé directement sur le bras gauche et le thorax du défunt. De même, c'est sans doute au même moment, ou peu 
après, que le pot $\mathbf{2}$, trouvée au-dessus des pieds, ainsi qu'un des clous en fer 4, qui l'accompagnait, ont été posés contre la tuile S.-E. restée en place, à la surface de l'US 18 qui était déjà présente dans la tombe. L'autre clou 4 a été trouvé près de la tuile N.-O., près de la tête. La lampe 3 était à l'intérieur du pot, le lécythe $\mathbf{1}$ près du bras gauche.

\section{Description anthropologique}

Anthropologie de terrain (observations d'après photographies) - Le sujet se présentait en décubitus dorsal, tête au N.-O., membres supérieurs en extension le long du corps, avec les mains à côté des fémurs homolatéraux et les membres inférieurs symétriquement en extension. Le crâne apparaissait par sa face antéro-latérale gauche, en connexion étroite avec la mandibule. Le thorax a subi une mise à plat partielle avec conservation du volume costal, surtout à droite. Les clavicules étaient verticalisées et les humérus semblaient apparaître par leur face latérale. Le coude gauche était totalement déconnecté, l'humérus était tombé en fond de fosse, tandis que le radius et l'ulna étaient maintenus contre l'os coxal gauche. Une grande tuile était en partie effondrée sur le membre supérieur et l'hémithorax droit, attestant un espace vide. La ceinture pelvienne était fermée à semiouverte, en butée contre les os des avant-bras, eux-mêmes en butée contre les parois de l'étroite fosse. Le membre inférieur droit était en position primaire, avec une légère éversion du fémur. Le membre inférieur gauche avait en revanche connu des déplacements, avec le fémur, apparaissant par sa face médiale, déconnecté de l'acetabulum et la patella ayant chuté sur le côté avec une faible amplitude. Il n'est pas possible d'apprécier la position des pieds d'après photo, mais il semble que ceux-ci présentaient des déconnexions, un métatarsien ayant migré hors du volume initial du corps.

De nombreux déplacements osseux ou déconnexions articulaires attestaient une décomposition en espace vide : la fosse étroite pouvait à l'origine être intégralement recouverte de tuiles.

Anthropologie biologique - L'individu est complet et les os assez bien conservés. Il s'agit d'un adulte mature de sexe plutôt féminin. Les sutures crâniennes sont en effet en cours de synostose et la denture montre une usure assez importante. Cependant, aucune pathologie dégénérative de type arthrose n'est à noter. La stature estimée est de 161-164 cm. Longueurs maximales : fémur droit $432 \mathrm{~mm}$; humérus gauche $305 \mathrm{~mm}$; radius droit $230 \mathrm{~mm}$. L'état dentaire est assez délabré : usure très importante des premières et deuxièmes molaires, pertes dentaires avec résorption alvéolaire. Aucune carie n'est décelable, mais un dépôt de tartre ainsi que de la parodontose sont à noter. Une importante pathologie osseuse est présente sur le sacrum et les deux dernières vertèbres lombaires, il peut s'agir d'une maladie infectieuse. Les deux talus comportent un os trigone, ce qui constitue une variation anatomique.

\section{Inventaire des objets}

1 - (= CC 154) Lécythe de fabrication locale. Inv. FR 1.30. Pl. 21g
2 - (= CC 183) Pot à une anse de fabrication locale.

Inv. FR 1.4.

3 - Lampe, argile orangée, traces de feu sur le bec. Pied discoïdal, intérieur du fond pointu; réservoir profond, profil biconique arrondi, bord incurvé entouré d'une rainure profonde et de trois sillons étroits ; bec allongé. $\mathrm{Ht} 4,5 \mathrm{~cm}$, long. $9 \mathrm{~cm}$. Inv. FR 1.18. Pl. 21c-d

Type 25 A Prime de l'Agora d'Athènes: Howland 1958, p. 70-71, pl. 10 et 38 (daté entre la fin du deuxième quart du $\mathrm{IV}^{\mathrm{e}}$ et le deuxième quart du $\mathrm{III}^{\mathrm{e}} \mathrm{s}$.).

4 - (= M 43) Deux clous en fer. Inv. FR 1.5.2 et 1.5.4.

\section{Datation, commentaire}

Le lécythe et la lampe indiquent une installation à la toute fin du $\mathrm{IV}^{\mathrm{e}}$ ou au début du $\mathrm{III}^{\mathrm{e}}$ s., ce que confirme le contexte stratigraphique de la sépulture.

\section{SP 283}

Tombe à fosse trouvée par l'équipe française le 11 septembre 2002 dans le secteur Sud, entre les points G 3 et G 4. Orientation N.-E. $\left(60^{\circ}\right)$. Niveau au fond de la fosse 5,42 . Pl. 22a-c

\section{Contexte stratigraphique}

Les limites de la fosse n'ont pas pu être appréhendées avec certitude. Les ossements du défunt étaient pris pour l'essentiel dans une couche de terre de couleur brun clair, partiellement sableuse (US 19/129), mais les jambes (très perturbées) reposaient dans l'US 7/126 (poche de sable jaune). La sépulture et son marqueur avaient été installés au-dessus du mur MR 3, dont ils sont séparés par l'US 19/114/129 et l'US 115/120/130 (couche moins sableuse, plus dure que la précédente, avec cailloutis). À l'E./N.-E., cette couverture recouvrait partiellement la partie supérieure du dépôt DP 33.

\section{Description archéologique}

Une structure en forme de $\Pi$, constituée de trois assises de blocs de pierre plus ou moins grossièrement équarris, entourait la partie supérieure du corps jusqu'au bassin. Elle se prolongeait au S.-E. sous la forme d'un alignement à une assise. La découverte de la partie supérieure d'une amphore appartenant au dépôt DP 24, posée contre le bloc formant la deuxième assise du côté méridional de la structure, montre de façon incontestable que celle-ci était restée partiellement visible après la mise en place de la sépulture et avait servi à signaler son emplacement dans l'espace de la nécropole.

L'individu se présentait couché sur le dos, les bras étendus le long du corps. Le squelette conservait des traces significatives de perturbations qui ont dû intervenir dès l'Antiquité, probablement peu après la décomposition du corps. Des charbons isolés, de taille réduite, ont été trouvés dans la zone autour du crâne. Les fragments du lécythe $\mathbf{1}$ étaient placés près du genou gauche (col avec l'embouchure), du côté droit du bassin (fond) et des deux côtés du thorax (deux fragments de la panse), les figurines 2-5 près des pieds et le clou 6 derrière le crâne.

L'association avec le dépôt DP 24 est assurée. 


\section{Description anthropologique}

Anthropologie de terrain (observations d'après photographies) - Le sujet, un jeune enfant, se présentait en décubitus dorsal avec les membres inférieurs fléchis latéralement. Le crâne apparaissait par sa face antérieure et le squelette présentait de nombreuses déconnexions. Le mauvais état de conservation osseuse empêche des observations précises, il semblerait que la décomposition du corps se soit plutôt effectuée en espace vide, mais ceci reste discutable.

Anthropologie biologique - L'individu est complet mais en très mauvais état de conservation, limitant l'étude biologique. Il s'agit d'un immature d'environ 7 ans.

\section{Inventaire des objets}

1 - Quatre fragments d'un lécythe à vernis noir. Inv. FR 1.52. [Non disponible lors de l'étude]

2 - (= TC 9) Figurine de coq en terre cuite. Inv. FR 1.7.1. Pl. 22b

3 - (= TC 7) Figurine d'acteur comique en terre cuite.

Inv. PIN 3510 (FR 1.7.2). Pl. 22b

4 - (= TC 8$)$ Figurine de singe ou de personnage grotesque en terre cuite. Inv. PIN 3512 (FR 1.7.3). Pl. 22b

5 - (= TC 14) Base de figurine en terre cuite. Inv. FR 1.7.4. Pl. 22b

6 - (= M 44) Clou en fer. Inv. FR 1.5.6.

\section{Datation, commentaire}

La position de la sépulture sous le remblai US 2/501 et son association avec DP 24, pris dans cette même couche, orientent vers le début du troisième quart $\mathrm{du}^{\mathrm{IV}} \mathrm{IV}^{\mathrm{e}} \mathrm{s}$., probablement autour de 340 .

\section{SP 287}

Tombe à fosse trouvée par l'équipe française le 12 septembre 2002 dans le secteur central, entre les points G-H 3-4. Orientation S.-E. $\left(130^{\circ}\right)$. Niveau supérieur du crâne $5,59 \mathrm{~m}$. Pl. 22d-f

\section{Contexte stratigraphique}

La sépulture était installée dans une fosse assez étroite, dont les limites n'ont pu être définies avec certitude que des épaules au niveau des genoux. Le remplissage était constitué d'un sédiment sableux de couleur brun clair (US 21). La fosse était recouverte par le remblai US 2/501, qui n'était plus qu'une couche de faible épaisseur à cet endroit, puis, partiellement, par la couche pierreuse US 5/502. Elle avait été creusée pour l'essentiel dans une couche de terre légèrement sableuse, de couleur brun foncé et de consistance similaire à 1'US 2/501 (US 20/507/514/593), accumulée contre le tumulus de SP 343 lors de la construction de MR 5.

Au niveau du crâne (au S.-E.), elle entamait l'US 10/527, identifiée comme un remblai recouvrant SP 329; lors de son installation, elle a perturbé de même la tombe SP 326, découverte immédiatement au S.-O. et orientée au N.-E. (soit perpendiculairement à SP 287) : le crâne du squelette manquait. Ces remarques permettent clairement d'affirmer que SP 287 est postérieure à SP 326 et 329.

\section{Description archéologique}

De nombreuses inclusions de charbons ont été notées dans le remplissage de la fosse, ainsi que deux masses d'argile pure de couleur brune, près des épaules. Le lécythe $\mathbf{1}$ était placé sur l'os coxal droit.

\section{Description anthropologique}

Anthropologie de terrain (observations d'après photographies) - Le sujet se présentait en décubitus dorsal, tête au S.-E., membres supérieurs en extension le long du corps, avec les mains sur les fémurs homolatéraux et membres inférieurs symétriquement en extension. Le crâne apparaissait par sa face antéro-supérieure, en connexion étroite avec la mandibule. Le thorax a subi une mise à plat totale dans le volume initial du corps. Les clavicules étaient verticalisées et les humérus apparaissaient par leur face latérale, preuve d'une forte compression bilatérale. L'humérus gauche était totalement replié sur le thorax, la scapula apparaissant en face latéro-postérieure, en connexion avec l'avant-bras. Le coude droit était apparemment déconnecté, de même que les os de la main. La ceinture pelvienne était totalement fermée, montrant un fort effet de paroi. Le membre inférieur droit était en position éversée, avec la tête fémorale hors de l'acétabulum, mais le genou et la cheville en connexion étroite. Le membre inférieur gauche montrait une connexion lâche au niveau du genou, avec déplacement de la patella et un pied en position primaire.

Quelques déplacements osseux et/ou déconnexions sont attestés, mais ils sont de faible amplitude et peuvent être mis en relation avec les importantes compressions observées. La position en déséquilibre du crâne et la position primaire des pieds évoquent plutôt une décomposition en espace colmaté, peut-être dans un linceul qui expliquerait les déconnexions anatomiques.

Anthropologie biologique - Le sujet est sub-complet et l'état de conservation des ossements est moyen. Il s'agit d'un adulte jeune de sexe masculin. Certains os comportent en effet des liserés d'ossification mais les troisièmes molaires sont sorties, ce qui permet de proposer un âge compris entre 20 et 25 ans. Il est assez gracile, sa stature estimée est de $163 \mathrm{~cm}$ (radius droit $225 \mathrm{~mm}$ ). Les dents sont peu usées mais une carie est à noter sur la première molaire supérieure droite. Un important dépôt de tartre est présent ainsi que des traces de parodontose.

\section{Inventaire des objets}

1 - (= CP 28) Lécythe aryballisque à décor réticulé. Inv. FR 1.14. Pl. 22f

\section{Datation, commentaire}

La situation stratigraphique permet de situer cette sépulture vers le début du troisième quart $\mathrm{du} \mathrm{IV}^{\mathrm{e}} \mathrm{s}$. : elle est en tout cas postérieure à SP 326, dont elle perturbe le squelette, et à SP 329, dont elle entame le remblai. 


\section{SP 289}

Tombe à ciste découverte par l'équipe bulgare le 24 septembre 2002, en secteur Sud, entre les points E-F 2-3. Orientation N.-O. Niveau supérieur des murs de la ciste : 5,115,12. Niveau du crâne 4,74. Pl. 23

\section{Contexte stratigraphique}

La ciste était installée dans une fosse profonde, creusée à partir de la surface du remblai US 19/114/129, qui traversait en profondeur l'US 115/120/130. Elle atteignait le mur MR 2, dont une section a été alors démontée afin de permettre son installation. On note cependant un souci manifeste visant à reconstituer cet alignement, entre autres la partie S.-E., par la pose, immédiatement au N.-E. de la ciste, de plusieurs blocs de pierre.

\section{Description archéologique}

La ciste, qui n'avait pas de couverture, était remplie de terre, de cailloutis et de tessons appartenant à l'embouchure et à la panse d'un vase (Inv. PIN 3149), à une cruche locale (Inv. PIN 3150) et à des amphores. Les parois sont constituées de blocs de grès couverts, à l'intérieur, d'un enduit à base de sable et de calcaire. Sur le mur N.-E. sont incisées des lettres (?), des symboles arrondis, des figures (chien, oiseau ?). Dimensions : $193 \times 70 \times 61 \mathrm{~cm}$. Le terrain sableux naturel sert de sol. Le pot 1 était situé près du côté droit du crâne, le miroir en bronze $\mathbf{2}$ sous le crâne et l'aiguille $\mathbf{3}$ sous le miroir. Au-dessus de l'épaule droite se trouvaient les fragments de la cruche $\mathbf{4}$, près de l'épaule gauche la cruche 5 locale, sur le coude gauche les objets en os 6-7, l'unguentarium 8 entre le bassin et les côtes et, à côté du poignet gauche, le clou en fer $\mathbf{9}$.

\section{Description anthropologique}

Le squelette était en décubitus dorsal, le crâne orienté au N.-E. La colonne vertébrale était recourbée en forme de S. Les pieds étaient posés l'un sur l'autre.

Le sujet est un adulte de sexe féminin, âgé d'au moins 50 ans.

\section{Inventaire des objets}

1 - (= CC 204) Pot à une anse de fabrication locale, miniature. Inv. PIN 3151.

2 - (= M 12) Miroir en bronze. Inv. PIN 3152. Pl. 23d

3 - (= M 25) Aiguille en bronze. Inv. PIN 3153.

4 - Partie inférieure d'une cruche, argile rouge. Inv. PIN 3154.

5 - Cruche de fabrication locale. Inv. PIN 3155.

Pl. 23e (en haut à dr.)

6 - (= D 7) Objet en os (quenouille), fragmentaire. Long. $16,4 \mathrm{~cm}$, diam. max. 0,6 cm. Inv. PIN 3156.

7 - (= D 8) Objet en os, probablement un fuseau. Long. 2,8 cm, diam. de la tête $1,4 \mathrm{~cm}$. Inv. PIN 3157. Pl. 23e (en bas)

8 - (= CC 159) Unguentarium de fabrication locale.

Inv. PIN 3158. Pl. 23e (en haut à g.)

9 - (= M 45) Clou en fer. Inv. PIN 3159.

\section{Datation, commentaire}

L'unguentarium oriente vers la toute fin du $\mathrm{IV}^{\mathrm{e}}$ ou le début $\mathrm{du}$ III $^{\mathrm{e}} \mathrm{s}$.

\section{SP 291}

Tombe à ciste découverte par l'équipe bulgare le 27 septembre 2002 dans le secteur Sud, au N.-O. du point F 2. Orientation N.-E. Niveau supérieur des parois de la ciste, de 4,73 à 4,80; à la base de la ciste 4,02. Pl. 24

\section{Contexte stratigraphique}

La ciste était installée dans une fosse qui entamait depuis l'US 108 l'ensemble des couches jusqu'à la dune US 218/627.

\section{Description archéologique}

La sépulture était recouverte par un remblai tumulaire de sable (US 105), conservé sur une hauteur maximale de $58 \mathrm{~cm}$. Le scellage n'a pas été observé. La ciste était couverte par quatre dalles, de dimensions suivantes (à partir du S.-O.) : A - 114 x 51 x $25 \mathrm{~cm}$; B - 117 x 51 x $25 \mathrm{~cm}$; C - 110 x 57 x 32 $\mathrm{cm}$; D -117 × 52 × $24 \mathrm{~cm}$. Sur la dalle B des pierres, disposées en cercle, entouraient le dépôt DP 2. Près de l'angle N.-O. des dalles de couverture a été trouvé le DP 3. Dimensions de l'intérieur de la ciste : 196 x 66/67 cm, profondeur environ $80 \mathrm{~cm}$. Elle est composée de six plaques en calcaire (deux sur les longs côtés), leurs dimensions sont les suivantes : long. 80 à $118 \mathrm{~cm}$; ép. 15 à $24 \mathrm{~cm}$; haut. 73 à $81 \mathrm{~cm}$. Près du coude gauche de l'individu avait été placé le lécythe $\mathbf{1}$, près du coude droit le lécythe $\mathbf{2}$ et près du côté droit du bassin le strigile $\mathbf{3}$. Le terrain sableux naturel sert de sol.

\section{L'association avec les dépôts DP 2 et DP 3 est assurée.}

\section{Description anthropologique}

Le squelette était en décubitus dorsal, le crâne orienté au N.-E. Les os sont très dégradés.

Le sujet est un adulte de sexe masculin, âgé de 18 à 35 ans (pour les pathologies osseuses, voir ci-dessous le diagnostic d'A. Keenleyside).

\section{Inventaire des objets}

1 - (= CP 16) Lécythe aryballisque à figures rouges. Inv. PIN 3172. Pl. 24e (à g.)

2 - (= CP 17) Lécythe aryballisque à figures rouges.

Inv. PIN 3173. Pl. 24e (à dr.)

3 - (= M 17) Strigile en bronze. Inv. PIN 3174.

\section{Datation, commentaire}

Les deux lécythes à figures rouges ne fournissent pas de date précise, mais leurs proportions et leur panse arrondie sont caractéristiques des exemplaires anciens, avant le milieu du $\mathrm{IV}^{\mathrm{e}} \mathrm{s}$. Le dépôt de céramique sur les dalles de couverture est plus important pour la chronologie. Il contient en effet une coupe-skyphos à vernis noir qui peut être datée du début du IV $^{\text {e }}$ s. Cette date est confirmée par le contexte stratigraphique de la tombe, dont la chronologie est relativement bien calée à la fois par le mur MR 2, qui repose sur un remblai (US 170) apposé contre la face orientale de sa couverture tumulaire, ainsi que par les couches supérieures, en particulier l'US 102/138 dans laquelle est installée SP 244. Cette position permet de dater SP 291 dans les années 390-380. 


\section{SP 296}

Tombe à ciste découverte par l'équipe bulgare le 3 octobre 2002 dans le secteur Sud, entre les points E-F 2-3. Orientation à l'Est. Niveau du fond de la ciste 4,90 à 4,94. Pl. 25

\section{Contexte stratigraphique}

La fosse était creusée à l'intérieur même du passage aménagé au cours de la phase 3 entre le mur MR 1 et l'enclos voisin au S.-E. En raison de sa situation périphérique, son contexte stratigraphique n'est pas clair, mais il semble qu'elle se soit installée à partir de la surface d'un des remblais recouvrant le mur MR 1, peut-être l'US 19/114/129.

\section{Description archéologique}

La tombe occupe une petite fosse (niveau 4,90 à 4,94), accolée contre la face extérieure du mur MR 2 dont les parois $\mathrm{N}$. et $\mathrm{S}$. sont doublées de trois assises de moellons de granit assez grossiers qui forment avec le mur MR 2 un caisson sommaire, sans couverture. Dimensions de l'intérieur de la ciste 90 × $32 \mathrm{~cm}$. Le crâne est orienté vers l'Est. Dans le comblement, au-dessus du genou gauche se trouvait le clou $\mathbf{1}$, à côté du crâne l'aiguille $\mathbf{2}$, au-dessus de la cheville gauche le bracelet 3 .

\section{Description anthropologique}

Inhumation d'enfant : sont conservées des parties du crâne, des côtes et des jambes.

\section{Inventaire des objets}

1 - (= M 46) Clou en fer. Inv. PIN 3229.

2 - (= M 26) Aiguille en bronze. Inv. PIN 3230.

3 - (= M 2) Bracelet en bronze. Inv. PIN 3231. PI. 25c

\section{Datation, commentaire}

La tombe ne contient pas de matériel permettant de la dater, seules sa position stratigraphique et la topographie générale du secteur donnent des indications.

D'une part, elle est accolée au mur MR 2, qui est lié à SP 291 (voir plus haut), à un moment où celui-ci était déjà recouvert par l'US 19/114/129, ce qui indique un terminus postérieur au second quart du $\mathrm{IV}^{\mathrm{e}} \mathrm{S}$. D'autre part, la proximité de SP 297 peut indiquer avec réserve une date plus tardive, contemporaine de la phase 4 .

\section{SP 297}

Tombe à tuiles découverte par l'équipe bulgare le 4 octobre 2002 dans le secteur Sud, dans la zone des points E-F 2-3. Orientation S.-E. Niveau du crâne 4,36, des jambes 4,37. Pl. 26

\section{Contexte stratigraphique}

La tombe, située immédiatement à l'Est de SP 296, présentait une situation stratigraphique très proche. Son creusement, plus profond, a perturbé la partie Sud du foyer F2. Le fond de la tombe $(4,36-4,37 \mathrm{~m})$ était situé 50 à $55 \mathrm{~cm}$ plus bas que celui de SP 296.

\section{Description archéologique}

La couverture était constituée de tuiles formant une double pente, l'une d'entre elles porte un timbre (Inv. PIN 3239). À l'extrémité Nord de la tombe se dressait une plaque de pierre en position verticale. La seule offrande est la pyxis ou lébès gamikos miniature $\mathbf{1}$.

\section{Description anthropologique}

Inhumation d'enfant.

\section{Inventaire des objets}

1 - (= CP 45) Pyxis ou lébès gamikos miniature.

Inv. PIN 3240. PI. 26c

\section{Datation, commentaire}

Le vase oriente vers le début du $\mathrm{III}^{\mathrm{e}} \mathrm{s}$.

\section{SP 300}

Tombe à ciste découverte par l'équipe bulgare le 5 octobre 2003 dans le secteur Sud, au Nord du point G 2. Orientation S.-E. Niveau supérieur des parois 5,26 à 5,31. Niveau du crâne 3,91, des jambes 3,98. Pl. 27a-c

\section{Contexte stratigraphique et description archéologique}

Un petit tertre de sable (US 106/144/608 et 107 ; hauteur conservée : $75 \mathrm{~cm}$, alt. max. 5,37), surmonté d'un scellage de terre (US 110/118/119), recouvrait la sépulture et venait s'appuyer sur la couverture de SP 325.

La ciste SP 300 (dimensions 210 x $70 \mathrm{~cm}$ ) était installée dans une fosse creusée de l'US 108 jusqu'aux dunes US 617/619 et US 218/627. Ses dalles en grès dunaire avaient été retravaillées sur place comme en témoignent les nombreux éclats qui parsemaient l'US 108. La ciste était couverte par quatre dalles en calcaire (longueur totale $217 \mathrm{~cm}$ ), au-dessus desquelles se trouvait une cruche de fabrique locale (Inv. PIN 3256a). Dimensions des dalles: A - (N.-O.) 106 x 58 x $38 \mathrm{~cm}$; B - 122 x 43 x $41 \mathrm{~cm}$; C - 116 x 46 x $30 \mathrm{~cm}$; D - 113 x 59 x $32 \mathrm{~cm}$. Le long côté N.-E. était constitué de deux assises de dalles, la première assise était faite de trois blocs, la deuxième d'un seul bloc entier. Une seule dalle, de 100 × 67 x $20 \mathrm{~cm}$, formait le petit côté S.-E. Le long côté S.-O. était constitué de deux assises de trois dalles. Le crâne était orienté au S.-E. Le strigile 1 était placé sous la mâchoire.

\section{Description anthropologique}

Le squelette était en position allongée, sur le dos, tourné un peu vers la droite. Le bras gauche était fléchi. Les os de la partie supérieure du squelette étaient en déconnexion.

Le sexe de l'individu, un adulte, n'a pas pu être déterminé.

\section{Inventaire des objets}

1 - (= M 18) Strigile fragmentaire en bronze. Inv. PIN 3271. Pl. 27c 


\section{Datation, commentaire}

L'enchaînement stratigraphique des différents tertres, observé dans cet espace, place la construction de SP 300 au cours de la phase 2, entre la mise en place de SP 325 et celle plus tardive de SP 291. Elle permet de dater cette sépulture vers 390-380.

\section{SP 303}

Tombe à fosse découverte par l'équipe bulgare le 11 octobre 2002 dans le secteur Sud, entre les points G 1 et G 2. Orientation à l'Est. Niveau du crâne 4,88, des pieds 4,80. Pl. 27d

\section{Contexte stratigraphique et description archéologique}

La fosse, sans limites claires, était creusée dans la dune US 617/619. La figurine $\mathbf{1}$ et l'anse de lécythe $\mathbf{3}$ se trouvaient au niveau de l'épaule droite, l'autre figurine $\mathbf{2}$ au niveau de l'épaule gauche. Association certaine avec le dépôt DP 6 : l'anse 3 recolle avec le lécythe du dépôt.

\section{Description anthropologique}

Enfant en bas-âge, allongé sur le dos. Le crâne et le bassin sont mal conservés, les pieds et les mains manquent. Les membres inférieurs sont en déconnection, fortement éloignés les uns des autres au niveau des articulations.

\section{Inventaire des objets}

1 - (= TC 15) Figurine de Satyre en terre cuite. Inv. PIN 3355.

2 - Figurine en terre cuite très mal cuite, type non identifié.

3 - Anse de lécythe.

\section{Datation, commentaire}

Le contexte stratigraphique, tout comme l'association avec le DP 6, oriente vers le début du IV e $\mathrm{s}$.

\section{SP 313}

Tombe à fosse découverte par l'équipe bulgare le 11 août 2003 dans le secteur Sud, entre les points G 1 et G 2. Orientation N.-E. Niveau au fond de la fosse 1,64. Pl. 28

\section{Contexte stratigraphique}

La fosse (dimensions 192/200 x 100/120 x $117 \mathrm{~cm}$ ) était creusée dans le substrat gris argileux (US 641), puis remblayée par du sable. Elle était recouverte par la dune US 617/619 (niveau supérieur 3,68 à 3,99 m).

\section{Description archéologique}

À $45 \mathrm{~cm}$ du haut de comblement de la fosse ont été trouvées des traces brunâtres dans le sable, correspondant aux restes d'un cercueil légèrement décalé vers la partie Ouest de la fosse. On distinguait clairement le couvercle, constitué de trois planches longitudinales fixées avec un clou en fer à chaque angle; au milieu de la planche centrale se trouvait un autre clou en fer; les planches étaient disjointes. Dimensions des traces du couvercle : long. $160 \mathrm{~cm}$, larg. $60 \mathrm{~cm}$. L'œnochoé 1 était placée au-dessus du crâne, les coupes $\mathbf{2}$ et $\mathbf{3}$ près du bras droit ; 18 astragales (dont quatre retouchés) se trouvaient sur la main droite, 38 autres près de la main gauche et 80 à côté du pied droit (dont 10 retouchés, l'un contenant du plomb). Le strigile 5 était situé au-dessus du pied droit. Dans la partie supérieure du comblement se trouvait la petite coupe à vernis noir 7. Le reste des offrandes avait été déposé dans le cercueil.

\section{Description anthropologique}

L'individu était un enfant de 6 à 8 ans, en position allongée sur le dos, les membres en extension. Le crâne était orienté vers le S.-E., incliné à gauche; il présentait des cribra orbitalia. La colonne vertébrale était recourbée en S. Les genoux étaient accolés.

\section{Inventaire des objets}

1 - (= CC 1) Enochoé de fabrication locale. Inv. PIN 3601.

2 - (= VN 12) Coupe à vernis noir. Inv. PIN 3602.

3 - (= VN 13) Coupe à vernis noir. Inv. PIN 3603.

4 - (= D 21) 136 astragales. Inv. PIN 3604.

5 - (= M 19) Strigile en bronze. Inv. PIN 3605.

6 - (= M 47) 13 clous en fer. Inv. PIN 3606.

7 - Petite coupe à vernis noir. Inv. PIN 3607.

\section{Datation, commentaire}

C'est une des tombes les plus anciennes dans le secteur étudié, dont la mise en place précède l'ensablement du site à la fin du $\mathrm{V}^{\mathrm{e}}$ s. Les deux coupes sans tige $\mathbf{2}$ et $\mathbf{3}$ orientent vers une date autour de 430-420.

\section{SP 315}

Tombe à fosse découverte par l'équipe bulgare le 12 août 2003 dans le secteur Nord, entre les points I et J 6. Orientation N.-O. Niveau du fond 6,01. Pl. 29a-b

\section{Contexte stratigraphique}

La fosse était creusée dans le remblai de terre (US 655). La tombe empiétait sur le dépôt de céramique DP 9.

\section{Description archéologique}

Les contours de la fosse n'ont pas été repérés. À côté des pieds, une pierre semblait marquer la limite S.-E. On a constaté la présence de petits cailloux sur et sous le sujet. À droite du crâne a été découvert l'objet en métal 1, à droite du fémur droit l'objet en bronze 2. Des charbons de bois se trouvaient dans la zone des côtes.

\section{Description anthropologique}

Le corps était posé sur le dos, les membres étendus (le poignet du bras droit placé sur le fémur droit).

Le sexe de l'individu, un adulte, n'a pas pu être déterminé.

\section{Inventaire des objets}

1 - (= M 67) Objet en métal (élément de fuseau).

Inv. PIN 3622. 
2 - (= M 66) Objet en bronze (crochet). Inv. PIN 3623. Pl. 29b

\section{Datation, commentaire}

Le creusement de la sépulture dans l'US 655, qui représente dans ce secteur le dernier horizon d'occupation du site, oriente vers une installation au cours de la phase 4 , soit au cours de la première moitié du $\mathrm{III}^{\mathrm{e}} \mathrm{s}$.

\section{SP 320}

Tombe à fosse découverte par l'équipe bulgare le 19 août 2003 dans le secteur Nord, entre les points I 6 et J 6. Orientation S.-E. Niveau 5,68 m. Pl. 29c-e

\section{Contexte stratigraphique}

La fosse était installée dans le sable US 652. Ses contours et le niveau de creusement n'ont pas pu être appréhendés.

\section{Description archéologique}

Le lécythe 1 était situé près du côté droit du crâne, la terre cuite 2 , très fragmentaire, du côté droit de la poitrine et l'aiguille $\mathbf{3}$ sous l'épaule droite. Au-dessous du crâne a été trouvée la boucle d'oreille 4 .

\section{Description anthropologique}

Le sujet est un enfant entre 5 et 7 ans. Le squelette était allongé sur le dos, membres en extension, le crâne orienté vers l'Est: tourné vers l'épaule gauche, il est écrasé ; manquent la main droite, les côtes du côté droit, une partie du bassin, le fémur droit et les pieds. Effet de paroi du côté gauche. Stature restituée environ $122 \mathrm{~cm}$. La découverte d'une boucle d'oreille en place incite à penser que l'enfant est une fille.

\section{Inventaire des objets}

1 - (= CP 20) Lécythe aryballisque à figures rouges. Inv. PIN 3698. PI. 29e

2 - (= TC 16) Figurine en terre cuite : personnage debout. Inv. PIN 3699.

3 - (= M 27) Aiguille en bronze. Inv. PIN 3700.

4 - (= M 3) Boucle d'oreille en argent, fragmentaire. Inv. PIN 3701

\section{Datation, commentaire}

L'installation de la sépulture dans le sable de l'US 652, dont la mise en place est datée du début du second quart du IV e $\mathrm{s}$., nous fournit un terminus post quem. Le lécythe $\mathbf{1}$, décoré d'une simple palmette, nous permet de rattacher cette tombe à la phase 3 .

\section{SP 321}

Tombe à fosse découverte par l'équipe bulgare le 19 août 2003 dans le secteur Nord, entre les points I 5 et I 6. Orientation à l'Est. Niveau 4,05. Pl. 30a-b

\section{Contexte stratigraphique et description archéologique}

La fosse, dont les contours n'ont pas été repérés avec précision, était creusée dans le remblai tumulaire (US 649) qui recouvrait la tombe SP 336 ; SP 322, découverte à un niveau inférieur, a visiblement détruit lors de son installation la partie Ouest de SP 321.

\section{Description anthropologique}

Le sujet est un adulte de sexe féminin, âgé de 30 à 35 ans. Décomposition en espace colmaté.

Le squelette, en position allongée sur le dos, membres en extension, n'est conservé que jusqu'au bassin (les bras jusqu'aux coudes); la partie inférieure a été probablement détruite lors de la construction de la tombe 322. Stature environ $145 \mathrm{~cm}$. Le crâne est orienté vers l'Est, incliné à droite ; il présentait des cribra orbitalia.

Inventaire des objets : néant

\section{Datation, commentaire}

L'installation de la sépulture dans le remblai de SP 336, tout comme son recoupement par SP 322, elle-même datée par son mobilier vers le milieu IV ${ }^{\text {e }}$ s., permet de situer la mise en place de SP 321 dans la phase 3 , au cours du second quart de ce siècle.

\section{SP 322}

Tombe à fosse découverte par l'équipe bulgare le 19 août 2003 dans le secteur Nord, entre les points I 5 et I 6. Orientation N.-E. Niveau 4,08. Pl. 30a-c

\section{Contexte stratigraphique}

La fosse présentait une situation stratigraphique identique à celle de SP 321, dont elle a entraîné la destruction partielle.

\section{Description archéologique}

Les contours de la fosse n'étaient pas visibles. Les forces en fer 1, sur lesquelles était posée l'écaille de coquillage $\mathbf{6}$, étaient situées près du côté droit du crâne. Le lécythe $\mathbf{2}$ se trouvait au-dessus de la tête, le guttus 3 à $20 \mathrm{~cm}$ du fémur droit ; autour de lui trois astragales, un autre à côté de la jambe (5). L'œnochoé 4 était placée à $40 \mathrm{~cm}$ du fémur droit.

\section{Description anthropologique}

Le squelette était allongé sur le dos, membres en extension. Le crâne était orienté vers le N.-E. La main gauche était placée sur le coude. Le sujet est un adulte de sexe indéterminé.

\section{Inventaire des objets}

1 - (= M 61) Forces (ciseaux) en fer. Inv. PIN 3702.

2 - (= CP 29) Lécythe à décor réticulé. Inv. PIN 3703.

3 - (= VN 109a) Guttus à vernis noir. Inv. PIN 3704.

Pl. 30c (à g.)

4 - (= VN 3) Petite œnochoé à vernis noir. Inv. PIN 3706.

Pl. 30c (à dr.)

5 - (= D 16) Quatre astragales. Inv. PIN 3705.

6 - Fragment de coquillage (moule). 


\section{Datation, commentaire}

Le matériel et le contexte stratigraphique indiquent une date autour du milieu du IV ${ }^{\mathrm{e}} \mathrm{s}$.

\section{SP 324}

Tombe à fosse découverte par l'équipe bulgare le 20 août 2003 dans le secteur Nord, à proximité immédiate du point I 5. Orientation S.-E. Pl. 30d-e

\section{Contexte stratigraphique et description archéologique}

La fosse était située dans les remblais tumulaires US 648 et 649 recouvrant les tombes SP 334 et 336. Ses contours n'étaient pas visibles. À $20 \mathrm{~cm}$ à peu près au-dessus des genoux du squelette a été découverte l'urne de la tombe à crémation SP 323. Aucune offrande n'était associée.

Association possible avec le dépôt DP 17.

\section{Description anthropologique}

Le squelette était allongé sur le dos, membres en extension. Le crâne était tourné à droite. L'individu était un adulte de sexe plutôt masculin, âgé de 36 à 50 ans (pour ses pathologies osseuses, voir ci-dessous le diagnostic d'A. Keenleyside).

Inventaire des objets : néant

\section{Datation, commentaire}

La chronologie est déterminée, dans le cadre d'une fourchette large, par la position de la sépulture à la périphérie des remblais tumulaires US 648 et 649, datés du premier quart du IV ${ }^{\text {e }}$ s., et par la mise en place de SP 323 durant le premier quart du $\mathrm{III}^{\mathrm{e}} \mathrm{s}$. au-dessus des genoux. L'installation peut être située avec réserve au cours de la phase 3.

\section{SP 325}

Tombe à fosse découverte par l'équipe bulgare le 22 août 2003 dans le secteur Sud, entre les points G-H 2-3, à environ $1 \mathrm{~m}$ sous le niveau de la tombe SP 300. Orientation S.-E. Pl. 31a-c

\section{Contexte stratigraphique et description archéologique}

La sépulture était recouverte d'un tertre de sable (US 615), lui-même scellé par une couche de terre (US 614).

La fosse, dont les contours n'ont pu être saisis avec précision, était creusée dans la dune US 617/619. Un alignement de pierres était placé des deux côtés des jambes du squelette. Un second a été trouvé $20 \mathrm{~cm}$ au-dessus du crâne, du côté droit.

Un mur de pierres semi-circulaire, postérieur à la sépulture, était disposé au Sud de la fosse (niveaux entre 4,91 et 4,15). Il présentait une hauteur de 40 à $50 \mathrm{~cm}$ à l'assise supérieure. L'ordonnance des pierres était perturbée, en raison sans doute de l'affaissement du terrain vers le S.-O. (le squelette accuse un même déplacement).

Le bolsal à vernis noir $\mathbf{1}$ était placé sous la pierre située à côté du tibia gauche. Le fragment de coupe à vernis noir 2 se trouvait entre les genoux, le fond de plat à poisson $\mathbf{3}$ entre les pierres.

\section{Description anthropologique}

L'individu est un adulte féminin, âgé de 36 à 50 ans, d'une stature de 157-159 cm (pour les pathologies osseuses, voir ci-dessous le diagnostic d'A. Keenleyside).

Le squelette était allongé sur le dos, la tête orientée vers l'Est. Le crâne est écrasé, tourné vers l'épaule gauche. Le squelette était très fortement courbé et affaissé vers la gauche. L'os de l'épaule droite était déplacé au-dessus de la colonne vertébrale, recourbée en $\mathrm{S}$; le bras droit était replié sur le bassin, le bras gauche étendu.

\section{Inventaire des objets}

1 - (= VN 20) Bolsal à vernis noir. Inv. PIN 3723. PI. 31c

2 - Fragment de coupe à vernis noir.

3 - Fond de plat à poisson, production locale.

\section{Datation, commentaire}

Le seul récipient qui appartient avec certitude à la tombe est le bolsal 1 qui, comme le contexte stratigraphique, indique une date au début du IV e s., vers 390-380.

\section{SP 326}

Tombe à fosse découverte par l'équipe française le 22 août 2003 dans le secteur central, entre les points G-H 3-4. Orientation N.-E. Niveau au fond de la fosse 5,49, sur le thorax 5,54. Pl. 31d-f

\section{Contexte stratigraphique}

Cette sépulture était installée dans une fosse creusée dans l'US 20/507/514/593, qui représentait le dernier élément d'un système de remblai couvrant le tumulus érigé sur SP 343. La fosse était recouverte par le remblai US 2/501. Le comblement était constitué de l'US 510 (terre sableuse assez homogène de couleur brun clair, comprenant quelques inclusions de coquillages).

Association probable avec le dépôt DP 25.

\section{Description archéologique}

La fosse, de forme oblongue (dimensions: long. cons. $180 \mathrm{~cm}$, larg. moyenne $50 \mathrm{~cm}$, ht max. cons. $7 \mathrm{~cm}$ ), a été détruite dans sa partie supérieure par le creusement de SP 287, qui a coupé le squelette à la base du crâne (non retrouvé). Ses parois sont verticales et le fond relativement plat, avec une légère déclivité vers l'Ouest (écart de $5 \mathrm{~cm}$ ). Deux blocs se trouvaient dans la partie inférieure de la fosse, mais il est difficile de les rattacher à un éventuel aménagement de la sépulture, puisque les limites de creusement n'étaient pas très nettes dans cette zone.

L'individu se présente en décubitus dorsal. Le lécythe $\mathbf{1}$ était placé contre la main droite, col brisé, et trois moules complètes (2), associées à un ossement animal, étaient posées 
sur le genou gauche. Il s'agit sans doute d'une offrande alimentaire, puisque les moules sont entières et posées directement sur les ossements de l'individu (genou gauche). Un fragment de panse d'amphore (3) était également présent contre le pied droit.

\section{Description anthropologique}

Anthropologie de terrain - Le crâne manque. Le rachis thoracique présentait des déconnexions ou des rotations par blocs de vertèbres : T6-T7 et T11-T12 se sont affaissées vers l'avant et latéralement, suivant le pendage du fond de fosse. La mise à plat des côtes est complète et les connexions thoraciques conservées sont strictes. Les bras étaient en adduction et les avant-bras placés symétriquement le long du corps, le gauche en pronation. La main gauche était située sous le bassin, la droite à côté du bassin. La clavicule gauche n'était pas verticalisée, tandis que l'humérus correspondant apparaissait par sa face latérale. Un effet de paroi était nettement sensible sur le côté gauche de l'individu. L'humérus droit apparaissait par sa face antérieure et toutes les connexions du membre supérieur étaient strictes, à l'inverse du gauche dont le coude était déconnecté. Il est possible que cette rupture soit due à la position contractée du membre, passant sous l'os coxal correspondant. La ceinture pelvienne était semi-ouverte et les connexions coxo-fémorales étaient étroites, avec toutefois une légère rotation latérale des fémurs. Tous deux apparaissaient par leur face antéro-médiale et les tibias-fibulas par leur face médiale. Les genoux et les chevilles étaient totalement déconnectés, avec un écartement bilatéral de 2 à $3 \mathrm{~cm}$. Les deux pieds, qui avaient subi une rotation latérale, étaient en parfaite connexion anatomique.

Toutes ces observations permettent de conclure à une décomposition en espace colmaté, avec un effet de paroi sur le côté gauche, sans doute dû à l'étroitesse de la fosse. La totale déconnexion des genoux et des chevilles est difficilement explicable, car ces articulations comptent parmi les plus robustes de l'organisme et il ne semble pas qu'un pendage $\mathrm{du}$ fond de la fosse puisse venir justifier ce phénomène de glissement.

L'éventuelle présence initiale de masses lourdes en matériau périssable (rappelons qu'une offrande alimentaire constituée de restes fauniques est placée sur le genou gauche) sur ces régions anatomiques semble être l'explication la plus plausible.

Anthropologie biologique - L'individu est incomplet : le crâne, la mandibule, la clavicule et la scapula droite, l'extrémité proximale de l'humérus droit ainsi que les 4 premières côtes de l'hémithorax droit et les vertèbres de $\mathrm{C} 1$ à $\mathrm{T} 4$ sont absents. L'état de conservation des ossements est moyen.

Le sujet est un adulte de sexe féminin, sa stature estimée est de 152-154 cm. Longueurs maximales : fémur gauche : $405 \mathrm{~mm}$; humérus gauche : $280 \mathrm{~mm}$; tibia droit : $318 \mathrm{~mm}$; radius droit : $206 \mathrm{~mm}$.

\section{Inventaire des objets}

1 - (= CP 30) Lécythe aryballisque à décor réticulé. Inv. PIN 3641 (FR 2.20). Pl. 31e (en haut)
2 - Trois moules et un os d'animal. Inv. FR 2.34.

Pl. 31e (en bas)

3 - Amphore de provenance indéterminée, argile orangée : fragment de la partie inférieure de la panse découvert près du pied droit. Long. du fragment 17,2 cm. Inv. PIN 2.33.

\section{Datation, commentaire}

Le contexte stratigraphique et l'association avec le dépôt DP 25 indiquent une date dans le second quart du IV ${ }^{\mathrm{e}} \mathrm{s}$.

\section{SP 327}

Tombe à fosse découverte par l'équipe bulgare le 25 août 2003 dans le secteur Nord, entre les points I-J 5-6. Orientation N.-E. Niveau 5,46. Pl. 32

\section{Contexte stratigraphique et description archéologique}

La fosse, dont les contours n'ont pas pu être repérés, était creusée le remblai de sable pur (US 652). Le squelette reposait directement sur la dernière assise du MR 6. La figurine en terre cuite 1 était située à droite du crâne, la 2 à l'emplacement du bras droit, la $\mathbf{3}$ sous la tête de la $\mathbf{2}$, la $\mathbf{4}$ entre les fémurs, l'aiguille en bronze $\mathbf{1 3}$ sur les tibias, la coupelle $\mathbf{8}$ à côté du tibia gauche, l'œnochoé $\mathbf{9}$ à côté de la coupelle, la figurine en terre cuite $\mathbf{5}$ à côté du fémur droit, le lécythe $\mathbf{1 0}$ à côté du bras gauche, l'embouchure du lécythe $\mathbf{1 1}$ à côté de l'œnochoé 9, les figurines en terre cuite $\mathbf{6}$ et $\mathbf{7}$ sur l'épaule gauche, le pendentif en verre 12 sous la figurine 7.

L'association avec le dépôt DP 16 est assurée.

\section{Description anthropologique}

L'individu était un jeune enfant dont le squelette est très mal conservé.

\section{Inventaire des objets}

1 - (= TC 11) Masque féminin en terre cuite. Inv. PIN 3725. Pl. 32b

2 - (= TC 3) Figurine en terre cuite : femme assise sur un trône. Inv. PIN 3726. Pl. 32b

3 - (= TC 4) Figurine en terre cuite: jeune homme assis (Eros ?). Inv. PIN 3727. Pl. 32b

4 - Figurine en terre cuite. Personnage assis sur un trône.

Inv. PIN 3728. [Non disponible au moment de l'étude]

5 - Figurine en terre cuite: Eros. Inv. PIN 3732. [Non disponible au moment de l'étude]

6 - (= TC 5) Figurine en terre cuite de garçon assis.

Inv. PIN 3735. Pl. 32b

7 - (= TC 6) Figurine en terre cuite de garçon assis.

Inv. PIN 3736. Pl. 32b

8 - (= VN 100) Salière à vernis noir. Inv. PIN 3730. Pl. 32d (au centre)

9 - (= TC 20) Enochoé plastique à tête féminine.

Inv. PIN 3731. Pl. 32d (à g.)

10 - (= CP 31) Lécythe aryballisque à décor réticulé.

Inv. PIN 3733. Pl. 32c

11 - (= CP 32) Lécythe à décor réticulé. Inv. PIN 3734.

Pl. 32d (à dr.) 
12 - (= D 1) Pendentif en verre polychrome : tête masculine barbue. Inv. N 3737. Pl. 32d (en haut.)

13 - (= M 28) Aiguille en bronze. Inv. PIN 3729.

\section{Datation, commentaire}

Le matériel, la situation stratigraphique et l'association avec le dépôt DP 16 permettent de dater cette sépulture vers $370-350$.

\section{SP 328}

Tombe à ciste découverte par l'équipe française le 28 août 2003 dans le secteur Est, entre les points F-G 3-4. Orientation S.-E. $\left(130^{\circ}\right)$. Niveaux sur les dalles de couverture 5,40 à 5,48; au fond, entre 4,03 et 4,13; sur le crâne 4,23, sur les pieds 4,30 . Pl. 33-34

\section{Contexte stratigraphique}

Les travaux préparatoires à l'installation de la ciste ont commencé à partir de la surface des remblais de terre US 143/537/598/634 et US 517/524. Du fait de l'irrégularité de cette surface d'origine et des pendages importants qu'elle suivait vers le S.-E. et le N.-E., un premier décaissement a été réalisé à ses abords S.-O., N.-O. et N.-E. Ce n'est qu'ensuite qu'on a entrepris le creusement de la fosse proprement dite (US 556). Celle-ci était fort étroite (dépassant à peine la largeur du coffrage) et profonde (plus de $1 \mathrm{~m}$ ), de section approximativement semi-circulaire. Elle a coupé les foyers F 10 et F 11 pour atteindre l'horizon US 198/221/223/586/642 qui appartient au substrat dunaire antérieur à l'occupation du $\mathrm{IV}^{\mathrm{e}} \mathrm{s}$. Le comblement de la fosse (US 536) était constitué d'un sable jaune clair contenant de nombreux éclats d'un grès identique au matériau utilisé pour la confection des blocs de la ciste. Ce fait semble suggérer que ces derniers avaient été taillés, ou plus probablement finis sur place. On a également constaté qu'au moins dans la partie inférieure de la fosse, ses parois avaient été doublées d'une couche de terre argileuse brune.

Après la mise en place de la sépulture et la fermeture définitive de la ciste, les espaces restés vacants autour des dalles de couverture ont été comblés par un sable jaune (US 522), L'ensemble avait été ensuite recouvert de terre (US 520), de sable (US 528) et d'une quantité importante de pierres qui formaient un amas au-dessus des dalles de couverture (US 521). Enfin, le grand remblai US 2/501 est venu définitivement sceller toute cette zone.

\section{Description archéologique}

L'amas de pierres US 521, composé essentiellement de moellons granitiques, auxquels étaient mêlés quelques blocs de taille plus importante, servait à signaler l'emplacement de la sépulture dans l'espace de la nécropole à un moment où le remblai US 2/501 n'était pas encore en place.

La ciste était couverte par quatre dalles de grès dunaire grossièrement équarries, de dimensions inégales : l'épaisseur varie de 35 à $40 \mathrm{~cm}$, la dalle Nord est la plus petite $(90$ x $46 \mathrm{~cm})$, la dalle Sud la plus grande $(140$ x $60 \mathrm{~cm})$. Les interstices entre les dalles et à la jointure avec les parois sont comblés par de petites pierres. Les parois sont constituées de deux assises de dalles de hauteur et d'épaisseur variables, disposées de chant ou en boutisse. Seule la dalle de chant de l'assise supérieure de la paroi N.-O. est soigneusement taillée, celles de la paroi S.-O. sont grossières. Des traces blanchâtres sont visibles sur les parois N.-O. et S.-E., à peu près à mi-hauteur des blocs latéraux. Le fond de la ciste est couvert, sauf sous et derrière la tête, de dalles en calcaire plus fin; à l'extrémité N.-O., au niveau des pieds, deux cavités à peu près circulaires sont séparées par deux petites dalles, suggérant la présence d'une kliné funéraire en bois. Dimensions intérieures 210 x $70 \mathrm{~cm}$.

Le comblement de l'espace intérieur était peu important (10 à $15 \mathrm{~cm})$ : il était constitué de sable d'infiltration marron clair (US 539). Le squelette était pris dans un sédiment gras de couleur brun foncé (US 544), limité à une zone étroite autour du corps et contenant une forte concentration de petits escargots thanatophages au niveau du thorax, qui a résulté probablement de la décomposition du corps. Enfin, on a noté, dans la cavité rectangulaire contre la paroi S.-E., la présence d'une troisième couche de sable brun foncé avec une concentration de charbons (US 543). Derrière la tête se trouvait le clou en fer $\mathbf{6}$; près de la tête étaient placés le lécythe $\mathbf{1}$ et le pot $\mathbf{3}$, près du coude droit la pyxis $\mathbf{4}$, près de l'omoplate gauche l'aiguille $\mathbf{5}$; les fragments du lécythe $\mathbf{2}$ étaient dispersés au-dessus du crâne, à côté du coude gauche et du bras droit. L'individu est complet et se présente couché sur le dos, membres en extension.

\section{Description anthropologique}

Anthropologie de terrain - Le crâne, au S.-E., apparaissait par sa face latérale gauche, mais sa position est secondaire : les articulations avec l'atlas et la mandibule sont déplacées. Il semble possible de restituer une surélévation initiale de la tête ayant entraîné ces déconnexions, d'autant que le dallage du fond est absent dans cette zone.

Toute la partie supérieure du rachis, de $\mathrm{C} 1$ à $\mathrm{T} 5$, était également totalement déconnectée, plusieurs vertèbres se retrouvant hors de l'espace initial du corps (l'atlas par exemple était situé à côté de l'extrémité proximale de l'humérus droit !). Le reste du rachis était en connexion étroite.

La mise à plat des côtes était complète et les deux clavicules étaient déplacées. Les bras étaient en adduction et les avantbras placés symétriquement en extension le long du corps. Les mains étaient situées dans le prolongement, à côté des fémurs. Les deux coudes étaient déconnectés, de même que les mains, placées à côté des fémurs. La ceinture pelvienne était ouverte, l'os coxal gauche présentant un déplacement vers le haut. Le membre inférieur droit, malgré quelques déconnexions, était en position anatomique, tandis que le gauche avait subi un important déplacement latéral : le fémur apparaissait ainsi par sa face postérieure, la tête totalement sortie de l'acetabulum, alors que le tibia correspondant était en face antérieure. Les deux fibulas n'étaient plus en position anatomique. Les deux pieds étaient totalement déconnectés, avec un éparpillement considérable des ossements.

Ces observations permettent de conclure à une décomposition en espace vide. Les déconnexions et importants déplacements 
osseux, surtout sensibles dans la partie supérieure du corps, peuvent laisser supposer un effondrement partiel du corps, dû à la présence initiale d'un lit funéraire.

Anthropologie biologique - L'individu est complet mais l'état de conservation des ossements est moyen, avec une importante fragilité osseuse due à la nature du contenant.

Le sujet est un adulte de sexe féminin, âgé d'au moins 45 ans. Des signes de pathologie dégénérative tels que de l'arthrose, notamment sur les vertèbres et les phalanges, ainsi qu'une presque totale synostose des sutures crâniennes, sont en effet présents. La stature estimée est de 143-145 cm. Longueurs maximales : fémur gauche : $360 \mathrm{~mm}$; humérus gauche : $250 \mathrm{~mm}$; radius droit : $190 \mathrm{~mm}$. L'état dentaire est assez délabré : usure très importante, deux incisives centrales supérieures fendues, abcès conséquent au-dessus de la deuxième incisive supérieure latérale droite, résorption alvéolaire de toutes les deuxièmes et troisièmes molaires. Aucune carie n'est en revanche présente, ce qui exclut une alimentation principalement à base de céréales. L'atteinte arthrosique est importante: becs de perroquet sur les vertèbres, éburnation de la phalange médiale du pouce droit et ostéophytes sur les phalanges.

\section{Inventaire des objets}

1 - (= CP 10) Lécythe aryballisque à figures rouges.

Inv. PIN 3647. Pl. 34e (au centre.)

2 - (= CP 11) Lécythe aryballisque à figures rouges et décor polychrome. Inv. PIN 3648. PI. 34e (à dr.)

3 - (= CC 202) Pot de fabrication locale, miniature.

Inv. PIN 3649. Pl. 34e (à g.)

4 - (= M 15) Petite pyxis en bronze. Inv. PIN 3650. Pl. 34d

5 - (= M 29) Aiguille à chas en bronze. Inv. PIN 3651.

Pl. 34e (en bas)

6 - (= M 48) Clou en fer. Inv. FR 2.29.5. Pl. 34e (en bas)

\section{Datation, commentaire}

Les deux lécythes à décor figuré et la séquence stratigraphique mise en évidence dans cette zone permettent de situer cette importante sépulture vers 360-350.

\section{SP 329}

Tombe à fosse trouvée par l'équipe française le 27 août 2003 dans le secteur central, au S.-O. du point G 4. Orientation N.-E. Niveaux en haut de la fosse 5,44 à 5,46, au fond 5,19; niveaux des vases 5,23 (1) et 5,34/5,35 (2-3). Pl. 35

\section{Contexte stratigraphique}

Cette sépulture occupait l'espace entre les murs MR 3 et 4. Elle était creusée pour l'essentiel dans l'US 517/524, mais entamait également au S.-E. l'US 149/519, sur laquelle était fondé l'alignement constituant la face S.-O. de MR 3 (US 518), ainsi que l'US 531 immédiatement inférieure. Le long de la paroi N.-O. de la fosse, contre le grand bloc coiffant MR 4, on a également noté la présence d'une couche pelliculaire argileuse comportant de nombreuses immixtions de petites pierres de couleur blanche (US 558), qui résultait probablement de la dégradation du grès composant le bloc.

\section{Description archéologique}

Une structure en forme de П, constituée de deux assises de moellons et de blocs de granit et de calcaire grossièrement travaillés, s'appuyait sur les murs MR 3 et 4. Placée du côté de la tête du défunt, elle entourait un petit remblai de sable (US 10/527). Reproduisant un dispositif proche de celui observé autour de SP 283, cette structure signalait l'emplacement de la sépulture.

Le sujet était installé dans une fosse de forme oblongue (long. $190 \mathrm{~cm}$, larg. 40-50 cm, ht max. cons. $20 \mathrm{~cm}$ ). Les limites de la fosse n'ont été saisies avec assurance que dans la zone du crâne et le long de la partie supérieure du corps jusqu'au niveau des genoux. Ses parois étaient verticales et le fond dépressif au centre du creusement, en cuvette (variation de plus de $20 \mathrm{~cm}$ entre les pieds et le bassin, de $10 \mathrm{~cm}$ entre le crâne et le bassin). Le comblement (US 532) était constitué d'un sable jaune foncé identique à 1'US 10/527. Il contenait plusieurs éléments en bronze de petites dimensions, certains attachés à de petits fragments de bois : un au centre, deux autres le long de son côté Nord. Malheureusement, l'état de conservation de ces éléments ne permet pas d'en dire plus sur leur fonction. Trois offrandes ont été placées à proximité du corps : le gobelet à vernis noir $\mathbf{1}$ était posé le long du bras gauche, au-dessus du coude. Le bol $\mathbf{2}$ près des pieds, tout comme la coupe-skyphos $\mathbf{3}$, placée à l'envers. Sous le squelette se trouvait l'aiguille en bronze 4 .

L'association avec le dépôt DP 28 est assurée.

\section{Description anthropologique}

Anthropologie de terrain - L'individu se présentait en décubitus dorsal. Le crâne, au Nord, apparaissait par sa face antéro-latérale droite, en connexion stricte avec l'atlas et lâche avec la mandibule qui a légèrement chuté vers le bas du fait de la déclivité du fond de fosse. Le rachis cervical et thoracique était en connexion stricte jusqu'à T11. La dernière thoracique et les deux premières lombaires ont subi un important déplacement latéral qui peut être dû à l'action d'animaux fouisseurs.

La mise à plat des côtes était complète et les connexions thoraciques strictes. Les clavicules étaient légèrement verticalisées du fait d'une légère compression due à l'étroitesse de la fosse. Les bras étaient en adduction et les avant-bras placés symétriquement le long du corps, le droit passant sous le bassin. Le membre supérieur gauche était appuyé contre la paroi orientale de la fosse et l'humérus apparaissait par sa face antéro-latérale. L'os coxal droit se présentait de chant contre la paroi de la fosse, en position fermée, tandis que le gauche s'était ouvert dans le volume initial du corps. Les deux fémurs étaient en connexion stricte et apparaissaient par leur face antérieure. Les deux tibias-fibulas, en revanche, se présentaient par leur face antéro-médiale ou médiale; ils ont subi une rotation externe, sans doute à cause du poids des deux offrandes céramiques posées sur les pieds. Ceux-ci présentaient de nombreuses déconnexions à mettre en relation 
avec la création de micros-espaces vides sous les offrandes.

Toutes ces observations permettent de conclure à une décomposition en espace colmaté, avec d'importants effets de paroi dus à l'étroitesse de la fosse et à sa forme légèrement en cuvette (remontée du fond à la tête et aux pieds).

Anthropologie biologique - L'individu est complet mais l'état de conservation des ossements est moyen, avec de nombreux écrasements post-mortem.

Le sujet est un adulte âgé de sexe féminin. Présence d'arthrose sur les vertèbres et pertes dentaires. La stature estimée est de 144-146 cm. Longueurs maximales : fémur gauche : $365 \mathrm{~mm}$; tibia droit: $285 \mathrm{~mm}$; radius gauche: $193 \mathrm{~mm}$

\section{Inventaire des objets}

1 - (= VN 10) Gobelet à vernis noir. Inv. PIN 3642 (FR 2.24). Pl. 35a (en haut)

2 - (= VN 74a) Bol à vernis noir. Inv. PIN 3643 (FR 2.26).

Pl. 35a (à g.)

3 - (= CP 4) Coupe-skyphos à figures rouges.

Inv. PIN 3644 (FR 2.3). Pl. 35a (à dr.)

4 - (= M 30) Aiguille à chas en bronze. Inv. PIN 3645 (FR 2.5.4).

\section{Datation, commentaire}

Le mobilier funéraire indique une date dans le second quart du IV e s., ce que confirme l'emplacement de la sépulture dans le passage entre MR 3 et 4 . Le chevauchement des marqueurs des SP 329 et 328 permet de réduire cette fourchette à la période 360-350.

\section{SP 330}

Tombe à fosse découverte par l'équipe bulgare le 27 août 2003 dans le secteur Sud, au N.-E. du point H 2. Orientation N.-E. Pl. 36

\section{Contexte stratigraphique}

La fosse, creusée à partir des niveaux inférieurs de la dune US 617/619, atteignait le substrat argileux US 641, lequel suivait à cet endroit une forte dénivellation vers le S.-O.

\section{Description archéologique}

La fosse est perturbée dans sa partie inférieure, au niveau des jambes du sujet. Le lécythe $\mathbf{1}$ se trouvait à $25 \mathrm{~cm}$ à l'Est du crâne. L'embouchure, cassée, a été trouvée à côté du vase. Le lécythe à figures rouges 2 était placé sur le fémur droit, son embouchure tournée vers l'intérieur de l'os. Dans le sable du remblai ont été trouvés les fragments d'un objet en bronze (strigile), d'un cratérisque et d'un lécythe.

\section{Description anthropologique}

Le sujet est un adulte de sexe masculin, âgé d'au moins 50 ans (pour les pathologies osseuses, voir ci-dessous le diagnostic d'A. Keenleyside). Stature 166-170 cm. Le squelette était allongé sur le dos, membres en extension; le crâne était orienté vers le N.-E., les fémurs étaient très inclinés, les os de la main gauche et les tibias manquaient.

\section{Inventaire des objets}

1 - (= CP 5) Lécythe à figures noires. Inv. PIN 3747. PI. 36d

2 - (= CP 12) Lécythe à figures rouges. Inv. PIN 3748. [Non disponible lors de l'étude]

\section{Datation, commentaire}

Le lécythe $\mathbf{1}$ indique une date dans le troisième quart du $\mathrm{V}^{\mathrm{e}} \mathrm{s}$., mais la mise en place de cette sépulture à partir des niveaux inférieurs de la dune US 617/619, à un moment où l'ensablement du littoral avait déjà débuté, amène à abaisser la chronologie jusque vers 420 .

\section{SP 331}

Tombe à fosse découverte par l'équipe bulgare le 27 août 2003 dans le secteur Sud, entre les points G-H 2-3. Orientation N.-E. Pl. 37a-c

\section{Contexte stratigraphique et description archéologique}

La tombe partageait le même contexte stratigraphique que SP 330. Le crâne était placé partiellement au-dessus de la rigole du milieu du $\mathrm{V}^{\mathrm{e}}$ s. qui traverse le secteur. Le lécythe $\mathbf{1}$ était posé sur la poitrine et un fragment de cruche à pâte grisnoir 2 à côté de la main gauche.

\section{Description anthropologique}

Le défunt est un adulte de sexe féminin, âgé d'au moins 50 ans. Le squelette est en position allongée; il est très détérioré, le crâne est détruit. Les mains sont posées sur le bassin.

\section{Inventaire des objets}

1 - (= CC 152) Lécythe de fabrication locale. Inv. PIN 3749.

Pl. 37c

2 - Fragment de cruche à pâte gris-noir.

\section{Datation, commentaire}

La situation stratigraphique, identique à celle de SP 330, indique une date vers 420 .

\section{SP 332}

Tombe à fosse trouvée par l'équipe française le $1^{\text {er }}$ septembre 2003 dans le secteur central ; orientation S.-E. (140). Niveau sur le crâne 5,08, sur les pieds 5,10 (Ouest) à 5,12 (Est). Pl. 37d-f

\section{Contexte stratigraphique}

La fosse, relativement profonde, était creusée à partir de l'US 8/516 et atteignait en profondeur le remblai tumulaire de SP 339 (US 515).

Association très probable avec le dépôt DP 27. 


\section{Description archéologique}

Les limites de la fosse étaient impossibles à déterminer. Le squelette reposait sur une mince couche de terre marron grasse (US 549). Il se présentait en décubitus dorsal, les membres supérieurs en extension le long du corps. Les offrandes se résumaient à la fibule $\mathbf{2}$ (entre le bas droit et la colonne vertébrale, sous les côtes) et au lécythe aryballisque 1, placé derrière la tête.

\section{Description anthropologique}

Anthropologie de terrain - Le crâne, à l'Est, apparaissait par sa face supéro-latérale droite, en position primaire puisque les connexions avec l'atlas et la mandibule sont strictes. Le rachis était en parfaite connexion anatomique et les connexions thoraciques étaient strictes.

La mise à plat des côtes était incomplète, une certaine conservation du gril costal gauche est visible, ce qui constitue un très bon indice de décomposition en espace colmaté. Les deux clavicules étaient verticalisées et les scapulas de chant, indiquant un important phénomène de compression transversale. Les bras étaient en forte adduction et les avantbras placés symétriquement le long du corps, passant tous deux sous le bassin. L'humérus droit apparaissait par sa face antérieure et le gauche par sa face latérale, en connexion étroite avec les avant-bras. Les mains avaient subi quelques déconnexions dans le volume initial du corps, puisqu'elles étaient placées en partie sous les cuisses. La main gauche était sur sa face verticale, contre le fémur correspondant.

La ceinture pelvienne était en position fermée. Les membres inférieurs étaient en position primaire, seuls les pieds, à partir des métatarsiens, avaient subi de nombreux déplacements et déconnexions. Toutes ces observations permettent de conclure clairement à une décomposition en espace colmaté. Les forts effets de contrainte bi-latérale et longitudinale peuvent indiquer une fosse courte et étroite, mais la nature du sédiment encaissant et du comblement (sable) n'a pas permis d'appréhender la forme initiale de la fosse. De plus, il faudrait restituer une largeur de creusement n'excédant pas $30 \mathrm{~cm}$, ce qui est difficilement supposable lorsque l'on restitue les chairs. Il paraît plus vraisemblable de supposer la présence d'un linceul initial - hypothèse corroborée par la présence de la fibule -, très serré et constrictif pour le haut du corps, plus lâche (voire absent) pour les pieds : les deux pieds sont en effet les seuls à présenter de nombreuses déconnexions, le gauche a subi un éversement latéral, tandis que le droit n'est pas dans la continuité de l'effet de paroi latéral, visible sur tout le côté droit de l'individu.

Anthropologie biologique - L'individu est complet et l'état de conservation des ossements est très bon.

Le sujet est un adulte mature de sexe masculin : les sutures crâniennes sont en effet en cours de synostose et les vertèbres sont légèrement arthrosiques. Les insertions musculaires sont marquées et le sujet est robuste. La stature estimée est de $155-157 \mathrm{~cm}$. Longueurs maximales : fémur gauche $385 \mathrm{~mm}$; humérus gauche $280 \mathrm{~mm}$; tibia droit $305 \mathrm{~mm}$; radius gauche $205 \mathrm{~mm}$. Les dents présentent une usure marquée et de nombreuses pertes (toutes les molaires supérieures et les premières molaires inférieures). Les deux calcanéus présentent des enthésopathies et les coudes et le rachis de légères atteintes arthrosiques.

\section{Inventaire des objets}

1 - (= CP 21) Lécythe aryballisque à figures rouges.

Inv. PIN 3656 (FR 2.19). Pl. 37d (en haut)

2 - (= M 8) Fibule en fer de type thrace. Inv. FR 2.29.20.

Pl. 37d (en bas)

\section{Datation, commentaire}

Le contexte stratigraphique, comme l'association avec le dépôt DP 27, oriente vers le milieu du IV $\mathrm{s}$.

\section{SP 333}

Tombe à fosse découverte par l'équipe bulgare le 29 août 2003 dans le secteur Nord, entre les points I-J 5-6. Orientation Nord. Niveau 5,00 m. Pl. 38a-c

\section{Contexte stratigraphique et description archéologique}

La fosse était creusée dans le remblai de sable (US 654) qui est venu recouvrir le mur MR 6 au début de la phase 3. Elle était entourée du côté gauche d'un alignement de moellons. Une pierre était placée sous le bassin, une autre du côté droit. Le lécythe 1 était placé près du coude droit, mais l'embouchure du vase était sur les côtes, à gauche. Le canthare $\mathbf{2}$ était posé, le fond vers le haut, sur des pierres à $40 \mathrm{~cm}$ du coude gauche. La cruche $\mathbf{3}$ se trouvait à côté du pied droit.

Association certaine avec les dépôts DP 19 et 20, probable avec DP 18.

\section{Description anthropologique}

Le squelette était en position allongée, sur le dos, membres en extension, la tête orientée vers le N./N.-O. Il était très mal conservé : le crâne est aplati et très détérioré, une partie de la main droite et des côtes manquent ; la main gauche est posée sur le fémur. Le sujet est un adulte de sexe féminin, âgé d'au moins 50 ans.

\section{Inventaire des objets}

1 - (= CP 9) Lécythe aryballisque à figures rouges avec dorure. Inv. PIN 3761. Pl. 38b

2 - (= VN 45) Canthare à vernis noir. Inv. PIN 3762. PI. 38c 3 - Cruche de fabrique locale, argile rouge. Inv. PIN 3763.

\section{Datation, commentaire}

La sépulture est postérieure au remblai US 654 dont la mise en place intervient au début de la phase 3. D'autre part, le canthare est sûrement antérieur au milieu du siècle, ce qui permet de placer cette sépulture vers 370-350. 


\section{SP 334}

Tombe à ciste découverte par l'équipe bulgare le 2 septembre 2003 dans le secteur Nord, immédiatement à l'Ouest du point H 5. Orientation N.-E. Niveau des dalles de couverture 5 à 5,10 , niveau supérieur des parois 4,70, du fond 3,75. Pl. 38d-e et 39a-d

\section{Contexte stratigraphique}

La fosse d'installation était creusée dans l'US 575/588, composée d'une succession serrée de couches horizontales sableuses et argilo-sableuses. Son niveau d'installation était situé $30 \mathrm{~cm}$ au-dessus du niveau supérieur des parois. La ciste était recouverte d'un remblai tumulaire de sable (US 647), scellé par une couche de terre argileuse épaisse de $25 \mathrm{~cm}$ (US 648), sur laquelle vient s'appuyer la couverture tumulaire de SP 336.

\section{Description archéologique}

La tombe était recouverte d'un tumulus (voir ci-dessus) dont la hauteur estimée était probablement de $150 \mathrm{~cm}$ à l'origine.

La ciste était couverte par cinq dalles d'une longueur totale de $260 \mathrm{~cm}$. Les deux dalles extérieures étaient plus petites que celles du centre ; dimensions : A - (S.-O.), 90 x 53 x $25 \mathrm{~cm}$; B - 105 x 46 x $36 \mathrm{~cm}$; C - 110 x 47 x $32 \mathrm{~cm}$; D - 111 x 51 x $28 \mathrm{~cm}$; E - 86 × 50 x $27 \mathrm{~cm}$. L'intérieur de la ciste avait les dimensions suivantes : 208 x 68 x $94 \mathrm{~cm}$. Le petit côté N.-E. était constitué de deux assises de blocs, celui du haut taillé en forme de $\Gamma$, le long côté $\mathrm{S}$.-E. de six blocs sur deux assises, le petit côté S.-O. de deux blocs, le long côté N.-O. de deux assises de deux dalles. Le terrain sableux naturel servait de sol. Le lécythe $\mathbf{1}$ était placé sur l'épaule gauche, mais son embouchure se trouvait à côté de l'épaule droite. L'instrument en bronze 2 était à côté de la main gauche et le strigile $\mathbf{3}$ sur les côtes, à côté du bras droit. Les 16 astragales 4 étaient dispersés à côté de la main droite et de l'épaule gauche.

L'association avec les dépôts DP 12 et 13 est assurée.

\section{Description anthropologique}

Le squelette était en position allongée, sur le dos, la tête orientée au N.-E.; les os étaient très détériorés, les mieux conservés sont ceux des membres inférieurs; les côtes sont déplacées. Le sujet est un adulte de sexe masculin, âgé de 15 à 20 ans.

\section{Inventaire des objets}

1 - (= CP 13) Lécythe aryballisque à figures rouges. Inv. PIN 3767. PI. 39b

2 - (= M 62) Instrument en bronze. Inv. PIN 3768. Pl. 39d

3 - (= M 20) Strigile en bronze. Inv. PIN 3769. PI. 39c

4 - (= D 18) 16 astragales. Inv. PIN 3770.

\section{Datation, commentaire}

L'étude stratigraphique et l'association de cette inhumation avec les dépôts DP 12-13 indiquent une date durant la deuxième phase d'occupation de cette zone, vers 390-380.

\section{SP 335}

Tombe à fosse découverte par l'équipe bulgare le 9 septembre 2003 dans le secteur Sud, à l'Est du point H 2. Orientation N.-E.

\section{Contexte stratigraphique et description archéologique}

Le contexte stratigraphique de la sépulture n'est pas connu.

\section{Description anthropologique}

Le squelette était en position allongée, sur le dos, les jambes orientées au S.-O. Il était très perturbé : il n'en reste que les fémurs, une partie du bassin et les phalanges d'une main.

On peut cependant déterminer qu'il s'agit d'un individu masculin, âgé de 36 à 50 ans, avec un discret remaniement sur l'extrémité distale de l'ulna (cubitus) droit.

Inventaire des objets : néant.

\section{Datation, commentaire}

Il n'est pas possible de fixer une date, même approximative.

\section{SP 336}

Tombe à fosse découverte par l'équipe bulgare le 2 septembre 2003 dans le secteur Nord, entre les points H-I 5-6. Orientation N.-E. Niveau supérieur de la fosse 4,75, du fond 3,70. Pl. 39e-i

\section{Contexte stratigraphique}

La fosse était creusée, tout comme SP 334, dans l'horizon US 575/588. On a noté, à l'extérieur de la sépulture, la présence d'un important remblai d'argile (US 649) qui l'entourait sur trois côtés (N.-E., N.-O., S.-O.). La fonction de cet aménagement, qui s'étendait jusqu'au mur MR 6, demeure obscure, bien qu'il ait pu être destiné à stabiliser le terrain. La sépulture était recouverte d'un remblai tumulaire de sable (US 650), scellé par une couche de terre sableuse (US 651) qui s'appuyait sur le tumulus de SP 334.

\section{Description archéologique}

La sépulture était dotée d'une couverture tumulaire (voir ci-dessus). La fosse avait une forme rectangulaire et des angles arrondis ; sa section était légèrement trapézoïdale, car elle s'élargissait dans la partie supérieure. Dimensions 265 x $160 \mathrm{~cm}$ en haut, 210 x 90 à $100 \mathrm{~cm}$ au fond. Le lécythe 1 était situé du côté interne de l'épaule droite, le bol $\mathbf{2}$ devant la main droite, qui tenait l'objet en os $\mathbf{3}$ et une partie des astragales (les autres étaient autour du vase). Au-dessous de la tête (sur l'épaule droite) se trouvait l'aiguille en bronze 5 .

Association probable avec le dépôt DP 15, possible avec DP 11.

\section{Description anthropologique}

Le squelette était en position allongée, sur le dos, les membres en extension, la tête orientée vers le N.-E. La colonne 
vertébrale était recourbée en $\mathrm{S}$. Indices de décomposition en espace vide.

Le sujet est un adulte de sexe plutôt féminin, âgé de 30 à 50 ans (pour les pathologies osseuses, voir ci-dessous le diagnostic d'A. Keenleyside); il portait peut-être des chaussures. Stature 160-163 cm.

\section{Inventaire des objets}

1 - (= CP 33) Lécythe aryballisque à décor réticulé.

Inv. PIN 3771. Pl. 39h (à dr.)

2 - (= VN 56) Bol à vernis noir. Le fond extérieur porte le graffiti $\Lambda$ II. Inv. PIN 3772. Pl. 39h (à g.) et i

3 - (= D 9) Objet en os. Inv. PIN 3773.

4 - (= D 17) Quatre astragales. Inv. PIN 3774.

5 - (= M 31) Aiguille en bronze. Inv. PIN 3783.

\section{Datation, commentaire}

La situation stratigraphique est proche de celle de SP 334, mais le chevauchement des remblais de couverture indique que SP 336 est un peu plus tardive ; elle appartient également à la décennie 390-380.

\section{SP 337}

Tombe à fosse trouvée par l'équipe française le 2 septembre 2003 dans le secteur Sud, entre les points F 3 et G 3. Orientation S.-E. Niveaux au fond de la fosse 5,18 (près de la tête) à 5,23 (près des pieds). Pl. 40

\section{Contexte stratigraphique}

La sépulture était disposée à cheval entre les remblais US 102/138 et US 19/114/129. Elle atteignait en profondeur l'US 116.

\section{Description archéologique}

L'extrémité S.-E. de la sépulture avait été entamée par les fouilles des années précédentes, mais le sujet était complet. Le creusement était beaucoup plus large à son sommet $(75 \mathrm{~cm})$ qu'à sa base $(40 \mathrm{~cm})$. La longueur conservée de la fosse était de $170 \mathrm{~cm}$, sa profondeur atteignait au moins $50 \mathrm{~cm}$. Les parois étaient verticales, le fond plat.

Le remplissage était constitué d'un sédiment sableux très homogène et pur, de couleur jaune clair (US 104/135), présentant dans sa partie supérieure une zone d'environ $120 \mathrm{x}$ $80 \mathrm{~cm}$ qui contenait des charbons de bois et quelques tessons, ainsi que des traces d'une bûche brûlée (US 123).

Dans la partie inférieure de cette couche, aux niveaux 5,73 à 5,60, sur la surface de l'US 111/136, étaient alignés le long de la paroi N.-E. cinq clous en fer, les uns plantés verticalement, les autres tordus $(\mathbf{P l} \mathbf{4 0 e})$. Juste à côté était posée à plat une pierre de granit, au niveau 5,78. Un charbon de bois se trouvait au-dessus des pieds, une pierre au niveau du bras droit. La jambe droite était fortement fléchie vers la gauche; le petit pot 1, situé au niveau du pubis, devait à l'origine être placé sur l'abdomen.

\section{Description anthropologique}

Anthropologie de terrain - L'individu se présentait en décubitus dorsal. Le crâne, au S.-E., apparaissait par sa face latérale gauche, dans une position primaire, mais contractée ; les connexions avec la mandibule et les premières vertèbres étaient strictes. La ceinture scapulaire montrait des signes d'importantes compressions: clavicules verticalisées, scapulas de chant et humérus sur leur face latérale.

Toutes les connexions de la partie supérieure du corps étaient strictes. Les membres supérieurs étaient en extension le long du corps, avec les mains passant sous le bassin. La main droite était légèrement verticalisée tandis que la gauche apparaissait par sa face dorsale, posée à plat sur le fond de la fosse.

La ceinture pelvienne était semi-ouverte, mais l'os coxal droit était fortement verticalisé, alors que le bord de fosse est distant de $8 \mathrm{~cm}$. Les membres inférieurs étaient fléchis latéralement : le droit apparaissait par sa face latérale et le gauche par sa face médiale. Le genou et la cheville gauche étaient déplacés, sans doute du fait d'une importante compression latérale. Les deux pieds, en position primaire, étaient disposés l'un sur l'autre avec les phalanges verticalisées.

Il s'agit d'un bon indice de décomposition en espace colmaté : l'effet de paroi dû à la présence d'un bloc en fond de fosse n'a pas occasionné l'effondrement des pieds. Toutes ces observations permettent d'attester une décomposition en espace colmaté, avec de fortes compressions.

Le fond de la fosse est étroit (40 cm en moyenne), mais les effets de paroi sensibles à divers endroits du corps ne sont pas dus à cette étroitesse (les os ne sont pas en butée contre les parois, à part les pieds). Il est donc possible d'attester un contenant initial serré, de type linceul.

Anthropologie biologique - L'individu est complet mais l'état de conservation des ossements est très médiocre.

Le sujet est un adulte de sexe féminin, sa stature estimée est de $144 \mathrm{~cm}$. Longueurs maximales : fémur droit $360 \mathrm{~mm}$; humérus gauche $265 \mathrm{~mm}$; tibia droit $285 \mathrm{~mm}$.

\section{Inventaire des objets}

1 - (= CC 203) Pot à une anse de fabrication locale, miniature. Inv. FR 2.23. Pl. 40e (en haut)

\section{Datation, commentaire}

Le niveau de creusement de la fosse, sous l'US 2/501, proche de celui de SP 264, tout comme son placement dans l'US 102/138 et 19/114/129, au-dessus des blocs provenant de la destruction de MR 2, permet de proposer une date vers le milieu du $\mathrm{IV}^{\mathrm{e}} \mathrm{s}$. Voir plus loin (p. 167-168) pour les hypothèses relatives aux clous.

\section{SP 338}

Tombe à fosse découverte par l'équipe bulgare le 2 septembre 2003 dans le secteur Nord, entre les points I-J 5-6, juste à côté de l'escalier de six marches qui descend devant la face N.-O. 
de MR 6. Orientation N.-E. Niveau 5,50 à côté de la marche supérieure. Pl. 41

\section{Contexte stratigraphique et description archéologique}

La fosse était creusée dans le remblai de sable (US 652) qui recouvrait le mur MR 6. Les contours de la fosse n'étaient pas visibles. Du côté gauche du crâne se trouvait une large pierre non travaillée. D'autres pierres étaient situées devant les pieds.

Le lécythe 1 était placé à gauche du crâne, près du fond se trouvait le lécythe $\mathbf{2}$; le lécythe $\mathbf{3}$ était au-dessous de l'épaule droite, le $\mathbf{4}$ sur le coude droit, le $\mathbf{5}$ sur la main gauche, à côté du poignet; l'askos $\mathbf{6}$ était situé à $10 \mathrm{~cm}$ des jambes ; du côté droit du bassin était posé le peson 7, l'astragale 8 se trouvait au-dessus du pied gauche.

Association possible avec le dépôt DP 18.

\section{Description anthropologique}

Le sujet était en position allongée sur le dos, membres en extension, la tête orientée vers le N.-O.

Il était très mal conservé : le crâne était détérioré, le bras droit (sauf la main) et les côtes du côté gauche manquent ; la colonne vertébrale était recourbée en forme de $\mathrm{S}$.

Le sujet est un adulte, probablement de sexe féminin, âgé d'au moins 50 ans (pour ses pathologies osseuses, voir ci-dessous le diagnostic d'A. Keenleyside). Stature 155$157 \mathrm{~cm}$. Indices de décomposition en espace colmaté.

\section{Inventaire des objets}

1 - (= CP 34) Lécythe aryballisque à décor réticulé.

Inv. PIN 3775. Pl. 41d (au centre)

2 - (= CP 22) Lécythe aryballisque à figures rouges

Inv. PIN 3776. PI. 41e

3 - (= CP 35) Lécythe aryballisque à décor réticulé.

Inv. PIN 3777. Pl. 41d (à g.)

4 - (= CP 23) Lécythe aryballisque à figures rouges.

Inv. PIN 3778. PI. 41d (à dr.)

5 - (= CP 36) Lécythe aryballisque à décor réticulé.

Inv. PIN 3779. PI. 41g

6 - Askos. Inv. PIN 3780.

7 - (= TC 17) Peson pyramidal en argile. Inv. PIN 3781.

Pl. 41h

8 - (= D 11) Astragale. Inv. PIN 3782.

\section{Datation, commentaire}

Les lécythes, très banals, ne permettent pas une datation précise, mais la situation stratigraphique et la position du dépôt DP 14 (daté vers 350-325) fournissent un intéressant terminus ante quem pour l'installation de la sépulture, indiquant une date dans le second quart ou vers le milieu du $\mathrm{IV}^{\mathrm{e}} \mathrm{s}$.

\section{SP 339}

Tombe à ciste découverte par l'équipe française le 4 septembre 2003 dans le secteur Sud, entre les points G 3 et $\mathrm{H}$ 3. Orientation N.-E. $\left(70^{\circ}\right)$. Niveaux sur les dalles de couverture, 4,89 à 4,93; au fond, 3,83 ; sur le crâne 3,87, sur les pieds 3,81 . Pl. 42

\section{Contexte stratigraphique}

La sépulture a été installée durant une période où les couvertures tumulaires des tombes SP 300, 325 et 343 étaient déjà en place. Sa fosse d'installation (US 204/565) entamait celles de SP 300 et 343 et atteignait l'horizon US 211/214/625, disposé au-dessus de la dune US 218/627.

\section{Description archéologique}

La sépulture était protégée par un tertre de sable, haut de $90 \mathrm{~cm}$, dont le remplissage était aisément visible dans le profil séparant les secteurs Sud et central (US 515 et 566). Il a cependant rapidement été recouvert par les différents remblais mis en place au moment de la construction du mur MR 3, avant d'être perturbé lors d'aménagements successifs au cours de la phase 3, en particulier par le creusement de SP 332.

La fosse d'installation était relativement étroite. Son comblement était assuré, comme dans le cas de SP 328, par un remplissage de sable clair très meuble (US 585) qui contenait de nombreux éclats de taille. Les perturbations liées à l'installation de cette sépulture couvraient, notamment vers le N.-E. et le S.-E., une zone bien plus large que les limites de la fosse, éclairant en retour un décaissement préalable des environs immédiats.

La ciste était fermée par quatre dalles, en grès dunaire grossièrement équarri : épaisseur d'Est en Ouest 24, 29, 27 et $22 \mathrm{~cm}$. L'agencement est assez maladroit, avec d'importants espaces entre les joints, colmatés par de petites pierres et par de l'argile marron foncé : cette même argile est disposée tout autour de la sépulture, à la jointure entre les dalles et les parois, afin d'assurer une certaine étanchéité (US 557). Les parois sont constituées de blocs de grès plus soigneusement équarris, la dalle de chant Ouest est taillée dans un grès beaucoup plus fin. Les petits côtés N.-E. et S.-O. sont constitués d'une seule dalle de chant. La paroi S.-E. comporte trois dalles, également de chant, la paroi N.-O. deux assises de deux blocs, complétées par une dalle de chant dans l'angle N.-O. Il n'y a pas de dalles au fond.

Le comblement (US 555), au-dessus du squelette, est supérieur à $20 \mathrm{~cm}$, en particulier près des parois N.-E. et $\mathrm{S}$.-O. Il est constitué d'un sable d'infiltration blanc, très meuble. Le sujet lui-même était pris dans une couche grasse de couleur brune foncée (US 560) résultant de la décomposition du corps. On observe sous le squelette une terre sableuse marron, qui comporte des éclats de pierre semblables aux dalles de la ciste (US 562) dans la zone de la tête et des côtes.

L'individu se présentait en décubitus dorsal. Son état de conservation, médiocre, témoigne du caractère humide de ce contexte, qui a affecté la conservation du mobilier funéraire. Les offrandes se composent du strigile en bronze 6, placé le long du bras gauche, de la fibule en bronze 7, à droite du crâne, du lécythe aryballisque $\mathbf{1}$, sur la partie droite du bassin (en très mauvais état, le goulot, brisé, se trouvait sur la main droite), 
ainsi que de 58 astragales (5) déposés à gauche du bassin. Les fragments de la péliké $\mathbf{2}$, du bol $\mathbf{3}$ et de l'œnochoé $\mathbf{4}$ ont été retrouvés après le prélèvement du squelette, lors du nettoyage du fond de la ciste.

Association possible avec les dépôts DP 26, DP 30 et DP 31.

\section{Description anthropologique}

Anthropologie de terrain - Le crâne, au N.-E., apparaissait apparemment par sa face latérale droite, mais son très mauvais état de conservation rend délicate l'appréhension de sa position initiale : il ne semble pas cependant que la position observée soit primaire, un déplacement latéral est envisageable. Le rachis était très perturbé : toutes les connexions anatomiques étaient rompues entre $\mathrm{C} 1$ et $\mathrm{T} 7$, les vertèbres étaient disséminées en divers endroits du fond de la ciste. À partir de T7, et pour tout l'étage lombaire, les connexions étaient strictes. Le thorax montrait des connexions lâches et une totale mise à plat du gril costal. Les bras étaient en adduction le long du corps, avec les deux mains passant sous le bassin. Les membres inférieurs, en extension symétrique, étaient en connexion stricte et apparaissaient par leur face antérieure, mais l'épiphyse proximale du fémur droit, non soudée, est étrangement située contre l'ilion gauche. Les pieds montrent de nombreuses déconnexions et migrations osseuses.

Ces observations permettent de conclure à une décomposition en espace vide, avec de nombreuses perturbations affectant surtout la partie supérieure du sujet, très mal conservée par ailleurs.

Anthropologie biologique - L'individu est complet mais en très mauvais état de conservation. L'inhumation en ciste semble, comme pour la sépulture SP 328, en être la cause, en raison d'une faible quantité de sédiment d'infiltration protégeant les ossements et, sans doute, d'une stagnation d'eau au fond de la ciste, favorisant la dégradation de la matière osseuse.

Le sujet est un immature de 7 ans \pm 24 mois d'après le diagramme dentaire (les dents définitives ne sont présentes que sous forme de germes). Cependant, les mensurations prises sur le terrain, eu égard au très mauvais état de conservation des ossements, indiquent un âge aux alentours de 9 ans. Il est donc probable que le sujet ait eu un léger retard au niveau de son éruption dentaire ou que celui-ci soit grand pour son âge. Nous retiendrons un âge de 8 ans \pm 12 mois. La stature estimée est de 143-145 cm. Longueurs maximales : fémur gauche 302 $\mathrm{mm}$; humérus gauche $205 \mathrm{~mm}$; tibia droit $215 \mathrm{~mm}$.

\section{Inventaire des objets}

1 - (= CP 37) Lécythe aryballisque à décor réticulé.

Inv. FR 2.4. Pl. 42e (en haut)

2 - (= CP 43) Fragment de péliké à figures rouges.

Inv. FR 2.35. Pl. 42e (à dr.)

3 - (= VN 72) Fragments de bol à vernis noir. Inv. FR 2.36.1.

4 - (= VN 113) Fragment d'anse d'une œnochoé (ou olpé) à vernis noir. Inv. FR 2.36.2.

5 - (= D 19) 58 astragales. Inv. PIN 3640 (FR 2.32). Pl. 42e (en haut à g.)
6 - (= M 21) Fragments d'un strigile en bronze. Inv. FR 2.5.17.

Pl. 42e (en bas)

7 - (= M 9) Deux fragments d'une fibule en bronze.

Inv. FR 2.5 .10 et 2.5.15.

\section{Datation, commentaire}

La situation stratigraphique situe la mise en place de cette sépulture dans une période étroite qui sépare l'installation des tombes SP 300, 325 et 343 et la construction du mur MR 3. Par ailleurs, son association possible avec les dépôts DP 30 et 31 indique une date vers 380 .

\section{SP 340}

Tombe à fosse découverte par l'équipe bulgare le 4 septembre 2003 dans le secteur central, entre les points H-I 4-5. Orientation N.-E. Niveau sur le crâne 4,13, sur les jambes 4,17. Pl. 43

\section{Contexte stratigraphique}

La fosse était installée à la périphérie des couvertures tumulaires associées aux tombes SP 334 et 343 qu'elle a perturbées successivement lors de son creusement. Elle atteignait en profondeur l'US 198/221/223/586/642, à travers l'US 575/588.

\section{Description archéologique}

La présence d'un imposant tas de pierres (US 509/513), situé immédiatement au S.-E. de la sépulture, soulève quelques questions sur sa fonction : il n'est pas exclu qu'il ait pu jouer le rôle d'un marqueur.

Le fond de la fosse était limité à droite du squelette par des pierres, à gauche par de petits blocs de grès sableux. Le lécythe $\mathbf{2}$ avait été préalablement cassé, les morceaux se trouvaient du côté droit du squelette, dans la zone comprise entre le coude et le genou. Les objets en verre $\mathbf{3}$ étaient situés à $15 \mathrm{~cm}$ du tibia droit, la pointe de flèche 4 à côté du même tibia, la monnaie 5, les pointes de flèches, l'objet en bronze $\mathbf{6}$ étaient à côté des objets en verre, les «punaises » en bronze 7 et l'aiguille 1 sous le miroir. Les objets $\mathbf{4}$ à $\mathbf{9}$ ont été trouvés en tas à côté du tibia droit : ils avaient été probablement déposés dans un petit sac ou une boîte. Autour des pointes de flèche et des « punaises » se trouvaient les restes corrodés d'un objet en fer et d'autres éléments métalliques. Les objets très détériorés en os ou en bois (10) étaient au-dessus de l'épaule droite et le long de la jambe droite, les astragales $\mathbf{1 1}$ à droite des pieds. La clé en bronze 12 était posée à côté du pied gauche, autour de la poignée de la clé se trouvaient les deux boules en terre cuite et le cylindre 13. Sur le tibia gauche était placé le miroir en bronze 14, sous les pointes de flèches les petits cailloux lisses 15, de même que les boutons en bronze et en os $\mathbf{1 6}$.

\section{Description anthropologique}

Le squelette était en position allongée sur le dos, membres en extension (bras légèrement repliés), la tête orientée vers le N.-E. Les genoux et les talons étaient accolés. Le crâne était 
très écrasé, fortement tourné vers la gauche. Le sujet est un adulte de sexe féminin âgé de 30-35 ans. Stature 157-159 cm.

\section{Inventaire des objets}

1 - (= M 32) Aiguille en bronze. Inv. PIN 3788.

2 - (= CP 14) Lécythe aryballisque à figures rouges, polychrome et doré. Inv. PIN 3789. Pl. 43a

3 - (= D 2) Deux objets en verre, en forme de bobine.

Inv. PIN 3790. Pl. 43b (à dr.)

4 - (= M 58) Trois pointes de flèches avec des emmanchements de type « scythe ». Inv. PIN 3791. Pl. 43b (en haut)

5 - (= M 36) Monnaie en bronze. Inv. PIN 3792.

6 - (= M 63) Objet en fine tôle de bronze. Inv. PIN 3793.

Pl. 43b (en bas à g.)

7 - (= M 64) Trois «punaises » en bronze. Inv. PIN 3794.

8 - (= D 6) Objet en os en forme de bâton à section circulaire. Inv. PIN 3795. Pl. 43b (en bas, au centre)

9 - Deux objets en pâte bleue et rouge. Inv. PIN 3796.

10 - Objets décomposés en os ou en bois. Inv. PIN 3797.

11 - (= D 14) Deux astragales. Inv. PIN 3798.

12 - (= M 59) Clé en bronze. Inv. PIN 3799. Pl. 43b (au centre)

13 - (= TC 18 et TC 19) Deux sphères et un cylindre en terre cuite. Inv. PIN 3800.

14 - (= M 13) Miroir en bronze. Inv. PIN 3801.

15 - (= D 22) Cailloux lisses. Inv. PIN 3802.

16 - (= D 3 et D 4) « Boutons » en bronze et en os.

Inv. PIN 3803.

\section{Datation, commentaire}

Le contexte stratigraphique, ainsi que la présence du grand lécythe polychrome, proche par sa forme de celui découvert dans SP 328, permettent de situer la sépulture vers 360-350.

\section{SP 341}

Tombe à fosse découverte par l'équipe française le 8 septembre 2003 dans le secteur central, au Sud du point H 4. Orientation N.-E. Niveau inférieur de la fosse 4,72; niveau des éléments de canalisation autour du squelette, au Nord 4,85, au Sud de 4,88 à 4,96, dans la berme Ouest au-dessus de la sépulture de 4,94 à 5,18. Pl. 44a-d

\section{Contexte stratigraphique}

Comme SP 340, la fosse de cette sépulture était creusée à partir de la surface du remblai 530/568/576/594 dans la couverture tumulaire de SP 343. Les limites de la fosse n'ont pas pu être déterminées.

\section{Description archéologique}

Trois tuyaux de canalisation en position horizontale (1 à 3), inclinés vers le S.-O., étaient installés au-dessus de la fosse et servaient probablement à en marquer la position. L'un (trouvé le 5 septembre) était placé au-dessus du crâne (niveau 5,48 à 4,94 ), un autre se trouvait au Sud, le troisième à l'Ouest dans le prolongement des pieds.

Au contact de ce dernier tuyau, le long de la jambe droite du défunt, se trouvait un petit bloc de conglomérat granitique gris avec inclusion de petites pierres. Une couche argileuse entourait la tête et longeait le côté droit jusqu'au bloc de granit (US 581). Le mobilier consistait dans le fragment de pithos 4 posé sur le fémur droit, contenant un os portant des traces de combustion; à gauche de la tête, un autre os avec traces de combustion.

\section{Description anthropologique}

Anthropologie de terrain - Il n'a pas été possible d'appréhender la position du sujet ni l'espace de décomposition en raison de la perturbation du sujet. L'inhumation en fosse semble cependant indiquer plutôt une décomposition en espace colmaté.

Anthropologie biologique - Le sujet est très incomplet et mal conservé. Le squelette était relativement perturbé : la jambe gauche manque, ainsi que la partie inférieure de la jambe droite et la main gauche. Peu d'os sont présents, mais le diagramme dentaire indique un âge aux alentours de 18 mois.

\section{Inventaire des objets}

1 - Tuyau de canalisation, argile orangée : environ la moitié est conservée, avec l'embout d'encastrement. Long. 48,1 cm, diam. 16,2 cm, diam. de l'embout $12,2 \mathrm{~cm}$. Inv. PIN 3665 (FR 2.31). Pl. 44b

2 - Tuyau de canalisation, argile orangée. Long. 70,6 cm, diam. 15,9 cm. Inv. PIN 4037 (FR 3.38). Pl. 44c

3 - Tuyau de canalisation, argile orangée, partiellement conservé. Long. 68,5 cm, diam. 15,4 cm. Inv. PIN 4036 (FR 3.39). Pl. 44d

4 - Fragment d'un grand vase (pithos ?), argile grise. Ht max. $12,5 \mathrm{~cm}$, long. max. $10,5 \mathrm{~cm}$. Inv. FR 2.37 .

5 - Deux petits os d'animal comportant des traces de combustion.

\section{Datation, commentaire}

Le contexte stratigraphique de la sépulture indique une date au cours de la phase 3 , mais elle ne peut être davantage précisée.

\section{SP 342}

Tombe à fosse découverte par l'équipe française le 10 septembre 2003 dans le secteur Sud, à l'Ouest du point G 3. Orientation N.-E., perpendiculaire à celle de SP 337 et SP 332. Voir ci-dessous pour les niveaux intérieurs. Pl. 44e-f et $\mathbf{4 5 a - b}$

\section{Contexte stratigraphique}

La fosse était creusée dans 1'US 8/516; elle atteignait en profondeur l'US 173/542, liée à l'installation du mur MR 3. La zone était recouverte par l'US 133, constituée de très nombreuses pierres associées à du sable; dans cette US ont été mis au jour un strigile en bronze (en trois fragments, l'un trouvé vers la ciste SP 339, au niveau 5,43), quelques tessons et des ossements d'animaux. 


\section{Description archéologique}

L'empierrement, d'une longueur d'environ $170 \mathrm{~cm}$, se situait au niveau 5,96 au N.-E., à 5,77 au S.-O. ; vers le centre une pierre de granit avec traces de rouge se trouvait au niveau 6,31. La fosse est creusée dans l'US 147, sableuse.

Dépôt - Ce dernier était lié à un petit muret en forme de $\Gamma$ qui entourait la tombe au N.-O. et au N.-E. Dans l'US 133 ont été mis au jour un strigile en bronze (en trois fragments, l'un trouvé vers la ciste SP 339, au niveau 5,43), ainsi que quelques tessons et des ossements d'animaux. De même, au-dessus de la sépulture, a été découvert pris dans l'US 2/501 le DP 29 qui lui est associé.

Sépulture - Le comblement est constitué d'un sédiment sableux de couleur brun foncé (US 147/150).

Dans la partie supérieure de la fosse se trouvaient, au niveau de la tête, quatre clous en fer, deux verticaux (niveaux 5,57 et 5,49; long. 12,5 cm), deux tordus (niveaux 5,58 et 5,38). Un clou vertical et un autre tordu étaient l'un contre l'autre à l'extrémité supérieure de la fosse ; au N.-E. de la fosse, en haut de la paroi, un grand clou tordu (PI. 45b). Contre la paroi N.-O., entre le genou et la cheville, fragment d'un autre clou (?) en fer, niveau 5,22, et fragment de fer contre la paroi Sud au niveau 5,39.

La fosse, de forme étroite et oblongue, a une longueur de $170 \mathrm{~cm}$, une largeur uniforme de $35 \mathrm{~cm}$ et une hauteur conservée variant entre $30 \mathrm{~cm}$ (à la tête) et $40 \mathrm{~cm}$ (aux pieds). Les parois sont verticales et le fond présente une forte déclivité vers le S.-O. La cruche 1 était placée au niveau du bassin, à droite. La monnaie en bronze 2 était insérée dans la bouche.

\section{Description anthropologique}

Anthropologie de terrain - L'individu se présentait en décubitus dorsal. Le crâne, au N.-E., apparaissait par sa face supéro-latérale droite, en position primaire très contractée. Le rachis était en parfaite connexion anatomique et les connexions thoraciques étaient strictes. La mise à plat des côtes était complète et les deux clavicules étaient fortement verticalisées, la scapula droite postéro-latérale, ce qui indique une très forte constriction. Les bras étaient en forte adduction, le gauche apparaissant par sa face postéro-latérale et le droit par sa face latérale. Les avant-bras étaient placés symétriquement en extension, le gauche passant sous l'os coxal homolatéral et le droit sur l'os coxal homolatéral. Les deux mains étaient en parfaite connexion anatomique. L'os coxal droit était verticalisé et les membres inférieurs, placés symétriquement en extension, présentaient des connexions strictes. Les deux pieds étaient éversés, avec une petite verticalisation des dernières phalanges, en butée contre la paroi de la fosse.

Ces observations permettent de conclure clairement à une décomposition en espace colmaté. Les forts effets de contrainte bi-latérale et longitudinale peuvent être mis en relation avec la présence initiale d'un linceul très serré et contraignant la tête.

En effet, malgré l'étroitesse de la fosse ( $35 \mathrm{~cm})$, les ossements du sujet, à part les pieds, ne sont pas en butée contre les parois de la fosse et le crâne, pourtant très comprimé, est placé à plus de $20 \mathrm{~cm}$ de l'extrémité de la fosse. Des similitudes dans la position et l'extrême constriction sont à noter entre ce sujet et celui de la tombe SP 332.

Anthropologie biologique - L'individu est complet et l'état de conservation des ossements est moyen, en raison d'une grande fragilité. Le sujet est un adulte mature de sexe féminin, sa stature estimée est de $157 \mathrm{~cm}$.

Longueurs maximales : fémur gauche $390 \mathrm{~mm}$; humérus droit $270 \mathrm{~mm}$; tibia droit $310 \mathrm{~mm}$; radius droit $200 \mathrm{~mm}$

La denture est en mauvais état, avec de nombreuses caries.

\section{Inventaire des objets}

1 - (= CC 37) Petite cruche de fabrication locale. Inv. FR 2.38. Pl. 45b (en haut)

2 - (= M 37) Monnaie en bronze. Inv. PIN 3667.

\section{Datation, commentaire}

La situation stratigraphique, tout comme l'association au dépôt DP 29, indique une date autour de 340.

\section{SP 343}

Tombe à fosse découverte par l'équipe française le 11 septembre 2003 dans le secteur central, entre les points $\mathrm{G} 4$ et $\mathrm{H} 4$. Orientation N.-E. Niveau supérieur 4,24 à 4,32, niveau inférieur 3,54 à 3,57. Pl. 45c-e

\section{Contexte stratigraphique}

L'US 198/221/223/586/622 marquait le niveau d'installation de la fosse (niveau 4,24) qui atteignait en profondeur la dune US 218/527. Elle était recouverte par un tumulus (US 552 et 553).

\section{Description archéologique}

La sépulture étaient protégée par un tumulus individuel de $6 \mathrm{~m}$ de diamètre et d'une hauteur approximative de 110 à $120 \mathrm{~cm}$. Il s'étendait au N.-E. jusqu'aux murs MR 3, 4 et 5, qui s'adossaient sur une série de remblais placés sur son flanc. Le remplissage était constitué d'un sable clair (US 552) auquel se superpose un sable brun compact, présent dans les deux tiers Ouest du tumulus (US 553).

L'horizon supérieur de la fosse était recouvert d'un imposant amas de terre argileuse (US 579) qui scellait la sépulture et isolait son comblement du remblai inférieur du tumulus (US 552). Les dimensions de la fosse sont particulièrement remarquables : profonde en son centre d'environ $80 \mathrm{~cm}$, elle présentait à son sommet une longueur maximale de $190 \mathrm{~cm}$ sur une largeur de $85 \mathrm{~cm}$. Les parois étaient relativement droites, avant de s'infléchir très nettement au niveau du squelette, où la largeur de la fosse ne représentait plus que $55-60 \mathrm{~cm}$ autour des épaules et des membres inférieurs; le fond était relativement plat. Les parois étaient revêtues par un plaquage d'argile dont la consistance était identique au scellage supérieur (US 579).

Le comblement (US 581) était constitué d'une succession complexe d'horizons sableux clairs entrecoupés par des 
couches de sable terreux, comprenant tous deux des nodules d'argile. L'individu se présentait en décubitus dorsal. Le crâne était pris dans une couche argileuse, tandis que les côtés du squelette reposaient dans du sable relativement terreux, sauf le long du bras gauche où il était plus grossier. Le lécythe aryballisque 1 constituait la seule offrande ; son col brisé avait été déposé sur le côté droit du bassin.

L'association avec les dépôts DP 32 et DP 34 est assurée.

\section{Description anthropologique}

Anthropologie de terrain.- Le crâne, au N.-E., se présentait sur sa face antéro-supérieure, trahissant un léger effet de paroi dû aux limites de la fosse. Le rachis était en parfaite connexion, sans aucun effet de torsion. La mise à plat des côtes était incomplète : une certaine conservation du volume costal était attestée, ce qui constitue un très fort indice de décomposition en espace colmaté. Les bras étaient en adduction, placés le long du corps, et les avant-bras étaient placés symétriquement, en supination. La main gauche était située sur le fémur gauche, tandis que la droite se situait en fond de fosse, posée à plat. Les clavicules ne montraient aucun effet de compression, et il est notable que le sternum soit resté en place, malgré la fluidité du sédiment. Les deux humérus apparaissaient par leur face antéro-médiale, ce qui correspond à une légère ouverture des bras, venant se caler contre les parois latérales. La ceinture pelvienne était fermée et les fémurs, en extension, ont subi une légère éversion. Les deux pieds, en parfaite connexion anatomique, étaient légèrement éversés et les phalanges étaient verticalisées, contre la paroi de la fosse.

Toutes ces observations permettent de conclure clairement à une décomposition en espace colmaté. Aucun effet de contrainte n'est visible sur le corps, si ce n'est quelques effets de paroi dus aux limites du creusement. Il semble donc que le sujet n'a pas été inhumé dans un linceul, ou alors très lâche et ne laissant aucune trace tangible. Ce sujet offre un très bel exemple de décomposition en espace colmaté, ce qui est même surprenant compte tenu de la nature très fluide du sédiment, remplaçant immédiatement les chairs décomposées.

Anthropologie biologique - L'individu, complet et en excellent état de conservation, est un adulte de sexe masculin très robuste et comportant des insertions musculaires très marquées. La stature estimée est de $166 \mathrm{~cm}$. Longueurs maximales : fémur droit $450 \mathrm{~mm}$; humérus gauche $300 \mathrm{~mm}$; tibia droit $310 \mathrm{~mm}$; radius droit $240 \mathrm{~mm}$. Les dents sont en bon état et très peu usées. Les troisièmes molaires sont absentes. Quelques enthésopathies sont à noter sur les patellas et les calcanéus.

\section{Inventaire des objets}

1 - (= CP 24) Lécythe aryballisque à figures rouges. Inv. PIN 3663 (FR 2.27). Pl. 45e

\section{Datation, commentaire}

Le contexte stratigraphique de cette sépulture indique qu'il s'agit de la première tombe de la phase 2 dans les secteurs concernés par nos fouilles. Elle peut être datée dans les années 400-390.

\section{SP 344}

Tombe à tuiles découverte par l'équipe bulgare les 11-12 septembre 2003 dans le secteur Nord, à l'Ouest du point H 6. Orientation S.-E. Niveaux : sur la tuile Est 4,79, sur le crâne 4,78, sur la tuile inclinée 4,47 , sur la pierre à côté du mur semi-circulaire 4,72, sur les pierres du côté Est de la tombe 4,93 et 5,20 m. Pl. 46

\section{Contexte stratigraphique et description archéologique}

La tombe était installée dans l'espace intermédiaire entre le mur MR 8 et l'enclos MR 6/7. Elle avait provoqué la destruction du parement interne du premier mur et perturbé les derniers vestiges de l'enclos. Lors du nettoyage des pierres de MR 8 ont été trouvés des fragments de céramique commune : une partie du fond d'une cruche rouge à pied annulaire ; les anses d'une cruche et d'une amphore; des fragments de panses de cruches et un objet très corrodé en bronze (couteau ? strigile ?). La tombe, en partie détruite, était revêtue de tuiles : l'une en position verticale du côté S.-E., une autre inclinée à côté d'elle, puis une tuile entière et le quart d'une autre posés horizontalement. L'une d'entre elles (Inv. PIN 3840) porte une marque qui a la forme du symbole dièse (\#). Le lécythe se trouvait sur l'épaule droite.

\section{Description anthropologique}

Le squelette était en position allongée, sur le dos, membres en extension. Le crâne, quelques côtes et d'autres os se trouvaient au niveau du sommet de la première tuile. La partie gauche du squelette était bien conservée, celle de droite (une partie de l'épaule et des côtes, un bras) a été perturbée par le déplacement des tuiles.

Le sujet est un adulte de sexe féminin âgé de 18 à 35 ans, qui présentait des cribra orbitalia.

\section{Inventaire des objets}

1 - (= CC 157) Lécythe de fabrication locale. Inv. PIN 3839. Pl. 46a

\section{Datation, commentaire}

Le contexte stratigraphique de la tombe indique qu'elle plus récente que MR 8 dont l'installation est datée par le foyer $\mathrm{F} 7$ vers 280-260. Par sa position sous l'US 1/101/117/194/500, on peut la situer vers le milieu du $\mathrm{III}^{\mathrm{e}} \mathrm{s}$.

\section{SP 346}

Tombe à tuiles découverte par l'équipe bulgare le 16 septembre 2003 dans le secteur Nord, au S.-O. du point G 5. Orientation S.-E. Niveau sur le crâne 4,33, sur les jambes 4,14; au sommet des tuiles de 4,26 à 4,83. Pl. 47

\section{Contexte stratigraphique et description archéologique}

Une sorte de caisson, placé sur la surface de l'US 589, entourait la sépulture sur trois côtés en prenant appui sur MR 5 et 6 (long. attestée $290 \mathrm{~cm}$, larg. 75 à $70 \mathrm{~cm}$ ). Le mur 
de façade était constitué de deux assises de gros blocs de granit grossièrement équarris. Deux alignements de moellons assuraient la liaison avec MR 5 et 6.

La sépulture était installée dans une fosse profonde, creusée à partir de l'US 589, jusqu'à l'US 575/588, qui entamait l'extrémité N. de MR 5. Elle était recouverte par l'US 1/101/117/194/500. Le sujet était protégé par trois paires de tuiles placées en bâtière (long. totale 1,65 m). Une tuile, posée de chant, fermait chacun des petits côtés Du côté S.-O., les tuiles s'étaient effondrées sur le sujet. Deux d'entre elles étaient timbrées : - AI (= TT 2), et $\Theta E O$ (= TT 6).

La monnaie en bronze 1 était placée du côté gauche du maxillaire inférieur, la couronne $\mathbf{2}$ dans la zone du crâne (au-dessus et au-dessous). L'unguentarium 3 était posé à côté du coude gauche, l'unguentarium 4 à l'intérieur du coude droit, l'objet en fer (clou) $\mathbf{5}$ entre les côtes gauches et la boucle d'oreille en bronze $\mathbf{6}$ du côté droit du crâne.

\section{Description anthropologique}

Le squelette était en position allongée, sur le dos, membres en extension, la tête orientée au S.-E. Le crâne était détérioré, surtout du côté gauche, par la chute de la tuile.

L'individu est une adulte féminin, âgé de 18 à 35 ans (pour ses pathologies osseuses, voir ci-dessous le diagnostic d'A. Keenleyside).

\section{Inventaire des objets}

1 - (= M 38) Monnaie en bronze. Inv. PIN 3842. Pl. 47b

2 - (= M 10) Couronne funéraire constituée d'un bandeau en plomb, avec des feuilles en bronze doré, des fleurs et des fruits. Inv. PIN 3843.

3 - (= CC 163) Unguentarium de fabrication locale.

Inv. PIN 3844. Pl. 47d

4 - (= CC 164) Unguentarium de fabrication locale.

Inv. PIN 3845. Pl. 47a

5 - (= M 49) Clou en fer. Inv. PIN 3846.

6 - (= M 4) Boucle d'oreille en bronze. Inv. PIN 3847.

\section{Datation, commentaire}

Cette sépulture présente une situation similaire à celle de SP 344, ce qui oriente également vers le milieu du III ${ }^{\mathrm{e}} \mathrm{s}$.

\section{SP 347}

Tombe à tuiles découverte par l'équipe bulgare le 18 septembre 2003 dans le secteur Nord, entre les points H-I 6-7. Orientation S.-E. Niveau sur le crâne 3,88, sur le bassin 3,74, sur les genoux 3, 94. PI. 48-49

\section{Contexte stratigraphique et description archéologique}

Du côté N.-E., un alignement de sept blocs grossièrement équarris prolongeait le mur MR 8 et venait isoler ainsi la tombe de la voie littorale. En haut du comblement de fosse, une structure de moellons de forme ovale, d'une longueur maximale de $140 \mathrm{~cm}$, entourait la sépulture.

La tombe était creusée dans l'US 575/588. Le sujet était couvert par trois paires de tuiles placées en bâtière, ses petits côtés fermés par une tuile posée verticalement. Celle du petit côté N.-O. était tombée à l'intérieur de la tombe. Des fragments de deux autres tuiles, placés au sommet de cette structure, en renforçaient l'étanchéité. Cinq de ces tuiles portaient un timbre en relief : AI (3 exemplaires, =TT3) et HPA (2 exemplaires, = TT5).

Dimensions de la fosse, $160 \times 110 \mathrm{~cm}$; longueur de la tombe $128 \mathrm{~cm}$. Les astragales 1 étaient placés dans le remblai au-dessus du squelette, la monnaie $\mathbf{2}$ à côté de la tuile tombée, le lagynos $\mathbf{3}$ à côté de la main gauche.

\section{Description anthropologique}

Le squelette était en décubitus dorsal. Le bras gauche était plié au niveau du coude, presque à angle droit, et reposait sur la zone du ventre. Le bras droit, allongé à côté du corps, se trouvait sous le bassin. Il est possible que, lors de sa chute, la tuile N.-O. ait déplacé les os des membres inférieurs : les deux fémurs étaient en effet croisés, le tibia gauche passait sous la partie droite du bassin, le tibia droit était posé sur le fémur droit. Les pieds se trouvaient à côté du genou gauche (sous la tuile qui est tombée).

Le sujet est un adulte de sexe féminin âgé d'au moins 50 ans (pour ses pathologies osseuses, voir ci-dessous le diagnostic d'A. Keenleyside).

\section{Inventaire des objets}

1 - (= D 12) Astragale. Inv. PIN 3850.

2 - (= M 39) Monnaie en bronze. Inv. PIN 3851.

3 - (= CC 101) Lagynos de fabrication locale. Inv. PIN 3852. Pl. 49b

\section{Datation, commentaire}

La sépulture est probablement contemporaine de SP 344 et 346, vers le milieu du III $^{\mathrm{e}}$ s.

\section{SP 362}

Tombe à tuiles découverte par l'équipe française le 12 août 2004, en secteur Est, au Nord du point F 3, dans le prolongement du mur MR 1. Orientation N.-O. Niveau supérieur des tuiles en place, de 4,37 à 4,22; inférieur 3,66 à 3,72. Pl. 50

\section{Contexte stratigraphique}

La fosse était signalée en surface par une structure de forme rectangulaire qui l'enserrait sur trois côtés, sauf à proximité du mur MR 2 (US 153, niveau 5,00 à 4,90 au S.-E., 5,10 à 4,98 au N.-O.).

La fosse (US 176) était creusée à partir du remblai US 19/114/129 jusqu'à l'horizon argileux US 211/214/625, qui recouvrait la dune US 218/627.

L'installation de la sépulture semble avoir provoqué l'enlèvement du bloc oriental de la ciste SP 345 et perturbé la périphérie du foyer F 1 (niveau 4,61). Elle contenait un clou en fer et un fragment de plomb. Entre les deux, un petit bloc de coquillages concrétionnés a été repéré au niveau 5,03. 


\section{Description archéologique}

La fosse était de forme oblongue, les parois verticales, les limites du creusement bien visibles du côté S.-O. Son comblement était constitué d'un sable meuble jaune (US 152). Deux tuiles formaient un coffrage sur les petits côtés, trois autres paires étaient placées en oblique, formant une couverture en bâtière. Seules cinq tuiles étaient à peu près complètes ( $T$ 1 à T 5), la T 3 (PI. 50d) portant la marque estampée ПO II (= TT 8); les autres fragments sont numérotés T 6 à T 11. Elles reposaient aux niveaux 3,66 à 3,72. Trois offrandes étaient placées dans la fosse : contre la paroi S.-O. la cruche $\mathbf{1}$ au niveau 4,33 et le pot 2 au niveau 4,27 , derrière la tuile $\mathrm{T} 1$, au N.-O., le fond de cruche $\mathbf{3}$; deux fragments d'une aiguille en bronze (4) étaient placés au niveau des cuisses de l'individu. Une pièce de monnaie $\mathbf{6}$ reposait sur le maxillaire supérieur.

\section{Description anthropologique}

Anthropologie de terrain - L'individu se présentait en décubitus dorsal. Le crâne, au N.-O., se présentait sur sa face antéro-supéro-latérale gauche, témoin d'un effet de paroi dû à la position de dépôt du défunt, tête butant contre la tuile de chant de l'aménagement. La mandibule était en connexion lâche avec le crâne, puisqu'elle avait chuté vers l'avant au niveau de C7-T1. L'atlas était en connexion stricte avec le crâne et avec l'axis, qui apparaissaient tous deux en face antérieure, sans aucune torsion. Le reste du rachis ne présentait que des connexions strictes, sans dislocations mais avec une légère torsion latérale. La mise à plat des côtes était incomplète : les deux hémithorax ont conservé un volume costal assez important, avec un dénivelé de plus de $10 \mathrm{~cm}$ entre les extrémités vertébrales et sternales de certaines côtes.

Cette conservation du volume du gril costal constitue un bon indice de décomposition en espace colmaté, où les sédiments remplacent directement les chairs décomposées. La ceinture scapulaire témoignait d'une compression importante, avec une verticalisation des deux clavicules. La ceinture pelvienne était fermée et des effets de parois étaient sensibles au niveau des membres inférieurs et des pieds, en position semi-verticale. De nombreux effets de compression sur le corps, ainsi que la position du défunt attestent la présence initiale d'un linceul assez contraignant.

Anthropologie biologique - Sujet robuste, sub-complet et en très bon état de conservation. Toutes les dents sont présentes. Usure tabulaire très prononcée. Caries sur PM1 gauche inférieur, début d'abcès également. Début de carie sur canine inférieur gauche. Importante carie sur M3 inf. droite. Léger dépôt de tartre. Début de parondontopathie. Maxillaire : perte et agénésie dentaire de M2 D. Perte des 3 molaires côté gauche et début de résorption alvéolaire partielle. Carie sur canine droite et PM1 D. Carie sur canine supérieure gauche et PM1 G, parondontopathie. Abcès au-dessus de la canine gauche (racine). Léger dépôt de tartre. Trace de bronze sur haut du maxillaire comprenant les 4 incisives. Sutures crâniennes en cours de synostose, suture coronale. Protubérance occipitale externe prononcée. Arcades sourcilières bien prononcées.

Le sujet est un adulte âgé de plus de 45 ans, de sexe masculin.

\section{Inventaire des objets}

1 - (= CC 70) Petite cruche de fabrication locale. Inv. PIN 4029.

2 - (= CC 207) Pot à deux anses de fabrication locale.

Inv. PIN 4030. PI. 50e (en bas à dr.)

3 - (= CC 100) Fond de cruche de fabrication locale. Inv. PIN 4031 (FR 3.1). Pl. 50e (au milieu à g.)

4 -Amphore de provenance indéterminée (héracléote?), argile orangée. Fragment représentant le sabot (endommagé) avec le départ de la tige du pied. Ht $7 \mathrm{~cm}$. Inv. FR 3.2.

Sabot peu articulé par rapport à la tige, à profil tronconique, avec une dépression arrondie dans la partie inférieure. Pl. 50e (en haut à g.)

5 - (= M 33) Deux fragments d'une aiguille à chas en bronze. Inv. PIN 4032. Pl. 50e (en bas)

6 - Monnaie en bronze. [Non disponible au moment de l'étude]

\section{Datation, commentaire}

Les offrandes ne donnent pas d'indication chronologique précise, mais la nature de cette sépulture et sa position le long de la route, analogue à celle des tombes SP 344,346 et 347 , oriente vers la phase 4 . Cette date dans la première moitié du III $\mathrm{s}$. est confirmée par la marque estampée de la tuile TT8, un même exemplaire ayant été trouvé dans un contexte de cette époque durant les fouilles de 1946-1949.

\section{SP 370}

Tombe à fosse, trouvée par l'équipe française le 18 août 2004 dans le secteur Est, entre les points F 3 et F 4. Orientation N.-E. Niveau au fond de la fosse 4,77 (tête), 4,78 (pieds). Pl. 51

\section{Contexte stratigraphique et description archéologique}

La sépulture était installée à la surface de la couche caillouteuse US 143/537/598/634. Aucune limite de fosse n'a été découverte, mais les observations anthropologiques ont permis de conclure à une décomposition en espace vide. Les ossements étaient directement recouverts par le foyer F 11.

Les fragments d'un lécythe étaient placés entre les jambes, l'embouchure reposant sur le bassin. Une aiguille en bronze se trouvait près de l'épaule gauche, au niveau 4,77.

\section{Description anthropologique}

La sépulture contenait les restes, assez mal conservés, d'un enfant de 3 ans ( \pm 12 mois). La décomposition du corps s'est effectuée en espace vide.

\section{Inventaire des objets}

1 - (= CC 151) Lécythe aryballisque de fabrication locale. Inv. PIN 4105 (FR 3.49).

2 - (= M 34) Aiguille à chas en bronze. Inv. PIN 4104 (FR 3.48). Pl. 51c

\section{Datation, commentaire}

La position de la sépulture, sous F 11, mais sur l'horizon stratigraphique qui recouvre $\mathrm{F} 9$, permet de la dater au début du second quart du IVe $s$. 


\section{SP 375}

Tombe à fosse trouvée par l'équipe française le 20 août 2004 dans le secteur Sud, entre les points G 3 et H 3. Orientation N.-O. Niveau du muret dans l'angle Nord 4,68, dans l'angle Sud 4,70, à l'Ouest 4,38; niveau au fond de la fosse 4,02 (embouchure de la cruche 4,10). PI. 52

\section{Contexte stratigraphique}

La sépulture était recouverte par le même tumulus que SP 339. La tombe a été installée contre le petit côté S.-O. de la tombe à ciste SP 339, après un intervalle de temps limité. Il n'a pas été possible de déterminer si sa fosse (US 621) a été creusée à un moment où le tumulus de SP 339 était déjà en place, en raison du sable jaune homogène US 515 qui la recouvrait à cet endroit, mais on constate que son remplissage se distinguait nettement de ce sable. Elle atteignait en profondeur les dunes US 218/627 et 617/619.

\section{Description archéologique}

Les parois de la fosse, longue d'1 m, sont revêtues d'un plaquage de petits moellons sur trois côtés, la dalle N.-O. de la ciste formant le quatrième. Parmi ces pierres, près des pieds, se trouvait un fragment du fond de la cruche 4 (niveau 4,33, US 632). Le comblement de la fosse (US 622) était constitué d'une terre sableuse brune dans laquelle ont été trouvés quelques charbons de bois (niveau 4,68) et un fragment d'amphore. L'alabastre 1 était posé le long du bras gauche (le goulot sur l'avant-bras droit) et le lécythe aryballisque 2 entre l'humérus droit et les côtes. Une boucle d'oreille en bronze (3) était en place contre la tempe gauche. Dans une couche noire, sous la tête, se trouvait la cruche de fabrique locale 4 .

Association possible avec les dépôts DP 26, DP 30 et DP 31.

\section{Description anthropologique}

La sépulture contenait les restes, assez bien conservés, d'un sujet de 8 ans $( \pm 12$ mois). L'analyse de la position et de la déconnexion des ossements sur le terrain permet d'attester une décomposition en espace vide, ce qui indique que la fosse devait sans doute être recouverte à l'origine de planches de bois, les blocs d'entourage servant probablement au calage de l'ensemble. La découverte d'une boucle d'oreille en place incite à penser que l'enfant est une fille.

\section{Inventaire des objets}

1 - (= CC 158) Alabastre de fabrication locale. Inv. PIN 4109a (FR 3.50). Pl. 52e (en bas à dr.)

2 - (= CC 150) Lécythe aryballisque de fabrication locale. Inv. PIN 4109b (FR 3.51).Pl. 52e (à g.)

3 - (= M 5) Boucle d'oreille en bronze. Inv. PIN 4111 (FR 3.53). Pl. 52e (en bas au centre)

4 - (= CC 46) Cruche de fabrication locale. Inv. PIN 4110 (FR 3.52). Pl. 52e (au centre)

\section{Datation, commentaire}

Le lien avec la ciste SP 339 est clair, l'écart chronologique entre les deux sépultures ne doit pas être important : une date vers 390-380 est donc probable. 


\section{Inventaire des dépôts : DP 1 à 20 et 35 fouilles bulgares ; DP 21 à 34, fouilles françaises}

\section{DP 1}

Découvert le 7 août 2002 dans le secteur Sud, au S.-E. du point G 2. Niveau. 6,83. Pl. 53a-b

\section{Contexte stratigraphique et description}

Le dépôt reposait parmi l'amas de moellons découvert en haut de comblement de la fosse supérieure de SP 244.

Association évidente avec cette sépulture.

\section{Inventaire des objets}

1 - (= CP 41) Lékanis à figures rouges avec son couvercle. Inv. PIN 2664a. Pl. 53a (à g.)

2 - (= CP 38) Lécythe aryballisque. Inv. PIN 2665a. PI. 53b

3 - (= VN 8) Gobelet à vernis noir. Inv. PIN 2666. PI. 53a (à dr.)

\section{Datation, commentaire}

Le gobelet, similaire à celui découvert dans SP 329, et la lékanis orientent vers le second quart du $\mathrm{IV}^{\mathrm{e}} \mathrm{s}$. Cette datation est confirmée par la position stratigraphique du dépôt et son association avec SP 244.

\section{DP 2}

Trouvé le 23 septembre 2002 dans le secteur Sud, au N.-O. du point H 2. Niveau 5,05. Pl. 53c

\section{Contexte stratigraphique et description}

Les objets, entourés d'un alignement circulaire de pierres, reposaient sur la dalle (B) de la couverture de la ciste SP 291. Le pot 1 était placé dans une des deux coupes.

Association évidente avec SP 291.

\section{Inventaire des objets}

1 - (= CC 187) Pot à une anse de fabrication locale.

Inv. PIN 3129. Pl. 53c (en haut)

2 - (= VN 34) Coupe-skyphos à vernis noir. Inv. PIN 3130.

Pl. 53c (à g.)

3 - (= VN 51) Coupe à une anse à vernis noir, trouvée posée à l'envers. Inv. PIN 3131. Pl. 53c (au centre)

4 - (= VN 52) Coupe à une anse à vernis noir. Inv. PIN 3131a. PI. 53c (à dr.)

\section{Datation, commentaire}

La coupe-skyphos 2 oriente vers le premier quart du IV e s., la position du dépôt sur une des dalles de couverture de SP 291 permet de proposer une date vers 390-380.

\section{DP 3}

Trouvé le 20 septembre 2002 dans le secteur Sud, au N.-O. du point $\mathrm{H}$ 2. Pl. 53d-g

\section{Contexte stratigraphique et description}

Le dépôt a été découvert près de l'angle N.-O. des dalles de couverture de SP 291.

Association évidente avec cette sépulture.

\section{Inventaire des objets}

1 - Amphore d'Héraclée du Pont, argile brun-beige fortement micacée. Seuls le bord, le col et les attaches supérieures des anses sont conservés. Ht 24,2 cm, diam. de l'embouchure 10,4 cm. Inv. PIN 3171. Pl. 53d

Col relativement haut, s'élargissant progressivement vers l'épaule ; bord évasé et épaissi en bourrelet ; les deux anses, de section ovale, étaient attachées sous le bord. Traces de peinture rouge sous le bord (bande), sur les anses et à mi-hauteur du col (zone en forme de 8). Sur la partie supérieure du col, timbre englyphique illisible.

Type I de $\mathrm{S}$. Monahov : fin du $\mathrm{V}^{\mathrm{e}}$ ou premier quart du $\mathrm{IV}^{\mathrm{e}} \mathrm{s}$. Cf. Monahov 2003, p. 126-132 et 316-320, pl. 86-90. Pour la marque peinte sur le col, ibid., p. 316, pl. 86, 4 ; Monahov 1999, p. 175, pl. 62, 1 : le timbre du fabricant Dionysos I (Groupe des fabricants anciens : Kats 2003, p. 275) oriente vers les premières années du $\mathrm{IV}^{\mathrm{e}} \mathrm{s}$.

2 - Amphore d'Héraclée du Pont, argile brun-orangé micacée. Seuls le bord, une petite partie du col et les attaches supérieures des anses sont conservés. Ht 6,4 cm, diam. de l'embouchure 10,2 cm. Inv. PIN 3120.

Le profil du bord est identique à celui de l'amphore $\mathbf{1}$; les deux anses, de section ovale, étaient attachées sous le bord. Traces de peinture rouge sur l'attache d'une des anses. Probablement même type que l'amphore 1 .

3 - Amphore d'Héraclée du Pont, argile beige-rosé micacée. Seuls le bord, une petite partie du col et les attaches supérieures des anses sont conservés. Ht 9,1 cm, diam. de l'embouchure 10,8 cm. Inv. PIN 3121. Pl. 53e

Le profil du bord est identique à celui de l'amphore 1 ; les deux anses, de section ovale, étaient attachées sous le bord. Traces de peinture rouge sous le bord. Probablement même type que l'amphore $\mathbf{1}$.

4 - Amphore d'Héraclée du Pont, argile beige fortement micacée. Seuls le bord, une petite partie du col et les attaches supérieures des anses sont conservés. Ht $6 \mathrm{~cm}$, diam. de l'embouchure $10 \mathrm{~cm}$. Inv. PIN 3122. Pl. 53f

Bord évasé à lèvre arrondie ; les deux anses, de section ovale, étaient attachées sous le bord. Traces de peinture rouge sous le bord. Probablement même type que l'amphore $\mathbf{1}$.

5 - Partie inférieure d'une cruche avec le fond percé. Argile brune. Pied bas annulaire. Ht $8 \mathrm{~cm}$, diam. de la panse $11,8 \mathrm{~cm}$. Inv. PIN 3125. Pl. 53g

6 - Charbon de la taille d'un bouchon.

\section{Datation, commentaire}

La position du dépôt et le lien évident qu'elle entretient avec SP 291 indiquent une date vers 390-380. 


\section{DP 4}

Trouvé le 30 septembre 2002 dans le secteur Sud, entre les points E 2 et F 2, près du mur MR 2. Pl. 54a

\section{Contexte stratigraphique et description}

Ce dépôt a été découvert près de l'extrémité Sud-Est du mur MR 2.

Il est probablement associé à l'enclos situé dans le prolongement de MR 1, en dehors des limites de l'espace couvert par les fouilles conjointes.

\section{Inventaire des objets}

1 - (= VN 65) Bol à vernis noir, trouvé posé à l'envers. Inv. PIN 3200. Pl. 54a (en bas)

2 - (= VN 66) Bol à vernis noir, trouvé posé à l'envers. Sous le pied graffito $\Phi I$. Inv. PIN 3201. Pl. 54a (à g.)

3 - Canthare à vernis noir, trouvé posé à l'envers.

Inv. PIN 3202. [Non disponible au moment de l'étude]

4 - Enochoé à vernis noir. Inv. PIN 3203. [Non disponible au moment de l'étude]

5 - (= CC 51) Cruche de fabrication locale. Inv. PIN 3204. Pl. 54a (au centre)

6 - (= CC 191) Pot miniature à une anse de fabrication locale, posé à l'envers à $28 \mathrm{~cm}$ de la poitrine du squelette de SP 295. Inv. PIN 3205. Pl. 54a (à dr.)

\section{Datation, commentaire}

Les deux bols $\mathbf{1}$ et $\mathbf{2}$ indiquent une date dans le second quart ou le milieu du $\mathrm{IV}^{\mathrm{e}} \mathrm{s}$.

\section{DP 5}

Trouvé le 2 octobre 2002 dans le secteur Sud, entre les points E 2 et F 2, à l'Est de DP 4. Pl. 54b

\section{Contexte stratigraphique et description}

Tout comme DP 4, DP 5 est associé à l'enclos qui se développe dans le prolongement du mur MR 1, à l'extérieur de la zone couverte par les fouilles conjointes.

\section{Inventaire des objets}

1 - (= VN 91) Coupelle à vernis noir, trouvée posée à l'envers. Inv. PIN 3219. Pl. 54b (au centre)

2 - (= VN 46) Canthare à vernis noir, posé à l'envers sur la coupelle 1 (entre les deux un coquillage noir). Inv. PIN 3220. Pl. 54b (à dr.)

3 - Canthare à vernis noir, une anse manque. Inv. PIN 3221. [Non disponible au moment de l'étude]

4 - (= CC 52) Cruche de fabrication locale. Inv. PIN 3222. Pl. 54b (à g.)

5 - Pot. Inv. PIN 3223. [Non disponible au moment de l'étude] 6 - (= CC 179) Pot de fabrication locale dont l'embouchure était collée à celle du pot 5. Inv. PIN 3224. Pl. 54b (en haut)

\section{Datation, commentaire}

La coupelle $\mathbf{1}$ et le canthare $\mathbf{2}$ orientent vers le deuxième quart ou le milieu du IV ${ }^{\mathrm{e}} \mathrm{s}$.

\section{DP 6}

Trouvé le 12 octobre 2002 dans le secteur Sud, entre les points $\mathrm{G} 1$ et $\mathrm{H}$ 2. Pl. 54c

\section{Contexte stratigraphique et description}

Le contexte stratigraphique est incertain, mais l'anse du lécythe $\mathbf{1}$ a été retrouvée dans la fosse de SP 303, ce qui indique l'association certaine d'une partie des objets avec cette sépulture.

\section{Inventaire des objets}

1 - (= CP 39) Lécythe à décor réticulé. Inv. PIN 3367. Pl. 54c (à g.)

2 - Lampe à deux becs, fragmentaire : cassure au centre, à l'emplacement d'une anse (?). Argile orange, traces d'engobe rouge. Deux larges becs opposés, le réservoir est ouvert. $\mathrm{Ht} 1,3 \mathrm{~cm}$; diam. du réservoir $8,9 \mathrm{~cm}$; diam. de l'embouchure $6 \mathrm{~cm}$. ; larg. au niveau des becs $12 \mathrm{~cm}$. Inv. PIN 3368.

3 - Cruche miniature, rudimentaire. Argile rouge brique avec du sable. Surface grise polie. Ht 5,6 cm; diam. de la base $3,7 \mathrm{~cm}$; diam. de l'embouchure $3,5 \mathrm{~cm}$; diam. max. de la panse 4,8 cm. Inv. PIN 3369. Pl. 54c (au milieu à g.)

4 - (= VN 26) Bolsal miniature à vernis noir. Inv. PIN 3370. Pl. 54c (à dr.)

5 - (= CC 102) Coupe de fabrication locale. Inv. PIN 3371.

6 - Pot à pâte grise. Sans numéro d'inventaire. [Non disponible au moment de l'étude] Pl. 54c (au milieu)

\section{Datation, commentaire}

Le dépôt associe des objets de différentes périodes: la lampe $\mathbf{2}$ et la coupe $\mathbf{5}$ appartiennent à une date relativement haute dans le $\mathrm{V}^{\mathrm{e}} \mathrm{s}$. ; le lécythe $\mathbf{1}$ et le bolsal $\mathbf{4}$ au $\mathrm{IV}^{\mathrm{e}} \mathrm{s}$. Le lécythe 1 est étroitement associé à SP 303 que le contexte stratigraphique rattache à une date relativement haute dans le $\mathrm{IV}^{\mathrm{e}} \mathrm{s}$., qui correspond par ailleurs à la chronologie du bolsal.

\section{DP 7}

Trouvé le 12 août 2003 dans le secteur Sud, au N.-E. du point H 2.

\section{Contexte stratigraphique et description}

Le dépôt a été découvert au-dessus des pierres du muret qui bordait au S.-O. les tombes SP 316 et 325 . Son association à une sépulture demeure indéterminée.

\section{Inventaire des objets}

1 - Amphore de Chios. Bord, col et quelques fragments de la panse. Sans numéro d'inventaire. [Non disponible au moment de l'étude] 
2 - (= VN 28) Bolsal à vernis noir, trouvé posé à l'envers. Inv. PIN 3620.

3 - (= CC 206) Pot à deux anses de fabrication locale, posé à

l'envers. Inv. PIN 3620a.

\section{Datation, commentaire}

La position stratigraphique du dépôt au-dessus du muret, dont la construction remonte aux années 350-340, oriente vers la seconde moitié du IV ${ }^{\mathrm{e}} \mathrm{s}$.

\section{DP 8}

Trouvé le 26 août 2003 dans le secteur Sud, au Sud du point H 3. Pl. 55a

\section{Contexte stratigraphique et description}

Le dépôt a été découvert contre la façade O. du muret qui entourait SP 316 et 325 , à proximité de la première des deux sépultures. Il reposait à la base du mur.

Son association à une sépulture demeure indéfinie.

\section{Inventaire des objets}

1 - Amphore de Thasos, argile rosée. Seuls le bord, le col avec le départ de la panse et une des anses sont conservés. À l'intérieur du col a été trouvé un élément organique.

Inv. PIN 3742. [Non disponible (étude d'après photos)]

Col haut, presque cylindrique dans sa partie supérieure, puis s'évasant vers l'épaule ; bord saillant à face supérieure aplatie et face extérieure oblique, de section triangulaire; deux anses verticales à section ovale étaient attachées à la partie supérieure du col et sur l'épaule.

Série II-B-3 de S. Monahov : vers 350-300. Cf. Monahov 2003, p. 70-71. Parallèles : ibid., p. 276, pl. 46, 2-3 ; Monahov 1999, p. 409, pl. 182, 1. Les timbres des éponymes récents Krinis et Hérakleitos (groupe I de Debidour 1986, p. 330 ; Avram 1996, p. 53, tabl. I) sur les deux premiers exemplaires permettent de les dater dans les années 320 ou au début des années $310^{37}$.

2 - (= CC 29) Cruche de fabrication locale. Inv. PIN 3743.

3 - (= CC 67) Cruche de fabrication locale. Inv. PIN 3744.

\section{Datation, commentaire}

La position du dépôt, immédiatement à l'Ouest du muret construit vers 350-340, et l'amphore thasienne 1 orientent vers une date autour de 330-320.

37 Le groupe était daté entre 345 et 335 par M. Debidour. La chronologie plus basse avancée ici tient compte de l'abaissement de la date traditionnelle du début du timbrage récent proposé plus tard par Y. Garlan, ce qui décale automatiquement de 5-10 ans en moyenne les éponymes du groupe: Garlan 1990; Avram 1996, p. 22-32 ; Garlan 1999, p. 48-54.

\section{DP 9}

Trouvé le 13 août 2003 dans le secteur Nord, au N.-O. du point I 6. Niveau 6,18. Pl. 55b

\section{Contexte stratigraphique et description}

Le dépôt était installé sur le remblai US 655, presque à la surface des couches supérieures d'occupation. Il était perturbé par SP 315, ce qui explique son engagement partiel sous cette dernière tombe. Son association à une sépulture demeure indéterminée, en raison des rapports chronologiques incertains qu'il entretient avec SP 320 et de son contenu, qui le rapproche des contextes de rejets réunissant des objets ayant servi à des libations sur les tombes avoisinantes.

\section{Inventaire des objets}

1 - (= CC 69) Cruche de fabrication locale. Inv. PIN 3624.

2 - (= CC 71) Cruche de fabrication locale, trouvée posée à l'envers. Inv. PIN 3625.

3 - (= CC 72) Cruche de fabrication locale, fond percé.

Inv. PIN 3626.

4 - Cruche de couleur rouge, très fragmentaire. Inv. PIN 3621. [Non disponible lors de l'étude]

5 - Fragments d'une cruche de couleur rouge. Inv. PIN 3622. [Non disponible lors de l'étude]

6 - Bol à engobe, fortement fragmentaire. Sans numéro d'inventaire. [Non disponible lors de l'étude]

7 - Trois cruches, argile rouge orangée, dont une avec le fond percé et une seconde avec le col décoré de cannelures horizontales. Sans numéro d'inventaire. [Non disponibles lors de l'étude]

8 - Quatre cruches, argile rouge. Sans numéro d'inventaire. [Non disponibles lors de l'étude]

9 - Fragments de quatre cruches, argile rouge. Sans numéro d'inventaire. [Non disponibles lors de l'étude]

\section{Datation, commentaire}

Le dépôt est antérieur à SP 315, qui vient le perturber, mais son association à SP 320 n'est pas certaine. Sa position stratigraphique indique une date tardive à la fin de la phase 3 ou au début de la phase 4.

\section{DP 10}

Trouvé le 13 août 2003 dans le secteur Nord, au centre des points I-J 5-6, au-dessus du mur MR 6.

Découvert au-dessus du MR 6 dans un contexte stratigraphique incertain. Son association à une sépulture demeure indéterminée.

\section{Inventaire des objets}

1 - Couvercle. Argile micacée rouge orangé. Ht $3,3 \mathrm{~cm}$, diam. 12 cm. Inv. PIN 3632.

2 - Skyphos à vernis noir. Inv. PIN 3633. [Non disponible au moment de l'étude] 
3 - Fragments de coupes. Sans numéro d'inventaire.

\section{Datation, commentaire}

La position du dépôt au-dessus du mur MR 6 oriente vers une date postérieure à la phase 2 .

\section{DP 11}

Trouvé le 14 août 2003 dans le secteur Nord, au Nord du point I 5.

\section{Contexte stratigraphique et description}

Le dépôt a été découvert entre SP 319 et 322, dans un contexte stratigraphique incertain.

Son association à SP 336 est possible en raison de la chronologie, mais non certaine.

\section{Inventaire des objets}

1 - (= CC 205) Pot à deux anses de fabrication locale, trouvé posé à l'envers, avec à l'intérieur un coquillage sombre de la mer Noire. Inv. PIN 3674.

2 - Skyphos à vernis noir, trouvé posé à l'envers avec une moule à l'intérieur. Inv. PIN 3675.

3 - (= CC 119) Bol de fabrication locale, trouvé posé à l'envers. Inv. PIN 3676.

\section{Datation, commentaire}

Le bol $\mathbf{3}$ trouve des parallèles précis dans les foyers $\mathrm{F} 2$ et $\mathrm{F} 5$, ce qui oriente vers le premier quart du $\mathrm{IV}^{\mathrm{e}} \mathrm{s}$.

\section{DP 12}

Trouvé le 15 août 2003 dans le secteur Nord, à l'Ouest du point H 5. Pl. 55c-d

\section{Contexte stratigraphique et description}

Le dépôt a été découvert dans le remblai tumulaire US 647, au-dessus de la ciste SP 334. Il couvrait une zone de $84 \mathrm{x}$ $47 \mathrm{~cm}$.

L'association avec SP 334 est assurée.

\section{Inventaire des objets}

1 - Amphore de Mendé, argile rosée micacée. La presque totalité de la panse et le pied manquent. $\mathrm{Ht} 28 \mathrm{~cm}$, diam. de l'embouchure 13,8 cm. Inv. PIN 3679. PI. 55c

Col légèrement concave, orné d'une arête en relief dans sa partie inférieure, reposant sur une épaule assez large et arrondie à son extrémité ; bord saillant à face supérieure convexe et face extérieure oblique; deux anses verticales à section ovale sont attachées sous le bord et à l'épaule.

Variante II-B de S. Monahov : premier quart du IV e $\mathrm{s}$. Cf. Monahov 2003, p. 91-92. Le diamètre de la panse de notre exemplaire est moins important que d'habitude, ce qui peut indiquer une date plus tardive, mais le col garde les proportions caractéristiques des amphores du premier quart du $\mathrm{IV}^{\mathrm{e}} \mathrm{s}$. Il s'agit vraisemblablement d'un sous-type de cette variante: voir Monahov 2003, p. 293, pl. 63, 3-6: le premier de ces exemplaires est attribué à la variante II-B finale, les autres comptent parmi les premiers représentants de la variante II-C ; tous ont un col plus long et de ce fait doivent être un peu plus récents.

2 - Amphore d'Héraclée du Pont, argile beige orangé. La presque totalité de la panse et le pied manquent. $\mathrm{Ht} 26,8 \mathrm{~cm}$, diam. de l'embouchure $8,8 \mathrm{~cm}$. Inv. PIN 3680 . PI. 55d

Col relativement haut, s'évasant progressivement vers l'épaule qui est fortement oblique ; bord épaissi en bourrelet ; deux anses verticales à section ovale attachées sous le bord et à l'épaule. Traces de peinture rouge sous le bord. Sur la partie supérieure du col, timbre englyphique sur deux lignes, illisible.

Type I de S. Monahov : fin du $\mathrm{V}^{\mathrm{e}}$ ou premier quart du $\mathrm{IV}^{\mathrm{e}} \mathrm{s}$. Cf. Monahov 2003, p. 126-132. Parallèles : ibid., p. 317, pl. 87, 6 ; Monahov 1999, p. 188, 204, 212, 226, pl. 72, 2. 80, 1. 87, 2 et 93, $1:$ le timbre du fabricant Onasos (Groupe des fabricants anciens : Kats 2003, p. 275) renvoie aux premières années du $\mathrm{IV}^{\mathrm{e}} \mathrm{s}$., ceux des éponymes Aristoklès et Ly (- -) (premier groupe de magistrats: Kats 2003, p. 275) et du fabricant Dionysos II vers les années 390-380.

3 - Amphore timbrée de provenance indéterminée.

Inv. PIN 3681. [Non disponible lors de l'étude]

\section{Datation, commentaire}

Les amphores $\mathbf{1}$ et $\mathbf{2}$ orientent vers une date dans le premier quart du IV ${ }^{\text {e }}$ s., sans doute vers 390-380 compte tenu de la position stratigraphique du dépôt.

\section{DP 13}

Trouvé le 15 août 2003 dans le secteur Nord, à l'Ouest du point H 5. Pl. 56a-c

\section{Contexte stratigraphique et description}

Le dépôt a été découvert dans le remblai tumulaire US 647, au-dessus de la ciste SP 334 à laquelle il est évidemment associé.

\section{Inventaire des objets}

1 - (= CC 185) Pot de fabrication locale. Inv. PIN 3682. Pl. 56a et b (à g.)

2 - (= VN 17) Bolsal à vernis noir, qui contenait une moule. Inv. PIN 3683. Pl. 56b (au centre)

3 - Lampe entièrement conservée (sauf l'anse). Argile beige rosé, trace de combustion sur le bec. Sous le disque supérieur, liserés concentriques en relief, arrachement de l'anse sur chaque bord. Ht $3,7 \mathrm{~cm}$; diam. de la base $3 \mathrm{~cm}$; diam. de l'ouverture 2,7 cm ; long. avec le bec 9,7 cm. Inv. PIN 3684 . Pl. 56b (à dr.) et c

Type 24 C Prime de l'Agora d'Athènes: Howland 1958, p. 66-67, pl. 9 et 37 (daté entre la fin du $\mathrm{V}^{\mathrm{e}} \mathrm{s}$. et le deuxième quart du IV ${ }^{\mathrm{e}}$.

\section{Datation, commentaire}

Le contexte stratigraphique du dépôt, ainsi que le bolsal $\mathbf{2}$, orientent vers les années 390-380. 


\section{DP 14}

Trouvé le 18 août 2003 dans le secteur Nord, au S.-E. du point J 6. Niveau 5,96. Pl. 56d-e

\section{Contexte stratigraphique et description}

Ce dépôt reposait à l'intérieur d'un alignement en pierre semi-circulaire d'orientation N.-O., qui chevauchait partiellement la fosse de SP 338. La fonction de cette structure, similaire à certains marqueurs de la phase 3 mis au jour à Kalfata (SP 283, 329 et 342), demeure relativement obscure.

Son orientation diffère des tombes voisines, en particulier SP 338, ce qui rend l'association avec cette dernière tombe problématique. L'hypothèse d'un cénotaphe n'est pas à exclure.

\section{Inventaire des objets. Pl. 56e}

1 - (= CC 57) Cruche de fabrication locale, embouchure orientée à l'Ouest, fond percé. Inv. PIN 3688.

2 - (= CC 8) Enochoé de fabrication locale, fond percé. Inv. PIN 3689.

3 - (= CC 58) Cruche de fabrication locale. Inv. PIN 3690.

4 - Cruche de couleur rouge, fragmentaire. Inv. N 3691.

5 - (= CC 40) Cruche de fabrication locale. Inv. PIN 3692.

6 - (=VN 47) Canthare à vernis noir, très fragmentaire.

Inv. PIN 3694.

7 - (= CC 59) Cruche de fabrication locale. Inv. PIN 3688a (ou BG J 06a).

8 - (= CC 41) Cruche de fabrication locale. Inv. PIN 3692a (Inv. BG J06b).

9 - (= CC 42) Cruche de fabrication locale. Inv. PIN 3692b (ou BG J06c).

10 - (= CC 60) Cruche de fabrication locale. Inv. PIN 3688b (ou BG J 06d).

\section{Datation, commentaire}

L'œnochoé $\mathbf{2}$ et le canthare à vernis noir $\mathbf{6}$ orientent vers le milieu ou le troisième quart du $\mathrm{IV}^{\mathrm{e}} \mathrm{s}$.

\section{DP 15}

Trouvé le 18 août 2003, en deux parties, au N-E. du point I 5. Pl. 57a-c

\section{Contexte stratigraphique et description}

Le dépôt a été découvert dans le remblai US 650 qui formait la couverture tumulaire de SP 336, au-dessus de cette sépulture, à laquelle il est peut-être associé.

\section{Inventaire des objets}

1 - (= CP 26) Lécythe aryballisque à figures rouges, fond percé. Inv. PIN 3685. Pl. 57c

2 - Amphore de provenance indéterminée. Seule une des anses est conservée, sur laquelle on distingue un timbre. Inv. PIN 3685a. [Non disponible lors de l'étude]
3 - Amphore d'Héraclée du Pont, argile rouge brun. Seuls le bord, la partie supérieure du col et les attaches supérieures des deux anses sont conservés. Ht 11,2 cm, diam. de l'embouchure $10 \mathrm{~cm}$. Inv. PIN 3685b. Pl. 57a

Col presque cylindrique dans sa partie supérieure; bord épaissi en bourrelet sur la face extérieure ; les deux anses, de section ovale, étaient attachées sous le bord. Sur la partie supérieure du col, timbre englyphique rectangulaire apposé à

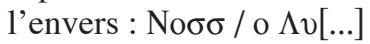

Le timbre de l'éponyme Ly(- -) (premier groupe de magistrats: Kats 2003, p. 275) oriente vers les années 390, vers le début de la décennie selon V. Kats ou plutôt vers la fin selon S. Monahov. Pour la date, cf. Monahov 1999, p. 629, annexe 4 ; Monahov 2003, p. 125 ; Kats 2003, p. 275.

4 - Amphore de Thasos, argile beige rosé. Seule une des anses est conservée. Ht 12,5 cm. Inv. PIN 3685c. Pl. 57b

Anse verticale à section ovale. Sur la partie supérieure, timbre en relief contenant une inscription partiellement effacée disposée tout autour d'un emblème central :

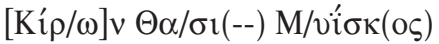

$$
\begin{aligned}
& \text { Boucle d'oreille } \leftarrow
\end{aligned}
$$

La magistrature de Myiskos (groupe E1 de Y. Garlan) peut être située vers 365-360. Cf. Garlan 1999, p. 182. Parallèles : ibid., p. $194, \mathrm{n}^{\circ} 490$.

\section{Datation, commentaire}

La chronologie fournie par les timbres amphoriques s'avère contradictoire. L'amphore thasienne $\mathbf{4}$ indique une date dans la seconde moitié des années 360, alors que l'amphore héracléote 3 est plus ancienne d'environ 30 ans. Cette situation révèle vraisemblablement un contexte archéologique perturbé.

\section{DP 16}

Trouvé le 20 août 2003 dans le secteur Nord, au S.-O. du point I 6. Niveau 5,87 .

\section{Contexte stratigraphique et description}

Le dépôt reposait en haut de comblement de la fosse de la tombe SP 327, elle-même installée directement au-dessus du mur MR 6.

L'association avec SP 327 est assurée.

\section{Inventaire des objets}

1 - Péliké à figures rouges, fragmentaire. Inv. PIN 3707. [Non disponible lors de l'étude]

2 - (=VN 74b) Bol à vernis noir. Inv. PIN 3708.

3 - (= VN 44) Canthare à vernis noir. Inv. PIN 3709.

\section{Datation, commentaire}

Le bol $\mathbf{2}$ et le canthare $\mathbf{3}$ indiquent une date dans le second quart du IV ${ }^{\text {e }}$ s., la situation stratigraphique du dépôt va dans le même sens (vers 370-350). 


\section{DP 17}

Trouvé le 21 août 2003 dans le secteur Nord, au Sud du point I 5. Niveau 5,01 à 5,12. Pl. 57d-g

\section{Contexte stratigraphique et description}

Le contexte stratigraphique demeure incertain. Néanmoins, le dépôt reposait au centre d'un alignement semi-circulaire de pierres, dans un sable similaire à l'US 9/508.

Association possible avec SP 323 ou SP 324.

\section{Inventaire des objets}

1 - Lampe miniature. Inv. PIN 3714.

2 - Anse en os. Inv. PIN 3715.

3 - (= CC 137) Bol de fabrication locale, trouvé posé à l'envers au niveau 5,12. Inv. PIN 3716. Pl. 57d et g (au centre) 4 - (= VN 29) Bolsal à vernis noir. Inv. PIN 3717. Pl. 57g (à g.)

5 - (= CC 160) Unguentarium de fabrication locale, placé sous la coupe 3. Inv. PIN 3718. Pl. 57g (à dr.)

6 - (= CC 68) Cruche de fabrication locale. Inv. PIN 3719.

Pl. 57e

7 - Astragale trouvé entre les pierres. Inv. PIN 3720.

\section{Datation, commentaire}

L'unguentarium 5 oriente vers la fin du $\mathrm{IV}^{\mathrm{e}}$ ou le début du III $\mathrm{e}$ s.

\section{DP 18}

Trouvé le 22 août 2003 dans le secteur Nord, au S.-E. du point J 6. Niveau 5,73. Pl. 58a

\section{Contexte stratigraphique et description}

Ce dépôt est probablement installé dans le remblai de sable US 654, sous la structure de pierres semi-circulaire liée à DP 14.

Association probable avec SP 333 ou SP 338.

\section{Inventaire des objets}

1 - (= CC 28) Cruche de fabrication locale, fond percé.

Inv. PIN 3721. Pl. 58a (à g.)

2 - (= VN 27) Bolsal à vernis noir trouvé posé à l'envers, entièrement conservé. Inv. PIN 3722. Pl. 58a (à dr.)

3 - Partie inférieure d'un amphoriskos. Sans numéro d'inventaire. [Non disponible lors de l'étude]

\section{Datation, commentaire}

La position du dépôt, sous DP 14, et le bolsal 2 orientent vers le second quart du IV e $\mathrm{s}$., ce qui est confirmé, par ailleurs, par l'association probable avec SP 333.

\section{DP 19}

Trouvé le 26 août 2003 dans le secteur Nord, au S.-E. du point $\mathrm{J} 6$.

\section{Contexte stratigraphique et description}

Le contexte stratigraphique demeure incertain, mais le dépôt reposait à un niveau supérieur à SP 333, tombe à laquelle il pourrait être associé.

\section{Inventaire des objets}

1.- (= CC 5) Enochoé de fabrication locale. Inv. PIN 3740.

2.- (= CC 33) Cruche de fabrication locale. Inv. PIN 3740a.

3.- Enochoé, surface rouge, embouchure tournée vers le Nord. Inv. PIN 3741. [Non disponible lors de l'étude]

4.- Cruche, surface rouge ; fragmentaire : manquent le col, l'embouchure et l'anse. Argile rouge orangé avec un peu de mica. Ht conservée $6,9 \mathrm{~cm}$; diam. de la base $5,4 \mathrm{~cm}$, diam. max. $8,6 \mathrm{~cm}$. Sans numéro d'inventaire.

\section{Datation, commentaire}

La position du dépôt, au-dessus de SP 333, et l'œnochoé 1 orientent vers le second quart ou le milieu du $\mathrm{IV}^{\mathrm{e}} \mathrm{s}$.

\section{DP 20}

Trouvé le 8 septembre 2003 dans le secteur Nord, entre les points $\mathrm{J} 5$ et $\mathrm{J} 6$. Niveau environ 4,90.

\section{Contexte stratigraphique et description}

Contexte stratigraphique incertain. Association probable avec SP 333.

\section{Inventaire des objets}

1 - (= CC 192) Pot de fabrication locale, trouvé posé à l'envers. Inv. PIN 3805.

2 - (= CC 193) Pot de fabrication locale. Inv. PIN 3806.

3 - Coupe ou bol à vernis noir, à décor estampé sur le fond. Inv. PIN 3807. [Non disponible lors de l'étude]

\section{Datation, commentaire}

Les deux pots ne donnent aucune date, mais la position et le niveau du dépôt suggèrent une association avec SP 333, dont la mise en place intervient vers 370-350.

\section{DP 21}

Trouvé en septembre 2002 dans le secteur Sud, au N.-E. de G 2. Niveau moyen 6,44. Pl. 58b

\section{Contexte stratigraphique et description}

Le dépôt reposait à la surface de l'US 2/501, sous l'US 1/101/117/194/500. Association probable avec SP 299, installée immédiatement à l'Ouest à partir du même niveau. 


\section{Inventaire des objets}

1 - (= CC 45) Cruche de fabrication locale. Inv. FR 1.53.

2 - Amphore, argile orangée: quelques fragments de panse dispersés à l'Est et à l'Ouest de la cruche. Type indéterminé. Inv. FR 1.45 .

\section{Datation, commentaire}

La situation stratigraphique et l'association probable avec SP 299 orientent vers la toute fin du IV ${ }^{\text {e }}$ s. ou le début du III ${ }^{\mathrm{e}}$.

\section{DP 22}

Trouvé en septembre 2002 dans le secteur Sud, au S.-E. du point F 3. Niveau moyen 6,29. Pl. 58c-d

\section{Contexte stratigraphique et description}

Le dépôt était déposé au sommet du petit remblai (US 3) qui formait la couverture de SP 264. Il était recouvert par l'US 2/501.

L'association avec la tombe SP 264 est assurée.

\section{Inventaire des objets}

1 - (= VN 4) Enochoé à vernis noir. Fond percé. Inv. FR 1.12. Pl. 58d

2 - (= M 35) Aiguille à chas en bronze. Inv. FR 1.6.2.

\section{Datation, commentaire}

L'association avec SP 264 permet de dater ce dépôt vers le milieu du IV ${ }^{\mathrm{e}} \mathrm{s}$.

\section{DP 23}

Vaste dépôt fouillé entre le 3 et le 10 septembre 2002 dans le secteur central, à l'Ouest de G 3. Niveau supérieur 6,21, inférieur 5,78 (strigile 5,86). Pl. 59-60

\section{Contexte stratigraphique et description}

Ce dépôt était disposé sur le pendage formé par la couche archéologique, de direction N.-E./S.-O. Il était entièrement pris dans le remblai de terre US 2/501, apparaissant dès la surface de cette couche, sous l'US 1/101/117/194/500. Il se développait sur une épaisseur importante jusqu'à SP 265 qu'il recouvrait partiellement. Stratigraphiquement, le dépôt est directement associé à SP 265, mais quelques trouvailles hétéroclites dans les couches supérieures (fragment de tuyau de canalisation, fragments de tuiles, ossements d'animaux épars) indiquent qu'à une étape ultérieure il avait également pu servir d'aire de rejet.

\section{Inventaire des objets}

\section{AMPHORES}

Parties supérieures (bords, cols et anses)

1 - Amphore d'Héraclée du Pont. Argile orangée. Plusieurs fragments recollés, représentant le col avec la totalité du bord, les anses et une partie de la panse. Ht totale $42,5 \mathrm{~cm}$, diam. de l'embouchure 10 à 8,9 cm. Inv. FR 1.26. Pl. 59d (à g.)-e et $60 b$

Panse conique à épaulement marqué ; col haut, légèrement concave, s'évasant plus fortement vers l'épaule ; bord épaissi en bourrelet sur la face extérieure; deux anses verticales à section ovale attachées sous le bord et à l'épaule. Sur la partie supérieure du col, timbre englyphique : lettre B.

Variante II-1 ou II-2 de S. Monahov: deuxième ou troisième quart du $\mathrm{IV}^{\mathrm{e}} \mathrm{s}$. Cf. Monahov 2003, p. 134-136. Parallèles : ibid., p. 323-324, pl. 93, 4-5 et 94, 3 ; Monahov 1999, p. 342-343 et 352, pl. 147, 2-3. 148, 1-2 et 152, 2 : les timbres des éponymes Amphitas, Bakchos, Agasillos, Simos et Apollonios, appartenant tous au quatrième groupe de magistrats (Kats 2003, p. 276), se situent vers 350-340.

Le timbre avec la lettre $B$ sur le col est très rare et ne peut être daté de façon indépendante. Nous le retrouvons sur notre amphore 2, ainsi que sur l'amphore du dépôt DP 27 (voir ci-dessous) dans un contexte du milieu du $\mathrm{IV}^{\mathrm{e}} \mathrm{s}$. Le seul parallèle qui nous soit connu provient de l'habitat d'Élizavetovskoe dans le delta du Don: Brashinskiy 1980, p. $177, \mathrm{n}^{\circ} 479$, pl. 30 . Un lien avec l'éponyme contemporain Bakchos mentionné plus haut n'est pas exclu.

2 - Amphore d'Héraclée du Pont. Argile orangée. Plusieurs fragments recollés représentant le col, avec la plus grande partie du bord, et les deux anses. Ht conservée 29,3 cm, diam. de l'embouchure 10,2 à 8,3 cm. Inv. FR 1.27. Pl. 59d (à dr.), f et 60c

Profil identique à l'amphore 1. Sur la partie supérieure du col, timbre englyphique : lettre B (rétrograde). Même variante que l'amphore 1. Le timbre indique une date étroitement contemporaine.

3 - Provenance incertaine (Héraclée du Pont ?). Argile rouge brun. Quatre fragments recollés représentant la plus grande partie du col. Ht conservée $19 \mathrm{~cm}$. Inv. FR 1.57.

Col haut, légèrement concave, évasé vers la base.

4 - Amphore de Thasos. Argile rosée. Plusieurs fragments recollés représentant le col avec la totalité du bord, une anse et le départ de la deuxième. Ht conservée $24,8 \mathrm{~cm}$, diam. de l'embouchure $10 \mathrm{~cm}$. Inv. FR 1.28. Pl. 59c, g et 60a

Col haut, s'évasant progressivement vers l'épaule ; bord saillant à face supérieure aplatie et face extérieure oblique, de section triangulaire; deux anses verticales à section ovale qui étaient attachées à la partie supérieure du col et à l'épaule. Sur l'anse conservée, timbre rectangulaire en relief :

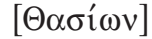 thyrse enrubanné $\rightarrow$ 'A $\mathrm{A}(\mathrm{\imath}) \sigma \tau \mathrm{\sigma} \tau\left[\varepsilon^{\prime} \lambda \eta \zeta\right] \leftarrow$}

Série II-B-3 de S. Monahov : 350-300. Cf. Monahov 2003, p. 70-71. Pour un profil similaire du col, voir ibid., p. 276, pl. 46, 4-5. Le timbre de l'éponyme Aristotelès (groupe I de M. Debidour : Debidour 1986, p. 330 ; Avram 1996, p. 53, tabl. I) oriente, d'après les dernières corrections dans la chronologie 
du timbrage récent ${ }^{38}$, vers les années 320. Parallèles : Bon 1957, p. 138 n 372 ; Garlan 1986, p. 244, tabl. B (de l'atelier de Kéramidi à Thasos); Avram 1996, p. 112, n² 224, pl. XVII.

5 - Argile brun orangé. Provenance : Thasos. Un fragment identifié représentant une partie du bord avec le départ d'une anse. Ht conservée $5 \mathrm{~cm}$. Inv. FR 1.59. Même profil que le bord de l'amphore 4.

\section{FONDS, PIEDS}

6 - Amphore d'Héraclée du Pont. Argile orangée. Deux fragments recollés représentant le pied avec une partie de la panse. Ht conservée $34,5 \mathrm{~cm}$, diam. du sabot 4,3 cm. Inv. FR 1.58.1. Pl. 60d

Pied non différencié, dans le prolongement de la partie inférieure de la panse ; sabot très peu articulé par rapport à la tige, à profil tronconique, dépression inférieure arrondie ; panse effilée, de forme conique.

Type II ou variante III-2 de S. Monahov: 375-300. Cf. Monahov 2003, p. 134-137 et 141-142. Pour un profil similaire du pied, voir ibid., p. 323-325, 328, pl. 93, 5. 94, 5. 95, 1-3. 98, 7 ; Monahov 1999, p. 335, 361 pl. 144, 2-3 et 158, 3-4 : deux de ces exemplaires remontent aux années 350, la plupart des autres portent des timbres des $\mathrm{IV}^{\mathrm{e}}$ et $\mathrm{V}^{\mathrm{e}}$ groupes de magistrats (Kats 2003, p. 276) qu'on peut attribuer aux années 340-330.

7 - Amphore d'Héraclée du Pont. Argile orangée. Un fragment identifié représentant une partie du pied. Ht $11 \mathrm{~cm}$, diam. du sabot 4,5 cm. Inv. FR 1.58.3. Même profil que le pied 6. Pl. 60h

8 - Argile orangée. Provenance indéterminée (Héraclée du Pont ?). Fragment de la partie inférieure de la panse avec le départ du pied. Ht $19 \mathrm{~cm}$. Inv. FR 1.58.5.

9 - Amphore d'Héraclée du Pont. Argile rouge brun. Trois fragments recollés représentant la totalité du pied avec le départ de la panse. Ht 16,5 cm, diam. du sabot 4,2 cm. Inv. FR 1.58.2. Même profil que le pied 6. PI. 60e

10 - Amphore d'Héraclée du Pont. Argile beige. Un fragment du pied. Ht 8,7 cm, diam. du sabot 5,5 cm. Inv. FR 1.58.4. Même profil que le pied 6. PI. 60c

11 - Amphore de Thasos. Argile beige-rosé. Un fragment représentant la presque totalité du pied. $\mathrm{Ht} 18,2 \mathrm{~cm}$, diam. du sabot $6,5 \mathrm{~cm}$. Inv. FR 1.58.6. Pl. 60f

Pied à tige longue, s'évasant légèrement vers le sabot qui est tronconique et légèrement concave dans la partie inférieure ; carène nettement marquée au raccord entre la tige et le sabot.

Série II-B-3 de S. Monahov : 350-300. Cf. Monahov 2003, p. 70-71. Pour un profil similaire du pied, voir ibid., p. 276, pl. 46, 2-7 ; Monahov 1999, p. 344, 393, pl. 149, 1 et 175, 1 : certains de ces exemplaires portent des timbres des groupes I et II de M. Debidour (Debidour 1986, p. 330-33 ; Avram 1996,

38 Voir le commentaire sur l'amphore du dépôt DP 8 ci-dessus. p. 53, tabl. I) qui orientent vers les années 330-310.

12 - Amphore de Thasos. Argile beige rosé. Un fragment représentant la presque totalité du pied. Ht 19,4 cm, diam. du sabot 6,2 m. Inv. FR 1.58.7. Pl. 60g. Même profil que le pied 11.

\section{CÉRAMIQUE À FIGURES ROUGES ET À VERNIS NOIR}

Formes complètes ou éléments significatifs

13 - (= VN 16) Coupe sans tige à vernis noir, le fond était probablement percé. Inv. FR 1.56.3.

Bords

14 - Couvercle de lékanis (?) à figures rouges. Trois fragments non jointifs du bord. Inv. FR 1.56.4.

Bord tombant à la verticale, décoré d'une frise d'oves sur la face extérieure (très effacée) ; départ de la paroi qui forme presque un angle droit avec le bord ; rainure à la transition entre les deux.

\section{Fonds, pieds}

15 - (= VN 77) Bol à vernis noir. Inv. FR 1.56.1.

16 - Lécythe à figures rouges. Fragment représentant un tiers $\mathrm{du}$ pied et du fond avec une partie de la panse. Ht $2,6 \mathrm{~cm}$. Inv. FR 1.56.2.

Pied annulaire bas. Sur la partie conservée de la panse, faibles traces d'un décor figuré illisible (palmette ?).

17 - Lékanis (?) à figures rouges ou vernis noir. Fragment représentant environ un quart du pied. Long. du fragment 4,6 cm. Inv. FR 1.56.5

Pied annulaire bas à plan de pose large et réservé. Le fragment (s'il s'agit bien du pied d'une lékanis) peut provenir du même vase que les fragments de couvercle $\mathbf{1 4}$.

18 - (= VN 78) Forme indéterminée (bol ?) à vernis noir.

Inv. FR 1.56.7.

\section{CÉRAMIQUE COMMUNE}

Formes complètes et éléments significatifs

19 - Cruche, argile rouge brun, en plusieurs fragments. Ht (notée sur le terrain avant prélèvement) $10,5 \mathrm{~cm}$, diam. de la panse (idem) 7,5 m. Inv. FR 1.29.

20 - (= CC 61) Cruche. Inv. FR 1.55.11.

21 - (= CC 25) Cruche. Inv. FR 1.55.8.

\section{Bords}

22 - (= CC 62) Cruche. Inv. FR 1.55.13.

23 - (= CC 63) Cruche. Inv. FR 1.55.14a. Même profil que le bord de la cruche $\mathbf{2 0 .}$

24 - (= CC 66) Cruche. Inv. FR 1.55.14b. Même profil que le bord de la cruche $\mathbf{2 0 .}$

25 - (= CC 64) Cruche. Inv. FR 1.55.14c. Même profil que le bord de la cruche $\mathbf{2 0}$.

26 - (= CC 65) Cruche. Inv. FR 1.55.14d. Même profil que le bord de la cruche $\mathbf{2 0}$.

27 - (= CC 43) Cruche. Inv. FR 1.55.14e.

28 - (= CC 44) Cruche. Inv. FR 1.55.14f. Même profil que 
le bord de la cruche 21, mais le vase était de plus petites dimensions.

Anses

29 - (= CC 99) Sept anses de cruches. Inv. FR 1.55.12a-f.

Fonds, pieds

30 - (= CC 90) Cruche. Inv. FR 1.55.2.

31 - (= CC 91) Cruche. Inv. FR 1.55.4.

32 - (= CC 92) Cruche. Inv. FR 1.55.5.

33 - (= CC 93) Cruche. Inv. FR 1.55.7.

34 - (= CC 94) Cruche. Inv. FR 1.55.9.

35 - (= CC 95) Cruche. Inv. FR 1.55.3.

36 - (= CC 96) Cruche. Inv. FR 1.55.6.

37 - (= CC 97) Cruche. Inv. FR 1.55.10. Forme très proche de celle de la cruche $\mathbf{3 1}$.

38 - (= CC 98) Cruche. Inv. FR 1.55.1.

Autres objets

39 - (= M 23) Strigile en bronze. Inv. FR 1.6.5.

\section{Datation, commentaire}

Les amphores héracléotes $\mathbf{1}$ et $\mathbf{2}$ portent le même timbre que l'amphore du dépôt DP 27, ce qui donne une limite chronologique supérieure vers le milieu du IV e s., alors que le timbre de l'amphore thasienne $\mathbf{4}$ ne date que des années 320.

Cependant, l'ensemble du dépôt est pris dans l'US 2/501 dont l'accumulation débute autour de 340, comme l'indique le timbre amphorique du DP 29. La constitution de ce vaste dépôt a donc dû s'étendre dans le troisième quart et le début du dernier quart du $\mathrm{IV}^{\mathrm{e}} \mathrm{s}$., plus précisément sans doute entre 340 et 320 .

\section{DP 24}

Découvert entre le 6 et le 10 septembre 2002 dans le secteur Sud, à l'Ouest du point F 3. Pl. 61a-c

\section{Contexte stratigraphique et description}

Les objets, en relation avec le marqueur de SP 283, étaient pris dans l'US 2/501. Plus que d'un ensemble cohérent, il s'agit d'un groupe d'objets dispersés à l'extérieur et à l'intérieur de la structure en forme de П qui entourait la tombe d'enfant, matérialisant les rites pratiqués sur cette sépulture. L'amphore 1 était posée contre un des blocs qui composaient l'extrémité Sud du marqueur; le lécythe 2 au N.-O. de la structure ; l'œnochoé $\mathbf{3}$ au-dessus de la tombe ; le canthare $\mathbf{4}$ à l'Est de l'œnochoé $\mathbf{3}$; les clous 5, l'un à l'extérieur près de l'angle Nord du marqueur et l'autre à l'intérieur, au S.-O. de l'œnochoé 3.

\section{Inventaire des objets}

1 - Amphore d'Héraclée du Pont, argile rosée. Fragmentaire, recollée. La plus grande partie de la panse et le pied manquent. Ht conservée $37 \mathrm{~cm}$, diam. de l'embouchure 9,4 cm.

Inv. FR 1.25. Pl. 61a

Panse biconique à épaulement arrondi se prolongeant dans un col presque cylindrique; bord évasé à lèvre arrondie, séparé du col par un léger ressaut; deux anses verticales à section ovale attachées sous le bord et à l'épaule.

Variante III-2 de S. Monahov: 375-300. Cf. Monahov 2003, p. 141-142. Parallèles : ibid., p. 328-329, pl. 98, 6 et 99, 1 ; Monahov 1999, p. 361, 370, pl. 158, 4-5 et 162, 1 et 3 ; les timbres des éponymes Silanos et Peisistratos (IV et $\mathrm{V}^{\mathrm{e}}$ groupes de magistrats : Kats 2003, p. 276) permettent de dater ces exemplaires vers 340-330.

2 - (= CP 40) Lécythe aryballisque à décor réticulé.

Inv. PIN 61 (FR 1.15). Pl. 61c (à dr.)

3 - (= VN 5) Enochoé à vernis noir, fond percé. Inv. FR 1.13.

Pl. 61c (à g.)

4 - (= VN 49) Canthare à vernis noir. Inv. FR 1.24.

5 - (= M 52) Deux clous en fer. Inv. FR 1.5.7.

\section{Datation, commentaire}

Les objets du dépôt et le contexte stratigraphique indiquent une date au début du troisième quart du $\mathrm{IV}^{\mathrm{e}} \mathrm{s}$.

\section{DP 25}

Trouvé le 12 septembre 2002 dans le secteur central, au N.-E. de H 3. Niveau supérieur 5,67, inférieur 5,57. Pl. 61d-e

\section{Contexte stratigraphique et description}

Pris dans le remblai US 2/501, il était placé à la surface de l'US 20/507/514/593, à proximité de la tombe SP 326 avec laquelle il est probablement en relation.

\section{Inventaire des objets}

1 - (= VN 83) Coupelle à vernis noir. Inv. FR 1.17. Pl. 61e (à g.)

2 - (= VN 112) Fragment d'une pyxis (?) à vernis noir.

Inv. FR 1.46.

3 - (= CC 180) Pot à une anse de fabrication locale.

Inv. FR 1.3. Pl. 25e (en haut)

4 - (= CC 181) Pot à une anse de fabrication locale, même profil que 3. Inv. FR 1.32.

5 - (= CC 121) Bol de fabrication locale. Inv. FR 1.31.

6 - Sept coquilles de moules entières et 20 valves. Inv. FR 1.22. Pl. 61e

\section{Datation, commentaire}

La coupelle 1 et le contexte stratigraphique orientent vers le second quart du $\mathrm{IV}^{\mathrm{e}} \mathrm{s}$.

\section{DP 26}

Trouvé le 12 septembre 2002 dans le secteur central, à l'Est du point H 3. Niveau 5,75. Pl. 62a-c

\section{Contexte stratigraphique et description}

Le dépôt affleurait à la surface de la couche de sable 
US 8/516 qui succédait à l'US 2/501, sous le DP 23. Association probable avec SP 339 et/ou SP 375.

\section{Inventaire des objets}

1 - (= CC 188) Pot à une anse de fabrication locale.

Inv. FR 1.2. Pl. 62b (à g.)

2 - (= CC 199) Pot à une anse de fabrication locale, miniature. Inv. FR 1.33. Pl. 62b (à dr.) et c. Profil similaire à celui du pot $\mathbf{1}$, mais panse plus trapue.

3 - (= CC 27) Cruche de fabrication locale. Inv. PIN 49 (FR 1.9). Pl. 62b (au centre)

4 - Fibule en bronze, découverte à l'intérieur du pot 2. Type thrace. Inv. FR 1.6.9.

\section{Datation, commentaire}

La situation du dépôt dans l'US 8/516, qui se développe au-dessus de SP 339, mais sous le DP23, indique une fourchette chronologique comprise entre la fin du premier quart et le début du troisième quart du $\mathrm{IV}^{\mathrm{e}} \mathrm{s}$. Cependant, la forme de la cruche 3, similaire à celle découverte au-dessus des dalles de couverture de SP 300 (Inv. PIN 3656a), mais moins évoluée que la cruche du DP 18 (Inv. PIN 3721), oriente plutôt vers une date précoce et permet de supposer une association avec SP 339 et/ou SP 375, donc vers 380-370.

\section{DP 27}

Trouvé en septembre 2002 dans le secteur central, au N.-E. du point H 3. Niveau supérieur 5,40. Pl. 62d-e et 63

\section{Contexte stratigraphique et description}

Comme le précédent dépôt, il reposait dans la couche de sable US 8/516, sous SP 265 et le remblai US 2/501, dans lequel cette couche était prise. Les objets s'étageaient en profondeur et semblent, du moins pour une partie d'entre eux, avoir été déposés dans une fosse dont les limites n'ont pas été appréhendées du fait du caractère fluide du sédiment. Association très probable avec SP 332.

\section{Inventaire des objets (voir Pl. 63d)}

1 - Amphore d'Héraclée du Pont, argile rouge brun. Fragmentaire, recollée. La totalité de la panse et le pied manquent. Ht cons. 26,5 cm, diam. de l'embouchure 9,2 cm. Inv. FR 1.34. Pl. 63a-c

Col haut, légèrement concave, s'évasant assez fortement vers l'épaule ; bord épaissi en bourrelet sur la face extérieure ; deux anses verticales à section ovale attachées sous le bord et à l'épaule. Sur la partie supérieure du col, timbre englyphique : sans doute la lettre B rétrograde, mais la barre verticale n'a pas été imprimée.

Variante II-1 ou II-2 de S. Monahov. Cf. Monahov 2003, p. 134-136. Profil similaire du col: Monahov 1999, p. 333 et 342 , pl. $143,1-2$ et $5.147,5$ : les timbres des éponymes Philinos, Euphronios et Amphitas (III ${ }^{\mathrm{e}}$ et $\mathrm{IV}^{\mathrm{e}}$ groupes de magistrats : Kats 2003, p. 276) orientent vers les années 350. Le timbre avec la lettre $B$, très rare, trouve un parallèle précis dans les amphores $\mathbf{1}$ et $\mathbf{2}$ du DP 22 qui doivent être tout à fait contemporaines de l'amphore du DP 27. Le seul autre parallèle que nous connaissons est un timbre non daté provenant de l'habitat d'Elizavetovskoe dans le delta du Don : Brashinskiy 1980, p. 177, n 479, pl. 30. La lettre B peut éventuellement se rapporter à l'éponyme Bakchos dont la magistrature se situe autour de 350.

2 - (= VN 1) Hydrie miniature à vernis noir. Inv. FR 1.35.

3 - (= VN 42) Fragment d'une coupe-canthare à vernis noir, fond percé. Inv. FR 1.42.

4 - (= CC 6) Enochoé de fabrication locale. Inv. FR 1.36.

5 - (= CC 7) Enochoé de fabrication locale. Inv. FR 1.40.

6 - (= CC 35) Cruche de fabrication locale. Inv. FR 1.11.

7 - (= CC 24) Cruche de fabrication locale. Inv. FR 1.49 (col) et 1.43 .3 (pied).

8 - (= CC 34) Cruche de fabrication locale. Inv. FR 1.10.

9 - (= CC 36) Cruche de fabrication locale. Inv. FR 1.37 (partie supérieure) et 1.43 .1 (pied).

10 - (= CC 54) Cruche de fabrication locale. Inv. FR 1.38 (partie supérieure) et 1.43 .2 (pied).

11 - (= CC 56) Cruche de fabrication locale. Inv. FR 1.39.

12 - (= CC 89) Cruche de fabrication locale. Inv. FR 1.41.

13 - (= CC 55) Cruche de fabrication locale. Inv. FR 2.40.

\section{Datation, commentaire}

L'amphore $\mathbf{1}$, l'hydrie $\mathbf{2}$ et le pied de coupe-canthare $\mathbf{3}$, tout comme la position stratigraphique du dépôt sous l'US 2/501, orientent vers le milieu du $\mathrm{IV}^{\mathrm{e}} \mathrm{s}$., confirmant l'association avec SP 332 toute proche.

\section{DP 28}

Trouvé le 12 septembre 2002 dans le secteur central, au Sud du point $\mathrm{G} 4$. Niveau 5,47 à 5,64. Pl. 64a

\section{Contexte stratigraphique et description}

Le dépôt était pris dans la couche de sable US 10/527 qui formait un petit remblai recouvrant la fosse de SP 329 : il était entouré par une structure à deux assises de pierres servant de marqueur. L'ensemble était recouvert par l'US 2/501.

L'association avec SP 329 est assurée.

\section{Inventaire des objets}

1.- (= CC 129) Bol de fabrication locale. Inv. FR 1.54.

2.- (= CC 88) Cruche de fabrication locale, trouvée contre le pied de 1. Inv. FR 1.44.1.

3.- Deux fragments de panses provenant d'une amphore et d'un vase de forme indéterminée, argile orangée ; trouvés à l'Ouest du bol 1. Inv. FR 1.44.2.

4.- (= M 53) Trois clous en fer trouvés au S.-O., au N.-O. et à l'Est du bol 1. Inv. FR 1.5.5a-c.

5.- Tige octogonale (rivet ?) en bronze, trouvé au Nord du bol 1. Long. $4,1 \mathrm{~cm}$, ép. $0,6 \mathrm{~cm}$. Inv. FR 1.6.1.

\section{Datation, commentaire}

L'association évidente du dépôt avec la tombe SP 329 permet de le dater dans les années 360-350. 


\section{DP 29}

Trouvé le 17 septembre 2002 dans le secteur Sud, au S.-O. du point G 3. Pl. 64b-d et 65

\section{Contexte stratigraphique et description}

Les objets, auxquels on doit associer quelques ossements d'animaux épars découverts lors des jours précédents (dont des dents et un tibia de mouton), étaient pris dans le remblai de terre US 2/501. Ils semblent avoir été déposés, du moins pour une partie, dans une petite fosse, ce qui est attesté notamment par le fait que la partie supérieure de l'amphore $\mathbf{1}$ et le pot $\mathbf{2}$ avaient été placés l'un au-dessus de l'autre. Le dépôt était disposé au-dessus de la fosse de SP 342, à laquelle il est étroitement associé.

\section{Inventaire des objets}

1 - Amphore d'Héraclée du Pont, argile rosée. La presque totalité de la panse, le pied, ainsi que la moitié d'une des anses manquent. Ht conservée $33,3 \mathrm{~cm}$, diam. de l'embouchure 10,5 cm. Inv. FR 1.47. Pl. 64b-d et 65a

Col haut, cylindrique dans la partie supérieure, évasé vers l'épaule qui formait un angle marqué avec la panse; bord épaissi en bourrelet sur la face extérieure ; deux anses verticales à section ovale sont attachées sous le bord et près de la base du col, sur l'épaule. Sur la partie supérieure du col, timbre englyphique sur deux lignes :

$$
\begin{gathered}
{[--] \tau v[--]} \\
\Sigma i ́ \lambda \alpha[\operatorname{vos}]
\end{gathered}
$$

Variante III-2 de S. Monahov: 375-300. Cf. Monahov 2003, p. 141-142. La magistrature de Silanos (IV e groupe de magistrats : Kats 2003, p. 276) est datée vers la fin des années 340 par V. Kats et un petit peu plus tard par S. Monahov : Monahov 1999, p. 635, annexe 4 ; Monahov 2003, p. 125 ; Kats 2003, p. 276. Les proportions fort élancées de notre exemplaire peuvent être comparées à celles d'une amphore des années 320 timbrée au nom de l'éponyme Thémist(- -) ( $\mathrm{V}^{\mathrm{e}}$ groupe de magistrats) : Monahov 2003, p. 329, pl. 99, 3. 2 - (= CC 195) Pot à une anse de fabrication locale.

Inv. FR 1.1. Pl. 64c (à g.)

3 - (= CC 38) Cruche de fabrication locale. Inv. FR 1.60.

4 - (= M 54) Clou en fer trouvé au Sud de l'amphore ; la partie supérieure manque. Surface corrodée. Long. cons. 6,2 cm. Inv. FR 1.5.1. Pl. 64c (en bas à g.)

\section{Datation, commentaire}

L'amphore timbrée $\mathbf{1}$ permet de dater ce dépôt autour de 340 .

\section{DP 30}

Trouvé le 29 août 2003 dans le secteur central, au N.-O. de G 3. Niveau moyen 5,35. Pl. 65b et d (en bas)

\section{Contexte stratigraphique et description}

Le dépôt était disposé à la surface de l'US 515, laquelle représente le remblai tumulaire de SP 339. Il était placé à $40 \mathrm{~cm}$ au-dessus des dalles de couverture de cette dernière. Association évidente avec SP 339 et/ou SP 375.

\section{Inventaire des objets}

1 - (= VN 18) Bolsal à vernis noir. Inv. FR 2.39. PI. 65d (en bas à dr.)

2 - (= VN 19) Bolsal à vernis noir. Inv. PIN 3654 (FR 2.18).

Pl. 65d ( en bas à g.)

\section{Datation, commentaire}

Les bolsals orientent vers le premier quart du $\mathrm{IV}^{\mathrm{e}} \mathrm{s}$. Le contexte stratigraphique du dépôt et son association avec SP 339 et/ou SP 375 permet d'affiner cette datation vers 390-380.

\section{DP 31}

Trouvé le $1^{\text {er }}$ septembre 2003 dans le secteur central, à l'Ouest du point G 3. Niveau supérieur 5,42; inférieur 5,10. Pl. 65b-d

\section{Contexte stratigraphique et description}

Le dépôt était installée dans une fosse creusée de l'US 8/516 à l'US 515. Seuls $20 \mathrm{~cm}$ séparaient sa partie inférieure des dalles de couverture de la ciste SP 339. Association certaine avec cette sépulture et/ou SP 375.

\section{Inventaire des objets}

1 - (= VN 53) Coupe à vernis noir. Inv. PIN 3652 (FR 2.17).

2 - (= CC 9) Enochoé de fabrication locale. Inv. PIN 3653 (FR 2.8).Pl. 65d (à dr.)

3 - (= VN 32) Coupe-skyphos à vernis noir. Inv. PIN 3656b (FR 2.16).Pl. 65c (à g.)

4 - (= VN 97) Salière à vernis noir. Inv. PIN 3658 (FR 2.22). Pl. 65c (au centre)

5 - (= CC 2) Enochoé de fabrication locale. Inv. PIN 3655 (FR 2.12).Pl. 65c (à dr.)

6 - (= CC 111) Bol de fabrication locale. Inv. FR 2.41.

7 - (= CC 112) Bol de fabrication locale. Inv. FR 2.42.

\section{Datation, commentaire}

La coupe-skyphos $\mathbf{3}$ et la salière $\mathbf{4}$ orientent vers le premier quart du $\mathrm{IV}^{\mathrm{e}} \mathrm{s}$. Le contexte stratigraphique du dépôt et son association avec SP 339 et/ou SP 375 permettent de proposer une date vers 390-380.

\section{DP 32}

Trouvé le 10 septembre 2003 entre les points G 3 et F 4 . Niveau moyen 4,23. Pl. 66a-b

\section{Contexte stratigraphique et description}

Le dépôt reposait sur la couche argileuse (US 579) qui 
scellait la fosse de SP 343, sous le sable de la couverture tumulaire. Association évidente avec cette sépulture.

\section{Inventaire des objets}

1 - (= VN 31) Coupe-skyphos à vernis noir, fond percé.

Inv. PIN 3639 (FR 2.15). Pl. 66a (à g.)

2 - (= CC 3) Enochoé de fabrication locale. Inv. FR 2.13.

Pl. 66a (à dr.)

\section{Datation, commentaire}

La position du dépôt oriente vers les années 400-390.

\section{DP 33}

Grand dépôt trouvé en septembre 2003 dans le secteur Est, au N.-O. du point F 3, dispersé et perturbé. Pl. 66c-e et 67a-b

\section{Contexte stratigraphique et description}

Les objets étaient répandus à la surface du remblai US 19/114/129, mélangés à une grande quantité de pierres. La partie inférieure du dépôt paraît provenir provient de la couche US 143/537/598/634. Il pourrait également s'agir d'une aire de rejet. L'association à une sépulture est impossible.

\section{Inventaire des objets (voir Pl. 66e)}

\section{AMPHORES}

Parties supérieures (bords, cols et anses)

1 - Provenance indéterminée (Égée du Nord ?). Argile rouge brun. Plusieurs fragments identifiés représentant le bord avec une partie du col et les deux anses. Ht. restituée $27 \mathrm{~cm}$. Inv. FR 2.56.1. Pl. 67b

Col haut, s'évasant progressivement vers l'épaule; bord à faces interne et externe convexes, souligné par un petit bourrelet en relief; les deux anses verticales à section ovale étaient attachées sous le bord et à l'épaule.

Type dit de Murighiol, première moitié du $\mathrm{IV}^{\mathrm{e}} \mathrm{s}$. Cf. Monahov 2003 , p. $79-80$ et 285 , pl. 55, 4-8. Cette amphore n'appartient sans doute pas aux exemplaires les plus anciens du type, dont elle se distingue par son bord assez épais et une facture plus grossière. L'association probable avec le pied $\mathbf{3}$, dont l'argile est très semblable, permettrait de restituer un récipient aux proportions fort allongées, proche des exemplaires du second quart du IV e s. illustrés par S. Monahov : ibid., p. 285, pl. 55, 7-8; Monahov 1999, p. 327, pl.139.

2 - Amphore de Thasos. Argile beige orangé. Fragment représentant la partie supérieure du col avec le départ d'une anse. Ht $15 \mathrm{~cm}$. Inv. FR 2.56.2. Pl. 66c-d. Découvert dans l'US 143/537/598/634, ce fragment n'appartient pas avec certitude au dépôt.

Col presque cylindrique; départ d'une anse verticale qui était attachée sous le bord. Sur le col, à hauteur de l'attache conservée de l'anse, timbre rectangulaire en relief avec une inscription fort effacée en quatre lignes : $\Lambda \varepsilon \omega v i(--) /[\Theta \alpha \sigma i ́] \omega(v) /$

$[\Delta \alpha] \mu \alpha^{\prime} \sigma-/[\tau \eta \varsigma] ?$
Le timbre de l'éponyme Léôni(- -) appartient au groupe B de Y. Garlan qui peut être daté vers 390-380. La place exacte de l'éponyme au sein du groupe n'est pas connue. Cf. Garlan 1999, p. 112. Parallèles : ibid., p. 130, nº 176.

Fonds, pieds

3 - Provenance indéterminée (Égée du Nord ?). Argile rouge brun. Deux fragments identifiés représentant le pied avec le départ de la panse. Ht $27 \mathrm{~cm}$, diam. du pied 5,1 cm.

Inv. FR 2.56.5.

Pied à tige relativement longue qui s'évase à la transition vers le sabot; sabot bas, tronconique, garni d'une petite dépression arrondie dans la partie inférieure, séparé de la tige par une carène marquée ; panse conique.

Type de Murighiol. Association probable avec les fragments 1 (voir ci-dessus).

4 - Amphore de Thasos. Argile rouge brun. Deux fragments recollés représentant le pied avec le départ de la panse. Ht 18,4 cm, diam. du pied $7 \mathrm{~cm}$. Inv. FR 2.56.3. PI. 67a

Pied à tige courte et concave, s'évasant vers le sabot qui est tronconique avec une dépression large et arrondie dans la partie inférieure ; carène nettement marquée à la jonction entre la tige et le sabot.

Série II-B-1 ou II-B-2 de S. Monahov. Cf. Monahov 2003, p. 66-70. Parallèles : Garlan 1999, p. 66, nos 142.6-8, 217.6, pl. II-III ; Monahov 1999, p. 231 et 288, pl. 95, 1. 119, 2. 125, 4 ; Monahov 2003, p. 274, pl. 44, 3. Ces exemplaires portent des timbres des groupes B et E 1 de Y. Garlan que l'on date respectivement vers 390-380 et 365-360 (Garlan 1999, p. 112 et 182). Par conséquent, on ne peut avancer pour cette amphore qu'une date assez large, dans les quatre premières décennies du $\mathrm{IV}^{\mathrm{e}} \mathrm{s}$.

5 - Amphore d'Héraclée du Pont. Argile rouge brun. Un fragment identifié représentant le pied avec le départ de la panse. Ht 21,5 cm., diam. du sabot 4,8 cm. Inv. FR 2.56.4.

Pied à tige courte, dans le prolongement de la partie inférieure de la panse ; sabot non différencié de la tige, à plan de pose arrondi, garni d'une dépression large et relativement profonde dans la partie inférieure; panse de forme conique.

Type I-A de S. Monahov. Cf. Monahov 2003, p. 132134. Parallèles : ibid., p. 322, pl. 92, 1 et 3 : les timbres des éponymes Kallias et Satyros (III ${ }^{\mathrm{e}}$ groupe de magistrats : Kats 2003, p. 276) permettent de dater ces exemplaires dans les années 360-350.

CÉRAMIQUE À FIGURES ROUGES ET À VERNIS NOIR

Formes complètes et éléments significatifs

6 - (= VN 37) Coupe-skyphos à vernis noir. Inv. FR 2.57.

\section{Bords, fragments de panse}

7 - Forme indéterminée, décor à figures rouges (traces d'une frise d'oves). Quatre fragments de la panse identifiés.

Inv. FR 2.64.6.

8 - (= VN 107) Plat à poisson à vernis noir. Inv. FR 2.64.2.

9 - (= VN 55) Coupe à vernis noir. Inv. FR 2.64.4.

10 - (=VN 63) Bol à vernis noir. Inv. FR 2.64.1.

11 - (=VN 76) Bol à vernis noir. Inv. FR 2.64.5. 
Pieds

12 - (= VN 64) Bol à vernis noir. Inv. FR 2.64.3.

13 - (= VN 41) Coupe-canthare à vernis noir. Inv. FR 2.64.7a.

14 - (= VN 70) Bol à vernis noir. Inv. FR 2.64.7b.

15 - (= VN 90) Coupelle à vernis noir. Inv. FR 2.64.7c.

\section{CÉRAMIQUE COMMUNE}

Formes complètes et éléments significatifs

16 - (= CC 32) Cruche. Inv. FR 2.11.

17 - (= CC 49) Cruche. Inv. FR 2.58.

18 - (= CC 126) Bol. Inv. FR 2.63.

19 - (= CC 31) Cruche. Inv. FR 2.10.

20 - (= CC 22) Cruche, fond percé. Inv. FR 2.59.

21 - (= CC 23) Cruche, fond percé. Inv. FR 2.60.

22 - (= CC 128) Bol. Inv. FR 2.61.

Bords

23 - (= CC 12) Oenochoé. Inv. FR 2.62.14.

24 - (= CC 50) Cruche. Inv. FR 2.62.13.

25 - (= CC 122) Bol. Inv. FR 2.62.15.

Anses

26 - (= CC 87) Six anses de cruches. Inv. FR 2.62.15.

Fonds, pieds

27 - (= CC 75) Cruche. Inv. FR 2.62.4.

28 - (= CC 76) Cruche. Inv. FR 2.62.8.

Fond discoïdal

29 - (= CC 77) Cruche. Inv. FR 2.62.9.

30 - (= CC 78) Cruche. Inv. FR 2.62.10.

31 - (= CC 79) Cruche. Inv. FR 2.62.11.

32 - (= CC 80) Cruche. Inv. FR 2.62.1.

33 - (= CC 81) Cruche. Inv. FR 2.62.2.

34 - (= CC 82) Cruche. Inv. FR 2.62.3.

35 - (= CC 83) Cruche. Inv. FR 2.62.5.

36 - (= CC 84) Cruche. Inv. FR 2.62.6.

37 - (= CC 85) Cruche. Inv. FR 2.62.7.

38 - (= CC 86) Cruche. Inv. FR 2.62.12.

\section{AUTRES OBJETS}

39 - (= TC 10) Taureau en terre cuite, fragmentaire.

Inv. PIN 4103.

40 - Lamelle en bronze percée à l'une des extrémités. Deux fragments jointifs. Long. des fragments $3,2 \mathrm{~cm}$ et $2,2 \mathrm{~cm}$. Inv. FR 2.5.8.

41 - Astragale. Inv. FR 2.65.

42 - Os d'animal et trois coquilles de moules. Inv. FR 2.66.

\section{Datation, commentaire}

Malgré son mauvais état de conservation, le matériel amphorique oriente vers 375-350 (à l'exception du timbre thasien $\mathbf{2}$ qui n'appartient pas avec certitude à ce contexte).

La position stratigraphique du dépôt, à la surface de l'US 19/114/129, indique qu'il est postérieur à l'enclos MR 1, mis en place au début du second quart du $\mathrm{IV}^{\mathrm{e}} \mathrm{s}$.

\section{DP 34}

Vase isolé trouvé le 4 septembre 2003 dans le secteur central, au S.-E. du point $\mathrm{H} 4$. Niveau supérieur 4,97, inférieur 4,81. Pl. 67c-d

\section{Contexte stratigraphique et description}

Le vase était situé à la surface de l'US 552, sous le sable US 553, couches qui constituaient la couverture tumulaire de SP 343.

\section{Inventaire des objets}

1 - (= CC 14) Cruche à deux anses de fabrication locale.

Inv. PIN 3638 (FR 2.7). Pl. 67d

\section{Datation, commentaire}

La position du vase, au sein du tumulus lié à SP 343, indique une date vers 400-390.

\section{DP 35}

Trouvé le 15 août 2002 dans le secteur Sud, au S.-O. du point F 2 .

\section{Contexte stratigraphique et description}

Le dépôt a été découvert autour des marches de l'escalier latéral qui conduisait à la sépulture, dans la fosse supérieure. Association évidente à la tombe SP 244.

\section{Inventaire des objets}

1.- Coupe à vernis noir. Inv. PIN 2667. [Non disponible lors de l'étude]

2.- Col d'une amphore timbrée. Inv. PIN 2668. [Non disponible lors de l'étude]

3.- Fragments d'une amphore.

\section{Datation, commentaire}

L'association évidente à SP 244 permet d'attribuer à ce dépôt une date dans le deuxième quart du $\mathrm{IV}^{\mathrm{e}} \mathrm{s}$. 


\section{Inventaire des objets trouvés dans les foyers (F 1 à F 11)}

\section{F 1}

Découvert par l'équipe bulgare les 6-7 octobre 2002 dans le secteur Est, à l'Ouest du point E 3. Pl. 68

\section{Contexte stratigraphique et description}

Le foyer était disposé à cheval sur les horizons US 174/ $195 / 196 / 199 / 210 / 219 / 602 / 635$ et US $198 / 221 / 223 / 586 / 642$ qui se rejoignaient dans ce secteur périphérique.

Il a été perturbé par l'installation du mur MR 1, avant d'être partiellement recouvert par l'US 143/537/598/634.

$\mathrm{Au}$ niveau 4,57/4,58, la couche charbonneuse recouvre une surface d'argile rubéfiée.

\section{Inventaire des objets}

1 - (= CP 1) Askos à figures rouges. Inv. PIN 3253. Pl. $68 f$

2 - (=VN 54) Coupe à vernis noir. Inv. PIN 3254. Pl. 68c

3 - (= VN 87) Coupelle à vernis noir. Inv. PIN 3274a. Pl. 68b

4 - (= VN 23) Bolsal à vernis noir. Inv. PIN 3276. Pl. 68d

5 - Bolsal à vernis noir (?). Inv. PIN 3276a. [Non disponible lors de l'étude]

6 - (= VN 24) Bolsal à vernis noir. Inv. PIN 3278. Pl. 68e

7 - (= VN 99) Salière à vernis noir. Inv. PIN 3274b. PI. 68a

8 - (= CC 136) Bol de fabrication locale. Inv. PIN 3273.

Pl. $68 \mathrm{~g}$

9 - Quatre pots. Inv. PIN 3275, 3275a-c. [Non disponibles lors de l'étude]

10 - Plat à poisson. Inv. PIN 3277. [Non disponible lors de l'étude]

11 - (= TC 24)《Gril à poisson ». Inv. PIN 3279. [Non disponible lors de l'étude]

12 - Trois bols. Inv. PIN 3279a-d. [Non disponibles lors de l'étude]

13 - Coupe-canthare (?) à vernis noir. [Non disponible lors de l'étude]

14 - (= TC 12) Petit masque en terre cuite. Inv. PIN 4163a.

\section{Datation, commentaire}

Les vases du foyer, qui trouvent des parallèles précis dans ceux qui composent F2 et F9, indiquent une date contemporaine, autour de 380 .

\section{F 2}

Découvert par l'équipe bulgare du 5 au 7 octobre 2002 dans le secteur Est, au N.-O. de E 2. Niveau 4,68. Dimensions : 90 x 90 cm. Pl. 69

\section{Contexte stratigraphique et description}

Le foyer reposait à la surface de l'US 174/195/196/199/2 10/219/602/635, contre la façade orientale du mur MR 2, et était recouvert par l'US 143/537/598/634. Il était constitué d'une première couche charbonneuse de $9 \mathrm{~cm}$ d'épaisseur qui surmontait une seconde couche d'argile rubéfiée. La première contenait 12 coquilles de noisette et des graines calcinées.

\section{Inventaire des objets}

1 - (= VN 103) Plat à poisson à vernis noir, très brûlé.

Inv. PIN 3282. Pl. 69b

2 - (= VN 104) Plat à poisson, très brûlé. Inv. PIN 3282a. Pl. 69a

3 - (= VN 85) Coupelle à vernis noir. Inv. PIN 3242a. Pl. 69c

4 - (= VN 86) Coupelle à vernis noir. Inv. PIN 3242b. Pl. 69d

5 - Couvercle de lékanis. Inv. PIN 3283. [Non disponible lors de l'étude]

6 - Skyphos. Inv. PIN 3284. [Non disponible lors de l'étude]

7 - Askos. Inv. PIN 3285. [Non disponible lors de l'étude]

8 - (= CC 114) Bol de fabrication locale. Inv. PIN 3243. Pl. 69i

9 - Deux bols de fabrication locale. Inv. PIN 3243a-b. [Non disponibles lors de l'étude]

10 - Deux bols de fabrication locale, posés à l'envers.

Inv. PIN 3245 et 3245a. [Non disponibles lors de l'étude]

11 - (= CC 115) Bol de fabrication locale. Inv. PIN 3281.

Pl. $69 \mathrm{f}$

12 - (= CC 116) Bol de fabrication locale. Inv. PIN 3281a.

Pl. 69g

13 - (= CC 189) Pot de fabrication locale. Inv. PIN 3244.

Pl. 69h

14 - (= CC 178) Pot de fabrication locale. Inv. PIN 3286.

Pl. 69j

15 - Fragment de cruche. Sans numéro d'inventaire. [Non disponible lors de l'étude]

16 - (= TC 25) «Gril à poisson». Inv. PIN 3241. [Non disponible lors de l'étude]

17 - (=D 13) Objet en bronze corrodé. Sans numéro inventaire. [Non disponible lors de l'étude]

18 - (= D 13) Astragale.

19 - (= VN 2) Enochoé à vernis noir. Inv. PIN 3325.

L'attribution du vase à ce foyer est incertaine. Pl. 69e

\section{Datation, commentaire}

Les vases du foyer, en particulier les deux coupelles $\mathbf{3}$ et $\mathbf{4}$, indiquent une date autour de 380 .

\section{F 3}

Découvert par l'équipe bulgare en septembre 2003, en secteur Nord, à l'Est du point $\mathrm{J} 5$.

\section{Contexte stratigraphique et description}

Le foyer était placé à l'extérieur du mur MR 6, du côté Ouest, au niveau de l'assise de pierres inférieure ; de forme presque circulaire, il mesurait 47 x $44 \mathrm{~cm}$. Il était constitué d'un petit tas de charbons au-dessus d'une couche de couleur rouge brique de $2,5 \mathrm{~cm}$ d'épaisseur.

\section{Inventaire des objets}

$\boldsymbol{I}$ - Bol à vernis noir. Inv. PIN 3738. [Non disponible lors de l'étude] 
2 - Askos à vernis noir. Inv. PIN 3739. [Non disponible lors de l'étude]

3 - Bol de fabrique commune. Sans numéro inventaire. [Non disponible lors de l'étude]

\section{Datation, commentaire}

La position du foyer contre le mur MR 6 indique une date à la fin de la phase 2 .

\section{F 4}

Découvert par l'équipe bulgare le 28 août 2003 dans le secteur Sud, entre les points H 2 et H 3. PI. 70

\section{Contexte stratigraphique et description}

Le foyer, de forme ovale, mesurait $45 \times 37 \mathrm{~cm}$. Il a été découvert sous le muret qui encadrait au S.-O. les tombes SP 316 et 325 .

\section{Inventaire des objets}

1 - Plat à poisson de fabrique locale, très fragmentaire; le fond manque. Argile sableuse de couleur rouge brique. Vasque large, en forme de cône tronqué renversé. Bord horizontal, étroit, avec deux entailles sur la surface. Ht conservée 2,5 cm, diam. max. 22,4 cm. Inv. PIN 3752. Pl. 70g

2 - (= CC 194) Pot à une anse de fabrication locale.

Inv. PIN 3753. PI. 70e

$2 \boldsymbol{a}$ - Pot à une anse de fabrication locale. Inv. PIN 3753a. [Non disponible lors de l'étude]

3 - (= CC 124) Bol de fabrication locale. Inv. PIN 3754. Pl. 70c

4 - (= VN 11) Skyphos à vernis noir. Inv. PIN 3755. PI. 70d

5 - (= TC 23) « Gril à poisson ». Inv. PIN 3756. PI. 70f

6 - (= VN 75) Bol à vernis noir. Inv. PIN 3757. Pl. 70a

7 - (= VN 67) Bol à vernis noir. Inv. PIN 3758. Pl. 70b

8 - Fragment de fond d'une cruche de fabrication locale. Sans numéro inventaire. [Non disponible lors de l'étude]

\section{Datation, commentaire}

Les vases à vernis noir du foyer, en particulier le skyphos $\mathbf{4}$, indiquent une date au début du troisième quart du $\mathrm{IV}^{\mathrm{e}} \mathrm{s}$. (vers 350-340).

\section{F 5}

Découvert entre le 3 et le 10 septembre 2003 par l'équipe française, dans le secteur central, au Sud du point G 4. Niveaux supérieurs, au N.-O. 4,87, au N.-E. 4,78 : inférieurs, au Sud 4,62, au S.-E. 4,58, à l'Est 4,45 (miroir en bronze 4,68, astragale 4,43, clou 4,45). Pl. 71

\section{Contexte stratigraphique et description}

Le foyer avait été perturbé, une partie des objets s'engageaient sous le mur MR 3. Il reposait à l'origine sur le scellage US 554/571/573/590/592/612 de la couverture tumulaire de SP 343.
Inventaire des objets (voir Pl. 71c)

1 - (=CP 2) Askos à figures rouges. Inv. PIN 3668b (FR 2.48).

2 - (= VN 33) Coupe-skyphos à vernis noir. Inv. PIN 3668d (FR 2.44).

3 - (= VN 38) Coupe-canthare à vernis noir. Inv. PIN 3668a (FR 2.45).

4 - (= VN 71) Bol à vernis noir. Inv. PIN 3668e (FR 2.47).

5 - (= CC 149) Plat à poisson de fabrication locale.

Inv. PIN 3668c (FR 2.43).

6 - (= CC 110) Bol de fabrication locale. Inv. PIN $3368 \mathrm{f}$ (FR 2.46).

7 - (= CC 165) Lékanis de fabrication locale. Inv. FR 2.50.

8 - (= CC 16) Cruche de fabrication locale. Inv. FR 2.54.

9 - (= CC 17) Cruche de fabrication locale. Inv. FR 2.51.

10 - (= CC 18) Cruche de fabrication locale. Inv. FR 2.67.

11 - (= CC 173) Pot à une anse de fabrication locale.

Inv. FR 2.52 .

12 - (= CC 174) Pot à une anse de fabrication locale. Inv. FR 2.53 .

13 - (=CC 198) Pot à une anse de fabrication locale, miniature. Inv. FR 2.68 .

14 - Amphore de provenance indéterminée, argile jaune brun. Plusieurs fragments, dont un du bord avec le départ du col, six fragments jointifs du fond (sans le pied) et des fragments de la panse. Traces de combustion. Inv. FR 2.55.1.

Col cylindrique ; départ du bord (ébréché) qui était épaissi et évasé à l'horizontale, probablement en forme de champignon.

La forme spécifique du bord rattache cet exemplaire au groupe hétéroclite dit « Soloha I » qui englobe des amphores d'origine très variée (Samos, Rhodes, Naxos, Paros, Cnide, Grande-Grèce et Sicile et probablement Ikos) : Zeest 1960, p. 91-92, pl. XIV-XVI ; Monahov 1999, p. 242-243. Son état très fragmentaire ne permet pas de l'attribuer à un des différents centres de production reconnus au sein du groupe, mais la couleur de l'argile exclut a priori son appartenance à la production de Cnide et de Samos : cf. Monahov 2003, p. 28-29 etp. 246, pl. 16; ibid., p. 102-104 et 301-302, pl. 71-72.

15 - Amphore de Péparéthos, argile orangée. Un fragment représentant le sabot avec le départ de la tige du pied et deux fragments de la panse. Diam. du sabot 7,6 cm. Inv. FR 2.55.2.

PI. 71b

Pied à tige, s'évasant vers le sabot qui est tronconique et légèrement concave par dessous ; raccord arrondi entre la tige et le sabot.

Le fragment du pied, qui conserve le profil complet du sabot, trouve un parallèle précis dans le matériel des ramassages de surface effectués sur l'île voisine d'Ikos (atelier de Tsoukalia) : Garlan, Doulgéri-Intzessiloglou 1990, p. 375, fig. 20. Par conséquent, cette île et plus spécialement l'atelier de Tsoukalia apparaissent comme le lieu de production le plus probable pour cette amphore.

Pour la typologie et la chronologie des amphores de Péparéthos, cf. Monahov 2003, p. 96-100 et 299-300, pl. 69-70: compte tenu du contexte de découverte, notre exemplaire appartient vraisemblablement à la variante I-A, datée de la première moitié du $\mathrm{IV}^{\mathrm{e}} \mathrm{s}$.

16 - Amphore de provenance indéterminée (Égée du Nord ?), argile rouge brun. Deux fragments non jointifs représentant le 
pied avec le départ de la panse. Traces de combustion. Diam. du pied $5 \mathrm{~cm}$. Inv. FR 2.55.3.

Pied à tige qui s'évase à la transition vers le sabot; sabot bas et tronconique, garni d'une petite dépression arrondie par dessous, séparé de la tige par une carène marquée; panse conique.

Type dit de Murighiol : première moitié du $\mathrm{IV}^{\mathrm{e}} \mathrm{s}$. (Monahov 2003, p. 79-80). Le profil assez fin et allongé du pied rapproche cette amphore des exemplaires les plus anciens du type, qui proviennent de contextes du premier quart du $\mathrm{IV}^{\mathrm{e}} \mathrm{s}$. : ibid., p. 285, pl. 55, 4-6 ; Monahov 1999, p. 226, pl. 93, 7.

17 - (= M 14) Disque de miroir en bronze. Un fragment manque. Diam. 10,3 cm. Inv. PIN 3668g (FR 2.5.2).

18 - Lamelle (applique ?) en bronze percée de deux trous de dimension inégale. Trois fragments, dont deux recollés. Long. $2 \mathrm{~cm}$. Inv. FR 2.5.9.

19 - Élément en bronze (ressort de fibule ?). Inv. FR 2.5.12.

20 - (= M 55) Clou en fer. Inv. PIN 3666 (FR 2.29.7).

21 - Deux astragales. Inv. FR 2.49.

\section{Datation, commentaire}

Les vases du foyer indiquent une date vers 390-380. Sur la question de l'association de ce foyer avec les sépultures voisines, voir ci-dessous, p. 162 et 172-173.

\section{F 6}

Découvert par l'équipe bulgare le 12 septembre 2003 dans le secteur Nord, au S.-O. du point G 5. Pl. 72

\section{Contexte stratigraphique et description}

Le foyer reposait à la surface de l'US 530/568/576/594, une partie était engagée sous les blocs du mur MR 7, du côté intérieur, ce qui explique qu'il n'ait pas été entièrement étudié. Il contenait des charbons de bois et des fragments de bûches calcinées. Dimensions : 117 x $28 \mathrm{~cm}$, épaisseur $7 \mathrm{~cm}$, dont $3 \mathrm{~cm}$ de terre de couleur rouge brique à la base. Association probable avec la tombe SP 334.

\section{Inventaire des objets}

1 - (= VN 101) Plat à poisson à vernis noir. Inv. PIN 3815. Pl. 72e

2 - (= VN 92) Salière à vernis noir. Inv. PIN 3816. Pl. 72c et i

3 - (= VN 93) Salière à vernis noir. Inv. PIN 3820. PI. 72b

4 - (= VN 36) Fragments d'une coupe-skyphos à vernis noir. Inv. PIN 3824. Pl. 72a

5 - (= CC 168) Couvercle de fabrication locale. Inv. PIN 3814. Pl. $72 f$

6 - (= CC 166) Lékanis de fabrication locale. Inv. PIN 3818.

Pl. 72h

7 - Bol de fabrication locale. Inv. PIN 3819.

8 - Bol de fabrication locale. Inv. PIN 3822.

9 - (= CC 113) Bol de fabrication locale. Inv. PIN 3823. Pl. 72g

10 - (= CC 175) Pot de fabrication locale. Inv. PIN 3821. Pl. 72d

11 - (= M 60) Couteau en bronze. Inv. PIN 3817.

\section{Datation, commentaire}

La position du foyer sur l'US 530/568/576/594, dont la mise en place peut être associée à la construction de l'enclos MR 6/7 (mais sous ce dernier), oriente vers la fin de la phase 2, à un moment contemporain du péribole (vers 380).

\section{F 7}

Découvert par l'équipe bulgare le 12 septembre 2003 dans le secteur Nord, au N.-E. du point H 5. Niveau 4,76. Pl. 73-74

\section{Contexte stratigraphique et description}

Le foyer reposait sur l'US 575/588, contre la façade N.-E. du mur MR 8. Dimensions : 145 x $86 \mathrm{~cm}$. Il était constitué d'une couche charbonneuse épaisse et de restes de bûches calcinées, contenant des ossements d'animaux (non étudiés) et de la vaisselle fragmentée. Pl. 73

\section{Inventaire des objets (voir Pl. 740)}

1 - (= VN 50) Canthare à vernis noir. Inv. PIN 3835. PI. 74g

2 - (= CC 147) Plat à poisson de fabrication locale.

Inv. PIN 3829. Pl. 74b

3 - (= CC 148) Plat à poisson de fabrication locale.

Inv. PIN 3833. PI. 74a

4.- (= CC 130) Bol de fabrication locale. Inv. PIN 3827. Pl. 74i

5 - (= CC 133) Bol de fabrication locale. Inv. PIN 3825.

Pl. 74d

6 - Bol de fabrique commune avec bord recourbé vers l'intérieur. Inv. PIN 3826. [Non disponible lors de l'étude]

7 - (= CC 134) Bol de fabrication locale. Inv. PIN 3831.

Pl. 74c

8 - (= CC 135) Bol de fabrication locale. Inv. PIN 3832.

Pl. 74h

9 - (= CC 131) Bol de fabrication locale. Inv. PIN 3837a.

Pl. 74e

10 - (= CC 132) Bol de fabrication locale. Inv. PIN 3837b.

Pl. 74f

11 - (= CC 144) Coupelle de fabrication locale. Inv. PIN 3828.

Pl. 74j

12 - (= CC 142) Coupelle de fabrication locale. Inv. PIN 3830.

PI. 74m

13 - (= CC 141) Coupelle de fabrication locale. Inv. PIN 3836.

Pl. 74k

14 - (= CC 143) Coupelle de fabrication locale. Inv. PIN 3834.

Pl. 741

15 - (= CC 145) Coupelle de fabrication locale. Inv. PIN 3838.

Pl. 74n

16 - Sous le plat à poisson 3 traces d'un objet en fer très corrodé.

\section{Datation, commentaire}

La situation stratigraphique du foyer, contre le mur MR 8, indique une date avancée au cours de la phase 4 , probablement vers 280-260 en raison du canthare $\mathbf{1}$. 


\section{F 8}

Découvert par l'équipe bulgare le 18 septembre 2003 dans le secteur Nord, immédiatement au Nord du point I 6. PI. 75

\section{Contexte stratigraphique et description}

Le foyer était installé à la surface de l'US 575/588, à l'extérieur du mur MR 6 sous lequel il s'engage partiellement. Il était constitué d'une épaisse couche charbonneuse contenant des ossements d'animaux, des amandes calcinées (sur le bol 8 posé à l'envers et tout autour) et des vases brisés. Du côté N.-E. était posée une pierre non taillée ; dans l'angle N.-O. a été trouvé un fragment de canalisation en terre cuite. L'association à la tombe SP 336 est probable.

\section{Inventaire des objets}

1 - (= VN 30) Coupe-skyphos à vernis noir. Inv. PIN 3860. Pl. 75c

2 - (= VN 57) Bol à vernis noir. Inv. PIN 3857. Pl. 75a

3 - (= VN 58) Bol à vernis noir à décor estampé.

Inv. PIN 3862. Pl. 75b

4 - Plat à poisson à vernis noir. Inv. PIN 3856. [Non disponible lors de l'étude]

5 - (=VN 98) Salière à vernis noir. Fragmentaire.

Inv. PIN 3861. Pl. 75d

6 - Coupelle à vernis noir. Inv. PIN 3858. [Non disponible lors de l'étude]

7 - Plat à poisson de fabrication locale. Inv. PIN 3859. [Non disponible lors de l'étude]

8 - Bol de fabrication locale, posé à l'envers. Argile grise. Sans numéro d'inventaire. [Non disponible lors de l'étude]

9 - (= CC 186) Pot de fabrication locale. Inv. PIN 3853. Pl. 75e 10 - (= CC 172) Pot à une anse de fabrication locale.

Inv. PIN 3854. PI. $75 f$

11 - Pot de fabrication locale, contenant des ossements animaux. Inv. PIN 3855. [Non disponible lors de l'étude]

\section{Datation, commentaire}

La coupe-skyphos 1 indique une date dans le premier quart du IV ${ }^{\mathrm{e}} \mathrm{s}$., ce que confirme la position stratigraphique du foyer sous le mur MR 6, ce qui le place vers 390-380.

\section{F 9}

Découvert par l'équipe française du 11 au 19 août 2004 dans le secteur Est, au N.-E. du point F 3. Niveau supérieur 4,94, inférieur 4,86. PI. 76

\section{Contexte stratigraphique et description}

Le foyer reposait à la surface de l'US US 174/195/ 196/199/210/219/602/635, contre le mur MR 3, sous l'US 143/537/598/634. Il était entouré de pierres et s'étendait sur une surface d'environ 75 sur $35 \mathrm{~cm}$.

Son épaisseur était d'environ $15 \mathrm{~cm}$. Six bûches ont pu être identifiées, correspondant d'après les analyses anthracologiques de Vanessa Py à de jeunes branches de chêne soumises à un feu très vif, dépassant les 600 degrés. Cette identification est confirmée par la présence de glands calcinés. Sur les ossements d'animaux voir p. 173.

Le matériel était dispersé sur l'ensemble de la surface, tous les objets portant des traces de combustion. Sur la question du lien éventuel entre ce foyer et les sépultures SP 339 et 375, voir ci-dessous, p. 162 et 172-173.

\section{Inventaire des objets (voir Pl. 76b)}

1 - (= CP 3) Askos à figures rouges. Inv. PIN 4033,1 (FR 3.23). 2 - (=VN 111) Lékanis à vernis noir avec son couvercle. Inv. PIN 4033 f (FR 3.22 et 3.24).

3 - (= VN 21) Bolsal à vernis noir. Inv. PIN 4033m (FR 3.16). 4 - (= VN 22) Bolsal à vernis noir. Inv. PIN 4033h (FR 3.25). 5 - (= VN 102) Plat à poisson à vernis noir. Inv. PIN $4033 \mathrm{c}$ (FR 3.18).

6 - (= VN 59) Bol à vernis noir. Inv. PIN 4033k (FR 3.15).

7 - (= VN 60) Bol à vernis noir. Inv. PIN 4033g (FR 3.17).

8 - (= VN 61) Bol à vernis noir. Inv. PIN 4033p (FR 3.28).

9 - (= VN 84) Coupelle à vernis noir. Inv. PIN 4033i (FR 3.21).

$10-(=$ VN 88) Coupelle à vernis noir. Inv. PIN 4033j (FR 3.29).

11 - (= VN 89) Coupelle à vernis noir. Inv. PIN 4033q (FR 3.62.2.).

12 - (= VN 94) Salière à vernis noir. Inv. PIN 4033n (FR 3.30).

13 - (= VN 95) Salière à vernis noir. Inv. PIN 4033o (FR 3.31).

14 - (= CC 127) Bol de fabrication locale. Inv. PIN 4033a (FR 3.32).

15 - (= CC 200) Pot à une anse de fabrication locale.

Inv. PIN 4033e (FR 3.26).

16 - (= CC 176) Pot à une anse de fabrication locale.

Inv. PIN 4033d (FR 3.19).

17 - (= CC 177) Pot à une anse de fabrication locale.

Inv. PIN 4033r (FR 3.20).

18 - (= CC 11) Enochoé de fabrication locale. Inv. FR 3.62.1.

19 - (= TC 21) «Gril à poisson ». Inv. PIN 4033b (FR 3.27).

20 - (= M 68) Stylet en bronze. Inv. PIN 4100 (FR 3.35).

21 - (= M 69) Petit objet conique en bronze. Inv. PIN 4107 (FR 3.34).

22 - (= M 65) Lamelle percée en bronze. Inv. PIN 4106 (FR 3.36).

23 - Deux éléments en bronze en forme de crochet.

Inv. PIN 4035 (FR 3.37).

24 - (= D 20) Plus de 60 astragales. Inv. PIN 4034 (FR 3.33).

Pour les restes de faune voir p. 173.

\section{Datation, commentaire}

La situation stratigraphique est identique à celle de F 2. Les vases à vernis noir indiquent une date autour de 380 .

\section{F 10}

Découvert par l'équipe française le 16 août 2004 dans le secteur Est, contre le mur MR 3, à $40 \mathrm{~cm}$ au Nord de F 3. Niveau à la base 4,80 . Pl. 77a 


\section{Contexte stratigraphique et description}

Identique à $\mathrm{F} 2$ et $\mathrm{F} 9$. Le foyer formait un petit bassin en argile crue dont la surface était rubéfiée. Sa partie N.-E. a été coupée par la mise en place de la ciste SP 328. Dimensions conservées $39 \mathrm{~cm} \mathrm{x} 40 \mathrm{~cm}$. Dans la partie N.-E., à la base du foyer, se trouvait un bol de fabrique commune 1 posé à l'envers, comme dans F 3, et le fragment de «gril» 3 . Sur la question d'un lien éventuel entre ce foyer et les sépultures situées à l'Ouest du mur MR 3, voir ci-dessous, p. 162.

\section{Inventaire des objets}

1 - (= CC 117) Bol de fabrication locale. Inv. FR 3.63.

2 - (= CC 10) Fragments d'une cruche de fabrication locale. Inv. FR 3.64.

3 - (= TC 26) Fragment de « gril à poisson ». Inv. FR 3.65.

\section{Datation, commentaire}

La position stratigraphique du foyer indique la même date que pour $F 2$ et $F$ 9, vers 380 .

\section{F 11}

Découvert par l'équipe française le 9 août 2004 dans le secteur Est, au N.-E. du point F 3. Niveaux supérieurs 4,97 et 5,10. Pl. 77b-c

\section{Contexte stratigraphique et description}

Il s'agit en fait de l'épandage d'un foyer, sur l'US 143/ $537 / 598 / 634$ et la tombe SP 370 (recouvert par l'US 19/114/129). Il était dispersé sur une zone d'environ 140 sur $100 \mathrm{~cm}$, entre les tombes SP 328 et 340 .

\section{Inventaire des objets (voir Pl. 77c)}

1 - (= VN 108) Askos à vernis noir. Inv. FR 3.10.

2 - (= VN 105) Plat à poisson à vernis noir. Inv. FR 3.6.

3 - (= VN 62) Bol à vernis noir. Inv. FR 3.8.

4 - (= VN 73) Bol à vernis noir. Inv. FR 3.11.

5 - (= VN 68) Bol à vernis noir. Inv. FR 3.9.

6 - (= VN 69) Bol à vernis noir. Inv. FR 3.7.
7 - (= VN 25) Bolsal à vernis noir. Inv. FR 3.12.

8 - (= VN 79) Coupelle à vernis noir. Inv. FR 3.3.

9 - (= VN 80) Coupelle à vernis noir. Inv. FR 3.5.

10 - (= VN 81) Coupelle à vernis noir. Inv. FR 3.13.

11 - (= VN 82) Coupelle à vernis noir. Inv. FR 3.59.1.

12 - (= VN 96) Salière à vernis noir. Inv. FR 3.14.

13 - (= VN 15) Coupe à vernis noir. Inv. FR 3.59.5.

14 - (= VN 6) Trois fragments d'une œnochoé à vernis noir.

Inv. FR 3.59.2.

15 - (= VN 7) Enochoé à vernis noir. Inv. FR 3.59.3.

16 - (= VN 110) Fragments de guttus à vernis noir.

Inv. FR 3.59.4.

17 - (= VN 15) Coupe à vernis noir. Inv. FR 3.59.5.

18 - (= CC 118) Bol de fabrication locale. Inv. FR 3.59.6.

19 - (= CC 125) Bol de fabrication locale. Inv. FR 3.59.12.

20 - (= CC 190) Pot à une anse de fabrication locale.

Inv. FR 3.59.7.

21 - (= CC 19) Cruche de fabrication locale. Inv. FR 3.59.8.

22 - (= CC 20) Cruche de fabrication locale. Inv. FR 3.59.14.

23 - (= CC 21) Cruche de fabrication locale. Inv. FR 3.59.13.

24 - (= CC 74) Cruche de fabrication locale. Inv. FR 3.59.9.

25 - (= CC 48) Cruche de fabrication locale. Inv. FR 3.59.11.

26 - (= CC 30) Cruche de fabrication locale. Inv. FR 3.59.10.

27 - Amphore de Mendé, argile orangée. Un fragment (Ht 8,5 cm) conserve une partie du bord et le départ du col, d'autres appartiennent au col et à la panse. Inv. FR 3.60.

Col cylindrique, séparé du bord par un sillon incisé ; bord arrondi et épaissi, à carène nettement marquée sur la face externe. Sous le bord, restes d'un cercle englyphique, dont seule une partie est conservée.

Selon S. Monahov, le cercle englyphique apparaît parfois sur le col ou l'épaule des amphores de la variante II-B (premier quart du IV e s.) : Monahov 2003, p. 92 et note 28. Pour un exemple de cette époque, voir Brashinskiy 1980, p. 111, nº 43. 28 - (= TC 22) « Gril à poisson ». Inv. FR 3.61.

29 - (= M 22) Strigile en bronze. Inv. FR 2.5.6.

30 - Deux astragales, dont l'un porte des traces de combustion. Inv. FR 3.4.

\section{Datation, commentaire}

Les vases du foyer indiquent une date vers 380-370, ce que confirme sa situation stratigraphique. 

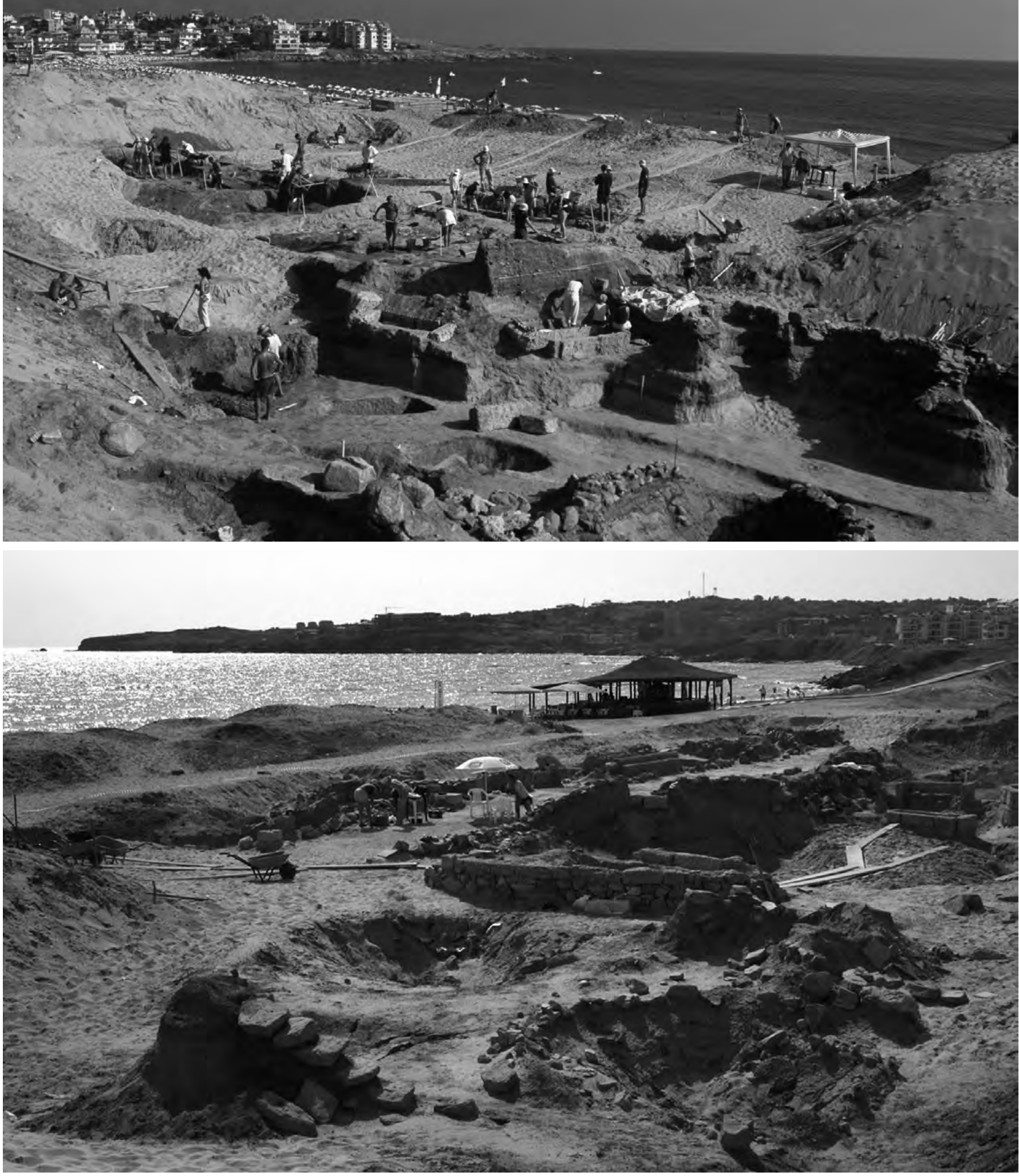

Deux vues de la nécropole d'Apollonia-Kalfata (Photos CCJ). 



\section{Troisième Partie}

\section{SYNTHÈSES}

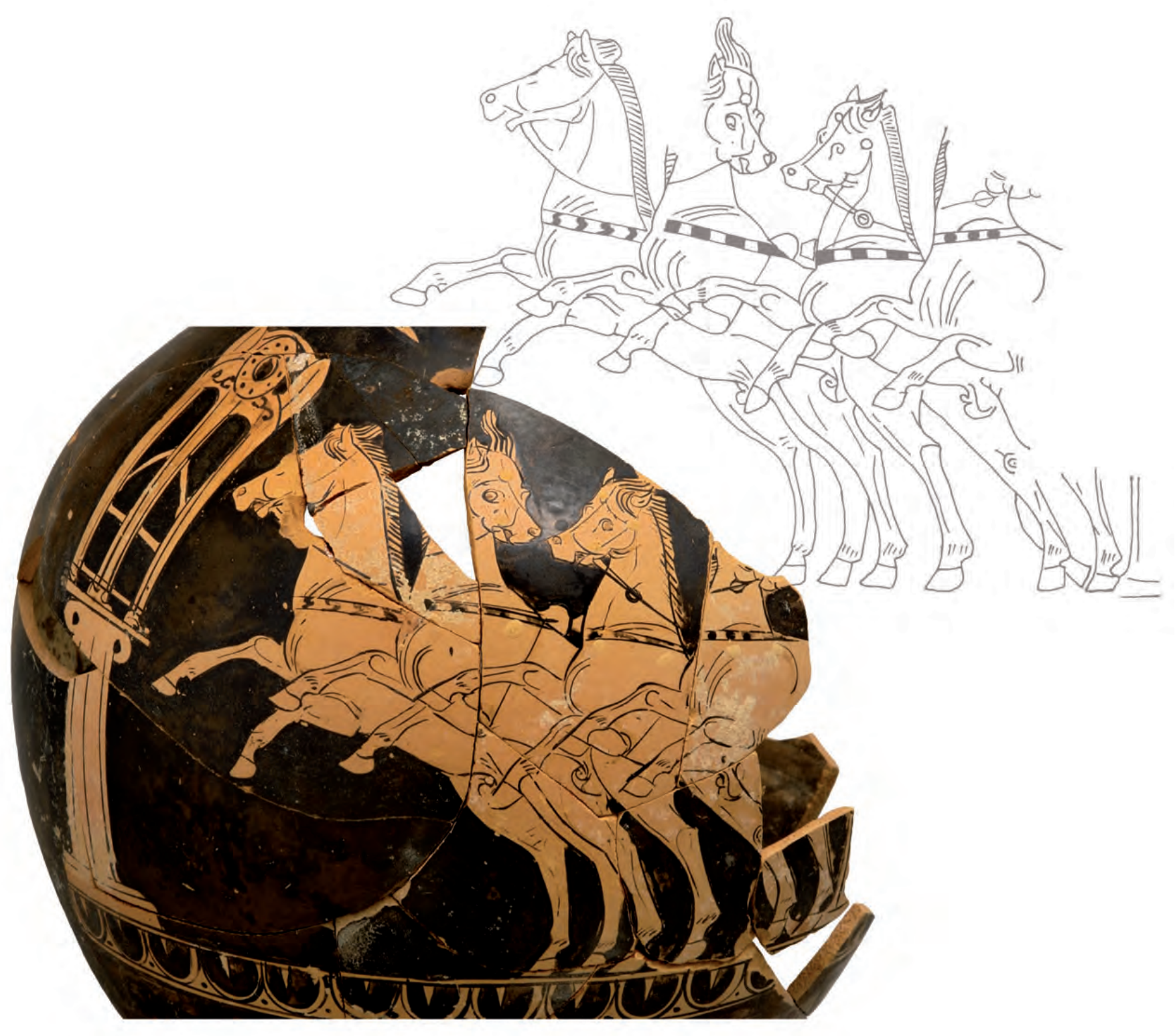

Oenochoé attique à figures rouges (CP 42) (Photo L. Damelet). 



\section{Chapitre 1}

\section{Pratiques et rituels funéraires}

\section{Commentaire général}

\subsection{Les sépultures}

Les observations qui peuvent être formulées portent sur 56 sépultures, inégalement réparties sur les quatre périodes définies plus haut, puisque la période 1 (vers 450-425) ne comporte que trois tombes, la période 2 (vers 400-375) neuf, la période 3 (vers 375300 ), de loin la plus longue, vingt-six tombes, et la période 4 (vers 300-250) dix-sept. En dépit du caractère restreint de cet ensemble, nos conclusions rejoignent généralement celles qui ont été formulées précédemment à propos de la même nécropole ${ }^{1}$, mais apportent un éclairage nouveau sur les pratiques rituelles liées à l'incinération ou l'inhumation des défunts.

Les sépultures découvertes dans le cadre des fouilles franco-bulgares ne contiennent qu'un seul sujet ${ }^{2}$. Aucun secteur réservé à une classe d'âge ou un sexe n'a été mis en évidence, quelle que soit la période considérée : adultes et immatures partagent le même espace, selon une organisation qui ne comporte aucune différenciation basée sur l'âge ou le sexe. On constate en revanche une nette surreprésentation des sujets de sexe féminin durant les périodes 3 et 4 . Ce déséquilibre peut s'expliquer durant la phase 4 par l'importance croissante des incinérations, lesquelles pourraient éventuellement concerner de façon privilégiée des sujets de sexe masculin, mais cet argument ne vaut pas pour la période 3 où onze des quinze sujets identifiés sont de sexe féminin, tandis que les incinérations ne sont représentées que par trois cas ;

1 Venedikov et al. 1963, p. 16 ; Panayotova 1998a, p. 102107 ; Nedev, Panayotova 2003, p. 130-140 ; Baralis Riapov 2006, p. 62-68 ; Panayotova, Baralis, Riapov 2006, p. 103-114 ; Hermary 2007, p. 164-166.

2 Cette situation apparaît conforme à celle observée précédemment au cours des fouilles d'I. Venedikov et de K. Panayotova. Durant les fouilles de 1947, seuls six cas de sépultures collectives ont été mis au jour, certains reflétant des contextes perturbés et incertains : Venedikov et al. 1963, p. 24-25 et 53. Sur les 72 sépultures étudiées durant la période 1992-1994, seule une tombe (SP 46) correspondait à une inhumation multiple, deux adultes accompagnés d'un enfant (Panayotova 1998a, p. 102). en regard, les hommes ne représentent que quatre individus. Certes, la caractérisation sexuelle de onze autres défunts demeure indéterminée, mais ce chiffre intègre six immatures pour deux adultes, le dernier défunt n'étant pas renseigné.

L'inhumation est la seule pratique attestée durant les périodes 1 et 2 . Aucun cas d'enchystrismos n'a été observé dans le cadre des fouilles conjointes, bien que cette pratique soit attestée à Kalfata, dans de faibles proportions, mais on note l'existence possible d'un cénotaphe ${ }^{3}$. L'introduction de l'incinération n'intervient que dans le second quart du $\mathrm{IV}^{\mathrm{e}} \mathrm{s}$., mais l'application de ce traitement aux défunts demeure peu fréquente au cours de la période 3 , où il ne concerne que 11,5\% des sépultures ${ }^{4}$. Cette proportion évolue fortement au cours du siècle suivant, puisque l'incinération est représentée, durant la première moitié du $\mathrm{III}^{\mathrm{e}} \mathrm{s}$., par six des dix-sept sépultures mises au jour, soit près de 35,3\% des tombes. Cette constatation faite sur un ensemble restreint devra être vérifiée dans le cadre d'une étude plus large, mais certains aspects sont permanents : ainsi, toutes les incinérations étudiées au cours de nos fouilles sont secondaires, c'est-à-dire que les ossements incinérés sont collectés dans une urne cinéraire et déposés en fosse ou dans un caisson 5 . Le lieu où se trouvaient les bûchers funéraires reste malheureusement inconnu.

3 La structure semi-circulaire en pierre découverte au-dessus de SP 338, à laquelle est associé le dépôt funéraire DP 14, présente une orientation divergente par rapport aux tombes voisines. Cet alignement, par sa forme, se rapproche de nombreux marqueurs reconnus à Kalfata (notamment près de SP 283 et 329), où ces derniers entourent le haut de la fosse, au niveau de la tête du défunt. Pourtant, aucun sujet n'a été mis au jour parmi ces pierres, ce qui nous invite à ne pas négliger l'hypothèse d'un éventuel cénotaphe.

4 Le pourcentage moyen observé durant les fouilles d'I. Venedikov à Kalfata était de 1,8\%. Il est revanche de 10,2\% dans le cadre des fouilles réalisées entre 1992 et 2003: Nedev, Panayotova 2003, p. 130. Il est à noter que l'incinération intervient ici à une date plus haute que celle avancée par I. Venedikov (Venedikov et al. 1963, p. 131).

5 L'incinération primaire demeure une pratique marginale à Kalfata, selon une situation également observée durant les fouilles de Venedikov où la tombe 721 constitue une exception. Cette incinération primaire était recouverte de tuiles (Venedikov et al. 1963, p. 14). 
Dans le cas des inhumations, la position habituelle des sujets au moment de leur déposition est le décubitus dorsal, les membres allongés le long du corps. Les variations observées à Kalfata s'avèrent ponctuelles et ne concernent aucune des sépultures étudiées ici (Nedev, Panayotova 2003, p. 130). Plusieurs aménagements particuliers sont attestés, en particulier, dès la phase la plus ancienne (SP 313), la présence d'un cercueil, doté d'un couvercle à quatre planches au centre duquel un clou, planté au milieu de la planche centrale, apparaît dépourvu de toute fonction structurelle: il pourrait être mis en relation avec la décoration du cercueil luimême, par exemple par la fixation d'une guirlande ou d'une couronne végétale. D'autres aménagements plus sommaires apparaissent, en particulier dans le cas de la tombe SP 337 où l'alignement de clous préservé en comblement de fosse pourrait laisser supposer la présence initiale d'une structure en bois destinée à sceller le haut de la fosse : sa résistance aurait cependant été faible, car l'étude anthropologique révèle que la décomposition du corps s'est effectuée en espace colmaté ; d'autres explications sont donc possibles (voir p. 167-168). Un dispositif similaire, sans clou, mais probablement sous la forme d'un simple alignement de planches, protégeait la tombe SP 370, où la décomposition du corps s'est opérée au sein d'un espace vide ${ }^{6}$. Enfin, la ciste SP 328 atteste l'introduction, vers le milieu du $\mathrm{IV}^{\mathrm{e}} \mathrm{s}$., d'une kliné funéraire en bois dont l'existence est confirmée à la fois par les trous aménagés à l'extrémité du dallage, au niveau des pieds, et par la disposition du squelette qui a connu un fort affaissement ${ }^{7}$. La diffusion de la kliné à Apollonia s'opère dans un contexte politique particulier. Ce phénomène intervient en effet à la même date dans le nord de l'Egée, notamment à Amphipolis

6 Deux cas semblables ont été identifiés dans la nécropole de Sainte-Barbe à Marseille : Moliner 1994, p. 80 ; Moliner et al. 2003, p. 72 .

7 Citons le commentaire complémentaire, par Anne Richier, de la description qu'elle donne dans le catalogue : «Le cas de ce sujet est intéressant, puisque les déplacements osseux sont trop importants pour en rendre uniquement responsable l'espace vide (c'est-à-dire un espace où les os ont la place de bouger lors des phénomènes de décomposition); la position secondaire du crâne, le déplacement des deux humérus et les migrations conséquentes au niveau des jambes peuvent indiquer la présence initiale d'un fond en matériau périssable, soit continu comme un lit funéraire, soit discontinu, comme un repose-tête et un repose-pieds. Dans le cas du lit funéraire, le sujet aurait subi un effondrement sur le dallage, moins important dans les zones les plus lourdes (au niveau des viscères). Dans l'autre cas, seuls tête et pieds auraient subi cet effondrement, pouvant entraîner un déplacement d'autres régions anatomiques. L'autre sujet inhumé dans une ciste, SP 339, est un enfant en très mauvais état de conservation, ce qui limite les observations de terrain. Il a cependant subi, à l'instar de SP 328, des déplacements osseux, mais ceux-ci sont moins conséquents et s'expliquent par l'espace de décomposition ».
(Samartzidou 1987), et il est contemporain à Kalfata de plusieurs innovations, comme la tombe à double fosse et escalier latéral (SP 244) dont le prototype apparaît au $\mathrm{V}^{\mathrm{e}} \mathrm{s}$. à Pydna ${ }^{8}$. Ces divers éléments laissent entrevoir une influence croissante de la Macédoine à une époque où elle étend son emprise dans le Nord de la mer Égée 9 .

\subsubsection{Orientation des sépultures (Graphique 3)}

L'orientation des sépultures à inhumation est connue sur la base d'un échantillon très inégal selon les phases. Pour la période 1, deux des trois sépultures sont orientées au Nord-Est, c'est-à-dire la tête placée perpendiculairement à la ligne du rivage, vers ce qui peut paraître le levant depuis la nécropole; la troisième est orientée strictement à l'Est. Cette disposition s'observe dans un espace funéraire caractérisé, durant le troisième quart du $\mathrm{V}^{\mathrm{e}} \mathrm{s}$., par une disposition relativement lâche des tombes, sans recherche de symétrie ou d'orientation précise. Une préférence pour une orientation à l'Est semble toutefois déjà se dessiner et se poursuit au cours des phases 2 et $3{ }^{10}$. Durant la période 2, en effet, la majorité des sépultures, soit cinq tombes $(55,6 \%)$, est orientée au Nord-Est, soit perpendiculairement à la mer, deux tombes au Sud-Est $(22,2 \%)$ et deux respectivement à l'Est et au NordOuest $(11,1 \%)$. On constate qu'au-delà de la rupture que connaît Kalfata dans son occupation entre les périodes 1 et 2 , et du changement important survenu dans sa topographie, le rivage, que suit peut-être dès cette période un axe de circulation, constitue le repère directeur choisis par les habitants, malgré l'effacement des anciennes tombes. Aucune discrimination n'est alors visible selon le type de tombe, puisqu'on trouve dans les diverses

8 Besios 1987, p. 209-210, 1990, p. 243 et 1991, p. 171-173. L'emploi d'un escalier latéral donnant accès à une ciste est également attesté dans le tombeau $\mathrm{X}$ d'Amphipolis qui date de la première moitié du $\mathrm{III}^{\mathrm{e}} \mathrm{s}$. et fait partie d'un groupe de sépultures présentant de fortes connexions avec la Macédoine, tant dans leur architecture que dans leur mobilier funéraire : Samartzidou 1987, p. 331.

9 Alexandre I ${ }^{\text {er }}$ est le premier souverain macédonien à porter les frontières de son royaume sur le Strymon, au début du $\mathrm{V}^{\mathrm{e}} \mathrm{s}$. Au siècle suivant, Philippe II conquiert Amphipolis en 357-356 et, en 353, se porte au secours du satrape Artabazos, lors d'une expédition qui le conduit à l'Est du Nestos. La Thrace égéenne passe sous son contrôle vers 346 et la plaine supérieure de Thrace vers 342-340. Rappelons qu'Apollonia signe un traité avec lui en 341. Voir les synthèses présentées par Hammond, Griffith 1979, p. 98-104 ; Chankowski, Bravo 1999, p. 307-308.

10 Ce choix préférentiel d'une orientation de la tête du défunt à l'est se retrouve dans la plupart des colonies grecques de mer Noire, en particulier dans les sépultures archaïques d'Olbia et de Berezan, de même que dans les tombes classiques et du début de l'époque hellénistique de Chersonèse, Panticapée et Nymphaion: Petersen 2007, p. 89 et 157, fig. 2.9. 


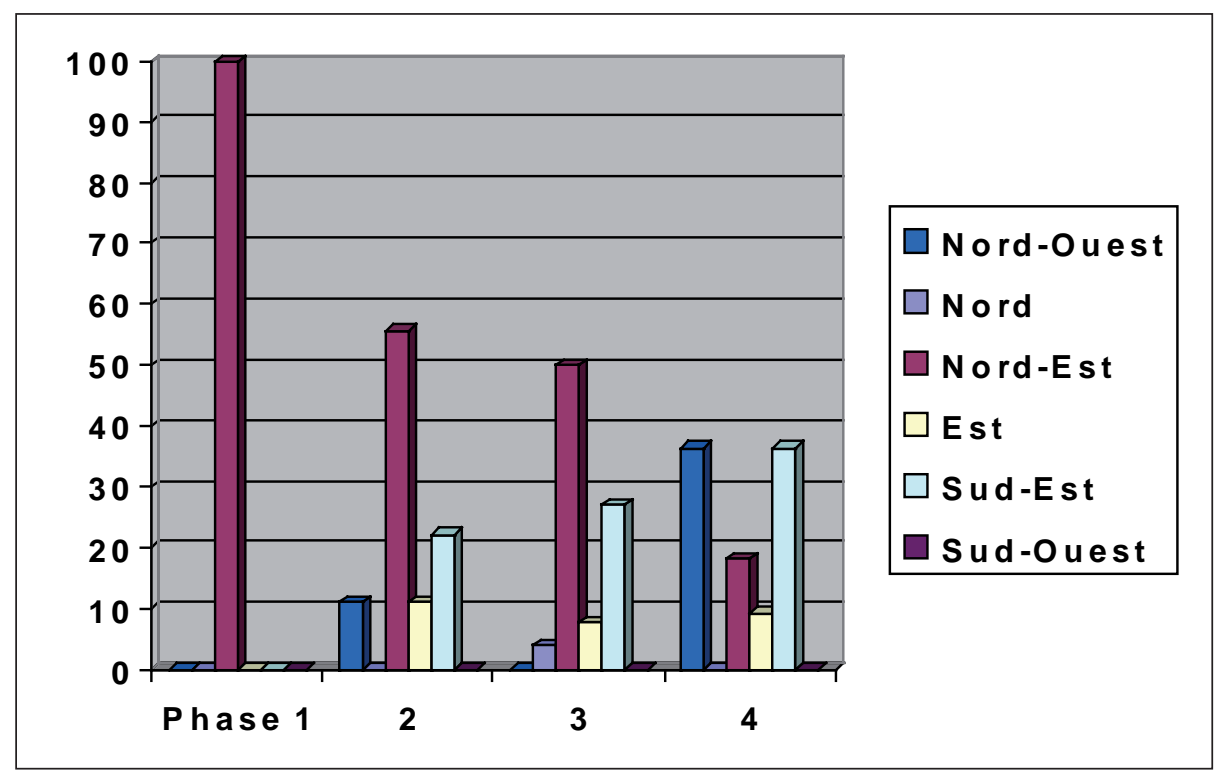

Graphique 3. Orientation des sépultures par phase.

orientations à la fois des tombes à ciste et à fosse ${ }^{11}$. De même, le sexe ou l'âge des défunts ne paraît jouer aucun rôle particulier ${ }^{12}$ : ainsi, les sépultures orientées au Nord-Est regroupent des hommes et des femmes de tout âge, de même que des immatures.

Durant la période 3, la prédominance d'une orientation des sépultures à l'Est persiste, au sein d'un échantillonnage élargi. Sur les vingt-six sépultures à inhumation renseignées, $50 \%$ (treize sépultures) sont en effet orientées au Nord-Est et 26,9\% au Sud-Est (sept sépultures), tandis que 7,7\% (deux sépultures) sont dirigées vers l'Est et seulement 3,8\% (une sépulture) vers le Nord-Ouest : cette dernière orientation ne semble donc pas avoir été privilégiée, tandis que celle au Sud-Ouest est systématiquement évitée, comme durant les deux périodes précédentes. Il apparaît, en tout cas, que le placement de la tête du défunt dans une direction considérée comme l'Ouest depuis la nécropole, en raison du trait oblique de la ligne de côte, constitue un interdit fermement respecté à Kalfata ${ }^{13}$. Il demeure en revanche

11 J. C. Carter a observé à Métaponte un traitement différencié selon le type de tombe : les cistes sont orientées au Nord, contrairement aux autres sépultures, placées vers le Sud (Carter 1998, p. 89).

12 Contrairement à plusieurs nécropoles de Macédoine centrale où la tête des hommes est située à l'Est et celle des femmes à l'Ouest (Vokotopoulou 1994, p. 84). De même, J. Petersen note que, durant les phases 2 et 3 de la nécropole d'Olbia, la moitié des enfants est placée tête à l'Ouest, alors que les sujets adultes sont inhumés à l'Est (Petersen 2007, p. 48).

13 Le sens exact de cet interdit ne nous est pas connu. Cette exclusion n'est toutefois pas universelle en Grèce, comme le démontre l'exemple de l'Argolide, où l'orientation du crâne à l'Ouest est fréquente parmi les tombes géométriques (Hägg 1998, p. 133). Elle est également appliquée au $\mathrm{VI}^{\mathrm{e}} \mathrm{s}$. à deux sépultures difficile d'affiner ces données en les confrontant au sexe du défunt, en raison du déséquilibre entre les deux sexes évoqué précédemment. On remarque toutefois que les quatre sujets masculins identifiés ne présentent aucune spécificité : deux d'entre eux sont orientés au NordEst et les deux autres vers le Sud-Est. Cette absence de discrimination s'étend également à l'âge des défunts, puisque, sur les six immatures, cinq sont orientés au Nord-Est et un au Sud-Est, ce qui est conforme aux tendances générales. De même, parmi les quatre personnes âgées, une est au Nord-Est, deux au Sud-Est et la dernière au Nord-Ouest. La large prédominance des fosses (22 des 26 sépultures) nous interdit par ailleurs de confronter ces conclusions au type des tombes. La tombe à ciste, orientée au Sud-Est, reste un exemple isolé, non significatif.

Ces proportions évoluent en revanche durant la dernière phase, puisque un peu plus d'un tiers des inhumations sont orientées au Nord-Ouest, suivant une proportion égale à celles orientées au Sud-Est (quatre sépultures respectivement). En regard, seules deux sépultures sont perpendiculaires à la mer, tête vers le Nord-Est, et une seule orientée vers l'Est. Cette évolution,

de la nécropole occidentale d'Eleusis et concerne quatre sépultures d'Argos: Mylonas 1975, tome 2, katalogos Г', entre les p. 224 et 225 ; Bruneau 1970, p. 524. Parfois, l'orientation du défunt peut renvoyer, du moins dans le discours, à son identité civique, comme en témoigne la dispute, rapportée par Plutarque, entre Athéniens et Mégariens : les Athéniens auraient ainsi enterré leurs morts la tête à l'Ouest et les Mégariens à l'Est (Plutarque, Solon, X, 4. Cette affirmation est toutefois contredite par Héréas de Mégare (ibid.) et Elien (Histoires variées, VII, 19). 
étonnante à première vue, s'explique par l'installation des tombes à inhumation le long de la route, dont elles sont contraintes de suivre l'orientation. Au sein de ce groupe, le placement de la tête vers le Nord ou vers le Sud intervient à part égale.

\subsubsection{Répartition des sujets par type de tombe}

Durant la période 1, homme et femme partagent le même type de fosse, tout comme les immatures. Cette similitude de traitement appliqué aux enfants se poursuit durant la phase 2, comme en témoigne le voisinage des cistes SP 339 et SP 291, qui abritent respectivement un jeune garçon et un homme adulte. Un clivage ténu semble en revanche se dessiner entre les sexes. On note en effet que les trois sépultures qui structurent l'espace de ce secteur - SP 334, 343 et 291 - abritent chacune un sujet masculin. Une même différenciation apparaît chez les immatures, puisque l'on observe la dépendance de SP 375 (très probablement une fille selon le mobilier qui l'accompagnait, en particulier la boucle d'oreille) par rapport à la ciste SP 339 (très probablement un garçon si on considère le strigile). Au-delà du lien familial qui lient ces deux sujets, souligné notamment par l'accolement des deux tombes et leur ensevelissement sous une même couverture tumulaire, on remarque que le garçon de SP 339 bénéficie d'une tombe relativement soignée et d'un mobilier funéraire complet, alors que la fille de SP 375 est inhumée dans une simple fosse dont les parois sont partiellement revêtues de moellons et que le mobilier apparaît plus modeste, avec un lécythe et un alabastre, tous deux étrangement dépourvus de vernis (voir ci-dessous pour d'autres commentaires sur ces sépultures). Cette différence de traitement n'apparaît cependant pas spectaculaire et la similitude des dimensions de SP 336 (femme mature) par rapport à celles de SP 343 (homme adulte) est là pour nous le rappeler. Ces deux derniers exemples démontrent par ailleurs que l'âge ne semble pas constituer un critère pertinent, comme le confirme la présence parmi les cistes de sujets âgés (SP 291) ou jeunes (SP 334), voire très jeunes (SP 339$)^{14}$.

Pour la période 3 , la surreprésentation des sujets de sexe féminin interdit de confronter ces conclusions à l'échantillon plus large dont nous disposons. Il serait toutefois tentant de rapprocher cette prédominance des tombes féminines avec l'appauvrissement contemporain de la typologie des structures, qui se résument désormais à une simple fosse ; il faut cependant noter que les deux exceptions, une ciste et une double fosse à escalier

14 À l'inverse, J.C. Carter note qu'à Métaponte les sujets inhumés en ciste sont plus âgés que ceux reposant dans des sarcophages: Carter 1998, p. 89. latéral, abritent chacune un sujet de sexe féminin, tandis que les quatre hommes sont inhumés dans de simples fosses. L'ensemble des immatures est également inhumé en fosse, sans discrimination visible, tandis que l'incinération est réservée aux sujets adultes. Certains d'entre eux s'avèrent jeune, comme dans le cas de SP 345, mais aucun n'est antérieur à l'adolescence.

Ces mêmes difficultés se présentent durant la période 4. Il est en effet à nouveau difficile de déterminer si l'incinération concerne davantage un des deux sexes, et le mobilier funéraire, parfois totalement absent, n'est pas particulièrement significatif. La tombe SP 362 démontre cependant que les hommes peuvent être eux aussi inhumés. Alors que l'incinération n'est appliquée qu' aux adultes, les onze inhumations rassemblent toutes les classes d'âge : deux enfants, neuf adultes dont deux sujets âgés. Les femmes sont ici surreprésentées, mais la typologie des tombes à inhumation reflète l'absence de toute discrimination sur la base de l'âge ou du sexe. Les deux cistes concernent en effet un immature - sans doute une fille selon le mobilier - et une femme âgée. Le seul homme repose, inversement, dans une tombe à tuiles, tout comme quatre autres femmes. Parmi les innovations, on observe une tendance croissante à adapter la taille des sépultures à celle des enfants, comme en témoigne l'apparition d'une ciste et d'une tombe à tuiles miniatures.

\subsubsection{Le mobilier funéraire}

\section{Répartition en fonction du sexe et de l'âge}

Toutes les sépultures appartenant aux périodes 1 et 2 sont accompagnées d'un mobilier funéraire. Cependant, il semble difficile de déceler d'éventuelles variations dans sa composition en fonction de l'âge et du sexe des défunts sur la base d'un échantillonnage aussi étroit. Tout au plus peut-on noter avec réserve, concernant la période 1, que SP 330 (homme âgé), avec deux lécythes importés, apparaît relativement mieux dotée que SP 331 (femme âgée) qui n'était accompagné que d'un seul lécythe local. Durant la période 2, les tombes féminines apparaissent en revanche tout aussi riches que celles des défunts de sexe masculin. Cette égalité de traitement se retrouve également parmi les tombes d'enfants (cf. ci-dessous).

Une certaine sobriété se manifeste dans les tombes SP 300 (sujet indéterminé) et SP 343 (homme adulte), malgré la position centrale occupée par cette dernière. On peut supposer que SP 300 concerne également un sujet adulte de sexe masculin, à la fois par les dimensions de son squelette et la déposition à ses côtés d'un strigile, bien que cet instrument se rencontre parfois à Kalfata 


\begin{tabular}{|l|c|c|c|c|c|c|}
\hline & $\begin{array}{c}\text { Aucun } \\
\text { objet }\end{array}$ & 1 & 2 & 3 & 4 & 5 et plus \\
\hline Homme & & I & & I & । & \\
\hline Femme & & & & I & । & \\
\hline Enfant & & & & I & । & । \\
\hline $\begin{array}{l}\text { Adulte } \\
\text { Indéterminé }\end{array}$ & & I & & & & \\
\hline
\end{tabular}

Tableau 5. Période 2. Répartition du mobilier funéraire par âge et sexe (les astragales et clous ne sont comptés que par ensemble).

durant la période 3 au côté de femmes. La répartition du mobilier par type de tombe démontre, d'autre part, que les fosses sont aussi bien dotées que les cistes, sans qu'aucune hiérarchie puisse être établie. (Tableau 5)

Durant la période 3, seules trois sépultures (SP 321, 324 et 345), quatre si l'on prend en compte SP 341, soit $15,4 \%$ de l'ensemble, sont dépourvues de tout mobilier. Trois d'entre elles consistent en de simples fosses, mais la dernière représente une incinération secondaire déposée dans un conteneur relativement luxueux (SP 345). Elle confirme le fait que le caractère réduit ou l'absence de mobilier constitue à Kalfata puisse répondre tout autant au niveau social de l'individu qu'à une volonté délibérée de sobriété. Ainsi, en excluant les offrandes alimentaires, en ne comptant les clous et les astragales que par ensemble, et en considérant que les boutons du fourreau de SP 272 sont indissociables du miroir qu'il abritait, on observe que, pendant la phase $3,11,5 \%$ des sépultures ne possèdent qu'un objet, $23,1 \%$ deux objets, $15,4 \%$ trois, $7,7 \%$ quatre, enfin $26,9 \%$ cinq et plus.

La trop forte proportion de tombes contenant un sujet féminin nous interdit cependant d'approfondir notre analyse. Tout au plus note-t-on que trois des quatre tombes masculines comptent parmi les plus modestes. Les tombes de femmes et d'enfants se répartissent en revanche sur l'ensemble des catégories. Rares sont les immatures à demeurer sans mobilier, à l'image de SP 341, mais ce dernier était accompagné d'offrandes alimentaires. (Tableau 6)

En prenant en compte le type des tombes, nous nous heurtons à nouveau au même obstacle : les cistes ne sont représentées que par un seul exemplaire. Encore cette dernière est-elle richement dotée. Ce n'est pas le cas en revanche de la sépulture à double fosse SP 244 dont le mobilier se réduit à deux lécythes. En regard, six des sept tombes comportant au moins cinq objets consistent en de simples fosses. L'une d'entre elles d'ailleurs (SP 340) dispose d'un matériel qui ne le cède en rien à celui de la ciste SP 328 (voir un commentaire plus détaillé ci-dessous). Il serait donc erroné de considérer que les fosses abritent systématiquement des sépultures modestes. (Tableau 7)

\begin{tabular}{|l|r|r|r|r|r|c|}
\hline & $\begin{array}{r}\text { Aucun } \\
\text { objet }\end{array}$ & \multicolumn{1}{|c|}{1} & \multicolumn{1}{c|}{2} & 3 & 4 & 5 et plus \\
\hline Homme & 1 & 1 & 1 & & & 1 \\
\hline Femme & 1 & 2 & 2 & 2 & 1 & 3 \\
\hline Enfant & 1 & & 1 & 1 & 1 & 2 \\
\hline $\begin{array}{l}\text { Adulte } \\
\text { Indéterminé }\end{array}$ & 1 & & 2 & 1 & & 1 \\
\hline
\end{tabular}

Tableau 6. Période 3. Répartition du mobilier funéraire par âge et sexe (les astragales et clous ne sont comptés que par ensemble).

\begin{tabular}{|l|r|r|r|r|r|r|}
\hline & $\begin{array}{r}\text { Aucun } \\
\text { objet }\end{array}$ & 1 & 2 & 3 & 4 & 5 et plus \\
\hline Urne & 1 & & 2 & & & \\
\hline Fosse & 3 & 3 & 4 & 4 & 2 & 6 \\
\hline Ciste & & & & & & 2 \\
\hline
\end{tabular}

Tableau 7. Période 3. Répartition du mobilier funéraire par type de tombe (les astragales et clous ne sont comptés que par ensemble).

La dernière période reproduit les mêmes tendances. Les sépultures d'immatures ne sont mieux dotées que celles des adultes, même si aucune d'entre elles n'est laissée sans offrande. Les sépultures féminines occupent tout l'éventail du tableau, des plus modestes aux plus richement dotées, alors que l'unique tombe d'homme ne peut prétendre à une quelconque représentativité.

Rapportée au type de tombe, cette analyse révèle l'existence d'un mobilier relativement modeste autour des incinérations. Le placement du mobilier à l'extérieur de la tombe et son identification éventuelle comme dépôt funéraire ne peuvent expliquer à eux seuls cette situation, car la période 4 n'a livré que deux contextes archéologiques de ce type (voir ci-dessous). Les cistes ne sont représentées que par une seule sépulture, une nouvelle fois assez richement dotée. Les deux fosses sont dotées d'un mobilier funéraire réduit, alors que les tombes à tuiles se répartissent sur l'ensemble des catégories.

\section{Composition du mobilier (Tableau 8)}

Les assemblages découverts à Kalfata comportent quelques particularités. Les armes sont totalement absentes et les bijoux, comme les autres éléments de parure, demeurent fort peu représentés. Au-delà de ces remarques préliminaires, la période 1 n'offre qu'un échantillon relativement étroit, interdisant toute conclusion. Les vases (huit exemplaires) prédominent, alors que les objets métalliques n'entrent en considération que pour deux exemplaires. Deux formes de vases sont représentées, le lécythe et la coupe, liées respectivement aux soins du corps et au banquet, mais elles ne cohabitent 


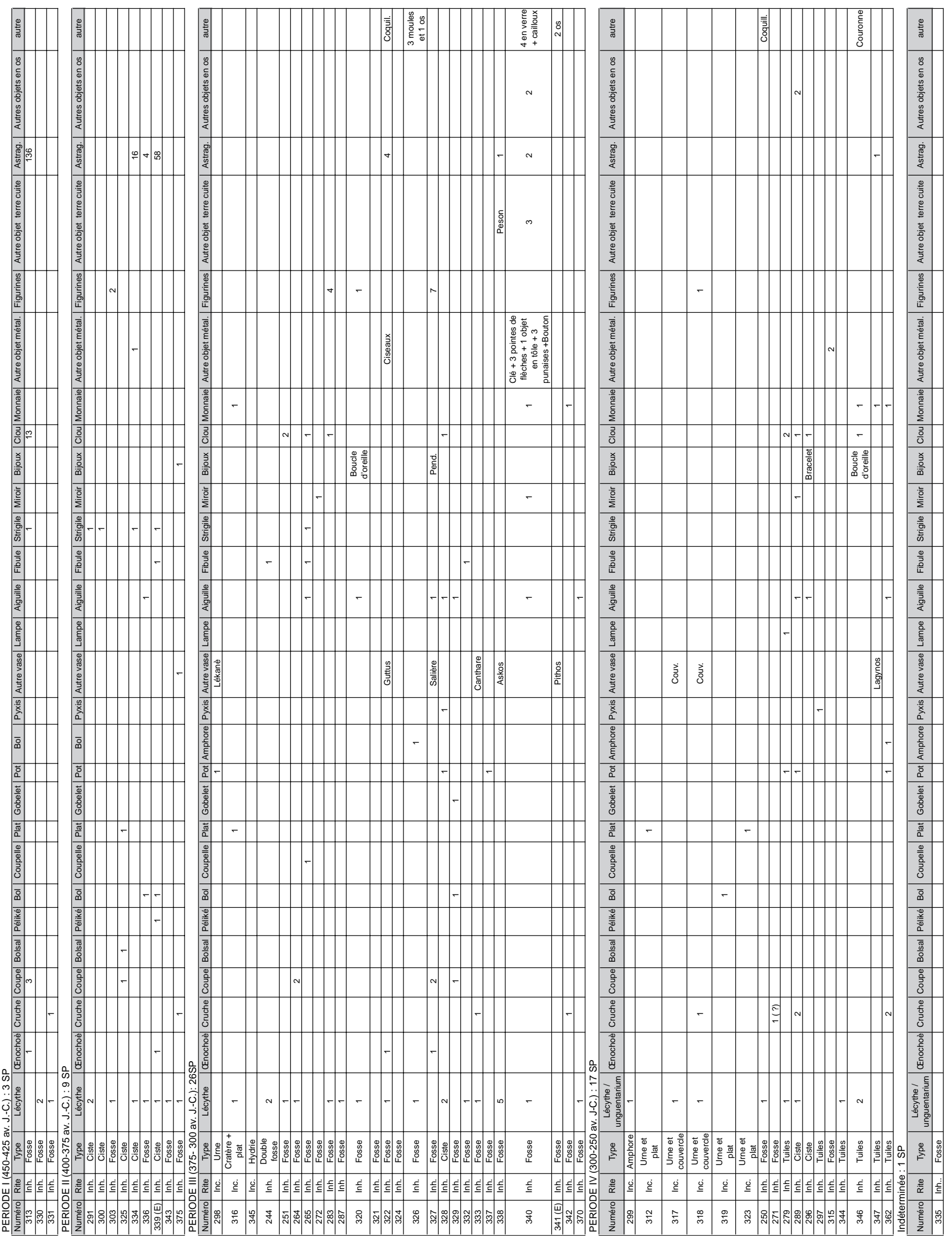

Tableau 8. Périodes 1 à 4. Répartition du mobilier funéraire par type de tombe (les astragales et clous ne sont comptés que par ensemble). 
pas dans les assemblages. Dans SP 313 les deux coupes et l'œnochoé reproduisent un service miniature. Il s'agit peut-être de la sépulture d'un jeune garçon, comme le suggère le strigile. SP 330 et 331 ne comportent en revanche qu'un lécythe, déposé aux côtés d'un homme et d'une femme adultes. Cet objet ne semble donc pas être connoté sexuellement.

On observe, parallèlement, l'apparition des astragales. C'est ici moins leur présence que leur nombre qui étonne, avec 136 exemplaires mis au jour dans SP 313. Ce chiffre dépasse de loin la quantité nécessaire au jeu et nous amène à chercher ailleurs le sens de cette déposition. SP 313 reproduit en effet les imposants assemblages découverts à Locres et Vélia, où ce matériel a parfois été interprété dans un sens rituel (discussion dans Elia, Caré 2004). Les astragales n'entourent cependant pas le défunt à Apollonia : ils se répartissent dans SP 313 en trois tas, disposés près des deux mains et du pied droit, en des points volontairement opposés, encadrant ainsi symboliquement le corps. Quatorze d'entre eux ont été retaillés et un alourdi par un ajout de plomb ${ }^{15}$. Cette sépulture n'est pas un cas isolé à Kalfata, comme le rappelle notamment la tombe SP 233, découverte en $2001^{{ }^{16}}$. SP 313 n'en demeure pas moins intéressante en raison du strigile étrangement placé aux côtés d'un immature de 7 ans \pm 24 mois. Cette caractérisation sexuelle d'un enfant qui est loin d'être parvenu à l'éphébie est en outre soulignée par l'œnochoé et les deux coupes qui nous renvoient au banquet. Elle reproduit ainsi une attitude relativement courante à Kalfata, que l'on retrouve durant la période suivante pour SP $339^{17}$. Cette caractérisation du jeune enfant peut n'être que symbolique, matérialisant le regret de voir partir un garçon aussi jeune qui n'a pas atteint le « bel âge » et la volonté parallèlement de le montrer, lors de ces funérailles, dans un statut qui n'était pas encore le sien de son vivant.

Parallèlement, d'autres objets font leur apparition durant cette période 2 , sinon parmi le mobilier funéraire des trois tombes mises au jour, du moins dans les dépôts externes qui les accompagnaient. On doit en ce sens

15 Une pratique connue dès les fouilles de Myrina : Pottier, Reinach 1888 , p. $216-217$.

16 Elle contenait également 92 astragales: Panayotova, Nedev 2002 , p. 81.

17 Cette pratique n'est pas non plus inconnue dans les nécropoles d'autres cités grecques. Le tumulus 9 d'Apollonia d'Illyrie a ainsi livré plusieurs sépultures de jeunes garçons associant strigile et astragales: Amore 2004, p. 310. Ce cas se révèle proche des rites observés à Poseidonia/Paestum où cette association intervient à partir de sept ans dans des proportions non précisées : Cipriani 1994, p. 177. Voir plus loin sur le cas d'Euphéros au Céramique. signaler la déposition d'une lampe dans un contexte qui apparait lié à SP 334 (cf. ci-dessous) ${ }^{18}$.

Durant la période 2, la composition du mobilier connaît une certaine diversification. Les vases ne comptent plus que pour $56,7 \%$ des ensembles, sur une base statistique désormais élargie (dix-sept vases), tandis que 26,7\% correspondent à des objets métalliques (huit objets) et $10 \%$ à des astragales (trois ensembles). Parmi les formes de vases les plus représentées, le lécythe confirme sa prédominance (huit exemplaires, soit $47 \%$ des vases) : on le trouve dans sept des huit sépultures, généralement en un seul exemplaire, sauf dans le cas de SP 291 où il apparaît en double. Il est de même associé dans SP 375 avec un second vase à parfum, en l'occurrence un alabastre. Cette importance des vases à parfum n'est évidemment pas propre à la nécropole de Kalfata. On note qu'à Apollonia le lécythe concerne durant le premier quart du $\mathrm{IV}^{\mathrm{e}} \mathrm{s}$. tous les types de tombes - ciste et fosse - et, conformément à l'usage observé durant la période précédente, des sujets masculins et féminins, quel que soit leur âge ${ }^{19}$. Leur effacement au profit des vases liés au banquet ne s'observe que dans une sépulture (SP 325), féminine au demeurant. Les deux types de vases - à parfum et liés au banquet - peuvent d'ailleurs coexister, ainsi que le démontre SP 336 où on note la déposition d'un lécythe et d'une coupe.

Les vases liés au banquet ne se rencontrent que dans près de la moitié des sépultures (quatre tombes sur neuf). Ils ne composent pratiquement jamais des services entiers, mais représentent quelques formes sélectionnées, parfois réduites à un seul vase : un bol dans SP 336, une cruche dans SP 375. En ce sens, deux sépultures, SP 325 - coupe, bolsal et plat - et SP 339 - œnochoé, péliké et bol - présentent les ensembles les plus larges. Les vases entrant dans cette catégorie ne sont pas liés à des tombes exclusivement masculines. Ils concernent tout autant les femmes (SP 325 et 336) et se retrouvent parfois dans des sépultures d'immatures où leur présence n'est pas toujours innocente (SP 339).

Parmi les autres catégories d'objets, les astragales continuent à figurer dans les assemblages (voir aussi p. 170-171), souvent en nombre important: 16 dans SP 334, 58 dans SP339, où leur présence n'est pas toujours liée à l'âge du défunt ${ }^{20}$. Les figurines en terre cuite viennent enrichir le mobilier funéraire (SP 303),

18 La lampe apparaît également à Akraiphia, en Béotie, au $\mathrm{V}^{\mathrm{e}} \mathrm{s}$., mais ne se diffuse qu'à partir du $\mathrm{IV}^{\mathrm{e}} \mathrm{s}$. (Andriomenou 1994, p. 112). 19 En revanche, il semble concerner à Nymphaion des sujets plutôt adultes (Petersen 2007, p. 194).

20 Des cas similaires sont connus en mer Noire, notamment à Nymphaion, où une sépulture d'enfant a livré 32 astragales (Sokolova 2003, p. 778). 
mais elles ne sont pas les plus anciennes, comme l'ont démontré les découvertes réalisées par I. Venedikov dans sept tombes du troisième quart du $\mathrm{V}^{\mathrm{e}} \mathrm{s} .{ }^{21}$. Les objets de parure font parallèlement une apparition discrète au travers d'une boucle d'oreille, tout comme les éléments liés à l'habillement qui ne sont représentés que par une seule fibule. Parmi les objets dédiés au soin du corps, le strigile se retrouve dans quatre sépultures : celle d'un jeune garçon (SP 339), d'un éphèbe (SP 334), d'un jeune homme (SP 291) et d'une personne adulte dont le sexe ne nous est pas connu (SP 300). On dénombre parallèlement la déposition des premières figurines en terre cuite au sein des sépultures (voir ci-dessous, p. 247).

Ces diverses tendances, apparues durant la phase 2, se maintiennent au cours de la période suivante. Sur 108 objets mis au jour dans les 26 sépultures, 41,7\% (45 objets) sont des vases en terre cuite (un seul exemplaire en bronze), 30,6\% (33 objets) sont en métal et $11,12 \%$ (12 objets) des figurines en terres cuites. Le lécythe, présent dans deux tiers des sépultures (16 sur 26), affiche une proportion stable et concerne tous les types de tombe, indépendamment du rite funéraire incinération ou inhumation -, de l'âge ou du sexe des défunts. Il représente bien souvent la base du mobilier funéraire autour duquel se greffent les autres éléments. En regard, les vases liés au banquet continuent à jouer un rôle important dans les offrandes faites aux défunts, où ils apparaissent dans $46,1 \%$ des tombes (12 sépultures sur 26). A nouveau, ils ne composent pas de service complet : on note que l'ensemble le plus significatif a été découvert dans une tombe féminine (SP 329). La coupe (trois exemplaires dans deux sépultures) et l'œnochoé (deux exemplaires dans deux sépultures) en sont les éléments les plus caractéristiques. Ces deux formes ne sont pas associées l'une à l'autre dans le mobilier. La coupe (isolée dans SP 264) peut être accompagnée d'un pot (SP 298) ou d'une cruche (SP 329); le canthare est associé dans un cas à la cruche (SP 333), laquelle constitue l'élément de loin le plus diffusé (quatre exemplaires dans quatre sépultures). On note, en revanche, l'essor du pot qui, par sa forme, est susceptible de répondre à des usages multiples, éventuellement non alimentaires. Ce dernier vase apparaît parfois seul (SP 337) ou dans des assemblages liés à la toilette (SP 328), ce qui nous incite à une certaine prudence quant à sa destination exacte. On note que ce type de vaisselle n'est pas absent des tombes d'enfants, comme le démontrent les deux coupes de SP 264 ou l'œnochoé de SP $327^{22}$. De même, la présence

21 Tombes $\mathrm{n}^{\text {os }} 153,188,299,389,392,397$ et 418 : Venedikov et al. 1963 , p. 24-26, 34, 43-44 et 47.

22 Les sujets immatures disposent également à Nymphaion de services liés au banquet (Petersen 2007, p. 194). d'un guttus dans SP 322 mérite d'être notée, bien qu'elle ne soit pas sans poser problème, car elle concerne un sujet adulte dont le sexe demeure indéterminé ${ }^{23}$. Ce vase entre en composition dans cette sépulture avec un jeu complet et fonctionnel d'astragales (quatre exemplaires), disposé tout autour du vase et placé sur le fémur, non loin du bassin. Il demeure impossible de déterminer, en l'absence d'observations anthropologiques précises, si ce vase s'adressait au défunt ou à un très jeune immature (nouveau né) dont les reste osseux se conservent en général assez mal. (Tableau 9)

\begin{tabular}{|l|c|}
\hline \multicolumn{1}{|c|}{ Type de vase } & Pourcentage \\
\hline Lécythe & 52,2 \\
\hline Coupe & 6,52 \\
\hline Oenochoé & 4,34 \\
\hline Askos & 2,17 \\
\hline Cratérisque & 2,17 \\
\hline Gobelet & 2,17 \\
\hline Pyxis & 2,17 \\
\hline Cruche & 4,34 \\
\hline Pot & 6,52 \\
\hline
\end{tabular}

Tableau 9. Période 3. Principales formes de vases représentées.

Le strigile, en revanche, se fait rare, un effacement qui semble s'expliquer aisément par le nombre limité de tombes d'homme. Pourtant, deux strigiles ont été retrouvés dans une sépulture féminine (SP 265), ainsi que dans un dépôt (DP 23) qui lui est associé ${ }^{24}$. Parmi les autres objets liés à la toilette, deux miroirs sont associés à des sujets féminins (SP 272 et 340), ainsi qu'une pyxis en bronze (SP 328), associée à deux lécythes et une aiguille, offrant un ensemble relativement complet. Les bijoux apparaissent rarement: ils ne concernent d'ailleurs, durant la période 3 , que deux sépultures d'enfants, comme dans la phase précédente. Enfin, trois sépultures ont livré des figurines en terre cuite, comportant chacune entre un et sept exemplaires. Il s'agit là encore sans exception de jeunes immatures ${ }^{25}$.

23 Sur l'usage du guttus et sa possible identification avec le

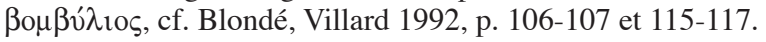

24 Voir ci-dessous, p. 168-169, de même que pour les miroirs et les aiguilles.

25 Voir ci-dessous la contribution d'A.-S. Koeller et le commentaire des figurines en terre cuite par K. Panayotova. 
Parmi les innovations de la période 3 , on note l'apparition de l' « obole à Charon » vers la fin du second quart du $\mathrm{IV}^{\mathrm{e}} \mathrm{s}$., reflétant une présence discrète déjà observée lors des précédentes fouilles ${ }^{26}$ : Apollonia suit donc fidèlement la chronologie définie par Bruck ${ }^{27}$. Cette déposition intervient dans des proportions bien plus modestes que celles observées à Olynthe ${ }^{28}$, car seules trois monnaies ont pu être récoltées, issues de trois sépultures différentes. Cette offrande ne concerne dans le secteur étudié que des sujets adultes ${ }^{29}$ et, contrairement à l'usage attique, elle ne s'adresse pas de façon privilégiée à des sujets de sexe masculin (Kurtz, Boardman 1971, p. 166). Les objets métalliques ou en verre se multiplient. Leur fonction demeure parfois obscure, en particulier pour ceux qui accompagnent le sujet féminin inhumé dans SP 340. Sur 32 objets métalliques découverts pour cette période, onze proviennent d'ailleurs de cette sépulture, notamment une clé qui permet de supposer pour cette personne une fonction particulière ${ }^{30}$. Les clous maintiennent leur présence, mais les grandes dépositions d'astragales cessent et leur nombre se rapproche désormais du minimum requis pour servir le jeu (SP 322).

Enfin, durant la période 4, les vases composent encore la majeure partie du mobilier funéraire ( 26 objets sur 47 , soit $55,31 \%$ du mobilier), tandis que l'importance des objets métalliques ne se dément pas ( 15 objets, soit $31,9 \%$ ). À l'inverse, certaines catégories s'effacent, notamment les figurines en terre cuite qui ne comptent que pour un seul objet. Parmi les vases, le lécythe, présent en quatre exemplaires (quatre sépultures), cède la place à l'unguentarium (cinq exemplaires dans quatre sépultures). Ensemble, ils démontrent l'importance toujours accordée, dans la première moitié du $\mathrm{III}^{\mathrm{e}} \mathrm{s}$., aux vases à parfum. Les vases qui composent le service lié au banquet accusent en revanche un net recul. L'œnochoé et la coupe disparaissent du mobilier, compensés partiellement par l'apparition du lagynos (un exemplaire). Seuls le bol (un exemplaire), le plat (deux exemplaires), le pot (trois exemplaires) et les cruches (six exemplaires dans

26 Pour un commentaire sur cette pratique, voir Kurtz, Boardman 1971, p. 211.

27 E.F. Bruck soutient en effet que l'obole à Charon apparaît au IV ${ }^{\mathrm{e}}$ s., mais ne se diffuse qu'au III' ${ }^{\mathrm{e}}$ s. : Bruck 1970, p. 145. D. C. Kurtz et J. Boardman soulignent que cette pratique ne se développe en Attique qu'à l'époque hellénistique (Kurtz, Boardman 1971, p. 166).

28136 monnaies ont en effet été découvertes à Olynthe dans 66 sépultures différentes : Robinson 1942, p. 202.

29 Une exclusion observée également durant l'époque hellénistique à Asiné, en dépit d'une forte proportion de tombes concernées par cette offrande (Fossey 1985, p. 22). À l'inverse, 21 des sujets concernés à Olynthe étaient des enfants.

30 Voir ci-dessous, p. 169. quatre tombes) maintiennent leur place. Trois sépultures (SP 279, 289 et 318) associent encore, durant la période 4 , un vase à parfum et un vase lié au banquet (un pot ou une cruche).

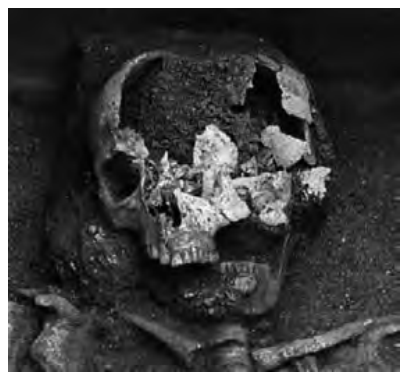

Fig. 53. "Obole de Charon» dans la bouche du défunt de SP 346.

Photo K. Panayotova.

L'obole à Charon (fig. 53), tout comme les clous, complète toujours les assemblages. Miroirs et aiguilles figurent toujours parmi les principaux objets liés à la toilette et à la parure, auxquels il convient d'ajouter les bijoux qui n'apparaissent une fois de plus que dans les tombes d'enfant. À l'inverse, la seule figurine en terre cuite a été découverte au sein d'une tombe d'adulte. Enfin, traduisant la circulation des usages funéraires caractéristiques de l'époque hellénistique, on observe l'apparition de la lampe (SP 279) et de la couronne funéraire dorée qui imite les prototypes en or. Cette dernière, mise au jour dans la sépulture SP 346 aux côtés d'une jeune femme, est composée de feuilles d'olivier en bronze doré et de fruits en argile attachés sur une fine bande en plomb. Ces transformations s'opèrent dans le cadre d'une forte décroissance de la richesse des offrandes au sein d'une nécropole où s'étend, de façon paradoxale, le rite onéreux de l'incinération. Ces évolutions traduisent donc moins un recul du niveau de vie qu'un bouleversement des habitudes sociales.

\section{Traitement et emplacement des objets}

Par le traitement spécifique dont il est l'objet, ainsi que la disposition particulière qui lui est donnée, le mobilier funéraire trahit parfois les gestes rituels associés à la toilette du défunt, ainsi qu'à sa présentation et à la cérémonie qui accompagne sa déposition ou sa crémation. (Tableau 10)

Les objets découverts à Kalfata aux côtés des sujets inhumés sont généralement placés dans la zone centrale et supérieure du corps, à savoir sur le bassin, les côtes, près des bras et sur les mains, de même qu'à proximité des épaules et de la tête. Le placement d'offrandes dans la zone inférieure du corps ou près des pieds, sans être exclu, s'avère beaucoup plus rare, excepté durant la période 3 . 


\begin{tabular}{|c|c|c|c|c|c|c|}
\hline & $\begin{array}{c}\text { Tête/Épaule/ } \\
\text { Poitrine }\end{array}$ & $\begin{array}{c}\text { Bassin/ } \\
\text { Main }\end{array}$ & $\begin{array}{c}\text { Genou/ } \\
\text { pied }\end{array}$ & $\begin{array}{c}\text { Comblement } \\
\text { inférieur }\end{array}$ & Extrémité sépulture & Autour du corps \\
\hline Période 1 & 3 & 4 & & 1 & & 1 \\
\hline Période 2 & 2 & 6 & 2 & 4 & 1 & 3 \\
\hline Période 3 & 9 & 15 & 12 & & 3 & \\
\hline Période 4 & 5 & 6 & 1 & & 3 \\
\hline
\end{tabular}

Tableau 10. Localisation des vases au sein des tombes.

Cette répartition connaît cependant quelques variations selon le type de vase concerné, voire au sein même de certaines catégories, selon le traitement qui lui est réservé : une particularité dont témoignent en tout premier lieu les vases à parfum. Les lécythes entrent, tout au long des périodes 1 à 3 , dans la composition du mobilier de près de deux tiers des sépultures. Leur nombre oscille entre un et cinq exemplaires. Il est intéressant de constater qu'une part considérable d'entre eux portent les traces d'une mutilation volontaire : le goulot et le col sont généralement cassés (SP 330, 291, 339, 244, 264, $320,326,327,333,338$ ) ; parfois l'ensemble du vase est intentionnellement brisé (SP 334, 251, 283, 303, 328, $340,370)$. Ce traitement n'est pas marginal, car il est appliqué durant la période 1 à la moitié des sépultures disposant d'un lécythe (fig. 54-55). Il touche, durant la période 2, cinq sépultures sur sept et concerne durant la période 3 douze des seize sépultures. Toutefois, dans les cas d'une déposition multiple, cette pratique n'est appliquée qu'à un seul lécythe, les autres exemplaires demeurant intacts (SP 330, 291, 244, 327, 328, 338),

Fig. 54-55. Lécythes au goulot cassé des tombes SP 343 et 326. Photos CCJ. sauf dans le cas particulier de SP 291. Cette règle n'est pas propre au lécythe et concerne l'ensemble des vases à parfum. On observe en effet qu'un même traitement est appliqué à l'alabastre de SP 375 dont le goulot est brisé, tandis que le second vase à parfum - un lécythe - demeure intact. L'emplacement du vase mutilé, tout comme celui des autres lécythes, n'est pas le fruit du hasard. Le second vase à parfum, intact, est placé de façon privilégié dans la partie supérieure du corps, à proximité de la tête ou des épaules (SP 330, 244, 322,

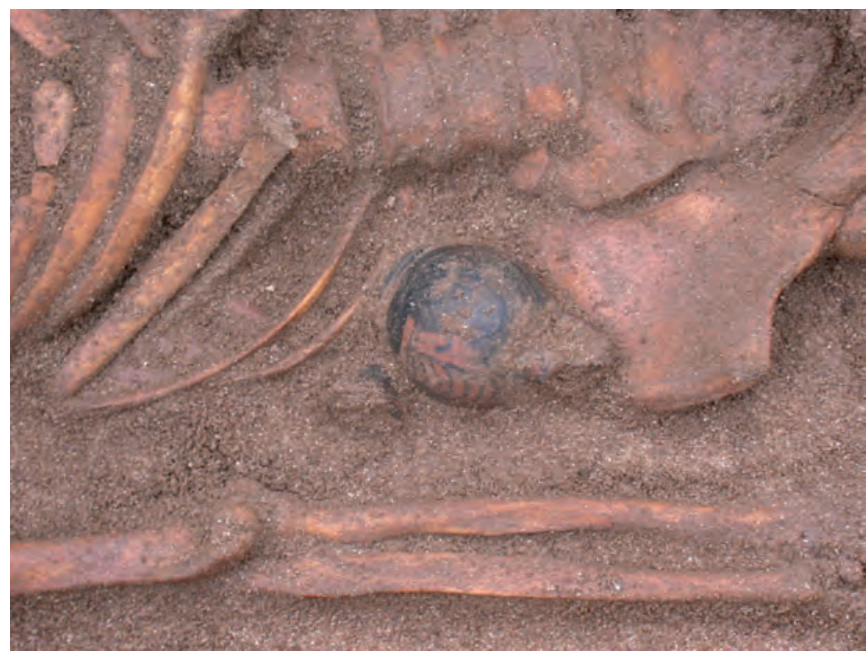

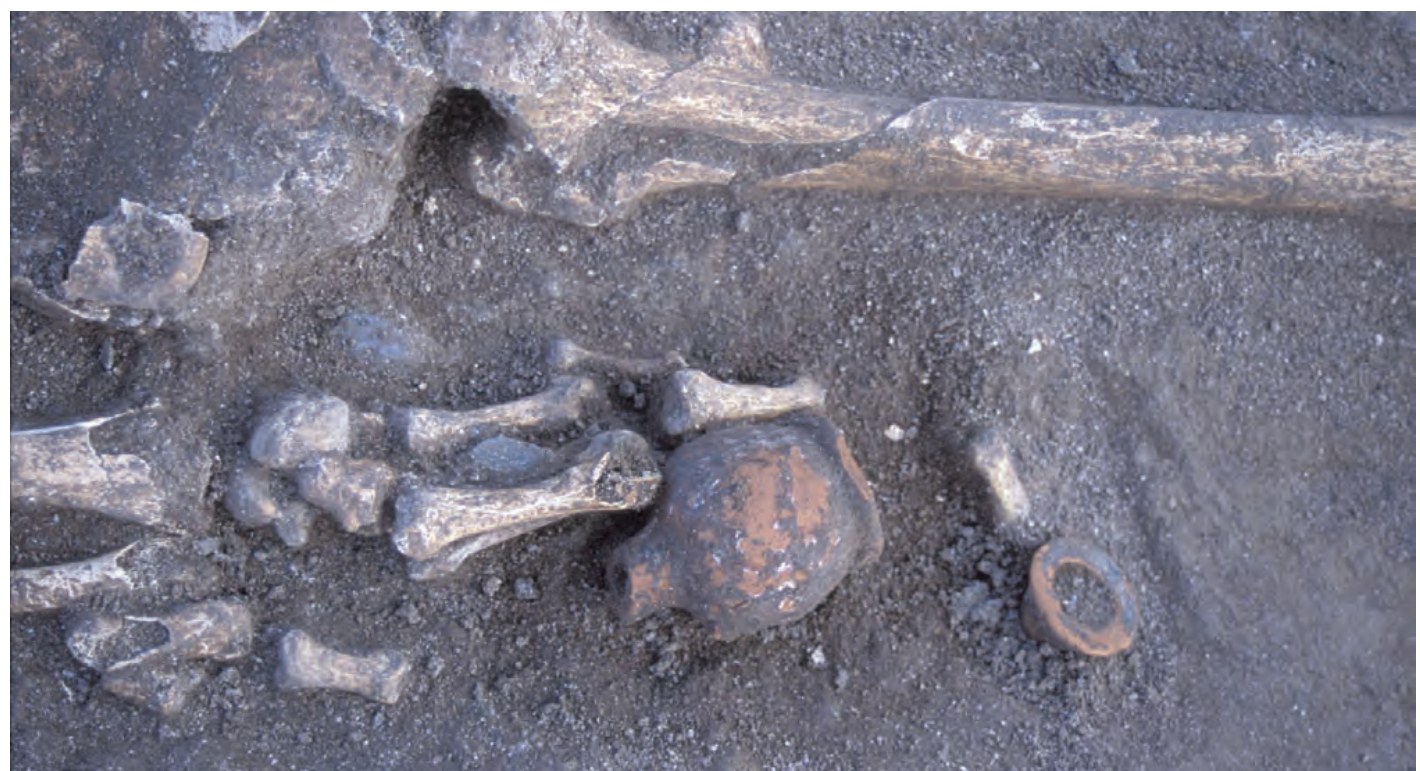




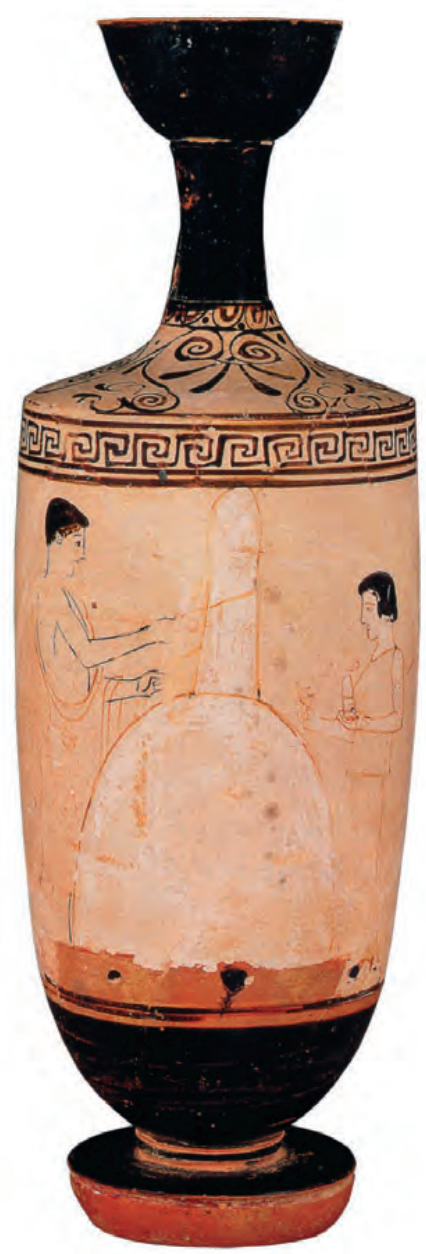

328,338 ), alors qu'un des fragments du lécythe mutilé est disposé à proximité de la main droite. Ce fragment peut correspondre soit à l'essentiel du vase si le goulot seul est sectionné (SP 330, 291, 339, 343, 244, 326, 340), soit au goulot lui-même quand tout le vase est brisé (SP 334, 320). Il peut s'agir plus ponctuellement d'autres éléments, comme le fond ou une partie de la panse (SP 251, 283). Les autres fragments sont répartis alors suivant des règles bien spécifiques. Dans de rares cas, le goulot demeure placé simplement à côté du vase (SP 343), mais on note le plus souvent une volonté perceptible de répartir les fragments tout autour du corps, ou du moins en des points opposés (SP 334, 375, 244, $283,320,328,338$ ), selon une situation observée dans d'autres nécropoles grecques ${ }^{31}$. Seules trois sépultures ne respectent pas ce modèle: dans SP 327, le lécythe

31 Deux sépultures découvertes à Myrmékion témoignent de ce rite. La première a livré un lécythe brisé dont le pied reposait sur le poignet droit, tandis qu'un second fragment était déposé de l'autre côté du squelette. La seconde - une inhumation d'adulte en fosse - concernait un lécythe à figures noires brisé, dont l'embouchure était déposée près de la tête, la panse près de la hanche droite et la base près des pieds : Vinogradov, Butyagin, Vakhtina 2003, p. 820-821.

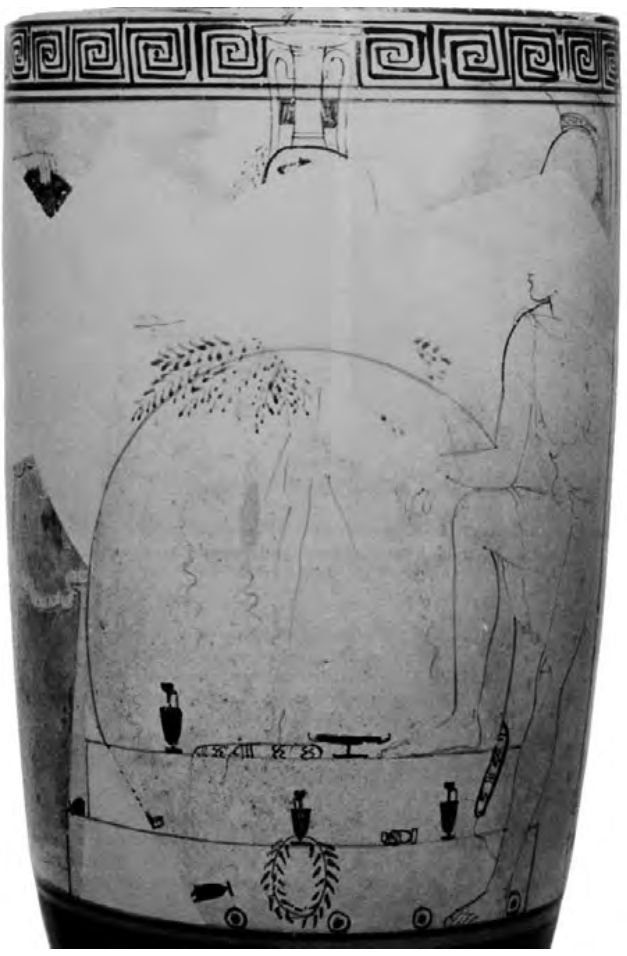

Fig. 56-57 Offrande de vases à parfum sur des lécythes attiques à fond blanc.

D'après Neils, Oakley 2003, fig. 113,

et Oakley 2004, fig. 168.

intact est en effet placé près de la main gauche; le lécythe brisé repose en revanche près de l'épaule droite dans SP 303, ou à proximité de la jambe gauche dans SP 264.

À l'inverse, les sépultures qui ne disposent que d'un lécythe intact ne privilégient aucun emplacement particulier. Le vase peut reposer aussi bien près de la main droite (SP 336), du bassin (SP 287), sur la poitrine (SP 331), autour de la tête ou des épaules (SP 250, $322,332)$, voire à proximité du bras gauche (SP 279). On observe de même, sur la base d'un échantillon réduit et peut-être non représentatif, que la mutilation des lécythes ne concerne durant les périodes 1 et 2 que des tombes d'homme, alors que cette pratique s'étend durant la période suivante aux deux sexes. Elle cesse en revanche durant la période 4 , où elle n'est pas reportée sur les unguentaria. L'enjeu, dès lors, est de comprendre à quel moment le bris du vase intervient, afin de saisir le sens que ce geste peut revêtir. Cette démarche peut paraître illusoire, car les vases à parfum comptent parmi les objets les plus représentés dans les scènes funéraires figurées sur les lécythes attiques à fond blanc : cependant, le vase à parfum est alors disposé comme une offrande 


\begin{tabular}{|c|c|c|c|c|c|}
\hline & Période 1 & Période 2 & Période 3 & Période 4 & Total \\
\hline Tête/Épaules & 1 & & 1 & 3 & 5 \\
\hline Coudes/Bassin/Fémurs & 2 & 1 & 6 & 1 & 10 \\
\hline Genoux/Tibias/Pieds & & 1 & 5 & 1 & 7 \\
\hline Sous le sujet & & 3 & & & 3 \\
\hline Parois des sépultures & & 2 & 2 & 3 & 7 \\
\hline Remplissage & 1 & & & & 1 \\
\hline
\end{tabular}

Tableau 11. Périodes 1 à 4. Répartition des vases associés au banquet.

sur la tombe elle-même (fig. 56-57) (Neils, Oakley 2003, p. 168, fig. 113 ; Oakley 2004, fig. IA et p. 147, fig. 106107 , p. 150 , fig. 112 , p. 206-207, fig. 167-168), et cet usage nous renvoie à des offrandes postérieures à l'inhumation du mort ou à sa crémation, donc à un moment où le tombeau est scellé ; ils ne peuvent expliquer le traitement réservé aux lécythes qui composent le mobilier funéraire. Le seul moment propice n'est autre que celui des funérailles, qui s'articulent autour de la prothésis, de l'ekphora et de la crémation ou de l'inhumation du défunt. Deux vases découverts dans les tombes SP 251 et 303 apportent sur ce point un témoignage précieux. Seuls en effet quelques fragments de ces deux lécythes ont pu être récoltés au terme d'un ramassage exhaustif réalisé dans le cadre de contextes non perturbés. On note ainsi que l'anse et le fond manquent dans la première tombe, tandis que seule l'anse du lécythe a été déposée, de façon très symbolique, dans SP 303. Cette déposition partielle nous indique que le bris de ces deux vases n'a pas eu lieu sur la tombe ou à proximité, c'est-à-dire au moment de la déposition du défunt, mais en un lieu distinct. Il semble difficile, dans cette perspective, de restituer un tel geste durant le transport de la personne de son domicile à sa sépulture. Il est en revanche un autre moment qui parait particulier adapté à cette pratique : celui de la toilette funéraire qui est opérée au domicile même du défunt. Le corps, une fois lavé, est en effet enduit de parfum, facilitant son exposition (De Schutter 1989, p. 54 ; Lévy 1994, p. 120). Il semble dès lors fort probable que le lécythe rituellement brisé soit précisément celui qui a servi à la préparation du corps ${ }^{32}$. La déposition de ce vase, ou de quelques-uns de ses fragments, tout autour du défunt, dans sa sépulture, revêt un sens symbolique fort en matérialisant le soin qui a été apporté et est censé donner à la personne disparue l'apparence qu'elle conservera dans le monde des morts. Le transport des fragments issus de ce bris ne semble cependant pas être obligatoire, comme en témoignent les tombes, minoritaires, qui ne possèdent pas de lécythe brisé. Cette pratique disparaît par la suite durant la première moitié

32 Figurée sur trois exemplaires du «Triglyph Painter »: Oakley 2004 , p. 83 , fig. 51-53. du III ${ }^{\mathrm{e}}$ s., où elle n'est identifiée dans aucune des sépultures de la période $4^{33}$. Les vases à parfum sont alors disposés de façon préférentielle près du bras droit.

Les différents vases qui composent le service lié au banquet funéraire ne sont pas, eux, concernés par le bris intégral. Toutefois, des traces de mutilation sont parfois visibles, qui se limitent aux seules anses, retrouvées cassées au sein de contextes non perturbés et sur des objets reposant dans du sable meuble (SP 264). La perforation du fond du vase, répandue parmi les objets qui composent les dépôts funéraires, n'est pas appliquée à ceux qui composent le mobilier funéraire ${ }^{34}$. La disposition des vases relavant du banquet s'opère de façon privilégiée dans la zone centrale du corps. Cet espace n'est cependant pas toujours disponible, en raison de la multiplicité des vases et de leur coexistence ponctuelle avec des lécythes. De fait, une partie d'entre eux est contraint de prendre place autour du corps, en particulier près des membres inférieurs, contrairement à ce qui a été observé pour les vases à parfum. (Tableau 11)

Une fois de plus, cette règle générale varie selon les formes de vases concernées. Les coupes demeurent ainsi majoritairement placées près de la main (cinq cas sur neuf) alors que les cruches occupent plus volontiers des zones secondaires. On les retrouve durant la période 2 sous le sujet, ou contre les parois de la sépulture durant les périodes 3 et 4 (quatre cruches sur six, sans intégrer dans ce décompte les fragments des SP 362 et 271).

Dans les cas, peu fréquents, où un lécythe partage l'espace autour du défunt avec des éléments propres au

33 Cette pratique se poursuit dans des proportions diverses au sein des nécropoles grecques hellénistiques. J.M. Fossey observe à Asinè des traces manifestes de bris rituel sur certains vases à parfum du $\mathrm{III}^{\mathrm{e}}$ s., alors que cette pratique semble alors minoritaire à Argos. Sur ce dernier site, seuls $14 \%$ des unguentaria étaient brisés : Fossey 1984, p. 290 et 1985, p. 22 ; Bruneau 1970, p. 531.

34 Le cas du fond de cruche percé découvert derrière une des tuiles de SP 362 apparaît douteux et l'hypothèse d'une contamination par des remblais adjacents, utilisés pour combler les espaces vacants entre la tuile et les bords de la fosse, n'est pas à exclure. Une tendance similaire à exclure les vases du mobilier de la perforation rituelle a été observée à Halieis où seule une coupe percée a été découverte dans une tombe, alors que les 19 autres vases percés étaient tous placés à l'extérieur des sépultures : Rafn 1984, p. 308. 
banquet, il n'a pas toujours la priorité. Quand survient l'association œnochoé/lécythe, la main droite est en effet occupée alternativement par le lécythe (SP 327) ou l'œnochoé (SP 322). Dans ce second cas, comme attendu, le lécythe est placé à la tête du défunt. En revanche, dans le cadre d'une association entre le lécythe et un vase lié à la boisson ou au service, ce dernier occupe l'emplacement de la main et le lécythe prend tantôt place à côté du premier vase (SP 336), tantôt est relégué plus loin (SP 264).

Doit-on imaginer pour autant que les vases liés au banquet contenaient au moment de leur déposition des offrandes alimentaires? La question n'est pas anodine et se pose avec d'autant plus d'acuité que, parfois, certains vases sont posés à l'envers. C'est le cas notamment d'une des deux coupes-canthares de SP 264, ainsi que de la coupe-skyphos de SP 329 ou du canthare de SP 333. Cette position semble peu propice au maintien d'un quelconque contenu. Parfois, cette présence est rendue manifestement impossible par d'autres objets disposés au sein des vases. Le bol de SP 336 contenait ainsi des astragales, tandis que le pot de SP 279 abritait une lampe. Tous ces indices démontrent qu'une partie des vases était donc soit laissée vide, soit remplissait d'autres usages.

La présence d'offrandes alimentaires au sein de la tombe n'est pourtant pas à exclure, comme le démontrent les deux os d'animal calcinés, déposés sur un fragment de pithos, qui accompagnaient le sujet de SP 341. De même, trois moules entières et un os animal ont été mis au jour sur le genou gauche du défunt de SP $326^{35}$. Dans ce dernier cas, les analyses anthropologiques ont démontré que la déconnexion observée sur les genoux et les chevilles demeurait difficilement explicable par des facteurs purement taphonomiques. Un poids particulier, dépassant les seuls coquillages, avait donc pesé sur cette partie du corps et provoqué un déplacement des membres inférieurs. Les offrandes alimentaires étaient plus abondantes que ce que laisseraient penser les quelques vestiges recueillis; elles étaient sans doute assemblées dans un conteneur en matière périssable similaire à ceux figurés sur les lécythes attiques à fond blanc, à savoir un panier ou un plateau tressé ${ }^{36}$. On constate par ailleurs que les offrandes de SP 326 montrent une cohérence frappante avec celles qui composent le dépôt funéraire associé à cette sépulture (DP 25), où plusieurs coquillages ont également été mis au jour (voir

35 Sur la question des coquillages dans les sépultures grecques voir Bruneau 1970, p. 529-530.

36 Cette utilisation des paniers pour le transport les offrandes figure sur de nombreux lécythes attiques à fond blanc: Oakley 2004, p. 123 , fig. 85 , et 171 , fig. 130 . Ces objets sont expressément mentionnés dans les règlements somptuaires attiques limitant la valeur et la quantité des offrandes alimentaires : Kurtz, Boardman 1971, p. 145. ci-dessous). En revanche, la présence dans les tombes de charbons, identifiée ponctuellement (SP 251, 283, 287, $315,328)$, sans qu'aucun foyer proche puisse expliquer ces immixtions, demeure obscure.

Un autre cas remarquable dans le traitement des vases consiste dans la déposition de plusieurs d'entre eux, brisés, sous le sujet. Cette pratique, observée durant la période 2, n'est pas spécifique de Kalfata, comme en témoigne le cas de Lagonisi en Attique (Tsaravopoulos, Papathanasiou 2006, p. 118). Les deux exemples d'Apollonia -SP 339 et 375 - sont relativement intéressants, car ils concernent deux sépultures parmi les plus anciennes $\mathrm{du} \mathrm{IV}^{\mathrm{e}} \mathrm{s}$. Chacune est installée au sommet du remblai dunaire et a donc peu de chance d'avoir perturbé, lors de son creusement, des tombes plus anciennes. Certes, les couches superficielles (notamment US 624/644) qui recouvrent les derniers horizons de sable (US 218/627) se sont avérées riches en fragments ${ }^{37}$. Toutefois, la cruche de SP 375 reposait, entière, sous le défunt. Elle semble donc appartenir au mobilier funéraire. Le cas de la péliké, du bol et de l'œnochoé de SP 339 apparaît plus discutable, mais leur mise en place à la base des dalles de la ciste permet également de les relier au sujet inhumé. Cette localisation démontre l'antériorité de leur déposition sur celle du défunt et nous amène, en retour, à nous interroger sur le sens de ce geste. Il n'est pas exclu, en effet, que ces vases aient servi à des libations destinées à consacrer les tombes avant que n'y prennent place ces deux défunts. Cette pratique se poursuit durant la période 4 où SP 362 a ainsi livré un pot et une cruche disposé contre les parois de la fosse.

Les objets de parure, peu nombreux à Kalfata, sont réservés la plupart du temps aux enfants ${ }^{38}$. Ils doivent leur présence dans la tombe au fait qu'ils sont portés par le sujet au moment de son inhumation, comme le démontre la localisation des boucles d'oreille dans la zone du crâne (SP 320, 346 et 375), que ce soit près de la tempe droite (SP 346) ou de la gauche (SP 375). Ils entrent donc dans la préparation du défunt, au même titre que l'huile parfumée des lécythes. Les boucles d'oreille semblent être associées en général à des tombes fémi-

37 Voir ci-dessus p. 59-61.

38 La richesse relative des sépultures d'enfants a été notée dans de nombreuses nécropoles, en particulier durant la période archaïque : Gras 1975, p. 51 ; Vokotopoulou 1994, p. 88 ; Zaphiropoulou 1994, p. 152. Bien souvent, ces tombes sont les seules à disposer d'objets de parure (Andreiomenou 1994, p. 116). Cette situation n'est cependant pas systématique en mer Noire. Durant la période archaïque, à Olbia, les objets de parure semblent réservés aux seuls adultes, et les tombes d'enfants apparaissent dans l'ensemble bien moins dotées, en particulier celles des sujets en bas âge (Petersen 2007, p. 50, 55, 57 et 71 ) ; cette différence de traitement s'estompe au cours de la période classique, durant la phase 3 , où les deux tombes d'enfant mises au jour présentent à l'inverse un riche mobilier (ibid., p. 52). 
nines, comme le suggère SP 346, ce qui éclaire en retour l'identité sexuelle des immatures de SP 375 et $320^{39}$. Le pendentif découvert dans SP 327, près de l'épaule gauche, paraît lui aussi avoir été porté par le défunt, autour d'un lacet en cuir ou d'un fil le long duquel il a glissé pour aboutir dans sa position finale. Seul le bracelet de SP 296 était placé au-dessus de la cheville gauche, non autour d'elle comme attendu.

Le traitement réservé aux objets liés à la toilette présente lui aussi certaines similarités. La déposition de ces éléments, en rapport direct avec l'intimité du défunt, s'avère relativement sensible. La position des miroirs ne semble pourtant répondre à aucune règle précise. Celui de SP 272, encore tenu par les doigts de la main droite de la défunte, apparaît à plus d'un titre exceptionnel ; les boutons en os découverts de part et d'autre de ce miroir indiquent qu'il était protégé à l'origine par un fourreau en matière périssable dont la fermeture était assurée à l'aide d'une lanière en cuir ou d'un fil. Le miroir de SP 340 reposait en revanche près du tibia gauche et celui de SP 289 était placé sous le crâne de la défunte. Les strigiles sont, pour leur part, déposés le plus souvent dans la zone centrale du corps, notamment sur le bassin (SP 291) ou sur les côtes droites (SP 334), à peu de distance de la main droite. On les retrouve cependant aussi près de la main gauche (SP 339) ou en des endroits plus insolites, comme le cou (SP 300) ou le thorax (SP 265). Les traces de mutilation, incertaines sur les miroirs, sont plus claires sur les strigiles, dont plusieurs exemplaires ont été tordus ou brisés en plusieurs morceaux (SP 265 et 339), sans que le contexte permette toujours d'expliquer cette dégradation. On note, en ce sens, que SP 339 correspond à une ciste qui, dans un espace non colmaté, a préservé l'ensemble des objets de toute pression extérieure.

Concernant la localisation des accessoires liés aux vêtements, on constate que les trois fibules reposaient respectivement près de l'abdomen (SP 244), de l'épaule droite (SP 265) et du crâne (SP 339). Cette variété se retrouve parmi les aiguilles dont aucune ne semble répondre à une règle fixe. Elles étaient placées à proximité du bras droit (SP 265), sous l'épaule droite (SP 320) ou près de l'épaule gauche (SP 328 et 370 ), voire sous (SP 389 et 296) ou sur le crâne (SP 336), ainsi que près du tibia (SP 327) ou des cuisses (SP 362) ${ }^{40}$.

Cette absence de logique dans le placement se retrouve parmi les terres cuites, découvertes dans des

39 Les sépultures abritant des jeunes filles, découvertes sous le tumulus 9 d'Apollonia d'Illyrie, sont ainsi caractérisées par la présence de bijoux en bronze (Amore 2004, p. 310).

40 À l'inverse, à Akraiphia, en Béotie, les fibules et les aiguilles reposent près des épaules (Andreiomenou 1994, p. 107). zones aussi diverses que les pieds (SP 283), la tête (SP 327), les épaules (SP 303) ou le long du flanc droit du défunt (SP 320). Vu leur fragilité, il semble difficile de déterminer si le bris de certains exemplaires était intentionnel ou non.

Étonnamment, la déposition des monnaies n'a pas toujours lieu dans la bouche, comme on le penserait. Cette situation, qui apparaît dans deux sépultures (SP 342 et 346), ne se retrouve pas dans SP 340, où la monnaie est associée, près du tibia, à d'autres objets en métal et en verre, peut-être au sein d'un sac ${ }^{41}$. De même, la monnaie de SP 347 était disposée près d'une tuile et celle de SP 316 reposait au-dessus de l'urne cinéraire. Ce dernier cas, particulièrement intéressant, démontre que l'obole à Charon n'était pas placée dans la bouche du défunt lors de l'incinération.

La question des clous est évoquée ci-dessous. J'ajoute simplement que leur présence est commune au mobilier funéraire et aux dépôts rituels extérieurs aux tombes. Au-delà du cas éventuel d'un support en bois soutenant un oreiller, placé sous la tête de certains défunts (voir ci-dessous, p. 166), il n'est pas impossible que certains d'entre eux répondent à une offrande partagée par ces deux contextes. Les couronnes funéraires, dont il fallait assurer à la fois le maintien et l'attache, sont abondamment illustrées sur les lécythes attiques à fond blanc où elles figurent tant dans la main du défunt que sur la couverture de sa tombe ${ }^{42}$. Elles s'ajoutent aux guirlandes végétales, reprises dans le répertoire pictural funéraire, et semblent toutes deux particulièrement bien adaptées pour expliquer la présence énigmatique des clous, que ce soit au niveau de la main de certains sujets, dans le comblement des tombes ou contre leur marqueur.

\subsection{Les dépôts funéraires}

\subsubsection{Cadre général}

La déposition de vases à l'extérieur des sépultures constitue en Grèce une pratique ancienne qui ne semble pas inconnue de l'âge du Bronze. Durant les périodes classique et hellénistique, ce type d'offrandes (enagismata) constitue la trace archéologique des cérémonies liées à la célébration et la commémoration du défunt (nomizomena). De telles pratiques sont suggérées par le répertoire figuré des lécythes attiques à fond blanc

41 L'obole à Charon est également placée à Thasos dans la bouche ou dans la main du défunt, voire dans des vases (KoukouliChrysanthaki, Sgourou, Agelarakis 1996, p. 774).

42 Oakley 2004, p. 48, fig. 20, p. 136, fig. 98 , p. 160161, fig. $120-$ 121 , p. 200 , fig. 162. 

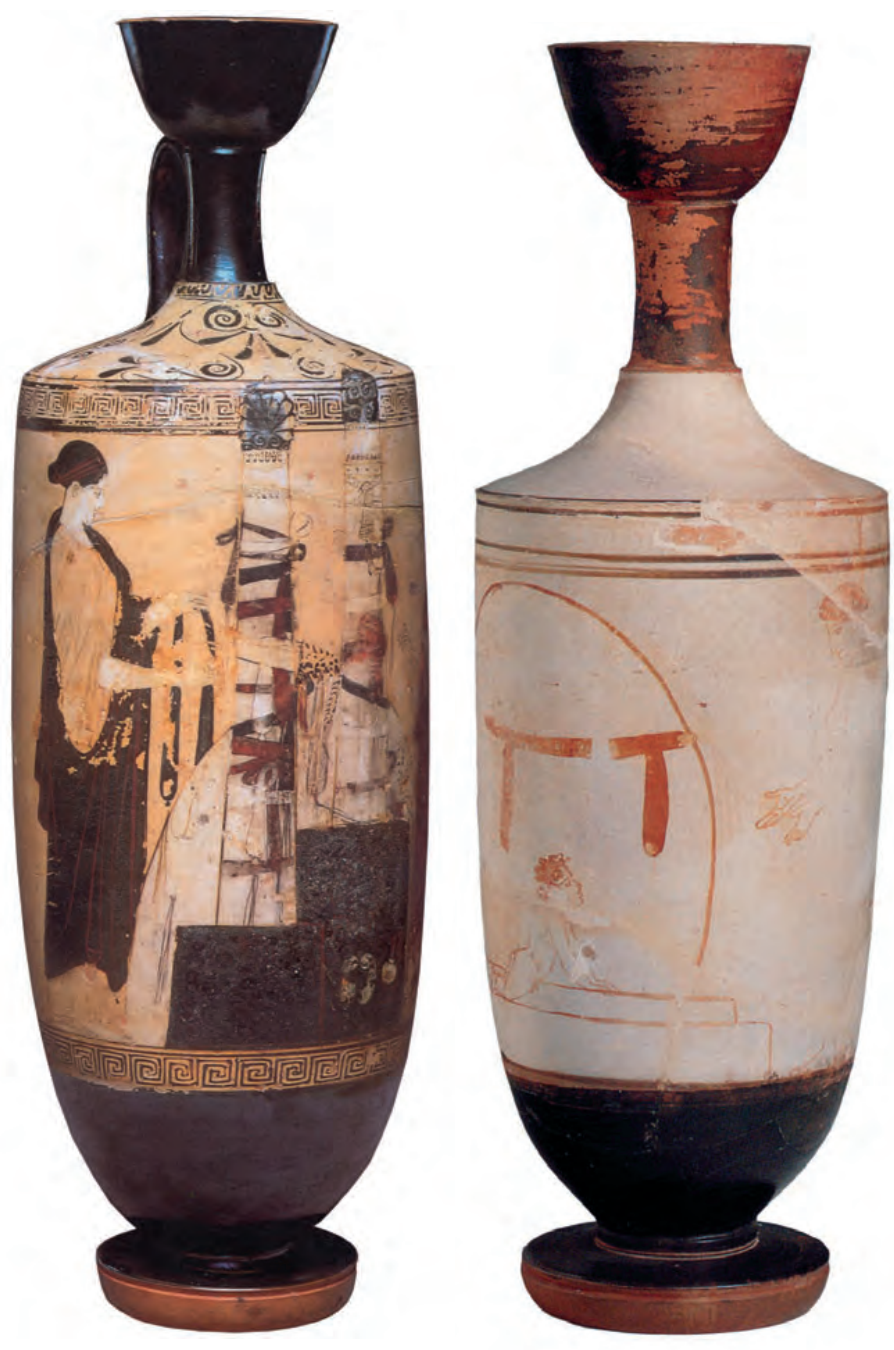

et par les textes anciens, qui insistent sur les devoirs dus au mort les troisième, neuvième et parfois trentième jours après les funérailles ${ }^{43}$. À ces premiers hommages succèdent des commémorations annuelles inscrites dans le calendrier religieux ou des visites personnelles plus ponctuelles ${ }^{44}$. Ces célébrations, qui occupent une place centrale dans les pratiques rituelles du monde grec antique, sont cependant souvent négligées lors des fouilles, car le matériel qui leur est associé est disposé à

43 La cérémonie du troisième jour ( $t a$ trita) est identifiée parfois avec les funérailles qui succèdent à la toilette du mort et son exposition (prothésis), elle-même longue d'une journée. Celle du neuvième jour apparaît particulièrement importante, non seulement d'un point de vue rituel et religieux, mais également dans la légitimité successorale qu'elle donne aux participants. En regard, celle du trentième jour apparaît plus modeste et intime. Voir Kurtz, Boardman 1971, p. 142148 ; Humphreys 1980, p. 99-101 ; Garland 1985, p. 41.

44 Deux périodes sont associées à la commémoration des morts : les genesia, partagés par l'ensemble du monde grec selon Hérodote $(\mathrm{IV}, 26)$ et les Anthestéries, associés en Attique à des cérémonies domestiques : Humphreys 1980, p. 100-101.
Fig. 58-59 Offrande de bandelettes et de couronnes végétales sur des lécythes attiques à fond blanc.

D'après Oakley 2004, fig. VIla, et Neils,

Oakley 2003, fig. 117.

l'extérieur de la sépulture. Bien souvent, ces concentrations de vases apparaissent avant que la tombe elle-même soit découverte, conduisant les fouilleurs à les traiter sans précaution comme des rebuts provenant de sépultures détruites. Les exemples de travaux archéologiques où ce type de contexte n'est tout simplement pas pris en compte abondent, y compris parmi des publications récentes, rendant difficile toute tentative de différenciation régionale au sein du monde grec.

Les dépôts funéraires revêtent au sein de la nécropole de Kalfata une importance particulière. Leur fréquence témoigne de l'existence d'un ensemble organisé de rites qui étaient réalisés près des sépultures. En raison toutefois des nombreuses perturbations engendrées par le creusement des nouvelles sépultures dans les remblais plus anciens, ainsi que du caractère très sableux de nombre d'entre eux, l'attribution de certains dépôts demeure problématique. La tentation est forte d'attribuer les dépôts funéraires sur des critères de proximité chronologique, mais, pour cohérente que puisse paraître cette démarche, elle comporte le risque d'ignorer la possibilité que l'attachement à un défunt puisse perdurer au-delà des premières années, aboutissant à des analyses à vue préconçue.

Une seconde précaution à prendre concerne la représentativité des vestiges archéologiques, auxquels il serait erroné d'accorder une valeur d'exhaustivité. La plupart des scènes de visite figurées sur les lécythes attiques à fond blanc témoignent de pratiques qui ne laissent pas forcément de traces archéologiques. C'est le cas en particulier des bandelettes ou des couronnes végétales, attachées toutes deux en nombre aux marqueurs ou simplement déposées sur la tombe (fig. 56 et 58-59) ${ }^{45}$.

45 Kurtz, Boardman 1971, p. 104-105 ; Oakley 2004, p. 48, fig. 20, p. 123 , fig. 85 , p. 136 , fig. 98 , p. $160-161$, fig. $120-121$. Noter une intéressante représentation sur laquelle les rubans sont mis en place par deux personnages sur la couverture d'un tumulus : Neils, Oakley 2003, p. 168 fig. 113 et 299, fig. 113 (fig. 56). Concernant les couronnes, Lucien de Samosate (Charon ou les observateurs, 22) souligne leur importance sur les monuments funéraires. Cette déposition est rappelée par les épigrammes à Nico, Artémias et Clitagoras, dans l'Anthologie grecque (VII, 187, 465, 657). Elle est également conforme aux pratiques observées sur le cénotaphe dédié aux membres de l'armée des Dix-Mille tombés lors d'une embuscade tendue par les Thraces vivant au voisinage de Kalpé : les offrandes consistaient seulement en des couronnes (Xénophon, Anabase, VI, 4, 9). 
TROISIÈME PARTIE : SYNTHÈSES

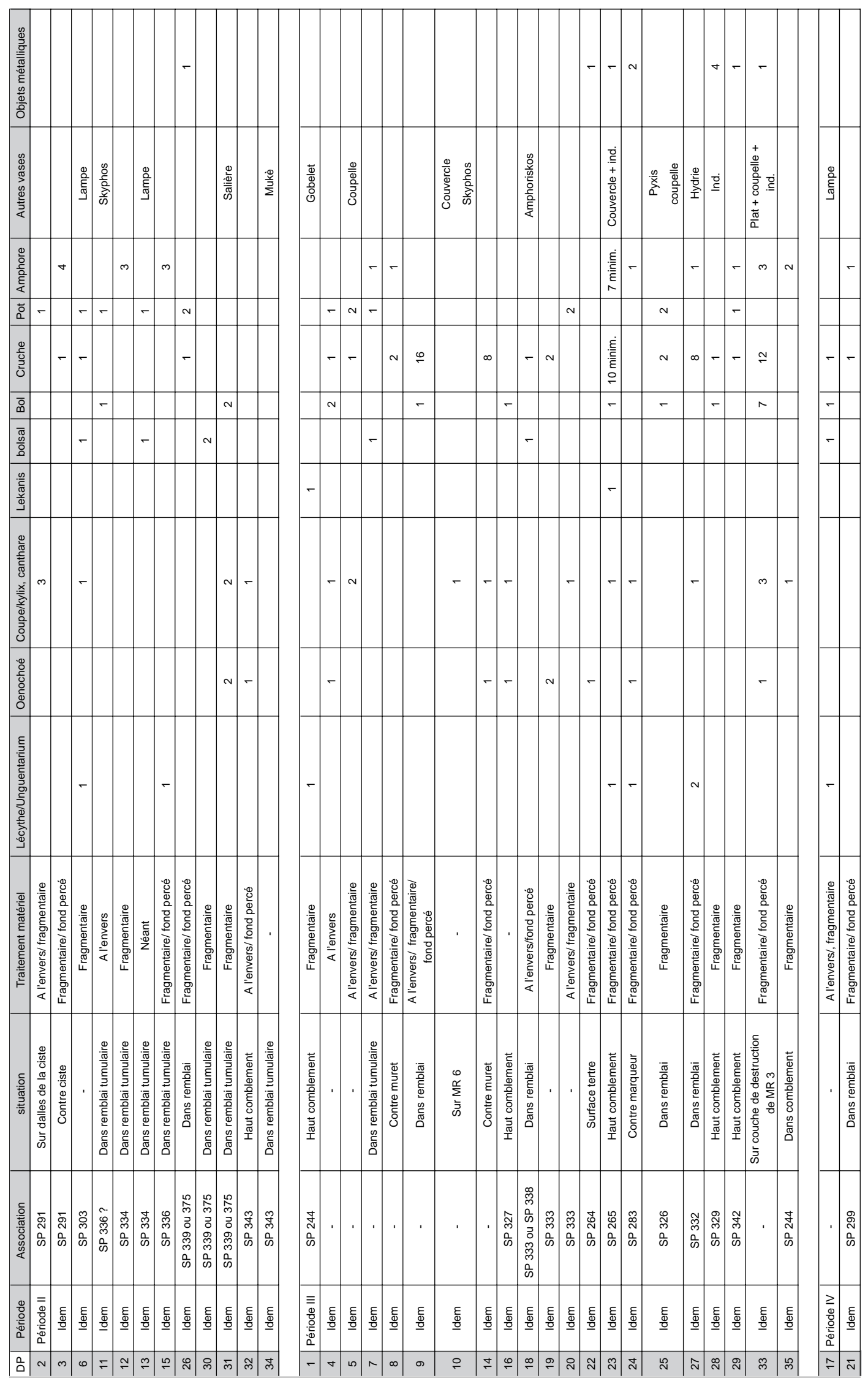

Tableau 12. Chronologie des dépôts funéraires. 
Ces deux objets constituent indéniablement la base des offrandes telles que nous le restituent les représentations figurées. Seuls quelques clous à la présence énigmatique, découverts en nombre limité autour des tombes, peuvent représenter des dispositifs d'attache pour les couronnes et donc le négatif de ces dons éminemment périssables. Ce geste est complété par l'offrande de parfum ${ }^{46}$ et de nourriture ${ }^{47}$, ainsi que par la déposition ponctuelle de vases au cours de visites dont il est difficile de déterminer exactement la chronologie. Cependant, la présence de raisins et de grenades (Oakley 2004, p. 149, fig. 111, et p. 171, fig. 130), attestée sur deux scènes, mérite d'être soulignée, car ces deux fruits nous renvoient à une période qui correspond à la fin de l'été et au début de l'automne, c'est-à-dire au moment des genesia, qui avaient lieu en Attique durant le mois de septembre. Malgré cette précision, il convient donc d'être conscient que toute réflexion menée sur les dépositions funéraires extérieures aux tombes ne peut être conduite que sur une base documentaire partielle et incomplète.

\subsubsection{Chronologie des dépôts funéraires (Tableau 12)}

L'absence de dépôts parmi les tombes de la période 1 n'appelle pas de commentaire particulier, car le nombre de sépultures est ici trop restreint pour être représentatif. On observe, à l'inverse, la forte diffusion de ce rite durant la période 2 , où douze dépôts ont été identifiés. Huit d'entre eux ne posent aucun problème d'association. Ils concernent six sépultures, deux cistes (SP 291 et 334) et trois fosses (SP 303, 336 et 343), et leur nombre varie entre un et deux dépôts pour chacune des sépultures. Les sujets concernés correspondent à un homme adulte, un homme jeune, un enfant, une femme mature et un adulte de sexe indéterminé. Le cas des dépôts DP 26, 30 et 31 est plus difficile à trancher, car ils sont susceptibles d'être rapprochés soit de SP 339, soit de SP 375. De même, l'association de DP 11 avec SP 336 ne repose que sur un lien de proximité chronologique, à défaut de proximité spatiale immédiate. Enfin, il n'est pas évident de déterminer si les dépôts de la phase 3 DP 7 et 8 sont liés à SP 316 ou SP 325, dont aucune ne leur est contemporaine, témoignant alors d'une intéressante continuité

46 Lucien évoque cette pratique visant à répandre du parfum sur le tombeau (Charon ou les observateurs, 22). Elle est attestée sur les scènes figurées où les visiteurs tiennent des alabastres ou des lécythes : Oakley 2004, p. 147, fig. 106, et p. 207, fig. 167.

47 Notamment de galettes, Aristophane, Lysistrata 601 (melittouta), et Lucien, La traversée pour les enfers ou le tyran, 2, 7 (popana). Ce type d'offrande demeure difficile à identifier sur les scènes figurées où elles accompagnent parfois des fruits (Oakley 2004, p. 202). L'épigramme à Euphorion propose comme offrande une grenade, une pomme ou un myrte (Anthologie grecque, VII, 406). de rites, ou si ces dépôts s'adressent, comme dans le cas supposé de DP 11, à des sépultures plus lointaines. Indépendamment de ces exemples problématiques, on note qu'au moins six tombes sur neuf durant la phase 2 sont accompagnées de ce type de contexte rituel. Cette association concerne tous les types de sépultures sans distinction - ciste et fosse - et des sujets d'âge et de sexe divers, y compris des personnes très jeunes, comme dans le cas de SP 339 et SP 375, ainsi que des sujets de sexe féminin, comme dans le cas de SP 336. Les sépultures auxquelles sont destinés ces dépôts présentent par ailleurs un mobilier funéraire très divers, depuis la tombe SP 343, relativement sobre avec un seul lécythe, jusqu'à des exemplaires plus richement dotés, comme SP 334.

Cette importante diffusion des dépôts funéraires se poursuit durant la période suivante, bien qu'à un rythme moindre, où dix des vingt-six sépultures de la phase 3 , soit près d'un tiers de l'ensemble, sont concernées par ce type d'offrande. Ce chiffre cependant ne prend pas en compte le cas de DP 18, difficile à départager entre les deux sépultures candidates (SP 333 et 338), ou ceux des DP 7 et 8 pour lesquels il n'est pas possible de déterminer s'ils sont à mettre en relation avec des sépultures contemporaines, mais parfois éloignées (SP 316 et 332), ou plus proches et plus anciennes (SP 326 et 339/375). Ainsi se pose la question d'une éventuelle permanence de la mémoire familiale et des rites dus aux ascendants, attestés ailleurs ${ }^{48}$. Cependant, à Kalfata, le maintien de la mémoire familial semble bref, comme l'attestent la rapide disparition des sépultures tumulaires du paysage funéraire, dans un intervalle chronologique inférieur au quart de siècle, et l'absence de généalogie longue sur les stèles. Les rites dus aux défunts interviennent de même dans un laps de temps relativement court, du moins si on considère les dépositions d'offrandes dont la composition a pu laisser une trace archéologique. Dans cette perspective, on note que seuls DP 7 et 8, ainsi que DP 10, sont susceptibles d'être rattachés, non sans réserve, à une tombe plus ancienne. A l'inverse, les treize autres dépôts s'avèrent strictement contemporains des sépultures auxquelles ils sont consacrés, démontrant que la pratique générale à Apollonia est d'honorer par des dépositions de matériel des tombes relativement récentes.

Le nombre de dépôt par tombe varie encore de un à trois, mais la norme semble être d'un dépôt par sépulture. Il est en revanche difficile, voire impossible, de rapporter cette distribution des offrandes au sexe des sujets ou au type de tombe, du fait de la surreprésentation des défunts de sexe féminin, ainsi que des simples fosses. Néanmoins, un cas mérite d'être souligné: la ciste

48 Zaphiropoulos 1994, p. 135 (Paros) ; Lungu 2000, p. 108-109 et 2006, p. 159 (Orgamé) ; voir aussi Humphreys 1980, p. 122. 
SP 328, malgré la richesse particulière de son mobilier et le caractère soigné de sa construction, ne dispose pas de déposition extérieure. Il en va de même pour l'incinération secondaire SP 345 dont la qualité du conteneur contraste non seulement avec l'absence de tout mobilier funéraire, ainsi que nous l'avons évoqué précédemment, mais également de tout dépôt funéraire extérieur à la tombe. La sobriété dans les dépositions rituelles, constatée dans le cas de certaines tombes à Kalfata, n'est donc pas toujours liée au niveau social du défunt. Il est à noter, d'ailleurs, qu'aucune sépulture dépourvue de mobilier n'est accompagnée dans ce secteur d'un dépôt, ce qui exclut tout report de matériel entre les deux contextes. Pour conclure nos remarques sur la période 3 , il convient de rappeler que toutes les tombes d'enfants ne sont pas accompagnées d'un dépôt : seules, en effet, trois sur six témoignent de cette pratique, ce qui représente une proportion supérieure à la moyenne générale.

Enfin, on note, durant la période 4, une diminution importante dans les offrandes extérieures aux tombes, puisque seuls deux dépôts ont pu être enregistrés pour seize tombes. Le relatif isolement de DP 17 rend toute association difficile, tandis que DP 21 peut-être rapproché de SP 299 (incinération). Le contraste est ainsi notable entre l'abondance des dépôts durant le $\mathrm{IV}^{\mathrm{e}} \mathrm{s}$. et leur soudain effacement au cours de la dernière phase de fonctionnement de la nécropole.

\subsubsection{Répartition spatiale des dépôts funéraires}

Deux classements de ces contextes rituels ont déjà été proposés lors des études préliminaires : le premier repose sur leur localisation, le second sur leur contenu (Panayotova, Riapov, Baralis 2006, p. 111-113 ; Baralis, Riapov 2006, p. 65-67). Ces deux approches s'avèrent complémentaires: la première nous renseigne sur la chronologie de ces dépositions, la seconde sur le sens qu'elles revêtent. Reprenant dans l'ordre ces questions, nous observons dès la période 2 une hiérarchie entre ces différents contextes. Durant cette phase, les dépôts se situent tout d'abord au sommet du comblement de la fosse ou à proximité immédiate des dalles de la ciste : c'est le cas respectivement des DP 2/3 et $16 / 29 / 32$. Sinon, ils se trouvent dans les remblais tumulaires qui recouvrent l'ensemble de ces tombes (DP 2, $12,13,15,26,30,31$ et 34). L'existence d'une éventuelle succession chronologique dans ces dépositions est suggérée par l'association des DP 32 et 34, dont le premier repose à proximité de la tombe, tandis que le second a été mis au jour dans la couverture qui lui est associée. Le dépôt DP 34 permet de préciser ce schéma, car sa position n'était pas fortuite: il reposait à la surface d'une des deux grandes unités qui composaient le tumulus, matérialisant une étape importante dans l'accumulation de la couverture de SP 343. Il n'est donc pas impossible que la première catégorie de dépositions, celles placées au plus près de la sépulture, intervienne au moment de l'inhumation du défunt, tandis que la seconde consacre une étape importante dans l'achèvement du tumulus, lequel peut être rehaussé éventuellement à une date ultérieure. Cette topographie des dépôts s'avère proche de celle décrite par $\mathrm{D}$. Triantaphyllos à Strymé où les dépôts (mais pas les foyers) ont été trouvés soit autour de la tombe, soit dans la couverture tumulaire, au-dessus du remblai initial (Triantaphyllos 2000, p. 90-91). Elle présente quelques similitudes avec celle en usage à Halieis en Argolide, au début de l'époque classique, où les dépôts découverts prennent place en différents points du remblai tumulaire (Rafn 1984, p. 305). À l'inverse, les offrandes d'un second tumulus archaïque étaient posées aux abords de la couverture (ibid., p. 305306), conformément aux scènes figurant sur les lécythes attiques à fond blanc, où la surface du tumulus est décorée de bandelettes (Neils, Oakley 2003, p. 168, fig. 113), tandis que des vases sont déposés à sa base (Oakley 2004, p. 207, fig. 168, et commentaire p. 205).

La disparition des couvertures tumulaires et le passage à une nécropole plate provoque durant la période 3 un déplacement des dépositions rituelles. L'usage consistant à marquer le comblement de la fosse, et donc sa fermeture par une dernière offrande, perdure, comme le démontrent les dépôts DP 1, 16, 19, 22, 28 et 29. De même, SP 244, de par sa double fosse, est l'objet de plusieurs gestes rituels successifs, réalisés à différents niveaux de son comblement, près des escaliers, ainsi qu'en haut de fosse. Toutefois, la fin des couvertures tumulaires engendre un changement de contextes: les dépôts se situent désormais sur les marqueurs des tombes ou le long des structures apparentes liées aux sépultures (murets, terrasses). Ainsi, DP 8 reposait contre le muret de soutènement retenant les remblais recouvrant SP 325, dans laquelle SP 316 est venue prendre place ; DP 24 associe plusieurs objets rituellement déposés contre le marqueur en pierre de SP 283. Certains dépôts (DP 20, 25 et 27) sont enfin installés à proximité des sépultures et parfois au même niveau, mais pas forcément immédiatement au-dessus d'elles, rendant leur association parfois problématique. C'est notamment le cas de DP 10, en apparence isolé. À l'inverse, l'attribution de DP 25 à SP 326 toute proche, et non à SP 265, semble évidente en raison des nombreuses similarités dans la composition du matériel du dépôt et de la tombe. Il n'est pas impossible que certains de ces contextes correspondent à des fosses à offrande. On observe en effet que DP 27 se développait en profondeur dans l'US 8/516, sans que des limites de fosses claires aient pu être saisies, en raison du 
contexte sableux de cet horizon. De même, DP 25 présentait une forme rectangulaire caractéristique ${ }^{49}$. Cette imprécision dans l'association des dépôts aux tombes qui les entourent s'accroît durant la période 4 où un des deux dépôts découverts (DP 17) pourrait, avec réserve, être attribué à SP 323 et 324 . La première est toutefois la plus éloignée, tandis que la chronologie de la seconde apparaît relativement problématique. Un même éloignement est visible dans le cas de DP 21 avec SP 299 dont l'association est suggérée par le caractère contemporain et l'isolement de ces deux ensembles.

Une dernière catégorie de contextes rituels apparaît au cours de la phase 3 . Leur présence s'avère remarquable, car il s'agit de dépositions imposantes dont le matériel révèle parfois une certaine diachronie. C'est le cas en particulier de DP 23, étroitement associé à sa base avec SP 265, mais dont le volume étonne, tout comme le matériel qui le compose, particulièrement stéréotypé, avec une forte prédominance des cruches. Cette dernière se retrouve également dans DP 9. DP 33 a livré à son tour un matériel abondant et relativement standardisé. On note sa localisation singulière entre plusieurs sépultures, contre les vestiges de destruction du mur MR 3. Par leurs caractéristiques, ces trois contextes se rapprochent des grands dépôts découverts par J. Carter à Pantanello (Métaponte) qu'il identifie avec des zones de déposition et d'abandon de vases utilisés lors de visites ponctuelles sur les tombes (Carter 1998, p. 115).

Les dépôts funéraires résultent donc d'un ensemble de rites funéraires qui peuvent être attribués par leur position à un moment proche de la déposition du défunt quand ils apparaissent en haut de comblement de fosse, soit à une période un peu plus tardive, quand ces offrandes reposent près du séma ou à peu de distance de la sépulture : ils peuvent alors correspondre à différentes cérémonies connues par les témoignages anciens, parmi lesquels on dénombre celles du neuvième ou du trentième jour, ainsi que celles annuelles inscrites au calendrier religieux. L'éventualité que ces dépositions découlent de visites plus ponctuelles n'est toutefois pas à exclure, comme le suggèrent deux représentations figurées sur des lécythes attiques à fond blanc. Sur la première, un ensemble de vases ornent le double emmarchement qui entoure la couverture tumulaire ; certains vases sont couchés sur le côté, d'autres déjà brisés, évoquant des offrandes successives étalées dans le temps

49 Selon un cas de figure attesté à Halieis, la sépulture concernée ne disposait pas de couverture tumulaire, mais de deux grandes plaques. Les dépôts sont disposés à proximité et au même niveau que la tombe. L'un d'entre eux prend place dans une structure rectangulaire, divisée et protégée par des dalles de calcaire. Aucune trace de charbons n'est évoquée, ce qui place ce contexte à mi-chemin entre les exemples d'Apollonia et les Opferrinne attiques : Rafn 1984, p. 305-306.
(Oakley 2004, p. 207, fig. 168, et commentaire p. 205) (fig. 56). Dans le second cas, un personnage féminin porte un panier d'offrandes contenant des bandelettes. Elle tient dans l'autre main un alabastre. Face à elle, de l'autre côté de la tombe, une autre personne joue de la musique et au pied de la tombe, devant le séma, gît la moitié supérieure d'un lécythe brisé qui suggère à son tour une visite plus ancienne (ibid., p. 147, fig. 106). Ces deux représentations illustrent donc des cérémonies relativement distantes des funérailles, peut-être réalisées à l'occasion de l'anniversaire de la mort du défunt ou lors des fêtes annuelles durant lesquelles la famille visitait les tombes des parents disparus. Comme le suggèrent ces deux documents, l'usage n'était pas forcément de nettoyer les vestiges des précédents hommages.

Cependant, les grands dépôts (DP 23 et 33, voire DP 9) démontrent que l'abandon des vases sur les tombes n'est pas systématique, du moins pour les formes les plus courantes, comme les cruches. Ces ensembles pourraient éventuellement constituer des zones d'amoncellement pour le matériel provenant de contextes détruits, notamment lors du creusement de nouvelles tombes, mais le faible nombre de tombes perturbées à Kalfata, tout comme l'absence de restes osseux parmi ces assemblages, ne nous permet pas de privilégier une telle hypothèse. À l'inverse, le matériel standardisé qu'ils recèlent suggère que les habitants d'Apollonia se sont servis de ces emplacements pour abandonner des vases ayant servi à des pratiques rituelles liées à la libation, comme le démontre le fond percé visible sur de nombreux vases, en particulier les cruches et les oenochoés (Tableau 13). Ces accumulations démontrent une double volonté : celle de ne pas laisser ces vases dans le périmètre de la tombe, sans doute pour ne pas l'encombrer, tout en ne ramenant pas ces objets avec soi, que ce soit pour répondre un interdit ou parce que certain nombre portent des traces de mutilation qui les rendent inopérants en milieu domestique. Le cas de DP 23 est particulièrement intéressant. Par sa position immédiatement au-dessus du corps de SP 265, ainsi que par la diachronie des objets qui le composent, cet ensemble semble illustrer un contexte qui a progressivement changé de sens. Initialement associé à la sépulture, il a fini par servir de zone de rejet, peut-être en raison de sa visibilité particulière, due à son volume, au sein de la zone funéraire et de l'effacement parallèle de la tombe.

\subsubsection{Composition et traitement du matériel (Tableau 13)}

La composition de ces dépôts et le traitement apporté au matériel qu'ils contiennent apportent des précisions complémentaires sur le sens de ces offrandes. On observe 


\begin{tabular}{|c|c|c|c|c|c|c|c|c|c|c|c|c|}
\hline & $\begin{array}{c}\text { Lécythe } \\
\text { Unguentarium }\end{array}$ & Oenochoé & $\begin{array}{l}\text { Coupe/kylix, } \\
\text { canthare }\end{array}$ & lekanis & bolsal & coupelle & Cruche & bol & plat & pot & amphore & Autres vases \\
\hline \multicolumn{13}{|l|}{ Période II } \\
\hline $\begin{array}{c}\text { Partie } \\
\text { manquantes }\end{array}$ & 1 & 4 & 3 & & 1 & & & 2 & & 1 & 10 & Lampe \\
\hline Fond percé & 1 & 1 & 1 & & & & 1 & & & & & skyphos \\
\hline Placé à l'envers & & 1 & & & & & & 1 & & 1 & & \\
\hline intact & & 1 & & & & & & & & & & Salière \\
\hline Indéterminé & & & & & 2 & & & & & 3 & & \\
\hline
\end{tabular}

\begin{tabular}{|c|c|c|c|c|c|c|c|c|c|c|c|}
\hline \multicolumn{12}{|l|}{ Période III } \\
\hline $\begin{array}{c}\text { Partie } \\
\text { manquantes }\end{array}$ & 3 & 6 & 9 & 2 & 1 & 1 & 50 & 11 & 4 & 17 & $\begin{array}{l}\text { Lampe, pyxis ; } \\
\text { pot; ; couvercle } \\
2 \text { ind. }\end{array}$ \\
\hline Fond percé & & 4 & 2 & & & & 16 & & & & \\
\hline Placé à l'envers & & & 1 & & 2 & 1 & 1 & 2 & 3 & & \\
\hline intact & 1 & 1 & 1 & & & 1 & 5 & 1 & 1 & & $\begin{array}{c}\text { Gobelet; } \\
\text { couvercle; } \\
\text { hydrie makè muke }\end{array}$ \\
\hline Indéterminé & & 2 & 2 & & & & 6 & & 3 & & $\begin{array}{l}\text { Skyphos; } \\
\text { amphorisos: } \\
\text { ind. }\end{array}$ \\
\hline
\end{tabular}

\begin{tabular}{c}
\begin{tabular}{c|}
\hline Période IV \\
$\begin{array}{c}\text { Partie } \\
\text { manquantes }\end{array}$
\end{tabular} \\
\hline Fond percé
\end{tabular}

Tableau 13. Traitement des vases dans les dépôts.

en effet que leur nature varie selon la place qu'ils occupent au sein de la nécropole.

Durant la période 2, une première catégorie de dépôts regroupe les ensembles disposés à proximité immédiate des sépultures, c'est-à-dire sur l'horizon supérieur du comblement des fosses ou contre les dalles des cistes. Ils reposent tous, sans exception, sous le remblai tumulaire qui a recouvert dans le secteur étudié l'ensemble des tombes de cette période. Ces dépositions s'articulent autour d'un nombre invariablement réduit de vases, parmi lesquels les formes liées à la boisson prédominent. Ainsi DP 32, étroitement lié à la tombe SP 343, associe une coupe-skyphos et une œnochoé, soit un ensemble cohérent organisé autour d'un conteneur et d'un vase permettant la consommation. Cette association reflète fidèlement la scène visible sur certains lécythes attiques à fond blanc où une libation est offerte pour le départ d'un jeune hoplite, au moyen d'une œnochoé et d'une coupe dont le contenu tombe à terre (Oakley 2004, p. 63, fig. 35). Le dépôt DP 3, placé contre SP 291, présente une autre variante : il s'organise autour d'une cruche et de trois amphores, donc de quatre conteneurs dont un seul est destiné au service de la boisson. Par leur position, ces dépôts représentent donc la trace archéologique d'un ensemble de rites réalisés au moment de l'inhumation du défunt, tous étroitement associés aux libations.
Cette analyse est confirmée par le traitement réservé à ces vases dont certains ont le fond percé. Le perçage est réalisé par une percussion minutieuse, témoignant du souci manifeste de ne pas briser l'ensemble de l'objet. C'est le cas notamment de la coupe-skyphos de DP 32 (fig. 60-61) et de la cruche de DP 26 (fig. 62). Il est impossible de préciser si le perçage vise à faciliter la libation ou si ce dispositif n'est destiné qu'à rendre l'objet inutilisable ${ }^{50}$. De même, le moment où cet acte intervient n'est pas sans poser problème, B. Rafn (ibid.) soulignant la forte probabilité que ces vases soient amenés sur la tombe déjà préalablement percés. Par ailleurs, la typologie des formes concernées par ce traitement durant la période 2 témoigne d'une diversité que l'on ne retrouve pas durant la période suivante. Lécythe, œnochoé et coupe, c'est-à-dire vase à parfum,

50 Apollonia fournit ainsi un parallèle direct à la nécropole d'Halieis, où B. Rafn a étudié cette pratique. Le perçage s'avère identique sur les deux sites, tant dans la technique appliquée (un clou ?) que dans la disposition du trou, imposées par la fragilité des vases. B. Rafn avance deux hypothèses pour expliquer ce geste : rendre le vase inutilisable pour tout visiteur; faciliter les libations. Elle note cependant qu'il serait plus facile dans ce premier cas de briser directement le vase, au lieu d'appliquer un traitement plus complexe, exigeant une certaine minutie : Rafn 1984, p. 307. 
à verser et à boire, sont ici traités de la même façon ${ }^{51}$. Tous trois constituent le négatif fidèle des scènes figurées où l'offrande de parfum et le versement de liquide représentent la base des pratiques rituelles. On constate cependant que ce traitement n'est pas exclusif. Une autre partie des objets est en effet brisée volontairement et, de façon troublante, une partie des fragments est absente du lieu de déposition. Cette situation, très commune à Kalfata, se retrouve ici sur l'œnochoé de DP 32, ainsi que sur les amphores de DP 3, dont le fond manque. À l'inverse, seul le fond de la cruche de DP 3 a été retrouvé ; il avait d'ailleurs été percé ${ }^{52}$. Le sens de cette destruction est à la fois pratique et symbolique. Elle révèle un acte délibéré qui peut, parfois, être complété par un dernier traitement spécifique. On observe en effet, à côté du perçage ou du bris, la déposition répétée de certains vases à l'envers, ce qui est le cas de la coupe-skyphos de DP 32, de la coupe et de la coupe-skyphos de DP 2 ou de l'ensemble des vases du DP 11. Cette situation, qui pourrait n'être qu'accidentelle, ne se retrouve pourtant que sur certains vases, en l'occurrence des formes ouvertes coupes, coupe-skyphos, coupelle, pot. Elle suggère une différenciation croissante des pratiques, articulée autour du perçage préférentiel des vases à verser - cruche, œnochoé - et du placement à l'envers des formes ouvertes quand le bris ne leur est pas appliqué. Cette tendance, perceptible dès la période 2, apparaît plus clairement durant la période suivante.

Toujours pour la période 2, nous constatons l'existence d'une seconde catégorie de déposition qui associe de façon privilégiée des formes ouvertes - coupe, lékanis, bolsal, bol, pot, salière - liés à la boisson ou au service en relation ponctuelle, mais non obligatoire, avec des vases à verser (DP 2, 13, 30, 31). Ces ensembles se caractérisent par la présence ponctuelle de vases miniatures, comme l'illustrent par exemple le pot (chytra), la cruche et le bolsal de DP 6 répondant à cette catégorie. L'usage de tels vases est d'autant plus remarquable qu'il répond à des exemplaires similaires découverts au sein du mobilier funéraire, à l'image du pot (chytra) de SP 298 ou de l'oenochoé de SP 322. Ils peuvent en outre s'enrichir d'objets divers que l'on s'attendrait à retrouver davantage au sein du mobilier funéraire. DP 13 contenait par exemple une lampe, et ce dernier dépôt se distingue en outre des autres par le fait qu'aucun des vases qui le

51 À l'inverse, les vases concernés à Halieis, au VI et au début du $\mathrm{V}^{\mathrm{e}} \mathrm{s}$., sont avant tout des cotyles et des coupes. Seule une œnochoé percée est recensée (ibid., p. 305 et suiv.).

52 La découverte à Halieis de fonds de vases isolés, par ailleurs percés, est également attestée. Le bris des vases y est également intentionnel, comme le démontre la déposition des fragments de certains d'entre eux en trois tas distincts, dont un placé sous une pierre (ibid., p. 307). composent n'est percé ou brisé. Une troisième catégorie, difficile souvent à identifier en tant que dépôt, concerne des vases isolés. DP 34 ne comportait ainsi qu'une cruche à deux anses (myké), mais sa position au centre du tumulus, à la jonction des deux remblais qui composent la couverture tumulaire associée à SP 343, laisse peu de doute sur le caractère intentionnel de cette déposition ${ }^{53}$. Enfin, certains dépôts présentent quelques divergences par rapport à ce schéma. Ainsi, DP 15 disposait de trois amphores, étrangement associées à un lécythe, mais ce dernier dépôt est conforme aux pratiques rituelles et atteste à la fois la libation due au défunt et le versement de parfum sur la tombe.

Ces différentes catégories de dépôts, en usage durant la période 2 , se retrouvent durant la période 3 , confirmant tout au long du $\mathrm{IV}^{\mathrm{e}} \mathrm{s}$. une continuité dans les pratiques rituelles que ne viennent pas perturber les diverses innovations visibles, comme l'introduction de l'incinération. Les ensembles déposés sur l'horizon supérieur du comblement des fosses associent toujours un nombre réduits de vases. DP 16, lié à SP 327, s'articule autour de l'association d'une oenochoé et d'une coupe, complétée par un bol selon un cas de figure déjà reconnue durant la période précédente au travers de DP 31 ; de même DP 19, lié à SP 333, comprend deux œnochoés et deux cruches. Ce type de dépôt incorpore désormais plus volontiers des formes ouvertes : DP 1, 28 et 29 ont livré une lékanis, un bol et un pot. Aucun de ces vases n'est percé, mais une proportion importante d'entre eux est brisée et seule une partie des fragments est déposée sur la tombe.

Le percement des vases continue d'être appliqué, mais il est réservé de préférence à une seconde catégorie de dépositions qui, suivant la disparition des couvertures tumulaires, prennent place désormais contre le marqueur des tombes ou contre les structures qui voisinent avec elles, ainsi qu'au sommet des tertres modestes qui recouvrent certaines sépultures. Ces ensembles (DP 8, $22,23,24)$ comportent un nombre variable de vases de un à sept -, reprenant une typologie large de formes. Démentant les représentations figurées sur les lécythes attiques à fond blanc, le lécythe n'en constitue pas la base et ne se retrouve que dans deux cas - DP 23 et 24 -, ce premier dépôt répondant à une double fonction comme nous le verrons plus tard. Laissant de côté ce cas ambigu, nous constatons que l'œnochoé, la coupe et la cruche constituent la majorité des vases, en relation parfois avec des amphores. L'adjonction d'autres objets plus insolites comme l'aiguille (DP 22) ou le clou (DP 24) intervient dans de rares cas. Le clou peut

53 Le tumulus de la première moitié $\mathrm{du} \mathrm{V}^{\mathrm{e}} \mathrm{s}$. étudié à Halieis a livré également de nombreuses dépositions de vases isolés (ibid., p. 306). 

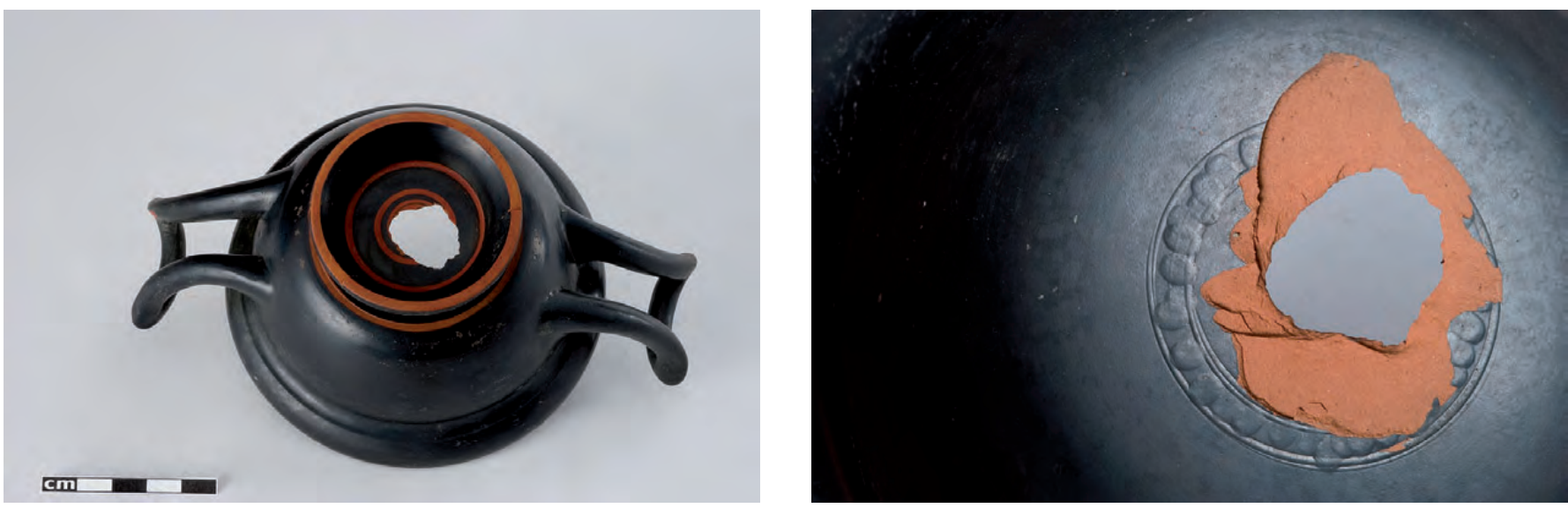

Fig. 60-61 : Coupes au fond délibérément percé du dépôt DP 32. Photos CCJ, L. Damelet.

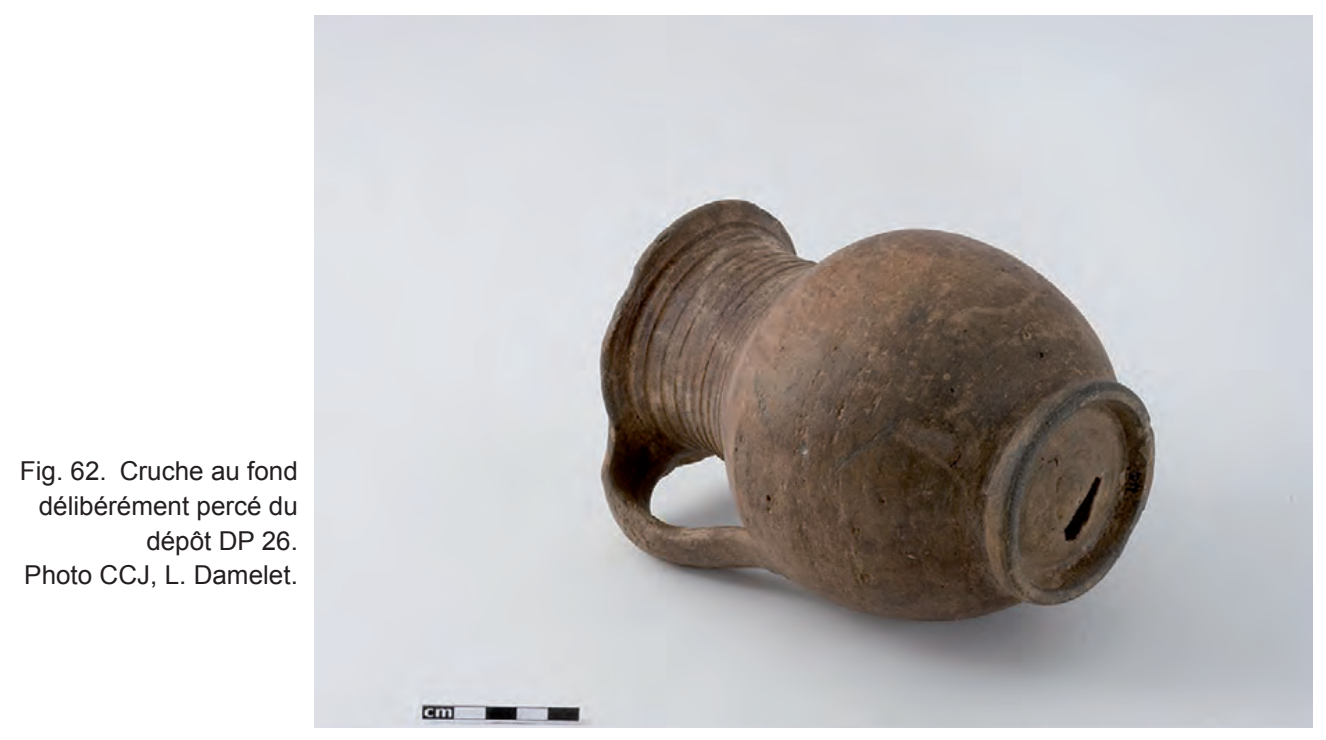

entretenir un lien avec les couronnes qui semblent, selon les représentations figurées, avoir été déposées en nombre au dessus des tombes, à moins qu'il ne se rapporte avec l'aiguille à des conteneurs - corbeilles, boîtes ou simples linges - associés à des offrandes périssables. Il peut également avoir servi au perçage des vases, car ce traitement continue d'être appliqué sur trois formes : les cruches, les œnochoés et plus rarement les coupes. Ce geste apparaît donc étroitement lié à la boisson. Cette mutilation s'ajoute parfois au bris du vase et à une déposition incomplète de ses fragments selon une pratique qui concerne tous les autres vases qui complètent ces ensembles, notamment les amphores.

Par leur composition et le traitement réservés aux objets, ces dépôts découverts contre le marqueur des tombes se rapprochent d'une troisième catégorie de dépôts qui regroupe ceux qui ont été mis au jour à une certaine distance des sépultures, sans que leur association avec un tertre ou un dispositif de marquage apparaisse de façon évidente. Ce placement, en apparence libre, pourrait ne résulter que d'un défaut de perspective, car la conservation même de ces modestes tertres au sein d'un espace littoral sableux n'est pas sans poser problème. Illustrant la disposition de ces dépôts, DP 27 reposait, par exemple, dans le même sable que SP 332, au-dessus de SP 339 dont il utilise à son tour le remblai de la couverture tumulaire. DP 25, lié à SP 326, reposait pour sa part immédiatement au Sud-Est de la tombe, à peu près au même niveau que cette dernière. Dans l'ensemble, il s'agit de dépositions nettement individualisées, dont l'association avec une sépulture peut être restituée avec plus ou moins d'assurance, sauf pour de rares cas. Le nombre total de vases qui compose ces contextes varie dans une fourchette relativement basse, ici de trois à treize vases. Leur composition s'articule autour de services plus ou moins complets : DP 27 disposait ainsi d'une coupe associée à deux œnochoés, ainsi qu'à sept cruches, une hydrie et une amphore. Cette typologie est 
parfois complétée par l'adjonction de pots, de coupelles ou de bolsals (DP 4, 5, 11) dont certains présentent des dimensions miniatures. Les pratiques qui accompagnent la déposition des vases sont assez similaires à celles décrites précédemment: les cruches et les œnochoés ont le fond percé ; les coupes, coupelles, pots et bolsals sont posés à l'envers. Le bris concerne en revanche l'ensemble des formes et s'étend aux amphores. Dans certains cas, des offrandes alimentaires sont également attestées (ossements d'animaux ou moules), comme l'illustre DP 25 qui a livré dix-sept moules, écho des trois moules découvertes dans la tombe.

Une quatrième et dernière catégorie de dépôts rassemble, durant la période 3 , des accumulations beaucoup plus importantes, pouvant atteindre plusieurs dizaines d'exemplaires ${ }^{54}$. Ces dépôts sont localisés généralement dans les zones intermédiaires qui séparent les sépultures, à l'image de DP 33. Toutefois, le répertoire des formes s'avère relativement réduit. Il s'agit pour l'essentiel d'amphores et de cruches, produites localement ou importées. DP 23 comportait ainsi au moins dix cruches et sept amphores; DP 9 près de 16 cruches. Ces dernières, sans surprise, ont généralement le fond percé. Elles sont également brisées, tout comme les amphores et la plupart des vases qui composent les dépôts. La fonction de ces accumulations n'est pas sans poser quelques questions, car elles ont livré parfois des objets dont on ne comprend pas vraiment la fonction dans un tel contexte : DP 33 contenait ainsi une lamelle en bronze provenant d'une structure en bois disparue et un astragale ; DP 23 possédait notamment un strigile. Par leur position et leur contenu, centré sur des vases liés essentiellement à la boisson, ces ensembles paraissent avoir servi de lieu de déposition d'objets qui avaient préalablement servi à des cérémonies réalisées sur les tombes aux alentours. Ils peuvent parfois accueillir des objets provenant de contextes rituels détruits, expliquant en retour la présence d'éléments métalliques. Le changement de fonction de certains dépôts n'est pas non plus exclu. DP 23 est, par exemple, étroitement associé à sa base à SP 265, et les vases qui composent les niveaux inférieurs du dépôt sont directement posés sur le squelette. Cependant, une fois le souvenir de cette tombe effacé, cet ensemble a continué à être utilisé sur une période assez longue en accueillant des vases utilisés sur d'autres sépultures, en particulier des cruches et des amphores.

Ces contextes archéologiques s'effacent de façon spectaculaire durant la phase 4 de la nécropole, sans pour autant disparaître. Seuls deux dépôts ont été découverts,

54 Parfois même plus d'une centaine, comme le montre un dépôt fouillé par l'équipe bulgare en 2002, qui contenait 119 vases : voir Panayotova, Nedev, Hermary 2003, p. 107. dont nous ne percevons pour l'un d'entre eux ni la fonction, ni la tombe à laquelle il peut être associé. Deux sépultures, plus au Nord, peuvent lui être rattachées sans certitude : SP 324, à la chronologie incertaine, ou SP 323, plus éloignée. Aucun vase n'est percé, mais la lékané est placée à l'envers et la cruche est brisée. Ce traitement se retrouve sur la cruche de DP 21 dont le fond est percé. Toutefois, la présence d'un lécythe et d'une lampe dans DP 17, selon un cas de figure déjà attesté durant la phase 1 , intrigue, tout comme celle d'un astragale ${ }^{55}$. Par leurs seuls exemples, DP 17 et 21 ne permettent pas de formuler des remarques significatives ${ }^{56}$.

\subsection{Les foyers}

\subsubsection{Localisation}

Les foyers rituels apparaissent fréquemment dans les nécropoles, où leur présence est systématiquement notée ; cependant, une certaine confusion a longtemps été entretenue avec la crémation de jeunes sujets. La difficulté pour un non-spécialiste à distinguer, au sein d'un ensemble fragmentaire, les restes osseux de jeunes animaux de ceux provenant de jeunes individus a conduit nombre d'archéologues à qualifier de façon erronée ces contextes d'incinérations primaires d'enfants ${ }^{57}$. On considérera donc avec prudence les témoignages sur les incinérations d'immatures issus de fouilles relativement anciennes. On observe par ailleurs, dans les études plus récentes, une tendance à ne pas différencier les foyers des dépôts funéraires, ces deux ensembles étant traités en même temps, sans qu'il soit toujours possible de différencier leurs caractéristiques propres.

Pourtant, dépôts et foyers répondent à une répartition spatiale spécifique, reflétant une fonction distincte dans les pratiques associées à la commémoration des défunts. On observe, par exemple, à Apollonia la relative absence

55 La présence d'astragales au sein des dépôts funéraires est toutefois conforme aux pratiques attestées sur les scènes figurées, où ces objets sont contenus dans des phormiskoi : Oakley 2004, p. 208209. Ils reproduisent ainsi une situation reconnue à Kalfata dans le mobilier funéraire, comme l'illustrent les astragales découverts dans SP 336, partiellement contenus dans une coupe.

56 Cette permanence à l'époque hellénistique de dépositions extérieures aux tombes est attestée dans d'autres nécropoles : ainsi à Argos, où $\mathrm{Ph}$. Bruneau souligne la découverte de 22 unguentaria hors des tombes, tous brisés (Bruneau 1970, p. 531).

57 Voir par exemple, pour Athènes, Eleftheratou 1997, p. 101. On retrouve une même confusion à Eleusis où, par un curieux raisonnement, seuls les foyers sans ossements sont qualifiés de foyers rituels, la plupart des autres étant invariablement interprétés comme des incinérations d'enfants : Mylonas 1975, p. 31 et suiv. 
de foyers aux abords immédiats des sépultures ${ }^{58}$. Seule ici la tombe SP 264 a livré un petit foyer, dépourvu de tout matériel, disposé aux abords de la fosse, non loin de la tête du défunt. Ce foyer, qui a vraisemblablement accueilli des offrandes périssables (alimentaires ou encens) nous rappelle cependant la découverte fréquente, à Kalfata, de charbons dans le remplissage des tombes, dont on ne saisit pas la provenance exacte.

Les foyers sont disposés de préférence à proximité des grandes structures qui entourent une ou plusieurs sépultures. Leur nombre n'est pas négligeable dans le secteur étudié, tout comme leurs dimensions. Ils sont mis en place durant les phases 2 à 4 , sans qu'il soit possible de déterminer leur existence au cours de la période 1 en raison de l'étroitesse de la zone concernée par les tombes de la fin du $\mathrm{V}^{\mathrm{e}} \mathrm{s}$. Durant la phase 2, on les trouve aux abords des grandes couvertures tumulaires, que ce soit le long de leur pente (F 1, 5, 6, 8) ou contre les murets circulaires qui les entourent (F 2, $3,9,10)$. Les foyers $F 3,6$ et 8 sont ainsi associés aux sépultures SP 334 et 336, toutes deux protégées par la même couverture tumulaire. De même, F 9 et 10, par leur disposition le long de MR 3, à proximité de la route, semblent se positionner aux limites d'une parcelle funéraire et sont susceptibles en ce sens de s'adresser autant à une sépulture qu'à un ensemble familial. Il est possible toutefois, par la composition du mobilier et sur la base de concordances chronologiques, d'essayer d'affiner cette approche et de tenter de mettre en lumière des associations individuelles. C'est notamment le cas ici pour $\mathrm{F} 9$ dont plusieurs éléments troublants orientent vers les deux sépultures d'immatures (SP 339 et 375) (voir p. 172-173). Le cas de F5 apparaît plus problématique, car ce foyer reposait sur la pente Sud-Est de la couverture tumulaire protégeant SP 343. Plus que le foyer lui-même, nous possédons en réalité un dépôt de bas de pente. Aucune terre rubéfiée n'a été identifiée et la dispersion des objets suggère un emplacement initial localisé plus haut sur le tumulus, à un niveau qui a été détruit lors de la phase 3 . Par sa position, F 5 pourrait

58 Particularité qui distingue nettement Apollonia des exemples nord-égéens: Ch. Koukouli-Chrysanthaki rappelle, dans le cas d'Abdère, la découverte fréquente, à côté des tombes de la nécropole tumulaire classique et du début de l'époque hellénistique, de foyers comportant des fragments de vases brisés et des ossements d'animaux (PAE, 1982, p. 13-14 ; ArchDelt, 37B, 1982, p. 334 ; KoukouliChrysantaki 1994, p. 52). Une même pratique se retrouve à Strymé, où un foyer reposait sur les dalles supérieures d'une ciste, elle-même recouverte d'un tumulus (Triantaphyllos 2000, p. 90). Le site de Polychrono, en Chalcidique, dont le faciès n'est pas exclusivement grec, a livré à son tour plusieurs foyers proches des tombes, dont un exemplaire particulièrement remarquable par son épaisseur, plutôt conforme aux apotephrotéria (Vokotopoulou 1994, p. 89). être rattaché en toute logique à SP 343. La présence d'un miroir, tout comme la chronologie des objets qui le composent, semble en inadéquation avec une telle identification, mais la recherche systématique d'une parfaite synchronie entre un contexte rituel et une tombe n'est pas sans danger et revient à refuser par avance toute continuité de rites et de mémoire du défunt audelà des quelques années qui succèdent à sa déposition. Une même difficulté se pose à nouveau ici dans le cas de $\mathrm{F} 1$ et 2 qui apparaissent par leur proximité étroitement liés à SP 291. Or, il n'est pas possible d'exclure par avance la possibilité que ces deux foyers associent aussi dans leur célébration d'autres tombes, disposées plus à l'Ouest, avec lesquelles SP 291 a pu partager une même parcelle funéraire dans un secteur où les limites sont difficiles à cerner.

Cette question des relations entre foyers et sépultures rejoint celle, cruciale, du moment exact où ces cérémonies ont eu lieu et de la place qu'elles occupent au sein du calendrier religieux. En ce sens, on note que les observations stratigraphiques permettent de déterminer à Kalfata l'existence d'un décalage chronologique sensible entre l'installation des sépultures et la réalisation de ces contextes rituels. Les foyers $F 9$ et 10 s'avèrent, par exemple, postérieurs par leur position à la mise en place des couvertures tumulaires de SP 343 et SP 339/375, de même qu'à l'accumulation de plusieurs remblais contre ces dernières, elle-même préalable à la construction du mur MR 3 contre lequel les foyers sont installés. Chronologiquement, ces deux foyers interviennent donc au terme d'une longue série de dépositions rituelles dont ils sont les derniers. F 9 et 10 succèdent ainsi au dépôt DP 32, placé en haut de comblement de la fosse de SP 343, et de DP 34, localisé à la jonction des deux remblais qui composent la couverture tumulaire de cette tombe. Ils succèdent également, dans le cas de SP 339 et 375, au dépôt DP 30, ainsi que peut-être aux DP 26 et 31 . Ils sont enfin postérieurs à $F 5$, démontrant par cette superposition la possibilité pour plusieurs foyers de s'adresser à un même ensemble de tombes, selon une situation observée également en secteur Nord dans le cas de DP 3, 6 et 8. Un même enchaînement se retrouve en secteur Sud avec F 1 et F 2. Ces deux foyers sont en effet postérieurs à la déposition de DP 3 contre la ciste SP 291 et de DP 2 dans le remblai tumulaire qui lui est associé. Il est à noter qu'après l'achèvement du tumulus, il a fallu ajouter plusieurs remblais contre sa face orientale avant que soit construit à son tour MR 2 et que soient enfin établis $\mathrm{F} 1$ et $\mathrm{F} 2$.

En raison de ces écarts chronologiques répétés, les foyers ont peu de chance de correspondre aux sacrifices, évoqués par les témoignages anciens, qui surviennent 
lors de l'inhumation du défunt (prosphagion) ${ }^{59}$. Ils ne semblent pas en adéquation avec les hommages dus les neuvième et trentième jours comme le démontre ici leur position autour du remblai tumulaire commun à SP 334 et 336 ou à l'extérieur d'une série de murs à peu près contemporains - MR 2 et 3 - construits autour de plusieurs ensembles de tombes. Ils sont en revanche davantage susceptibles de répondre aux cérémonies dues chaque année dans le cadre du calendrier religieux de la cité ou lors de l'anniversaire du décès de la personne (Kurtz, Boardman 1971, p. 144-148). Dans ce dernier cas, les foyers peuvent représenter un marqueur précieux pour estimer la durée de la conservation de la mémoire du défunt ou d'un ensemble familial, de même que la permanence éventuelle des rites qui leur sont destinés. Ces observations nous invitent donc à faire preuve de prudence dans l'attribution des foyers qui, même si elle parait possible pour F 9 (voir aussi p. 172), doit prendre en compte la possibilité pour certains d'entre eux d'avoir une valeur qui ne soit pas étroitement individuelle en s'adressant à un groupe plus important de tombes entretenant entre elles un lien familial. Ce dernier lien est notamment matérialisé à Kalfata par une couverture tumulaire commune (SP 334/ 336 et 339/375) ou par l'installation des tombes sur des parcelles dont l'unité est soulignée par les murets qui l'entourent (MR 6/7, MR 2).

Au cours de la période suivante, le nombre de foyers connaît une décroissance spectaculaire, si on compare les deux foyers mis au jour aux vingt-six sépultures contemporaines. La localisation de ces ensembles rituels ne connaît en revanche aucune modification. On les retrouve placés systématiquement aux limites de l'espace funéraire, apposés contre les murets : F11 s'étend à proximité de MR 3, le long de la route principale, tandis que $\mathrm{F} 4$ prend place contre le muret soutenant le remblai qui recouvre SP 325, c'est-à-dire à l'extrémité occidentale du secteur funéraire. L'association de ces foyers avec une sépulture n'est, une fois de plus, pas évidente. F 4 repose à proximité de SP 316, mais il n'est pas impossible que cet ensemble s'adresse à un groupe plus large de sépultures, à l'image de F 11, placé au-dessus de

59 De Schutter 1989, p. 57. Le Pseudo-Platon (Minos, 315c) note que la coutume ancienne voulait que ce sacrifice soit réalisé à la maison, avant l'ekphora. S'il n'est pas impossible que la présence ponctuelle de charbons dans les sépultures de Kalfata soit en rapport avec un acte rituel réalisé avant la déposition du défunt, il est intéressant d'observer que l'absence à Apollonia de restes de sacrifice sur la tombe ou à proximité immédiate semble en accord avec cette analyse. L'absence de « fosses à offrandes » (Opferrinne), similaires aux exemplaires découverts au Céramique, mérite en ce sens d'être soulignée. Cette situation n'est toutefois valable que pour Apollonia et ne se retrouve pas sur d'autres nécropoles grecques. $\mathrm{Cf}$. note précédente.
SP 370, entre SP 328 et 345 . Il demeure dès lors difficile d'estimer un éventuel décalage chronologique entre les foyers et les tombes auxquelles ils sont consacrés ; F 4 et SP 316 ne sont, par exemple, pas strictement contemporains, mais il n'est pas impossible que $\mathrm{F} 4$ puisse être mis en relation avec les sépultures situées immédiatement au Nord-Est.

Cet usage perdure durant la phase 4 , où le seul foyer (F 7) repose, à l'image de F 9, 10 et 11 avant lui, le long d'un muret qui borde la route principale. La valeur collective qu'il revêt est ici indéniable, du fait de l'absence de tombes proches contemporaines. Il semble au contraire que F 7 s'adresse à l'ensemble des sujets incinérés - SP 312, 317, 318, 319 et 323 - déposés en urne de l'autre côté du muret MR 8, dans les remblais tumulaires de SP 334 et 336.

\subsubsection{Composition des assemblages}

Les foyers de Kalfata contiennent souvent une quantité importante de matériel, essentiellement des vases brisés, dont peu sont percés. Seuls en effet une cruche de F 5, cinq vases de F 9 (une lékanis, deux plats à poisson, une grande coupe et une œnochoé) et de F 11 (deux coupes, un bol et deux cruches) sont concernés par ce traitement spécifique. L'ensemble des objets porte en revanche des traces plus ou moins importantes de combustion.

Durant la période 2, les foyers se composent de trois à dix-neuf vases. En raison de la proportion importante de vases indisponibles lors de cette étude, pour cause de restauration, toute statistique apparaît périlleuse. Il est dès lors nécessaire de limiter notre analyse à des remarques d'ordre général. On note un vaste éventail de formes liées au banquet. Celles qui se rapportent à la boisson se déclinent en vases à boire et à verser. Les huit foyers de la période 2 comprennent ainsi, parmi les vases à boire, des skyphoi, des bolsals et des coupes-canthares. Ils ne sont présents qu'en nombre très limité : F 2 n'a livré qu'un skyphos, forme que l'on retrouve également dans $\mathrm{F} 3$ et F 5, dans ce dernier cas aux côtés d'une coupe-canthare. Paradoxalement, F 3 n'a livré aucun vase de cette catégorie, posant en retour la question de l'usage du bol dont la diffusion s'avère relativement large. Concernant les vases à verser, ils s'organisent autour de la cruche, présente dans quatre foyers (F 2, 4, 5, 10) et de l'oenochoé $(F 1,9)$, en association parfois avec la première. De façon troublante, cette catégorie de vases ne se retrouve pas dans tous les foyers ; une situation similaire à celle des conteneurs comme l'amphore, observés dans seulement un de ces contextes (F 5). Ce déséquilibre souligne en retour la forte prépondérance des vases liés au service qui reflètent une typologie plus large. Lékanis, plat 
à poisson, coupelle et salière représentent aux côté des bols les formes les plus courantes. Ils s'ajoutent aux pots (chytrai), lesquelles sont de dimensions miniatures, soulevant quelques questions quant à leur rôle fonctionnel. De même, les askoi, découverts dans cinq des foyers de la période 2 , méritent une attention particulière, car ce vase demeure associé à des fonctions diverses, notamment au conditionnement du vin, de l'huile ou de l'huile parfumée, voire à des usages médicaux ${ }^{60}$. Par leurs dimensions, les askoi de Kalfata nous renvoie vers un contenu modeste, du moins par son volume, peu en adéquation avec du vin. L'huile parfumée semble dès lors la meilleure candidate, bien que des analyses apparaissent souhaitables dans ce type de détermination. Enfin, l'usage réel des "grils à poisson », représentés par un seul exemplaire dans six contextes différents (F 1, 2, 4, 9, 10 et 11), mérite une attention particulière (voir p. 171-172). La répartition des vases entre vernis noir et céramique de facture commune durant la période 2 peut être appréhendée au travers de F 9. Treize vases sur dix-neuf sont en effet vernis, correspondant à 68,4\% de l'ensemble, tandis que les six autres relèvent de productions de facture commune. On retrouve sans surprise dans cette dernière catégorie les pots, ainsi qu'un des bols, une oenochoé et le « gril ».

On note par ailleurs l'adjonction ponctuelle d'objets divers : ainsi, F 2 a livré un accessoire en bronze ; F 5 une lamelle en bronze, un miroir, deux clous et un fragment de bronze ; F 6 un couteau ; F 9 une lamelle, un stylet et un troisième objet en bronze. La signification de ces objets au sein des foyers n'est pas toujours comprise, comme celle des astragales déposés en un seul exemplaire dans F 2 ou en grand nombre - près de 60 - dans F 9. Une analyse spécifique leur est consacrée plus loin, p. 169-170.

Si le nombre de contextes faiblit durant la période 3, leur composition s'avère en revanche tout aussi remarquable. L'un d'entre eux (F 11) représente sans doute le plus imposant de ceux étudiés dans le cadre des fouilles conjointes, avec pas moins de vingt-sept vases, auxquels s'ajoutent différents objets en bronze et deux astragales. L'oenochoé et la cruche - six exemplaires - composent toujours la catégorie des vases à verser. Ils entrent en association avec une amphore. Les vases à boire suivent une typologie proche de celle observée durant la période 2 : bolsal, coupe et peut-être bol. Le skyphos, absent dans F 11, est attesté dans F 4. La lékanis ne parait plus dans les vases liés au service, mais on note la

60 Richter 1935, p. 17-18 ; Sparkes, Talcott 1970, p. 157 ; Bruneau, Bovon 1966, p. 131 et suiv., dont la forme étudiée est désignée par S. Rotroff comme « double cruet » (Rotroff 1997, p. 179) ; Blondé, Villard 1992, p. 111-112. présence toujours énigmatique du guttus. La ventilation des productions démontre dans $\mathrm{F} 11$ la prépondérance continue des vases à vernis noir - 59,2\% -, dans des proportions légèrement moins importantes que celles observées dans F 9. Enfin, on observe la présence d'un strigile, ainsi que celle d'un astragale.

Durant la phase 4, la composition du seul foyer découvert se limite à une typologie beaucoup plus simple, en dépit d'un nombre de vases qui ne le cède en rien aux périodes précédentes. On retrouve en effet, sur les seize vases qui le composent, une écrasante majorité de bols (sept exemplaires) et de coupelles (cinq exemplaires), auxquelles s'ajoutent deux plats et un objet métallique, en fer. Le seul vase porteur d'un vernis noir est un canthare qui à lui seul ne représente que $6,25 \%$ de l'ensemble des vases.

\subsubsection{Organisation interne des foyers}

L'ensemble de ces foyers nous permet de comprendre la préparation et le déroulement des cérémonies associées à ces contextes. Contrairement au témoignage de Lucien (Charon ou les observateurs, 22), aucun bothros n'est creusé pour permettre la mise en place des foyers. Tous étaient disposés au niveau même du sol, sans qu'aucune structure, comme une table d'offrande ou un coffrage, ait été construite par faciliter la combustion du bois et des objets. Seul F 8 disposait, pour tout aménagement, d'une pierre et d'un fragment de canalisation. L'épaisseur moyenne de ces foyers est inférieure à $10 \mathrm{~cm}$ : F 9, avec près de $15 \mathrm{~cm}$, apparaît comme une exception que ne dément pas F 11, dont les charbons étaient mélangés avec la terre sableuse alentour. La couche rubéfiée n'est pas supérieure à 2 ou $3 \mathrm{~cm}(2,5 \mathrm{~cm}$, par exemple, dans le cas de F 3) ${ }^{61}$. Au-dessus d'elle s'étend une couche de charbons dont la dimension des fragments permet parfois de distinguer encore les vestiges de bûches. Six d'entre elles ont ainsi été identifiées dans F 9, correspondant, d'après les analyses anthracologiques ${ }^{62}$, à de jeunes branches de chêne soumises à un feu très vif, dépassant les 600 degrés. La présence de glands calcinés, provenant des branches elles-mêmes, nous permet de préciser la période durant laquelle cette cérémonie a eu lieu, à savoir l'été ou l'automne. Tous les foyers présents à Kalfata semblent n'avoir servi qu'au cours d'une

61 La présence d'une couche rubéfiée sous ces foyers invalide le raisonnement de Mylonas, qui justifiait l'interprétation de certains foyers comme des enagismoi par l'absence, à leur base, d'une couche rubéfiée, signe sans doute d'un foyer moins intense que les pyrés funéraires (Mylonas 1975, p. 41).

62 Dues à Vanessa Py, du LAMM, Aix-en-Provence. 
seule cérémonie, car, au-delà de leur faible épaisseur, aucune trace de nettoyage n'a pu être observée ${ }^{63}$.

Des offrandes alimentaires accompagnaient systématiquement ces ensembles. Bien qu'il soit impossible de reconstituer l'intégralité des mets déposés dans les foyers, en particulier les nombreux liquides offerts ${ }^{64}$, on note la découverte fréquente de fruits secs. C'est le cas notamment dans F 5, sans qu'il possible d'identifier leur nature exacte. F 2 a livré douze coquilles de noisettes, F 8 des restes d'amandes dont la position, autour et sur un bol posé à l'envers, mérite d'être noté. Les ossements d'animaux sont également bien attestés : ceux du foyer F 9, décrits plus loin, appartiennent à un jeune ovicapriné. Plusieurs autres espèces ont pu être identifiées dans le matériel provenant des couches générales (voir p. 173).

Ces offrandes posent la question d'une éventuelle consommation de ces mets sur la tombe par les participants aux cérémonies. D. Triantaphyllos le suppose dans le cas de la nécropole de Strymé où il restitue volontiers un repas pris lors des «tiers » (trita), avant celui qui a lieu au domicile familial (Triantaphyllos 2000, p. 90-91). Il rejoint en cela l'interprétation de W. Burkert, qui place le perideipnon autour du tombeau (Burkert 1985, p. 193). Pourtant, une telle hypothèse s'accorde mal avec le témoignage des sources anciennes. Lucien, donnant la parole à Hermès dans son dialogue avec Charon (Charon ou les observateurs, 22), évoque non la cuis-

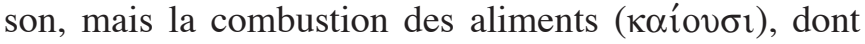
les âmes se régalent de la fumée, tandis qu'ils boivent les liquides jetés dans le foyer. Cette description est peu compatible avec un repas partagé que l'on a du mal à restituer à Kalfata au bord de la route, contre un mur. L'hypothèse la plus vraisemblable est que l'on se trouve ici face à un sacrifice non consommé, accompagné de libations, plus en adéquation avec un rite destiné à des personnes défuntes, reposant sous la terre. La forte calcination des ossements contenus dans F 9 n'a hélas pas permis à $\mathrm{Ph}$. Columeau de déterminer la présence de traces de découpes, mais cette lecture rejoint les doutes exprimés par D.C. Kurtz et J. Boardman (1971, p. 146147). L'idée selon laquelle le perideipnon ait eu lieu sur la tombe est également réfutée par X. De Schutter (1989, p. 58-60) qui note que, pour Homère déjà, le perideipnon se prenait au domicile du défunt.

63 Contrairement aux quatre foyers découverts à Polychrono, en Chalcidique (Vokotopoulou 1994, p. 89).

64 Lucien évoque du vin et du lait mélangé de miel versés dans les foyers (Charon ou les observateurs, 22).

\section{Remarques complémentaires sur certains aspects des rituels funéraires}

\subsection{La question des linceuls}

$\mathrm{Au}$ cours de ce qui a été défini comme la phase 3 de l'occupation de la nécropole, la plupart des inhumations ont lieu dans des fosses étroites et les observations anthropologiques de terrain rendent compte de l'exiguïté de ces creusements ${ }^{65}$ : dans trois cas les crânes sont largement contraints par la paroi de la fosse et apparaissent en face supérieure, dans deux cas les pieds sont en position verticale, appuyés contre l'extrémité de la fosse. Dans quatre autres cas cependant (SP 332, SP 337 , SP 342, SP 362), de forts effets de contraintes, aussi bien longitudinales (tête et pieds) que transversales (épaules, bras et bassin) ont été observés, sans pour autant que les ossements butent contre les parois des fosses. Il est donc envisageable de restituer des contenants initiaux du type linceul, très constrictifs. La position des défunts, avec les membres supérieurs en forte adduction (vers l'intérieur du corps), paraît confirmer cette hypothèse de la présence d'un linceul. Les observations effectuées sur d'autres sépultures, fouillées en 2004 par nos collègues bulgares, ont permis de constater, de la même manière, une forte constriction des corps à mettre en rapport avec le port initial d'un linceul : c'est le cas pour les tombes à fosses 360, 364, 367, 368, 373, 374, 386, 388, 389, 390 ; il s'agit dans la majorité des cas de sujets féminins adultes.

Même si elles ne portent que sur un nombre limité d'individus, ces constatations sont importantes, car elles ont très rarement été faites lors de fouilles de nécropoles grecques pour la période qui nous concerne. Elles complètent donc une documentation qui, pour cet aspect des pratiques funéraires, était limitée à l'iconographie et à quelques textes.

Les documents figurés présentant le défunt enserré dans une étoffe qui, quelle que soit sa fonction d'origine, n'est pas drapée comme un vêtement et que l'on peut donc désigner comme un linceul ${ }^{66}$, ont été plusieurs fois reproduits et commentés dans le cadre d'études plus ou moins générales sur les pratiques funéraires dans le monde grec. On pourra se référer en particulier à un article assez récent qui reprend en détail la question de

65 Les observations qui suivent sont dues à Anne Richier : pour plus de détails, voir ci-dessus le catalogue des sépultures.

66 Il est préférable d'employer ce mot plutôt que celui de suaire qui, malgré la désignation comme «saint suaire » du linceul dans lequel le Christ a été enveloppé, s'applique plutôt au linge qui couvrait la tête et le visage des morts. 
la prothésis (l'exposition du mort) en Grèce et en Étrurie (Brigger, Giovannini 2004). Le linceul qui enveloppe le défunt est représenté de manière diverse : sur une plaquette en ivoire provenant du sanctuaire d'Artémis Orthia à Sparte, datée du VII ${ }^{\mathrm{e}}$ s., le corps - y compris les pieds et le sommet du crâne - est emmailloté dans un tissu uni et serré qui donne au personnage l'apparence d'une momie (Brigger, Giovannini 2004, p. 202, fig. 4) ; sur quelques peintures attiques à figures noires ou à fond blanc, qui s'échelonnent de la fin du $\mathrm{VI}^{\mathrm{e}} \mathrm{s}$. au milieu du $\mathrm{V}^{\mathrm{e}} \mathrm{s}$., le corps est entièrement enveloppé, mais la tête reste découverte (fig. 63) ${ }^{67}$.

Cette documentation figurée, peu abondante et plutôt schématique, est complétée par de rares sources écrites. Les principales références sont données dans l'étude par G. Rougemont du « cippe des Labyades », trouvé dans le sanctuaire d'Apollon à Delphes : l'inscription gravée sur ce bloc, datée du $\mathrm{V}^{\mathrm{e}} \mathrm{s}$., énonce, sur une de ses faces, des prescriptions relatives aux $\dot{\varepsilon} v \tau \alpha \dot{\varphi} \varphi 1 \alpha$, c'est-à-dire à tout ce qui est placé dans la tombe avec le mort (Rougemont 1977 , p. 34-35 et 51-57). Il est dit tout d'abord qu' « on ne mettra pas dans la tombe pour plus de trente-cinq drachmes, tant en achats qu'en objets pris à la maison », puis que la « couverture épaisse » $(\pi \alpha \chi \varepsilon i \hat{\imath} \alpha \lambda \lambda \alpha \hat{\imath} v \alpha)$ sera brune et, un peu plus loin, que l' « on placera sous le mort un seul matelas $(\sigma \tau \rho \hat{\omega} \mu \alpha)$ et on ajoutera un seul oreiller $\left(\pi \circ \varepsilon_{\varepsilon} \varphi \alpha \lambda_{\alpha} \alpha \mathrm{lov}\right) »$. Ce texte ne comporte pas d'indications sur d'autres vêtements ou étoffes, contrairement à une inscription trouvée à Kéos, dans les Cyclades, qui date de la même époque (Sokolowski 1969, n 97, 1. 2-6 ; Rougemont 1977 , p. 53-54) : on y précise que le mort doit être enterré dans trois i $\mu \alpha$ '́ $1 \alpha$ blancs, l'un $(\sigma \tau \rho \hat{\omega} \mu \alpha)$ placé sous le corps, l'autre ( $\left.\varepsilon^{\prime} v \delta v \mu \alpha\right)$ qui enveloppe le défunt, le troisième ( $\dot{\varepsilon} \pi i \beta \lambda \eta \mu \alpha)$ qui le recouvre ; cette règle de ne pas placer plus de trois "étoffes » (i $\left.\mu \alpha \tau^{\prime} \downarrow \alpha\right)$ avec le mort avait déjà été édictée par Solon, d'après Plutarque (Solon, 21, 6). L'étoffe qui nous intéresse ici est l'है $v \delta v \mu \alpha$, probable équivalent du linceul qui enserrait certains défunts d'Apollonia. Aux époques plus récentes, cette pièce de tissu est également appelée $\sigma \iota v \delta \omega_{v}$ : c'est le mot qui est utilisé pour le linceul dans lequel est enveloppé le Christ (Matthieu, 27, 59-60). On comparera une inscription chypriote du II ${ }^{\mathrm{s}}$ s. ap. J.-C. : la défunte est enterrée « avec des plantes aromatiques, des couronnes de roses et dans un linceul ( $\left.\sigma \iota v \delta \delta_{v} v\right)$ finement tissé » ${ }^{6}$.

67 Ainsi sur une plaque trouvée au Céramique (Brigger, Giovannini 2004, p. $203 n^{\circ}$ 4.1, fig. 5), sur un vase attribué au Peintre de Sappho (Neils, Oakley 2003, p. 297-298 n 112) ou sur un lécythe attribué au Peintre de Sabouroff (ibid., p. 165, fig. 4).

68 Oziol (Th.) - Une inscription funéraire au Musée de la Fondation Piéridès à Larnaka. Report of the Department of Antiquities Cyprus, 1999, p. 255-258.
Le développement de l'anthropologie de terrain apportera probablement d'autres informations sur la possible présence d'un linceul dans les sépultures du monde grec. Nos fouilles de Kalfata permettent de soulever, à ce sujet, une autre question.

\subsection{Aiguilles et clous}

L'étoffe qui enserrait le corps de certains défunts était-elle attachée à la manière d'un vêtement ou cousue ? La question se pose à propos des fibules et, surtout, des aiguilles à coudre ${ }^{69}$ trouvées dans plusieurs tombes de Kalfata.

Pour les aiguilles, la tombe du jeune Euphéros au Céramique d'Athènes constitue, vers 430-420, un exemple particulièrement intéressant (Stroszeck 2002) ${ }^{70}$. La stèle trouvée en place au-dessus de la sépulture assure en effet qu'il s'agit d'un garçon (adolescent ou pré-adolescent), près duquel se trouvait, avec bien d'autres objets, une aiguille à coudre. Celle-ci ne peut guère être interprétée comme un symbole du sexe ou de l'activité domestique du défunt et, vu sa position dans la tombe (à côté de la jambe droite), il est peu vraisemblable qu'elle ait servi à fixer un véritable vêtement. Quel sens lui donner alors? Une nouvelle restauration des objets, effectuée bien après la fouille, a mis en évidence des restes de tissus qui adhéraient aux lécythes placés contre le corps du garçon : cette étoffe était probablement le linceul dans lequel Euphéros avait été enveloppé ${ }^{71}$. Un cas assez similaire est attesté à Kalfata, puisque l'aiguille de la tombe SP 362 (M 33) a été trouvée au niveau des cuisses et que le personnage, un adulte de sexe masculin, avait probablement été enveloppé dans un linceul. S. Houby-Nielsen (1997, p. 236 et 251) cite d'autres tombes du Céramique dans laquelle une aiguille est associée à un strigile et se demande si, au cas où le strigile désignerait le sexe masculin des personnages, l'instrument de couture n'indiquerait pas une activité dans le domaine du textile. L'exemple de

69 Contrairement à des objets plus longs et plus épais, utilisés « pour passer des lacets, des ficelles, des laines, pour coudre de grossières coutures ; celles qui sont incurvées servent comme aujourd'hui aux tapissiers, aux matelassiers, aux fabricants de voiles » (Deonna 1938, p. 265), les aiguilles de Kalfata sont certainement des instruments de couture. Ce type d'objet, attesté en contexte funéraire un peu partout dans le monde grec, ne semble pas avoir donné lieu à une étude d'ensemble.

70 Des aiguilles ont été mises au jour dans d'autres tombes de la grande nécropole athénienne : Kovacsovics 1990, p. 39-40, fig. 74,5, pl. 37,5 ; Kunze-Götte et al. 1999, p. 79, n² 275, etc.

71 «Es dürfte sich um Abdrücke des Leichentuches handeln, in welches der Tote gehüllt war. Solche Leichentücher sind im Kerameikos mehrfach beobachtet worden » (Stroszeck 2002, p. 468). 
la tombe d'Euphéros rend cette interprétation douteuse, comme probablement celui d'une autre tombe d'enfant du Céramique, datée autour de 420, qui contenait, avec une aiguille, quatorze astragales, deux strigiles, deux œufs en terre cuite et des figurines de lièvre et d'oiseaux (Kunze-Götte et al. 1999, p. 79, $\mathrm{n}^{\circ} 275$ ).

Il est donc possible que, à Kalfata comme au Céramique, l'aiguille ait parfois été associée, réellement ou symboliquement, à la fermeture du linceul : nos fouilles n'apportent cependant pas d'élément déterminant en faveur de cette interprétation, déjà évoquée par d'autres ${ }^{72}$. La fonction de substitut d'une fibule ou d'une épingle ne saurait être écartée dans certains cas (ainsi pour les tombes SP 320, 326, 370), mais elle est peu vraisemblable pour les tombes SP 327 (l'aiguille était placée au niveau des tibias) et SP 265, où une fibule se trouvait près de l'épaule droite et l'aiguille le long du bras droit ; elle serait d'autre part étonnante pour des tombes aussi riches que SP 328 et SP 340. Pour les tombes féminines, l'interprétation traditionnelle de l'aiguille de couture comme symbole des activités domestiques de la femme, ou de son rang social de maîtresse de maison, reste tout à fait envisageable: c'est probablement le sens des aiguilles offertes dans les sanctuaires de certaines divinités féminines ${ }^{73}$. La présence de ce type d'objet dans la tombe masculine SP 362 (comme dans celle d'Euphéros) montre, en tout cas, qu'une aiguille ne suffit pas à établir à elle seule le sexe féminin du défunt : en l'absence d'une autre raison déterminante (stèle en place, bijoux exclusivement féminins) c'est l'étude anthropologique qui doit permettre de trancher.

On passe de façon assez naturelle des aiguilles aux clous, puisque, dans la moitié des exemples de notre petit corpus, les deux objets sont associés. Quand ils ne proviennent pas d'une tombe construite où ils pouvaient fixer une offrande sur la paroi, ou quand ils ne sont pas clairement associés à un cercueil en bois, les clous relativement fréquents, semble-t-il, dans les sépultures grecques (voir Houby-Nielsen 1997, p. 233 et 257 n. 23) - posent eux aussi des problèmes d'interprétation. On a tenté de mettre les exemplaires isolés en relation avec le percement rituel de vases ou d'autres objets offerts

72 Ainsi D. Palermo: «Potrebbe trattarsi, a titolo di ipotesi, di un elemento legato alla presenza nel sepolcro di stoffe, forse per avvolgere il defunto, come sembra spesso indicare la posizione dell'ago, al di sotto della testa o del torace del schelettro » (In : Scavi nelle necropoli di Leontini [1977 - 1982], Cronache di Archeologia, 21, 1982, p. 85 n. 55). Pour la Sicile, de nombreuses références sont données par M. Pizzo, NotSc, 1998-1999, p. 377.

73 Ainsi pour celui de Déméter à Corinthe : Coldstream 1973, p. 151-152, pl. 91-92 (exemplaires en métal), et p. 170-171 (exemplaires en os). au défunt, ou de les lier à des croyances superstitieuses sur les dangers présentés par les morts ${ }^{74}$, mais d'autres hypothèses peuvent être envisagées.

Sur les neuf sépultures qui contenaient des clous près du défunt, seules huit seront prises en considération, puisque, dans le cas de la tombe d'enfant SP 313, les treize clous (M 47) proviennent certainement d'un cercueil en bois. Les autres tombes ont livré un clou en fer, parfois deux (SP 251 et SP 279). S'agit-il d'éléments de fixation d'une seule paroi d'un cercueil, ou de son couvercle (voir ci-dessus pour SP 313) ? L'hypothèse n'est pas recevable pour la tombe SP 265, puisque la décomposition du corps a eu lieu en espace colmaté, donc directement dans un remblai de terre, pas plus que pour la tombe à ciste SP 328 : dans cette sépulture, les deux trous d'encastrement dans le sol au niveau des pieds et la déconnexion des ossements de la défunte indiquent, selon toute vraisemblance, qu'elle avait été placée sur un lit funéraire en bois. La partie antérieure du lit, dont les pieds n'ont pas laissé de traces, reposait directement sur le sol naturel, puisque le dallage est absent à ce niveau. Il est possible que le clou en fer, trouvé juste sous le crâne de la défunte (M 48), ait servi à fixer un support en bois avec un oreiller sur lequel aurait reposé la tête du

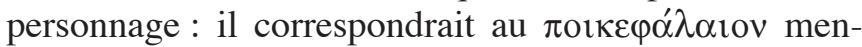
tionné dans l'inscription de Delphes (voir ci-dessus). De même, le clou mis au jour derrière le crâne de l'enfant de la tombe SP 283 (M 44) pourrait attester la présence d'un support en bois derrière la tête ${ }^{75}$. La tombe SP 251 témoigne peut-être de la même intention délicate, bien que l'un des clous ait été trouvé au niveau des tibias (l'autre près du crâne ; M 41). Dans deux autres cas, la position du clou est moins significative : près du poignet gauche dans la tombe SP 289 (M 45), du côté gauche des côtes pour la tombe à tuiles SP 346 (M 49); dans la tombe d'enfant SP 296, le clou (M 46) se trouvait dans le remblai de terre au-dessus du genou gauche.

On constate que ces clous isolés ont été découverts dans cinq tombes de femmes adultes (le sexe du défunt de SP 251 n'a pas pu être déterminé) et deux d'enfants. L'observation porte cependant sur une série trop limitée pour que l'on en tire des conclusions générales sur les pratiques funéraires : il faudrait faire une recherche plus large, à Kalfata ou dans d'autres nécropoles du monde grec, pour vérifier s'il existe une association privilégiée entre des clous isolés et des tombes de femmes

74 «The most likely explanation for this practice is to be sought after in the field of superstition, for instance as an attempt to kill spirits of the dead » (Houby-Nielsen 1997, p. 233).

75 On note que deux clous (M 52) ont été mis au jour dans le dépôt DP 24, associé à cette même sépulture. Comme ceux des dépôts DP 28 et DP 29, ils peuvent avoir servi à fixer des offrandes sur des planchettes en bois. 


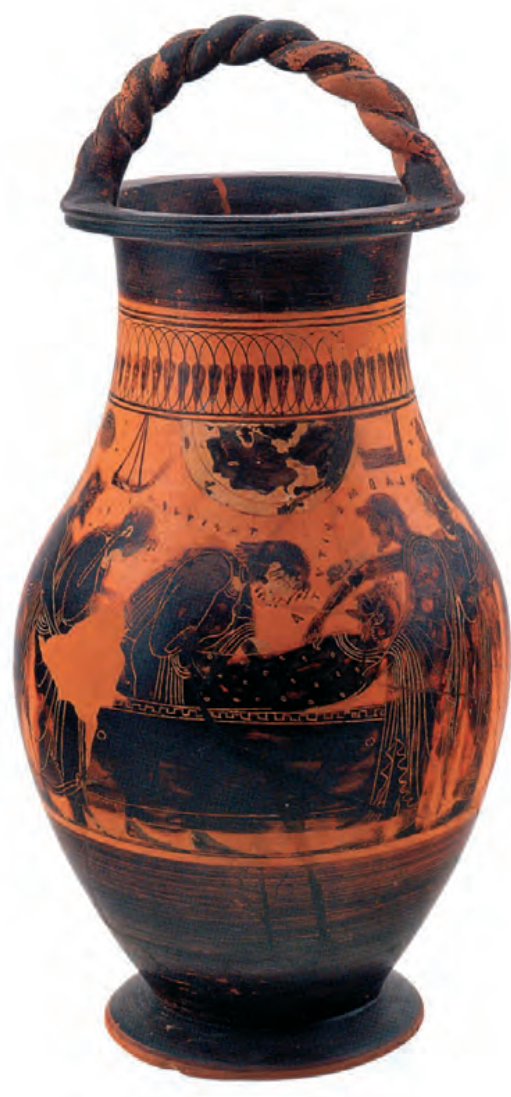

Fig. 63. Mise en bière d'un défunt enveloppé dans un linceul (vase attique à figures noires, Bowdoin College). D'après Neils, Oakley 2003, fig. 112

et d'enfants, qui indiquerait une pratique funéraire particulière à l'égard de cette catégorie de défunts, en particulier par la mise en place d'oreillers ou de coussins.

Enfin, le cas des petits ensembles de clous (cinq exemplaires au moins) mis au jour au sommet de la fosse des tombes SP 337 (M 50) et 342 (M 51) est original : ils pourraient avoir servi à fixer des supports en bois pour des offrandes déposées juste au-dessus de la sépulture.

\subsection{Spécificités des tombes féminines}

Indépendamment des bijoux - très rares dans la nécropole de Kalfata - le miroir est considéré comme le principal «marqueur » du sexe féminin, le strigile étant celui des hommes ou des jeunes garçons. Cependant, dès 1a fin du XIX ${ }^{\mathrm{e}}$ s., André De Ridder avait noté que le strigile n'était pas un instrument réservé aux hommes ${ }^{76}$

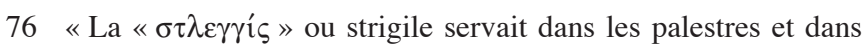
les bains. Elle n'était pas spécialement réservée aux hommes. Le témoignage formel d'Aristophane [Thesmophories 556 ; scholie aux Cavaliers 580] et toute une série de monuments, dont un manche de strigile venant de Palestrine, montrent la « $\sigma \tau \lambda \varepsilon \gamma \gamma i ́ \varsigma$ » employée par des femmes. Aussi la découverte d'un strigile dans une tombe ne suffit-elle pas à prouver le sexe du mort » (Catalogue des bronzes de la Société Archéologique d'Athènes. Paris, 1894, p. 104-105). et S. Houby-Nielsen (1997) a présenté d'importantes remarques sur cette question, à partir des tombes athéniennes : elle montre comment, à partir du $\mathrm{IV}^{\mathrm{e}} \mathrm{s}$., ces objets semblent être plus généralement liés à l'hygiène et à la toilette des deux sexes, même si, sur les stèles funéraires, leur symbolique reste distincte, miroirs pour les femmes, strigiles pour les hommes.

Notre corpus comporte quatre miroirs (trois trouvés dans des sépultures, un dans le foyer F 5) et huit strigiles (six provenant de sépultures, un provenant du foyer F 11, un autre isolé) : les deux types d'objets ne sont jamais associés. Les miroirs proviennent de tombes de femmes adultes. Dans l'une d'entre elles (SP 272), l'objet a été trouvé en place dans la main droite de la défunte, sans aucun autre mobilier (les «boutons en os » devaient fermer une enveloppe en tissu qui s'est décomposée, voir le commentaire à M 11). Les deux autres comportaient un mobilier relativement abondant : la défunte de SP 340 était un personnage important, très vraisemblablement une prêtresse, et l'aiguille placée sous le miroir (M 13) est sans doute un autre "marqueur» féminin (voir ci-dessus). La même association miroir-aiguille est attestée dans SP 289 (M 12), plus récente de plus d'un demi-siècle et, dans ce cas, un objet en os, s'il s'agit bien d'une quenouille, renforce ce symbolisme.

Les strigiles sont, de façon assez banale, associés à des astragales dans les tombes d'enfants SP 313 (M 19) et SP 339 (M 21), comme dans la sépulture d'un jeune homme de 15 à 20 ans, SP 334 (M 20). Celui de SP 291 (M 17) était placé près d'un jeune adulte masculin. Le sexe du défunt de la ciste SP 300 n'étant pas déterminé, il reste la tombe SP 265, datée vers 340-320 et qui appartient à un adulte âgé dont le sexe a été défini par Anne Richier comme "plutôt féminin ». Il s'agit donc, vraisemblablement, d'un cas comparable à ceux étudiés par S. Houby-Nielsen (1997), où le strigile est désigné comme un instrument de toilette féminin ${ }^{77}$. On note qu'il est associé à une aiguille à coudre et à un clou.

On a vu précédemment que la période 3 marquait l'occupation la plus importante de la zone et que les tombes masculines étaient alors mal représentées. Les tombes féminines du deuxième quart/milieu du $\mathrm{IV}^{\mathrm{e}} \mathrm{s}$. contiennent, pour au moins deux d'entre elles, le mobilier le plus abondant et le plus riche de l'ensemble des tombes publiées ici. Cette plus grande richesse des offrandes peut être évaluée, d'abord, par la présence de vases à décor figuré, attiques ou de type attique, qui sont commentés plus loin. Le plus important d'entre eux, l'hydrie de la tombe SP 345, ouvre sans doute cette nouvelle série d'importations, et l'analyse anthropologique comme le

77 De même, dans la nécropole de Métaponte-Pantanello, plusieurs exemplaires proviennent de tombes féminines : Carter 1998, p. 801. 
type et la scène peinte sur le vase laissent supposer, sans preuve décisive, que le défunt était un jeune adulte féminin. On notera en tout cas que le choix d'une hydrie n'est pas anodin : ce type de vase faisait certainement partie des contenants cinéraires les plus prisés. Seule une autre hydrie attique à figures rouges est attestée comme urne à Apollonia (Cat. Bruxelles 2002, p. 203 n 306), où a été mis au jour un exemplaire en bronze qui, cependant, ne comporte pas de décor figuré, contrairement aux deux hydries de la nécropole de Mésambria (Cat. Bonn 2004, $\left.\mathrm{n}^{\circ} 184\right)$. Des vases du même type ont été utilisés comme urnes funéraires un peu partout dans le monde grec à l'époque classique ${ }^{78}$, et c'est aussi dans une hydrie que sont recueillis, d'après le Pseudo-Lucien (Éloge de Démosthène, 28), les restes incinérés de Démosthène, puis (Plutarque, Philopemen, 21, 3), en 183 av. J.-C., ceux du général achéen Philopœmen, «le dernier des Grecs ». ${ }^{79}$

Pour la tombe à ciste SP 328, le squelette est sans aucun doute celui d'une femme âgée qui a bénéficié d'un traitement assez exceptionnel dans cette zone de la nécropole, comme l'indiquent la présence très probable d'un lit en bois - dont il déjà été question -, celle d'une petite pyxis en bronze et de deux lécythes à décor figuré, l'un d'une taille exceptionnelle, l'autre qui porte une scène relative au culte d'Aphrodite, appropriée au sexe de la défunte. La proximité entre cette ciste et l'incinération SP 345 laisse penser à un rapport familial entre les deux personnages, sans qu'on puisse en dire plus sur leur rang social - sans doute élevé - ou leur fonction dans la cité d'Apollonia.

Il n'en va pas de même pour la défunte - plus jeune - de la tombe SP 340, enterrée dans un contexte topographique différent. Parmi les nombreux objets placés près de cette femme (dont un miroir et une aiguille mentionnés plus haut), la clé en bronze donne en effet une indication importante, qui va certainement au-delà d'une désignation comme gardienne du foyer familial ${ }^{80}$. Dans l'iconographie de cette époque, un personnage féminin tenant une clé doit en effet normalement être interprété comme une prêtresse. Les exemples les plus clairs et les plus nombreux sont donnés par la représentation d'Iphi-

78 Pour le début de l'époque hellénistique, on connaît à Alexandrie l'importante série des «hydries de Hadra ».

79 Quelques indications sur les usages funéraires de l'hydrie sont données dans l'article de E. Trinkl, Sacrificial and profane use of Greek hydriai. In: Tsingarida (A.) éd., Shapes and Uses of Greek Vases $\left(7^{\text {th }}-4^{\text {th }}\right.$ centuries B.C.). Bruxelles, CReA-Patrimoine, 2009, p. 161.

80 C'est pourtant l'interprétation avancée par A.K. Andreiomenou (ArchDelt, 56, 2001, Meletes, p. 194, fig. 11) à propos d'une clé en fer trouvée dans une tombe d'Akraiphia en Béotie (noter que la sépulture contenait aussi un couteau en fer). génie dans son rôle de prêtresse d'Artémis en Tauride, principalement sur des vases italiotes datés autour du milieu du $\mathrm{IV}^{\mathrm{e}} \mathrm{s} .{ }^{81}$ : la sœur d'Oreste tient dans sa main gauche la clé du temple qui est figuré en arrière-plan. On connaît à la même époque une série de stèles et de lécythes funéraires en marbre sur lesquels la fonction de prêtresse occupée par la défunte est, de même, signifiée par la clé qu'elle tient à la main ${ }^{82}$; d'autres documents vont dans le même sens, et l'on note que, sur une hydrie à figures rouges attique datée d'environ 460, la femme à la clé tient dans la main gauche un sceptre ${ }^{83}$, peut-être comparable à l'objet allongé, en matériau périssable, placé près de la défunte de SP 340.

Le fait que la scène peinte sur le lécythe déposé dans cette tombe se rapporte également à Aphrodite doit-il laisser penser que la prêtrise concernait cette déesse, dont le culte est attesté à Apollonia (voir plus haut) ? Certains objets plus énigmatiques déposés dans la tombe - des pointes de flèches, des supports en verre, des cailloux et une sorte de bâton en matériau périssable - ont-ils un rapport avec cette fonction religieuse ? Malgré la différence de date et de lieu, on peut rappeler que la tombe la plus ancienne qui ait été trouvée sur le site de Salamine de Chypre (vers le milieu du $\mathrm{XI}^{\mathrm{e}} \mathrm{s}$. av. J.-C.) contenait une femme - à en juger par l'abondance des bijoux près de laquelle avaient été déposés un astragale, une aiguille à coudre (en or) et des pointes de flèches, comme dans la sépulture SP $340^{84}$. Il faut ajouter que les pointes de flèches étaient à l'époque archaïque, à Apollonia et dans sa région, des objets votifs investis d'une valeur monétaire (voir ci-dessus, p. 38).

Malgré le caractère restreint de la documentation présentée ici, l'offrande des osselets ou astragales, provenant du petit bétail sauf dans un cas isolé, est intéressante, qu'il s'agisse de ceux qui ont été déposés dans des foyers, même s'il est difficile de les attribuer à un défunt précis, ou des exemplaires trouvés dans les tombes. Alors que, comme il paraît normal, les ensembles les plus nombreux ont été mis au jour dans des sépultures d'enfants de moins de dix ans (136 astragales dans SP 313 et 58 dans SP 339) et que seize autres accompagnaient un jeune homme de 15 à 20 ans (SP 334), des

81 Kahil (L.) - Iphigeneia. In : LIMC VI, 1990, p. 713-715, pl. 468471. Comparer la clé en bronze portant l'inscription « de l'Artémis de Lousoi » (Arcadie) : IG V 2, 399.

82 Connelly (J.B.) - Portrait of Priestress. Women and Ritual in Ancient Greece. Princeton University Press, 2007, p. 252-254, fig. 8.5-7.

83 Pirenne-Delforge (V.) - Personnel de culte. In: ThesCRA, V, 2005 , p. $30 \mathrm{n}^{\circ} 133$, pl. 4. D'autres exemples de prêtresse tenant une clé sont cités, p. 6 et 29-31, pl. 1 et 5.

84 Yon (M.) - Salamine de Chypre II. La tombe T. 1 du XI ${ }^{e}$ s. av. J.-C. Paris, de Boccard, 1971 (voir la liste des objets p. 9). 
osselets en nombre beaucoup plus restreint sont attestés dans cinq tombes d'adultes (SP 322, 336, 338, 340, 347), dont quatre certainement féminins ${ }^{85}$. Ces femmes sont, d'après les critères retenus par les anthropologues, soit vraiment âgées (SP 338 et 347), soit d'âge mûr (SP 336), soit, pour la quatrième, une adulte et non une adolescence (SP 340); on a déposé auprès d'elles un, deux ou quatre osselets.

La question des astragales trouvés en contexte funéraire a fait l'objet, à propos de la nécropole de Locres, d'une excellente mise au point à laquelle on se reportera (Elia, Carè 2004). Quand on dispose de données suffisamment précises, on constate que la fréquence de ce type d'offrande et la répartition entre tombes d'enfants et tombes d'adultes est variable, y compris dans une même région et pour une période comparable (essentiellement $\mathrm{V}^{\mathrm{e}}-\mathrm{IV}^{\mathrm{e}}$ s. av. J.-C.). Ainsi, alors qu'environ $12 \%$ des sépultures de Locres-Lucifero contenaient au moins un osselet - dans certains cas plusieurs centaines - (Elia, Carè 2004, p. 77 et fig. 1), seules cinq des 359 tombes fouillées par l'équipe américaine à Pantanello, dans la chôra de Métaponte, ont livré ce type d'objet (Erickson, in Carter 1998, p. 838-839). D'autre part, les astragales trouvés dans la nécropole de Locres étaient dans $53 \%$ des cas associés à des tombes d'adultes (Elia, Carè 2004, p. 79), proportion qui contredit l'idée couramment admise que ces objets se rattachent naturellement à l'enfance, et qui rejoint les observations que l'on peut faire sur notre série très limitée. Enfin, les osselets paraissent être nettement plus fréquents, à Locres, dans les tombes féminines, mais ce jugement repose sur le matériel associé, non sur des diagnostics anthropologiques.

Le fait que des femmes qui ont très largement dépassé l'âge de la puberté aient reçu un ou plusieurs osselets pose un problème d'interprétation, car on ne peut pas expliquer cette offrande comme l'évocation d'une mort prématurée avant le mariage ${ }^{86}$. En attendant une éventuelle étude sur une série de tombes féminines plus importante, on avancera l'hypothèse d'un lien entre l'offrande de ces astragales et le monde d'Aphrodite, déjà évoqué à propos du décor des lécythes aryballisques des tombes SP 328 et 340 (voir aussi ci-dessous le commentaire de ces vases). Cette relation a été mise en évidence à propos du «coup de Vénus », obtenu quand quatre astragales retombent chacun sur une face différente : la représentation de ce coup heureux sur des jas d'ancre est

85 Le sexe de l'individu de la tombe SP 322 n'a pas pu être déterminé.

86 Comme le suggère V. Jeammet (In: Tanagra 2003, p. 164) à propos d'une joueuse d'osselets en terre cuite : «Quand la figurine était déposée dans la tombe d'une adolescente, le jeu symbolisait peut-être le destin contrarié de la future épousée, morte avant l'heure ». certainement liée au rôle protecteur d'Aphrodite dans la navigation ${ }^{87}$. Bien que le nombre de quatre osselets ne revienne pas plus souvent que d'autres dans les offrandes funéraires, on notera qu'il est attesté dans deux de nos tombes, SP 322 et 336, et que Venedikov avait mis au jour dans la tombe 726 de ses fouilles quatre astragales naturels et quatre imitations en verre (Venedikov et al. 1963, p. 62, pl. 166). Quoiqu'il en soit, le lien entre la déesse Aphrodite et les osselets est largement attesté, en particulier dans la documentation iconographique attique ${ }^{\mathbf{8}}$. Ursula Mandel mentionne à juste titre, dans une étude sur l'ephedrismos et d'autres jeux liés à Aphrodite, un lécythe aryballisque du "groupe d'Apollonia », trouvé à la fin du XIX ${ }^{\mathrm{e}} \mathrm{s}$. dans une tombe de Kalfata ou d'une autre nécropole de la ville, qui représente une femme assise et un Satyre jouant aux osselets, près d'une femme voilée accompagnée d'un Eros: que la déesse soit la femme assise - ce qui paraît plus vraisemblable - ou celle qui est debout, comme le pense U. Mandel, la scène évoque le destin d'une future mariée, qui se joue entre Aphrodite et le compagnon de Dionysos ${ }^{89}$. Ainsi, les astragales paraissent indiquer, comme certains lécythes décorés, l'appartenance de la femme, même âgée, à la sphère d'Aphrodite et au rôle qu'elle lui permettait de jouer au sein de la société d'Apollonia.

Il est regrettable que le sexe de l'individu adulte inhumé dans la tombe SP 322 n'ait pas pu être déterminé, car, en plus des quatre osselets, des forces (ciseaux) en fer avaient été déposées près du défunt. Cet instrument pouvait servir tantôt à couper les cheveux, comme le montre une terre cuite béotienne du début du $\mathrm{V}^{\mathrm{e}} \mathrm{s}$. (Tanagra 2003, p. 100), tantôt à tondre les moutons ${ }^{\mathbf{9 0}}$. On en connaît d'autres exemples dans des tombes d'époque classique, dont un à Métaponte-Pantanello, déposé près d'une femme âgée de 50 à 60 ans (Carter 1998, p. 266, $\mathrm{T} 76$, et p. 818), et un autre au Céramique, contemporain de SP 322 et qui appartenait probablement aussi à une tombe féminine, en raison de la présence d'un miroir (Kovacsovics 1990, p. 17, T 16, 9, pl. 30, 4). D'autres

87 Queyrel (Fr.) - Le motif des quatre osselets figuré sur des jas d'ancre. Archaeonautica, 7, 1987, p. 207-212. Voir aussi Marcadé (J.), Sabrié (M. et R.) - Sculptures du Clos de la Lombarde à Narbonne. $R A N, 32,1999$, p. 330-333, à propos d'une base de statue décorée de quatre osselets.

88 Mandel 1999, p. 230-232: l'hypothèse d'une pratique de l'astragalomancie dans le sanctuaire d'Aphrodite à Paphos est séduisante, mais l'attribution à cette cité de monnaies du début du $\mathrm{V}^{\mathrm{e}}$ s. montrant un astragale au revers n'est pas tout à fait assurée. Sur la fonction oraculaire des osselets, voir Amandry 1984, p. 377-378.

89 Voir ci-dessous p. 181, fig. 65, et Hermary, sous presse.

90 Sur une stèle funéraire d'époque impériale trouvée dans la région de Bursa, des forces sont figurées à côté d'un mouton et d'un couteau : Robert (L.) - Études anatoliennes. Paris, de Boccard, 1937, p. 206, pl. XXVIII, 3. 
forces trouvées en contexte funéraire sont plus récentes, comme celles du Jardin maritime d'Apollonia ${ }^{91}$. La question de la signification de ces objets reste posée, mais, dans la petite série ancienne dont fait partie l'instrument de SP 322, le contexte féminin paraît privilégié et, donc, être plutôt en faveur d'un usage pour le soin des cheveux : il est difficile de dire si cette offrande est liée à des activités rituelles, comme l'offrande des cheveux à différentes divinités à la fin de l'adolescence.

\subsection{Aspects particuliers des dépôts et des foyers}

Plusieurs objets trouvés isolément n'ont pas été pris en compte dans le catalogue des dépôts. Le plus spectaculaire est le fragment d'œnochoé attique à figures rouges décoré d'un char en course et d'un trépied (CP 42, trouvé près du point I 5). Dans la zone publiée ici, les autres vases à décor figuré servent d'urnes cinéraires ou sont déposés dans les tombes, mais il ne s'agit pas d'œnochoés : on peut donc supposer que celui-ci avait une valeur particulière dans les rituels pratiqués autour d'une ou plusieurs sépultures, plus particulièrement pour les libations.

Au Sud-Ouest de la fosse de SP 343, la tombe la plus ancienne du secteur, une grande assiette fragmentaire porte sur chaque face le graffite $\mathrm{XH} \Sigma[. .$. ?] écrit de droite à gauche sur la face externe (fig. 64) ${ }^{92}$. Dans les deux cas, la cassure a mutilé le sigma et empêche de savoir si le texte s'arrêtait là ou continuait. Les lettres conservées (de même que le redoublement de l'inscription) se prêtent mal à la restitution d'un nom propre, qu'il ait été écrit en entier ou en abrégé, et il ne s'agit certainement pas d'une marque commerciale comme sur l'hydrie $\mathrm{CP} 47$. Il est donc difficile de proposer une interprétation ${ }^{93}$. Au Sud de la même fosse, un fragment d'une

91 Venedikov et al. 1963 , p. $318 \mathrm{n}^{\text {os }} 1086-1087$, pl. 171 ; d'autres découvertes sur le territoire bulgare sont signalées ci-dessous par K. Panayotova (p. 261). Des exemplaires d'Argos (Bruneau 1970, p. 454-456, fig. 47, et 459-466, fig. 61) datent aussi de l'époque hellénistique, comme probablement les forces trouvées dans une sépulture à crémation du Céramique, avec un strigile et une sorte de dé à coudre (Kovacsovics 1990, p. 87, T 105, 2, pl. 48, 11). Celles provenant d'une tombe d'Aigai en Éolide ne sont pas précisément datées : Clerc (M.) - Fouilles d'Aegae en Éolide. BCH, 15, 1891, p. 236 , fig. 7.

92 US $562+624$. Le fond et environ un tiers de la vasque sont conservés; diam. max. $15 \mathrm{~cm}$. Inv. PIN 4162. Ce vase de bonne qualité, à l'argile orangée recouverte d'un engobe rouge, n'est pas une importation attique et se distingue des productions locales ordinaires.

93 Vouloir rattacher ces lettres au verbe $\chi \dot{\varepsilon} \omega$ (verser), en en faisant un impératif aoriste, supposerait une faute d'orthographe : l'hypothèse ne peut donc être sérieusement envisagée. grande coupe attique porte le graffite -HTO (Pl. 94a) ${ }^{94}$, probablement la fin d'un nom propre au génitif, donc une marque de propriété. Par une coïncidence assez troublante, K. Panayotova a découvert à peu de distance une stèle funéraire portant l'inscription НГОY $\Sigma$ АРНTO : il est possible que le nom inscrit sur la coupe doive être restitué en Arétos et que ce personnage soit de la même famille que celui de la stèle, voire le père d'Hégous luimême. Signalons encore la découverte, à l'Ouest de la fosse de SP 343, de deux astragales brûlés (US 628).

Enfin, le bucrane en plomb décoré d'une tête de Gorgone (M 57), trouvé entre les murs MR 2 et MR 3, fournit un nouvel exemplaire d'un type d'objet particulier aux nécropoles d'Apollonia (voir plus loin le commentaire de K. Panayotova): la figuration de la Gorgone permet sans aucun doute de donner à ces offrandes un sens apotropaïque, mais on ignore si elles étaient fixées sur un support (en bois ?) et si elles avaient un sens précis dans les pratiques rituelles locales.

La question se pose pour un autre type d'objet connu uniquement à Apollonia, que l'on appelle traditionnellement « gril à poisson ». Les premiers exemplaires ont été découverts dans les fouilles de Degrand, puis, en nombre plus important, dans celles de Venedikov et au cours des recherches plus récentes. L'interprétation de cet objet a connu plusieurs étapes. Maxime Collignon (1905, p. 301) a proposé d'y voir «l'imitation d'un esquif avec ses bancs », hypothèse reprise et précisée par Edmond Pottier dans la fiche descriptive de l'exemplaire arrivé au Louvre. Georges Seure cite le jugement de Pottier et consacre un assez long commentaire à cet objet : « comme hypnotisé par sa forme », il est dans «l'obligation inéluctable de songer à une semelle de chaussure » (pour un pied droit) qui, par sa taille, se rapporterait à une femme ou à un adolescent; il s'agirait de « la reproduction en terre cuite d'un modèle local de sandales, tressées probablement avec des tiges et feuilles de roseau » (Seure 1924, p. 334). Il envisage cependant une autre hypothèse, celle d'un gril à poisson : « le genre de pêche pratiqué à Apollonie, la forme et les dimensions de l'outil, suggèrent même cette précision qu'il s'agirait d'un gril destiné au maquereau de taille médiocre qui fait la nourriture et la fortune des pêcheurs indigènes »; il lui semble cependant que la forme est plus celle d'un pied que d'un poisson (ibid., p. 334-335). Jiri Frel revient à l'idée de Collignon et considère qu' « il s'agit sans doute du modèle d'une barque funéraire ... figurant l'ossature en bois, qui aurait été recouverte de peau » (Frel 1960, p. $250 \mathrm{n}^{\circ}$ 44, fig. 4). Trois ans plus tard, Venedikov

94 = VN 14. Dimensions max. conservée 17 cm. Inv. PIN 4108. 

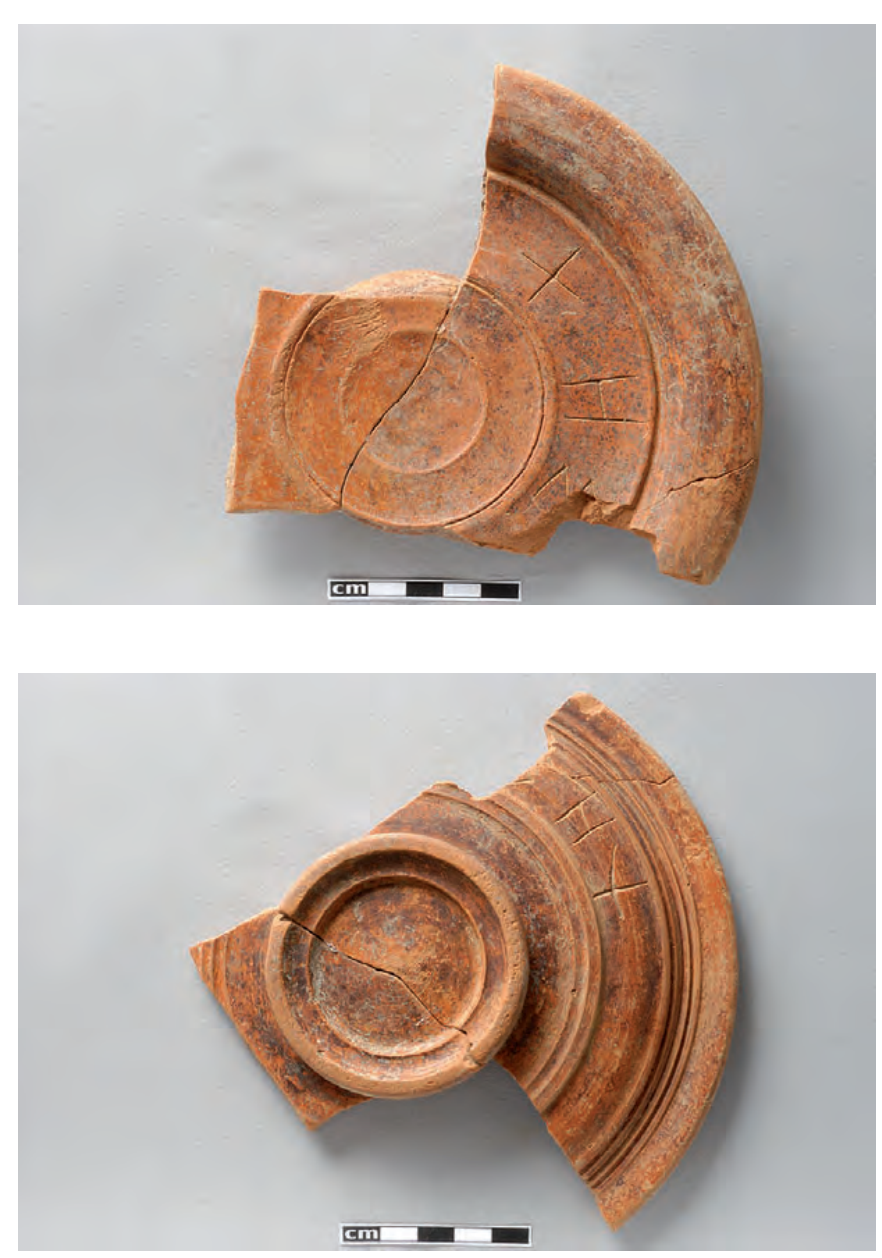

Fig. 64. Assiette portant le double graffite XHI (inv. PIN 4162). Photo CCJ, L. Damelet.

(et al. 1963, p. 264-266 $\mathrm{n}^{\text {os }} 772-777$, pl. 133) revient sur ces différentes interprétations et se décide en faveur du gril à poisson, désignation reprise jusqu'à maintenant par les fouilleurs des nécropoles d'Apollonia (par exemple Panayotova 2007, p. 111, fig. 4, 5).

Les exemplaires trouvés dans les fouilles de 20022004 proviennent tous de foyers $(\mathrm{F} 1,2,4,9,10,11=$ TC 21-26), sauf celui qui a été trouvé isolément dans la zone Nord-Ouest de la fouille (TC 27). Ils sont associés à divers types de vases se rapportant à la boisson ou à la nourriture semi-liquide, à la présentation et à l'assaisonnement des aliments. On note que les plats à poisson font partie de cet ensemble, ce qui serait un argument en faveur de l'interprétation de ces objets comme des grils à poisson si les plats ont nécessairement l'usage que leur nom indique. L'exemple du foyer F 9, dont le contenu était resté intégralement en place, ne va cependant pas dans ce sens. Ce foyer contenait en effet un service complet lié à un repas : une œnochoé et deux autres fragments de cruches, deux bolsals, trois pots à une anse, trois bols à vernis noir, deux plats à poisson, un askos à figures rouges et quatre coupelles, plus une lékanis dont la fonction n'est pas assurée ${ }^{95}$. Les restes de faune trouvés dans ce même foyer (prélevés de manière exhaustive par V. Bignani, un étudiant formé à cette pratique) et étudiés par Ph. Columeau (voir ci-dessous) ne comprenaient cependant aucune arête de poisson, mais se rapportaient à au moins un jeune capriné, âgé de six à dix-huit mois. D'autres offrandes brûlées à cet endroit avaient une autre fonction, qu'il s'agisse des objets en bronze - dont l'interprétation est difficile, en dehors d'un très probable stylet - ou des nombreux astragales. La question de savoir si le «gril » faisait partie des objets utilitaires liés aux aliments ou si, reproduisant en terre cuite un autre type d'objet, il aurait plutôt un sens symbolique reste donc ouverte. Sa forme ne paraît renvoyer de façon claire ni à un poisson, ni à une sandale, ni à une barque, mais l'hypothèse d'un gril n'est guère compatible avec le fond plat de l'objet ${ }^{96}$, ni avec la largeur parfois importante de ses petites barres ${ }^{97}$. Un point certainement important pour l'interprétation est le fait que ces « grils » ne sont pas déposés dans les sépultures, mais dans les foyers rituels et, éventuellement, dans les dépôts : ce contexte n'est apparemment pas en faveur d'un objet lié symboliquement au voyage du défunt, comme le seraient des modèles de sandale ou de barque déposés dans la sépulture elle-même ${ }^{98}$. Comme on l'a vu plus haut, il est difficile d'associer les foyers à des sépultures ou à des groupes de sépultures. Cependant, dans le cas du foyer F 9, sa date et la présence d'une quantité importante d'astragales - ainsi, peut-être, que le «stylet», qui pourrait évoquer l'apprentissage de la lecture - rendent probable une relation avec les tombes d'enfants SP 339 et SP 375 situées de l'autre côté du mur. On peut même supposer que ce foyer a pris la suite, pour la célébration des rites en souvenir des deux enfants, probablement le frère et la sœur, du foyer $\mathrm{F} 5$, dispersé quand on a construit le mur MR 3 pour retenir la terre des tumuli érigés au-dessus de SP 343, 339 et 375 ; il est difficile de dire si, dans cette hypothèse, le foyer F 10 - lui-même en grande partie détruit lors de la mise

95 La grande coupe trouvée renversée, le fond percé, à la base du foyer, avait visiblement une fonction différente de celle des autres vases.

96 Les grils antiques traditionnels, de forme carrée ou rectangulaire, sont montés sur des pieds et n'ont pas de montants latéraux : voir par exemple Schipporeit (S. Th.) - Geräte zum Braten und Rösten. In : ThesCRA V, 2005, p. 333.

97 Noter que le fond d'un des exemplaires trouvés par Venedikov (et al. 1963, pl. $133 \mathrm{n}^{\circ}$ 777), à vrai dire assez atypique, est à peine ajouré.

98 On en connaît des exemples sur différents sites du monde méditerranéen antique. 
en place de SP 328 - était associé aux tombes d'enfants ou à celle de l'adulte masculin de SP 343.

Il faut enfin noter que cinq des six foyers où ont été déposés les « grils » sont datés autour de 380 , le sixième étant un peu plus récent (vers 350-340) : il semblerait donc que l'offrande de ces objets a été un phénomène relativement limité dans le temps, mais l'enquête devrait être étendue à d'autres découvertes récentes.

La signification des "grils à poisson » est loin d'être résolue, mais nos fouilles conjointes permettent d'apporter au dossier quelques éléments plus précis que ceux dont l'on disposait auparavant.

\subsection{Rapport sur les restes de faune découverts durant la campagne 2004}

Les ossements d'animaux découverts lors des précédentes fouilles de la nécropole de Kalfata n'ont pas été étudiés par un archéozoologue. Il paraît donc utile de publier ici le rapport rédigé par $\mathrm{Ph}$. Columeau (chercheur au Centre Camille Jullian) sur les restes mis au jour en 2004. Un premier groupe provient du foyer F 9 (déjà mentionné ci-dessus), un autre rassemble les éléments dispersés dans la zone fouillée par la mission française.

1) «Les fouilles de la campagne 2004 sur le site de la nécropole de Kalfata à Apollonia pontique ont mis au jour un petit ensemble d'ossements animaux calcinés. Ces débris animaux se trouvaient en connexion avec un foyer [F 9], lui-même situé entre les tombes. Cet ensemble comprend un sachet contenant 48 fragments d'os de caprinés, très fragmentés, provenant d'au moins un animal jeune ( $>6<18$ mois). L'émiettement de ces débris n'a pas permis de les peser, ni de les mesurer. Leur exposition à la chaleur d'un feu a été intense car leur coloration est blanc-ivoire pour la plupart, noire pour quelques-uns. Il n'y a pas d'ossements intacts dans ce lot. On note la présence, parmi les restes d'animaux, d'un fragment de vertèbre humaine, provenant du squelette d'un très jeune enfant. La présence d'un os humain dans ce lot peut s'expliquer par l'existence d'une tombe d'enfant à proximité du foyer ».

2) «Le second lot est plus conséquent. Il rassemble 174 gr. d'ossements animaux, dont $37(21,2 \%)$ n'ont pas pu être déterminés. Le fractionnement et la carbonisation des os sont très avancés, mais 178 fragments ont pu être déterminés et pesés, plus 2 fragments de microfaune ${ }^{99}$.

99 Talpa europaea, Microtus arvalis, Glis glis, Mus musculus.
Les restes les plus nombreux sont attribués au mouton, avec 87 restes de deux individus jeunes-adultes et 46 fragments de deux agneaux. Il faut noter la présence de 35 fragments de talus de mouton ou de chèvre, provenant de plusieurs animaux jeunes, qui n'ont pas pu être dénombrés. Toutefois, le nombre minimal d'individus induit par ces fragments de talus est bien supérieur à celui restituable d'après le reste des débris de squelette de mouton. Ils doivent donc être écartés du contexte alimentaire de cet ensemble et faire l'objet d'une étude séparée.

Des restes de porc ont été retrouvés dans cet ensemble de débris : 14 fragments ont été attribués à cette espèce, 11 à un animal sub-adulte, 3 à un porcelet très jeune (périnatal), pour un poids global de 20 gr. $(11,5 \%$ du poids des restes total).

Enfin, 10 restes d'oiseau ont été attribués à la poule domestique (Gallus domesticus), 9 à un individu jeune et 1 à un jeune poussin.

La proximité de la mer de cette nécropole est évoquée par la présence de deux fragments de coquilles marines, l'une appartenant à une palourde, l'autre à un bigorneau.

La totalité de ces restes osseux porte des traces de carbonisation, le plus souvent d'une exposition à un feu vif $\left(>600^{\circ} \mathrm{C}\right)$. L'éclatement des os à la chaleur ne permet pas de distinguer d'éventuelles traces de découpe.

Malgré son volume réduit, ce lot de faune du début du $\mathrm{IV}^{\mathrm{e}} \mathrm{s}$. av. J.-C. apparaît comme une exception, en l'absence de témoignages d'autres ensembles comparables dans un milieu funéraire grec, pouvant attester une consommation de viande autour des tombes ».

Mesures: Mouton Phalange proximale SD 10,8; Bd nbre : 2 moyenne : 11, 4 var. : 11,4 - 11,4

Bp nbre : 2 moyenne : 12,25 Var. : 11,9 - 12,6

Os triquetrum (carpe) DT : 13,8. (Tableau 14)

\section{Les sépultures d'enfants étudiées dans un contexte plus large}

Au cours des trois campagnes de fouilles franco-bulgares qui ont eu lieu à Kalfata de 2002 à 2004, onze sépultures d'enfants ${ }^{100}$ ont été mises au jour, soit $21 \%$ de l'ensemble. Ce pourcentage paraît faible si l'on considère le taux de mortalité infantile élevé durant cette période. De plus, le nombre de sépultures d'enfants fouillées, sur un espace restreint, ne permet pas de tirer des conclusions très pertinentes sur les rites

100 Il s'agit des sépultures SP 264, 283, 296, 297, 313, 320, 327, 339, 341, 370, 375. Les numéros de tombes qui ne sont pas précédés des lettres SP n'appartiennent pas à l'ensemble publié ici. 


\begin{tabular}{|c|c|c|}
\hline Espèce & NR & $\% \mathrm{NR}$ \\
\hline Crâne & 2 & 1,3 \\
\hline \multicolumn{3}{|l|}{ Max } \\
\hline Mand & 2 & 1,3 \\
\hline \multicolumn{3}{|l|}{ Dents Sup. } \\
\hline \multicolumn{3}{|l|}{ Dents inf. } \\
\hline Vertèbres & 9 & 5,9 \\
\hline Côtes & 12 & 7,9 \\
\hline \multicolumn{3}{|l|}{ Scapula } \\
\hline Humérus & 2 & 1,3 \\
\hline Radius & 2 & 1,3 \\
\hline Ulna & 1 & 0,6 \\
\hline Carpe & 6 & 3,9 \\
\hline Métacarpe & 24 & 15,8 \\
\hline Phalange I & 6 & 3,9 \\
\hline Phalange II & 8 & 5,2 \\
\hline Phalange III & 11 & 7,2 \\
\hline Bassin & 1 & 0,6 \\
\hline Fémur & 5 & 3,2 \\
\hline \multicolumn{3}{|l|}{ Patella } \\
\hline Tibia & 1 & 0,6 \\
\hline \multicolumn{3}{|l|}{ Fibula } \\
\hline Talus & 35 & 23 \\
\hline \multicolumn{3}{|l|}{ Calcaneum } \\
\hline \multicolumn{3}{|l|}{ Scpho-cub. } \\
\hline Métatarse & 25 & 16,4 \\
\hline Total & 152 & 99,4 \\
\hline
\end{tabular}

Tableau 14. Distribution anatomique des restes de mouton (fouilles françaises 2004).

\begin{tabular}{|c|c|c|}
\hline $\begin{array}{c}\text { Catégories } \\
\text { d'âges }\end{array}$ & $\begin{array}{c}\text { Nombre } \\
\text { d'individus }\end{array}$ & $\begin{array}{c}\text { Numéro d'inventaire des } \\
\text { sépultures }\end{array}$ \\
\hline Périnataux & 0 & SP 264 \\
\hline Nourrissons & 1 & SP $341 / 370$ \\
\hline Enfants de 1 à 4 ans & 2 & SP 296 / 297 / 327 \\
\hline Enfants de 5 à 9 ans & 5 & SP 283 / 313 / 320 / 339 / 375 \\
\hline Indéterminés & 3 & \\
\hline
\end{tabular}

Tableau 15. Tableau récapitulatif des sépultures d'immatures mises au jour dans le secteur franco-bulgare entre 2002 et 2004

pratiqués dans cette nécropole aux $\mathrm{V}^{\mathrm{e}}$ et $\mathrm{IV}^{\mathrm{e}} \mathrm{s}$. av. J.-C. Toutefois, les données concernant ces tombes peuvent être confrontées à celles des sépultures d'enfants mises au jour au cours de fouilles antérieures et postérieures à celles présentées dans cet ouvrage. En effet, au cours des six dernières campagnes de fouilles (2002-2007), 103 inhumations d'enfants ont été mises au jour ${ }^{101}$. On peut ajouter à ces dernières les 61 sépultures identifiées comme des sépultures d'enfants parmi les 800

101 Soit $24 \%$ de l'ensemble des tombes fouillées.

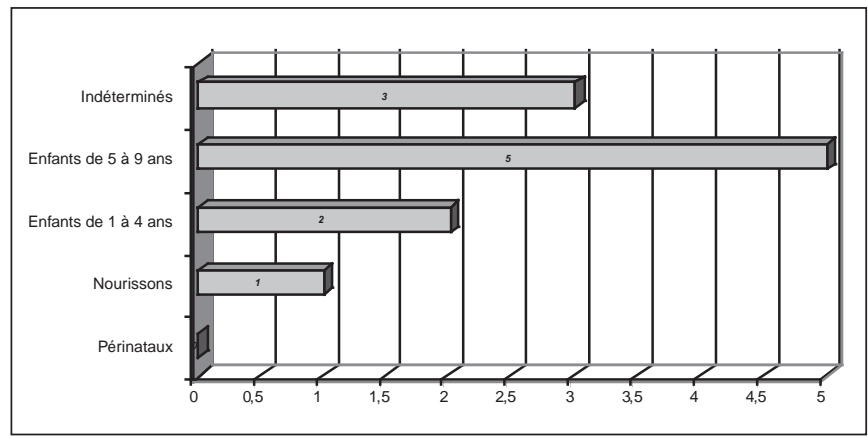

Graphique 4. Répartition des onze sépultures d'immatures par catégorie d'âge.

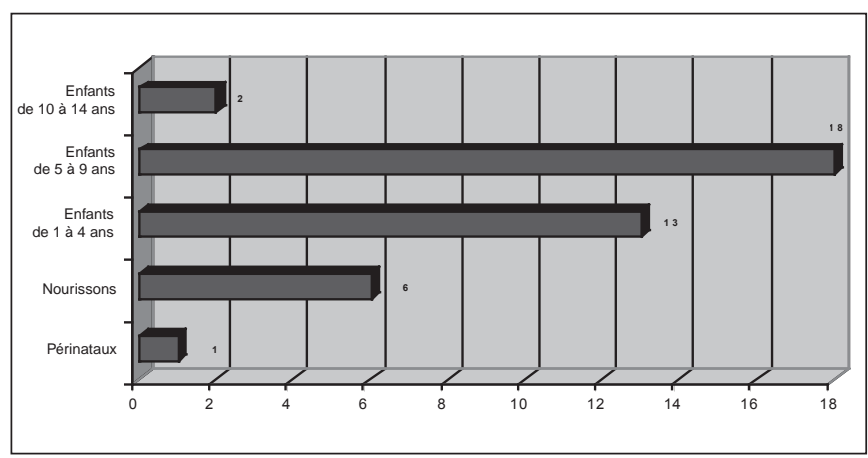

Graphique 5. Nombre d'individus par classe d'âge, d'après les études anthropologiques menées au cours des six campagnes de fouilles entre 2002 et 2007.

tombes qui avaient été fouillées sous la direction d'Ivan Venedikov dans les années 1940. Ces 164 tombes d'enfants font actuellement l'objet d'une étude approfondie dans le cadre du programme de recherche «L'enfant et la mort dans l'Antiquité : des pratiques funéraires à l'identité sociale » $(\mathrm{EMA}){ }^{102}$. Ainsi, les résultats obtenus suite à l'étude des onze sépultures d'enfants présentées dans le catalogue peuvent être comparés à d'autres analyses et s'inscrivent dans une étude plus large et, en conséquence, plus pertinente ${ }^{103}$.

\subsection{Catégories d'âge des immatures}

Les classements par catégorie d'âge varient en fonction des anthropologues. Ces découpages correspondent à différents passages dans la vie biologique et sociale de l'enfant. Pour Kalfata, la répartition proposée permet de

102 Programme de recherche international financé par l'Agence Nationale de la Recherche (ANR) [http://sites.univ-provence.fr/ccj/ spip.php?article23].

103 Un premier bilan a été présenté, lors de la première Table Ronde du programme EMA à Athènes (29-30 mai 2008), par A.-S. Koeller avec la collaboration de K. Panayotova. Cet article paraîtra prochainement dans les Actes du colloque. 
trouver un compromis entre les études anthropologiques faites par deux chercheurs et les catégories d'âge proposées dans le cadre du programme EMA (voir plus loin). Les tombes d'immatures, au nombre de onze, se répartissent donc comme suit.(Graphiques 4-5 et Tableau 15)

\subsubsection{Les périnataux}

Les périnataux sont les fœetus ou nouveau-nés n'ayant pas survécu plus d'un mois. Aucun périnatal n'a été découvert au cours de ces campagnes. En revanche, sur les 164 tombes d'immatures fouillées entre 2002 et 2007, trois périnataux ont été mis au jour. L'individu de la sépulture $\mathrm{n}^{\circ} 381$ a fait l'objet d'observations anthropologiques sur le terrain. Les deux autres immatures de cette catégorie n'ont pas été étudiés par des anthropologues, mais leur stature, prise sur le terrain (environ $50 \mathrm{~cm}$ ), laisse penser qu'ils n'avaient pas plus d'un mois. Cette catégorie d'âge est donc faiblement représentée à Kalfata. Il est possible que les tombes de ces bébés aient été mal identifiées sur le terrain, ou encore que les restes osseux se soient mal conservés. On peut également imaginer qu'un espace leur avait été réservé ailleurs dans la nécropole ou hors des limites de celle-ci ${ }^{104}$.

\subsubsection{Les nourrissons}

Les nourrissons sont les individus âgés de 1 à 12 mois. La tombe SP 264 ne contenait que très peu de restes osseux, mais la taille de l'humérus préservé a permis d'estimer l'âge du défunt à 12 mois environ. Cette catégorie, comme la précédente, est peu représentée puisque le nombre de nourrissons ne constitue que $15 \%$ de l'ensemble (Graphique 5).

\subsubsection{Les enfants de $1 \grave{a} 4$ ans}

Les individus âgés de 1 à 4 ans sont au nombre de deux, ce qui correspond à $18 \%$ de l'ensemble. Cette catégorie est donc moins bien représentée dans ce secteur que sur l'ensemble de la nécropole (33\%) (Graphique 5). Cette différence pourrait s'expliquer par le découpage arbitraire de la zone fouillée et le hasard des découvertes.

\subsubsection{Les enfants de 5 à 9 ans}

La catégorie des enfants de 5 à 9 ans est représentée par cinq individus, soit $46 \%$ de l'ensemble. Ce résultat

104 L'inhumation des enfants dans les maisons est un phénomène bien connu dans l'Antiquité, mais pas du tout attesté à ce jour à Apollonia. semble cohérent lorsqu'il est comparé au pourcentage obtenu pour la même catégorie sur l'ensemble de la nécropole, c'est-à-dire $44 \%$ de l'ensemble.

\subsubsection{Les enfants de 10 à 14 ans}

Les immatures de cette catégorie sont totalement absents du catalogue et ne sont représentés que par deux individus parmi les sépultures qui ont fait l'objet d'une étude anthropologique à Kalfata. Il est possible que les individus de cette classe d'âge aient parfois été considérés comme des adultes par les fouilleurs, la stature ou les dimensions de la tombe pouvant les induire en erreur. Seule une étude anthropologique globale permettrait de mieux comprendre pourquoi les enfants de 10 à 14 ans ressortent si peu dans les études statistiques.

\subsection{Répartition et types de sépultures}

Les onze sépultures d'enfants qui ont été mises au jour entre 2002 et 2004 se répartissent dans tout le secteur, sans répondre à une orientation particulière. Les enfants sont inhumés à proximité des adultes et il n'y a visiblement aucune zone qui ait été réservée à leur ensevelissement. Il est probable que l'on est en présence de regroupements funéraires d'origine sociale ou familiale (Koeller 2008), mais l'emplacement des sépultures d'enfants dans ce secteur ne permet pas d'associer les tombes entre elles. Les dimensions de la zone fouillée et le nombre de sépultures découvertes sont trop faibles pour que l'on puisse proposer une analyse détaillée portant sur les liens entre les sépultures d'enfants entre elles ou avec celles des adultes. De plus, la configuration et la nature du terrain rendant délicate une fouille stratigraphique, il est difficile d'associer les sépultures autrement que par leur situation. Toutefois, certaines tombes paraissent avoir été volontairement placées côte à côte. C'est notamment le cas de deux sépultures : la tombe à fosse SP 375 semble avoir été placée intentionnellement contre la tombe à ciste SP $339^{105}$. Il s'agit dans les deux cas de sépultures d'enfants âgés d'environ 8 ans (+/-12 mois). La première est une tombe à ciste qui contenait une inhumation primaire. La seconde est une inhumation primaire en fosse. La fosse était limitée au Nord et au Sud par un aménagement de pierres, les pierres plus au Sud recouvrant les pieds. L'analyse sur le terrain de la position des ossements et de la disjonction des articulations a permis d'observer que la décomposition s'était faite en espace vide. Ceci indique que la fosse

105 Ces deux sépultures sont attribuées à la phase 2 et datées vers 380-370, SP 339 étant la plus ancienne. 
devait être recouverte, à l'origine, par un aménagement en matériau périssable aujourd'hui disparu : il s'agissait sans doute de planches de bois, les blocs d'entourage servant au calage de l'ensemble. Ces pierres ont également pu servir à marquer l'emplacement de la sépulture. Il faut noter qu'aucune stèle marquant l'emplacement de la sépulture n'a pu être associée à une tombe d'enfant à Kalfata ${ }^{106}$. Cependant, les amas de pierre retrouvés autour de plusieurs tombes ont pu rester visibles pendant un temps et avoir également servi à signaler la présence de la sépulture. Ainsi, si l'emplacement de la tombe était connu, il était tout à fait possible d'enterrer les défunts « côte à côte » pour diverses raisons.

Tous les types de sépultures étaient utilisés pour les enfants à Kalfata. Toutefois, les tombes à fosse sont le plus fréquemment utilisées, elles constituent $82 \%$ de l'ensemble des tombes d'immatures mises au jour jusqu'à présent. Parmi les onze sépultures découvertes au cours de ces campagnes, neuf étaient des tombes à fosse ; les deux autres défunts avaient été inhumés l'un dans une tombe à tuiles, l'autre dans une tombe à ciste.

Aucune tombe à enchytrisme n'est représentée dans ce catalogue, alors que certaines ont été trouvées dans d'autres zones de la nécropole d'Apollonia. Au cours des fouilles plus récentes, deux inhumations d'enfants en amphore et deux inhumations en pithos ont été mises au jour, ce qui ne représente que $4 \%$ du total des tombes d'enfants découvertes (Koeller, à paraître). En revanche, au cours des fouilles des années 40, les inhumations en vase (pithos ou amphore) découvertes par Venedikov représentaient $31 \%$ de l'ensemble des sépultures d'enfants ${ }^{107}$. Ainsi, si on prend uniquement en considération les résultats des fouilles récentes, il apparaît que ce modèle de sépulture était peu utilisé mais, sur l'ensemble de la nécropole, le pourcentage d'inhumations en vase est relativement conséquent. Il est donc possible d'envisager que ce mode d'ensevelissement ait été privilégié pour les enfants, à une période ou dans un secteur de la nécropole de Kalfata.

Dans certains cas, l'utilisation de contenants autres que des amphores et des pithoi a pu être mise en évidence au moment de la fouille. Dans la sépulture SP 313, le corps du défunt avait été déposé dans un cercueil ${ }^{108}$ : les traces laissées par les planches de bois étaient nette-

106 Peu de stèles inscrites ont été mises au jour à Kalfata et aucune d'entre elles n'a pu être associée à une sépulture en particulier : voir Giuzelev 2002 et Gyuzelev 2005.

107 Il s'agissait de quatorze inhumations en amphore, quatre inhumations en pithos et d'une inhumation dans un vase dont la forme n'est pas précisée.

108 Koeller, à paraître. Neuf fosses étudiées dans le cadre du programme EMA contenaient les restes de cercueil en bois. ment visibles dans le sable au moment de la fouille. De plus, treize clous en fer ont été retrouvés in situ: sept d'entre eux appartenaient vraisemblablement au couvercle et six autres au cercueil lui-même ${ }^{109}$. Il s'agissait de la sépulture d'un enfant âgé d'environ sept ans. Le mobilier était constitué d'une œnochoé de production locale, de deux kylikes à vernis noir, de 136 astragales et d'un strigile en bronze. Cette sépulture appartient à la première phase d'occupation du secteur, elle est datée vers $430-420$.

Deux types de tombes à tuiles ont été utilisés à Kalfata. Le premier type semble un peu moins représenté ${ }^{110}$. Les tuiles y étaient posées le long des quatre parois de la fosse, formant ainsi un coffre ${ }^{111}$. La tombe à tuiles en bâtière a été plus utilisée à Kalfata. Les tuiles protégeaient le défunt en formant une couverture au-dessus du son corps. C'est le cas de la sépulture SP 297, qui contenait un enfant dont l'âge n'a pu être déterminé.

À Kalfata, les sépultures à crémation ne représentent qu'environ $10 \%$ de l'ensemble. Le contenu des urnes n'ayant pu être étudié ${ }^{112}$, il est impossible d'affirmer que la pratique de la crémation était réservée aux adultes. Concernant les inhumations, nous avons vu que tous les types de tombes ont été utilisés pour les enfants. On trouve des tombes à tuiles, des tombes à ciste, des inhumations en amphore et en pithos, mais ce sont les tombes à fosse qui étaient le plus fréquemment utilisées pour les enfants, comme pour les adultes d'ailleurs. Toutefois, il semblerait que les tombes à ciste aient été moins utilisées pour l'inhumation des immatures que pour celle des adultes.

L'âge au décès des enfants est un élément très important pour notre étude. Il est en effet particulièrement intéressant de voir si l'âge avait une influence sur le traitement du défunt. Toutefois, il s'agit là d'un échantillon relativement faible et il faut donc rester prudent quant aux conclusions que nous pourrions en tirer. Au cours des fouilles récentes, une étude anthropologique a été menée sur 40 immatures ${ }^{113}$. La publication des fouilles

109 Les clous ont été découverts dans les angles de la fosse, sur les longs côtés et dans la partie centrale de la tombe : voir ci-dessus, p. 140. 110 Sur les neuf tombes à tuiles découvertes à ce jour à Kalfata deux d'entre elles étaient de ce type.

111 Koeller, à paraître : la tombe à tuile $n^{\circ}$ 5518-12 (campagne de fouilles 2007) fait partie de cette catégorie de tombe. Aucune couverture n'était en place sur la sépulture au moment de la fouille. Cependant, la perte de connexions anatomiques entre les ossements laisse penser que la décomposition du corps s'est faite en espace vide. Nous pouvons donc dire que la sépulture était certainement recouverte, au moins pendant un temps.

112 À l'exception du contenu de l'urne de la sépulture SP 345, étudié ci-dessus par Anne Richier.

113 Rappelons que les études anthropologiques ont été menées par Anne Richier (Archéologue - Anthropologue, INRAP Méditerranée) 


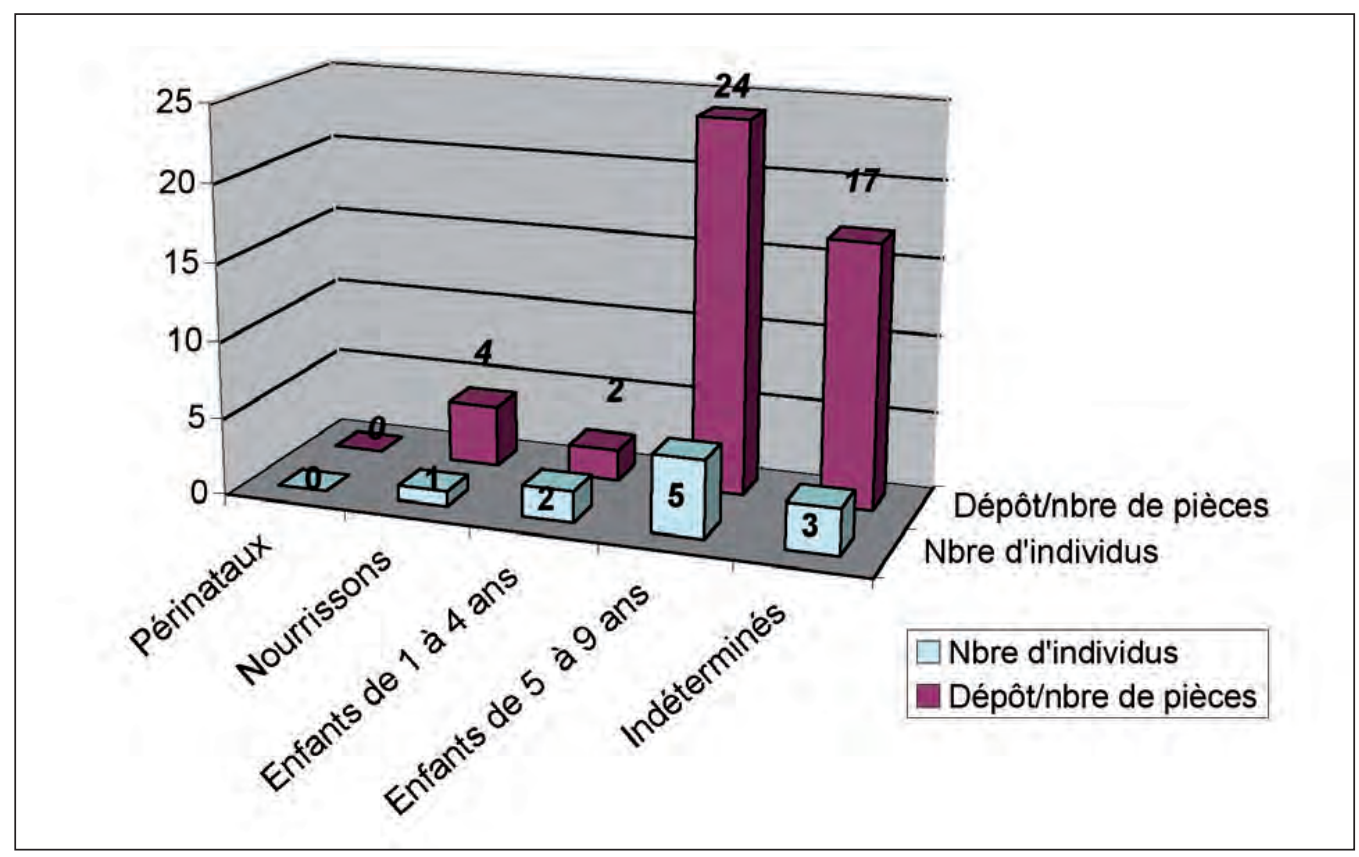

Graphique 6. Nombre d'objets par classe d'âge.

anciennes (Venedikov et al. 1963) permet d'avoir une vision plus large du traitement des défunts à Apollonia et confirme l'ampleur de la nécropole de Kalfata, mais aucune étude anthropologique n'avait alors été faite. Nous ignorons donc comment les enfants ont été identifiés. De ce fait, il est possible que les jeunes adolescents de 12-13 ans aient été considérés comme des adultes par Ivan Venedikov et ses collaborateurs et qu'ils n'apparaissent pas dans le catalogue.

À ce stade de l'étude, il apparaît que l'âge de l'enfant n'a eu aucune influence sur le choix de la sépulture. Par exemple, les tombes à tuiles pouvaient aussi bien être utilisées pour un jeune enfant de moins d'un an que pour un enfant de 8 ou 9 ans. Les tombes à fosse étant le mode d'inhumation le plus fréquent, elles contenaient des enfants de 0 à 13 ans.

\subsection{Mobilier associé au défunt}

Il est rare qu'aucun objet ne soit associé à une sépulture à Kalfata. En effet, un seul défunt sur les onze découverts - celui de la sépulture SP 341 - n'était pas accompagné par du mobilier ${ }^{114}$. Le mobilier funéraire

pour la partie française et par Anne Keenleyside (Professeur associé, Département d'Anthropologie, Université de Trent, Ontario).

114 Plus généralement, sur les 40 défunts pour lesquels nous connaissons l'âge au décès et qui sont étudiés dans le cadre du programme EMA, seuls cinq avaient été inhumés sans mobilier. On a découvert jusqu'à 14 types d'objets différents par tombe. est hétérogène et le nombre d'objets placés auprès du corps varie d'une sépulture à l'autre. On a pu trouver, en moyenne ${ }^{115}$, quatre objets par tombe d'immatures (Graphique 6). Cette moyenne semble cohérente, puisque l'on arrive à peu près au même résultat en étendant les statistiques aux 164 tombes d'enfants identifiées à Kalfata. Manifestement, plus d'objets ont été déposés auprès des enfants : chez les adultes, on a en effet retrouvé en moyenne 2,5 objets par tombe, tout type confondu.

On a découvert jusqu'à quatorze types d'objets différents par tombe. Les vases en céramique sont les plus fréquents. Il s'agit pour la plupart de vases importés, mais la céramique locale est également bien représentée. Les vases importés sont de types et de formes variés : un grand nombre sont originaires d'Athènes. Il s'agit essentiellement de lécythes, de vases à verser et de coupes, parfois miniatures.

L'iconographie des céramiques peintes n'est jamais liée au monde de l'enfance, comme cela est souvent le cas dans le monde grec, notamment sur les choés retrouvées dans les sépultures d'enfants. En revanche, les vases de ce type sont attestés à Apollonia du Pont : par exemple, trois lécythes à figures rouges représentant

115 Pour ce calcul les astragales ont été considérés comme un groupe, nous n'avons pas tenu compte ici du nombre d'osselets par tombe. 
un enfant marchant à quatre pattes ont été découverts au cours des fouilles récentes (Koeller, à paraître).

Les figurines en terre cuite faisaient souvent partie du mobilier qui accompagnait les enfants ${ }^{116}$. Elles représentent des animaux, des personnages féminins, masculins ou des groupes. Elles ont parfois été trouvées en grand nombre, jusqu'à une quinzaine par tombe. Ainsi, plusieurs figurines représentant des papposilènes (parfois à cheval), des acrobates et des «temple boys » avaient été déposées dans une tombe à fosse, découverte lors de la campagne de fouille 2002 (Hermary, Panayotova 2006, p. 59). Divers animaux en terre cuite ont été mis au jour : des sangliers, des tortues, des oiseaux et des coqs. Ces objets associés à l'enfant sont souvent considérés comme des jouets (Papaikonomou 2006, p. 243-247). Dans le cas du coq de la sépulture SP 283, il est possible qu'il s'agisse d'une sorte de hochet ${ }^{117}$. En effet, une terre cuite similaire avait été mise au jour par I. Venedikov en $1946^{118}$; elle contenait des petits grains ou des cailloux à l'intérieur, si bien que l'objet produisait un son lorsqu'on le secouait. Malheureusement, le coq découvert en 2002 est fragmentaire. Il n'est donc pas possible de savoir s'il s'agissait également d'un hochet. Cette sépulture contenait également d'autres figurines : un acteur, un personnage grotesque et une petite base.

Les astragales ont été déposés en grand nombre, parfois par centaines, dans quelques sépultures. Ils étaient placés autour du corps, en petits tas, à différents endroits. Certains d'entre eux étaient travaillés ou sciés.

116 Les figurines en terre cuite ont été retrouvées dans $25 \%$ des sépultures d'enfants fouillées entre 2002 et 2007. D'après le catalogue de I. Venedikov, 10 sépultures d'enfants mises au jour dans les années quarante contenaient des figurines (ce qui représente environ $16 \%$ de l'ensemble).

117 Voir Cavalier (O.) et al. - Jouets et jeu de l'enfance. In : Jouer dans l'Antiquité. Catalogue d'exposition, Marseille, 1991, p. 50-52.

118 Venedikov et al. 1963, p. 283, pl. 153. Un autre exemple de figurine représentant un coq avait été mis au jour en 1946 dans la sépulture $n^{\circ} 44$ (Dremsizova 1948, p. 57, fig. 40).
Hormis les vases miniatures, les astragales et les terres cuites qui ont été en majorité, mais pas exclusivement, découverts dans les sépultures d'enfants, le mobilier n'est pas très différent de celui découvert dans les tombes d'adultes. Il s'agit du mobilier retrouvé traditionnellement dans les sépultures grecques d'époque classique (Kurtz, Boardman 1971, p. 100-102) : vases en céramique, strigiles, petits objets métalliques, quelques bijoux et plus rarement des monnaies.

En raison de l'échantillon relativement faible de sépultures d'immatures que nous présentons dans cet ouvrage, il est difficile de tirer de véritables conclusions. Toutefois, il semblerait qu'à Apollonia du Pont, les enfants aient bénéficié du même traitement que les adultes. En effet, les sépultures à inhumation sont du même type que celles utilisées pour les adultes et elles sont situées dans le même secteur. À quelques exceptions près, le mobilier déposé dans les sépultures d'enfants diffère peu de celui que l'on a retrouvé dans les tombes d'adultes. De plus, il apparaît que les sépultures d'immatures n'avaient pas été séparées de celles des adultes : jusqu'à aujourd'hui, aucune nécropole ni aucun espace proprement réservé aux enfants n'a été mis au jour à Apollonia. Le regroupement de défunts de tout âge, matérialisé par les murs de périboles, permet de suggérer que nous sommes en présence d'espaces funéraires réservés à des groupes sociaux ou familiaux, mais, en l'absence de données épigraphiques, il est impossible de définir la nature des liens qui unissaient ces défunts.

L'étude en cours dans le cadre du programme de recherche EMA prend en considération un nombre de sépultures plus élevées, ce qui permettra d'obtenir des résultats plus précis et plus représentatifs. Ainsi, comparées aux données révélées dans d'autres nécropoles grecques, les tombes d'enfants d'Apollonia permettront d'élargir de manière significative nos connaissances sur les pratiques funéraires, mais aussi plus largement sur le monde de l'enfance. 


\section{Chapitre 2}

\section{Études par catégories d'objets}

$\mathrm{L}$ a portée des synthèses présentées ci-dessous est limitée par le nombre réduit des tombes, dépôts et foyers fouillés en commun entre 2002 et 2004, si l'on songe aux centaines de sépultures fouillées avant et après ces dates. D'autre part, le commentaire de certains ensembles est développé de manière détaillée, alors que pour les céramiques communes, qui constituent numériquement le lot le plus important, il n'a été possible que de donner un catalogue typologique avec le rappel des datations fournies par le contexte de découverte : notre contribution servira de base de travail sur un sujet qui devra donner lieu à d'autres développements.

\section{Les céramiques peintes}

On regroupe ici les vases de la nécropole qui présentent un décor peint, quelle que soit sa nature ou son importance, par opposition aux céramiques à vernis noir et aux productions locales non décorées ${ }^{119}$. Cet ensemble relativement modeste (47 documents) comporte une part d'importations attiques difficile à déterminer, à côté de vases qui sortent sans doute d'ateliers locaux ou régionaux, dans un sens plus ou moins large (depuis les sites de la côte occidentale de la mer Noire jusqu'à ceux du Nord de la mer Egée) : la question de la distinction entre ces différentes productions, extrêmement complexe ${ }^{\mathbf{1 2 0}}$, ne sera abordée ici qu'à partir de quelques observations à l'œil nu sur l'argile et le vernis.

Apollonia est, de loin, le site de la côte occidentale de la mer Noire qui a livré le plus de céramiques à figures rouges ${ }^{121}$ : les découvertes effectuées au cours des deux dernières décennies confirment largement cette

119 Différents fragments isolés, mentionnés dans le catalogue des tombes, des dépôts ou des foyers, n'ont pas été pris en compte ici. 120 Blondé 2000, p. 273 : «L'expression 'attique ou pseudo-attique' est une des identifications courantes dans les publications les plus diverses et demande solution »; voir aussi Drougou 2005, p. 71.

121 Pour la Thrace bulgare, voir Reho 1990: sur 470 vases catalogués, 330 viennent d'Apollonia/Sozopol, dont 80 à $90 \%$ de la nécropole de Kalfata. Voir aussi Fless 2002, p. 67-77 et 177-188. observation, mais la plus grande partie d'entre elles restent inédites. Il s'agit essentiellement de vases du IV ${ }^{\mathrm{e}} \mathrm{s}$. av. J.-C. qui, en l'absence de monnaies lisibles ou bien datées, constituent, avec les céramiques à vernis noir et quelques timbres amphoriques thasiens, les principaux marqueurs chronologiques pour comprendre l'évolution de cette zone de la nécropole de Kalfata. La datation des vases attiques à figures rouges $d u \mathrm{IV}^{\mathrm{e}} \mathrm{s}$. est moins bien établie que celle des céramiques du $\mathrm{V}^{\mathrm{e}} \mathrm{s}$. : après les recherches fondamentales de Schefold et Beazley, celles des dernières décennies ont concerné plus particulièrement les exportations vers la Méditerranée centrale et occidentale (Sabattini 2000 ; Cabrera, Rouillard 2003a et b ), mais la découverte à Érétrie d'un ensemble d'amphores panathénaïques précisément datées a permis de faire progresser nos connaissances sur plusieurs peintres ou ateliers attiques autour du milieu du $\mathrm{IV}^{\mathrm{e}} \mathrm{s} .{ }^{122}$, tandis que la publication des céramiques du Grand Tumulus de Vergina donnait de nouvelles indications sur les dernières productions à figures rouges, dans les années 330-320 (Drougou 2005). Malgré tous les débats qui ont eu lieu (voir Rotroff 1997, p. 18-20), la céramique d'Olynthe constitue toujours une référence fondamentale, la destruction de la ville en 348 fournissant un terminus ante quem à peu près sûr pour les vases trouvés dans les fouilles américaines.

La répartition des vases peints dans le secteur publié ici mérite quelques remarques, même si le nombre limité de tombes fouillées interdit d'en tirer des conclusions générales pour la nécropole de Kalfata.

- Les vases de grandes dimensions ne sont qu'au nombre de deux, le cratère en cloche $\mathrm{CP} 46$ et l'hydrie CP 47. Ils sont utilisés comme urne cinéraire et l'on constate que, dans cette zone, il s'agit des deux sépultures à incinération les plus anciennes : pour les autres, qui datent de la fin du $\mathrm{IV}^{\mathrm{e}}$ et surtout du $\mathrm{III}^{\mathrm{e}}$ s., on a recours à des vases produits localement.

122 Valavanis 1991, qui est amené à remonter la chronologie proposée par Schefold pour plusieurs peintres ou groupes du «style de Kertch » ; Bentz 1998. 
- La plupart des vases peints sont déposés comme offrandes dans les tombes : il s'agit dans la très grande majorité des cas de lécythes aryballisques, donc de vases à parfum. Quelques autres lécythes de ce type, sans décor figuré, sont placés dans des dépôts extérieurs à la sépulture, mais une catégorie, celle des askoi, est associée aux foyers (voir le chapitre sur les pratiques funéraires).

- L'examen de la relation entre le sexe et l'âge du défunt et l'offrande d'un vase à décor peint semble montrer une nette préférence pour les tombes d'enfants et, surtout, de femmes. Les lécythes aryballisques qui portent le décor le plus élaboré proviennent de sépultures

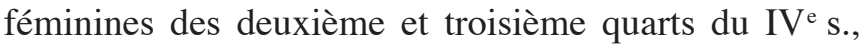
mais il se trouve que, pour une raison difficilement explicable, aucune tombe d'individu masculin adulte n'a été identifiée dans le secteur, en dehors de SP 334 qui appartient à un très jeune adulte (15 à 20 ans). Il faudrait disposer, pour étendre la discussion sur ce point, d'informations suffisantes sur les autres secteurs de la nécropole fouillés récemment.

Les questions de chronologie, d'ateliers de production, de réseaux de diffusion, mais aussi d'adaptation des scènes iconographiques au contexte de découverte seront principalement abordées à propos de l'hydrie cinéraire de la tombe SP 345 (CP 47) et d'un ensemble de lécythes aryballisques à décor figuré qui complète la série, déjà très importante, provenant des fouilles d'Apollonia du Pont.

Pour des raisons de mise en page des planches, les vases de petites dimensions sont présentés, par ordre alphabétique, avant le cratère et l'hydrie.

\subsection{Askoi}

Ces petits vases ne sont pas déposés en offrande dans les tombes, mais proviennent de dépôts extérieurs, ici exclusivement de foyers (toutefois celui de F 5 n'est pas brûlé). Il en va de même pour une autre catégorie, dont aucun exemplaire décoré n'a été mis au jour dans nos fouilles, celle des plats à poisson. Ces deux types de vases étaient donc utilisés principalement dans des cérémonies en l'honneur des défunts, soit que les vivants aient pris un repas en l'honneur des défunts, avant d'en brûler les restes avec différents objets, soit, plus probablement, qu'ils aient symboliquement offert le repas aux défunts : les ossements de petits animaux contenus dans le foyer F 9 sont en tout cas les restes de ce repas réel ou symbolique. Dans ce foyer, comme dans d'autres, askos et plat à poisson sont associés aux " grils à poisson », objet caractéristique des nécropoles d'Apollonia, dont le sens n'est pas encore élucidé (voir ci-dessus, p. 171-172).
CP 1. - Foyer F 1. Diam. $\max 8,8 \mathrm{~cm} ; \mathrm{Ht}$ avec l'anse $7,2 \mathrm{~cm}$. Inv. PIN 3253. Pl. 68f et 83a

Brûlé. Partie inférieure conique, l'embouchure est fixée sur la partie la plus large du réceptacle. Décor de deux palmettes, de onze et douze feuilles.

Vers 380 d'après le contexte.

CP 2. - Foyer F 5. Diam. max. $9,1 \mathrm{~cm}$; Ht $5 \mathrm{~cm}$. Inv. PIN 3668b. Pl. 78a et 83b

Argile beige tendre, l'anse et d'autres petits fragments manquent. Deux palmettes stylisées sont peintes sur la paroi supérieure. Le fait que le vase ne soit pas fortement brûlé permet de constater que l'argile n'est pas attique.

Vers 390-380 d'après le contexte.

CP 3. - Foyer F 9. Diam. max. $8,4 \mathrm{~cm}$; Ht $4,8 \mathrm{~cm}$. Inv. PIN 4033, 1. Pl. 78b et 83c

Brûlé, fragmentaire. Décor constitué de trois palmettes, très détérioré. Filtre au sommet du réceptacle.

Vers 380 d'après le contexte.

\subsection{Coupe-skyphos}

CP 4. - Tombe à fosse SP 329. Ht $8 \mathrm{~cm}$, diam. avec les anses $18,5 \mathrm{~cm}$, sans les anses 12,2 cm. Inv. PIN 3644 . Pl. 78c et 83d

Argile orangée fine, vernis d'assez bonne qualité. $\mathrm{Au}$ fond un cercle et cinq palmettes estampées, sur chaque face deux jeunes gens nus face à face, entre deux palmettes. En A), le jeune homme de gauche tient un oiseau (?) sur sa main droite, un strigile (?) dans la gauche ; celui de droite est appuyé sur un bâton, une étoffe tombe à l'arrière. En B), scène identique, sans le « strigile », style encore plus négligé.

Le contexte indique une date vers 360-350, qui convient pour le style du décor.

\subsection{Lécythes}

CP 5. - Tombe à fosse SP 330 . Ht 23,5 cm. Inv. PIN 3747. Pl. 36d et 78d

Argile beige orangé, vernis marron plus ou moins dilué, vernis noir autour du goulot, sur l'anse et sur le pied. Décor à figures noires, sans incisions. En bas de la panse, motif de feuilles de lierre de part et d'autre d'une branche, avec des grappes de points (baies ?), plus haut quadrillage très irrégulier et méandres, sur l'épaule languettes maladroitement dessinées, surmontées de traits.

Le contexte indique une date vers 430-420, le vase pourrait être un peu plus ancien. 
CP 6. - Découverte isolée dans la zone du point G 2. Le col et l'anse manquent. Ht 14,5 cm. Inv. PIN 3393. Pl. 78e et 83e

Deux rangs de languettes sur l'épaule. Décor en vernis noir dilué sur la panse, de haut en bas : bande, méandres, bandes et quadrillage, branche de lierre avec baies, quadrillage.

Même date que le précédent.

\subsection{Lécythes aryballisques}

Il s'agit du type de vase le mieux attesté - de très loin - dans la nécropole d'Apollonia, comme l'avaient déjà montré les fouilles de Venedikov ${ }^{123}$ : il n'y a là rien d'étonnant, puisque le dépôt auprès du mort d'un ou plusieurs vases à parfum est d'usage courant partout dans le monde grec. Ils représentent ici 34 vases sur 47, soit près de $75 \%$. On distinguera trois catégories dans cet ensemble: les lécythes qui portent un décor à figures rouges, parfois polychrome (huit exemplaires seulement), mis au jour uniquement dans les sépultures ; ceux sur lesquels est peinte une simple palmette en figures rouges, et ceux dont la panse est couverte d'un réseau de losanges rehaussé de points blancs, que l'on appellera décor réticulé : ces deux dernières catégories ont été trouvées à peu près en même quantité, le plus souvent dans les sépultures, parfois dans des dépôts, mais pas dans les foyers.

Pour chaque catégorie se pose la question de l'atelier de fabrication du vase : attique, local ou régional au sens large, y compris la Grèce du Nord (voir aussi Tchongarska 2001). Les indications qui sont données ici reposent sur la couleur et la consistance de l'argile, la qualité du vernis et le style du décor, elles devront être vérifiées à partir d'analyse scientifique précise et d'une étude fondée sur des bases statistiques plus larges.

\subsubsection{Avec décor figuré, souvent polychrome}

À cette série appartiennent trois grands lécythes aryballisques attribués au «groupe d'Apollonia » trouvés dans des tombes de la ville à la fin du $\mathrm{XIX}^{\mathrm{e}} \mathrm{s} .{ }^{124}$ :

123 Cf. Reho 1990, p. 33 : «Per la variante «squat» si possono seguire a Kalfata tutti gli stadi evolutivi tra metà V e fine IV sec. a.C., dagli esemplari più antichi ai numerosissimi più evoluti a corpo sia globulare schiacciato, sia ovoidale, sempre più allungato e ristretto in basso, man mano che si scende verso il pieno IV secolo. Sono per la maggior parte di piccole e medie dimensioni; soltanto pochi vasi raggiungono i $\mathrm{m} .0,30$ di altezza ».

124 Ils proviennent des fouilles commanditées par le consul de Grèce Goffas en 1884-1885. D'après W. Fröhner (1892, nos 98-99), les lécythes actuellement à Berlin et Saint-Pétersbourg auraient

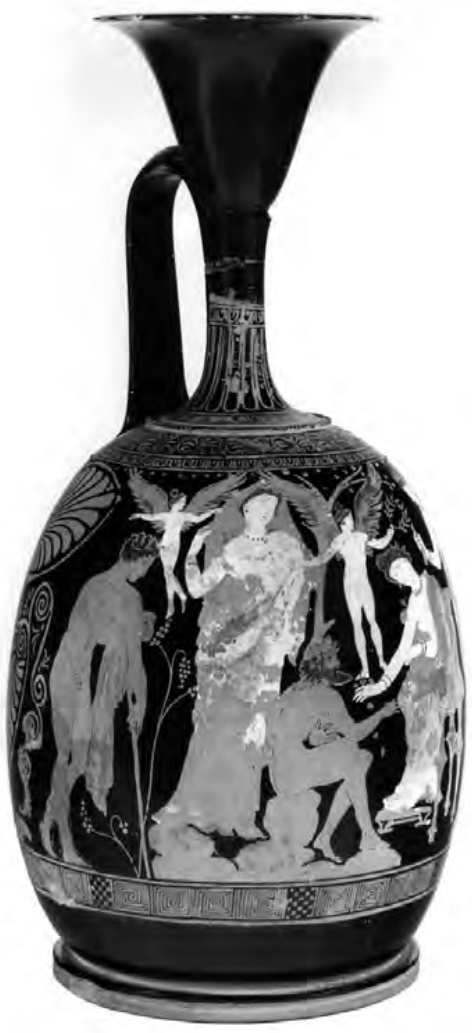

Fig. 65. Lécythe attique à figures rouges attribué au « Groupe d'Apollonia ». Baltimore, Walters Art Gallery. Photo du musée.

l'un est conservé à Saint-Pétersbourg ${ }^{125}$, un autre à Berlin ${ }^{126}$, le troisième à Baltimore (fig. 65) ${ }^{127}$. D'autres lécythes, au décor figuré plus modeste, sont entrés à la même époque dans la collection Margaritis, ensuite dispersée : plusieurs exemplaires de Würzburg ont gardé l'indication de leur provenance ${ }^{\mathbf{1 2 8}}$. Enfin, un lécythe aryballisque à reliefs, autrefois à Berlin, montre, sur une kliné, un jeune homme allongé et deux femmes assises, à gauche une femme debout, à droite, assis sur le sol, un Eros en attitude triste ou pensive (Zervoudaki 1968, p. $29 \mathrm{n}^{\circ}$ 43, pl. 19, 5 ; Mandel 1999, p. 232, pl. 68, 5).

été trouvés dans deux sarcophages en marbre, dont l'un portait l'inscription «Kallias Kratippo », mais, comme me le fait remarquer A. Riapov, il doit s'agir d'une confusion avec une stèle funéraire portant les mêmes noms (Mihailov 1970, p. 375 n $^{\circ}$ 408).

125 Ermitage B 2024, fête des Adonies : $A R V^{2} 1482$, 6 et 1695 ; Reho 1990, p. 110 n $^{\circ} 232$; Hermary, sous presse.

126 Staatliche Museen 3248, fête des Adonies: $A R V^{2} 1482$, 5 et 1695 ; Reho 1990, p. 111 n $^{\circ} 233$; Hermary, sous presse.

127 Walters Art Gallery 48.84, composition complexe autour d'une femme jouant aux osselets avec un Satyre: Simon 1962-63 ; Schefold 1981, p. 287, fig. 408 ; CVA Baltimore, Walters Art Gallery 1, pl. 39-40 ; Hermary, sous presse.

128 Langlotz 1932, $\mathrm{n}^{\text {os }} 596-598$ et 600 ; Reho 1990, p. 113-114 $\mathrm{n}^{\text {os }} 248-251$; Hermary, sous presse. 
Comme les lécythes précédents et ceux des fouilles de Venedikov, presque tous les vases présentés ici sont décorés de thèmes relatifs à Eros et Aphrodite. Ils proviennent des tombes féminines 328, 333, 340 et de la tombe d'enfant 264. Or, on constate que la riche tombe 283 des fouilles de Venedikov, qui a livré cinq lécythes aryballisques décorés d'Erotes et de femmes ${ }^{129}$, était certainement une tombe de femme, puisqu'elle contenait une paire de boucles d'oreilles et un bracelet ${ }^{130}$, et que plusieurs vases du même type proviennent de tombes d'enfants : un lécythe avec deux têtes féminines entourant un objet conique dans la tombe 31 (Ivanov 1963, p. 101 n$^{\circ} 53$; Reho 1990, p. 114 n$^{\circ} 253$ ), une œnochoé avec un Eros poursuivant un oiseau dans la tombe 54 (Ivanov 1948, p. 42, fig. 46-47), un lécythe avec Eros et une femme séparés par un xoanon, ainsi qu'un chous du type des Anthestéries dans la tombe 229 (Ivanov 1963, p. $100 \mathrm{n}^{\circ}$ 50, pl. 41-42, et p. $148 \mathrm{n}^{\circ} 269$, pl. 75-77 ; Reho 1990, p. 100 n $^{\circ} 174$, pl. XIV, et p. 112 $\mathrm{n}^{\circ}$ 244), un autre lécythe et un autre chous dans la tombe 508 (Ivanov 1963, p. $91 \mathrm{n}^{\circ} 34$ et p. $148 \mathrm{n}^{\circ} 268$, fig. 59; Reho 1990, p. 99 n 170, pl. XIV). Même si, en l'absence d'analyses anthropologiques pour les autres tombes contenant des offrandes comparables, il est impossible de tirer des conclusions générales, il apparaît donc que les vases portant ce type de représentation paraissaient particulièrement convenir à des sépultures de femmes et d'enfants (voir aussi ci-dessus, p. 169).

CP 7. - Tombe à fosse SP 244. Ht $16,5 \mathrm{~cm}$. Inv. PIN 2731. Pl. 17e,79a et 83f

Argile orangée pure, vernis de qualité médiocre : production probablement attique. Le col, étroit, porte sur la zone opposée à l'anse un décor peint en noir, composé de languettes et de lignes bouletées. Sur la panse, à gauche une tête féminine de profil à droite, avec le cou et le départ de l'épaule droite. La bouche est ouverte, le nez pointu est dans le prolongement du très haut front, l'œil forme un triangle ouvert. En haut du front, un bandeau ou une partie du sakkos qui couvre le crâne et tombe sur la nuque, avec en haut un «bouton». Sur l'oreille une tache noire figure peut-être des cheveux, prolongés

129 Ivanov 1963, p. 96-97 nos 40, pl. 23-24 (Eros et deux femmes, pierre ovoïde), 41, pl. 25-26 (même thème), 42, pl. 27-28 (Eros en vol poursuivant une femme, une autre à l'arrière), p. 99 n 48 , pl. 39-40 (Eros et une femme), p. $101 \mathrm{n}^{\circ}$ 52, pl. 44 (deux têtes féminines entourant un objet ovale); Reho 1990, nos 234-236, 242 et 252.

130 La tombe 150, en raison de la présence d'un miroir et de la bague trouvée près de la main gauche du défunt, est très vraisemblablement féminine : elle contenait un lécythe avec un Eros, deux femmes, un éphèbe et un xoanon, et un autre avec un Eros, une femme et un oiseau (Ivanov 1963, $\mathrm{n}^{\text {os }} 38$, pl. 20-23, et 39 ; Reho 1990, $\mathrm{n}^{\circ} 247$, pl. XXIII). par une longue mèche tire-bouchonnée ; bijou sur le lobe d'oreille? Devant la tête est dessinée un rinceau en volute, à droite une femme est debout vers la gauche, vêtue d'un chitôn visible sur les pieds et d'un himation qui la couvre presque entièrement ; son visage est sommairement dessiné, chignon à l'arrière du crâne.

Vers 370-360.

L'association entre la tête féminine et la femme qui lui fait face, drapée à la manière des traditionnels éphèbes, témoigne d'une certaine originalité, même si une œnochoé fragmentaire des fouilles de Venedikov montre une tête féminine entre deux personnages drapés (Ivanov 1963, p. 150 n $^{\circ}$ 276, pl. 84). On comparera un lécythe d'Odessos/Varna qui montre deux têtes féminines séparées par un rinceau (Lazarov 1990, n 56) et, en particulier pour la masse des cheveux au niveau de l'oreille, le tondo d'une coupe découverte dans l'épave d'El Sec, au large des Baléares ${ }^{131}$, qui confirme la chronologie proposée ici, puisque le naufrage est daté vers le milieu du $\mathrm{IV}^{\mathrm{e}} \mathrm{s}$.

CP 8. - Tombe à fosse SP 264. Ht $9,5 \mathrm{~cm}$. Inv. FR 1.19. Pl. 19b et 83h

Argile orangée pure, vernis de qualité médiocre. À la jonction entre le col et l'épaule, frises de godrons et d'oves. Sur la panse deux têtes féminines se font face, séparées par un objet conique avec traces de rehauts blancs (Ht $2 \mathrm{~cm})$. Le haut du torse des femmes est visible, les rehauts blancs sur le visage sont mal conservés. Sous le sakkos de la femme de gauche est figurée une frange de cheveux ; elle portait un collier de perles en barbotine (deux points conservés). Celle de droite paraît voilée (bande rouge en bas de l'étoffe), frange de cheveux sur le front, oreille dégagée, collier autour du cou, figuré par trois boules de barbotine. Sous l'anse (restaurée), une palmette à 17 feuilles flanquée d'une volute surmontée d'une feuille.

Le contexte indique une date vers le milieu du $\mathrm{IV}^{\mathrm{e}} \mathrm{s}$., qui convient pour le style du décor.

CP 9. - Tombe à fosse SP 333. Ht $11,5 \mathrm{~cm}$. Inv. PIN 3761. Pl. 38b, 79b et 83g

Deux têtes féminines coiffées d'un sakkos se font face, au-dessus d'une ligne rouge, entourant un objet conique. Des volutes encadrent la composition. Palmette à l'arrière.

La sépulture est peut-être légèrement antérieure à la précédente, vers 370-350.

131 Arribas et al. 1987 , p. $98 \mathrm{n}^{\circ}$ 58, fig. 16 et pl. XXXVII (P. de Vienne 116, $2^{\text {e }}$ quart du $\mathrm{IV}^{\mathrm{e}} \mathrm{s}$.). D'autres vases de l'épave portent le même type de décor. 
Les vases de ce type ${ }^{132}$ sont bien attestés à Kalfata par les fouilles des années $1940^{133}$ et par des découvertes plus récentes ${ }^{134}$. Un bon nombre de lécythes aryballisques portant le même décor avaient précédemment été mis au jour à Olynthe ${ }^{135}$, un vase comparable est attesté à Mieza en Macédoine (Rhomiopoulou, Touratsoglou 2002 , p. $43 \mathrm{n}^{\circ} \mathrm{P} 1544$ ) et trois exemplaires inédits, proviennent de la nécropole de Pydna ${ }^{136}$. Un vase autrefois dans la collection Czartoryski est dit provenir d'Attique (CVA Goluchow [Pologne 1], pl. 41, 5), deux ont été découverts à Tarente (NotSc 1936, p. 206-208, fig. 112) et un dans une tombe d'enfant de Spina, en contexte étrusco-italique ${ }^{137}$. Quelques-uns sont de provenance inconnue ${ }^{138}$. On a proposé de reconnaître dans les bustes féminins des "protomés d'Aphrodite chthonienne » (Metzger 1951, p. 82 nos 31-32), mais, à Olynthe, les vases n'ont pas été trouvés en contexte funéraire. L'objet ovoïde, de taille variable et qui revêt la forme d'un disque ellipsoïdal ${ }^{139}$, d'un œuf ou d'un cône, a donné lieu à diverses interprétations. Ivanov décrivait l'image comme les «bustes de deux fillettes tournées de profil l'une en face de l'autre entre lesquels on aperçoit parfois un objet ellipsoïde (un miroir) » (Ivanov 1963, p. 375), ce qui n'est guère satisfaisant, pas plus que la dénomination d'omphalos avancée par Robinson (1950, p. 143, mais le texte de la page suivante est beaucoup plus nuancé). On a pensé aussi à un «bétyle » semblable à celui du sanctuaire de Paphos à Chypre : c'est ce qui est proposé dans l'article «Aphrodite » du LIMC, de façon très prudente et presque allusive (Delivorrias 1984, p. $10 \mathrm{n}^{\text {os }} 4$ et 6). La comparaison avec des vases de même type qui montrent

132 Voir aussi Hermary, sous presse, et Sgouropoulou 2000, p. 213-214, fig. 1-4, et 226-227, qui aboutit à peu près aux mêmes conclusions que moi.

133 Un exemplaire est reproduit dans Ivanov 1948, p. 36, fig. 34, cinq autres sont catalogués (quatre illustrés) dans Ivanov 1963, p. $101-102$ nos $52-56$ pl. $44-45$; Reho 1990 , p. $114-115$ n $^{\text {os }} 252-256$ et 258 .

134 Une dizaine d'exemplaires, conservés à Sozopol, viennent des fouilles les plus récentes; sept ou huit autres, découverts antérieurement, sont au Musée National de Sofia.

135 Robinson 1933, p. 171-172 nos 392-399, pl. 139 (noter que ces vases ne proviennent pas d'un contexte funéraire ; les n ${ }^{\text {os }} 392$ et 394 ont été mis au jour dans la «Maison du comédien »); Robinson 1950, p. 143-144 n ${ }^{\text {os }} 89-90$, pl. 102 (de la maison A-VIII-10).

136 Je remercie Zoï Kotitsa pour cette information.

137 Muggia (A.) - Impronte nella sabbia. Tombe infantili e di adolescenti dalla necropoli di Valle Trebba a Spina. Bologne, 2004, p. 139, fig. 76.

138 CVA Mainz, Römisch-Germanisches Museum 1, pl. 39, 6-7; CVA Michigan University 1, pl. 15, 3 ; CVA Japan 1, pl. 7, 1-3 (l'objet est comme suspendu entre les têtes féminines).

139 Sur un lécythe conservé au musée Bénaki, il est figuré transversalement entre un cygne et une tête féminine : Sabetai 2006a, p. $32-33 n^{\circ} 14$, fig. $33-37$. une statue cultuelle féminine, très probablement identifiable à un xoanon d'Aphrodite, irait dans ce sens (voir ci-dessous). Sur un lécythe inédit d'Apollonia, l'objet conique se trouve derrière Aphrodite elle-même, tandis que sur d'autres la ligne blanche qui cerne l'objet et le point doré qui le surmonte paraissent souligner son caractère sacré. Si ces lécythes aryballisques évoquent effectivement la déesse sous la forme d'une pierre dressée, comme à Paphos, on pourrait établir un lien avec les amphores de type chypriote trouvées dans la nécropole d'Apollonia (Panayotova 2005b), comme sur différents sites de Grèce du Nord ${ }^{140}$. L'importante série de lécythes de cette catégorie trouvés à Apollonia et à Olynthe pose, d'autre part, la question de leur origine : ils se rattachent à la production attique par leur forme, leur vernis, leur décor, mais le fait qu'ils aient été principalement trouvés en Grèce du Nord et à Apollonia, associé au caractère original de la représentation figurée, conduit à se demander s'ils n'ont pas été en grande partie fabriqués dans des ateliers locaux. I. McPhee a montré qu'un groupe de lécythes aryballisques décorés d'une figure féminine («the Agrinion Group»), trouvés principalement en Grèce du Nord-Ouest et diffusés jusqu'à Spina, avaient sans doute été fabriqués dans un atelier d'Épire (McPhee 1979). Pour ce qui concerne les nombreux exemplaires d'Apollonia, on ne saurait se prononcer sans un examen plus détaillé de l'ensemble de la série et, en particulier, de l'argile utilisée.

La présence importante de ces vases à Olynthe, le contexte de la tombe de Mieza (les années 380-360) ${ }^{141}$ et celui des tombes d'Apollonia indiquent pour ces productions une date dans le deuxième quart du $\mathrm{IV}^{\mathrm{e}} \mathrm{s}$.

CP 10. - Tombe à ciste SP 328 . Ht $20,5 \mathrm{~cm}$. Inv. PIN 3647. Pl. 34e,79c et 84a

En bas du col sept languettes sont peintes grossièrement en noir. Sur la panse est figurée une grande tête d' "Amazone » de profil à droite, coiffée d'un bonnet oriental décoré de points et de postes sur la bordure antérieure. La bouche est ouverte, le nez retroussé, les cheveux tombent en mèches ondulées au-dessus des oreilles. En face d'elle une tête de griffon au long cou couvert de cinq écailles, avec un bec au contour ondulé, des oreilles en pointe. Les palmettes sont sommairement dessinées. La surface est partiellement détériorée à l'arrière.

Vers 360-350.

140 Lydia Trakatelli a soutenu une thèse sur ce sujet à l'université de Thessalonique.

141 L'obole de Charon placée dans la bouche du mort est en effet une monnaie du roi Amyntas III, frappée entre 381 et 369. 
Le décorde ce grand lécythe se rattache au « groupe $\mathrm{G}$ » de Beazley, dont l'évolution et la durée d'activité ont été diversement appréciées : cette question est d'autant plus délicate que les vases de ce type ont pu être produits dans d'autres cités qu'Athènes. Pour le décor de mèches en forme de postes le long du bonnet, comparer une péliké d'Aineia en Macédoine, qui a été datée vers 350-340 (Vokotopoulou 1990, p. 88 n 2, pl. 55 a-b).

CP 11. - Tombe à ciste 328 . Ht $13,8 \mathrm{~cm}$. Inv. PIN 3648. Pl. 34e,79d et 84b

Décor polychrome. Cinq languettes sont figurées en bas du col et dix oves sur l'épaule, chacune marquée d'une boule dorée en relief. Sous l'anse, palmette à 18 feuilles, frise d'oves en bas de la panse. Le décor figuré montre un Eros séparé d'une femme assise par un xoanon et un brûle-parfum. Le dieu est agenouillé sur une feuille d'acanthe (traces de peinture rouge) et tient une tige dorée; son corps est peint en blanc, ses ailes sont bleues, cernées d'un filet doré (avec des points dorés sur celle de droite, abaissée), il porte un diadème doré. La femme assise en face de lui tend une tige portant une boule dorée; elle porte un vêtement peint en vert au niveau des hanches et des cuisses (partie inférieure détériorée) ; une boucle d'oreille est figurée par une boule dorée, un diadème est posé sur la tête, les cheveux forment un chignon à l'arrière. Entre les deux personnages se dresse un xoanon, petite statue de culte archaïsante (traces de rouge sur le torse, partie inférieure détériorée), et un brûle-parfum ; devant la tête de la femme, une tige avec une boule et un pendentif dorés.

Vers 360-350.

Bibl. : Hermary, Panayotova 2006, fig. coul. p. 59 ; Hermary 2007, p. 165, fig. 11 ; Panayotova, Reho, Nedev 2009, fig. p. 27.

Dans le cadre d'une étude sur «Aphrodite dans les jardins », E. Langlotz a, le premier, attiré l'attention sur une série de lécythes aryballisques décorés d'Erotes, de femmes et, plus rarement, de personnages masculins associés à une petite statue de culte et, parfois, à un brûle-parfum (Langlotz 1953-54). Même si, dans un cas au moins, le xoanon porte les attributs d'Artémis (Langlotz 1953-54, pl. 7, 1 ; Kahil 1984, n 113a*), la déesse est généralement identifiée avec Aphrodite. Pour les vases attiques de la fin du $\mathrm{V}^{\mathrm{e}} \mathrm{s}$. L. Burn est revenue en détail sur le sujet (Burn 1987, p. 26-32, pl. 12-21) : on notera, en particulier, un lécythe aryballisque d'Oxford qui montre une statue de la déesse entourée de deux grands brûle-parfums, de deux Erotes et de deux femmes faisant un geste d'adoration $\left(A R V^{2} 1325,51\right.$; Delivorrias 1984, n 44*; Burn 1987, p. 31, pl. 13c-d, 14a ); le culte rendu à Aphrodite est ici clairement exprimé. Le thème est repris, avec des variantes, sur une série de lécythes du IV ${ }^{\mathrm{e}}$ s., y compris au Céramique (Schlörb-Vierneisel 1966, p. 52 n $^{\circ}$ 104, Beil. 40, 8 et 41, 1) et en Apulie (CVA Gotha 2, pl. 66 (de Bari) ; Mannino, Roubis 2000, p. 72, fig. 9-11), mais sous une forme simplifiée, sans xoanon ou brûle-parfum. Les tombes d'Apollonia ont probablement livré la série la plus nombreuse, si l'on ajoute aux lécythes trouvés dans les années $1940^{142}$ ceux des fouilles plus récentes, presque tous inédits ${ }^{143}$. Le schéma de base montre Eros face à une femme assise, qui n'est pas spécialement caractérisée comme Aphrodite, avec le petit xoanon de la déesse posé entre eux ; d'autres femmes, un oiseau et, parfois, un homme peuvent compléter la scène, dont la présence d'un thymiatérion renforce éventuellement le sens cultuel ${ }^{144}$. L'association de la statuette et du brûle-parfum se trouve également sur un exemplaire provenant des fouilles plus récentes de Kalfata : Eros, une jambe posée sur une sorte de coffre, reçoit un collier d'une femme ; un petit xoanon est posé entre eux ; à droite, un brûle-parfum et une autre femme, à gauche une femme tenant un tambourin (Baralis, Riapov 2002, p. $202 n^{\circ} 303$ avec fig. coul.; Dimitrov 2004, fig. coul. p. 194 en bas ). Sur le lécythe de la tombe SP 328 la position d'Eros, agenouillé sur une feuille d'acanthe, est tout à fait originale; on comparera cependant un lécythe aryballisque de New York ${ }^{145}$, proche par son style des exemplaires d'Apollonia, sur lequel Eros présente un collier à une femme (Aphrodite ?) assise devant lui : les deux personnages sont séparés par une grande colonne d'acanthe surmontée d'un brûle-parfum.

Une variante montre le xoanon entre deux têtes féminines, comme sur plusieurs lécythes aryballisques d'Apollonia (Ivanov 1948, pl. 41-42; Cat. Bruxelles $\mathrm{n}^{\circ} 303$ ) et sur des exemplaires trouvés à Olynthe (Robinson 1950, pl. $142 \mathrm{n}^{\text {os }} 86$ et 88, pl. 84 et 101 ; Oenbrink 1997, p. 378-379 n ${ }^{\text {os }}$ B 20-B 21, pl. 24), à Akanthos (Kaltsas 1998, p. 31-32, pl. 11), à Volos ${ }^{146}$ et sur un vase de provenance inconnue conservé à Francfort (Delivorrias 1984, $\mathrm{n}^{\circ} 53^{*}$ ). Dans une autre variante les deux têtes sont séparées par un brûle-parfum (CVA

142 Ivanov 1963, p. $96 n^{\circ} 38$, pl. 20-22, et p. $100 n^{\circ}$ 50, pl. 41-42; Reho 1990, p. 112-113 n ${ }^{\text {os }} 244,247$ (pl. XXIII) et 250 ; ce dernier vase, conservé à Würzburg, provient de l'ancienne collection Margaritis, avec la provenance «Apollonia, Thrakien »: Langlotz 1932, n 598, pl. 208.

143 Voir cependant Cat. Bonn 2004, p. 107 nos 175-177 ; Dimitrov 2004, fig. p. 193-199 ; Cat. Bâle 2007, p. 155 n 114e.

144 Sur un lécythe des fouilles de Venedikov (tombe 624), Eros dépose des grains d'encens sur le thymiatérion, entre deux femmes assises et près d'un oiseau : Ivanov 1963, p. 98 n ${ }^{\circ} 45$, p. 33-34.

145 Metropolitan Museum of Art 1972.118.149, inédit. Le fait qu'il provienne de la collection Stroganoff indique qu'il pourrait avoir été trouvé sur un site de la mer Noire, peut-être Apollonia même.

146 Oenbrink 1997, p. 379 n B 22, pl. 24. Je remercie Z. Kotitsa pour cette référence. 
Berkeley 1, pl. 51, 2 [d'Athènes ?] ; Robinson 1950, p. $142 \mathrm{n}^{\circ} 87$, pl. 101). Comme on l'a vu, le schéma le plus courant est cependant celui du « bétyle » entre les deux têtes féminines.

CP 12. - Tombe à fosse SP 330. Inv. PIN 3748. [Non disponible au moment de l'étude].

CP 13. - Tombe à ciste SP 334 . Ht 10,3 cm. Inv. PIN 3767. PI. 39b

Fragmentaire, surface très détérioré, décor presque entièrement effacé.

Le contexte indique une date vers 390-380.

CP 14. - Tombe à fosse SP 340 . Ht $20 \mathrm{~cm}$. Inv. PIN 3789. Pl. 43a,79e et 85

En partie restauré. Argile beige orangé, vernis noir de qualité. Décor polychrome. En bas du col languettes en vernis noir, séparées par des filets. Sur l'épaule est figurée une branche portant de longues feuilles pointues, chaque groupe de trois est séparé par deux boules dorées. Frise d'ove en bas de la panse ; petite palmette à la base de l'anse, au-dessous une autre de plus grandes dimensions : une boule dorée est placée à la base de chacune d'entre elles.

La scène figurée montre au centre Aphrodite audessus de la mer - indiquée par une bande sinueuse -, chevauchant un cygne à la tête triangulaire dont la peinture blanche a disparu, comme sur le corps de l'animal : elle n'est plus visible que sur les pattes et les ailes, mais la partie supérieure de celle de gauche est dorée, avec de petits points en relief. La déesse, dont ne voit que le buste, porte apparemment deux vêtements : l'un, de couleur rose, est visible sur le ventre, tandis qu'elle écarte l'autre, de couleur bleue, de sa main gauche levée (il n'est discernable que dans le creux du bras gauche). Elle tient en oblique de la main droite un long sceptre en relief, terminé par un fleuron. Un bracelet doré en léger relief entoure chaque poignet (simple à droite, double à gauche). D'autres bijoux sont figurés par de petites boules dorées : un collier à la base du cou (cinq boules), des boucles d'oreilles et un diadème (trois boules); les ongles portent un vernis de couleur brune. La tête de la déesse dépasse la limite du champ figuré, elle incline son visage souriant de trois quarts vers sa droite; les cheveux, figurés en vernis dilué, sont de couleurs nuancées, à dominante blonde. À droite (zone en partie restaurée) vole un Eros adolescent au corps blanc, ses ailes ont perdu leurs rehauts peints, en dehors du bleu partiellement conservé sur l'aile droite; le haut de ses cheveux et son chignon sont marqués en vernis dilué ; une étoffe avec des rehauts blancs tombe à l'avant et à l'arrière du corps, jusqu'au niveau des hanches; sa main droite tendue tient un objet difficile à identifier, sans doute une sorte de plateau. Devant lui un dauphin saute au-dessus des flots (corps couleur argile, rehauts disparus). À gauche d'Aphrodite vole un autre Eros adolescent, qui se retourne vers la déesse, il tient dans sa main droite tendue un brûle-parfum dont subsistent le pied et un fragment de la tige sous l'extrémité de l'aile gauche. Son corps et le vêtement qui tombe jusqu'au niveau des hanches sont peints en blanc, sur ses ailes restent des traces de peinture bleue, le haut de l'aile droite est dorée, avec des points en relief ; ses cheveux et son chignon sont figurés en argile diluée. Plus loin à gauche un troisième Eros paraît courir sur la mer, main gauche tendue, la droite posée sur la hanche; devant lui flotte son vêtement (couleur argile, rehauts disparus); il reste des traces de peinture bleue sur les ailes accolées; ses cheveux bouclés sont figurés en argile diluée, ils sont entourés d'un diadème représenté par un filet doré, une longue tresse tombe dans le dos. Entre les deux Erotes vole un oiseau aux ailes déployées (couleur argile, rehauts disparus).

Le contexte et le style du décor indiquent une date vers 360-350.

Le thème d'Aphrodite chevauchant une oie ou, plus fréquemment, un cygne est bien connu dans l'iconographie grecque (Delivorrias 1984, p. 96-98), principalement au $\mathrm{IV}^{\mathrm{e}} \mathrm{s}$., sous la forme d'un voyage marin dont le schéma est proche de celui d'Apollon revenant de chez les Hyperboréens. Le fait que la déesse ne soit jamais entièrement nue et porte les insignes de son pouvoir différencie cette scène de celles de la naissance ou du transport dans une coquille, mais on peut penser que cette épiphanie de la déesse a pu aussi évoquer sa naissance dans les flots et son arrivée sur la terre (Böhr 2002, p. 75, avec les références bibliographiques). Une œnochoé à figures rouges de Berlin constitue, vers le début du IV ${ }^{\mathrm{e}}$ s., une tête de série : on y voit Aphrodite debout sur un cygne, encadrée de deux Erotes portant des couronnes, de deux Néréides chevauchant des dauphins, d'Hermès, de Dionysos et deux femmes assises (Delivorrias 1984, n 919*). Deux vases du style de Kertch mis au jour dans la nécropole d'Amphipolis présentent des scènes un peu moins développées : sur une hydrie utilisée comme urne cinéraire la déesse vole au-dessus de deux dauphins - dont un chevauché par un Eros -, entourée de plusieurs personnages ${ }^{147}$; sur une péliké elle est précédée par Hermès, un Eros lui tend une couronne et une femme un collier, un autre personnage ferme la scène à gauche (Delivorrias 1984, $\mathrm{n}^{\circ}$ 928). Une hydrie conservée à Berlin, probablement originaire de Cumes, montre Aphrodite en vol,

147 Le vase n'est pas publié en détail : voir P. Malama, AEMTh, 14, 2000 , p. 64-65, fig. 18 . 
accompagnée d'un Eros, au-dessus de deux dauphins, entourée à gauche de Pan et d'une femme qui s'éloigne en courant, à droite d'Hermès et d'une autre femme, qui s'enfuient eux aussi ${ }^{148}$. La surface plus restreinte des lécythes aryballisques ne permet pas de représenter une scène aussi développée : sur un exemplaire de Berlin, la déesse est associée à un jeune homme assis et - comme ici - à un Eros portant un brûle-parfum ; sur un autre, trouvé à Bari, elle est encadrée de deux Erotes (Delivorrias 1984, $n^{\text {os }}$ 922-923*). Sur un lécythe conservé à Providence, Aphrodite se déplace sur un char tiré par des cygnes, accompagnée d'une femme portant un brûle-parfum et une phiale (ibid., $\mathrm{n}^{\circ} 1212 *$ ). Un cratère attribué au " groupe $G$ », mis au jour dans une tombe de Numana-Sirolo, sur la côte adriatique, montre Hermès courant au-dessus de la mer devant la déesse, dont le bas du visage est voilé ; un Eros vole derrière elle (Landolfi 2000, p. 89, fig. 25). Le thème était déjà attesté à Apollonia par deux lécythes aryballisques à reliefs, l'un, très fragmentaire, trouvé dans les fouilles de Venedikov (Ivanov 1963, p. 117 n $^{\circ} 133$, fig. 51, pl. 52), l'autre, inédit, provenant des fouilles de K. Panayotova. Il l'est maintenant par un autre lécythe aryballisque à figures rouges mis au jour dans les fouilles néerlandaises (tombe 103) : le cygne semble prendre son envol, la déesse est entourée de deux femmes assises ${ }^{149}$. Cette iconographie, clairement associée à Aphrodite Ourania par une stèle inscrite un peu plus récente, provenant de Panticapée, doit probablement être rattachée au culte de « l'Aphrodite Syrienne », maintenant attesté à Apollonia (voir ci-dessus, p. 34), les deux formes de la déesse étant certainement très proches ${ }^{150}$.

Le décor du vase est de grande qualité, l'image de la déesse est particulièrement soignée : noter, en particulier, le vernis de couleur violette qu'elle porte sur les ongles, un détail qui paraît unique dans la céramique attique ${ }^{151}$. Ce n'est pas par hasard si ce lécythe a été trouvé dans une tombe elle-même remarquable dans le contexte de Kalfata: elle contenait le squelette d'une femme d'environ 30-35 ans qui est désignée par le reste

$148 A R V^{2}$ 1483,2; Delivorrias 1984, n 924 ; Böhr 2002, p. 73-75, pl. 48-49, avec une date (vers 330-320) sans doute un peu trop tardive.

149 Docter et al. 2008, p. 156, fig. 6-7. La tombe, datée de 375-350 à partir de ce vase, est considérée comme masculine en raison de la présence d'un strigile (p. 34, fig. 6).

150 Voir sur cette question mon article dans les Actes du colloque sur la mer Noire qui s'est tenu à Istanbul en septembre 2009, sous presse.

151 Je n'ai, en tout cas, pas encore trouvé d'exemple comparable ; voir, pour une période beaucoup plus ancienne, certaines peintures murales de Théra-Akrotiri : Doumas (C.) - The Wall-paintings of Thera. Athènes, Thera Foundation, 1992, p. 141, fig. 104, p. 153154, fig. 117-118. du mobilier qui l'accompagnait comme un personnage important, probablement une prêtresse en raison de la présence d'une clé en bronze (voir le commentaire cidessus, p. 169-170). La qualité du vase et la nature de la scène qui le décorait montrent qu'il avait très probablement été choisi dans une intention précise.

\subsubsection{Avec décor de palmette en figure rouge}

Ce type de lécythe aryballisque, au décor rudimentaire, est extrêmement répandu pendant environ un siècle, de la fin du $\mathrm{V}^{\mathrm{e}}$ à la fin du $\mathrm{IV}^{\mathrm{e}} \mathrm{s}$. Il est difficile d'en retracer l'évolution ${ }^{152}$, les dates proposées dépendent des contextes exposés plus haut.

CP 15. - Tombe à fosse SP 244. Ht $6,3 \mathrm{~cm}$. Inv. PIN 2733. Pl. 17e et 79f

Argile orangée pure. La palmette est figurée légèrement de travers, les feuilles forment un éventail ; de chaque côté un motif en triangle recourbé, à droite une longue coulée rouge.

Le contexte indique une date dans le deuxième quart du $\mathrm{IV}^{\mathrm{e}} \mathrm{s}$.

CP 16. - Tombe à fosse SP 291. Ht 9,6 cm. Inv. PIN 3172. Pl. 24e,79g et 86a

Argile orangée fine, vernis de bonne qualité. Palmette à onze feuilles, trois motifs en triangle sur le côté.

Le contexte indique une date vers 390-380.

CP 17. - Tombe à fosse SP 291. Ht 9,4 cm. Inv. PIN 3173. Pl. 24e, 79b et 86b

Argile orangée fine, vernis de bonne qualité. Palmette à douze feuilles, trois motifs en triangle sur le côté.

Même date.

CP 18. - Dépôt au Nord de SP 297. Ht $3,5 \mathrm{~cm}$. Inv. PIN 3234. Pl. 80a et 86c

D'après le contexte, le vase daterait de la fin du IV ou du début du $\mathrm{III}^{\mathrm{e}} \mathrm{s}$.

CP 19. - Sépulture à crémation SP 316. Inv. PIN 3631. [Non disponible au moment de l'étude]

Une date dans le deuxième quart du $\mathrm{IV}^{\mathrm{e}} \mathrm{s}$. est donnée par le cratère $\mathrm{CP} 46$.

CP 20. - Tombe à fosse SP 320. Ht conservée $4,7 \mathrm{~cm}$, diam. 3,5 cm. Inv. PIN 3698. PI. 29e

Fragmentaire. Probablement vers 350-320, d'après le contexte.

152 Voir cependant Valavanis 1999, p. 196, pl. 27, 3. 
CP 21. - Tombe à fosse SP 332 . Ht $5,5 \mathrm{~cm}$. Inv. PIN 3656a. PI. 86d

Vers le milieu du IV ${ }^{\mathrm{e}} \mathrm{s}$., d'après le contexte.

CP 22. - Tombe à fosse SP 338. Ht $10 \mathrm{~cm}$. Inv. PIN 3776. Pl. 41e, 80b et 86e

En partie restauré. Argile orangée, vernis d'assez bonne qualité. Peut-être une production attique.

Le contexte indique une date dans le deuxième quart ou le milieu du $\mathrm{IV}^{\mathrm{e}} \mathrm{s}$.

CP 23. - Tombe à fosse SP 338 . Ht 9,7 cm. Inv. PIN 3778. Pl. 41d (à dr.) et 80c

En partie restauré. Argile beige, vernis de mauvaise qualité. La palmette est en grand partie détruite. L'argile indique que la fabrication n'est pas attique. Même date que le précédent.

CP 24. - Tombe à fosse SP $343 . \mathrm{Ht} 12 \mathrm{~cm}$. Inv. PIN 3663. Pl. 45f et $86 f$

Forme presque globulaire; grande palmette aux feuilles recourbées.

Vers 400-390 d'après le contexte.

CP 25. - Découverte isolée dans la zone du point $\mathrm{G} 2$. $\mathrm{Ht} 8,3 \mathrm{~cm}$. Inv. PIN 2708. Pl. 80d et 87a

L'embouchure manque. Argile beige friable. Palmette à 12 feuilles entourée par une sorte d'arceau ondulé, motif végétal de chaque côté. Probablement pas attique.

CP 26. - Dépôt DP 15. Ht conservée $9,5 \mathrm{~cm}$, diam. max. 5,5 cm. Inv. PIN 3685. Pl. 57c et 87b

Fragmentaire (embouchure et anse manquent), restauré. Vernis très médiocre. Palmette à quatorze feuilles dans une sorte de double arceau, motif en triangle de chaque côté. Fond du vase percé.

Production probablement attique. Une amphore thasienne trouvée dans le dépôt indique une date dans les années 360 .

\subsubsection{Avec décor réticulé}

CP 27. - Tombe à fosse SP 251. Ht $6,5 \mathrm{~cm}$. Inv. PIN 2717. Pl. 18c

Fragmentaire (l'anse et le fond manquent).

Le contexte n'indique pas de date précise : probablement deuxième moitié du $\mathrm{IV}^{\mathrm{e}} \mathrm{s}$.

CP 28. - Tombe à fosse SP 287. Ht $8,2 \mathrm{~cm}$. Inv. Ma-Sozopol 60 (FR 1.14). Pl. 22f et 81a

Argile orangée pure. Sur le col, languettes blanches alternant avec des lignes verticales de vernis noir, mal disposées. Sur la panse, décor de lignes de vernis noir dessinant un réseau de losanges rehaussés de points blancs, posés au hasard. Il est difficile de dire s'il s'agit d'une production attique ou d'une imitation.

Le contexte indique une date vers 350-340.

CP 29. - Tombe à fosse SP 322. Inv. PIN 3703. [Non disponible au moment de l'étude]

Vers le milieu du $\mathrm{IV}^{\mathrm{e}} \mathrm{s}$., d'après le contexte.

CP 30. - Tombe à fosse SP $326 . \mathrm{Ht} 7,9 \mathrm{~cm}$. Inv. PIN 3641. Pl. 31e et 81b

Argile beige très tendre, vernis noir fragile. L'anse manque. Décor réticulé composé de lignes rouges et de points blancs ; l'anse manque.

Imitation de modèles attiques, le contexte indique une date dans le deuxième quart du $\mathrm{IV}^{\mathrm{e}} \mathrm{s}$.

CP 31. - Tombe à fosse $\mathrm{SP} 327 . \mathrm{Ht} 7,2 \mathrm{~cm}$. Inv. PIN 3733. Pl. 32c

Argile orangée, vernis noir de qualité médiocre sur l'anse et presque tout le col. Décor réticulé irrégulier, lignes noires à rouge sombre, points blancs en grande partie effacés.

Vers 370-350 d'après le contexte.

CP 32. - Tombe à fosse SP 327. Inv. PIN 3734. PI. 32d (à dr.) et 81c

Très restauré. Même date.

CP 33. - Tombe à fosse SP 336 . Ht $9,5 \mathrm{~cm}$. Inv. PIN 3771. Pl. 81d et 87c

Argile beige clair tendre, traces d'engobe rouge, vernis noir écaillé sur le goulot et en haut de l'anse. Sur le col, lignes noires transversales et languettes blanches verticales. Décor réticulé irrégulier, avec des lignes noires à rouge sombre et de nombreux points blancs, presque disparus d'un côté. Série de taches sur le pied.

Le contexte indique une date vers 390-380. Production non attique.

CP 34. - Tombe à fosse SP 338. Ht 9,1 cm. Inv. PIN 3775. Pl. 41d (au centre) et 81e

Argile beige pâle friable. Décor maladroit de lignes noires diluées et de points blancs répartis sans régularité. Le col et le haut de l'anse sont couverts de vernis noir.

Production non attique, deuxième quart ou milieu du $\mathrm{IV}^{\mathrm{e}} \mathrm{s}$. d'après le contexte.

CP 35. - Tombe à fosse SP 338 . Ht $9,5 \mathrm{~cm}$. Inv. PIN 3777. Pl. 41d (à g.) et 81f

Argile orangée fine, assez friable, surface assez soigneusement lustrée. Anse vernie, col allongé avec lignes noires et languettes blanches sous une partie vernie. 
Décor réticulé assez sommaire, les points blancs sont en partie effacés.

Production attique, ou imitation de meilleure qualité que le précédent, même date.

CP 36. - Tombe à fosse SP 338. Ht $11 \mathrm{~cm}$. Inv. PIN 3779. Pl. 41g

Fragmentaire. Même date que les précédents.

CP 37. - Tombe à ciste SP 339. Ht 12,4 cm. Inv. FR 2.4. Pl. 87d

En mauvais état de conservation, restauré.

Vers 380 d'après le contexte.

CP 38. - Dépôt DP 1. Ht conservée $7 \mathrm{~cm}$, diam. max. $5 \mathrm{~cm}$. Inv. PIN 2665a. Pl. 53b

Fragmentaire (manquent l'embouchure et l'anse). Des rangées de points blancs indiquent la présence d'un décor réticulé.

Le contexte indique une date dans le deuxième quart du $\mathrm{IV}^{\mathrm{e}} \mathrm{s}$.

CP 39. - Dépôt DP 6. Ht 8 cm, diam. max. $4,4 \mathrm{~cm}$. Inv. PIN 3367. Pl. 81g et 87e

Argile orangée. Vernis noir sur l'embouchure et le dessus de l'anse (presque entièrement cassée) ; sur le col lignes noires et languettes blanches. Sur la panse décor réticulé irrégulier, points blancs dispersés, taches noires sur le pied.

Production probablement attique, début du $\mathrm{IV}^{\mathrm{e}} \mathrm{s}$. d'après le contexte.

CP 40. - Dépôt DP 24. Ht 5,7 cm. Inv. MA-Sozopol 61. PI. 61c et 81h

Vernis noir sur l'embouchure, le haut du col et l'anse. Trois languettes blanches en bas du col, sur la panse réseau de lignes noires rehaussées de points blancs.

Le contexte indique une date vers 350-340.

\subsection{Lékanis}

CP 41. - Dépôt DP 1, au-dessus de la tombe SP 244. Diam. du couvercle $20 \mathrm{~cm}$, du vase $19 \mathrm{~cm}$ au sommet, $10 \mathrm{~cm}$ à la base; Ht totale 7,2 cm, du couvercle $3 \mathrm{~cm}$. Inv. PIN 2664a et 2664b. PI. 53a, 82a et 88a

Lékanis et son couvercle, fragmentaires. Décor à figures rouges sur le couvercle : deux Erotes volent vers deux femmes en fuite (une troisième manque). Chaque Eros lève la main droite et tient une étoffe de la gauche.

Production attique; le contexte et le style du décor indiquent une date dans le deuxième quart du $\mathrm{IV}^{\mathrm{e}} \mathrm{s}$. (voir le commentaire de CP 7).

\subsection{Oenochoé (chous)}

CP 42. - Dépôt isolé dans la zone du point I 5. Ht 19 cm. Inv. PIN 3678. Pl. 82b et 88b (et p. 137)

Fragmentaire. Décor à figures rouges. Embouchure trilobée, l'attache supérieure de l'anse est légèrement en saillie, une branche de feuilles très minces (olivier ou laurier ?) est figurée autour du col. Le décor figuré est placé au-dessus d'une frise d'oves. Un quadrige court devant un trépied placé sur une petite colonne ionique. Les deux chevaux du centre se regardent, le toupet central de la crinière est relevé ; des pastilles d'argile marquent différents points du harnachement. Le fond du vase est percé.

Vers 350-340.

Il est difficile de préciser le sens de la scène: concours hippique, enlèvement dans un sanctuaire? La forme du vase, les motifs du trépied sur la colonne et du quadrige en course, avec les chevaux du centre tournés l'un vers l'autre, pourraient faire penser à une œuvre de la fin du $\mathrm{V}^{\mathrm{e}} \mathrm{s} .{ }^{153}$, mais, pour les chevaux, la meilleure comparaison est fournie, me semble-t-il, par une amphore panathénaïque de l'archontat de Lykiskos (344-343) (Bentz 1998, p. 175 n$^{\circ} 4.075$, pl. 116). Elle est attribuée au Peintre de Marsyas, comme la très belle tête de cheval d'un grand cratère à figures rouges d'Al Mina (Boardman 1989, fig. 387), qui rivalise brillamment avec la grande peinture de l'époque (tombes dites de Perséphone et d'Eurydice à Vergina). Un chous du Metropolitan Museum of Art de New York, avec Pompé et Dionysos, donne une comparaison contemporaine pour le type du vase (Boardman 1989, fig. 394 ; Picón et al. 2007, fig. 167).

\subsection{Pélikés}

CP 43. - Tombe à ciste SP 339. Ht 7,9 cm. Inv. FR 2.35. Pl. 42e

Reste une partie du col et de la panse. Sur la partie inférieure du col, frise d'oves alternant avec des points. Du décor de la panse ne subsiste que la tête d'un personnage masculin.

Vers 380 d'après le contexte.

CP 44. - Trouvaille isolée près du point $\mathrm{G} 2$ (29-92002). Ht cons. $13 \mathrm{~cm}$, diam. de l'embouchure $13,5 \mathrm{~cm}$. Inv. PIN 3161. PI. 82c et 89a

Seule reste la partie supérieure. Décor à figures rouges : A) Sous une frise de six oves deux jeunes gens

153 Voir par exemple Burn 1987, pl. 5b (quadrige), et Moore 1997, pl. $72 n^{\circ} 676$ et $75 n^{\circ} 714$ (trépied sur colonne ionique). 
drapés se font face, celui de gauche tient un objet ovale décoré d'une croix et de quatre points. B) Sous une frise de quatre oves un jeune homme est debout vers la droite, une boule est figurée sous sa main droite.

Le contexte indique une date vers 370-350, qui convient au style du décor.

\subsection{Pyxis}

CP 45. - Tombe à fosse SP 297. Ht avec les anses $11,5 \mathrm{~cm}$, diam. du couvercle $6 \mathrm{~cm}$. Inv. PIN 3240. Pl. 26c, 82d et 89b

Argile beige très pure, surface lustrée. Vase à épaule très marquée, d'où partent deux anses verticales. Décor en peinture noire à beige clair, irrégulièrement disposée : autour du pied et à la base de la panse large bande mal peinte et bandeau plus clair. Sur la panse, décor de branches d'olivier (?) et de points. ; deux traits à la base de l'épaule. Branches et points aussi entre les anses, marquées d'un trait de peinture dans la partie supérieure. Couvercle soigneusement lustré, sur le rebord lignes plus ou moins claires, comme à la base du bouton de préhension et sur le bouton lui-même.

Vers 300-280.

\subsection{Cratère en cloche}

CP 46. - Sépulture à incinération SP 316 . Ht $33,8 \mathrm{~cm}$, diam. à l'embouchure $34,2 \mathrm{~cm}$. Inv. PIN 3628. Pl. 13d, 82e et 90

Le vase servait d'urne cinéraire, avec pour couvercle un plat à poisson. Décor à figures rouges. Une branche d'olivier ou de laurier fait le tour du vase sous la lèvre. Décor figuré, face $\mathrm{A}$, scène dionysiaque, face $\mathrm{B}$, jeunes gens drapés. Une palmette sous chaque anse.

A) Un personnage en habit oriental chevauche un griffon qui bondit vers la droite; sa main droite tendue passe derrière l'oreille du monstre. L'homme est vêtu d'un pantalon et d'une tunique à manches longues, il porte un bonnet à l'arrière du crâne, une longue mèche torsadée tombe sur le côté. L'aile du griffon est rectiligne, un motif de postes la décore en haut. Une Ménade court devant ce groupe, la tête retournée; elle tient devant elle un très grand tambourin; elle est vêtue de deux chitôns, l'un, peint en blanc, visible entre les pieds, les plis de l'autre sont marqués en vernis noir, les cheveux et le chignon sont figurés en argile diluée. Devant elle un personnage est assis en amazone sur un fauve (léopard ou guépard plutôt que panthère) bondissant vers la droite; sa tête est retournée, la main droite est levée vers le visage ; il porte un vêtement long transparent (rebords et plis marqués en vernis noir), arrondi au niveau du sein gauche : il s'agit d'une femme, même si ses cheveux qui tombent du côté droit cachent en grande partie le menton, à la manière d'une barbe ; une autre nappe de cheveux tombe sur l'épaule gauche. Dans la partie gauche de la scène, derrière le griffon, se tient un Silène barbu, main gauche levée : il a une oreille animale et porte une pardalide sur le bras gauche.

B) Trois jeunes gens drapés sont figurés de façon sommaire, celui de droite est appuyé sur un bâton, celui du centre est retourné vers celui de gauche. Deux objets ronds décorés d'une croix séparent les personnages.

Vers 370-350.

Pour la période qui nous concerne, Maria Reho ne citait, à côté de neuf exemplaires provenant de la nécropole d'Apollonia-Harmanité, que trois cratères en cloche trouvés à Kalfata ${ }^{154}$; le Peintre du Thyrse noir et son cercle auraient décoré l'essentiel de ces vases (huit sur douze). Le cratère de la tombe 316 constitue donc un complément intéressant, avec sans doute quelques autres exemplaires inédits issus des fouilles récentes. Sa forme est très proche de celle des cratères de Harmanité, mais, alors que ceux-ci montrent des scènes de banquet ou des groupes dionysiaques assez banals (Zanewa 1982), l'image de la face principale fait ici preuve de plus d'originalité : il semble même que l'assemblage, dans cette scène de poursuite, de personnages par ailleurs bien attestés dans le «style de Kertch » ne trouve pas d'équivalent exact. On notera cependant que sur une péliké trouvée précédemment dans les fouilles de Kalfata, la femme qui chevauche une panthère est très proche de celle du cratère (Cat. Bonn 2004, p. $106 \mathrm{n}^{\circ} 170$ («Dionysos »); Dimitrov 2004, fig. p. 186 ; Cat. Bâle 2007, p. 156 $\mathrm{n}^{\circ} 114 \mathrm{~g}$ ). Ce type de décor rappelle les sujets traités par les peintres du groupe $\mathrm{G}$ ( Griffon group » de Beazley), comme le grand lécythe aryballisque de la tombe 328 . Ce cratère et ceux d'Apollonia qui ont été précédemment évoqués sont sans doute chronologiquement très proches. Cependant, le contexte de nos fouilles indiquerait une date antérieure au milieu du $\mathrm{IV}^{\mathrm{e}} \mathrm{s}$., alors que Maria Reho proposait les années 360-340. Une péliké trouvée dans le grand tumulus de Vergina, décorée de Dionysos (?) à cheval sur un griffon et poursuivant un Satyre est sensiblement plus récente, vers 330 (Drougou 2005, p. 90-92, fig. 96).

154 Reho 1990, p. $93 \mathrm{n}^{\circ}$ 137, pl. X (ARV 1432, 13 : P. du Thyrse noir ; Ivanov 1948, p. 31-33, fig. 29-31), p. 94 n$^{\circ} 145$, pl. XIII ( $A R V^{2}$ 1693, 2bis : P. de Ferrare T 463 ; Ivanov 1963, p. 168-169, pl. 89-92) et p. $95 \mathrm{n}^{\circ} 148$ (Ivanov 1963, p. $176 \mathrm{n}^{\circ}$ 397, fig. 72, pl. 84). 


\subsection{Hydrie}

CP 47. - Sépulture à crémation SP 345, avec les restes d'un individu gracile. Production attique, attribuable au « groupe d'Apollonia ». Ht $42 \mathrm{~cm}$, larg. au niveau des anses $32 \mathrm{~cm}$, diam. de l'embouchure $15 \mathrm{~cm}$, diam. du pied $15 \mathrm{~cm}$. Inv. PIN 3664. Pl. 16 et $91-92$

Pied mouluré (traces de peinture rosâtre dans la « scotie ») dont le vernis est partie effacé ; sur le fond lettres incisées EY $\Delta \mathrm{PI}$, plus loin un signe difficile à lire. À $13,5 \mathrm{~cm}$ du bas, une frise d'oves, haute de $1,6 \mathrm{~cm}$, marque la limite inférieure du décor figuré ; sur le vernis devant la palmette de l'anse de gauche (pour le spectateur), des traces d'autres oves ont été laissées par un autre vase au moment de la cuisson. Le vernis est en mauvais état sous les deux autres anses. La largeur des anses horizontales $(9,5 \mathrm{~cm})$ est égale à la hauteur de l'anse verticale, qui est légèrement décalée vers l'anse de gauche pour laisser plus de place à l'Eros qui grimpe dans les rinceaux.

Le décor de l'arrière, autour de l'anse verticale, se compose d'une palmette à 18 feuilles au dessin assez négligé, d'une volute et de demi-palmettes qui encadrent une grande palmette à 22 feuilles, posée sur une double volute. À gauche le motif végétal se développe vers l'anse horizontale sous la forme de deux palmettes placées tête-bêche et d'un quart de palmette ; la surface est détériorée. À droite un Eros adolescent grimpe dans un rinceau à quatre volutes terminé par une feuille ; son genou droit est levé, sa main droite tient le rinceau, la gauche est posée sur le genou ; son visage est détérioré, ses ailes ont été restaurées. Derrière lui sont peintes deux grandes palmettes placées presque tête-bêche, celle du haut (27 feuilles) prolonge le rinceau de l'Eros, celle du bas compte 21 feuilles. Sous chaque anse horizontale une palmette à 19 feuilles posée sur des rinceaux terminés par des feuilles.

À l'avant et sur les côtés, la scène figurée est surmontée d'une tige en barbotine dorée à laquelle sont suspendus des baies - parfois accrochées à de petites branches -, deux grappes de raisin, des tiges supportant des fruits (?), un motif en faucille et un autre difficile à identifier.

La scène figurée occupe la plus grande partie de la panse. Au centre, un «couple» est assis sur un rocher, devant un petit arbre dont on voit le sommet; ses branches sont dénudées, mais portent quatre boules dorées (une cinquième est un peu décalée). Le plus grand personnage porte sur ses genoux un personnage nu, levant au-dessus de sa tête une étoffe que le petit personnage tient de la main gauche et ramène devant son sexe. Le grand personnage est vêtu d'un chitôn à manches longues décoré de petits cercles qui couvre presque entièrement les pieds, tournés vers la droite (pour le spectateur) ; l'extrémité de la manche droite est marquée par deux ourlets. On ne voit que le départ en oblique de son bras gauche. Son visage est tourné de trois quarts vers sa gauche, la tête et le regard sont légèrement levés; la bouche et le menton sont détériorés. Le crâne est couvert par un foulard surmonté d'une sorte de bandeau bouffant ; deux longues tresses tombent sur la poitrine et deux mèches devant les oreilles, une petite boule en barbotine décore le lobe de l'oreille droite. Le personnage assis sur ses genoux a les jambes croisées vers la gauche. Son corps, entièrement nu, est peint en blanc, la surface est détériorée, surtout sur le visage ; la main droite tient l'étoffe devant le sexe, un bracelet est passé autour du poignet. La tête est tournée de trois quarts vers sa droite, elle est légèrement inclinée vers le bas ; l'œil gauche, en partie conservé, est surmonté d'une épaisse paupière. La coiffure est composée de mèches ondulées qui couvrent les oreilles et sont relevées au centre du crâne.

À gauche du «couple» une danseuse se dirige vers la gauche, mais elle se retourne vers les deux personnages. Ses pieds reposent sur la pointe, son vêtement flottant couvre les bras. Elle porte un voile qui couvre son nez et sa bouche, un diadème composé de 10 boules de barbotine est posé sur ses cheveux courts ondulés. Au-dessus d'elle un Eros en vol se dirige en oblique vers le «couple »; son visage est détérioré, son corps nu est peint en blanc, un himation est posé sur son bras gauche, ses ailes sont dorées ; il tient un objet arrondi avec un pendentif, très probablement un collier. À droite du couple une autre danseuse, assez détériorée, est dans la même attitude que la précédente, mais ses pieds sont placés plus haut ; sa main gauche est placée au-dessus de la poitrine, elle porte une bague à l'annulaire ; le bas du visage est voilé, le regard est clairement dirigé vers le «couple»; elle porte un diadème composé de six boules de barbotine, ses cheveux sont bouffants, ils forment un chignon à l'arrière. Un Eros est en vol derrière elle, en direction du « couple » (haut du corps et visage détériorés) ; nu et peint en blanc, il tient un collier à trois boules ; ses ailes sont dorées, celle de droite, très longue, a une position bizarre.

Plus loin sur la gauche, au-dessus d'un canard qui regarde le «couple», se tient une danseuse, les pieds placés haut ; entièrement drapée dans un vêtement flottant, elle lève le bras droit, le bras gauche est plié au niveau de la hanche. Sa tête, de profil, est renversée en arrière à l'horizontale, le bas du visage est voilé, les yeux sont levés vers le ciel. Elle porte un bijou en forme de boule sur l'oreille gauche et autour du crâne un diadème terminé par une boule. Sur la partie droite de la scène une joueuse d'aulos est assise sur un tabouret dont trois pieds moulurés sont visibles. Tournée de profil à gauche, 
elle porte un vêtement long (surface détériorée); on ne distingue de son visage que sa joue gonflée ; ses cheveux, qui tombent dans le dos, sont coiffés en côtes de melon à l'arrière d'un diadème torsadé en relief, doré ; elle porte un bracelet au poignet gauche, un collier de chien à sept boules et probablement un autre collier à trois boules. À l'extrême droite une femme, placée nettement plus haut, danse et joue du tambourin. Elle se dirige vers la droite, mais retourne la tête; une partie de son torse est dénudée, son pied droit, nu est figuré presque de face; elle lève un tambourin qu'elle frappe de la main droite ; elle porte un bracelet au poignet et un collier de chien à sept boules; son visage, de profil, est incliné vers le bas, ses cheveux flottent sur la nuque, son diadème est uniquement peint, contrairement aux autres.

Vers 370-360.

Bibl. : Hermary, Panayotova 2006, p. 61 et fig. p. 63 ; Panayotova, Riapov, Baralis 2006, p. 109, fig. 8-9; Hermary 2007, p. 165, fig. 8-9 ; Docter et al. 2008, p. 10, fig. 7 ; Guldager Bilde 2008, p. 119, fig. 5 ; Panayotova, Reho, Nedev 2009, fig. p. 30-31.

La scène évoque une fête dans un paysage marqué par un arbre, en l'honneur d'un « couple » ou du personnage nu sur les genoux de l'autre. Le contexte amoureux est indiqué par les deux Erotes en vol et renforcé par la présence à l'arrière du vase d'un troisième Eros, dont la position sur le rinceau végétal n'a pas vraiment d'équivalent dans la céramique attique à figures rouges. Le fait que les danseuses soient voilées constitue un élément original de cette fête, mais l'attention est d'abord attirée par le groupe central, avec le grand personnage habillé à l'orientale portant sur ses genoux un plus petit personnage nu.

Le motif est attesté à Athènes dans le dernier quart du $\mathrm{V}^{\mathrm{e}} \mathrm{s}$. dans différentes scènes : sur la frise de l'Erechtheion pour un jeune garçon assis sur les genoux d'une femme (Holtzmann 2003, p. 168 fig. 153), pour Hélène qu'Aphrodite persuade d'aimer Pâris (Burn 1987, pl. 45a ; Kahil 1990, no 140*), ou encore sur une célèbre hydrie du Peintre de Meidias figurant Paidia - l'Enfance, figurée comme une grande jeune fille - assise sur les genoux d'Hygieia, la Santé ${ }^{155}$. Vers le début du IV ${ }^{\mathrm{e}} \mathrm{s}$. il est repris pour Eros assis sur Aphrodite ${ }^{156}$, mais ensuite, plus que le schéma du couple amoureux - avec la femme immobile sur les genoux de l'homme (Schefold 1981, p. 287

155 Burn 1987, p. 33, pl. 23b. Une œnochoé de l'ancienne collection Vlastos présente une version probablement parodique de ce type de groupe (avec deux hommes), dans un contexte théâtral : Hughes (A.) - Oxford Journal of Archaeology, 25, 2006, p. 413-443.

156 Miroir en bronze provenant d'Erétrie: Delivorrias 1984, n 874*; Schwarzmaier 1997, p. 243 Kat.19 (daté vers 390). fig. 409 : vase plastique, la femme est entièrement nue) ou accrochée à son cou pour l'embrasser (Schwarzmaier 1997, pl. 20, 1-2 : miroirs en bronze) - c'est celui de la fille assise sur les genoux de sa mère qui se diffuse assez largement, en Italie du Sud, en Etrurie (avec une jeune fille nue) et en Grèce : ainsi pour Déméter avec Koré/Perséphone, comme sur un lécythe aryballisque trouvé dans les fouilles plus anciennes d'ApolloniaKalfata (Reho 1990, p. 110 n $^{\circ}$ 231, pl. XX-XXI, voir ci-dessous), pour Léda et la jeune Hélène ${ }^{157}$, ou encore Hécube et Iole et, peut-être, Hécube et Polyxène (Jucker 1986, p. 129 fig. 3 et 133 fig. 6: miroirs étrusques). Un fragment de cratère d'Oxford, trouvé à Al-Mina, constitue un cas particulier (Metzger 1965, p. 52-53, pl. XXV en bas ) : la femme assise, dont le haut du corps manque, tient sur ses genoux un petit personnage vêtu d'une tunique courte bariolée et chaussé de bottines; cette tenue ne convient pas pour Perséphone qui, en fait, est figurée à gauche tenant deux torches; un guerrier est debout à gauche, un autre personnage masculin à droite. L'identification de «l'enfant» a été discutée : Metzger l'interprétait comme Dionysos, M. Tiverios comme Artémis, sans doute à juste titre ${ }^{158}$. On peut se demander si, dans le cas de l'hydrie d'Apollonia comme dans d'autres, il ne s'agit pas plutôt d'un mortel placé sous la protection d'une divinité, sans doute pour symboliser la préparation au mariage (voir Mandel 1999, p. 231-232). Un vase plastique fragmentaire offert dans le sanctuaire d'Artémis Mounychia au Pirée pourrait en donner un exemple, à peu près contemporain de l'hydrie (Palaiokrassa 1991, p. $165 \mathrm{n}^{\circ}$ 12, pl. 45), et des reliefs en terre cuite qui imitent des couvercles de miroir en bronze apportent des témoignages intéressants pour le début du III $\mathrm{s} .{ }^{159}$ : sur l'un d'entre eux, une femme de petite taille, entièrement nue, est assise sur une plus grande femme qui la couvre en partie de son voile, tandis qu'au-dessus vole un Eros tendant une bandelette et qu'à côté se tient une autre femme (Peithô ?) ; l'oiseau posé sur le sol est certainement un paon qui désigne comme Héra, déesse protectrice du mariage, la grande femme assise.

L'exemple le plus proche du vase d'Apollonia est cependant, à la fois pour le « couple » central surmonté d'un Eros, les danseuses voilées et la joueuse de crotales, une hydrie à figures rouges dite provenir d'Egypte : les

157 Jucker 1986, p. 133 fig. 7 (miroir étrusque).

158 Tiverios 2004, p. 156, pl. 38, 2. Callimaque, au siècle suivant, évoque la petite Artémis assise sur les genoux de son père (Hymne à Artémis, 4-5).

159 Hermary $1986, n^{\circ} 833^{*}$ (l'interprétation de la femme comme Aphrodite doit être abandonnée) ; Schwarzmaier 1997, p. 346 Kat. 277-278 et 349 Kat. 286, pl. 35, 1-2 (datés vers 280). 


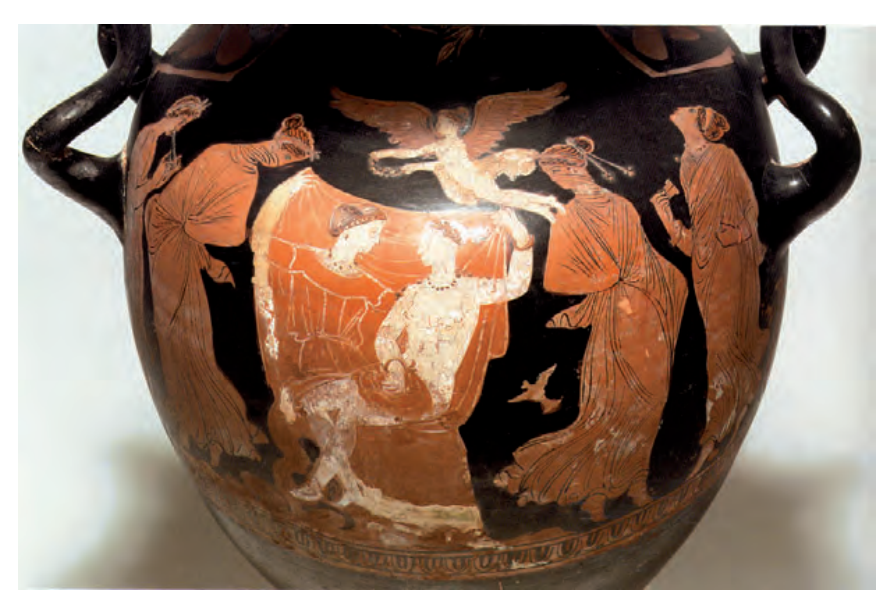

Fig. 66. Hydrie attique à figures rouges.

D'après H. Mielsch, Das Akademische Kunstmuseum. Antikensammlung der Universität Bonn, pl. 23.

deux femmes tendent un voile derrière elles, celle qui est nue cache son sexe par un pan d'étoffe (fig. 66) ${ }^{\mathbf{1 6 0}}$. Il s'agit très probablement d'Aphrodite et d'une future mariée, comme l'indique aussi U. Mandel (1999, p. 237 : «Aphrodite und eine mythische Braut auf dem Schoß»). Cette scène, ajoutée à celles qui figurent sur les imitations de miroir, apporte en tout cas une indication décisive pour définir le sexe des deux personnages centraux de l'hydrie d'Apollonia : il s'agit certainement de deux femmes et la plus grande est une divinité.

Des publications récentes ont mis en évidence, pour une époque proche de celle qui nous occupe, les liens entre les représentations de femmes nues et les divinités associées au mariage ou à ses phases préparatoires. Ainsi, parmi les terres cuites consacrées à Artémis découvertes dans les nouvelles fouilles françaises de Claros figurent une série de femmes nues assises qui ne sont pas des «poupées » au sens de jouets, mais des consécrations de jeunes filles parvenues à la puberté et, donc, promises au mariage (Dewailly 2007, p. 148-150, fig. 9). Le même type d'offrande est attesté à l'Artémision de Dyrrachion (Muller, Tartari 2006, p. 85, fig. 13), et il faut rappeler que la nudité caractérise aussi certaines des filles représentées sur les cratérisques de l'Artémision de Brauron, où elles reçoivent une initiation relative au passage à l'état nubile et, donc, au mariage ${ }^{161}$. On constate que des fragments de «poupées» nues ont

160 Cette œuvre ne semble pas avoir été publiée en détail : elle est reproduite dans le petit catalogue de H. Mielsch, Das Akademische Kunstmuseum. Antikensammlung der Universität Bonn, s. d., p. 72-73.

161 Pour les représentations voir Kahil 1965, p. 21, pl. 7, 3 et 5, et Kahil 1977, fig. B et 3, pl. 19. Pour le lien entre le culte et l'initiation au mariage, voir Gentili, Perusino 2002 et Lippolis 2005. En Attique, des « poupées » nues sont également offertes à Artémis Mounychia : Palaiokrassa 1991, p. 120-121, pl. 21. aussi été mis au jour à l'Heraion de Samos (Isler 1978, p. 83-84 $\mathrm{n}^{\text {os }} 61-74, \mathrm{pl} .42$ ) et dans d'autres sanctuaires de déesses matronales. D'autres figurines de ce type ont été déposées dans des tombes : un des plus beaux exemples provient de Tarente (Mollard-Besques 1954, p. $124 \mathrm{n}^{\circ} \mathrm{C}$ 249, pl. 88 : la femme tient une demi-grenade dans la main droite).

Ainsi, il est très vraisemblable que la jeune fille nue, qui cache son sexe avec pudeur, soit présentée comme si elle était promise à un mariage, heureuse perspective fêtée par les danseuses, les musiciennes et, naturellement, les Erotes apportant des colliers. Le fait que les danseuses soient voilées n'est certainement pas indifférent. En attendant les conclusions d'une étude actuellement en cours ${ }^{162}$, il faut noter qu'un parallèle important est fourni par une hydrie du British Museum $\left(A R V^{2}\right.$ p. 1482, 1 ; CVA British Museum 6, pl. 96, 4), au décor stylistiquement très proche, sur laquelle est figurée la fête des Adonies : les danseuses voilées y figurent donc dans un contexte à la fois religieux et funéraire, celui de l'amour entre Aphrodite et Adonis, brisé par la mort prématurée du jeune homme. Le lien entre danse voilée musique et cérémonie funéraire est clairement exprimé dans le décor d'un vase campanien à figures rouges qui montre sur une face une scène de prothésis (une défunte pleurée par trois femmes debout), sur l'autre deux danseuses, dont le menton et la bouche sont couverts, entourant une joueuse de tympanon (Schauenburg 2003, p. 33-35, fig. 87a-c et II-V).

L'autre particularité, plus frappante, est constituée par la tenue de la grande femme assise, dont le vêtement à manches longues souligne la nature " orientale». On peut se demander si, dans la mesure où ce vase provient d'une ville grecque installée en Thrace pontique, cette tenue ne désigne pas une divinité thrace : cela impliquerait que le motif a, dans ce cas, été adapté par le peintre de vase athénien au contexte auquel il était destiné, alors que, sur le lécythe aryballisque du même « groupe d'Apollonia » trouvé dans les fouilles de Venedikov, le motif de Perséphone assise sur les genoux de sa mère restait intégré dans une thématique traditionnelle à Athènes. J'ai traité ailleurs, à partir d'exemples pris dans la céramique attique du $\mathrm{V}^{\mathrm{e}} \mathrm{s}$., la question du transfert des formes et des images entre la Grèce et le monde thrace (Hermary 2010) : la découverte à Apollonia et sur un site proche de deux pichets de forme locale décorés de guerriers thraces est un élément particulièrement frappant. Le fait que notre hydrie, décorée d'une jeune fille nue sur les genoux d'une divinité orientale ou thrace, ait été utilisée comme urne cinéraire pour un défunt « gracile »

162 Thèse sur les femmes voilées - en particulier les danseuses préparée sous ma direction, à Aix-en-Provence, par Nathalie Martin. 
dans une ville grecque de Thrace pontique ne soit sans doute rien au hasard, et l'on peut supposer que cette personne était une jeune fille d'un certain rang social, décédée avant le mariage. La question du lien entre l'usage funéraire de certaines hydries et le décor qu'elle porte mériterait une plus large discussion, comme le montre, entre autres, le commentaire par V. Sabetai (2006b, p. 15-29) de plusieurs exemplaires conservés au musée Bénaki à Athènes: elle note, par exemple, que « the rape of a youth by Eos can be interpreted as a metaphor of premature death. The subject-matter seems pertinent for the decoration of a vase offered to an aoros, a dead person of a special age-class » (ibid., p. 16); l'image la plus frappante est cependant celle d'une hydrie recomposée à partir d'un fragment conservé au Musée National d'Athènes qui montre, exactement comme sur les lécythes à fond blanc, la défunte près de sa stèle funéraire surmontée d'un grand lécythe et deux femmes qui apportent des vases à parfum (ibid., p. 24, pl. 11 et pl. I [photomontage]).

On a envisagé plus haut la possibilité que certains vases à figures rouges aient été fabriqués sur place ou dans la région. En ce qui concerne l'hydrie, la présence sous le pied d'une marque commerciale indique très probablement que le vase a été expédié depuis Athènes : toutefois, s'il s'agit d'une commande précise, cela suppose que les restes incinérés du défunt n'ont été définitivement enfouis qu'après un certain délai. Le graffite $\mathrm{EY} \Delta \mathrm{PI}$ gravé sur le fond donne le nom abrégé du vase, $\mathrm{Y} \Delta \mathrm{PIA} /$ « hydrie », précédé d'un epsilon difficile à interpréter : il ne s'agit sans doute pas du chiffre 5, qui serait plutôt marqué $\Pi$ et serait placé après le nom du vase pour indiquer son prix ou la quantité d'hydries transportées. Ce type de marque commerciale est bien connu sur des hydries attiques à figures rouges qui datent principalement du $\mathrm{V}^{\mathrm{e}} \mathrm{s}$. et proviennent en majorité d'Étrurie, d'Italie du Sud ou de Sicile ${ }^{163}$.

La comparaison du décor végétal et figuré avec celui des vases attribués par Beazley au "groupe d'Apollonia », en particulier l'hydrie du British Museum déjà citée, incite à attribuer le vase à ce même atelier attique, actif dans les années 370-350. La place prise par Apollonia du Pont dans la diffusion des vases de ce groupe apparait de plus en plus importante, en particulier pour les lécythes aryballisques (voir ci-dessus) et justifie le nom donné par Schefold, puis Beazley. La question devrait être reprise plus largement, certains autres vases découverts récemment à Apollonia apportant des éléments intéressants.

163 Johnston 1979 , p. 165, et 2006, p. 160. Voir aussi D. Williams, $R A$, 1996, p. 228-229, fig. 1, et A. Romualdi, Ostraka, 9, 2000, p. $354-355$, fig. 1 .

\section{Les céramiques à vernis noir}

\subsection{Hydrie}

Cette forme, peu fréquente dans le répertoire de la céramique attique à vernis noir ${ }^{164}$, est représentée par un seul exemplaire provenant de l'important dépôt DP 27 près de SP 332, une des sépultures du secteur central que nous avons attribuées à la phase 3 d'occupation du site. Il s'agit d'un vase de petites dimensions, à col allongé et panse ovoïde, qui reproduit assez fidèlement les proportions des grandes hydries à figures rouges et à vernis noir du deuxième quart ou du milieu du $\mathrm{IV}^{\mathrm{e}} \mathrm{s} .{ }^{165}$. Les parallèles les plus proches se trouvent dans le matériel d'Olynthe, où l'on trouve plusieurs petites hydries similaires à vernis noir (dont aucune toutefois ne présente un décor de godrons sur la panse) ${ }^{\mathbf{1 6 6}}$, ainsi que quelques exemplaires à figures rouges, de dimensions identiques ou légèrement supérieures, décorés de représentations schématiques d'une tête féminine ou de scènes très simples à un ou deux personnages ${ }^{167}$. Les dates proposées par D. Robinson pour l'ensemble de ces vases sont comprises dans la première moitié du $\operatorname{IV}^{\mathrm{e}} \mathrm{s}$. De même,

164 Voir à ce sujet les remarques de B. Sparkes, dans Sparkes, Talcott 1970, p. 53. Selon le savant américain, les hydries à vernis noir sont rares avant la fin du $\mathrm{V}^{\mathrm{e}} \mathrm{s}$. av. J.-C. : à partir de ce moment-là, et tout au long du siècle suivant, leur production s'intensifie et se trouve attestée par plusieurs vases de dimensions différentes (ibid., notes 2-3 avec bibliographie). Cependant, nous devons préciser qu'elle reste fort secondaire par rapport à celle des formes réservées exclusivement au vernis noir, comme le bolsal, la coupe-skyphos, la coupe-canthare, le canthare, les différents types de bols et de coupelles etc., qui constituent l'essentiel des exportations attiques. Il est intéressant d'ailleurs de constater que, dans le riche matériel de l'Agora d'Athènes, les hydries à vernis noir ne sont représentées que par sept exemplaires (dont deux incertains) pour l'ensemble de la période $\mathrm{VI}^{\mathrm{e}}-\mathrm{IV}^{\mathrm{e}}$ s. av. J.-C. (ibid., p. 239, nos 45-51, fig. 20, pl. 3), ce qui semble suggérer qu'elles étaient très peu utilisées sur le lieu même de leur production.

165 Pour les modèles à figures rouges, voir surtout la grande hydrie du Groupe d'Apollonia provenant de SP 345 (CP 47), ainsi que la liste de vases contemporains proposée dans Schefold 1934, p. 138 ; pour le vernis noir, cf. l'hydrie de Toledo dans Boulter, Luckner 1976, p. 38, pl. 59 et 60, 2.

166 Robinson 1933, p. 204-205, $\mathrm{n}^{\text {os }}$ 663-665, pl. 162 ; Robinson 1950 , p. 204-205, nos 246-249, pl. 142-145. Deux autres petites hydries à vernis noir, qui semblent antérieures à notre exemplaire, proviennent de la nécropole du Céramique à Athènes: SchlörbVierneisel 1966, p. 63, n 114.1, pl. 45, $4:$ milieu du premier quart du IV e s. ; Knigge 1966, p. 127, n 10, fig. 15, pl. 70.4 : vers 390. Au tout début de la série se situent quelques vases de la Fosse de la Purification de Rhénée et d'Olynthe, qui doivent dater des années 430-400 : Dugas 1952, p. 56, n ${ }^{\text {os }} 133-135$, pl. 39, 41 ; Robinson 1933, p. 204, n ${ }^{\text {os }} 661-662$, pl. 162.

167 Robinson 1933, p. 118-119, 129, 149, n ${ }^{\text {os }} 139-140,149,262$, pl. 84, 88, 118 ; Robinson 1950, p. 93-96, n 42-45, pl. 57-59. 
on notera de fortes similitudes entre VN 1 et une série de petites hydries à palmette dont l'une, datée du deuxième ou du troisième quart du $\mathrm{IV}^{\mathrm{e}} \mathrm{s}$. par $\mathrm{T}$. Ivanov, provient des fouilles de la nécropole de Kalfata en 1946-1949 ${ }^{168}$.

Dans le cas de notre hydrie, une date vers le milieu du $\mathrm{IV}^{\mathrm{e}} \mathrm{s}$. paraît plausible, compte tenu de la position stratigraphique de DP 27 et SP 332 sous le remblai US 2/501, daté par des timbres amphoriques dans les années 340320 av. J.-C, au même niveau que SP 264 et 329 qui ont livré des vases attribuables à la période 360-350 (cf. en particulier VN 39, 40, 74a). Notons également la découverte dans le même dépôt d'un pied appartenant à une coupe-canthare à vasque hémisphérique dont la datation ne devrait pas non plus dépasser le milieu du siècle (VN 47).

VN 1. - Dépôt DP 27. Ht conservée $9,7 \mathrm{~cm}$, diam. $\max .7,3 \mathrm{~cm}$. Inv. FR 1.35. PI. 93a

Une grande partie de la panse, le fond avec le pied, ainsi que les deux anses horizontales manquent. Panse ovoïde à épaulement marqué, décorée de godrons ; col concave; bord horizontal épaissi, à lèvre arrondie, décoré d'une moulure sur la face supérieure ; anse verticale à courbe continue joignant la partie supérieure du col à l'épaule et traces des attaches de deux anses horizontales. Face supérieure du bord réservée.

Vers 350.

\subsection{Oenochoés}

\subsubsection{Forme 3 («chous »)}

On peut classer dans cette catégorie quatre vases qui représentent des petites fractions (VN 2 et 4 ) ou de véritables miniatures (VN 3 et 5). VN 3 faisait partie du mobilier d'une tombe appartenant à un adulte de sexe indéterminé (SP 322, secteur Nord), alors que VN 4 et 5 proviennent respectivement de DP 22 et 24 qu'il est possible d'associer à deux sépultures d'enfants (SP 264 et SP 283 en secteur Sud). Les trois sépultures appartiennent à la phase 3 d'occupation du site. Enfin, VN 2 a été découverte aux abords du foyer rituel F 2 en secteur Est (fin de la phase 2), mais son appartenance à ce contexte n'est pas certaine. Sur la base de critères purement morphologiques, nos oenochoés peuvent être divisées en deux groupes distincts qui trouvent des parallèles précis dans le matériel des fouilles plus anciennes à Kalfata :

168 Ivanov 1963, p. 172, n ${ }^{\circ} 372$, pl. 93 (= Reho 1990, p. 103, $\mathrm{n}^{\circ} 191$; Reho 1992 , p. $55, \mathrm{n}^{\circ} 93$ : vers le milieu du IV ${ }^{\text {e }}$ s.). Deux vases semblables sont conservés à Cracovie et Sèvres : Bulas 1935, p. 42, pl. 10, 9 ; Massoul 1936, p. 39, pl. 21, 15.
VN 2, 3 et 4 sont caractérisés par un pied relativement large, une panse presque globulaire et un col court et concave, correspondant au type 3 de la classification des oenochoés attiques à vernis noir de $\mathrm{T}$. Ivanov ${ }^{169}$, tandis que VN 5 a un pied plus étroit, une panse parfaitement ovoïde et un col allongé se terminant par une embouchure à ressauts nettement marqués, ce qui permet de l'attribuer au type 4 de cette même classification ${ }^{170}$. Les types définis par T. Ivanov semblent copier des séries contemporaines d'oenochoés à figures rouges de petites et moyennes dimensions, principalement décorées de scènes se rapportant à la fête des Anthestéries, dont les fouilles à Kalfata ont livré plusieurs exemplaires ${ }^{171}$; ils présentent notamment de fortes ressemblances avec les plus petits de ces vases, ornés de représentations parfois polychromes d'un petit enfant en train de jouer ou d'une jeune fille poursuivant un oiseau ${ }^{172}$, avec lesquelles ils partagent plusieurs points communs (dimensions, forme, association fréquente avec des tombes d'enfants, etc.), ce qui indique qu'il s'agissait vraisemblablement de vases destinés à être offerts en cadeau aux enfants à l'occasion de cet événement ${ }^{173}$. Les dates proposées par l'archéologue bulgare - milieu ou $3^{\mathrm{e}}$ quart du $\mathrm{IV}^{\mathrm{e}} \mathrm{s}$. - peuvent paraitre quelque peu basses, surtout dans le cas des oenochoés de type 3 qui évoquent des exemples de la fin du $\mathrm{V}^{\mathrm{e}}$ ou du début du IV ${ }^{\mathrm{e}} \mathrm{s}$. de l'Agora d'Athènes ${ }^{174}$, mais elles

169 Ivanov 1963, p. $156, n^{\text {os }} 294-294 a$, pl. 85.

170 Ibid., $\mathrm{n}^{\text {os }} 295-297 \mathrm{~b}$, pl. 85.

171 Types 2 et 3 des oenochoés attiques à figures rouges selon la classification de T. Ivanov: ibid., p. 147-150, $\mathrm{n}^{\text {os }} 264-275$, fig. 59-61, pl. 75-77 (= Reho 1990, p. 99-101, nos 170-180 ; Reho 1992, p. 39-44, nos 43, 45-54). T. Ivanov attribue les deux types à figures rouges au $2^{\mathrm{e}}$ quart/milieu du $\mathrm{IV}^{\mathrm{e}} \mathrm{s}$., mais ses datations sont révisées plus tard par M. Reho qui remonte certains exemplaires dans le premier quart du $\mathrm{IV}^{\mathrm{e}} \mathrm{s}$. Tout en admettant leur bien-fondé, il nous paraît difficile d'adopter ces corrections qui ne semblent reposer que sur des critères purement formels et ne tiennent aucun compte du contexte de découverte des trouvailles : ainsi, dans les limites d'un même ensemble rituel (le grand foyer 2 du sondage II de 1949), on trouve des vases datés du premier quart (Reho 1990, nos $171-173$; Reho 1992, ${ }^{\text {os }} 45-47$ = Ivanov $\left.1963, \mathrm{n}^{\text {os }} 264-266\right)$ et du milieu du $\mathrm{IV}^{\mathrm{e}}$ s. (Reho 1990, ${ }^{\text {os }} 177,180-181$; Reho 1992, ${ }^{\text {os }} 50,54=$ Ivanov $\left.1963, \mathrm{n}^{\text {os }} 272-273,275\right)$, ce qui est pour le moins improbable quand on considère le caractère chronologiquement très homogène que présentent habituellement ces contextes.

172 Cf. notamment Ivanov 1963, nos $269-270,272-274 a$ (= Reho $1990, \mathrm{n}^{\text {os }} 174,176-180$; Reho 1992, $\left.\mathrm{n}^{\text {os }} 48-51,53-54\right)$. Ajouter à cette liste trois petites oenochoés polychromes découvertes en 1946 (Ivanov 1948, p. 42, fig. 46-47), ainsi que deux exemplaires similaires mis au jour lors des fouilles récentes en 1998 et 2002 (Panayotova 1998b, p. 17, fig. 13 ; Hermary, Panayotova 2006, p. 59).

$173 \mathrm{Ce}$ rapprochement est également souligné par le fait qu'ils sont parfois associés dans le mobilier des sépultures d'enfants: cf. Venedikov 1948, p. 19 (tombe 54); Venedikov 1963a, p. 30 (tombe 229).

174 Sparkes, Talcott 1970, p. 245, $\mathrm{n}^{\text {os }} 120-125$, pl. 6-7 (400-390). Pour les œnochoés appartenant au type 4 de la classification de T. Ivanov, 
sont confirmées pour VN 4 et 5 par l'analyse du contexte stratigraphique de DP 22 et 24. Le premier dépôt était en effet situé à proximité immédiate de SP 264, sous l'US 2/501 (datée vers 340-320), alors que le second était entièrement pris dans ce dernier remblai, mais, du fait de son placement au-dessus de la fosse de SP 283, recouverte elle aussi par cette couche, il doit dater du début de la période de son accumulation (vers 340). Ce raisonnement semble concorder également avec la chronologie des autres vases à vernis noir issus de SP 264 et DP 24 (cf. VN 39, 40 et 49). VN 3 doit être un peu plus ancien, probablement du second quart du $\mathrm{IV}^{\mathrm{e}} \mathrm{s}$., si on se base sur la forme du guttus qui provient de la même sépulture (cf. VN 109a). Malheureusement, dans ce dernier cas, le contexte stratigraphique de SP 322 ne permet pas une datation plus précise et indépendante.

VN 2. - Foyer F 2 (?). Ht 11,5 cm, diam. max. 7,3 cm. Inv. PIN 3325. Pl. 69e

Fragmentaire. L'anse et la plus grande partie du bord manquent. Pied annulaire bas ; panse ovoïde ; col court et concave se prolongeant sur le bord, évasé et trilobé ; trace d'attache d'une anse verticale sur l'épaule.

Vers 380-350 (?)

VN 3. - Tombe SP 322. Ht 6,1 cm, diam. max. $4,5 \mathrm{~cm}$. Inv. PIN 3706. Pl. 93b

Pied annulaire bas ; panse globulaire ; col court et concave; l'anse verticale présente une courbe continue depuis le bord jusqu'à l'épaule. Miniature.

Vers 375-350.

VN 4. - Dépôt DP 22. Ht 7,4 cm, diam. max. 4,4 cm. Inv. FR 1.12. Pl. 93c

Fond percé. Restaurée. Fond annulaire; panse ovoïde ; col plus long et concave ; le bord forme deux saillies verticales prononcées de chaque côté de l'ouverture ; anse verticale à courbe continue joignant le bord à l'épaule. Face extérieure du fond réservée. Miniature.

Vers 350.

cf. ibid., $\mathrm{n}^{\text {os }} 127-128$, avec des dates vers le milieu ou dans le troisième quart du $\mathrm{IV}^{\mathrm{e}} \mathrm{s}$. qui sont concordantes avec celles proposées par le savant bulgare. Il convient néanmoins de préciser qu'à l'exception de quelques vases miniatures (ibid., p. 333, ${ }^{\text {os }} 1373-1374$, du milieu du $\mathrm{IV}^{\mathrm{e}} \mathrm{s}$.), trop peu nombreux pour pouvoir offrir de véritables parallèles, le matériel de l'Agora se compose essentiellement d'exemplaires de grande taille (plus de $20 \mathrm{~cm}$ ) qui semblent avoir suivi une évolution différente et peut-être plus linéaire que celle des petits vases dont il est question ici (voir ibid., p. 61 pour le schéma général d'évolution). Sans doute la fonction plus spécifique, ainsi que la volonté de copier des productions équivalentes à figures rouges, expliquent dans notre cas cette différence.
VN 5. - Dépôt DP 24. Ht sans l'anse 9,2 cm, diam. max. $6,2 \mathrm{~cm}$. Inv. FR 1.13. Pl. 93d

Bord et fond ébréchés. Fond percé. Restaurée. Pied annulaire bas ; panse globulaire ; col court et concave ; anse verticale à courbe continue joignant le bord à l'épaule. Réservés : le plan de pose, la face intérieure du pied et le fond extérieur.

Vers 340.

\subsubsection{Forme 3 (?)}

Nous rangeons ici quelques fragments du foyer F 11 en secteur Est (début de la phase 3) qui doivent appartenir à des oenochoés de forme 3 , sans qu'on puisse en avoir la certitude absolue compte tenu de l'état de conservation des bords. Il s'agit en tout cas de vases de taille plus importante que les exemples répertoriés ci-dessus, dont la hauteur avoisine ou dépasse $20 \mathrm{~cm}$. Leur date peut être assez précisément établie grâce à la présence dans le même foyer de nombreux autres vases à vernis noir (cf. en particulier VN 62, 68-69, 73, 79-82, 96).

VN 6. - Foyer F 11. Inv. FR 3.59.2.

Trois fragments, deux représentant la presque totalité de l'anse et un fragment du bord. Bord évasé et probablement trilobé ; anse verticale à arête médiane.

Vers 380-370.

VN 7. - Foyer F 11. Inv. FR 3.59.3.

Cinq fragments, trois fragments représentant la plus grande partie de l'anse et deux fragments recollés provenant du bord. Traces de combustion. Bord évasé, probablement trilobé ; anse verticale à arête médiane. Forme sans doute similaire à VN 6, mais de plus petites dimensions.

Vers 380-370.

\subsection{Gobelets (« mugs ») ${ }^{175}$}

Les vases VN 8-10 appartiennent au type à une anse dit « Pheidias shape » qui est attesté à l'Agora d'Athènes uniquement dans des contextes antérieurs à la fin du

175 Dans le cadre du présent catalogue, nous préférons traiter les gobelets comme un forme à part entière plutôt que comme un type d'œnochoé, ainsi que le suggère la classification communément acceptée de J. D. Beazley ( $A R V^{2}$, p. XLIX-L : forme 8). Les études plus récentes ont démontré en effet qu'il s'agit de vases ayant connu des usages différents et attestés par un nombre important de variantes, ce qui permet de leur accorder une place indépendante dans la production attique à figures rouges et vernis noir. Voir Sparkes, Talcott 1970, p. 70 avec une bibliographie détaillée sur le sujet. 
$\mathrm{V}^{\mathrm{e}} \mathrm{s} .{ }^{176}$. Or, comme le montrent quelques exemples isolés de la nécropole du Céramique à Athènes ${ }^{177}$, d'Olynthe ${ }^{178}$, des environs de Sozopol ${ }^{179}$, de l'intérieur de la Thrace ${ }^{180}$ et du littoral septentrional de la mer Noire ${ }^{181}$, auxquels nous devons maintenant ajouter les trois gobelets répertoriés ci-dessous, sa production semble se poursuivre dans la première moitié du $\mathrm{IV}^{\mathrm{e}} \mathrm{s}$., probablement jusqu'au milieu du siècle. VN 8 et 10 proviennent de contextes clairement attribuables à la phase 3 d'occupation du site : le premier a été découvert dans le dépôt DP 1, associé à SP 244 en secteur Sud, où il était accompagné d'une lékanis à figures rouges du groupe d'Otchet datée vers 375-350 (CP 41), alors que le second faisait partie du mobilier de SP 329 en secteur central, comprenant également une coupe-skyphos de l'atelier du Peintre Q (CP 4) et un bol à riche décor estampé (VN 73), que les arguments stratigraphiques permettent de placer vers la fin de ce même quart de siècle (360350). Quant au gobelet VN 9, il s'agit d'une trouvaille isolée du secteur Est sans contexte précis, mais, compte tenu de sa ressemblance avec les deux autres vases, il doit leur être strictement contemporain.

176 Sparkes, Talcott 1970, p. $72-74$ (description générale) et p. 250$252, \mathrm{n}^{\text {os }}$ 201-222, fig. 3, pl. 11. Le type est également bien représenté dans le matériel des fouilles de Kalfata en 1946-1949, où l'on compte six exemplaires, regroupés dans le type 2 des cruches attiques à vernis noir, qui proviennent de sépultures datées du troisième et du dernier quart du $\mathrm{V}^{\mathrm{e}} \mathrm{s}$. : Ivanov 1963, p. 153-155, nos 284-289, fig. 66, pl. 81.

177 Knigge 1966, p. 127, n 9, pl. 70, 4 : vers 390.

178 Robinson 1950, p. $213, \mathrm{n}^{\circ} 279$, pl. 150 : première moitié du IVe $\mathrm{s}$.

179 Un gobelet à une anse, malheureusement non publié, provient d'un foyer rituel découvert lors des fouilles d'un tumulus sur le cap Kolokita, au Sud-Est de Sozopol, en 1981-1985 : Tsaneva 1985b et 1986b ; Damyanov 2005, p. 214-216. Le tumulus a livré entre autres une grande quantité d'amphores timbrées de Thasos et d'Héraclée du Pont qui permettent de dater son accumulation dans les années 370. Un vase similaire se trouve dans le matériel découvert lors du dragage du port de Sozopol en 1927, mais, du fait des limites chronologiques très larges de cet ensemble, il ne peut être daté que par comparaison avec d'autres exemplaires de la série : Galabov 1965, p. 34, n 100 , fig. 37.

180 Batsova, Kanchev 1974, p. 54, n 22. Le gobelet faisait partie du mobilier d'une tombe découverte près du village de Mladovo, département de Nova Zagora, qui a livré également un cratère à figures rouges attribué par I. McPhee au Peintre de Nova Zagora 3314. Ce dernier est daté par M. Lazarov et M. Reho dans le premier quart ou, plus généralement, dans la première moitié du $\mathrm{IV}^{\mathrm{e}} \mathrm{s}$. (Reho 1990 , p. $145, n^{\circ} 425$, pl. 28 ; Lazarov 2003, p. 139-140, n49).

181 Monahov, Rogov 1990b, p. 145, pl. 8, n 85 (de la nécropole de Panskoe I en Crimée). Noter la découverte dans la même tombe d'une amphore héracléote non timbrée de la variante I-A-1, datée par les auteurs vers 375-350, mais qu'il convient maintenant de remonter jusqu'aux années 380-370 selon la chronologie la plus récente proposée par S. Monahov. Cf. Monahov, Rogov 1990a, p. 133, n 12, pl. 2 et 7 ; Monahov 2003, p. 132.
Les trois gobelets sont presque identiques en ce qui concerne les dimensions et la forme. Leurs particularités morphologiques (hauteur réduite, panse surbaissée avec un diamètre maximal situé un peu au-dessus de la transition vers le pied) permettent de les rattacher à la deuxième variante distinguée par $\mathrm{B}$. Sparkes dans les limites du type à une anse ${ }^{\mathbf{1 8 2}}$, dont ils peuvent être considérés, avec les gobelets du Céramique, d'Olynthe, de Sozopol et de Mladovo (cité en note ci-dessus) qui fournissent des parallèles très proches, comme les manifestations les plus tardives. On insistera notamment sur l'absence du décor de godrons caractéristique des exemplaires de la deuxième moitié du $\mathrm{V}^{\mathrm{e}} \mathrm{s}$., bien que, compte tenu de l'échantillonnage limité dont nous disposons, il serait peut-être prématuré d'avancer des conclusions plus générales à ce sujet. De même, un autre trait caractéristique des vases plus anciens, la double anse verticale, ne se retrouve que chez $\mathrm{VN} 8$, alors que $\mathrm{VN} 10$, qui est plus récent, est muni d'une simple anse de section ovale.

VN 8. - Dépôt DP 1. Ht 7,2 cm, diam. max. $7,3 \mathrm{~cm}$. Inv. PIN 2666. PI. 93e

Restauré. Pied annulaire bas; panse tronconique, séparée du col par une rainure ; col court et concave, se prolongeant dans un bord horizontal à lèvre arrondie ; double anse verticale à courbe continue joignant le bord à l'épaule.

Vers 375-350.

VN 9. - Trouvaille isolée au N.-E. du mur MR 2. Ht cons. $6 \mathrm{~cm}$, diam. max. 7,6 cm. Inv. PIN 3236. Pl. 93f

Fragmentaire. Une grande partie du col, la totalité $\mathrm{du}$ bord et l'anse manquent. Pied annulaire bas ; panse globulaire surbaissée, séparée du col par un ressaut ; col court et concave ; trace de l'attache d'une anse verticale sur l'épaule. Le fond extérieur est décoré d'un petit bourrelet en relief entourant un disque central.

Vers 375-350.

VN 10. - Tombe SP 329. Ht 7,7 cm, diam. max. 7,4 cm. Inv. PIN 3642 (FR 2.24). Pl. 93g

Restauré. Pied annulaire bas ; panse globulaire surbaissée, séparée du col par une rainure; col court et concave, bord horizontal à lèvre arrondie ; anse verticale à courbe continue et section ovale joignant le bord à l'épaule. Le fond extérieur est décoré d'un petit bourrelet en relief entourant un disque central. Réservés : le disque central du fond extérieur (engobe rougeâtre), le plan de pose.

Vers 360-350.

182 Sparkes, Talcott 1970 , p. 73 et p. 251 , nos $215-220$, fig. 3 , pl. 11. 


\subsection{Skyphos}

L'unique skyphos à vernis noir découvert lors des fouilles conjointes appartient au type $\mathrm{A}^{183}$. Il provient du foyer $\mathrm{F} 4$, un contexte perturbé situé à la limite entre les secteurs central et Sud, qui ne saurait être mis en relation avec aucune des tombes situées à proximité (SP 316 du début de la phase 3 et SP 325 de la phase 2, toutes deux plus anciennes). Du fait de son état fragmentaire, nous ne nous basons pour la description ci-dessous que sur une reconstitution graphique susceptible de comporter quelques erreurs ; il paraît établi néanmoins qu'il s'agit d'un vase à rétrécissement assez fortement marqué dans la partie inférieure et à profil en forme de $\mathrm{S}$ (convexeconcave) dans sa partie supérieure. Des exemplaires possédant des caractéristiques similaires sont connus par les fouilles plus anciennes de Kalfata en 1946-1949, où ils sont classés par T. Ivanov dans le type 4 des skyphoi attiques à vernis noir ${ }^{184}$. Le même complexe comporte également deux skyphoi à figures rouges du Groupe Fat Boy dont la forme est proche (ou identique) de celle de notre VN $11^{185}$. L'ensemble de ces vases sont datés dans le deuxième quart du $\mathrm{IV}^{\mathrm{e}} \mathrm{s}$., sans doute à cause de la chronologie généralement admise pour le Groupe du Fat Boy ${ }^{186}$ et de la présence de skyphoi à base rétrécie dans le matériel d'Olynthe ${ }^{187}$, mais il est important de préciser qu'aucun des exemplaires publiés par D. Robinson ne présente des courbes aussi accentuées que certains des skyphoi catalogués par T. Ivanov188 ou notre VN 11. Ces derniers trouvent en effet leurs meilleurs parallèles dans les ensembles plus tardifs de l'Agora d'Athènes ou de Corinthe, où nous remarquons plusieurs skyphoi de proportions similaires datables de toute la deuxième moitié du $\mathrm{IV}^{\mathrm{e}}$, voire du début du III ${ }^{\mathrm{s}}{ }^{189}$. Dans le cas

183 Cf. Sparkes, Talcott 1970, p. 84-85 pour la description du type à vernis noir et son évolution aux $\mathrm{VI}^{\mathrm{e}}-\mathrm{IV}^{\mathrm{e}} \mathrm{s}$.

184 Ivanov 1963, p. 203, nos 499-503, fig. 78, pl. 109, s.

185 Ibid., p. 200-201, nos 487-488, pl. 106 (= Paralipomena, p. 498 ; Reho 1990 , p. 96, nos $154-155$; Reho 1992, p. 31-32, nos $25-26$ ).

$186 \mathrm{Au}$ sujet des problèmes posés par la chronologie des skyphoi de ce groupe, se reporter aux remarques formulées par B. Sabattini à partir de l'étude du matériel de la nécropole de Spina : Sabattini 2000. Notons également que M. Reho attribue aux deux skyphoi à figures rouges discutés ci-dessus une date plus récente : milieu/ $3^{\mathrm{e}}$ quart du $\mathrm{IV}^{\mathrm{e}} \mathrm{s}$.

187 Voir notamment Robinson 1933, p. 243-245, nos 962, 965-966, 971-980, pl. 184-185; Robinson 1950, p. 309-311, n ${ }^{\text {os }} 579-590$, pl. 200-202.

188 Voir par exemple Ivanov 1963, nos 488 et 503.

189 Sparkes, Talcott 1970 , p. 260, n ${ }^{\text {os }} 351-354$, fig. 4, pl. 17 ; Rotroff 1997, p. 257-258, nos 150-153, fig. 12, pl. 14. Pour Corinthe, où l'essentiel du matériel consiste en imitations locales de la forme attique, voir Blegen, Palmer, Young 1964, p. 128, fig. 13, pl. 75-76, 78 ; Edwards 1975, p. $69-71, \mathrm{n}^{\text {os }} 310,317-320,329-331,341-$ 348, 356-366, 370-371, pl. 13-14, 50 ; Pemberton 1989, p. 93, 97 , particulier du skyphos VN 11, une date au début du troisième quart $\mathrm{du} \mathrm{IV}^{\mathrm{e}} \mathrm{s}$. paraît la plus vraisemblable, compte tenu de l'aspect assez trapu de la pièce (diamètre du bord largement supérieur à la hauteur), qui semble la rapprocher des skyphoi d'Olynthe, et des repères chronologiques procurés par les autres vases à vernis noir provenant du même foyer (cf. VN 67 et 75).

VN 11. - Foyer F 4. Ht 9,3 cm, diam. de l'embouchure $12 \mathrm{~cm}$. Inv. PIN 3755. Pl. 70d

Fragmentaire. Pied annulaire bas en forme de tore ; vasque profonde à paroi convexe-concave, fortement rétrécie dans sa partie inférieure; bord évasé à lèvre arrondie ; deux anses horizontales en fer à cheval attachées sous le bord.

Vers 350-340.

\subsection{Coupes sans tige (« stemless »)}

\subsubsection{Coupes de Rhénée («Rheneia cups»)}

VN 12 et 13, parfaitement identiques, proviennent de SP 313 en secteur Sud (phase 1), une des sépultures les plus anciennes de la zone concernée par les fouilles conjointes dont la mise en place précède l'ensablement général du site vers la fin du $\mathrm{V}^{\mathrm{e}} \mathrm{s}$. Les deux coupes sont caractérisées par un pied bas à face intérieure et extérieure convexe, une vasque fort basse et évasée, des anses relativement longues et recourbées, ainsi que par un bord haut à concavité prononcée, ce qui permet de les rattacher aux représentants les plus avancés du type selon le schéma d'évolution proposé par B. Sparkes ${ }^{190}$. Le catalogue des vases à vernis noir de l'Agora d'Athènes comporte en effet quelques exemplaires similaires pour ce qui est de la forme ou du décor estampé, tous datés entre 430 et $420^{191}$, mais les parallèles les plus proches sont fournis par une série de coupes provenant de la Fosse de Purification à Rhénée, sans doute immédiatement antérieures à la mise en place

156-157, nos 80-81, 115-116, 158, 410-412, fig. 7, pl. 12, 15, 18, 46. Comparer également, en dehors des exemples attiques et corinthiens, et en ce qui concerne plus particulièrement notre VN 11, les profils des skyphoi découverts dans une fosse près de Porto Heli en Argolide, laquelle a livré un riche lot de vases du milieu ou du troisième quart du IVe s. : Rudolph 1974, p. 113-115, nos $13-21$, fig. 3.

190 Sparkes, Talcott 1970, p. 100-101.

191 Ibid., p. 267, nos 458-463, fig. 5, pl. 21. Comparer également Corbett 1949, p. 331, ${ }^{\circ} 76$, pl. 93 ; Young 1951b, p. 219, ${ }^{\circ} 1$, pl. 73 ; Kunze-Götte, Tancke, Vierneisel 1999, p. 109, pl. 72.4 : 437.2-3 (de la nécropole du Céramique). Il est à noter toutefois que, malgré la similitude générale dans les profils, les anses des exemplaires d'Athènes présentent une courbe moins prononcée que celles de VN 12 et 13 . 
du dépôt en $425^{192}$, tout comme par quelques vases issus des fouilles à Kalfata en 1946-1949 qui ont été regroupés par T. Ivanov dans son type 2 des coupes attiques à vernis noir ${ }^{193}$. Ces derniers sont datés par l'archéologue bulgare dans des limites chronologiques fort larges (du troisième quart du $\mathrm{V}^{\mathrm{e}}$ au milieu du $\mathrm{IV}^{\mathrm{e}} \mathrm{s}$.) qu'il convient sans doute de rétrécir considérablement à la lumière des connaissances actuelles ${ }^{194}$; il apparaît néanmoins que, du moins dans le cas de la paire $\mathrm{n}^{\text {os }} 401-402$, les coupes proviennent d'une sépulture qui peut difficilement être antérieure aux années 380-370 ${ }^{195}$, suggérant ainsi la survivance probable du type au-delà de la date généralement admise pour son extinction (avant 400 selon B. Sparkes). Malgré ces manifestations tardives, la position stratigraphique de SP 313 sous les dunes US 218/627 et 617/619 ne laisse aucun doute quant au synchronisme de VN 12 et 13 avec les exemples d'Athènes et de Rhénée et une date vers 430-420 paraît donc la plus vraisemblable.

VN 12. - Tombe SP 313 . Ht $4 \mathrm{~cm}$, diam. de l'embouchure $12,1 \mathrm{~cm}$. Inv. PIN 3602.

Pied annulaire bas; vasque basse et évasée, séparée du bord par un ressaut nettement marqué à l'ext. et à l'int. ; bord concave à lèvre pointue ; deux anses horizontales attachées sous le bord et relevées jusqu'au niveau de l'embouchure. Entièrement couverte de vernis. Décor du fond intérieur : rangée d'oves estampées entre deux cercles incisés; deuxième rangée d'oves plus espacées, positionnée directement sous une zone de

192 Dugas 1952, p. 58-60, nos 150-152, 157, 159, 163, pl. 48, 50-51 : cf. en particulier $\mathrm{n}^{\text {os }} 151-152$ avec un décor estampé presque identique à celui des vases étudiés ici, l'unique différence étant l'absence d'une deuxième rangée d'oves positionnée sous la zone de palmettes.

193 Ivanov 1963, p. 179-180, $\mathrm{n}^{\text {os }} 400-404$, fig. 73 , pl. 100-101. On notera que la coupe $n^{\circ} 401$ présente un décor estampé identique aux vases de Rhénée mentionnés ci-dessus. Très proche des exemplaires de Kalfata est une coupe sans date provenant du dragage du port de Sozopol en 1927 : Galabov 1965, p. 29, n 56, fig. 23.

194 Ainsi, la coupe $n^{\circ} 400$, découverte dans la tombe 152 avec un lécythe à décor géométrique qui évoque la production la plus tardive de l'atelier du Peintre de Beldam (ibid., p. 83, n 12, fig. 35, pl. 2 $=$ Reho 1990, p. 84, n 91), ne peut dater avant 430-420 si l'on se base sur le développement esquissé par B. Sparkes. De même, rien ne justifie l'attribution des fragments $n^{\text {os }} 403$ et 404 au milieu du $I^{\mathrm{e}} \mathrm{s}$., compte tenu du fait qu'il s'agit dans les deux cas de trouvailles isolées dont on ignore entièrement le contexte.

195 Il s'agit de la tombe 290, datée vers 360-350 par les fouilleurs, dont le mobilier comportait également, entre autres, deux lécythes polychromes décorés de scènes du gynécée, ainsi qu'une coupecanthare à vasque hémisphérique qui appartient sans doute aux exemples les plus anciens du type, selon le schéma proposé pour l'Agora d'Athènes par B. Sparkes. Cf. Venedikov 1963a, p. 34 ; Ivanov 1963, p. 98, 100, 183, nos 44, 51, 422, fig. 73, pl. 26, 31-32, 43, 100. Pour les lécythes polychromes, voir également Reho 1990, p. 111, 113, n 237,245 ; Reho 1992, p. 76, 81, nos 139,147 , pl. $21 \mathrm{a}$ (vers 350 ). treize palmettes reliées par des arcs incisés, de façon à ce que chaque palmette soit doublée d'une ove.

Vers 430-420.

VN 13. - Tombe SP 313. Inv. PIN 3603.

Dimensions, forme et décor identiques à VN 12.

Vers 430-420. Pl. 93h

\subsection{2. «Castulo cups »}

La forme spécifique des bords de VN 14 et 15 permet de les rattacher aux coupes sans tige du type dit « Castulo cup » ${ }^{196}$ ou « inset lip » selon la terminologie adoptée par B. Sparkes (Sparkes, Talcott 1970, p. 101-102). Il s'agit dans les deux cas de représentants tardifs, la diffusion du type ayant pris place essentiellement durant les trois derniers quarts du $\mathrm{V}^{\mathrm{e}} \mathrm{s} .{ }^{197}$ : VN 14, dont l'unique anse conservée ne présente plus sur sa face intérieure la zone réservée caractéristique de la grande majorité des exemplaires du $\mathrm{V}^{\mathrm{e}} \mathrm{s}$., provient de l'US 623/643 (secteur central), un horizon sableux qui se superpose à la dune US 218/627 et précède de peu la mise en place de SP 343 au tout début de la phase 2 (400-390); VN 15 faisait partie du foyer F 11 en secteur Est, un riche ensemble du début de la phase 3 que les observations stratigraphiques et la présence de nombreux autres vases à vernis noir permettent de dater vers 380-370 (cf. VN 62, 68-69, 73, 79-82, 96). Malheureusement, l'état de conservation de nos vases, réduits à quelques fragments, n'autorise que des comparaisons très générales avec d'autres exemplaires issus de contextes de la fin $\mathrm{du} \mathrm{V}^{\mathrm{e}}$ et de la première moitié du $\mathrm{IV}^{\mathrm{e}} \mathrm{s} .{ }^{198}$. De même, il convient de signaler que l'association du bord et du pied de VN 15 n'est pas certaine : alors que le premier fragment appartient sans

196 Pour l'histoire de ce terme, largement utilisé par les spécialistes aujourd'hui, cf. Shefton 1996, p. 163, note 1 avec bibliographie complète. Voir également ibid., p. 168-170, pour une description des éléments caractéristiques des coupes de ce type et leur évolution.

197 Ibid., p. 102 ; Py, Sabattini 2000, p. 171 et note 10. Selon B. Shefton (1996, p. 169), la diffusion de la « Castulo cup » a atteint son apogée au second quart du $\mathrm{V}^{\mathrm{e}} \mathrm{s}$.

198 Des exemplaires aussi tardifs sont de toute évidence très rares sur les sites de mer Noire et de Méditerranée orientale. En effet, la liste publiée par B. Shefton pour ces deux régions ne comporte qu'un seul exemplaire qui puisse dater du début du IV ${ }^{\mathrm{e}} \mathrm{s}$. : Shefton 1996, p. 172 (Londres 1864. 10-7.1599 : de la nécropole de Fikellura à Rhodes). La situation est cependant différente en Méditerranée centrale et occidentale, et tout particulièrement dans le Sud de la péninsule ibérique (Andalousie orientale), où on trouve encore un nombre important de "Castulo cups" dans des contextes de la première moitié du IV e s. : Domínguez, Sánchez 2001, p. 223, n 235, fig. 117 ; p. $233, \mathrm{n}^{\circ} 289$, fig. 126 ; p. $238, \mathrm{n}^{\circ} 323$, fig. 133 ; p. 259 $260, \mathrm{n}^{\text {os }} 438,442,447-448$, fig. $160-161 ;$ p. $275-276, \mathrm{n}^{\text {os }} 561-592$; p. $279, \mathrm{n}^{\text {os }} 620-622$; p. $290-291, \mathrm{n}^{\text {os }} 704-717$; p. $305, \mathrm{n}^{\text {os }} 855-857$; p. $319, n^{\circ} 966$; Py, Sabattini 2000, p. 171, fig. 4. 
doute possible à une " Castulo cup », le second s'éloigne des caractéristiques habituelles du type, notamment par le fait qu'il est plus étroit et, à l'exception d'une rainure réservée sur le plan de pose, entièrement couvert de vernis noir en-dessous. Ces particularités le différencient des autres coupes contemporaines qui présentent un décor de bandes de vernis noir sur le fond extérieur et un plan de pose réservé ${ }^{199}$. Il est cependant difficile de rattacher ce fragment à une autre forme ${ }^{200}$ et, compte tenu de nos faibles connaissances sur l'évolution du type dans la première moitié du $\mathrm{IV}^{\mathrm{e}} \mathrm{s}$., les différences notées ci-dessus peuvent être simplement dues aux nouvelles tendances dans le décor des vases à vernis noir qui s'imposent vers $375^{201}$.

VN 14. - US 623/643. Ht cons. $5 \mathrm{~cm}$, diam. de l'embouchure $19 \mathrm{~cm}$. Inv. PIN 4108 (FR 3.54). PI. 94a

Trois fragments recollés : un grand fragment de la vasque avec une partie du bord et deux petits fragments représentant le départ d'une des anses. Vasque basse et évasée, séparée du bord par un ressaut qui n'est clairement marqué qu'à l'intérieur, où la transition se situe un peu plus bas; bord à face externe légèrement concave, épaissi à la base, se terminant par une lèvre mince et arrondie. Sous le bord, à l'extérieur, graffite partiellement conservé : [...]HTO (voir p. 171).

Vers 400.

VN 15. - Foyer F 11. Diam. du pied $5,5 \mathrm{~cm}$. Inv. FR 3.59.5.

Deux fragments : un fragment du bord avec le départ de la vasque et un fragment représentant la moitié du fond avec une partie du pied. Le fond était probablement percé. Pied annulaire à face extérieure moulurée (moulure soulignée par un sillon) et face interne concave, décoré d'une rainure réservée sur le plan de pose ; la vasque était séparée du bord par un ressaut qui n'est

199 Shefton 1996, p. 170 ; Domínguez, Sánchez 2001, p. 445. 200 Notons que, malgré une certaine ressemblance dans le profil, nous ne trouvons pas ici les proportions plus allongées et la division bipartite de la face extérieure qui caractérisent les pieds des coupesskyphoi et des coupes-canthares du $\mathrm{IV}^{\mathrm{e}} \mathrm{s}$. ou ceux des coupes sans tige tardives de la Classe Délicate.

201 Il est généralement accepté que les dernières coupes sans tige conservent le fond extérieur réservé et le décor de cercles et de bandes de vernis noir, à une époque où d'autres formes sont déjà entièrement recouvertes de vernis noir (à l'exception fréquente du plan de pose) et affichent l'ombilic caractéristique sous le fond extérieur : cf. Sparkes, Talcott 1970, p. 103 et les références indiquées plus haut au sujet du décor des «Castulo cups » au IV e s. Pour peu que l'association avec le fragment de bord soit correcte, le pied de VN 15, tout comme celui de VN 16 dont il sera question plus loin, fournit la preuve que ces tendances ont également pu concerner dans une certaine mesure les coupes sans tige. conservé qu'à l'extérieur où il se situe beaucoup plus haut ; bord à face externe nettement concave, se terminant par une lèvre arrondie.

Vers 380-370.

\subsubsection{Type indéterminé}

Comme VN 15, les fragments VN 16 n'appartiennent pas avec certitude à un seul vase, mais nous avons préféré tout de même ne pas les dissocier. Le fait qu'ils aient été trouvés dans une zone restreinte du grand dépôt DP 23, directement au-dessus des ossements de SP 265 (secteur central, phase 3), et qu'ils ne correspondent à aucune des autres formes à vernis noir ou figures rouges provenant du dépôt (toutes très lacunaires, il est vrai), constitue à notre avis un argument suffisant pour motiver un tel choix et ceci malgré quelques incohérences d'ordre typologique qui permettent de jeter le doute sur leur association. Plusieurs éléments semblent suggérer en effet qu'on se trouve ici en présence d'un type hybride de coupe sans tige : le pied évoque ceux des "Castulo cups », mais il est beaucoup plus fin que ces derniers, à plan de pose pointu, et ne présente pas le profil en tore qui les caractérise ; de même, la partie conservée du fond intérieur garde un reste de décor estampé, alors que les «Castulo cups » à vernis noir que nous connaissons en sont généralement dépourvues ${ }^{202}$; le fragment de vasque comporte, pour sa part, une arête bien marquée à l'intérieur qu'on considère d'ordinaire comme un trait dinstinctif des coupes de la Classe délicate et des coupes-skyphoi à paroi fine ; l'unique anse conservée est également assez fine et allongée, ce qui la différencie des anses plus courtes et épaisses des "Castulo cups ». Si ces observations sont exactes, notre vase ne serait pas un cas isolé, car nous connaissons au moins un autre exemple de coupe sans tige présentant un croisement similaire d'éléments de "Castulo cup » et de coupe de la Classe délicate, mais agencés de façon différente ${ }^{\mathbf{2 0 3}}$. Bien qu'antérieur d'une quarantaine d'années, ce parallèle montre que des essais sporadiques visant la création d'un type intermédiaire devaient être en cours au IV ${ }^{\mathrm{e}} \mathrm{s}$., sans aboutir de toute évidence à un résultat définitif.

Les nombreuses amphores du DP 23 indiquent que le dépôt a fonctionné durant une période de 20 ans environ, s'étalant approximativement entre la fin des années 340

202 Quelques coupes, portant pour la plupart un décor à figures rouges à l'extérieur, font seules figure d'exception à cette règle : cf. Sparkes, Talcott 1970, p. 102, note 19 ; Ure 1936, p. 206, nos 2 et 4, fig. 3-4, pl. 11.1 et p. $208, n^{\circ} 13$, fig. 13.

203 Rohde 1990, p. 45-46, annexe 4.7, pl. 27, 1-3 : Cercle du Peintre de Iéna, début du $\mathrm{IV}^{\mathrm{e}} \mathrm{s}$. Cet exemplaire figuré est doté du pied typique des coupes tardives de la Classe Délicate, mais d'un bord de « Castulo cup ». 
et celle des années 320. Cependant, les fragments VN 16 proviennent de la couche inférieure du dépôt, qui suit de peu la mise en place de la SP 265, et doivent dater de ce fait du début de cette période (vers 340). Aux remarques exposées plus haut, nous ajouterons également que le fond extérieur et le pied du vase sont entièrement couverts de vernis noir, ce qui constitue un argument supplémentaire en faveur de sa date tardive et confirme les soupçons exprimés au sujet de VN 15, à savoir que les dernières coupes sans tige ont pu connaître une évolution similaire à celle des autres formes contemporaines à vernis noir.

VN 16. - Dépôt DP 23. Diam. du pied environ $8 \mathrm{~cm}$. Inv. FR 1.56.3.

Six fragments : deux représentant à peu près la moitié $\mathrm{du}$ fond avec une partie du pied, trois fragments d'une des anses et un fragment de la vasque. Le fond était probablement percé. Pied annulaire bas à face extérieure moulurée (moulure soulignée par un sillon) et plan de pose arrondi ; fond extérieur plat; départ de la vasque qui rejoignait la moulure du pied sans aucune transition ; les anses étaient horizontales, relevées et légèrement courbées vers l'intérieur. Arête sur la paroi interne de la vasque. Décor du fond intérieur: rangée d'oves estampées entre deux cercles incisés ; zone de palmettes estampées reliées par des arcs incisés (trois conservées) ; deuxième rangée d'oves encadrées de part et d'autre par un double cercle incisé.

Vers 340.

\subsection{Bolsals}

Les bolsals VN 17-29 peuvent être divisés en deux séries distinctes qui fournissent des jalons précieux pour illustrer le développement de la forme au cours du $\mathrm{IV}^{\mathrm{e}} \mathrm{s}$. et dans les premières années du $\mathrm{III}^{\mathrm{e}} \mathrm{s}$. Les vases de la première série (VN 17-26), de loin les plus nombreux, proviennent de contextes funéraires ou rituels attribuables par une multitude de critères indépendants à la phase 2 et au début de la phase 3 d'occupation du site (vers 400-370) : SP 325 en secteur Sud, les dépôts DP 6, 13, 30 près des SP 303, 334, 339 en secteurs Sud, central et Nord, et les foyers F 1, 9, 11 en secteur Est. Bien que présentant des nuances considérables dans le traitement des détails morphologiques et ornementaux, ils partagent plusieurs traits communs : une vasque peu profonde, à paroi relativement épaisse et à concavité plus ou moins prononcée dans sa partie inférieure, des anses en forme de fer à cheval aux attaches rapprochées, un fond extérieur souvent réservé et décoré de bandes et de cercles de vernis noir, ainsi qu'un décor estampé fort simple à l'intérieur qui se limite à quelques motifs de base (croix de palmettes ; quelques palmettes reliées par des arcs incisés), mais ignore encore l'emploi de guillochis. Ces spécificités permettent de rapprocher nos vases des exemplaires du premier quart du $\mathrm{IV}^{\mathrm{e}} \mathrm{s}$. provenant d'Athènes ${ }^{204}$, d'Olynthe ${ }^{205}$, de Thasos ${ }^{206}$, du littoral occidental et septentrional de la mer Noire ${ }^{207}$ et de Méditerranée occidentale ${ }^{208}$, ainsi que d'une partie des bolsals découverts lors des fouilles de Kalfata en

204 Pour le matériel de l'Agora, cf. Sparkes, Talcott 1970, p. 275 , $\mathrm{n}^{\text {os }}$ 556-557, fig. 6, pl. 24 et 53. Comparer Young 1951a, p. 119-120, $\mathrm{n}^{\circ}$ 5.2, pl. 51b ; Corbett 1955, p. 178-179, n 3, pl. 66 ; SchlörbVierneisel 1966, p. 52, $\mathrm{n}^{\circ} 104.2$, pl. 41.1 et p. 61, $\mathrm{n}^{\circ} 110.1$, pl. 46, 9 (de la nécropole du Céramique) ; Knigge 1966, p. 127, nos 7-8, pl. 70, 2-4 (du Céramique).

205 Robinson 1933, p. 190-194, $\mathrm{n}^{\text {os }} 543-554,568-569,571-572$, 574-575, pl. 151-152, 154 ; p. 245-246, n $^{\text {os }}$ 981-986, 988-989, pl. 186 ; Robinson 1950, p. 328-333, ${ }^{\text {os }} 655-676$, pl. 205, 207-209, 212-213, 215. Le décor des fonds extérieurs n'est que rarement noté, mais l'ensemble de ces bolsals présentent de fortes similitudes dans la forme et le décor qui permettent de les considérer comme étroitement contemporains. La date proposée pour la plupart des exemplaires publiés dans Robinson 1950 est sans doute correcte : début du $\mathrm{IV}^{\mathrm{e}} \mathrm{s}$., en tout cas le premier quart de ce siècle.

206 Ghali-Kahil 1960, p. 130, n 56, pl. 57 ; Blondé 1985, p. 296-297, $\mathrm{n}^{\text {os }} 80-81$, fig. 10. Les deux exemplaires du Jardin de l'EFA font partie d'un groupe de cinq bolsals (nos 77, 79-81, 83) qui sont datés par Fr. Blondé dans le dernier quart du $\mathrm{V}^{\mathrm{e}} \mathrm{s}$. Dans ces deux cas cependant, la concavité bien exprimée de la partie inférieure de la vasque plaide plutôt en faveur d'une date dans le premier quart du $\mathrm{IV}^{\mathrm{e}} \mathrm{s}$.

207 Cf. Alexandrescu 1978, p. 87, n 554, pl. 65 (de la nécropole tumulaire d'Histria): daté du deuxième quart du $\mathrm{IV}^{\mathrm{e}} \mathrm{s}$., mais probablement plus ancien ; Brashinskiy 1980, p. 127-128, $\mathrm{n}^{\text {os }} 165-$ 168, pl. 14, 20 (de la nécropole tumulaire d'Elisavetovskoe sur le Don inférieur) : notons que les $n^{\text {os }} 165,167$ et 168 ont été découverts avec des amphores héracléotes portant des timbres des fabricants Archestratos, Aristippos et Dionysios II (ibid., p. 113-115, n ${ }^{\text {os }} 63$, 66, 78 ; Monahov 1999, p. 188-189, pl. 72 ; Kats 2003, p. 275), ce qui permet de les dater des deux premières décennies du $\mathrm{IV}^{\mathrm{e}} \mathrm{s}$. ; Monahov, Rogov 1990b, p. 140-141, pl. 3-4, nos 53, 55-57 (de la nécropole tumulaire de Panskoe I en Crimée) : les nos 53,55 et 57 étaient accompagnés d'amphores héracléotes portant des timbres de fabricants anciens du début du $\mathrm{IV}^{\mathrm{e}} \mathrm{s}$. (Onassos, Hérakleidas, Archestratos, probablement aussi Dionysios I et Satyrion : Monahov, Rogov 1990a, p. 130-132, nos 1-5, pl. 1 et 7 ; Monahov 1999, p. 171 173, pl. 61 ; Kats 2003, p. 275); le nº 56 a été trouvé avec une amphore thasienne non timbrée de la série biconique ancienne (II$\mathrm{B}-1$ selon la typologie de $\mathrm{S}$. Monahov) qui donne également une date à la toute fin du $\mathrm{V}^{\mathrm{e}} \mathrm{s}$. ou au début du IV e s. (Monahov, Rogov 1990a, p. 140-142, n 42, pl. 6 et pl. 7 ; Monahov 2003, p. 66-67).

208 Eiseman, Ridgway 1987, p. 26-28, n ${ }^{\text {os }}$ G1-G4 (de l'épave de Porticello) : l'épave a livré, entre autres, 13 amphores de Mendé de la variante dite de Porticello (II-B selon la typologie de S. Monahov) et 2 amphores de Péparéthos de la variante de Soloha (I-A selon S. Monahov) que les parallèles nord-pontiques permettent d'attribuer aux années 390-380 (cf. Monahov 1999, p. 243-245, pl. 99 ; Monahov 2003, p. 91-92, 97-99) ; Py, Sabattini 2000 p. 173-174, fig. 5-6 (de l'habitat de Lattes, Hérault) : plusieurs exemplaires semblables à notre première série datés de la première moitié $\mathrm{du}^{\mathrm{IV}} \mathrm{e} \mathrm{s}$. 
1946-1949, que l'on peut attribuer à la même époque ${ }^{209}$. Elles les caractérisent comme une étape intermédiaire entre les bolsals raffinés du dernier quart du V ${ }^{\mathrm{e}} \mathrm{s}$., dotés d'un décor similaire ou légèrement plus complexe, et les exemplaires plus grossiers, entièrement couverts de vernis noir par dessous et fréquemment ornés de bandes de guillochis à l'intérieur, qui se répandent après 375 .

Cependant, ce sont justement les nuances dans la morphologie et le décor des vases de cette série qui s'avèrent les plus instructives et offrent l'opportunité de mieux comprendre les différentes expériences qui étaient en cours dans les ateliers des potiers attiques pendant le premier quart du IV e s. av. J.-C. Ainsi, VN 18 paraît encore très proche des bolsals des années 400 avec sa facture fine, une carène bien marquée sur la face extérieure du pied, une concavité à peine perceptible dans la partie inférieure de la vasque et des anses parfaitement horizontales ; le décor du fond extérieur et le motif estampé à l'intérieur semblent également se conformer de près aux modèles de l'époque précédente ${ }^{210}$. Pris isolément de son contexte stratigraphique, ce vase pourrait être daté sans difficulté vers 410-400, si ce n'est pour l'absence de sillon à la jonction entre la partie supérieure et inférieure de la vasque qui représente l'unique élément permettant de le différencier. Il provient cependant du même dépôt que VN 19, un bolsal de plus petites dimensions sans décor estampé qui se distingue par le décor simplifié du fond extérieur, un pied moins élaboré, privé de carène extérieure, et des anses légèrement relevées préfigurant les développements postérieurs. Ce dernier est assez proche de VN 22, un autre petit bolsal, où nous retrouvons la position relevée des anses et le profil simplifié du pied, auxquels s'ajoute également une volonté

209 Ivanov 1948, p. 39, fig. 38.1; Ivanov 1963, p. 182, n 410, 412, 416-417, 420. Ces derniers vases ne sont pas illustrés et se sont vu attribuer des dates fort contradictoires englobant l'ensemble $\mathrm{du} \mathrm{IV}^{\mathrm{e}} \mathrm{s}$. Cependant, si l'on se base sur les notices descriptives du catalogue de T. Ivanov, leur décor extérieur et intérieur est proche de celui des bolsals de notre première série. Ils proviennent pour la plupart de sépultures dont le mobilier ne contenait pas d'autres vases permettant une datation indépendante. Aux exemplaires issus des anciennes fouilles à Kalfata, il convient d'ajouter un bolsal miniature découvert par l'équipe bulgare en 2002, dont la date proposée est également trop basse au vu des parallèles stratifiés que nous publions ici, ainsi que quatre bolsals probablement contemporains, ou tout au plus légèrement antérieurs, qui proviennent du dragage du port de Sozopol en 1927 : Hermary, Panayotova 2006, p. 59 ; Galabov 1965, p. $30, \mathrm{n}^{\text {os }} 68-70,72$, fig. 27.

210 Comparer par exemple, pour la forme et le décor, Sparkes, Talcott 1970, p. 274, n 551, pl. 24, 53 : ca. 400 ; Corbett 1949, p. $344-345$, n ${ }^{\text {os }} 157,161$, fig. 1 , pl. $94-95$. Plus ancien, mais toujours proche dans la forme et le décor estampé à l'intérieur : Talcott 1935, p. 503, $\mathrm{n}^{\circ} 14$, fig. 20-21. Le motif de quatre palmettes disposées en forme de croix autour d'un cercle semble avoir été également fort répandu dans le premier quart du $\mathrm{IV}^{\mathrm{e}} \mathrm{s}$., comme le montrent plusieurs des exemples méditerranéens et pontiques cités en note ci-dessus. de simplification manifeste dans le décor estampé (du motif originel de quatre palmettes disposées en forme de croix autour d'un cercle incisé, on n'a gardé ici que la disposition cruciforme des palmettes espacées en supprimant le cercle qui les séparait ${ }^{211}$ ). VN 22, de son côté, est issu du même contexte que VN 21, un bolsal qu'on peut considérer avec VN 17 comme représentant la norme pour le premier quart du $\mathrm{IV}^{\mathrm{e}} \mathrm{s} .{ }^{212}$. Ce sont des vases de facture plus épaisse et de proportions légèrement plus trapues que VN 18 et les exemplaires de la fin du $\mathrm{V}^{\mathrm{e}}$ s., mais qui se situent dans la continuité directe de ces derniers en ce qui concerne la position presque horizontale des anses et le traitement du décor intérieur et extérieur ${ }^{213}$. On peut éventuellement leur rattacher VN 26, un vase de dimensions encore plus modestes que VN 19 et $22^{214}$, ainsi que VN 23-24, mais l'absence des anses de ces vases interdit des comparaisons détaillées. Enfin, VN 20 représente un cas à part : il a des anses légèrement relevées et un fond extérieur entièrement couvert de vernis noir avec une rainure réservée sur le plan de pose et une sorte de renflement central évoquant l'ombilic des bolsals plus tardifs ; cependant, les anses gardent encore la forme en fer à cheval et le décor de palmettes reliées à l'intérieur est assez élaboré, sans les entrelacs typiques de l'époque postérieure, ce qui permet de confirmer sa date ancienne ${ }^{215}$.

211 La popularité de ce motif simplifié au cours du premier quart $\mathrm{du} \mathrm{IV}^{\mathrm{e}} \mathrm{s}$. semble se rapprocher de celle du motif dont il est originaire (voir par exemple les bolsals d'Olynthe). Malheureusement, l'absence d'illustrations ou la mauvaise qualité des reproductions ne permettent pas toujours de faire la différence entre les deux, ni de le distinguer de la croix de palmettes avec quatre éléments accolés (cf. VN 26).

212 Cf. Sparkes, Talcott 1970, p. 275, n 556, pl. 24.

213 Le décor intérieur et extérieur de VN 21 est identique à celui de VN 18. Pour le décor extérieur de VN 17, comparer notamment : Sparkes, Talcott 1970 , p. $274, \mathrm{n}^{\circ}$ 549, pl. 24, 53: 420-400 ; Alexandrescu 1978, p. 86, $n^{\circ}$ 548-552, pl. 64, 66 (d'Histria) : fin du $\mathrm{V}^{\mathrm{e}}$ s. ; Brashinskiy 1980, p. 127, n 163, pl. 14, 20 (de la nécropole tumulaire d'Elisavetovskoe sur le Don inférieur): dernier quart du V'e s. ; Py, Sabattini 2000, p. 173, fig. 5 (de l'habitat de Lattes). Pour le motif estampé : Sparkes, Talcott 1970, p. 274, n 550, pl. 53 : 420-400 av.J.-C. ; Alexandrescu 1978, p. 86, n 546 : 420-400 ; Brashinskiy 1980, p. $127, \mathrm{n}^{\circ} 164$ : fin du Ve s.

214 Pour d'autres bolsals miniatures de la fin du $V^{\text {e }}$ et du IV ${ }^{\mathrm{e}} \mathrm{s}$., cf. Sparkes, Talcott 1970, p. 273, n 540, fig. 22 (et les exemplaires cités à titre de parallèles); Young 1951a, p. 117, n 3.3, pl. 50c. Les exemplaires suivants de la nécropole d'Apollonia, issus pour la plupart de tombes d'enfants, peuvent être également classés dans cette catégorie : Ivanov 1948, p. 39, fig. 38.1 ; Ivanov 1963, p. 182, $\mathrm{n}^{\text {os }} 412$ et 417 ; Hermary, Panayotova 2006, p. 59.

215 Comme les précédents, le motif de six palmettes reliées trouve ses origines dans le dernier quart du $\mathrm{V}^{\mathrm{e}} \mathrm{s}$., mais sur les vases de cette époque les palmettes sont toujours disposées autour d'un cercle central : cf. Sparkes, Talcott 1970, p. 274, n 479, pl. 53 : 420-400 ; Alexandrescu 1978, p. 86, n ${ }^{\circ}$ 549, pl. 64 : fin du V ${ }^{\mathrm{e}}$ s. Plus tard, nous le retrouvons inchangé sur un exemplaire qu'on peut attribuer au 
L'analyse présentée ci-dessus nous amène à une conclusion importante. Elle suggère que les bolsals VN 17-26 sont issus de différents ateliers du premier quart du $\mathrm{IV}^{\mathrm{e}} \mathrm{s}$. (leur nombre n'était pas nécessairement élevé) dont certains préféraient suivre les traditions héritées des décennies précédentes, alors que d'autres expérimentaient la nouvelle forme, en essayant de la rendre plus solide et mieux adaptée à une production de masse, conformément aux nouvelles tendances affectant la céramique attique à cette époque. Il serait intéressant de comparer cette situation avec celle que l'on observe dans le cas des bols à bord saillant VN 56-62 qui, bien que contemporains des bolsals de la première série, sont caractérisés par une très forte unité dans la forme et le décor, permettant de les considérer comme les produits d'un ou deux ateliers.

La deuxième série de bolsals (VN 27-29) provient de contextes rituels plus récents appartenant aux phases 3 et 4 de l'occupation de cette partie de la nécropole : DP 7 en secteur Sud et DP 17-18 en secteur Nord. Ils affichent une facture plus grossière et des proportions plus trapues que les vases de la première série, ainsi que des traits indéniablement tardifs, à savoir un fond extérieur entièrement couvert de vernis noir et des anses de forme triangulaire, qu'ils partagent avec nombre d'exemplaires du deuxième quart et de toute la deuxième moitié du $\mathrm{IV}^{\mathrm{e}} \mathrm{s} .{ }^{216}$. On doit ajouter à ceci d'autres éléments tout aussi significatifs, comme la rainure réservée sur le plan de pose et l'ombilic central sous le fond extérieur, qui

premier quart du IV ${ }^{\text {e }}$ s. : Alexandrescu 1978, p. 87, n 554, pl. 65. Il s'agit d'une simple variante d'un motif très commun dans les dernières décennies du $\mathrm{V}^{\mathrm{e}} \mathrm{s}$., qui peut comporter un nombre variable de palmettes $(4,5,6,8$, etc.) et que l'on rencontre également sur notre VN 17, mais avec une palmette de moins.

216 Pour Athènes, cf. Sparkes, Talcott 1970, p. 275, nos 558-560, fig. 6 , pl. 24,53 ; Rotroff 1997 , p. $259-260$, nos $168-169$, fig. 13 , pl. 16, 143. Comparer Corbett 1949, p. 345, n 162, fig. 1 ; Corbett 1955, p. 182-183, nos 16-18, fig. 2, pl. 68-69 ; Rotroff, Camp 1996, p. 280, fig. 7.2-3 ; Braun 1970, p. 134, n 11, pl. 54.3 ; Miller 1974, p. $234, \mathrm{n}^{\circ} 36, \mathrm{pl}$. 32. Voir aussi la liste suivante, qui ne prétend à aucune exhaustivité : Porto Heli (Argolide) : Rudolph 1974, p. 116, $\mathrm{n}^{\circ}$ 26, fig. 3 ; Olynthe: Robinson 1933, p. 194, n 572, pl. 154 ; Robinson 1950, p. $328, \mathrm{n}^{\circ} 654$, pl. 208 et p. 332-333, $\mathrm{n}^{\circ} 674$; Thasos: Blondé 1985, p. 297, nº 78, fig. 10 ; Blondé 1989, p. 496, nos 45-46, fig. 8 ; Apollonia : Ivanov 1963, p. 182-183, nos 418-419 (de Kalfata); Galabov 1965, p. 30, n 71 (du port de Sozopol) ; Histria et arrière-pays : Alexandrescu 1978, p. 87, $\mathrm{n}^{\text {os }}$ 555-558, fig. 13 ; Lungu 1993 , p. $170, \mathrm{n}^{\text {os }} 6-7$, pl. 2 et 8 ; Andalousie orientale : Domínguez, Sánchez 2001, p. 194, n 61 ; p. 224-225, n² 245, fig. 119 ; p. 244, $\mathrm{n}^{\circ} 374$, fig. 140 ; p. 262 , $\mathrm{n}^{\text {os }} 463-464$, fig. 162 ; p. $271-272, \mathrm{n}^{\text {os }} 536$ et 542, fig. 167 ; p. 314-315, $\mathrm{n}^{\text {os }} 923-924$, fig. 175 ; Lattes (Hérault) : Py, Sabattini 2000, p. 173-174, fig. 5-6; Alexandrie (Sciatbi): Breccia 1912, p. 68-69, nos 183-187, pl. 46, 121. La plupart de ces exemples présentent à l'intérieur un décor de palmettes entourées de bandes de guillochis. n'apparaissent que sur certains de nos exemplaires, mais qu'on retrouve systématiquement tout au long de cette période. Ces persistances sur une période de temps relativement prolongée s'expliquent par le fait que la forme semble se figer vers le milieu du siècle et ne subit pas d'évolution notable au cours des décennies suivantes lorsqu'elle n'est plus produite que de façon sporadique ${ }^{217}$.

Dans le cas des bolsals de notre deuxième série, les observations effectuées sur les contextes de découverte sont suffisantes pour nous permettre d'établir leur chronologie relative et absolue. Ainsi, VN 27 est sans doute le plus ancien des trois exemplaires. Le DP 18, dont il est issu, n'a livré en plus du bolsal qu'une cruche à col cannelé qu'il n'est pas possible de dater de façon indépendante ; toutefois, l'association probable du dépôt avec SP 333, une tombe que l'on peut attribuer aux années 360-350 sur la base de son contexte stratigraphique et du mobilier qui l'accompagnait (cf. VN 45), plaide en faveur d'une date relativement haute. Le vase présente des proportions fort trapues et un profil simplifié du pied, mais un décor intérieur « archaïsant », sans emploi de guillochis, qui reste proche de celui des bolsals de la première série ${ }^{218}$. VN 28, sans décor estampé, est un peu plus tardif. Comme l'exemplaire précédent, il provient d'un petit dépôt (DP 7) qui ne contenait aucun vase permettant de le situer dans des limites chronologiques tant soit peu précises. Cependant, la position de DP 7 contre un alignement sommaire de blocs de pierre au Sud-Ouest de SP 316 et SP 325, dont la construction peut être datée avec une relative certitude dans les années 340 grâce aux vases du foyer F 4 qu'il recouvre (cf. VN 11, 67, 75), indique qu'une date dans le troisième quart du $\mathrm{IV}^{\mathrm{e}} \mathrm{s}$. est fort probable pour ce contexte. Enfin, VN 29 est incontestablement le plus récent des trois bolsals, comme le suggère la découverte dans le même dépôt (DP 17) d'un unguentarium des dernières années $\mathrm{du}_{\mathrm{IV}} \mathrm{e}^{\mathrm{e}}$ ou du tout début du $\mathrm{III}^{\mathrm{e}} \mathrm{s}$. Il s'agit donc d'un des derniers représentants de cette forme qui disparaît peu après le début $\mathrm{du} \mathrm{III}^{\mathrm{e}} \mathrm{s} .{ }^{219}$. Le vase est intéressant, puisqu'il montre des signes évidents de dégénération dus à son caractère très tardif. On observe ainsi que la concavité de la partie inférieure de la vasque a disparu, le fond est très épais,

217 Voir à ce sujet les remarques de S. Rotroff dans son analyse des représentants tardifs de la forme : Rotroff 1997, p. 97.

218 Un motif similaire de palmettes entourant un cercle central décore l'intérieur d'un bolsal contemporain d'Andalousie orientale : Domínguez, Sánchez 2001, p. 262, n 463, fig. 162 : 380-350. Pour d'autres exemples de bolsals de la même époque présentant un décor proche de celui de notre première série, cf. ibid., p. 194, 271, nos 61 et 536 .

219 Rotroff 1997, p. 97. 
privé d'ombilic central par dessous, et le pied adopte un profil en tore évoquant celui des pieds des skyphoi de type A220. Comme VN 28, cet exemplaire est privé de décor estampé.

VN 17. - Dépôt DP 13. Ht 7,9 cm, diam. de l'embouchure $16 \mathrm{~cm}$. Inv. PIN 3683. PI. 94b

Restauré. Pied annulaire bas et évasé, à face extérieure nettement carénée et face intérieure convexe se prolongeant dans le plan de pose ; vasque peu profonde, à paroi convexe-concave dans sa partie inférieure, presque verticale dans sa partie supérieure ; bord non distinct de la paroi, à lèvre pointue ; anses horizontales en fer à cheval attachées sous le bord. Fond extérieur réservé (couvert d'engobe rougeâtre), décoré d'un disque et d'une large bande en vernis noir, sur lesquels ont été incisés après cuisson un point central et cinq cercles. Décor du fond intérieur : cinq palmettes estampées reliées par des arcs incisés ; au centre, cercle incisé.

Vers 390-380.

VN 18. - Dépôt DP 30. Ht 4,3 cm, diam. de l'embouchure $9,6 \mathrm{~cm}$. Inv. FR 2.39. PI. 94c

Fragmentaire. Restauré. Pied annulaire bas et évasé, à face extérieure carénée et face intérieure convexe ; vasque légèrement concave dans sa partie inférieure, convexe dans sa partie supérieure ; anses en fer à cheval. Fond extérieur réservé (couvert d'engobe rougeâtre), décoré d'un point central, deux cercles et une bande en vernis noir. Fond intérieur décoré de quatre palmettes estampées disposées en forme de croix autour d'un cercle incisé.

Vers 390-380.

VN 19. - Dépôt DP 30. Ht 3,5 cm, diam. de l'embouchure $6,8 \mathrm{~cm}$. Inv. PIN 3654 (FR 2.18). PI. 94d

Une anse manque. Restauré. Pied annulaire bas à faces intérieure et extérieure convexes ; vasque légèrement concave dans sa partie inférieure, convexe dans sa partie supérieure ; anses légèrement relevées, en fer à cheval. Fond extérieur réservé (traces d'engobe rougeâtre qui a presque complètement disparu) avec un disque central et une bande en vernis noir.

Vers 390-380.

VN 20. - Tombe SP 325 . Ht $8,1 \mathrm{~cm}$, diam. de l'embouchure $16,4 \mathrm{~cm}$. Inv. PIN 3723. Pl. 94e

220 On doit reconnaître néanmoins que d'autres exemples contemporains restent beaucoup plus proches des bolsals du deuxième et du troisième quart du $\mathrm{IV}^{\mathrm{e}} \mathrm{s}$. : cf. Rotroff 1997, p. 259, $\mathrm{n}^{\circ} 168$, fig. 13, pl. 16 ; Miller 1974, p. 234, n 36, pl. 32 ; Breccia 1912 , p. $68-69, \mathrm{n}^{\text {os }} 183-187$, pl. 46.121.
Pied annulaire bas et évasé, à face extérieure carénée et face intérieure convexe ; rainure réservée sur le plan de pose ; vasque à paroi convexe-concave dans sa partie inférieure, verticale dans sa partie supérieure ; anses légèrement relevées, en fer à cheval. Décor du fond intérieur: six palmettes estampées reliées par des arcs incisés.

Vers 390-380.

VN 21. - Foyer F 9. Ht 4,2 cm, diam. de l'embouchure 9,4 cm. Inv. PIN 4033m (FR 3.16). PI. 94f

Fragmentaire, recollé. Des fragments des anses, de la vasque et du bord manquent. Traces de combustion. Pied annulaire bas et évasé, à face extérieure carénée et face intérieure convexe; vasque à paroi convexe-concave dans sa partie inférieure, presque verticale dans sa partie supérieure ; anses en fer à cheval. Fond extérieur réservé, décoré d'un point central, deux cercles et une bande en vernis noir (vernis très effacé). Fond intérieur décoré de quatre palmettes estampées disposées en forme de croix autour d'un cercle incisé.

Vers 380.

VN 22. - Foyer F 9. Ht 3,7 cm, diam. de l'embouchure $7 \mathrm{~cm}$. Inv. PIN 4033h (FR 3.25). PI. 95a

Fragmentaire, recollé. Une partie de l'une des anses, quelques fragments de la vasque et la plus grande partie du pied manquent. Traces de combustion. Pied annulaire bas et évasé, à face extérieure carénée et face intérieure convexe ; vasque à paroi convexe-concave dans sa partie inférieure, presque verticale dans sa partie supérieure ; anses légèrement relevées, en fer à cheval. Fond extérieur réservé, décoré probablement d'un point central (à présent effacé), deux cercles et une bande en vernis noir. Décor du fond intérieur: quatre palmettes estampées disposées en forme de croix.

Vers 380.

VN 23. - Foyer F 1. Ht 4,9 cm, diam. de l'embouchure $10 \mathrm{~cm}$. Inv. PIN 3276 . Pl. 68d

Fragmentaire. Les anses et des fragments de la panse manquent. Pied annulaire bas et évasé, à face extérieure carénée et intérieure convexe ; vasque concave près de la transition vers le pied, presque tronconique dans sa partie supérieure. Décor du fond intérieur: trois palmettes estampées reliées par des arcs incisés.

Vers 380.

VN 24. - Foyer F 1. Inv. PIN 3278. Pl. 68e

Les anses manquent. Dimensions et forme identiques à VN 23.

Vers 380 . 
VN 25. - Foyer F 11. Inv. FR 3.12.

Plusieurs fragments (certains recollés) provenant du bord et de la vasque, auxquels s'ajoutent un fragment conservant une partie du pied et un autre avec le départ d'une anse. Pied annulaire bas ; vasque à paroi convexe, décorée d'un sillon incisé après cuisson près de la jonction avec le pied ; bord non différencié, à lèvre pointue. Restes de décor estampé sur la paroi intérieure : trois rangées de points estampés et traces de deux palmettes formant probablement un motif cruciforme.

Vers 380-370.

VN 26. - Dépôt DP 6. Ht 3,3 cm, diam. de l'embouchure $7 \mathrm{~cm}$. Inv. PIN 3370. Pl. 95b

Fragmentaire, les anses manquent. Pied annulaire bas et évasé, à face extérieure carénée et face intérieure convexe ; vasque à paroi convexe-concave dans sa partie inférieure, presque verticale dans sa partie supérieure ; traces des attaches des anses horizontales sous le bord. Fond extérieur réservé et décoré de deux cercles en vernis noir. Décor du fond intérieur : quatre palmettes estampées formant un motif cruciforme.

Vers 400-375.

VN 27. - Dépôt DP 18. Ht 7,1 cm, diam. de l'embouchure $17 \mathrm{~cm}$. Inv. PIN 3722. Pl. 95c

Pied annulaire bas et évasé, à faces extérieure et intérieure convexes, décoré d'un ombilic sous le fond extérieur et d'une rainure réservée sur le plan de pose ; vasque à paroi convexe-concave dans sa partie inférieure, parfaitement verticale dans sa partie supérieure ; anses légèrement relevées, de forme triangulaire. Décor du fond intérieur : cinq palmettes estampées entourant un cercle incisé.

Vers 370-350.

VN 28. - Dépôt DP 7. Ht 7,5 cm, diam. de l'embouchure $15,3 \mathrm{~cm}$. Inv. PIN 3620 . Pl. 95d

Restauré. Pied annulaire bas et évasé, à face extérieure carénée et face intérieure convexe ; rainure réservée sur le plan de pose ; vasque à paroi convexe-concave dans sa partie inférieure, verticale dans sa partie supérieure ; anses légèrement relevées, de forme triangulaire. Vernis de mauvaise qualité, non homogène.

Vers 350-325.

VN 29. - Dépôt DP 17. Ht 5,1 cm, diam. de l'embouchure 10,3 cm. Inv. PIN 3717. PI. 57g

Pied annulaire bas à faces extérieure et intérieure convexes; vasque à paroi doucement carénée sans concavité inférieure; anses légèrement relevées, de forme triangulaire. Entièrement couvert de vernis noir.

Vers 310-290.

\subsection{Coupes-skyphoi}

\subsection{1. À paroi fine (« light-wall»)}

Ce type de coupe-skyphos est représenté par un seul exemplaire issu du foyer F 8 en secteur Nord. Le contexte en question doit sans doute être mis en rapport avec des rites pratiqués auprès de la couverture tumulaire de SP 336, peu après l'installation de cette dernière sépulture au cours de la phase 2, mais en tout cas avant la construction de l'enclos ovale MR 6/7 vers 380, lequel vient partiellement recouvrir les restes du foyer. Si l'on compare notre vase aux exemplaires des années 440400 , lorsque la production de coupes-skyphoi à paroi fine atteint son apogée ${ }^{221}$, quelques différences significatives ressortent immédiatement : une facture plus épaisse de la paroi et du pied, une vasque plus étroite se terminant par un bord évasé, des anses relevées au-dessus de l'embouchure, aux attaches rapprochées et à l'extrémité probablement recourbée vers l'intérieur, enfin un décor estampé très simple qui semble fort éloigné des arrangements complexes ornant les vases des années 440-420 ou même de ceux, moins ambitieux, que nous trouvons dans les années 420-400 222. Ces spécificités permettent de rapprocher VN 30 des représentants les plus tardifs du type qu'on retrouve de façon plus ou moins sporadique dans des contextes datant de toute la première moitié $\mathrm{du} \mathrm{IV}^{\mathrm{e}} \mathrm{s}{ }^{223}$ et même au-delà ${ }^{224}$. Bien que présentant

221 Pour cette période, comparer par exemple certaines des coupesskyphoi mieux conservées de l'Agora d'Athènes: Sparkes, Talcott 1970 , p. 277-278, nos 580-583, 586, 593, fig. 6, pl. 26 et 54 ; Corbett 1949 , p. 323 , nos $37-38$, pl. 86,89 et 90 . L'évolution au cours de la deuxième moitié du $\mathrm{V}^{\mathrm{e}} \mathrm{s}$. et au début du $\mathrm{IV}^{\mathrm{e}}$ est clairement illustrée par les profils publiés dans Talcott 1935, p. 503, fig. 20 ( ${ }^{\text {os }} 11$ et 114-116).

222 Pour un aperçu du développement des décors, en plus des exemplaires cités dans la note précédente, cf. Sparkes, Talcott 1970, p. 277-278, nos 584-585, 587-592, 596-599, pl. 54-55.

223 Voici une petite liste de coupes-skyphoi à paroi fine de cette époque, se limitant aux publications qui nous ont été accessibles : Agora d'Athènes: Sparkes, Talcott 1970, p. 278-279, $\mathrm{n}^{\text {os }}$ 600-611, fig. 6 , pl. 26 et 55 ; Corbett 1949, p. 343, n 148, pl. 86, 89-90; Talcott 1935, p. 522, $\mathrm{n}^{\circ} 115$, fig. 8, 20 ; Athènes, Pnyx : Rotroff, Camp 1996, p. 278, fig. 7.4-5 ; Thasos : Blondé 1985, p. 302, nos 119-120, fig. 15 ; Blondé 1989 , p. $498, \mathrm{n}^{\text {os }} 49-51$, fig. 8 ; Apollonia, Kalfata : Ivanov 1963, p. 184-185, ${ }^{\text {os }} 428-430$, fig. 73, pl. 101 ; nécropole tumulaire de Panskoe I (Crimée) : Monahov, Rogov 1990b, p. 142, pl. $5, \mathrm{n}^{\circ} 68$ : le vase a été découvert avec une coupe-skyphos à paroi épaisse et deux amphores héracléotes portant des timbres des éponymes Kerkinos et Satyros ( $\mathrm{II}^{\mathrm{e}}$ et $\mathrm{III}^{\mathrm{e}}$ groupe de magistrats selon V. Kats), qui donnent une date approximative dans le second quart ou le milieu du IVe s. (Monahov, Rogov 1990a, p. 132-134, nos 10, 14, pl. 2 et 7 ; Monahov 2003, p. 321-322, pl. 91, 6 et 92, 9 ; Kats 2003, p. 275-276)

224 Quelques exemples isolés proviennent de contextes attribuables au dernier quart du IVe et du début du IIIe s., suggérant ainsi que le type à paroi fine était probablement encore produit à ce moment-là : 
encore quelques variations dans la facture et le profil, ces vases affichent une unité considérable sur le plan de leur morphologie. En effet, il semble que, comme pour les coupes-skyphoi à paroi épaisse de la même époque, le seul élément fiable permettant de les différencier et d'établir des séquences chronologiques cohérentes soit leur décor: les exemplaires datant des deux premières décennies du $\mathrm{IV}^{\mathrm{e}} \mathrm{s}$., auxquels appartient notre VN 30, ont généralement un fond extérieur réservé et orné de cercles et de bandes de vernis noir, ainsi qu'un décor de motifs estampés relativement simples à l'intérieur (souvent une croix de palmettes entourée d'une zone d'oves comprise entre deux cercles incisés), sans emploi de bandes de guillochis 225 ; au contraire, ceux des décennies suivantes sont caractérisés par un fond extérieur entièrement couvert de vernis noir et muni d'un ombilic central, une rainure réservée sur le plan de pose et un décor intérieur constitué d'une ou plusieurs bandes de guillochis entourant un motif central très similaire à la croix de palmettes de la série antérieure ${ }^{226}$. Il est cependant difficile de tracer une limite claire, et vers 380-375 on trouve plusieurs exemplaires de transition présentant des croisements différents des éléments constitutifs de chacune des deux séries ${ }^{227}$.

VN 30. - Foyer F 8. Ht 5,6 cm, diam. de l'embouchure 11,2 cm. Inv. PIN 3860. PI. 75c

Fragmentaire. Pied annulaire bas et évasé, à face extérieure moulurée et face intérieure rectiligne ; petite concavité à la transition entre le pied et la vasque ; vasque hémisphérique se terminant par un bord légèrement évasé à lèvre arrondie ; deux anses horizontales attachées sur la partie supérieure de la vasque et relevées un peu au-dessus du bord. Décor du fond intérieur : trois palmettes estampées.

Vers 390-380.

Schlörb-Vierneisel 1966, p. 86, n 148.1, pl. 57, 3-4 (de la nécropole du Céramique à Athènes); Parovich-Peshikan 1974, p. 69, fig. 68, 1-2 (de la nécropole hellénistique d'Olbia); Hannestad 2005, p. 190191, fig. 12 (de l'habitat de Panskoe I en Crimée). Ces vases restent encore assez proches du groupe précédent dont ils ne se distinguent que par l'extrémité plus fortement recourbée des anses et, dans le cas de la coupe-skyphos d'Olbia, un profil plus allongé de ces dernières. Il n'est guère certain cependant qu'il s'agisse de productions attiques. 225 Cf. Sparkes, Talcott 1970, p. 278, nos $601-603$, pl. 26 et 55 ; Corbett 1949, p. 343, n 148, pl. 86, 89 et 90 ; Blondé 1985, p. 302, $\mathrm{n}^{\text {os }} 119-120$, fig. 15 . Notons néanmoins que le décor estampé de ces exemples est plus élaboré que celui de VN 30.

226 Sparkes, Talcott 1970, p. 278-279, nos 608 et 610-611, fig. 6, pl. 26 et 55 ; Rotroff, Camp 1996, p. 280, fig. 7, 4-5.

227 Les exemplaires suivants peuvent être classés dans cette catégorie intermédiaire : Sparkes, Talcott 1970, p. 278-279, nos 600 , 604-607, 609, fig. 6, pl. 26 et 55 ; Talcott 1935 , p. 522, n 115 , fig. 8 , 20 ; Blondé 1989, p. 498, n 51, fig. 8 ; Ivanov 1963, p. 184-185, $\mathrm{n}^{\text {os }} 28-30$, fig. 73 , pl. 101 .

\subsection{2. À paroi épaisse (« heavy-wall»)}

Contrairement au type à paroi fine, les coupes-skyphoi à paroi épaisse sont assez bien représentées dans le matériel des fouilles conjointes et ceci pour la même époque que VN 30. Nous comptons en effet sept exemplaires qui, à l'exception de VN 37, semblent presque contemporains et proviennent de différents contextes rituels de la phase 2 : DP $31-32$ et le foyer $F 5$ près de SP 343 et 339 en secteur central, DP 2 au-dessus des dalles de couverture de la ciste SP 291 en secteur Sud, et le foyer F 6 qu'on doit probablement mettre en rapport avec SP 334 en secteur Nord ${ }^{228}$. VN 37, dont seule une partie du bord et de la vasque est conservée, est sans doute un peu plus tardif. Il est issu de DP 33, un contexte hétérogène de la phase 3 qui peut être daté, sur la base du matériel amphorique qu'il contenait, du second quart du IV e $s$.

Les vases VN 31-36 illustrent les développements caractéristiques qui affectent le type au cours du premier quart du $\mathrm{IV}^{\mathrm{e}} \mathrm{s}$. : une facture assez épaisse, un pied étroit et parfois assez haut, une vasque peu profonde se terminant par un bord épaissi en forme d'amande et des anses relevées au-dessus de l'embouchure, aux attaches rapprochées et à l'extrémité recourbée vers l'intérieur. Conformément à la tradition de l'époque, le fond extérieur est systématiquement réservé avec deux ou trois cercles et une bande en vernis noir, alors que le fond intérieur est décoré de quelques motifs estampés fort simples, consistant en une croix de palmettes entourée d'oves (parfois négligées au point de devenir de simples impressions circulaires) ou encore, comme dans le cas de VN 32, d'une série petites impressions en forme d'arc de cercle qui préfigurent les bandes de guillochis postérieures. Malgré ces points communs, qu'on retrouve dans nombre de parallèles contemporains ${ }^{229}$, des divergences

228 VN 35 représente un cas particulier, puisqu'il s'agit d'une trouvaille isolée. Cependant, le vase a été découvert le même jour et dans le même secteur que le dépôt DP 2 et, comme ce dernier, il était probablement associé à la couverture tumulaire de SP 291.

229 Comparer, par exemple, les exemplaires suivants: Agora d'Athènes: Sparkes, Talcott 1970, p. 280, $\mathrm{n}^{\text {os }}$ 621-622, fig. 6, pl. 27, 55 ; Corinthe: Williams 1979, p. 133-134, n 48, fig. 6 a-b ; Thasos, Jardin de l'EFA: Blondé 1985, p. 301-302, nos 107-111, fig. 14 (contexte de la première moitié du $\mathrm{IV}^{\mathrm{e}} \mathrm{s}$., seules les vasques sont conservées, certains des vases peuvent être plus récents que le premier quart du $\mathrm{IV}^{\mathrm{e}} \mathrm{s}$.) ; Apollonia, Kalfata: Ivanov 1948, p. 41, fig. 41 ; Ivanov 1963, p. 183-184, nos 424-427, fig. 73, pl. 100 (les vases sont datés sans arguments valables de la première moitié, du troisième quart et de la deuxième moitié du $\mathrm{IV}^{\mathrm{e}} \mathrm{s}$., mais remontent sans doute au premier quart du siècle); Apollonia, zone portuaire: Galabov 1965, p. 28-29, nos 50-51, 54, fig. 21 ; nécropole d'Enisala (arrière-pays d'Histria): Alexandrescu 1978, p. 87, $\mathrm{n}^{\text {os }}$ 560-561, pl. 65 ; Lungu 1993, p. 174-176, nos 9-10, pl. 3, 9 (datés par V. Lungu 
considérables sont à noter dans l'épaisseur de la paroi et surtout dans le traitement des bords : nous passons ainsi de vases à bord relativement court et fin (VN 31-33) ${ }^{230}$ à des exemplaires qui présentent un bord d'épaisseur plus importante (VN 35-36) ${ }^{231}$ ou de longueur presque démesurée (VN 34) ${ }^{232}$. Compte tenu des synchronismes évidents mis en valeur par l'analyse stratigraphique, ces divergences ne sont manifestement pas dues à une évolution chronologique et doivent plutôt être considérées comme le résultat du travail de différents ateliers qui ont produit parallèlement au cours du premier quart du $\mathrm{IV}^{\mathrm{e}} \mathrm{s}$.

Le mauvais état de conservation de VN 37 nous empêche malheureusement d'entrevoir un développement cohérent durant le deuxième quart du $\mathrm{IV}^{\mathrm{e}} \mathrm{s}$., mais les quelques exemples mieux conservés qui nous sont parvenus de cette époque permettent de compléter quelque peu cette image ${ }^{233}$. Comme la coupe-skyphos à paroi fine, le type semble se figer durant la phase finale de son existence et le décor extérieur et intérieur apparaît là encore comme un repère chronologique déterminant. Après ca. 380 prédominent les fonds entièrement couverts de vernis noir, à ombilic central, ainsi que les plans de pose réservés et ornés d'une rainure, alors que le décor intérieur voit l'apparition des omniprésentes bandes de guillochis qui caractérisent l'ensemble de la production attique tardive à vernis noir.

dans le second quart du IV ${ }^{\mathrm{e}} \mathrm{s}$., mais probablement plus anciens); nécropole tumulaire d'Elisavetovskoe (Don inférieur) : Brashinskiy 1980 , p. 128-129, n 171, pl. 14 (daté du milieu ou du troisième quart du $\mathrm{IV}^{\mathrm{e}} \mathrm{s}$. selon les parallèles de la nécropole d'Apollonia : voir ci-dessus) ; nécropole tumulaire de Panskoe I (Crimée) : Monahov, Rogov 1990b, p. 141, pl. 4, n 61 (contexte du début du $\mathrm{IV}^{\mathrm{e}} \mathrm{s}$. d'après l'amphore chiote associée, variante V-A selon la typologie de Monahov: Monahov, Rogov 1990a, p. 138, n 33, pl. 5 et 7 ; Monahov 2003, p. 240, pl. 10.4 ; pour la chronologie de la variante, cf. ibid., p. 20-21).

230 Cf. également, avec un bord similaire, Sparkes, Talcott 1970, p. 280, n 621, fig. 6, pl. 27, 55 ; Blondé 1985, p. 301, n 107, fig. 14. 231 Comparer Sparkes, Talcott 1970, p. 280, n 622, pl. 27, 55 ; Williams 1979, p. 133-134, n 48, fig. 6 a-b ; Blondé 1985, p. 301, $\mathrm{n}^{\text {os }} 108-111$, fig. 14 ; Ivanov 1963 , p. $183-184, \mathrm{n}^{\text {os }} 424-425$, fig. 73 , pl. 100 ; Brashinskiy 1980 , p. 128-129, n 171, pl. 14.

232 Voir en particulier les deux exemplaires d'Enisala : Lungu 1993, p. 174-176, nos 9-10, pl. 3 et 9.

233 Agora d'Athènes: Sparkes, Talcott 1970, p. 280, n 623, pl. 27, 55 (vers 380) ; Thasos, puits Valma: Blondé 1989, p. 498, $\mathrm{n}^{\circ} 47$, fig. 8 (contexte des deuxième et troisième quarts du $\mathrm{IV}^{\mathrm{e}} \mathrm{s}$.) ; Apollonia, Kalfata: Ivanov 1948, p. 39, fig. 38, 2 et 39 ; Apollonia, zone portuaire : Galabov 1965, p. 28-29, $\mathrm{n}^{\text {os }} 52-53$, fig. 21 ; nécropole d'Enisala (arrière-pays d'Histria) : Lungu 1993, p. 176, n 11, pl. 3, 9 (milieu ou troisième quart $\mathrm{du} \mathrm{IV}^{\mathrm{e}} \mathrm{s}$.) ; nécropole tumulaire de Panskoe I (Crimée) : Monahov, Rogov 1990b, p. 142-147, pl. 5-10, $\mathrm{n}^{\mathrm{os}} 64,60,65,40,67$ (contextes des deuxième et troisième quarts du $\mathrm{IV}^{\mathrm{e}} \mathrm{s}$. d'après le matériel amphorique et céramique associé).
VN 31. - Dépôt DP 32. Ht sans les anses $6,3 \mathrm{~cm}$, diam. de l'embouchure 11,6 cm. Inv. PIN 3639 (FR 2.15). Pl. 95e

Fond percé. Restaurée. Pied annulaire à face extérieure moulurée (moulure soulignée par un sillon) et face intérieure rectiligne; sillon à la transition vers la vasque ; celle-ci est hémisphérique et séparée du bord par une petite concavité ; bord évasé, biconvexe, à lèvre pointue ; deux anses horizontales attachées à la partie supérieure de la vasque, relevées un peu au-dessus du bord et légèrement recourbées. Réservés : le fond extérieur avec deux cercles et une bande en vernis noir, le plan de pose, ainsi que le sillon à la transition entre le pied et la vasque. Traces d'engobe rougeâtre sur le fond extérieur et le plan de pose. Fond intérieur décoré d'une rangée d'impressions circulaires entre deux cercles incisés.

Vers 400-390.

VN 32. - Dépôt DP 31. Ht sans les anses $6,2 \mathrm{~cm}$, diam. de l'embouchure 11,5 cm. Inv. PIN 3656 (FR 2.16). Pl. $95 f$

Une anse manque. Restaurée. Pied annulaire à face extérieure moulurée et face intérieure rectiligne ; sillon à la transition vers la vasque, qui est séparée du bord par une concavité peu marquée ; bord biconvexe à lèvre pointue ; anses relevées un peu au-dessus du bord et légèrement recourbées. Réservés : le fond extérieur (traces d'engobe marron) avec un point central, trois cercles et une bande en vernis noir, le plan de pose, le sillon entre le pied et la vasque. Décor du fond intérieur: quatre palmettes estampées entourant un élément en forme de volute ; tout autour, rangée d'impressions irrégulières en forme d'arc de cercle.

Vers 390-380.

VN 33. - Foyer F 5. Ht sans les anses $7 \mathrm{~cm}$, diam. de l'embouchure 11,6 cm. Inv. PIN 3368d (FR 2.44). Pl. 96a

Fragmentaire, recollée. Plusieurs fragments des anses, du bord, de la vasque, du pied et du fond manquent. Pied annulaire à face extérieure moulurée et face intérieure rectiligne ; sillon à la transition vers la vasque, qui est séparée du bord par une petite concavité ; bord biconvexe à lèvre pointue; les anses étaient relevées un peu au-dessus du bord et légèrement recourbées. Réservés : le fond extérieur (partiellement conservé) avec traces d'un cercle et une bande en vernis noir, le plan de pose, le sillon entre le pied et la vasque. Traces d'engobe rougeâtre sur le fond extérieur et le plan de pose. Décor du fond intérieur : rangée d'oves estampées entre deux cercles incisés.

Vers 390-380. 
VN 34. - Dépôt DP 2. Ht sans les anses 6,2 cm, diam. de l'embouchure 11,2 cm. Inv. PIN 3130. Pl. 96b

Fragmentaire, recollée. Les anses manquent. Pied annulaire à face extérieure moulurée et face intérieure convexe; sillon à la transition vers la vasque, qui est séparée du bord par une concavité peu marquée ; bord biconvexe à lèvre pointue ; traces des attaches de deux anses horizontales sur la partie supérieure de la vasque. Décor du fond intérieur : trois palmettes estampées disposées de façon asymétrique autour d'un cercle incisé ; tout autour, rangée d'oves estampées entre deux cercles incisés.

Vers 390-380.

VN 35. - Trouvaille isolée dans la zone du point G 3 . Ht cons. $6 \mathrm{~cm}$, diam. de l'embouchure 12,6 cm. Inv. PIN 3140. Pl. 96c

Fragmentaire. La totalité du pied et les anses manquent. Sillon à la transition entre le pied et la vasque ; petite concavité entre la vasque et le bord ; bord biconvexe à lèvre pointue; traces des attaches de deux anses horizontales sur la partie supérieure de la vasque. Décor du fond intérieur : six palmettes estampées formant un cercle.

Vers 390-380.

VN 36. - Foyer F 6. Ht cons. 3,6 cm, diam. de l'embouchure $11,6 \mathrm{~cm}$. Inv. PIN 3824. Pl. 72a

Fragmentaire. La partie inférieure de la vasque et la totalité du fond et du pied manquent. Sillon à la transition entre le pied et la vasque ; petite concavité entre la vasque et le bord ; bord biconvexe à lèvre pointue ; anses relevées au-dessus du bord et légèrement recourbées.

Vers 380 .

VN 37. - Dépôt DP 33. Ht cons. $6,1 \mathrm{~cm}$, diam. de l'embouchure $10,9 \mathrm{~cm}$. Inv. FR 2.57. Pl. 96d

Deux fragments recollés. Les anses, la moitié du bord et de la vasque, ainsi que le fond avec le pied manquent. Sillon à la transition entre le pied et la vasque ; petite concavité entre la vasque et le pied ; bord biconvexe à lèvre pointue ; traces des attaches de deux anses horizontales sur la partie supérieure de la vasque.

Vers 375-350.

\subsection{Coupes-canthares}

\subsection{1. À bord mouluré (« moulded rim»)}

Les vases VN 38-40 illustrent deux étapes différentes de l'évolution des coupes-canthares à bord mouluré. VN 38 peut être classé parmi les premiers représentants du type et constitue sans aucun doute le plus ancien exemple de la variante à bord très large parmi les vases que nous connaissons. Il est issu du foyer $\mathrm{F} 5$ en secteur central, un riche ensemble rituel dont la position sur la pente de la couverture tumulaire de SP 343, sous les remblais associés à la construction du mur MR 3, indique une date précoce au cours de la phase 2. Le vase offre plusieurs points de comparaison avec quelques coupes-canthares de l'Agora d'Athènes et de Corinthe que B. Sparkes a placées au tout début de la série avec une date vers $390-380^{234}$ : un pied relativement haut, à face extérieure moulurée et face intérieure convexe, dont le profil reste encore très proche de celui des pieds des coupes-skyphoi à paroi épaisse ; un fond extérieur plat et réservé, décoré de cercles et de bandes de vernis noir, formant un angle ouvert avec la face extérieure du pied ; une vasque très basse et un col relativement court qui, dans notre cas, se trouve presque entièrement caché par le déversement du bord. Il est intéressant également de remarquer que, comme sur certains parallèles attiques et corinthiens, le décor estampé à l'intérieur se conforme déjà au schéma qui sera largement la norme au cours des décennies suivantes : quelques palmettes reliées, disposées autour d'un cercle central, sont inscrites dans une série de petites impressions en forme d'arc de cercle, similaires à celles de VN 32, qui annoncent les bandes de guillochis postérieures ${ }^{235}$.

VN 39-40, qu'on peut rattacher respectivement à la variante courante à bord mouluré plus fin et à celle relativement rare à bord très large, présentent des traits indéniablement plus tardifs. Les deux vases faisaient partie du mobilier de SP 264 en secteur Sud, que les observations stratigraphiques attribuent à la phase 3 d'occupation du site. Leurs proportions sont un peu plus allongées, le pied plus étroit, à face intérieure concave et plan de pose réservé, alors que le fond extérieur affiche l'ombilic central caractéristique des exemplaires récents. Le décor intérieur s'inscrit dans la continuité de celui de $\mathrm{VN} \mathrm{38}$, à cette différence près que les impressions maladroites du premier quart du $\mathrm{IV}^{\mathrm{e}} \mathrm{s}$. sont maintenant remplacées par des guillochis «classiques » évoquant un décor fait à la roulette. Les nombreux parallèles

234 Sparkes, Talcott 1970, p. 282, nos 648-649, 651-652, fig. 6-7, pl. $28,56$.

235 Cf. ibid., p. 282, nos 651-652 et le fragment de Corinthe C-37229 cité dans le commentaire pour le ${ }^{\circ} 651$. Il convient néanmoins de remarquer que les bandes de guillochis sur ces exemplaires sont bien plus élaborées que les impressions quelque peu maladroites décorant l'intérieur de VN 38 et VN 32, ce qui, indépendamment des observations stratigraphiques, constitue un argument supplémentaire pour attribuer à ces derniers une date un peu plus ancienne. 
méditerranéens et pontiques ${ }^{236}$ permettent d'avancer dans le cas de ces vases une date relativement précise vers le milieu du IV e s., qui se trouve confirmée par une analyse plus approfondie du contexte stratigraphique de la sépulture dont ils proviennent.

VN 38. - Foyer F 5. Ht 8 cm. Inv. PIN 3368a (FR 2.45). Pl. 96e

Fragmentaire, recollée. Les anses, une partie du bord et quelques fragments du col manquent. Pied annulaire à face extérieure moulurée (moulure soulignée par un sillon incisé après cuisson) et face intérieure convexe ; plan de pose arrondi ; sillon incisé après cuisson à la transition entre le pied et la vasque ; vasque basse, arrondie ; col haut et concave se terminant par un bord déversé en corniche creuse qui recouvre la plus grande partie du col ; départ de deux anses horizontales attachées à la partie supérieure de la vasque. Réservés : le fond extérieur avec un point central, deux bandes et quatre cercles en vernis noir, le plan de pose. Décor du fond intérieur : quatre palmettes estampées autour d'un cercle incisé ; tout autour, deux rangées d'impressions irrégulières en forme d'arc de cercle.

Vers 390-380.

VN 39. - Tombe SP 264. Ht 9,4 cm, diam. de l'embouchure $8,8 \mathrm{~cm}$. Inv. FR 1.8.2. PI. 96f

Une anse manque. Restaurée. Pied annulaire à face extérieure moulurée et face intérieure concave, décoré d'un ombilic central sous le fond extérieur et d'une rainure sur le plan de pose; vasque basse ; col haut et concave; bord déversé en corniche massive qui redescend jusqu'à mi-hauteur du col ; anses relevées à hauteur de l'embouchure et courbées à angle droit vers l'intérieur. Réservés : le plan de pose et le sillon sous

236 Pour VN 40, cf. la liste suivante: Agora d'Athènes: Sparkes, Talcott 1970 , p. $283, \mathrm{n}^{\circ} 658$, pl. 28 (comparer les proportions plus allongées que présente la coupe-canthare ${ }^{\circ} 659$ du même catalogue, datée du troisième quart du $\mathrm{IV}^{\mathrm{e}} \mathrm{s}$.) ; Olynthe : Robinson 1933, p. 187$188, \mathrm{n}^{\text {os }} 518-520,522$, pl. 149-150 ; Robinson 1950, p. 286-287 et $291, \mathrm{n}^{\text {os }} 504,509,518$ (cette dernière est à vasque godronnée), pl. 186-187, 189, 191 (ces trois vases ont des proportions similaires à VN 40, mais un pied plus large et sont probablement un peu plus anciens); Thasos, puits Valma: Blondé 1989, p. 499, n 53, fig. 8 (contexte des deuxième et troisième quarts du IV $\mathrm{s}$ s.); Apollonia, Kalfata: Ivanov 1948, p. 39, fig. 38-39; Ivanov 1963, p. 187, n 435, fig. 74, pl. 104 (ces deux exemples des anciennes fouilles de Kalfata ont un pied légèrement plus large que celui de VN 40); Apollonia, zone portuaire: Galabov 1965, p. $26, \mathrm{n}^{\circ} 35$, fig. $19 \mathrm{~b}$; nécropole d'Enisala (arrière-pays d'Histria) : Lungu 1993, p. 176, 179, n 12 , pl. 4 et 9. Pour VN 39, cf. Sparkes, Talcott 1970, p. 283, n 657, pl. 28 (deuxième quart du $\mathrm{IV}^{\mathrm{e}} \mathrm{s}$., mais col légèrement plus allongé que celui de notre exemplaire) ; Robinson 1950, p. 284-285, nos 500-501, pl. 184, 186-188 ; Blondé 1989, p. 499, n 54, fig. 8 ; Ivanov 1963 , p. $189, \mathrm{n}^{\circ} 446$, fig. 74 , pl. 103. la moulure de la face extérieure du pied. Décor du fond intérieur : six palmettes estampées reliées par des arcs incisés ; tout autour, deux rangées de guillochis.

Vers 350 .

VN 40. - Tombe SP 264. Ht 10,6 cm, diam. de l'embouchure $13 \mathrm{~cm}$. Inv. FR 1.8.1. Pl. 97a

Les anses manquent, sauf un fragment d'attache. Restaurée. Pied annulaire à face extérieure moulurée et face intérieure concave, décoré d'un ombilic central sous le fond extérieur ; vasque basse ; col haut et concave ; bord déversé en corniche massive; les anses étaient relevées à hauteur de l'embouchure et courbées à angle droit vers l'intérieur. Réservés : le plan de pose, le sillon sous la moulure de la face extérieure du pied. Décor du fond intérieur : quatre palmettes estampées reliées par des arcs incisés ; au centre, cercle incisé ; tout autour, rangée de guillochis.

Vers 350 .

\subsection{2. À bord trapu (« squat rim») (?)}

Le fragment de pied VN 41 appartenait probablement à une coupe-canthare à bord trapu, mais, compte tenu de l'état de conservation, il nous est très difficile d'être affirmatif à ce sujet. La face extérieure du pied est décorée de deux moulures alternant avec deux sillons, ce qui est un trait caractéristique des vases de ce type ${ }^{237}$. Cependant, le même traitement se retrouve sur les pieds de certaines coupes-canthares à vasque hémisphérique (cf. VN 42), compliquant ainsi tout effort d'identification. En effet, le seul argument permettant de trancher en faveur de l'un plutôt que de l'autre des deux types tient au fait que les pieds des coupes-canthares à bord trapu adoptent un profil plus élancé dès le second quart du $\mathrm{IV}^{\mathrm{e}} \mathrm{s}$., alors qu'à la même époque ceux des coupes-canthares à vasque hémisphérique restent encore relativement bas ${ }^{238}$. Or, notre fragment appartient sûrement à la première catégorie et il provient en même temps d'un contexte dont la date, d'après le matériel amphorique associé, ne devrait pas dépasser le milieu du siècle (375-350). Malgré son identification douteuse, VN 41 s'inscrit parfaitement dans la tradition céramique de son époque : le vase avait un fond extérieur entièrement couvert de vernis noir, doté d'un ombilic central, et un plan de pose réservé, lequel toutefois est privé de la rainure caractéristique que nous trouvons sur d'autres exemplaires du même type.

237 Sparkes, Talcott 1970, p. 120.

238 Ibid., p. 284, n 681, pl. 28 (375-350). Comparer p. 285, n ${ }^{\text {os }} 686-$ 687 , fig. 7 , pl. 28 (datées respectivement vers 380 et 350 ). 
VN 41. - Dépôt DP 33. Inv. FR 2.64.7a.

Fragment du pied avec le départ de la vasque. Pied annulaire à face extérieure moulurée (deux moulures alternant avec deux sillons) et face intérieure concave. Plan de pose réservé.

Vers 375-350.

\subsection{3. À vasque hémisphérique («bowl-shaped»)}

Comme VN 41, le pied VN 42 est décoré de deux moulures et de deux sillons sur la face extérieure. Toutefois, il est plus bas, relativement large et, autant qu'il nous est possible de juger, privé de décor estampé sur le fond intérieur, ce qui indique qu'il appartenait plutôt à une coupe-canthare à vasque hémisphérique ${ }^{239}$. Le catalogue de la céramique à vernis noir de l'Agora d'Athènes contient en effet un exemplaire avec un pied de proportions similaires qui, comme notre fragment, est entièrement couvert de vernis noir par dessous, doté d'un ombilic central et réservé sur le plan de pose ${ }^{240}$. La date fournie par ce parallèle - vers 350 - est confirmée par les observations effectuées de façon indépendante sur le contexte de découverte de $\mathrm{VN} 42$, le dépôt $\mathrm{DP} 27$ près de SP 332 en secteur central (phase 3). La position de cet important ensemble sous le remblai US $2 / 501$, daté vers 340-320 par les timbres amphoriques, au même niveau que SP 264 et 329 (cf. VN 39, 40 et 74a), permet de l'attribuer au milieu du siècle.

VN 43 illustre, de son côté, l'étape suivante du développement du type. Ce vase, presque complet à l'exception de quelques fragments de la vasque et de la totalité des anses, provient de l'US 217/626, un horizon de sable du début de la phase 2 , où il constitue manifestement une intrusion tardive. Comparé aux exemplaires des années 380-350, il présente des traits incontestablement plus évolués : un pied plus haut, de forme conique, muni d'une courte tige et une vasque qui reste encore assez basse, mais se termine par un bord nettement incurvé. Ces spécificités, qui annoncent déjà les profils élancés de l'époque hellénistique, trouvent des parallèles précis dans deux coupes-canthares de l'Agora d'Athènes datées par B. Sparkes du troisième quart du IV ${ }^{\mathrm{e}} \mathrm{s} .{ }^{241}$. Il convient donc de placer notre exemplaire dans le même quart de siècle.

239 Selon B. Sparkes, les coupe-canthares de ce type portent plus rarement un décor estampé à l'intérieur, lequel se limite dans la plupart des cas à une simple bande de guillochis. Les exemplaires les plus tardifs ne sont pas décorés de motifs estampés (ibid., p. 121).

240 Ibid., p. $285, \mathrm{n}^{\circ} 687$, pl. 28.

241 Ibid., n $^{\circ} 688$, fig. 7, pl. 28.
VN 42. - Dépôt DP 27. Diam. du pied $5,3 \mathrm{~cm}$. Inv. 1.42. Pl. 97b

Fragment représentant le fond et le pied du vase. Fond percé. Pied annulaire à face extérieure moulurée (deux moulures alternant avec deux sillons) et face intérieure concave, décoré d'une rainure sur le plan de pose. Moulure à la transition entre le pied et la vasque. Plan de pose réservé.

Vers 350.

VN 43. - US 217/626. Diam. de l'embouchure $12 \mathrm{~cm}$. Inv. PIN 4161b. PI. 97c

Fragmentaire, recollée. Quelques fragments de la vasque et du bord, ainsi que les anses, manquent. Pied annulaire à face extérieure moulurée (moulure soulignée par un sillon) et face intérieure concave, décoré d'un ombilic central sous le fond extérieur et d'une rainure sur le plan de pose ; courte tige entre le pied et la vasque ; vasque hémisphérique se terminant par un bord incurvé, à lèvre pointue. Plan de pose réservé.

Vers 350-325.

\subsection{Canthares}

\subsection{1. À bord mouluré (« moulded rim »)}

Selon B. Sparkes, la production de canthares à bord mouluré a commencé un peu plus tard que celle des coupes-canthares du même type, vers le début du second quart du $\mathrm{IV}^{\mathrm{e}} \mathrm{s}$. Cette hypothèse se trouve confirmée par les résultats de nos fouilles de Kalfata. En effet, tous les exemplaires répertoriés ci-dessous proviennent de contextes attribuables à la phase 3 de l'occupation du site, soit le deuxième et le troisième quart du $\mathrm{IV}^{\mathrm{e}} \mathrm{s}$. : DP 5 au Sud de SP 296 en secteur Sud; le remblai US 2/501 en secteur central ; SP 333, DP 16 et DP 14 près de SP 327 et SP 338 en secteur Nord.

Les critères morphologiques semblent déterminants pour établir le développement du type au cours de cette période. VN 44-46 ont un pied bas et relativement large, ainsi qu'une hauteur inférieure au diamètre du bord. Ils trouvent des parallèles précis dans le matériel de l'Agora d'Athènes et d'Olynthe, ce qui oriente vers une date avant le milieu du $\mathrm{IV}^{\mathrm{e}} \mathrm{s} .{ }^{242}$. Cette datation pourrait être affinée davantage dans le cas de VN 44 et 45 si l'on

242 Sparkes, Talcott 1970, p. 286, nos 697-698, pl. 29, 56 ; Robinson 1933 , p. $185, \mathrm{n}^{\text {os }} 505-506$, pl. 148 ; Robinson 1950, p. $289, \mathrm{n}^{\text {os }} 512-$ 513, 514-516, pl. 183-185, 192. Voir également Ivanov 1948, p. 41, fig. 42 ; Ivanov 1963, p. 194-195, $\mathrm{n}^{\text {os }} 460$ et 470, fig. 76, pl. 104 (des fouilles de Kalfata en 1946-1949: les deux vases sont datés du troisième quart et de la deuxième moitié du $\mathrm{IV}^{\mathrm{e}} \mathrm{s}$., mais les proportions assez basses et la largeur relativement importante du pied 
considère les contextes stratigraphiques de SP 333 et de SP 327 sous le dépôt DP 16. Les sépultures en question étaient installées dans deux remblais de sable (US 652 et 654) dont la mise en place est intervenue vraisemblablement au début du second quart du IV ${ }^{\mathrm{e}} \mathrm{s}$., en tout cas peu après la construction à la fin de la phase 2 (vers 380 ) de l'enclos MR 6/7 qu'ils couvraient partiellement. Cette observation fournit un précieux terminus post quem pour les deux canthares qui, de ce fait, pourraient être placés un peu plus tard au cours du même quart de siècle, dans les années 360-350.

VN 47-48 présentent des traits indéniablement plus tardifs, caractéristiques des canthares du milieu ou du troisième quart $\mathrm{du} \mathrm{IV}^{\mathrm{e}} \mathrm{s}$. Les proportions sont légèrement plus élancées (hauteur presque égale au diamètre du bord pour VN 47), mais restent encore proches de celles de VN 44-46. Le pied est plus haut et étroit, de forme conique. VN 48, qui provient du remblai US 2/501 (vers 340-320 d'après les timbres amphoriques), illustre la morphologie courante au cours de cette période ${ }^{243}$. VN 47, pour lequel nous ne disposons pas d'une fourchette plus précise, a un col à concavité plus prononcée qui s'éloigne quelque peu de la norme.

VN 44. - Dépôt DP 16. Ht 7,4 cm, diam. de l'embouchure $10 \mathrm{~cm}$. Inv. PIN 3709. Pl. 97d

Pied annulaire bas à face extérieure moulurée (moulure soulignée par un sillon) et face intérieure concave, décoré d'une rainure sur le plan de pose ; vasque peu profonde, arrondie ; col légèrement concave ; bord déversé en corniche massive; deux anses verticales à poucier attachées au bord et à la partie supérieure de la vasque.

Vers 370-350.

VN 45. - Tombe SP 333. Ht $6,8 \mathrm{~cm}$, diam. de l'embouchure $8,2 \mathrm{~cm}$. Inv. PIN 3762. Pl. 38c et 97e

Vernis fortement dégradé. Pied annulaire bas à face extérieure moulurée, marqué par une rainure sur le plan de pose ; vasque peu profonde ; col presque tronconique ; bord déversé formant une corniche massive ; anses verticales à poucier.

Vers 370-350.

indiquent qu'ils sont probablement plus anciens); Galabov 1965, p. $32-33, \mathrm{n}^{\text {os }} 86$ et 88 , fig. 30 (du dragage du port de Sozopol). 243 Pour les parallèles, cf. Sparkes, Talcott 1970, p. 286, $\mathrm{n}^{\text {os }} 699-702$, fig. 7, pl. 29 ; Galabov 1965, p. 33, nos 91-92, fig. 31 ; Alexandrescu 1978, p. 89, $\mathrm{n}^{\circ} 577$, pl. 65 (Histria) ; Lungu 1993, p. 132, ${ }^{\text {os }} 14-17$, pl. 4, 11 (de la nécropole d'Enisala dans l'arrière-pays d'Histria); Brashinskiy 1980, p. 132, $\mathrm{n}^{\text {os }}$ 200-202, pl. 16 (de la nécropole tumulaire d'Elisavetovskoe sur le Don inférieur) ; Monahov, Rogov 1990b, p. 147, 149-150, pl. 10, 12-13, nos 76-80 (de la nécropole tumulaire de Panskoe I en Crimée).
VN 46. - Dépôt DP 5. Ht 7,1 cm, diam. de l'embouchure $8,8 \mathrm{~cm}$. Inv. PIN 3220 . PI. 97f

Pied annulaire bas à face extérieure moulurée et face intérieure concave, décoré d'un ombilic central sous le fond extérieur et d'une rainure sur le plan de pose ; vasque peu profonde; col légèrement concave ; bord déversé en corniche massive ; anses verticales à poucier. Décor du fond intérieur: quatre palmettes estampées (une légèrement déplacée) formant un motif cruciforme ; tout autour, cercle de guillochis.

Vers 375-350.

VN 47. - Dépôt DP 14. Ht 7,9 cm, diam. de l'embouchure $7,8 \mathrm{~cm}$. Inv. PIN 3694 . Pl. $\mathbf{9 7 g}$

Très fragmentaire, recollé. Pied annulaire à face extérieure moulurée et face intérieure concave, décoré d'un ombilic central sous le fond extérieur et d'une rainure sur le plan de pose ; vasque peu profonde ; col fortement concave ; bord déversé en corniche massive ; anses verticales à poucier.

Vers 350-325.

VN 48. - US 2/501. Ht 7,4 cm, diam. de l'embouchure $8,7 \mathrm{~cm}$. Inv. FR 1.21. PI. 98a

Fragmentaire, recollé. Une anse, ainsi que des fragments de la vasque, du fond et du pied manquent. Pied annulaire à face extérieure moulurée et face intérieure concave, décoré d'un ombilic central sous le fond extérieur, d'une rainure sur le plan de pose et d'un sillon incisé après cuisson sous la moulure de la face extérieure; sillon incisé également à la transition entre le pied et la vasque ; vasque peu profonde ; col concave ; bord déversé en corniche massive; anses verticales se terminant par un poucier de forme rectangulaire. Plan de pose réservé. Décor du fond intérieur : trois rangées de guillochis, sur lesquelles sont apposées des palmettes estampées (trois conservées et départ d'une quatrième).

Vers 340-325.

\subsection{2. À une anse}

Ce type relativement rare, qui n'a eu vraisemblablement qu'une existence limitée, est représenté par un seul exemplaire provenant de DP 24. Il s'agit d'un contexte rituel de la phase 3 qu'il est possible de mettre en relation avec SP 283 en secteur central. VN 49 a un profil très proche de celui des coupes-canthares et des canthares à bord mouluré de la même époque, mais un diamètre inférieur du bord; il était muni à l'origine d'une anse de section ovale sans poucier dont seules les attaches sont conservées. Les parallèles qui nous sont connus indiquent plutôt une date vers le second quart 
ou le milieu du IVe s. ${ }^{244}$, mais la position de DP 24 dans le remblai US 2/501, ainsi que son association avec SP 283, installée dans le niveau immédiatement inférieur, suggèrent que notre vase doit être légèrement postérieur au milieu du siècle ${ }^{245}$.

VN 49. - Dépôt DP 24. Ht cons. 6,5 cm, diam. de l'embouchure $6,5 \mathrm{~cm}$. Inv. FR 1.24. Pl. 98b

Deux fragments recollés. L'anse, l'ensemble du pied et du fond, ainsi qu'une partie de la vasque manquent. Vasque relativement profonde, à épaulement marqué ; col haut et concave se terminant par un bord déversé en corniche massive qui redescend à mi-hauteur du col. L'anse (deux attaches conservées) était verticale, attachée à l'extrémité inférieure de la corniche du bord et la partie supérieure de la vasque.

Vers 340.

\subsection{3. À bord simple («plain rim»)}

Comme le précédent, le type à bord simple est représenté par un seul exemplaire, provenant du foyer F 7 en secteur Nord (phase 4). Comparé aux canthares décrits ci-dessus, VN 50 présente d'importantes différences qui signalent une date bien plus avancée : un pied plus haut, parfaitement conique, dessinant une courte tige au point de jonction avec la vasque ; une vasque profonde, en forme de cône inversé, se prolongeant dans un col fort allongé ; enfin, un diamètre du bord largement inférieur à la hauteur, ce qui contribue à conférer

244 Agora d'Athènes: Sparkes, Talcott 1970, p. 286, n 705, pl. 29 ; Marion (Chypre) : Karageorghis 1962, p. 360-361, fig. 42, 10 et 47 ; Olynthe : Robinson 1933, p. 185, n 508, pl. 148 ; Robinson 1950, p. 288, $\mathrm{n}^{\text {os }} 510-511$, pl. 188 ; Thasos, jardin de l'EFA : Blondé 1985 , p. $304-305, n^{\text {os }} 128$ et 130 , fig. 16 (contexte de la première moitié du IVe s.) ; Apollonia, Kalfata: Ivanov 1963, p. 191, n 452, pl. 103 (vasque godronnée : trouvaille isolée, le vase est daté de la deuxième moitié du $\mathrm{IV}^{\mathrm{e}} \mathrm{s}$., mais doit être contemporain des autres exemples du type); Apollonia, zone portuaire: Galabov 1965, p. $35, \mathrm{n}^{\circ} 101$, fig. 37 ; nécropole tumulaire de Panskoe I (Crimée) : Monahov, Rogov 1990b, p. 146, pl. 9, n 86 (contexte du milieu du $\mathrm{IV}^{\mathrm{e}} \mathrm{s}$. d'après l'amphore héracléote non timbrée [variante II-1 de S. Monahov: Monahov, Rogov 1990a, p. 134, n 19, pl. 3 et 7 ; Monahov 2003, p. 134-135] et le skyphos à vernis noir découverts dans la même tombe); nécropole tumulaire dans la banlieue occidentale de Rostov-sur-le-Don : Monahov 1999, p. 301, pl. 126, 4 (le vase a été découvert avec une amphore héracléote timbrée au nom de l'éponyme Kerkinos [II' groupe de magistrats : Kats 2003, p. 275] qui oriente vers une date dans les années 370).

245 Pour d'autres exemples probablement tardifs du type, cf. Robinson 1933, p. 212, n ${ }^{\circ} 728$, pl. 166 (= Robinson 1950, p. 288, $\mathrm{n}^{\circ}$ 510A, pl. 153, 185) : selon B. Sparkes (Sparkes, Talcott 1970, p. 123, n. 68), postérieur à la destruction d'Olynthe en 348 ; Lamb 1936, p. 50, pl. 30, n 2 (d'après l'auteur, l'origine attique de ce vase n'est pas assurée). Ce dernier exemplaire semble très proche par ses proportions de notre $\mathrm{VN} 49$. au vase des proportions très élancées. Le profil général évoque celui des canthares attiques des années 270$260^{246}$, mais quelques nuances dans le traitement du corps et du pied, la présence de cannelures sur la vasque (au lieu des godrons habituels), ainsi que le décor simplifié en barbotine sur le col permettent de penser que notre exemplaire est le produit d'un atelier non attique. En effet, des nuances similaires dans le traitement de la forme et du décor se retrouvent dans une série de canthares provenant de différents sites du littoral occidental et septentrional de la mer Noire qui ont été réunis récemment par A. Bojkova dans le type I.1 de son « Groupe de céramiques pontiques » («Pontic Pottery Group») ${ }^{247}$. Il s'agit, selon toute vraisemblance, d'une production régionale imitant le type à bord simple attique de la première moitié du III' $\mathrm{s}$. ${ }^{248}$

VN 50. - Foyer F 7. Ht 10,9 cm, diam. de l'embouchure $6,8 \mathrm{~cm}$. Inv. PIN 3835 . Pl. 74g

Fragmentaire. Pied annulaire haut, conique, à face extérieure moulurée et face intérieure rectiligne, séparé de la vasque par une courte tige concave ; vasque profonde à paroi légèrement convexe et épaulement marqué, décorée de cannelures; haut col concave; bord évasé dans la prolongement du col, à lèvre arrondie ; les deux anses verticales se terminent par un poucier légèrement relevé et fortement saillant, à extrémité élargie. Vernis brun dense à l'intérieur et à l'extérieur. À mi-hauteur du col, couronne de laurier en barbotine.

Vers 280-260.

246 Comparer Rotroff 1997, p. 243-244, $\mathrm{n}^{\text {os }} 16-24$, fig. 4-5, pl. 2-3 ; ibid., p. 244-255, $\mathrm{n}^{\text {os }} 28-35$, fig. 5-6, pl. 3-4 pour la version à vasque godronnée et décor de barbotine sur le col. Voir également certaines des coupes-canthares à bord simple de la même époque qui, comme VN 50, présentent une concavité prononcée du col et une vasque presque conique : ibid., p. 248-249, $\mathrm{n}^{\text {os }} 66-68,71,73-78$, fig. 7-8, pl. 7-8.

247 Bojkova 1997, p. 9-11 et pl. 1.

248 Pour d'autres exemples plus ou moins contemporains (avec ou sans décor de barbotine sur le col) qui appartiennent probablement à la même catégorie, cf. la liste suivante (non exhaustive) : Apollonia, Kalfata: Ivanov 1963 , p. $197, \mathrm{n}^{\text {os }} 479-481$, fig. 77 , pl. 105 ; Apollonia, zone portuaire : Galabov 1965, p. 34, n ${ }^{\text {os }} 94$ et 96 , fig. 32a et 34 ; Cabylé (Thrace, vallée de la Tundja) : Getov 1991, p. 169, fig. 4 ; Odessos : Toncheva 1953, p. 36-37, n 15, fig. 63 ; Toncheva 1961, p. 31, fig. 14 ; Albeşti (arrière-pays de Callatis) : Buzoianu, Bărbulescu 2002-2003, p. 72 et 75, pl. 4 et 7, n $^{\circ} 29.777$; Tomis: Bucovala 1967, p. 18, 20, 23-24, 26-27, pl. 7b, 9a, 12a, 13a, 15a, 16a; Histria : Alexandrescu 1978, p. 89, n ${ }^{\text {os }} 578-579$, fig. 14 ; Olbia : Parovich-Peshikan 1974, p. 76, fig. 74, 3-4, et 8-9; Établissement d'Elisavetovskoe (Don inférieur): Brashinskiy 1980, p. 65, pl. 38, 14. Après l'extinction des séries attiques vers 250 , la production de canthares à bord simple dans ces ateliers non localisés de mer Noire se poursuit de façon indépendante jusqu'à une date avancée du II ${ }^{\mathrm{e}}$ s., comme le montrent les exemples classés dans le type I. 2 de A. Bojkova : Bojkova 1997, p. 11 et pl. 1. 


\subsection{Coupes à une anse (« one-handler »)}

Le problème de l'existence d'ateliers locaux ou régionaux imitant la production attique à vernis noir, soulevé plus haut au sujet de VN 50, se pose également pour une période plus ancienne dans le cas des coupes à une anse VN 51-53. Bien que présentant quelques nuances dans le traitement de certains détails, ces trois exemplaires semblent être étroitement contemporains : VN 51-52 faisaient partie du dépôt rituel DP 2, placé sur les dalles de couverture de la ciste SP 291 en secteur Sud, alors que VN 53 provient d'un dépôt similaire, DP 31, découvert dans la couverture tumulaire de la ciste SP 339 en secteur central. Les deux sépultures appartiennent à la phase 2 de l'occupation du site et pourraient être datées, d'après leur contexte stratigraphique et les vases contenus dans les dépôts associés, vers 390-380. VN 53 a une vasque relativement basse, à double courbe, qui reste proche des exemples attiques contemporains, tandis que VN 51 et 52 ont une vasque plus profonde, dessinant une carène douce à la transition vers le bord. Les trois coupes ont une facture fort épaisse; elles sont munies d'une anse en forme de fer à cheval, aux attaches rapprochées, dont la position varie de presque horizontale dans le cas de VN 51-52 à légèrement relevée dans celui de VN 53. Le vernis, de mauvaise qualité et d'une couleur variant du noir au rouge brun, couvre tout l'intérieur des trois vases, mais ne se retrouve que sur une partie de l'extérieur de VN 51-52 (la paroi supérieure). Il a sans doute été posé par la méthode du trempage, comme l'attestent les coulées clairement visibles sur la paroi extérieure de ces deux exemplaires et la face extérieure du pied de VN 53. Le pied et le fond des vases est systématiquement réservé, sans décor en vernis noir ajouté.

Il est naturellement très difficile, dans l'état actuel de nos connaissances et en l'absence de toute analyse de pâte, de se prononcer sur l'éventuel centre de production ou même la région d'où sont originaires ces vases. Un exemplaire similaire à notre VN 53 provient des fouilles de Kalfata en 1946-1949249 ; deux autres semblables, mais sans vernis, ont été découverts dans la nécropole tumulaire d'Elisavetovskoe sur le Don inférieur ${ }^{250}$. De

249 Ivanov 1963, p. 190, n 451, fig. 75, pl. 102 : deuxième quart $\mathrm{du} \mathrm{IV}^{\mathrm{e}} \mathrm{s}$. Le contexte de découverte de la coupe n'est pas clair. Selon T. Ivanov, elle a été trouvée à proximité de la tombe 8 avec d'autres vases à figures rouges et à vernis noir dont aucun, toutefois, ne figure dans son catalogue. La tombe, de son côté, n'avait pas de mobilier, mais affleurait presque à la surface des couches culturelles, dans un niveau qui a livré plusieurs sépultures d'époque hellénistique.

250 Brashinskiy 1980 , p. 141-142, nos 242 et $242 \mathrm{a}$, pl. 18 et $20:$ le deuxième vase était accompagné d'un gobelet attique à une anse du type «Pheidias shape » et d'une amphore chiote de la variante V-B de S. Monahov (ibid., p. 109, n 21 ; Monahov 2003, p. 241, même, quelques coupes à une anse partiellement couvertes de vernis noir à l'extérieur, dont une au profil presque identique à VN 51-52, proviennent d'Histria, où elles apparaissent dans des contextes s'échelonnant de la fin de l'époque archaïque à la fin ${\mathrm{du} \mathrm{IV}^{\mathrm{e}} \mathrm{s} .}^{251}$. Enfin, une grande partie des exemplaires d'Olynthe publiés par D. Robinson présentent des caractéristiques proches de celles de nos vases et, comme ces derniers, ne sont probablement pas attiques 252 .

VN 54 et le fragment VN 55 sont, pour leur part, des représentants typiques de la production attique de la première moitié du $\mathrm{IV}^{\mathrm{e}} \mathrm{s}$. VN 54 a été trouvé dans le foyer F 1 en secteur Est qui peut être daté vers la fin de la phase 2 (vers 380) grâce à sa position stratigraphique et aux autres vases à vernis noir qu'il contenait. VN 55 vient du dépôt DP 33 dans le même secteur (phase 3) que l'on peut attribuer au second quart du $\mathrm{IV}^{\mathrm{e}} \mathrm{s}$. sur la base du matériel amphorique associé. Malgré leur mauvais état de conservation, ces deux exemplaires semblent se conformer au schéma de développement de la forme esquissé par B. Sparkes ${ }^{253}$ : VN 54 a une vasque à courbe continue évoquant des exemples du $\mathrm{V}^{\mathrm{e}}$ et du début du IV ${ }^{\mathrm{e}}$ S., provenant de l'Agora d'Athènes ${ }^{254}$ et de Thasos ${ }^{255}$, tandis que VN 55 présente une carène

pl. 11.4 ; pour la chronologie, cf. ibid., p. 22), laquelle oriente vers le début du $\mathrm{IV}^{\mathrm{e}} \mathrm{s}$.

251 Alexandrescu 1978, p. 119-120, nos 777-780. Deux de ces coupes $\left(\mathrm{n}^{\text {os }} 777-778\right)$ sont notées comme étant de production locale. La 780, datée de la fin du $\mathrm{V}^{\mathrm{e}}$ ou du début du $\mathrm{IV}^{\mathrm{e}} \mathrm{s}$., a un décor de bandes de vernis à l'intérieur qui évoque certaines des coupes d'Olynthe (cf. ci-après).

252 Voir Robinson 1933, p. 234-240, nos $895-942$, pl. 178-181 et surtout Robinson 1950, p. 333-345, nos 679-741, pl. 214-218: les coupes $\mathrm{n}^{\mathrm{os}} 681-686$, datées de la deuxième moitié du $\mathrm{V}^{\mathrm{e}} \mathrm{s}$., ne sont pas couvertes de vernis, à l'exception de quelques bandes à l'intérieur qui évoquent le décor des coupes à une anse attiques des années 520-450 (cf. Sparkes, Talcott 1970, p. 288-289, n ${ }^{\text {ss }} 724-743$, pl. 30 : « banded one-handler »; les n ${ }^{\text {os }} 692,695,720,725$ sont sans vernis ; les $n^{\text {os }} 680$, 688-689, 723, 727, 734, 738 n'ont pas de vernis sur une partie de la paroi extérieure de la vasque ou le pied ; le vernis des $\mathrm{n}^{\text {os }} 689$, 700, 707, 719, 729-731, 736-737 est décrit comme étant de couleur rouge ou d'une couleur variant du noir au rouge. Aux exemples cités ci-dessus, il faudrait probablement ajouter certaines des coupes à une anse provenant de la nécropole tumulaire de Panskoe I en Crimée, mais en l'absence de toute description et de photographies de ces vases, il est impossible d'avoir une quelconque certitude à ce sujet : cf. en particulier Monahov, Rogov 1990b, p. 142, 144, pl. 5, 7, nos 90 , 98-99. Notons tout de même que les vases en question proviennent de contextes datés du deuxième quart du $\mathrm{IV}^{\mathrm{e}} \mathrm{s}$.

253 Sparkes, Talcott 1970, p. 126.

254 Cf. ibid., p. 289-290, $\mathrm{n}^{\text {os }} 745-755$, fig. 8, pl. 31 : la coupe $\mathrm{n}^{\circ} 755$, datée vers 400 , semble assez proche de VN 54, bien que la vasque paraisse un peu plus profonde et le pied moins haut.

255 Blondé 1985 , p. 295 , nos $62-64$, fig. 8 (jardin de l'EFA) : contexte de la première moitié du $\mathrm{IV}^{\mathrm{e}} \mathrm{s}$., mais datés par l'auteur du premier quart du siècle ; Blondé 1989, p. 496, n 42, fig. 7 (puits Valma) : contexte des deuxième, troisième quarts du $\mathrm{IV}^{\mathrm{e}} \mathrm{s}$. 
douce à la transition entre la vasque et le bord qui est caractéristique des coupes plus tardives à partir du début du second quart du $\mathrm{IV}^{\mathrm{e}} \mathrm{s} .{ }^{256}$.

VN 51. - Dépôt DP 2. Ht 5,4 cm, diam. de l'embouchure $13,2 \mathrm{~cm}$. Inv. PIN 3131 . Pl. 53c et 98c

Restaurée. Pied annulaire bas; vasque relativement profonde, à paroi faiblement convexe; bord vertical à lèvre aplatie et biseautée vers l'intérieur ; anse horizontale en fer à cheval attachée au niveau du bord. Tout l'intérieur, le bord, ainsi que la partie supérieure de la vasque à l'extérieur sont couverts d'un vernis non homogène de mauvaise qualité et d'une couleur variant du rouge brun au noir, le reste est réservé.

Vers 390-380.

VN 52. - Dépôt DP 2. Ht 5,1 cm, diam. de l'embouchure $13,4 \mathrm{~cm}$. Inv. PIN 3131 a. PI. 53c et 98d

Restaurée. Pied annulaire bas; vasque relativement profonde et évasée, à paroi presque rectiligne ; bord vertical à lèvre aplatie et biseautée vers l'intérieur; anse horizontale en fer à cheval. Vernis non homogène, rouge brun à l'intérieur, brun à noir sur le bord et la partie supérieure de la vasque à l'extérieur, le reste réservé.

Vers 390-380.

VN 53. - Dépôt DP 31 . Ht 4, 4 cm, diam. de l'embouchure $13 \mathrm{~cm}$. Inv. PIN 3652 (FR 2.17). Pl. 98e

Fragmentaire et restaurée, sauf quelques fragments non recollés. Un quart de la vasque et du bord manquant. Pied annulaire bas à face extérieure doucement carénée ; vasque peu profonde à double courbe ; bord non distinct de la paroi, à lèvre aplatie et biseautée vers l'intérieur ; anse horizontale en fer à cheval relevée un peu au-dessus du bord. Vernis non homogène rouge brun à noir à l'intérieur et à l'extérieur. Réservés : le plan de pose, la face intérieure du pied et le fond extérieur.

Vers 390-380.

VN 54. - Foyer F 1. Ht $4 \mathrm{~cm}$, diam. de l'embouchure 11,4 cm. Inv. PIN 3254. Pl. 68c

Fragmentaire. Anse manquante. Pied annulaire bas à face extérieure convexe; vasque peu profonde à paroi

256 Sparkes, Talcott, p. 290, $\mathrm{n}^{\text {os }} 757-763$, fig. 8, pl. 31 ; Rotroff 1997 , p. 329 , n ${ }^{\text {os }} 856-860$, fig. 58 , pl. 71 : notons que le bord de notre fragment ne présente pas la saillie caractéristique vers l'extérieur de la plupart des exemplaires tardifs de l'Agora. Voir également Rotroff, Camp 1996, p. 279, fig. 10.4-5 (de la Pnyx); Lungu 1993, p. 172, n 8, pl. 2 et 9 (de la nécropole d'Enisala dans l'arrière-pays d'Histria, datée vers 420-400, mais sans doute plus tardive compte tenu du profil de la vasque); Py, Sabattini 2000, p. 175, fig. 7 (de l'habitat de Lattes, Hérault) : Us 50086, datée du premier quart du $\mathrm{IV}^{\mathrm{e}} \mathrm{s}$. convexe ; bord non distinct de la paroi, à lèvre aplatie et biseautée vers l'intérieur.

Vers 380 .

VN 55. - Dépôt DP 33. Inv. FR 2.64.4.

Fragment du bord et de la vasque. Vasque à carène douce ; bord dans le prolongement de la paroi, à lèvre aplatie et biseautée vers l'intérieur.

Vers 375-350.

\subsection{Bols}

\subsection{1. à bord saillant (« outturned rim»)}

Les bols à bord saillant sont attestés par une douzaine d'exemplaires, tous datant du $\mathrm{IV}^{\mathrm{e}} \mathrm{s}$., qui présentent des similitudes dans le profil de la vasque et du bord, mais se différencient assez nettement par la forme du pied et le traitement décoratif du fond extérieur et intérieur. Deux groupes peuvent être distingués en s'appuyant sur ces critères. Un premier groupe de bols (VN 56-62) est doté d'un pied annulaire assez haut, à faces convexes et plan de pose très étroit; leur fond extérieur est réservé, orné de deux ou trois cercles et une bande plus large de vernis noir, alors que le fond intérieur porte un riche décor estampé, constitué le plus souvent de deux registres d'oves alternant avec deux zones de palmettes. Tous les vases affichant ces caractéristiques proviennent de contextes attribuables à la phase 2 et au début de la phase 3 d'occupation du site, à savoir le premier et le début du second quart du $\mathrm{IV}^{\mathrm{e}} \mathrm{s}$. : SP 336 en secteur Nord et les foyers F 8, 9 et 11 en secteur Nord et Est. Leur profil général et le décor du fond extérieur sont proches des exemplaires du premier quart du $\mathrm{IV}^{\mathrm{e}} \mathrm{s}$. de l'Agora d'Athènes, mais la forme du pied est originale et les motifs estampés à l'intérieur sont plus complexes et d'une exécution plus soignée que ceux que nous trouvons pour la même époque dans le catalogue de B. Sparkes ${ }^{257}$, évoquant les agencements en vogue au cours de la période précédente (vers 430-410) ${ }^{258}$. Ces particularités, qui se retrouvent dans le matériel des fouilles plus anciennes à Kalfata ${ }^{259}$ et de quelques sites contemporains ${ }^{260}$, tout comme le fait que, du moins dans le

257 Cf. Sparkes, Talcott 1970, p. 293, nos $800-803$, fig. 8, pl. 32 et 58. 258 Comparer par exemple ibid., p. 292, nos 780-784, 789, 791-792, pl. 57.

259 Ivanov 1963 , p. 215-217, nos 532-542, fig. 85, pl. 115 : ces bols se sont vu attribuer des dates contradictoires s'étalant sur l'ensemble $\mathrm{du} \mathrm{IV}^{\mathrm{e}} \mathrm{s}$.

260 Cf. Knigge 1966, p. 131, nos 14-17, fig. 17, pl. 71, 1-3 (de la nécropole du Céramique); Blondé 1985, p. 293, n ${ }^{\text {os }} 53-56$, fig. 7 (Thasos, jardin de l'EFA, contexte de la première moitié du 
cas de VN 56, 57, 59 et 62, le décor intérieur semble avoir été exécuté avec le même poinçon, nous amènent à supposer qu'il s'agit de la production d'un ou deux ateliers non représentés dans les séries connues de l'Agora d'Athènes, dont l'activité a pris place au cours des deux ou trois premières décennies du $\mathrm{IV}^{\mathrm{e}} \mathrm{s}$.

Le second groupe de bols (VN 65-67) présente moins d'originalité. Ils sont caractérisés par un pied annulaire plus bas, à plan de pose réservé et orné d'une rainure, ainsi que par un fond extérieur entièrement couvert de vernis noir et muni d'un ombilic central, que nous retrouvons dans l'ensemble des séries plus tardives du second quart et de toute la seconde moitié du $\mathrm{IV}^{\mathrm{e}} \mathrm{s}$., découvertes à Athènes et ailleurs ${ }^{261}$. Le décor estampé à l'intérieur consiste, dans le cas de VN 65 et 67, d'une zone de palmettes reliées entourées de larges bandes de guillochis, alors que VN 66 comporte deux registres de palmettes séparées par une bande d'oves qui restent encore proches des motifs complexes qui ornent l'intérieur des bols du premier groupe. Les contextes de découverte - DP 4 et le foyer F 4 en secteur Sud - ne permettent malheureusement pas d'affiner la chronologie fournie par les parallèles attiques, mais on notera que les particularités du décor estampé de VN 66 indiquent une date relativement haute (le second quart ou le milieu du $\mathrm{IV}^{\mathrm{e}} \mathrm{s}$.) pour ce vase et VN 65, qui provient du même dépôt, alors que VN 67 a été découvert avec un skyphos à vernis noir (VN 11) qui n'est que légèrement plus évolué que les vases les plus récents de ce type trouvés à Olynthe et doit être attribué de ce fait à la décennie suivant le milieu du siècle (vers 350-340).

VN 56. - Tombe SP 336 . Ht $5 \mathrm{~cm}$, diam. de l'embouchure $14,3 \mathrm{~cm}$. Inv. PIN 3772. Pl. $98 f$

Restauré. Pied annulaire à faces extérieure et intérieure convexes ; plan de pose étroit et pointu ; vasque peu profonde, à double courbe ; petit bord horizontal

$\mathrm{IV}^{\mathrm{e}} \mathrm{s}$., mais datés par l'auteur de la fin du $\mathrm{V}^{\mathrm{e}} \mathrm{s}$.). De même, les bols mentionnés ci-après ont un pied de forme différente, ne sont pas suffisamment conservés ou ne sont pas illustrés d'une façon permettant la comparaison avec nos exemplaires, mais présentent néanmoins des similitudes dans le décor estampé: Olynthe: Robinson 1933, p. 192, $\mathrm{n}^{\circ}$ 559, pl. 153 ; Robinson 1950, p. 352, $\mathrm{n}^{\circ}$ 770, pl. 220 ; Apollonia, Kalfata: Ivanov 1948, p. 41, fig. 44 ; Établissement d'Elisavetovskoe (Don inférieur) : Brashinskiy 1980, p. 63, pl. 37, 6 ; Andalousie orientale: Domínguez, Sánchez 2001, p. $195-198, \mathrm{n}^{\text {os }} 66-70,78,82$, fig. $91-94,96$; p. 225-227, $\mathrm{n}^{\text {os }} 246-247$, 249-250, fig. $117-118$; p. $235, \mathrm{n}^{\circ} 297$; p. 263, n 471 , fig. 163.

261 Agora d'Athènes: Sparkes, Talcott 1970, p. 293-294, $\mathrm{n}^{\text {os }} 804-$ 807 , fig. 8, pl. 32 et 58 ; Rotroff 1997, p. 329-330, nos 866-868, fig. 59, pl. 72 et 144-145 ; nécropole tumulaire d'Elisavetovskoe (Don inférieur): p. 135, $\mathrm{n}^{\circ}$ 208, pl. 17 et 20 ; Andalousie orientale: Domínguez, Sánchez 2001, p. 196-198, n ${ }^{\text {os }} 71$, 79-81, fig. 92 et 95 ; p. $235-236, \mathrm{n}^{\text {os }} 298-301$, fig. $130-132$. saillant à lèvre arrondie. Réservés : le fond extérieur avec trois cercles et une bande en vernis noir, la partie supérieure de la face intérieure du pied. Décor du fond intérieur : au centre, rangée d'oves estampées encadrées de deux cercles incisés ; tout autour, dans l'ordre, zone de quatre palmettes estampées, deuxième rangée d'oves estampées entre deux cercles incisés, deuxième zone de treize palmettes estampées reliées par des arcs incisés. Graffite $\Lambda \Lambda \mathrm{I}$ sur le fond extérieur.

Vers 390-380.

VN 57. - Foyer F 8. Ht 6,6 cm, diam. de l'embouchure $17,6 \mathrm{~cm}$. Inv. PIN 3857. Pl. 75a

Fragmentaire. Pied annulaire à faces extérieure et intérieure légèrement convexes ; plan de pose arrondi ; vasque à double courbe ; petit bord saillant à lèvre pointue. Décor du fond intérieur : au centre, frise d'oves estampées encadrées de deux cercles incisés; tout autour, dans l'ordre, zone de treize palmettes estampées, deuxième frise d'oves estampées entre deux cercles incisés, deuxième zone de palmettes estampées reliées par des arcs incisés (seize conservées).

Vers 390-380.

VN 58. - Foyer F 8. Ht 5,8 cm, diam. de l'embouchure $15,7 \mathrm{~cm}$. Inv. PIN 3862. Pl. 75b

Fragmentaire. Pied annulaire à faces extérieure et intérieure légèrement convexes ; plan de pose pointu ; vasque à double courbe ; petit bord saillant à lèvre pointue. Décor du fond intérieur: au centre, zone de six palmettes estampées (cinq conservées) reliées par des arcs incisés, qui entourent un cercle incisé ; tout autour, dans l'ordre, frise d'oves estampées entre deux cercles incisés, deuxième zone de palmettes estampées (dix conservées) reliées par des arcs incisés.

Vers 390-380.

VN 59. - Foyer F 9. Ht $6,4 \mathrm{~cm}$, diam. de l'embouchure 14,2 cm. Inv. PIN 4033k (FR 3.15). Pl. 99a

Fragmentaire, recollé. Quelques fragments de la vasque manquent. Traces de combustion. Pied annulaire à faces extérieure et intérieure convexes ; plan de pose arrondi ; vasque à double courbe ; petit bord saillant à lèvre arrondie. Réservés : le fond extérieur avec trois cercles et une bande en vernis noir, la partie supérieure de la face intérieure du pied. Décor du fond intérieur : au centre, rangée d'oves estampées encadrées de deux cercles incisés ; tout autour, dans l'ordre, zone de six palmettes estampées reliées par des arcs incisés, deuxième rangée d'oves estampées entre deux cercles incisés, deuxième zone de quatorze palmettes semblable à la précédente.

Vers 380. 
VN 60. - Foyer F 9. Ht 5,4 cm, diam. de l'embouchure 14,5 cm. Inv. PIN 4033g (FR 3.17). Pl. 99b

Fragmentaire, recollé. Une partie de la vasque et du bord manque. Traces de combustion. Pied annulaire à face extérieure presque rectiligne et face intérieure convexe ; plan de pose arrondi ; vasque à double courbe ; petit bord saillant à lèvre arrondie. Réservés : le fond extérieur avec deux cercles et une large bande en vernis noir, la partie supérieure de la face intérieure du pied, un filet à la jonction entre le pied et la vasque. Traces d'engobe rougeâtre sous la bande vernissée du fond extérieur et sur la face intérieure du pied. Décor du fond intérieur : au centre, zone de huit palmettes estampées autour d'un cercle incisé ; tout autour, dans l'ordre, rangée d'oves estampées entre deux cercles incisés, deuxième zone de palmettes estampées (dix conservées) reliées par des arcs incisés.

Vers 380.

VN 61. - Foyer F 9. Ht 5,2 cm, diam. de l'embouchure $15 \mathrm{~cm}$. Inv. PIN 4033p (FR 3.28). Pl. 99c

Des fragments du bord et de la vasque manquent, tout comme un fragment du fond (percement ?). Pied annulaire à faces extérieure et intérieure convexes ; plan de pose pointu; vasque à double courbe; petit bord saillant à lèvre arrondie. Réservé : le fond extérieur avec une bande (fort effacée) tracée au vernis noir sur une bande plus large d'engobe rougeâtre, la partie supérieure de la face intérieure du pied. Décor du fond intérieur : au centre, rangée d'oves estampées encadrées de deux cercles incisés ; tout autour, dans l'ordre, zone de palmettes estampées (cinq conservées), deuxième rangée d'oves estampées entre deux cercles incisés, deuxième zone de palmettes semblable à la précédente (dix palmettes conservées).

Vers 380.

VN 62. - Foyer F 11. Ht $6,5 \mathrm{~cm}$, diam. de l'embouchure $21 \mathrm{~cm}$. Inv. FR 3.8. Pl. 99d

Fragmentaire, recollé. La plus grande partie du bord et de la vasque, ainsi que des fragments du fond et du pied, manquent. Empreinte digitale à l'extérieur, près du pied. Traces de combustion. Pied annulaire à faces extérieure et intérieure convexes ; plan de pose pointu ; sillon incisé après cuisson à la jonction entre le pied et la vasque ; vasque à double courbe, presque verticale dans sa partie supérieure ; petit bord saillant à lèvre arrondie. Réservés : le fond extérieur avec un point central, deux cercles et une bande en vernis noir, la partie supérieure de la face intérieure du pied. Décor du fond intérieur : au centre, rangée d'oves estampées encadrées de deux cercles incisés; tout autour, dans l'ordre, zone de sept palmettes estampées (six conservées) reliées par des arcs incisés, deuxième rangée d'oves estampées entre deux cercles incisés, deuxième zone de palmettes semblable à la précédente (onze palmettes conservées).

Vers 380-370.

VN 63. - Dépôt DP 33. Inv. FR 2.64.1.

Fragment du bord et de la vasque. Paroi presque verticale; petit bord saillant à lèvre arrondie.

Vers 375-350.

VN 64. - Dépôt DP 33. Inv. FR 2.64.3.

Fragment du pied. Pied annulaire assez haut, à plan de pose étroit et arrondi.

Vers 375-350.

VN 65. - Dépôt DP 4. Ht 4,4 cm, diam. de l'embouchure $13 \mathrm{~cm}$. Inv. PIN 3200. Pl. 99e

Pied annulaire à face extérieure convexe, concave à l'intérieur, décoré d'un ombilic central sous le fond extérieur et d'une rainure sur le plan de pose ; vasque à carène douce; petit bord saillant à lèvre pointue. Plan de pose réservé. Décor du fond intérieur: huit palmettes estampées reliées par des arcs incisés; au centre, deux cercles incisés ; tout autour, deux rangées de guillochis.

Vers 375-350.

VN 66. - Dépôt DP 4. Ht 4,3 cm, diam. de l'embouchure $13,8 \mathrm{~cm}$. Inv. PIN 3201. Pl. $99 f$

Pied annulaire à face extérieure convexe, concave à l'intérieur, décoré d'un ombilic central sous le fond extérieur et d'une rainure sur le plan de pose ; vasque à carène douce ; petit bord saillant à lèvre pointue. Plan de pose réservé. Décor du fond intérieur : quatre palmettes estampées disposées de façon asymétrique autour d'un cercle incisé ; tout autour, dans l'ordre, rangée d'oves estampées entre deux cercles incisés, zone de dix palmettes estampées reliées par des arcs incisés. Graffite sur le fond extérieur : $\Phi \mathrm{I}(?)$.

Vers 375-350.

VN 67. - Foyer F 4. Ht 3,6 cm, diam. de l'embouchure $11,6 \mathrm{~cm}$. Inv. PIN 3758. Pl. 70b

Pied annulaire à face extérieure convexe, concave à l'intérieur, décoré d'un ombilic central sous le fond extérieur et d'une rainure sur le plan de pose ; vasque carénée ; petit bord saillant à lèvre arrondie. Fond intérieur couvert de concrétions, sur lequel on distingue une zone de palmettes estampées entourées d'une large bande de guillochis.

Vers 350-340. 


\subsection{2. à profil convexe-concave ("shallow wall and convex-concave profile »)}

Comme les bols à bord saillant VN 56-62, les bols à paroi convexe-concave VN 68-70 viennent combler quelques lacunes dans les séries publiées de l'Agora d'Athènes, en particulier en ce qui concerne la fin du premier et le début du second quart du $\mathrm{IV}^{\mathrm{e}} \mathrm{s}$. VN 68-69 sont issus du riche foyer F 11 en secteur Est, dont la mise en place semble intervenir très tôt au cours de la phase 3 (vers 380-370), alors que le fragment VN 70 provient du grand dépôt DP 33 qui se superpose directement au foyer en question et a livré du matériel datant de l'ensemble du second quart du $\mathrm{IV}^{\mathrm{e}} \mathrm{s}$. Ce dernier fragment ne conserve que le profil du pied et une partie du fond, mais il semble bien qu'il s'agisse d'un vase similaire aux deux autres. La principale particularité de nos bols tient à la forme du pied, très bas et fin, à plan de pose réservé et décoré d'une rainure peu profonde, ainsi qu'au traitement du fond extérieur, qui comporte un disque central réservé, entouré d'un bourrelet en relief et orné d'un point et un cercle de vernis noir. Ces détails, qu'on ne retrouve plus chez les représentants les plus récents du type ${ }^{262}$, évoquent directement les bols à paroi convexe-concave du dernier quart $\mathrm{du} \mathrm{V}^{\mathrm{e}} \mathrm{s}$., où nous trouvons un traitement identique du fond extérieur et du pied, l'unique différence étant l'absence, sur les exemplaires plus anciens, de rainure sur le plan de pose ${ }^{263}$. Un autre élément incontestablement tardif, qui confirme les dates fournies par les contextes de découverte, est le décor estampé conservé à l'intérieur de VN 68 et 69 : les deux bols présentent un même motif central d'oves et de palmettes, mais, dans le cas de VN 68, il est entouré d'une bande de points estampés selon quelque procédé mécanique, alors que dans celui de VN 69, nous avons une zone de guillochis «classiques ». Le décor de VN 68 prouve en particulier que nous nous trouvons à un moment précoce du $\mathrm{IV}^{\mathrm{e}} \mathrm{s}$., où les schémas caractéristiques des décennies suivantes n'ont pas encore été définitivement adoptés et où différentes expériences visant à mettre au point des

262 Voir par exemple Sparkes, Talcott 1970, p. 295, nos $822-824$, fig. 8, pl. 32 ; Blondé 1985 , p. $298, n^{\circ} 88$, fig. 11 (Thasos, jardin de l’EFA) ; Domínguez, Sánchez 2001, p. 200, n 96, fig. 99 (Andalousie orientale). Les bols de Thasos et d'Andalousie orientale, à rainure sur le plan de pose et ombilic central sous le fond extérieur, semblent représenter la norme pour la période postérieure à 375 environ, bien qu'il soit difficile de suivre un développement cohérent compte tenu du nombre limité d'échantillons disponibles.

263 Pour quelques exemples de l'Agora d'Athènes, cf. Sparkes, Talcott 1970, p. 294-295, $\mathrm{n}^{\text {os }}$ 819-821, fig. 8, pl. 32 ; Boulter 1953, p. $115, \mathrm{n}^{\circ} 202$, fig. 3. Comparer également Kunze-Götte et al. 1999, p. 143, pl. 91, 559.2 (de la nécropole du Céramique); Brashinskiy 1980, p. 135, $\mathrm{n}^{\circ}$ 207, pl. 16-17 (de la nécropole tumulaire d'Elisavetovskoe sur le Don inférieur). procédés de décoration mécaniques adaptés aux besoins accrus de production pouvaient être en cours.

Nous devons malheureusement reconnaître que, dans l'état actuel de nos connaissances, il s'avère très difficile d'identifier des parallèles contemporains de nos bols. Quelques vases de ce type susceptibles de dater des premières décennies du $\mathrm{IV}^{\mathrm{e}} \mathrm{s}$. proviennent des fouilles de Kalfata en 1946-1949 ${ }^{264}$, d'Olynthe ${ }^{265}$ et de Thasos ${ }^{266}$, mais leur état de conservation ou la qualité des descriptions et des illustrations (en ce qui concerne en particulier le matériel d'Olynthe et, dans une moindre mesure, celui d'Apollonia) interdit dans la plupart des cas des comparaisons plus précises. Notre plus grande difficulté vient notamment du fait que, lorsque nous ne disposons pas d'ensembles clos datés dans des limites chronologiques étroites, il est souvent impossible de distinguer les séries du premier quart du $I^{\mathrm{e}} \mathrm{s}$. de celles de la fin du $\mathrm{V}^{\mathrm{e}} \mathrm{s}$. Le décor estampé conservé sur certains des vases n'est que rarement utile à cet égard. En tout cas, pour gênantes qu'elles soient, ces difficultés d'identification permettent manifestement de confirmer l'hypothèse de B. Sparkes que les bols à paroi convexe-concave sont les produits d'un atelier unique ${ }^{267}$ : il est clair à présent que, du moins en ce qui concerne les séries de la fin du $\mathrm{V}^{\mathrm{e}}$ et du début du $\mathrm{IV}^{\mathrm{e}} \mathrm{s}$., les similitudes sont telles qu'un lieu de fabrication commun paraît fortement probable.

VN 68. - Foyer F 11. Ht 4,8 cm, diam. de l'embouchure $14,6 \mathrm{~cm}$. Inv. FR 3.9 .

Fragmentaire, partiellement recollé. La moitié de la vasque, du bord et du fond manquent. Traces de combustion. Pied annulaire bas, décoré d'une rainure sur le plan de pose ; petit bourrelet en relief sur le fond extérieur entourant un disque central ; vasque basse à paroi extérieure concave se prolongeant en un bord à face extérieure convexe et à lèvre arrondie et légèrement pointue, décoré à la base d'un sillon souligné par une

264 Ivanov 1963, p. 219, n 551. Le vase n'est pas illustré, mais, d'après la description qui en est donnée par T. Ivanov, il semble identique aux bols à paroi convexe-concave de notre catalogue. Malgré la date tardive proposée par l'archéologue bulgare (milieu $\mathrm{du} \mathrm{IV}^{\mathrm{e}} \mathrm{s}$.), il convient de remarquer que cet exemplaire provient d'un foyer rituel du sondage V (1948), où il était notamment accompagné d'un bol à bord saillant similaire à VN 56-62 ci-dessus (ibid., p. 217, $\left.\mathrm{n}^{\circ} 540\right)$ et de quatre plats à poisson qui indiquent également une date ancienne (ibid., p. 231-232, nos 621-624, fig. 90, pl. 120).

265 Robinson 1950, p. 355-356, nos 778-779, pl. 224.

266 Blondé 1985 , p. $297-298$, n ${ }^{\text {os }} 82,84-88$, fig. $10-11$ (jardin de l'EFA), contexte de la première moitié du $\mathrm{IV}^{\mathrm{e}} \mathrm{s}$.). Les fragments $\mathrm{n}^{\text {os }} 84-88$ ne conservent que le profil des vasques et des bords; le fond $\mathrm{n}^{\circ} 82$, classé parmi les bolsals et les kylikes apodes, est doté à l'extérieur d'un disque central réservé et entouré d'un bourrelet en relief.

267 Sparkes, Talcott 1970, p. 131. 
moulure ; courbe continue entre le bord et la vasque à l'intérieur. Réservés : le disque central du fond extérieur avec un cercle et un point en vernis noir; le plan de pose ; le sillon de la face extérieure du bord. Décor du fond intérieur : au centre, rangée d'oves estampées entre deux cercles incisés; tout autour, zone de palmettes estampées (trois conservées) inscrites dans une bande de points estampés.

Vers 380-370.

VN 69. - Foyer F 11. Ht 3,4 cm, diam. de l'embouchure $14 \mathrm{~cm}$. Inv. FR 3.7. PI. 100a

Fragmentaire, partiellement recollé. Quelques fragments du fond et du pied manquent. Traces de combustion. Pied annulaire bas, décoré d'une rainure sur le plan de pose; petit bourrelet en relief sur le fond extérieur, entourant un disque central ; profil extérieur convexe-concave ; bord à lèvre arrondie et légèrement pointue, décoré à la base d'un sillon souligné par une moulure. Réservés : le disque central du fond extérieur avec probablement un décor vernissé qui a disparu, le plan de pose, le sillon de la face extérieur du bord. Décor du fond intérieur : rangée d'oves estampées entre deux cercles incisés ; tout autour, zone de palmettes estampées (quatre conservées) inscrites dans une rangée de guillochis.

Vers 380-370.

VN 70. - Dépôt DP 33. Inv. FR 2.64.7b.

Fragment du fond avec une partie du pied et de la vasque. Pied annulaire bas à face extérieure moulurée et face intérieure rectiligne, décoré d'une rainure sur le plan de pose ; fond extérieur plat; départ de la vasque qui était basse et évasée, à paroi extérieure concave. Plan de pose réservé.

375-350.

\subsection{3. À bord incurvé (« incurving rim »)}

Selon B. Sparkes, les bols à bord incurvé sont essentiellement une création du $\mathrm{IV}^{\mathrm{e}} \mathrm{s}$., bien qu'on leur connaisse quelques précurseurs dès la seconde moitié du $\mathrm{V}^{\mathrm{e}} \mathrm{s}$. et probablement plus tôt encore ${ }^{268}$. Cependant, en ce qui concerne précisément le $\mathrm{IV}^{\mathrm{e}} \mathrm{s}$., les séries publiées de l'Agora d'Athènes ne sont pas sans poser quelques problèmes. Elles se groupent assez bien autour du milieu et de la seconde moitié du siècle, mais restent lacunaires pour l'ensemble de la période 400-350, à laquelle le catalogue de B. Sparkes n'attribue que trois exemplaires (dont deux seulement sont illustrés par des dessins de

268 Cf. Sparkes, Talcott 1970, p. 131-132. Voir également ibid., p. $295, n^{\circ} 825$, fig. 8 et le commentaire sous la description de ce vase. profil) qui s'avèrent insuffisants pour donner une image cohérente de l'évolution du type ${ }^{269}$. Par chance, la majorité des bols à bord incurvé découverts lors de nos fouilles sont issus de contextes datant de cette période, ce qui nous permet de combler en grande partie ces lacunes et de proposer une séquence de développement suivie.

VN 71 illustre l'étape la plus ancienne de l'existence du type. Il s'agit d'un vase de facture assez lourde, à bord épaissi, reposant sur un pied bas à plan de pose réservé et orné d'une moulure. Le fond extérieur est également réservé, avec les restes d'un décor de cercles et d'une bande de vernis noir, alors que le fond intérieur porte un motif d'oves et de palmettes estampées sans emploi de guillochis. Le bol provient du foyer F 5 en secteur central (phase 2) qui peut être daté vers 390-380 sur la base des observations stratigraphiques et des autres vases à vernis noir qu'il a livrés (cf. VN 33 et 38). On peut lui ajouter les fragments VN 72, découverts dans le remplissage de la ciste SP 339 immédiatement au Sud-Ouest, qui appartiennent sans doute à un vase identique par sa forme et son décor. Ces deux bols, étroitement contemporains, semblent très proches de l'exemplaire du début du IV ${ }^{\text {e }}$ s. figurant dans le catalogue de B. Sparkes ${ }^{270}$.

L'étape suivante est représentée par VN 73 et 74a-b qui proviennent de contextes du second quart du $\mathrm{IV}^{\mathrm{e}} \mathrm{s}$. (phase 3) : le foyer F 11 en secteur Est, SP 329 et DP 16 en secteurs central et Nord. Sur le plan de leur morphologie, ces bols ne font pas preuve d'une évolution notable par rapport à VN 71-72. Cependant, le traitement décoratif du pied et du fond extérieur affiche des traits indéniablement tardifs : le plan de pose est réservé et orné d'une rainure assez large, alors que le fond extérieur est entièrement couvert de vernis noir et, dans le cas de VN 74a et b, muni d'un ombilic central. Le décor intérieur n'est pas vraiment révélateur de la chronologie des vases et peut s'avérer d'une complexité étonnante pour une période aussi tardive : le motif estampé de VN 73 (malheureusement incomplet) est probablement identique à celui du bol à paroi convexe-concave VN 68, qui vient du même foyer, tandis que les agencements plus compliqués d'un ou deux registres d'oves alternant avec des zones de palmettes sur le fond intérieur de VN 74a et b trouvent des parallèles précis dans le décor des bols à bord saillant VN 56-62 et 66. Bien que peu représentés dans le matériel de l'Agora ${ }^{271}$, des bols simi-

269 Ibid., $\mathrm{n}^{\text {os }} 826-828$, fig. 8 et pl. 33 .

270 Ibid., ${ }^{\circ}$ 826, fig. 8, pl. 59.

271 Le bol n 828 du catalogue de B. Sparkes (ibid., fig. 8, pl. 33) a des dimensions presque identiques à VN 74b et, comme ce dernier, est plus petit que la norme pour l'époque. Il s'agit peut-être d'une fraction intermédiaire entre la taille «standard» représentée par 
laires à nos trois exemplaires et parfois ornés de motifs estampés tout aussi riches sont attestés sur plusieurs autres sites de Méditerranée et de mer Noire, ainsi qu'à Athènes même ${ }^{272}$. Les dates attribuées à ces parallèles, lorsqu'elles sont disponibles et suffisamment précises, sont généralement en accord avec celles que nous avançons ici.

Enfin, VN 75 s'inscrit parfaitement dans les séries attiques du milieu et de la deuxième moitié du $\mathrm{IV}^{\mathrm{e}} \mathrm{s} .{ }^{273}$. Le vase reprend certains des traits caractéristiques des bols antérieurs, à savoir le plan de pose réservé et orné d'une rainure et et le fond à ombilic central, mais se différencie par son pied plus fin et plus haut, le bord moins épais et le profil plus rectiligne de la vasque. Le type évoluant très peu au cours de cette époque, il est difficile de proposer une fourchette chronologique plus étroite en se basant uniquement sur des parallèles contemporains, mais on rappellera que le foyer F 4 en secteur Sud (phase 3), où a été découvert notre exemplaire, a également livré un skyphos à vernis noir (VN 11) qui oriente vers le début du troisième quart du $\mathrm{IV}^{\mathrm{e}} \mathrm{s}$. (350-340).

VN 71. - Foyer F 5. Ht $6,8 \mathrm{~cm}$, diam. de l'embouchure $17 \mathrm{~cm}$. Inv. PIN 3368e (FR 2.47). Pl. 100b

VN 73 et $74 b$ et les coupelles à bord incurvé dont nous parlerons plus loin.

272 La liste proposée ici tente de prendre en compte à la fois les exemplaires mieux conservés et les fragments significatifs de bords ou de pieds permettant l'identification: Athènes, Pnyx: Rotroff, Camp 1996, p. 279, fig. 11, 1 (huit exemplaires provenant du remblai de Pnyx III) ; Olynthe: Robinson 1933, p. 192, 194-196, $\mathrm{n}^{\mathrm{os}} 557,573,577,579,582-584,586-587,590,592$, pl. $152,154-$ 156 ; Robinson 1950, p. 350, 352-354, $\mathrm{n}^{\text {os }} 759$, 768-769, 771-772, 774-775, 775A-B, pl. 219-220, 222-223 ; Thasos, jardin de l'EFA : Blondé 1985 , p. 300-301, n ${ }^{\text {os }} 100-106$ (contexte de la première moitié du IV ${ }^{\mathrm{e}}$ s., mais datés du second quart de ce siècle); Thasos, puits Valma: Blondé 1989, p. 493 et 495-496, $\mathrm{n}^{\text {os }} 25-29$, 34-39, fig. 7 et 9 (contexte des deuxième, troisième quarts du $\mathrm{IV}^{\mathrm{e}} \mathrm{s}$., certains des fonds $\mathrm{n}^{\text {os }}$ 34-36 peuvent appartenir à des coupelles du même type) ; nécropole de Chersonnèse Taurique: Monahov, Abrosimov 1993, p. $138, \mathrm{n}^{\circ} 53$, pl. 10 et 16 (notons que le vase a été découvert avec une amphore de Chersonnèse de la variante I-A de $\mathrm{S}$. Monahov qui oriente vers le milieu du IV ${ }^{\text {e }}$ s., cf. ibid., p. 133-134, n ${ }^{\circ} 33$, pl. 10 et 15) ; Domínguez, Sánchez 2001, p. 197-199, nos 76-77, 83 et 85, fig. 94,96 ; p. 227, n ${ }^{\text {os }} 261-262$, fig. 119.

273 Pour les parallèles de l'Agora d'Athènes, cf. Sparkes, Talcott 1970 , p. 295 , n 832 , fig. 8 : 350-325 ; Rotroff 1997 , p. 338-339, $\mathrm{n}^{\text {os }} 967,970,979$, fig. 62 (325-300). Comparer également Rotroff, Camp 1996, p. 279, fig. 11, 3 (de la Pnyx); Jones, Graham, Sackett 1973, p. 377, n 27, fig. 6-7, pl. 72 (de Vari, Attique); Rudolph 1974, p. $119, \mathrm{n}^{\circ} 38$, fig. 4, pl. 13a-b (de Porto Heli, Argolide) ; Alexandrescu 1978, p. 90, n 591 (d'Histria, daté du deuxième quart du $\mathrm{IV}^{\mathrm{e}} \mathrm{s}$., mais sans doute un peu plus récent); Brashinskiy 1980, p. 136, $\mathrm{n}^{\circ} 212$, pl. 17 et 21 (de la nécropole tumulaire d'Elisavetovskoe); Domínguez, Sánchez 2001, p. 199, n 87, fig. 97 (daté du deuxième quart du $\mathrm{IV}^{\mathrm{e}} \mathrm{s}$.).
Fragmentaire, partiellement recollé (une partie du fond et de la vasque). Des fragments du pied, du fond, de la vasque et du bord manquent. Pied annulaire bas à faces extérieure et intérieure convexes ; plan de pose décoré d'une moulure à l'extrémité intérieure ; vasque peu profonde et évasée, à paroi convexe s'épaississant vers le bord, qui est légèrement incurvé, à lèvre arrondie. Réservés : le fond extérieur (partiellement conservé) avec un cercle et une bande en vernis noir, le plan de pose, ainsi qu'un filet à la transition entre le pied et la vasque. Décor du fond intérieur : rangée d'oves estampées entre deux cercles incisés et traces d'une palmette.

Vers 390-380.

VN 72. - Tombe SP 339. Diam. du pied environ $10,5 \mathrm{~cm}$. Inv. FR 2.36.1.

Deux fragments jointifs représentant à peu près la moitié du pied avec une partie du fond et le départ de la vasque. Pied annulaire bas, décoré d'une moulure à l'extrémité intérieure du plan de pose. Réservés : le plan de pose et le fond extérieur, qui conserve des restes de décor vernissé (portions d'une bande et d'un cercle) et des traces d'engobe rougeâtre. Décor du fond intérieur : palmettes estampées (une seule partiellement conservée), entourées d'une rangée d'oves estampées entre deux cercles incisés.

Vers 390-380.

VN 73. - Foyer F 11. Ht 5,4 cm, diam. de l'embouchure $16,8 \mathrm{~cm}$. Inv. FR 3.11. Pl. 100c

Fragmentaire, partiellement recollé. Quelques fragments du fond et une partie du pied manquent. Le fond était probablement percé. Traces de combustion. Pied annulaire bas, décoré d'une rainure sur le plan de pose ; fond extérieur légèrement convexe ; sillon incisé après cuisson à la jonction entre le pied et la vasque ; vasque basse et évasée, à paroi convexe ; bord légèrement épaissi et incurvé, à lèvre pointue. Plan de pose réservé. Décor du fond intérieur : zone de palmettes estampées dont une seule est conservée ; tout autour, large bande de points estampés.

Vers 380-370.

VN 74a. - Tombe SP 329. Ht $5 \mathrm{~cm}$, diam. de l'embouchure 14,3 cm. Inv. PIN 3643 (FR 2.26). Pl. 100d

Restauré. Pied annulaire bas, décoré d'un ombilic central sous le fond extérieur et d'une rainure sur le plan de pose ; vasque basse et évasée, à paroi légèrement convexe ; bord épaissi et incurvé, à lèvre pointue. Réservés : un filet à la transition entre le pied et la vasque, le plan de pose. Décor du fond intérieur : au centre, rangée d'oves estampées encadrées de deux cercles incisés; tout autour, dans l'ordre, zone de dix 
palmettes estampées reliées par des arcs incisés, deuxième rangée d'oves estampées entre deux cercles incisés, deuxième zone de vingt-quatre palmettes semblable à la précédente.

Vers 360-350.

VN 74b - Dépôt DP 16. Ht. 3,2 cm, diam. de l'embouchure $9,4 \mathrm{~cm}$. Inv. PIN 3708 . Pl. 100e

Pied annulaire bas, décoré d'un ombilic central sous le fond extérieur et d'une rainure sur le plan de pose ; vasque basse et évasée, à paroi légèrement convexe ; bord épaissi et incurvé, à lèvre pointue. Réservés : un filet à la transition entre le pied et la vasque, le plan de pose. Décor du fond intérieur : au centre, rangée d'oves estampées encadrées de deux cercles incisés; tout autour, zone de six palmettes estampées reliées par des arcs incisés.

Vers 370-350.

VN 75. - Foyer F 4. Ht 4,7 cm, diam. de l'embouchure $15 \mathrm{~cm}$. Inv. PIN 3757. Pl. 70a

Surface couverte de concrétions. Pied annulaire bas, décoré d'un ombilic central sous le fond extérieur et d'une rainure sur le plan de pose ; vasque basse et évasée, à paroi légèrement convexe ; bord incurvé, à lèvre pointue. Le fond intérieur porte un décor estampé qu'il est impossible de reconstituer faute de nettoyage.

Vers 350-340.

\subsubsection{Type indéterminé}

Nous rangeons ici quelques fragments des DP 23 et 33 en secteurs central et Est (phase 3) qui appartiennent sans doute à des bols à bord saillant ou incurvé, mais dont le type exact ne peut être déterminé. Les fonds VN 76 et 77 sont intéressants, parce qu'ils conservent des restes d'un riche décor estampé qui évoque celui de VN 56-62, 66 et 74a-b. Le fait que le fragment VN 77 provient d'un contexte tardif, qui peut être daté vers 340-320 par le matériel amphorique associé, pose en particulier la question de savoir si la production de bols décorés de cette façon s'est poursuivie après le milieu du $\mathrm{IV}^{\mathrm{e}} \mathrm{s}$., mais, en l'absence d'autres exemples contemporains et compte tenu de l'état de conservation, il n'est pas exclu qu'il s'agisse simplement d'une intrusion.

VN 76. - Dépôt DP 33. Inv. FR 2.64.5.

Deux fragments jointifs représentant une partie du fond. Décor du fond intérieur : traces de deux palmettes et d'une frise d'oves.

Vers 375-350.
VN 77. - Dépôt DP 23. Inv. FR 1.56.1.

Fragment représentant une partie du fond. Décor du fond intérieur : au centre, rangée d'oves estampées entre deux cercles incisés ; tout autour, dans l'ordre, zone de palmettes estampées (six conservées), deuxième rangée d'oves estampées entre deux cercles incisés.

Vers 350-340 (?)

VN 78. - Dépôt DP 23. Long. 4,5 cm. Inv. FR 1.56.7. Fragment représentant une partie du pied. Pied annulaire à face extérieure convexe, concave à l'intérieur, s'épaississant vers le plan de pose ; ce dernier est large et décoré de deux moulures aux extrémités.

340-320.

\subsection{Coupelles}

\subsection{1. À bord incurvé}

Les coupelles VN 79-83 ne sont que des répliques à plus petite échelle des bols à bord incurvé du second quart du IV ${ }^{\mathrm{e}} \mathrm{s}$. commentés ci-dessus (cf. VN 71-73 et 74a-b). Le diamètre du bord de ces derniers, tout comme celui des autres exemples contemporains que nous connaissons, est généralement supérieur à $10 \mathrm{~cm}$ pour une hauteur variant entre 4 et $6 \mathrm{~cm}(\mathrm{VN} 74 \mathrm{~b}$, avec un diamètre de $9,4 \mathrm{~cm}$, fait plutôt figure d'exception), alors que, dans le cas des coupelles, il avoisine en moyenne 7-8 $\mathrm{cm}$ pour une hauteur de 2,5-3 cm. En dehors des différences évidentes de taille, tous les détails de profil, ainsi que le traitement du pied et du fond extérieur, sont identiques et les développements perceptibles parfaitement synchrones. Ainsi, VN 79-82 du foyer F 11 en secteur Est (vers 380-370), à fond plat ou légèrement convexe et rainure sur le plan de pose, reproduisent les éléments caractéristiques du bol VN 73 découvert dans le même foyer. Le profil de VN 83, qui provient d'un contexte un peu plus tardif - DP 25 près de SP 326 en secteur central - s'enrichit d'un ombilic sous le fond extérieur qu'on retrouve dans les bols des années 360350 (VN 74a-b). Compte tenu des dimensions réduites, le décor estampé à l'intérieur de nos coupelles est fort simple et se limite pour les exemplaires les plus anciens à une ou deux rangées d'impressions en forme d'arc de cercle, parfois entourant des palmettes, ou à quelques palmettes reliées autour d'un cercle central pour VN 83.

Des coupelles similaires à la série que nous publions ici proviennent des fouilles de Kalfata en 1946-1949 ${ }^{274}$,

274 Ivanov 1963 , p. 221, $\mathrm{n}^{\text {os }} 566-567$, fig. 86, pl. 117 : datées respectivement du milieu ou du troisième quart et de la deuxième moitié du $\mathrm{IV}^{\mathrm{e}} \mathrm{s}$., mais sans doute plus anciennes, comme le montre 
d'Olynthe et de Thasos ${ }^{275}$. Le type n'est pas représenté dans le matériel de l'Agora d'Athènes. Il n'a eu qu'une existence limitée et n'était probablement plus produit après le milieu du $\mathrm{IV}^{\mathrm{e}} \mathrm{s}$.

VN 79. - Foyer F 11 . Ht $2,4 \mathrm{~cm}$, diam. de l'embouchure $8,1 \mathrm{~cm}$. Inv. FR 3.3 .

Fragmentaire, recollée. La moitié de la vasque et du bord, ainsi que quelques fragments du fond et du pied manquent. Traces de combustion. Pied annulaire bas, décoré d'une rainure réservée sur le plan de pose ; fond extérieur légèrement convexe ; vasque basse et évasée, à paroi convexe s'épaississant vers le bord, qui est incurvé, à lèvre pointue. Décor du fond intérieur : deux rangées d'impressions irrégulières en forme d'arc de cercle.

Vers 380-370.

VN 80. - Foyer F 11. Ht $2,5 \mathrm{~cm}$, diam. de l'embouchure $8,3 \mathrm{~cm}$. Inv. FR 3.5. Pl. 101a

Fragmentaire, partiellement recollée. Une partie du fond et du pied manque. Fortes traces de combustion. Pied annulaire bas, décoré d'une rainure sur le plan de pose ; fond extérieur légèrement convexe ; vasque basse et évasée, à paroi convexe ; bord épaissi et incurvé, à lèvre pointue. Plan de pose réservé. Décor du fond intérieur: zone de palmettes estampées (deux conservées) inscrite dans une rangée d'impressions irrégulières en forme d'arc de cercle.

Vers 380-370.

VN 81. - Foyer F 11. Ht 2,9 cm, diam. de l'embouchure $8,4 \mathrm{~cm}$. Inv. FR 3.13 . PI. 101b

Fragment représentant approximativement un tiers de la vasque, du bord, du fond et du pied. Pied annulaire bas, décoré d'un léger ombilic sous le fond extérieur et d'une rainure sur le plan de pose ; vasque basse et évasée, à paroi convexe ; bord épaissi et incurvé, à lèvre pointue. Réservés : le plan de pose, une bande à la transition entre le pied et la vasque. Décor du fond intérieur : rangée d'impressions irrégulières en forme d'arc de cercle.

Vers 380-370.

VN 82. - Foyer F 11. Diam. du pied $5,5 \mathrm{~cm}$. Inv. FR 3.59.1.

Trois fragments recollés représentant la moitié du fond et du pied. Pied annulaire bas, décoré d'une rainure

la découverte avec $n^{\circ} 566$ de quelques coupelles de type «later and light » (ibid., p. 220, n ${ }^{\text {os }} 555-558$, fig. 86, pl. 117).

275 Robinson 1933, p. 231-232, $\mathrm{n}^{\text {os }} 872-875,877-878$, pl. 175 ; Robinson 1950, p. 358, n 790, pl. 224 ; Blondé 1985, p. 300, $\mathrm{n}^{\text {os }} 98-99$, fig. 13 (jardin de l'EFA, contexte de la première moitié du $\mathrm{IV}^{\mathrm{e}} \mathrm{s}$., mais datées du second quart du siècle). sur le plan de pose ; départ de la vasque qui était basse et évasée. Réservés : le plan de pose, une bande à la transition entre le pied et la vasque. Décor du fond intérieur : deux rangées d'impressions irrégulières en forme d'arc de cercle.

Vers 380-370.

VN 83. - Dépôt DP 25. Ht 3,3 cm, diam. de l'embouchure $7 \mathrm{~cm}$. Inv. FR 1.17. Pl. 101c

Restaurée. Pied annulaire bas, décoré d'un ombilic central sous le fond extérieur et d'une rainure sur le plan de pose ; vasque basse et évasée, à paroi convexe ; bord épaissi et incurvé, à lèvre pointue. Plan de pose réservé. Décor du fond intérieur: quatre palmettes estampées reliées par des arcs incisés ; au centre, cercle incisé.

Vers 375-350.

\subsection{2. À bord simple ou légèrement épaissi (« later and light »)}

D'après B. Sparkes, les coupelles de type «later and light » n'ont eu qu'une existence limitée d'une cinquantaine d'années environ, apparaissant vers 430 et disparaissant vers la fin du premier quart $d u I^{e} \mathrm{~s}$., lorsqu'elles sont remplacées par les séries à large base annulaire («broad base ») ${ }^{276}$. Durant cette période, le type reste très stable, gardant ses proportions et ses principales caractéristiques: une vasque peu profonde, à bord simple ou légèrement incurvé, souvent épaissi, qui repose sur un pied annulaire assez bas, parfois décoré d'une moulure concave sur la face intérieure. Le plan de pose et le fond extérieur sont systématiquement réservés avec, dans ce dernier cas, un décor de deux ou trois cercles et un point central de vernis noir. L'évolution, lorsqu'elle est perceptible, concerne surtout la facture des vases, les exemplaires de la fin du $\mathrm{V}^{\mathrm{e}}$ et du début du $\mathrm{IV}^{\mathrm{e}} \mathrm{s}$. étant généralement de facture plus fine que ceux de l'époque précédente.

Les observations effectuées sur les contextes de découverte de VN 84-87 montrent qu'elles appartiennent à l'étape finale de l'histoire du type. En effet, toutes nos coupelles proviennent des foyers rituels $F 1,2$ et 9 en secteur Est, dont la mise en place a dû intervenir au cours d'un intervalle chronologique relativement bref à la fin de la phase 2 de l'occupation du site. Leur fréquence dans ces foyers et leur absence respective du foyer $\mathrm{F} 11$ dans le même secteur, qui a livré une riche collection de coupelles datant de la transition entre le premier et le second quart du IV ${ }^{\mathrm{e}} \mathrm{s}$., sont d'une grande

276 Sparkes, Talcott 1970, p. 134. 
importance pour déterminer la limite chronologique entre les phases 2 et 3 : elle peut être située très précisément autour de 380 sur la base de ces critères. VN 85-86 sont proches des autres exemplaires contemporains que nous connaissons ${ }^{277}$; VN 84 est quelque peu différent, présentant un profil plus angulaire de la vasque et du pied, ainsi qu'une concavité nettement marquée à la transition entre les deux. Notons également que ces trois coupelles ont un fond extérieur légèrement convexe, ce qui pourrait être vu comme un trait tardif, annonçant l'ombilic des décennies postérieures.

VN 84. - Foyer F 9. Ht 3,1 cm, diam. de l'embouchure $8,6 \mathrm{~cm}$. Inv. PIN 4033i (FR 3.21). Pl. 101d

Fragmentaire, recollée. Quelques fragments de la vasque manquent. Traces de combustion. Pied annulaire bas, à carène douce sur la face extérieure, séparé de la vasque par une petite concavité ; fond extérieur légèrement convexe ; vasque basse et évasée, à paroi convexe, s'épaississant progressivement vers le bord; bord non différencié de la paroi, à lèvre arrondie. Réservés : le fond extérieur avec un disque central et un cercle en vernis noir, le plan de pose et probablement un filet à la transition entre pied et vasque, mais vernis très effacé.

Vers 380.

VN 85. - Foyer F 2. Ht $3 \mathrm{~cm}$, diam. de l'embouchure 8,9 cm. Inv. PIN 3242a. Pl. 69c

Fragmentaire. Pied annulaire bas à profil galbé ; vasque basse et évasée, à paroi convexe ; bord légèrement épaissi sur la face intérieure, à lèvre arrondie. Fond extérieur réservé et décoré d'un point central et deux cercles en vernis noir.

Vers 380 .

VN 86. - Foyer F 2. Ht $3 \mathrm{~cm}$, diam. de l'embouchure 8,4 cm. Inv. PIN 3242b. Pl. 69d

Fragmentaire. Pied annulaire bas à profil galbé ; vasque basse et évasée, à paroi convexe ; bord légèrement épaissi sur la face intérieure, à lèvre arrondie.

Vers 380.

VN 87. - Foyer F 1. Ht cons. $1,9 \mathrm{~cm}$, diam. de l'embouchure $8,4 \mathrm{~cm}$. Inv. PIN 3274a. PI. 68b

Fragmentaire. La partie inférieure de la vasque et le pied manquent. Vasque basse et évasée, à paroi

277 Cf. ibid., p. 298, n 876, fig. 9, pl. 33 ; Blondé 1985, p. 293, $\mathrm{n}^{\circ} 59$, fig. 8 (Thasos, jardin de l'EFA, contexte de la première moitié du IV e s.) ; Ivanov 1963, p. 220-221, nos 555-558, 560-561, fig. 86, pl. 117 (datées du milieu et de la seconde moitié du IVe s., mais certainement plus anciennes); Domínguez, Sánchez 2001, p. 263, $n^{\circ} 472$, fig. 164 (Andalousie orientale). convexe ; bord légèrement épaissi sur la face intérieure, à lèvre arrondie.

Vers 380 .

\subsection{3. À pied plat («flat foot »)}

VN 88-90 appartiennent à un type très rare de coupelles, dénommé «flat foot»par B. Sparkes, que nous n'avons rencontré jusqu'à présent qu'à l'Agora d'Athènes ${ }^{278}$. Le profil du bord évoque les coupelles « later and light », mais la vasque est plus basse, à paroi presque rectiligne ; le pied est également très bas, à plan de pose large et s'apparente presque à un fond annulaire. L'exécution n'est pas très soignée, le vernis a vraisemblablement été posé par trempage, comme l'attestent les importantes zones réservées au niveau de la paroi extérieure de la vasque, du fond extérieur et du pied, ainsi que les traces de coulées conservées à l'extérieur de VN 88. Les deux exemplaires de l'Agora sont datés vers 400 par B. Sparkes, mais le spécialiste américain précise que les coupelles de ce type apparaissent dans des dépôts du dernier quart $d u \mathrm{~V}^{\mathrm{e}} \mathrm{s}$. et de toute la première moitié $\mathrm{du} I \mathrm{IV}^{\mathrm{e}} \mathrm{s}$. Cette fourchette chronologique est en accord avec les contextes de découverte de VN 88-90 : les deux premières coupelles proviennent du foyer $\mathrm{F} 9$ en secteur Est (fin de la phase 2), pour lequel on peut proposer une date autour de 380, alors que le fragment VN 90 faisait partie du dépôt DP 33 (phase 3) qui peut être daté du second quart du IVe s. par le matériel amphorique associé.

VN 88. - Foyer F 9. Ht 2,3 cm, diam. de l'embouchure $8,6 \mathrm{~cm}$. Inv. PIN 4033j (FR 3.29). PI. 101e

Fragmentaire, recollée. Quelques fragments du bord, de la vasque, du fond et du pied manquent. Le fond était probablement percé. Pied annulaire très bas, à plan de pose large ; vasque basse et évasée, à paroi presque rectiligne qui s'épaissit progressivement vers le bord ; bord non différencié de la paroi, à lèvre arrondie. Réservés : le fond extérieur, la face intérieur du pied, le plan de pose. De même, la vasque est très irrégulièrement couverte de vernis à l'extérieur, ce qui a laissé de larges zones réservées au-dessus du pied.

Vers 380 .

VN 89. - Foyer F 9. Ht 2,3 m, diam. de l'embouchure environ 8,2 cm. Inv. PIN 4033q (FR 3.62.2). PI. 101f

Fragmentaire. La moitié du bord et de la vasque, ainsi qu'un tiers du pied et du fond manquent. Le fond était probablement percé. Pied annulaire très bas, à plan

278 Cf. Sparkes, Talcott 1970 , p. $134-135$ et p. 298 , nos $877-878$, pl. 33 . 
de pose large ; vasque basse et évasée, à paroi presque rectiligne ; bord légèrement épaissi à lèvre arrondie. Le fond extérieur, le plan de pose et les faces intérieure et extérieure du pied sont réservés.

Vers 380.

VN 90. - Dépôt DP 33. Inv. FR 2.64.7c.

Fragment du pied avec une partie de la vasque. Pied annulaire très bas au plan de pose large et réservé ; départ de la vasque qui était basse et évasée.

Vers 375-350.

\subsubsection{Avec large base annulaire («broad base »)}

L'unique coupelle de ce type découverte lors de nos fouilles provient du dépôt DP 5 en secteur Sud. Elle se distingue par son pied massif, à plan de pose réservé et légèrement biseauté, et par sa vasque très basse se terminant par un petit bord incurvé. Le fond extérieur, couvert de vernis noir, est entièrement occupé par un ombilic nettement prononcé. Ces spécificités, qu'on retrouve dans nombre d'exemplaires du second quart et de l'ensemble de la seconde moitié du IV ${ }^{\text {e }}$ s. ${ }^{279}$, n'ont pas une grande valeur chronologique, mais la découverte dans le même dépôt d'un canthare à vernis noir (VN 46) appartenant à l'étape initiale de développement du type à bord mouluré oriente plutôt vers le début de cette période $(375-350)^{280}$.

VN 91. - Dépôt DP 5. Ht 2,6 cm, diam. de l'embouchure $8,4 \mathrm{~cm}$. Inv. PIN 3219. PI. 101g

Pied annulaire bas et massif, à plan de pose large et légèrement biseauté vers l'intérieur, décoré d'un ombilic sous le fond extérieur et d'une rainure sur le plan de pose ; vasque basse et évasée se terminant par un bord incurvé à lèvre pointue. Réservés : le plan de pose, ainsi qu'une bande à la transition entre le pied et la vasque.

279 Agora d'Athènes: Sparkes, Talcott 1970, p. 299, nos $883-889$, fig. 9 et pl. 33 ; Rotroff 1997, p. 345 , n ${ }^{\text {os }} 1050-1053$, fig. 65 , pl. 78 et 146 ; Corbett 1949, p. 344, $\mathrm{n}^{\circ}$ 155, fig. 5 ; Thorikos (Attique): Mussche 1961, p. 198, nos 5-8, fig. 24 ; Vari (Attique) : Jones, Graham, Sackett 1973, p. 377, 380, nos 33-34, fig. 6-7, pl. 72-73 ; Porto Heli (Argolide) : Rudolph 1974, p. 119, n 39, fig. 4, pl. 13c ; Olynthe : Robinson 1950, p. 357, n 787, pl. 224 ; Thasos, puits Valma : Blondé 1989 , p. 495, $\mathrm{n}^{\mathrm{os}} 31-33$, fig. 6 ; Apollonia, Kalfata: Ivanov 1963, p. 221, nos 564-565, fig. 86 ; Histria et arrière-pays: Alexandrescu 1978 , p. $92, \mathrm{n}^{\text {os }} 600$ et 602 , fig. 15 ; Lungu 1993, p. 186, n 24, pl. 6 et 12 ; nécropole tumulaire de Panskoe I : Monahov, Rogov 1990b, p. 149, pl. 12, n ${ }^{\circ} 92$; Lattes (Hérault) : Py, Sabattini 2000, p. 178, fig. 11 ; Andalousie orientale: Domínguez, Sánchez 2001, p. 200, nos $92-95$, pl. 99.

280 Ajoutons que, selon B. Sparkes, la présence d'un filet réservé à la transition entre la vasque et le pied, constitue un trait caractéristique des exemplaires les plus anciens : Sparkes, Talcott 1970, p. 135.
Décor du fond intérieur: quatre palmettes estampées formant un motif cruciforme.

Vers 375-350.

\subsection{Salières}

\subsection{1. À paroi concave (« concave wall»)}

Tous les exemplaires répertoriés ci-dessous sont à peu près contemporains et proviennent des foyers rituels de la fin de la phase 2 et du début de la phase 3 : F 6 près de SP 334 en secteur Nord et F 9 et 11 en secteur Est. En terme de chronologie absolue, nous nous situons donc vers la fin du premier et le début du second quart $\mathrm{du} \mathrm{IV}^{\mathrm{e}} \mathrm{s}$. À l'exception de quelques détails mineurs, le profil des salières est identique et montre que, dès les premières décennies du $\mathrm{IV}^{\mathrm{e}} \mathrm{s}$., elles avaient déjà adopté tous les éléments spécifiques qui vont caractériser le type jusqu'à son extinction vers la fin de ce même siècle ${ }^{281}$ : une courbe concave continue depuis l'extrémité du bord jusqu'à la base du pied qui se trouve reproduite à l'intérieur de la vasque, un plan de pose étroit, nettement différencié des faces extérieure et intérieure du pied, un fond extérieur convexe, un bord épaissi et saillant vers l'extérieur et des proportions généralement plus élancées que celles des salières à paroi concave de la fin du $\mathrm{V}^{\mathrm{e}} \mathrm{s}$. Cette forte unité dans la morphologie des vases au cours d'une période de temps prolongée révèle une production de masse, sans doute issue d'un ou deux ateliers spécialisés, que confirme la large diffusion du type sur les sites méditerranéens et pontiques de l'époque ${ }^{282}$.

281 Selon S. Rotroff, les salières à paroi concave ne sont plus produites après 315 . Elles sont alors remplacées par une version hellénistique plus grossière dite « spool saltcellar » dont la production commence quelques années auparavant pour disparaître à son tour au début du III' s. : Rotroff 1997, p. 165-166.

$282 \mathrm{La}$ liste suivante contient certains des principaux sites du IV ${ }^{\mathrm{e}} \mathrm{s}$. qui ont livré des salières similaires à VN 92-96: Agora d'Athènes : Sparkes, Talcott 1970, p. 302, $\mathrm{n}^{\text {os }}$ 936-938, fig. 9, pl. 34 ; Rotroff 1997, p. 346, nos 1064-1066, fig. 65, pl. 78 ; Athènes, Pnyx : Rotroff, Camp 1996, p. 279, fig. 13 ; Athènes, Céramique : Schlörb-Vierneisel 1966 , p. $51,53,63,96, \mathrm{n}^{\text {os }} 102.13,105,114.3,171.12-13$, fig. 5 , pl. 41, 2, 45, 4 et 59, 5; Knigge 1966, p. 121, n ${ }^{\text {os }}$ 215.3-6, pl. 67, 1-9 (versions miniatures); Corinthe : Williams 1979, p. 134, $\mathrm{n}^{\circ} 52$, pl. 50 ; Porto Heli (Argolide) : Rudolph 1974, p. 121, n 44, fig. 5 ; Olynthe : Robinson 1933, p. 253, nos 1041-1042, pl. 189 ; Robinson 1950, $\mathrm{n}^{\text {os }} 929,931,933-938,940-942,944$, pl. 232, 238-239 (certains exemplaires peuvent être antérieurs à la fin du $\mathrm{V}^{\mathrm{e}} \mathrm{s}$.) ; Thasos, jardin de l'EFA : Blondé 1985, p. 299, n $^{\text {os }}$ 90-94, fig. 12 ; Thasos, puits Valma: Blondé 1989, p. 491, $\mathrm{n}^{\text {os }}$ 20-21, fig. 6; Apollonia, Kalfata : Ivanov 1948, p. 42, fig. 49a ; Ivanov 1963, p. 226, nos $592-$ 601, fig. 87, pl. 117 ; Apollonia, zone portuaire: Galabov 1965, p. $41, \mathrm{n}^{\circ} 140$, fig. 52a ; nécropole tumulaire d'Elisavetovskoe (Don inférieur) : Brashinskiy 1980, p. 137, n²20, pl. 17 et 20 ; nécropole 
VN 92. - Foyer F 6. Ht $2,6 \mathrm{~cm}$, diam. de l'embouchure $6,1 \mathrm{~cm}$. Inv. PIN 3816 . PI. 72c

Pied annulaire bas, évasé ; fond extérieur légèrement convexe; vasque peu profonde à paroi concave dans la même courbe que le pied ; bord épaissi et saillant vers l'extérieur et l'intérieur, à face supérieure arrondie. Entièrement couverte de vernis.

Vers 380.

VN 93. - Foyer F 6. Ht $2,6 \mathrm{~cm}$, diam. de l'embouchure $6,2 \mathrm{~cm}$. Inv. PIN 3820 . Pl. 72b

Pied annulaire bas, évasé ; fond extérieur légèrement convexe ; vasque peu profonde à paroi concave ; bord épaissi et saillant vers l'extérieur, à face extérieure carénée (profil triangulaire). Entièrement couverte de vernis.

Vers 380.

VN 94. - Foyer F 9. Ht 3,1 cm, diam. de l'embouchure $6,6 \mathrm{~cm}$. Inv. PIN 4033n (FR 3.30). PI. 102a

La moitié du bord manque. Pied annulaire bas, évasé ; fond extérieur légèrement convexe; vasque peu profonde à paroi concave ; petit bord saillant vers l'extérieur, à faces supérieure et extérieure arrondies. Entièrement couverte de vernis.

Vers 380.

VN 95. - Foyer F 9. Ht 2,8 cm, diam. de l'embouchure $6,6 \mathrm{~cm}$. Inv. PIN 4033o (FR 3.31). Pl. 102b

La moitié du bord, ainsi que quelques fragments $\mathrm{du}$ pied et du fond manquent. Traces importantes de combustion. Pied annulaire bas, évasé ; fond extérieur légèrement convexe; vasque peu profonde à paroi concave ; bord épaissi et saillant vers l'extérieur et l'intérieur, à face supérieure arrondie. Vernis très effacé, mais sans doute présent partout.

Vers 380.

VN 96. - Foyer F 11. Ht 3,1 cm., diam. de l'embouchure $6,5 \mathrm{~cm}$. Inv. FR 3.14 . Pl. 102c

Fragmentaire, partiellement recollée. Quelques fragments de la vasque, du fond et du pied manquent. Pied ébréché. Fortes traces de combustion. Pied annulaire bas, évasé ; fond extérieur légèrement convexe ; vasque peu profonde à paroi concave ; bord épaissi et saillant vers l'extérieur et l'intérieur, à face supérieure arrondie. Entièrement couverte de vernis noir, à présent très effacé suite à la combustion.

Vers 380.

tumulaire de Panskoe I (Crimée) : Monahov, Rogov 1990b, p. 140, 144 , pl. 3, 7, nos $94-95$.

\subsection{2. À bord incurvé («footed saltcellar »)}

Les salières à bord incurvé sont étroitement associées aux séries de bols et de coupelles à bord incurvé dont il a été question plus haut et il ne serait sans doute pas erroné de les considérer, à l'instar de certains chercheurs, comme la plus petite fraction de cette classe de vases ${ }^{283}$. Leur diamètre à l'embouchure avoisine généralement 5-6 cm contre 7-8 $\mathrm{cm}$ pour les coupelles et plus de $10 \mathrm{~cm}$ pour les bols; la hauteur est équivalente ou légèrement supérieure à celle des coupelles, autour de 3-4 $\mathrm{cm}$ en moyenne. Le profil général reste proche de celui des bols, mais il convient de signaler que l'évolution n'est pas toujours parallèle, notamment en ce qui concerne le traitement du bord, qui reste légèrement épaissi jusqu'à une époque très avancée de l'histoire du type ${ }^{284}$. En même temps, le pied présente des variations originales qui ont été utilisées par B. Sparkes pour distinguer des séquences chronologiques valables au sein $\mathrm{du} \mathrm{IV}^{\mathrm{e}} \mathrm{s}$. Selon lui, les salières à plan de pose large et réservé, avec ou sans rainure, sont plus anciennes et peuvent être datées dans les limites du second quart ou au plus tard du milieu du siècle, alors que celles à plan de pose étroit, réservé et orné d'une rainure appartiennent à la seconde moitié du IV e s. ${ }^{285}$.

Ce raisonnement, fort logique, pose cependant quelques problèmes dans le cas des salières que nous publions ici. Ainsi, le pied très fin de VN 97 ferait penser plutôt à une date tardive, mais les parois sont épaisses et le fond extérieur réservé avec un décor de cercles et d'une bande de vernis noir. Le contexte de découverte de ce vase - le dépôt DP 31 près de la ciste SP 339 en secteur central (phase 2) - oriente vers le premier quart $\mathrm{du} \mathrm{IV}^{\mathrm{e}} \mathrm{s}$., une époque non représentée dans les séries de l'Agora publiées jusqu'à présent. Le parallèle le plus proche dans le catalogue de B. Sparkes est une salière datée du dernier quart du $\mathrm{V}^{\mathrm{e}} \mathrm{s}$., qui a des proportions plus élancées, mais un profil similaire du bord et du pied ${ }^{286}$. Il

283 Tel est notamment l'avis de S. Rotroff en ce qui concerne les salières à bord incurvé d'époque hellénistique : Rotroff 1997, p. 161 et 167. Dans ses études du matériel céramique du jardin de l'EFA et du puits Valma à Thasos, F. Blondé considère également les bols et les salières de ce type comme représentant des variantes de formats différents d'une même forme : Blondé 1985, p. 299 ; Blondé 1989, p. 492-493.

284 Selon S. Rotroff, la disparition définitive de cet élément ne se fait que vers 275 . Voir par exemple les séries hellénistiques illustrées dans Rotroff 1997, fig. 65, et comparer avec sa fig. 62 qui montre l'évolution des profils des bols à bord incurvé à la même époque. 285 Sparkes, Talcott 1970, p. 137-138.

286 Ibid., p. 302, n 942, fig. 9, pl. 34. Proches également et probablement anciennes, mais avec une rainure sur le plan de pose et un ombilic sous le fond : Rotroff, Camp 1996, p. 279, fig. 14, 5 (de la 
nous semble que ce vase (il s'agit d'une trouvaille isolée) pourrait bien être contemporain de notre exemplaire ou tout au plus légèrement antérieur. Notons également que les contours doucement arrondis de la vasque et du bord des deux salières trouvent un parallèle dans le profil du bol VN 71, découvert dans le foyer F 5 tout proche, qu'on peut attribuer à la même époque

Le cas de VN 99 est plus problématique. Cette salière s'inscrit parfaitement dans le schéma esquissé par B. Sparkes pour les séries postérieures au milieu du $\mathrm{IV}^{\mathrm{e}} \mathrm{s}$. et, si nous ne connaissions pas son contexte de découverte, nous serions sans doute tentés de la dater de cette époque ${ }^{287}$, mais la chronologie du foyer F 1 en secteur Est est assez bien calée autour de 380 par les observations stratigraphiques et les autres vases à vernis noir qu'il contenait (cf. VN 23-24, 54, 87). VN 99 n'est donc que légèrement postérieure à $\mathrm{VN} 97$, pour laquelle on peut proposer sur les mêmes bases une date vers $390-380^{288}$.

VN 98 et 100 sont les seules à avoir un plan de pose large, conformément à l'idée que nous nous faisons du développement du type avant le milieu du siècle. La première provient du foyer $\mathrm{F} 8$ en secteur Nord (phase 2), dont la date est proche de celle de DP 31, alors que la seconde faisait partie du mobilier de SP 327 dans le même secteur (phase 3), qui vient s'installer au cours des années 360-350. Les deux salières ont un profil très proche et ne se différencient que par l'épaisseur de la paroi, celle-ci étant plus importante dans le cas de VN $98^{289}$.

Les remarques exposées ci-dessus nous amènent à quelques conclusions importantes. Il apparaît d'abord que la production de salières à bord incurvé au cours de

Pnyx) ; Ivanov 1963, p. 222, n 569, fig. 86, pl. 117 (des fouilles de Kalfata en 1946-1949).

287 Cf. Sparkes, Talcott 1970, p. 302-303, nos 948-950, fig. 9, pl. 34 (350-325).

288 L'incohérence dans la division chronologique établie par B. Sparkes a été soulignée également par Fr. Blondé qui mentionne une trouvaille collective de salières à bord incurvé des deux variantes sur un même sol lors des fouilles de la Porte du Silène à Thasos : cf. Blondé 1989, p. 493 avec références bibliographiques. De même, on notera qu'une salière à plan de pose étroit de la nécropole d'Elisavetovskoe (bassin inférieur du Don) provient d'une tombe qui a livré une amphore de Péparéthos de la variante de Soloha (I-A selon S. Monahov : Monahov 2003, p. 97-99), dont la date ne dépasse pas le premier quart du IV ${ }^{\mathrm{e}} \mathrm{s}$., ainsi qu'une coupelle à bord large (« broad rim ») qu'on peut dater de la même époque. Cf. Brashinskiy 1980, p. $137, \mathrm{n}^{\circ} 219$, pl. 17 et 19 ; pour le matériel associé, ibid., p. 122 et $137, \mathrm{n}^{\text {os }} 135$ et 217 , pl. 17.

289 Pour les parallèles, cf. Sparkes, Talcott 1970, p. 302, n ${ }^{\text {os }} 943-$ 945, fig. 9, pl. 34 ; Blondé 1985, p. 299, nos 96-97, fig. 13 (Thasos, jardin de l'EFA) ; Blondé 1989, p. 493, n² 24, fig. 6 (Thasos, puits Valma) ; Ivanov 1963, p. 222, n 570 , fig. 86 (des fouilles de Kalfata en 1946-1949); Alexandrescu 1978, p. 92, n 606, fig. 15 (de la nécropole tumulaire d'Histria). la première moitié du $\mathrm{IV}^{\mathrm{e}} \mathrm{s}$. était bien plus diversifiée que ce qui est généralement accepté, avec notamment la coexistence de plusieurs versions du type autour de 380 . Il nous semble que la meilleure explication de cette diversité serait la variété des sources d'inspiration disponibles : ainsi, dans le cas des salières à plan de pose large, il est difficile de ne pas voir une influence de la part des coupelles à large base annulaire ("broad base »), alors que pour celles à plan de pose étroit et orné d'une rainure, les bols et les coupelles à bord incurvé de la fin du premier et du second quart du $\mathrm{IV}^{\mathrm{e}} \mathrm{s}$. offrent un modèle évident. Durant l'ensemble de la période en question, le seul élément qui s'avère plus ou moins déterminant sur le plan chronologique n'est autre que l'épaisseur de la paroi : les exemplaires les plus anciens sont généralement d'une facture nettement plus épaisse que ceux dont les dates se rangent vers le milieu du siècle.

VN 97. - Dépôt DP 31. Ht 4 cm, diam. de l'embouchure $5,5 \mathrm{~cm}$. Inv. PIN 3658 (FR 2.22). Pl. 102d

Restaurée. Pied annulaire bas, à carène douce sur la face extérieure ; vasque peu profonde, à paroi épaisse et profil convexe ; bord incurvé dans la même courbe que la paroi, à lèvre arrondie. Réservés : le plan de pose, le fond extérieur (traces d'engobe rougeâtre) avec deux cercles et une bande en vernis noir, un filet à la transition entre le pied et la vasque; de même, zone sans vernis à la base de la vasque, due sans doute au fait que le vase avait été trempé.

Vers 390-380.

VN 98. - Foyer F 8. Ht 3,5 cm, diam. de l'embouchure $5,4 \mathrm{~cm}$. Inv. PIN 3861. Pl. 75d

Fragmentaire. Pied annulaire bas, à face extérieure carénée ; vasque peu profonde, à paroi épaisse et profil convexe ; bord incurvé à lèvre pointue.

Vers 390-380.

VN 99. - Foyer F 1. Ht $3,2 \mathrm{~cm}$, diam. de l'embouchure $6 \mathrm{~cm}$. Inv. PIN 3274b. PI. 68a

Pied annulaire bas décoré d'un ombilic central sous le fond extérieur et d'une rainure sur le plan de pose ; vasque peu profonde, à profil convexe, s'épaississant vers le bord incurvé, à lèvre pointue.

Vers 380.

VN 100. - Tombe SP 327. Ht 3,5 cm, diam. de l'embouchure $6 \mathrm{~cm}$. Inv. PIN 3730 . PI. 102e

Pied annulaire bas, à plan de pose large et face extérieure légèrement carénée ; ombilic central sous le fond extérieur ; vasque peu profonde, à profil convexe ; bord légèrement épaissi et incurvé, à lèvre pointue.

Vers 375-350. 


\subsection{Plats à poisson}

Bien qu'ils se répartissent sur une période d'une trentaine d'années environ, entre 380 et 350, les plats à poisson VN 101-107 présentent une diversité étonnante qui pourrait servir une fois de plus à démontrer la richesse de la production à vernis noir au cours de la première moitié du $\mathrm{IV}^{\mathrm{e}} \mathrm{s}$. et les différentes expériences qui étaient en cours dans les ateliers des potiers attiques. Trois variantes peuvent être distinguées.

La première variante, illustrée par VN 101 et 106, se distingue par un pied élaboré à face extérieure moulurée et face intérieure nettement concave, ainsi que par la présence de moulures supplémentaires sous la paroi extérieure de la vasque. Le bord déversé, fin et légèrement biseauté, s'arrête à mi-hauteur du pied dans le cas de VN 101, ou un peu plus haut pour VN 106, mais en laissant toujours visibles les moulures du pied. Le fond extérieur est réservé et décoré d'un point central, un ou deux cercles et une bande de vernis noir. Il s'agit de vases de facture assez fine et de fabrication soignée. VN 101 provient du foyer rituel F 6 près de SP 334 en secteur Nord (fin de la phase 2), qui peut être daté très précisément autour de 380 par sa position sous l'enclos MR 6/7, mais à la surface des remblais associés à la construction de cet important ensemble, alors que VN 106 a été utilisé pour couvrir le cratère à figures rouges (CP 46) contenant l'incinération secondaire SP 316 en secteur Sud, qui s'installe dans le remblai tumulaire de SP 325 à une date précoce au cours de la phase 3 (375-350). Le profil élaboré des pieds des deux plats trouve des parallèles précis dans les spécimens les plus anciens de l'Agora d'Athènes, datés autour de 400 par B. Sparkes ${ }^{290}$, mais la longueur des bords les rapproche plutôt d'un exemplaire du premier quart du $\mathrm{IV}^{\mathrm{e}} \mathrm{s}$. dans le même catalogue ${ }^{291}$. Notons également la profondeur relativement importante de la dépression centrale dans le cas de VN 106, qui constitue, selon B. Sparkes, un trait relativement tardif ${ }^{292}$. Ce dernier vase représente sans doute un des derniers exemples de la série à pied mouluré.

La seconde variante est représentée par VN 102-104. Ces trois exemplaires se différencient de la série précédente par un pied plus simple, sans moulures, et un bord plus épais. La paroi extérieure n'est plus décorée.

290 Cf. Sparkes, Talcott 1970, p. 310, n ${ }^{\text {os }} 1063-1064$, fig. 10, avec un décor identique. Comparer également un fragment de pied du puits Valma à Thasos qui doit provenir d'un vase contemporain aux plats attiques : Blondé 1985, p. 489, n 14, fig. 5.

291 Ibid., $\mathrm{n}^{\circ} 1066$, fig. 10.

292 Ibid., p. 148.
Le plan de pose est réservé, tout comme le fond extérieur qui porte un décor de cercles et une bande de vernis noir similaire à celui des plats à poisson de la première variante. Les contextes de découverte - les foyers $\mathrm{F} 2$ et $\mathrm{F} 9$ en secteur Est (fin de la phase 2) - indiquent une date contemporaine de VN 101 (vers 380), qui semble confirmée par les parallèles attiques ${ }^{293}$.

La troisième variante, comprenant VN 105 et le fragment de bord VN 107, présente d'autres traits originaux. On note l'absence totale du bord déversé caractéristique des deux variantes précédentes, qui est remplacé par un bord simple, à lèvre aplatie et légèrement saillante vers l'intérieur, situé dans le prolongement de la paroi de la vasque. Le pied est moins haut et plus épais, avec un plan de pose réservé et orné d'une rainure. Le fond extérieur (partiellement conservé sur VN 105) était entièrement couvert de vernis noir, entouré d'un sillon incisé après cuisson et probablement doté d'un ombilic central. Ces spécificités dénotent le caractère plus tardif de VN 105 et 107, ce qui est en accord avec les dates des contextes rituels dont ils sont issus : le foyer F 11 et le dépôt DP 33 en secteur Est (phase 3). Le premier oriente vers 380370 , alors que le second a livré du matériel datant de l'ensemble du second quart du IV $\mathrm{IV}^{\mathrm{e}} \mathrm{s}$. Notons que les vases de cette variante trouvent également des correspondants proches dans les séries de l'Agora d'Athènes, bien que les exemplaires en question aient un bord légèrement différent et généralement plus épais ${ }^{294}$. Leur date se situe dans le second quart et vers le milieu du $\mathrm{IV}^{\mathrm{e}} \mathrm{s}$.

VN 101. - Foyer F 6. Ht $4 \mathrm{~cm}$, diam. de l'embouchure 21,8 cm. Inv. PIN 3815. Pl. 72e

Fragmentaire. Pied annulaire bas à face extérieure moulurée et face intérieure concave ; vasque très évasée, à paroi rectiligne décorée de moulures à l'extérieur et dépression centrale hémisphérique ; bord tombant légèrement en biseau, à lèvre pointue. Réservés : la lèvre du bord, une bande autour de la dépression centrale.

Vers 380 .

293 Ibid., p. 310-311, nos 1067-1068, fig. 10, pl. 37. Les deux exemplaires sont datés autour de 375. Comparer également : Rotroff, Camp 1996, p. 288, fig. 21, 2-3 (de la Pnyx); Robinson 1950, p. 377-378, nos $892,895-897$, pl. 231-233 (d'Olynthe) ; Ivanov 1963, p. 231-232, nos 620-622, 624, fig. 90, pl. 121.

294 Ibid., p. 311, nos 1069-1071, fig. 10, pl. 37. Un exemplaire complet de cette variante provient des fouilles à Kalfata en 19461949 : Ivanov 1963 , p. $232, n^{\circ} 625$, fig. 90, pl. 121. Le plan de pose est réservé et orné d'une profonde rainure. Le fond extérieur est également réservé avec les restes d'un décor constitué d'une bande et de cercles de vernis noir. Malgré la date tardive que lui attribue $\mathrm{T}$. Ivanov - deuxième moitié du $\mathrm{IV}^{\mathrm{e}} \mathrm{s}$. - le plat est probablement plus ancien que notre VN 105 et les parallèles de l'Agora indiqués ci-dessus. 
VN 102. - Foyer F 9. Ht $2,8 \mathrm{~cm}$, diam. de l'embouchure $14,7 \mathrm{~cm}$. Inv. PIN 4033c (FR 3.18). Pl. $102 f$

Fragmentaire, recollé. Deux petits fragments de la vasque et un fragment plus important du fond manquent (percement volontaire ?). Traces de combustion. Pied annulaire bas à face extérieure convexe et face intérieure rectiligne ; vasque très évasée, à paroi rectiligne et dépression centrale hémisphérique ; bord tombant à la verticale, à profil convexe et lèvre aplatie. Réservés : le fond extérieur (partiellement conservé) avec un cercle et une large bande en vernis noir, le plan de pose, la lèvre du bord.

Vers 380 .

VN 103. - Foyer F 2. Ht $3 \mathrm{~cm}$, diam. de l'embouchure $16,5 \mathrm{~cm}$. Inv. PIN 3282. PI. 69b

Fragmentaire. Fortes traces de combustion. Pied annulaire bas à face extérieure convexe et face intérieure rectiligne ; vasque très évasée, à paroi rectiligne et dépression centrale hémisphérique ; bord tombant légèrement en oblique, à profil biconvexe et lèvre pointue ; sillon autour de la cupule centrale et à la transition entre la paroi intérieure et le bord.

Vers 380.

VN 104. - Foyer F 2. Ht $3 \mathrm{~cm}$, diam. de l'embouchure $16,6 \mathrm{~cm}$. Inv. PIN 3282a. PI. 69a

Fragmentaire. Fortes traces de combustion. Forme identique au précédent ; sillon autour de la cupule centrale et à la transition entre la paroi int. et le bord.

Vers 380 .

VN 105. - Foyer F 11. Ht 3,2 cm, diam. de l'embouchure $23 \mathrm{~cm}$. Inv. FR 3.6. Pl. $102 \mathrm{~g}$

Fragmentaire, partiellement recollé. La moitié de la vasque et du bord, ainsi que la plus grande partie du pied et du fond, manquent. Traces de combustion. Pied annulaire bas à face extérieure convexe et face intérieure rectiligne, décoré d'une rainure sur le plan de pose et d'un sillon incisé après cuisson sur le pourtour du fond extérieur; vasque très évasée, à paroi rectiligne et dépression centrale arrondie (très partiellement conservée) ; bord non différencié de la vasque, à lèvre aplatie, légèrement saillante vers l'intérieur; sillon autour de la cupule centrale et à la transition entre la paroi intérieure et le bord. Sur la paroi intérieure, deux rangées de guillochis.

Vers 380-370.

VN 106. - Tombe SP 316. Ht $4.7 \mathrm{~cm}$, diam. de l'embouchure $28,4 \mathrm{~cm}$. Inv. PIN 3629 . Pl. 13c

Restauré. Pied annulaire bas à face extérieure moulurée et face intérieure concave ; deux sillons à la transition entre la vasque et le pied ; vasque très évasée, à paroi rectiligne et dépression centrale hémisphérique; bord tombant à la verticale, à profil biconvexe et lèvre pointue ; sillons autour de la cupule centrale et à la transition entre la paroi intérieure et le bord. Réservés : le fond extérieur avec un point central, un cercle et une bande en vernis noir, les sillons autour de la cupule centrale et entre la paroi intérieure et le bord.

Vers 370-350.

VN 107. - Dépôt DP 33. Inv. FR 2.64.2.

Fragment du bord et de la vasque. Vasque à paroi rectiligne ; bord non différencié de la vasque, à lèvre aplatie et légèrement saillante vers l'intérieur ; sillon à la transition entre la paroi intérieure et le bord.

Vers 375-350.

\subsection{Askos}

Les fragments VN 108 appartiennent à une variante relativement commune d'askos à corps bas ( « shallow ») dont la diffusion semble se limiter à la première moitié $\mathrm{du} \mathrm{IV}^{\mathrm{e}} \mathrm{s}$. Elle se distingue par un petit élément en relief au centre de la partie supérieure du corps qui reproduit la forme d'un couvercle avec un bouton de préhension. Tout autour de cet élément se développe généralement un décor à figures rouges constitué de deux têtes féminines, de griffons ou de motifs végétaux ${ }^{295}$, mais on connaît également quelques askoi qui, comme VN 108, sont décorés de languettes peintes en noir sur un fond réservé ${ }^{296}$. L'originalité de notre exemplaire tient surtout à la forme de l'anse : celle-ci est petite et annulaire et était attachée à l'origine sur la partie supérieure du corps, perpendiculairement à l'axe du goulot. Or, à notre connaissance, les anses de ce type ne sont jamais associées aux askoi à pseudo-couvercle (qui sont dotés d'une anse en panier classique), mais sont caractéristiques d'une autre variante d'askos, celle à passoire («strainer top ») ${ }^{297}$, dont un exemplaire presque complet, orné de palmettes, vient du foyer F 9 (cf. CP 3). On peut parler donc d'un cas de croisement des éléments spécifiques de ces deux variantes. Notons également que plusieurs askoi de la variante « strainer top » portent un décor de languettes similaire à celui de notre exemplaire ${ }^{298}$.

295 Cf. par exemple, les exemples suivants d'Olynthe : Robinson 1933 , p. $172-173$, nos $401,403-404,407$, pl. 140 ; Robinson 1950 , p. $259, \mathrm{n}^{\circ} 460 \mathrm{~A}$, pl. 174

296 Robinson 1950, p. 259, n 459, pl. 174.

297 Pour le terme, cf. Sparkes, Talcott 1970, p. 159-160.

298 Cf. Ivanov 1963, p. 214, nos 527-528, pl. 114 (des fouilles à Kalfata en 1946-1949) ; Robinson 1933, p. 85, nos 85 et 87, pl. 59 ; Robinson 1950, p. 259-260, nos 460 et 461, pl. 174. 
Le contexte de découverte de VN 108 - le foyer F 11 en secteur Est (début de la phase 3) - oriente vers la fin du premier ou le début du second quart du $\mathrm{IV}^{\mathrm{e}} \mathrm{s}$.

VN 108. - Foyer F 11. Inv. FR 3.10.

Plusieurs fragments (certains recollés) représentant l'anse et une partie de la panse avec le fond. Fortes traces de combustion. Fond annulaire, réservé par dessous ; corps bas et circulaire, à carène douce, renflé dans sa partie supérieure où il est décoré d'un élément central en relief imitant un couvercle avec son bouton de préhension ; anse verticale en anneau décorée de trois sillons. Tout autour de l'élément central, sur fond réservé, décor peint au vernis noir en trois registres: deux rangées d'oves (une autour du bouton central, l'autre très partiellement conservée à la transition vers la partie inférieure de la panse), entre lesquelles est représentée une large bande de godrons.

Vers 380-370.

\subsection{Gutti}

VN 109a remonte vraisemblablement au second quart du $\mathrm{IV}^{\mathrm{e}} \mathrm{s}$. Le vase a des proportions fort trapues et repose sur un pied large et relativement bas qui est séparé de la vasque par un petit élément concave, sans développer toutefois la tige caractéristique des périodes plus tardives. Il peut être comparé, pour ce qui est de la forme, à un guttus des anciennes fouilles de Kalfata ${ }^{299}$, ainsi qu'à deux exemplaires similaires découverts à Athènes et Olynthe ${ }^{300}$, qui proviennent tous de contextes antérieurs au milieu du siècle. Malheureusement, cette fourchette chronologique ne peut être confirmée par des critères indépendants : le mobilier de SP 322, en secteur Nord, ne contenait qu'une petite oenochoé dont la date dépend largement de celle du guttus (cf. VN 3) et le contexte stratigraphique de la sépulture nous apprend simplement qu'elle est postérieure à 380 environ, car elle est creusée dans les remblais recouvrant les tombes de la phase 2 (SP 336 et 334).

VN 109b, une trouvaille isolée dont on ignore le contexte précis, est sans doute plus tardif, comme l'attestent son pied plus étroit et la présence d'une courte tige. Cependant, ces deux éléments sont assez massifs et n'atteignent pas la légèreté et les proportions allon-

299 Ivanov 1963, p. 210, n 515, fig. 80, pl. 112.

300 Schlörb-Vierneisel 1966, p. 69, no 129.1, pl. 46, 7 (de la nécropole du Céramique, début du deuxième quart du $\mathrm{IV}^{\mathrm{e}} \mathrm{s}$.) ; Robinson 1950, p. 267, n 480, pl. 178 (deuxième quart du $\mathrm{IV}^{\mathrm{e}} \mathrm{s}$., avant 360 d'après le mobilier de la tombe où il a été trouvé). gées des exemples hellénistiques ${ }^{301}$. Un parallèle de la nécropole du Céramique à Athènes permettrait, non sans quelques réserves, de situer ce vase dans les limites du troisième quart du $\mathrm{IV}^{\mathrm{e}} \mathrm{s} .{ }^{302}$

VN 109a. - Tombe SP 322. Ht 4,4 cm, diam. max. $5,7 \mathrm{~cm}$., diam. de l'embouchure 2,2 cm. Inv. PIN 3704. Pl. 103a

Pied annulaire, légèrement concave en-dessous; vasque profonde, à paroi convexe, se terminant par un bord horizontal incurvé à lèvre pointue ; anse verticale joignant le bord à la partie inférieure de la vasque ; bec verseur tubulaire implanté à la transition entre le bord et la vasque, à angle droit par rapport à l'anse. Face supérieure du bord réservée et décorée de six spirales en vernis noir formant un motif continu.

Vers 375-350.

VN 109b. - Découverte isolée dans la zone du point J 6. Ht 5,2 cm, diam. max. 5,4 cm, diam. de l'embouchure 2,4 cm. Inv. PIN 3677. Pl. 103b

Anse et bec verseur manquent. Pied annulaire, légèrement concave par dessous, séparé de la vasque par une courte tige; vasque profonde à paroi convexe se terminant un bord incurvé presque horizontal. L'anse verticale et le bec verseur (seules les attaches conservées) formaient un angle droit. Sur la face supérieure réservée du bord, motif continu de six spirales en vernis noir.

Vers 350-325 (?).

VN 110. - Foyer F 11. Inv. FR 3.59.4.

Deux fragments du bec verseur. Traces de combustion. Bec verseur tubulaire.

Vers 380-370.

\subsection{Lékanis avec son couvercle réversible (coupe-couvercle)}

Lorsqu'il rédigeait son commentaire sur les couvercles réversibles («reversible lids») du IV ${ }^{\mathrm{e}} \mathrm{s}$. découverts à l'Agora d'Athènes, B. Sparkes soulignait

301 Comparer par exemple Ivanov 1963, p. 210-211, nos 516-518, fig. 84, pl. 112 (datés du milieu ou du troisième quart du $\mathrm{IV}^{\mathrm{e}} \mathrm{s}$., mais sans doute plus tardifs, comme le montrent les exemples suivants); Schlörb-Vierneisel 1966, p. 90-91, $\mathrm{n}^{\text {os }} 155.3,158.2$, pl. 57, 1 et 58, 2 ; Parovich-Peshikan 1974, p. 85, fig. 81, 5 (de la nécropole hellénistique d'Olbia). Ces vases doivent appartenir aux dernières années du $\mathrm{IV}^{\mathrm{e}} \mathrm{ou}$ au début du $\mathrm{III}^{\mathrm{e}} \mathrm{s}$. d'après le matériel qui leur est associé.

302 Schlörb-Vierneisel 1966, p. 54, n 106.3, pl. 42, 5 (daté du premier quart du $\mathrm{IV}^{\mathrm{e}}$ s., mais découvert avec un skyphos de type corinthien du milieu ou du troisième quart du $\mathrm{IV}^{\mathrm{e}} \mathrm{s}$.). 
qu'aucune lékanis correspondant à ces couvercles n'avait pu être identifiée. Cependant, les quelques parallèles à vernis noir et figures rouges qui lui étaient connus suggéraient qu'il s'agissait de vases sans anses ${ }^{303}$.

La découverte de VN 111 permettra, nous l'espérons, de combler une partie de ces lacunes et de jeter un éclairage précieux sur l'évolution de cette variante très rare de lékanis à la fin du premier et au début du second quart $\mathrm{du} \mathrm{IV}^{\mathrm{e}} \mathrm{s}$. Notre exemplaire est presque complet et provient du foyer rituel F 9 en secteur Est, un contexte de la fin de la phase 2 qui est très bien daté vers 380 par le matériel associé et les observations stratigraphiques détaillées effectuées lors des fouilles de la zone. En dehors de l'absence d'anses, le vase proprement dit ne se distingue guère du type à anses horizontales de la première moitié du $\mathrm{IV}^{\mathrm{e}} \mathrm{s}$., comme l'atteste la comparaison avec la lékanis à figures rouges du dépôt DP 1 en secteur Sud (cf. CP 41) et les exemplaires figurés des anciennes fouilles de Kalfata et d'Olynthe ${ }^{304}$. Toutes ces lékanides ont un pied bas à plan de pose large, similaire à celui des séries de la seconde moitié du $\mathrm{V}^{\mathrm{e}} \mathrm{s}$., mais une vasque peu profonde à profil doucement caréné qui s'éloigne des courbes continues de l'époque précédente $^{305}$. Le couvercle de VN 111 est, quant à lui, proche par ses dimensions et sa forme d'un des deux couvercles réversibles de l'Agora publiés par B. Sparkes ${ }^{306}$. On note cependant quelques différences dans le traitement du pied qui sert de bouton de préhension : ainsi, le fond extérieur du couvercle attique est réservé et orné d'un cercle et une bande de vernis noir, la face extérieure du pied est moulurée et comporte des zones réservées, tandis que le pied de notre couvercle est entièrement couvert de vernis noir, avec pour seul décor une rainure large et profonde sur le plan de pose. Cette dernière est également couverte de vernis, mais le reste du plan de pose est réservé, ce qui contribue à créer un effet visuel très plaisant ${ }^{307}$. Ces particularités pourraient faire croire que notre exemplaire est plus récent, mais si la date proposée par B. Sparkes pour le couvercle de l'Agora est correcte (375-350), VN 111 est en réalité plus ancien. Il semble plutôt, comme le montre bien le profil du pied, que nous soyons ici face à une volonté consciente de

303 Cf. Sparkes, Talcott 1970, p. 168 et n. 19-20.

304 Ivanov 1963, p. 144, n 254, pl. 64 et 67 ; Robinson 1933, p. 84, $86, \mathrm{n}^{\text {os }} 81,91$, pl. 58, 60 ; Robinson 1950, n $^{\text {os }} 56-56$ A et-57, pl. 81 et 83. 305 Comparer par exemple, pour les profils de la seconde moitié du V e s., Sparkes, Talcott 1970, p. 322, n ${ }^{\text {os }}$ 1220-1221, fig. 11, pl. 40. 306 Ibid., p. 323, n 1240, fig. 11 et pl. 41.

307 Nous retrouvons le même traitement du plan de pose sur un couvercle réversible à figures rouges d'Olynthe: Robinson 1950, $\mathrm{n}^{\circ}$ 63, p. 119-121, pl. 86. Le reste du pied et le fond extérieur sont couverts de vernis noir. copier les fonds des bols à bord incurvé de l'époque qui, vers 380 justement, commencent à être uniformément décorés de cette façon (cf. VN 73 et 74a-b).

VN 111. - Foyer F 9. Ht de la lékanis $6,5 \mathrm{~cm}$, diam. de l'embouchure $16,5 \mathrm{~cm}$, ht du couvercle $3,4 \mathrm{~cm}$, diam. de l'embouchure 16,4 cm. Inv. PIN 4033f (FR 3.22, 3.24). Pl. 103c

Fragmentaires, recollés. Des fragments du bord, de la vasque, du fond et du pied de la lékanis manquent, tout comme des fragments de la coupe-couvercle dont le fond semble volontairement percé. Traces de combustion.

a) Lékanis : pied annulaire bas à plan de pose large ; vasque peu profonde, à carène douce, s'épaississant vers le bord, dont elle est séparée par un large ressaut servant à accueillir le couvercle ; bord mince à lèvre pointue. Réservés : une bande à la périphérie du fond extérieur, le plan de pose et la lèvre du bord ;

b) Coupe-couvercle : vasque évasée à paroi presque rectiligne, munie d'une dépression centrale hémisphérique sur la face inférieure ; bord tombant à la verticale, à faces extérieure et intérieure rectilignes, se terminant par une lèvre aplatie; bouton de préhension en forme de pied annulaire, décoré d'un ombilic sous le fond extérieur et d'une rainure large et profonde sur le plan de pose. Réservés : le plan de pose de part et d'autre de la rainure, la lèvre du bord.

Vers 380.

\subsection{Fragments indéterminés}

VN 112. - Dépôt DP 25. Diam. du pied 4,8 cm. Inv. FR 1.46 .

Fragment d'une forme fermée indéterminée (pyxis ?) représentant le pied avec une partie du fond et le départ de la paroi. Pied annulaire bas à face extérieure moulurée (deux moulures séparées par un sillon). Début de la paroi qui formait presque un angle droit avec le pied. Réservés : les fonds extérieur et intérieur, le plan de pose, le sillon entre les moulures de la face extérieure du pied, ainsi que probablement une bande à la transition entre le pied et la vasque. Traces d'engobe rougeâtre sur le fond extérieur et le plan de pose ; engobe brun sur le fond intérieur.

Vers 350 .

VN 113. - Tombe SP 339. Long. $3,8 \mathrm{~cm}$. Inv. FR 2.36.2.

Fragment d'anse à section ronde.

Vers 390-380. 


\section{Céramique commune ${ }^{308}$}

\subsection{Oenochoés}

\section{Forme 1 (types I-II de Ivanov 1963)}

CC 1. - Tombe SP 313. Ht 20,2 cm, diam. max. 15,4 cm. Inv. PIN 3601. Pl. 104a

Argile grise. Pied annulaire bas ; panse globulaire ; col presque cylindrique ; bord évasé trilobé ; anse verticale surélevée, de section ovale, joignant le bord à l'épaule. Sillon incisé à la base du col.

Vers 430-420.

CC 2. - Dépôt DP 31. Ht sans l'anse 11,8 cm, diam. max. 9,7 cm. Inv. PIN 3655 (FR 2.12). Pl. 104b

Argile grise. Une partie du bord manque. Restaurée. Pied annulaire bas ; panse globulaire séparée du col par un léger bourrelet ; col assez court, concave ; bord évasé et trilobé ; anse verticale surélevée à courbe continue, de section ovale, joignant le bord à l'épaule.

Vers 390-380.

\section{Forme 3 (types IV-V de Ivanov 1963)}

CC 3. - Dépôt DP 32. Ht 10,6 cm, diam. max. 7,6 cm. Inv. FR 2.13. Pl. 66a (à dr.)

Argile rouge-brun, engobe rouge foncé. Une partie du pied et du fond manquent. Restaurée. Pied annulaire bas ; panse globulaire ; col très court et concave se prolongeant sur le bord, qui est évasé et trilobé ; anse verticale à courbe continue, de section ovale, joignant le bord à l'épaule.

Vers 400-390.

CC 4. - Trouvaille isolée entre les points $\mathrm{G} 3$ et $\mathrm{F} 3$. Ht 13,6 cm, diam. max. 10,6 cm. Inv. PIN 3051. Pl. 104c Argile rouge orangée, engobe rouge foncé. Fragmentaire. Plusieurs fragments de la panse et toute l'anse manquent. Pied annulaire bas ; panse globulaire ; col concave se terminant par un bord évasé et trilobé.

400-375 (?)

308 Il n'a pas été possible, dans les délais fixés pour la publication, de présenter un commentaire de cette catégorie de céramique: A. Riapov compte le faire dans une étude séparée. Le catalogue typologique et les datations issues des contextes apportent cependant une contribution à un dossier peu étudié, qu'il nous a paru utile de présenter ici.
CC 5. - Dépôt DP 19. Ht 13,4 cm, diam. max. 9,4 cm. Inv. PIN 3740. PI. 104d

Argile rouge brun. La plus grande partie du bord et des fragments du col manquent. Pied annulaire bas; panse ovoïde ; col concave se prolongeant sur le bord qui est évasé et trilobé ; anse verticale à courbe et contrecourbe et arête médiane joignant le bord à l'épaule.

Vers 370-350.

CC 6. - Dépôt DP 27. Ht 18,4 cm, diam. max. $12,4 \mathrm{~cm}$. Inv. FR 1.36.

Argile rouge orangé, engobe rouge foncé. Reste la moitié du pied et de la panse. Le fond était probablement percé. Pied annulaire bas; panse ovoïde ; col concave se prolongeant sur le bord qui est évasé et trilobé ; anse verticale de section ovale joignant le bord à l'épaule.

Vers 350.

CC 7. - Dépôt DP 27. Ht sans l'anse 11,4 cm, diam. max. 11,4 cm. Inv. FR 1.40.

Argile rouge-brun, engobe marron. Reste la moitié du pied et de la panse avec l'anse. D'après les observations effectuées sur le terrain, le col était brisé. Pied annulaire bas ; panse ovoïde ; col concave ; bord évasé et trilobé ; anse verticale de section ovale joignant le bord à l'épaule.

Vers 350 .

CC 8. - Dépôt DP 14. Ht 19 cm, diam. max. 13,2 cm. Inv. PIN 3689. Pl. 104e

Argile rouge-brun, engobe rouge foncé. Fragmentaire. Pied annulaire bas ; panse ovoïde ; col concave ; bord évasé et trilobé, formant deux saillies verticales prononcées de chaque côté de l'ouverture; anse verticale à courbe et contre-courbe et arête médiane joignant le bord à l'épaule.

Vers 350-325.

\section{Forme 9}

CC 9. - Dépôt DP 31. Ht sans l'anse $14 \mathrm{~cm}$, diam. max. 12,8 cm. Inv. PIN 3653 (FR 2.8). Pl. 104f

Argile gris-noir. Anses brisées. Restaurée. Pied annulaire bas ; panse globulaire ; col haut et concave, se prolongeant sur le bord qui est horizontal, à lèvre arrondie, avec une moulure sur la face supérieure ; deux anses verticales rapprochées et surélevées, attachées au niveau de la moulure de la face supérieure du bord et à l'épaule.

Vers 390-380.

\section{Type VII de Ivanov 1963}

CC 10. - Foyer F 10. Ht conservée (sans l'anse) $6,8 \mathrm{~cm}$. Inv. FR 3.64. 
Fragmentaire, partiellement recollée. Toute la partie inférieure de la panse et le pied manquent. Panse globulaire ; col presque cylindrique ; bord évasé et trilobé ; anse verticale surélevée à courbe et contre-courbe, de section ovale, attachée au bord et à l'épaule.

Vers 380 .

\section{Type indéterminé}

CC 11. - Foyer F 9. Diam. du pied environ $6,5 \mathrm{~cm}$. Inv. FR 3.62.1.

Argile brune, surface gris-noir. Quatre fragments, deux représentant la moitié du pied avec le départ du fond, un de l'anse et un autre du bord. Le fond était probablement percé. Pied annulaire bas ; bord trilobé ; anse verticale de section ovale.

Vers 380.

CC 12. - Dépôt DP 33. Inv. FR 2.62.14.

Argile orangée. Quatre fragments du bord, trilobé. Vers 375-350.

\subsection{Olpé}

CC 13. - Tombe SP 318. Ht $13,2 \mathrm{~cm}$, diam. max. $6,8 \mathrm{~cm}$. Inv. PIN 3668. Pl. 104g

Argile brun beige, traces d'engobe rouge brun. Le vase a subi une déformation lors de la cuisson, il est plus penché d'un côté. Pied annulaire à profil biconique, concave en-dessous ; panse ovoïde ; col court, concave, se prolongeant en un bord évasé et légèrement épaissi, à lèvre aplatie ; anse verticale surélevée, de section ovale, attachée au bord et à l'épaule.

Vers 300-275.

\subsection{Cruches}

\section{«Mushroom jug »}

CC 14. - Dépôt DP 34. Ht 15,3 cm, diam. max. $22,2 \mathrm{~cm}$. Inv. PIN 3638 (FR 2.7). Pl. 67d et 105a

Argile rouge orangé. Anses et bord endommagés, recollés. Quelques fragments de l'une des deux anses et du bord manquent. Pied annulaire bas ; panse biconique à paroi supérieure et inférieure faiblement convexe ; col très court prolongé par un bord évasé à lèvre arrondie ; deux anses verticales rapprochées et surélevées, attachées au bord et à mi-hauteur de l'épaule.

Vers 400-390.
CC 15. - Trouvaille isolée au N./N-E. de SP 298. $\mathrm{Ht}$ cons. sans les anses 2,6 cm, diam. de l'embouchure $7,5 \mathrm{~cm}$. Inv. PIN $3246 \mathrm{~b}$.

Argile rouge orangé, traces d'engobe rouge. Fragmentaire. L'ensemble de la panse et du pied, ainsi que la partie inférieure des anses manquent. Col très court, concave ; bord évasé à lèvre arrondie et légèrement épaissie; départ de deux anses verticales rapprochées et surélevées qui devaient joindre le bord à l'épaule.

Vers 380-350 (?).

\section{À bord simple ou légèrement épaissi et pied annulaire (type III de Ivanov 1963)}

CC 16. - Foyer F 5. Diam. de l'embouchure $11 \mathrm{~cm}$, diam. du pied 8,5 cm. Inv. FR 2.54.

Argile brun clair, surface grise. Plusieurs fragments représentant la plus grande partie du bord avec le départ du col, l'anse, ainsi que les deux tiers du pied et du fond avec le départ de la panse. Fond percé. Pied annulaire bas ; col concave ; bord évasé dans le prolongement du col, à lèvre aplatie et légèrement épaissie sur la face extérieure, de section triangulaire; anse verticale de section ovale.

Vers 390-380.

CC 17. - Foyer F 5. Diam. du pied $8,2 \mathrm{~cm}$. Inv. FR 2.51.

Argile grise. Un fragment du bord, trois fragments représentant presque la quasi-totalité du pied et du fond, ainsi que plusieurs fragments de la panse. Fond percé. Pied annulaire bas ; bord à lèvre aplatie et épaissie sur la face extérieure, de section triangulaire.

Vers 390-380.

CC 18. - Foyer F 5. Diam. du pied $8 \mathrm{~cm}$. Inv. FR 2.67. Argile rouge brun. Deux fragments du bord (probablement jointifs) et un fragment conservant la moitié du pied et du fond. Pied annulaire bas ; col concave ; bord évasé, à lèvre arrondie.

Vers 390-380.

CC 19. - Foyer F 11. Diam. du pied environ $7,5 \mathrm{~cm}$. Inv. FR 3.59.8.

Argile gris vert, surface gris noir. Plusieurs fragments représentant une partie du bord et du col, ainsi que la moitié du pied avec le départ du fond. Le fond était probablement percé. Pied annulaire bas ; bord évasé, à lèvre arrondie et épaissie, carénée sur la face extérieure ; bourrelet en relief à la transition entre le col et la panse.

Vers 380-370.

CC 20. - Foyer F 11. Inv. FR 3.59.14.

Argile brun rouge, surface gris noir. Un fragment du 
bord, un autre de l'anse et deux fragments du pied. Pied annulaire bas ; bord à lèvre arrondie et épaissie, carénée sur la face extérieure ; anse verticale de section ovale.

Vers 380-370.

CC 21. - Foyer F 11. Inv. FR 3.59.13.

Argile brune, surface gris noir. Un fragment du bord et deux fragments du pied. Pied annulaire bas ; bord à lèvre aplatie et épaissie sur la face extérieure, de section nettement triangulaire.

Vers 380-370.

CC 22. - Dépôt DP 33. Diam. de l'embouchure environ $11 \mathrm{~cm}$, diam. du pied 11,4 cm. Inv. FR 2.59. Pl. 66e

Argile grise, surface gris noir. Fragmentaire. Quelques fragments du bord, du col et de la panse manquent. Fond percé. Pied annulaire bas ; panse globulaire ; col concave ; bord évasé, à lèvre aplatie et épaissie sur la face extérieure, de section triangulaire ; anse verticale à courbe et contre-courbe attachée au bord et à l'épaule.

Vers 375-350.

CC 23. - Dépôt DP 33. Diam. du pied 7,2 cm. Inv. FR 2.60.

Argile brune, surface gris noir. Très fragmentaire. La plus grande partie du bord manque. Fond percé. Pied annulaire bas; panse globulaire; col presque cylindrique, séparé de la panse par un bourrelet en relief; bord légèrement évasé, à lèvre arrondie ; anse verticale de section ovale attachée au bord et à l'épaule.

Vers 375-350.

CC 24. - Dépôt DP 27. Ht conservée du col $6,9 \mathrm{~cm}$, diam. de l'embouchure 10,2 cm. Inv. FR 1.49 (col); 1.43.3 (pied).

Argile brune, surface gris noir. Quelques fragments recollés représentant la moitié du bord et du col, ainsi qu'une partie du pied et du fond avec le départ de la panse. Pied annulaire bas; col légèrement concave; bord évasé, à lèvre aplatie et épaissie sur la face extérieure, de section triangulaire.

Vers 350 .

CC 25. - Dépôt DP 23. Ht conservée du col 4,1 cm. Inv. FR 1.55.8.

Argile grise, surface gris noir. Trois fragments, dont un fragment représentant un tiers du pied avec le départ de la panse, un fragment du bord avec une partie du col et un fragment de la panse. Pied annulaire bas ; col haut, presque cylindrique; bord évasé se terminant par une lèvre aplatie et épaissie sur la face extérieure, de section triangulaire.

Vers 340-320.

\section{À col orné de cannelures horizontales (types IV et VII de Ivanov 1963)}

CC 26. - Trouvaille isolée près de l'angle N.-E. de SP 300. Ht conservée $12 \mathrm{~cm}$., diam. max. 12,6 cm. Inv. PIN 3256a. Pl. 105b

Argile grise. La plus grande partie de la panse, le pied et le fond manquent. Panse globulaire ; col assez haut, cylindrique, décoré de trois larges cannelures horizontales ; bord évasé dans le prolongement du col, se terminant par une lèvre aplatie et épaissie sur la face extérieure, de section triangulaire; anse verticale à courbe et contre-courbe, de section ovale, joignant le bord à l'épaule.

Vers 390-380.

CC 27. - Dépôt DP 26. Ht 17,4 cm, diam. max. 12,6 cm. Inv. PIN 49 (FR 1.9). Pl. 105c

Argile grise. Fond percé. Restaurée. Pied annulaire bas; panse globulaire; col assez haut, cylindrique, décoré de plusieurs cannelures horizontales ; bord évasé se terminant par une lèvre aplatie et légèrement épaissie sur la face extérieure, de section triangulaire ; anse verticale à courbe et contre-courbe, de section ovale, joignant le bord à l'épaule.

Vers 390-380.

CC 28. - Dépôt DP 18. Ht 18,1 cm, diam. max. 13,3 cm. Inv. PIN 3721. PI. 106a

Argile orangée. Pied annulaire bas; panse globulaire ; col haut, concave, décoré de plusieurs cannelures horizontales ; bord fortement évasé, à lèvre arrondie, décoré d'une moulure aiguë sur la face supérieure ; anse verticale à courbe continue, de section ovale, joignant le bord à l'épaule.

Vers 370-350.

CC 29. - Dépôt DP 8. Ht 15,3 cm, diam. max. 12,4 cm. Inv. PIN 3743.

Argile gris noir. Fragmentaire : la plus grande partie de l'anse manque. Pied annulaire bas; panse globulaire à épaulement marqué ; col assez haut, cylindrique, décoré de plusieurs cannelures horizontales ; bord fortement évasé, décoré d'une moulure aiguë sur la face supérieure ; anse verticale de section ovale joignant le bord à l'épaule.

Vers 330-320.

\section{À bord simple ou légèrement épaissi et fond annulaire (type V de Ivanov 1963)}

CC 30. - Foyer F 11. Diam. du fond environ $6 \mathrm{~cm}$. Inv. FR 3.59.10. 
Argile orangée. Un fragment du bord et deux fragments $\mathrm{du}$ fond. Fond annulaire, légèrement concave en-dessous ; bord évasé dans le prolongement du col, à lèvre aplatie.

Vers 380-370.

CC 31. - Dépôt DP 33. Ht 10,3 cm, diam. max. $7,5 \mathrm{~cm}$. Inv. FR 2.10. Pl. 106c

Argile grise. Fond annulaire ; panse globulaire ; col concave se prolongeant sur le bord évasé, à lèvre aplatie ; anse verticale à courbe continue, de section ovale, joignant le bord à l'épaule.

Vers 375-350.

CC 32. - Dépôt DP 33. Ht $10 \mathrm{~cm}$, diam. max. $7 \mathrm{~cm}$. Inv. FR 2.11. Pl. 106d

Argile rouge brun. Fond annulaire; panse globulaire ; col assez haut, presque cylindrique ; bord évasé à lèvre arrondie ; anse verticale à courbe et contre-courbe, de section ovale, joignant le bord à l'épaule.

Vers 375-350.

CC 33. - Dépôt DP 19. Ht 9,5 cm, diam. max. 8,2 cm. Inv. PIN 3740a. Pl. 106e

Argile rouge brun. Fragmentaire. Fond annulaire; panse biconique arrondie; col presque cylindrique; bord évasé à lèvre aplatie et saillante vers l'intérieur, de section triangulaire ; anse verticale à courbe et contrecourbe, de section ovale, joignant le bord à l'épaule.

Vers 370-350.

CC 34. - Dépôt DP 27. Ht 10,5 cm, diam. max. $8,1 \mathrm{~cm}$. Inv. FR 1.10. Pl. 107a

Argile rouge brun. Fond percé. Restaurée. Fond annulaire ; panse globulaire ; col concave ; bord évasé à lèvre aplatie ; anse verticale à courbe et contre-courbe, de section ovale, joignant le bord à l'épaule.

Vers 350 .

CC 35. - Dépôt DP 27. Ht 11,5 cm, diam. max. $8 \mathrm{~cm}$. Inv. FR 1.11.

Argile grise. Une partie du bord et l'anse manquent. Fond percé. Restaurée. Fond annulaire ; panse globulaire ; col haut, presque cylindrique ; bord évasé à lèvre aplatie et épaissie sur la face extérieure, de section triangulaire. Sillon incisé sur l'épaule.

Vers 350 .

CC 36. - Dépôt DP 27. Ht de la partie supérieure $8,7 \mathrm{~cm}$., diam. max. 8,4 cm., diam. du pied $5 \mathrm{~cm}$. Inv. FR 1.37 (partie supérieure) ; 1.43 .1 (pied). Pl. 107b

Argile orangée. Deux fragments, l' un représentant la totalité du bord et du col, l'anse et la moitié supérieure de la panse, l'autre le fond avec le pied et le départ de la panse. Fond annulaire ; panse globulaire ; col concave ; bord évasé à lèvre aplatie et légèrement épaissie sur la face extérieure ; anse verticale à courbe continue, de section ovale, joignant le bord à l'épaule. Sillon incisé à la transition entre le col et l'épaule.

Vers 350 .

CC 37. - Tombe SP 342. Ht 9,1 cm, diam. max. 7,7 cm. Inv. FR 2.38.

Argile rouge brun, engobe marron. Quelques fragments du bord et de la panse manquent. Fond percé, annulaire ; panse globulaire ; col concave ; bord évasé à lèvre aplatie et légèrement épaissie sur la face extérieure, de section triangulaire; anse verticale à courbe et contre-courbe, de section ovale, joignant le bord à l'épaule.

Vers 340.

CC 38. - Dépôt DP 29. Ht 10,2 cm, diam. max. $8,4 \mathrm{~cm}$. Inv. FR 1.60 .

Argile rouge brun. L'anse et un fragment du bord manquent. Fond annulaire; panse globulaire; col concave ; bord évasé à lèvre aplatie, légèrement épaissie sur la face extérieure ; traces de l'attache d'une anse verticale sur l'épaule.

Vers 340 .

CC 39. - Découverte isolée au N.-E. de SP 312. Ht 9,3 cm, diam. max. 8 cm. Inv. PIN 3600. Pl. 107c

Argile grise. Fond annulaire, concave en-dessous ; panse globulaire ; col presque cylindrique ; bord évasé à lèvre aplatie et légèrement épaissie sur les faces extérieure et intérieure; anse verticale à courbe et contre-courbe, de section presque rectangulaire, joignant le bord à l'épaule.

Vers 375-325 (?).

CC 40. - Dépôt DP 14. Ht 10,7 cm, diam. max. 8,2 cm. Inv. PIN 3692. Pl. 107d

Argile rouge brun. Fragmentaire. Fond annulaire, légèrement concave en-dessous ; panse globulaire ; col presque cylindrique ; bord évasé à lèvre aplatie et épaissie vers l'intérieur, de section triangulaire ; anse verticale à courbe et contre-courbe, de section ovale, joignant le bord à l'épaule.

Vers 350-325.

CC 41. - Dépôt DP 14. Ht 10,2 cm, diam. max. 8,5 cm. Inv. PIN 3692a. Pl. 107e

Argile brune. Traces de tournage. Fond annulaire; panse globulaire ; col concave ; bord évasé à lèvre aplatie et légèrement épaissie sur la face extérieure; anse 
verticale à courbe continue, de section ovale, joignant le bord à l'épaule.

Vers 350-325.

CC 42. - Dépôt DP 14. Ht 10,6 cm, diam. max. $8,2 \mathrm{~cm}$. Inv. PIN 3692b. Pl. 107f

Argile rouge brun, traces d'engobe rouge foncé. Fond annulaire ; panse globulaire ; col concave ; bord évasé à lèvre arrondie ; anse verticale à courbe et contre-courbe, de section ovale, joignant le bord à l'épaule.

Vers 350-325.

CC 43. - Dépôt DP 23. Inv. FR 1.55.14e.

Argile orangée. Fragment du bord avec le départ du col. Bord évasé à lèvre aplatie.

Vers 340-320.

CC 44. - Dépôt DP 23. Inv. FR 1.55.14f.

Argile brune, surface gris noir. Fragment du bord avec le départ du col. Col presque cylindrique, bord évasé à lèvre aplatie et épaissie sur la face extérieure, de section triangulaire.

Vers 340-320.

CC 45. - Dépôt DP 21. Ht 9,1 cm, diam. max. 8,2 cm. Inv. FR 1.53. Pl. 107g

Argile grise. Embouchure fragmentaire. Fond percé annulaire, légèrement concave en-dessous ; panse globulaire ; col concave ; bord évasé à lèvre aplatie ; anse verticale à courbe et contre-courbe, de section trapézoïdale, joignant le bord à l'épaule.

Vers 300-290 (?)

\section{À col bas et anse surélevée (type VI de Ivanov 1963)}

CC 46. - Tombe SP 375. Ht de la partie supérieure $16,8 \mathrm{~cm}$, diam. de l'embouchure $11,9 \mathrm{~cm}$. Inv. PIN 4110 (FR 3.52). Pl. 108a

Argile brune, surface grise. Seule subsistent la partie supérieure du vase et un fragment de la partie inférieure de la panse, avec une portion du pied et du fond. Pied annulaire bas; panse large, globulaire; col presque cylindrique ; bord évasé à lèvre épaissie en bourrelet sur la face extérieure ; anse verticale surélevée, de section rectangulaire, joignant le bord à l'épaule.

Vers 390-380.

CC 47. - Trouvaille isolée dans la zone du point H 3. Ht 15,2 cm, diam. max. 13,4 cm. Inv. PIN 3686. Pl. 108b

Argile gris brun. Fragmentaire. Pied annulaire bas ; panse globulaire ; col cylindrique ; bord évasé à lèvre aplatie et légèrement épaissie sur la face extérieure, de section triangulaire ; anse verticale surélevée, de section ovale, joignant le bord à l'épaule.

Vers 400-375 (?)

\section{À ressaut sous le bord (type VIII de Ivanov 1963)}

CC 48. - Foyer F 11. Inv. FR 3.59.11.

Argile rouge brun. Deux fragments du bord, un grand fragment de l'anse et un fragment du pied. Pied annulaire bas à faces intérieure et extérieure convexes ; col probablement cylindrique ; bord dans le prolongement du col, à profil concave et à lèvre arrondie et déversée ; anse verticale à courbe continue, de section ovale.

Vers 380-370.

CC 49. - Dépôt DP 33. Ht $16,4 \mathrm{~cm}$, diam. max. $13,4 \mathrm{~cm}$. Inv. FR 2.58. Pl. 108c

Argile orangée. L'anse, ainsi que la plus grande partie du bord et du col manquent. Fond percé. Pied annulaire bas ; panse large, globulaire ; col haut, presque cylindrique, se rétrécissant légèrement vers le bord, dont il est séparé par un ressaut ; bord dans le prolongement du col, à profil concave et à lèvre aiguë déversée.

Vers 375-350.

CC 50. - Dépôt DP 33. Diam. de l'embouchure $6,7 \mathrm{~cm}$. Inv. FR 2.62.13.

Argile brune, surface gris noir. Cinq fragments représentant à peu près la moitié du bord avec une petite partie du col. Col presque cylindrique dans sa partie supérieure, séparé du bord par un ressaut ; bord à profil concave et à lèvre aiguë déversée.

Vers 375-350.

CC 51. - Dépôt DP 4. Ht 15,2 cm, diam. max. 11,6 cm. Inv. PIN 3204. Pl. 109a

Argile rose orangé. Pied annulaire bas ; panse globulaire ; col haut, presque cylindrique, séparé du bord par un ressaut nettement marqué ; bord en retrait par rapport au col, évasé, à lèvre légèrement déversée, formant un second ressaut à mi-hauteur ; anse verticale à courbe continue, de section ovale, attachée au niveau du ressaut sous le bord et à l'épaule.

Vers 375-350.

CC 52. - Dépôt DP 5. Ht 13,2 cm, diam. max. 11,2 cm. Inv. PIN 3222. PI. 109b

Argile beige rosé. Défauts de cuisson. Pied annulaire bas ; panse globulaire à épaulement marqué ; col haut, cylindrique, séparé du bord par un ressaut nettement marqué ; bord dans le prolongement du col, à profil concave et à lèvre épaissie légèrement déversée ; anse verticale à courbe continue, de section ovale, 
attachée au niveau du ressaut sous le bord et à l'épaule. Vers 375-350.

CC 53. - Découverte isolée dans la zone du point J 5. Ht 15,2 cm, diam. max. 12,7 cm. Inv. PIN 3812. Pl. 109c

Argile rouge brun. Pied annulaire bas ; panse globulaire ; col haut, se rétrécissant vers le bord, dont il est séparé par un ressaut ; bord dans le prolongement du col, à lèvre épaissie déversée ; anse verticale à courbe continue, de section ovale, attachée au niveau du ressaut de la partie supérieure du col et à l'épaule.

Vers 375-350 (?).

CC 54. - Dépôt DP 27. Ht de la partie supérieure $11,4 \mathrm{~cm}$, diam. de l'embouchure $8,5 \mathrm{~cm}$, diam. du pied 7,8 cm. Inv. FR 1.38 (partie supérieure); 1.43 .2 (pied). Pl. 109d

Argile orangée. Plusieurs fragments recollés représentant le bord, le col avec l'anse et une partie de la panse, ainsi que la moitié du pied avec le départ du fond. Le reste du vase manque, à l'exception de quelques fragments non jointifs de la panse. Le fond était probablement percé. Pied annulaire bas; panse globulaire; col haut et large à la base, peu articulé par rapport à la panse, se rétrécissant vers le bord, dont il est séparé par un ressaut nettement marqué ; bord évasé à lèvre arrondie et très légèrement déversée ; anse verticale à courbe continue, de section ovale, attachée au niveau du ressaut de la partie sup. du col et à l'épaule.

Vers 350.

CC 55. - Dépôt DP 27. Ht cons. $11,3 \mathrm{~cm}$, diam. max. $10,5 \mathrm{~cm}$. Inv. FR 2.40.

Argile orangée. Bord fragmentaire, la totalité du pied et le fond manquent. Panse globulaire à épaulement marqué ; col haut, presque cylindrique, séparé du bord par un ressaut ; bord dans la continuité du col, à profil concave et à lèvre arrondie déversée ; anse verticale à courbe continue, de section ovale, attachée au niveau du ressaut sous le bord et à l'épaule.

Vers 350 .

CC 56. - Dépôt DP 27. Ht cons. 8,4 cm, diam. max. $11,7 \mathrm{~cm}$. Inv. FR 1.39. PI. 109e

Argile rouge brun. Restent le pied avec le départ du fond et un peu plus de la moitié de la panse. Fond percé. Pied annulaire bas ; panse globulaire à épaulement marqué ; col plus large à la base, se rétrécissant vers le bord.

Vers 350.
CC 57. - Dépôt DP 14. Ht $17 \mathrm{~cm}$, diam. max. 15,2 cm. Inv. PIN 3688. Pl. 110a

Argile rouge brique. Fragmentaire. L'anse et des fragments du bord, du col et de la panse manquent. Pied annulaire bas ; panse biconique arrondie ; col haut, presque cylindrique, se rétrécissant vers le bord, dont il est séparé par un ressaut ; bord évasé, à lèvre épaissie et très légèrement déversée ; traces des attaches d'une anse verticale sur le col et l'épaule.

Vers 350-325.

CC 58. - Dépôt DP 14. Ht. 17,7 cm, diam. max. 15,3 cm. Inv. PIN 3690. PI. 110b

Argile orangée. Fragmentaire. Pied annulaire bas ; panse biconique arrondie ; col haut, presque cylindrique, se rétrécissant vers le bord, dont il est séparé par un ressaut ; bord en léger retrait par rapport au col, épaissi en bourrelet; anse verticale à courbe continue, de section ovale, attachée au niveau du ressaut de la partie supérieure du col et à l'épaule.

Vers 350-325.

CC 59. - Dépôt DP 14. Ht cons. $8,8 \mathrm{~cm}$, diam. max. 9,6 cm. Inv. PIN 3688a. Pl. 110c

Argile orangée. Fragmentaire. La partie inférieure de la panse, le pied et le fond manquent. Panse globulaire; col haut, presque cylindrique, se rétrécissant vers le bord, dont il est séparé par un ressaut ; bord évasé, à lèvre épaissie, orné d'une moulure peu marquée à l'extérieur ; anse verticale à courbe continue, de section ovale, attachée au niveau du ressaut de la partie supérieure du col et sur l'épaule.

Vers 350-325.

CC 60. - Dépôt DP 14. Ht cons. 8,5 cm, diam. max. $12 \mathrm{~cm}$. Inv. PIN 3688b. Pl. 110d

Argile rouge brun. Fragmentaire. La partie inférieure de la panse, le pied et le fond manquent. Panse globulaire ; col presque cylindrique, se rétrécissant vers le bord, dont il est séparé par un ressaut ; bord évasé, à lèvre aplatie et épaissie sur la face extérieure, de section triangulaire ; anse verticale à courbe continue, de section ovale, attachée au niveau du ressaut de la partie supérieure du col et sur l'épaule.

Vers 350-325.

CC 61. - Dépôt DP 23. Diam. de l'embouchure $7,5 \mathrm{~cm}$. Inv. FR 1.55.11.

Argile rouge brun. Plusieurs fragments recollés représentant un peu plus de la moitié du bord et du col, ainsi que l'anse avec un fragment de la panse. Col presque cylindrique, séparé du bord par un ressaut ; bord dans la continuité du col, à profil concave et à lèvre arrondie et 
légèrement déversée ; anse verticale à courbe continue, de section ovale.

Vers 340-320.

CC 62. - Dépôt DP 23. Inv. FR 1.55.13.

Argile rouge brun. Dix fragments représentant la plus grande partie du bord. Ressaut à la transition entre le col et le bord ; bord à lèvre arrondie et légèrement déversée.

Vers 340-320.

CC 63. - Dépôt DP 23. Inv. FR 1.55.14a.

Argile rouge brun. Trois fragments du bord. Bord à lèvre légèrement déversée.

Vers 340-320.

CC 64. - Dépôt DP 23. Inv. FR 1.55.14c.

Argile orangée. Fragment du bord. Bord à lèvre arrondie légèrement déversée.

Vers 340-320.

CC 65. - Dépôt DP 23. Inv. FR 1.55.14d.

Argile orangée. Fragment du bord. Bord à lèvre arrondie légèrement déversée.

Vers 340-320.

CC 66. - Dépôt DP 23. Inv. FR 1.55.14b.

Argile rouge brun. Fragment du bord. Bord à lèvre légèrement déversée.

Vers 340-320.

CC 67. - Dépôt DP 8. Ht 16,1 cm, diam. max. 14,4 cm. Inv. PIN 3744. Pl. 110e

Argile grise. Fragmentaire : l'anse manque. Restaurée. Pied annulaire bas; panse biconique arrondie ; col haut, cylindrique, séparé du bord par un ressaut ; bord dans le prolongement du col, à lèvre épaissie et déversée ; traces d'attaches d'une anse verticale au niveau du ressaut de la partie supérieure du col et sur l'épaule.

Vers 330-320.

CC 68. - Dépôt DP 17. Ht 21,3 cm, diam. max. $16 \mathrm{~cm}$. Inv. PIN 3719. Pl. 57e

Argile rose brun. Fragmentaire. Pied annulaire bas ; panse biconique à paroi supérieure et inférieure faiblement convexe; col haut, presque cylindrique, se rétrécissant vers le bord, dont il est séparé par un ressaut ; bord évasé, à lèvre épaissie légèrement déversée ; anse verticale à courbe continue, de section ovale, attachée au niveau du ressaut de la partie supérieure du col et à l'épaule.

Vers 310-290.
CC 69. - Dépôt DP 9. Ht 11,2 cm, diam. max. 9,3 cm. Inv. PIN 3624. Pl. 111a

Argile orangée. Fragmentaire. Fond annulaire ; panse à paroi faiblement convexe et épaulement marqué ; col presque cylindrique, se rétrécissant légèrement vers le bord, dont il est séparé par un ressaut; bord en léger retrait par rapport au col, à profil concave, se terminant par une lèvre épaissie en forme d'amande ; anse verticale à courbe continue, de section ovale, attachée au niveau du ressaut de la partie supérieure du col et à l'épaule.

Vers 325-275 (?).

CC 70. - Tombe SP 362 . Ht $12,8 \mathrm{~cm}$, diam. max. 9,6 cm. Inv. PIN 4029 (FR 3.41). Pl. 111b

Agile orangée. Bord, col et anse fragmentaires, partiellement recollés. Fond percé, annulaire, légèrement concave en-dessous ; panse biconique arrondie ; col haut et large à la base, peu articulé par rapport à la panse, se rétrécissant vers le bord, dont il est séparé par un ressaut ; bord évasé à lèvre arrondie et légèrement déversée ; anse verticale à courbe continue, de section ovale, joignant la partie sup. du col à l'épaule.

Vers 300-250.

\section{Variantes}

CC 71. - Dépôt DP 9. Ht cons. 8,3 cm, diam. max. 7,2 cm. Inv. PIN 3625. Pl. 111c

Argile rosée. Fragmentaire. La partie inférieure de la panse, le pied et le fond manquent. Panse ovoïde à épaulement marqué ; col concave, décoré de plusieurs cannelures horizontales ; bord évasé, à lèvre épaissie en bourrelet à l'extérieure, ornée d'une moulure aiguë sur la face intérieure; anse verticale à courbe continue, de section ovale, joignant le bord à l'épaule.

Vers 325-275 (?).

CC 72. - Dépôt DP 9. Ht 9,8 cm, diam. max. 7,6 cm. Inv. PIN 3626. Pl. 111d

Argile orangée. Le vase est déformé, légèrement penché sur le côté. Fond annulaire ; panse globulaire ; col haut et concave ; bord évasé dans le prolongement du col, à lèvre épaissie en bourrelet sur la face extérieure ; anse verticale à courbe continue, de section ovale, attachée sous le bord et à l'épaule.

Vers 325-275 (?).

CC 73. - Trouvaille isolée dans la zone du point I 7. Ht $11 \mathrm{~cm}$, diam. max. 8,1 cm. Inv. PIN 3785. Pl. 111e

Argile brune, engobe rouge foncé. Fragmentaire. Fond plat; panse globulaire; col haut et concave, décoré de plusieurs cannelures horizontales ; bord dans 
le prolongement du col, à lèvre aplatie et saillante vers l'extérieur et vers l'intérieur ; anse verticale à courbe et contre-courbe, de section rectangulaire, joignant le bord à l'épaule.

Vers 300-250 (?).

\section{Type indéterminé}

CC 74. - Foyer F 11. Diam. du pied environ $7 \mathrm{~cm}$. Inv. FR 3.59.9.

Argile grise. Restent un fragment du pied avec le départ du fond, un grand fragment de la partie supérieure de la panse et un fragment de l'anse. Le fond était probablement percé. Pied annulaire bas ; anse verticale de section ovale fixée sur l'épaule et sans doute au niveau du bord (non conservé).

Vers 380-370.

CC 75. - Dépôt DP 33. Diam. du pied 8,2 cm. Inv. FR 2.62.4.

Argile rouge brun. Trois fragments (deux recollés) représentant à peu près la moitié du pied et du fond avec le départ de la panse. Pied annulaire bas.

Vers 375-350.

CC 76. - Dépôt DP 33. Inv. FR 2.62.8.

Argile rouge brun. Deux fragments représentant environ un tiers du fond avec le départ de la panse. Le fond, annulaire, était probablement percé.

Vers 375-350.

CC 77. - Dépôt DP 33. Inv. FR 2.62.9.

Argile rouge brun. Deux fragments représentant environ un quart du fond annulaire et le départ de la panse.

Vers 375-350.

CC 78. - Dépôt DP 33. Inv. FR 2.62.10.

Argile rouge brun. Deux fragments représentant environ un quart du pied. Pied annulaire bas.

Vers 375-350.

CC 79. - Dépôt DP 33. Inv. FR 2.62.11.

Argile rouge brun. Fragment représentant une partie du fond annulaire et le départ de la panse.

Vers 375-350.

CC 80. - Dépôt DP 33. Inv. FR 2.62.1.

Argile orangée. Fragment représentant environ un tiers du pied avec une partie de la panse. Pied annulaire bas.

Vers 375-350.
CC 81. - Dépôt DP 33. Diam. du fond $4,3 \mathrm{~cm}$. Inv. FR 2.62.2.

Argile orangée. Fragment du fond annulaire avec le départ de la panse.

Vers 375-350.

CC 82. - Dépôt DP 33. Diam. du fond $3,8 \mathrm{~cm}$. Inv. FR 2.62.3.

Argile orangée. Restent le fond annulaire et le départ de la panse.

Vers 375-350.

CC 83. - Dépôt DP 33. Inv. FR 2.62.5.

Argile orangée. Deux fragments représentant environ un tiers du pied bas, annulaire.

Vers 375-350.

CC 84. - Dépôt DP 33. Diam. du fond $6,8 \mathrm{~cm}$. Inv. FR 2.62.6.

Argile orangée. Restent le fond percé, annulaire, et le départ de la panse.

Vers 375-350.

CC 85. - Dépôt DP 33. Diam. du fond $6,3 \mathrm{~cm}$. Inv. FR 2.62.7.

Argile orangée. Restent le fond annulaire, percé, et le départ de la panse.

Vers 375-350.

CC 86. - Dépôt DP 33. Inv. FR 2.62.12

Argile grise, surface gris noir. Fragment représentant une partie du pied bas, annulaire, et du fond avec le départ de la panse.

Vers 375-350.

CC 87. - Dépôt DP 33. Inv. FR 2.62.15.

Six anses de cruches: deux en argile rouge brun et quatre en argile orangée. Une seule est presque complète.

Vers 375-350.

CC 88. - Dépôt DP 28. Inv. FR 1.44.1.

Argile orangée. D'après les observations effectuées sur le terrain, seule la moitié du vase (une partie du bord, du col et de la panse) était conservée. Panse globulaire, col concave se prolongeant en un bord évasé.

Vers 360-350.

CC 89. - Dépôt DP 27. Ht cons. 8,2 cm. Inv. FR 1.41.

Argile orangée, traces d'engobe rouge. Plusieurs fragments représentant une partie du pied et de la moitié inférieure de la panse. Pied annulaire bas.

Vers 350 . 
CC 90. - Dépôt DP 23. Diam. du pied $6,3 \mathrm{~cm}$. Inv. FR 1.55.2.

Argile rouge brun. Deux fragments représentant l'ensemble du pied et du fond avec le départ de la panse. Pied annulaire bas.

Vers 340-320.

CC 91. - Dépôt DP 23. Diam. du fond $6 \mathrm{~cm}$. Inv. FR 1.55.4.

Argile rouge brun. Six fragments représentant l'ensemble du fond annulaire, percé, avec le départ de la panse.

Vers 340-320.

CC 92. - Dépôt DP 23. Diam. du pied 6,9 cm. Inv. FR 1.55.5.

Argile rouge brun. Cinq fragments représentant l'ensemble du pied avec la plus grande partie du fond et le départ de la panse. Pied annulaire bas.

Vers 340-320.

CC 93. - Dépôt DP 23. Inv. FR 1.55.7.

Argile rouge brun. Trois fragments non jointifs représentant la plus grande partie du pied annulaire bas.

Vers 340-320.

CC 94. - Dépôt DP 23. Inv. FR 1.55.9.

Argile rouge brun. Deux fragments non jointifs représentant une partie du pied avec le départ de la panse. Pied annulaire bas.

Vers 340-320.

CC 95. - Dépôt DP 23. Diam. du pied 5,8 cm. Inv. FR 1.55.3.

Argile orangée. Quatre fragments représentant l'ensemble du pied avec le départ du fond, probablement percé, et de la panse. Pied annulaire bas.

Vers 340-320.

CC 96. - Dépôt DP 23. Diam. du pied 6,1 cm. Inv. FR 1.55.6.

Argile orangée. Deux fragments représentant la moitié du pied et du fond avec le départ de la panse. Pied annulaire bas.

Vers 340-320.

CC 97. - Dépôt DP 23. Inv. FR 1.55.10.

Argile orangée. Fragment représentant à peu près la moitié du fond annulaire, avec le départ de la panse.

Vers 340-320.

CC 98. - Dépôt DP 23. Diam. du pied 7,8 cm. Inv. FR 1.55.1.

Argile grise, surface gris noir. Un fragment représentant l'ensemble du pied et du fond (percé) avec le départ de la panse, un autre une partie de la panse. Pied annulaire bas, paroi très épaisse.

Vers 340-320.

CC 99. - Dépôt DP 23. Inv. FR 1.55.12a-f.

Sept anses de cruches : six en argile rouge brun et une en argile orangée. Cinq anses sont plus ou moins complètes.

Vers 340-320.

CC 100. - Tombe SP 362. Diam. du fond $6,5 \mathrm{~cm}$. Inv. PIN 4031 (FR 3.1). Pl. 50e

Argile orangée. Fragment représentant le fond (percé au centre) et le départ de la panse. Fond annulaire légèrement concave en-dessous.

Vers 300-250.

\subsection{Lagynos}

CC 101. - Tombe SP 347. Ht 10,8 cm, diam. max. 9,3 cm. Inv. PIN 3852. Pl. 49b

Argile rouge brique. Fond annulaire, légèrement concave en-dessous ; panse surbaissée à paroi inférieure convexe et paroi supérieure rectiligne formant une épaule large et oblique ; col cylindrique ; bord épaissi en bourrelet sur la face extérieure ; anse verticale à courbe continue, de section ovale, attachée sous le bord et à l'épaule.

Vers 260-250.

\subsection{Coupe à tige (?)}

CC 102. - Dépôt DP 6. Ht 5,1 cm, diam. de l'embouchure $12 \mathrm{~cm}$. Inv. PIN 3371 . PI. $111 f$

Argile beige. Le fond et le pied manquent. Vasque profonde, hémisphérique ; bord légèrement évasé, à face intérieure rectiligne et extérieure convexe, se terminant par une lèvre arrondie; deux anses horizontales en fer à cheval sont implantées sur la partie supérieure de la panse et relevées jusqu'au niveau du bord. Tout l'intérieur de la coupe est couvert d'un vernis de couleur rouge ; l'extérieur est décoré de deux bandes de vernis noir, disposées sur le bord et à mi-hauteur de la panse.

Vers 475-450 (?).

\subsection{Jarres ("storage bins")}

CC 103. - Tombe SP 317. Ht $30 \mathrm{~cm}$, diam. max. $33 \mathrm{~cm}$. Inv. PIN 3634a. Pl. 13h 
Argile rouge brique. Pied annulaire oblique à face extérieure légèrement carénée ; vasque ovoïde se prolongeant directement sur le bord vertical; deux anses horizontales en fer à cheval, flanquées de chaque côté d'un bouton conique et marquées par une profonde cannelure sur la face supérieure, sont implantées au niveau de l'épaule et relevées à la verticale.

Vers 300-275.

CC 104. - Tombe SP 323. Ht 20,2 cm, diam. max. 25,3 cm. Inv. PIN 3710a. Pl. 111g

Argile brun beige. Traces de tournage sur la surface. Pied annulaire divergent à face extérieure légèrement carénée ; vasque ovoïde à épaulement marqué ; bord vertical ; deux anses horizontales en fer à cheval, bordées de chaque côté d'un bouton conique et ornées d'une cannelure sur la face supérieure, sont implantées au niveau de l'épaule et relevées à la verticale.

Vers 300-275.

CC 105. - Tombe SP 318. Ht $34 \mathrm{~cm}$, diam. max. 37,4 cm. Inv. PIN 3669a. PI. 14c

Argile rouge brique. Fragmentaire. Pied annulaire oblique ; vasque ovoïde à épaulement marqué ; col très court et concave se terminant par un bord déversé à lèvre arrondie, orné au sommet d'un bourrelet de section rectangulaire.

Vers 275-250.

\subsection{Cratères}

CC 106. - Tombe SP 298. Ht 22,6 cm, diam. de l'embouchure 23,6 cm. Inv. PIN 3250. Pl. 112a

Argile rouge brun, engobe rouge à l'intérieur, plus foncé à l'extérieur. Pied annulaire oblique ; vasque globulaire à épaulement marqué ; col cylindrique ; bord évasé à l'horizontale; deux doubles anses horizontales en fer à cheval, de section ronde, sont implantées sur l'épaule et relevées jusqu'au bord. Trois sillons incisés sur l'épaule, ainsi qu'à la base du col.

Vers 370-360.

CC 107. - Tombe SP 312. Ht $20 \mathrm{~cm}$, diam. de l'embouchure $22 \mathrm{~cm}$. Inv. PIN 3598 . Pl. 12e et 112b

Argile rouge brun. Fragmentaire. Pied annulaire oblique ; vasque globulaire à épaulement marqué ; col un peu plus large à la base, se rétrécissant vers le bord, fortement évasé, à lèvre arrondie; deux petites anses horizontales en forme d'arc de cercle, de section circulaire, sont implantées sur l'épaule et recourbées à angle presque droit vers le col.

Vers 300-275.
CC 108. - Tombe SP 319. Ht 24,3 cm, diam. de l'embouchure $24 \mathrm{~cm}$. Inv. PIN 3672. Pl. 14d et 112c

Argile orangée. Fragmentaire. Pied annulaire bas; vasque ovoïde; col cylindrique ; bord évasé, à face supérieure aplatie et face inférieure convexe, se terminant par une lèvre pointue ; deux anses horizontales, de forme rectangulaire et de section ronde, sont implantées sur l'épaule et collées contre le col et le bord.

Vers 300-275.

\subsection{Lékané}

CC 109. - Tombe SP 298. Ht 12,2 cm, diam. de l'embouchure $27 \mathrm{~cm}$. Inv. PIN 3251. PI. 112d

Argile grise, surface gris noir. Pied annulaire bas à face extérieure carénée ; vasque peu profonde, à paroi rectiligne, s'incurvant vers le col, très court, qui se prolonge sur le bord évasé, avec lèvre légèrement arrondie ; deux larges anses horizontales de forme rectangulaire sont collées contre le col et le bord.

Vers 370-360.

\subsection{Bols}

\section{À bord mince}

CC 110. - Foyer F 5. Ht $7 \mathrm{~cm}$, diam. de l'embouchure $20,7 \mathrm{~cm}$. Inv. PIN $3368 f$ (FR 2.46). Pl. 113a

Argile orangée. Fragmentaire, partiellement recollé. Une partie de la vasque et du bord, ainsi que des fragments du pied et du fond manquent. Traces de combustion. Pied annulaire ; vasque peu profonde et évasée, à paroi légèrement convexe ; bord vertical dans la même courbe que la paroi, à lèvre mince et pointue.

Vers 390-380.

CC 111. - Dépôt DP 31. Diam. du fond environ $5,5 \mathrm{~cm}$. Inv. FR 2.41.

Argile rouge brun. Fragmentaire. Le fond était probablement percé. Fond annulaire ; vasque évasée à paroi rectiligne ; bord vertical ou très légèrement incurvé, à lèvre mince et arrondie.

Vers 390-380.

CC 112. - Dépôt DP 31. Inv. FR 2.42.

Argile brune, surface noire. Fragmentaire. La plus grande partie du pied, ainsi qu'une partie du bord semblent manquer. Pied annulaire bas ; vasque évasée à paroi rectiligne ; bord vertical ou très légèrement incurvé, à lèvre mince et arrondie.

Vers 390-380. 
CC 113. - Foyer F 6. Ht 6,2 cm, diam. de l'embouchure $19,8 \mathrm{~cm}$. Inv. PIN 3823. Pl. 72g

Argile brun orangé, traces d'engobe rouge foncé. Fragmentaire. Pied annulaire bas, à face extérieure carénée et face intérieure convexe ; vasque évasée à paroi convexe ; bord légèrement incurvé, à lèvre mince et arrondie.

Vers 380.

CC 114. - Foyer F 2. Ht $6,3 \mathrm{~cm}$, diam. de l'embouchure 21,4 cm. Inv. PIN 3243. Pl. 69i

Argile orangée. Fortes traces de combustion. Pied annulaire oblique légèrement caréné ; vasque évasée à paroi faiblement convexe ; bord vertical ou légèrement incurvé, à lèvre mince et pointue. Décor en vernis rouge foncé à l'intérieur: deux bandes étroites autour du fond et une bande plus large sous la lèvre du bord.

Vers 380.

CC 115. - Foyer F 2. Ht 5,3 cm, diam. de l'embouchure $17,4 \mathrm{~cm}$. Inv. PIN 3281. PI. 69f

Argile rouge brun, surface gris noir. Plusieurs fragments manquent. Pied annulaire bas; vasque évasée à paroi légèrement convexe ; bord vertical à lèvre mince et arrondie.

Vers 380 .

CC 116. - Foyer F 2. Ht 6,5 cm, diam. de l'embouchure 20,4 cm. Inv. PIN 3281a. Pl. 69g

Argile rouge brun, surface gris noir. Plusieurs fragments manquent. Pied annulaire bas ; vasque évasée à paroi convexe ; bord vertical à lèvre arrondie.

Vers 380 .

CC 117. - Foyer F 10. Long. du fragment principal $13 \mathrm{~cm}$. Inv. FR 3.63

Argile gris beige. Deux fragments de la vasque avec une partie du bord. Vasque peu profonde et évasée, à paroi légèrement convexe ; bord vertical à lèvre mince et pointue.

Vers 380.

CC 118. - Foyer F 11. Diam. du pied $8,9 \mathrm{~cm}$. Inv. FR 3.59.6.

Argile gris vert. Plusieurs fragments identifiés représentant une partie du bord et de la vasque, ainsi que la totalité du pied avec le départ du fond. Fond percé. Pied annulaire bas ; vasque profonde, hémisphérique ; bord droit ou légèrement incurvé, à lèvre mince et arrondie.

Vers 380-370.

CC 119. - Dépôt DP 11. Ht 6,1 cm, diam. de l'embouchure 20,2 cm. Inv. PIN 3676. Pl. 113b
Argile rouge brun, surface marron. Pied annulaire divergent à face extérieure légèrement carénée ; vasque évasée à paroi faiblement convexe ; bord légèrement incurvé à lèvre mince et pointue. Décor en vernis rouge foncé à l'intérieur: disque entouré d'une bande étroite au centre; deux autres bandes similaires autour $\mathrm{du}$ fond et une bande plus large sous la lèvre.

Vers 400-375 (?).

CC 120. - Découverte isolée dans la zone du point H 5. Ht 7,7 cm, diam. de l'embouchure $22,6 \mathrm{~cm}$. Inv. PIN 3671. Pl. 113c

Argile rouge brun, surface rose. Pied annulaire divergent à face extérieure carénée ; vasque évasée à paroi convexe ; bord vertical à lèvre mince et arrondie. Décor en vernis rouge foncé à l'intérieur : deux bandes étroites au centre, entourées de deux bandes similaires sur la paroi inférieure et d'une bande plus large sous la lèvre du bord.

Vers 400-375 (?).

CC 121. - Dépôt DP 25. Ht 6,5 cm, diam. de l'embouchure $19 \mathrm{~cm}$. Inv. FR 1.31 .

Argile orangée. Fragmentaire, partiellement recollé. La moitié de la vasque, ainsi qu'une grande partie du bord, du fond et du pied manquent. Pied annulaire divergent ; vasque peu profonde et évasée, à paroi faiblement convexe ; bord presque vertical dans le prolongement de la paroi, à lèvre mince et arrondie.

Vers 375-350.

CC 122. - Dépôt DP 33. Inv. FR 2.62.15.

Argile brune, surface grise. Fragment du bord et de la vasque. Vasque à paroi convexe ; bord vertical, à lèvre arrondie légèrement pointue.

Vers 375-350.

CC 123. - US 11 (près de l'angle Nord de la fosse de SP 264). Ht 4,5 cm, diam. de l'embouchure $15 \mathrm{~cm}$. Inv. FR 1.48 .

Argile brune, surface gris noir. La moitié de la vasque et du bord, ainsi que la plus grande partie du fond manquent. Le fond était probablement percé. Pied annulaire bas ; vasque peu profonde à paroi convexe ; bord vertical dans la courbe de la paroi, à lèvre mince et arrondie.

Vers 350 .

CC 124. - Foyer F 4. Ht 4,5 cm, diam. de l'embouchure $12 \mathrm{~cm}$. Inv. PIN 3754. Pl. 70c

Argile rouge. Fragmentaire. Fond annulaire, légèrement concave en-dessous; vasque relativement profonde à paroi rectiligne ; bord vertical ou très légèrement incurvé, à lèvre arrondie.

Vers 350-340. 


\section{À bord simple}

CC 125. - Foyer F 11. Inv. FR 3.59.12.

Argile rouge brun. Un fragment du bord et deux fragments du pied identifiés. Pied annulaire bas divergent ; vasque hémisphérique à paroi épaisse ; bord non distinct de la paroi, à lèvre arrondie.

Vers 380-370.

CC 126. - Dépôt DP 33. Inv. FR 2.63.

Argile rouge brun. Deux fragments du bord, un fragment du pied et plusieurs fragments de la vasque identifiés. Pied annulaire bas ; vasque hémisphérique; bord non différencié de la paroi, à lèvre arrondie.

Vers 375-350.

\section{À bord incurvé (variante locale)}

CC 127. - Foyer F 9. Ht $6,8 \mathrm{~cm}$, diam. de l'embouchure $23 \mathrm{~cm}$. Inv. PIN 4033a (FR 3.32). PI. 113d

Argile brune, surface grise. Fragmentaire, un tiers du pied manque. Fond percé. Pied annulaire bas; vasque profonde et évasée, à paroi légèrement convexe se prolongeant jusqu'au bord, lequel est épaissi en bourrelet et nettement saillant vers l'intérieur.

Vers 380.

CC 128. - Dépôt DP 33. Ht 9,3 cm, diam. de l'embouchure $22 \mathrm{~cm}$. Inv. FR 2.61. Pl. 113e

Argile grise, surface gris noir. Plusieurs fragments identifiés représentant plus de la moitié du bord, une partie de la vasque et environ un quart du fond. Pied annulaire bas ; vasque profonde à paroi rectiligne ; bord dans le prolongement de la paroi, à lèvre épaissie et pointue sur la face intérieure.

Vers 375-350.

CC 129. - Dépôt DP 28. Ht 8,8 cm, diam. de l'embouchure $18,7 \mathrm{~cm}$. Inv. FR 1.54. PI. 114a

Argile brune, surface gris noir. Une partie du bord et de la vasque, ainsi que la moitié du pied, manquent. Fond percé. Pied annulaire bas ; vasque profonde à paroi presque rectiligne ; bord fortement incurvé se terminant par une lèvre arrondie.

Vers 360-350.

\section{À bord incurvé (variante attique)}

CC 130. - Foyer F 7. Ht 9,6 cm, diam. de l'embouchure $22 \mathrm{~cm}$. Inv. PIN 3827 . Pl. 74i

Argile rouge. Pied annulaire bas oblique; vasque profonde à paroi légèrement convexe se terminant par un bord incurvé à lèvre arrondie.

Vers 280-260.

CC 131. - Foyer F 7. Ht 4,7 cm, diam. de l'embouchure $15,8 \mathrm{~cm}$. Inv. PIN 3837a. PI. 74e

Argile grise, surface rougeâtre. Pied annulaire bas oblique ; vasque basse évasée, à paroi convexe ; bord incurvé à lèvre arrondie.

Vers 280-260.

CC 132. - Foyer F 7. Ht 4,5 cm, diam. de l'embouchure $16,5 \mathrm{~cm}$. Inv. PIN 3837b. PI. $74 \mathbf{f}$

Argile rouge orangée. Fragmentaire. Pied annulaire bas oblique; vasque basse évasée, à paroi convexe ; bord incurvé à lèvre arrondie.

Vers 280-260.

CC 133. - Foyer F 7. Ht 4,4 cm, diam. de l'embouchure $14,8 \mathrm{~cm}$. Inv. PIN 3825 . Pl. 74d

Argile grise. Fragmentaire. Traces de combustion. Pied annulaire bas; vasque basse et évasée, à paroi convexe ; bord incurvé à lèvre pointue. Tout l'intérieur et la partie supérieure de la vasque à l'extérieur sont couverts d'un vernis brun de mauvaise qualité.

Vers 280-260.

CC 134. - Foyer F 7. Ht 3,7 cm, diam. de l'embouchure $11,6 \mathrm{~cm}$. Inv. PIN 3831. Pl. 74c

Argile brun orangé. Fragmentaire. Fond annulaire, concave en-dessous; vasque basse évasée, à paroi convexe ; bord incurvé à lèvre arrondie.

Vers 280-260.

CC 135. - Foyer F 7. Ht 4,3 cm, diam. de l'embouchure $13,2 \mathrm{~cm}$. Inv. PIN 3832. Pl. 74h

Argile rouge brun, surface gris noir. Fragmentaire. Fortes traces de combustion. Fond annulaire, légèrement concave en-dessous; vasque basse et évasée, à paroi convexe ; bord incurvé à lèvre arrondie.

Vers 280-260.

\section{Autres types}

CC 136. - Foyer F 1. Ht 8,5 cm, diam. de l'embouchure 22,6 cm. Inv. PIN 3273. Pl. $68 \mathrm{~g}$

Argile rouge brun. Pied annulaire bas ; vasque profonde, hémisphérique ; bord dans le prolongement de la paroi, très légèrement incurvé, à lèvre aplatie, décoré de cinq sillons sur la face extérieure.

Vers 380.

CC 137. - Dépôt DP 17. Ht 9,2 cm, diam. de l'embouchure $27,4 \mathrm{~cm}$. Inv. PIN 3716 . Pl. 57d 
Argile rouge rosée, surface rose. Pied annulaire bas ; fond extérieur convexe; vasque profonde à double courbe ; bord évasé de section triangulaire, à face supérieure aplatie décorée de trois sillons.

Vers 310-290.

CC 138. - Découverte isolée au Nord de SP 297. Ht $8,1 \mathrm{~cm}$, diam. de l'embouchure $19 \mathrm{~cm}$. Inv. PIN 3235. Pl. 114c

Argile brun orangé. Déformation lors de la cuisson. Pied annulaire bas à face extérieure carénée ; vasque profonde, hémisphérique; bord dans le prolongement de la paroi, à lèvre aplatie épaissie sur la face intérieure.

Vers 350-300 (?).

CC 139. - Tombe SP 319. Ht 7,4 cm, diam. de l'embouchure 20,6 cm. Inv. PIN 3673. Pl. 114b

Argile rose orangé. Déformation lors de la cuisson. Pied annulaire bas; vasque profonde à paroi rectiligne; bord vertical à lèvre aplatie, épaissie sur la face intérieure.

Vers 300-275.

\subsection{Coupelles}

\section{À bord saillant}

CC 140. - Tombe SP 265. Ht 2,8 cm, diam. de l'embouchure 9,1 cm. Inv. FR 1.16. Pl. 114d

Argile rouge brun, engobe marron. Fond annulaire, légèrement concave en-dessous ; vasque basse et évasée à paroi extérieure légèrement carénée ; bord saillant à section triangulaire.

Vers 340 .

\section{À bord incurvé}

CC 141. - Foyer F 7. Ht $3 \mathrm{~cm}$, diam. de l'embouchure 7,4 cm. Inv. PIN 3836. Pl. 74k

Argile grise, surface gris beige. Fragmentaire. Fond annulaire, légèrement concave en-dessous ; vasque basse à paroi convexe, s'épaississant vers le bord incurvé, à lèvre pointue.

Vers 280-260.

CC 142. - Foyer F 7. Ht 3,1 cm, diam. de l'embouchure $7,8 \mathrm{~cm}$. Inv. PIN 3830 . PI. 74m

Argile grise. Fragmentaire. Fond annulaire, concave en-dessous ; vasque basse et évasée, à paroi convexe ; bord incurvé à lèvre arrondie.

Vers 280-260.
CC 143. - Foyer F 7. Ht 2,9 cm, diam. de l'embouchure $7,4 \mathrm{~cm}$. Inv. PIN 3834. Pl. 74l

Argile gris brun. Fragmentaire. Fond annulaire, concave en-dessous, avec ombilic central ; vasque basse à paroi convexe ; bord incurvé à lèvre arrondie.

Vers 280-260.

CC 144. - Foyer F 7. Ht 3,5 cm, diam. de l'embouchure $8 \mathrm{~cm}$. Inv. PIN 3828. Pl. 74j

Argile rose brun. Fragmentaire. Fond annulaire, concave en-dessous ; vasque basse à paroi convexe ; bord épaissi et légèrement incurvé, à lèvre pointue.

Vers 280-260.

CC 145. - Foyer F 7. Ht 3,1 cm, diam. de l'embouchure 7,6 cm. Inv. PIN 3838. Pl. 74n

Argile brun beige. Fragmentaire. Fond annulaire, concave en-dessous; vasque basse à paroi convexe ; bord légèrement incurvé, à lèvre pointue.

Vers 280-260.

\subsection{Plats à poisson}

\section{À bord tombant}

CC 146. - Tombe SP 312. Ht 3,7 cm, diam. de l'embouchure 24,6 cm. Inv. PIN 3599. Pl. 12d

Argile rouge brique. Pied annulaire bas, face extérieure carénée ; vasque très évasée, à paroi rectiligne et dépression centrale hémisphérique; bord tombant en biseau, à profil biconvexe et lèvre pointue. Sillon autour de la cupule centrale et à la transition entre la paroi intérieure et le bord.

Vers 300-275.

CC 147. - Foyer F 7. Ht 4,7 cm, diam. de l'embouchure $22 \mathrm{~cm}$. Inv. PIN 3829. Pl. 74b

Argile brun orangé. Pied annulaire oblique, à face extérieure légèrement carénée ; vasque évasée, à paroi rectiligne et dépression centrale hémisphérique ; bord tombant en biseau, à profil biconvexe et lèvre pointue. Sillon autour de la cupule centrale.

Vers 280-260.

CC 148. - Foyer F 7. Ht 4,7 cm, diam. de l'embouchure $22,2 \mathrm{~cm}$. Inv. PIN 3833. Pl. 74a

Argile brun orangé. Pied annulaire oblique, à faces extérieure et intérieure convexes ; vasque évasée, à paroi rectiligne et dépression centrale hémisphérique ; bord tombant en biseau, à profil biconvexe et lèvre pointue. Sillon autour de la cupule centrale.

Vers 280-260. 


\section{À bord horizontal}

CC 149. - Foyer F 5. Ht 5,8 cm, diam. de l'embouchure 25,7 cm. Inv. PIN 3668c (FR 2.43). Pl. 114e

Argile orangée, engobe rouge. Quelques fragments de la vasque et un fragment du bord manquent. Traces de combustion. Pied annulaire, épaissi en bourrelet vers l'extérieur à la base ; vasque très évasée, à paroi rectiligne et dépression centrale hémisphérique ; bord horizontal à peine saillant vers l'extérieur, à lèvre arrondie. Deux cannelures horizontales sur la face supérieure du bord et à la transition avec la paroi intérieure.

Vers 390-380.

\subsection{Lécythes}

\section{Lécythes aryballisques}

CC 150. - Tombe SP 375. Ht $8,8 \mathrm{~cm}$, diam. max. $4,8 \mathrm{~cm}$. Inv. PIN 4109b (FR 3.51). Pl. 52e et 115a

Argile orangée. Restauré. Fond annulaire, légèrement concave en-dessous ; panse ovoïde ; col court, presque cylindrique, se prolongeant en un bord concave à lèvre aplatie, légèrement saillante vers l'intérieur ; anse verticale à courbe et contre-courbe, de section ovale, attachée sur la partie supérieure du col et l'épaule.

Vers 390-380.

CC 151. - Tombe SP 370. Inv. PIN 4105 (FR 3.49).

Argile rouge brun. Très fragmentaire. Le col, l'anse et le fond semblent manquer. L'état de conservation du vase ne permet pas la reconstitution précise de la forme. Toutefois, d'après le bord concave, à lèvre aplatie, il s'agit vraisemblablement d'un lécythe semblable au précédent.

Vers 370 .

\section{Variantes à panse globulaire et ovoüde}

CC 152. - Tombe SP 331. Ht $13,3 \mathrm{~cm}$, diam. max. 12,6 cm. Inv. PIN 3749. Pl. 37c. Pl. 37c et 115b

Argile gris noir. Fond annulaire, légèrement concave en-dessous; panse globulaire; col court concave se terminant en bord vertical; anse verticale à courbe continue, de section ovale, attachée à la base du col et à l'épaule.

Vers 420.

CC 153. - Découverte isolée dans la zone du point I 5. Ht jusqu'au sommet de l'anse $10,7 \mathrm{~cm}$, diam. max. 8,1 cm. Inv. PIN 3808. Pl. 115c
Argile brun beige. Fragmentaire. Traces de tournage sur la surface intérieure. Fond annulaire, légèrement concave en-dessous; panse globulaire; col haut, presque cylindrique, s'élargissant légèrement vers la panse ; anse verticale à courbe continue, de section ovale, joignant le col à l'épaule. La partie supérieure de la panse et le col sont couverts d'un vernis de mauvaise qualité dont la couleur varie du brun au rouge, le reste est réservé.

Vers 400-350 (?).

CC 154. - Tombe SP 279. Ht 13,5 cm, diam. max. $8,9 \mathrm{~cm}$. Inv. FR 1.30. Pl. 21g et 115d

Argile gris noir. Restauré. Fond annulaire ; panse ovoïde à épaulement marqué ; col court, concave, ceint d'un bourrelet en relief; bord évasé dans le prolongement du col, à lèvre arrondie légèrement saillante vers l'intérieur; anse verticale à courbe continue, de section ovale, attachée au niveau du bourrelet du col et à l'épaule.

Vers 300-290.

CC 155. - Tombe SP 299. Ht $12,1 \mathrm{~cm}$, diam. max. $8,4 \mathrm{~cm}$. Inv. PIN 3256. Pl. 12a et 115e

Argile brun clair. Pied annulaire bas ; panse ovoïde à épaulement marqué ; col court, concave, marqué par un bourrelet en relief ; bord fortement évasé, à lèvre arrondie saillante, de section triangulaire; anse verticale à courbe continue, de section ovale, attachée à mi-hauteur du col et sur l'épaule. La partie supérieure de la panse, le col et le bord sont couverts d'un vernis brun, le reste est réservé.

Vers 300-290.

CC 156. - Tombe SP 250. Ht 11,6 cm, diam. max. 9,6 cm. Inv. PIN 2711. Pl. $115 f$

Argile brun beige. Restauré. Fond annulaire, concave en-dessous ; panse globulaire ; col court et concave se prolongeant en un bord fortement évasé, à lèvre aplatie et saillante au-dessus, de section triangulaire ; l'anse verticale, décorée de deux cannelures sur la face supérieure, est attachée à mi-hauteur du col et sur l'épaule.

La partie supérieure de la panse, le col et le bord sont couverts d'un vernis brun non homogène, devenu rouge par endroits, le reste est réservé.

Vers 300-290.

CC 157. - Tombe SP 344. Ht 8,1 cm, diam. max. $6,7 \mathrm{~cm}$. Inv. PIN 3839. PI. 46a

Argile rouge. Pied annulaire oblique ; fond extérieur pointu ; panse globulaire ; col très court concave se prolongeant en un bord évasé à lèvre aplatie ; anse verticale à courbe continue, de section ovale, attachée sur le col et 
l'épaule. Deux bandes de vernis sur la partie supérieure de la panse.

Vers 260-250.

\subsection{Alabastre}

CC 158. - Tombe SP 375. Ht 13 cm. Inv. PIN 4109a (FR 3.50). Pl. 52e et 115g

Argile orangée. Embouchure brisée. Traces de peinture blanche. Fond convexe ; panse fortement allongée, se rétrécissant progressivement vers le col, concave et peu marqué ; bord horizontal se terminant par une lèvre arrondie ; deux petites anses verticales, pleines et aplaties, sont attachées sous le col.

Vers 390-380.

\subsection{Unguentaria}

CC 159. - Tombe SP 289. Ht 9,5 cm, diam. max. $6,2 \mathrm{~cm}$. Inv. PIN 3158. Pl. 23e et 116a

Argile beige. Pied bas, biconique, concave en-dessous ; panse globulaire à épaulement marqué ; col haut, s'élargissant progressivement vers le bord ; bord saillant de section triangulaire.

Vers 310-290.

CC 160. - Dépôt DP 17. Ht 8,3 cm, diam. max. 5,6 cm. Inv. PIN 3718. Pl. 116b

Argile brun beige. Pied annulaire ; panse globulaire à épaulement marqué ; col haut, s'élargissant progressivement vers le bord, saillant et de section triangulaire. La partie supérieure de la panse, le col et le bord sont couverts d'un vernis rouge brun partiellement conservé, le reste est réservé.

Vers 310-290.

CC 161. - Tombe SP 317. Ht 7,3 cm, diam. max. $4,4 \mathrm{~cm}$. Inv. PIN 3635. Pl. 13f et 116c

Argile rose brun. Pied annulaire oblique; panse ovoïde à épaulement marqué ; col haut, s'élargissant progressivement vers le bord saillant, de section triangulaire. Décor de bandes de vernis de couleur rouge foncé : une première, large, sur la lèvre et la partie supérieure du col ; trois, plus étroites, à la transition entre le col et la panse, deux autres, une étroite et une plus large sur la partie supérieure de la panse.

Vers 300-275.

CC 162. - Tombe SP 318. Ht 9,1 cm, diam. max. 6,3 cm. Inv. PIN 3667. Pl. 116d

Argile brun rose. Pied massif, tronconique; panse globulaire à épaulement marqué ; haut col s'élargissant vers le bord légèrement saillant, de section triangulaire.

Vers 300-275.

CC 163. - Tombe SP 346. Ht $8,8 \mathrm{~cm}$, diam. max. $4,2 \mathrm{~cm}$. Inv. PIN 3844. Pl. 47d et 116e

Argile beige. Pied annulaire, légèrement concave endessous, séparé de la panse par une courte tige massive ; panse ovoïde ; col haut, s'élargissant vers bord, épaissi et légèrement saillant vers l'extérieur.

Vers 260-250.

CC 164. - Tombe SP 346. Inv. PIN 3845. Pl. 47a

Identique au précédent. Très mal conservé.

Vers 260-250.

\subsection{Lékanides}

CC 165. - Foyer F 5. Diam. de l'embouchure $16 \mathrm{~cm}$. Inv. FR 2.50. Pl. $116 f$

Argile beige. Plusieurs fragments (recollés pour la plupart) provenant du bord, de la vasque, du pied et du fond. Pied annulaire bas ; vasque peu profonde, à paroi convexe ; bord non différencié de la paroi, à lèvre aplatie et creusée d'une profonde rainure probablement destinée à recevoir un couvercle.

Vers 390-380.

CC 166. - Foyer F 6. Ht $8 \mathrm{~cm}$, diam. de l'embouchure $23,4 \mathrm{~cm}$. Inv. PIN 3818. Pl. 72h

Argile rouge brique, engobe rouge. Fortes traces de combustion. Pied annulaire oblique, à face extérieure carénée et face intérieure rectiligne; vasque peu profonde évasée, à double courbe, séparée du bord par un ressaut nettement marqué sur la paroi extérieure, de section triangulaire, qui servait à supporter le couvercle ; bord légèrement incurvé, à lèvre arrondie.

Vers 380 .

CC 167. - Découverte isolée dans la zone du point H 3. Ht 7,4 cm, diam. de l'embouchure $18,8 \mathrm{~cm}$. Inv. PIN 3787. Pl. 116h

Argile rouge brun, engobe rouge. Très fragmentaire. Pied annulaire bas, à face extérieure moulurée et plan de pose biseauté vers l'intérieur; vasque peu profonde, à courbe continue, séparée du bord par un ressaut nettement marqué sur la paroi intérieure, de section triangulaire ; bord vertical à lèvre arrondie. Sur la paroi extérieure de la vasque, lettre $\mathrm{H}$ gravée après cuisson.

Vers IVe s. (?). 


\subsection{Couvercles}

\section{Couvercles réversibles}

CC 168. - Foyer F 6. Ht 5,6 cm, diam. de l'embouchure $20 \mathrm{~cm}$. Inv. PIN 3814. Pl. $72 f$

Argile brun orangé, engobe rouge foncé. Fragmentaire. Vasque évasée à paroi presque rectiligne, avec une dépression centrale hémisphérique ; bord tombant en léger biseau vers l'intérieur, à faces rectilignes et lèvre arrondie ; large bouton de préhension annulaire mouluré. Sillon incisé en haut et en bas de la vasque.

Vers 380.

CC 169. - Tombe SP 323. Ht 6,2 cm, diam. de l'embouchure 19,2 cm. Inv. PIN 3710b. Pl. 15b-d

Argile rouge brun. Vasque évasée à paroi faiblement convexe, munie d'une dépression centrale hémisphérique sur la face inférieure; bord tombant à la verticale, décoré de deux sillons sur la face extérieure, lèvre légèrement biseautée vers l'intérieur ; bouton de préhension en forme de pied annulaire à face extérieure carénée ; fond extérieur convexe.

Vers 300-250.

\section{Autres couvercles}

CC 170. - Tombe SP 317. Ht $7 \mathrm{~cm}$, diam de l'embouchure 19,5 cm. Inv. PIN 3634b. Pl. 13g

Argile rouge brique. Fragmentaire. Vasque relativement haute, à paroi rectiligne ; bord non différencié à lèvre pointue; bouton conique.

Vers 300-275.

CC 171. - Tombe SP 318. Ht 5,4 cm, diam. de l'embouchure $25 \mathrm{~cm}$. Inv. 3669b. Pl. 14b

Argile rouge brique. Fragmentaire. Vasque évasée, à paroi rectiligne ; bord non différencié à lèvre pointue ; bouton conique.

Vers 300-275.

\subsection{Chytrai}

\section{Pots à une anse (grandes et moyennes dimensions)}

CC 172. - Foyer F 8. Ht 11,4 cm, diam. max. $16,2 \mathrm{~cm}$. Inv. PIN 3854. Pl. $75 f$

Argile rouge brun. Fond plat; panse globulaire dans sa partie inférieure, puis tronconique à la transition vers le bord évasé, se terminant par une lèvre aplatie; anse verticale à courbe continue et arête médiane, de section ovale, attachée sur le bord et la partie supérieure de la panse.
Vers 390-380.

CC 173. - Foyer F 5. Ht cons. de la partie sup. $4,5 \mathrm{~cm}$, diam. du fond $3 \mathrm{~cm}$. Inv. FR 2.52 .

Argile brune. Trois fragments du bord avec une partie de la panse, un fragment représentant la moitié de l'anse et un fragment du fond plat. Panse globulaire ; bord évasé se terminant par une lèvre aplatie ; anse verticale de section ovale.

Vers 390-380.

CC 174. - Foyer F 5. Ht cons. 5,3 cm, diam. de l'embouchure $11 \mathrm{~cm}$. Inv. FR 2.53. Pl. $116 \mathrm{~g}$

Argile brun rouge, surface gris noir. Trois fragments du bord avec une partie de la panse, globulaire dans sa partie inférieure, tronconique à la transition vers le bord ; bord évasé se terminant par une lèvre aplatie.

Vers 390-380.

CC 175. - Foyer F 6. Ht 9,7 cm (d'après la reconstitution graphique), diam. max. $14 \mathrm{~cm}$. Inv. PIN 3821. Pl. 72d

Argile brun rouge. L'anse manque. Fond plat; panse globulaire dans sa partie inférieure, puis tronconique à la transition vers le bord évasé, se terminant par une lèvre aplatie.

Vers 380 .

CC 176. - Foyer F 9. Ht 10,5 cm. Inv. PIN 4033d (FR 3.19). Pl. 116i

Argile orangée. Quelques fragments du bord et de la panse manquent. Fond arrondi ; panse basse et globulaire, séparée du bord par un col très court et concave ; bord évasé à lèvre arrondie ; anse verticale à courbe continue, de section ovale, joignant le bord à la partie supérieure de la panse.

Vers 380 .

CC 177. - Foyer F 9. Diam. de l'embouchure environ $11 \mathrm{~cm}$. Inv. PIN 4033r (FR 3.20). Pl. 116j

Argile orangée. Plusieurs fragments de la panse et du bord manquent. Panse basse et globulaire, séparée du bord par un col très court et concave ; bord évasé à lèvre arrondie ; anse verticale à courbe continue, de section ovale, joignant le bord à la partie supérieure de la panse. Vers 380 .

CC 178. - Foyer F 2. Ht 13,8 cm (d'après la reconstitution graphique), diam. max. 16,6 cm. Inv. PIN 3286. Pl. 69j

Argile grise. Fragmentaire. Fond arrondi; panse 
globulaire ; bord évasé se terminant par une lèvre aplatie ; l'anse verticale, de section ovale, était attachée sur le bord et sur la partie supérieure de la panse.

Vers 380.

CC 179. - Dépôt DP 5. Ht 10,2 cm, diam. max. $14 \mathrm{~cm}$. Inv. PIN 3224. Pl. 54b et 117a

Argile gris brun. Défauts de cuisson. Fond plat; panse globulaire, séparée du bord par un large col tronconique; bord évasé à face intérieure rectiligne et extérieure convexe, se terminant par une lèvre pointue ; anse verticale à courbe continue, de section ovale, joignant le bord à la partie supérieure de la panse.

Vers 375-350.

CC 180. - Dépôt DP 25. Ht $11,5 \mathrm{~cm}$, diam. max. $18,6 \mathrm{~cm}$. Inv. FR 1.3. Pl. 117b

Argile grise. Fragmentaire. Fond plat; panse basse et globulaire; bord évasé se terminant par une lèvre arrondie; anse verticale à courbe continue, de section rectangulaire, attachée au bord et à mi-hauteur de la panse.

Vers 375-350.

CC 181. - Dépôt DP 25. Ht cons. $11 \mathrm{~cm}$, diam. max. 17,2 cm. Inv. FR 1.32. Pl. 117c

Argile rouge brun. Très fragmentaire (deux fragments du bord, un fragment de l'anse et plusieurs fragments de la panse). Panse globulaire ; bord évasé se terminant par une lèvre arrondie.

Vers 375-350.

CC 182. - US 11 (au S.-O. de la fosse de SP 264). Ht cons. 7,6 cm, diam. max. 12,7 cm. Inv. FR 1.50 . Pl. 117d

Argile gris noir. Quatre fragments : l'un représente environ la moitié de la panse et du bord, un autre la totalité de l'anse, deux plus petits appartiennent à la panse globulaire. Col très court concave ; bord évasé se terminant par une lèvre arrondie ; anse verticale à courbe angulaire, de section ovale, joignant le bord à l'épaule et remontant un peu au-dessus du bord.

Vers 350.

CC 183. - Tombe SP 279. Diam. de l'embouchure $12,6 \mathrm{~cm}$. Inv. FR 1.4.

Argile brune, surface noire. Restent des fragments du bord avec le départ de l'anse et une grande partie de la panse avec le fond, arrondi. Panse globulaire; bord évasé se terminant par une lèvre arrondie ; anse verticale de section ovale.

Vers 300-290.
CC 184. - Découverte isolée près de l'angle N.-E. de SP 289. Ht 12,2 cm, diam. max. 15,8 cm. Inv. PIN 3351. Pl. 117e

Argile grise. Fond arrondi; panse globulaire; amorce d'un col très court et tronconique ; bord évasé se terminant par une lèvre aplatie ; anse verticale à courbe continue, de section ovale, attachée au bord et à mi-hauteur de la panse.

Vers $\mathrm{IV}^{\mathrm{e}}$ ou début du $\mathrm{III}^{\mathrm{e}} \mathrm{s}$. (?)

\section{Pots à une anse (petites dimensions)}

CC 185. - Dépôt DP 13. Ht 8,2 cm, diam. max. 11,6 cm. Inv. PIN 3682. PI. 56a et b

Argile gris noir. Fond plat ; panse basse et globulaire ; col court se rétrécissant vers le bord évasé, à face supérieure aplatie et lèvre arrondie ; anse verticale à courbe continue, de section rectangulaire, joignant le bord à la partie supérieure de la panse.

Vers 390-380.

CC 186. - Foyer F 8. Ht 8,7 cm, diam. max. $12,1 \mathrm{~cm}$. Inv. PIN 3853. Pl. 75e

Argile rouge brun, surface grise. Fragmentaire. Fond plat, légèrement concave en-dessous ; panse globulaire dans sa partie inférieure, tronconique à la transition vers le bord évasé, se terminant par une lèvre arrondie ; anse verticale à courbe continue, de section ovale, joignant le bord à la partie supérieure de la panse.

Vers 390-380.

CC 187. - Dépôt DP 2. Ht 8,3 cm, diam. max. $12 \mathrm{~cm}$. Inv. PIN 3129. Pl. 117f

Argile brun noir. Fond plat; panse globulaire ; col très court, se rétrécissant vers le bord évasé, à faces intérieure et extérieure rectilignes et lèvre arrondie ; anse verticale à courbe continue, attachée au bord et à mihauteur de la panse, décorée de deux cannelures sur la face supérieure.

Vers 390-380.

CC 188. - Dépôt DP 26. Ht 8,6 cm, diam. max. $11,4 \mathrm{~cm}$. Inv. FR 1.2. Pl. 62b et 118a

Argile grise. Fond plat; panse globulaire dans sa partie inférieure, tronconique à la transition vers le bord évasé, se terminant par une lèvre aplatie ; anse verticale à courbe continue, de section ovale, joignant le bord à la partie supérieure de la panse.

Vers 390-380.

CC 189. - Foyer F 2. Ht 7,5 cm, diam. $\max .11 \mathrm{~cm}$. Inv. PIN 3244. Pl. 69h

Argile gris foncé. L'anse manque. Fond légèrement 
concave ; panse globulaire ; bord évasé ; l'anse verticale était attachée sur le bord et à mi-hauteur de la panse.

Vers 380.

CC 190. - Foyer F 11. Ht du fragment principal (bord, anse et partie sup. de la panse) $5,8 \mathrm{~cm}$, diam. de l'embouchure $9 \mathrm{~cm}$. Inv. FR 3.59.7. Pl. 118b

Argile grise. Plusieurs fragments représentant la moitié du bord et du fond, l'anse, ainsi qu'une partie de la panse. Fond plat; panse globulaire dans sa partie inférieure, tronconique vers le bord évasé, se terminant par une lèvre arrondie ; anse verticale à courbe continue, de section ovale, attachée au bord et à mi-hauteur de la panse.

Vers 380-370.

CC 191. - Dépôt DP 4. Ht 7,8 cm, diam. max. $10 \mathrm{~cm}$. Inv. PIN 3205. PI. 54a et 118c

Argile brun noir. Fond arrondi ; panse globulaire ; col très court, se rétrécissant vers le bord évasé, à lèvre arrondie; anse verticale à courbe et contre-courbe, de section ovale, joignant le bord à la partie supérieure de la panse.

Vers 375-350.

CC 192. - Dépôt DP 20. Ht $8,2 \mathrm{~cm}$, diam. max. 11,7 cm. Inv. PIN 3805. Pl. 118d

Argile grise, surface gris beige. Fond plat, légèrement concave en-dessous; panse globulaire dans sa partie inférieure, tronconique à la transition vers le bord ; bord évasé se terminant par une lèvre aplatie ; anse verticale à courbe continue, de section rectangulaire, joignant le bord à la partie supérieure de la panse.

Vers 370-350.

CC 193. - Dépôt DP 20. Ht 8,3 cm, diam. max. $12 \mathrm{~cm}$. Inv. PIN 3806. Pl. 118e

Argile gris foncé. Fond plat ; panse globulaire dans sa partie inférieure, tronconique à la transition vers le bord évasé, se terminant par une lèvre aplatie ; anse verticale à courbe continue, de section ovale, joignant le bord à la partie supérieure de la panse.

Vers 370-350.

CC 194. - Foyer F 4. Ht 6,5 cm, diam. max. $10,1 \mathrm{~cm}$. Inv. PIN 3753. Pl. 70e

Argile rouge. Fond plat, légèrement concave en-dessous; panse biconique arrondie; bord évasé à lèvre arrondie ; anse verticale à courbe continue joignant le bord à la partie supérieure de la panse.

Vers 350-340.

CC 195. - Dépôt DP 29. Ht 8,8 cm, diam. max. $11,5 \mathrm{~cm}$. Inv. FR 1.1. PI. 64c et $\mathbf{1 1 8 f}$
Argile orangée, surface grise. Fond plat ; panse globulaire ; bord évasé se terminant par une lèvre arrondie ; anse verticale à courbe continue, de section rectangulaire, joignant le bord à la partie supérieure de la panse.

Vers 340.

CC 196. - Découverte isolée dans la zone du point H 2. Ht 7,8 cm, diam. max. 10,8 cm. Inv. PIN 3357. Pl. 118g

Argile grise. Fond plat ; panse basse globulaire ; bord évasé à lèvre pointue ; anse verticale à courbe continue, de section ovale, joignant le bord à la partie supérieure de la panse.

Vers $\mathrm{IV}^{\mathrm{e}}$ ou début du $\mathrm{III}^{\mathrm{e}} \mathrm{s}$. (?).

CC 197. - Découverte isolée dans la zone du point $\mathrm{H} 2$. Ht $7 \mathrm{~cm}$, diam. max. $9 \mathrm{~cm}$. Inv. PIN 3287 . Pl. 118h

Argile gris noir. Fond plat; panse biconique ; bord évasé à lèvre pointue ; anse verticale à courbe continue, de section ovale, joignant le bord à la partie supérieure de la panse.

Vers IVe ou début du III' ${ }^{\mathrm{e}}$ s. (?).

\section{Pots à une anse (miniatures)}

CC 198. - Foyer F 5. Ht conservée $2 \mathrm{~cm}$, long. conservée de l'anse $4 \mathrm{~cm}$. Inv. FR 2.68.

Argile orangée. Restent un fragment du bord avec le départ de la panse et un fragment de l'anse. Bord évasé se terminant par une lèvre arrondie ; départ de la panse, large et globulaire ; anse verticale de section ovale.

Vers 390-380.

CC 199. - Dépôt DP 26. Ht 6 cm, diam. max. 10,1 cm. Inv. FR 1.33. Pl. 62b-c et 119a

Argile grise. Les deux tiers du bord et une grande partie de la panse manquent. Fond arrondi ; panse basse et globulaire ; bord évasé se terminant par une lèvre arrondie ; anse verticale à courbe continue, de section ovale, attachée au bord et à mi-hauteur de la panse.

Vers 390-380.

CC 200. - Foyer F 9. Ht 5,2 cm, diam. max. 7,6 cm. Inv. PIN 4033e (FR 3.26). Pl. 119b

Argile rouge brun. Une partie du bord et de la panse manquent. Traces de combustion. Fond arrondi ; panse basse et globulaire ; col très court, se rétrécissant vers le bord évasé, à lèvre arrondie ; anse verticale à courbe continue, de section ovale, attachée au bord et à mi-hauteur de la panse.

Vers 380 . 
CC 201. - Tombe SP 298. Ht 5,2 cm, diam. max. 9,2 cm. Inv. PIN 3252. PI. 119c

Argile brun beige. Fond arrondi; panse surbaissée ; col très court, se rétrécissant vers le bord évasé, lèvre arrondie; anse verticale à courbe continue, de section ovale, joignant le bord à la partie supérieure de la panse.

Vers 370-350.

CC 202. - Tombe SP 328. Ht 4,8 cm, diam. max. $6,5 \mathrm{~cm}$. Inv. PIN 3649 (FR 2.25). Pl. 34e

Argile grise. Fond arrondi; panse basse et globulaire ; col très court, se rétrécissant vers le bord évasé, à lèvre arrondie; anse verticale à courbe continue, de section ovale, attachée au bord et à mi-hauteur de la panse.

Vers 360-350.

CC 203. - Tombe SP 337. Ht 5,5 cm, diam. max. $7 \mathrm{~cm}$. Inv. FR 2.23. Pl. 119d

Argile rouge brun. Quelques fragments de la panse manquent. Fond arrondi ; panse globulaire; col court, se rétrécissant vers le bord évasé, à lèvre arrondie ; anse verticale à courbe continue, de section ovale, attachée au bord et à mi-hauteur de la panse.

Vers 350 .

CC 204. - Tombe SP 289. Ht 4,5 cm, diam. max. $6,3 \mathrm{~cm}$. Inv. PIN 3151. Pl. 23e et 119e

Argile brun orangé. Fond arrondi ; panse basse globulaire ; col court, se rétrécissant vers le bord évasé, à lèvre arrondie ; anse verticale à courbe continue, de section ovale, joignant le bord à la partie supérieure de la panse.

Vers 300-290.

\section{Pots à deux anses}

CC 205. - Dépôt DP 11. Ht 10,5 cm, diam. max. 14,4 cm. Inv. PIN 3674. Pl. 119f

Argile rouge brun, surface gris noir. Fond légèrement concave ; panse globulaire, séparée du bord par un col large et tronconique; bord évasé se terminant par une lèvre arrondie; les deux anses verticales sont ornées de deux cannelures sur la face supérieure et attachées au bord et à la partie supérieure de la panse.

Vers 400-375 (?).

CC 206. - Dépôt DP 7. Ht (d'après la reconstitution graphique) $6,8 \mathrm{~cm}$, diam. max. $13 \mathrm{~cm}$. Inv. PIN 3620a. Pl. 119g

Argile rouge brun, surface rouge. Plusieurs fragments manquent. Fond arrondi ; panse surbaissée ; bord évasé à face extérieure rectiligne et intérieure convexe, muni à l'intérieur d'une moulure pointue servant à accueillir un couvercle; deux anses verticales à courbe continue, de section ovale, sont attachées au bord et à mi-hauteur de la panse.

Vers 350-325.

CC 207. - Tombe SP 362. Ht 4,9 cm, diam. max. $8 \mathrm{~cm}$. Inv. PIN 4030 (FR 3.42). Pl. 50e et 119h

Argile orangée. Les anses manquent, bord ébréché. Partie inférieure et fond noircis par l'exposition au feu. Fond plat; panse basse, globulaire ; bord évasé à faces intérieure et extérieure rectilignes, se terminant par une lèvre arrondie ; traces des attaches de deux anses horizontales relevées sur l'épaule.

Vers 300-250.

\section{Figurines et objets divers en terre cuite, vase plastique}

\subsection{Figurines}

On trouve souvent dans les nécropoles d'Apollonia, parmi les offrandes des tombes et des foyers, des figurines en terre cuite qui représentent des divinités, des personnages, des animaux, des oiseaux, des masques de théâtre, etc. Les exemplaires les plus anciens proviennent des tombes du site de Harmanité et appartiennent à la deuxième moitié du $\mathrm{VI}^{\mathrm{e}} \mathrm{s}$. av. J.-C. Les statuettes, qui proviennent le plus souvent de tombes d'enfants ou de femmes, ont des sujets différents. Les plus anciennes représentent des divinités et des personnages mythologiques : les images de divinités en relation avec le monde funéraire sont bien attestées, dans les tombes d'Apollonia, par des terres cuites figurant Cybèle, Déméter, Perséphone, Hermès, Aphrodite et Eros. L'importance du thiase de Dionysos - Pan, silènes, satyres et bacchantes -, ainsi que les statuettes de musiciens, danseurs, acteurs, les masques de théâtre, les représentations de boucs, de taureaux et les bucranes, qu'on trouve souvent parmi les offrandes des tombes d'Apollonia, montrent les applications du culte du dieu dans ses aspects chthoniens.

Pour le reste, en dehors de quelques terres cuites représentant des sujets mythologiques, on a mis au jour dans un grand nombre de tombes des figurines se rapportant à des scènes de la vie quotidienne ou à des scènes de genre, les images de jeunes filles étant les plus nombreuses.

Une partie des terres cuites découvertes dans les colonies grecques de la côte bulgare de la mer Noire se rattache aux productions des ateliers de coroplathes 
d'Athènes, de Tanagra, de Rhodes, de Chypre et de Cyrénaïque. L'autre partie a été produite sur place d'après des modèles ou avec des moules importés (Dremsizova 1963a, p. 285). Nous ne disposons pas de sources écrites concernant la coroplathie à Apollonia du Pont et nous n'avons trouvé à ce jour aucun vestige d'atelier, mais la qualité de la pâte et le mode de fabrication de certaines figurines, ainsi que la découverte de moules, attestent l'existence d'une production locale, surtout au $\mathrm{IV}^{\mathrm{e}} \mathrm{s}$.

Il est difficile de déterminer avec certitude si ces terres cuites étaient des objets appartenant au mort ou s'il s'agissait d'offrandes déposées par les vivants pour se concilier les divinités souterraines, ou pour évoquer une situation de la vie terrestre. Certaines représentent des animaux que l'on sacrifiait dans les cultes chtoniens. Les terres cuites des nécropoles d'Apollonia sont en tout cas en relation avec l'âge du défunt, car elles proviennent en général, et souvent en grande quantité (jusqu'à 10-15 exemplaires), de tombes d'enfants (Panayotova 2007, p. 106-107, et Koeller, ci-dessus) : c'est le cas pour la plupart des figurines présentées ici, trouvées dans les tombes SP 283 (individu âgé d'environ sept ans) et 327 (jeune enfant, mais le squelette est trop mal conservé pour que l'on puisse déterminer l'âge). Les comparaisons sont nombreuses dans le monde grec. Pour l'époque classique, les tombes d'enfants d'Olynthe constituent toujours une référence essentielle (Robinson 1931, 1942 et 1952).

\subsubsection{Femmes assises}

TC 1. - Découverte isolée, au Sud du point H 3. Ht conservée 7,7 cm. Inv. PIN 3636.

Fragmentaire. Manquent la tête et la partie inférieure des jambes. Argile bien épurée, de couleur rouge orangé. Figurine moulée creuse, ouverture rectangulaire à l'arrière. La femme est assise sur un trône à haut dossier (relief sommaire, sans détails); de sa main droite elle tient devant sa poitrine un objet indéterminé, le bras gauche est posé sur la cuisse gauche.

TC 2. - Découverte isolée dans la zone du point J 6 . Ht 12,6 cm, base rectangulaire 6,3 x 4,4 cm. Inv. PIN 3746.

Argile bien épurée, de couleur marron, presque entièrement recouverte de concrétions. Figurine moulée, creuse jusqu'au niveau des épaules, ouverture rectangulaire à l'arrière $(4 \times 3 \mathrm{~cm})$. Le personnage, entièrement conservé, est assis sur un trône à haut dossier et à accoudoirs ; les pieds sont posés sur un petit support. La pose est souple, le bras gauche est plié, la main dirigée vers la poitrine ; le bras droit est posé sur la jambe droite. La tête est recouverte d'un bonnet pointu ou d'une capuche. Le visage est ovale avec des sourcils arqués, un nez droit, une petite bouche, un menton épais. Le dos est lissé.

TC 3. - Tombe SP 327. Ht 12,6 cm, base carrée, 5 x $5 \mathrm{~cm}$. Inv. PIN 3726. Pl. 120a

Argile brun orangé avec de petits trous, entièrement recouverte de concrétions. Figurine moulée entièrement conservée, creuse jusqu'au niveau des épaules, ouverture rectangulaire à l'arrière $(2,8$ x $3,5 \mathrm{~cm})$.

Les formes sont sommairement représentées, on ne distingue pas les détails. La femme est probablement assise sur un trône à haut dossier, ses pieds sont joints. Le bras droit est posé sur le genou droit, le bras gauche est plié, la main est placée du côté gauche de la poitrine. Une ligne en relief passe en travers du torse, de l'épaule gauche jusqu'au-dessous du bras droit, qui représente probablement une partie du vêtement (un himation qui couvre aussi la tête ?). Le personnage est sans doute vêtu d'un chitôn long, puisque le contour des pieds n'est pas bien visible, donnant l'impression qu'ils sont recouverts d'un tissu. La coiffure est sommairement représentée, avec une sorte d'épais anneau autour du visage épais, terminé par une extrémité conique à l'arrière (peut-être une capuche). Le dos n'est pas travaillé.

Le contexte indique une date vers 370-350.

Ces trois terres cuites représentant des femmes assises sur un trône à haut dossier correspondent à un type déjà connu à Apollonia, avec de petites variantes ${ }^{309}$. Pour deux d'entre elles, le bras gauche est plié, la main levée vers la poitrine, et le droit posé sur la jambe droite, tandis que la troisième tient de sa main droite, devant sa poitrine, un objet indéterminé, la main gauche étant posée sur la cuisse gauche. Les caractéristiques de l'argile et la représentation sommaire des détails laissent supposer que ces terres cuites ont été fabriquées dans des ateliers locaux.

Tandis que TC 1 constitue une découverte isolée, TC 2 a été trouvée au même endroit qu'un récipient miniature (Inv. PIN 3750), non loin de la tombe SP 327. Le fait que le récipient soit de petite taille et que la terre cuite comporte les mêmes caractéristiques que celle de la tombe, permet de supposer que ces deux objets sont des restes de rituels liés à l'enfant enterré dans la tombe SP 327.

309 Dremsizova (1948, p. 57 , fig. 71 ; 1963a, p. 280 nos $826-828$, pl. 143, 147: tombe d'enfant du milieu du $\mathrm{IV}^{\mathrm{e}} \mathrm{s}$.) assimile ces personnages à des scènes de genre. Elle date les figurines représentant des scènes de la vie quotidienne du milieu et de la deuxième moitié du IV es. (Dremsizova 1963a, p. 285). 
Le type de la femme assise, très populaire, répond à différents usages : décor dans l'habitat, offrande dans un sanctuaire ou dans une tombe. Les trois terres cuites présentées ici sont creuses, avec une ouverture dans la partie inférieure et une autre plus grande à l'arrière, qui permet de les suspendre. La position assise, rigide et frontale, et l'expression majestueuse suggèrent qu'il s'agit de l'image d'une déesse: elle s'inscrit dans le style des représentations pré-classiques de femmes assises (deuxième quart du $\mathrm{V}^{\mathrm{e}} \mathrm{s}$.), certaines habillées du chitôn et de l'himation, un bras posé devant la poitrine, type qui évolue dans la deuxième partie du $\mathrm{V}^{\mathrm{e}}$ et au $\mathrm{IV}^{\mathrm{e}} \mathrm{s}$. (Higgins 1967, p. 74, fig. 24 ; Mollard-Besques 1954, pl. LXXXII, C187, et CV, 619 ; Vierneisel-Schlörb 1997, pl. 21, 100). Il est difficile d'identifier la déesse, à Apollonia comme ailleurs, surtout quand l'objet tenu par la femme n'est pas identifiable (TC 3) : le contexte funéraire laisse penser qu'il s'agit d'une déesse chtonienne (Déméter ou Perséphone/Coré : Merker 2000, p. 43, pl. 9, C 79), mais il est impossible de le démontrer.

\subsubsection{Personnage masculin assis}

TC 4. - Tombe SP 327. Ht 5,2 cm, diam. de la base $4 \mathrm{~cm}$. Inv. PIN 3727. Pl. 120b

Figurine moulée pleine. Argile brune sableuse. Jeune homme (Eros, Hypnos ?) assis sur le sol : les formes sont sommairement rendues, il est difficile de distinguer les détails. La jambe gauche pliée est présentée de face, le genou droit est posé à terre, le tibia est dirigé vers l'intérieur, la plante du pied est posée en haut de l'autre jambe. La figure s'appuie de la main droite par terre, son torse est légèrement penché vers la droite. Le bras droit n'est pas clairement visible, il est possible qu'il soit posé sur les jambes ou placé derrière la jambe gauche. La tête est penchée vers la gauche, les traits du visage sont juste esquissés. Une boucle de cheveux tombe du côté droit du cou. Un élément semi-circulaire qui fait saillie sur l'épaule droite appartenait probablement à une aile. Quelques plis tombant sur la jambe gauche indiquent probablement la présence d'un vêtement, de même qu'une ligne en relief, en zigzag, visible de la hanche droite à la plante du pied. Le dos n'est pas travaillé.

Même date que TC 3.

Des figurines du même type ont été mises au jour dans la nécropole d'Apollonia. Les traits fins du visage et les boucles tombantes sur les épaules font penser à un Eros, surtout si la saillie ovale au-dessus de l'épaule droite appartient bien à une aile pliée derrière le dos.

Le trait le plus original de cette terre cuite est sa pose, les jambes pliées et la tête penchée vers l'épaule. Une figure ailée assise avec la tête penchée vers l'épaule gauche, située à la base de l'anse d'une œnochoé en bronze du Metropolitan Museum de New York, datée vers 470, constitue un parallèle intéressant : pour $\mathrm{D}$. von Bothmer (1979, p. 67, pl. XXII, 2 et XXIII, 3-5) il s'agit, comme sur deux vases attiques à figures rouges, d'une représentation du Sommeil, Hypnos. Cette divinité bienfaisante et bienveillante est souvent représentée endormie, la tête penchée sur son épaule gauche ou appuyée sur son bras gauche. Il est figuré nu ou portant un manteau court, ses cheveux longs tombent en boucles sur les épaules. Son iconographie est donc proche de celle d'Eros, mais on peut parfois l'identifier grâce à des inscriptions. Les représentations d'Hypnos ou Somnus dans un contexte funéraire peuvent illustrer simplement la vision consolante de la mort comme sommeil, ou faire allusion aux différents mythes dans lesquels le sommeil est comme la préfiguration d'une vie dans l'au-delà. Les liens d'Hypnos/Somnus avec l'au-delà sont parfois très clairs, dans les Hymnes orphiques il a un rôle psychopompe (Lochin 1990, p. 591 et 608-609).

\subsubsection{Jeunes garçons assis}

TC 5. - Tombe SP 327. Ht 7,1 cm, diam. de la base $4,8 \mathrm{~cm}$. Inv. PIN 3735. Pl. 120c

Figurine moulée creuse jusqu'au niveau des épaules. Argile brun orangé avec des vacuoles. Jeune garçon assis coiffé d'un bonnet conique, sur un support arrondi. Les formes sont sommairement rendues, les détails peu perceptibles. Le garçon, au corps arrondi, au ventre et à la poitrine proéminents, est assis sur le sol, la jambe droite pliée figurée de face, le pied en appui, la jambe gauche repliée sous le ventre, posée à terre. Le bras droit, plié, paraît posé sur le genou droit, le gauche tombe le long du corps, la main appuyée sur le sol. Les traits du visage sont juste esquissés. Le personnage porte un bonnet conique, aucun vêtement ne semble être indiqué. L'arrière n'est pas travaillé.

Même date que TC 3 et 4.

TC 6. - Tombe SP 327. Ht $6,8 \mathrm{~cm}$, diam. de la base $5 \mathrm{~cm}$. Inv. PIN 3736. Pl. 120d

Figurine moulée, creuse jusqu'au niveau des épaules. Argile brun orangé avec des vacuoles. Semblable au précédent.

Dans la nécropole d'Apollonia (Kalfata), les terres cuites représentant un garçon nu assis, avec ou sans bonnet conique, proviennent souvent de tombes d'enfants. Le type y est connu depuis la deuxième moitié du $\mathrm{VI}^{\mathrm{e}} \mathrm{s} .{ }^{310}$.

310 Dremsizova 1948, p. 55-56, fig. 69 (deuxième moitié du IV e s.), et $1963 \mathrm{a}, \mathrm{n}^{\text {os }} 836-837$ (troisième quart $\mathrm{du} \mathrm{V}^{\mathrm{e}} \mathrm{s}$.) ; Panayotova et al. 2006, p. 245 ; Panayotova, Gyuzelev, Nedev 2008. Un bonnet conique indépendant, probablement destiné à une figurine du même 
Des statuettes comparables d'enfants assis, les jambes pliées ou avec un des genoux levé, ont été découvertes sur de nombreux sites de Grèce, aussi bien dans des sanctuaires de divinités kourotrophes que dans des tombes ou des habitats ${ }^{311}$. Ce type, largement diffusé en Méditerranée orientale, dérive probablement de prototypes égyptiens, en raison de la pose qui n'est pas inhabituelle dans l'art égyptien. L'un des plus anciens exemplaires découverts en Grèce est en effet une statuette en faïence provenant de Rhodes et produite à Naucratis (Hadzisteliou-Price 1969, p. 96).

Les terres cuites de la tombe 327 d'Apollonia correspondent au type ionien archaïque, ou type I (garçon nu avec un bonnet, plus tard recouvert d'un manteau court) dans la classification de Hadzisteliou-Price, ainsi qu'à la première variante du type "garçon nu coiffé d'un pilos » (Hadzisteliou-Price 1969, p. 98, pl. 21). Ce type, qui ne semble pas apparaître avant le $\mathrm{V}^{\mathrm{e}} \mathrm{s}$., est en usage pendant les époques classique et hellénistique, avec des variantes et des adaptations.

Il existe différentes interprétations de ces représentations : enfants divins (Dionysos, Attis, etc.) ; enfants réels ; jeunes prostitués dans les sanctuaires (voir la discussion dans Hadzisteliou-Price 1969, p. 107-110). Pour A. A. Peredolskaya le chapeau conique d'une figurine similaire trouvée dans la péninsule de Bérézan, conservée au musée de l'Ermitage, apporte la preuve d'un culte des Cabires (Peredolskaya 1960, p. 27), mais, pour E. N. Hodza, le bonnet conique ne peut être considéré avec certitude comme un attribut des Cabires : représenté sur un grand nombre de terres cuites rhodiennes, il témoignerait plutôt d'une influence chypriote et pourrait s'appliquer à différents personnages (Hodza 2000, p. 128, fig. 1).

On a aussi supposé que des figurines de ce type, souvent déposées dans les tombes ou offertes dans les sanctuaires de différentes divinités, faisaient allusion à des sacrifices offerts par de jeunes garçons (Schmaltz 1974, p. 105 et 107). Mais d'après Baudat, le pilos qui coiffe un homme accroupi sur une terre cuite de la nécropole de Myrina (d'un type béotien de la fin $\mathrm{du} \mathrm{V}^{\mathrm{e}} \mathrm{s}$.) le lie aux cultes funéraires et chtoniens, et il considère que cette pose typique d'un esclave incite à voir dans le personnage un serviteur des morts, destiné

type, a été découvert dans la nécropole d'Apollonia, sur le site du Jardin maritime (Panayotova 2006, p. 139). Ajouter une terre cuite fragmentaire conservée au Louvre (Mollard-Besques 1954, p. 42, B 248, pl. XXX).

311 Winter 1903, p. 266 (type VI) ; Hadzisteliou-Price 1969, p. 98-99, pl. 21, 12-13 (type I) ; Robinson 1931, p. 74-76, pl. 36, et 1952, p. 213-218, pl. 91-94 ; Merker 2000, p. 68-69 ; VierneiselSchlörb 1997, pl. 34-35, nºs 183-188. à accomplir cette fonction dans l'au-delà (Baudat 1953, p. $45 n^{\circ}$ 51, pl. XIX ). Hadzisteliou-Price pense, quant à elle, que ces terres cuites, découvertes sur de nombreux sites de Grèce, doivent être interprétées comme la représentation d'un enfant mort à l'âge représenté par la figurine et mis sous la protection d'une déesse chtonienne (Déméter ou Koré), puisqu'on les trouve souvent associées à des figurines de femmes assises (Hadzisteliou-Price 1969, p. 110). C'est effectivement le cas dans la tombe 327, ainsi que dans d'autres tombes d'enfants de la nécropole d'Apollonia, ce qui invite à considérer cette hypothèse comme la plus vraisemblable. Ajoutons, pour aller dans ce sens, qu'il existe de nombreuses variantes dans les représentations du garçon assis, aussi bien dans la pose que dans les accessoires (bonnet, bandeau ou bracelet avec des amulettes), ce qui s'explique probablement par l'existence de différents prototypes. L'usage important de ce type de figurine dans la nécropole classique d'Apollonia explique la réalisation d'une production locale, probablement d'après des modèles importés.

\subsubsection{Autres types}

TC 7. - Acteur comique. Tombe SP 283. Ht conservée $10 \mathrm{~cm}$. Inv. PIN 3510 (FR 1.7.2). Pl. 120e

Argile beige pure. La partie supérieure de la tête manque, à partir du bas du nez. Figurine moulée creuse, trou d'évent à la base des fesses. Un acteur comique est debout sur une base carrée. Les pieds, le bas des fesses, le sexe et, probablement, les jambes sont nus ; le contour des genoux est bien marqué. Un vêtement drapé sur l'épaule gauche couvre le ventre, très proéminent, et le haut des grosses fesses. Un autre vêtement couvre l'épaule droite, un troisième (?) le bras droit. La main droite est posée en haut du ventre, la gauche tient par une double lanière un panier à trois bandes horizontales. La tête est légèrement tournée vers la gauche. Le personnage porte une barbe en pointe, vaguement ondulée, et une moustache (traces de rose à la base de la joue droite) ; la bouche est largement ouverte, les dents du haut sont visibles ; le nez est épaté.

Le contexte et le style de la figurine indiquent une date vers 350-340.

Le panier que tient le personnage permet de l'identifier comme un type de cuisinier qui se rattache à la comédie ancienne et moyenne ${ }^{312}$. Les figurines d'ac-

312 Bieber 1961, p. 40 fig. 143 (comédie ancienne) et 46 fig. 189 (comédie moyenne, dans un ensemble de 14 figurines d'acteurs comiques trouvées dans une même tombe d'Athènes). Pour l'évolution du thème du cuisinier dans la nouvelle comédie, voir aussi Biers 1985. 
teurs comiques ont été trouvées en nombre relativement important dans la nécropole de Kalfata : aux exemples issus des fouilles de Venedikov ${ }^{313}$ s'en ajoutent d'autres, en partie inédits, qui proviennent souvent de tombes d'enfants ${ }^{314}$.

TC 8. - Singe ou personnage grotesque. Tombe SP 283. Figurine moulée pleine, en partie restaurée. Ht 7 cm. Inv. PIN 3512 (1.7.3). Pl. 121a

Singe ou personnage simiesque assis, nu, penché en avant, les mains posées sur les genoux les jambes et les bras repliés contre le corps. Les bras sont très maigres, le dos creux, la colonne vertébrale saillante. La tête, chauve, est rejetée vers l'arrière, la pomme d'Adam est marquée. En dehors de l'oreille, le visage n'a pas une apparence humaine : mâchoire étroite tendue vers l'avant, nez écrasé, presque crochu. Même date que le précédent.

La figurine de singe déposée auprès du jeune Euphéros dans le cimetière du Céramique, vers 430, a un aspect différent (Vierneisel-Schlörb 1997, p. 175 n 585, pl. 101). Le motif a ici évolué dans le sens du grotesque. Les deux types de figurines ont certainement une valeur prophylactique qui explique leur offrande dans une tombe d'enfant.

TC 9. - Coq. Tombe SP 283. Figurine moulée creuse. Argile beige orangé très pure. La tête et le cou manquent. Ht 8,7 cm. Inv. FR 1.7.1. Pl. 121b

Coq debout sur une base circulaire, couverte d'un engobe blanc. Plumage bien dessiné, haute queue dressée (fragmentaire), traces de peinture bleue sur les pattes. Même date.

Les figurines de coq sont attestées dans les tombes d'enfants : on en connaît, entre autres, deux exemples à Olynthe ${ }^{315}$.

TC 10. - Taureau fragmentaire. Dépôt DP 33. Ht 18,5 cm. Inv. PIN 4103. Pl. 121c

Figurine moulée creuse. Argile orangée, très noire à l'intérieur. Deux fragments jointifs trouvés dans les US 137 et 148. Tête et patte avant d'un taureau; les détails de la tête et les fanons sont bien indiqués.

Cet objet de belle qualité ne semble pas avoir d'équivalent dans la nécropole d'Apollonia, où la présence de figurines en terre cuite dans les dépôts est rare. Bien

313 Dremsizova 1963a, p. 279-280, pl. 143, 146 et 151.

314 Comme pour le petit groupe mis au jour dans la tombe 278 : Hermary, Panayotova 2006, fig. p. 59.

315 Robinson 1942, p. 39 (tombe 179, associé à un Silène et un Satyre) et p. 54-55 (tombe 254, associé à deux Satyres et deux Erotes). qu'il soit relativement perturbé, le contexte parait indiquer une date dans le deuxième quart du $\mathrm{IV}^{\mathrm{e}} \mathrm{s}$.

\subsubsection{Masques}

TC 11. - Tombe SP 327 . Ht $5,5 \mathrm{~cm}$, larg. max. cons. 4,9 cm. Inv. N 3725. Pl. 121d

Moulé en creux, deux trous de suspension dans la partie supérieure. Argile brun clair avec des inclusions de sable et des cailloutis. La partie droite du visage et un fragment inférieur gauche manquent. Tête d'une jeune femme aux traits délicats, avec des yeux largement ouverts, un nez droit et une bouche légèrement souriante. La tête était peut-être couverte d'un voile : la surface supérieure est lisse, mais des boucles en relief apparaissent en haut du front.

Vers 370-350 d'après le contexte.

TC 12. - Foyer F 1. Ht $5 \mathrm{~cm}$, larg. $4,5 \mathrm{~cm}$ Inv. PIN 4163a. Pl. 121e

Argile orangée à inclusions blanches. Petit masque fragmentaire, dont le rebord est conservé en bas à droite. Visage juvénile à la bouche largement ouverte, proche d'un masque de théâtre. Les cheveux et la partie inférieure gauche du visage manquent; petit nez retroussé, les paupières inférieures sont mal sorties.

Vers 380 d'après le contexte.

\subsubsection{Divers}

TC 13. - Découverte isolée dans la zone du point H 5. Long. 8,2 cm, diam. max. 1,8 cm. Inv. PIN 3804. Pl. 122a

Argile brun clair, trace d'un engobe rouge marron. Massue couverte de protubérances, cassée dans la partie inférieure, arrondie dans la partie supérieure qui était probablement tournée vers le bas et fixée à un support. Elle pouvait appartenir à une figurine d'Héraclès, mais il peut aussi s'agir d'un objet à valeur prophylactique ${ }^{316}$.

TC 14. - Tombe SP 283. Ht $3,4 \mathrm{~cm}$. Inv. 1.7.4.

\section{Pl. 122b}

Très fragmentaire : il ne reste que le socle d'une figurine, de forme grossièrement trapézoïdale ; sur un des côtés, qui doit correspondre à la face, motif de petites boules en relief évoquant des grappes. Même date que TC 7-9.

316 Comparer Winter 1903, p. 378 (type X) ; Laumonier 1956 p. 271, pl. 96, n 1278 (II ${ }^{\mathrm{e}}-\mathrm{I}^{\mathrm{er}}$ S. av. J.-C.). 
TC 15. - Tombe SP 303. Inv. PIN 3355.

Figurine très mal conservée, représentant probablement un Satyre. Début du IV ${ }^{\mathrm{e}} \mathrm{s}$. d'après le contexte.

TC 16. - Tombe SP 320. Inv. PIN 3699.

Personnage debout, très fragmentaire.

\subsection{Petits objets divers}

TC 17. - Tombe SP 338. Ht $2,7 \mathrm{~cm}$, diam. du fond $3,7 \mathrm{~cm}$, diam. supérieur $1,6 \mathrm{~cm}$, diam. de l'embouchure $0,6 \mathrm{~cm}$. Inv. PIN 3781. Pl. 41f

Argile grossière, gris brun, non homogène ; surface lissée ; fine fissure horizontale sur la base. Objet en forme de cône tronqué à fond arrondi, percé verticalement : poids pyramidal (comparer Davidson 1952, p. $175 \mathrm{n}^{\circ} 1219$, pl. $78: \mathrm{V}^{\mathrm{e}} \mathrm{s}$.) ? Le contexte indique une date vers $370-350$.

TC 18. - Tombe SP 340. Inv. PIN 3800.

Argile épurée, brune. Deux «billes », l'une de forme sphérique (diam. 1,7 cm), l'autre légèrement bi-conique (diam. 1,6 à 1,8 cm). La tombe est datée vers 360-350.

TC 19. - Tombe SP 340 . Ht $1,3 \mathrm{~cm}$, diam. $1,7 \mathrm{~cm}$. Inv. PIN 3800.

Argile épurée brune. Objet de forme cylindrique avec des traces de collage. Même date.

Les trois «billes» en terre cuite de la tombe 340 ne sont pas trouées : il ne s'agit donc ni de perles, ni d'objets à suspendre. On les considérera plutôt Comme des « objets magiques », aussi originaux que d'autres offrandes de cette tombe (clé en bronze, pointes de flèches et cailloux lissés) : la femme qui y avait été inhumée avait probablement, de son vivant, des occupations différentes de celles des habitantes ordinaires d'Apollonia et un statut particulier (voir ci-dessus). On constate en tout cas que, dans la nécropole d'Apollonia, les objets miniatures en forme de sphère, de cylindre, de cône, de triangle, etc., proviennent souvent de tombes de femmes (Panayotova et al. 2006, p. 245; Panayotova et al. 2007, p. 367).

\subsection{Vase plastique}

TC 20. - Tombe SP 327. Ht 9,1 cm, diam. de la base $4,8 \mathrm{~cm}$. Inv. PIN 3731. Pl. 32d et 122c

Vase modelé à la main. Argile beige sableuse avec des inclusions de sable et de mica, sans traces de vernis ou d'engobe. L'anse est cassée. Oenochoé dont la partie inférieure a la forme d'une tête féminine avec son cou, coiffée d'un haut bonnet. Les mèches frontales forment un arc décoré de demi-cercles. À la place des oreilles sont figurés deux éléments ovales, peut-être des boucles d'oreilles en forme de disques. Le col du vase part du sommet du bonnet : le bord est pincé, mais n'a pas la forme trilobée traditionnelle.

La sépulture est datée vers 370-350.

Cette œnochoé, trouvée dans une tombe d'enfant, ne possède pas de parallèles directs dans la série des vases plastiques du $\mathrm{IV}^{\mathrm{e}} \mathrm{s}$. Il est cependant possible que l'artisan, qui travaillait probablement à Apollonia même, ait connu et copié des modèles importés (Panayotova et al. 2006, p. 245; Panayotova et al. 2007, p. 367).

Le traitement de la partie supérieure du voile audessus de la tête donne une impression étrange. Cette représentation frontale avec une sorte de visière triangulaire rappelle l'« Athéna Lenormant », copie romaine de l'Athéna Parthénos, qui, comme d'autres copies miniatures (de Macédoine, d'Argos et d'ailleurs) introduisait, semble-t-il, quelques changements par rapport à l'original de Phidias (Demargne 1984, p. 977 no 221 et p. 1031). L'ovale du visage, le contour des lèvres et les boucles rondes indiquent que l'auteur de cette œnochoé connaissait probablement quelques sculptures réalisées dans la manière de Phidias au cours du $\mathrm{IV}^{\mathrm{e}} \mathrm{s}$.

L'absence de décor peint et la sévérité de l'expression du visage permettent aussi de rapprocher l'œnochoé d'Apollonia d'un groupe de vases et de terres cuites d'Olynthe en forme de têtes féminines coiffées d'un bonnet phrygien (Robinson 1952, n ${ }^{\text {os }}$ 404-405, pl. 123-124). Ils se caractérisent par l'absence de vernis noir et par le dessin spécifique des lèvres. D'après M. Trumpf-Lyritzaki, la majeure partie des vases plastiques découverts à Olynthe est de production locale (Trumpf-Lyritzaki 1969, p. 109 et 113). On pourrait, d'autre part, comparer la coiffure d'une figurine en terre cuite de Délos, qui date cependant de la fin de l'époque hellénistique ${ }^{317}$.

Les vases plastiques de forme humaine, animale ou végétale ont été principalement produits en Attique au IV ${ }^{\text {e }}$ s. av. J.-C. : ces vases ont servi de modèles en Béotie, à Olynthe, en Campanie et dans d'autres centres (Higgins 1959, p. 7 et 57). Depuis l'époque archaïque, les vases à têtes humaines fabriqués à Athènes représentent presque exclusivement des têtes de femmes, de Satyres et d'Africains. D'après Beazley (1929, p. 39), les femmes sont des korai ordinaires, et on interprétera donc ainsi celle d'Apollonia. E. Reeder (1995) considère

317 Seule est conservée la partie gauche de la boucle d'oreille, sans le visage (Laumonier 1956, p. 231, pl. 80, 972). 
que l'œnochoé est un récipient approprié à la représentation d'une tête humaine, puisque la forme trilobée de l'ouverture se pose sur elle comme un chapeau. D'autre part, les contours courbes de la panse du vase sont tellement similaires à la forme de la tête humaine qu'ils s'estompent partiellement lors de la transformation en tête humaine. Même si la majeure partie de ces vases a été trouvée dans des tombes, ils étaient sans doute utilisés à l'origine lors du symposion.

Le fait que les deux autres vases plastiques d'Apollonia ont été trouvés dans des tombes d'enfants amène enfin à rappeler le rôle et l'usage de l'œnochoé dans les rituels liés à la croissance des enfants, spécialement les garçons. Plus généralement, une grande partie des vases plastiques antiques ont été découverts dans des contextes funéraires. Ils ont donc joué un rôle dans le culte des morts et dans les croyances populaires sur la vie après la mort.

\section{4. « Grils à poisson »}

Ces objets, caractéristiques du site d'Apollonia, posent un problème d'interprétation : voir la discussion ci-dessus, p. 171-172.

TC 21. - Foyer F 9. Long. $22 \mathrm{~cm}$, larg. $9 \mathrm{~cm}$. Inv. PIN 4033b (FR 3.27). Pl. 123a-c

Argile orangée. Un fragment de l'extrémité arrondie et de l'une des traverses manquent. Traces de combustion.

Vers 380 .

TC 22. - Foyer F 11. Inv. FR 3.61.

Argile grise. Plusieurs fragments manquent.

Vers 380-370.

TC 23. - Foyer F 4. Long. conservée $7 \mathrm{~cm}$, larg. $6,2 \mathrm{~cm}$. Inv. PIN 3756. Pl. 70f

Fragmentaire. Seule une partie de la paroi et deux traverses sont conservées.

Vers 350-340.

TC 24. - Foyer F 1. Inv. PIN 3279. [Non disponible au moment de l'étude]

Vers 380.

TC 25. - Foyer F 2. Inv. PIN 3241. [Non disponible au moment de l'étude]

Vers 380.

TC 26. - Foyer F 10. Très fragmentaire. Inv. FR 3.65. Vers 380.
TC 27. - Découverte isolée dans la partie N.-O. de la zone fouillée. Long. du fragment principal $9 \mathrm{~cm}$. Sans numéro d'inventaire. Pl. 123d

\section{Tuiles timbrées}

\subsection{Marque A, sans cadre, hastes écartées ${ }^{318}$ :}

TT 1. - Découverte isolée.

\subsection{Marque AI, sans cadre ${ }^{319}$ :}

TT 2. - Tombe SP 346, deux exemplaires. Inv. PIN 3848 .

La tombe est datée vers le milieu du III ${ }^{\mathrm{s}} \mathrm{s}$.

TT 3. - Tombe SP 347, trois exemplaires. Inv. PIN 3849a.

Même date.

\subsection{Marque HГ, sans cadre, rétrograde ${ }^{320}$ :}

TT 4. - Tombe SP 279, un exemplaire. PI. 124b

La tombe est datée à la fin du $\mathrm{IV}^{\mathrm{e}}$ ou au début du III $\mathrm{e}$.

\subsection{Marque HPA, sans cadre ${ }^{321}$ :}

TT 5. - Tombe SP 347, deux exemplaires. Inv. PIN 3849b.

Même date que TT 3.

\subsection{Marque $\Theta E O$, sans cadre, le $\mathrm{E}$ de plus grandes dimensions :}

TT 6. - Tombe SP 346, un exemplaire. Inv. PIN 3841. Même date que TT 2.

318 Dremsizova 1963b, p. $322 \mathrm{n}^{\text {os }} 1105-1106$, pl. 173 (début et $2^{\mathrm{e}}$ moitié du III' $\mathrm{e}$.) ; Panayotova et al. 2007, p. 365.

319 Même type à Apollonia : Dremsizova 1963b, p. 322 nos 1108 1116 , pl. 172 ( $3^{\mathrm{e}}$ quart ou $2^{\mathrm{e}}$ moitié du III $\mathrm{e}$ s.).

320 Elle n'est pas attestée dans Dremsizova 1963b.

321 Même type à Apollonia : Dremsizova 1963b, p. 322 nos $1117-$ 1118, pl. 173 (3 e $^{\mathrm{q} u a r t}$ du IV ${ }^{\mathrm{e}}$ s.) ; Ahmérov 1948, p. 164 fig. 5 ; Panayotova et al. 2006, p. 243. 


\subsection{Marque $\mathrm{ON} / \mathrm{A} \Sigma$, sur deux lignes, sans cadre :}

TT 7. - Découverte isolée, fragmentaire $(10 \times 9 \mathrm{~cm})$. Pl. 124a

\subsection{Marque $\Pi O \Sigma I$, sans cadre ${ }^{322}$ :}

TT 8. - Tombe SP 362, un exemplaire. Inv. PIN 4028. Pl. 50d et 124c

Phase 4 de la nécropole (III ${ }^{\mathrm{e}} \mathrm{s}$.).

On mentionnera aussi un graffito ayant à peu près la forme du symbole dièse (\#), gravé sur une tuile de la tombe SP 344. Inv. PIN 3840.

Une partie des tuiles plates utilisées dans la nécropole d'Apollonia portent la lettre A en positif, d'autres le timbre HPA : dans l'un des cas, les lettres $\mathrm{H}$ et $\mathrm{P}$ sont ligaturées. D'Atya provient un fragment de brique avec le même timbre, mais avec une légère différence dans la hauteur des lettres (Detchev 1932-1934, p. 51, 9, fig. 30). R. Ahmérov complète le nom d'un timbre analogue, trouvé en Chersonnèse Taurique, en HPA[K $\Lambda \mathrm{EY}]$, mais d'après Tz. Dremsizova (1963b, p. 323), il est plus vraisemblable que HPA soit l'abréviation du nom Hérakleidès, attesté dans des inscriptions d'Apollonia.

\section{Objets en métal}

\subsection{Bague}

M 1. - Découverte isolée dans l'US 216, entre les tombes SP 328 et SP 345, niveau 4,45. Ht $2 \mathrm{~cm}$, larg. 2,2 cm. Inv. PIN 4163. Pl. 126a

Bague en bronze, avec un chaton ovale sur lequel est gravé en creux un motif difficile à interpréter, probablement un animal.

Cet objet se trouvait dans une couche de sable antérieure aux aménagements de la phase $2:$ il date donc au plus tôt du tout début du IV ${ }^{\mathrm{e}} \mathrm{s}$.

\subsection{Bracelet}

M 2. - Tombe d'enfant SP 296 (trouvé au-dessus de la cheville gauche). Diam. 6,1 et $5,2 \mathrm{~cm}$; section $0,5 \mathrm{~cm}$. Inv. PIN 3231. Pl. 25c, 125a et 126c

Bracelet en bronze, ouvert, de section circulaire légèrement épaissie au milieu, se terminant par des têtes de

322 Voir Dremsizova 1963b, p. 322 n 1131, pl. 172, tombe datée du III $\mathrm{s}$. serpent stylisées (en forme de losange irrégulier) ; la partie inférieure est plate, le sommet décoré de hachures qui représentent les détails anatomiques de l'animal.

La tombe n'est pas datée de façon précise (deuxième moitié du $\mathrm{IV}^{\mathrm{e}}$ ou première moitié du $\mathrm{III}^{\mathrm{e}} \mathrm{s}$.).

Les bracelets ouverts à têtes de serpent stylisées sont attestés en Thrace à l'époque classique et au début de l'époque hellénistique. Un exemplaire a été découvert dans la nécropole du « réservoir Batak» (Tsontchev, Miltchev 1970, p. 153 fig. 3 : VI $\mathrm{V}^{\mathrm{e}} \mathrm{V}^{\mathrm{e}}$ s.), un autre provient d'une fosse rituelle du sanctuaire thrace du village de Malko Tranovo, près de Tchirpan (matériel inédit des $\mathrm{V}^{\mathrm{e}}-\mathrm{IV}^{\mathrm{e}} \mathrm{s}$., fouilles de $\mathrm{M}$. Tonkova ); un bracelet en argent avec une représentation plus sommaire d'une tête de serpent a été mis au jour dans le tumulus $\mathrm{V}$, tombe 4, de la nécropole de Kabilé, daté du début du III ${ }^{\mathrm{e}} \mathrm{s}$. (Getov 1991, p. 173 fig. 49).

D'autres bracelets ouverts arrondis, en argent, en bronze ou en fer, ont été découverts dans les nécropoles d'Apollonia et de Mesambria. Ils proviennent de tombes de femmes ou d'enfants, et le défunt en portait parfois de deux à quatre. Certains sont simplement faits d'un fil métallique arrondi, leurs extrémités se croisent et s'enroulent en forme de spirale. Les bracelets en argent les plus anciens proviennent de tombes d'Apollonia datées du troisième quart du $\mathrm{V}^{\mathrm{e}} \mathrm{s}$. : ils sont en forme d'anneaux ouverts dont les extrémités se terminent par une boule à extrémité conique, avec des rainures ou des têtes de serpents schématisées (Mladenova 1963b, p. 297-299, fig. 106, pl. 160).

La présence de bracelets dans les tombes d'enfants est fréquente dans d'autres nécropoles grecques d'époque classique $^{323}$. Ils ne constituent pas un critère d'identification sexuelle déterminant.

\subsection{Boucles d'oreilles}

M 3. - Tombe d'enfant SP 320 (trouvée sous le crâne). Inv. PIN 3701.

Boucle d'oreille en argent, fragmentaire.

La tombe appartient à la phase 3 (du deuxième quart à la fin du $\mathrm{IV}^{\mathrm{e}} \mathrm{s}$.).

M 4. - Tombe à tuiles SP 346. Inv. PIN 3847. Pl. 125b

Boucle d'oreille en bronze fragmentaire, les extrémités manquent. Probablement ouverte, elle est faite d'un fil métallique arrondi, avec un épaississement central résultant de l'enroulement de la tige.

323 Pour Olynthe, voir Robinson 1942, tombes 177, 191 (trois exemplaires), 200, 203, 248, 254, 266, 267, 301, 363, 576. 
Le contexte indique une date vers le milieu du III ${ }^{\mathrm{e}} \mathrm{s}$.

M 5. - Tombe d'enfant SP 375 (trouvée contre la tempe gauche). Long. 2,7 cm. Inv. PIN 4111. Pl. 126b

Boucle d'oreille en bronze, en spirale, de section circulaire ; à chaque extrémité un ornement conique surmonté d'un bouton.

La tombe est datée vers 380 .

Ce type est bien représenté dans le monde grec ${ }^{324}$.

La majorité des boucles d'oreilles en bronze découvertes dans la nécropole d'Apollonia sont fabriquées très simplement, au moyen d'une tige métallique arrondie, formant un anneau ouvert qui s'épaissit au milieu ou à une des extrémités. Curieusement, les exemplaires trouvés dans nos fouilles ne vont pas par paire, comme on l'attendrait pour des boucles d'oreilles. L'identification des objets paraît cependant assurée, même pour la boucle en spirale $M 5$, qui pourrait faire penser aussi à un anneau de cheveux : cependant, l'emplacement de l'objet, contre la tempe gauche et les nombreuses comparaisons dont on dispose ne laissent guère de doute sur sa fonction (voir Williams, Ogden 1994, p. 34 fig. 30 et $\left.\mathrm{n}^{\text {os }} 5,47,171-174\right)$. Les tombes d'enfants de la nécropole d'Olynthe ont livré un nombre assez important de boucles d'oreilles, le plus souvent au nombre de deux ${ }^{325}$, mais il y en avait trois dans la tombe 108 et une seule dans les tombes 370 et 597 (Robinson 1942, p. 24, 78 et 117); dans la tombe 563 une boucle était en place à hauteur du lobe de l'oreille droite, une autre était posée sur l'épaule droite (ibid., p. 110).

Dans le monde grec les boucles d'oreille sont presque nécessairement associées, à l'époque classique, à des personnages de sexe féminin ${ }^{326}$ : les défunts des tombes 320 et 375 sont donc selon toute vraisemblance des petites filles.

\subsection{Fibules}

M 6. - Tombe SP 244. Bronze. Inv. PIN 2732. La tombe est datée du deuxième quart du $\mathrm{IV}^{\mathrm{e}} \mathrm{s}$.

M 7. - Tombe SP 265. Bronze. Inv. FR 1.6.3. Pl. 126e La tombe est datée vers 350-340.

324 Voir Mladenova 1963b, p. 294-297, fig. 105 n 299 (fin III ${ }^{-}-$ début II $\mathrm{e}$ s.) ; Robinson 1941, p. 83-85, n 286-295, pl. XVII (fin du $\mathrm{V}^{\mathrm{e}}$ s.) ; Coldstream 1973, p. 138-139, ${ }^{\circ}$ 59, fig. 31, pl. 87 (milieu du $\mathrm{I}^{\text {er }}$ s. av. J.-C.) ; Solovyov 2003, p. 103, fig. 248 (pendentif en bronze, $2^{\mathrm{e}}$ moitié $\mathrm{du} \mathrm{V}^{\mathrm{e}} \mathrm{s}$.).

325 Robinson 1942, p. 32 (tombe 150), 43 (tombe 203), 49 (tombe 239), 57 (tombe 267), 77 (tombe 366).

326 Voir Hermary, Markou, 2003. Les hommes qui les portent sont des Orientaux ou des personnages de sexe ambigu, comme Eros.
M 8. - Tombe SP 332. Fer, fortement corrodée. Ht 2,8 cm, long. cons. 7,5 cm. Inv. FR 2.29.20. Pl. 126d

La tombe est datée vers le milieu du $\mathrm{IV}^{\mathrm{e}} \mathrm{s}$.

M 9. - Tombe d'enfant SP 339. Bronze. Deux fragments, long. 1,2 et $2,2 \mathrm{~cm}$. Inv. FR 2.5.10 et 2.5.15.

La tombe est datée vers 380 .

Ces fibules, d'un type attesté à Apollonia (Venedikov 1963b, p. 313-315, fig. 108 ; Panoyotova, Nedev, Hermary 2003, p. 106), proviennent de tombes de femmes (SP 244 et 265 : avec une aiguille), d'un homme âgé (SP 332) et d'un enfant (SP 339). Considérées traditionnellement comme un élément du vêtement féminin, elles étaient essentiellement portées sur l'épaule par les habitants d'Apollonia au IV ${ }^{\mathrm{e}} \mathrm{s}$. Comme celles des nécropoles d'Apollonia, les fibules trouvées à Mesambria (Galabov 1955, p. 134, 144-145, tombe 10/50) et Odessos (Tonceva 1956, p. 51) sont du type dit thrace. Elles sont réalisées en bronze ou en fer, l'enroulement et l'ardillon sont tournés vers le haut.

\subsection{Couronne funéraire}

M 10. - Tombe SP 346. Inv. PIN 3843. PI. 47c

Couronne en plomb, bronze et argile. Sur un bandeau en plomb (détérioré) sont accrochées par des fils en bronze des feuilles en bronze doré, probablement des feuilles d'olivier. Cette couronne comportait aussi des fleurs et des fruits : les fleurs à six pétales, en argile, portent un décor polychrome (deux feuilles bleues, deux rouges, deux de couleur argile; le bouton central est doré) ; les fruits sont disposés en grappes de trois, alternativement rouges et dorés. Comparer un exemplaire de la nécropole d'Apollonia, daté de la deuxième moitié du III s. (Mladenova 1963a, p. 290, pl. 156 n 881).

La couronne funéraire de la tombe SP 346 était posée sur la tête d'une femme encore jeune, décédée vers le milieu du $\mathrm{III}^{\mathrm{e}} \mathrm{s}$. Une autre femme, enterrée au début de l'époque hellénistique dans le dromos du tumulus du site de Mapité, portait probablement une couronne avec des feuilles en bronze doré, des fruits et des fleurs en argile doré. Le squelette d'un homme, dans la chambre funéraire du même tumulus, portait une couronne circulaire en bois avec des feuilles dorées (Seure 1924, p. 335-336). Il est intéressant de noter qu'aucune des 25 couronnes funéraires de la nécropole d'Apollonia déjà publiées n'est clairement liée à une tombe féminine : deux des tombes qui contenaient ce type de couronne abritaient des enfants (687 et 694) et le mobilier de six autres comportait un strigile $(667,690,695,708,703,715)$; dans la tombe 733 se trouvait un couteau en fer. 
Dans les tombes à inhumation de la nécropole d'Apollonia ces couronnes étaient posées sur le crâne (Venedikov 1963a, tombes 20, 667, 671, 704). Dans la tombe à crémation du Jardin maritime de Sozopol on a constaté que le défunt avait été brûlé sur place avec sa couronne (Venedikov 1963a, tombe 715). À Kalfata, les couronnes en argile et en bronze doré sont attestées à la fin du $\mathrm{IV}^{\mathrm{e}}$ et au $\mathrm{III}^{\mathrm{e}}$ s., plus tardivement que les couronnes en or. Dans la nécropole du Jardin maritime, ce type apparaît à la fin du $\mathrm{III}^{\mathrm{e}}$ et dans la première moitié du II ${ }^{\mathrm{e}}$ s. (Mladenova 1963a, p. 289).

La coutume de déposer dans les tombes des couronnes en bronze et en argile doré est attestée en Thrace (Georguieva 1999, p. 219), en Grèce et dans les colonies grecques de Méditerranée et de mer Noire ; elles souvent associées à un riche mobilier ou à des monnaies ${ }^{327}$. Dans la nécropole de Thasos, des couronnes et des tiares dorées sont caractéristiques des tombes masculines des $\mathrm{IV}^{\mathrm{e}}-\mathrm{II}^{\mathrm{e}}$ s. av. J.-C. (Koukouli-Chrysanthaki, Sgourou, Agelarakis 1996, p. 790).

Aristophane voit dans la couronne funéraire le prix que reçoit l'homme à la fin des épreuves de la vie, et d'après Lucien (Charon ou les observateurs, 22) la couronne funéraire de fleurs naturelles semble jouer le même rôle que les parfums. Les couronnes dorées représentent probablement une variante, plus chère et plus durable, des couronnes de fleurs naturelles et des branches que l'on déposait traditionnellement pour les morts. En Thrace, les couronnes et les diadèmes accompagnent surtout les inhumations d'hommes et semblent avoir une signification complexe. La couronne est considérée comme un symbole de pouvoir ou d'immortalité, mais sa déposition sur la tête du défunt est plutôt liée à une héroïsation qu'à une investiture royale (Georguieva 1999, p. 220).

\subsection{Miroirs}

M 11. - Tombe SP 272. Diam. 10,2 cm. Inv. FR 1.52. Pl. 20e et 127a

Miroir circulaire en bronze, disque sans décor. La femme, âgée de 25 à 35 ans environ, le tenait dans sa main droite.

La tombe est datée vers le milieu du IVe $\mathrm{s}$.

M 12. - Tombe à ciste SP 289 (trouvé sous le crâne). Diam. 9,4 cm, épaisseur 0,2 cm. Inv. PIN 3152. Pl. 23d, $125 \mathrm{c}$ et $127 \mathrm{c}$

327 Hempel 2001, pl. 19, 25, n 7 ; Vermeule 1981, p. 15 ; Ori Taranto 1984-1985, p. 71-101, fig. 16, 19 ; Zavatin-Coman 1972, p. 271 ; Prouchevskaia 1955, p. 349 fig. 36.
Miroir circulaire en bronze. Disque très fin légèrement convexe, irrégulier sur le rebord, légèrement recourbé ; sans décor.

La tombe est datée vers la fin du $\mathrm{IV}^{\mathrm{e}}$ ou le début $\mathrm{du} \mathrm{III}^{\mathrm{e}} \mathrm{s}$.

M 13. - Tombe SP 340. Diam. $10,3 \mathrm{~cm}$, épaisseur avec le rebord $0,3 \mathrm{~cm}$, sans le rebord $0,2 \mathrm{~cm}$. Inv. PIN 3801. Pl. 125d et 127d

Miroir circulaire en bronze. Disque sans décor, rebord recourbé d'un côté avec une tache ronde qui atteste la présence d'un manche. Près de cet objet a été découverte une « punaise » en bronze, recourbée à angle droit, de section circulaire (diam. de la tête 1 à $0,8 \mathrm{~cm}$, longueur 1,8 , ép. $0,2 \mathrm{~cm}$ ), qui devait servir à fixer le manche en matériau périssable.

La tombe est datée vers 360-350.

M 14. - Foyer F 5. Diam. 10,3 cm. Inv. PIN 3668g. Pl. 127b

Miroir circulaire en bronze. Disque sans décor, un fragment manque.

Le foyer est daté vers 390-380.

Ce type de miroir sans décor est attesté aussi bien à Apollonia (Venedikov 1963b, p. 320 nos 1100-1101, pl. 171 : milieu du IV ${ }^{\mathrm{e}} \mathrm{s}$.) qu'à Seuthopolis, dans l'intérieur de la Thrace (Ognenova-Marinova 1984, p. 182, fig. $11: 2^{\mathrm{e}}$ moitié du $\mathrm{IV}^{\mathrm{e}}$ ou début du $\mathrm{III}^{\mathrm{e}} \mathrm{s}$.), que sur d'autres sites grecs (pour Métaponte, voir Carter 1998, p. 788, type 2 : vers 325-275). Les quatre exemplaires présentés ici sont constitués de minces disques en bronze, avec ou sans rebord recourbé d'un côté, légèrement convexes de l'autre côté. Trois d'entre eux proviennent de tombes féminines datées entre le milieu du IVe et le milieu du III ${ }^{\text {e }}$ s., le quatrième d'un foyer un peu plus ancien. Au milieu du disque du miroir de la tombe SP 340 on note un léger épaississement et des traces de soudure, probablement pour fixer un manche. Le miroir de la tombe SP 289 est plus fin et ne possède pas de rebord très prononcé, ses bords sont irréguliers. Il est possible qu'il ait été placé dans un cadre en matériau périssable qui devait cacher les irrégularités.

Les parallèles les plus proches pour ce type de miroir sont, en Thrace, des exemplaires trouvés dans un tumulus près du village de Iankovo, dans la région de Shoumen (tumulus I, t. 1 et 3), daté du IV e s. ${ }^{328}$ : Comme à Apollonia, les manches sont absents. Des miroirs à

328 Dremsizova 1955 , p. 68-70. Dans cette région du N.-E. de la Bulgarie ont été mises au jour des monnaies d'Apollonia, qui témoignent d'échanges économiques entre la population locale et les colons grecs. 
rebord avec manche soudé au milieu de la face arrière étaient fréquemment utilisés par les Scythes au $\mathrm{VI}^{\mathrm{e}} \mathrm{s}$. (Kouznetsova 1987, p. 36 ; Kaminsky 1987, p. 255). Un miroir similaire, avec manche en fer à section rectangulaire, collé à l'arrière, a été découvert lors des fouilles de la nécropole d'Apollonia en 1946 (Venedikov 1948, p. 15).

Les disques en bronze plus simples, sans traces de manche ou de soudure, sont caractéristiques de l'époque hellénistique (Georguieva 1992, p. 74). On les trouve dans la nécropole de Tomis, aux $\mathrm{III}^{\mathrm{e}}-\mathrm{II}^{\mathrm{e}} \mathrm{s}$. av. J.-C. (Bucovalà 1967, p. 170, fig. 44, p. 94, fig. 59, et p. 97, fig. 60), ainsi qu'au Nord de la mer Noire. Ce type de miroir remplace les autres à la fin du $\mathrm{IV}^{\mathrm{e}}$ ou au début du $\mathrm{III}^{\mathrm{e}}$ s., et reste le seul en usage jusqu'au début de l'époque romaine.

Les miroirs de la nécropole de Métaponte sont classés en cinq types, dont le deuxième se caractérise par l'absence de manche : il s'agit d'un disque épais, plus grand que celui du type 1 («pocket mirrors », d'un diamètre d'environ $5 \mathrm{~cm}$ seulement), avec un rebord du côté concave et des cercles concentriques de l'autre. Ces miroirs ont été déposés dans des tombes datées entre 325 et 275 environ. Le même type est attesté sur de nombreux sites de Grèce dès le milieu du VIII ${ }^{\mathrm{e}} \mathrm{s}$., mais on le trouve le plus souvent dans des contextes datés entre le début du $\mathrm{IV}^{\mathrm{e}} \mathrm{s}$. et la fin de l'époque hellénistique (Carter 1998, p. 788). Les miroirs en bronze de la nécropole d'Apollonia se présentent également, le plus souvent, sous la forme d'un disque sans décor avec, dans de rares cas, un manche en bronze, parfois décoré de volutes. Leur emplacement dans la tombe, où ils peuvent être au nombre de deux, ne semble pas régulier (Venedikov 1948 , t. 35 et 39 , fig. $16 ; 1963 a$, t. $378 ; 1963 b$, nos $1100-$ 1101 ; Panayotova 2007, p. 102), bien qu'on les trouve le plus souvent à droite du crâne ou à côté de la main ${ }^{329}$. De ce point de vue, le miroir de la tombe SP 272 est particulièrement intéressant, puisqu'il était placé dans la main droite de la femme : il n'avait visiblement pas de manche, mais il est possible que les «boutons » en os trouvés à proximité aient appartenu à un cadre en cuir ou en bois qui se serait désintégré.

Il n'est pas surprenant que les trois tombes qui ont livré les exemplaires ci-dessus soient féminines: en Grèce, les miroirs et les récipients de toilette sont, traditionnellement, des objets appartenant au mobilier funéraire féminin (Kurtz, Boardman 1971, p. 208, et cidessus, p. 168).

329 Noter la position curieuse d'un miroir dont le manche en fer était planté dans le sol (Venedikov 1948, p. 15, t. 23, fig. 16).

\subsection{Pyxis}

M 15. - Tombe à ciste SP 328 (femme de plus de 45 ans). Ht $2 \mathrm{~cm}$, diam. $4,5 \mathrm{~cm}$; couvercle, ht $1 \mathrm{~cm}$, diam. 4,8 cm. Inv. PIN 3650 . Pl. 34d et 128a

Petite boîte cylindrique en bronze avec son couvercle. Le bouton de préhension, probablement en bois, a disparu.

La tombe est datée vers 360-350.

Cette pyxis est comparable à un exemplaire trouvé à Apollonia, dans la tombe 19 de la parcelle 5083 (inv. 100). Elle accompagnait également une femme âgée de plus de 45 ans, inhumée probablement vers 340330. Ce type d'objet est relativement fréquent dans les nécropoles grecques.

\subsection{Strigiles (tous en bronze)}

M 16. - Tombe SP 265 (sujet probablement féminin, de plus de 45 ans). Long. conservée $8,4 \mathrm{~cm}$. Inv. FR 1.6.4. Pl. 19e

Reste seulement la moitié de la lame; la torsion visible près de la cassure paraît intentionnelle.

La tombe est datée du troisième quart du $\mathrm{IV}^{\mathrm{e}} \mathrm{s}$.

M 17. - Tombe SP 291 (homme de 21 à 35 ans, trouvé près du bassin, très fragmentaire). Inv. PIN 3174.

La tombe est datée vers 390-380.

M 18. - Tombe à ciste SP 300 (trouvé sous la mâchoire, fragmentaire). Inv. PIN 3271. Pl. 27c

Forme massive allongée, lame en faucille, manche épais de section rectangulaire.

La tombe est datée vers 390-380.

M 19. - Tombe SP 313 (enfant de 5 à 10 ans, trouvé au-dessus du pied droit). Inv. PIN 3605.

Très fragmentaire, lame en faucille.

La tombe est datée vers 430-420.

M 20. - Tombe SP 334 (homme de 15 à 20 ans). Inv. PIN 3769. Pl. 39c

Fragmentaire, courbure courte et section semi-circulaire. L'attache est étroite ; manche plat, l'extrémité se termine par un talon foliacé.

La tombe est datée vers 390-380.

M 21. - Tombe à ciste SP 339 (enfant de sept ou huit ans), fragmentaire. Inv. FR 2.5.17. Pl. 42e

La tombe est datée vers 380 . 
M 22. - Foyer F 11. Très fragmentaire. Inv. FR 2.5.6. Le foyer est daté vers 380-370.

M 23. - Dépôt DP 23. Brisé en deux fragments. Long. des fragments $11,5 \mathrm{~cm}$ et $6,5 \mathrm{~cm}$. Inv. FR 1.6.5. PI. 128c

L'essentiel du dépôt date d'environ 340-320.

Les huit strigiles en bronze répertoriés ici ${ }^{330}$, entiers ou fragmentaires, sont du même type, réalisés dans une fine tôle de bronze, avec une lame longue et étroite en forme de faucille (comparer Venedikov 1963b, p. 315317, pl. 170, et, pour Métaponte, Carter 1998, p. 797). L'extrémité du manche est ovale ou foliacée (pointue). Ce type est en usage à Apollonia aux $\mathrm{V}^{\mathrm{e}}$ et $\mathrm{IV}^{\mathrm{e}} \mathrm{s}$.

Le fait que l'on trouve principalement des strigiles dans des tombes masculines et que la plupart des représentations les associent à des athlètes a fait penser qu'il s'agissait d'un objet essentiellement masculin. Leur découverte à Apollonia, Comme sur d'autres sites (Robinson 1941, p. 172), dans des tombes d'enfants ou de femmes impose de reconsidérer la question de leur usage et de leur place dans les rites funéraires. Ainsi, un strigile en bronze faisait partie du mobilier funéraire d'une femme enterrée sous un tumulus près d'Anchialos : il paraît associé à des produits cosmétiques; il est daté par P. Balabanov (1979, p. 23-32) de la fin du I ${ }^{\mathrm{er}} \mathrm{s}$. av. ou du début du ${ }^{\text {er }}$ s. ap. J.-C. Les femmes ont sans doute principalement utilisé des strigiles pour gratter leur crème épilatoire (psilothrum) (Vagalinski 1993, p. 22). Pour ce qui concerne les exemplaires M 19 et M 21, on a tendance à penser que les défunts sont de jeunes garçons auprès de qui on a déposé un objet caractéristique des activités qui leur étaient promises au gymnase, mais les remarques précédentes montrent qu'il faut rester prudent (voir ci-dessus, p. 168) ${ }^{331}$.

Les habitants d'Apollonia Commencent à déposer des strigiles en bronze dans la nécropole de Kalfata à partir de la deuxième moitié $\mathrm{du} \mathrm{V}^{\mathrm{e}} \mathrm{s}$., comme offrandes funéraires ou lors de cérémonies postérieures à l'enterrement. Au cours de l'époque hellénistique, à Apollonia (Venedikov 1963b, p. 315-317, pl. 170-171) comme à Mesambria, Odessos (Tonceva 1974, p. 288 ; Škorpil 1930-31, p. 69-76) et Bizoné (Salkin 1989, p. 10, fig. 1 et 7), on dépose des strigiles en fer dans les tombes à inhumation et à crémation. La majorité des strigiles découverts dans la nécropole de Mesambria étaient mal conservés, parfois sous la forme de simples fragments

330 Ajouter le strigile fragmentaire trouvé entre les tombes SP 339 et 342 (Inv. PIN 3646). Pl. 128b

331 On note cependant que, dans les tombes d'enfants d'Olynthe, les boucles d'oreille - objet féminin, voir ci-dessus - ne sont jamais associées à des strigiles.
(Galabov 1955, t. 4/50, 12/52, 13/52, 19/52 ; Čimbuleva 1969, p. 173-174, et 2005, p. 97-98, 103, 105-107 ; Petrov, Čimbuleva, 1963, p. 25). Les fragments de strigiles en fer trouvés dans des tombes construites de la nécropole de Callatis appartenaient, d'après K. Preda, à des objets cassés rituellement (Preda 1961, p. 290).

\subsection{Aiguilles (toutes en bronze)}

M 24. - Tombe SP 265 (femme de plus de 45 ans). Deux fragments, long. conservée 7,6 cm. Inv. FR 1.6.7.

M25. - Tombe à ciste SP 289 (femme de plus de 50 ans) ; trouvée sous le miroir (sous le crâne). Inv. PIN 3153.

M 26. - Tombe d'enfant SP 296 (trouvée près du crâne). Inv. PIN 3230.

M 27. - Tombe SP 320 (enfant de 5 à 10 ans, trouvée sous l'épaule droite). Inv. PIN 3700.

M 28. - Tombe SP 327. Inv. PIN 3729.

M 29. - Tombe à ciste SP 328 (femme de plus de 45 ans). Long. $9,2 \mathrm{~cm}$. Inv. PIN 3651 . Pl. 128d (en haut) Aiguille à chas, en deux fragments.

M 30. - Tombe SP 329. Deux fragments, long. cons. 5,2 et $2,1 \mathrm{~cm}$. Inv. PIN 3645 .

Aiguille à chas.

M 31. - Tombe SP 336. Inv. PIN 3773.

M 32. - Tombe SP 340 (femme adulte). Inv. PIN 3788.

M 33. - Tombe à tuile SP 362 (homme de plus de 45 ans). Long. cons. $3,8 \mathrm{~cm}$. Inv. PIN 4032. Pl. 128d (en bas)

Deux fragments d'une aiguille à chas.

M 34. - Tombe SP 370 (enfant d'environ 3 ans, trouvée près de l'épaule gauche). Long. cons. $7,1 \mathrm{~cm}$. Inv. PIN 4104. Pl. 128d (au centre)

M 35. - Dépôt D 22. Quatre fragments, l'extrémité du chas manque. Long. cons. 8,1 cm. Inv. FR 1.6.2.

Les douze aiguilles à coudre découvertes dans cette zone de la nécropole ${ }^{332}$ sont faites d'un fil de bronze

332 Ajouter un fragment isolé découvert près du point I 6 (Inv. PIN 3809). Voir les catalogues de la deuxième partie pour les contextes chronologiques. 
arrondi à l'extrémité. Elles diffèrent en fonction de la forme du chas, qui peut être allongé et arrondi ou en forme de losange. La plupart d'entre elles proviennent de tombes de femmes âgées (SP 265, 289, 328, 336, 329 et 340) et d'enfants (SP 296, 320, 327, 370). Seule l'aiguille de la tombe SP 362 a été mise au jour près du fémur d'un homme âgé. Pour K. Panayotova, le lieu de leur découverte semble montrer que des aiguilles ont été utilisées pour maintenir le vêtement, le plus souvent sur l'épaule droite (SP 265, 320, 336, 340), parfois sur l'épaule gauche (SP 296, 328), Comme dans d'autres tombes d'Apollonia, où on les a découvertes en très grand nombre (Venedikov 1963b, p. 318 n $^{\circ}$ 1067-1085; Panayotova, Gyuzelev, Nedev 2008, p. 367): on les trouve en général à côté de la tête ou de l'épaule, surtout dans des tombes de femmes et d'enfants. Cette pratique débute au troisième quart du $\mathrm{V}^{\mathrm{e}} \mathrm{s}$. et continue jusqu'à la fin du III' $s$.

En Grèce les aiguilles en bronze ont un usage largement diffusé, sur une très longue période (voir par exemple Carter 1998, p. 808 ; Coldstream 1973, p. 151152, pl. 91), tandis que les aiguilles en fer sont très peu nombreuses et celles en argent et en or exceptionnellement attestées dans le mobilier funéraire (Jacobsthal 1956, p. 87-89 et, pour Salamine de Chypre, ci-dessus, p. 169). En général, on trouve dans les tombes féminines une aiguille sur le thorax et une sur chaque épaule, et dans les tombes masculines une seule aiguille. Elles étaient utilisées à la fois pour attacher le vêtement et pour fixer divers éléments complémentaires : voile, chapeau ou le linceul dans lequel était enveloppé le défunt (Gansisniec 1978, p. 68-69 ; sur ce dernier point, voir ci-dessus, p. 166-167).

Les aiguilles à coudre et les fibules sont considérées Comme des attributs féminins. Nous ne pouvons, bien sûr, pas déterminer si le défunt portait ses propres vêtements ou si l'on a utilisé une pièce d'étoffe spéciale pour le couvrir, qui pouvait être la même pour les hommes et les femmes. Les résultats des recherches dans la nécropole de Pantanello montrent que les aiguilles et les fibules sont principalement associées à des femmes âgées, quel que soit leur vêtement. Les modes d'attache des vêtements sont difficiles à étudier d'après la peinture sur vase, mais nous disposons cependant de quelques images montrant l'usage des fibules, par exemple pour Dionysos (Prohaszka 1995, p. 184).

\subsection{Monnaies en bronze}

M 36. - Tombe SP 340 (femme adulte), datée vers 360-350. Inv. PIN 3792. Illisible.
M 37. - Tombe SP 342 (femme adulte, placée dans la bouche), datée vers 340. Inv. PIN 3667. Pl. 129a

Monnaie d'Apollonia: Av, Tête d'Apollon. Rv, Ancre inversée, légende AP (?).

M 38. - Tombe à tuiles SP 346 (vers le milieu du III ${ }^{\mathrm{e}}$ s.). Inv. PIN 3842. Pl. 47b

Monnaie d'Apollonia (ancre au revers).

M 39. - Tombe à tuile SP 347 (vers le milieu du III s.). Inv. PIN 3851.

Monnaie d'Apollonia: Av, Tête d'Apollon. Rv, Ancre inversée.

M 40. - Découverte isolée près du point H 3. Inv. PIN 3627.

Monnaie d'Apollonia.

Ces monnaies, découvertes dans quatre tombes et un foyer, sont toutes en bronze ${ }^{333}$. Elles sont en très mauvais état de conservation, les motifs sont très effacés. Quatre d'entre elles appartiennent au monnayage d'Apollonia. Il est intéressant de remarquer que, dans les tombes, elles étaient associées à des femmes âgées, dont l'une avait plus de 50 ans (voir aussi ci-dessus, p. 147, fig. 53).

La découverte de monnaies dans les tombes est traditionnellement interprétée comme une taxe de passage pour Charon. On ignore quand et dans quel endroit en Grèce est née l'idée qu'il fallait payer Charon pour le transport des âmes des morts. Dans les textes anciens, «l'obole de Charon» est mentionnée pour la première fois chez Aristophane, en 405 av. J.-C., dans les Grenouilles : Dionysos, accompagné par son esclave, en route vers l'au-delà, doit payer deux oboles. Les monnaies en bronze - plus rarement en argent - découvertes dans les nécropoles d'Apollonia témoignent que les habitants de cette colonie grecque pratiquaient le rite de déposer dans la tombe une obole pour Charon, à partir du milieu du IV ${ }^{\mathrm{e}} \mathrm{s}$. d'après la documentation disponible. Les monnaies émises à Apollonia sont majoritaires, mais on trouve également des monnaies provenant des villes de la Propontide, de certaines îles de la Méditerranée et de quelques villes d'Asie Mineure (Gerasimov 1963, p. 331-340). Le plus souvent une seule monnaie était placée dans la bouche du défunt, mais on en trouve parfois deux, trois, ou plus : dans une tombe d'Apollonia, 51 monnaies ont été découvertes entre les os du bassin du défunt, qui étaient probablement rassemblées dans un petit sac. On considère que la quantité des monnaies déposées indique différentes pratiques : quand elles sont

333 Pour d'autres découvertes dans la nécropole de Kalfata, voir Gerasimov 1963, p. 331-337, pl. 180. 
très nombreuses, elles n'étaient pas destinées à Charon, mais constituaient plutôt une offrande ou un pécule pour le défunt dans l'au-delà (Grinder-Hansen 1991, p. 215).

Onze monnaies en argent proviennent d'une autre tombe d'Apollonia, avec sept en bronze et une pointe de flèche à trois barbelures. D'après T. Gerasimov, les pointes de flèche de ce type avaient à cette époque une valeur monétaire : elles auraient été déposées pour cette raison dans les tombes avec des monnaies (Gerasimov 1963, p. 333). Quatre pointes de flèche de ce type ont été découvertes dans une tombe à tuiles située sur la péninsule d'Atyia (Pandaleev 1928-29, p. 328). Les deux derniers exemples montrent que, même après la mise en place d'un monnayage par les villes de la côte occidentale de la mer Noire, les pointes de flèche en bronze continuent à être utilisées, plutôt comme l'équivalent de l'obole à Charon que comme une monnaie d'échange.

\subsection{Clous ${ }^{334}$}

\subsubsection{En fer, trouvés au niveau du squelette}

M 41. - Tombe SP 251, deux exemplaires. Inv. PIN 2718.

M 42. - Tombe SP 265 (femme de plus de 45 ans), fragmentaire, très corrodé. Inv. FR 1.5.3. Pl. 19e

M 43. - Tombe SP 279 (femme de plus de 45 ans), deux exemplaires, long. 8,6 et 10,3 cm. Inv. FR 1.5 .2 et 1.5.4.

M 44. - Tombe SP 283 (enfant de 5 à 9 ans), un exemplaire. Inv. FR 1.5.6.

M 45. - Tombe SP 289 (femme de 21 à 35 ans). Inv. PIN 3159.

M 46. - Tombe SP 296 (enfant, trouvé au-dessus du genou gauche). Inv. PIN 3229.

M 47. - Tombe SP 313 (enfant). 13 clous en fer provenant d'un cercueil en bois. Inv. PIN 3606.

M 48. - Tombe à ciste SP 328 (femme de plus de 45 ans), très corrodé, avec des traces de bois. Long. 5,5 cm. Inv. PIN 2.29.5. Pl. 34e

M 49. - Tombe à tuile SP 346. Inv. PIN 3846.

334 Pour les contextes chronologiques voir les catalogues de la deuxième partie.

\subsubsection{En fer, trouvés en haut de la fosse}

M 50. - Tombe SP 337 (US 136), cinq exemplaires au moins, long. max. $13 \mathrm{~cm}$. Inv. PIN 3666. Pl. 40e

M 51. - Tombe SP 342 (US 150), cinq exemplaires au moins, long. max. 12,2 cm. Inv. PIN 3666. Pl. 45b

\subsubsection{En fer, autres contextes}

M 52. - Dépôt DP 24, deux exemplaires. Inv. FR 1.5.7.

M 53. - Dépôt DP 28, trois exemplaires. Long. cons. 6,5 et $3,1 \mathrm{~cm}$. Inv. FR 1.5.5.

M 54. - Dépôt DP 29, fragmentaire (long. cons. $6,2 \mathrm{~cm}$ ), corrodé. Inv. FR 1.5.1. Pl. 64c

M 55. - Foyer F 5. Cassé à chaque extrémité. Surface fortement corrodée. Long. 12,5 cm. Inv. PIN 3666 (FR 2.29.7) ${ }^{335}$. Pl. 71c

\subsubsection{Petits clous en bronze, de type punaises}

M 56. - Tombe SP 340 (femme adulte), trois exemplaires. Inv. PIN 3794.

Une partie des clous découverts dans les tombes ont probablement été utilisés pour clouer des sarcophages en bois. Dans la nécropole de Kalfata deux types de sarcophages sont utilisés simultanément : les uns construits par emboîtage, les autres cloués. Seule la tombe SP 313 donne l'exemple clair d'un sarcophage cloué, avec un couvercle. Il est possible que les sarcophages emboîtés aient été cloués à certains endroits, ce qui expliquerait la présence d'un ou deux clous dans le reste des tombes (voir ci-dessus, p. 140 et 167, pour d'autres hypothèses). D'après la forme du sarcophage et du couvercle on distinguera deux types :

- Coffre à paroi inclinée et couvercle à double pente.

- Coffre à couvercle plat (Venedikov 1963a, p. 9-10 ; Panayotova 1998b, p. 12 ; Panayotova 2001b, p. 100 ; Panayotova, Nedev, Hermary 2004, p. 153).

On utilisait parfois des agrafes en fer pour fixer les parois, à la place de clous. Aucun décor n'est attesté sur ces deux types de sarcophages, qui étaient probablement fabriqués sur place, peut-être par certains habitants pour leur usage personnel (Panayotova 2007, p. 93-94). L'usage de sarcophages en bois est diffusé dans tout le

335 Autres fragments, avec le même numéro d'inventaire, dans les US 147, 148 et 154. 
monde grec : il s'agit du larnax, simple coffre réalisé le plus souvent en chêne, en micocoulier, peuplier, tilleul, cèdre (le plus fréquent en Asie Mineure), cyprès ou if, l'arbre dit de la mort.

Les clous trouvés en place en haut de la fosse peuvent avoir servi à fixer une sorte de couvercle ou un marqueur de la sépulture (voir ci-dessus, p. 140 et 168).

\subsection{Bucrane en plomb}

M 57. - Trouvé le 16 août 2004 dans l'US 149, entre les murs MR 2 et MR 3. Ht 7,9 cm. Inv. PIN 4098.

Les bucranes en plomb ont probablement été utilisés par les habitants d'Apollonia comme des apotropaia. Vingt-sept objets de ce type, qui devaient être appliqués sur une plaquette ou un autre support, ont été mis au jour dans les nécropoles de Kalfata et du Jardin maritime ${ }^{336}$, mais ils ne paraissent pas attestés dans le reste du monde grec. La tête de taureau ajourée porte, sur son front, un masque de Gorgone ou une rosette (Panayotova 2001a, p. 63-66). Ces bucranes proviennent de tombes (posés sur le thorax des défunts), de remblais au-dessus des tombes, ou "d'espaces commémoratifs », sacrificiels, de la deuxième moitié du IV e et du III' ${ }^{\mathrm{e}} \mathrm{s}$. (Nedev, Panayotova 2003, p. 136, pl. 5, fig. 8a-b ).

\subsection{Autres objets métalliques}

M 58. - Trois pointes de flèches en bronze, tombe SP 340 (femme de 21 à 35 ans). a) Long. 3,7 cm, diam. 0,4 $\mathrm{cm}$; b) Long. 3,4 cm, diam. 0,5 cm ; c) Long. $2,3 \mathrm{~cm}$ (l'extrémité manque). Inv. PIN 3791. Pl. 43b et 125e

Pointes de flèches avec emmanchements de type scythe; sur l'une figure une ouverture dans la partie supérieure de l'emmanchement.

La tombe est datée vers 360-350.

Ce type de flèche est fréquent en Thrace et attesté en Grèce ${ }^{337}$.

M 59. - Clé en bronze. Tombe SP 340. Long. $11,1 \mathrm{~cm}$, Ht. 3,6 cm, Long. des dents $2 \mathrm{~cm}$, diam. de l'anneau $2,5 \mathrm{~cm}$. Inv. PIN 3799. Pl. 43b et $\mathbf{1 2 5 f}$

336 Voir Venedikov 1963b, p. 319-320, pl. 169, nos 1097-1099 (fin du IVe-début du III s.) ; Panayotova 2001a, p. 63-65 ; Konova 2002, p. 46-55 ; Wasowicz, Zdrojewska 1998 ; Cat. Bâle 2007, p. 155 $\mathrm{n}^{\circ} 114 \mathrm{~b}$ ( $2^{\mathrm{e}}$ moitié du IVe $\mathrm{s}$.).

337 Ognenova-Marinova 1984, p. 165, 183, fig. 13 (2e moitié du $\mathrm{IV}^{\mathrm{e}}$ ou début du III e s.) ; Melyukova 1964 (groupe 3) ; Mielczarek 1995, p. 60 fig. 17 ; Kitov, Dimitrova, Petrov 2007, p. 148-151, fig. 3 (pointe de flèche en bronze avec tige en bois conservée); Davidson 1952, p. $200, \mathrm{n}^{\circ} 1516$, pl. $91\left(\mathrm{IV}^{\mathrm{e}} \mathrm{s}\right.$.)
La tige de la clé a une section hexagonale, l'anneau une section quadrangulaire. L'extrémité servant à l'ouverture est courbée à angle droit, elle comporte trois éléments horizontaux.

Même date que M 58.

Le fait qu'une clé soit déposée dans une tombe est intéressant, même si on connaît des exemples comparables ${ }^{338}$, mais nous avons déjà noté que les offrandes déposées auprès de la défunte de la tombe SP 340 conféraient à cette femme un statut privilégié (voir ci-dessus, p. 169).

M 60. - Couteau en bronze, foyer F 6. Long. totale environ 15,8/16 cm, long. de la lame 11,6 cm (restituée), larg. max. de la lame $2,1 \mathrm{~cm}$, du manche $1,5 \mathrm{~cm}$. Inv. PIN 3817. Pl. 125g

La pointe est cassée, légère courbure à la jonction entre le manche et la lame. Le côté opposé à la lame est presque droit, légèrement recourbé vers la pointe ; la partie coupante est recourbée à l'avant, avec une extrémité pointue. À l'arrière, la base métallique du manche est découpée en V. Le manche, fixé en deux points, est en matériau périssable; il devait être épais d'un centimètre environ (cf. Ognenova-Marinova 1984, p. 166, 185, fig. 19-22 : Seuthopolis, deuxième moitié du IV $\mathrm{e} s$. ou début du $\mathrm{III}^{\mathrm{e}}$ ).

Le foyer est daté vers 380.

M 61. - Forces (ciseaux) en fer. Tombe SP 322. Inv. PIN 3702.

D'après le mobilier (guttus et astragales), on penserait plutôt à une tombe féminine, datée du milieu du $\mathrm{IV}^{\mathrm{e}} \mathrm{s}$. environ. Des forces de ce type (psalidion) sont attestées comme offrandes funéraires en Thrace, en Grèce et dans d'autres colonies grecques ${ }^{339}$. Elles sont considérées comme des objets féminins et sont décrites en tant que tels par Pollux $(10,126)$. On les trouve également dans des contextes celtiques en Europe centrale, et surtout en Italie, où elles sont datées vers 300 av. J.-C. Leur usage donne lieu à des interprétations différentes (voir Carter 1998, p. 818 n. 124) : elles auraient été utilisées soit pour tondre les moutons (Åström 1970, p. 13 fig. 1), soit comme des ciseaux pour couper les cheveux, comme le montre une terre cuite de Tanagra (voir ci-dessus, p. 170-171, avec d'autres références).

338 Ognenova-Marinova 1984, p. 166, 188, fig. 26 (2e moitié du IV ${ }^{\mathrm{e}}$ ou début du III' s.) ; Carter 1998, p. 817-819 n H 3 (type laconien). 339 Venedikov 1963b, p. 318 pl. $171 \mathrm{n}^{\text {os }} 1086-1087$ (Apollonia); Ognenova-Marinova 1984,p. 166, 186-187, fig. 23-24 (Seuthopolis); Prohaszka 1995, p. 137 fig. 30, pl. 40, A ; Carter 1998, p. 817-819, fig. 20, 19 (vers 400); Hempel 2001, p. 276, pl. 45. 
M 62. - Instrument en bronze très corrodé (non restauré), tombe SP 334. Long. 11,2 cm ; diam. max. env. 0,4 cm. Pointe cassée. Inv. PIN 3768. Pl. 39d

L'objet représente une tige en bronze de section presque circulaire, au milieu duquel se trouvent des stries encadrant sept petits anneaux en relief; elle est légèrement aplatie de ce côté, où est percé un trou. L'un des côtés était probablement inséré dans un manche en bois doté de bagues décoratives, qui facilitent la prise de l'instrument, probablement à fonction médicale (cf. Davidson 1952, p. 187 pl. 84 : Corinthe, fin de l'Antiquité).

La tombe est datée vers 390-380.

M 63. - Objet en fine tôle de bronze, tombe SP 340. Ht 1,2 cm, diam. max. 2,8 cm. Inv. PIN 3793.

Objet en tronc de cône, d'usage incertain. Deux couches de tôle, avec espace intermédiaire; le bord supérieur est créé par le pliage de la tôle (cf. Prohaszka 1995, p. 137 fig. 30, pl. 40 E H12, H13 : Métaponte, objets interprétés comme des entonnoirs).

M 64. - Cinq lamelles dont deux percées, tombe SP 340. 0,8 à $1 \mathrm{~cm}$. Inv. PIN 3794 et 3794a.

L'une d'entre elles est recourbée à angle droit.

M 65. - Lamelle percée en bronze. Foyer F 9. Long. 4 cm. Inv. PIN 4106.

M 66. - Crochet en bronze, tombe SP 315 (première moitié du III s.). Ht 4,1 cm. Inv. PIN 3623. Pl. 29b

Objet recourbé à angle droit, dont la partie la plus courte est de section circulaire, l'autre de section quadrangulaire avec une extrémité pointue.

M 67. - Poids de fuseau (?), tombe SP 315 . Ht $2,4 \mathrm{~cm}$, long. $3,7 \mathrm{~cm}$, diam. 1,5 cm. Inv. PIN 3622.

Forme conique trapue.

M 68. - Stylet en bronze. Foyer F 9 (vers 380). Long. 14 cm. Inv. PIN 4100. Pl. 129d

La forme de l'objet, pointu à une extrémité, aplati à l'autre, fait penser à un stylet; d'autres interprétations ne sont cependant pas exclues.

M 69. - Cône percé en bronze. Foyer F 9. Ht 2,6 cm. Inv. PIN 4107. Pl. 129c

\section{Objets divers}

\subsection{Objets en verre}

D 1. - Tombe d'enfant SP 327. Ht avec l'anneau $3,3 \mathrm{~cm}$. Inv. PIN 3737. Pl. 32d

Pendentif en verre opaque, de trois couleurs, en forme de tête d'homme barbu. La barbe et les cheveux sont bruns, le visage jaune, les yeux et les mèches frontales bleu foncé. Forme cylindrique, avec un anneau vertical. Les cheveux sont faits d'un boudin de verre torsadé sur le front, les sourcils ne sont pas indiqués. Le globe oculaire est de forme circulaire. Le nez est long et large, la narine gauche est ouverte. La bouche est située juste sous le nez, au-dessus de la barbe, qui n'est pas séparée des cheveux. L'oreille gauche est arrachée, la droite est en forme de losange.

La tombe est datée vers 370-350.

Les masques en verre de ce type apparaissent en Méditerranée au $\mathrm{V}^{\mathrm{e}} \mathrm{s}$. (ainsi à Al-Mina, sur la côte syrienne, et à Preddio Ibba en Sardaigne), ils sont encore bien attestés au $\mathrm{IV}^{\mathrm{e}} \mathrm{s}$. Au V $\mathrm{V}^{\mathrm{e}} \mathrm{s}$., de nombreux centres de production de ces pendentifs se trouvent en Phénicie, à Chypre et à Rhodes, mais au $\mathrm{IV}^{\mathrm{e}} \mathrm{s}$. Carthage est le principal lieu de production (Seefried 1982, p. 27-28 et 65). Notre exemplaire correspond au type C 1 de Seefried (1982, p. 7 et 27-28, pl. I : vers 450-300).

D'après F. J. Bliss et R. A. Macalister, qui ont trouvé un grand nombre de ces masques à Tell es Safi, ces pendentifs d'aspect grotesque avaient un usage apotropaïque. Picard et Jannoray sont du même avis et G. Pesce, dans son étude sur la magie en Sardaigne, propose de voir dans ces objets des amulettes plus que des ornements. Les visages de ces masques seraient «les yeux des anciens », ils auraient le pouvoir magique de protéger les morts contre les dangers auxquels ils sont exposés dans la tombe. D'après tous les auteurs, ces pendentifs sont supposés apporter un repos paisible aux défunts (voir la discussion dans Seefried 1982, p. 56-58).

D 2. - Tombe SP 340. Ht 0,8 et $0,9 \mathrm{~cm}$; diam. max. $2,6 \mathrm{~cm}$, minimum $1,9 \mathrm{~cm}$; diam. de l'ouverture centrale 0,9 et $1 \mathrm{~cm}$. Inv. PIN 3790. Pl. 43b

Deux objets intacts en verre mat, semi-transparent, de couleur jaune. Ils ont une forme de bobine, mais le diamètre est différent à chaque extrémité ; ouverture centrale allant en se rétrécissant vers l'extrémité la plus large.

Ces deux objets en verre, d'une forme inhabituelle, font partie du mobilier funéraire d'une femme de 21 à 35 ans au statut particulier, enterrée vers le milieu du 
$\mathrm{IV}^{\mathrm{e}} \mathrm{s}$. Deux objets analogues proviennent d'une autre tombe d'Apollonia, datée de la même époque : ils ont été interprétés comme les bords d'un récipient (alabastre) ou les extrémités d'une agrafe (sic, Mladenova 1963b, p. $310 n^{\circ}$ 997, pl. 163-164). La fonction de ces objets, comme d'autres du même genre, demeure incertaine (Panayotova, Gyuzelev, Nedev, 2008, p. 367). Des supports pour des amphorisques miniatures en verre et des aryballes de la collection Borowski, d'authenticité assurée, sont de forme comparable, mais, à la différence des objets d'Apollonia, ils sont constitués d'une fine lamelle en or ; ils sont datés entre le milieu du $\mathrm{V}^{\mathrm{e}}$ et le milieu du III ${ }^{\mathrm{e}}$ s., mais n'étaient pas directement associés aux récipients en verre (Bianchi et al. 2002, p. 58 V-11, 64 $\mathrm{V}-16,65,69 \mathrm{~V}-21)$.

D 3. - Tombe SP 340. Diam. 1,4 cm. Inv. PIN 3802.

Pion en verre opaque brun clair à reflets verdâtres, de forme plano-convexe.

\subsection{Objets en os (autres que les astragales)}

D 4. - Tombe SP 340. Diam. 1 à 1,4 cm. Inv. PIN 3803. Quatre «pions» plano-convexes, recouverts d'un fine feuille en bronze.

Ces petits objets, les pions en verre et les boutons (?) ont été trouvés avec des pointes de flèches, à côté du tibia droit de la défunte. Ils ont été probablement déposés dans un petit sac en matériau périssable. Leur forme et leur dimension permettent de les interpréter comme des pions de jeu. Ce type d'objet, cependant de forme et de taille différentes, est connu dans la nécropole préromaine d'Aléria (Jehasse 1973, pl. 165, $491 \mathrm{n}^{\circ} 2007$ : vers 500-340 av. J.-C.). Les pions, faits en différents matériaux, ont pu servir dans l'Antiquité pour des jeux comme les dames ou le jacquet ${ }^{340}$. On connaît des exemplaires plus luxueux, en ivoire, en pierre précieuse, en argent et même en or (May 1992, p. 33, fig. 3, et 188, fig. $182 \mathrm{n}^{\circ} 298$ ).

D 5. - Tombe SP 272. Diam. 1,2 à 1,5 cm. Inv. FR 1.23. Pl. 20f

Quatre «boutons » plano-convexes (pour la forme, voir Coldstream 1973, p. 167-169, $\mathrm{n}^{\text {os }} 301-303$, fig. 43, pl. 98).

D 6. - Tombe SP 340. Long. 4,8 cm, diam. min. 0,6 à $0,8 \mathrm{~cm}$. Inv. PIN 3795.

340 Ainsi pour les 87 pions en pierre, en os et en verre (dimensions 0,6 à 2,3 cm), d'époque romaine, conservés au musée Calvet d'Avignon.
Objet en forme de bâton à section circulaire, s'élargissant légèrement vers une de ses extrémités. Le côté plus large comporte six rainures, l'objet est percé d'un trou sur toute sa longueur.

Le fait que cet objet cylindrique ait été trouvé avec un miroir et des « punaises » en bronze laisse penser qu'il faisait partie du décor du manche de miroir, qui devait être en matériau périssable ${ }^{341}$.

D 7. - Tombe SP 289. Long. $16,4 \mathrm{~cm}$; diam. max. 0,6 cm. Inv. PIN 3156. Pl. 23e

La forme de l'objet (fragmentaire), sa taille et un autre fragment découvert avec lui permettent de l'interpréter Comme une quenouille.

La tombe est datée à la fin du $\mathrm{IV}^{\mathrm{e}}$ ou au début du III $s$.

Ce type de quenouille est connu jusqu'à l'époque contemporaine. Elles sont faites en bois ou en os, avec une longueur de 15 à $20 \mathrm{~cm}$. D'après les représentations sur les vases, il semblerait qu'il existait au sommet de la quenouille un anneau ou un ornement un peu plus large qui empêchait le fil de se dérouler (Biro 1994, p. 49, fig. 19 ; Barnett, Mendelson 1987, p. 143, 2/30, et 164, 9/42). Sur une œnochoé à fond blanc datant d'environ 490 av. J.-C., attribuée au peintre de Brygos, est figurée une jeune femme qui tient une quenouille dans sa main gauche et défile un fil en laine de sa main droite vers un fuseau, qui dispose d'un poids qui accélère et stabilise la rotation (Jenkins 1986, p. 22, fig. 22 ; voir aussi fig. 19). La plupart des exemples de quenouilles et de fuseaux en os datent de l'époque romaine (Béal 1984, p. 20, fig. 33, pl. V, et fig. 35-36), mais leur usage n'a guère varié avec le temps.

D 8. - Tombe SP 289. Long. 2,8 cm, diam. max. de la «tête » 1,4 cm. Inv. PIN 3157. Pl. 23e

Objet cylindrique, pointu en bas, en tronc de cône du côté de la «tête». Cette forme particulière permet de supposer qu'il s'agirait d'un élément de fuseau. Les deux objets en os trouvés dans la tombe féminine SP 289 sont probablement des objets rituels ou symboliques. Il est possible qu'ils aient une relation avec les signes gravés sur le mur Est de la chambre (signes magiques ?).

Même date que le précédent.

D 9. - Tombe SP 336 (femme entre 36 et 50 ans). Long. 4,5 cm, diam. 0,6 cm. Inv. PIN 3773.

Objet cylindrique, avec recreusement central.

341 Comparer Rodziewicz 2007, p. 125, n 145, pl. 33, 145 et 105, 7 (Alexandrie, probablement un manche de miroir); Davidson 1952, p. 177, $\mathrm{n}^{\circ} 127$, pl. 79, et $\mathrm{n}^{\circ} 1410$, pl. 85 (Corinthe, « bobine » d'époque romaine ou byzantine). 
D 10. - Manche en os, trouvaille isolée dans la zone du point J 5. Inv. PIN 3715.

\subsection{Astragales (classés selon leur nombre dans chaque contexte ${ }^{342}$ )}

D 11. - Tombe SP 338 (femme d'environ 50 ans), un exemplaire (2,9 x 1,9 x 1,5cm). Inv. PIN 3782.

D 12. - Tombe SP 347 (femme de plus de 50 ans), un exemplaire (2,6 x 1,6 x 1,1 cm). Inv. PIN 3850 .

D 13. - Foyer F 2, un exemplaire.

D 14. - Tombe SP 340 (femme entre 21 et 35 ans), 2 exemplaires, l'un cassé (long. de l'autre 2,6 cm). Inv. PIN 3798.

D 15. - Près du point I 6 , deux exemplaires, un de bovidé, un de petit bétail. Inv. PIN 3711.

D 16. - Tombe SP 322 (adulte), quatre exemplaires. Inv. PIN 3705.

D 17. - Tombe SP 336 (femme entre 36 et 50 ans), quatre exemplaires. Inv. PIN 3774. PI. 39g

D 18. - Tombe SP 334 (jeune homme entre 15 et 20 ans), 16 exemplaires. Inv. PIN 3770.

D 19. - Tombe à ciste SP 339 (enfant de 7-8 ans), 58 exemplaires, dont certains légèrement retaillés et deux sciés au milieu. Inv. PIN 3640. PI. 42e

D 20. - Foyer F 9, au moins 60 exemplaires brûlés (un bon nombre fragmentaires). Inv. PIN 4034. Pl. 76b

D 21. - Tombe SP 313 (enfant entre 5 et 10 ans), 136 exemplaires, dont 10 travaillés et un contenant du plomb. Inv. PIN 3604. Pl. 28c

Le mobilier des huit tombes ci-dessus comportait des astragales d'agneau ou de chevreau, en quantité très différente : de 1 à 136 exemplaires; ils ont été déposés dans les tombes d'individus d'âge et de sexe divers (voir le commentaire ci-dessus, p. 145 et 169-170).

L'opinion traditionnelle veut que les astragales soient des offrandes généralement déposées dans des tombes

342 On s'y reportera pour les datations. d'enfants ou d'adolescents (Kastanaian 1959, p. 266), mais on en trouve aussi dans des tombes d'adultes. Ils sont souvent présents par centaines dans des tombes d'hommes, de femmes et surtout d'enfants, de la Sicile jusqu'au Sud de la Russie (May 1992, p. 100). Leur quantité importante et le fait qu'ils soient souvent en nombre impair indiquent qu'ils ne sont pas uniquement en relation avec le jeu qui, d'après la légende, avait été inventé par Palamède durant le siège de Troie (Press 1978, p. 251-253). Pour les enfants grecs ces ossements sont l'équivalent de nos billes en verre, mais si les Grecs les ont considérés comme des pièces de jeu, ils n'étaient pas le privilège exclusif des enfants.

La coutume de déposer des astragales dans les tombes est largement diffusée à Apollonia. Leur quantité varie d'un exemplaire unique à plusieurs centaines. Dans une tombe d'enfant du troisième quart du $\mathrm{IV}^{\mathrm{e}} \mathrm{s}$., découverte en 2006 dans la partie Sud de la nécropole du lieu-dit Boudjaka, 333 osselets de taille différente ont été déposés, en plusieurs tas. Leur disposition montre clairement qu'ils avaient été rassemblés dans des sacs en matériau périssable (tissu, cuir), qui ont disparu. Les habitants d'Apollonia ont parfois utilisé comme conteneur une carapace de tortue (Kalfata, parcelle 5536, tombe $\left.n^{\circ} 5 / 2008\right)$. À Locres des centaines d'astragales avaient été dispersés sur le couvercle du sarcophage d'une vieille femme, et d'autres, encore plus nombreux, à l'intérieur (Kurtz, Boardman 1971, p. 208-209). Certains de ces astragales, comme dans la nécropole d'Apollonia, ont été taillés des deux côtés pour obtenir la forme d'un domino, portant parfois, sur l'un ou les deux côtés aplatis, des lettres de l'alphabet grec. D'autres sont plus simples, avec un remplissage de plomb et un ou plusieurs trous circulaires (Amandry 1984, p. 348-375).

Dans l'Antiquité, on a utilisé, en plus des os d'animaux (brebis, chèvres et porcs), des matériaux précieux comme l'ivoire, le verre, le marbre, l'agate, le bronze pour fabriquer des astragales (Neils 1992, p. 233234, fig. 13 ; Borell 1989, p. 48, n50, pl. 21). Dans la tombe 726 de la nécropole de Kalfata, datée de la fin du $\mathrm{IV}^{\mathrm{e}}$ ou du début du $\mathrm{III}^{\mathrm{e}}$ s., ont été déposés quatre astragales en verre, incolore ou de couleur bleu foncé et jaune (Venedikov et al. 1963, p. 31, n 999, pl. 163, 166). Dans les nécropoles d'Apollonia ils ont été utilisés à la fois comme offrande dans la tombe, souvent pour les enfants, mais aussi lors de rituels après l'enterrement, dans des foyers. Citons par exemple les 106 astragales découverts dans et entre les récipients du foyer rituel de la parcelle 5037, associés à une lékané (11 exemplaires) et à un couvercle de lékané (18 exemplaires), ainsi qu'à un plat à poisson (4 exemplaires). 


\subsection{Cailloux}

D 22. - Tombe SP 340. Inv. PIN 3802.

Cinq petits cailloux à surface très lisse. Deux d'entre eux sont plats (long. 2 et $2,4 \mathrm{~cm}$ ), un autre a la forme d'un rein (long. 1,8 cm), les deux derniers ont une forme irrégulière (long. 1,6 et 1,5 cm).

L'apparence de ces cailloux montre qu'ils ne se trouvaient pas par hasard près de la défunte qui, comme on l'a vu, exerçait probablement la fonction de prêtresse. 



\title{
Appendice
}

\section{A Bioarchaeological Study of the Kalfata Necropolis}

\author{
Anne Keenleyside
}

\section{Introduction}

Bioarchaeology, the study of human remains from archaeological contexts, can yield a wealth of information on the health, diet, and activity patterns of past populations. Numerous studies have been conducted on ancient Greek skeletal remains, but few have focused on remains from Greek colonial sites, and most of these have been restricted to skeletal samples from southern Italy. These include the analysis of nearly 700 skeletons from Metaponto $\left(7^{\text {th }}-2^{\text {nd }}\right.$ century $B C$; Henneberg and Henneberg 1990, 1994, 1998, 2003 ; Henneberg et al. 1992), 129 burials from Pithekoussai ( $8^{\text {th }}-7^{\text {th }}$ century BC; Becker and Donadio 1992 ; Becker 1995), and 16 skeletons from Morgantina $\left(8^{\text {th }}-5^{\text {th }}\right.$ century BC ; Becker 1996). With a few exceptions, there have been no bioarchaeological studies of skeletal remains from the Black Sea region. As a result, little is known about the biological and behavioural adaptations of the ancient Greeks who inhabited this region. This chapter presents the results of a demographic and palaeopathological analysis of human remains recovered from the Kalfata necropolis at Apollonia ${ }^{1}$.

\section{Materials and Methods}

A total of 240 skeletons were examined in this study. The majority of these skeletons were fairly well preserved and relatively complete. Sex determination of the adult skeletons was done using standard morphological criteria of the crania and pelvic bones (Bass 1987 ; Ubelaker 1989). With the exception of late adolescents (15-18 years of age), no attempt was made to determine the sex of the subadults in the sample due to the difficulty of accurately sexing such individuals (Ubelaker

1 I would like to thank Dr. Kristina Panayotova for inviting me to work on the skeletal material from Kalfata, and Dr. Dimitar Nedev, Director of the Archaeological Museum in Sozopol, for providing permission and facilities to study these remains. Financial support from the Leverhulme Foundation (A.K.) and the Social Sciences and Humanities Research Council of Canada (A.K.) is gratefully acknowledged.
1989). Subadult age-at-death was estimated using dental formation (Moorrees et al. 1963a, 1963b), dental eruption, diaphyseal length, and degree of epiphyseal union (Ubelaker 1989). Subadults were assigned to one of five age categories : fetal, birth to 5 years, 5 to 10 years, 10 to 15 years, and 15 to 18 years. Adult age estimation was based on pubic symphysis morphology (Brooks and Suchey 1990), auricular surface morphology (Lovejoy et al. 1985), and ectocranial suture closure (Meindl and Lovejoy 1985), and adults were assigned to one of three age categories : 18 to 35 years, 36 to 50 years, and $50+$ years.

The health and nutritional status of the individuals in the sample was assessed using a number of skeletal and dental indicators. All crania were visually examined for cribra orbitalia and porotic hyperostosis, conditions characterized by porosity and thickening of the superior orbital plates and cranial vault respectively. Cribra orbitalia was recorded for all individuals with at least one orbital roof preserved. The severity of the condition was categorized following the scale utilized by StuartMacadam (1991), and lesions were classified as active or healed based on the criteria outlined in Mensforth et al. (1978). Porotic hyperostosis was scored as present if the affected crania exhibited both pitting and thickening of the bone. Traumatic lesions were classified by type (e.g. fracture, dislocation), location in the skeleton, size and location on each affected bone, and stage of healing. Elements exhibiting evidence of infection secondary to a traumatic injury were included under the category of trauma. Infectious lesions were classified by type (e.g. bone formation, bone loss, or both), location in the skeleton, size and location on each affected bone, and stage of healing. Long bones that were less than two thirds complete were eliminated from the calculation of trauma and infection frequencies unless they exhibited evidence of these conditions.

Dental caries, antemortem tooth loss, abscesses, and calculus were recorded by individual and by tooth/tooth socket following the methodology outlined in Buikstra and Ubelaker (1994). Carious lesions were recorded as present only if they had penetrated the enamel surface. The number and location of lesions per tooth were also 
noted. Teeth were scored as being lost antemortem if their sockets exhibited evidence of resorption. Dental abscesses were identified by the presence of a drainage channel through the alveolar bone at the apex of the tooth root, and their number and location was recorded for each affected tooth. Teeth were examined for the presence of dental calculus, and the location and degree of calculus were documented for each tooth involved. The degree of tooth wear was recorded using Smith's (1984) 8-stage system for the incisors, canines, and premolars, and Scott's (1979) 10-stage system for the molars. Enamel hypoplasia was classified according to the Developmental Defects of Enamel (DDE) Index (Commission on Oral Health 1982). Hypoplastic defects were identified by visual examination and were scored as present or absent for each of the six anterior maxillary and mandibular teeth. All observed defects were classified as either linear arrangements of pits, horizontal grooves, or both, and the total number of defects was recorded for each affected tooth. Those teeth that exhibited severe wear resulting in the loss of more than one third of the tooth crown, heavy calculus deposits, severe caries, or trauma were excluded from the analysis.

Osteoarthritis, or degenerative joint disease, was not systematically scored in the skeletal sample. The condition was, however, recorded when observed in the remains. Similarly, other pathological conditions were documented if they were present.

\section{Results}

\subsection{Age and Sex Distribution}

The sex and age distribution of the sample are illustrated in Table 1. Of the 240 skeletons examined, 69 were male, 87 were female, and 84 were individuals of indeterminate sex. Eighty-two individuals were subadults $(<18$ years of age), and the majority of these ( $84 \%$ ) were under the age of ten at the time of their death. Of the 158 adults for whom age-at-death could be estimated, 60 (38\%) were young adults (18-35 years), 60 (38\%) were middle-aged adults (36-50 years), and 38 (24\%) were older adults (50+ years).

\subsection{Skeletal Pathology}

A complete list of all individuals in the sample with skeletal pathology is provided at the end of this chapter (Table 21). Fifty-one out of 156 crania (32.7\%) with preserved orbits had cribra orbitalia (Table 16). There

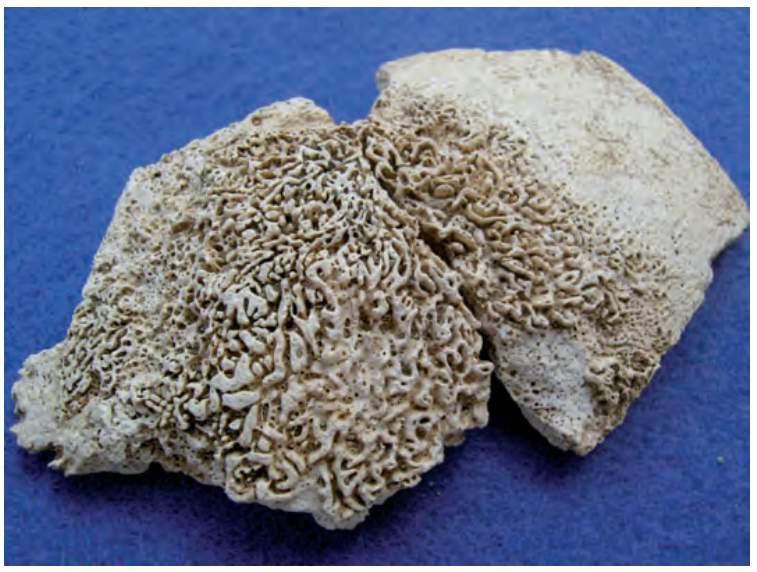

Fig. 67. Porotic hyperostosis in a subadult.

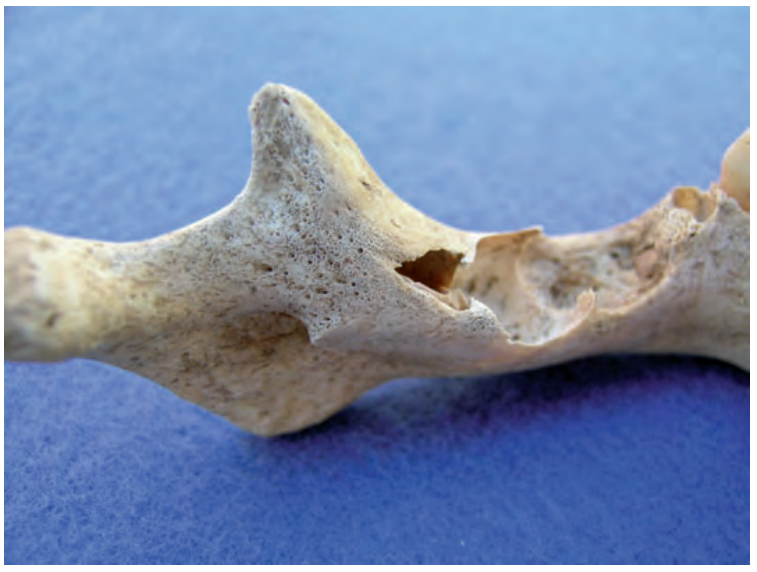

Fig. 68. Abnormal porosity on the left coronoid process of a subadult mandible.

was no statistically significant difference between males and females; however, a significantly greater proportion of subadults were affected than adults $\left(x^{2}=10.315\right.$, $\mathrm{p}=0.0013$ ). The majority of the observed lesions were categorized as mild to moderate. Of the 25 affected adults, 24 had lesions that were partly or completely healed at the time of their death, while 18 of the 26 affected subadults had active lesions.

Only 8 of the 158 crania $(5.1 \%)$ with observable frontal, parietal, and occipital bones showed evidence of porotic hyperostosis (fig. 67). Six of these specimens also exhibited cribra orbitalia. Significantly more subadults were affected than adults $\left(x^{2}=4.278, p=0.0386\right)$, and four of the six affected subadults had active lesions.

Three subadults, two with cribra orbitalia and one with porotic hyperostosis, displayed abnormal porosity on other cranial bones as well. Individual \#314 had porosity on the right sphenoid bone, the palatine process of the left and right maxillary bones, and the medial surface of the left and right coronoid processes of the mandible (fig. 68). Individual \#413 had porosity on the 


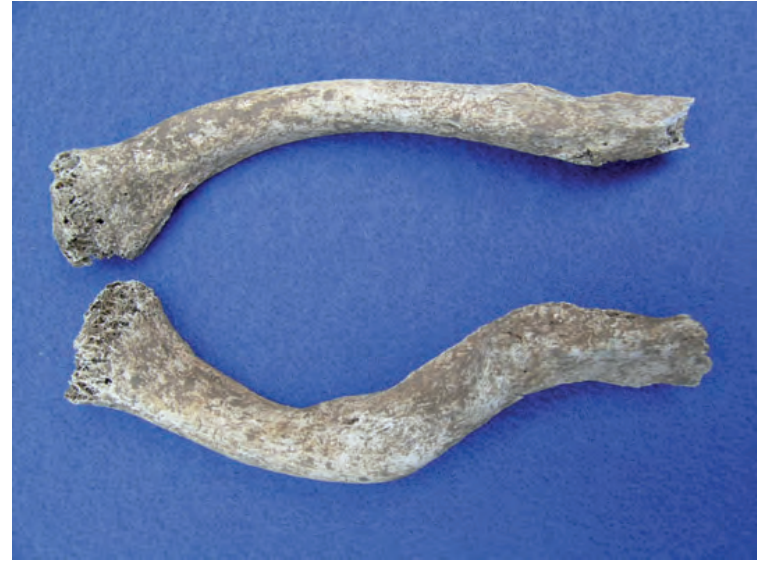

Fig. 69. Healed fracture to the left clavicle of an older adult male (bottom). The normal right clavicle is shown above it for comparison.

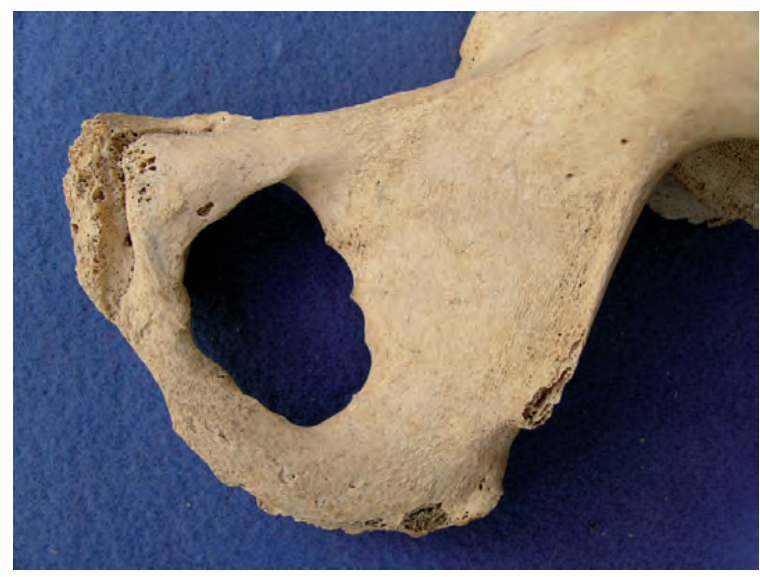

Fig. 70. Healed fracture to the right pubic bone of an older adult female.

greater wing of the sphenoid bone, and individual \#431 had porosity on the right maxillary bone and on the left and right zygomatic bones.

Seven out of 159 observable crania (4.4\%), all of them adult, displayed evidence of trauma (Table 16). A higher proportion of males had cranial trauma than females (8.9\% compared to $4.9 \%$ ) but the difference was not statistically significant. Four of the affected individuals were males and three were females. Four individuals, all of them middle-aged or older, had well-healed depression fractures involving the left frontal bone (\#10 and $\# 215$ ) or the left parietal bone (\#112 and \#164). In three of these cases, the depression fracture was shallow and affected only the outer table of bone. In the fourth case (\#10), however, the fracture extended through the inner table of the frontal bone. Three individuals, a young adult male (\#63a) and two older adult females (\#140 and 179), had possible perimortem trauma involving the frontal, parietal, temporal, and/or maxillary bones. The

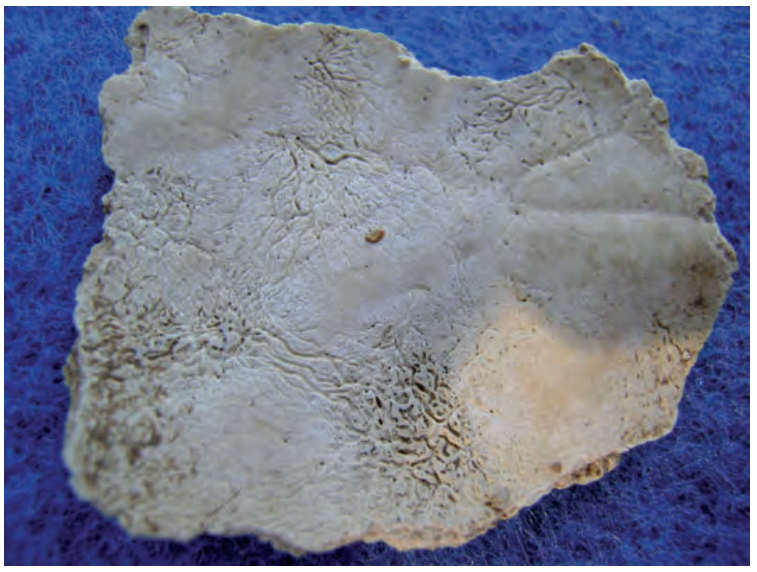

Fig. 71. Endocranial lesions in a subadult.

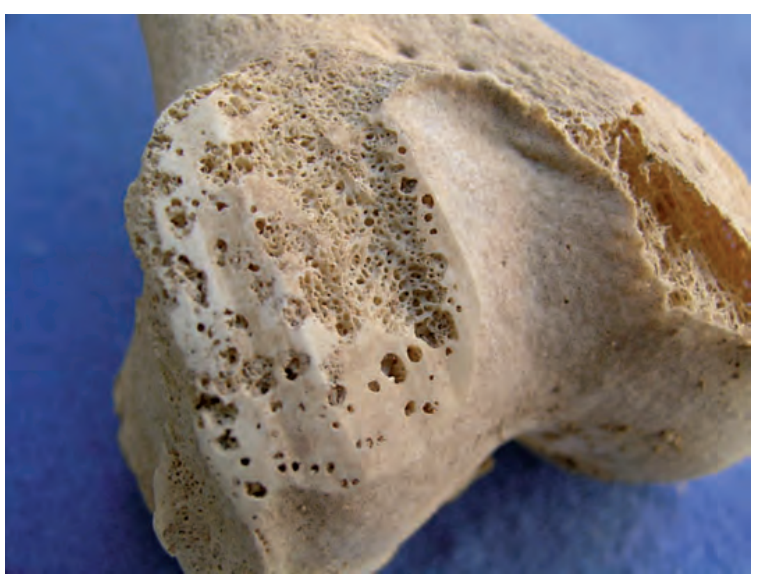

Fig. 72. Osteoarthritis, as indicated by the presence of eburnation, on the distal femur of an older adult female.

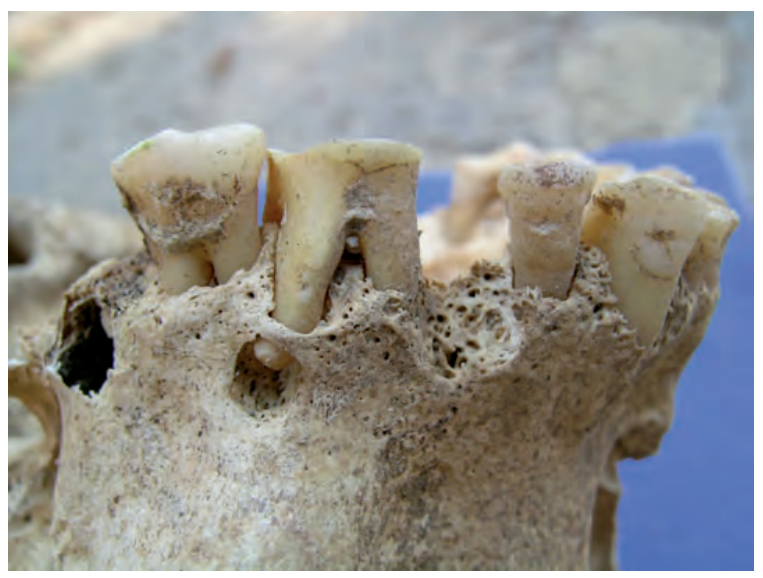

Fig. 73. The maxillary dentition of this individual displays dental abscessing, antemortem tooth loss, calculus, and tooth wear. 
male had a large, radiating fracture line extending from the right temporal bone to the right frontal bone, and one of the females (\#179) displayed a circular depression fracture through the right frontal bone, with several fracture lines extending from the depression and several fracture lines radiating through the right parietal bone directly posterior to the coronal suture, and through the anterior half of the left parietal bone. The other female (\#140) had a possible perimortem fracture to the left frontal bone and maxilla, with a fracture line radiating from the superior margin of the left orbit and another one extending from the inferior margin of the left orbit through the left maxilla. This individual also exhibited a well-healed fracture of the nasal bones, and a healed Colles fracture to the right radius.

Twenty-eight out of 205 individuals (13.7\%) with preserved infracranial remains, 14 adult females and 14 adult males, exhibited evidence of infracranial trauma (Table 16). A slightly higher proportion of males had infracranial trauma than females $(21.9 \%$ compared to $17.3 \%$ ) but the difference was not statistically significant. Twenty-three of the affected individuals had sustained an injury to only one bone, while the remaining five individuals displayed trauma to multiple elements. In all cases, the injuries were well-healed at the time of death. Four of the affected individuals (\#50, $140,176,277)$, three of them females, had a Colles fracture of the distal radius. One of these females (\#176) had also sustained a fracture to the distal end of the right ulna and to the shaft of the right clavicle. One middleaged male (\#349) had a fracture of the distal right ulna, and two individuals, a young adult female (\#46a) and an older adult male (\#352), displayed a fracture through the shaft of the left clavicle (fig. 69). The latter individual also showed evidence of healed trauma to the anterior midshaft of the right humerus. One older female (\#347) had myositis ossificans on the midshaft of the left ulna, a condition characterized by ossification in the muscle tissue resulting from trauma to the muscle. One older adult female (\#112) had a possible healed fracture of the left $2^{\text {nd }}$ metacarpal, and two individuals, a middle-aged female (\#250) and an older male (\#249), had fractures to the shaft of the right first metacarpal. Six individuals, two middle-aged males (\#67 and \#374), two older males (\#46b and an individual of unknown provenience), and two older females (\#198 and \#347) had rib fractures involving one or more ribs. One older male (\#63b) had a compression fracture of an unidentified lumbar vertebra. Four individuals had suffered traumatic injuries to their lower limbs. An older adult female (\#189) had sustained a fracture to the distal left fibula, a middle-aged male (\#209) had a fracture to the distal shaft of a left tibia, an older male (\#249) had a fracture of the distal right fibula, and an older adult female (\#338) had possible healed trauma to the antero-medial shaft of the right femur. Two individuals (\#347 and \#456), both of them older females, displayed well-healed fractures of the left ischio-pubic ramus and right pubic bone respectively (fig. 70). One adult (\#257) had osteochondritis dissecans on the left talus, femoral condyle, and the left and right radius. This condition results from the death of bone tissue due to a trauma-related disruption in the blood supply (Roberts and Manchester 2005). Finally, four individuals (\#63a, \#135, \#154, \#447) had spondylolysis, a condition characterized by the separation of the neural arch from the vertebral body at the pars interarticularis. In two of the cases, the fourth lumbar vertebra was affected, and in the other two cases, the fifth lumbar vertebra was involved.

When analysed by element, infracranial trauma was recorded in only 13 out of 1308 (1\%) long bones in the sample (Table 17). Of the six major long bones, the ulna was most frequently affected $(2.6 \%)$, followed by the radius $(1.9 \%)$, fibula $(1.2 \%)$, tibia $(0.4 \%)$, and femur $(0.4 \%)$. Individuals over the age of 50 exhibited a significantly higher frequency of infracranial trauma than individuals under the age of $50\left(x^{2}=7.435, \mathrm{p}=0.0064\right)$.

Six out of $159(3.8 \%)$ observable crania in the sample exhibited evidence of possible infection (Table 16). One individual (\#25), an older adult male, had a small lytic (i.e. destructive) lesion in the left parietal bone. The lesion had destroyed the inner table of bone, leaving the outer table unaffected. No new bone formation was associated with the lesion. The remaining five individuals (\#199, 266, 273, 372, 413), all of whom were subadults, had endocranial lesions on the frontal, parietal, occipital, sphenoid and/or temporal bones (fig. 71).

Nineteen of the 150 individuals $(12.7 \%)$ whose infracranial remains were sufficiently preserved to allow for examination displayed evidence of infracranial infection (Table 16). A slightly higher proportion of females had infracranial infection than males (19\% compared to $15.4 \%$ ) but the difference was not statistically significant. Significantly more adults had infracranial infection than subadults $\left(\mathrm{x}^{2}=4.927, \mathrm{p}=0.0264\right)$. Periostitis, inflammation of the periosteum, was the most common type of infectious lesion recorded in the sample, affected primarily the lower limb bones. Multiple bones were affected in ten individuals, suggesting some type of systemic infection, while single bones were affected in the remaining individuals. In all but one case (\#307) the lesions were healed at the time of death. Three individuals (\#70, \#140, and \#182), two males and one female, had lytic lesions involving the tibia, fibula, and humerus, respectively.

When analysed by element, infracranial infection was recorded in 30 out of 906 (3.3\%) long bones in the 
sample (Table 17), and an almost identical proportion of younger and older adults were affected. Of the six major long bones, the tibia was most frequently involved $(12.6 \%)$, followed by the fibula $(4.9 \%)$, femur $(1.7 \%)$, and humerus $(0.6 \%)$.

A number of other pathological conditions were also documented in the Kalfata remains. These included osteoarthritis, or degenerative joint disease, vertebral osteophytosis, and Schmorl's nodes. Among the most severe cases of osteoarthritis were individuals \#198 and \#286, both of whom exhibited eburnation on the articular facets of the right and/or left patella and the condyles of the corresponding femora (fig. 72). Five individuals exhibited fusion of two or more bones. Three of these individuals (\#445, \#447, and \#456) had fused thoracic vertebrae, one (\#274) displayed fused cervical vertebrae, and one (\#438) had fused distal phalanges of the foot. Finally, one individual (\#198) had a button osteoma on the frontal bone, and a second individual (\#437) had a small osteoma on the distal shaft of the left tibia.

\subsection{Dental Pathology}

Dental calculus was the most common dental condition observed in the sample, affecting $63.7 \%(128 / 201)$ of individuals (Table 18) and $45.8 \%(1146 / 2502)$ of permanent teeth (Table 19). In contrast, only $6.2 \%$ $(34 / 546)$ of the deciduous teeth had calculus deposits (Table 20). There were no significant sex differences when comparisons were made by the number of affected individuals. When comparisons were made by the number of affected teeth, however, males had a significantly higher prevalence of calculus than females overall $\left(\mathrm{x}^{2}=29.022, \mathrm{p}=.0001\right)$, and young adult males had a higher prevalence than females of the same age group $\left(\mathrm{x}^{2}=10.413, \mathrm{p}=.0013\right)$. For both sexes, the prevalence of calculus increased with age.

When recorded by individual, dental caries was the second most common dental disease observed in the sample, affecting $45.5 \%(92 / 202)$ of individuals (Table 18). In contrast, only $8.4 \%(215 / 2543)$ of permanent teeth (Table 19), and $7.2 \%(38 / 525)$ of deciduous teeth had carious lesions (Table 20). Of the four tooth types, the molars were most frequently involved, reflecting their more complex morphology. There were no significant sex differences when comparisons were made by the number of affected individuals. When comparisons were made by the number of affected teeth, however, middle-aged females had a significantly higher frequency of lesions than males of the same age $\left(x^{2}=13.947, p=.0002\right)$. Both sexes showed an increased prevalence of carious lesions with age.
Antemortem tooth loss affected $35.1 \%(72 / 205)$ of individuals (Table 18) and $11.3 \%$ (408/3616) of permanent teeth (Table 19). Of the four tooth types, the molars were most frequently lost antemortem. There were no significant sex differences when comparisons were made by the number of affected individuals. When comparisons were made by the number of affected teeth, however, significantly more young adult males had lost teeth prior to death than females of the same age group $\left(x^{2}=31.856, p=.0001\right)$, while a significantly higher number of middle-aged females had lost teeth compared to males of the same age $\left(x^{2}=10.910, p=.0010\right)$. For both sexes, the prevalence of antemortem tooth loss increased with age.

Abscesses were the least common type of dental pathology observed in the sample, affecting only $16.4 \%$ (32/195) of individuals (Table 18), $1.7 \%(55 / 3161)$ of permanent teeth (Table 19), and $0.2 \%(1 / 524)$ of deciduous teeth (Table 20). The molars were the most frequently involved teeth (fig. 73). There were no significant sex differences when comparisons were made by the number of affected individuals or teeth. For both sexes, however, the prevalence of abscesses increased with age.

Enamel hypoplasia involving the canines and/or incisors was recorded in $17.4 \%(29 / 167)$ of individuals (Table 18) and $10 \%$ (83/827) of permanent teeth (Table 19). There were no significant sex differences when comparisons were made by the number of affected individuals. When comparisons were made by the number of affected teeth, however, middle-aged males had a significantly higher frequency than females of the same group $\left(x^{2}=7.755, p=.0054\right)$. For both sexes, young adults showed a higher prevalence of defects than older individuals.

\section{Discussion}

\subsection{Demographic Profile}

Seventy-eight of the 240 individuals (32.5\%) in the sample were under the age of 15 , and thirty-nine individuals $(16.2 \%)$ were under the age of five. This high proportion of infants and children is comparable to that seen in other pre-industrial skeletal samples and suggests a high rate of infant and child mortality. The period from birth to three years is particularly critical for growth, and it is during this time that children are most sensitive to the effects of infectious disease and malnutrition.

In a recent study of infant feeding practices using stable nitrogen isotope analysis of the remains of 64 
subadults from the Kalfata necropolis, Kwok and Keenleyside (n.d.) determined that weaning at Apollonia began between 6 months and 1 year of age and was completed between the ages of 2 and 4 . Likely causes of morbidity in these young children included the use of solid foods low in nutrients and gastrointestinal infections resulting from the consumption of contaminated food and water.

\subsection{Skeletal Pathology}

The etiology of cribra orbitalia and porotic hyperostosis in past populations has received considerable attention in the literature. Among Mediterranean populations these lesions have typically been attributed to genetic anaemia, most notably thalassemia, due to the presumed presence of endemic malaria in the Mediterranean region in antiquity (Angel 1966). Similarly, cribra orbitalia and porotic hyperostosis in Greek colonial samples from Italy have been linked to thalassemia (Ascenzi and Balistreri 1977 ; Becker 1995 ; Benassi and Toti 1958; Henneberg and Henneberg 1998). Other disorders can also cause these lesions, however, and the significance of cribra orbitalia and porotic hyperostosis must therefore be interpreted with caution. The most common of these disorders is iron deficiency anaemia, a condition that results from a low dietary intake of iron, poor intestinal absorption of iron, and/or excess loss of iron due to parasitic and other infections. Other conditions such as scurvy, eye infections, and osteoporosis can also produce these lesions (Wapler et al. 2004).

Examination of the remains from the Kalfata necropolis revealed no evidence of infracranial lesions characteristic of thalassemia. In addition, the lack of severe lesions typically seen in individuals, especially children, with this form of anaemia, the decreasing prevalence of lesions from younger to older age groups, and the presence of primarily healed lesions in adults suggest that the cases of cribra orbitalia and porotic hyperostosis recorded in the sample more likely reflect iron deficiency anaemia (Keenleyside and Panayotova 2006). This is consistent with a previously conducted stable isotopic analysis of the remains of 54 individuals from the necropolis (Keenleyside, Schwarcz, Panayotova 2006), which revealed a heavy reliance on plant foods such as wheat and barley, both of which contain compounds known to inhibit the intestinal absorption of iron. Other factors that may also have contributed to the development of iron deficiency anaemia in these individuals include malnutrition and parasitic and other infections (Keenleyside and Panayotova 2006).
As noted earlier, three subadults, two with cribra orbitalia and one with porotic hyperostosis, also displayed porous lesions involving other cranial bones, including the sphenoid, mandible, and maxillary bones. Abnormal porosity of the greater wing of the sphenoid has been identified as a diagnostic feature of vitamin $\mathrm{C}$ deficiency, or scurvy (Ortner et al. 2001), and porosity of the coronoid process of the mandible, and the maxillary, zygomatic and temporal bones has also been linked to this disease. Lesions in these particular locations are believed to result from hemorrhages of the blood vessels associated with the use of the temporalis muscle in chewing (Ortner et al. 2001 ; Brickley and Ives 2006). Derived from fresh fruits and vegetables, vitamin $\mathrm{C}$ is essential for the synthesis of collagen and other connective tissues, and a deficiency leads to subperiosteal hemorrhaging that can result in new bone formation, and bleeding of the gums with subsequent tooth loss (Roberts and Manchester 2005). Based on the skeletal evidence noted above, the possibility exists that some of the children buried in the Kalfata necropolis suffered from scurvy.

Trauma to the skeleton can provide valuable insight into the activity patterns of past populations, as well as levels of interpersonal conflict within and between populations. Previous bioarchaeological studies have revealed that the ancient Greeks suffered from a variety of traumatic injuries (Angel 1971; Ortner and Theobald 1993 ; Papathanasiou et al. 2000). In the Kalfata sample, the age of the affected individuals (primarily older individuals), and the location and nature of the injuries suggest that they were primarily accidental. Cranial trauma, including perimortem fractures, can result from both accidents and interpersonal violence. Fractures of the clavicle and Colles fractures of the distal radius, which result when an individual extends their arm to break a fall, are both indicative of accidental falls (Lovejoy and Heiple 1981), and compression fractures of the vertebrae, such as that recorded in one male over the age of 50 , are commonly seen in older adults with osteoporosis (Roberts and Manchester 2005). The fact that all of the infracranial fractures recorded in the sample were wellhealed at the time of death indicates that the affected individuals survived their traumatic injuries with few, if any, complications.

Acute infectious diseases leave no evidence in bone and skeletal evidence of infection therefore represents chronic conditions which may or may not have been the immediate cause of death (Ortner 2003). Non-specific infections are more common in archaeological remains and include periostitis, an inflammation of the periosteum, and osteomyelitis, an inflammation of the marrow 
cavity (Roberts and Manchester 2005). Specific infections that can affect bone include tuberculosis, leprosy, and venereal syphilis. Determining the prevalence of infection in past populations is hindered by the fact that many diseases leave no evidence in bone, some affect the skeleton in only a small percentage of cases, and others affect the skeleton only years after the initial infection (Lovell 2000). Thus a low frequency of lesions in a skeletal sample does not necessarily indicate that infectious diseases were not a significant health problem among the population, as individuals with no skeletal lesions may have succumbed to infections before bone involvement occurred.

The majority of the infectious lesions documented in the Kalfata sample consisted of periostitis and were non-specific in nature, meaning that the specific pathogenic microorganism responsible cannot be identified. This condition may result from localized trauma or a chronic skin ulcer, or from a systemic infection, the latter often involving more than one bone, as seen in ten individuals in the sample. As noted earlier, endocranial lesions in the form of primarily reactive new bone on the frontal, parietal, occipital, and/or temporal bones were recorded in five subadults. While the etiology of the lesions seen in these individuals is uncertain, possible causes include meningitis, scurvy, rickets, and tuberculosis (Lewis 2004). Given that three of these individuals also had cribra orbitalia and/or porotic hyperostosis, and two of them had abnormal porosity on the greater wing of the sphenoid, it is possible that scurvy was the cause of the endocranial lesions seen in at least some of these individuals. No conclusive evidence of specific infectious diseases such as tuberculosis, brucellosis, treponemal infection or leprosy was found in any of the Kalfata remains. The presence of a single lytic lesion in three individuals (\#70,\#140,\#182), may reflect a localized infection, but the causative agent is impossible to determine.

One individual in the sample (\#46b), an older adult male, is particularly interesting as it manifests multiple lytic lesions throughout its skeleton (fig. 74). Affected elements include several cranial bones, the left clavicle, right scapula, left and right pelvic bones, humeri, and femora, a number of ribs, two cervical, nine thoracic, and four lumbar vertebrae, and the sacrum. While infectious diseases cannot be completely ruled out as the cause of these lesions, their appearance, size, shape, number, and distribution suggest the possibility of a malignant neoplasm, possibly multiple myeloma or metastatic carcinoma. A detailed macroscopic and radiographic examination would be required to confirm this diagnosis.
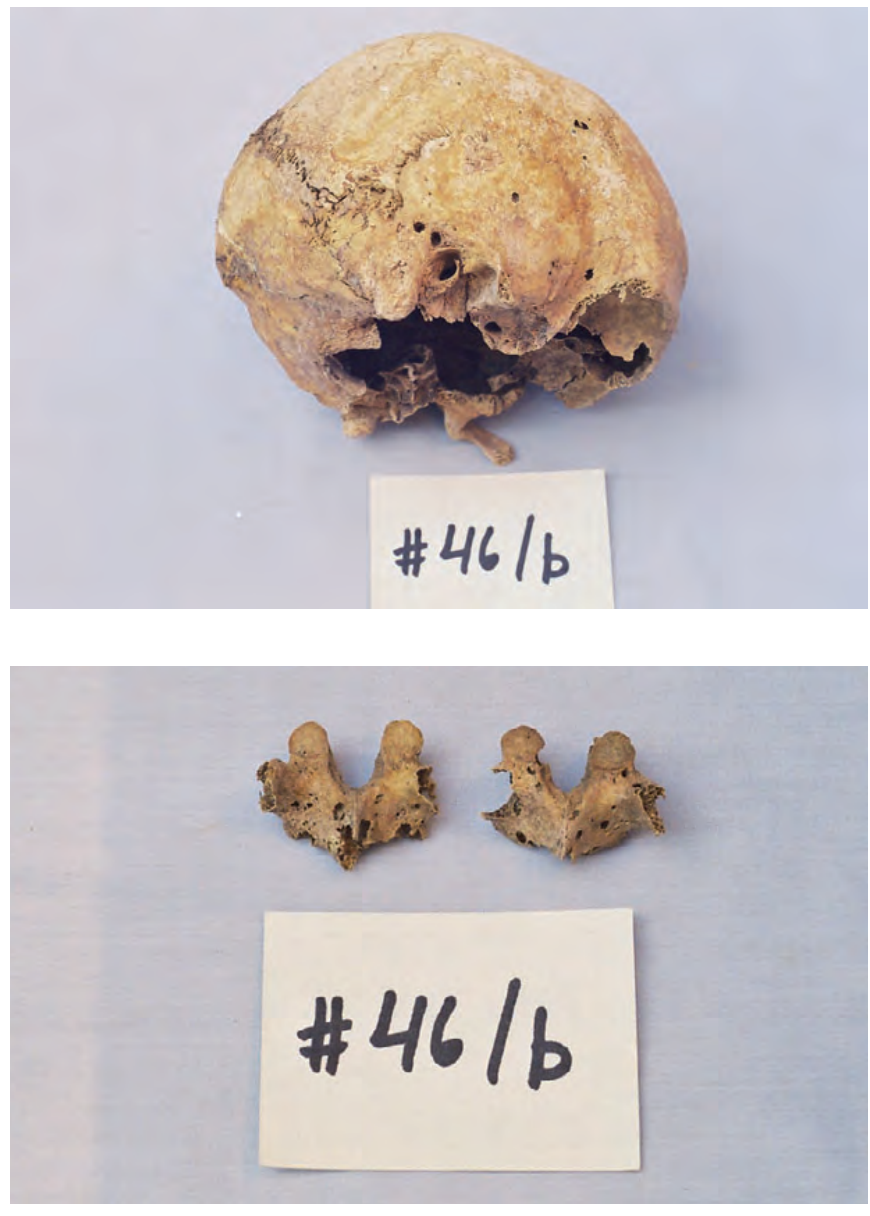

Fig. 74. Multiple lytic lesions throughout the skeleton of this older adult male may be indicative of a malignant neoplasm.

\subsection{Dental Pathology}

Dental pathology is commonly recorded in archaeological samples and can provide valuable insight into the general level of health and nutritional status of a population. Teeth can provide information on the type and nature of foods consumed and the level of oral hygiene. They can also provide evidence of nutritional and disease stress, as well as non-dietary functions i.e. their use as tools. Dental caries is an important indicator of diet, and high caries rates are associated with the consumption of carbohydrates, especially refined sugars. Antemortem tooth loss can result from the extraction of carious teeth, heavy tooth wear, trauma, or periodontal disease (Hillson 2005). Abscesses occur when bacteria invade a pulp cavity that has been exposed due to heavy tooth wear, caries, or trauma, and proceed down the root canal into the alveolar bone, causing an infection of the surrounding tissue (Hillson 2005). The formation of dental calculus, or mineralized plaque, has been linked to both high protein and high carbohydrate diets 
(Meiklejohn and Zvelebil 1991; Lieverse 1999; Lillie and Richards 2000), but it is also influenced by a number of non-dietary factors, including oral hygiene, the mineral content of drinking water, the rate of salivary flow, and the use of the teeth as tools (Lieverse 1999). Enamel hypoplasia, a deficiency in enamel thickness caused by a disruption in the secretory phase of enamel formation, has been linked to more than a hundred different factors, most notably nutritional stress and childhood infections (Goodman and Rose 1990). Finally, high levels of tooth wear in past populations have been attributed to a diet of uncooked and unrefined food items such as coarse cereal grains, the consumption of poorly washed foods, and the use of grinding stones (Larsen 1997).

A review of dental pathology in a smaller sample of human remains from the Kalfata necropolis has previously been conducted (Keenleyside 2008), and the results obtained in that study closely match those gathered in the current study. The frequent occurrence of dental calculus in the sample resembles that of other agricultural populations and points to the consumption of a high carbohydrate diet and/or poor oral hygiene. The significantly higher prevalence of the condition in older individuals compared to younger ones has been observed in other populations as well, and reflects the progressive build-up of calculus with age.

At $8.4 \%$ of permanent teeth, the prevalence of carious lesions in the sample falls at the lower end of the range reported by Turner (1979) for agricultural populations $(2.1-26.9 \%$, average $=10.43 \%)$, and within the range reported for populations with a mixed economy $(1.0-10.3 \%$, average $=4.84 \%)$. The higher frequency of carious lesions in older individuals compared to younger ones is consistent with previous studies of caries in archaeological populations, and reflects the age-progressive nature of this disease (Hillson 2000, 2001). Sex differences in caries rates have been observed in both archaeological and modern populations, with females typically showing higher rates than males (Hillson 2001 : 253 ; Walker and Hewlett 1990). This has been attributed to a higher carbohydrate intake by females, earlier eruption of teeth, and behavioural differences in subsistence pursuits (Larsen 1997 ; Walker and Hewlett 1990). Changes in salivary composition during pregnancy and lactation have also been implicated in the development of caries in women (Laine 2002). In the Kalfata sample, middle-aged females had a significantly higher prevalence of caries by tooth count than males of the same age group, but rates were only slightly higher in females overall, suggesting that in general, males and females consumed foods with similar cariogenic properties.
The rate of antemortem tooth loss in the sample is similar to that seen in other agricultural populations and likely reflects, in part, the higher rate of caries typically seen in such populations. The significantly higher number of older individuals who had lost teeth prior to their death than younger individuals mirrors the age-related increase in antemortem tooth loss seen in modern populations. Periodontal disease was not scored in the sample, but may also have contributed to tooth loss among the colonists.

Calculating the prevalence of abscesses in archaeological samples is complicated by the fact that teeth may have been extracted prior to pulp exposure and infection. Alternatively, abscesses, if present, may not have penetrated the alveolar bone and are therefore not visible to the naked eye. Consequently, reported frequencies likely underestimate the actual prevalence of this condition in past populations. Nevertheless, the low frequency of abscessing in the sample parallels the low rate of caries by tooth count and the low to moderate rate of tooth wear recorded in the sample. The higher frequency of abscesses in older individuals compared to younger ones is seen in other archaeological samples as well, and reflects the higher rate of caries and tooth wear typically seen in this age group.

The presence of enamel hypoplasia in the sample, while relatively low, indicates that episodes of childhood stress occurred in some individuals. Hypoplastic defects in ancient Greek skeletal remains have been interpreted as evidence of nutritional stress, childhood infections and/or weaning stress (Angel 1984; Henneberg and Henneberg 1998, 2001), and it is likely that one or more of these factors contributed to the formation of defects in the Apollonians as well. As noted earlier, the presence of cribra orbitalia in $32.7 \%$ of the individuals in the sample likely reflects iron deficiency anaemia resulting from a heavy reliance on a terrestrial plant diet, although other causes cannot be completely discounted (Keenleyside and Panayotova 2006). The higher frequency of enamel hypoplasia in younger adults compared to older ones has also been noted in other populations (Larsen 1997), and supports the hypothesis that individuals who experience stress during childhood are more likely to die at a younger age (Duray 1996).

Finally, the low to moderate levels of tooth wear recorded in the sample match those documented in other agricultural samples such as those from Pithekoussai (Becker 1995) and rural Metaponto (Henneberg and Henneberg 1998), and point to the consumption of a relatively soft diet. 


\section{Conclusions}

Analyses of human skeletal remains can provide valuable insight into the health, diet, and activities of past populations. As the present study has illustrated, the individuals buried in the Kalfata necropolis suffered from a variety of health problems, including metabolic disorders such as iron deficiency anaemia and possibly scurvy, fractures, infections, osteoarthritis, and poor dental health. To what extent these individuals represent the entire population who lived at Apollonia during the $5^{\text {th }}$ to $3^{\text {rd }}$ centuries remains unknown. What is clear, however, is that these individuals experienced some of the same health challenges faced by modern populations. Future studies of additional skeletal remains recovered from the necropolis will hopefully provide a more complete picture of the health of this population and their dietary and behavioural adaptations, particularly when integrated with archaeological evidence derived from the site.

\begin{tabular}{|c|c|c|c|c|}
\hline & Males & Females & Indeterminate & Total \\
\hline & & & & \\
\hline Subadults & & & & \\
\hline Fetal & 0 & 0 & 0 & 0 \\
\hline $0-5$ & 0 & 0 & 39 & 39 \\
\hline $5-10$ & 0 & 0 & 30 & 30 \\
\hline $10-15$ & 0 & 1 & 8 & 9 \\
\hline $15-18$ & 1 & 1 & 2 & 4 \\
\hline Total subadults & 1 & 2 & 79 & 82 \\
\hline & & & & \\
\hline Adults & & & & 60 \\
\hline $18-35$ & 21 & 35 & 4 & 60 \\
\hline $36-50$ & 33 & 26 & 1 & 38 \\
\hline $50+$ & 14 & 24 & 0 & 158 \\
\hline Total adults & 68 & 85 & 5 & \\
\hline
\end{tabular}

Table 15. Age and sex distribution of the sample.

\begin{tabular}{|c|c|c|c|c|c|c|c|c|c|c|}
\hline & \multicolumn{2}{|c|}{ Males } & \multicolumn{2}{|c|}{ Females } & \multicolumn{2}{|c|}{ Adults } & \multicolumn{2}{|c|}{ Subadults } & \multicolumn{2}{|c|}{ Total } \\
\hline & $\mathrm{A} / \mathrm{O}^{*}$ & $\%$ & $\mathrm{~A} / \mathrm{O}$ & $\%$ & $\mathrm{~A} / \mathrm{O}$ & $\%$ & $\mathrm{~A} / \mathrm{O}$ & $\%$ & $\mathrm{~A} / \mathrm{O}$ & $\%$ \\
\hline Cribra orbitalia & $14 / 45$ & 31.1 & $13 / 61$ & 21.3 & $25 / 105$ & 23.8 & $26 / 51$ & $51.0^{* *}$ & $51 / 156$ & 32.7 \\
\hline $\begin{array}{c}\text { Porotic } \\
\text { hyperostosis }\end{array}$ & $1 / 44$ & 2.3 & $1 / 61$ & 1.6 & $2 / 103$ & 1.9 & $6 / 55$ & $10.9^{* *}$ & $8 / 158$ & 5.1 \\
\hline Cranial trauma & $4 / 45$ & 8.9 & $3 / 61$ & 4.9 & $7 / 104$ & 6.7 & $0 / 55$ & 0.0 & $7 / 159$ & 4.4 \\
\hline Infracranial trauma & $14 / 64$ & 21.9 & $14 / 81$ & 17.3 & $28 / 144$ & $19.4^{* *}$ & $0 / 61$ & 0.0 & $28 / 205$ & 13.7 \\
\hline Cranial infection & $1 / 45$ & 2.2 & $1 / 61$ & 1.6 & $1 / 104$ & .96 & $5 / 55$ & $9.1^{* *}$ & $6 / 159$ & 3.8 \\
\hline $\begin{array}{c}\text { Infracranial } \\
\text { infection }\end{array}$ & $6 / 39$ & 15.4 & $11 / 58$ & 19.0 & $17 / 96$ & $17.7^{* *}$ & $2 / 54$ & 3.7 & $19 / 150$ & 12.7 \\
\hline
\end{tabular}

${ }^{*}$ Affected/observed

${ }^{* *}$ statistically significant difference

Table 16. Frequency of cribra orbitalia, porotic hyperostosis, trauma, and infection by individual. 
TROISIÈME PARTIE : SYNTHÈSES

\begin{tabular}{|c|c|c|c|c|c|c|c|c|c|c|c|c|c|c|}
\hline & \multicolumn{2}{|c|}{ Humerus } & \multicolumn{2}{|c|}{ Radius } & \multicolumn{2}{|c|}{ Ulna } & \multicolumn{2}{|c|}{ Femur } & \multicolumn{2}{|c|}{ Tibia } & \multicolumn{2}{|c|}{ Fibula } & \multicolumn{2}{|c|}{ Total } \\
\hline & $\mathrm{A} / \mathrm{O}$ & $\%$ & $\mathrm{~A} / \mathrm{O}$ & $\%$ & $\mathrm{~A} / \mathrm{O}$ & $\%$ & $\mathrm{~A} / \mathrm{O}$ & $\%$ & $\mathrm{~A} / \mathrm{O}$ & $\%$ & $\mathrm{~A} / \mathrm{O}$ & $\%$ & $\mathrm{~A} / \mathrm{O}$ & $\%$ \\
\hline \multicolumn{15}{|l|}{ Trauma } \\
\hline Younger adults* & $0 / 174$ & 0.0 & $1 / 150$ & 0.7 & $3 / 143$ & 2.1 & $0 / 203$ & 0.0 & $1 / 181$ & 0.5 & $0 / 129$ & 0.0 & $5 / 980$ & 0.5 \\
\hline Older adults** & $0 / 56$ & 0.0 & $3 / 55$ & 5.4 & $2 / 50$ & 4.0 & $1 / 62$ & 1.6 & $0 / 61$ & 0.0 & $2 / 44$ & 4.5 & $8 / 328$ & $2.4^{* * *}$ \\
\hline Total & $0 / 230$ & 0.0 & $4 / 205$ & 1.9 & $5 / 193$ & 2.6 & $1 / 265$ & 0.4 & $1 / 242$ & 0.4 & $2 / 173$ & 1.2 & $13 / 1308$ & 1.0 \\
\hline \multicolumn{15}{|l|}{ Infection } \\
\hline Younger adults & $0 / 115$ & 0.0 & 0/101 & 0.0 & 0/102 & 0.0 & $3 / 131$ & 2.3 & $15 / 115$ & 13.0 & $3 / 85$ & 3.5 & $21 / 649$ & 3.2 \\
\hline Older adults & $1 / 41$ & 2.4 & $0 / 43$ & 0.0 & $0 / 43$ & 0.0 & $0 / 48$ & 0.0 & $5 / 44$ & 11.4 & $3 / 38$ & 7.9 & $9 / 257$ & 3.5 \\
\hline Total & $1 / 156$ & 0.6 & $0 / 144$ & 0.0 & $0 / 145$ & 0.0 & $3 / 179$ & 1.7 & $20 / 159$ & 12.6 & $6 / 123$ & 4.9 & $30 / 906$ & 3.3 \\
\hline
\end{tabular}

*18-50 years of age

Table 17. Frequency of infracranial trauma and infection by element.

**50+ years of age

${ }^{* * *}$ statistically significant difference

\begin{tabular}{|c|c|c|c|c|c|c|c|c|}
\hline Age (yrs) & Males & $\%$ & Females & $\%$ & Indeterminate & $\%$ & Total & $\%$ \\
\hline \multicolumn{9}{|c|}{ Dental Caries } \\
\hline$<18$ & $0 / 1$ & 0.0 & $0 / 2$ & 0.0 & $14 / 58$ & 24.1 & $14 / 61$ & 22.9 \\
\hline $18-35$ & $8 / 18$ & 44.4 & $13 / 32$ & 40.6 & $0 / 2$ & 0.0 & $21 / 52$ & 40.4 \\
\hline $36-50$ & $17 / 29$ & 58.6 & $16 / 24$ & 66.7 & $1 / 1$ & 100.0 & $34 / 54$ & 63.0 \\
\hline $50+$ & $9 / 13$ & 69.2 & $14 / 22$ & 63.6 & $0 / 0$ & 0.0 & $23 / 35$ & 65.7 \\
\hline Total & $34 / 61$ & 55.7 & $43 / 80$ & 53.7 & $15 / 61$ & 24.6 & $92 / 202$ & 45.5 \\
\hline \multicolumn{9}{|l|}{ AMTL } \\
\hline$<18$ & $0 / 1$ & 0.0 & $0 / 2$ & 0.0 & $1 / 58$ & 1.7 & $1 / 61$ & 1.6 \\
\hline $18-35$ & $5 / 18$ & 27.8 & $4 / 33$ & 12.1 & $0 / 2$ & 0.0 & $9 / 53$ & 17.0 \\
\hline $36-50$ & $11 / 29$ & 37.9 & $16 / 24$ & 66.7 & $0 / 1$ & 0.0 & $27 / 54$ & 50.0 \\
\hline $50+$ & $12 / 13$ & 92.3 & $23 / 24$ & 95.8 & $0 / 0$ & 0.0 & $35 / 37$ & 94.6 \\
\hline Total & $28 / 61$ & 45.9 & $43 / 83$ & 51.8 & $1 / 61$ & 1.6 & $72 / 205$ & 35.1 \\
\hline \multicolumn{9}{|l|}{ Abscesses } \\
\hline$<18$ & $0 / 0$ & 0.0 & $0 / 2$ & 0.0 & $0 / 53$ & 0.0 & $1 / 55$ & 1.8 \\
\hline $18-35$ & $1 / 15$ & 6.7 & $3 / 33$ & 9.1 & $0 / 2$ & 0.0 & $4 / 50$ & 8.0 \\
\hline $36-50$ & $8 / 29$ & 27.6 & $6 / 24$ & 25.0 & $1 / 1$ & 100.0 & $15 / 54$ & 27.8 \\
\hline $50+$ & $6 / 13$ & 46.1 & $6 / 23$ & 26.1 & $0 / 0$ & 0.0 & $12 / 36$ & 33.3 \\
\hline Total & $15 / 57$ & 26.3 & $15 / 82$ & 18.3 & $2 / 56$ & 3.6 & $32 / 195$ & 16.4 \\
\hline \multicolumn{9}{|l|}{ Calculus } \\
\hline$<18$ & $0 / 1$ & 0.0 & $1 / 2$ & 50.0 & $14 / 58$ & 24.1 & $15 / 61$ & 24.6 \\
\hline 18-35 & $15 / 18$ & 83.3 & $22 / 32$ & 68.7 & $2 / 2$ & 100.0 & $39 / 52$ & 75.0 \\
\hline $36-50$ & $26 / 29$ & 90.0 & $20 / 24$ & 83.3 & $1 / 1$ & 100.0 & $47 / 54$ & 87.0 \\
\hline $50+$ & $10 / 12$ & 83.3 & $17 / 22$ & 77.3 & $0 / 0$ & 0.0 & $27 / 34$ & 79.4 \\
\hline Total & $51 / 60$ & 85.0 & $60 / 80$ & 75.0 & $17 / 61$ & 27.9 & $128 / 201$ & 63.7 \\
\hline \multicolumn{9}{|c|}{ Enamel Hypoplasia } \\
\hline$<18$ & $1 / 1$ & 100.0 & $0 / 2$ & 0.0 & $6 / 56$ & 10.7 & $7 / 59$ & 11.9 \\
\hline 18-35 & $5 / 14$ & 35.7 & $7 / 29$ & 24.1 & $0 / 2$ & 0.0 & $12 / 45$ & 26.7 \\
\hline $36-50$ & $6 / 27$ & 22.2 & $3 / 17$ & 17.6 & $0 / 1$ & 0.0 & $9 / 45$ & 20.0 \\
\hline $50+$ & $0 / 6$ & 0.0 & $1 / 12$ & 8.3 & $0 / 0$ & 0.0 & $1 / 18$ & 5.5 \\
\hline Total & $12 / 48$ & 25.0 & $11 / 60$ & 18.3 & $6 / 59$ & 10.2 & $29 / 167$ & 17.4 \\
\hline
\end{tabular}

Table 18. Dental pathology by individual. 
APPENDICE - A BIOARCHAEOLOGICAL STUDY OF THE KALFATA NECROPOLIS

\begin{tabular}{|c|c|c|c|c|c|c|c|c|}
\hline Age (yrs) & Males & $\%$ & Females & $\%$ & Indeterminate & $\%$ & Total & $\%$ \\
\hline \multicolumn{9}{|c|}{ Dental Caries } \\
\hline $18-35$ & $11 / 297$ & 3.7 & $34 / 716$ & 4.7 & $0 / 38$ & 0.0 & $45 / 1051$ & 4.3 \\
\hline $36-50$ & $42 / 620$ & 6.8 & $61 / 440$ & $13.9^{*}$ & $1 / 31$ & 3.2 & $104 / 1091$ & 9.5 \\
\hline $50+$ & $28 / 160$ & 17.5 & $38 / 241$ & 15.8 & $0 / 0$ & 0.0 & $66 / 401$ & 16.5 \\
\hline Total & $81 / 1077$ & 7.5 & $133 / 1397$ & 9.5 & $1 / 69$ & 1.4 & $215 / 2543$ & 8.4 \\
\hline \multicolumn{9}{|l|}{ AMTL } \\
\hline $18-35$ & $21 / 385$ & $5.4^{*}$ & $4 / 876$ & 0.5 & $0 / 45$ & 0.0 & $25 / 1306$ & 1.9 \\
\hline $36-50$ & $31 / 759$ & 4.1 & $53 / 624$ & $8.5^{*}$ & $0 / 31$ & 0.0 & $84 / 1414$ & 5.9 \\
\hline $50+$ & $124 / 360$ & 34.4 & $175 / 536$ & 32.6 & $0 / 0$ & 0.0 & $299 / 896$ & 33.4 \\
\hline Total & $176 / 1504$ & 11.7 & $232 / 2036$ & 11.4 & $0 / 76$ & 0.0 & $408 / 3616$ & 11.3 \\
\hline \multicolumn{9}{|c|}{ Abscesses } \\
\hline $18-35$ & $1 / 289$ & 0.3 & $5 / 819$ & 0.6 & $0 / 42$ & 0.0 & $6 / 1150$ & 0.5 \\
\hline $36-50$ & $12 / 643$ & 1.9 & $10 / 551$ & 1.8 & $2 / 30$ & 6.7 & $24 / 1224$ & 2.0 \\
\hline $50+$ & $12 / 302$ & 4.0 & $13 / 485$ & 2.7 & $0 / 0$ & 0.0 & $25 / 787$ & 3.2 \\
\hline Total & $25 / 1234$ & 2.0 & $28 / 1855$ & 1.5 & $2 / 72$ & 2.8 & $55 / 3161$ & 1.7 \\
\hline \multicolumn{9}{|l|}{ Calculus } \\
\hline $18-35$ & $127 / 294$ & $43.2^{*}$ & $230 / 713$ & 32.3 & $13 / 38$ & 34.2 & $370 / 1045$ & 35.4 \\
\hline $36-50$ & $343 / 615$ & 55.8 & $203 / 430$ & 47.2 & $5 / 31$ & 16.1 & $551 / 1076$ & 51.2 \\
\hline $50+$ & $90 / 156$ & 57.7 & $135 / 225$ & 60.0 & $0 / 0$ & 0.0 & $225 / 381$ & 59.0 \\
\hline Total & $560 / 1065$ & $52.6^{*}$ & $568 / 1368$ & 41.5 & $18 / 69$ & 26.1 & $1146 / 2502$ & 45.8 \\
\hline \multicolumn{9}{|c|}{ Enamel Hypoplasia } \\
\hline $18-35$ & $21 / 100$ & 21.0 & $36 / 254$ & 14.2 & $0 / 12$ & 0.0 & $57 / 366$ & 15.6 \\
\hline $36-50$ & $21 / 205$ & $10.2^{*}$ & $2 / 126$ & 1.6 & $0 / 10$ & 0.0 & $23 / 341$ & 6.7 \\
\hline $50+$ & $0 / 37$ & 0.0 & $3 / 83$ & 3.6 & $0 / 0$ & 0.0 & $3 / 120$ & 2.5 \\
\hline Total & $42 / 342$ & 12.3 & $41 / 463$ & 8.8 & $0 / 22$ & 0.0 & $83 / 827$ & 10.0 \\
\hline
\end{tabular}

Table 19. Dental pathology by tooth (permanent teeth).

* statistically significant difference between males and females

\begin{tabular}{|c|c|c|}
\hline Dental Pathology & Affected/Observed & $\%$ \\
\hline & & 7.2 \\
\hline Dental Caries & $38 / 525$ & 0.0 \\
\hline Antemortem Tooth Loss & $0 / 671$ & 0.2 \\
\hline Dental Abscess & $1 / 524$ & 6.2 \\
\hline Calculus & $34 / 546$ & 0.0 \\
\hline Enamel Hypoplasia & $0 / 261$ & \\
\hline
\end{tabular}

Table 20. Dental pathology by tooth (deciduous teeth). 


\begin{tabular}{|c|c|c|c|}
\hline Skeleton \# & Sex & Age (yrs) & Pathology \\
\hline $2 a$ & male & $21-35$ & Cribra orbitalia \\
\hline 9 & female & $36-50$ & Healed periostitis on the right tibia \\
\hline 10 & male & $36-50$ & Healed depression fracture to the left frontal bone \\
\hline 21 & male & $21-35$ & Cribra orbitalia, healed fracture to the acromial end of the right clavicle \\
\hline 25 & male & $50+$ & $\begin{array}{l}\text { Cribra orbitalia, possible lytic lesion on the left parietal bone, heavy lipping on the dens } \\
\text { of the second cervical vertebra }\end{array}$ \\
\hline 31 & female? & $50+$ & Moderate lipping around the lateral facet of the right patella \\
\hline $46 a$ & female & 21-35 & Healed fracture to the shaft of the left clavicle \\
\hline $46 \mathrm{~b}$ & male & $50+$ & $\begin{array}{l}\text { Cribra orbitalia, healed fracture to the shaft of an unidentified rib, moderate lipping of } \\
\text { the left temporo-mandibular joint, osteophytosis on the } 4 \text { th and } 5 \text { th lumbar vertebrae, } \\
\text { possible lytic lesions in the right temporal, right parietal, and sphenoid bones, left } \\
\text { clavicle, right scapula, ribs, left and right pelvic bones, humeri, femora, } 2 \text { cervical } \\
\text { vertebrae, } 9 \text { thoracic vertebrae, } 4 \text { lumbar vertebrae, and sacrum }\end{array}$ \\
\hline 50 & male? & $50+$ & $\begin{array}{l}\text { Healed Colles fracture to the left radius, osteophytosis on several unidentified thoracic } \\
\text { vertebrae }\end{array}$ \\
\hline 52 & indeterminate & $4-5$ & Cribra orbitalia \\
\hline 60 & indeterminate & $2.5-3$ & Cribra orbitalia \\
\hline $63 a$ & male & $21-35$ & $\begin{array}{c}\text { Possible perimortem trauma to the right parietal, right frontal, and right temporal } \\
\text { bones, spondylolysis of the } 4 \text { th lumbar vertebra, lipping on the distal femora, proximal } \\
\text { tibiae, distal humeri, proximal radii and ulnae, osteophytosis on the } 4 \text { th and 5th lumbar } \\
\text { vertebrae }\end{array}$ \\
\hline $63 b$ & male & $50+$ & $\begin{array}{l}\text { Compression fracture of an unidentified lumbar vertebra, eburnation on the distal left } \\
\text { and right humerus, lipping on the proximal right ulna, and on the articular facets of the } \\
\text { 9th, 10th, and 11th thoracic vertebrae, osteophytosis on the 10th thoracic vertebra }\end{array}$ \\
\hline 67 & male & $36-50$ & $\begin{array}{c}\text { Healed fracture to the shafts of three unidentified ribs, lipping and/or porosity on the } \\
\text { articular facets of the 8th, 9th, } 11 \text { th, and } 12 \text { th thoracic vertebrae and the } 3 \text { rd, } 4 \text { th, and } \\
\text { 5th lumbar vertebrae, osteophytosis on the cervical vertebrae, 10th, 11th, and 12th } \\
\text { thoracic vertebrae, and 3rd to 5th lumbar vertebrae }\end{array}$ \\
\hline 69 & female & $36-50$ & $\begin{array}{l}\text { Lipping and porosity on the articular facet and dens of the 1st and 2nd cervical } \\
\text { vertebrae }\end{array}$ \\
\hline 70 & male & $21-35$ & Lytic lesion on the right distal tibia \\
\hline 78 & female & $50+$ & $\begin{array}{l}\text { Ossification of costal cartilage of the 1st ribs, slight lipping around the acetabulum of } \\
\text { the left and right pelvic bones, moderate lipping of the articular facets of the } 5 \text { th lumbar } \\
\text { and } 1 \text { st sacral vertebrae, osteophytosis on the 3rd and 4th lumbar vertebrae and on four } \\
\text { unidentified thoracic vertebrae }\end{array}$ \\
\hline 112 & female & $50+$ & $\begin{array}{l}\text { Healed depression fracture to the left parietal bone, healed fracture to the left second } \\
\text { metacarpal, osteophytosis on the } 4 \text { th lumbar vertebra }\end{array}$ \\
\hline 135 & female & $36-50$ & Spondylolysis and osteophytosis of the 4th lumbar vertebra \\
\hline 140 & female & $50+$ & $\begin{array}{l}\text { Possible perimortem trauma to the left frontal and left maxillary bones, healed fracture } \\
\text { to the nasal bones, healed Colles fracture to the right radius, possible lytic lesion on the } \\
\text { distal right fibula, osteophytosis on the middle to lower thoracic vertebrae }\end{array}$ \\
\hline 145 & female & $13-17$ & Cribra orbitalia \\
\hline $151 a$ & male & $21-35$ & Porotic hyperostosis, cribra orbitalia \\
\hline
\end{tabular}

Table 21. Summary of skeletal pathology in the Kalfata remains. 


\begin{tabular}{|c|c|c|c|}
\hline Skeleton \# & Sex & Age (yrs) & Pathology \\
\hline 154 & male & $36-50$ & $\begin{array}{l}\text { Spondylolysis of the 5th lumbar vertebra, osteophytosis on the } 4 \text { th and } 5 \text { th lumbar } \\
\text { vertebrae, moderate lipping of the acetabula of the left and right pelvic bones }\end{array}$ \\
\hline 156 & female & $50+$ & $\begin{array}{c}\text { Moderate to heavy lipping and/or porosity on the articular facets of the } 1 \text { st to } 5 \text { th cervical } \\
\text { vertebrae }\end{array}$ \\
\hline 158 & female? & $36-50$ & Slight lipping around the glenoid fossa of the right scapula \\
\hline 159 & female & $50+$ & Osteophytosis on the thoracic and lumbar vertebrae \\
\hline 162 & female & $18-20$ & Cribra orbitalia \\
\hline 164 & male & $36-50$ & $\begin{array}{c}\text { Cribra orbitalia, healed depression fracture to the left parietal bone, moderate lipping of } \\
\text { the right temporo-mandibular joint }\end{array}$ \\
\hline 165 & indeterminate & $1-2$ & Cribra orbitalia \\
\hline 170 & female? & $21-35$ & Healed periostitis on the shafts of the left and right tibiae and femora \\
\hline 172 & indeterminate & $6-8$ & Porotic hyperostosis, cribra orbitalia \\
\hline 176 & female & $50+$ & $\begin{array}{l}\text { Healed fracture to the shaft of the right clavicle, healed Colles fracture to the right radius, } \\
\text { healed fracture to the distal right ulna, osteophytosis on the thoracic, lumbar, and first } \\
\text { sacral vertebrae, slight to moderate pitting and/or lipping on the glenoid fossa of the right } \\
\text { scapula, the articular facets of the right trapezoid, right lunate, right patella, } 2 \text { nd and } 3 \text { rd } \\
\text { thoracic vertebrae, and proximal facet of a proximal phalange }\end{array}$ \\
\hline 178 & female & $36-50$ & $\begin{array}{l}\text { Healed periostitis on the proximal and midshaft of the right tibia, osteophytosis on one } \\
\text { unidentified cervical vertebra }\end{array}$ \\
\hline 179 & female & $50+$ & $\begin{array}{l}\text { Cribra orbitalia, possible perimortem trauma to the frontal bone and the left and right } \\
\text { parietal bones, osteophytosis on the cervical, thoracic, and lumbar vertebrae }\end{array}$ \\
\hline 182 & male & $50+$ & $\begin{array}{l}\text { Lytic lesion on the proximal right humerus, healed periostitis on the midshaft of the left } \\
\text { fibula and the left and right tibiae, moderate to heavy lipping on the distal right ulna } \\
\text { and radius, the distal articular facet of a proximal phalange, severe porosity and/or } \\
\text { eburnation on the articular facets of the cervical vertebrae, osteophytosis on the thoracic } \\
\text { and lumbar vertebrae }\end{array}$ \\
\hline 183 & indeterminate & $5-7$ & Porotic hyperostosis, cribra orbitalia \\
\hline 184 & female & $21-35$ & Healed periostitis on the midshaft of the left and right tibiae \\
\hline 186 & male? & $36-50$ & Osteophytosis on one unidentified cervical vertebra \\
\hline 189 & female & $50+$ & $\begin{array}{l}\text { Healed fracture to the distal shaft of the left fibula, pitting and/or lipping on the articular } \\
\text { facets of the } 1 \mathrm{st} \text {, } 2 \text { nd and } 12 \text { th thoracic vertebrae and the } 1 \text { st to } 5 \text { th lumbar vertebrae, } \\
\text { osteophytosis on the } 4 \text { th and } 5 \text { th lumbar vertebrae and the } 1 \text { st sacral vertebra }\end{array}$ \\
\hline 194 & male & $18-20$ & Cribra orbitalia \\
\hline 196 & indeterminate & $3-5$ & Cribra orbitalia \\
\hline 198 & female & $50+$ & $\begin{array}{l}\text { Healed periostitis on the shafts of the left and right tibiae, button osteoma on the frontal } \\
\text { bone, biparietal thinning, eburnation on the distal right femur and right patella, lipping } \\
\text { and/or porosity on the right } 1 \text { st to } 3 \text { rd cuneiform, left } 2 \text { nd cuneiform and the proximal } \\
\text { articular facets of all metatarsals, healed fracture to the shaft of an unidentified rib, } \\
\text { osteophytosis on one thoracic and one lumbar vertebra }\end{array}$ \\
\hline 199 & indeterminate & $6-18$ months & Cribra orbitalia, endocranial lesions on the frontal and occipital bones \\
\hline 202 & indeterminate & $6-9$ & Cribra orbitalia \\
\hline 209 & male & $36-50$ & $\begin{array}{l}\text { Healed fracture to the distal shaft of the left tibia, slight to moderate lipping on the distal } \\
\text { femora, patellae, acetabulum of the left pelvic bone, Schmorl's nodes on the lumbar } \\
\text { vertebrae }\end{array}$ \\
\hline 212 & indeterminate & $5-7$ & Healed periostitis on the midshaft of the left tibia \\
\hline
\end{tabular}

Table 21. Summary of skeletal pathology in the Kalfata remains. 


\begin{tabular}{|c|c|c|c|}
\hline Skeleton \# & Sex & Age (yrs) & Pathology \\
\hline 215 & male & $36-50$ & $\begin{array}{l}\text { Healed depression fracture to the frontal bone, healed periostitis on the midshaft of the } \\
\text { left tibia, moderate to severe pitting and/or lipping on the articular facets of the right } \\
\text { calcaneus, talus, navicular, and cuboid, the acetabulum and auricular surface of the } \\
\text { right pelvic bone, and the auricular surface of the sacrum, osteophytosis on the lumbar } \\
\text { vertebrae }\end{array}$ \\
\hline 216 & indeterminate & $11-13$ & $\begin{array}{l}\text { Partially healed periostitis on shaft of right second metatarsal, left and right third } \\
\text { metatarsals }\end{array}$ \\
\hline 219 & male & $36-50$ & Osteophytosis on one lumbar vertebra \\
\hline 222 & female? & $50+$ & $\begin{array}{l}\text { Osteophytosis on two unidentified thoracic vertebrae, lipping and/or eburnation on the } \\
\text { articular facets of several phalanges }\end{array}$ \\
\hline $229 a$ & male & $36-50$ & $\begin{array}{c}\text { Osteophytosis on one unidentified thoracic vertebra and on the 12th thoracic vertebra, } \\
\text { slight lipping on distal right humerus, glenoid fossa of right scapula, distal facets of one } \\
\text { proximal and one middle phalange of the hand }\end{array}$ \\
\hline $229 b$ & male? & $36-50$ & Osteophytosis on an unidentified lumbar vertebra \\
\hline 241 & indeterminate & $4-6$ & Cribra orbitalia \\
\hline 246 & female & $21-35$ & Cribra orbitalia \\
\hline 249 & male & $50+$ & $\begin{array}{l}\text { Possible healed fracture to distal shaft of right fibula, possible healed fracture to right } \\
\text { 1st metacarpal, slight lipping around the glenoid fossa of the left and right scapula, } \\
\text { the acetabulum of the left and right pelvic bones, and the articular facets of the right } \\
\text { calcaneus, moderate to heavy lipping and/or porosity of the sternal end of the right } \\
\text { clavicle and the articular facets of the 2nd to 5th cervical vertebrae, osteophytosis on } \\
\text { 10th to 12th thoracic vertebrae and all lumbar vertebrae }\end{array}$ \\
\hline 250 & female & $36-50$ & $\begin{array}{l}\text { Healed fracture to right } 1 \text { st metacarpal, moderate lipping on the right inferior articular } \\
\text { facet of an unidentified lumbar vertebra, osteophytosis on the 5th and 6th cervical } \\
\text { vertebrae }\end{array}$ \\
\hline 254 & female & $36-50$ & Healed periostitis on distal shaft of right femur \\
\hline 257 & female & $36-50$ & $\begin{array}{l}\text { Osteochondritis dissecans on left talus, femoral condyle, and head of left and right } \\
\text { radius }\end{array}$ \\
\hline 266 & indeterminate & $1-2$ & Endocranial lesions on right and left temporal bones, and porosity on the sphenoid bone \\
\hline 268 & indeterminate & $5-7$ & Cribra orbitalia \\
\hline 273 & indeterminate & $4-6$ & $\begin{array}{l}\text { Cribra orbitalia, porotic hyperostosis, endocranial lesions on unidentified cranial bone } \\
\text { fragments }\end{array}$ \\
\hline 274 & female & $36-50$ & $\begin{array}{l}\text { Fusion of } 4 \text { th and } 5 \text { th cervical vertebrae, osteophytosis on } 4 \text { th and } 5 \text { th cervical } \\
\text { vertebrae, lipping and porosity on the articular facets of the } 2 \text { nd and } 3 \text { rd cervical } \\
\text { vertebrae }\end{array}$ \\
\hline 277 & female & $36-50$ & $\begin{array}{l}\text { Healed Colles fracture to left radius, slight lipping around the acetabulum of the left and } \\
\text { right pelvic bones, osteophytosis on cervical vertebrae, 4th and 5th lumbar vertebrae, } \\
\text { and 1st sacral vertebra }\end{array}$ \\
\hline 286 & female & $50+$ & $\begin{array}{l}\text { Possible healed fracture to shaft of right second rib, heavy lipping, pitting, and } \\
\text { eburnation of the articular facets of the left and right patella and the left and right distal } \\
\text { femora, moderate lipping and porosity of the sternal end of the left clavicle, slight to } \\
\text { moderate lipping around the glenoid fossa of the left and right scapulae, slight lipping } \\
\text { around head of right humerus and the articular facets of } 3 \text { carpal bones and the } 1 \text { st and } \\
\text { 3rd metacarpals, heavy porosity on acromial end of right clavicle, slight to moderate } \\
\text { lipping around the acetabulum of the left and right pelvic bones, osteophytosis on 4th to } \\
\text { 6th cervical vertebrae, thoracic and lumbar vertebrae, 1st sacral vertebra }\end{array}$ \\
\hline 288 & indeterminate & $4-6$ & Cranial deformation \\
\hline 291 & male & $21-35$ & Schmorl's nodes on 5 thoracic and 4 lumber vertebrae \\
\hline 292 & male & $50+$ & Cribra orbitalia, slight lipping on distal right humerus, eburnation on proximal left radius \\
\hline
\end{tabular}

Table 21. Summary of skeletal pathology in the Kalfata remains. 


\begin{tabular}{|c|c|c|c|}
\hline Skeleton \# & Sex & Age (yrs) & Pathology \\
\hline 295 & indeterminate & $2-4.5$ & Cribra orbitalia \\
\hline 302 & male & $50+$ & $\begin{array}{l}\text { Cribra orbitalia, healed periostitis of the left fibula and tibia, degenerative joint changes } \\
\text { throughout the skeleton }\end{array}$ \\
\hline 307 & female & $18-20$ & Cribra orbitalia, active periostitis on proximal shaft of right fibula \\
\hline 310 & female & $50+$ & $\begin{array}{l}\text { Osteophytosis, slight to moderate lipping around the proximal facets of the proximal } \\
\text { phalanges of the big toe, osteophytosis on cervical, thoracic, and lumbar vertebrae, } \\
\text { Schmorl's nodes on lumber vertebrae }\end{array}$ \\
\hline 311 & female & $17-19$ & Cribra orbitalia \\
\hline 313 & indeterminate & $6-8$ & Cribra orbitalia \\
\hline 314 & indeterminate & $3-5$ & Cribra orbitalia, porosity on the mandible, maxillary bones, and sphenoid bone \\
\hline 321 & female & $21-35$ & Cribra orbitalia \\
\hline 324 & male & $36-50$ & $\begin{array}{l}\text { Hyperostosis frontalis interna, lipping on the left superior articular facets of the } 3 r d \text { and } \\
\text { 4th cervical vertebrae, osteophytosis on the 3rd and 4th cervical vertebrae }\end{array}$ \\
\hline 325 & female & $36-50$ & Healed fracture to distal shaft of left ulna \\
\hline 330 & male & $50+$ & $\begin{array}{c}\text { Cribra orbitalia, moderate lipping around glenoid fossa of right scapula, acetabulum } \\
\text { of left pelvic bone, osteophytosis on lower thoracic vertebrae, lower lumbar vertebrae, } \\
\text { cervical vertebrae, Schmorl's nodes }\end{array}$ \\
\hline 335 & male & $36-50$ & Slight lipping on distal right ulna \\
\hline 336 & female & $36-50$ & Osteophytosis on 11th and 12th thoracic vertebrae and on lumbar vertebrae \\
\hline 338 & female & $50+$ & $\begin{array}{c}\text { Possible healed periostitis on left and right tibiae, possible trauma to shaft of right femur, } \\
\text { osteophytosis on lumbar vertebrae, Schmorl's nodes }\end{array}$ \\
\hline 344 & female & $21-30$ & Cribra orbitalia \\
\hline 346 & female & $21-35$ & Schmorl's nodes on 1 cervical, 3 thoracic, and 2 lumbar vertebrae \\
\hline 347 & female & $50+$ & $\begin{array}{l}\text { Healed fractures to midshaft of left ulna with myositis ossificans, left ischio-pubic ramus, } \\
\text { right 3rd metatarsal, two unidentified ribs, osteophytosis }\end{array}$ \\
\hline 348 & indeterminate & $2-4$ & Cribra orbitalia \\
\hline 349 & male & $36-50$ & Healed fracture to the distal right ulna \\
\hline 350 & female & $36-50$ & Partially healed periostitis on the proximal metaphysis of the left tibia \\
\hline 352 & male & $50+$ & $\begin{array}{l}\text { Healed fracture to the shaft of the left clavicle, healed trauma to the midshaft of the right } \\
\text { humerus }\end{array}$ \\
\hline 354 & male & $36-50$ & Osteophytosis on two unidentified thoracic vertebrae \\
\hline 357 & male & $36-50$ & Cribra orbitalia \\
\hline 358 & indeterminate & $5-7$ & Cribra orbitalia \\
\hline 360 & male? & $18-20$ & Cribra orbitalia, porotic hyperostosis \\
\hline 372 & indeterminate & $0-6$ months & Endocranial lesions on parietal bone fragments \\
\hline 373 & male & $36-50$ & Healed periostitis on the shafts of the left and right tibiae and fibulae \\
\hline 374 & male & $36-50$ & Healed fracture to the shaft of one unidentified rib \\
\hline 380 & indeterminate & $3-5$ & Cribra orbitalia \\
\hline 391 & male & $21-35$ & $\begin{array}{l}\text { Cribra orbitalia, healed periostitis on middle and distal shaft of left and right tibia, } \\
\text { osteophytosis on cervical, thoracic, and lumbar vertebrae, lipping and/or porosity on the } \\
\text { articular facets of the thoracic vertebrae }\end{array}$ \\
\hline 393 & indeterminate & $2-4$ & Porotic hyperostosis \\
\hline
\end{tabular}

Table 21. Summary of skeletal pathology in the Kalfata remains. 
TROISIÈME PARTIE : SYNTHÈSES

\begin{tabular}{|c|c|c|c|}
\hline Skeleton \# & Sex & Age (yrs) & Pathology \\
\hline 397 & female & $21-35$ & Cribra orbitalia \\
\hline 403 & indeterminate & $2-4$ & Cribra orbitalia \\
\hline 413 & female & $11-13$ & $\begin{array}{l}\text { Cribra orbitalia, endocranial lesions on the frontal bone, porosity on the greater wings of } \\
\text { the sphenoid bone }\end{array}$ \\
\hline 427 & male & $50+$ & $\begin{array}{l}\text { Osteophytosis on cervical vertebrae and on the 1st sacral vertebra, Schmorl's nodes on } \\
\qquad \text { lower thoracic vertebrae }\end{array}$ \\
\hline 431 & indeterminate & $6-7$ & Porotic hyperostosis, porosity on right maxillary and left and right zygomatic bones \\
\hline 436 & male & $21-35$ & $\begin{array}{l}\text { Schmorl's nodes on the 5th to } 12 \text { th thoracic vertebrae, the lumbar vertebrae, and the } 1 \mathrm{st} \\
\text { sacral vertebra }\end{array}$ \\
\hline 437 & female & $36-50$ & $\begin{array}{l}\text { Healed fracture to the distal shaft of left ulna, small osteoma on the distal shaft of the left } \\
\text { tibia, Schmorl's nodes on the lumbar vertebrae, osteophytosis on five thoracic vertebrae }\end{array}$ \\
\hline 438 & female & $50+$ & $\begin{array}{l}\text { Cribra orbitalia, Schmorl's nodes on thoracic and lumbar vertebrae, fusion of a middle } \\
\text { and distal phalanx of the foot }\end{array}$ \\
\hline 440 & indeterminate & $6-8$ & Cribra orbitalia, porotic hyperostosis \\
\hline 442 & female & $36-50$ & $\begin{array}{l}\text { Slight to moderate lipping around the glenoid fossa of the left and right scapulae and } \\
\text { distal left humerus, osteophytosis on one cervical, } 6 \text { thoracic, and } 4 \text { lumbar vertebrae }\end{array}$ \\
\hline 443 & indeterminate & $9-11$ & Cribra orbitalia \\
\hline 445 & female & $36-50$ & $\begin{array}{l}\text { Fusion of 3rd and 4th thoracic vertebrae, osteophytosis on 7th, 8th, and 9th thoracic } \\
\text { vertebrae }\end{array}$ \\
\hline 447 & male & $36-50$ & $\begin{array}{l}\text { Cribra orbitalia, osteophytosis on 8th, 9th, } 10 \text { th, and } 11 \text { th thoracic vertebrae and the } 4 \text { th } \\
\text { and 5th lumbar vertebrae, fusion of 9th and } 10 \text { th thoracic vertebrae, spondylolysis of the } \\
\text { 5th lumbar vertebra }\end{array}$ \\
\hline $448 a$ & indeterminate & $4-6$ & Cribra orbitalia \\
\hline 456 & female & $50+$ & $\begin{array}{l}\text { Cribra orbitalia, healed fracture to the right pubic bone, fusion of } 4 \text { unidentified thoracic } \\
\text { vertebrae, osteophytosis on the } 3 \text { rd, } 4 \text { th and } 5 \text { th lumbar vertebrae }\end{array}$ \\
\hline 458 & female & $50+$ & Biparietal thinning, osteophytosis on 5th and 6th cervical vertebrae \\
\hline$?^{*}$ & indeterminate & $2-4$ & Cribra orbitalia \\
\hline ? & indeterminate & $3-4$ & Cribra orbitalia \\
\hline$?$ & male & $50+$ & Cribra orbitalia, healed fractures to the shafts of two rib fragments \\
\hline$?$ & female & $21-35$ & Healed periostitis on midshaft of left and right tibia \\
\hline ? & indeterminate & $11-13$ & Cribra orbitalia \\
\hline$?$ & female & $<50$ & $\begin{array}{l}\text { Lipping around the glenoid fossa of the right scapula, osteophytosis on 5th lumbar and } \\
\qquad 1 \text { st sacral vertebrae }\end{array}$ \\
\hline ? & male & $36-50$ & $\begin{array}{l}\text { Schmorl's node on an unidentified thoracic vertebra, osteophytosis on two unidentified } \\
\text { thoracic vertebrae and on the lumbar vertebrae }\end{array}$ \\
\hline
\end{tabular}

* indicates individuals of unknown provenience

Table 21. Summary of skeletal pathology in the Kalfata remains. 


\section{Bibliographie}

\section{Abréviations}

AMA Античний мир и археология / Antichniy mir i arheologiya [Monde antique et archéologie]

AOP/AOR Археологически открития и разкопки / Arheologicheski otkritiya i razkopki [Découvertes et fouilles archéologiques]

ГHM/GNM Годишник на Народния музей / Godisnik na Narodniya muzey [Annuaire du Musée National] ГCУ ИФФ/GSU IFF Годишник на Софийския университет, Историко-Филологически факултет / Godishnik na Sofiyskiya universitet, Istoriko-Filologicheski Fakultet [Annuaire de l'Université de Sofia, Faculté d'histoire et de philologie] ГСУ ФИФ/ GSU FIF Годишник на Софийския университет, Философско-Исторически факултет / Godishnik na Sofiyskiya universitet, Filosofsko - Istoricheski Fakultet [Annuaire de l'Université de Sofia, Faculté de philosophie et d'histoire]

ИБАД/IBAD Известия на Българското археологическо дружество / Izvestiya na Balgarskoto arheologichesko drujestvo

[Bulletin de la Société archéologique bulgare]

ИБАИ/ІВАІ Известия на Българския археологическия институт / Izvestiya na Balgarskiya Arheologicheski Institut

[Bulletin de l'Institut archéologique bulgare]

ИHMB/INMV Известия на Народния музей - Варна / Izvestiya na Narodniya Muzey - Varna [Bulletin du Musée national - Varna]

ИВАД/IVAD Известия на Варненското археологическо дружество / Izvestiya na Varnenskoto arheologichesko drujestvo

[Bulletin de la Société archéologique de Varna]

ИНМБ/INMВ Известия на Народния музей - Бургас / Izvestiya na Narodniya Muzey - Burgas

[Bulletin du Musée National - Bourgas]

ИМЮИБ/IMYUIB Известия на музеите в Югоизточна България / Izvestiya na museite v Yugoiztochna Balgaria

[Bulletin des musées de la Bulgarie du Sud-Est]

ИНИМ/INIM Известия на Националния исторически музей / Izvestiya na Natsionalniya istoricheski musey

[Bulletin du Musée National d'Histoire]

МПК/МРК Музеи и паметници на културата / Musei i pametnitsi na kulturata

[Musées et monuments de la culture]

PП/RP Разкопки и проучвания / Razkopki i prouchvaniya

[Fouilles et recherches]

С6нУНK/SbNUNK Сборник за народни умотворения, наука и книжнина / Sbornik za narodni umotvoreniya, nauka i knijnina

[Recueil de sagesse populaire, science et littérature] 


\section{Abréviations}

$\boldsymbol{A A}:$ Archäologischer Anzeiger

$\boldsymbol{A B}:$ Archaeologia Bulgarica

ABSA : Annual of the British School at Athens

AEM : Archaeologisch-epigraphische Mitteilungen aus Oesterreich-Ungarn

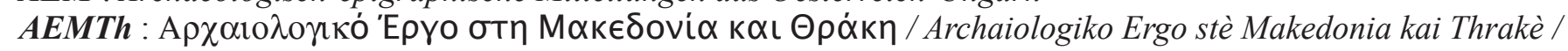
Travaux archéologiques en Macédoine et en Thrace

$\boldsymbol{A J \boldsymbol { A }}$ : American Journal of Archaeology

AM : Athenische Mitteilungen

ArchDelt : Archaiologikon Deltion

$\boldsymbol{B C H}:$ Bulletin de Correspondance Hellénique

CCEC : Cahiers du Centre d'Études chypriotes

CRAI : Comptes rendus de l'Académie des Inscriptions et Belles-Lettres

IstMitt : Istanbuler Mitteilungen

$\boldsymbol{J H S}$ : Journal of Hellenic Studies

J्̈AI : Jahreschefte des Österreichischen Archäologischen Instituts

MEFRA : Mélanges de l'École française de Rome. Antiquité

NotSc : Notizie degli Scavi di Antichità

$\boldsymbol{P A E}$ : Praktika tès Archaiologikès Hetairias

$\boldsymbol{R A}:$ Revue archéologique

$\boldsymbol{R P h}:$ Revue de philologie, de littérature et d'histoire anciennes

SAUS : Studia Archaeologica Universitatis Serdicensis

$A \boldsymbol{R} \boldsymbol{V}^{2}$ : Beazley (J.D.) - Attic Red-Figure Vase-Painters. Oxford, Clarendon Press, 1963

Atti Taranto : Atti del Convegno internazionale di studi sulla Magna Grecia. Naples et Tarente

$\boldsymbol{B A R}$ : British Archaeological Reports

$\boldsymbol{C V A}$ : Corpus Vasorum Antiquorum. Union Académique Internationale

IG : Inscriptiones Graecae

LIMC : Lexicon Iconographicum Mythologiae Classicae. VIII vol. Zurich et Munich, puis Zurich et Dusseldorf, Artemis Verlag, 1981-1997

Paralipomena : Beazley (J.D.) - Paralipomena : Additions to Attic Black-Figure Vase-Painters and to Attic RedFigure Vase-Painters. Oxford, Clarendon Press, 1971

SEG : Supplementum Epigraphicum Graecum

ThesCRA : Thesaurus Cultus et Rituum Antiquorum. 5 vol. Los Angeles, The J. Paul Getty Museum, 2004-2005 


\section{Références}

\begin{abstract}
Ahmerov 1948: АХMЕРОВ (Р.) - Клейменые черепицы древнегреческого Херсонеса. В: Вестник Древней Истории, 1948, 1, 1948, p. 163-169.

[AHMEROV (R.) - Tuiles à estampilles grecques antiques de Chersonèse. Vesnik Drevney Istorii, 1948, p. 163-169.]

Åkerström 1966 : ÅKERSTRÖM (Å.) - Die architektonischen Terrakotten Kleinasiens. Lund, CWK Gleerup, 1966.

Alexandrescu 1978: ALEXANDRESCU (P.) - La céramique d'époque archaïque et classique (VII $-I V^{e}$ s.). Bucarest, Editura Academiei Republicii Socialiste România, 1978 (Histria, 4).

Alexandrov 2007 : АЛЕКСАНДРОВ (С.) - Спасителни разкопки в м. Колокита, гр. Созопол. АОР през 2006 г. София, 2007,
\end{abstract} c. 234.

[ALEXANDROV (S.) - Fouilles de sauvetage sur le cap Kolokita, ville de Sozopol. In : AOR année 2006. Sofia, 2007, p. 234.]

Amandry 1984 : AMANDRY (P.) - Os et coquilles. In : L'antre corycien II. Athènes, EfA, et Paris, de Boccard, 1984, p. 347-380 (BCH Suppl. IX).

Amore 2004 : AMORE (M.G.) - Necropolis of Apollonia: tumulus 9. In : Cabanes (P.), Lamboley (J.L.) dir., L'Illyrie méridionale et l'Epire dans l'Antiquité IV, Actes du IV colloque international de Grenoble, 10-12 octobre 2002. Paris, de Boccard, 2004, p. 307-310.

Andreiomenou 1994 : ANDREIOMENOU (A.K.) - La nécropole d'Akraiphia. In : La Genière 1994, p. 99-126.

Angel 1966 : ANGEL (J.L.) - Porotic hyperostosis, anemias, malarias, and marshes in the prehistoric eastern Mediterranean. Science, 153, 1966, p. $760-763$.

Angel 1971 : ANGEL(J.L.) - The People of Lerna: Analysis of a Prehistoric Aegean Population. Volume 2. The People. Washington D.C., American School of Classical Studies at Athens and Smithsonian Institution, 1971.

Angel 1984 : ANGEL (J.L.) - Health as a crucial factor in the changes from hunting to developed farming in the eastern Mediterranean. In : Cohen (M.N.), Armelagos (G.J.) eds, Paleopathology at the Origins of Agriculture. New York, Academic Press, 1971, p. 51-73.

Angelescu 1992 : ANGELESCU (M.) - Un problème controversé : l'expédition de Périclès dans le Pont-Euxin. Pontica, 25, 1992, p. 45-54.

Angelova, Draganov 2003 : ANGELOVA (H.), DRAGANOV (V.) Underwater Archaeological Excavations of Submerged Late Eneolithic and Early Bronze Age Settlements in Kiten and Sozopol (South Bulgarian Black Sea coast). In : Angelova (H.) dir., In honorem M. Lazarov. Proceedings of the International Symposium. Sofia, Center for Underwater Archaeology/Institute of Thracology \& Bulgarian Academy of Science, 2003, p. 9-22.

Angelova, Draganov, Dimitrov 1994 : АНГЕЛОВА (Х.), ДРАГАНОВ (В.), ДИМИТРОВ (Б.). - Потънали селища от финала на халколита и ранната бронзова епоха в созополското пристанище. В: АОР през 1992-1993 г. Велико Търново, 1994, с. 17-20.

[ANGELOVA (H.), DRAGANOV (V.), DIMITROV (B.) - Sites submergés de la fin du Chalcolithique ou du Bronze ancien dans le Port de Sozopol. In : AOR année 1992-1993. Veliko Tarnovo, 1994, p. 17-20.]

Archibald 2001 : ARCHIBALD (Z.H.) - The Odrysian River Port near Vetren, Bulgaria, and the Pistiros Inscription. Talanta, 32-33, 2000-2001, p. 253-275.
Arribas et al. 1987 : ARRIBAS (A.), TRIAS (M.G.), CERDA (D.), DE HOZ (J.) - El barco de El Sec (Calvià, Mallorca), estudio de los materiales. Majorque, 1987.

Ascenzi, Balisteri 1977 : ASCENZI (A.), BALISTRERI (P.) - Porotic hyperostosis and the problem of the origin of thalassemia in Italy. Journal of Human Evolution, 6, 1977, p. 595-604.

Åström 1970 : ÅSTRÖM (P.) - What we Know About Ancient Fibres. In : Gullberg (E.), Åström (P.) dir., The Thread of Ariadne. A Study of Ancient Greek Dress. Göteborg, Åström ed., 1970, p. 12-18.

Avram 1995: AVRAM (A.) - Poleis und nicht-Poleis im ersten und zweiten attischen Seebund. In : Hansen (M.H.), Raaflaub (K.) eds., Studies in the Ancient Greek Polis. Stuttgart, F. Steiner, 1995, p. 191-200.

Avram 1996: AVRAM (A.) - Les timbres amphoriques. 1. Thasos. Bucarest, Editura encyclopedică, et Paris, de Boccard, 1996 (Histria, 8).

Avram 2003 : AVRAM (A.) - Histria. In : Grammenos, Petropoulos 2003, p. 279-340.

Avram, Hind, Tsetskhladze 2004: AVRAM (A.), HIND (J.), TSETSKHLADZE (G.) - The Black Sea Area. In: Hansen (M.H.), Nielsen (T.H.) dir., An Inventory of Archaic and Classical Poleis : An Investigation Conducted by the Copenhagen Polis Centre for the Danish National Research Foundation. Oxford University Press, 2004, p. 924-973.

Balabanov 1979: БАЛАБАНОВ (П.) - Антични селища на територията на Бургас. ИМЮИБ, 2, с. 27-32.

[BALABANOV (P.) - Habitats antiques sur le territoire de Bourgas. IMYUIB, 2, 1979, p. 27-32.]

Balabanov 1986: БАЛАБАНОВ (П.)/BALABANOV (Р.) Фракийское святилище возле Дебелта/Sanctuaire thrace près de Debelt. In : Fol (A.) dir., Les Thraces et les colonies grecques, VII $-V^{e} s . a v$. J.-C. Actes du III symposium international "Thracia Pontica" (Sozopol, 6-12 octobre 1985). Sofia, Centre d'histoire maritime et d'archéologie sous-marine \& Institut de thracologie auprès de l'Académie bulgare des sciences, 1986, p. 221-237.

Balabanov 1999 : БАЛАБАНОВ (П.) - Тракийски ритуални ями край с. Дебелт, Бургаска област. Археология, 40, 3-4, 1999, c. 62-76.

[BALABANOV (P.) - Fosses rituelles thraces près du village de Debelt, département de Bourgas. Arheologiya, 40, 3-4, 1999, p. 62-76.]

Balabanov 2003 : BALABANOV (P.) - Trois inscriptions de la haute époque hellénistique. In : Angelova (H.) dir., In honorem M. Lazarov, Proceedings of the International Symposium. Sofia, Center for Underwater Archaeology \& Institute of Thracology, Bulgarian Academy of Science, 2003, p. 23-29.

Balabanov, Drajeva 1985 : БАЛАБАНОВ (П.), ДРАЖЕВА (Ц.) Тракийски некрополи в кв. “Победа” в Бургас. ИМЮИБ, 8, 1985, с. 9-29.

[BALABANOV (P.), DRAJEVA (Ts.) - Nécropoles thraces dans le quartier "Pobeda" à Bourgas. IMYIB, 8, 1985, p. 9-29.]

Baladié 1989 : BALADIÉ (R.) - Strabon, Géographie. Tome IV : Livre VII (Europe centrale, Balkans). Paris, Les Belles Lettres, 1989.

Baralis, Riapov 2002 : BARALIS (A.), RIAPOV (A.) - Apollonia Pontica. In : Cat. Bruxelles 2002, p. 198-203. 
Baralis, Riapov 2006 : BARALIS (A.), RIAPOV (A.) - La nécropole classique et hellénistique d'Apollonia du Pont. Premier bilan des résultats obtenus dans le secteur français. In : Manucu-Adamesteanu (M.) dir., À la recherche d'une colonie, Actes du colloque international " 40 ans de recherche archéologique à Orgamè/Argamum" (Bucarest-Tulcea-Jurilovca, 3-5 octobre 2005), Bucarest, Agir, 2006, p. 53-78.

Baralis, Riapov, sous presse : BARALIS (A.), RIAPOV (A.) - Les fouilles franco-bulgares de la nécropole classique et hellénistique d'Apollonia du Pont, lieu-dit Kalfata (Sozopol, Bulgarie). In : Black Sea Area in the System of the Hellenistic World, Actes du XI ${ }^{\mathrm{e}}$ symposium international de Vani (septembre 2005). Besançon, PUFC, sous presse.

Barnett, Mendelson 1987 : BARNETT (R.D.), MENDELSON (C.) eds. Tharros: A Catalogue of Material in the British Museum from Phoenician and other Tombs at Tharros, Sardinia. Londres, British Museum, 1987.

Bass 1987 : BASS (W.M.) - Human Osteology: A Laboratory and Field Manual of the Human Skeleton. Columbia, Missouri Archaeological Society, $3^{\circ}$ éd., 1987.

Batsova, Kanchev 1974 : БАЦОВА (Е.), КЪНЧЕВ (М.) - Новооткрити тракийски погребения в Новозагорско. Археология, 26, 1 , 1974 , с. 50-57.

[BATSOVA (E.), KANCHEV (M.) - Tombes thraces récemment découvertes dans la région de Nova Zagora. Arheologiya, 26, 1, 1974, p. 50-57.]

Baudat 1953: BAUDAT (B.) - Terres cuites de l'École française d'Athènes. $B C H, 77,1953$, p. 1-45, pl. I-XX.

Béal 1984 : BÉAL (J.-C.) - Les objets en os et en ivoire. Musées de la ville de Vienne, 1984.

Beazley 1929 : BEAZLEY (J.D.) - Charinos. JHS, 49, 1929, p. 38-78.

Becker 1995 : BECKER (M.J.) - Human skeletal remains from the precolonial Greek emporium of Pithekoussai on Ischia (NA) : Culture contact in Italy from the early eighth to the second century B.C. In : Christie (N.) ed., Settlement and Economy in Italy 1500 B.C. to A.D. 1500. Papers of the Fifth Conference on Italian Archaeology. Oxford, 1995, p. 273-281.

Becker 1996 : BECKER (M.J.) - The human skeletons from the Archaic cemeteries. Appendix in Lyons (C.L.), The Archaic Cemeteries. Morgantina Studies, Volume 5. Princeton University Press, 1996, p. 227-237.

Becker, Donadio 1992 : BECKER (M.J.), DONADIO (A.) - A summary of the analysis of cremated human skeletal remains from the Greek colony of Pithekoussai at Lacco Ameno, Ischia, Italy. Old World Archaeology Newsletter, 16, 1, 1992, p. 15-23.

Becker et al. 2002 : BECKER (M.), RICHTER (B.), GARATE (J.), ZERBINI (S.), GEORGIEV (I.), LOBAZOV (V.), KOTZEV (V.), NEGUSINI (M.), GALANIS (J.), BÜRKI (B.), YUZEFOVICH (P.), MARSON (I.), VEIS (G.), KAHLE (H.G.), BAKER (T.) - Assessment of Height Variations by GPS at Mediterranean and Black Sea Coast Tide Gauges from the SELF Projects. Global and Planetary Change, 34, 1-2, 2002, p. 5-35.

Belyashki 1985 : BELIASHKI (T.) - Study of Recent Vertical Crustal Movements along the Bulgarian Sea Coast Using Tide Gauge Data and Precise Levelling. Doctorat du Laboratoire central de Géodésie, Académie bulgare des sciences, Sofia, 1985.

Benassi, Toti 1958 : BENASSI (E.), TOTI (A.) - Osservazioni sulle ossa rinvenute negli scavi della necropoli di Spina. Atti e Memorie della Accademia di Storia dell Arte Sanitaria, II, 24, 1958, p. 16-28.

Bentz 1998 : BENTZ (M.) - Panathenäische Preisamphoren. Eine athenische Vasengattung und ihre Funktion vom 6.-4. Jahrhundert v. Chr. Bâle, 1998 (Antike Kunst, 18. Beiheft).

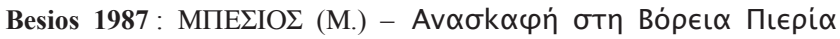
[Fouilles en Piérie du Nord]. AEMTh 1, 1987, p. 209-218.

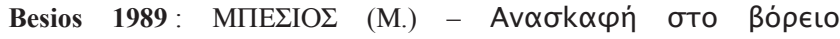

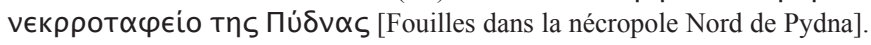
AEMTh, 3, 1989, p. 155-163.

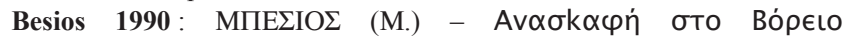

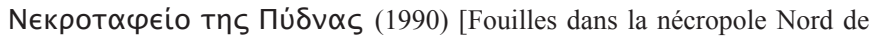
Pydna (1990)]. AEMTh, 4, 1990, p. 241-246.

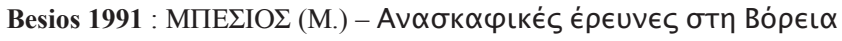

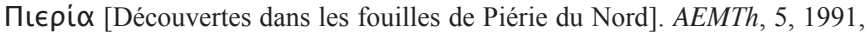
p. $171-178$.
Bianchi et al. 2002: BIANCHI (R.S.), SCHLICK-NOLTE (B.), BERNHEIMER (G.M.), BARAG (D.) - Reflections on Ancient Glas from the Borowski Collection. Bible Lands Museum, Jerusalem. Mayence, von Zabern, 2002.

Bieber 1961 : BIEBER (M.) - The History of the Greek and Roman Theater. Princeton University Press, $2^{e}$ éd., 1961.

Biers 1985 : BIERS (W.R.) - Culinary Chaos. A Scene from New Comedy. Antike Kunst, 28, 1985, p. 40-44, pl. 14.

Biro 1994 : BIRO (M.T.) - The Bone Objects in the Roman Collection. In memoriam Gizella Erdélyi. Budapest, Magyar Nemezeti Muzeum, 1994.

Blavatskaya 1952 : БЛАВАТСКАЯ (Т.В.) - Западнопонтийские города в VII - I веках до нашей эры. Москва, Издательство Академии Наук СССР, 1952.

[BLAVATSKAYA (T.V.) - Les cités du Pont occidental aux VII $-I^{e r}$ s. av. J.-C. Moscou, éditions de l'Académie des Sciences de l'URSS, 1952.]

Blegen, Palmer, Young 1964: BLEGEN (C.W.), PALMER (H.), YOUNG (R.S.) - Corinth, vol. XIII. The North Cemetery. Princeton, The American School of Classical Studies at Athens, 1964.

Blondé 1985 : BLONDÉ (Fr.) - Un remblai thasien du IVe siècle avant notre ère : la céramique. $B C H, 109,1985$, p. 281-344.

Blondé 1989 : BLONDÉ (Fr.) - Le comblement d'un puits public à Thasos : la céramique. $B C H, 113,1989$, p. 481-545.

Blondé 2000 : BLONDÉ (Fr.) - La céramique attique du IVe s. en Grèce du Nord : quelques commentaires. In : Sabattini 2000, p. 272-276.

Blondé, Villard 1992a : BLONDÉ (Fr.), VILLARD (L.) - Les vases dans la Collection Hippocratique : vocabulaire et usage. $B C H, 116,1992$, p. 73-117.

Boardman 1989 : BOARDMAN (J.) - Athenian Red Figure Vases. The Classical Period. Londres, Thames and Hudson, 1989.

Böhr 2002 : BÖHR (E.) - CVA Deutschland 74, Berlin 9. Attische rotfigurige Hydrien. Attische Firnis-Hydrien. Munich, C.H. Beck, 2002.

Bojilova, Beug 1992 : BOZILOVA (E.), BEUG (H.-J.) - On the Holocene History of Vegetation in SE Bulgaria (Lake Arkutino, Ropotamo Region). Vegetation History and Archaeobotany, 1, 1, 1992, p. 19-32.

Bojkova 1997 : BOZKOVA (A.) - A Pontic Pottery Group of the Hellenistic Age (A Survey Based on Examples from the Bulgarian Black Sea Coast). AB, 1, 2, 1997, p. 8-17.

Bojkova 2000: БОЖКОВА (А.) - Чернофирнисова керамика от българското Черноморие. Общи наблюдения. ИНИМ, 11, 2000, с. 91-98.

[BOJKOVA (A.) - Céramique à vernis noir du littoral bulgare de la mer Noire. Observations générales. INIM, 11, 2000, p. 91-98.]

Bojkova, Petrova 2007: БОЖКОВА (А.), ПЕТРОВА (А.) Спасителни проучвания на надгробна могила на н. Колокита, рег. № 6000008 по АКБ, Созопол (УПИ 6080-6113, кв. XIX6143). В: АОР през 2006 г. София, 2007, с. 244-247.

[BOZKOVA (A.), PETROVA (A.) - Fouilles de sauvetage d'un tumulus sur le cap Kolokita, $\mathrm{n}^{\circ} 6000008$ selon la Carte archéologique de Bulgarie, Sozopol (UPI 6080-6113, carré XIX-6143). In : AOR année 2006. Sofia, 2007, p. 244-247.]

Bon 1957 : BON (A.M. et A.) - Les timbres amphoriques de Thasos. Paris, de Boccard, 1957 (Études thasiennes IV).

Bonucci, Graziani 1975 : BONUCCI (E.), GRAZIANI (G.) - Comparative thermogravimetric $\mathrm{x}$-ray diffraction and electron microscope investigations of burnt bones from recent, ancient and prehistoric age. Rendiconti della classe di Scie. Fis. e nat., VIII, LIX, 5, 1975, p. 517-533.

Borell 1989 : BORELL (B.) - Katalog der Sammlung antiker Kleinkunst des archäologischen Instituts der Universität Heidelberg. Vol. 3, 1. Statuetten. Gefässe und andere Gegenstände aus Metal. Mayence, von Zabern, 1989.

von Bothmer 1979 : von BOTHMER (D.) - A bronze oinochoe in New York. In : Kopcke (G.), Moore (M.B.) eds., Studies in Classical Art and Archaeology. A Tribute to Peter Heinrich von Blanckenhagen. Locust Valley (NY), J.J. Augustin, 1979, p. 63-73, pl. XVII-XXIII.

Boulter 1953 : BOULTER (C.) - Pottery from the Mid-Fifth Century from a Well in the Athenian Agora. Hesperia, 22, 1953, p. 59-115. 
Boulter, Luckner 1976 : BOULTER (C.G.), LUCKNER (K.T.) - CVA United States of America 17, The Toledo Museum of Art 1. Toledo, The Toledo Museum of Art, 1976.

Bouzek 1999 : BOUZEK (J.) - Pistiros and the South: Land and River Connections. Apx $\alpha i \alpha$ M $\alpha \kappa \in \delta o v i \alpha, 6,1999$, p. 189-196.

Brashinskiy 1980: БРАШИНСКИЙ (И.Б.) - Греческий керамический импорт на Нижнем Дону в V-III вв. до н. э. Ленинград, Наука, 1980.

[BRASHINSKIY (I.B.) - Les importations de céramique grecque sur le Don inférieur aux Ve-III ${ }^{e}$ s. av. J.-C. Leningrad, Nauka, 1980.]

Braun 1970 : BRAUN (K.) - Der Dipylon Brunnen B. Die Funde. AM, 85, 1970, p. 129-269.

Braund 2005: BRAUND (D.) - Pericles, Cleon and the Pontus. The Black Sea in Athens c. 440-421. In : Braund (D.) ed., Scythians and Greeks. Cultural interactions in Scythia, Athens and the Early Roman empire. Exeter, University of Exeter Press, 2005, p. 80-99.

Breccia 1912 : BRECCIA (E.) - Catalogue général des antiquités égyptiennes (Musée d'Alexandrie). La necropoli di Sciatbi. Le Caire, Imprimerie de l'Institut français, 1912.

Brickley, Ives 2006 : BRICKLEY (M.), IVES (R.) - Skeletal manifestations of infantile scurvy. American Journal of Physical Anthropology, 129, 2 , 2006, p. 163-172.

Brigger, Giovannini 2004: BRIGGER (E.), GIOVANNINI (A.) Prothésis : étude sur les rites funéraires chez les Grecs et chez les Étrusques. MEFRA, 116, 2004, p. 179-248.

Brooks, Suchey 1990 : BROOKS (S.), SUCHEY (J.) - Skeletal age determination based on the Os Pubis: A comparison of the Acsádi-Nemeskéri and Suchey-Brooks Methods. Human Evolution, 5, 1990, p. 227-238.

Bruck 1970 : BRUCK (E.F.) - Totenteil und Seelgerät im griechischen Recht. Eine entwicklungsgeschichtliche Untersuchung zum Verhältnis von Recht und Religion mit Beiträgen zur Geschichte des Eigentums und des Erbrechts. Munich, Beck, $2^{e}$ éd., 1970.

Bruneau 1970 : BRUNEAU (Ph.) - Tombes d'Argos. BCH, 94, 1970, p. 437-531.

Bruneau, Bovon 1966 : BRUNEAU (Ph.), BOVON (A.) - Huiliers hellénistiques. $B C H, 90,1966$, p. 131-143.

Bucovală 1967: BUCOVALĂ (M.) - Necropole elenistice la Tomis. Constantza, Muzeul Regional de Arheologie Dobrogea, 1967.

Buikstra, Ubelaker 1994 : BUIKSTRA (J.E.), UBELAKER (D.) eds. - Standards for Data Collection from Human Skeletal Remains. Fayetteville (Arkansas), Arkansas Archaeological Survey Research Series $n^{\circ} 44,1994$.

Bulas 1935 : BULAS (K.) - CVA Pologne 2, Collections de Cracovie. Varsovie, Cracovie, Librairie Gebethner et Wolff, 1935.

Burkert 1985 : BURKERT (W.) - Greek Religion. Oxford, Blackwell, 1985.

Burn 1987 : BURN (L.) - The Meidias Painter. Oxford, Clarendon Press, 1987.

Buzoianu, Bărbulescu 2002-2003 : BUZOIANU (L.), BĂRBULESCU (M.) - Categorii ceramice de import în aşezarea greco-indigenă de la Albeşti (jud. Constanţa). Pontica, 35-36, 2002-2003, p. 61-77.

Cabrera, Rouillard 2003a : CABRERA (P.), ROUILLARD (P.) - Le groupe de Telos. Des peintres athéniens au milieu du IVe siècle av. J.-C. In : Rouillard, Verbanck-Piérard 2003, p. 91-98

Cabrera, Rouillard 2003b : CABRERA (P.), ROUILLARD (P.) - L'épave d'El Sec, dans la baie de Palma de Majorque (milieu du IVe siècle av. J.-C.). In : Rouillard, Verbanck-Piérard 2003, p. 125-131.

Čaneva 1980 [voir aussi Tsaneva] : ČANEVA (M.) - Die neusten Forschungen in der Nekropole von Apollonia Pontica. In: Vulpe (R.) dir., Actes du II congrès international de thracologie (Bucarest, 4-10 septembre 1976), vol. 1 : Histoire et archéologie. Bucarest, Editura academiei republicii socialiste Romania, 1980, p. 447-450.

Carter 1998: CARTER (J.C.), en collaboration avec MORTER (J.), TOXEY (A.P.) - The Chora of Metaponto: The Necropoleis. Austin, University of Texas Press, 1998
Cat. Bâle 2007: Die alten Zivilisationen Bulgariens. Das Gold der Thraker. Catalogue d'exposition, Bâle, Antiken Museum und Sammlung

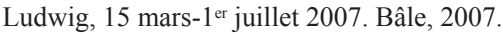

Cat. Bonn 2004 : Die Thraker. Das goldene Reich des Orpheus. Catalogue d'exposition, Bonn, Kunst- und Ausstellunghalle, 23 juillet-28 novembre 2004. Bonn, 2004.

Cat. Bruxelles 2002 : L'or des Thraces. Trésors de Bulgarie. Catalogue d'exposition, Bruxelles, Palais des Beaux-Arts, 5 octobre 2002-5 janvier 2003. Bruxelles, Snoeck, 2002.

Cazenave et al. 2002: CAZENAVE (A.), BONNEFOND (P.), MERCIER (F.), DOMINH (K.), TOUMAZOU (V.) - Sea Level Variations in the Mediterranean Sea and Black Sea from Satellite Altimetry and Tide Gauges. Global and Planetary Change, 34, 1-2, 2002, p. 59-86.

Chankowski, Bravo 1999 : CHANKOWSKI (A.S.), BRAVO (B.) - Cités et emporia dans le commerce avec les barbares à la lumière du document dit à tort « inscription de Pistiros ». BCH, 119, 1999, p. 275-317.

Chepalyga 1984: CHEPALYGA (A.L.) - Inland Sea Basins. In: WRIGHT (H.E.), BARNOSKY (C.W.) dir., Late Quaternary Environments of the Soviet Union. Londres, Longman, 1984, p. 229-247.

Čimbuleva 1969: ČIMBULEVA (J.) - Trouvailles de la nécropole de Nessèbre. In : Nessebre I. Sofia, Académie bulgare des Sciences, 1969, p. 165-178.

Čimbuleva 2005: ČIMBULEVA (J.) - La nécropole antique de Messambria. Matériaux et études. In : Nessebre III. In memoriam Jeannae Čimbuleva. Bourgas, Spring LTD, 2005, p. 91-117.

Cipriani 1994: CIPRIANI (M.) - Necropoli del V secolo A.C. a Poseidonia : il caso di contrada S. Venera. In : La Genière 1994, p. 169-180.

Coldstream 1973 : COLDSTREAM (J.N.) - Knossos. The Sanctuary of Demeter. Athènes \& Londres, 1973 (ABSA Suppl. 8).

Collignon 1905 : COLLIGNON (M.) - Note sur les fouilles exécutées à Apollonie du Pont par M. Degrand, Consul de France à Philippopoli. CRAI, 1905, p. 300-306

Commission on Oral Health 1982 - An epidemiological index of developmental defects of dental enamel (DDE Index). International Dental Journal, 32, 1982, p. 159-167.

Corbett 1949 : CORBETT (P.) - Attic Pottery from the Late Fifth Century from the Athenian Agora. Hesperia, 18, 1949, p. 298-351.

Corbett 1955 : CORBETT (P.) - Palmette Stamps from an Attic BlackGlaze Workshop. Hesperia, 24, 1955, p. 172-186.

Damyanov 2005 : DAMYANOV (M.) - Graves with Circles of Amphorae in the Greek Necropoleis in the Black Sea. In : Stoyanov (T.), Angelova (S.), Lozanov (I.) dir., Stephanos Archaeologicos in honorem Prof. L. Getov. Sofia, Presses universitaires "Sveti Kliment Ohridski", 2005, p. 214-223.

Danov 1937 : ДАНОВ (Х.) - Новооткрити старини. ИБАИ, 11, 1937, c. 314-315.

[DANOV (H.) - Antiquités récemment mises au jour. IBAI, 11, 1937, p. 314-315.]

Danov 1947 : ДАНОВ (X.) - Западният бряг на Черно море в древността. София, Университетска печатница, 1947.

[DANOV (H.) - Le littoral occidental de la mer Noire dans l'Antiquité. Sofia, Presses universitaires, 1947.]

Danov 1952 : ДАНОВ (X.) - Към историята на Тракия и Западното Черноморие от втората половина на III век до средата на I век преди н. е. ГСУ ФИФ, 47, 2, 1952, с. 105-156.

[DANOV (H.) - Contribution à l'histoire de la Thrace et du littoral occidental de la mer Noire entre la deuxième moitié du III ${ }^{2}$ siècle et le milieu du Ier siècle av. J.-C. GSU FIF, 47, 2, 1952, p. 105-156.]

Danov 1969 : ДАНОВ (Х.) - Древна Тракия. Изследвания върху историята на българските земи, Северна Добруджа, Източна и Егейска Тракия от края на IX до края на IIIв. пр. н. е. София, Наука и изкуство, 1969.

[DANOV (H.) - Thrace ancienne. Recherches sur l'histoire des territoires bulgares, de la Dobroudja du Nord, de la Thrace égéenne et orientale depuis la fin du IX jusqu'à la fin du III e s. av. J.-C. Sofia, Nauka i Izkustvo, 1969.] 
Davidson 1952 : DAVIDSON (G.R.) - Corinth. Volume XII. The Minor Objects. Princeton (N.J.), The American School of Classical Studies at Athens, 1952.

Debidour 1986 : DEBIDOUR (M.) - En classant les timbres récents. In : Empereur (J.-Y.), Garlan (Y.) dir., Recherches sur les amphores grecques, Actes du colloque international organisé par le CNRS, l'Université de Rennes II et l'École française d'Athènes (Athènes, 10-12 septembre 1984). Athènes, EfA, et Paris, de Boccard, 1986, p. 311-334 (BCH, Suppl. XIII).

De Boer, Stronk 2000-2001 : DE BOER (G.), STRONK (J.P.) - Two Greek Emporia south of Apollonia Pontica. Talanta, 32-33, 2000-2001, p. 233-239.

Delivorrias 1984 : DELIVORRIAS (A.), en collaboration avec BERGERDOER (G.) et KOSSATZ-DEISSMANN (A.) - Aphrodite. In : LIMC II, 1984, p. 2-151, pl. 6-153.

Demargne 1984 : DEMARGNE (P.) - Athena. In : LIMC II, 1984, p. 9551044, pl. 702-765.

Deonna 1938 : DEONNA(W.) - Exploration archéologique de Délos XVIII. Le mobilier délien. Paris, École française d'Athènes et de Boccard, 1938.

De Schutter 1989: DE SCHUTTER (X.) - Rituel funéraire et coût des obsèques en Grèce à l'époque classique. Kernos, 2, 1989, p. 53-66.

Detchev 1932-34 : ДЕЧЕВ (Д.) - Антични паметници. ГНМ, 6, 1932-34, p. 47-59.

[DETCHEV (D.) - Monuments antiques. GNM, 6, 1932-34, p. 47-59.]

Devillers 2008: DEVILLERS (B.) - Holocene Morphogenesis and Anthropisation of a Semi-Arid Watershed, Gialias River, Cyprus. Oxford, Archaeopress, 2008.

Dewailly 2007 : DEWAILLY (M.) - Une collection tanagréenne pour Artémis dans le sanctuaire de Claros. In : Jeammet (V.) ed., Tanagra. De l'objet de collection à l'objet archéologique. Paris, Picard et Musée du Louvre, 2007, p. 133-154.

Dimitrov 1973 : ДИМИТРОВ (Б.)-Тракийски крепости и селища в околностите на Аполония Понтика. Студентски проучвания, 1, 1973, c. 5-19.

[DIMITROV (B.), Forteresses et habitats thraces dans les environs d'Apollonia Pontique. Studenski Prouchvanya, 1, 1973, p. 5-19.]

Dimitrov 1975a : ДИМИТРОВ (Б.)-Един паметник на йонийското изкуство. Изкуство, 25, 3-4, 1975, с. 30-31.

[DIMITROV (B.) - Un monument de l'art ionien. Izkustvo, 25, 3-4, 1975, p. 30-31.]

Dimitrov 1975b : DIMITROV (B.) - Beobachtungen über die antike Topographie der südlichen Schwarzmeerküste. Studia Balcanica, 10, 1975, p. 11-18.

Dimitrov 1987 : DIMITROV (B.) - Sozopol in den Jahrhunderten. Sofia, Sofia Press, 1987.

Dimitrov 2004 : ДИМИТРОВ (Б.) - Аполония Понтика. София, УИ “Климент Охридски”, 2004.

[DIMITROV (B.) - Apollonia Pontica. Sofia, Presses universitaires "Sveti Kliment Ohridski”, 2004.]

Dimitrov, Porojanov, Orachev 1982 : ДИМИТРОВ, (Б.), ПОРОЖАНОВ (К.), ОРАЧЕВ (А.) - Пристанищата на Аполония и Месамбрия. В: Фол (А.) ред., Тракийски паметници, том 3: Мегалитите в Тракия, част 2: Тракия Понтика, София, Наука и изкуство, 1982 , c. $438-458$.

[DIMITROV (B.), POROJANOV (K.), ORACHEV (A.) - Les ports d'Apollonia et de Mesambria. In: Fol (A.) dir., Monuments thraces, vol. 3 : Les mégalithes en Thrace, $2^{e}$ partie : La Thrace pontique, Sofia, Nauka i izkustvo, 1982, p. 438-458.]

Dimitrov 1942-43 : ДИМИТРОВ (Д.П.) - Нови наблюдения върху надгробната плоча на Анаксандър от Аполония (Созопол). ГСУ ИФФ, 39, 1, 1942-1943, с. 1-16.

[DIMITROV (D.P.) - Nouvelles remarques sur la stèle funéraire d'Anaxandros d'Apollonia (Sozopol). GSU IFF, 39, 1, 1942-1943, p. 1-16.]

Dobruski 1896 : ДОБРУСКИ (В.) - Материали по археологията на България. СбНУНК, 13, 1896, с. 398-441.

[DOBRUSKI (V.) - Matériaux sur l'archéologie de la Bulgarie. SbNUNK, 13, 1896, p. 398-441.]
Docter et al. 2008 : DOCTER (R.), PANAYOTOVA (K.), DE BOER (J.), DONNELLAN (L.), VAN DE PUT (W.), BECHTOLD (B.) - Apollonia Pontica 2007. Gand, Department of Archaeology, Ghent University, 2008.

Domínguez 2000 : DOMÍNGUEZ (A.J.) - Phocaeans and other Ionians in Western Mediterranean. In : Krinzinger (F.) dir., Die Ägäis und das westliche Mittelmeer : Beziehungen und Wechselwirkungen 8. bis 5. Jh. v. Chr., Akten des Symposions (Wien, 24. bis 27. März 1999). Vienne, Österreichische Akademie der Wissenschaften, 2000, p. 507-513.

Domínguez, Sánchez 2001 : DOMíNGUEZ (A.J.), SÁNCHEZ (C.) Greek Pottery from the Iberian Peninsula: Archaic and Classical Periods. Leiden, Boston, Cologne, Brill, 2001.

Draganov 1995 : DRAGANOV (V.) - Submerged Coastal Settlements from the Final Eneolithic and the Early Bronze Age in the Sea around Sozopol and Urdoviza Bay near Kiten. In : Bailey (D.W.), Panayotov (I.) dir., Prehistoric Bulgaria. Madison, Prehistory Press, 1995, p. 225-242.

Drajeva, Nedev 1994a : ДРАЖЕВА (Ц.), НЕДЕВ (Д.) - Разкопки на антични обекти в старата част на Созопол през 1993 г. В: АОР през 1992-1993 г. Велико Търново, 1994, с. 52-53.

[DRAJEVA (Ts.), NEDEV (D.) - Fouilles de sites antiques dans la partie ancienne de Sozopol en 1993. In : AOR années 1992-1993. Veliko Tarnovo, 1994, p. 52-53.]

Drajeva, Nedev 1994b : ДРАЖЕВА (Ц.), НЕДЕВ (Д.) - Разкопки в старата част на Созопол. В: АОР през 1992-1993 г. Велико Търново, 1994, с. 110-111.

[DRAJEVA (Ts.), NEDEV (D.) - Fouilles dans le centre ancien de Sozopol. In: AOR années 1992-1993. Veliko Tarnovo, 1994, p. 110-111.]

Drajeva, Nedev 1995 : ДРАЖЕВА (Ц.), НЕДЕВ (Д.) - Разкопки на антични обекти в старата част на Созопол през 1994 г. В: АОР през 1994 г. Смолян, 1995, с. 91.

[DRAJEVA (Ts.), NEDEV (D.) - Fouilles de sites antiques dans la partie ancienne de Sozopol en 1994. In : AOR année 1994. Smolyan, 1995, p. 91.]

Drajeva, Nedev 1996 : ДРАЖЕВА (Ц.), НЕДЕВ (Д.) - Антични жилищни сгради и водоснабдителни съоръжения /кр. на V - II в. пр. н. е./ от Аполония Понтийска (Созопол). В: АОР през 1995 г. София, 1996, с. 54-55.

[DRAJEVA (Ts.), NEDEV (D.) - Habitations antiques et équipements d'approvisionnement en eau à Apollonia-Sozopol. In : AOR année 1995. Sofia, 1996 p. 54-55.]

Drajeva, Nedev 2003 : ДРАЖЕВА(Ц.), НЕДЕВ (Д.)-Археологически проучвания на територията на ААР Аполония - Созопол. В: АОР през 2002 г. София, 2003, с. 107-109.

[DRAJEVA (Ts.), NEDEV (D.) - Recherches archéologiques sur le territoire de la réserve Apollonia-Sozopol. In : AOR année 2002. Sofia, 2003, p. 107-109.]

Drajeva, Nedev 2005 : ДРАЖЕВА (Ц.), НЕДЕВ (Д.) - Спасителни археологически проучвания в АИР “Старинен Созопол”. В: АОР през 2004 г. София, 2005, с. 235-237.

[DRAJEVA (Ts.), NEDEV (D.) - Fouilles archéologiques de sauvetage dans la réserve « Sozopol ancienne ». In : AOR année 2004. Sofia, 2005, p. 235-237.]

Dremsizova 1948 : ДРЕМСИЗОВА (Ц.) - Теракоти от некропола на Аполония. В: Venedikov et al. 1948, с. 53-58.

[DREMSIZOVA (Ts.) - Figurines en terre cuite d'Apollonia. In : Venedikov et al. 1948, p. 53-58.]

Dremsizova 1955 : ДРЕМСИЗОВА (Ц.) - Надгробни могили при с. Янково. ИБАИ, 19, 1955, с. 61-83.

[DREMSIZOVA (Ts.) - Tumuli funéraires près du village Yankovo. IBAI, 19, 1955, p. 61-83.

Dremsizova 1963a : ДРЕМСИЗОВА (Ц.) - Теракоти от некропола на Аполония. В: Venedikov et al. 1963, с. 275-285.

[DREMSIZOVA (Ts.) - Figurines en terre cuite d'Apollonia. In : Venedikov et al. 1963, p. 275-285.]

Dremsizova 1963b : ДРЕМСИЗОВА (Ц.) - Керемиди с печати от некропола на Аполония. В: Venedikov et al. 1963, с. 321-324. [DREMSIZOVA (Ts.) - Tuiles à estampilles de la nécropole d'Apollonia. In : Venedikov et al. 1963, p. 321-324.] 


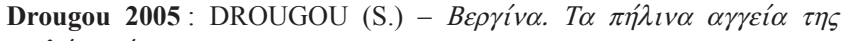

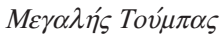

[Vergina. Les vases en argile du Grand Tumulus]. Athènes, Archaiologiké Hetaireia, 2005.

Duday 1987 : DUDAY (H.) - L'étude anthropologique des sépultures à incinération. In : Nécropoles à incinération du Haut-Empire. Table-ronde de Lyon, 30 et 31 mai 1986. Lyon, Direction des Antiquités Historiques, 1987, p. 105.

Dugas 1952 : DUGAS (Ch.) - Exploration Archéologique de Délos XXI. Les vases attiques à figures rouges. Paris, de Boccard, 1952.

Dupont 2007 : DUPONT (P.) - Le Pont-Euxin archaïque : lac milésien ou lac nord-ionien? Un point de vue de céramologue. In : Bresson (A.), Ivantchik (A.), Ferrary (J.L.) eds., Une koinè pontique : cités grecques, sociétés indigènes et empires mondiaux sur le littoral nord de la mer Noire (VII ${ }^{e}$ s. a.C - III s. p.C). Bordeaux, Ausonius, 2007, p. 29-36.

Duray 1996 : DURAY (S.) - Dental indicators of stress and reduced age at death in prehistoric Native Americans. American Journal of Physical Anthropology, 99, 2, 1996, p. 275-286.

Edwards 1975 : EDWARDS (G.R.) - Corinth VII, 3. Corinthian Hellenistic Pottery. Princeton, The American School of Classical Studies at Athens, 1975.

Ehrhardt 1989 : EHRHARDT (N.) - Apollon Ietros. Ein verschollener Gott Ioniens? IstMitt, 39, 1989, p. 115-122.

Eiseman, Ridgway 1987 : EISEMAN (C.J.), RIDGWAY (B.S.) - The Porticello Shipwreck: A Mediterranean Merchant Vessel of 415-385 B.C. College Station (Texas), A\&M University Press, 1987.

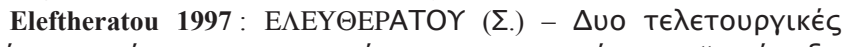

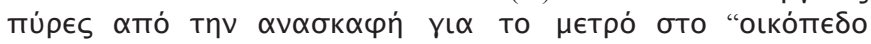

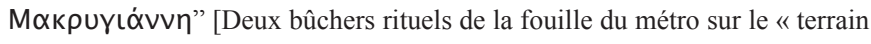
Makryiannis »]. ArchDelt, 51-52, 1996-1997, Meletes, p. 99-117.

Elia, Carè 2004 : ELIA (D.), CARÈ (B.) - Ancora sull' 'astragalomania' a Locri Epizefiri. La documentazione dalla necropoli in contrada Lucifero. Orizzonti, 5, 2004, p. 77-90.

Fairbanks 1989 : FAIRBANKS (R.G.) - A 17.000-year Glacio-Eustatic Sea Level Record : Influence of Glacial Melting Rates on the Younger Dryas Event and Deep-Ocean Circulation. Nature, 342, 1989, p. 637-642.

Filov 1912-1913: ФИЛОВ (Б.) - Археологически сондажи в Созопол. ИБАД, 2, 1912-1913, с. 316.

[FILOV (B.) - Sondages archéologiques à Sozopol. IBAD, 2, 1912-1913, p. 316.$]$

Fleming et al. 1998 : FLEMING (K.), JOHNSTON (P.), ZWARTZ (D.), YOKOYAMA (Y.), LAMBECK (K.), CHAPPELL (J.) - Refining the Eustatic Sea Level Curve since the Last Glacial Maximum Using Far- and IntermediateField Sites. Earth and Planetary Science Letters, 163, 1-4, 1998, p. 327-342.

Fless 2002 : FLESS (F.) - Rotfigurige Keramik als Handelsware. Erwerb und Gebrauch attischer Vasen im mediterranen und pontischen Raum während des 4. Jhs. v. Chr. Rahden/Westf., Marie Leidorf, 2002.

Fol 1985 : FOL (A.) dir. - Le littoral thrace et son rôle dans le monde ancien, Actes du II symposium international "Thracia Pontica" (Sozopol, 4-7 octobre 1982). Yambol, Centre d'histoire maritime et d'archéologie sous-marine, et Institut de thracologie auprès de l'Académie bulgare des Sciences, 1985.

Fossey 1984 : FOSSEY (J.M.) - Ritual aspects of vase among grave goods at hellenistic Asine, Argolis. In: Brijder (H.) dir., Ancient Greek and related pottery, Proceedings of the International Vase Symposium, Amsterdam, 12-15/04/1984. Amsterdam, 1984, p. 289-291.

Fossey 1985 : FOSSEY (J.M.) - The ritual breaking of objects in Greek funerary contexts : a note. Folklore, 96, 1985, p. 21-23.

Fossey 1999 : FOSSEY (J.M.) - Boiotia and the Pontic Cities in the Archaic to Hellenistic Periods. In : Lordkipanidze (O.), Lévêque (P.) dir., La mer Noire, zone de contacts, Actes du VII ${ }^{\mathrm{e}}$ symposium de Vani (Colchide, 26-30 septembre 1994). Besançon, PUFC, et Paris, Les Belles Lettres, 1999, p. 35-40.

Frel 1960 : FREL (J.) - Monuments d'Apollonie Pontique au Musée du Louvre. ИБАИ, 23, 1960, p. 239-251.

Fröhner 1892 : FROEHNER (W.) - Collection Van Branteghem : vases peints et terres cuites archaïques. Paris, Ménard et Cie, 1892.

Galabov 1950a : ҐЪЛЪБОВ (И.) - Един новооткрит надпис от Несебър. ИНМБ, 1, 1950, с. 7-22.
[GALABOV (I.) - Une inscription récemment découverte de Nesebar. INMB, 1, 1950, p. 7-22.]

Galabov 1950b : ГЪЛЪБОВ (И.) - Археологически приноси за историята на град Бургас. І. Сладки кладенци. ИНМБ, 1, 1950, c. 241-251.

[GALABOV (I.) - Contributions archéologiques à l'histoire de Bourgas. Sladki Kladentsi. INMB, 1, 1950, p. 241-251.]

Galabov 1952 : ГЪЛЪБОВ (И.) - Аполонийски приноси. ИБАИ, 18,1952 , c. $102-118$.

[GALABOV (I.) - Contributions apolloniates. IBAI, 18, 1952, p. 102-118.]

Galabov 1955 : ҐЪЛЪБОВ (И.) - Каменни гробници от Несебър. ИБАИ, 19, 1955, с.129-147.

[GALABOV (I.) - Tombeaux en pierre de Nessebar. IBAI, 19, 1955, p. 129-147.]

Galabov 1965 : ҐЪЉБОВ (И.) - Предримска керамика от Аполония. ИНМБ, 2, 1965, с. 11-47.

[GALABOV (I.) - Céramique préromaine d'Apollonia. INMB, 2, 1965, p. 11-47.]

Gansisniec 1978 : GANSINIEC (Z.) - Odziez. Kultura materialna starozytnej Grecji. Wroclav, Cracovie, Varsovie, 1978.

Garlan 1986: GARLAN (Y.) - Quelques nouveaux ateliers amphoriques à Thasos. In : Empereur (J.-Y.), Garlan (Y.) dir., Recherches sur les amphores grecques, Actes du colloque international organisé par le CNRS, 1'Université de Rennes II et l'École Française d'Athènes (Athènes, 10-12 septembre 1984). Athènes, EfA, et Paris, de Boccard, 1986, p. 201-276 (BCH, Suppl. XIII).

Garlan 1990 : GARLAN (Y.) - À propos de la chronologie des timbres

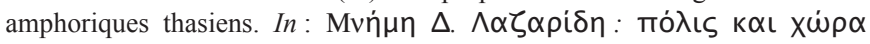

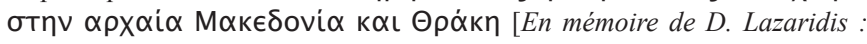
cité et territoire dans la Macédoine et la Thrace antiques], Actes du congrès de Kavala, 9-11 mai 1986. Ministère de la Culture, Musée Archéologique de Kavala, École francaise d'Athènes, 1990, p. 479-483.

Garlan 1999: GARLAN (Y.) - Les timbres amphoriques de Thasos. I: Timbres protothasiens et thasiens anciens. Athènes, EfA, 1999 (Études thasiennes vol. XVIII).

Garlan, Doulgeri-Intzessiloglou 1990 : GARLAN (Y.), DOULGERIINTZESSILOGLOU (A.) - Vin et amphores de Péparéthos et d'Ikos. $B C H$, 64, 1990, p. 361-389.

Garland 1985 : GARLAND (R.) - The Greek Way of Death. Londres, G. Duckworth, 1985.

Gentili, Perusino 2002 : GENTILI (B.), PERUSINO (F.) - Le orse di Brauron, un rituale di iniziazione femminile nel santuario di Artemide. Pise, éd. ETS, 2002.

Georgieva 1992 : ГЕОРГИЕВА (М.) - Гробни находки от околностите на Варна. ИНМВ, 28/43, 1992, с. 73-80.

[GEORGIEVA (M.) - Découvertes funéraires dans les environs de Varna. INMV, 28/43, 1992, p. 73-80.]

Georgieva 1999 : ГЕОРГИЕВА (Р.) - Погребението (края на II - I хилядолетие пр.н.е.). В: Георгиева (Р.), Спиридонов (Т.), Рехо (М.) ред., Етнология на траките, с. 216-232.

[GEORGIEVA (R.) - La sépulture (fin du II -I Ir $^{\text {er }}$ millénaire av. n.è.). In : Georgieva (R.), Spiridonov (T.), Reho (M.) dir., Ethnologie des Thraces. Sofia, 1999, p. 216-232.]

Gerasimov 1938: ГЕРАСИМОВ (Т.) - Мряморна архаична главичка от Созопол. ИБАИ, 12, 1938, с. 399-400.

[GERASIMOV (T.) - Une tête en marbre archaïque de Sozopol. IBAI, 12, 1938, p. 399-400.]

Gerasimov 1963 : ГЕРАСИМОВ (Т.) - Монетите от некропола на Аполония. В: Venedikov et al. 1963, с. 331-340.

[GERASIMOV (T.) - Les monnaies de la nécropole d'Apollonia. In : Venedikov et al. 1963, p. 331-340.]

Gerasimov 1965 : ГЕРАСИМОВ (Т.) - Статуята на Аполон от Каламис в Аполония на Черно море. ИНМБ, 2, 1965, с. 1-9.

[GERASIMOV (T.) - La statue d'Apollon de Calamis à Apollonia. INMB, 2, 1965, p. 1-9.] 
Gergov 2000-2001 : GERGOV (G.) - Archaeological Evidence of Dune Formation on the West Pontic Coast in the $4^{\text {th }}-3^{\text {rd }}$ centuries BC. Talanta, 32-33, 2000-2001, p. 223-231.

Getov 1991 :ГЕТОВ(Л.)-Могилен некропол отелинистическата епоха при Кабиле. В: Велков (В.) ред., Кабиле, том 2. София, БАН, 1991, с. 168-197.

[GETOV (L.) - Une nécropole tumulaire d'époque hellénistique près de Kabylè. In : Velkov (V.) dir., Kabylè, vol. 2. Sofia, Académie bulgare des Sciences, 1991, p. 168-197.]

Ghali-Kahil 1960 : GHALI-KAHIL (L.) - La céramique grecque (fouilles 1911-1956). Paris, de Boccard, 1960 (Études thasiennes, vol. VII).

Giuzelev 2002 : GIUZELEV (M.) - Ancient Funerary Monuments at Sozopol Archaeological Museum. ИНМБ, 4, 2002, p. 119-132.

Goiran et al. 2005 : GOIRAN (J.-P.), MARRINER (N.), MORHANGE (C.), ABD EL-MAGUIB (M.), ESPIC (K.), BOURCIER (M.), CARBONEL (P.) Evolution géomorphologique de la façade maritime d'Alexandrie (Egypte) au cours des six derniers millénaires. Méditerranée, 104, 1-2, 2005, p. 61-64.

Goodman, Rose 1990 : GOODMAN (A.H.), ROSE (J.C.) - Assessment of systemic physiological perturbations from dental enamel hypoplasias and associated histological structures. Yearbook of Physical Anthropology, 33, 1990, p. 59-110.

Graham 1992 : GRAHAM (A.J.) - Abdera and Teos. JHS, 112, 1992, p. 44-73.

Grammenos, Petropoulos 2003 : GRAMMENOS (D.V.), PETROPOULOS (E.K.) dir., Ancient Greek Colonies in the Black Sea. Thessalonique, Archaeological Institute of Northern Greece, 2003.

Gras 1975 : GRAS (M.) - Nécropole et histoire : quelques réflexions à propos de Mégara Hyblaea. Kokalos, 21, 1975, p. 37-53.

Grévin 1990 : GRÉVIN (G.) - La fouille en laboratoire des sépultures à incinération. Son apport à l'archéologie. Bulletin de la Société d'Anthropologie de Paris, n. s., 2, 3-4, 1990, p. 66-74.

Grinder-Hansen 1991 : GRINDER-HANSEN (K.) - Charon's fee in Ancient Greece ? Some remarks on a well-known death rite. Acta Hyperborea, 3, 1991, p. 207-218.

Guldager Bilde et al. 2008: GULDAGER BILDE (P.) ET ALII Archaeology in the Black Sea region in Classical antiquity 1993-2007. Archaeological Reports for 2007-2008, p. 115-173.

Gyuzelev 2005 : GYUZELEV (M.) - Ancient Funerary Monuments found in the Necropolis of Kalfata (Sozopol) in the year 2002. In: Heros Hephaistos. Studia in honorem Liubae Ognenova-Marinova. Veliko Tarnovo, 2005, p. 131-138.

Gyuzelev 2007 : ГЮЗЕЛЕВ (М.) - Спасителни археологически проучвания на обект "Старата община" в УПИ - II, кв. 28, гр. Созопол. В: АОР през 2006 г. София, 2007, с. 273-275.

[GYUZELEV (M.) - Fouilles archéologique de sauvetage du site "Starata obshtina" dans la parcelle UPI - II, carré 28, Sozopol. In : AOR année 2006. Sofia, 2007, p. 273-275.]

Gyuzelev 2008: GYUZELEV (M.) - The West Pontic Coast between Emine Cape and Byzantion during the First Millenium B.C. Bourgas, Lotus Advertising Publishing House, 2008.

Hadzisteliou-Price 1969 : HADZISTELIOU-PRICE (T.) - The Type of the Crouching Child and the "Temple Boys". ABSA, 64, 1969, p. 85-111, pl. 20-23.

Hägg 1998 : HÄGG (R.) - Argos and its neighbours: Regional variations in the burial practices in Protogeometric and Geometric periods. In :

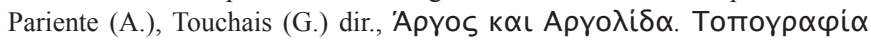

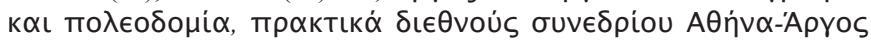
(28/4-1/5/1990) [Argos et l'Argolide, topographie et urbanisme, Actes du Congrès International, Athènes et Argos (28 avril-1 ${ }^{\text {er }}$ mai 1990)]. Athènes, Nauplie, Ministère de la Culture, $4^{\mathrm{e}}$ Éphorie et École française d'Athènes, 1998, p. 131-135.

Hammond, Griffith 1979 : HAMMOND (N.G.L.), GRIFFITH (G.T.) A History of Macedonia, vol. 2. Oxford, Clarendon Press, 1979.

Hannestad 2005 : HANNESTAD (L.) - The dating of the monumental building U6 at Panskoe I. In : Stolba (V.), Hannestad (L.) dir., Chronologies of the Black Sea Area in the Period c. 400-100 B.C. Aarhus University Press, 2003, p. 179-192.

Hempel 2001 : HEMPEL (K.G.) - Die Nekropole von Tarent im 2. und 1. Jahrhundert v. Chr. Studien zur materialen Kultur / La necropoli di Taranto nel II e I sec. a.C. Studi sulla cultura materiale. Tarente, éd. Scorpione, 2001.

Henneberg, Henneberg 1990 : HENNEBERG (M.), HENNEBERG (R.J.)

- Biological characteristics of the population in the chora. In : Carter (J.C.) ed., The Pantanello Necropolis 1982-1989. An Interim Report. Austin (Texas), University of Texas Press, 1990, p. 76-92.

Henneberg, Henneberg 1994 : HENNEBERG (M.), HENNEBERG (R.J.) - Treponematosis in an ancient Greek colony of Metaponto, Southern Italy, 580-250 BC. In : Dutour (O.), Palfi (G.), Berato (J.), Brun (J.-P.) eds., L'origine de la syphilis en Europe : avant ou après 1493 ? Naples, Centre Jean Bérard, 1994, p. 92-98.

Henneberg, Henneberg 1998 : HENNEBERG (M.), HENNEBERG (R.J.) - Biological characteristics of the population based on analysis of skeletal remains. In : Carter 1998, p. 503-562.

Henneberg, Henneberg 2001 : HENNEBERG (M.), HENNEBERG (R.J.) - Analysis of human skeletal and dental remains from Metaponto ( $7^{\text {th }}$ $2^{\text {nd }}$ c. BC). AttiTaranto, 40, 2001, p. 461-474.

Henneberg, Henneberg 2003 : HENNEBERG (M.), HENNEBERG (R.J.) - The diet of the Metapontine population as reconstructed from the physical remains. In : Carter (J.C.) ed., Living Off the Chora: Diet and Nutrition at Metaponto. Austin (Texas), University of Texas Press, 2003, p. 29-36.

Henneberg et al. 1992 : HENNEBERG (M.), HENNEBERG (R.J.), CARTER (J.C.) - Health in colonial Metaponto. National Geographic Research and Exploration, 8, 4, 1992, p. 446-459.

Hermary 1986 : HERMARY (A.), en collaboration avec CASSIMATIS (H.) et VOLLKOMMER (R.) - Eros. In : LIMC III, 1986, p. 850-942, pl. $609-668$.

Hermary 2003 : HERMARY (A.) - The Greeks in Marseilles and the Western Mediterranean. In : Karageorghis (V.) dir., The Greeks beyond the Aegean: From Marseilles to Bactria, Papers Presented at an International Symposium Held at the Onassis Cultural Center (New York, 12 October 2002). New York, Alexander S. Onassis Public Benefit Foundation, 2003, p. 59-77.

Hermary 2007 : HERMARY (A.) - Les fouilles franco-bulgares de la nécropole d'Apollonia du Pont. Eirene, 43, 2007, p. 161-175.

Hermary 2010 : HERMARY (A.) - Les vases et leur décor à l'époque classique : transfert de formes et d'images entre Grecs et Thraces, (Ve s. av. J.-C.). In : Tréziny (H.) dir., Grecs et indigènes de la Catalogne à la mer Noire. Paris et Aix-en-Provence, 2010, p. 481-486.

Hermary sous presse : HERMARY (A.) - Céramiques à figures rouges d'Apollonia du Pont, découvertes anciennes et récentes. Ancient West \& East, sous presse.

Hermary, Markou 2003 : HERMARY (A.), MARKOU (E.) - Les boucles d'oreilles, bijoux masculins à Chypre et en Méditerranée orientale (VII ${ }^{\mathrm{e}}$ IVe siècles avant J.-C.). CCEC, 33, 2003, p. 211-236.

Hermary, Panayotova 2006 : HERMARY (A.), PANAYOTOVA (K.) - La nécropole d'Apollonia du Pont : nouvelles découvertes de la mission francobulgare. Archéologia, 431, mars 2006, p. 52-63.

Higgins 1959 : HIGGINS (R.A.) - Catalogue of the Terracottas in the Department of Greek and Roman Antiquities, British Museum. Londres, British Museum, 1959.

Higgins 1967 : HIGGINS (R.A.) - Greek Terracottas. Londres, Butler \& Tamner, 1967.

Hiller 1975 : HILLER (H.) - Ionische Grabreliefs der ersten Hälfte des 5. Jahrhunderts v. Chr. Tübingen, Ernst Wasmuth, 1975 (IstMitt, Beiheft 12).

Hillson 2000 : HILLSON (S.W.) - Dental Pathology. In: Katzenberg (M.A.), Saunders (S.R.) eds., Biological Anthropology of the Human Skeleton. New York, Wiley-Liss, 2000, p. 249-286.

Hillson 2001 : HILLSON (S.W.) - Recording dental caries in archaeological human remains. International Journal of Osteoarchaeology, 11, 2001, p. 249-289.

Hillson 2005 : HILLSON (S.W.) - Teeth. Cambridge University Press, $2^{\mathrm{e}}$ éd., 2005. 
Hind 1985 : HIND (J.G.F.) - Anchors, Crayfish and Facing Heads : Silver Coins of Apollonia on the Euxine Sea. In : Fol 1985, p. 89-104.

Hind 1999: HIND (J.) - The Dates and Mother Cities of the Black Sea Colonies (Pseudo-Skymnus and the Pontic Contact Zone). In : Lordkipanidze (O.), Lévêque (P.) dir., La mer Noire, zone de contacts, Actes du VII ${ }^{e}$ symposium de Vani (Colchide, 26-30 septembre 1994). Besançon, PUFC, et Paris, Les Belles Lettres, 1999, p. 25-34.

Hodza 2000 : ХОДЗА (Е.Н.) - Терракотовые статуэтки мальчиков из собрании Эрмитажа. В: Зуев (В.Ю.), Шадричева (Л.В.) сост.,

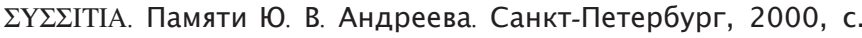
$125-131$.

[HODZA (E.N.) - Les statuettes en terre cuite d'enfants de la collection de

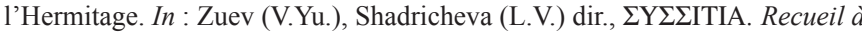
la mémoire de Yu. V. Andreeva. Saint Pétersbourg, 2000, p. 125-131.]

Holtzmann 2003 : HOLTZMANN (B.) - L'Acropole d'Athènes. Monuments, cultes et histoire du sanctuaire d'Athèna Polias. Paris, Picard, 2003.

Houby-Nielsen 1997 : HOUBY-NIELSEN (S.) - Grave gifts, women, and conventional values in Hellenistic Athens. In : Bilde (P.) et alii eds., Conventional Values of the Hellenistic Greeks. Aarhus, University Press, 1997, p. 220-262, pl. 8-14

Howland 1958: HOWLAND (R.H.) - The Athenian Agora. Volume IV. Greek Lamps and their Survivals. Princeton, The American School of Classical Studies, 1958.

Humphreys 1980 : HUMPHREYS (S.C.) - Family tombs and tomb cult in ancient Athens : Tradition or traditionalism. JHS, 100, 1980, p. 96-126.

Irechek 1899 (voir aussi Jireček): ИРЕЧЕК (К.) - Княжество България. Част ІІ: Пътувания по България. Пловдив, Хр. Г. Данов, 1899.

[IRECHEK (K.) - Principauté de Bulgarie. $\mathrm{II}^{\mathrm{e}}$ partie : Voyages en Bulgarie. Plovdiv, Hr. G. Danov, 1899.]

Isaac 1986 : ISAAC (B.) - The Greek Settlements in Thrace until the Macedonian Conquest. Leiden, E.J. Brill, 1986.

Isler 1978 : ISLER (H.P.) - Samos IV. Das archaische Nordtor. Bonn, R. Habelt, 1978 .

Ivanov 1948: ИВАНОВ (Т.) - Керамиката от некропола на Аполония. B: Venedikov et al. 1948, с. 31-52.

[IVANOV (T.) - Les céramiques de la nécropole d'Apollonia. In : Venedikov et al. 1948, p. 31-52.]

Ivanov 1963 : ИВАНОВ (Т.) - Антична керамика от некропола на Аполония. В: Venedikov et al. 1963, с. 65-273.

[IVANOV (T.) - La céramique antique de la nécropole d'Apollonia. In : Venedikov et al. 1963, p. 65-273.]

Jacobsthal 1956 : JACOBSTHAL (P.) - Greek Pins, and their Connexions with Europe and Asia. Oxford, Clarendon Press, 1956.

Jehasse 1973 : JEHASSE (J. et L.) - La nécropole préromaine d'Aléria (1960-1968). Paris, éd. du CNRS, 1973 (Gallia, Suppl. XXV).

Jenkins 1986 : JENKINS (I.) - Greek and Roman Life. Londres, British Museum, 1986.

Jireček 1886 : JIREČEK (K.) - Archäologische Fragmente aus Bulgarien. AEM, 10, 1886, p. 129-208.

Johnston 1979: JOHNSTON (A.W.) - Trademarks on Greek Vases. Warminster, 1979

Johnston 2006 : JOHNSTON (A.W.) - Trademarks on Greek Vases : Addenda. Oxford, Aris \& Philips, 2006.

Jones, Graham, Sackett 1973 : JONES (J.E.), GRAHAM (A.J.), SACKETT (L. H.) - An Attic Country House below the Cave of Pan at Vari. ABSA, 68, 1973, p. 356-452.

Jucker 1986 : JUCKER (I.) - Hercle bei Lamtu. Ein neuer etruskischer Spiegel. Antike Kunst, 29, 1986, p. 126-136, pl. 24-26.

Kahil 1965 : KAHIL (L.) - Autour de l'Artémis attique. Antike Kunst, 8 , 1965, p. 20-33, pl. 7-10.

Kahil 1977 : KAHIL (L.) - L'Artémis de Brauron : rites et mystères. Antike Kunst, 20, 1977, p. 86-98, pl. 18-21.

Kahil 1984 : KAHIL (L.), en collaboration avec ICARD (N.) - Artemis. In : LIMC II, 1984, p. 618-753, pl. 442-463.
Kahil 1990 : KAHIL (L.), en collaboration avec ICARD (N.) - Helene. In : LIMC IV, 1990, p. 498-563, pl. 291-358.

Kalinka 1905 : KALINKA (E.) - Antike Denkmäler in Bulgarien. Vienne, A. Hölder, 1905.

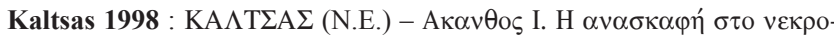

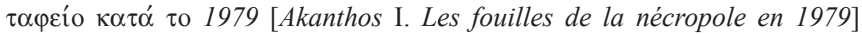
Athènes, Publications de l'ArchDelt nº 65, 1998.

Kaminsky 1987 : КАМИНСКИЙ (В.Н.) -Погребальные комплекси из окръга Краснодара. Советская археология, 2, 1987, с. 254-260.

[KAMINSKY (V.N.) - Complexe funéraire de la région de Krasnodar. Sovietskaia Arhéologia, 2, 1987, p. 254-260.]

Karageorghis 1962 : KARAGEORGHIS (V.) - Chronique des fouilles et découvertes archéologiques à Chypre en 1961. BCH, 86, 1962, p. 327-414.

Karamitrou-Mentessidi 1995: KARAMITROU-MENTESSIDI (G.) - Aianè, ville de Macédoine. In : Les Macédoniens, les Grecs du Nord et l'époque d'Alexandre le Grand, Cat. d'exposition, Marseille 1995. Athènes, éd. Kapon, 1995, p. 32-36.

Karayotov 1990 : KARAYOTOV (I.) - The Antique and Medieval Port at the Mouth of the River Ropotamo. In : Velkov (V.), Najdenova (V.), Petrov (P.) dir., Studies on Settlement Life in Ancient Thrace. Sofia, International Association "Terra Antiqua Balcanica", 1990, p. 64-65.

Karayotov 1992: KARAYOTOV (I.) - Explorations archéologiques sous-marines dans la baie devant l'embouchure du Ropotamo (1985-1986). In : Gyuzelev (V.) dir., Bulgaria Pontica Medii Aevi, Actes du III ${ }^{\mathrm{e}}$ colloque international, Nessebar, 27-31 mai 1985. Sofia, Presses universitaires "Sveti Kliment Ohridski”, 1992, p. 277-279.

Karayotov 2002 : KARAYOTOV (I.) - Nouveaux monuments des villes antiques du littoral ouest de la mer Noire. In : Gicheva (R.), Rabadjiev (K.) eds., Пıтún. Studia in honorem Prof. Ivani Marazov. Sofia, Anubis, 2002, p. $558-567$.

Kastanian 1959: КАСТАНАЯН (Е.Г.) - Грунтовые некрополи боспорских городов V - IV вв. дон.э. и местные их особенности. МИА, 69, 1959, с. 183-284.

[KASTANIAN (E.G.) - La nécropole plate des cités du Bosphore Ve-IVe s. av. J.-C. Materialy i issledovaniya po arkheologii SSSR, 69, 1959, p. 183-284.]

Kats 1994: КАЦ (В.И.) - Керамические клейма Херсонеса Таврического. Каталог-определитель. Саратов, Издательство Саратовского Университета, 1994.

[KATS (V.I.) - Les timbres céramiques de Chersonnèse Taurique. Catalogue illustré. Saratov, éditions de l’Université de Saratov, 1994.]

Kats 2003 : KATS (V.) - A New Chronology for the Ceramic Stamps of Herakleia Pontike. In : Guldager Bilde (P.), Munk Højte (J.), Stolba (V.) dir., The Cauldron of Ariantas. Studies Presented to A. N. Sceglov on the Occasion of his $70^{\text {th }}$ Birthday. Aarhus, University Press, 2003, p. 261-278.

Katsarova 2007 : КАЦАРОВА (В.) - Спасителни археологически проучвания на надгробна могила № 10 на н. Колокита, гр. Созопол. В: АОР през 2006 г. София, 2007, с. 307-310.

[KATSAROVA (V.) - Fouilles archéologiques de sauvetage du tumulus funéraire ${ }^{\circ} 10$ sur le cap Kolokita, ville de Sozopol. In : AOR année 2006. Sofia, 2007, p. 307-310.]

Kazarow 1917 : KAZAROW (M.) - Ein neue Thrakische Inschrift. JÖAI, 15, 1917, p. 97-101.

Keenleyside 2008 : KEENLEYSIDE (A.) - Dental pathology and diet at Apollonia, a Greek colony on the Black Sea. International Journal of Osteoarchaeology, 18, 2008, p. 262-279.

Keenleyside, Panayotova 2005: KEENLEYSIDE (A.), PANAYOTOVA (K.) - A Bioarchaeological Study of the Greek Colonial Population of Apollonia Pontica. AB, 9, 2, 2005, p. 21-38.

Keenleyside, Panayotova 2006: KEENLEYSIDE (A.), PANAYOTOVA (K.) - Cribra orbitalia and porotic hyperostosis in a Greek colonial population from the Black Sea. International Journal of Osteoarchaeology, 16, 2006, p. 373-384.

Keenleyside, Schwarcz, Panayotova 2006: KEENLEYSIDE (A.), SCHWARCZ (H.), PANAYOTOVA (K.) - Stable Isotopic Evidence of Diet in 
a Greek Colonial Population from the Black Sea. Journal of Archaeological Science, 33, 2006, p. 1205-1215.

Kerey et al. 2004: KEREY (I.E.), MERIÇ (E.), TUNOĞLU (C.), KELLING (G.), BRENNER (R.L.), DOĞAN (A.U.) - Black Sea - Marmara Sea Quaternary Connections : New Data from the Bosphorus, Istanbul, Turkey. Palaeogeography, Palaeoclimatology, Palaeoecology, 204, 3-4, 2004, p. 277-295.

Kitov, Dimitrova, Petrov 2007 : КИТОВ (Г.), ДИМИТРОВА, (Д.), ПЕТРОВ, (И.) - Могила Келешева чука край село Конуш в Хасковско. В: АОР през 2006 г. София, 2007, с. 148-151.

[KITOV (G.), DIMITROVA (D.), PETROV (I.) - Le tumulus « Kelesheva Chuka » près du village Konoush, département de Haskovo. In : AOR année 2006. Sofia, 2007, p. 148-151.]

Knigge 1966 : KNIGGE (U.) - Eridanos - Nekropole II : Gräber hS 205230. $A M, 81,1966$, p. 112-134.

Koeller 2008 : KOELLER (A.-S.) - Structures funéraires grecques et regroupements familiaux au IVe siècle avant J.-C. : les exemples de Marseille et d'Apollonia Pontique. In: Özbek (O.) ed., Funeral Rites, Rituals and Ceremonies from Prehistory to Antiquity, Actes du colloque international "Troas and its Neighbours", 2-6 octobre 2006. Istanbul, IFEA, p. 45-58.

Koeller, à paraître: KOELLER (A.-S.), en collaboration avec PANAYOTOVA (K.) - Les sépultures d'enfants de la nécropole d'Apollonia du Pont (Bulgarie) : résultats des fouilles récentes. In : L'enfant et la mort dans l'Antiquité : des pratiques funéraires à l'identité sociale. Table Ronde 1, Athènes, 29-30 mai 2008, sous presse.

Konova 1997: КОНОВА (Л.) - Червенофигурни съдове с изображения на амазонки от некропола на Аполония Понтика. Опит за интерпретация. Проблеми на изкуството, 30, 3-4, 1997, c. 42-46.

[KONOVA (L.) - Vases à figures rouges avec scènes d'Amazones de la nécropole d'Apollonia du Pont. Essai d'interprétation. Problemi na izkustvoto, 30, 3-4, 1997, p. 42-45.]

Konova 2002 : КОНОВА (Л.) - Оловни букрании от некропола на Аполония Понтика. Опит за интерпретация. ИНИМ, 13, 2002 , c. 46-55.

[KONOVA (L.) - Bucranes en plomb de la nécropole d'Apollonia du Pont. Tentative d'interprétation. INIM, 13, 2002, p. 46-55].

Koshelenko 2007 : KOSHELENKO (G.A.) - Les premiers contacts entre Grecs et barbares aux franges du Bosphore Cimmérien : écologie, archéologie et histoire. In : Bresson (A.), Ivantchik (A.), Ferrary (J.-L.) dir., Une koinè pontique : cités grecques, sociétés indigènes et empires mondiaux sur le littoral nord de la mer Noire (VII ${ }^{e}$ s. a.C-III ${ }^{e}$ s. p.C). Bordeaux, Ausonius, 2007, p. 21-28.

Koukouli-Chrysanthaki 1994 : KOUKOULI-CHRYSANTHAKI (Ch.) The cemeteries of Abdera. In : La Genière 1994, p. 33-77.

Koukouli-Chrysanthaki 2006: KOUKOULI-CHRYSANTHAKI (Ch.) - Les nécropoles de la Pérée Thasienne : Oisymè et Galepsos. In : GuimierSorbets (A.M.), Hatzopoulos (M.B.), Morizot (Y.) dir., Rois, cités, nécropoles, institutions, rites et monuments en Macédoine, Actes des colloques de Nanterre (décembre 2002) et d'Athènes (janvier 2004). Athènes, KERA et Paris, de Boccard, 2006, p. 169-184.

Koukouli-Chrysanthaki, Sgourou, Agelarakis 1996: KOYKOY $\Lambda$ H-

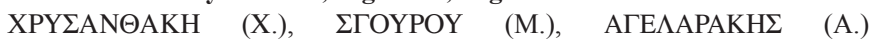

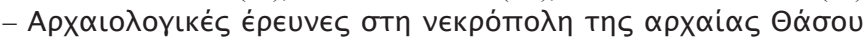
[Découvertes archéologiques dans la nécropole antique de Thasos]. AEM $\Theta$, $10 \beta, 1996$, p. 769-794.

Kouznetsova 1987 : КУЗНЕЦОВА (Т.М.) - Зеркала из скифских памятников VI - III вв. до н.э. Класификация и хронологическое распределение. Советская археология, 1, 1987, с. 35-47.

[KOUZNETSOVA (T.M.) - Miroirs de monuments scythes, VI ${ }^{\mathrm{e}}-\mathrm{III}{ }^{\mathrm{e}} \mathrm{s}$. av. n.è. Classification et répartition chronologique. Sovietskaia Arhéologia, 1, 1987, p. 35-47.]

Kovacsovics 1990 : KOVACSOVICS (W.K.) - Kerameikos XIV. Die Eckterrasse an der Gräberstrasse des Kerameikos. Berlin et New York, W. De Gruyter, 1990.
Krogman 1978 : KROGMAN (W.M.) - The Human Skeleton in Forensic Medicine. Springfield (Illinois), Charles C. Thomas, 3e éd., 1978.

Kunze-Götte et al. 1999: KUNZE-GÖTTE (E.), TANCKE (K.), VIERNEISEL (K.) - Kerameikos VII, 2. Die Beigaben. Munich, Hirmer, 1999.

Kurtz, Boardman 1971 : KURTZ (D.), BOARDMAN (J.) - Greek Burial Customs. Londres, Thames and Hudson, 1971.

Kwok, Keenleyside sous presse : KWOK (C.), KEENLEYSIDE (A.) - Baby bones, food, and health: isotopic evidence for infant feeding practices in the Greek colony of Apollonia Pontica ( $5^{\text {th }} 2^{\text {nd }}$ centuries B.C.). In : Richards (M.), Papathanasiou (A.) eds., Stable Isotope Dietary Studies of Prehistoric and Historic Greek Populations. Hesperia, Occasional Wiener Laboratory Series, sous presse.

Laborel et al. 1994 : LABOREL (J.), MORHANGE (C.), LAFONT (R.), LE CAMPION (J.), LABOREL-DEGUEN (F.), SARTORETTO (S.) Biological Evidence of Sea-Level Rise during the Last 4500 Years on the Rocky Coasts of Continental Southwestern France and Corsica. Marine Geology, 120, 3-4, 1994, p. 203-223.

Lacroix 1949: LACROIX (L.) - Les reproductions de statues sur les monnaies grecques. La statuaire archaïque et classique. Liège, Faculté de philosophie et lettres, 1949.

La Genière 1994 : LA GENIÈRE (J. de), Nécropoles et Sociétés antiques (Grèce, Italie, Languedoc), Actes du Colloque International du Centre de Recherches Archéologiques de l'Université de Lille III (Lille, 2-3 décembre 1991). Naples, Centre Jean Bérard, 1994.

Laine 2002 : LAINE (M.A.) - Effect of pregnancy on periodontal and dental health. Acta Odontologica Scandinavica, 60, 5, 2002, p. 257-264.

Lamb 1936 : LAMB (W.) - CVA Great Britain 11, Cambridge, Fitzwilliam Museum 2. Oxford University Press, 1936.

Landolfi 2000 : LANDOLFI (M.) - Il Pittore di Filottrano e la tarda ceramica attica a figure rosse nel Piceno. In : Sabattini 2000, p. 77-91.

Langlotz 1932 : LANGLOTZ (E.) - Griechische Vasen in Würzburg. Munich, J. B. Obernetter, 1932.

Langlotz 1953-54: LANGLOTZ (E.) - Aphrodite in den Gärten. Heidelberg, Carl Winter, 1953-54.

Langlotz 1975 : LANGLOTZ (E.) - Studien zur nordostgriechischen Kunst. Mayence, Ph. von Zabern, 1975.

Larsen 1997 : LARSEN (C.S.) - Bioarchaeology. Interpreting Behaviour from the Human Skeleton. Cambridge University Press, 1997.

Laumonier 1956 : LAUMONIER (A.) - Exploration archéologique de Délos XXIII. Les figurines de terre cuite. Athènes, EfA, et Paris, de Boccard, 1956.

Lazarov 1969 : ЛАЗАРОВ (М.) - Археологическите разкопки и проучвания в Бургаски окръг. Резултати, проблеми и задачи. Известия на българските музеи, 1, 1969, с. 3-20.

[LAZAROV (M.) - Les fouilles et recherches archéologiques dans le département de Bourgas. Résultats, problèmes et objectifs. Izvestiya na balgarskite muzei, 1, 1969, p. 3-20.]

Lazarov 1974 : LAZAROV (M.) - Localités prégrecques sur le littoral thrace de la mer Noire. Thracia, 3, 1974, p. 107-123.

Lazarov 1993 : LAZAROV (M.) - Les sites submergés le long du Pont Ouest dans le contexte de l'histoire pontique et méditerranéenne. Pontica, 26, 1993, p. 7-18.

Lazarov 2000 : ЛАЗАРОВ (М.), Българското Черноморие през архаичния период. Състояние на проучванията. ИНМБ, 3 , 2000, c. 23-41.

[LAZAROV (M.) - Le littoral bulgare de la mer Noire durant la période archaïque. Etat des recherches. INMB, 3, 2000, p. 23-41.]

Lazarov 1990/2003 : ЛАЗАРОВ (М.) - Древногръцката рисувана керамика от България. Варна, Славена, 1990/2003.

[LAZAROV (M.) - La céramique grecque peinte de Bulgarie. Varna, Slavena, 1990/2003.]

Lévy 1994 : LÉVY (Ed.) - La mort en Grèce. In : Amouretti (M.-Cl.), Villard (P.) eds., EYKPATA. Mélanges offerts à Claude Vatin. Aix-en-Provence, PUP, 1994, p. 119-127. 
Lewis 2004 : LEWIS (M.E.) - Endocranial lesions in non-adult skeletons: understanding their aetiology. International Journal of Osteoarchaeology, 14, 2004, p. 82-97.

Lieverse 1999 : LIEVERSE (A.R.) - Diet and the aetiology of dental calculus. International Journal of Osteoarchaeology, 9, 4, 1999, p. 219-232.

Lillie, Richards 2000 : LILLIE (M.C.), RICHARDS (M.) - Stable Isotope Analysis and Dental Evidence of Diet at the Mesolithic-Neolithic Transition in Ukraine. Journal of Archaeological Science, 27, 2000, p. 965-972.

Lippolis 2005 : LIPPOLIS (E.) - Pratica rituale e coroplastica votiva a Taranto. In : Nava (M.L.), Osanna (M.) eds., Lo spazio del rito. Santuari e culti in Italia meridionale tra Indigeni e Greci. Atti delle giornate di studio (Matera, 28 e 29 giugno 2002). Bari, Edipuglia, 2005, p. 91-102.

Lochin 1990 : LOCHIN (C.) - Hypnos/Somnus. In : LIMC V, 1990, p. 591609, pl. 403-418.

Lovejoy, Heiple 1981 : LOVEJOY (C.O.), HEIPLE (K.G.) - The analysis of fractures in skeletal populations, with an example from the Libben site, Ottowa County, Ohio. American Journal of Physical Anthropology, 55, 1981, p. 529-541.

Lovejoy et al. 1985: LOVEJOY (C.O.), MEINDL (R.S.), PRYZBECK (T.R.), MENSFORTH (R.P.) - Chronological metamorphosis of the auricular surface of the ilium: a new method for the determination of age at death. American Journal of Physical Anthropology, 68, 1985, p. 15-28.

Lovell 2000: LOVELL (N.C.) - Paleopathological Description and Diagnosis. In : Katzenberg (M.A.), Saunders (S.R.) eds., Biological Anthropology of the Human Skeleton. New York, Wiley-Liss, 2000, p. 217-248.

Lungu 1993: LUNGU (V.) - Pour une chronologie de la céramique attique du Nord de la Dobroudja (IVe-III' siècles av. J.-C.). Pontica, 26, 1993, p. $159-190$.

Lungu 2000 : LUNGU (V.) - Pratiques funéraires, forme d'organisation spatiale et formes d'organisation sociale dans la nécropole de la cité grecque d'Orgamè. In : Simion (G.), Lungu (V.) eds., Tombes tumulaires de l'Áge du Fer dans le Sud-Est de l'Europe, Actes du II ${ }^{e}$ colloque international d'archéologie funéraire. Tulcea, Publications de l'Institut de recherches écomuséologiques, 2000, p. 101-118.

Lungu 2006 : LUNGU (V.) - Nécropoles grecques du Pont gauche. In : Lungu (V.), Simion (G.), Topoleanu (F.) eds., Pratiques funéraires et manifestations de l'identité culturelle (Âge du Bronze et Âge du Fer), Actes du IVe colloque international d'archéologie funéraire. Tulcea, Publications de l'institut de recherches éco-muséologiques, 2006, p. 157-176.

Major et al. 2002: MAJOR (C.), RYAN (W.), LERICOLAIS (G.), HADJAS (I.) - Constraints on Black Sea Outflow to the Sea of Marmara during the Last Glacial-Interglacial Transition. Marine Geology, 190, 1-2, 2002, p. 19-34.

Mandel 1999: MANDEL (U.) - Die ungleichen Spielerinnen - Zur Bedeutung weiblicher Ephedrisposgruppen. In: Hellenistische Gruppen. Gedenkschrift für Andreas Linfert. Mayence, von Zabern, 1999, p. 213-266.

Mannino, Roubis 2000 : MANNINO (K.), ROUBIS (D.) - Le importazioni attiche del IV secolo nell'Adriatico meridionale. In : Sabattini 2000, p. 67-76.

Mansova 1972: MANSOWA (L.) - Neue Untersuchungen des Marmorkopfes aus Apollonia. ИБАИ, 33, 1972, p. 85-90.

Marriner, Morhange 2007: MARRINER (N.), MORHANGE (C.) Geoscience of Ancient Mediterranean Harbours. Earth Science Reviews, 80, 3-4, 2007, p. 137-194.

Marriner, Morhange, Meule 2007 : MARRINER(N.), MORHANGE (C.), MEULE (S.) - Holocene Morphogenesis of Alexander the Great's Isthmus at Tyre in Lebanon. Proceedings of the National Academy of Sciences, 104, 22, 2007, p. 218-223.

Marriner, Goiran, Morhange 2008 : MARRINER (N.), GOIRAN (J.-P.), MORHANGE (C.) - Alexander the Great's Tombolos at Tyre and Alexandria, Eastern Mediterranean. Geomorphology, 100, 3-4, 2008, p. 377-400.

Massoul 1936 : MASSOUL (M.) - CVA France 13, Musée National de Sèvres. Paris, Librairie ancienne Honoré Champion, 1936.

May 1992 : MAY (R.) - Pions de jeu romains. In : Jouer dans l'Antiquité, Cat. de l'exposition du Musée d'Archéologie Méditerranéenne (22 novembre 1991-16 février 1992). Marseille, 1992, p. 188-189.
McKinley 1993 : McKINLEY (J.I.) - Bone fragment size and weights of bone from modern british cremations and the implications for the interpretation of archaeological cremations. International Journal of Osteoarchaeology, 3, 1993, p. 283-287.

McPhee 1979 : McPHEE (I.) - The Agrinion Group. ABSA, 74, 1979, p. 159-162, pl. 18-20.

Meiklejohn, Zvelebil 1991 : MEIKLEJOHN (C.), ZVELEBIL (M.) Health status of European populations of the agricultural transition and the implications for the adoption of farming. In : Bush (H.), Zvelebil (M.) eds., Health in Past Societies: Biocultural Interpretations of Human Remains in Archaeological Contexts. British Archaeological Reports, International Series $\mathrm{n}^{\circ} 567,1991$.

Meindl, Lovejoy 1985 : MEINDL (R.S.), LOVEJOY (C.O.) - Ectocranial suture closure: a revised method for the determination of skeletal age at death based on the lateral-anterior sutures. American Journal of Physical Anthropology, 68, 1985, p. 57-66.

Melyukova 1964 : МЕЛЮКОВА (А. И.) - Вооружение скифов. В: Свод археологических источников, Д. 1-4, 1964, с. 14-32.

[MELYUKOVA (A.I.) - L'armement scythe. In : Svod arheologicheskih Istochnikov, 1-4, 1964, p. 14-32.]

Mensforth et al. 1978: MENSFORTH (R.C.), LOVEJOY (C.O.), LALLO (J.), ARMELAGOS (G.J.) - The role of constitutional factors, diet and infectious disease in the etiology of porotic hyperostosis and periosteal reactions in prehistoric infants and children. Medical Anthropology, 2, 1978, p. 1-59.

Merker 2000 : MERKER (G.L.) - Corinth vol. XVIII, IV. The Sanctuary of Demeter and Kore: Terracotta Figurines of the Classical, Hellenistic and Roman Periods. Princeton (N.J.), American School of Classical Studies, 2000.

Metzger 1951 : METZGER (H.) - Les représentations dans la céramique attique du IVe siècle. Paris, de Boccard, 1951.

Metzger 1965 : METZGER (H.) - Recherches sur l'imagerie athénienne. Paris, de Boccard, 1965.

Mielczarek 1995 : MIELCZAREK (M.) - Armes grecques, scythes et sarmates du littoral septentrional de la mer Noire dans la collection du Musée de l'Armée Polonaise à Varsovie. Torun, Université Nicolas Copernic, Institut d'archéologie et d'ethnologie, 1995.

Mihailov 1955 : МИХАЙЛОВ (Г.)-Към историята на Тракия през IV-III в. пр. н. е. ИБАИ, 19, 1955, с. 149-165.

[MIHAILOV (G.) - Contribution à l'histoire de la Thrace aux IVe-III' s. av. J.-C. IBAI, 19, 1955, p. 149-165.]

Mihailov 1970 : MIHAILOV (G.) - Inscriptiones Graecae in Bulgaria Repertae. Vol. 1: Inscriptiones Orae Ponti Euxini. Sofia, Académie Bulgare des Lettres, $2^{e}$ éd., 1970.

Mihailov 1972 : МИХАЙЛОВ (Г.) - Траките. София, Държавно военно издателство, 1972, 319 с.

[MIHAILOV (G.) - Les Thraces. Sofia, Presses militaires de l'État, 1972.]

Mikov 1925: МИКОВ (В.) - Разкопки при Созопол. ИБАИ, 3, 1925 , c. 236-241.

[MIKOV (V.) - Fouilles près de Sozopol. IBAI, 3, 1925, p. 236-241.]

Mikov 2007 : МИКОВ (Р.) - Спасително проучване на надгробна могила № 9 на н. Колокита. АОР през 2006 г. София, 2007, с. 341-344.

[MIKOV (R.) - Fouilles de sauvetage du tumulus funéraire $\mathrm{n}^{\circ} 9$ sur le cap Kolokita. In : AOR année 2006. Sofia, 2007, p. 341-344.]

Miller 1974 : MILLER (S. G.) - Memnon's Cistern. Hesperia, 43, 1974, p. 194-245.

Mladenova 1963a : МЛАДЕНОВА (Я.) - Погребалните венци от некропола на Аполония. В: Venedikov et al. 1963, с. 287-292. [MLADENOVA (Y.) - Les couronnes funéraires de la nécropole d'Apollonia. In : Venedikov et al. 1963, p. 287-292.]

Mladenova 1963b : МЛАДЕНОВА (Я.) - Накитите от некропола на Аполония. В: Venedikov et al. 1963, с. 293-304.

[MLADENOVA (Y.) - Les objets de parure de la nécropole d'Apollonia. In : Venedikov et al. 1963, p. 293-304.]

Moliner 1994 : MOLINER (M.) - Dispositifs de couverture et de signalisation dans la nécropole grecque de Sainte-Barbe à Marseille. In : Les sépultures 
protohistoriques dans le Midi de la France. Couvertures et dispositifs de signalisations. Dossier des Documents d'Archéologie Méridionale, 17, 1994, p. 74-92.

Moliner et al. 2003 : MOLINER (M.), MELLINAND (P.), NAGGIAR (L.), RICHIER (A.), VILLEMEUR (I.) - La nécropole de Sainte-Barbe à Marseille (IV e s. av. J.-C. $-I I^{\text {e }}$ s. ap. J.-C.). Aix-en-Provence, Edisud, 2003.

Mollard-Besques 1954 : MOLLARD-BESQUES (S.) - Musée National du Louvre. Catalogue raisonné des figurines et reliefs en terre-cuite grecs, étrusques et romains. I. Époques préhellénique, géométrique, archaïque et classique. Paris, éditions des Musées Nationaux, 1954.

Monahov 1989: МОНАХОВ (С.Ю.) - Амфоры Херсонеса Таврического IV-II вв. до н. э. Опыт системного анализа. Саратов, Издательство Саратовского Университета, 1989.

[MONAHOV (S.Yu.) - Les amphores de Chersonnèse Taurique, $I V^{e}-I I^{e} s$. av. J.-C. Essai d'analyse systématique. Saratov, éditions de l'Université de Saratov, 1989.]

Monahov 1999: МОНАХОВ (С.Ю.) - Греческие амфоры в Причерноморье. Комплексы керамической тары VII - II веков до н. э. Саратов, Издательство Саратовского университета, 1999.

[MONAHOV (S.Yu.) - Les amphores grecques sur le littoral de la mer Noire. Complexes d'emballage céramique VII $-I I^{e}$ s. av. J.-C. Saratov, éditions de l’Université de Saratov, 1999.]

Monahov 2003: МОНАХОВ (С.Ю.) - Греческие амфоры в Причерноморье. Типология амфор ведущих центров-экспортеров товаров в керамической таре : Каталогопределитель. Москва / Саратов, Кимерида / Издательство Саратовского университета, 2003.

[MONAHOV (S.Yu.) - Les amphores grecques sur le littoral de la mer Noire. Typologie des amphores des principaux centres exportateurs de produits en emballage céramique: Catalogue illustré. Moscou et Saratov, Kimerida et éditions de l'Université de Saratov, 2003.]

Monahov, Abrosimov 1993 : МОНАХОВ (С.Ю.), АБРОСИМОВ (Э.Н.) - Новое о старых материалах из Херсонесского некрополя. AMA, 9, 1993, с. 118-159.

[MONAHOV (S.Yu.), ABROSIMOV (E.N.) - Nouvelles données sur le matériel des anciennes fouilles de la nécropole de Chersonnèse. AMA, 9, 1993, p. 118-159.]

Monahov, Rogov 1990a : МОНАХОВ (С.Ю.), РОГОВ (Е.Я.) - Амфоры некрополя Панское I. AMA, 7, 1990, с. 128-153.

[MONAHOV (S.Yu.), ROGOV (E.Ya.) - Les amphores de la nécropole de Panskoe I. AMA, 8, 1990, p. 128-153.]

Monahov, Rogov 1990b: МОНАХОВ (С.Ю.), РОГОВ (Е.Я.) Керамические комплексы некрополя Панское І. АМА, 8, 1990, c. $122-151$.

[MONAHOV (S.Yu.), ROGOV (E.Ya.) - Les complexes céramiques de la nécropole de Panskoe I. AMA, 8, 1990, p. 122-151.]

Moore 1997 : MOORE (M.B.) - The Athenian Agora. Volume XXX. Attic Red-figured and White-ground Pottery, Athènes et Princeton, The American School of Classical Studies, 1997.

Moorres et al. 1963a : MOORREES (C.F.A.), FANNING (E.A.), HUNT (E.E.) - Formation and resorption of three deciduous teeth in children. American Journal of Physical Anthropology, 21, 1963, p. 205-213.

Moorres et al. 1963b: MOORREES (C.F.A.), FANNING (E.A.), HUNT (E.E.) - Age variation of formation stages for ten permanent teeth. Journal of Dental Research, 42, 6, 1963, p. 1490-1502.

Moreno 2001 : MORENO (P.) - Kalamis. In : Vollkommer (R.) dir., Künstlerlexikon der Antike, vol. 1. Munich et Leipzig, K. G. Saur, 2001, p. 373-382.

Morhange 2001 : MORHANGE (C.) - Mobilité littorale de quelques sites portuaires antiques de Méditerranée : Marseille, Pouzzoles, Cumes, Kition et Sidon. Habilitation à Diriger des Recherches, Université de Provence, CEREGE, 2001

Morhange, Laborel, Hesnard 2001 : MORHANGE (C.), LABOREL (J.), HESNARD (A.) - Changes of Relative Sea Level during the Past 5000 Years in the Ancient Harbour of Marseilles, Southern France. Palaeogeography, Palaeoclimatology, Palaeooecology, 166, 3-4, 2001, p. 319-329.

Muller, Tartari 2006 : MULLER (A.), TARTARI (F.) - L'Artémision de Dyrrachion : offrandes, identification, topographie. CRAI, 2006, p. 65-92.

Mussche 1961 : MUSSCHE (H.F.) - La forteresse maritime de Thorikos. $B C H, 85,1961$, p. 176-205.

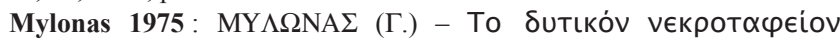

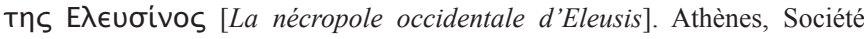
Archéologique, 1975, 3 volumes.

Nedev 2006 : НЕДЕВ (Д.) - Спасителни проучвания в старата част на Созопол. В: АОР през 2005 г. София, 2006, с. 240-241. [NEDEV (D.) - Fouilles de sauvetage dans le centre ancien de Sozopol. In : AOR année 2005. Sofia, 2006, p. 240-241.]

Nedev 2007: НЕДЕВ (Д.) - Спасителни археологически проучвания в старата част на гр. Созопол (УПИ 226, кв. 18, УПИ XI-XII - 515, кв. 27). В: АОР през 2007 г. София, 2008, с. $312-313$.

[NEDEV (D.) - Fouilles de sauvetage dans la partie ancienne de la ville de Sozopol (UPI 226, parc. 18, UPI XI-XII-515, parc. 27). In : AOR année 2007. Sofia, 2008, p. 312-313.]

Nedev, Drajeva 2007 : НЕДЕВ (Д.), ДРАЖЕВА (Ц.) - Спасителни археологически проучвания в старата част на гр. Созопол УПИ 226, кв. 18. В: АОР през 2006 г. София, 2007, с. 356-358. [NEDEV (D.), DRAJEVA (Ts.) - Fouilles archéologiques de sauvetage dans le centre ancien de Sozopol - UPI 226, carré 18. In : AOR année 2006. Sofia, 2007, p. 356-358.]

Nedev, Giuzelev, sous presse : NEDEV (D.), GIUZELEV (M.) - Archaic Painted Pottery from Apollonia Pontica (According the Latest Data from the Archaeological Excavations in the Old Town of Sozopol). In :Local Populations of The Black Sea Littoral and Their Relations with the Greek, Roman And Byzantine Worlds and Near Eastern Civilisations (8th Century B.C. - ca. AD 1000), Proceedings of the Second International Congress on the Black Sea Antiquities (Ankara, 2-9 September 2001). Oxford, Archaeopress, sous presse.

Nedev, Gospodinov 2007: НЕДЕВ (Д.), ГОСПОДИНОВ (К.) Спасителни археологически проучвания на територията на старата част на гр. Созопол (УПИ XI-XII-515, кв. 27; УПИ XIX525, кв. 27; УПИ Х-393, кв. 36). В: АОР през 2006 г., София, 2007 , c. $353-356$.

[NEDEV (D.), GOSPODINOV (K.) - Fouilles archéologiques de sauvetage sur le territoire du centre ancien de Sozopol (UPI XI-XII-515 ; UPI XIX-525, carré 27 ; UPI X-393, carré 36). In : AOR année 2006. Sofia, 2007, p. 353-357.]

Nedev, Panayotova 2003 : NEDEV (D.), PANAYOTOVA(K.) - Apollonia Pontica (end of the $7^{\text {th }}-1^{\text {st }}$ Centuries B.C.). In : Grammenos, Petropoulos 2003, p. $95-155$

Nedev, Panayotova 2005: НЕДЕВ (Д.), ПАНАЙОТОВА (К.) Спасителни проучвания на некропола на Аполния. В: АОР през 2005 г., София, 2005, с. 241-246.

[NEDEV (D.), PANAYOTOVA (K.) - Fouilles de sauvetage sur la nécropole d'Apollonia. In : AOR année 2005. Sofia, 2005, p. 241-246.]

Nedyalkov 2008 : NEDYALKOV (K.) - Local Pottery from Apollonia Pontica $6^{\text {th }}-5^{\text {th }}$ Century BC. $A B, 12,1,2008$, p. 1-28.

Neils 1992 : NEILS (J.) - The Morgantina Phormiskos. AJA, 96, 1992, p. 225-235.

Neils, Oakley 2003 : NEILS (J.), OAKLEY (J.H.) dir. - Coming of Age in Ancient Greece. Images of Childhood from the Classical Past. New Haven et Londres, Yale University Press, 2003.

Oakley 2004 : OAKLEY (J.H.) - Picturing Death in Classical Athens : The evidence of the White Lekythoi. Cambridge University Press, 2004.

Oenbrink 1997 : OENBRINK (W.) - Das Bild im Bilde. Zur Darstellung von Götterstatuen und Kultbildern auf griechischen Vasen. Francfort et New York, Peter Lang, 1997.

Ognenova-Marinova 1984 : ОГНЕНОВА-МАРИНОВА (Л.) - Дребни находки, теракоти, скулптура. В: Димитров (Д. П.) ред., Севтополис, т. І, Бит и култура. София, 1984, р. 159-223.

[OGNENOVA-MARINOVA (L.) - Petits objets, figurines en terre cuite, 
sculptures. In : Dimitrov (D.P.) dir., Seuthopolis, vol. 1. Sofia, Bit i Kultura, 1984, p. 159-223.]

Oppermann 2004: OPPERMANN (M.) - Die westpontischen Poleis und ihr indigenes Umfeld in vorrömischer Zeit. Langenweissbach, Beier und Beran, 2004

Ori Taranto 1984 : Gli ori di Taranto in età ellenistica, Catalogue d'exposition 1984-1985. Milan, 1984.

Ortner 2003 : ORTNER (D.J.) - Identification of Pathological Conditions in Human Skeletal Remains. New York, Academic Press, 2éd., 2003.

Ortner, Theobald 1993 : ORTNER (D.J.), THEOBALD (G.) - Diseases in the Pre-Roman world. In : Kiple (K.F.) ed., The Cambridge World History of Human Disease. Cambridge University Press, 1993, p. 247-261.

Ortner $\boldsymbol{e}$ t al. 2001 : ORTNER (D.J.), BUTLER (W.), CAFARELLA (J.), MILLIGAN (L.) - Evidence of probable scurvy in subadults from archeological sites in North America. American Journal of Physical Anthropology, 114, 2001, p. 343-351.

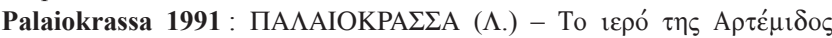
Movvixías [Le sanctuaire d'Artémis Mounichia]. Athènes, Bibliothèque de la Société Archéologique n 115, 1991.

Panayotova 1994: PANAYOTOVA (K.) - Once Again about the Archaeological Material from the Harbour of Sozopol (1927). In : Lazarov (M.), Angelova (H.) dir., Les ports dans la vie de la Thrace ancienne, Actes du Ve symposium international "Thracia Pontica" (Sozopol, 7-12 octobre 1991). Varna, Centre d'archéologie subaquatique et Institut de thracologie auprès de l'Académie bulgare des Sciences, 1994, p. 128-130.

Panayotova 1998a : PANAYOTOVA (K.) - Apollonia Pontica: Recent Discoveries in the Necropolis. In: Tsetskhladze (G.R.) dir., The Greek Colonisation of the Black Sea Area. Historical Interpretation of Archaeology. Stuttgart, F. Steiner, 1998, p. 97-113.

Panayotova 1998b: ПАНАЙОТОВА (К.) - Некропольт на Аполония Понтийска в местността Калфата. Археология, 39, 3-4, 1998, с. 11-24.

[PANAYOTOVA (K.) - La nécropole d'Apollonia Pontique au lieu-dit "Kalfata". Arheologiya, 39, 3-4, 1998, p. 11-24.]

Panayotova 2001a : ПАНАЙОТОВА (К.)-О свинцовых букраниях из Аполлонии Понтийской. В: Международные отношения в бассейне Черного моря в древности и средние века. Ростовна-Дону, 2001, с. 63-66.

[PANAYOTOVA (K.) - À propos des bucranes en plomb d'Apollonia du Pont. In : Les relations internationales dans le bassin de la mer Noire durant l'Antiquité et le Moyen Âge. Rostov sur le Don, 2001, p. 63-66.]

Panayotova 2001b: ПАНАЙОТОВА (К.) - Некоторые итоги раскопок некрополя Аполлонии Понтийской в последнее десятилетие двадцатого века. В: Ольвія та античний світ. Матеріали наукових читань присвячених 75-річчю утворення історико-археологічного заповідника Ольвія НАН Украіни Киів, 2001, с. 100-103.

[PANAYOTOVA (K.) - Quelques résultats des fouilles dans la nécropole d'Apollonia du Pont durant la dernière décennie du vingtième siècle. In : Olbia et le monde antique. Lectures scientifiques pour le $75^{\text {eme }}$ anniversaire de la fondation de la réserve historique et archéologique de l'Académie Nationale des Sciences à Olbia, Ukraine. Kiev, 1991, p. 100-103.]

Panayotova 2003a: ПАНАЙОТОВА (К.) - Каменни гробове в некропола на Аполония Понтика в м. Калфата. В: Димитрова (Д.) ред., Пътят. Сборник научни статии, посветен на живота и творчеството на д-р Г. Китов. София, Гео Прес, 2003, с. 156-166.

[PANAYOTOVA (K.) - Tombeaux en pierre dans la nécropole d'Apollonia Pontique au lieu-dit Kalfata. In : Dimitrova (D.) dir., Le chemin. Recueil d'articles scientifiques consacré à la vie et à l'œuvre du Dr. G. Kitov. Sofia, Geo Press, 2003, p. 156-166.]

Panayotova 2003b : ПАНАЙОТОВА (К.) - Обредни огнища в некрополите на Аполония Понтика. В: Ангелова (С.) ред., Сборник в памет на д-р П. Горбанов. София, УИ „Климент Охридски", 2003, с. 133-140.
[PANAYOTOVA (K.) - Foyers rituels dans les nécropoles d'Apollonia Pontique. In: Angelova (S.) dir., Recueil à la mémoire du Dr. P. Gorbanov. Sofia, Presses universitaires "Sveti Kliment Ohridski", 2003, p. 133-140.]

Panayotova 2005a : ПАНАЙОТОВА (К.) - Теракоти с подвижни крайници от Аполония Понтийска. В: Heros Hephaistos, Studia in honorem Liubae Ognenova-Marinova. Велико Търново, Фабер, 2005, p. 140-147.

[PANAYOTOVA (K.) - Figurines en terre cuite à membres amovibles d'Apollonia Pontique. In: Heros Hephaistos. Studia in honorem Liubae Ognenova-Marinova. Veliko Tarnovo, Faber, 2005, p. 140-147.]

Panayotova 2005b : ПАНАЙОТОВА (К.) - Амфори „кипърски”тип от Аполония Понтика. В: Стоянов (Т.), Ангелова (С.), Лозанов (И.) ред., Stephanos Archaeologicos in honorem Prof. L. Getov, София, УИ "Климент Охридски", 2005, с. 540-554.

[PANAYOTOVA (K.) - Amphores de type dit " chypriote » d'Apollonia Pontica. In : Stoyanov (T.), Angelova (S.), Lozanov (I.) dir., Stephanos Archaeologicos in honorem Prof. L. Getov, Sofia, Presses universitaires "Sveti Kliment Ohridski”, 2005, p. 540-554.]

Panayotova 2006 : ПАНАЙОТОВА (К.)- Теракоти от некропола на Аполония в Морската градина на Созопол. Археология, 47, 1-4, 2006, p. 139-146.

[PANAYOTOVA (K.) - Figurines en terre cuite de la nécropole d'Apollonia dans le Jardin maritime de Sozopol. Arheologiya, 47, 1-4, 2006, p. 139-146.]

Panayotova 2007 : PANAYOTOVA (K.) - Burial and Post-Burial Rites in the Necropoleis of the Greek Colonies on the Bulgarian Black Sea Littoral. In : Grammenos (D.M.), Petropoulos (E.K.) dir., Ancient Greek Colonies in the Black Sea 2, vol. 1. Oxford, Archaeopress, 2007, p. 85-126.

Panayotova 2008a : ПАНАЙОТОВА (К.) - Аскоси с форма на астрагалоси от некропола на Аполония. В: Генчева (Е.) ред., Studia in honorem Aleksandrae Dimitrova-Milcheva. Югоизточна Европа през античността (VI в. пр. Хр. - VII в. сл. Хр.). Велико Търново, Фабер, 2008, с. 104-114.

[PANAYOTOVA (K.) - Askoi en forme d'astragales de la nécropole d'Apollonia. In: Gencheva (E.) dir., Studia in honorem Aleksandrae Dimitrova-Milcheva. L'Europe du Sud-Est durant l'Antiquité (VIe s. av. J.-C. - VII s. ap. J.-C.). Veliko Tarnovo, Faber, 2008, p. 104-114.]

Panayotova 2008b : ПАНАЙОТОВА (К.) - За водоснабдяването на Аполония Понтийска в средата на І-то хилядолетие пр.Хр. B: Петрунова (Б.) ред., Каварна - средище на българския Североизток. Велико Търново, Фабер, 2007, с. 66-82.

[PANAYOTOVA (K.) - Concernant l'approvisionnement en eau d'Apollonia Pontique au milieu du Ir millénaire av. J.-C. In : Petrunova (B.) dir., Kavarna - centre de la Bulgarie du Nord-Est. Veliko Tarnovo, Faber, 2007, p. 66-82.]

Panayotova 2008c : PANAYOTOVA (K.) - The Necropolis of Apollonia Pontica in the Kalfata/Budjaka locality. In : Docter et al. 2008, p. 5-28.

Panayotova, Drajeva 2003 : ПАНАЙОТОВА (К.), ДРАЖЕВА (Ц.) Аполония Понтика - Созополис. В: Иванов (Р.) ред., Римски и ранновизантийски селища в България, т. 2. София, Иврай, 2003, c. 215-234.

[PANAYOTOVA (K.), DRAJEVA (Ts.) - Apollonia Pontica - Sozopolis. In : Ivanov (R.) dir., Agglomérations romaines et paléobyzantines en Bulgarie, vol. 2. Sofia, Ivray, 2003, p. 215-234.]

Panayotova, Gyuzelev, Nedev 2008 : ПАНАЙОТОВА (К.), ГЮЗЕЛЕВ (М.), НЕДЕВ (Д.) - Спасителни проучвания на територията на некропола на Аполония Понтийска. В: АОР през 2007 г. София, 2008, с. 317-321.

[PANAYOTOVA (K.), GYUZELEV (M.), NEDEV (D.) - Fouilles de sauvetage sur le territoire de la nécropole d'Apollonia du Pont. In : AOR année 2007. Sofia, 2008, p. 317-321.]

Panayotova, Nedev, Hermary 2003 : ПАНАЙОТОВА (К.), НЕДЕВ (Д.), ЕРМАРИ (А.) - Античен некропол на Аполония Понтика в м. Калфата. В: AОР през 2002 г. София, 2003, с. 105-107.

[PANAYOTOVA (K.), NEDEV (D.), HERMARY (A.) - La nécropole 
antique d'Apollonia Pontique au lieu-dit Kalfata. In : AOR année 2002. Sofia, 2003, p. 105-107.]

Panayotova, Nedev, Hermary 2005 : ПАНАЙОТОВА (К.), НЕДЕВ (Д.), ЕРМАРИ (А.) - Българо-френски проучвания на некропола на Аполония през 2004 г. В: АОР през 2004 г., София, 2005, с. 238-241.

[PANAYOTOVA (K.), NEDEV (D.), HERMARY (A.) - Les fouilles francobulgares de la nécropole d'Apollonia en 2004. In : AOR année 2004. Sofia, 2005, p. 105-107.]

Panayotova, Penkova, Nedev 1994 : ПАНАЙОТОВА (К.), ПЕНКОВА (Е.), НЕДЕВ (Д.) - Спасителни разкопки на елинистически некропол в Созопол. В: АОР през 1992-1993 г. Велико Търново, 1994, с. 51.

[PANAYOTOVA (K.), PENKOVA (E.), NEDEV (D.) - Fouilles de sauvetage de la nécropole hellénistique de Sozopol. In : AOR années 1992-1993. Veliko Tarnavo, 1994, p. 51.]

Panayotova, Reho, Nedev 2009: ПАНАЙОТОВА (К.), PЕХО (М.), НЕДЕВ (Д.) - Аполония, столетие археологически проучвания. Каталог на изложбата в Археологически Музея (ноември 2009 - януари 2010). Българската Академия на Науките и Националния Археологически Институт и Музей, София, 2009.

[PANAYOTOVA (K.), REHO (M.), NEDEV (D.) - Apollonia, un siècle de recherche archéologique. Catalogue de l'exposition du Musée Archéologique de Sofia (novembre 2009-janvier 2010). Académie des Sciences et Musée Archéologique National, Sofia, 2009.]

Panayotova, Riapov, Baralis 2006 : PANAYOTOVA (K.), RIAPOV (A.), BARALIS (A.) - Les fouilles franco-bulgares de la nécropole classique et hellénistique d'Apollonia du Pont (2002-2004) : résultats préliminaires. Pontica, 39, 2006, p. 95-121.

Panayotova et al. 2006 : ПАНАЙОТОВА (К.), НЕДЕВ (Д.), НИКОВ (К.), ГЮЗЕЛЕВ (М.) - Спасителни проучвания на некропола на Аполония. B: АОР през 2005 г. София, 2006, с. 242-246.

[PANAYOTOVA (K.), NEDEV (D.), NIKOV (K.), GYUZELEV (M.) Fouilles de sauvetage dans la nécropole d'Apollonia. In : AOR année 2005. Sofia, 2006, p. 242-246.]

Panayotova et al. 2007 : ПАНАЙОТОВА (К.), НЕДЕВ (Д.), НИКОВ (К.), ГЮЗЕЛЕВ (М.) - Спасителни проучвания на некропола на Аполония през 2006 г. В: АОР през 2006 г. София, 2007, с. 364-367.

[PANAYOTOVA (K.), NEDEV (D.), NIKOV (K.), GYUZELEV (M.) Fouilles de sauvetage dans la nécropole d'Apollonia en 2006. In : AOR année 2006. Sofia, 2007 p. 364-367.]

Pandaleev 1928-1929 : ПАНДАЛЕЕВ (И.) - Нови археологически находища в Бургаско. ИБАИ, 5, 1928-1929, с. 325-328.

[PANDALEEV (I.) - Nouveaux sites archéologiques dans la région de Bourgas. IBAI, 5, 1928-1929, p. 325-328.]

Papaikonomou 2006 : PAPAIKONOMOU (I.-D.) - L'interprétation des « jouets » trouvés dans les tombes d'enfants d'Abdère. In : Guimier-Sorbets (A.-M.) et alii eds., Rois, cités, nécropoles : institutions, rites et monuments en Macédoine. Actes des colloques de Nanterre (décembre 2002) et d'Athènes (janvier 2004). Athènes, Centre de recherche de l'Antiquité grecque et romaine, 2006, p. 239-248.

Papaïoannidis 2004: ПАПАЙОАНИДИС (К.) - История на Аполония Понтийска - Созопол (от създаването й до днес). София, Фабер, 2004.

[PAPAÏOANNIDIS (K.) - Histoire d'Apollonia Pontique - Sozopol (depuis sa création jusqu'à nos jours). Sofia, Faber, 2004.]

Papathanasiou et al. 2000 : PAPATHANASIOU (A.), LARSEN (C.S.), NORR (L.) - Bioarchaeological inferences from a Neolithic ossuary from Alepotrypa Cave, Diros, Greece. International Journal of Osteoarchaeology, 10, 2000, p. 210-228.

Parovich-Peshikan 1974 : ПАРОВИЧ-ПЕШИКАН (М.) - Некрополь Ольвии эллинистического времени. Киев, Наукова думка, 1974.
[PAROVICH-PESHIKAN (M.) - La nécropole hellénistique d'Olbia. Kiev, Naukova dumka, 1974.]

Pemberton 1989 : PEMBERTON (E.G.) - Corinth XVIII, 1. The Sanctuary of Demeter and Core : The Greek Pottery. Princeton, The American School of Classical Studies at Athens, 1989.

Peredolskaya 1960 : ПЕРЕДОЛЬСКАЯ (А.А.) - Следы культа кабиров на Березани. Сообщения Государственного Эрмитажа, 19,1960 , с. 23-27.

[PEREDOLSKAJA (A.A.) - Traces du culte des Cabires à Berezan. Soobshenya Gosudarstvennogo Ermitaja, 19, 1960, p. 23-27.]

Perreault, Bonias 1998 : PERREAULT (J.), BONIAS (Z.) - Nouvelles

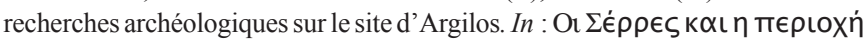

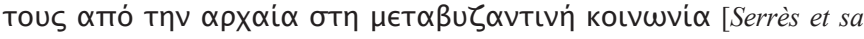
région, de la société antique à la société byzantine], Actes du congrès international de Serrès (29 septembre-3 octobre 1993). Serrès, 1998, p. 37-48.

Petersen 2007 : PETERSEN (J.H.) - Cultural Interactions and Social Strategies on the Pontic Shores. Burial Customs in the Northern Black Sea Area ca. 550-270 BC. Thèse de doctorat, Université d'Aarhus, 2007.

Petrov, Čimbuleva 1963 : ПЕТРОВ (Т.), ЧИМБУЛЕВА (ж.) Новооткрита гробница от античния некропол на Месамбрия. МПК, 2, 1963, с. 23-26.

[PETROV (T.), ČIMBULEVA (J.) - Tombeau nouvellement découvert dans la nécropole antique de Mésambria. MPK, 2, 1963, p. 23-26.]

Picón et al. 2007 : PICÓN (C.A.), MERTENS (J.R.), MILLEKER (E.J.), LIGHTFOOT (C.S.), HEMINGWAY (S.) - Art of the Classical World in the Metropolitan Museum of Art. Greece, Cyprus, Etruria, Rome. New York, New Haven et Londres, Metropolitan Museum of Art et Yale University Press, 2007.

Pippidi, Popescu 1959 : PIPPIDI (D.M.), POPESCU (E.) - Les relations d'Istros et d'Apollonie à l'époque hellénistique. Dacia, 3, 1959, p. 235-258.

Popov, Mishev 1974 : ПОПОВ (В.), МИШЕВ (К.) - Геоморфология на Българското черноморско крайбрежие и шелф. София, БАН, 1974.

[POPOV (V.), MISHEV (K.) - Géomorphologie du littoral et du plateau continental bulgares de la mer Noire. Sofia, Académie bulgare des Sciences, 1974.]

Pottier, Reinach 1888 : POTTIER (E.), REINACH (S.) - La nécropole de Myrina. Paris, de Boccard, 1888.

Preda 1961 : PREDA (C.) - Archaeological discoveries in the Greek cemetery of Kallatis-Mangalia (IV - III centuries before our era). Dacia, 5, 1961, p. 275-303.

Preisinger, Aslanian 2003 : PREISINGER (A.), ASLANIAN (S.) - The Black Sea Level during the Last 20.000 Years, Sea Level, Salinity and Climate. The Geological Society of America, Seattle Annual Meeting (November 2-5, 2003).

Preisinger, Aslanian 2004 : PREISINGER (A.), ASLANIAN (S.) - The Sea Level of the Black Sea during the Holocene. In: Proceedings of the International Symposium on Earth System Science, (Istanbul, Turkey, 8-10 September 2004). Istanbul University, 2004, p. 225-232.

Preisinger, Aslanian, Heinitz 2001 : PREISINGER (A.), ASLANIAN (S.), HEINITZ (W.D.) - Geomorphologic Development of the Bay of Sozopol, Bulgaria (Black Sea) during the Last 7500 Years. ИНМВ, 36-37 (51-52), 2000-2001, p. 7-16.

Press 1978 : PRESS (L.) - Zabawy, nauczanie, sport. Kultura materialna starozitnej Grecji, III. Wroclaw et Varsovie, 1978, p. 231-291.

Prohaszka 1995 : PROHASZKA (M.) - Reflection from the Dead. The Metal Finds from the Pantanello Necropolis at Metaponto. A Comprehensive Studi of Grave Goods from the $5^{\text {th }}$ to the $3^{\text {rd }}$ Centuries B.C. Jonsered, P. Aström, 1995.

Prouchevskaia 1955: ПРУШЕВСКАЯ (Е.С.) - Художественная обработка металла (торевтика). Античные Города Северного Причерноморья. Москва - Ленинград, 1955, с. 325-355.

[PROUCHEVSKAIA (E.S.) - Métallurgie artistique (toreutique). In: Antichnye Goroda Servernogo Prichernomor 'ya. Moscou et Léningrad, 1955, p. 325-355.] 
Py, Sabattini 2000 : PY (M.), SABATTINI (B.) - La céramique attique du IVe s. à Lattes (Hérault). In : Sabattini 2000, p. 167-200.

Rafn 1984 : RAFN (B.) - The ritual use of pottery in the necropolis at Halieis. In : Brijder (H.) dir., Ancient Greek and Related Pottery, Proceedings of the International Vase Symposium, Amsterdam, 12-15/04/1984. Amsterdam, Allard Pierson Series, 1984, p. 305-308.

Reeder 1995 : REEDER (E.D.) - Pandora. Princeton University Press, 1995.

Reho 1985: PEXO (М.) - Художникът на “Черния тирс" в България. Изкуство, 35, 4, 1985, с. 32-38.

[REHO (M.) - Le peintre du « thyrse noir » en Bulgarie. Izkustvo, 35, 4, 1985 , p. 32-38.]

Reho 1990 : REHO (M.) - La ceramica attica a figure nere e rosse nella Thracia bulgara. Rome, Giorgio Bretschneider, 1990.

Reho 1992 : PEXO (М.) - Атическа червенофигурна керамика в Националния археологически музей - София. София, УИ “Климент Охридски", 1992.

[REHO (M.) - La céramique attique à figures rouges au Musée National d'Archéologie de Sofia. Sofia, Presses universitaires "Sveti Kliment Ohridski", 1992.]

Rhomiopoulou, Touratsoglou 2002: RHOMIOPOULOU (K.),

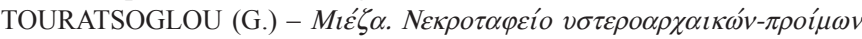

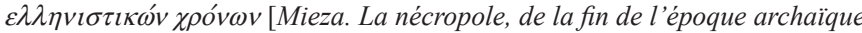
au début de l'époque hellénistique]. Athènes, publications de 1'ArchDelt $\mathrm{n}^{\circ} 83,2002$

Richier 1997 : RICHIER (A.) - Les sépultures primaires à incinération de la nécropole romaine de Sainte-Barbe (Marseille). Méthodes, analyses et contribution à l'étude des ossements humains incinérés. Mémoire de DEA de Paléoanthropologie, Université Bordeaux I, 1997.

Richter 1935: RICHTER (G.M.A.) - Shapes and Names of Athenian Vases. New York, Plantin Press, 1935.

Robert 1959 : ROBERT (L.) - Les inscriptions grecques de Bulgarie. $R P h$, 33, 1959, p. 165-236.

Robert 1961 : ROBERT (J. et L.) - Les inscriptions grecques. Bulletin Épigraphique, 1961, p. 187-201.

Roberts, Manchester 2005 : ROBERTS (C.A.), MANCHESTER (K.) The Archaeology of Disease. Ithaca (New York), Cornell University Press, $3^{e}$ éd., 2005 .

Robinson 1931 : ROBINSON (D.M.) - Excavations at Olynthus, IV. The Terra-cottas of Olynthus found in 1928. Baltimore, The Johns Hopkins Press, 1931.

Robinson 1933 : ROBINSON (D.M.) - Excavations at Olynthus, V. Mosaics, Vases and Lamps of Olynthus found in 1928 and 1931. Baltimore, The Johns Hopkins Press, 1933.

Robinson 1942: ROBINSON (D.M.) - Excavations at Olynthus, XI. Necrolynthia, a Study in Greek Burial Customs and Anthropology. Baltimore, The Johns Hopkins Press, 1942.

Robinson 1950 : ROBINSON (D.M.) - Excavations at Olynthus, XIII. Vases found in 1934 and 1938. Baltimore, The Johns Hopkins Press, 1950.

Robinson 1952 : ROBINSON (D.M.) - Excavations at Olynthus, XIV. Terracottas, Lamps and Coins Found in 1934 and 1938. Baltimore, The Johns Hopkins Press, 1952.

Rodziewicz 2007 : RODZIEWICZ (E.) - Bone and Ivory Carvings from Alexandria: French Excavations 1992-2004. Le Caire, IFAO, 2007.

Rohde 1990 : ROHDE (E.) - CVA Deutsche Demokratische Republik 3, Staatliche Museen zu Berlin, Antikensammlung 1. Berlin, Akademie-Verlag, 1990.

Rolley 1994 : ROLLEY (C.) - La sculpture grecque. 1. Des origines au milieu du Ve siècle. Paris, Picard, 1994.

Rotroff 1997 : ROTROFF (S.I.) - The Athenian Agora. Volume XXIX. Hellenistic Pottery. Athenian and Imported Wheelmade Table Ware and Related Material, 2 vol. Athènes et Princeton, The American School of Classical Studies, 1997

Rotroff, Camp 1996 : ROTROFF (S.I.), CAMP (J.M.) - The Date of the Third Period of the Pnyx. Hesperia, 65, 1996, p. 263-294.
Rougemont 1977 : ROUGEMONT (G.) - Corpus des inscriptions de Delphes. Tome I. Lois sacrées et règlements religieux, Paris, École française d'Athènes et de Boccard, 1977.

Rudolph 1974: RUDOLPH (W.W.) - Excavations at Porto Heli and Vicinity, Preliminary Report III: Excavations at Metohi 1970. Hesperia, 13, 1974, p. 105-131.

Ruseva 2002 : РУСЕВА (М.) - Тракийска гробнична архитектура в българските земи през V - III в. Ямбол, изд. “Я”, 2002.

[RUSEVA (M.) - L'architecture funéraire thrace sur le territoire bulgare aux $V^{e}-I I I^{e}$ s. av. J.-C. Yambol, éd. "Ya", 2002.]

Ryan et al. 1997 : RYAN (W.B.F.), PITMAN III (W.C.), MAJOR (C.O.), SHIMKUR (K.), MOSKALENKO (V.), JONES (G.A.), DIMITROV (P.), GORÜR (N.), SAKINÇ (M.), YÜCE (H.) - An Abrupt Drowning of the Black Sea Shelf. Marine Geology, 138, 1-2, 1997, p. 119-126.

Sabattini 2000 : SABATTINI (Br.) dir. - La céramique attique du $I V^{e}$ siècle en Méditerranée occidentale. Actes du colloque international organisé par le Centre Camille Jullian, Arles, 7-9 décembre 1995. Naples, Centre Jean Bérard, 2000.

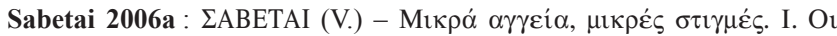

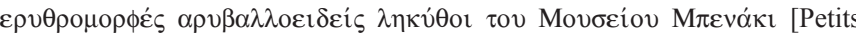
vases, petites mises au point : I. Les lécythes aryballisques à figures rouges du Musée Bénaki]. Mouseio Benaki, 6, 2006, p. 23-44.

Sabetai 2006b : SABETAI (V.) - CVA Greece 9, Athens, Benaki Museum 1. Académie d'Athènes, 2006

Salkin 1989: САЛКИН (А.) - Два тракийски гроба от околностите на Бизоне. ИНМВ, 25 (40), 1989, р. 9-12.

[SALKIN (A.) - Deux tombes thraces des environs de Bizonè. INMV, 25 (40), 1989, p. 9-12.]

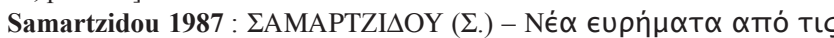

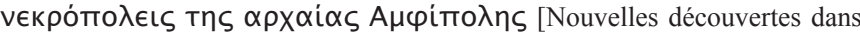
les nécropoles antiques d'Amphipolis]. AEMTh, 1, 1987, p. 327-341.

Schauenburg 2003 : SCHAUENBURG (K.) - Studien zur unteritalischen Vasenmalerei VI. Kiel, Ludwig, 2003.

Schefold 1934 : SCHEFOLD (K.) - Untersuchungen zu den Kertscher Vasen. Berlin, De Gruyter, 1934.

Schefold 1981 : SCHEFOLD (K.) - Die Göttersage in der klassischen und hellenistischen Kunst. Munich, Hirmer, 1981

Schlörb-Vierneisel 1966 : SCHLÖRB-VIERNEISEL (B.) - Eridanos, Nekropole I. Gräber und Opferstellen hs 1-204. AM, 81, 1966, p. 4-111, Beil. 1-63, pl. 1-5.

Schmaltz 1974 : SCHMALTZ (B.) - Das Kabirenheiligtum bei Theben, vol. V. Terrakotten aus dem Kabirenheiligtum bei Theben. Berlin, De Gruyter, 1974.

Schwarzmaier 1997: SCHWARZMAIER (A.) - Griechische Klappspiegel. Untersuchungen zu Typologie und Stil. Berlin, Gebr. Mann, 1997 (AM, 18. Beiheft).

Scott 1979 : SCOTT (E.C.) - Dental wear scoring technique. American Journal of Physical Anthropology, 51, 1979, p. 213-218.

Seefried 1982 : SEEFRIED (M.) - Les pendentifs en verre sur noyau des pays de la Méditerranée antique. Rome et Paris, École française de Rome, 1982.

Seure 1924 : SEURE (G.) - Archéologie thrace. Documents inédits ou peu connus (deuxième série). $R A$, $5^{\mathrm{e}}$ série, 19, 1, 1924, p. 307-350.

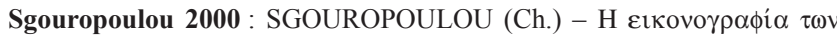

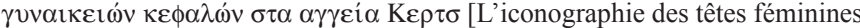
sur les vases du style de Kertch]. ArchDelt, 55, 2000 [2004], p. 213-234.

Shefton 1996: SHEFTON (B.B.) - Castulo cups in the Aegean, the Black Sea Area and the Near East with their Respective Hinterland. In : Lordkipanidze (O.), Lévêque (P.) dir., Sur les traces des Argonautes, Actes du VIe Symposium de Vani (Vani, Colchide, $22-29$ septembre 1990). Paris, Les Belles Lettres, 1996, p. 163-186.

Shilik 1997 : SHILIK (K.K.) - Oscillations of the Black Sea and Ancient Landscapes. In : Chapman (J.), Dolukhanov (P.) dir., Landscapes in Flux. Central and Eastern Europe in Antiquity. Oxford, Oxbow Books, 1997, p. $115-130$. 
Simon 1962-63 : SIMON (E.) - Daphnis and Nymphe. A late Classical lekythos in the Walters Art Galley. The Journal of the Walters Art Gallery, 25-26, 1962-63, p. 29-37.

Škorpil 1891 : ШКОРПИЛ (Х. и К.) - Черноморското крайбрежие и съседните подбалкански страни в Южна България. Археологически изследвания. СбНУНК, 4, 1891, с. 102-155.

[ŠKORPIL (H. et K.) - Le littoral de la mer Noire et les pays sub-balkaniques voisins en Bulgarie méridionale. Recherches archéologiques. SbNUNK, 4, 1891, p. 102-155.]

Škorpil 1930/1931 : ШКОРПИЛ (К.) - Археологически бележки от черноморското крайбрежие. ИБАИ, 6, 1930/31, с. 57-88.

[ŠKORPIL (K.) - Notes archéologiques du littoral de la mer Noire. IBAI, 6 , 1930-31, p. 57-88.]

Škorpil 1999 : ШКОРПИЛ (Х. и К.) - Могили. София, Сфера, 1999.

[ŠKORPIL (H. et K.) - Tumuli. Sofia, Sfera, 1999.]

Smith 1984 : SMITH (B.H.) - Patterns of molar wear in hunter-gatherers and agriculturalists. American Journal of Physical Anthropology, 63, 1, 1984, p. 39-56.

Sokolova 2003 : SOKOLOVA (O.Y.) - Nymphaeum. In : Grammenos, Petropoulos 2003, p. 759-802.

Sokolowski 1969 : SOKOLOWSKI (F.) - Lois sacrées des cités grecques. Paris, de Boccard, 1969.

Solovyov 2003 : СОЛОВЬЕВ (С.Л.) - Археологические памятники сельской округи и некрополя Нимфея : итоги работ Керченской археологической экспедиции Государственного Эрмитажа (1992-1996 гг.). Санкт Петербург, Гос. Эрмитаж, 2003.

[SOLOVYOV (S.L.) - Monuments archéologiques du territoire rural et de la nécropole de Nymphaion : résultats du travail de l'expédition archéologique de Kerch auprès du Musée National de l'Hermitage (1992-1996). SaintPétersbourg, Musée national de l'Hermitage, 2003.]

Sparkes, Talcott 1970 : SPARKES (B.A.), TALCOTT (L.) - The Athenian Agora XII. Black and Plain Pottery of the $6^{\text {th }}, 5^{\text {th }}$ and $4^{\text {th }}$ Centuries B.C. Princeton, The American School of Classical Studies at Athens, 1970.

Stefanova 1980 : СТЕФАНОВА (А.) - Монетите и тьрговията на Аполония Понтика V-IV в. пр. н.е. Нумизматика, 4, 1980, с. 3-9. [STEFANOVA (A.) - Les monnaies et le commerce d'Apollonia Pontique, Ve-IVe s. av. J.-C. Numizmatika, 4, 1980, p. 3-9.]

Stefanova 1985 : STEPHANOVA (A.) - Observations sur le monnayage de bronze d'Apollonie du Pont. In : Fol 1985, p. 272-282.

Stoyanov 1993 : СТОЯНОВ (Т.) - Археологически данни за неизвестно тракийско селище край Анхиало (Поморие). Археология, 35, 1993, р. 17-25.

[STOYANOV (T.) - Données archéologiques sur un habitat thrace inconnu près d'Anchialos (Pomorie). Arheologia, 35, 1993, p. 17-25.]

Stroszeck 2002 : STROSZECK (J.) - Das Grab des Eupheros. In : Die griechische Klassik. Idee oder Wirklichkeit, Catalogue d'exposition Berlin et Bonn 2002. Berlin, 2002, p. 468-472.

Stuart-Macadam 1991 : STUART-MACADAM (P.) - Anemia in Roman Britain: Poundbury Camp. In: Bush (H.), Zvelebil (M.) eds., Health in Past Societies. Biocultural Interpretations of Human Skeletal Remains in Archaeological Contexts. Oxford, BAR International Series n ${ }^{\circ}$ 567, 1991, p. 101-113.

Talcott 1935 : TALCOTT (L.) - Attic Black-Glazed Stamped Ware and Other Pottery from a Fifth Century Well. Hesperia, 4, 1935, p. 476-523.

Tanagra 2003 : TANAGRA. Mythe et archéologie, Catalogue d'exposition, Montréal et Paris, septembre 2003-mai 2004. Paris, Réunion des Musées Nationaux, 2003.

Tchongarska 2001 : ЧОНГАРСКА (М.) - Нови наблюдения върху червено фигурните арибаловидни лекити от некропола на Аполония. Колекция от НАМ. Архология, 42, 1-2, 2001, с. 45-47.

[TCHONGARSKA (M.) - Nouvelles observations sur les lécythes décorés de figures rouges de la nécropole d'Apollonia. Collection du Musée National d'Archéologie. Arheologia, 42, 1-2, 2001, p. 45-47.]
Teplyakov 1833 : ТЕПЛЯКОВ (В.) - Письма из Болгарии. Москва, 1833.

[TEPLYAKOV (V.) - Lettres de Bulgarie. Moscou, 1833.]

Tiverios 2004: TIVERIOS (M.) Artemis, Dionysos und Eleusinische Gottheiten. AM, 119, 2004, p. 147-162, pl. 31-39.

Toncheva 1953: ТОНЧЕВА (Г.) - Старогръцката керамика в музея на гр. Сталин. ИВАД, 9, 1953, с. 29-51.

[TONCHEVA (G.) - La céramique grecque ancienne dans les collections du musée de la ville de Stalin. IVAD, 9, 1953, p. 29-51.]

Toncheva 1956 : ТОНЧЕВА (Г.) - Тракийското влияние в Одесос. ИВАД, 10, 1956, с. 51-64.

[TONCHEVA (G.) - L'influence thrace à Odessos. IVAD, 10, 1956, p. 51-64.]

Toncheva 1961 : ТОНЧЕВА (Г.) - Гробни находки от Одесос. ИВАД, 12, 1961, с. 29-51.

[TONCHEVA (G.) - Tombes découvertes à Odessos. IVAD, 12, 1961, p. 29-51.]

Toncheva 1974 : ТОНЧЕВА (Г.) - Некрополът край светилището на Херос Карабазмос в Одесос. ИНМВ, 25, 1974, с. 277-302.

[TONCHEVA (G.) - La nécropole près du sanctuaire du Héros Karabazmos à Odesos. INMV, 25, 1974, p. 277-302.]

Triantaphyllos 2000: TRIANTAPHYLLOS (D.) - La nécropole de la colonie thasienne de Strymè. In : Lungu (V.) dir., Pratiques funéraires dans l'Europe des XIII ${ }^{e}-I V^{e}$ s. av. J.-C., Actes du III e colloque d'archéologie funéraire (Tulcea, 15-20 septembre 1997). Tulcea, Institut de recherches écomuséologiques, 2000, p. 87-104.

Trumpf-Lyritzaki 1969: TRUMPF-LYRITZAKI (M.) - Griechische Figurenvasen des Reichen Stils und der späten Klassik. Bonn, H. Bouvier, 1969.

Tsaneva 1975 : ЦАНEBA (М.) - Апликация от некропола на Аполония. Изкуство, 25, 3-4, 1975, с. 32-33.

[TSANEVA (M.) - Une applique de la nécropole d'Apollonia. Izkustvo, 25, 3-4, 1975, p. 32-33.]

Tsaneva 1976: ЦАНЕВА (М.) - Разкопки в некропола на Аполония Понтика. В: АОР през 1975 г. Смолян, 1976, с. 38.

[TSANEVA (M.) - Fouilles dans la nécropole d'Apollonia Pontique. In : AOR année 1975. Smolyan, 1976, p. 38.]

Tsaneva 1977: ЦАНЕВА (М.) - Разкопки в некропола на Аполония Понтика. В: АОР през 1976 г. София, 1977, с. 50.

[TSANEVA (M.) - Fouilles dans la nécropole d'Apollonia Pontique. In : AOR année 1976. Sofia, 1977, p. 50.]

Tsaneva 1980 : (voir Čaneva)

Tsaneva 1982 : (voir Zanewa)

Tsaneva 1983 : ЦАНЕВА (М.) - Разкопки на тракийска надгробна могила на н. "Колокита" край Созопол. В: АОР през 1982 г. Плевен, 1983, с. 45-46.

[TSANEVA (M.) - Fouilles d'un tumulus thrace sur le cap Kolokita près de Sozopol. In : AOR année 1982. Pleven, 1983, p. 45-46.]

Tsaneva 1985a : ЦАНЕВА (М.) - Тракийска надгробна могила при н. "Колокита" край Созопол. В: АОР през 1984 г. Сливен, 1985, c. 104-105.

[TSANEVA (M.) - Tumulus thrace sur le cap Kolokita près de Sozopol. In : AOR année 1984. Sliven, 1985, p. 104-105.]

Tsaneva 1985b : TZANEVA (M.) - Thrakisches Hügelgrab bei Kolokita. In : Fol 1985, p. 352-359.

Tsaneva 1986a : ЦАНЕВА (М.) - Тракийска надгробна могила при н. “Колокита” край Созопол. В: АОР през 1985 г. В. Търново, 1986, с. 61-62.

[TSANEVA (M.) - Tumulus thrace sur le cap Kolokita près de Sozopol. In : AOR année 1985. V. Tarnovo, 1986, p. 61-62.]

Tsaneva 1986b : ZANEVA (M.) - Die Thraker und Apollonia nach den Vorschungen der Hügelgrabmäler. In : Fol (A.) et al. eds., Thracia Pontica III, Actes du III e symposium international, Sozopol, 6-12 oct. 1985. Sofia, 1986, p. 166-173.

Tsaneva, Dimitrov 1976 : ЦАНЕВА (М.), ДИМИТРОВ (Б.) - Каменни гробници от некропола на Аполония Понтика. МПК, 16, 3, 1976 , с. $5-8$. 
[TSANEVA (M.), DIMITROV (B.) - Tombeaux en pierre de la nécropole d'Apollonia. $M P K, 16,3,1976$, p. 5-8.]

Tsaneva, Panayotova 1991 : ЦАНЕВА (М.), ПАНАЙОТОВА (К.) Античен некропол на Аполония. В: АОР през 1990 г. Ловеч, 1991, c. 77-79.

[TSANEVA (M.), PANAYOTOVA (K.) - Nécropole antique d'Apollonia. In : AOR année 1990. Lovech, 1991, p. 77-79.]

Tsaneva, Stoyanov 1981: ЦАНЕВА (М.), СТОЯНОВ (Т.) Спасителни разкопки в Созопол, обект “Културен дом”. В: АОР през 1980 г. София, 1981, с. 69-71.

[TSANEVA (M.), STOYANOV (T.) - Fouilles de sauvetage à Sozopol, site « Maison de la culture ». In : AOR année 1980. Sofia, 1981, p. 69-71.]

Tsaravopoulos, Papathanasiou 2006: TSARAVOPOULOS (A.), PAPATHANASIOU (D.) - The cemetery at Lagonissi in Attica (8th-4th centuries BC) - Typology of tombs, burial rites. In : Lungu (V.), Simion (G.), Topoleanu (F.) dir., Pratiques funéraires et manifestations de l'identité culturelle (Âge du Bronze et Âge du Fer), Actes du IVe colloque international d'archéologie funéraire. Tulcea, Publications de l'institut de recherches écomuséologiques, 2006, p. 117-128.

Tsonchev, Milchev 1970 : ЦОНЧЕВ (Д.), МИЛЧЕВ (А.) - Разкопки в чашата на язовир “Батак”. ИБАИ, 32, 1970, с. 149-157.

[TSONCHEV (D.), MILCHEV (A.) - Les fouilles dans la cuve du barrage « Batak ». IAI, 32, 1970, p. 149-157.]

Turner 1979 : TURNER (C.G.) II - Dental anthropological indications of agriculture among the Jomon People of Central Japan. American Journal of Physical Anthropology, 51, 1979, p. 619-636.

Ubelaker 1989: UBELAKER (D.H.) - Human Skeletal Remains. Washington, D.C., Taraxacum, $2^{\mathrm{e}}$ éd., 1989.

Ure 1936 : URE (A. D.) - Red Figure Cups with Incised and Stamped Decoration I. JHS, 56, 1936, p. 205-215.

Vagalinski 1993 : ВАГАЛИНСКИ (Л.) - Стригили от римската епоха от територията на днешна България. Археология, 35, 2, 1993, c. 22-35.

[VAGALINSKI (L.) - Strigiles d'époque romaine du territoire de l'actuelle Bulgarie. Arheologia, 35, 2, 1993, p. 22-35.]

Vajarova 1960 : ВъЖАРОВА (Ж.) - Руските учени и българските старини. Изследване, материали и документи. София, БАН, 1960.

[VAJAROVA (J.) - Les savants russes et les antiquités bulgares. Étude, matériaux et documents. Sofia, Académie bulgare des Sciences, 1960.]

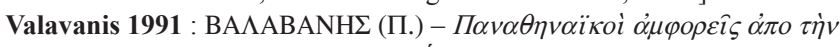

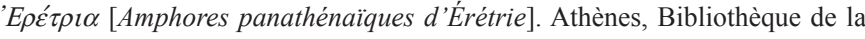
Société Archéologique, 1991.

Valavanis 1999 : VALAVANIS (P.) - Das stolze Denkmal. Bemerkungen zum Grabmonument am dritten Horos. AM, 114, 1999, p. 185-205, pl. 27.

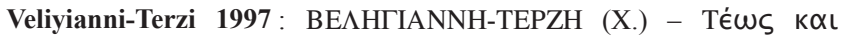

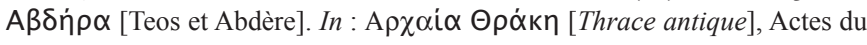
deuxième symposion international d'études thraces, vol. II. Komotini, Centre Culturel, 1997, p. 691-705.

Venedikov 1948 : ВЕНЕДИКОВ (И.) - Разкопките в некропола на Аполония през 1946 г. В: Venedikov et al. 1948, с. 7-27.

[VENEDIKOV (I.) - Les fouilles de la nécropole d'Apollonia en 1946. In : Venedikov et al. 1948, p. 7-27.]

Venedikov 1963a: ВЕНЕДИКОВ (И.) - Разположение на некропола и организация на разкопките през 1947 - 1949 г. B: Venedikov et al. 1963, c. 7-64.

[VENEDIKOV (I.) - Situation de la nécropole et organisation des fouilles en 1947-1949. In : Venedikov et al. 1963, p. 7-64.]

Venedikov 1963b : ВЕНЕДИКОВ (И.) - Металически и костени предмети от Аполония. B: Venedikov et al. 1963, с. 313-320.

[VENEDIKOV (I.) - Objets en métal et en os de la nécropole d'Apollonia. In : Venedikov et al. 1963, p. 313-320.]

Venedikov 1980: VENEDIKOV (I.) - La Mesambria thrace. In: Velkov (V.) dir., Nessèbre, vol. 2. Sofia, Académie bulgare des sciences, 1980, p. 7-22.
Venedikov, Fol 1976 : ВЕНЕДИКОВ (И.), ФОЛ (А.) ред. - Тракийски паметници. Том 1: Мегалитите в Тракия. София, Наука и изкуство, 1976, 219 р.

[VENEDIKOV (I.), FOL (A.) dir. - Les monuments thraces. Vol. 1 : Les mégalithes en Thrace. Sofia, Nauka i izkustvo, 1976, 219 p.]

Venedikov, Velkov 1963: ВЕНЕДИКОВ (И.), ВЕЛКОВ (В.) Надгробни плочи от некропола на Аполония. В: Venedikov et al. 1963, c. 325-330.

[VENEDIKOV (I.), VELKOV (V.) - Stèles funéraires de la nécropole d'Apollonia. In : Venedikov et al. 1963, p. 325-330.]

Venedikov et al. 1948: ВЕНЕДИКОВ (И.), ИВАНОВ (Т.), ДРЕМСИЗОВА (ЦВ.), МИХАЙЛОВ (Г.) - Аполония на Черно море. София, Държавна печатница, 1948.

[VENEDIKOV (I.), IVANOV (T.), DREMSIZOVA (Ts.), MIHAILOV (G.) Apollonia en mer Noire. Sofia, Imprimerie de l'état, 1948.]

Venedikov et al. 1963: ВЕНЕДИКОВ (И.), ГЕРАСИМОВ (Т.), ДРЕМСИЗОВА (ЦВ.), ИВАНОВ (Т.), МЛАДЕНОВА (Я.), ВЕЛКОВ (В.) - Аполония. Разкопките в некропола на Аполония през 19471949 г., София, БАН, 1963.

[VENEDIKOV (I.), GERASIMOV (T.), DREMZISOVA (Ts.), IVANOV (T.), MLADENOVA (Y.), VELKOV (V.) - Apollonia. Les fouilles dans la nécropole d'Apollonia en 1947-1949. Sofia, Académie bulgare des Sciences, 1963.]

Venedikov et al. 1976: ВЕНЕДИКОВ (И.), ДИМИТРОВ (Б.), ДОМАРАДСКИ (М.), КАРАЙОТОВ (И.), ЦАНЕВА (М.) - ТракиЙскИ селища и крепости в Странджа. В: Венедиков (И.), Фол (А.) ред., Тракийски паметници, том 1: Мегалитите в Тракия. София, Наука и изкуство, 1976, с. 128-157.

[VENEDIKOV (I.), DIMITROV (B.), DOMARADSKI (M.), KARAYOTOV (I.), TSANEVA (M.) - Habitats et fortifications thraces dans la Strandja. In : Venedikov, Fol 1976, p. 128-157.]

Vermeule 1981 : VERMEULE (E.) - Aspects of death in early Greek art and poetry. Berkeley, University of California Press, 1981.

Vierneisel-Schlörb 1997 : VIERNEISEL-SCHLÖRB (B.) - Kerameikos XV. Die figürlichen Terrakotten I. Spätmykenisch bis späthellenistisch. Munich, Hirmer, 1997.

Vinogradov, Butyagin, Vakhtina 2003 : VINOGRADOV (Yu.A.), BUTYAGIN (F.M.), VAKHTINA (M.Yu.) - Myrmekion-Portmeus. Two "small" towns of Ancient Bosporus. In : Grammenos, Petropoulos 2003, p. 821-840.

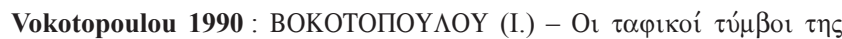
Aívelas [Les tumuli funéraires d'Aineia]. Athènes, Publications de l'ArchDelt, 1990.

Vokotopoulou 1994 : VOKOTOPOULOU (J.) - Anciennes nécropoles de la Chalcidique. In : La Genière 1994, p. 79-98.

Walker, Hewlett 1990 : WALKER (P.L.), HEWLETT (B.S.) - Dental health, diet, and social status among central African foragers and farmers. American Anthropologist, 92, 1990, p. 383-398.

Wapler et al. 2004 : WAPLER (U.), CRUBÉZY (E.), SCHULTZ (M.) Is cribra orbitalia synonymous with anaemia? Analysis and interpretation of cranial pathology in Sudan. American Journal of Physical Anthropology, 123, 2004, p. 333-339.

Wasowicz, Zdrojewska 1998 : WASOWICZ (A.), ZDROJEWSKA (W.) - Monuments en plomb d'Olbia Pontique au Musée National de Varsovie. Torun, Université Nicolas Copernic, Institut d'archéologie et d'ethnologie, 1998

Williams 1979 : WILLIAMS (Ch.K.) - Corinth, 1978: Forum Southwest. Hesperia, 48, 1979, p. 105-144.

Williams, Ogden 1994 : WILLIAMS (D.), OGDEN (J.) - Greek Gold. Jewellery of the Classical World. Londres, British Museum, 1994.

Winniczuk 1988: WINNICZUK (L.) - Ludzie, zwyczaje i obyczaje starożytnej Grecji i Rzymu. Varsovie, Państwowe Wydawnictwo Naukowe, 1988.

Winter 1903 : WINTER (F.) - Die Typen der figürlichen Terrakotten. Berlin et Stuttgart, W. Speman, 1903. 
Young 1951a : YOUNG (R.) - Sepulturae intra urbem. Hesperia, 20, 1951, p. $67-134$.

Young 1951b : YOUNG (R.) - An Industrial District of Ancient Athens. Hesperia, 20, 1951, p. 135-288.

Zaneva 1986 : (voir Tsaneva 1986b.)

Zanewa 1982 [voir aussi Tsaneva] : ЦАНEBA (М.) - Кратери от Аполония. София, Септември, 1982.

[ZANEWA (M.) - Cratères d'Apollonia. Sofia, Septemvri, 1982.]

Zaphiropoulou 1994: ZAPHIROPOULOU $(\mathrm{Ph}$.$) - Une nécropole à$ Paros. In : La Genière 1994, p. 127-152.

Zavatin-Coman 1972 : ZAVATIN-COMAN (E.) - La tombe grecque avec kalpis de Mangalia. Dacia, 16, 1972, p. 271-280.
Zeest 1960 : ЗЕЕСТ (И. Б.) - Керамическая тара Боспора. Москва, Издательство Академии Наук СССР, 1960.

[ZEEST (I.B.) - L'emballage céramique du Bosphore. Moscou, éditions de l'Académie des Sciences de l'URSS, 1960.]

Zervoudaki 1968: ZERVOUDAKI (E.) - Attische polychrome Reliefkeramik des späten 5. und des 4. Jahrhunderts v. Chr. AM, 83, 1968, p. 1-88, pl. 1-30.

Zubar 1993 : ЗУБАРЬ (В.М.) - Херсонес Таврический в античную эпоху (экономика и социальные отношения). Киев, Наукова думка, 1993.

[ZUBAR (V.M.) - La Chersonèse Taurique dans l'Antiquité (économie et relations sociales). Kiev, Naukova dumka, 1993.] 
Planche 1

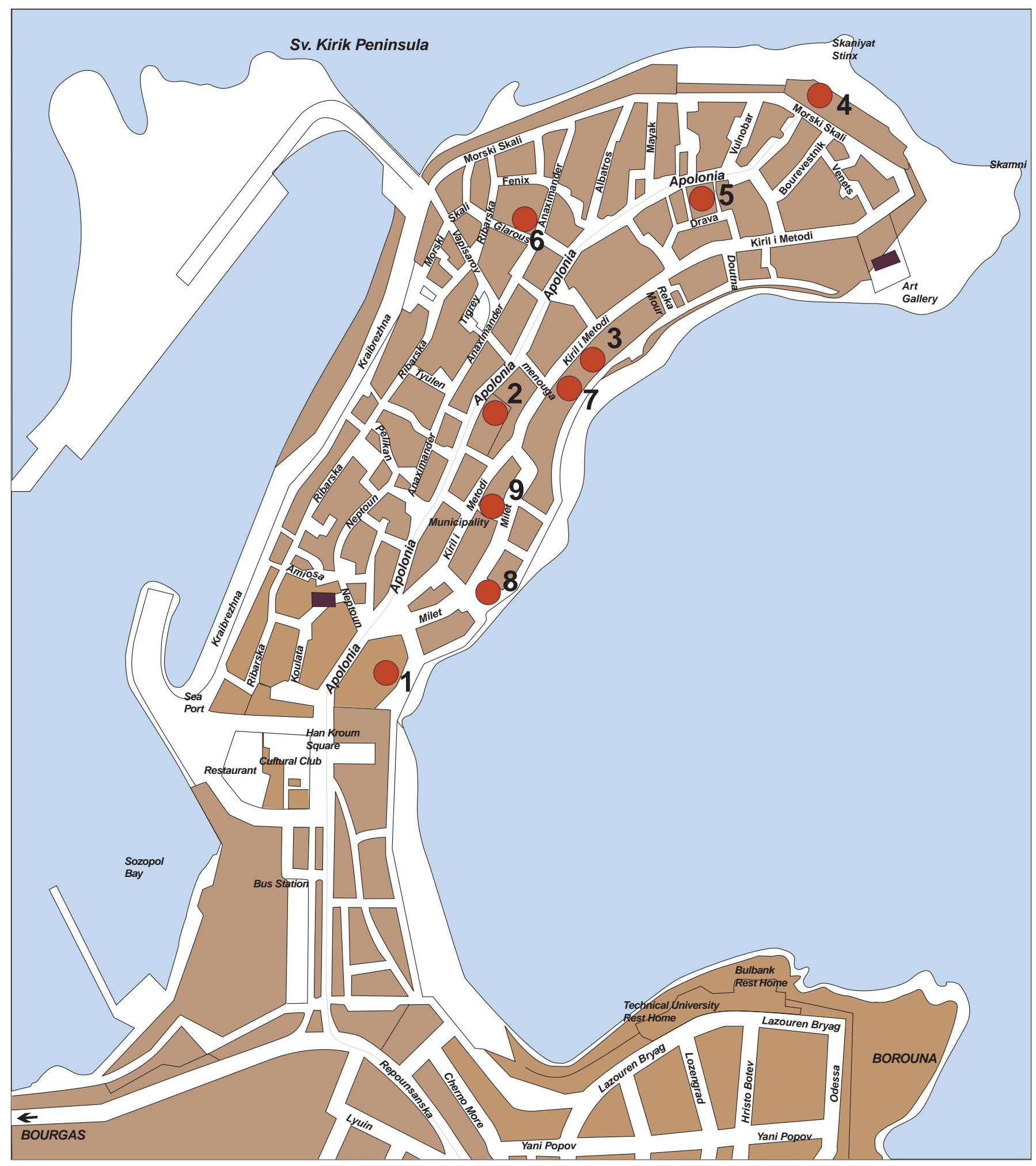

1 - Krepostni steni i saorazhenia Site / Murs de fortification ; 2 - Antichen zhilisten complex Site / Complexe d'habitat antique ; 3 - Starata darvodelna Site / Ancienne menuiserie ; 4 - Morski skali Site / Roches marines ; 5. 9 - Drava Str.-Pit / Rue Drava $n^{\circ} 9$; 6. 29 - Anaximander Str.-Pit / Rue Anaximandre $n^{\circ} 29$; 7.35 - Kiril i Metodi Str.-Pit / Rue Cyrille et Méthode $n^{\circ} 35$; 8. 8 - Milet Str. Site / Rue Milet $n^{\circ} 8 ; 9$ - Strarata obshtina / Ancienne mairie 


\section{Planche 2}

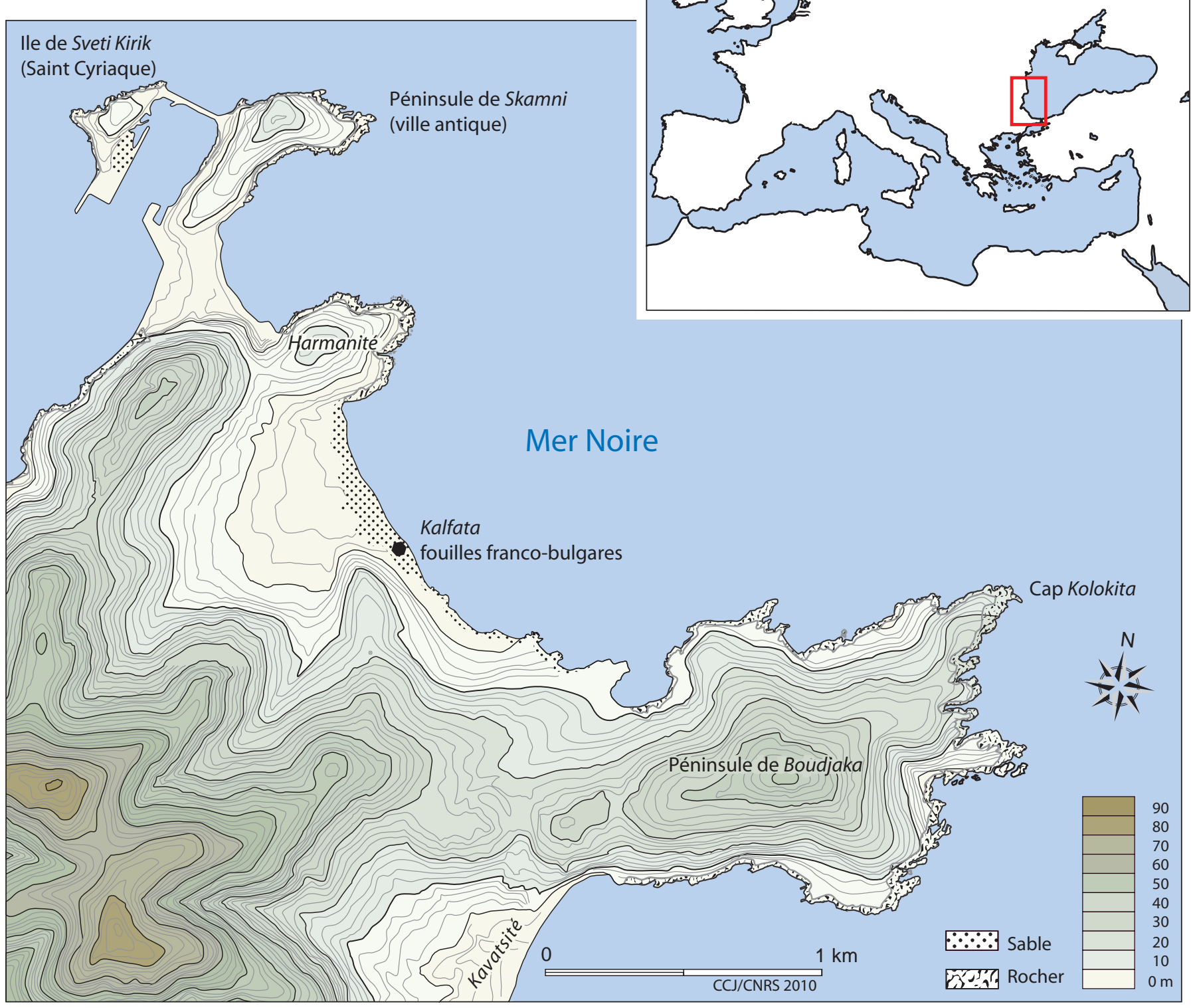

Plan général du site d'Apollonia (@ CCJ). 
Planche 3

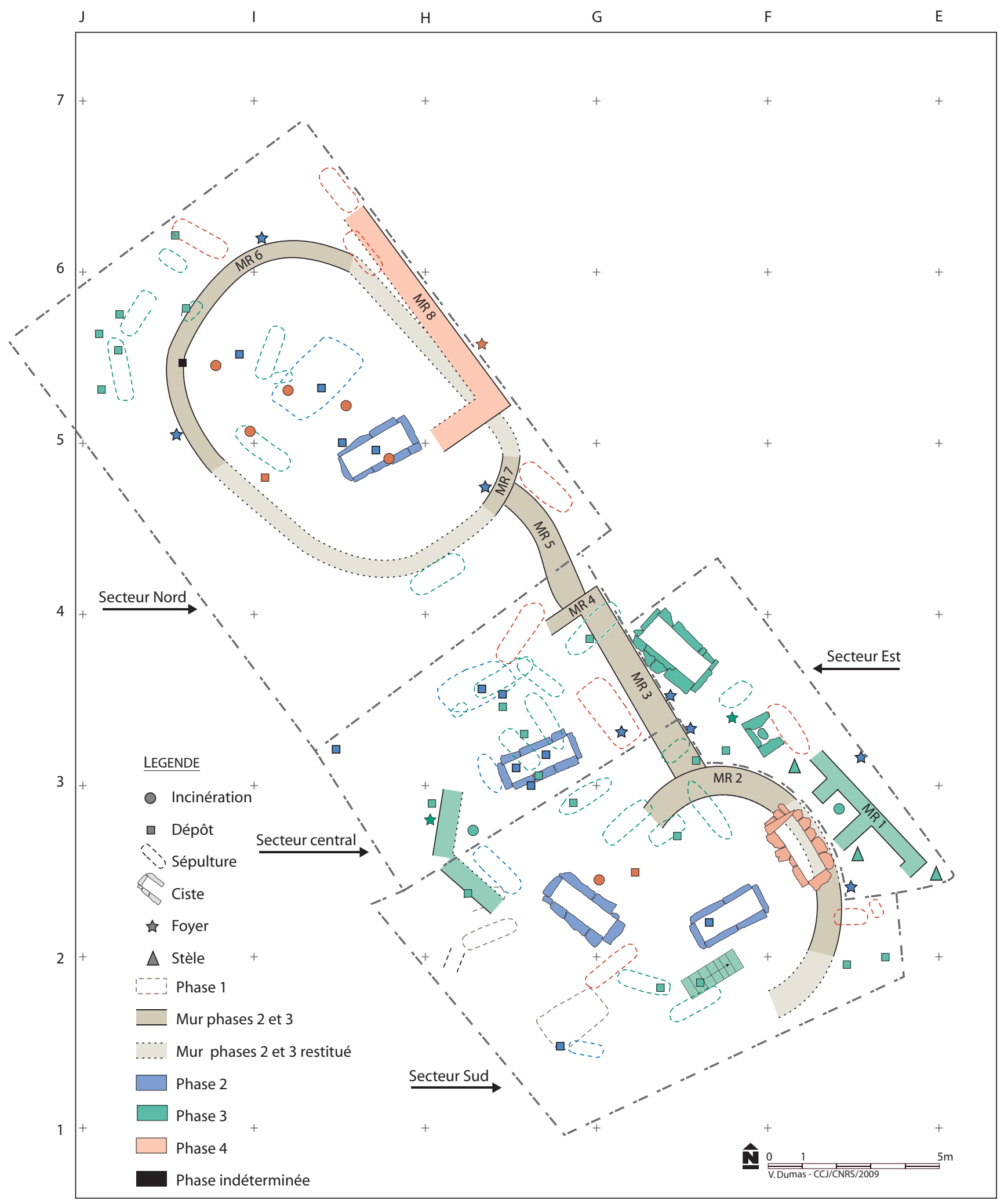

Plan des fouilles franco-bulgares, 2002-2004, avec la délimitation des secteurs (@ CCJ). 


\section{Planche 4}

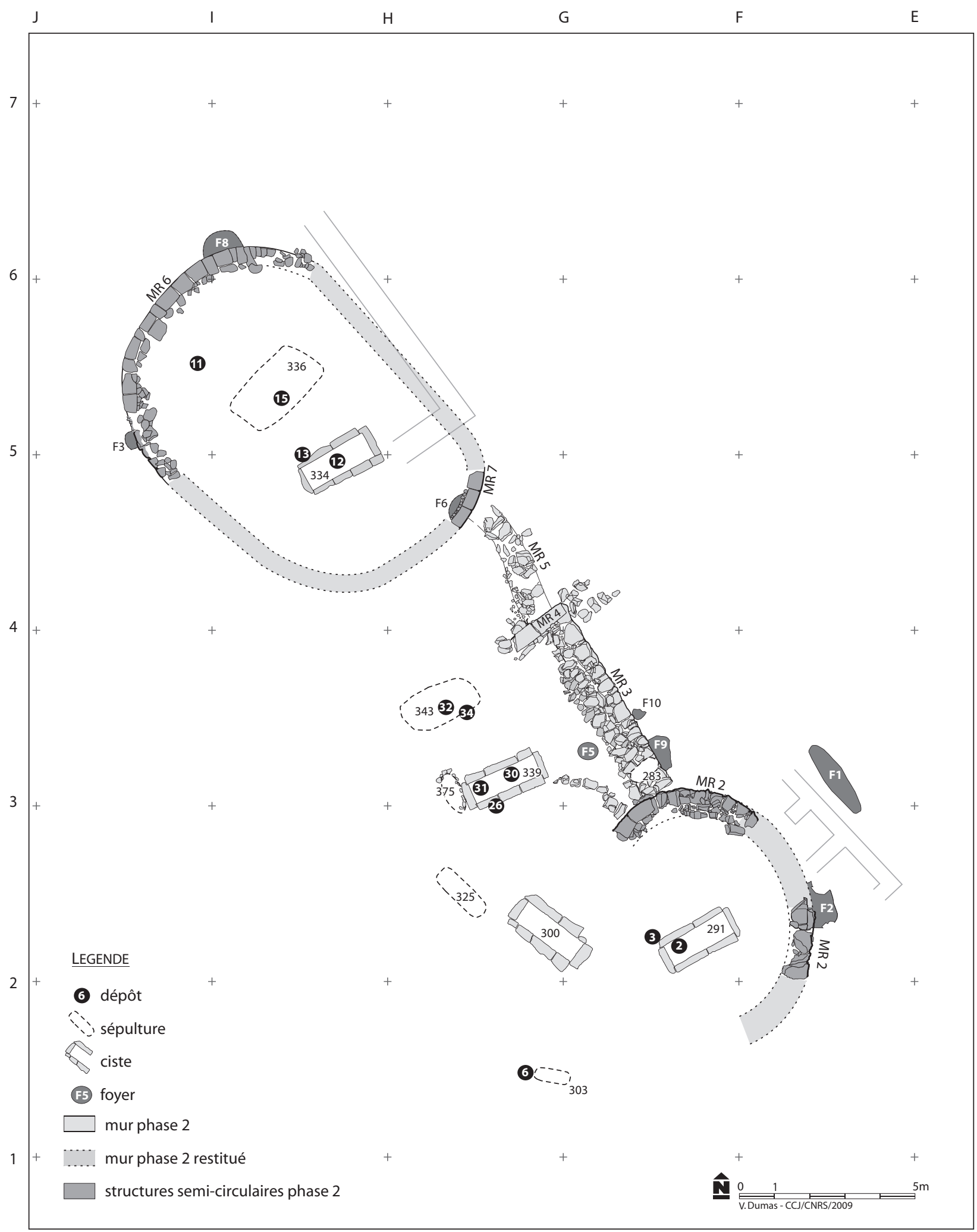

Occupation de la zone lors de la phase 2 (@ CCJ). 
Planche 5

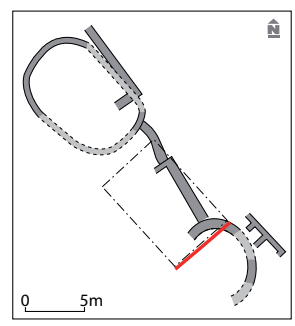

S.O.

N.E.

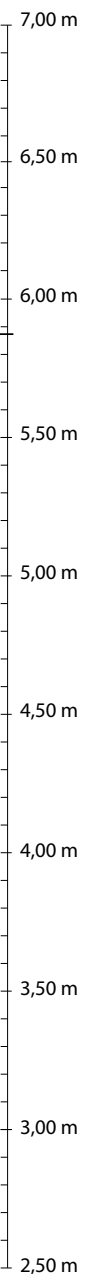

\begin{tabular}{|l|l|l|}
\hline & $1 / 101 / 117 / 194 / 500$ & Terre sableuse brun clair \\
\hline $102 / 138$ & Terre brune, argileuse et compacte, comportant de nombreuses immixtions pierreuses \\
\hline $103 / 139$ & Terre argileuse de couleur ocre \\
\hline $104 / 135$ & Sable brun clair.Comblement de SP 337 \\
\hline 105 & Sable brun clair \\
\hline $106 / 144 / 608$ & Sable brun clair \\
\hline 107 & Sable brun clair \\
\hline 108 & Terre sableuse brun clair comportant de nombreux éclats de grès \\
\hline $109 / 212 / 215 / 637$ & Sable jaune \\
\hline $19 / 114 / 129$ & Terre sableuse \\
\hline $115 / 120 / 130$ & Terre compacte brune \\
\hline 116 & Terre sableuse brun foncé \\
\hline $180 / 216 / 604 / 618 / 636$ & Terre sableuse brun clair \\
\hline $609 / 610 / 639$ & Sable brun clair \\
\hline $198 / 221 / 223 / 586 / 642$ & Terre sableuse brune \\
\hline 200 & Creusement de la fosse d'installation de la ciste 300 \\
\hline 201 & Sable.Comblement de la fosse de la ciste 300 \\
\hline $211 / 214 / 625$ & Terre argileuse compacte brun foncé \\
\hline $617 / 619$ & Sable jaune meuble \\
\hline $217 / 626$ & Terre sableuse brun clair \\
\hline $218 / 627$ & Sable jaune meuble \\
\hline 225 & Terre sableuse \\
\hline 226 & Terre argileuse compacte \\
\hline $623 / 643$ & Sable brun clair \\
\hline 640 & Paléosol de couleur brune foncée \\
\hline & & \\
\hline
\end{tabular}

Coupe E.-O. sur les US déterminées dans le secteur Sud (@ CCJ). 


\section{Planche 6}

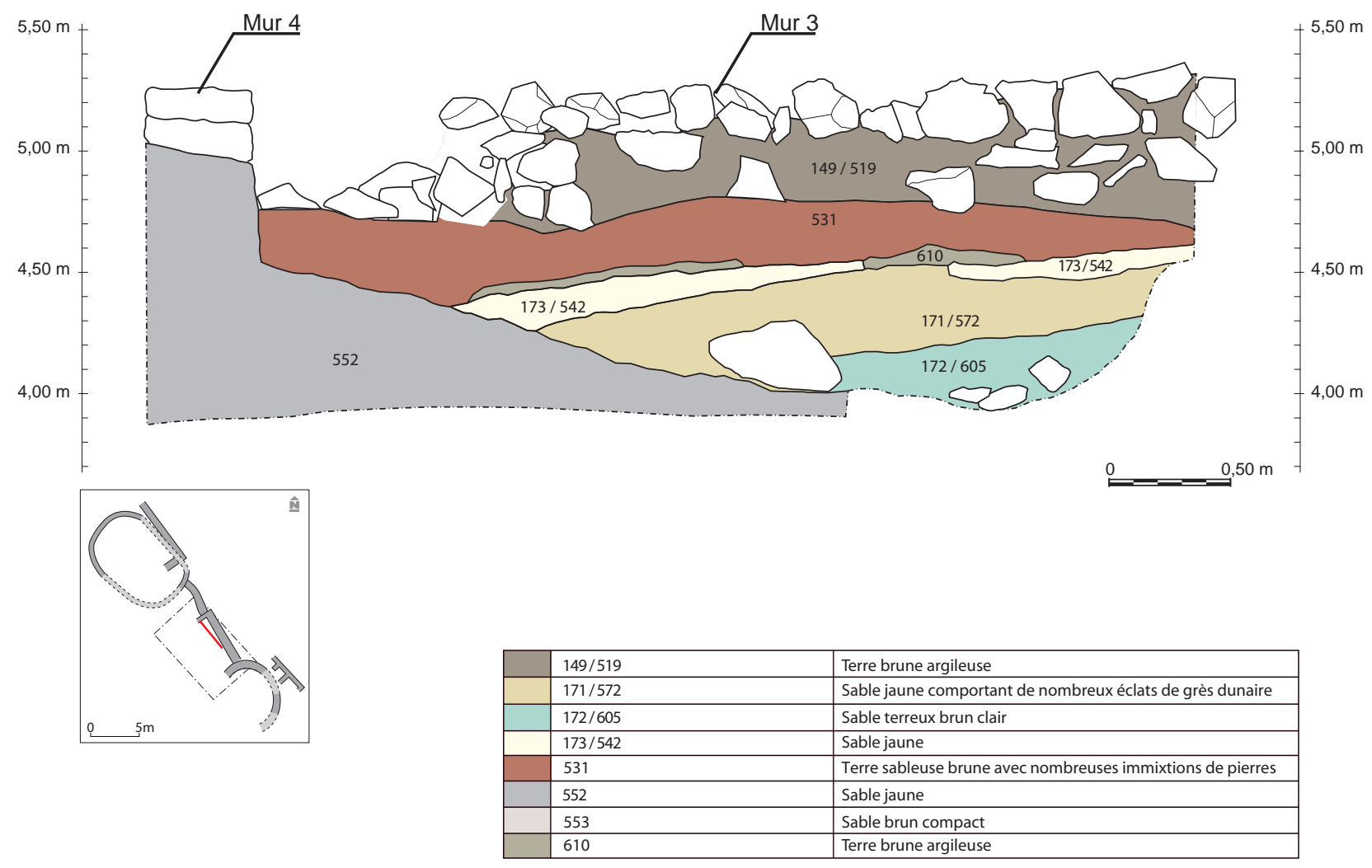

Coupe sur les remblais en secteur central, sous le mur MR 3 (@ CCJ). 

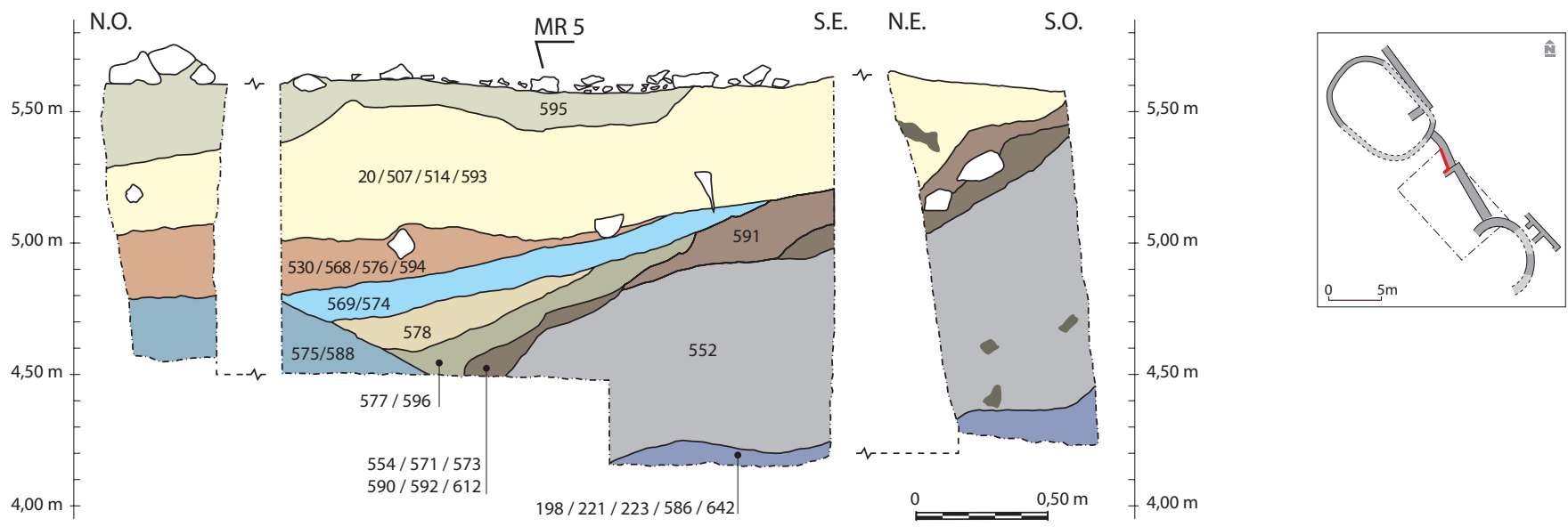

7a. Coupe sur le tumulus de SP 343 et les remblais sous le mur MR 5 (๑ CCJ).

\begin{tabular}{|l|l|l|}
\hline & $1 / 101 / 117 / 194 / 500$ & Terre sableuse claire \\
\hline & $20 / 507 / 514 / 593$ & Terre sableuse brune \\
\hline & $198 / 221 / 223 / 586 / 642$ & Terre sableuse brune \\
\hline $530 / 568 / 576 / 594$ & Terre argileuse brune avec nombreuses immixtions de pierres \\
\hline 552 & Sable jaune \\
\hline & 553 & Sable brun compact \\
\hline $554 / 571 / 573 / 590 / 592 / 612$ & Terre brune argileuse \\
\hline & $569 / 574$ & Terre sableuse brune \\
\hline & $575 / 588$ & Alternance de couches fines de sable et de terre \\
\hline & $577 / 596$ & Terre brune argileuse \\
\hline & 578 & Terre brune argileuse \\
\hline & 591 & Terre sableuse brune avec immixtions de pierres \\
\hline & 595 & Sable jaune \\
\hline- & & Amphore \\
\hline & & Argile \\
\hline$\diamond$ & & Pierres \\
\hline
\end{tabular}

S.O.

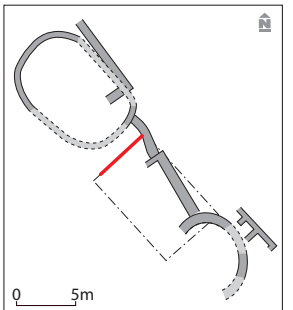

N.E.

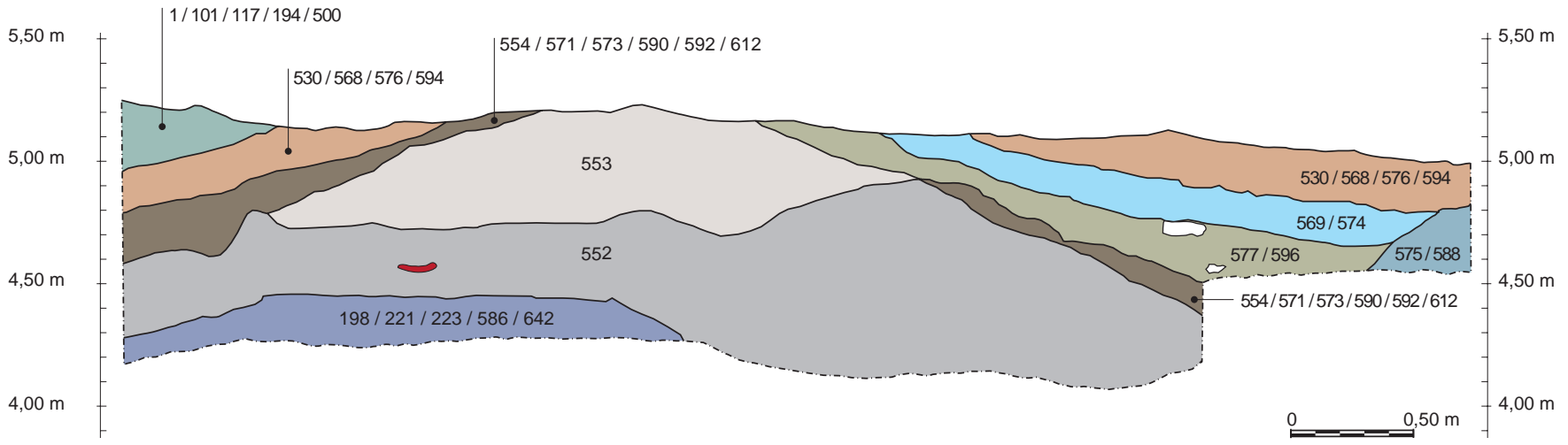

7 b. Coupe sur le tumulus de SP 343 et les remblais adjacents (@ CCJ). 


\section{Planche 8}

N.E.

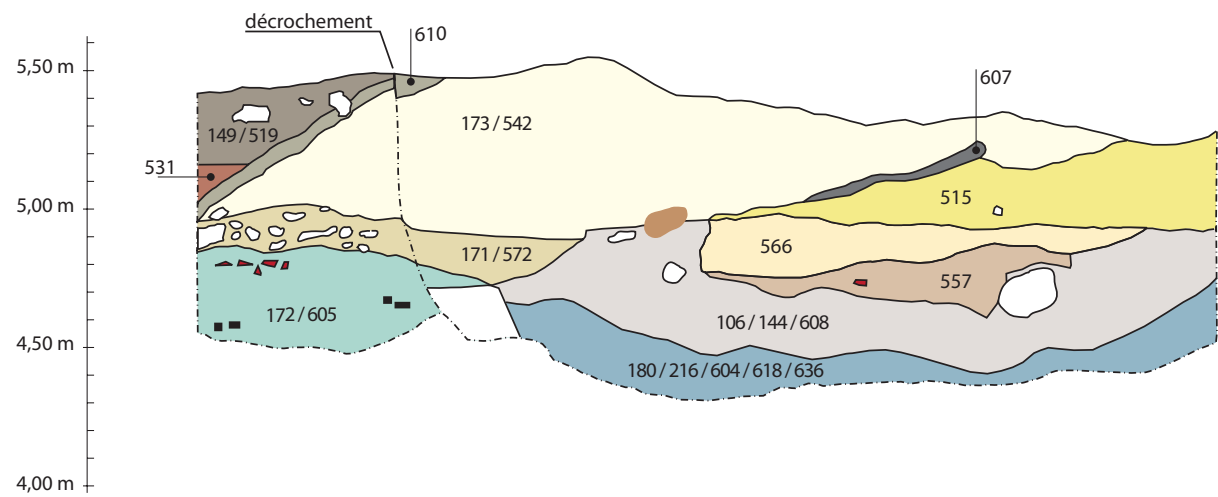

S.O.
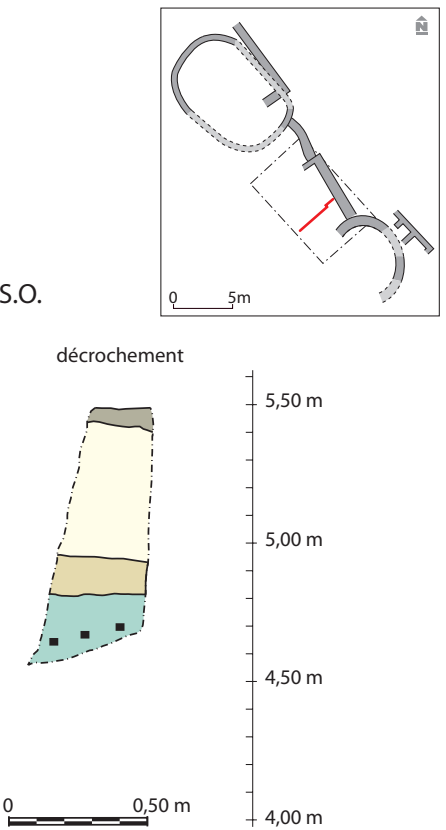

8a. Coupe S.-O. sur le secteur central (phase 2) (๑ CCJ).

\begin{tabular}{|c|c|c|}
\hline & $8 / 516$ & Sable terreux brun clair \\
\hline & $106 / 144 / 608$ & Sable brun clair \\
\hline & $149 / 519$ & Terre brune argileuse \\
\hline & $171 / 572$ & Sable jaune comportant de nombreux éclats de grès dunaire \\
\hline & $172 / 605$ & Sable terreux brun clair \\
\hline & $173 / 542$ & Sable jaune \\
\hline & $180 / 216 / 604 / 618 / 636$ & Terre sableuse brune claire \\
\hline & 515 & Sable jaune \\
\hline & 531 & Terre sableuse brune avec nombreuses immixtions de pierres \\
\hline & 552 & Sable jaune \\
\hline & 553 & Sable brun compact \\
\hline & $554 / 571 / 573 / 590 / 592 / 612$ & Terre brune argileuse \\
\hline & 557 & Argile brune \\
\hline & 566 & Sable jaune clair \\
\hline & 607 & Sable terreux brun \\
\hline & 610 & Terre brune argileuse \\
\hline & Sp 339 (Coupe 8b) & Dallage de couverture de la ciste \\
\hline$-4^{-2}$ & & Céramique \\
\hline - - & & Charbon \\
\hline 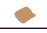 & & Inclusion d'argile \\
\hline $0: 0$ & & Pierres \\
\hline
\end{tabular}
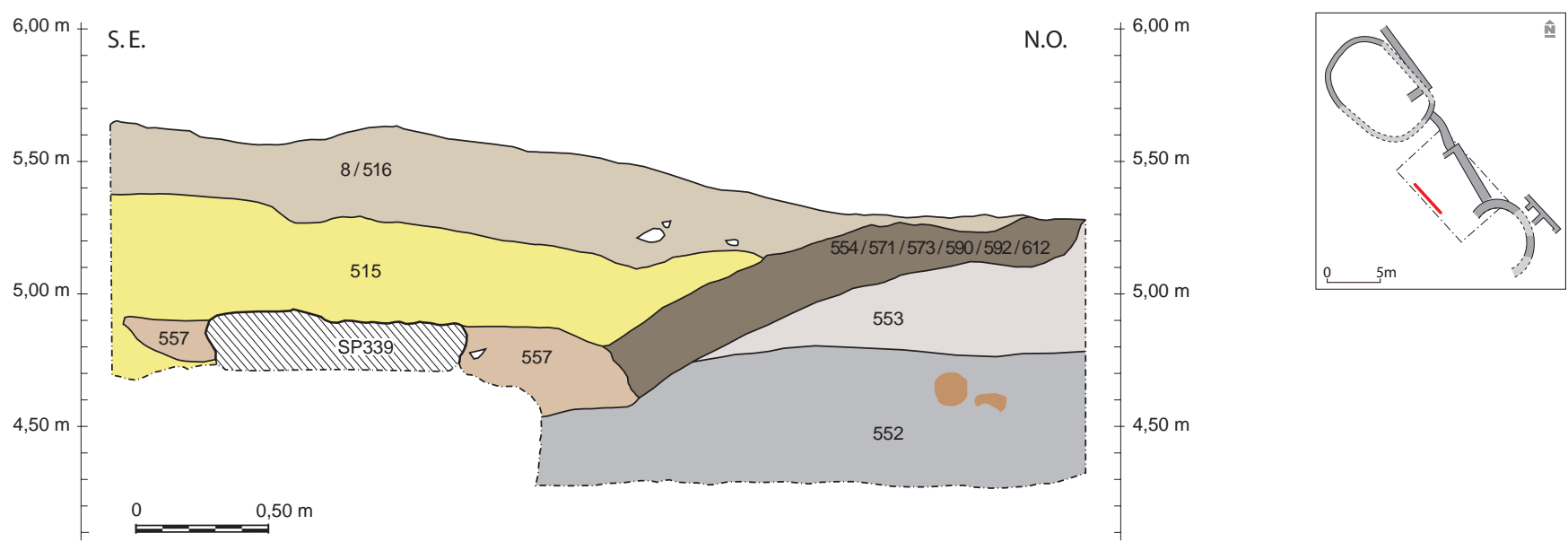

8b. Coupe sur les couvertures tumulaires de SP 343 et SP 339 (@ CCJ). 


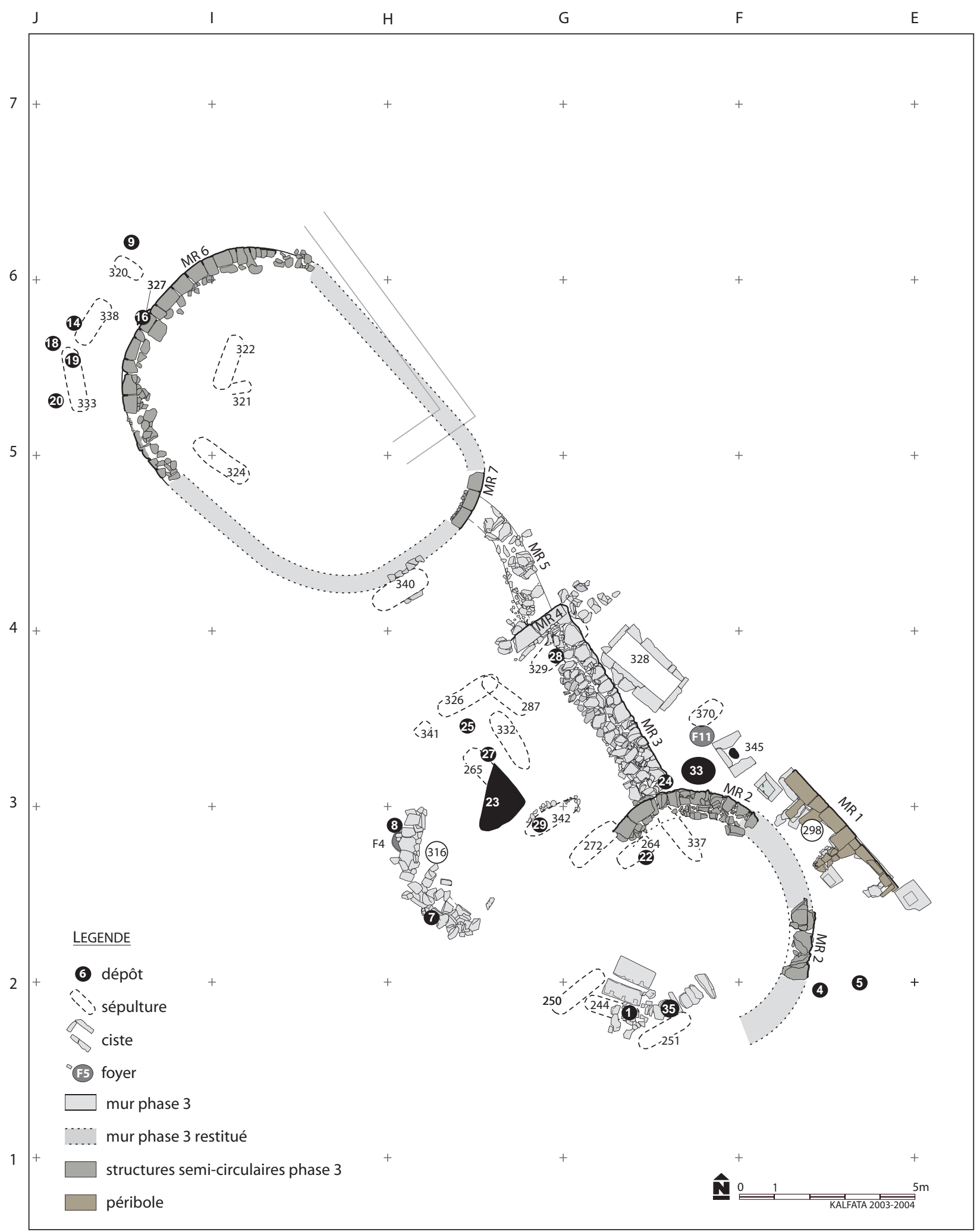

Occupation de la zone lors de la phase 3 (@ CCJ). 
Planche 10

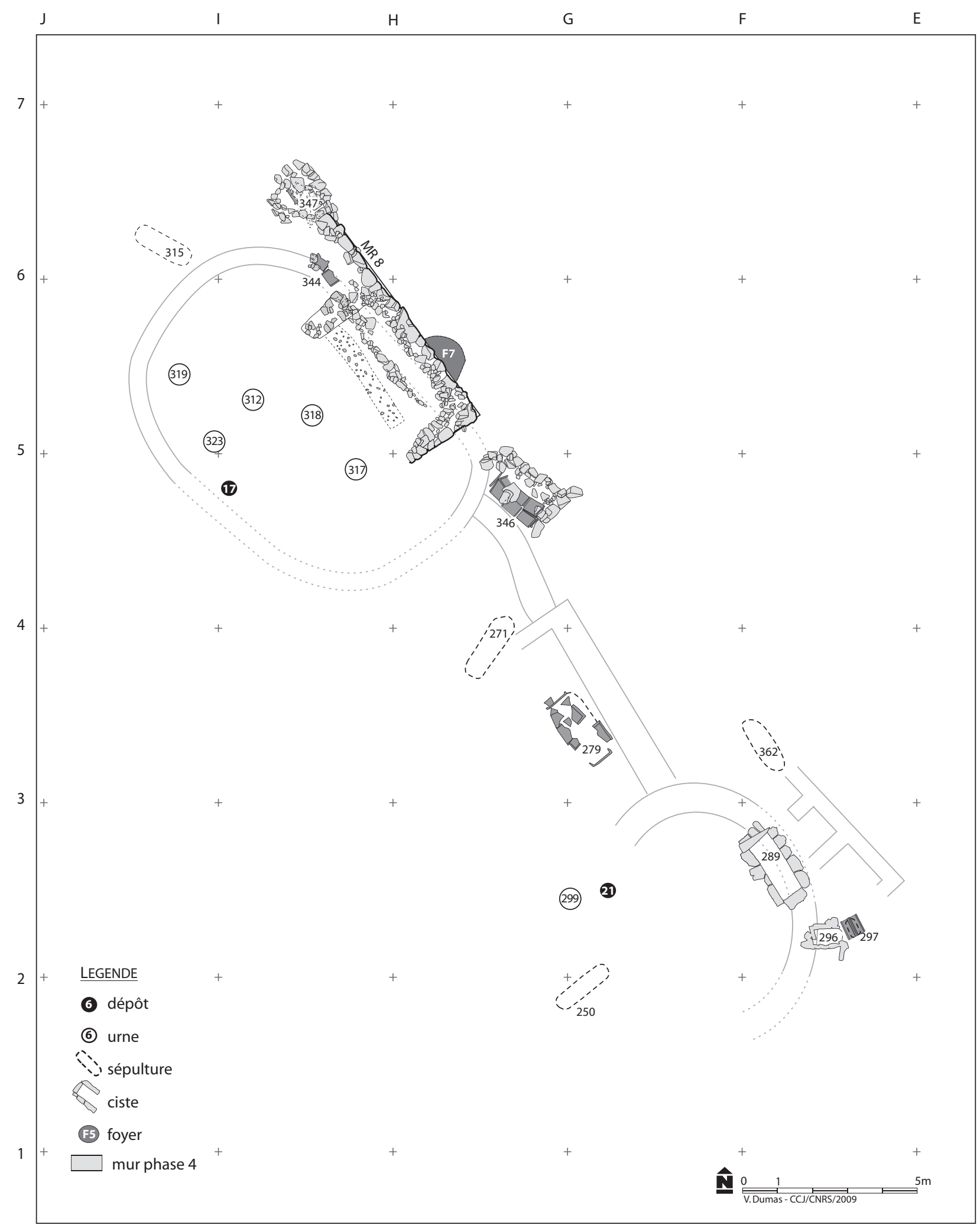

Occupation de la zone lors de la phase 4 (๑ CCJ). 
Planche 11

Tombe 298
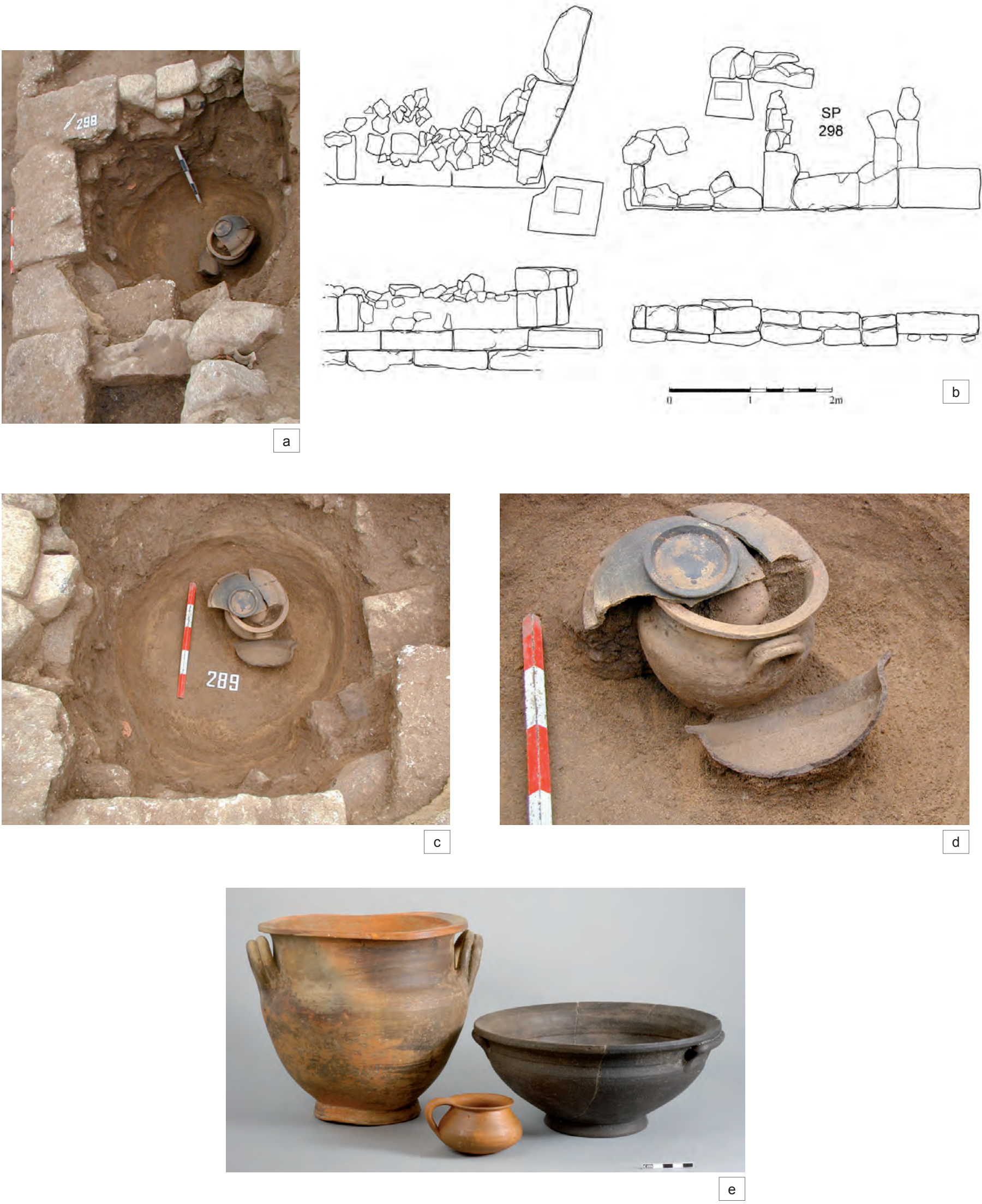
Planche 12

Tombe 299
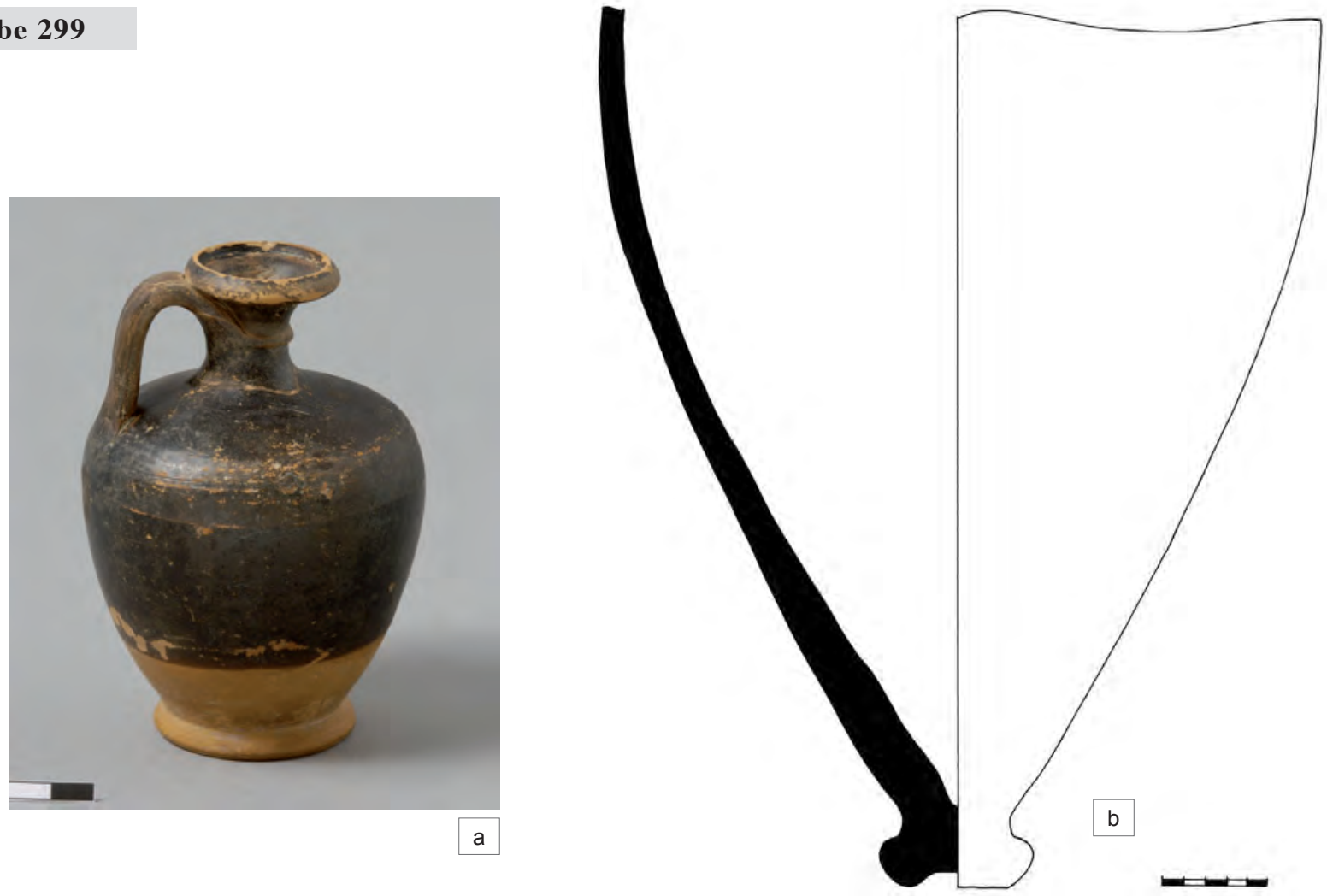

Tombe 312
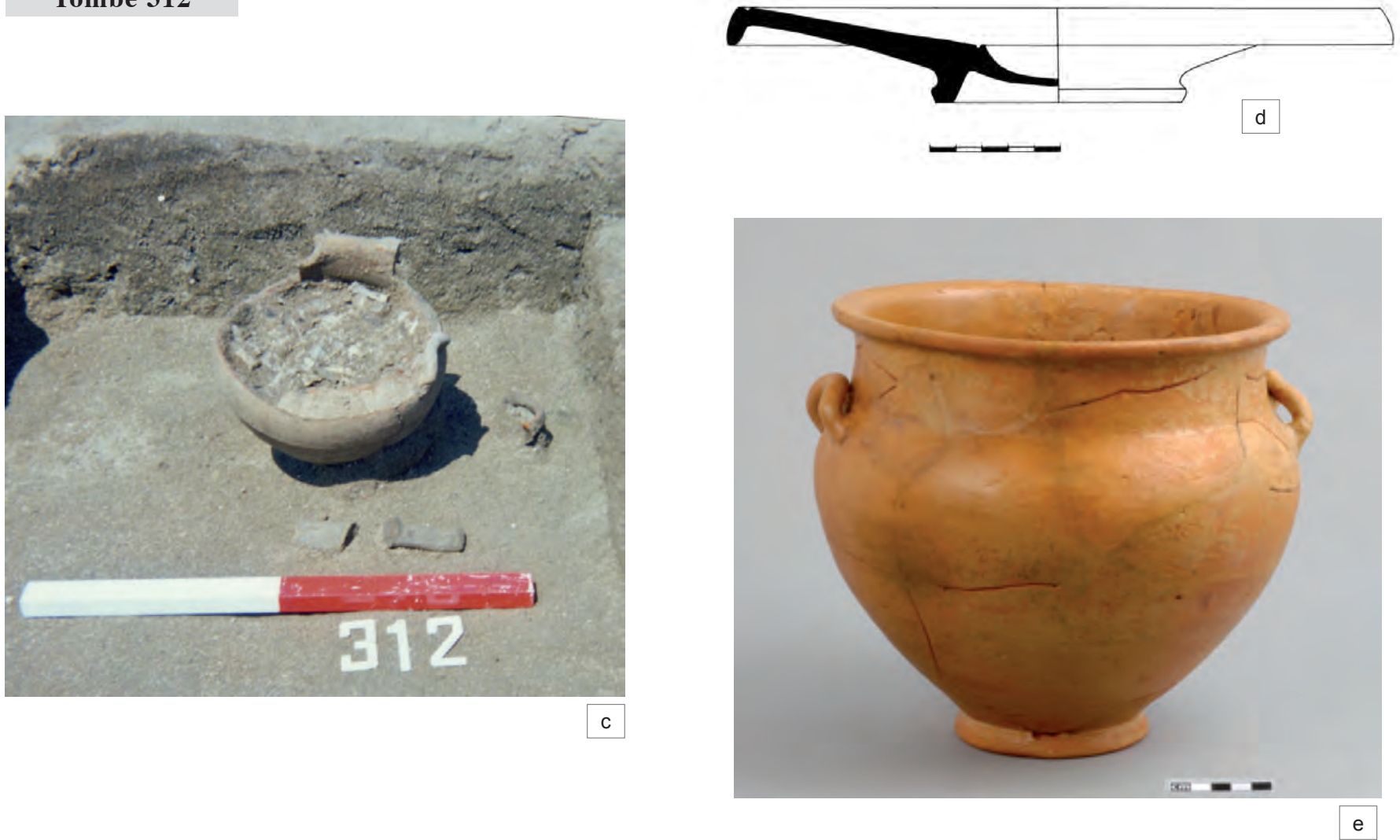
Planche 13

Tombe 316
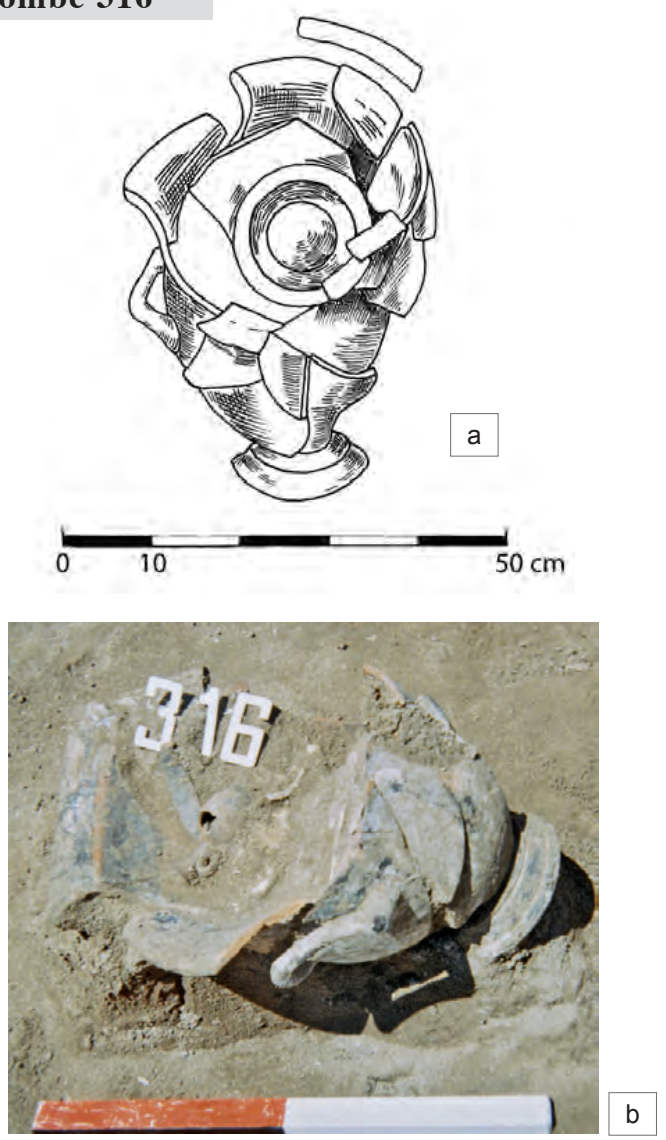
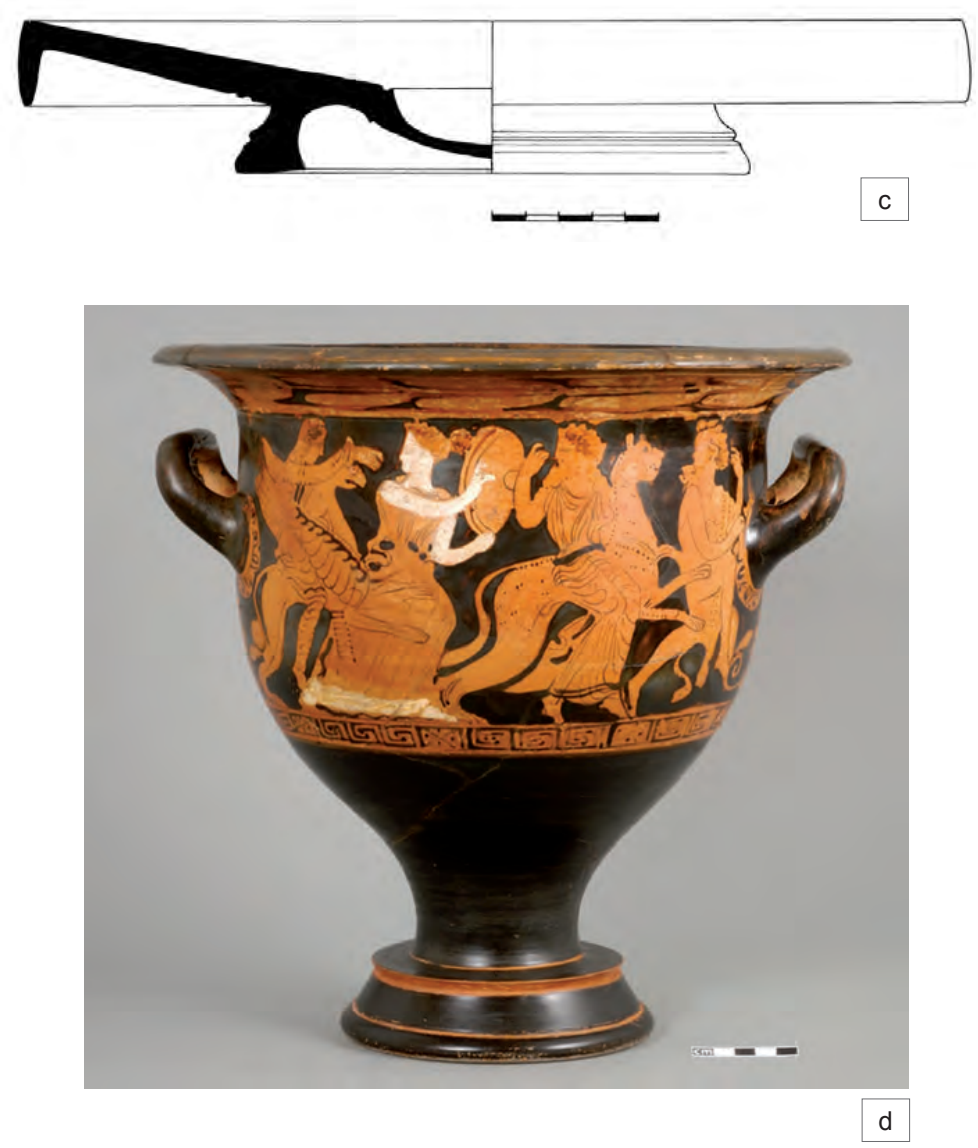

Tombe 317

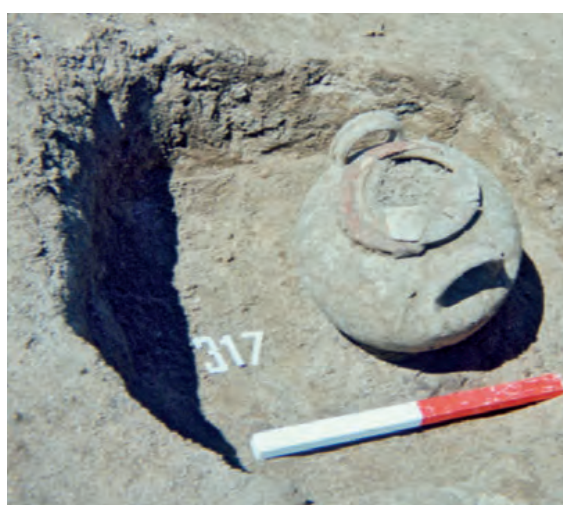

e
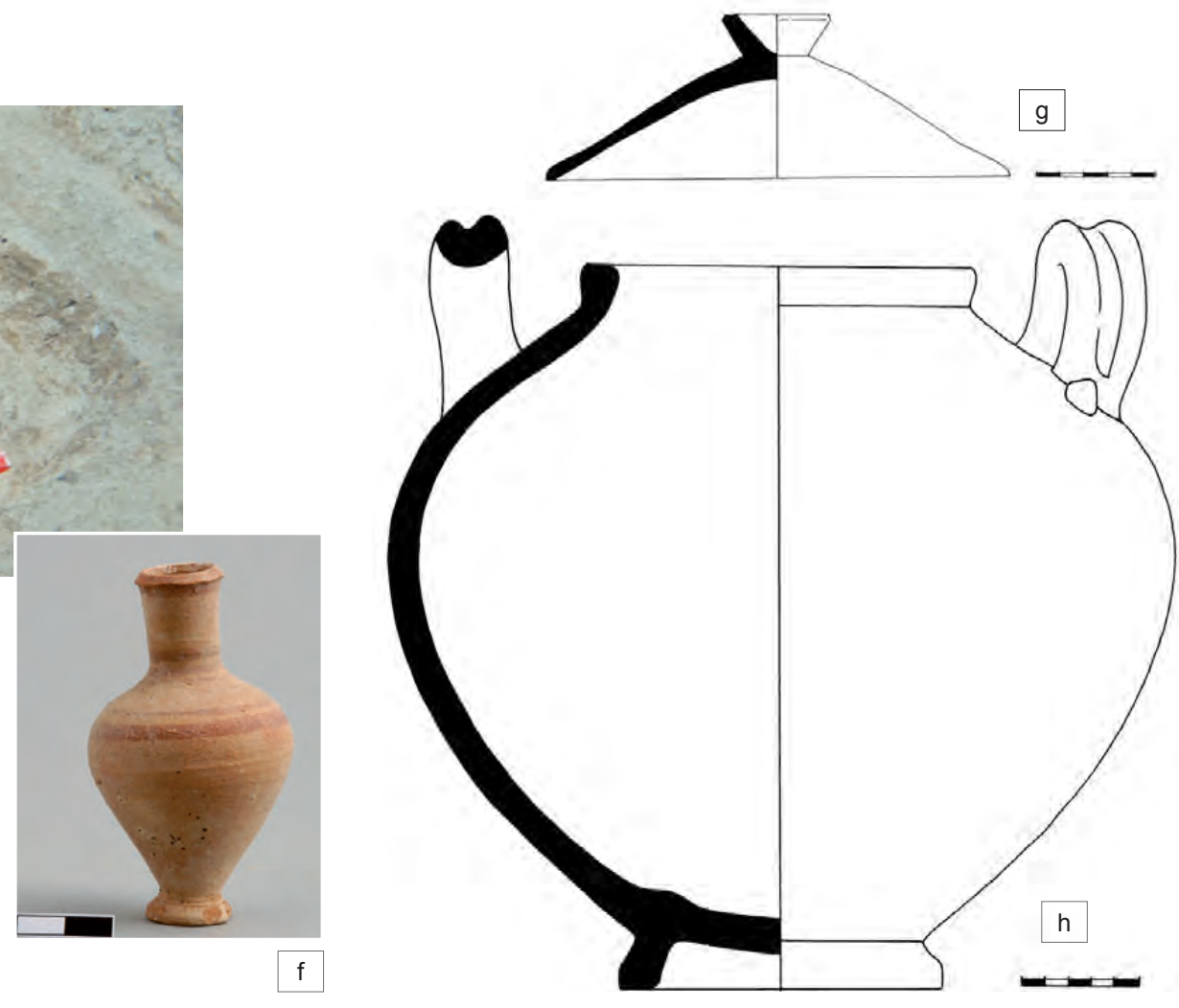
Planche 14

Tombe 318
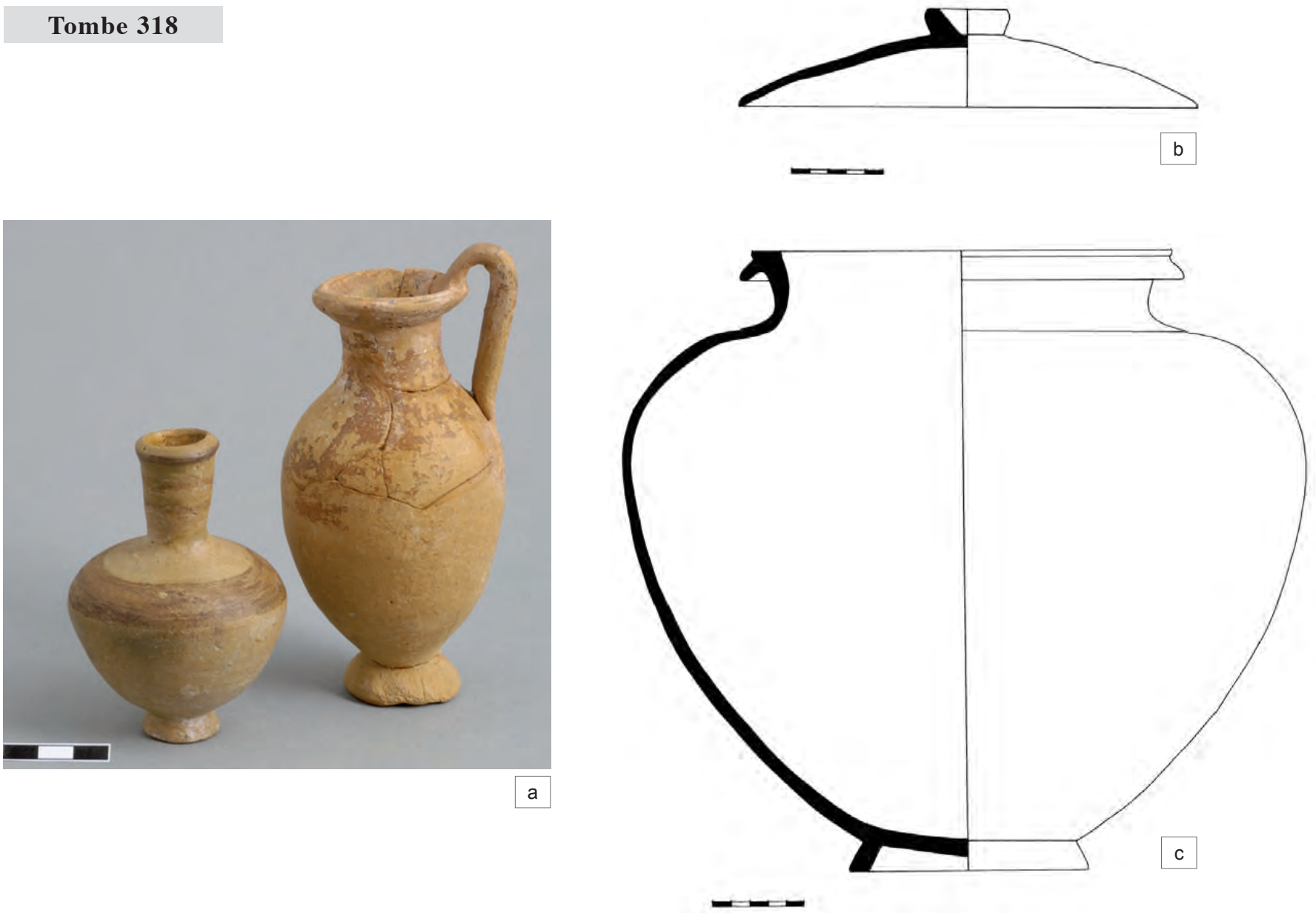

Tombe 319

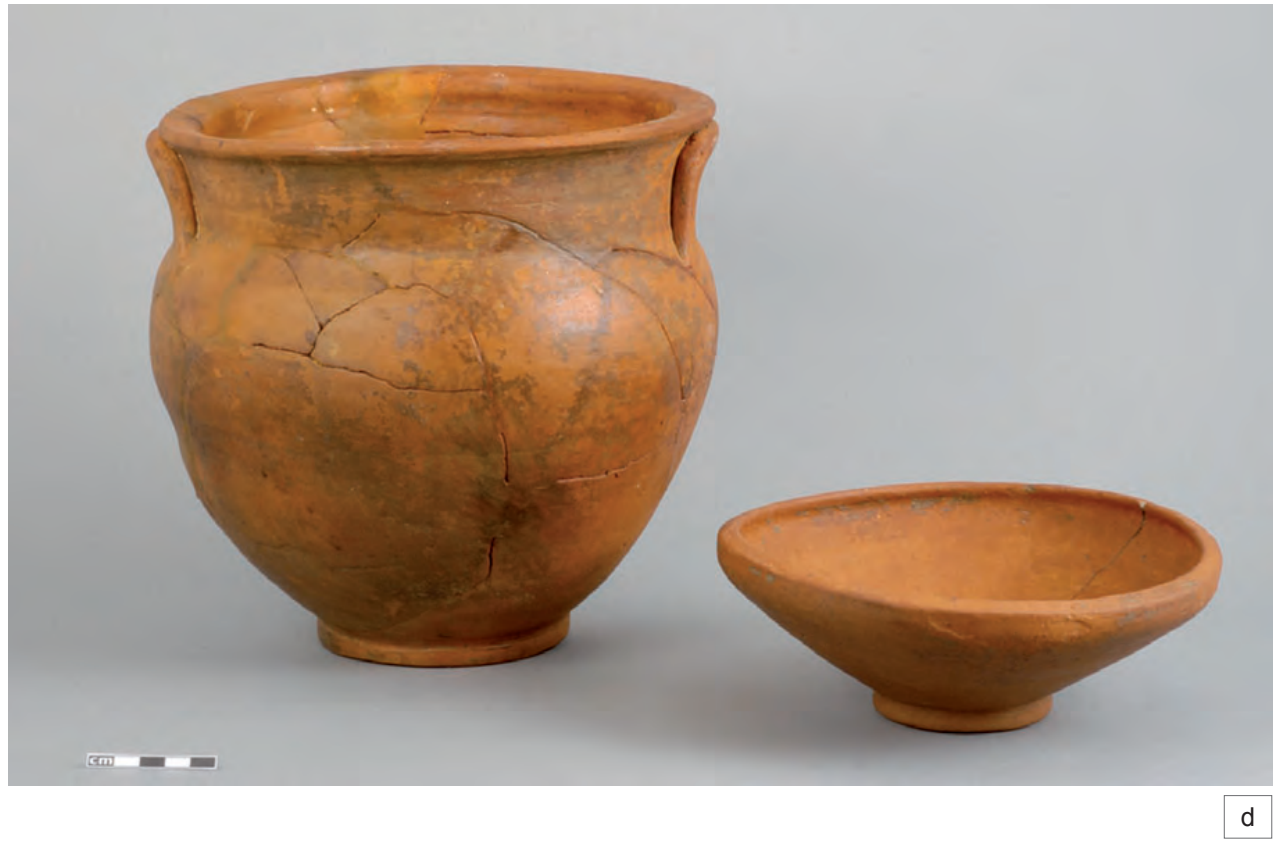


Planche 15

Tombe 323
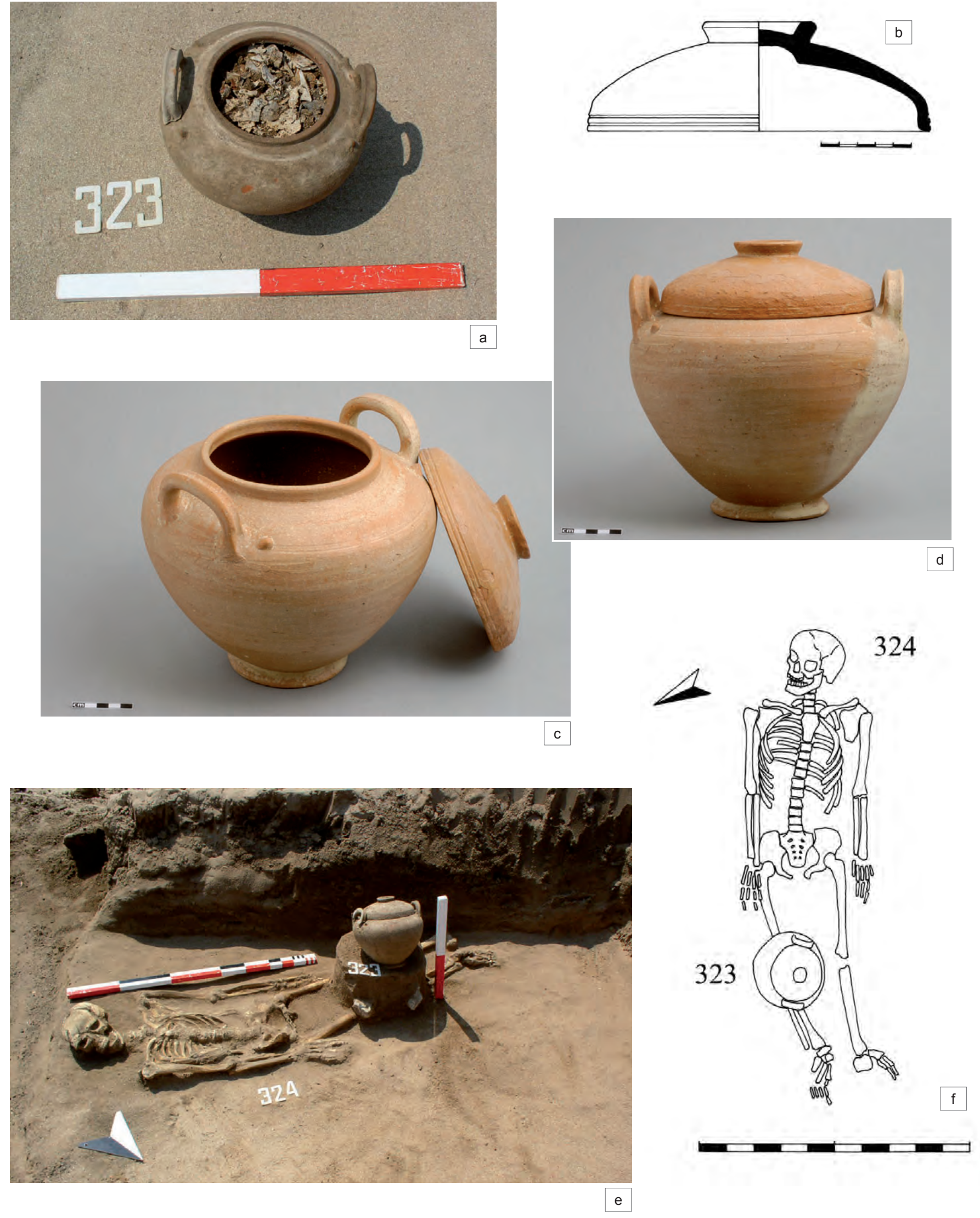
Planche 16

Tombe 345
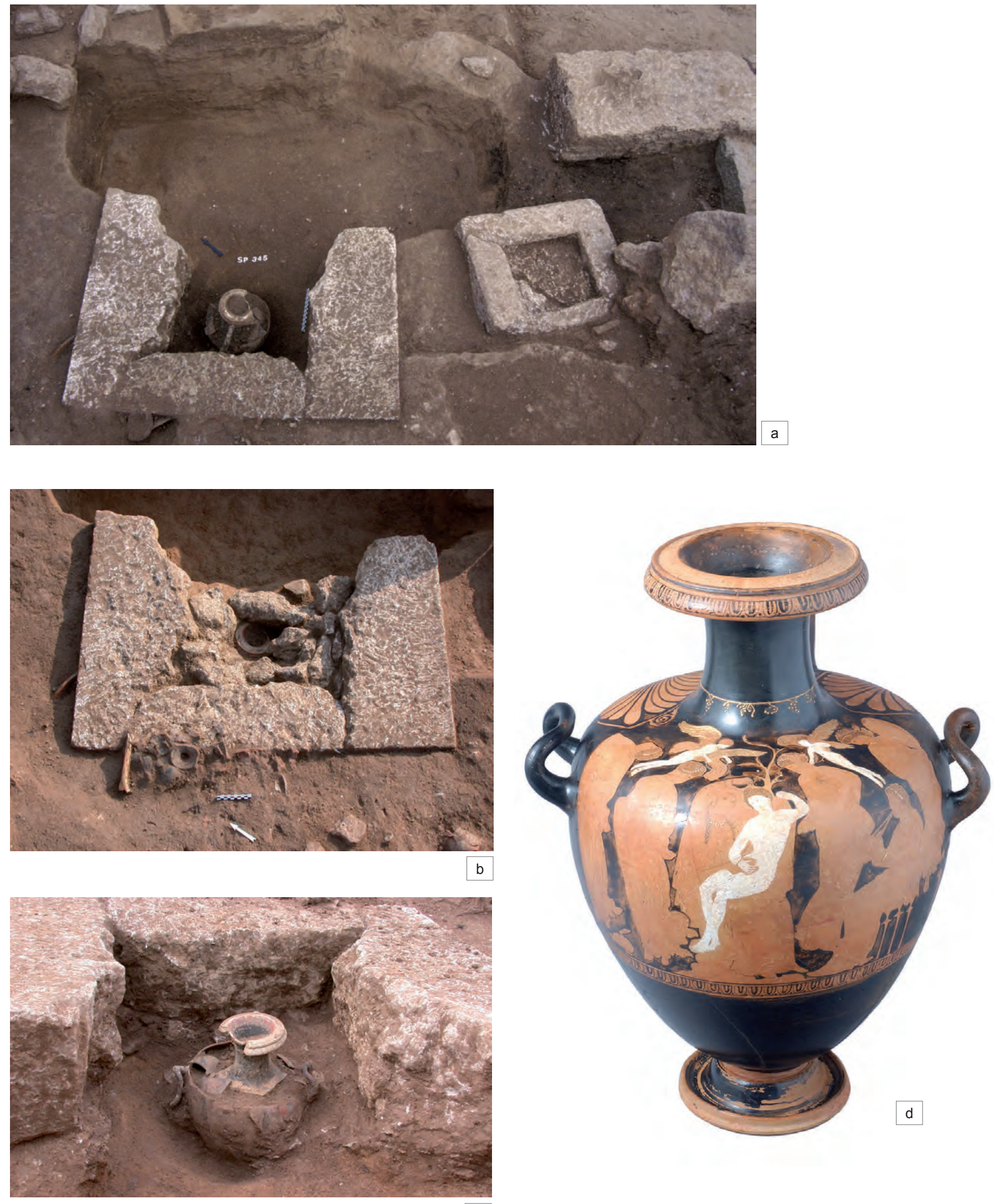
Tombe 244
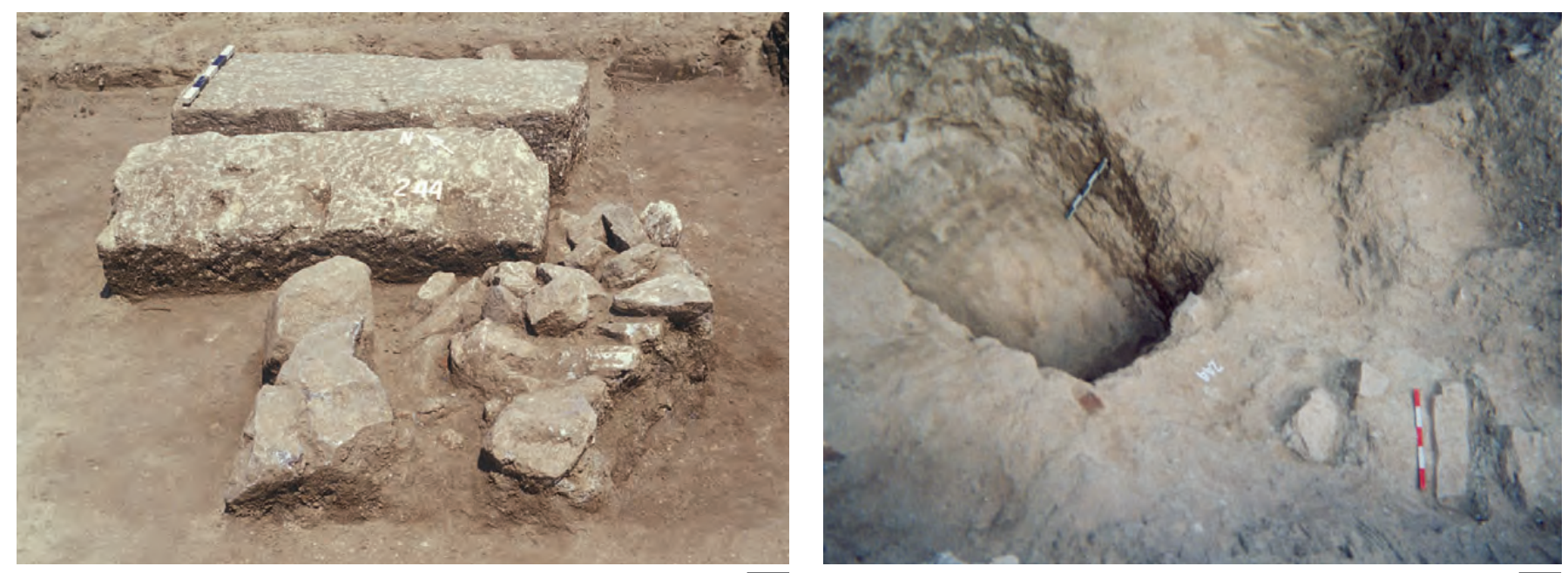

$a$

b
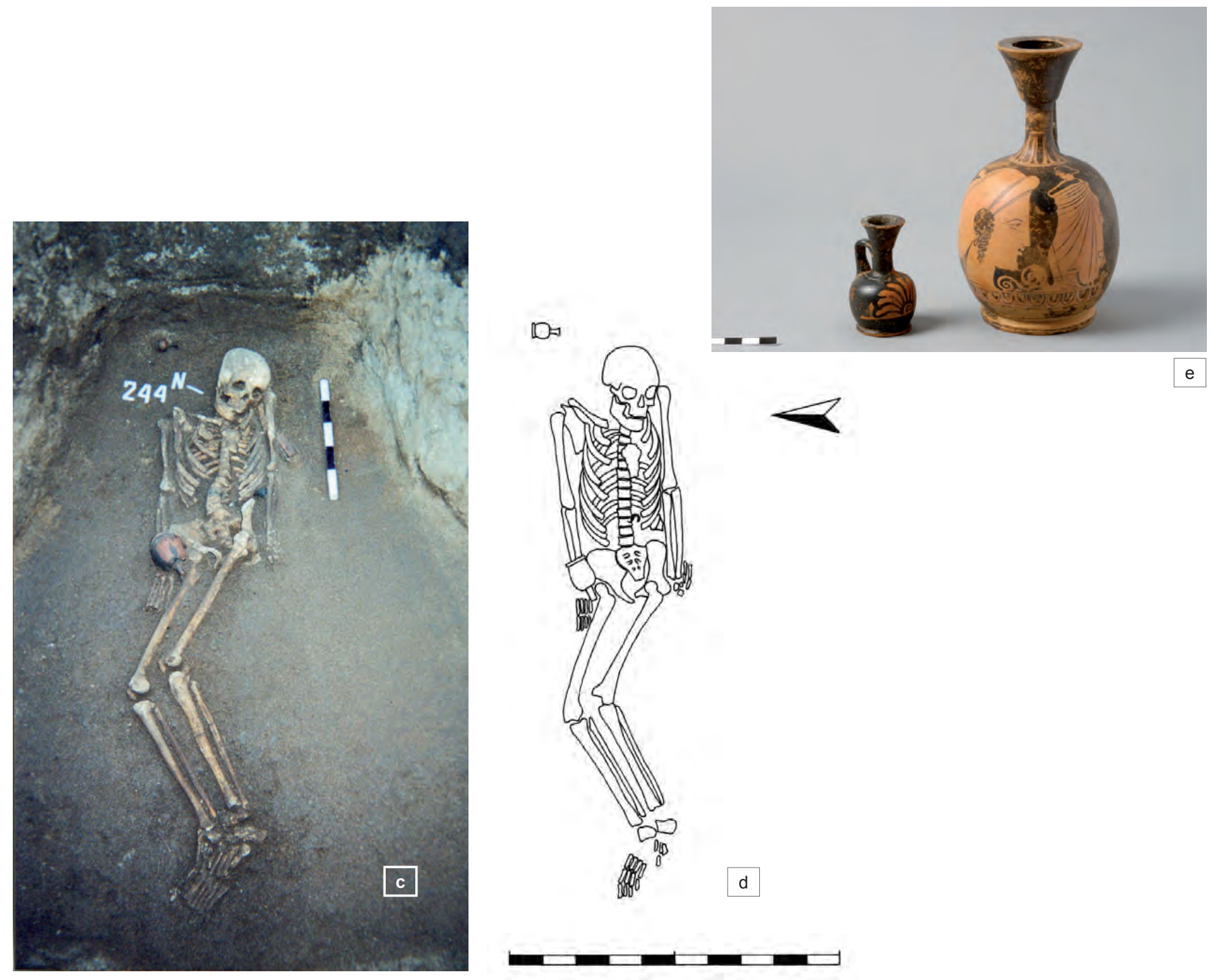
Planche 18

Tombe 250
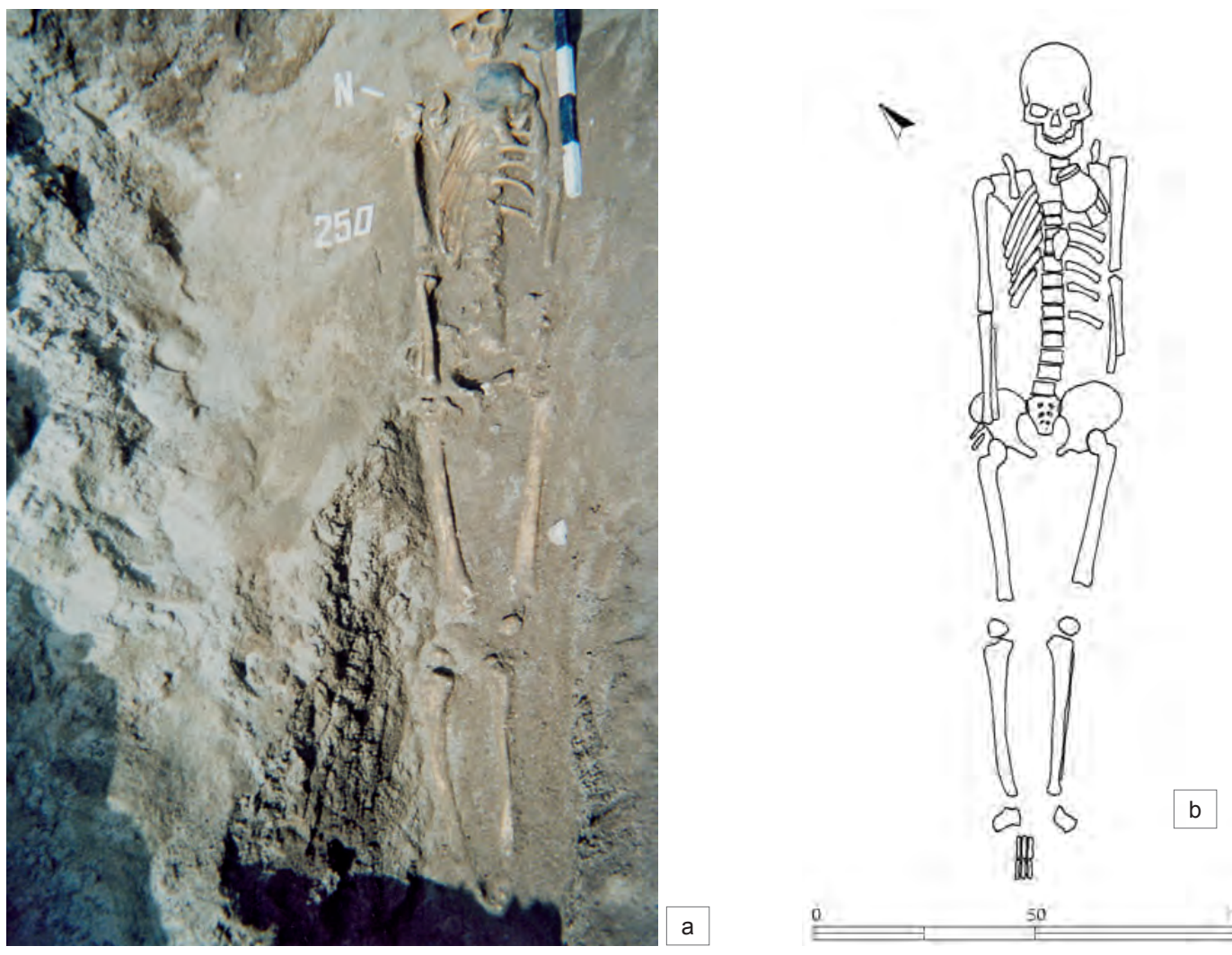

a

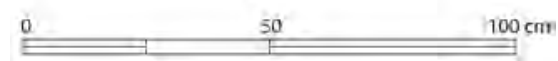

Tombe 251
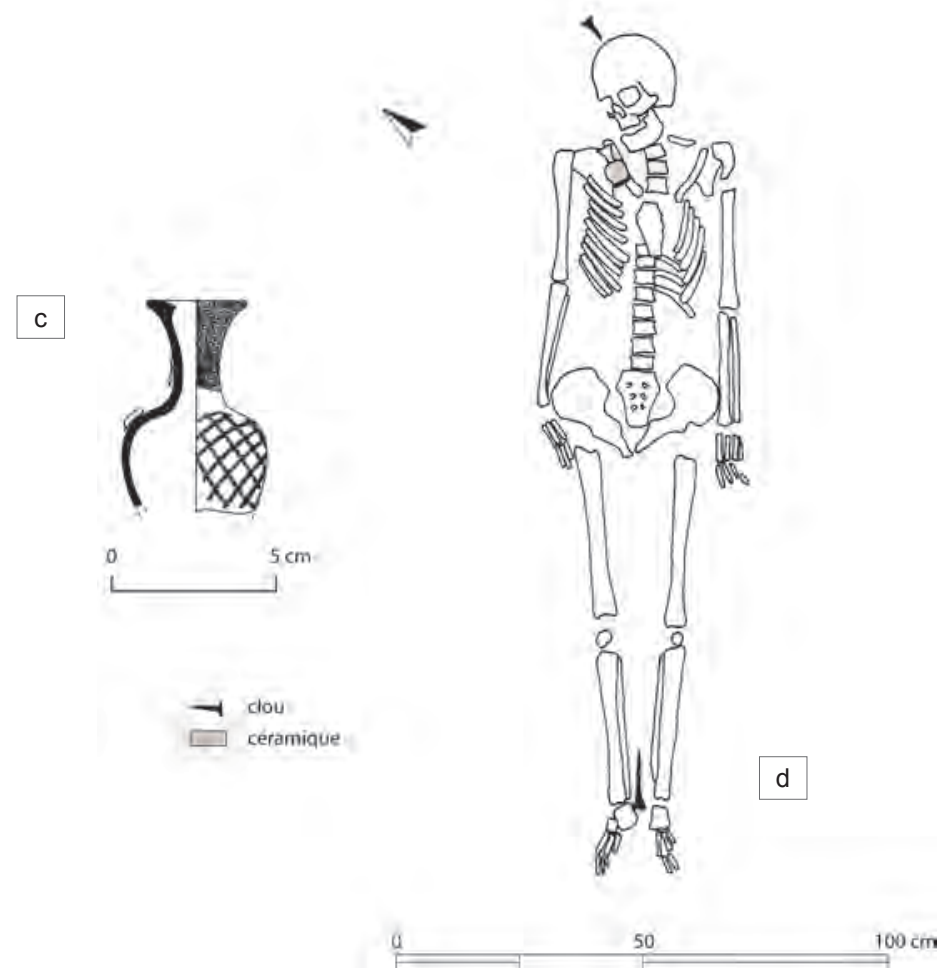


\section{Tombe 264}

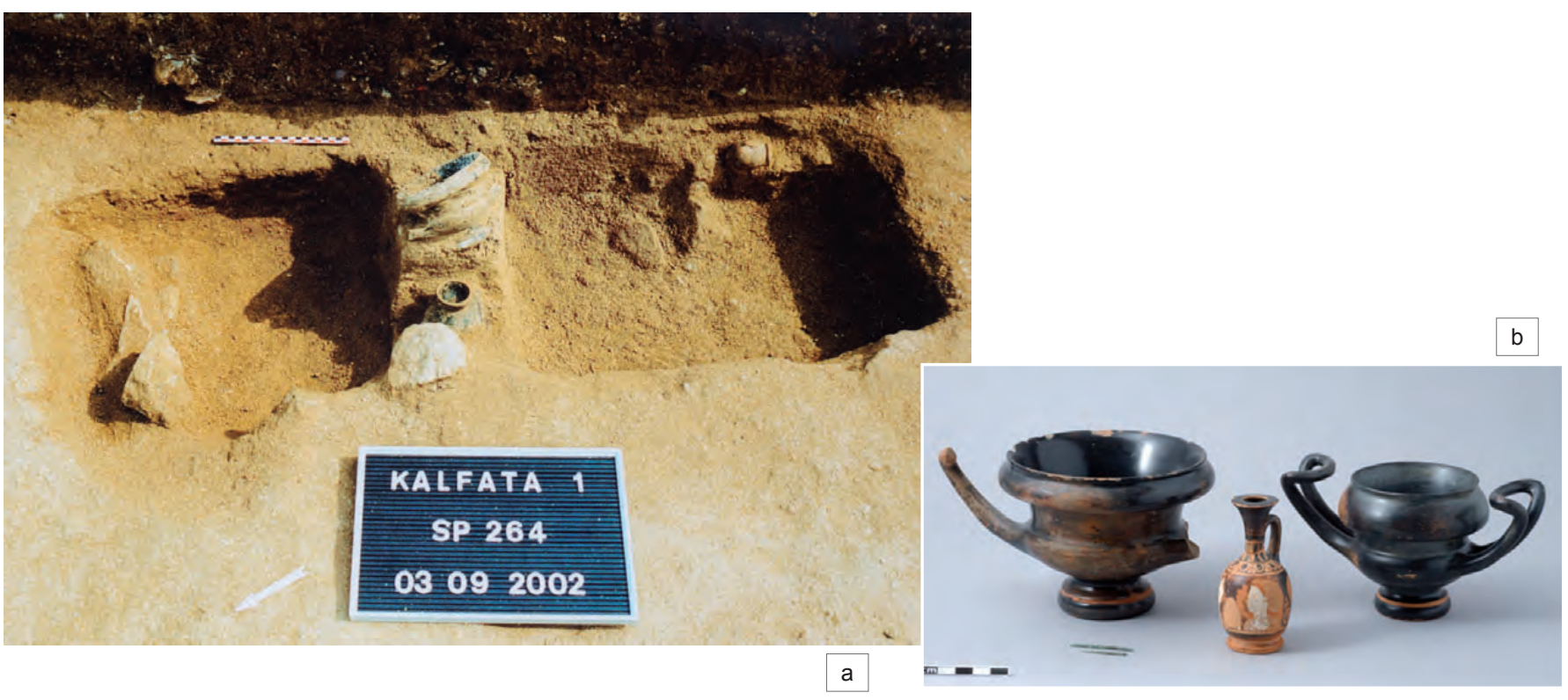

Tombe 265
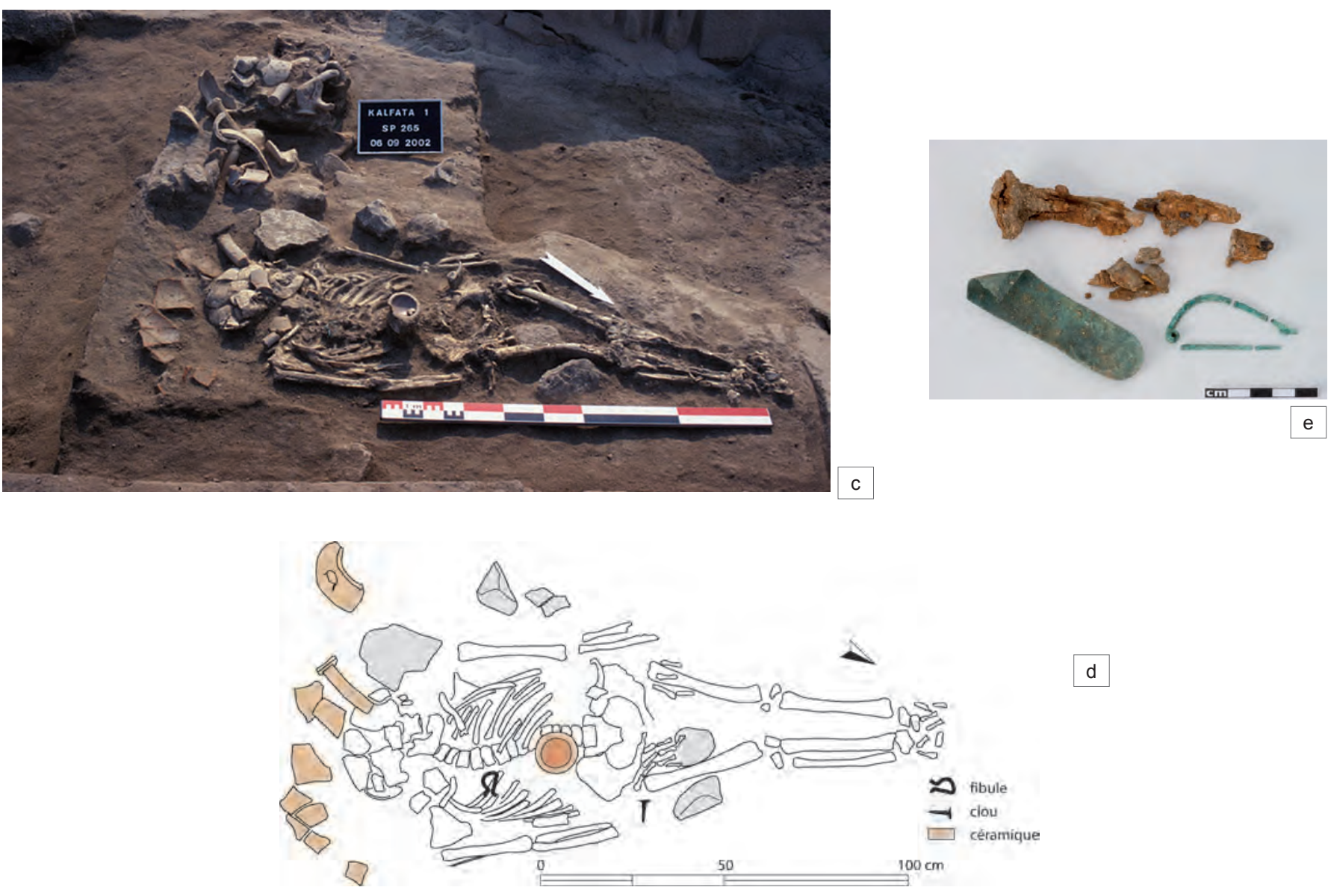
Planche 20

Tombe 271
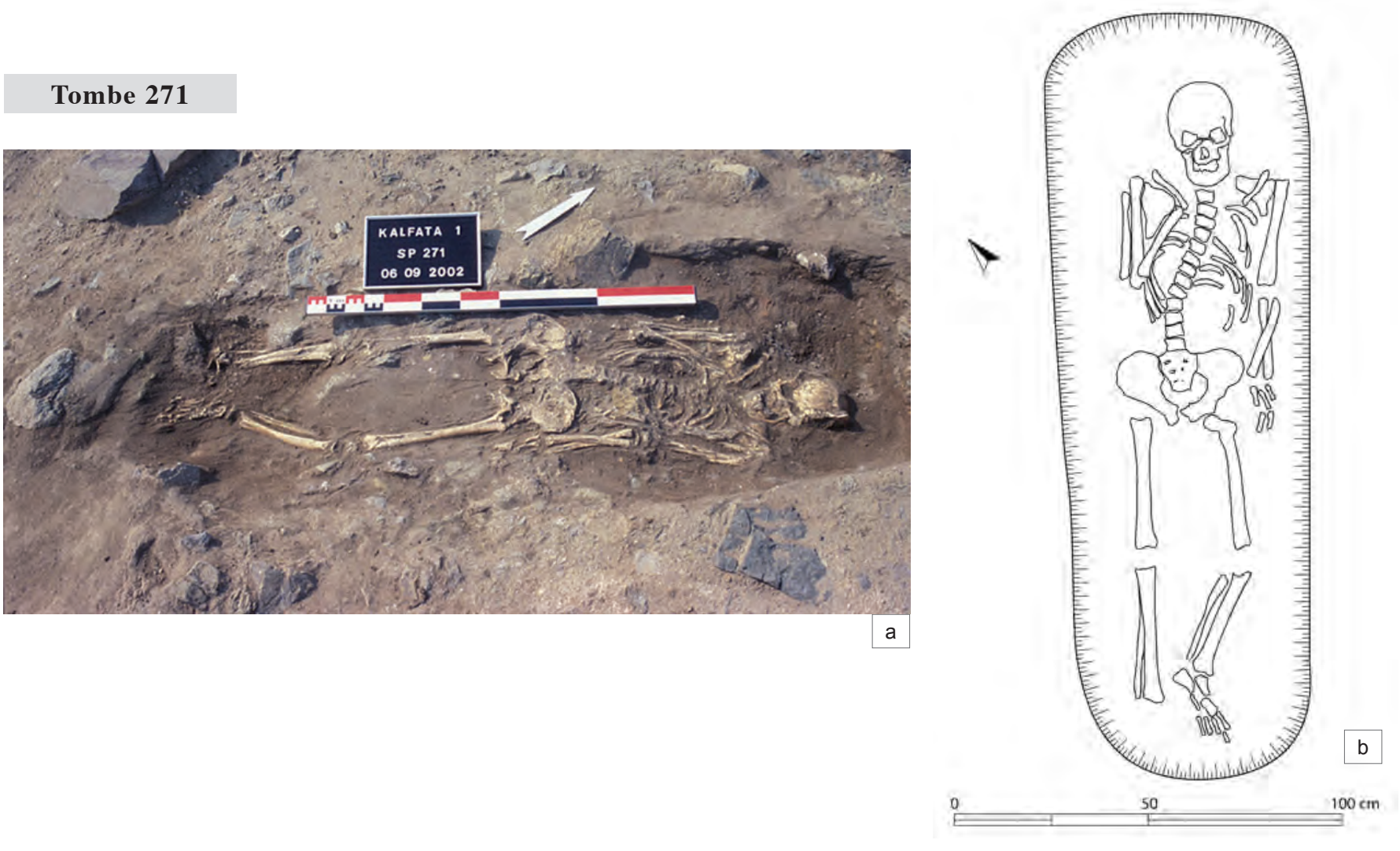

Tombe 272
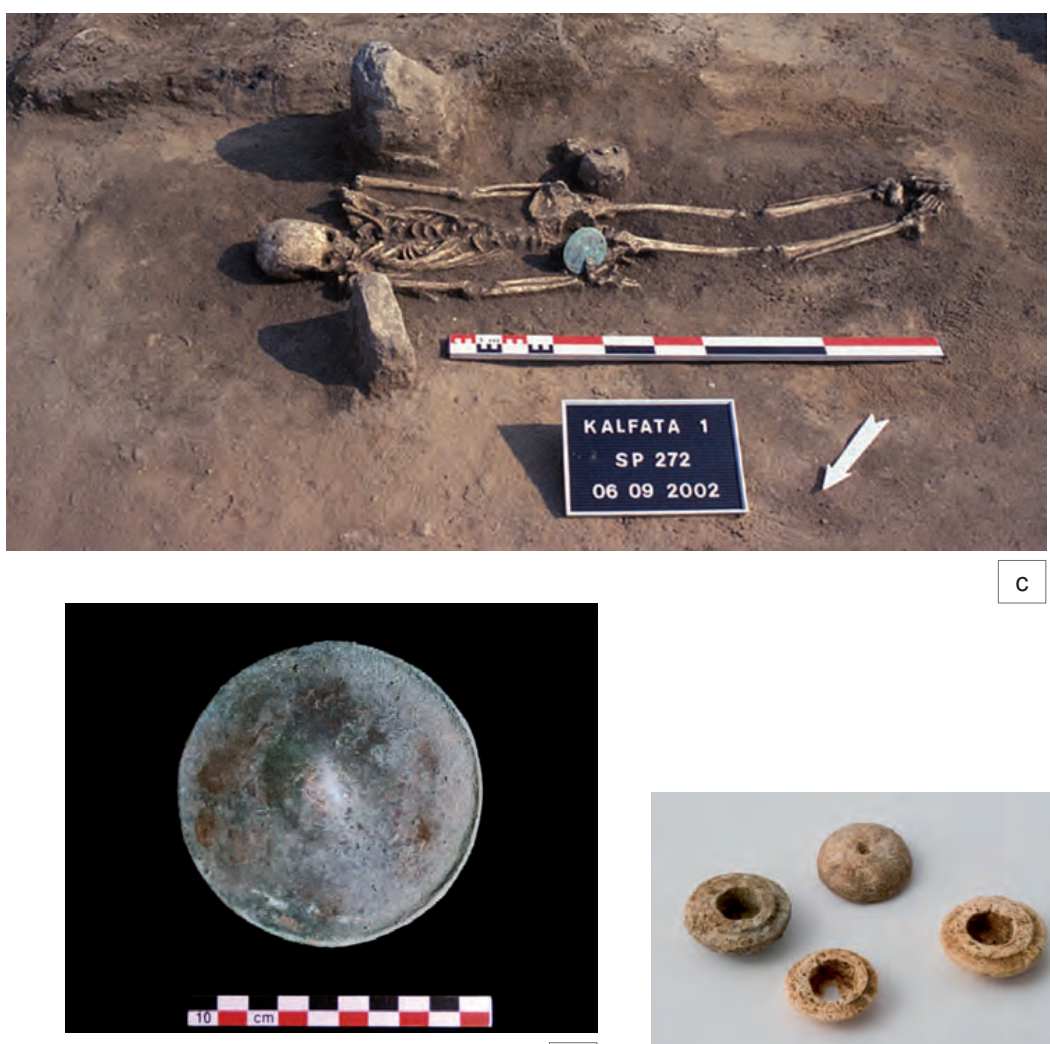

C

e
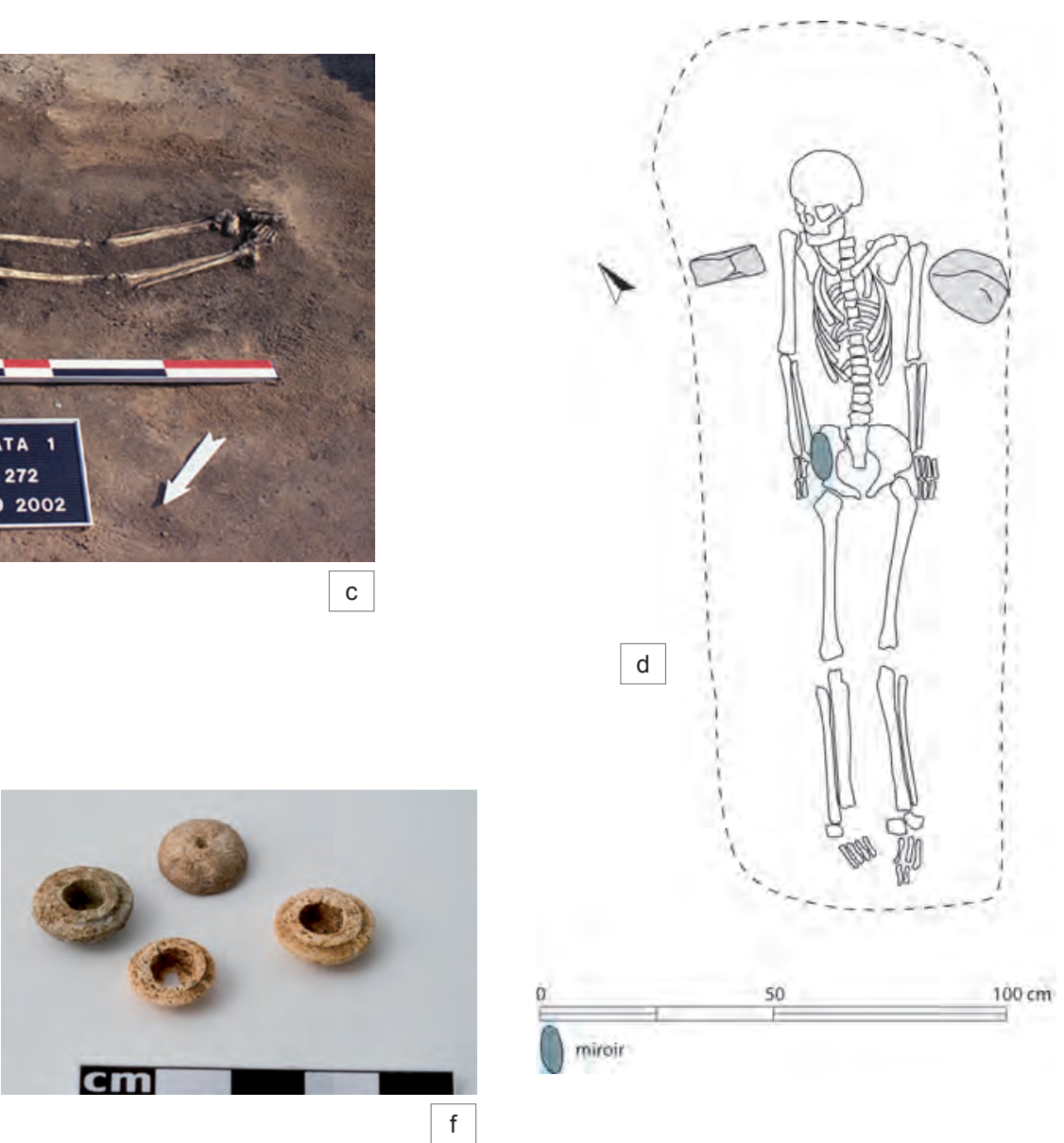
Planche 21

Tombe 279

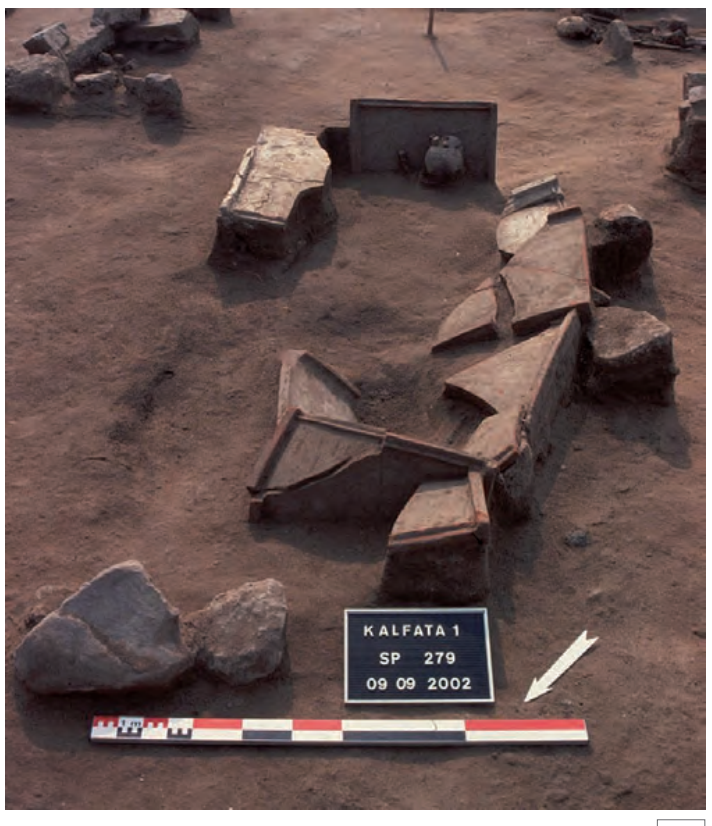

a

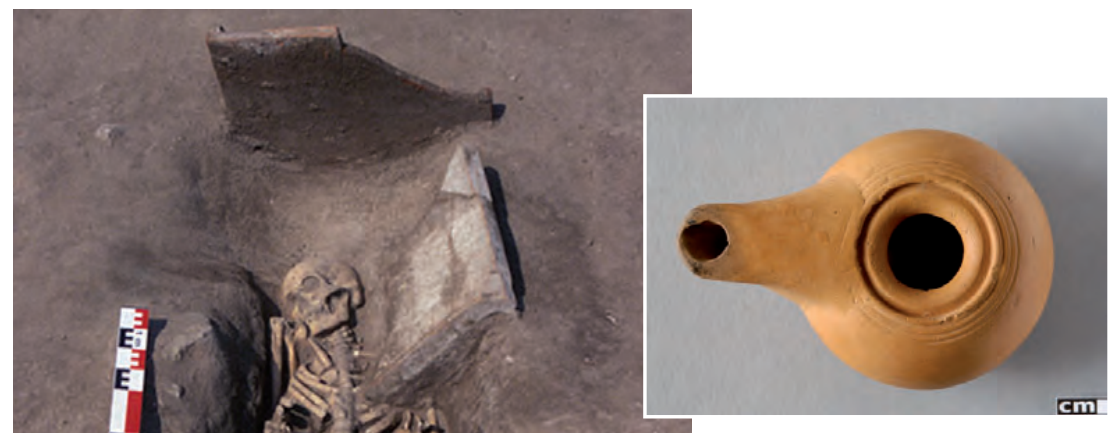

C

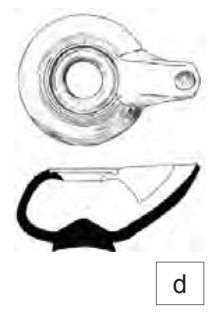

b
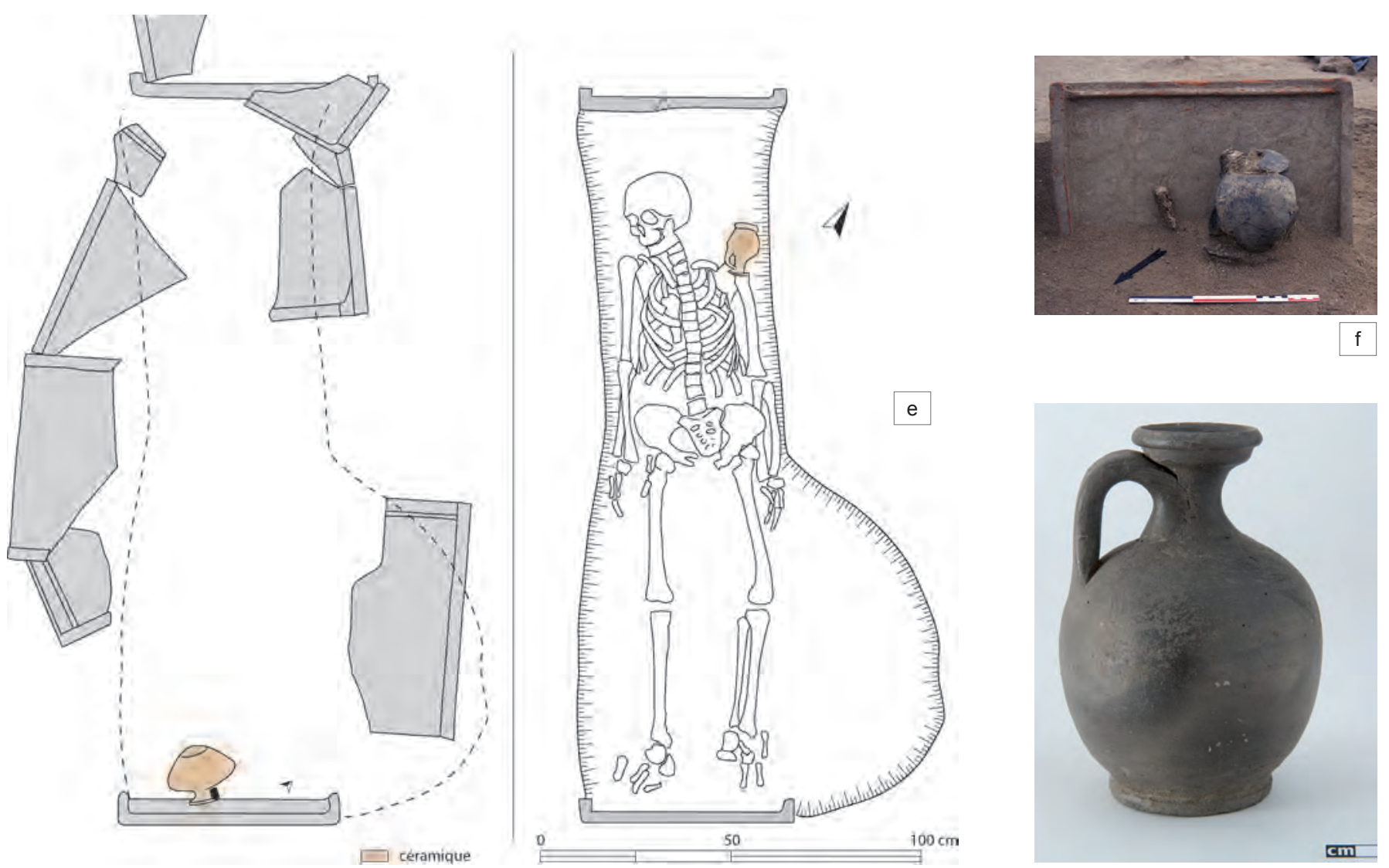

$\square$ ceramique

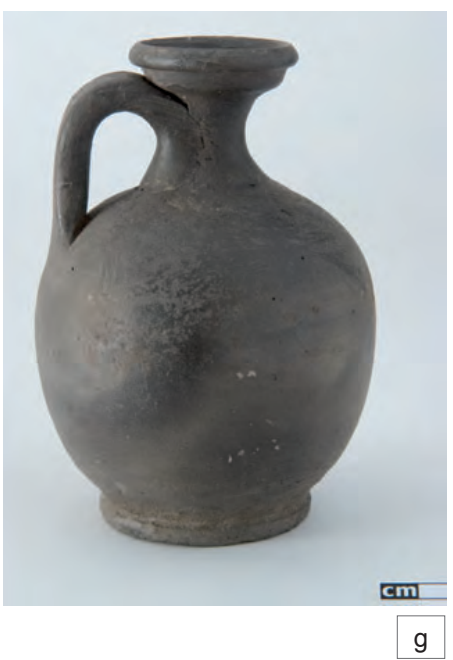


Planche 22

Tombe 283
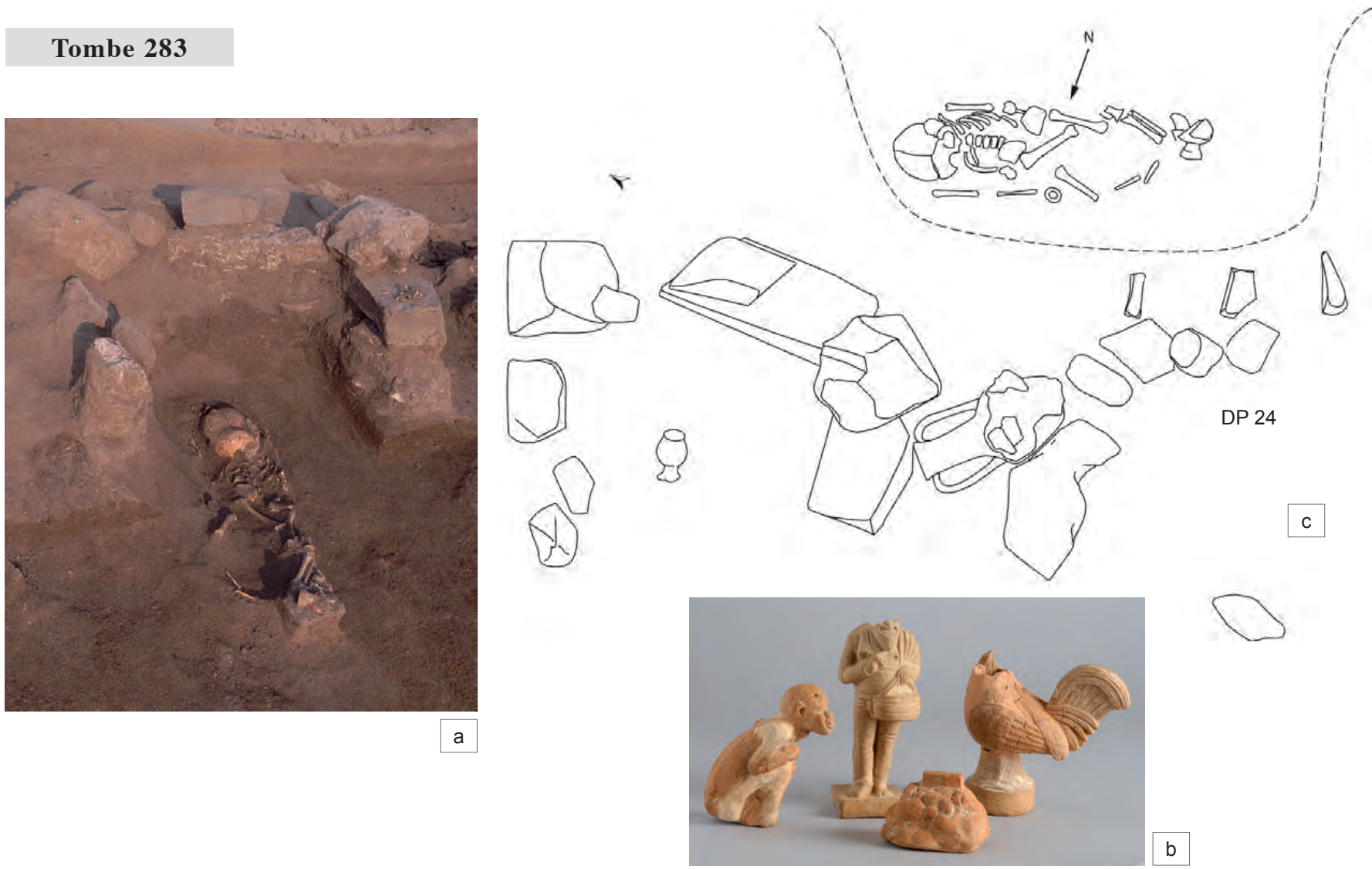

Tombe 287
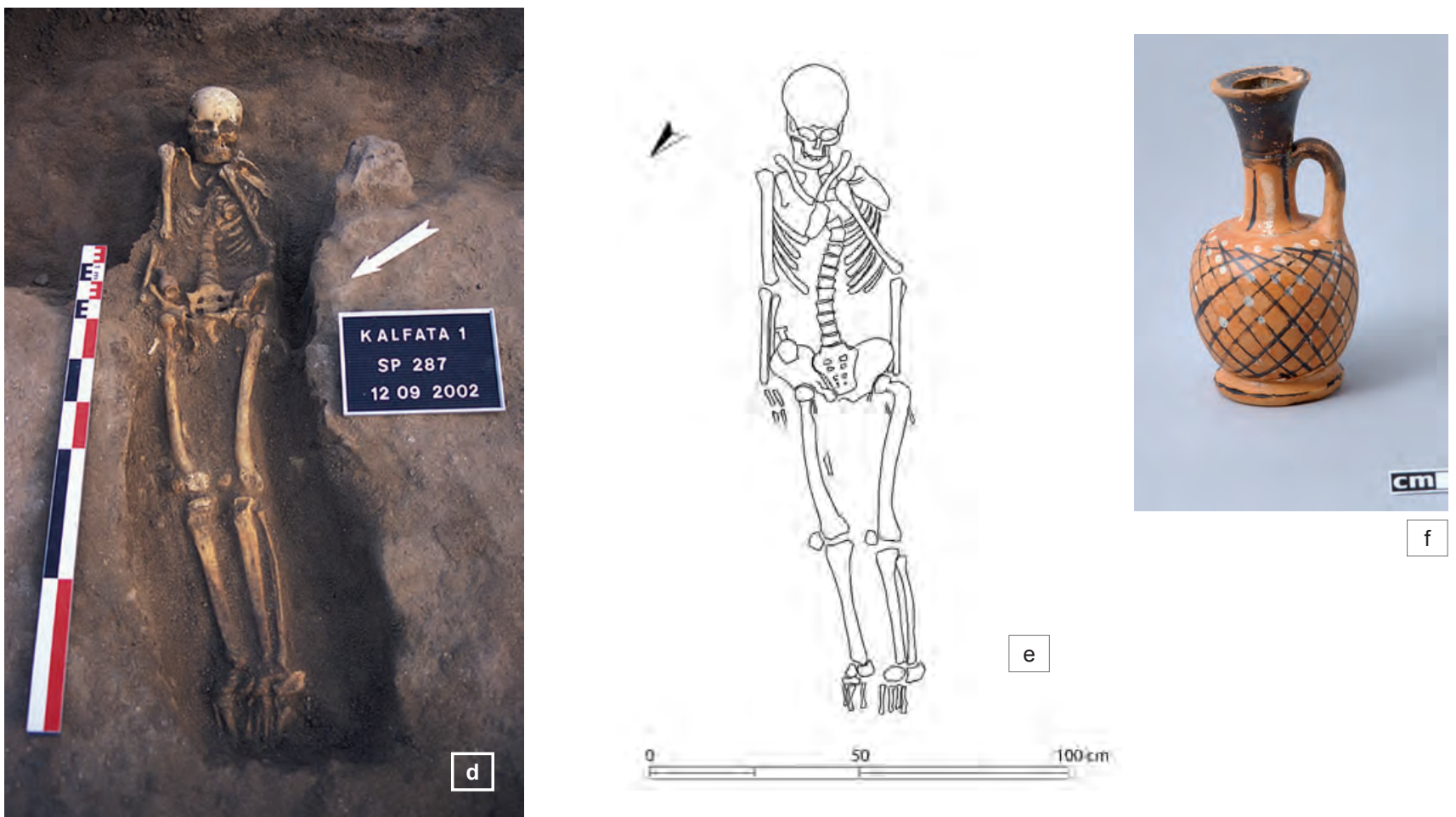
Planche 23

Tombe 289

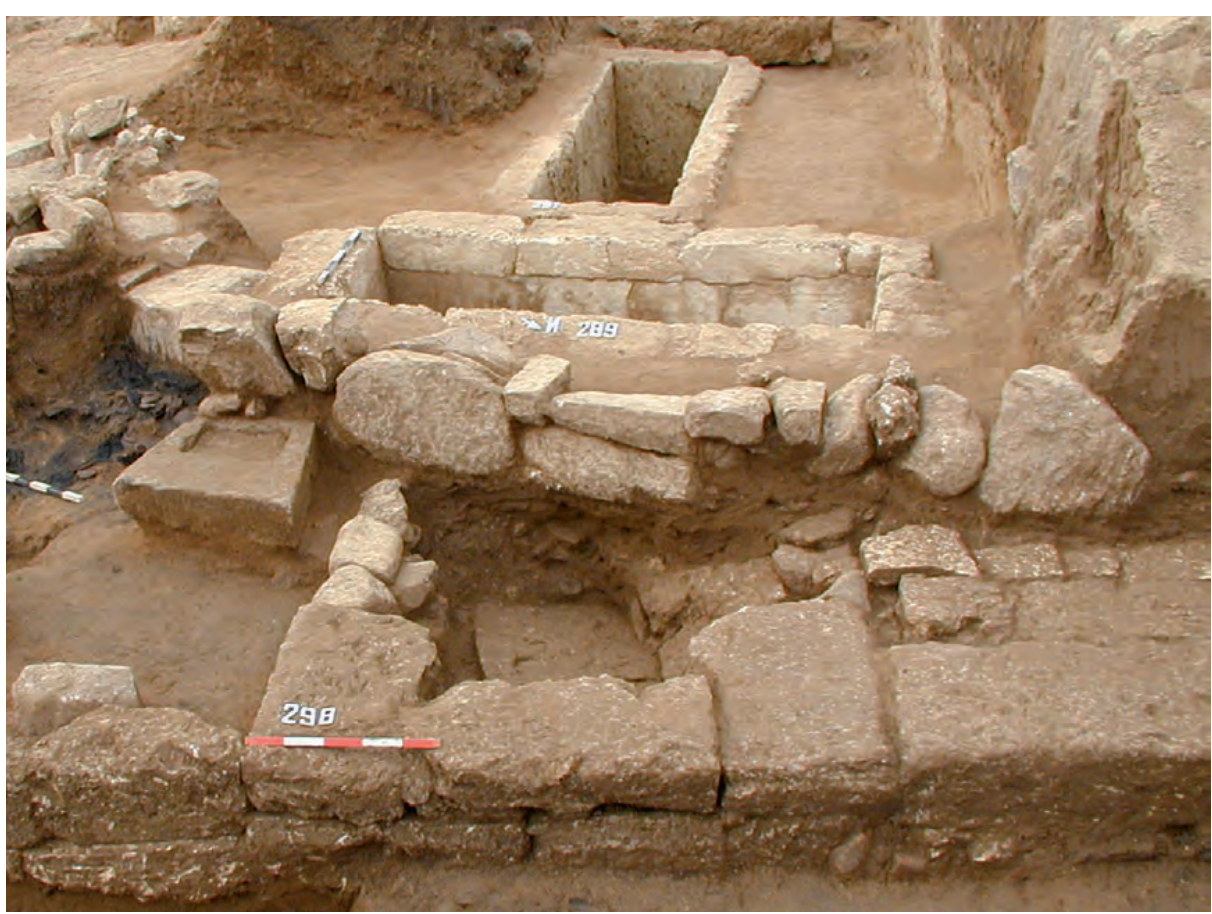

a

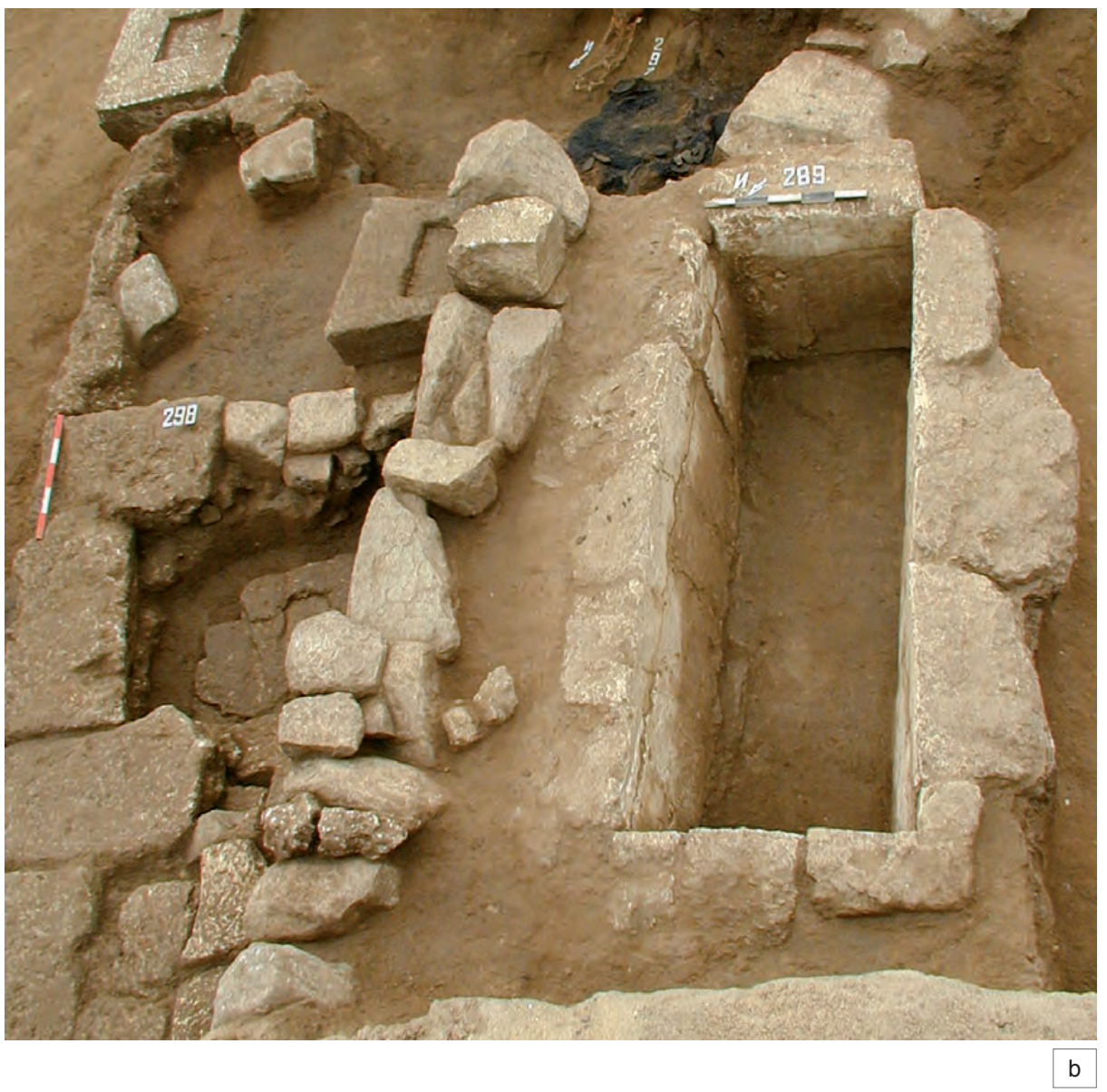

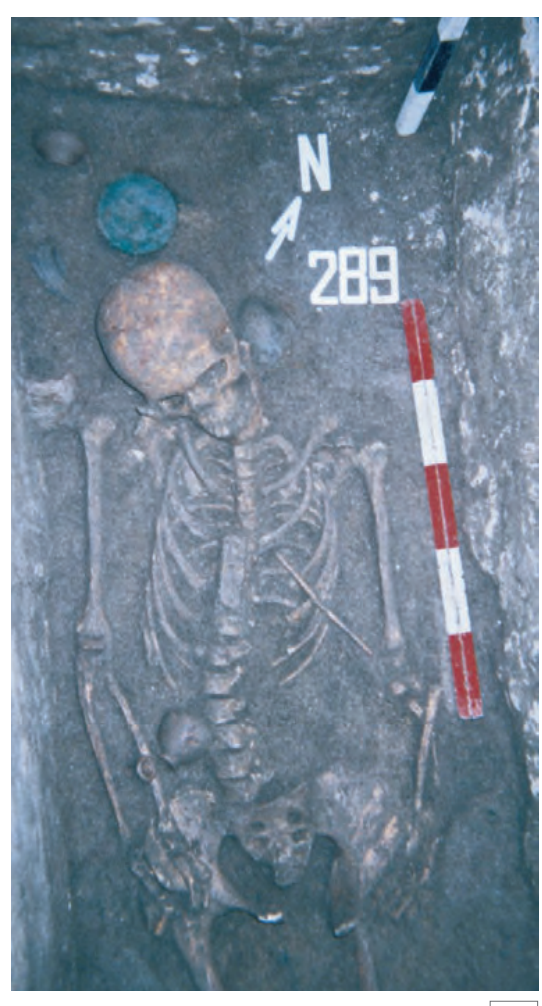

C
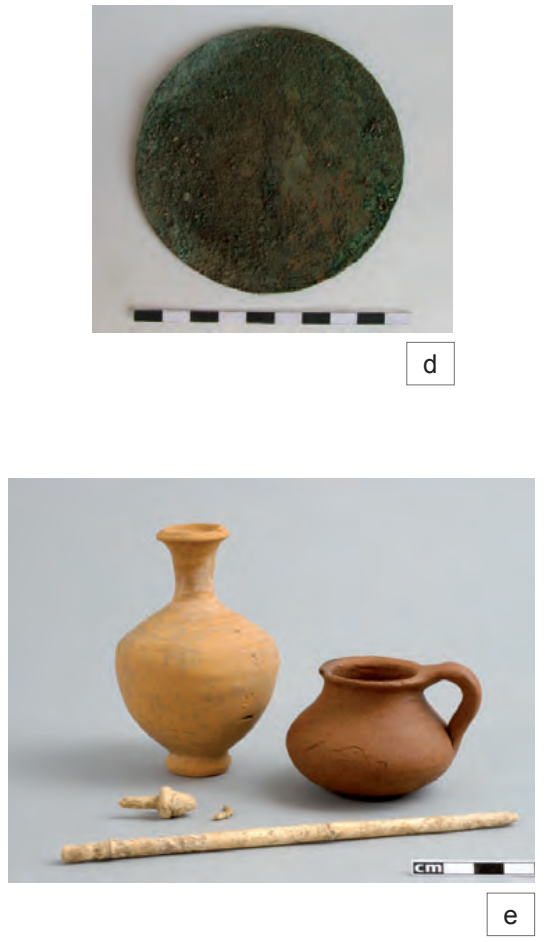
Planche 24

Tombe 291
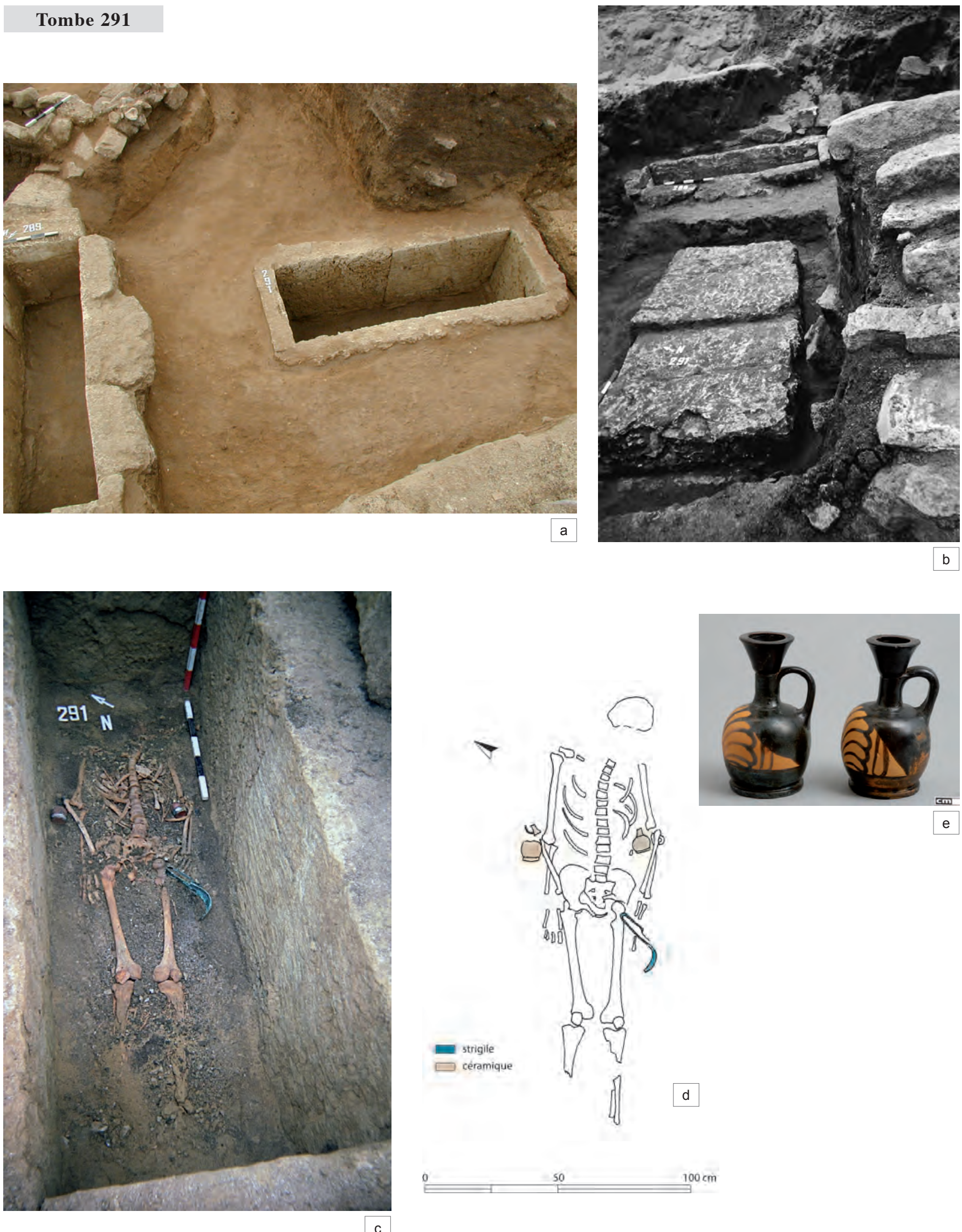
Tombe 296
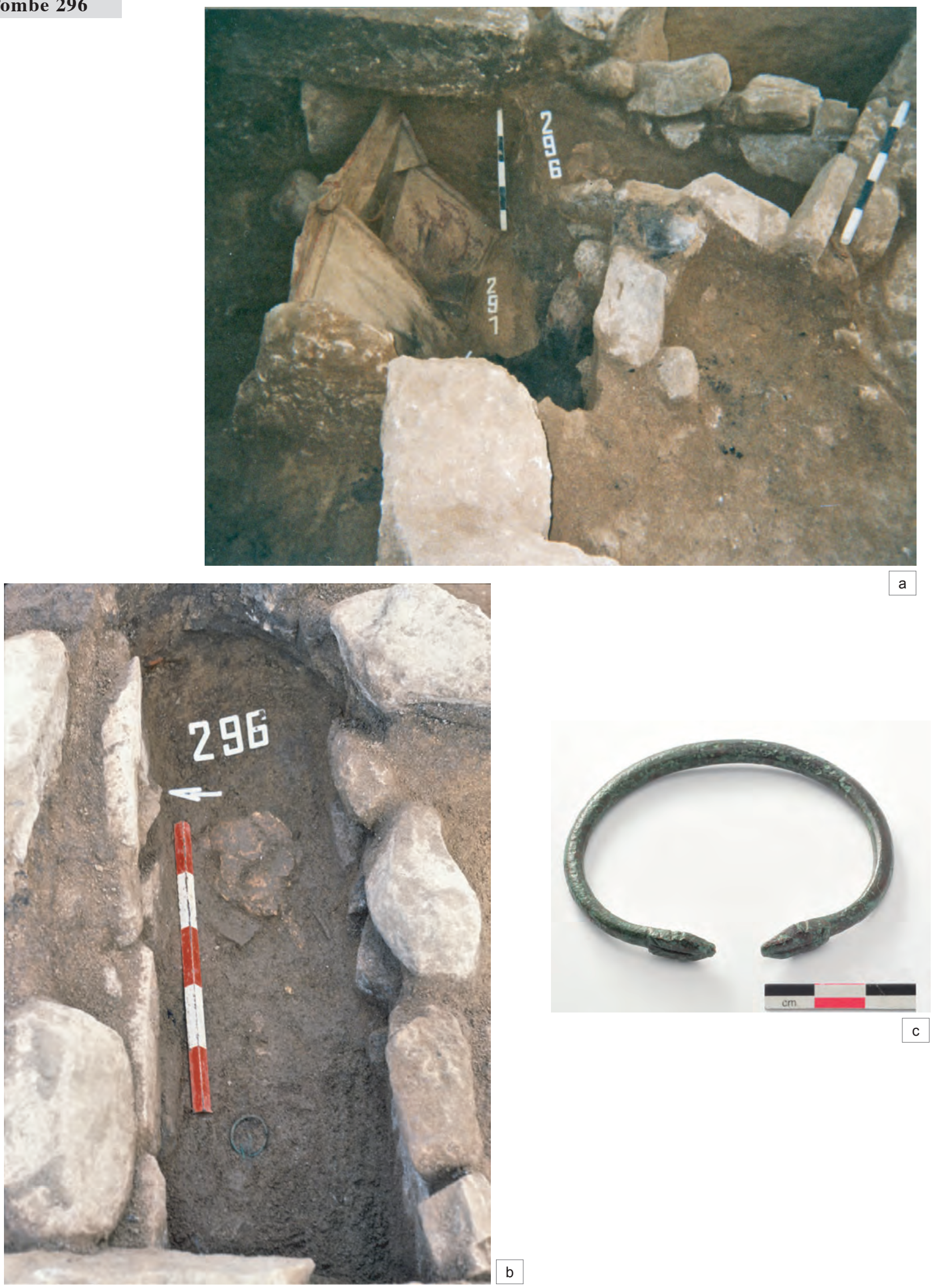
Planche 26

Tombe 297
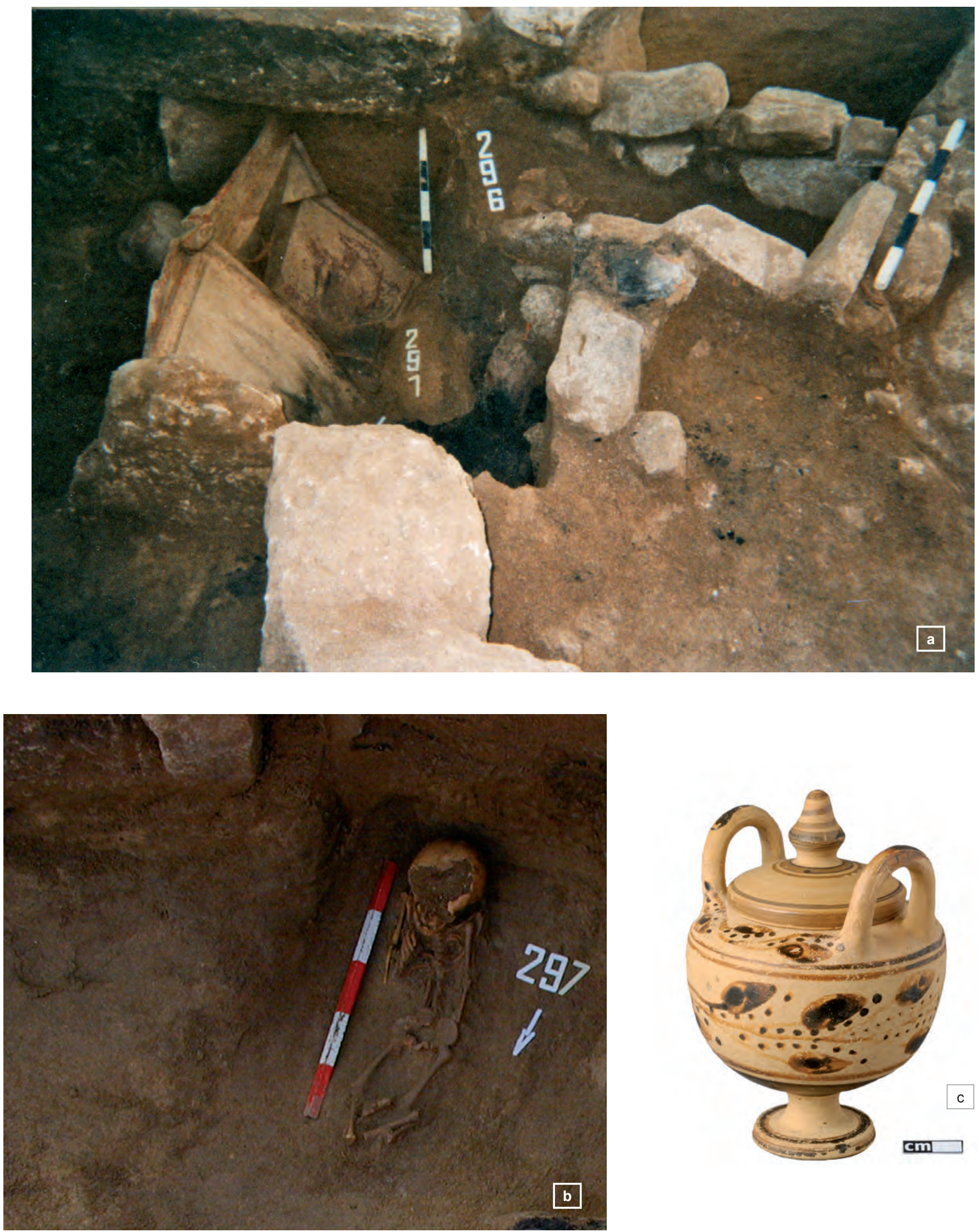
Tombe 300
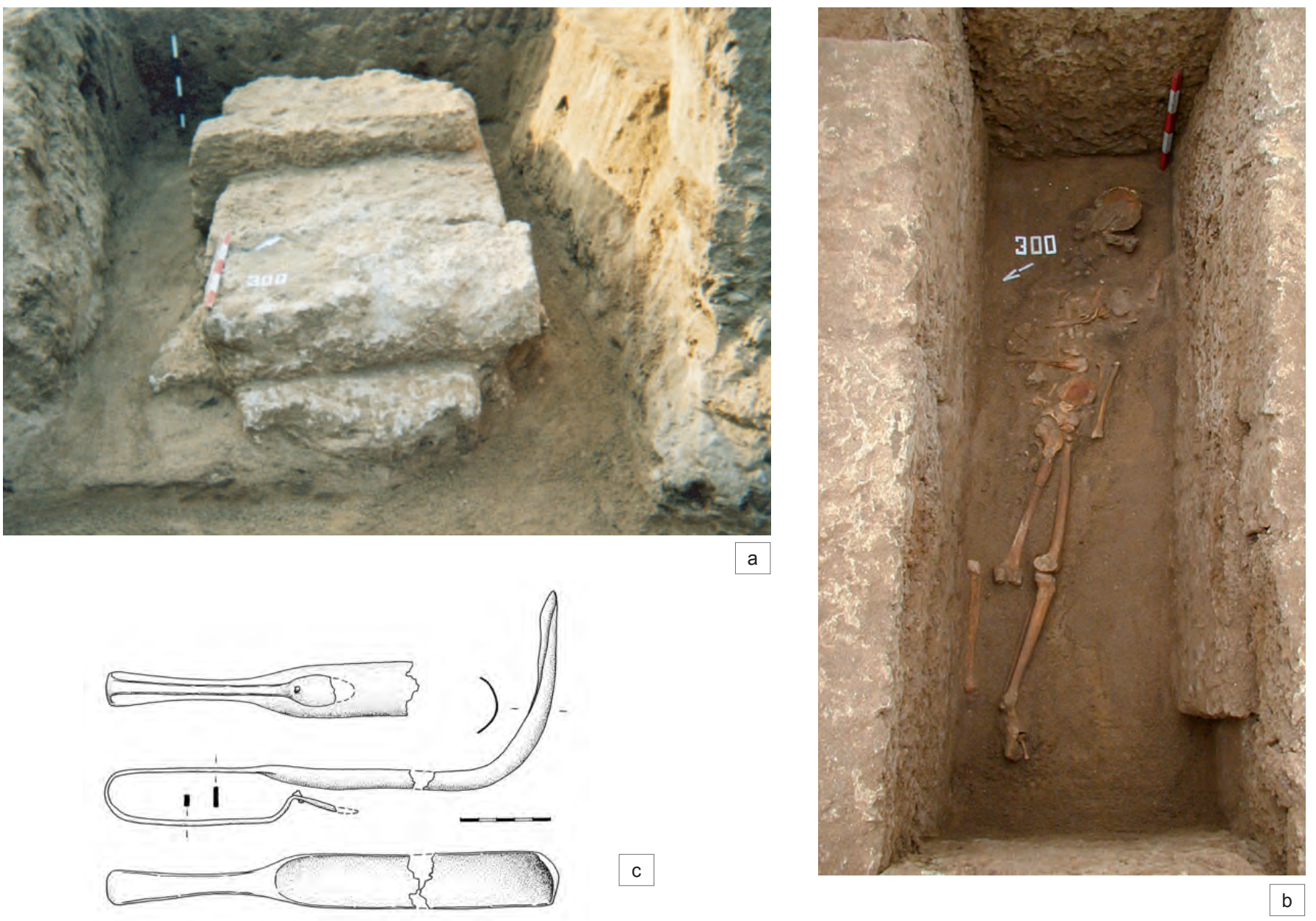

Tombe 303

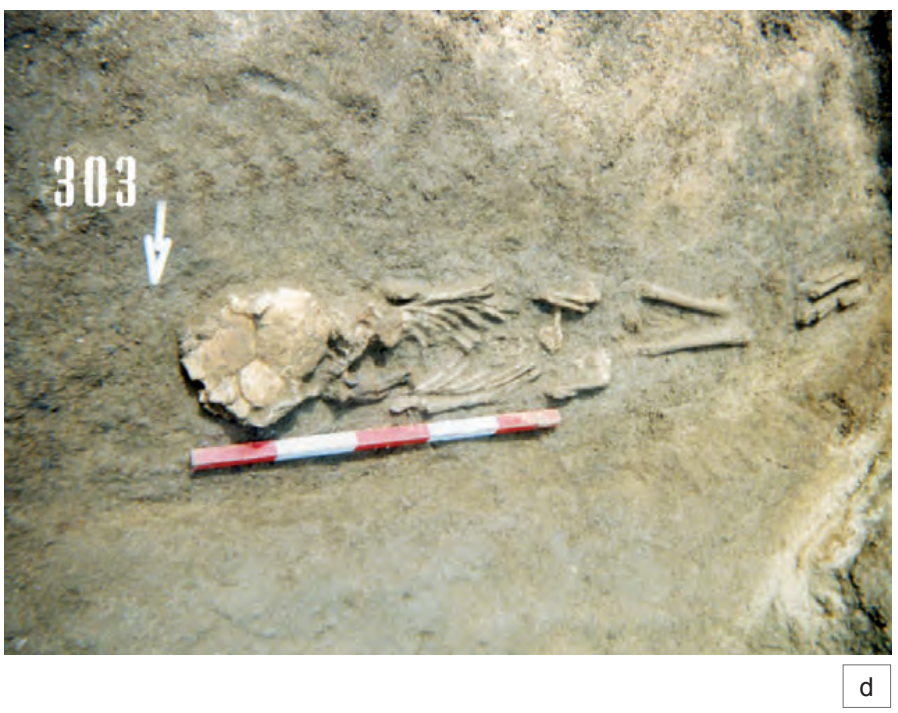


Planche 28

Tombe 313
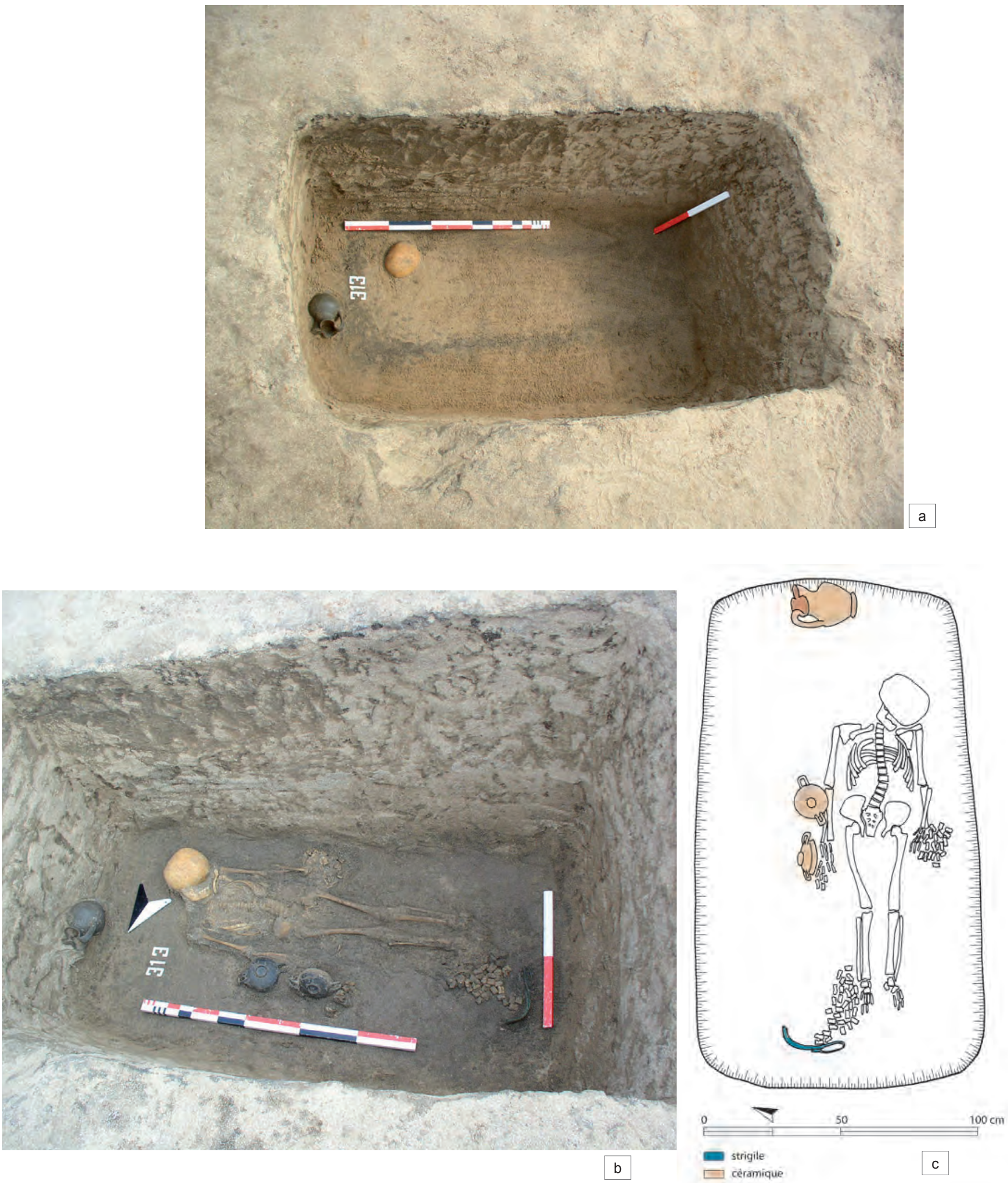
Planche 29

Tombe 315

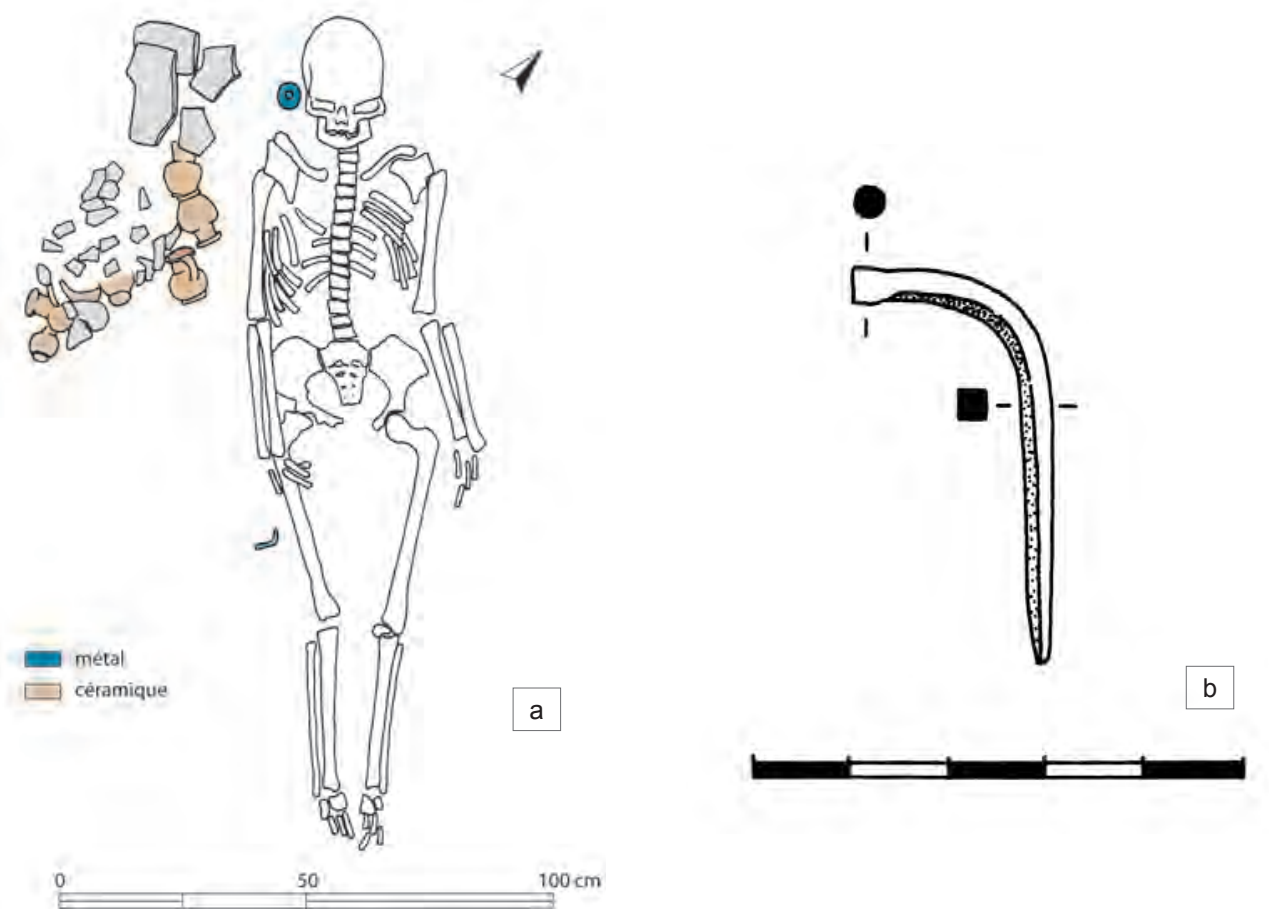

Tombe 320
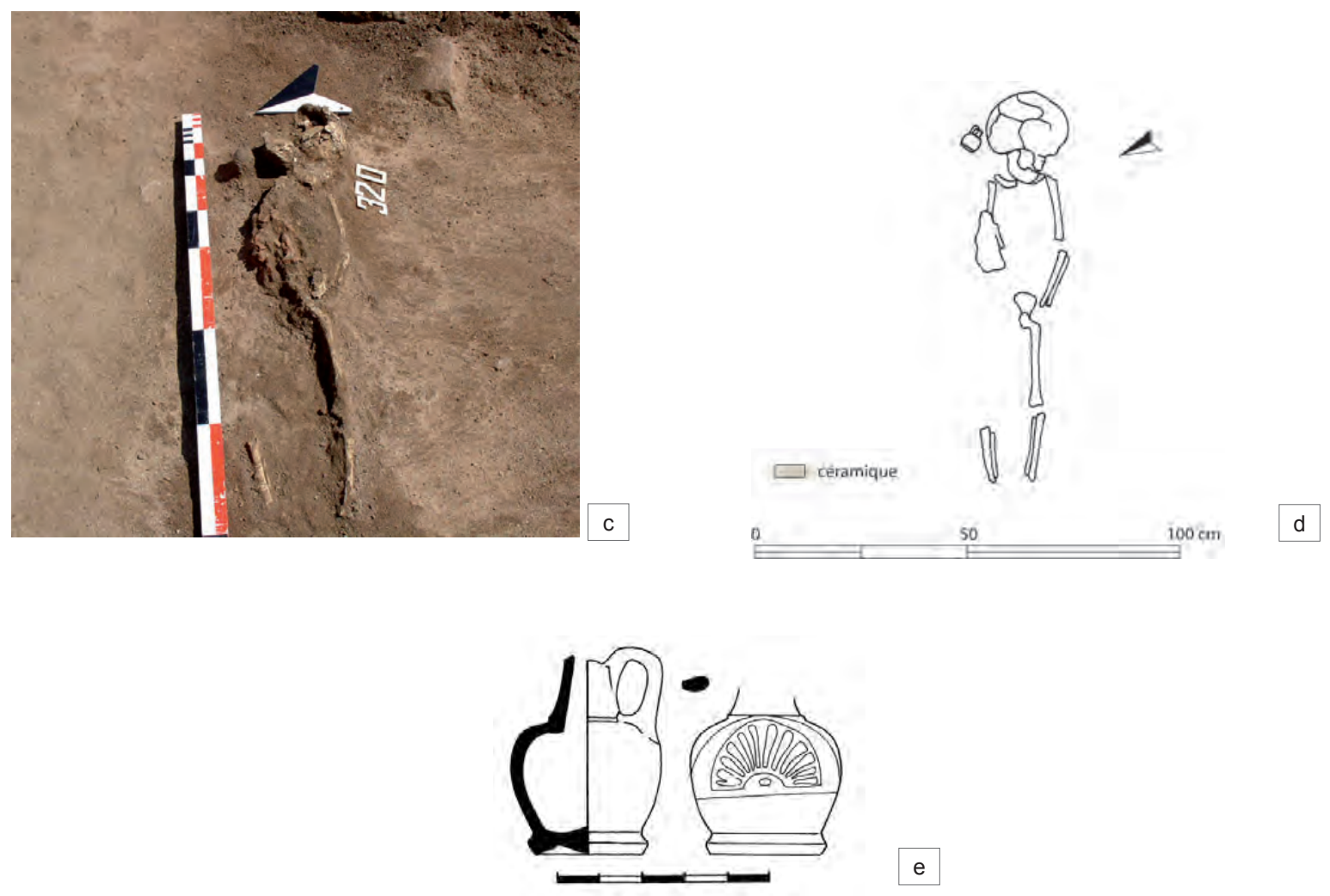
Planche 30

Tombe 321/322
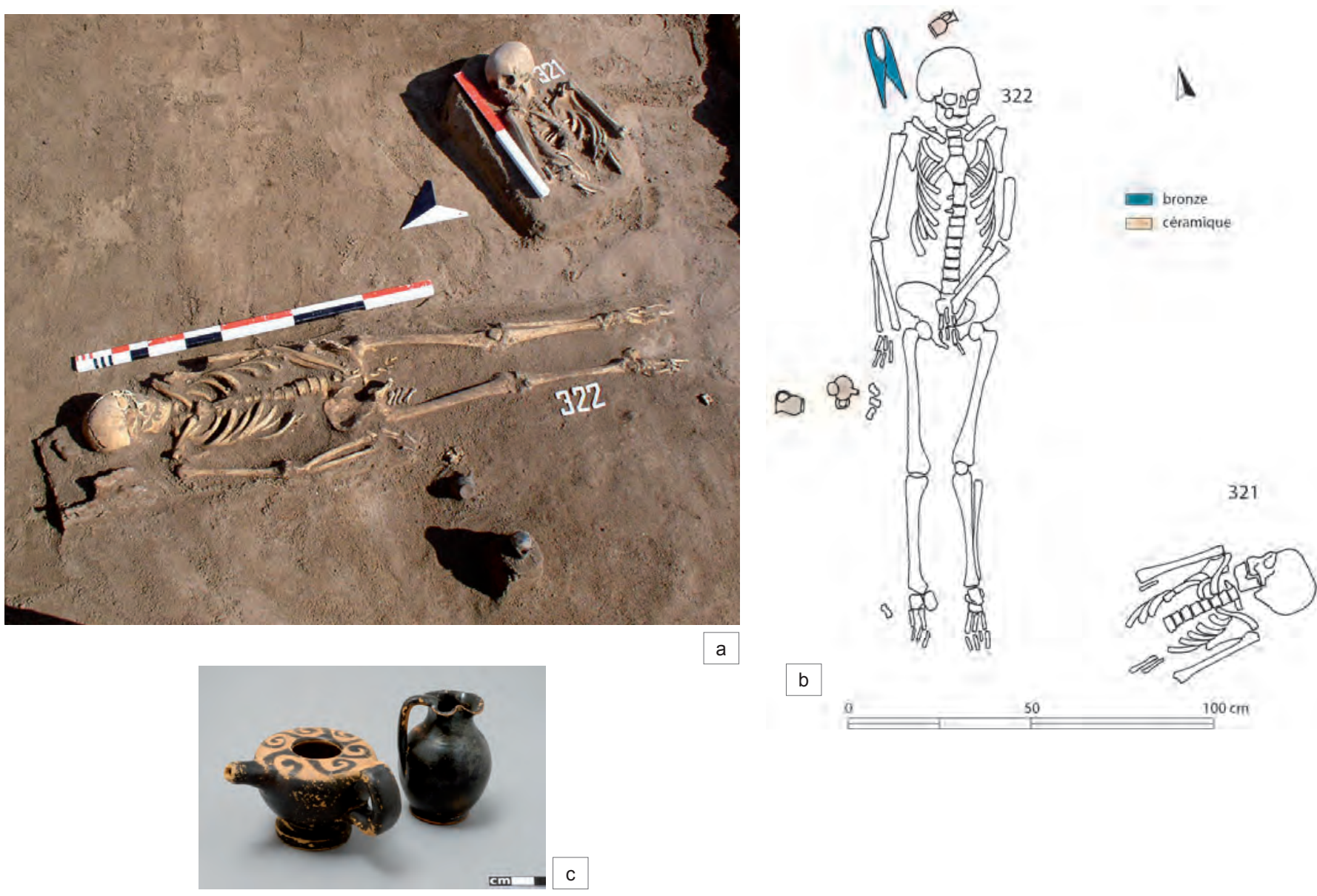

Tombe 324
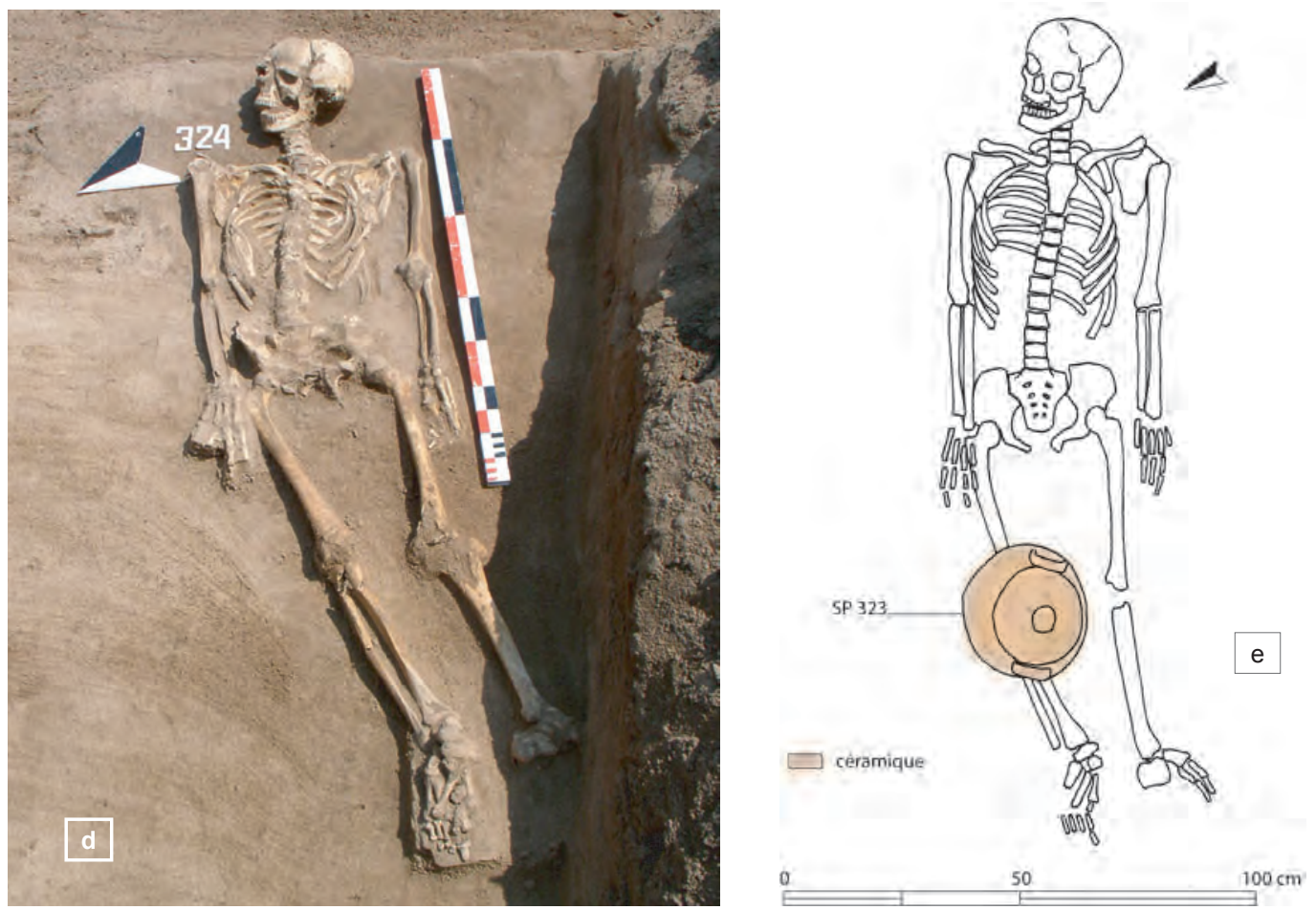
Tombe 325

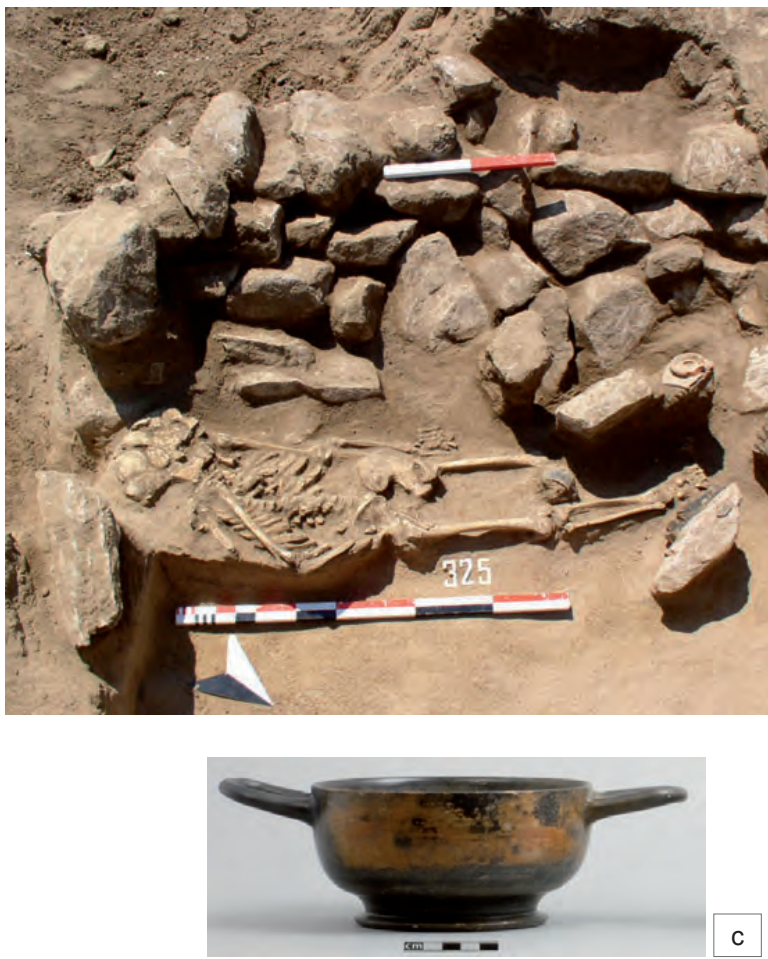

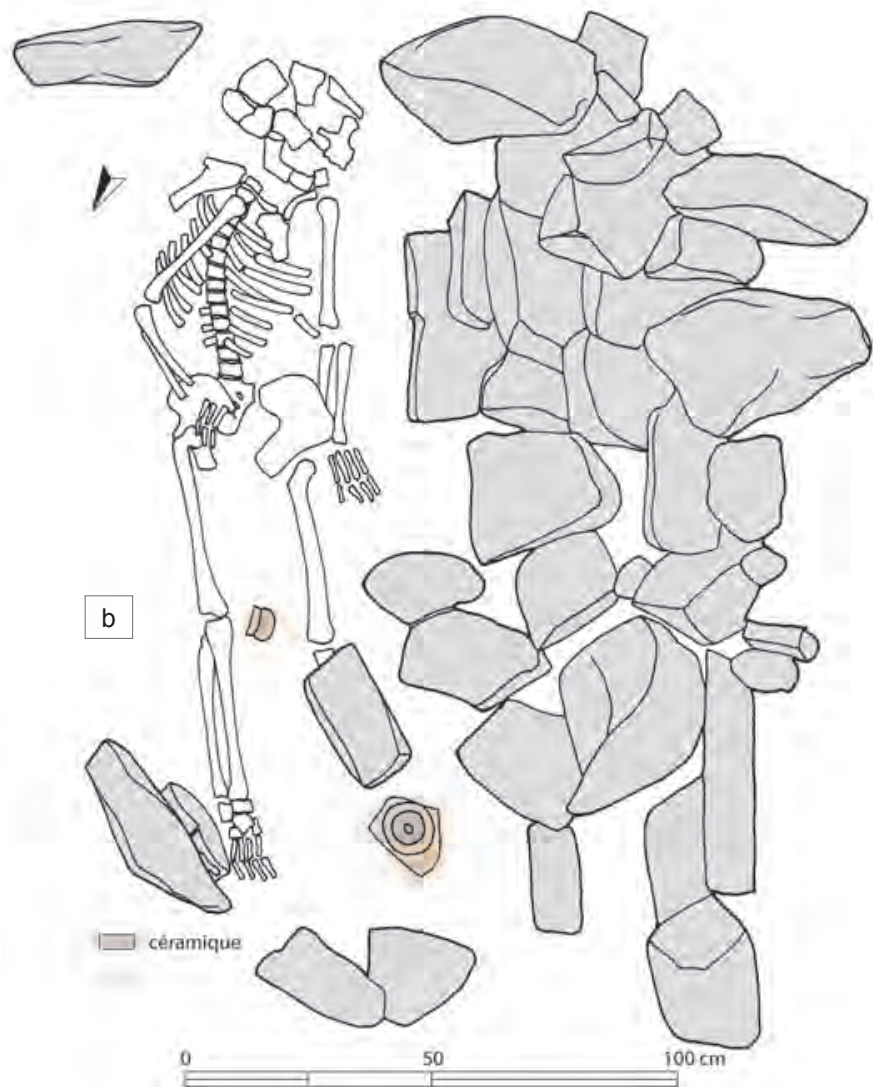

Tombe 326

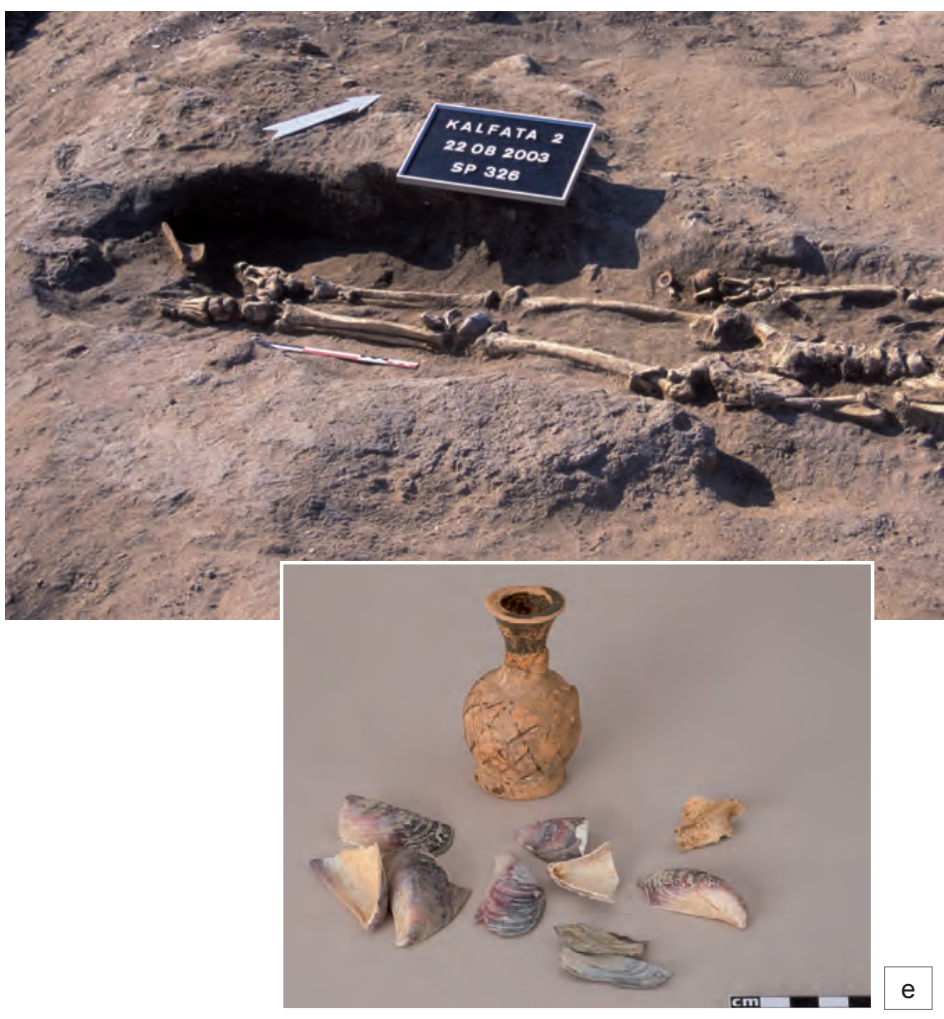

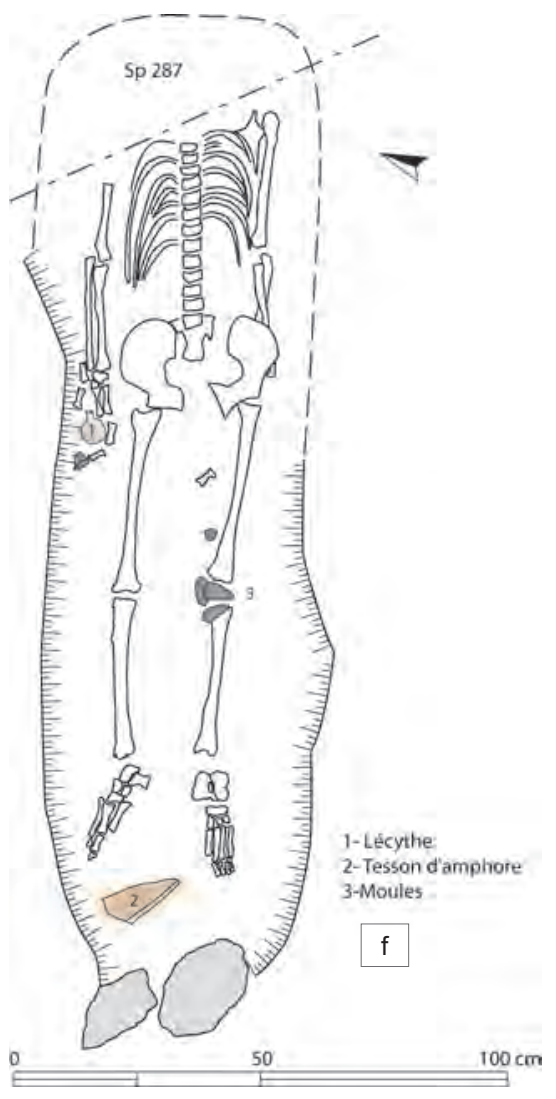


Planche 32

Tombe 327
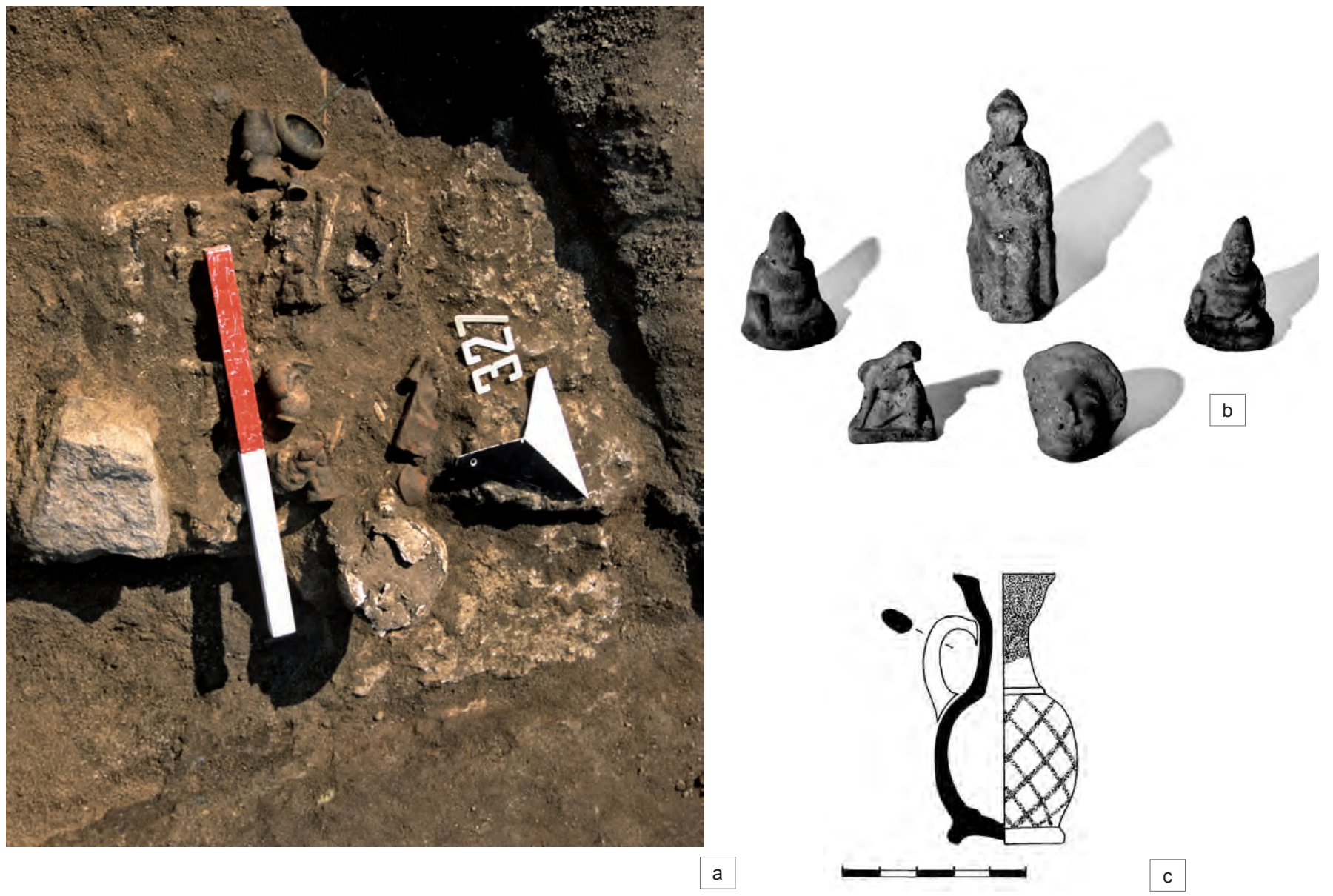

C

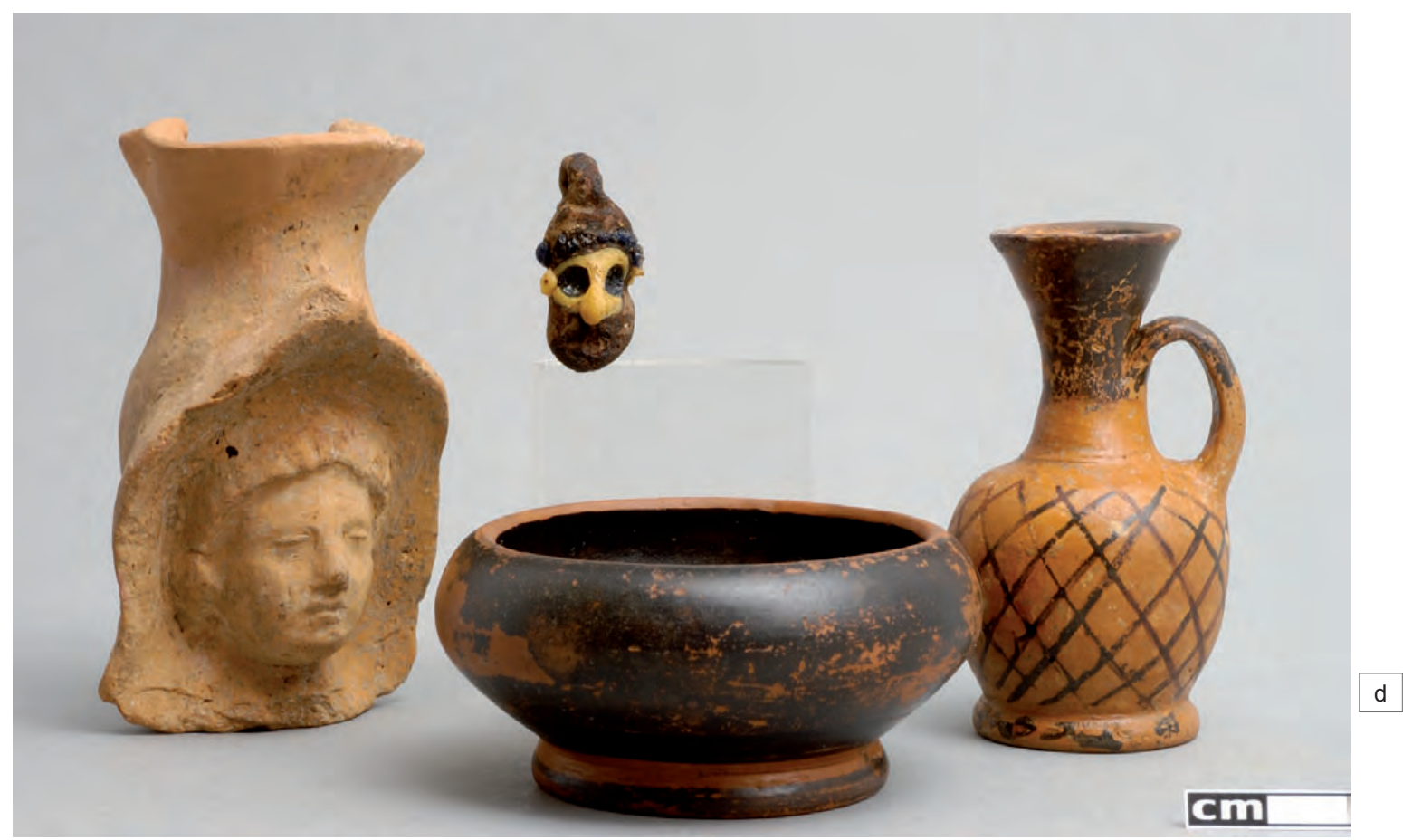


Planche 33

Tombe 328
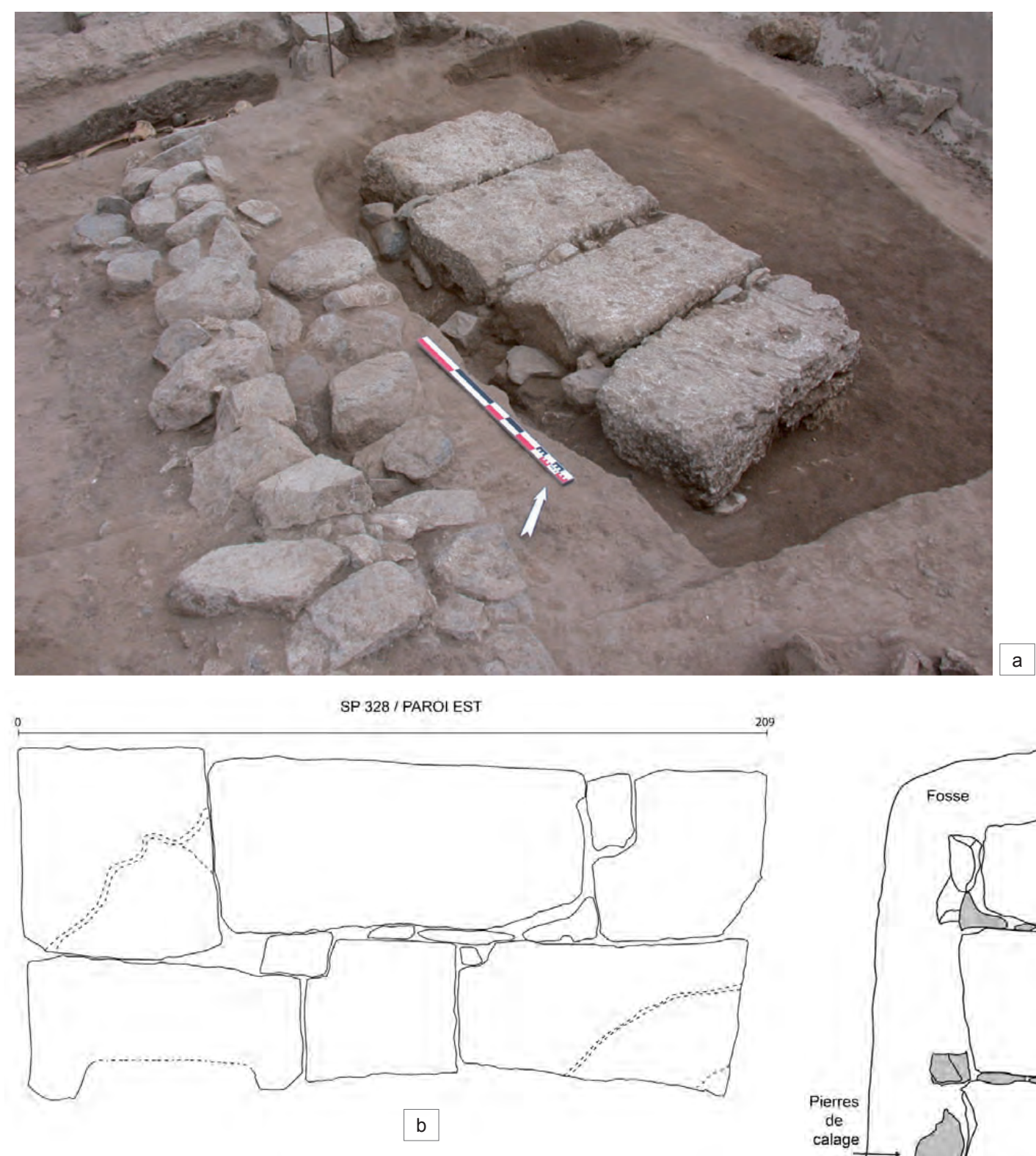

209

SP 328 / PAROI OUEST
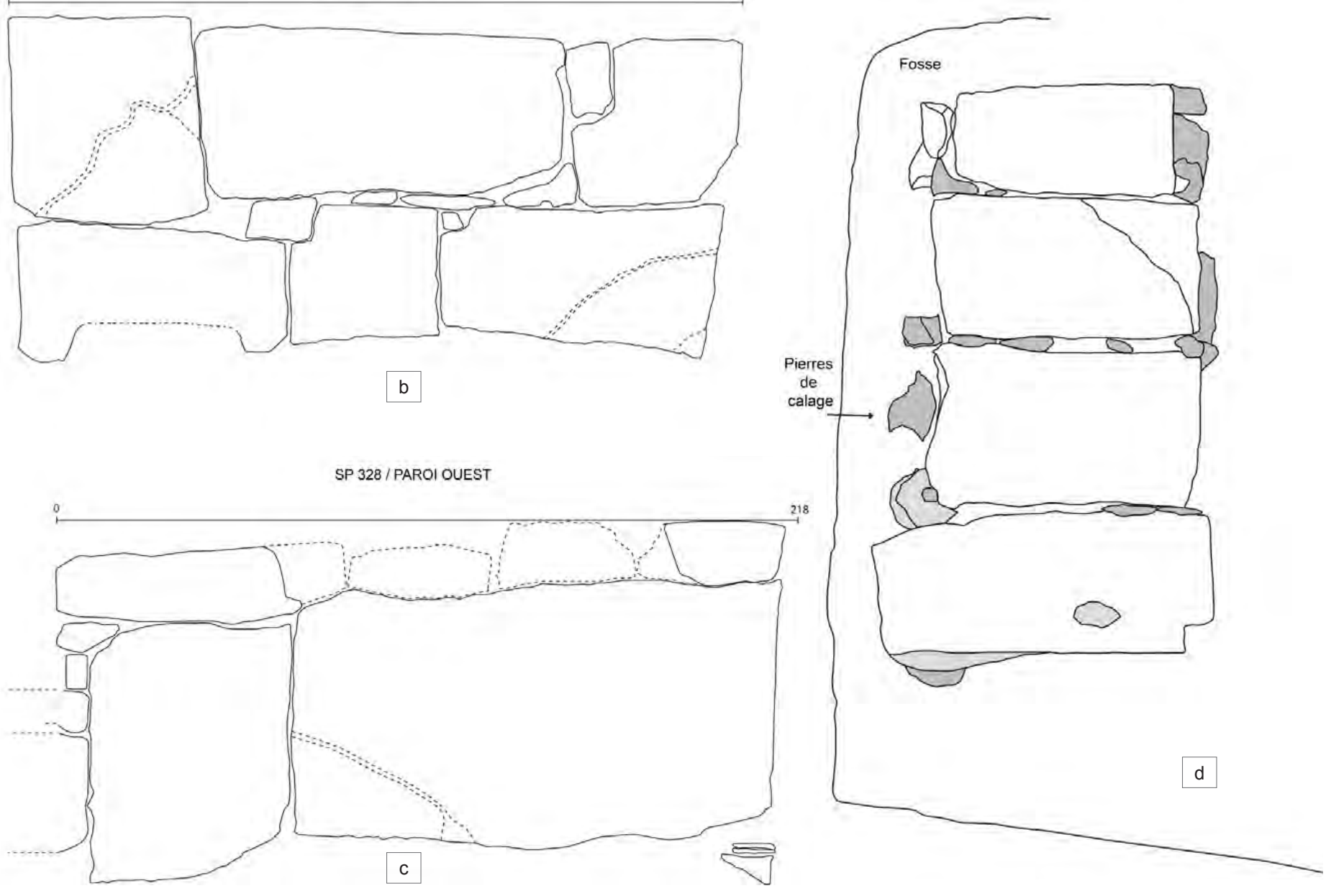


\section{Planche 34}

\section{Tombe 328}
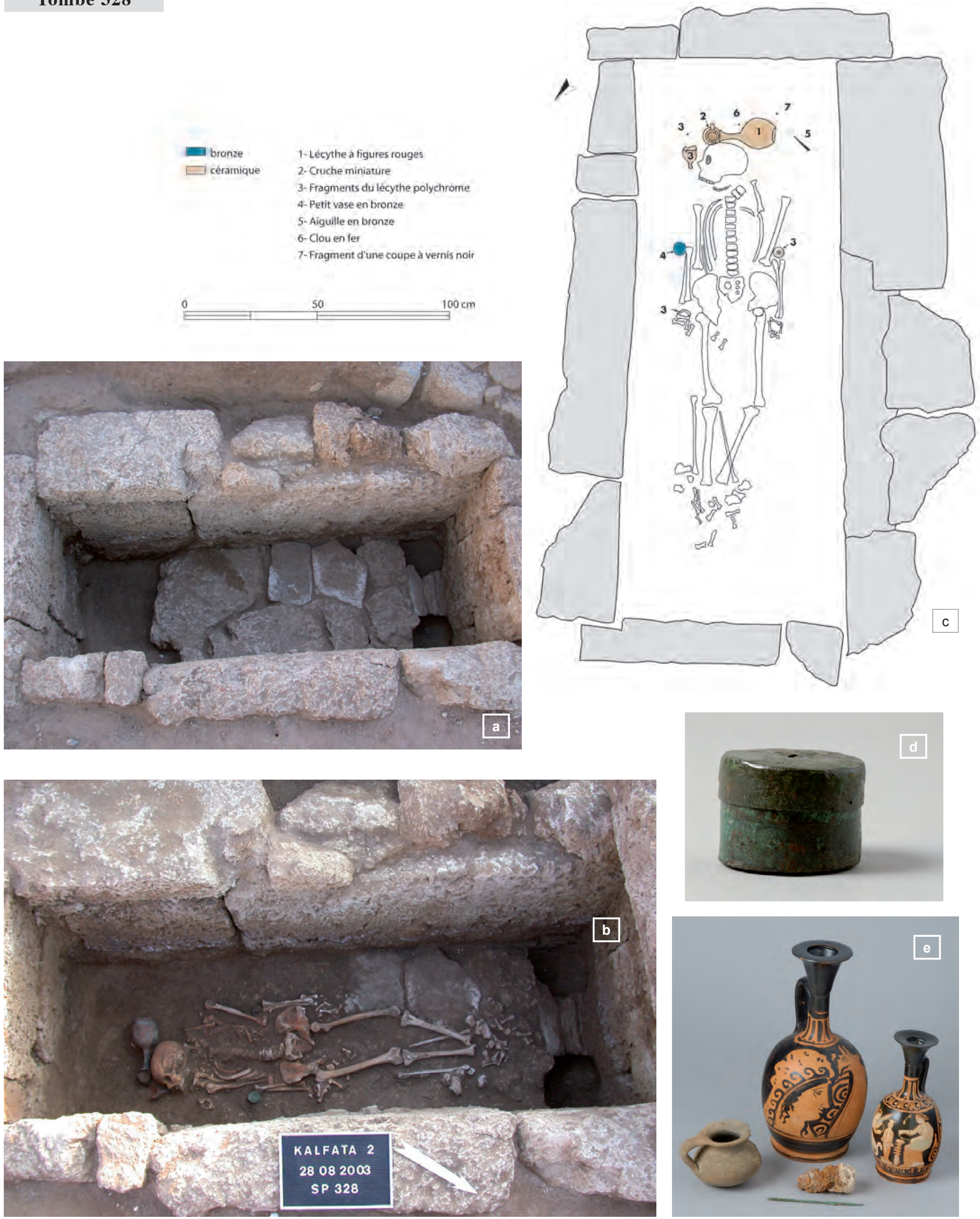

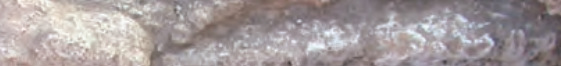

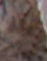


Planche 35

Tombe 329
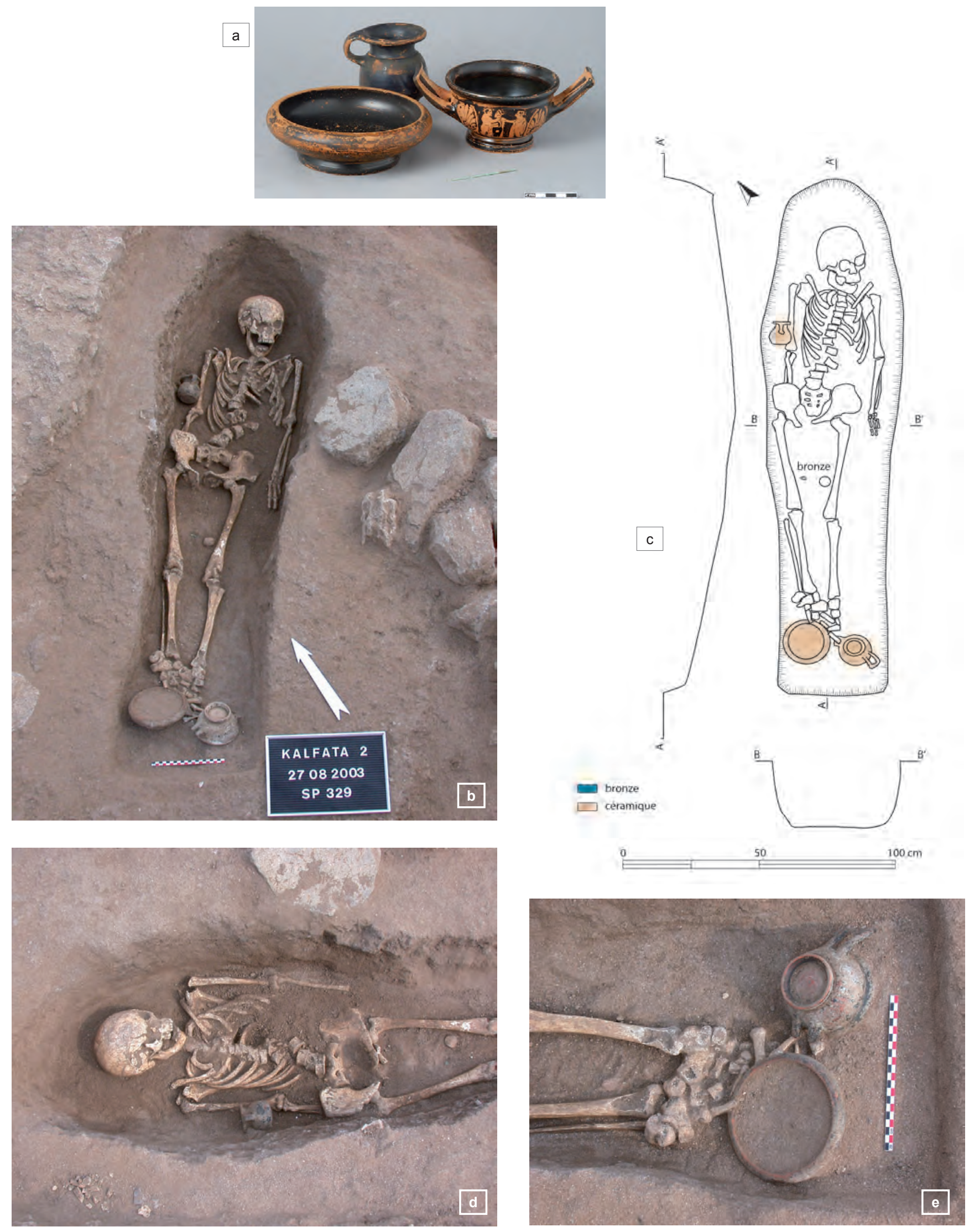
Planche 36

Tombe 330
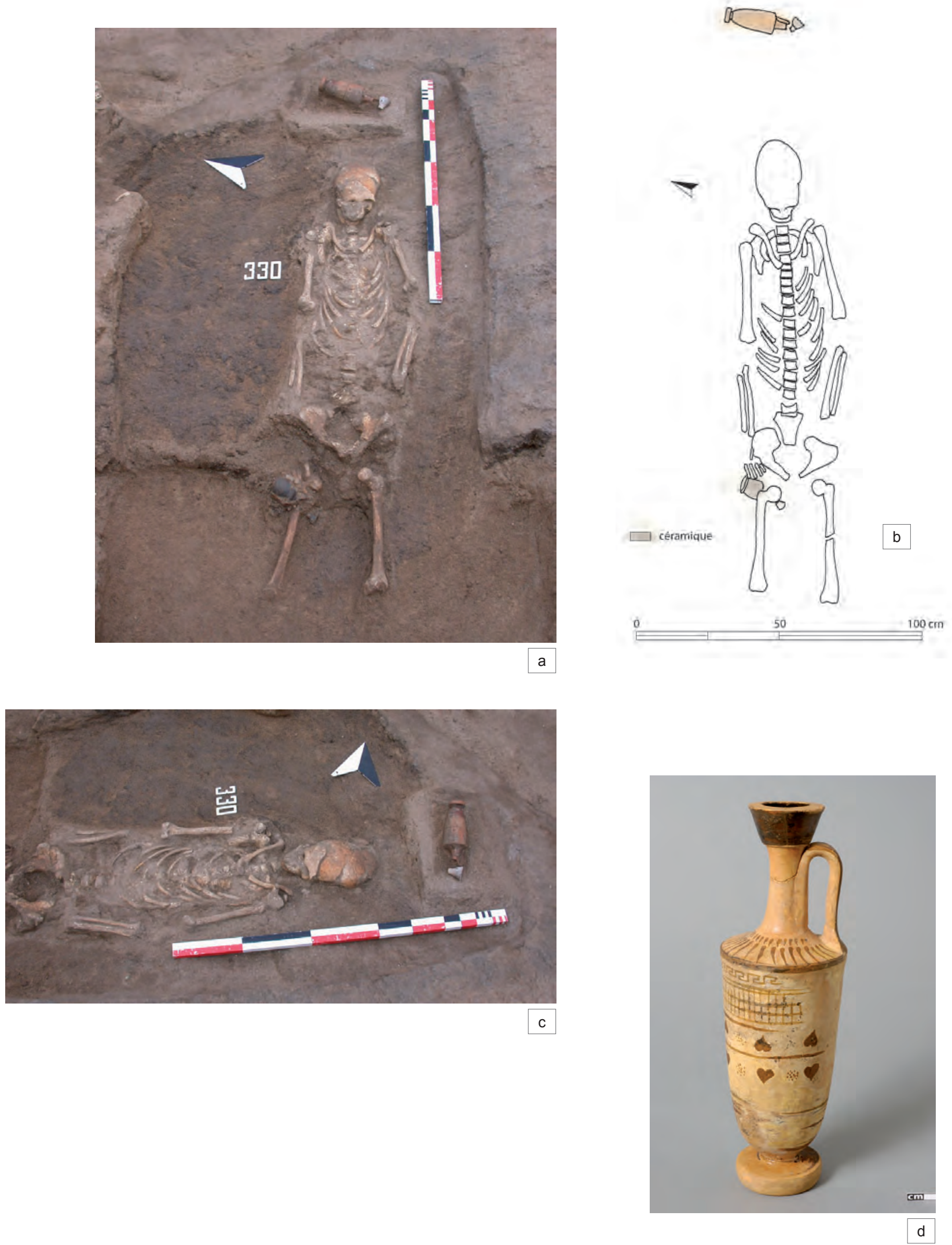
Planche 37

Tombe 331
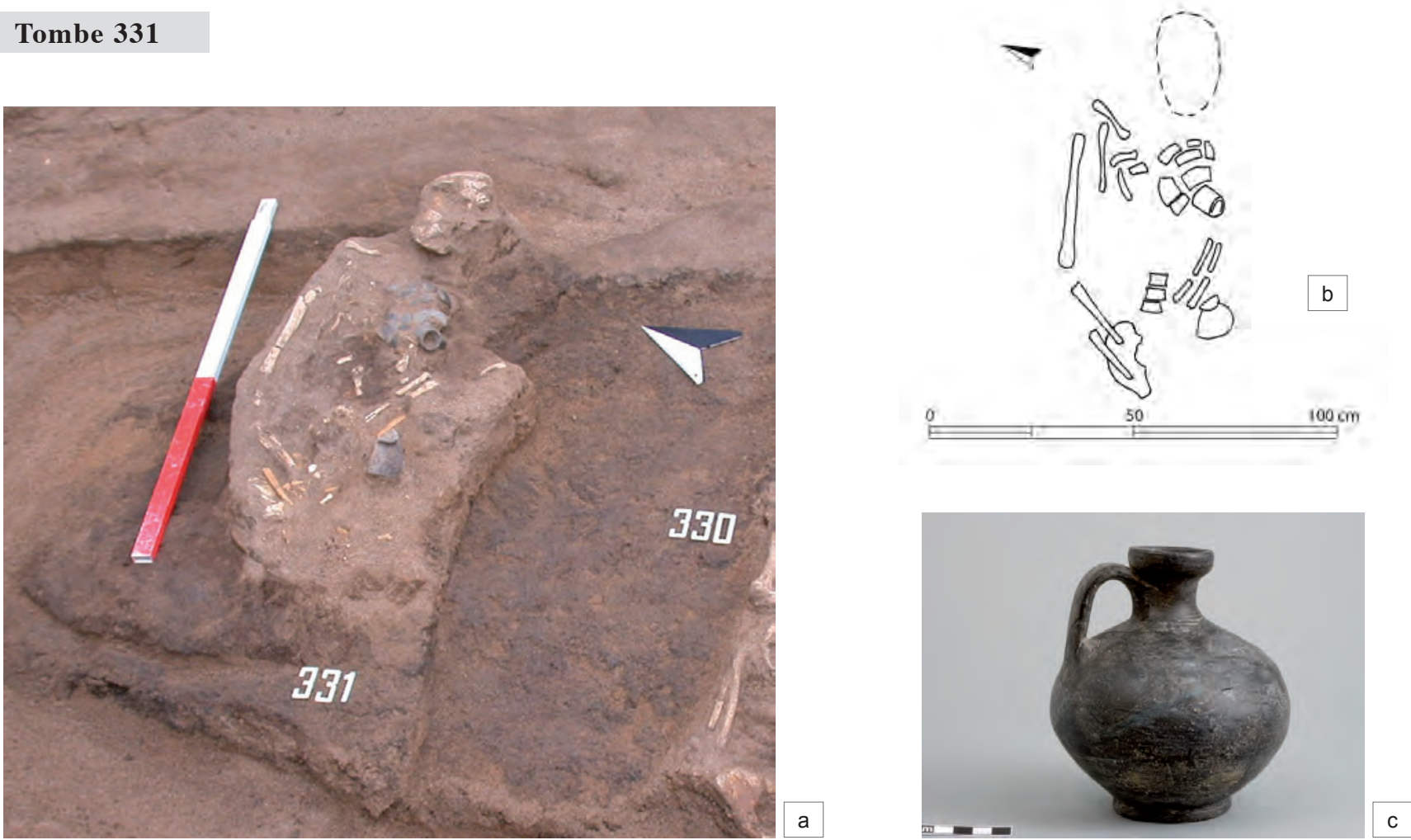

Tombe 332
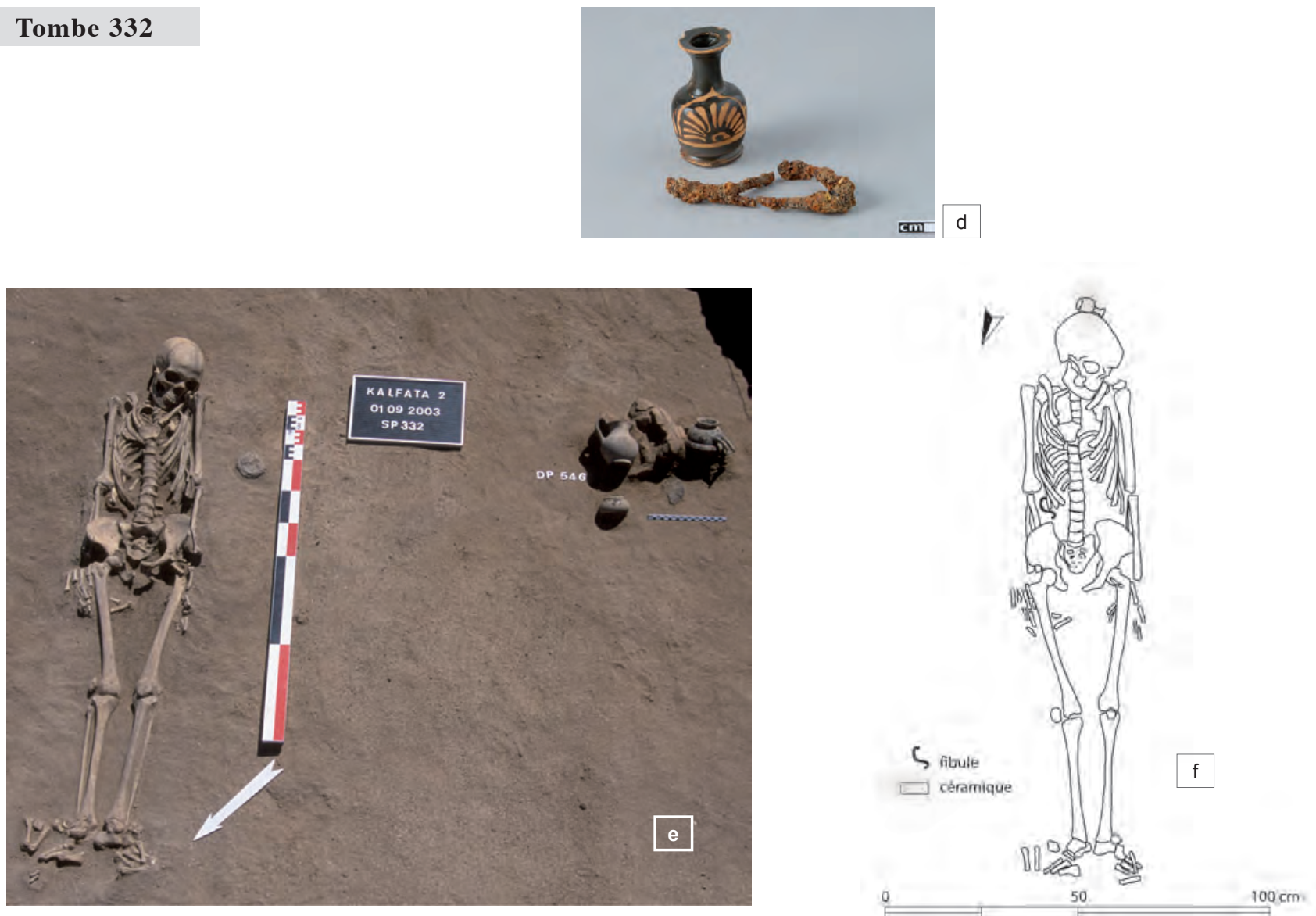
Planche 38

Tombe 333
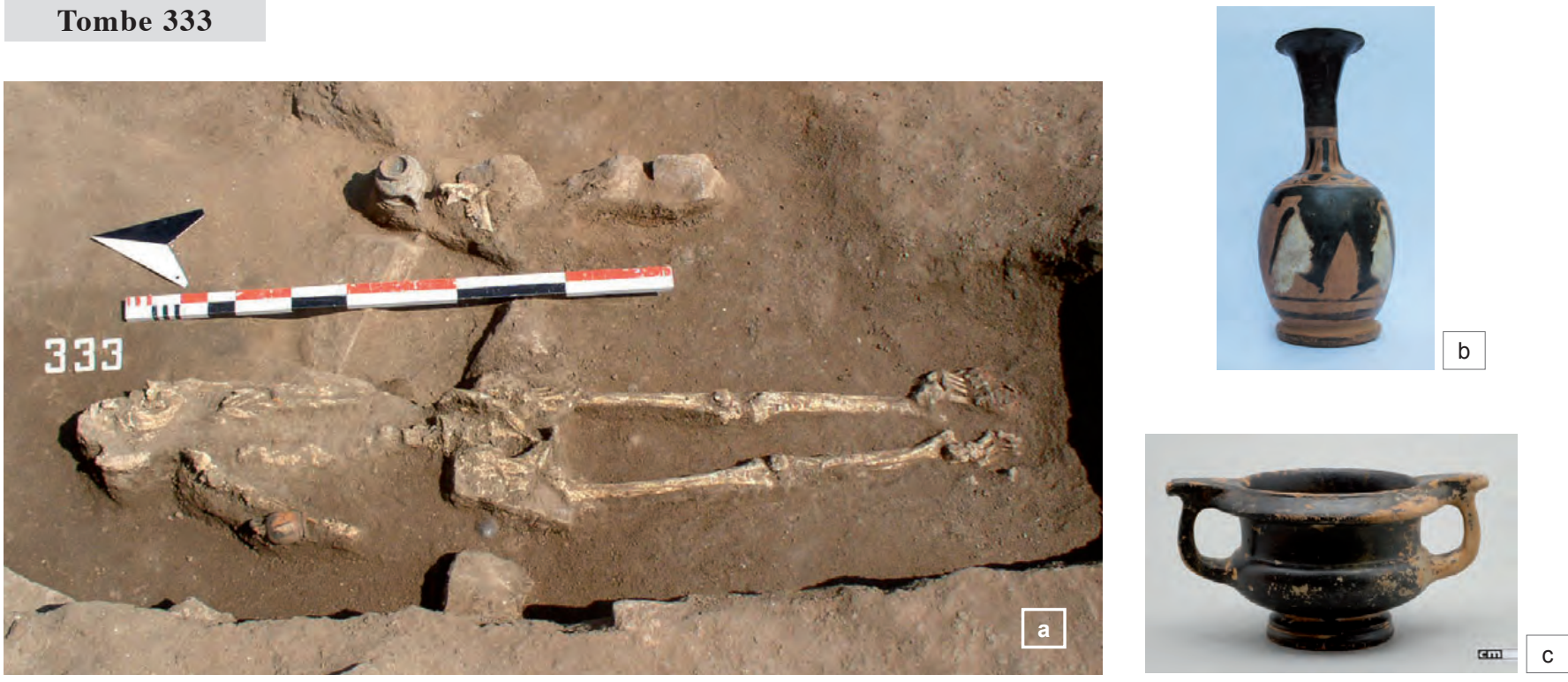

Tombe 334
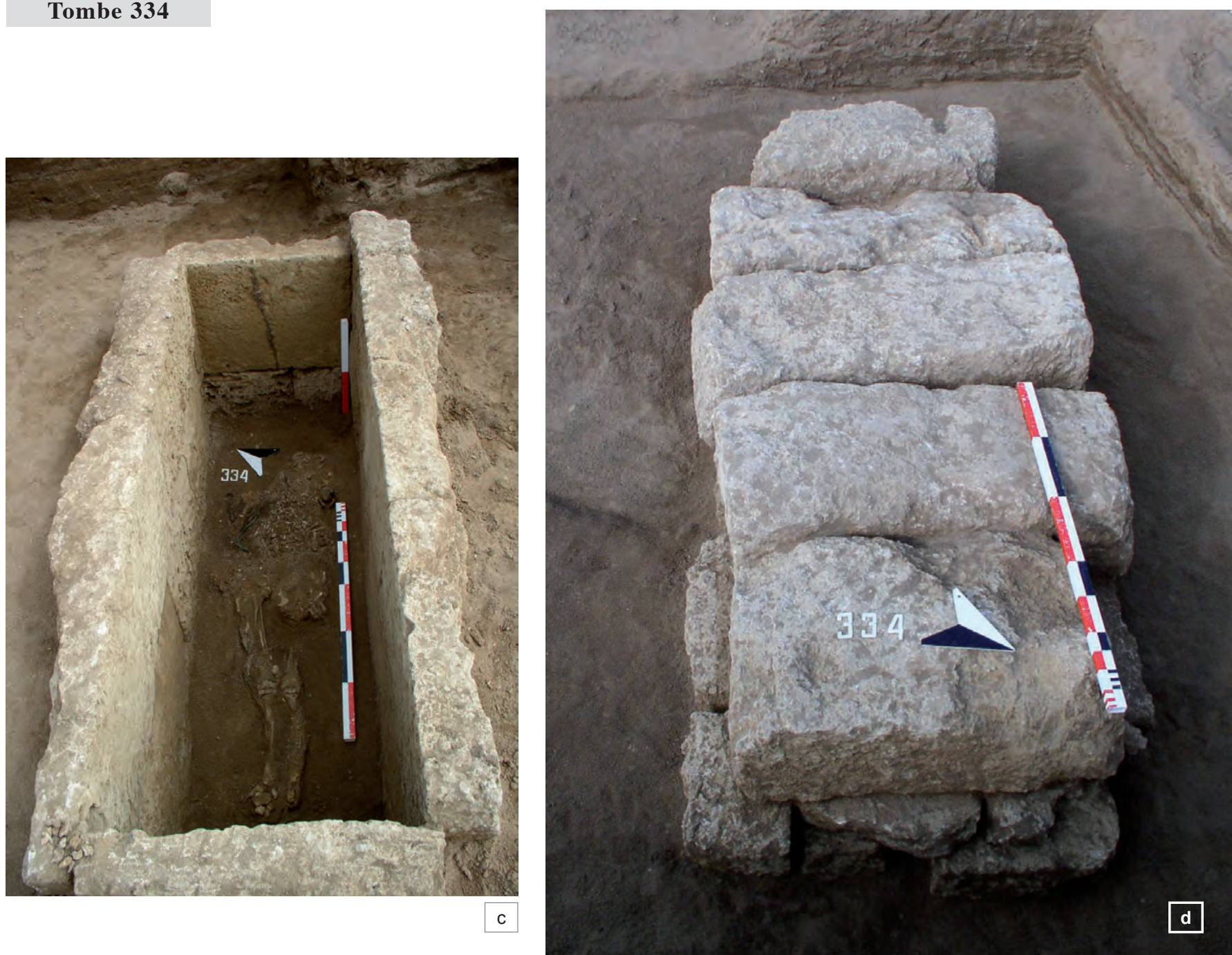
Planche 39
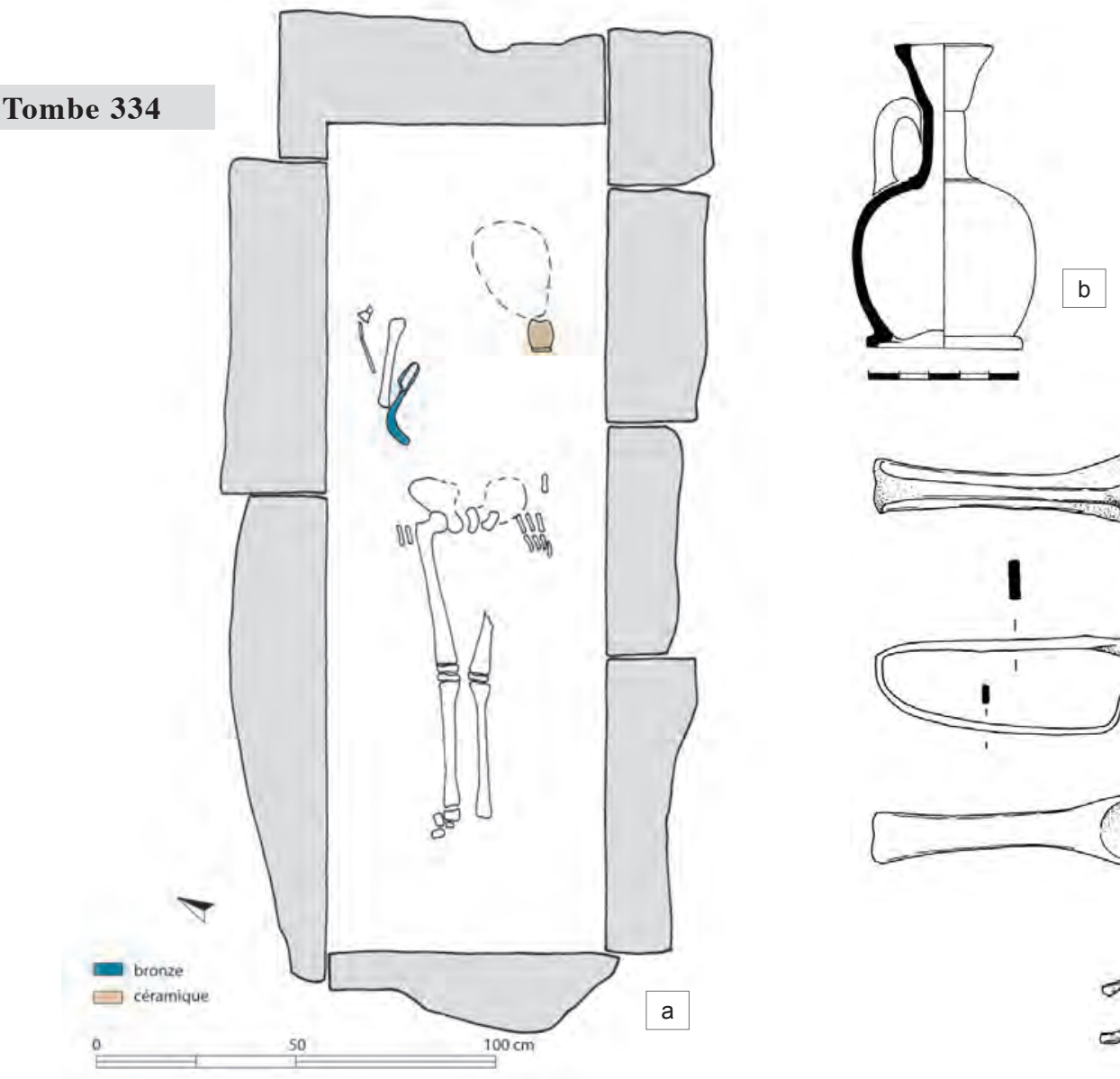

C
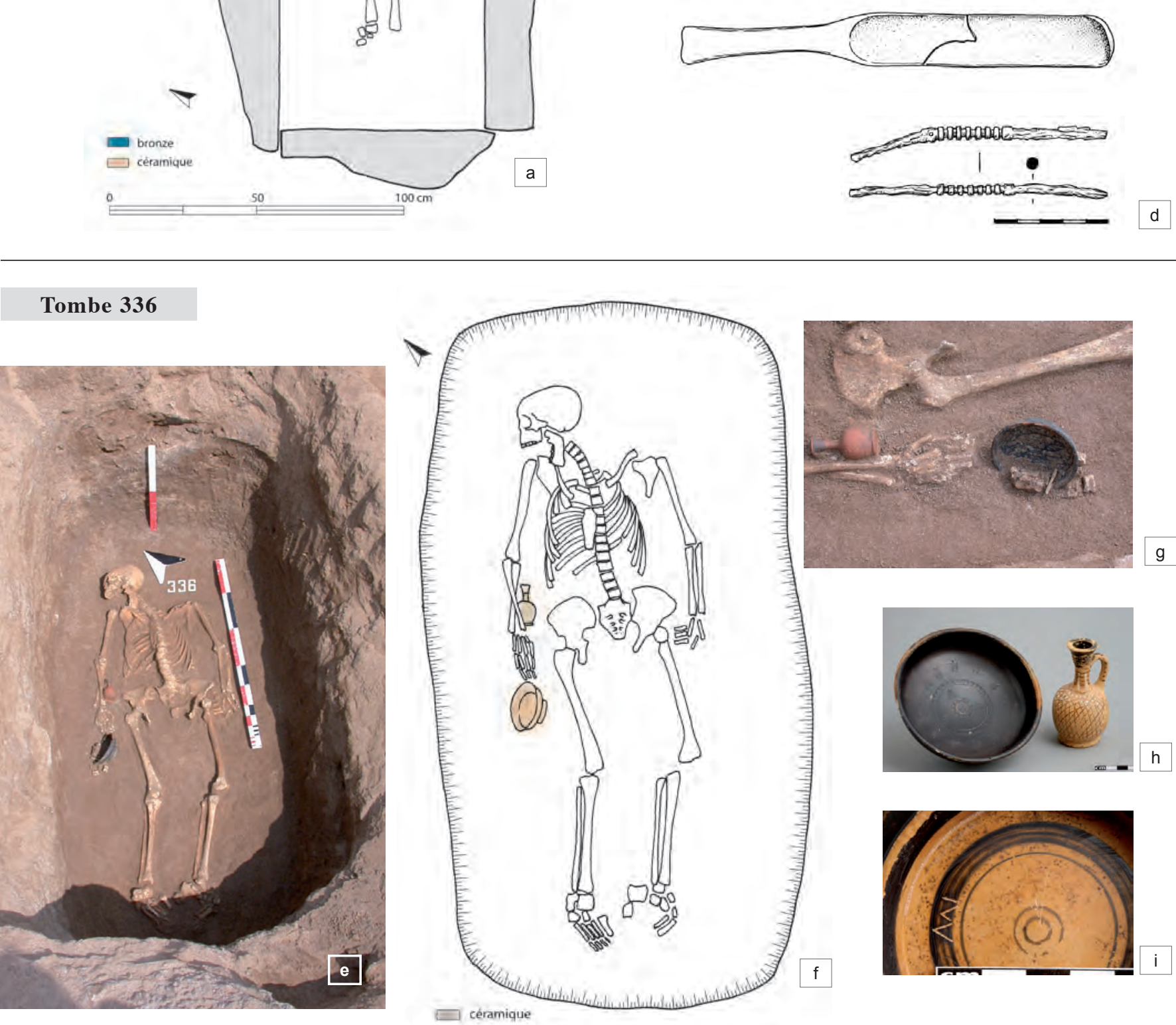
Planche 40

Tombe 337
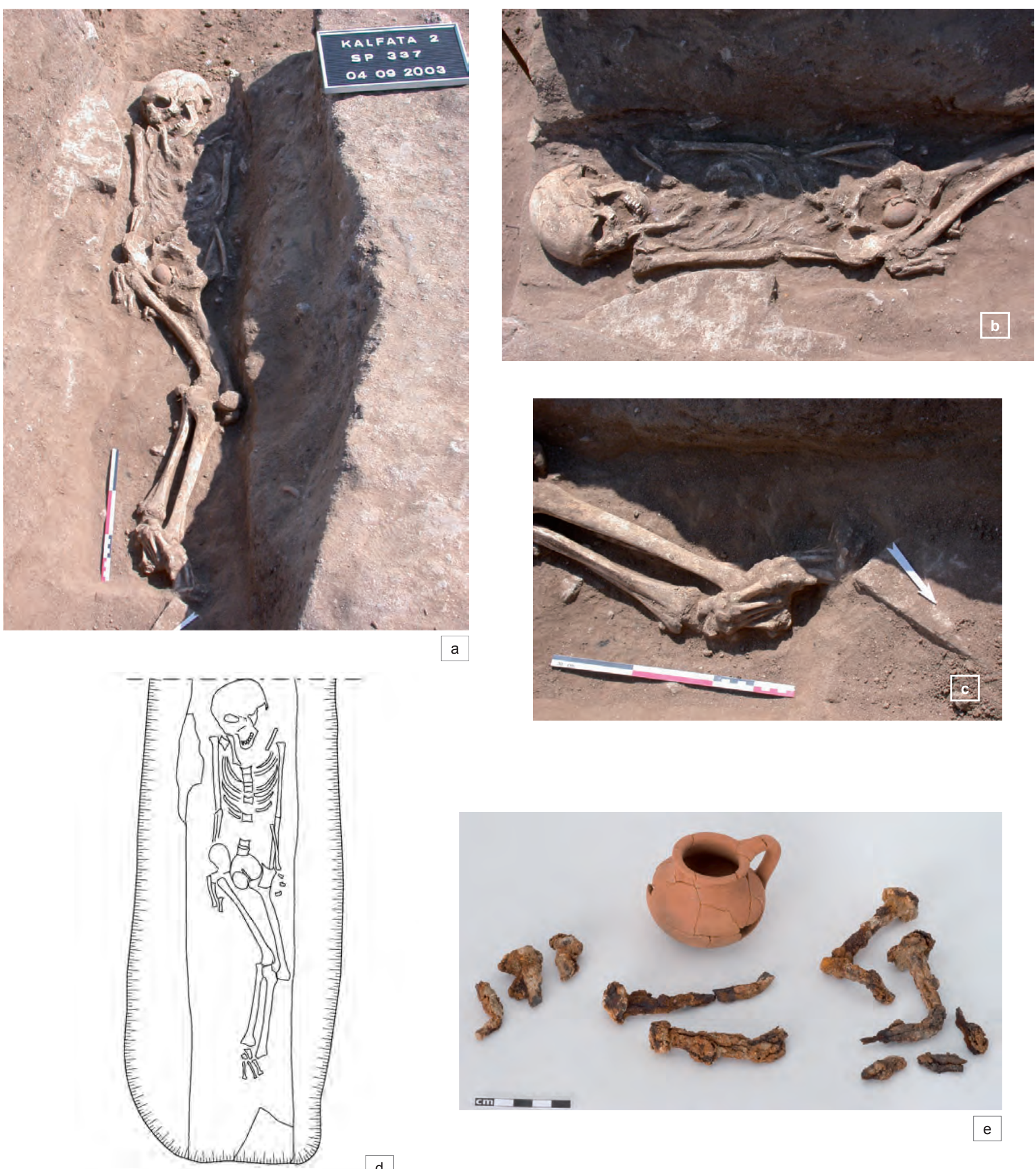

d $100 \mathrm{~cm}$ 


\section{Tombe 338}
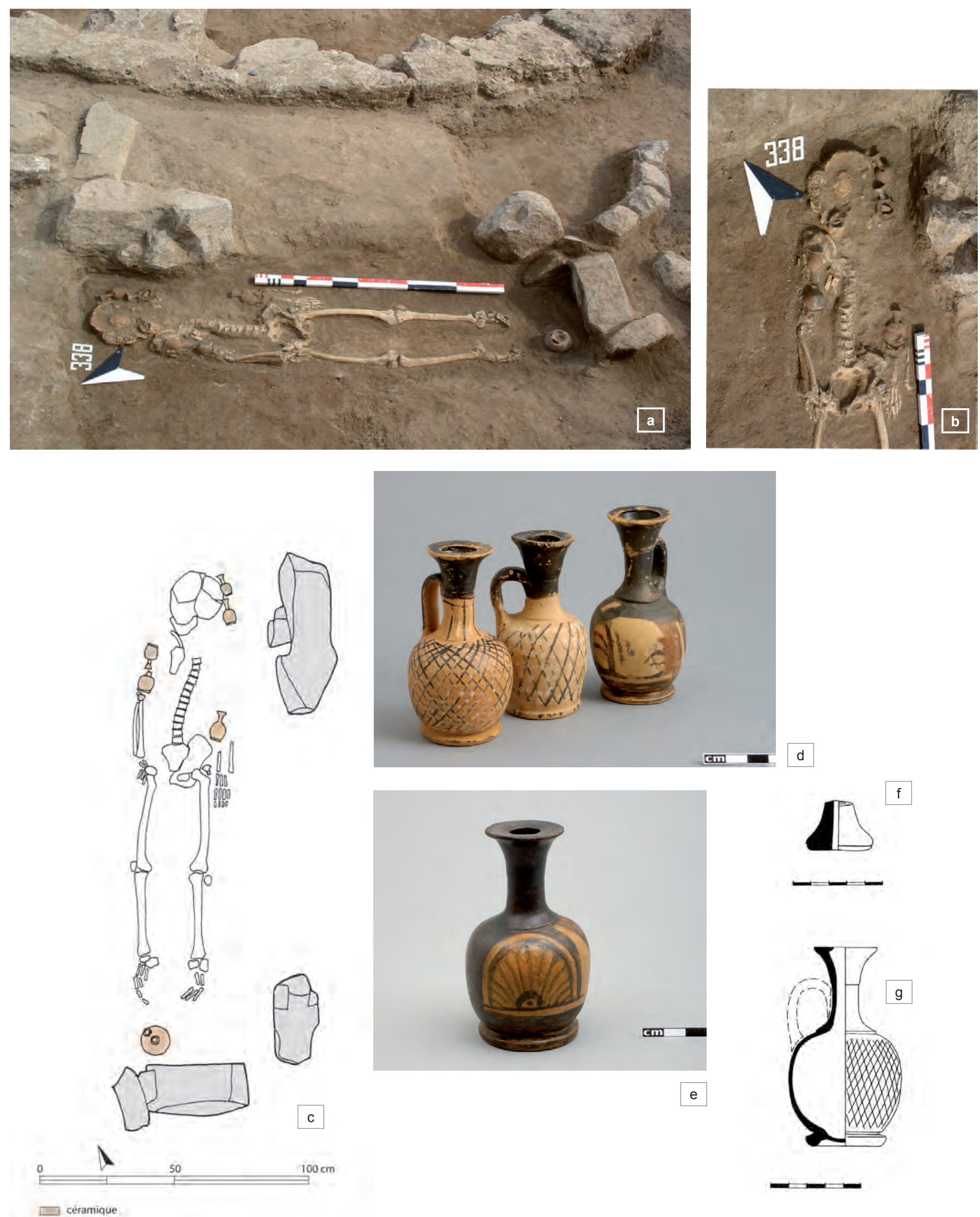
Planche 42

\section{Tombe 339}
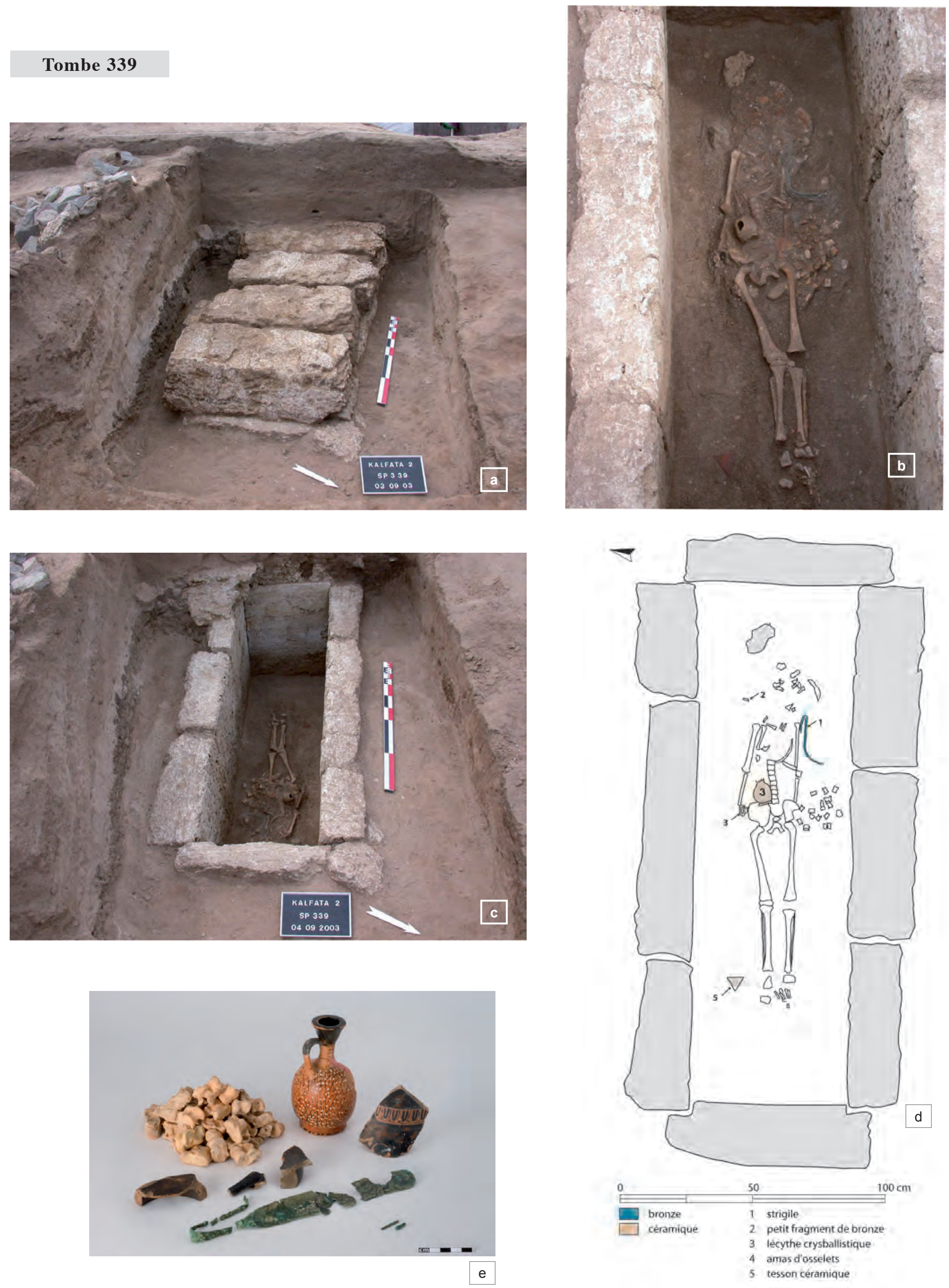
Tombe 340

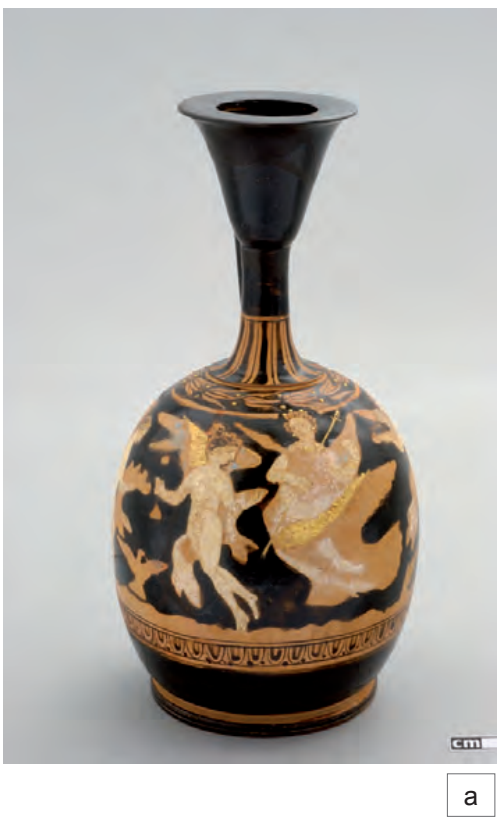

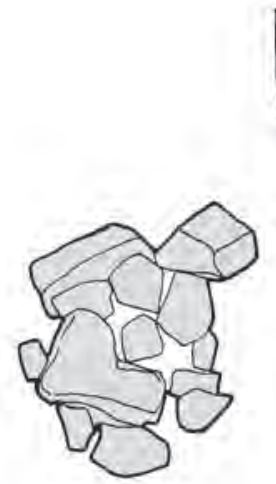

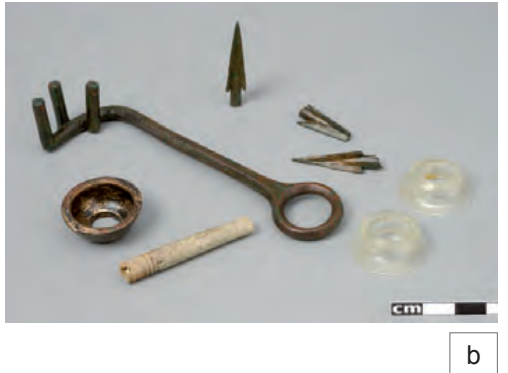

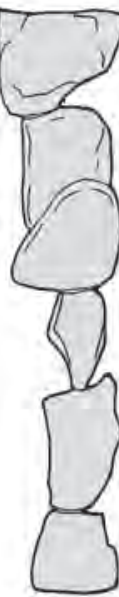

Oa
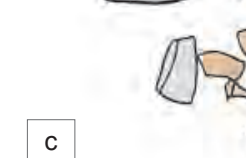

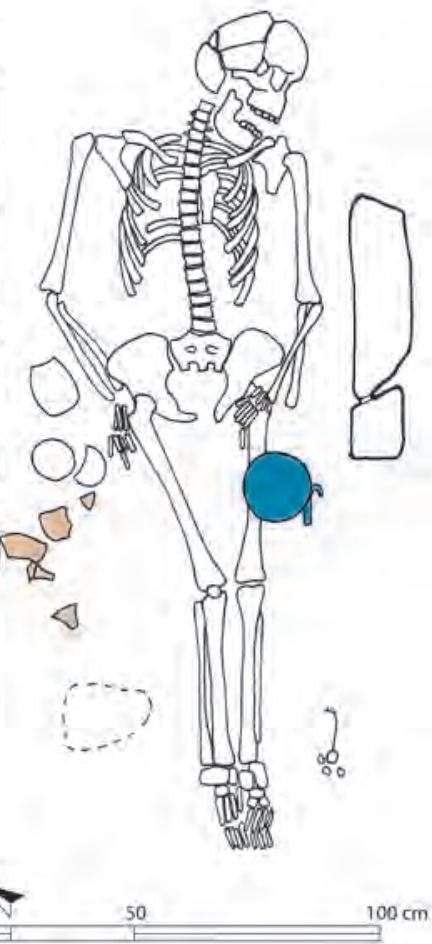
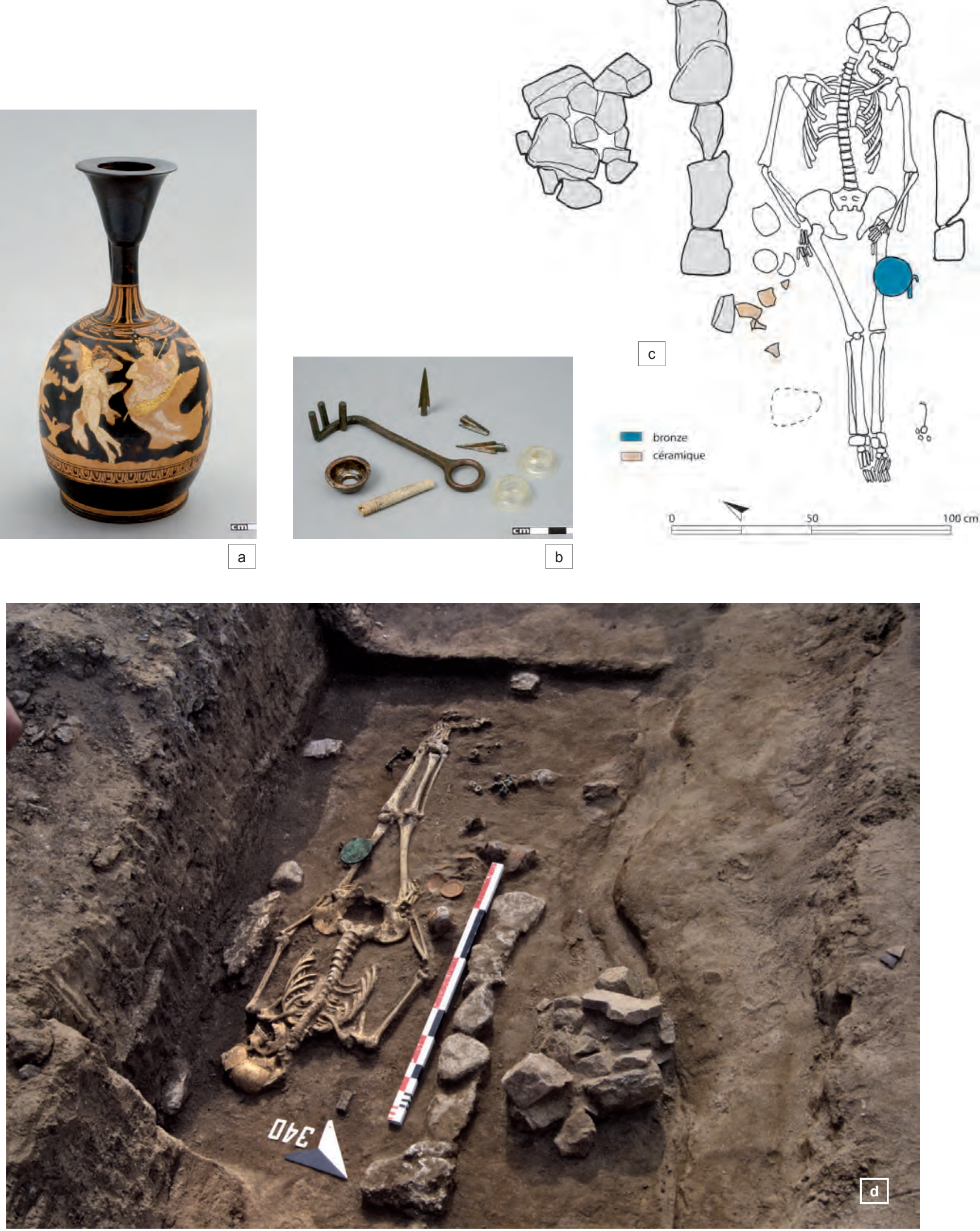
Planche 44

Tombe 341

b
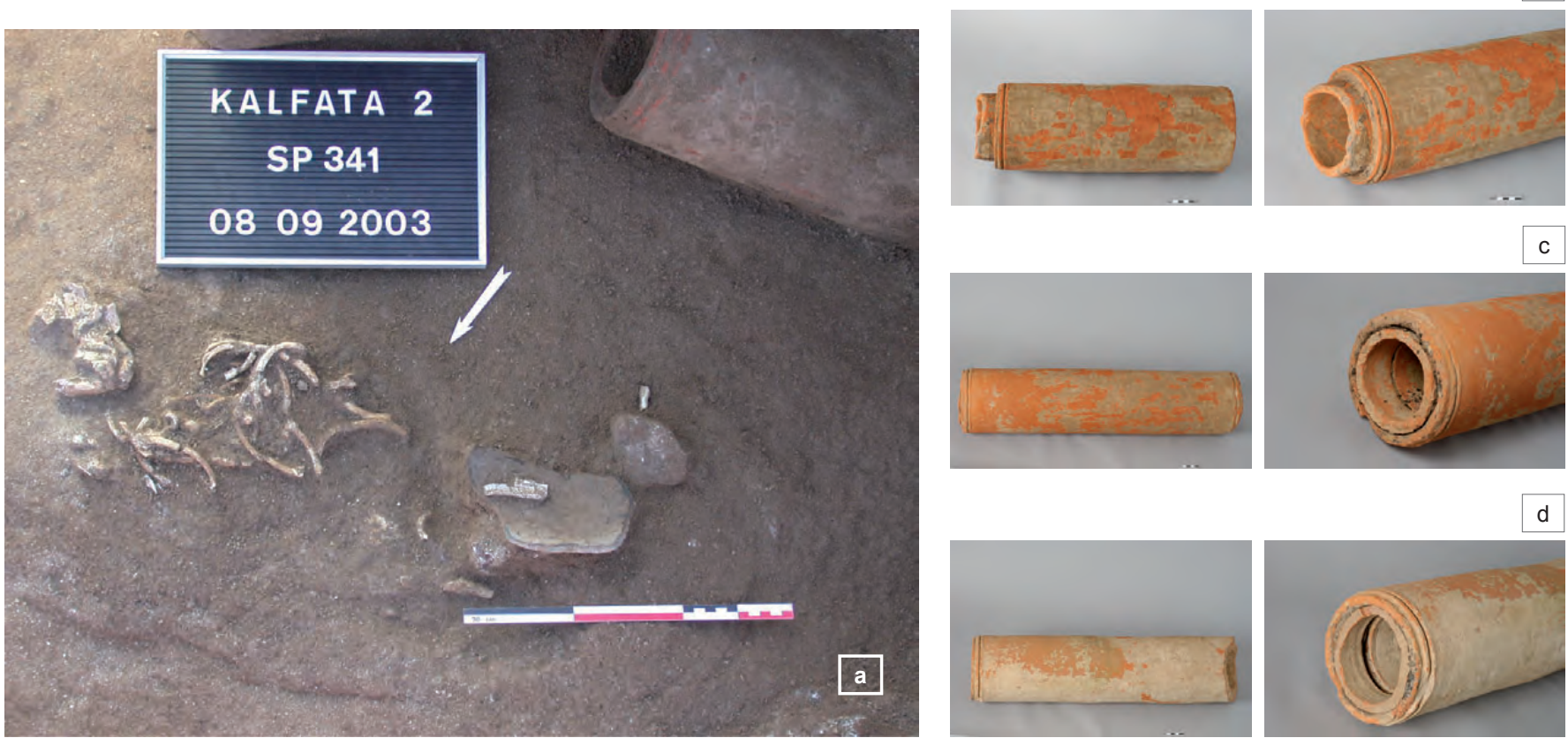

\section{Tombe 342}
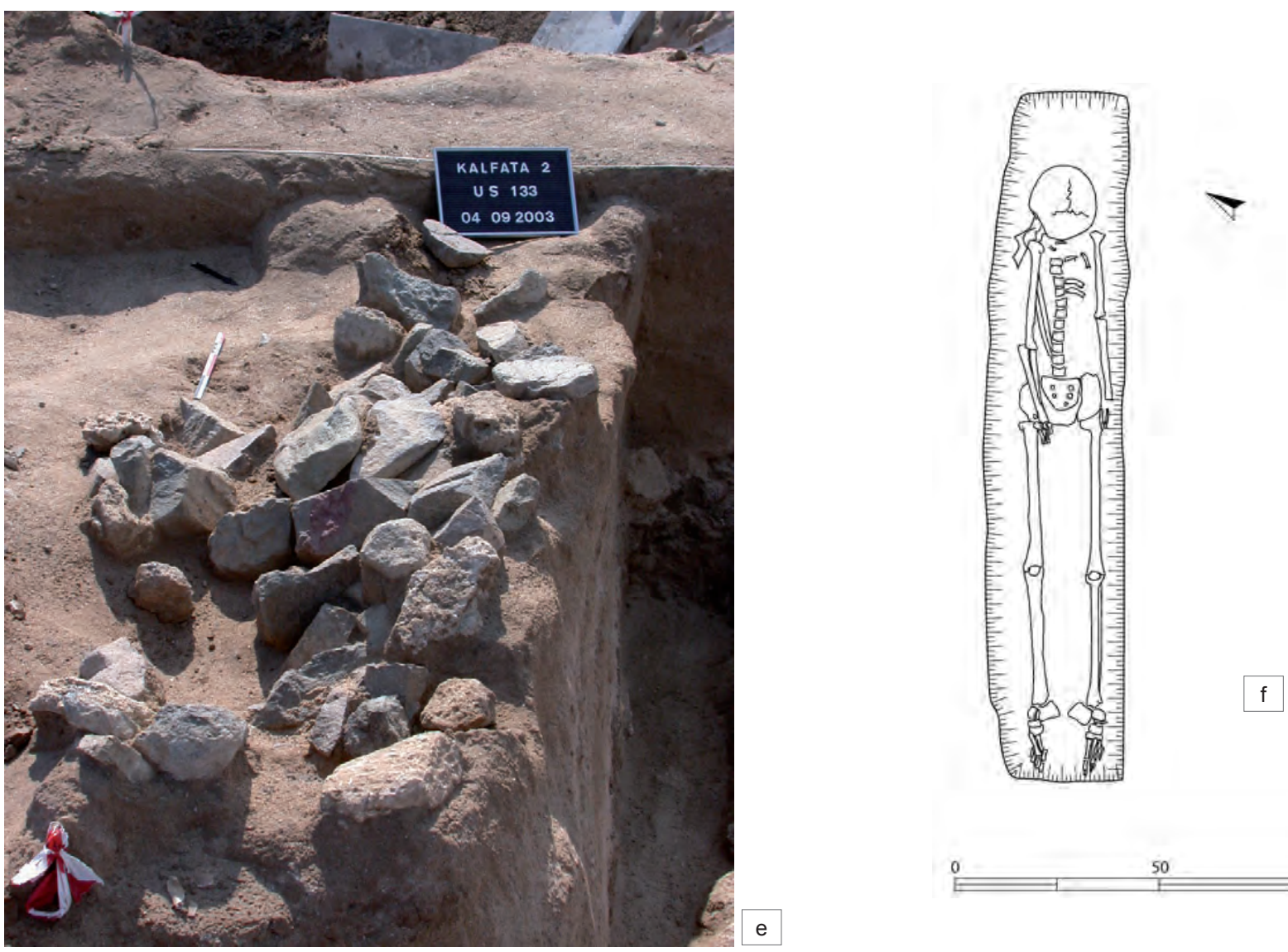
Tombe 342
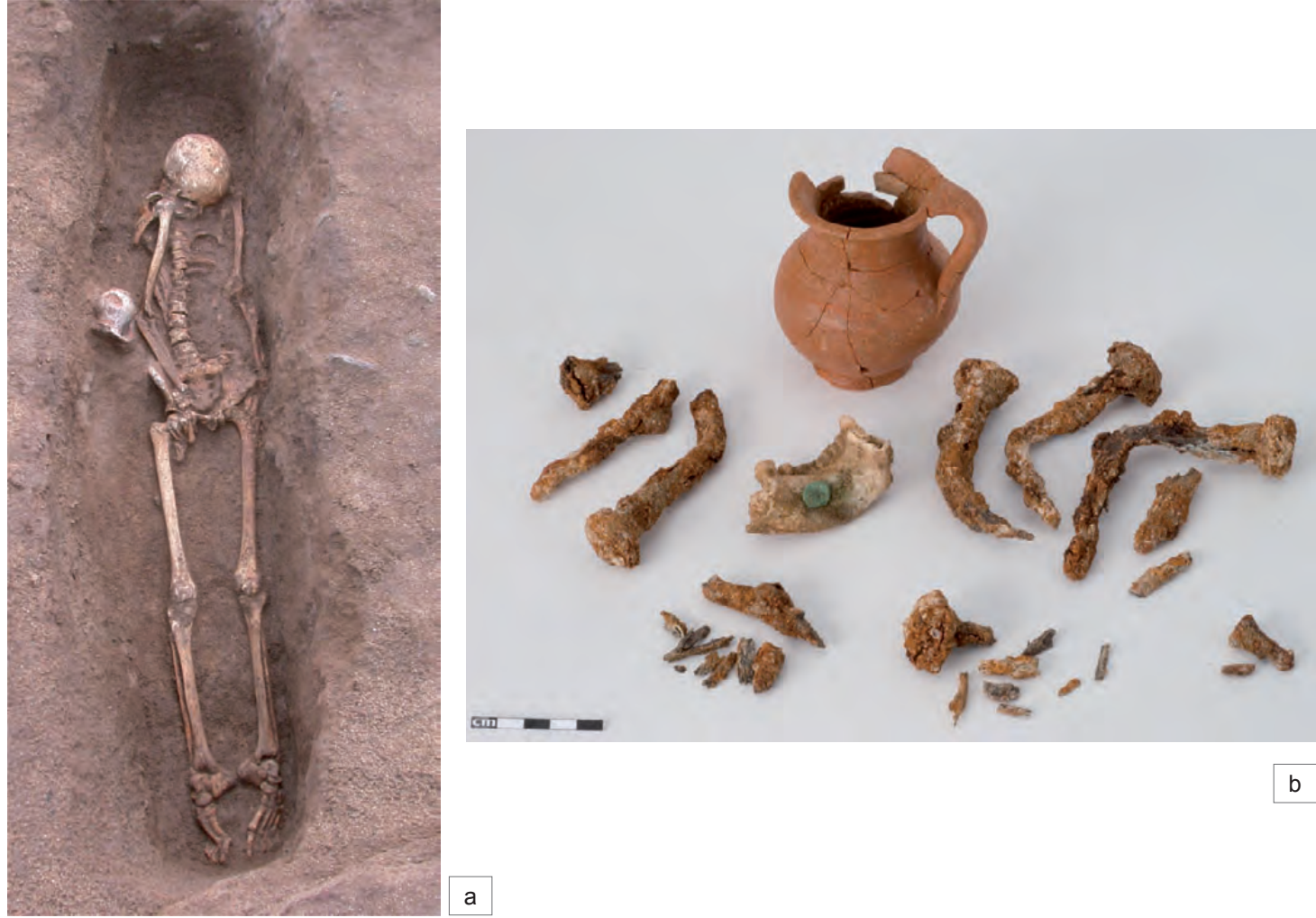

$\mathrm{b}$

Tombe 343
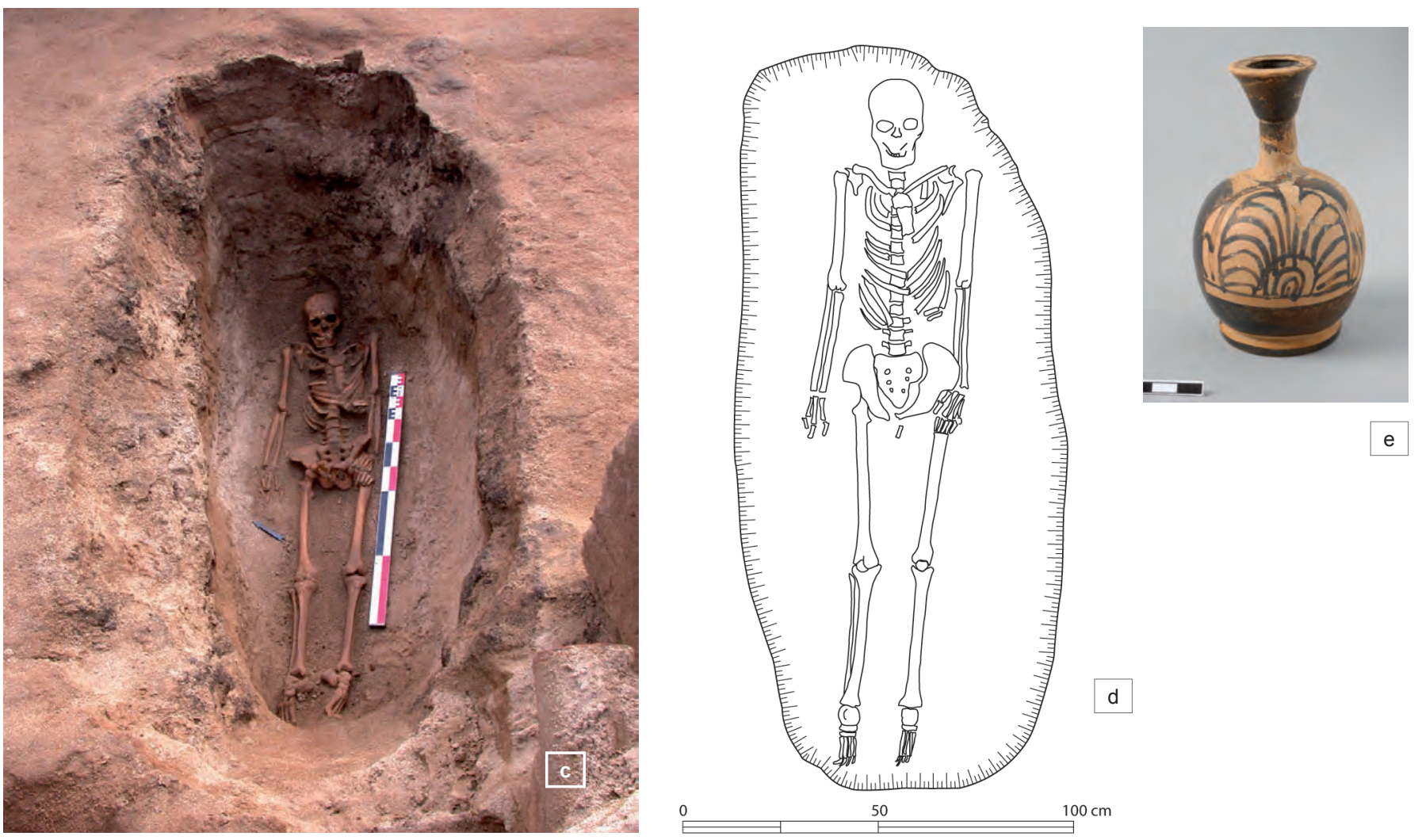
Planche 46

\section{Tombe 344}
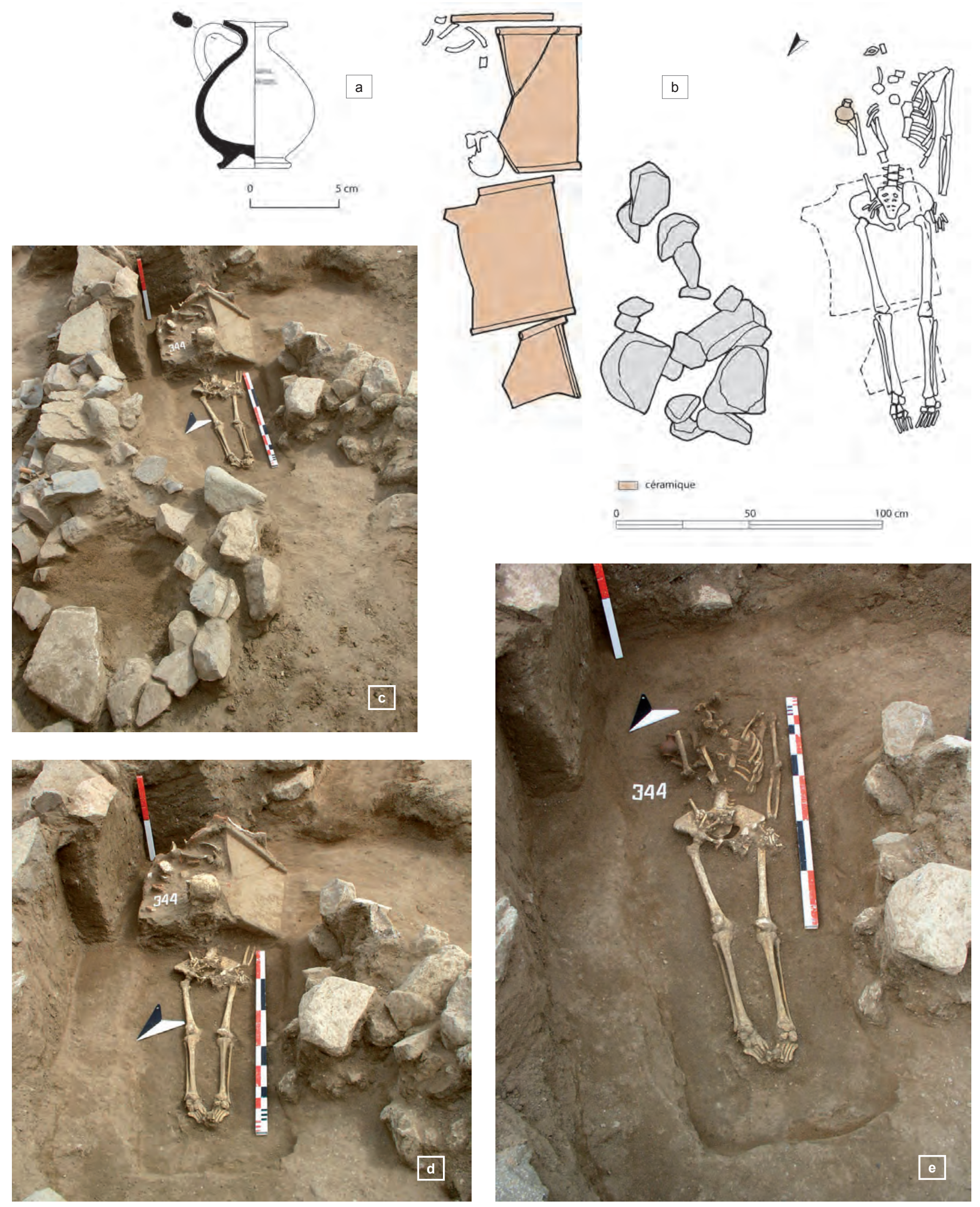
Tombe 346
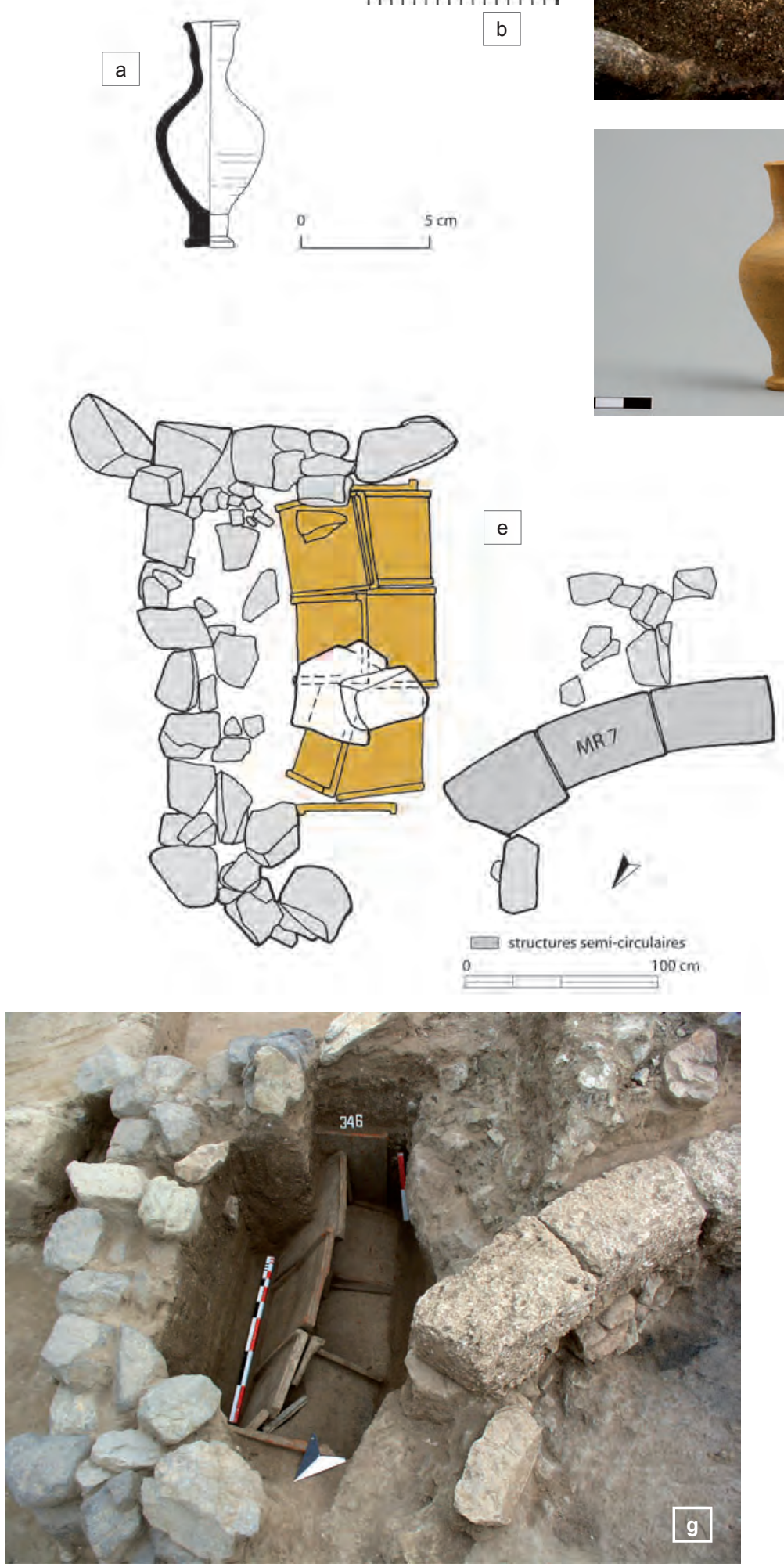
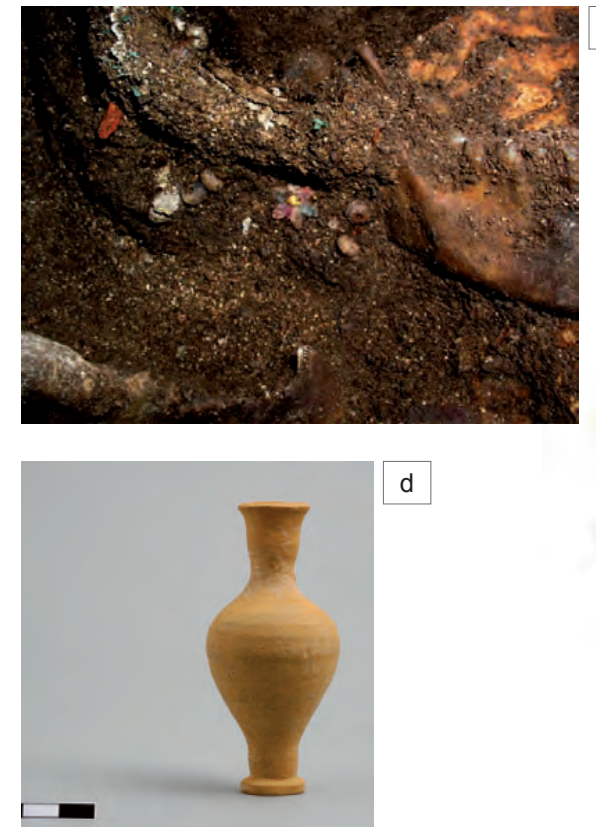

b

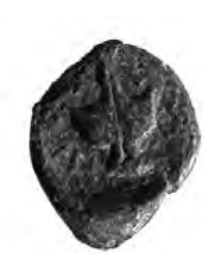


Planche 48

Tombe 347
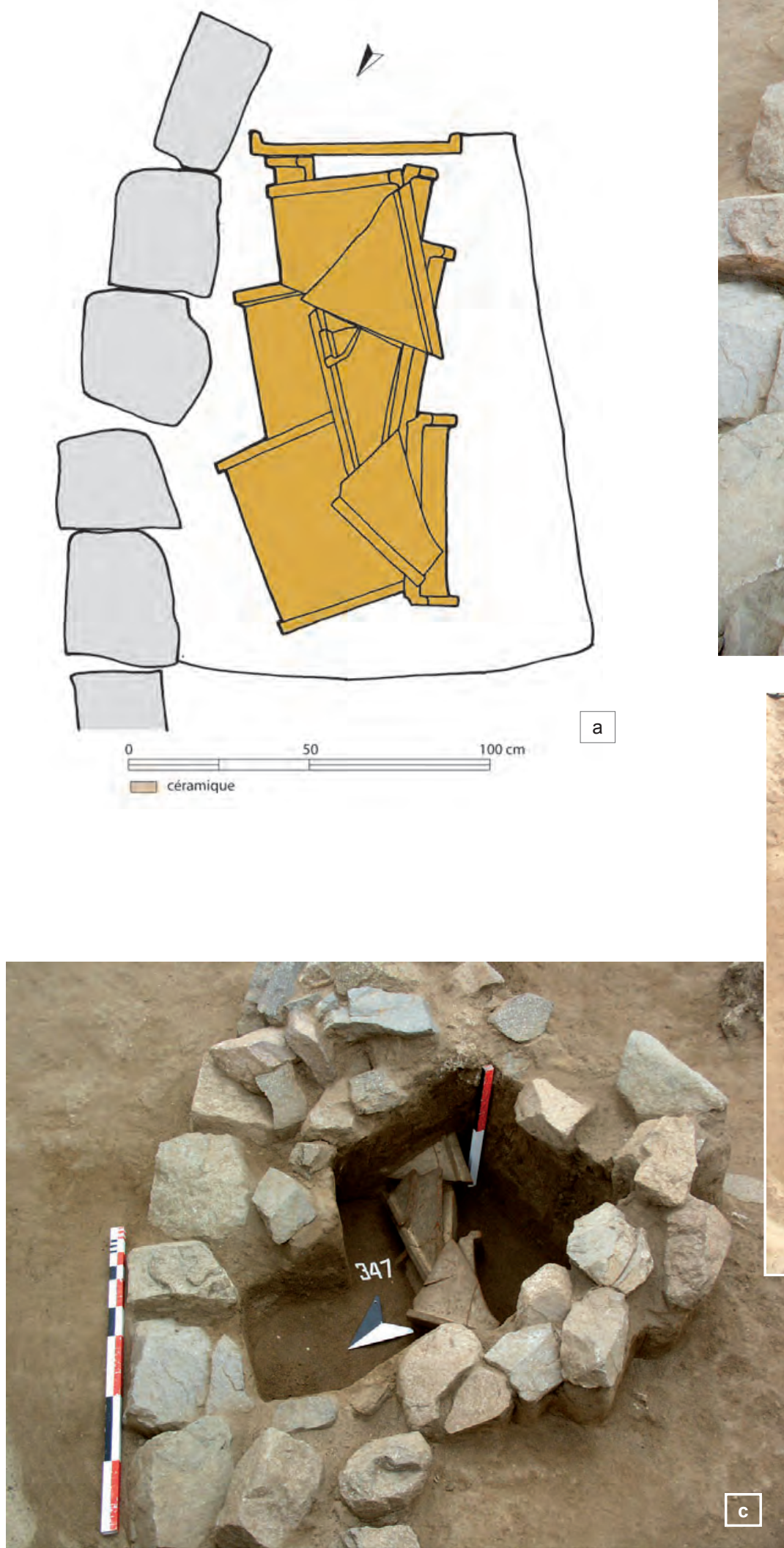
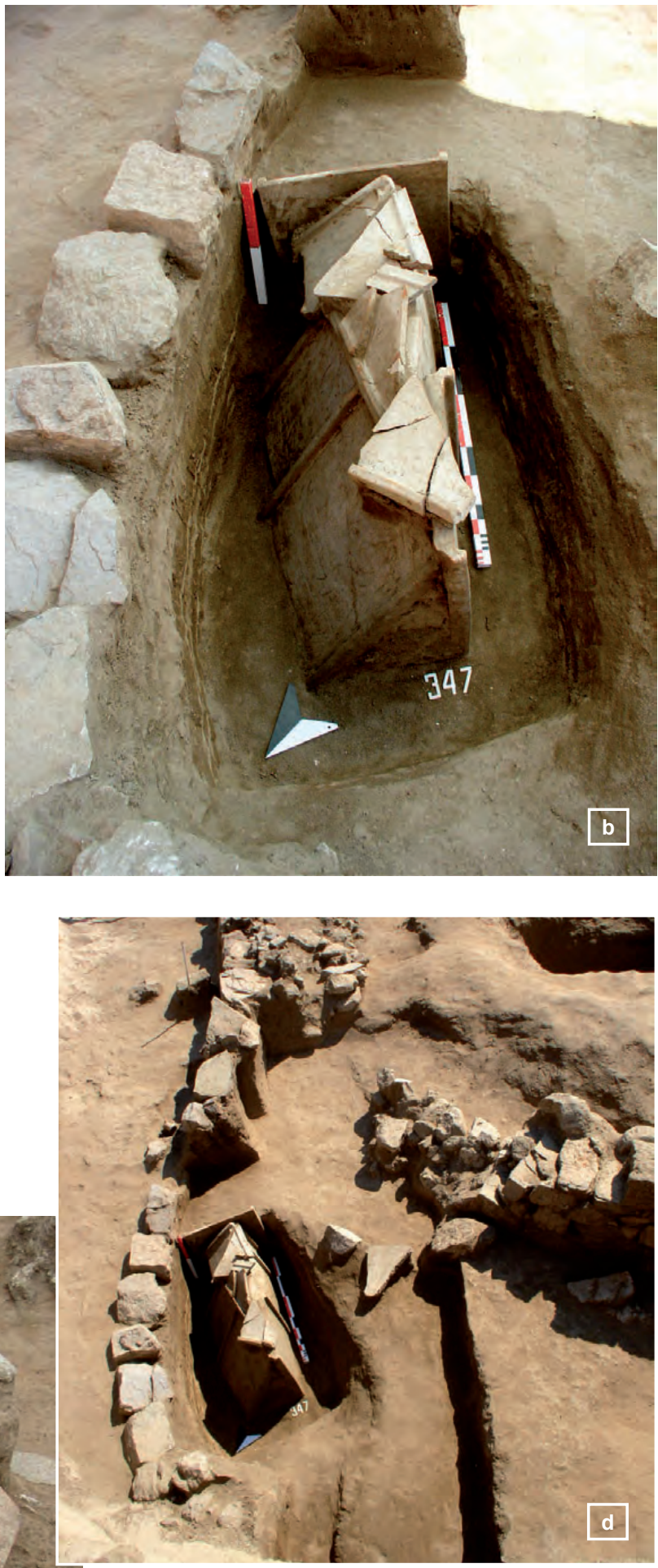
Planche 49

Tombe 347
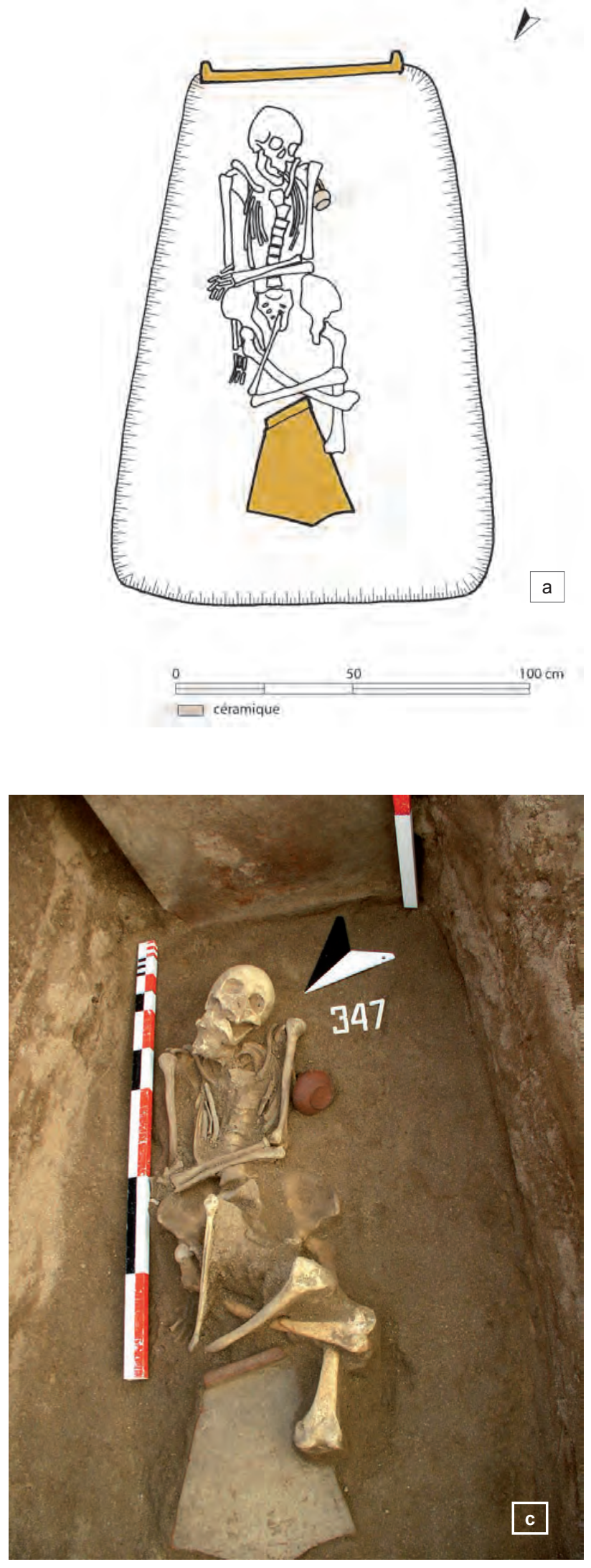
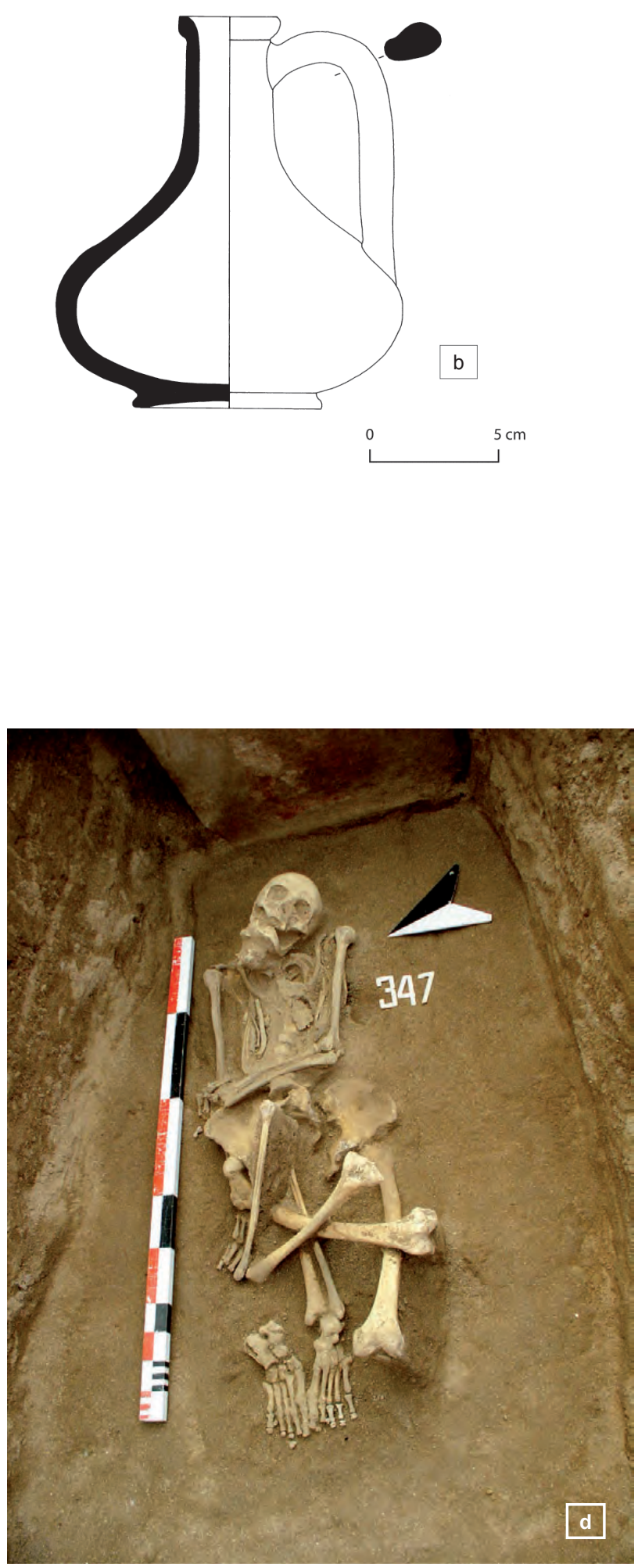
Planche 50

\section{Tombe 362}
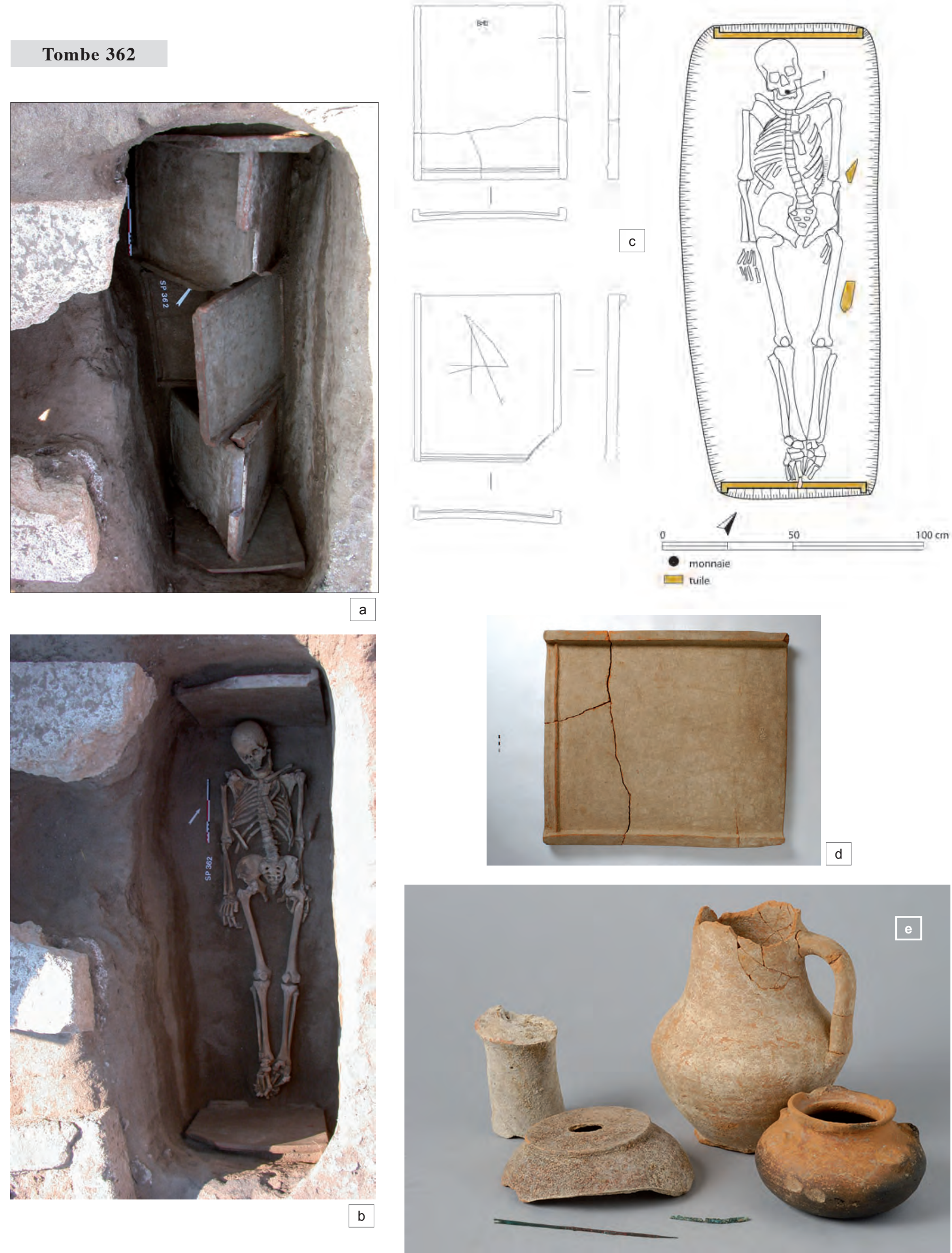
Planche 51

Tombe 370

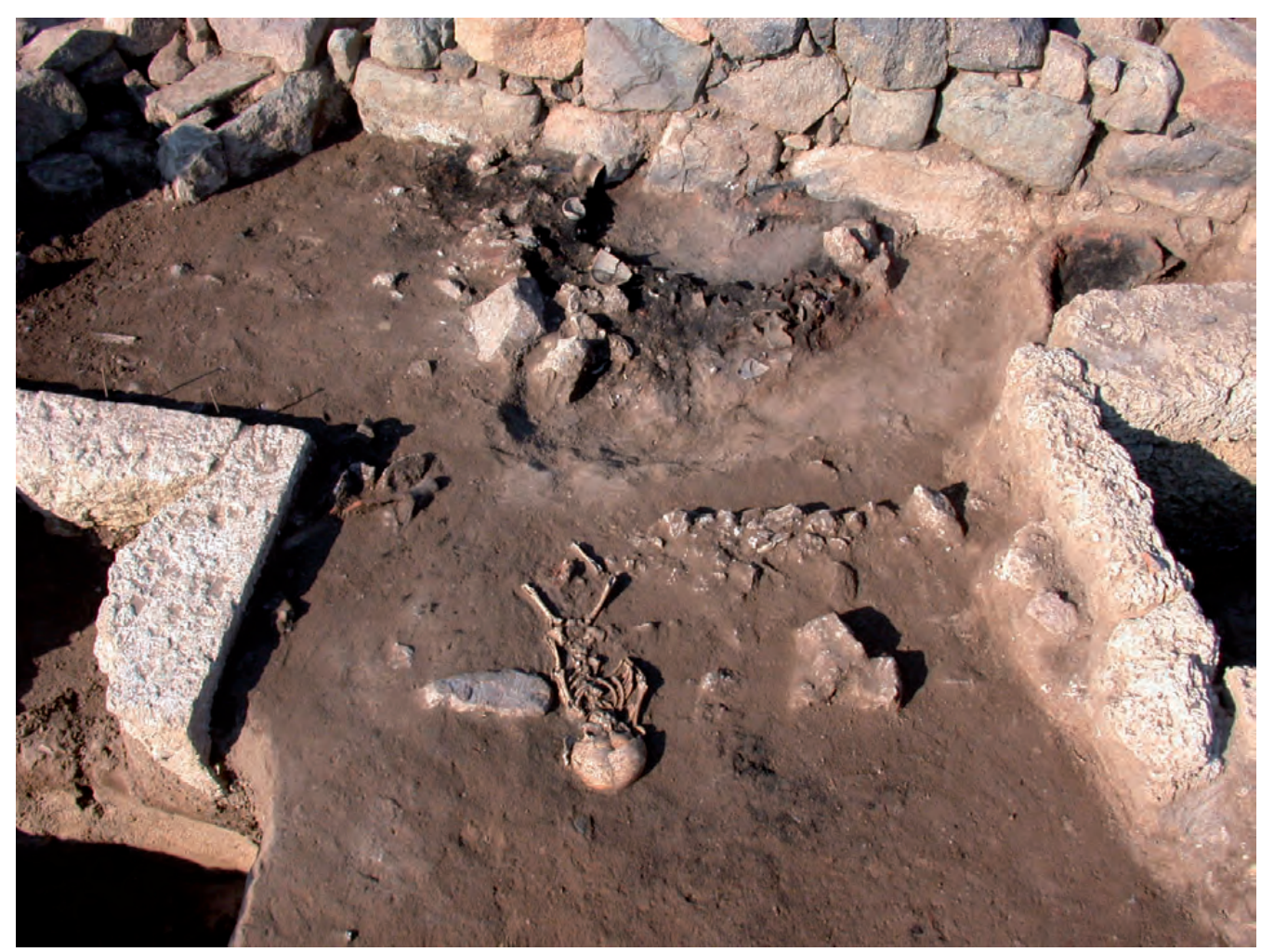

a

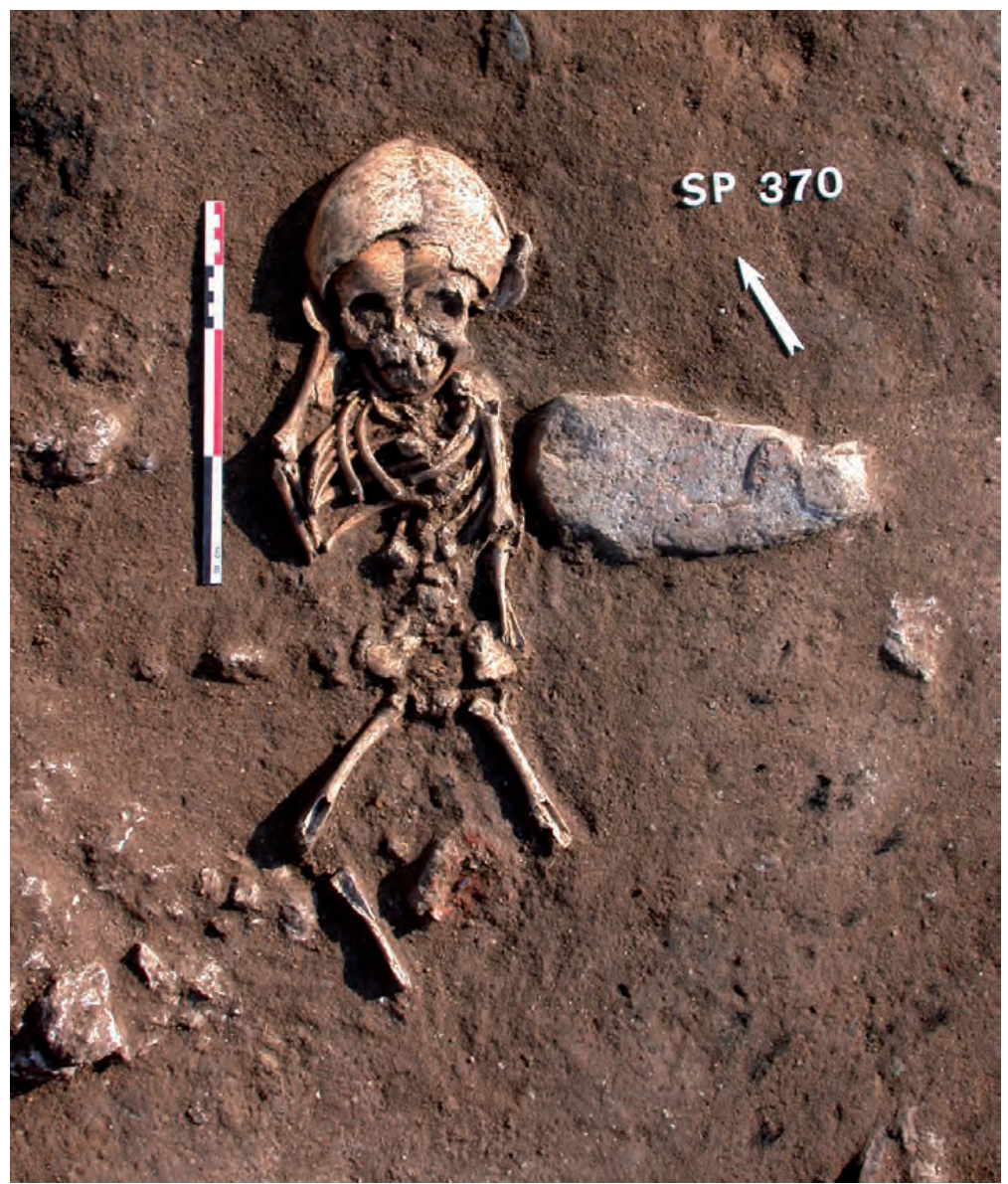


Planche 52

Tombe 375
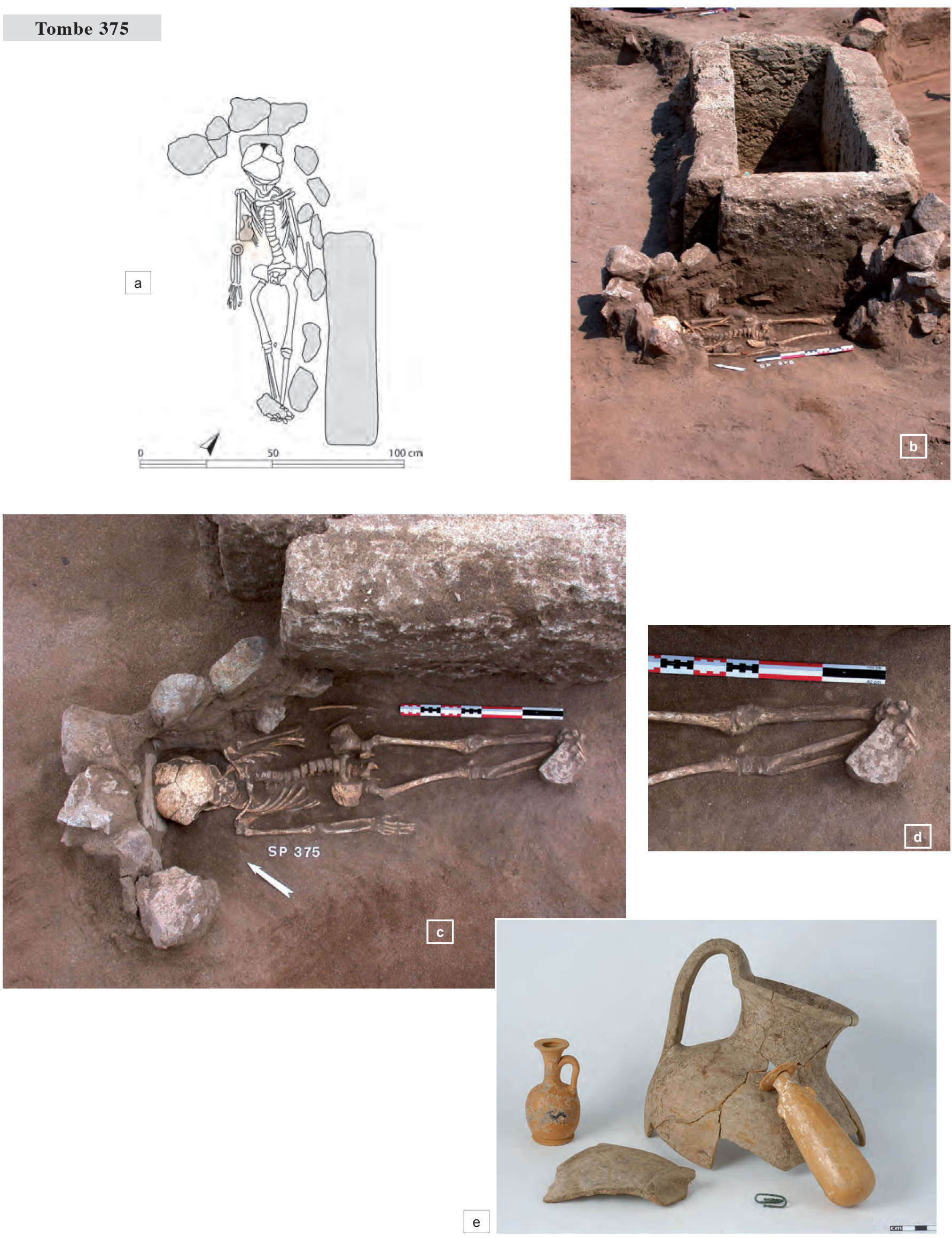
Planche 53

\section{DP 1}

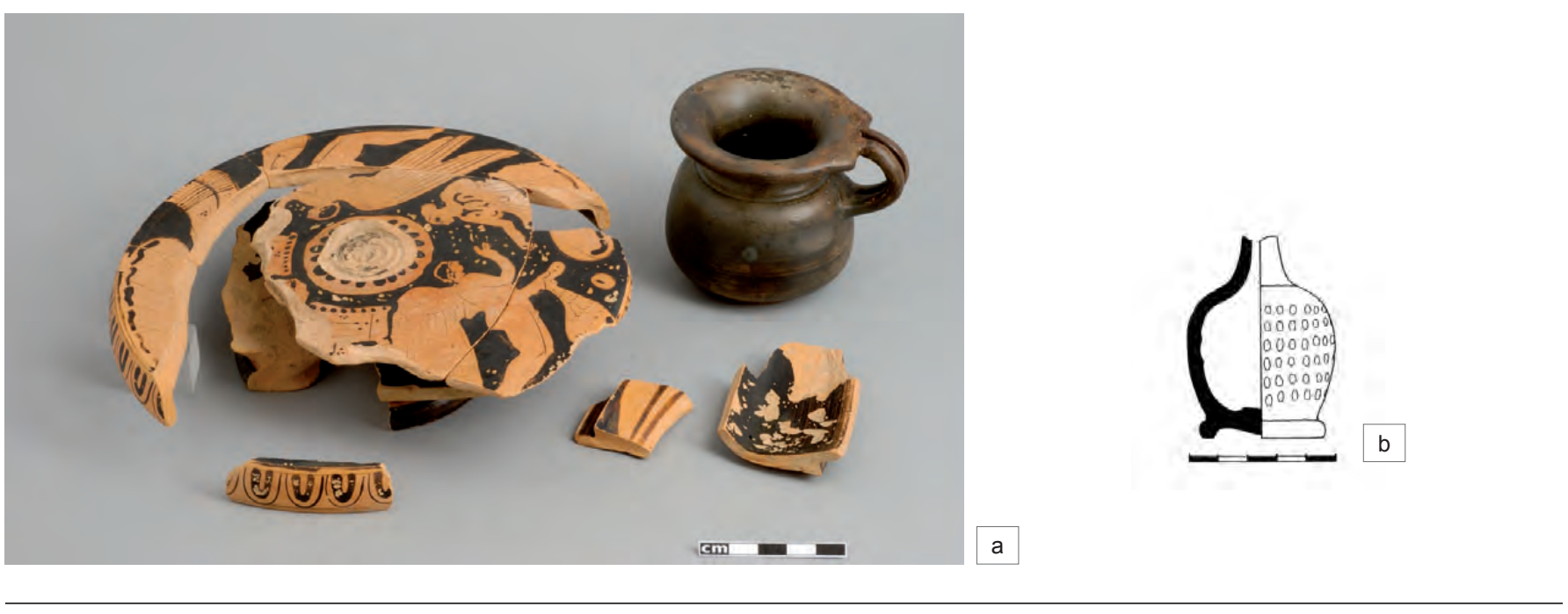

DP 2

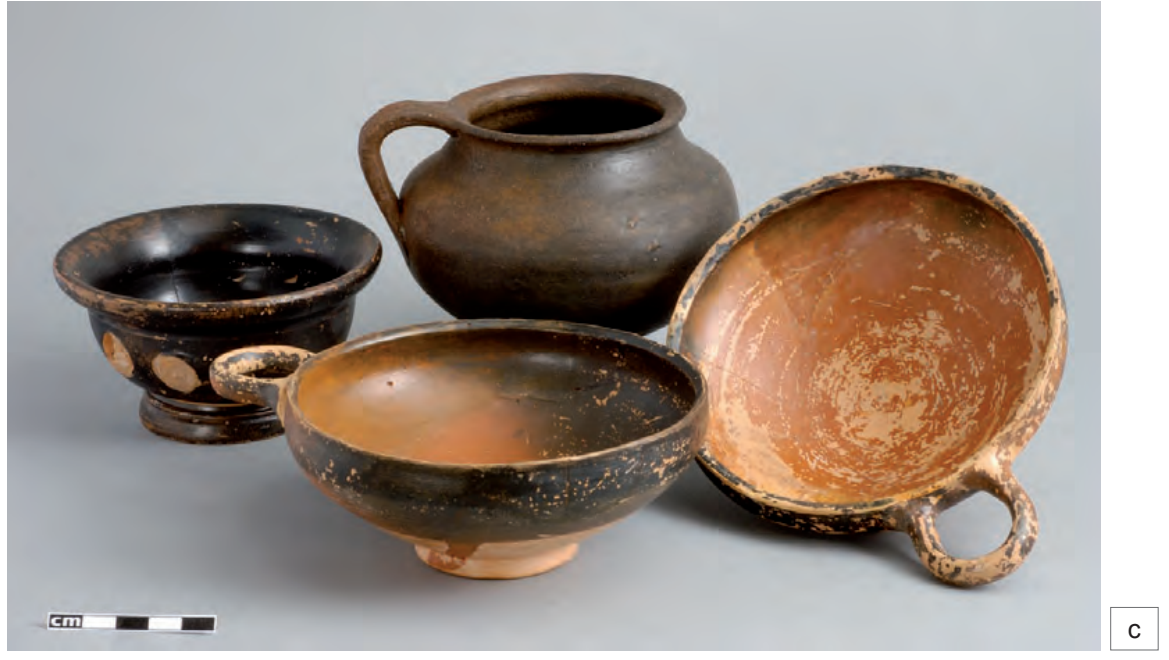

\section{DP 3}
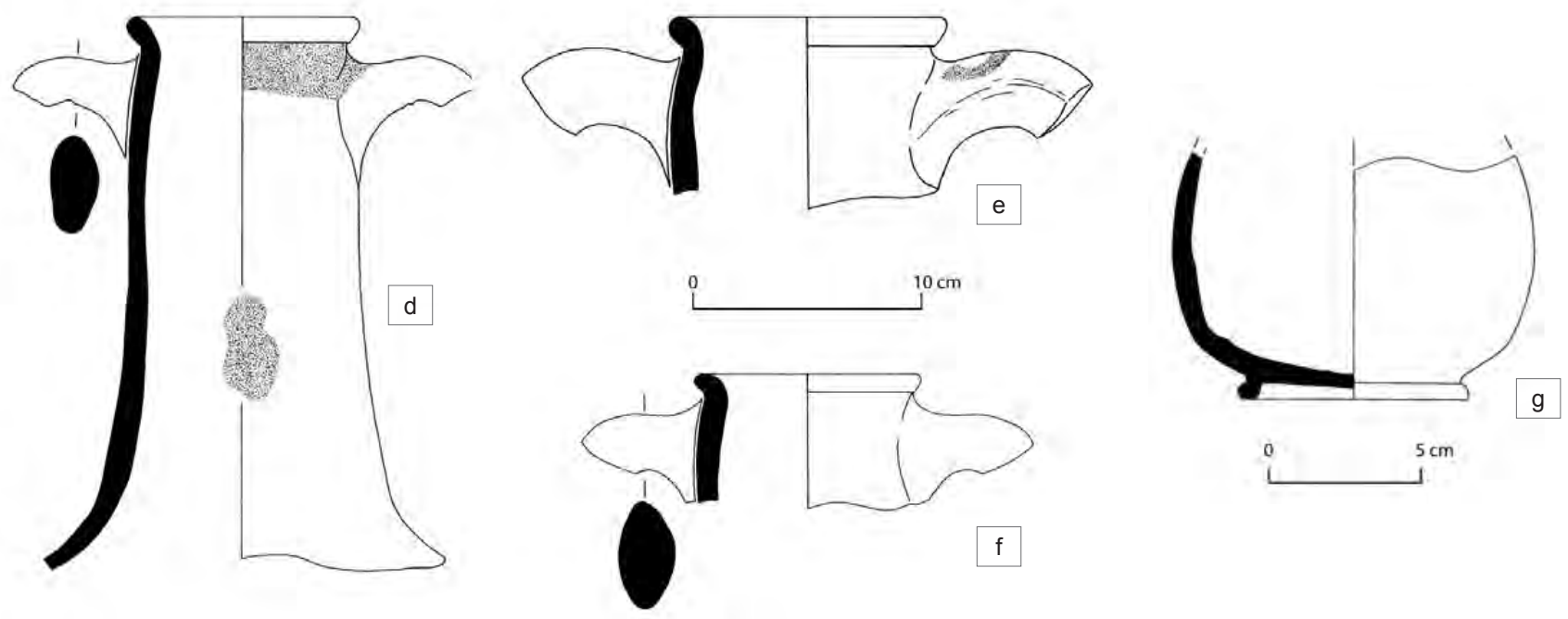
Planche 54

DP 4

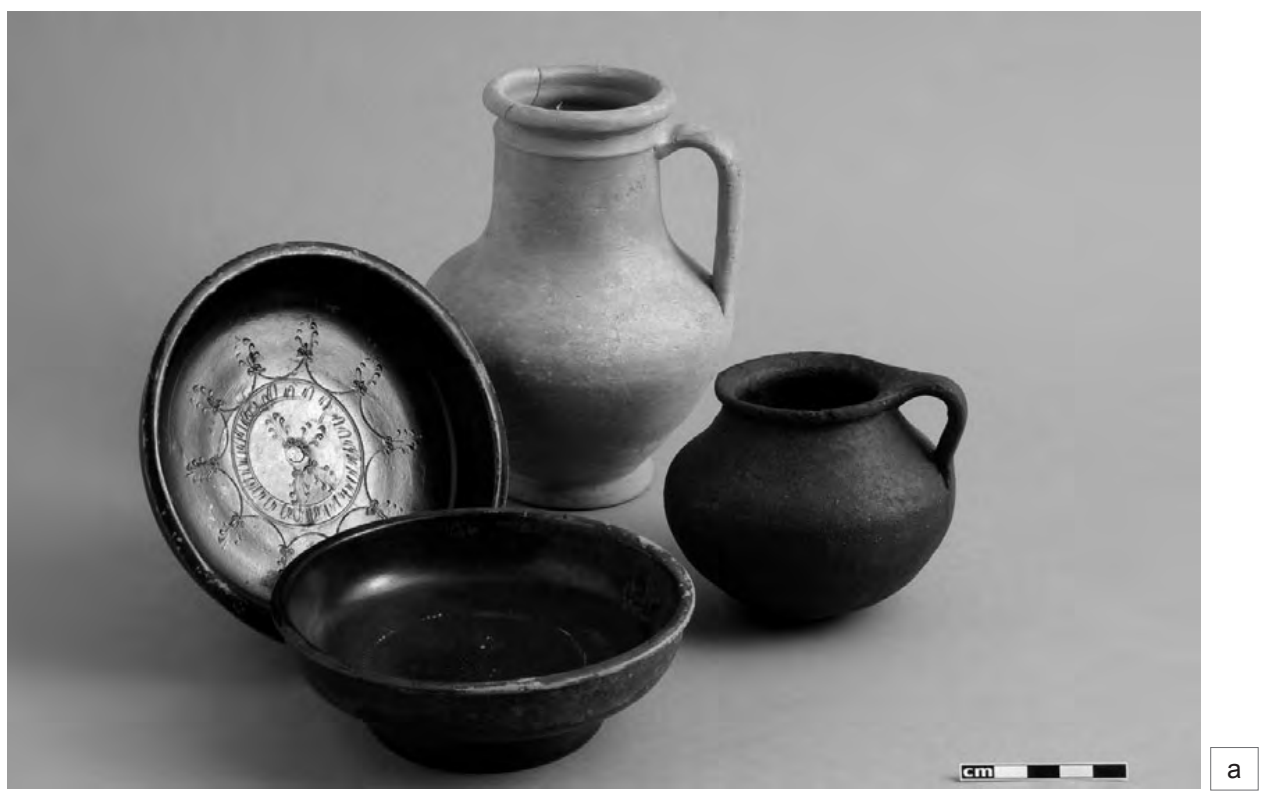

DP 5

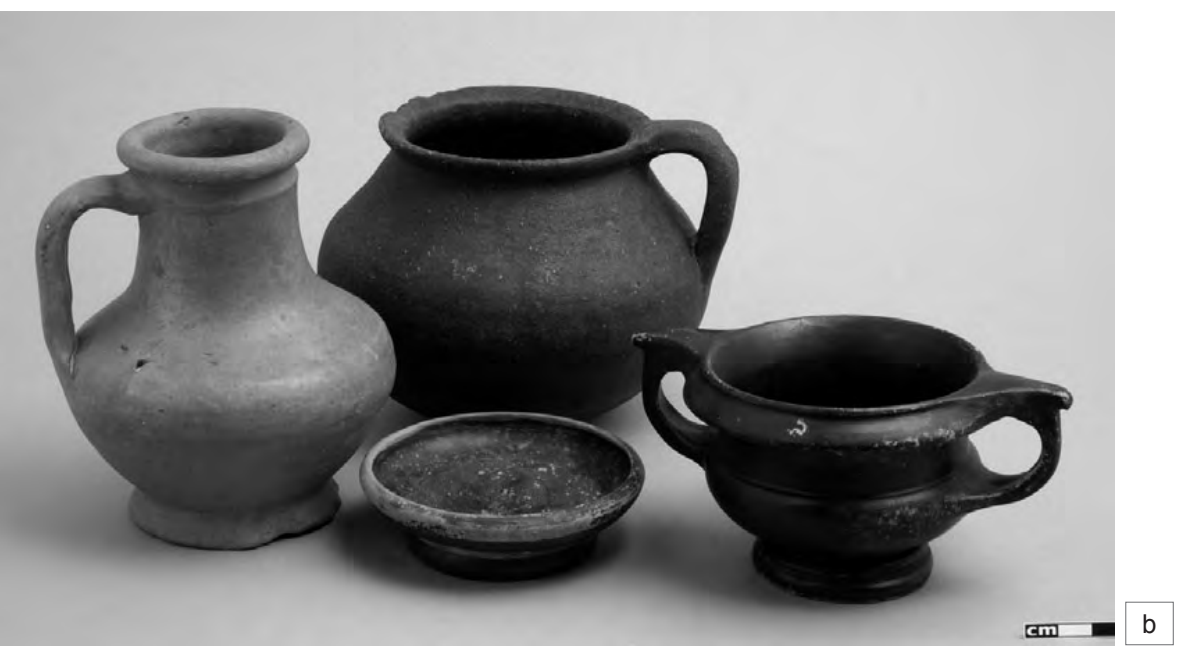

DP 6

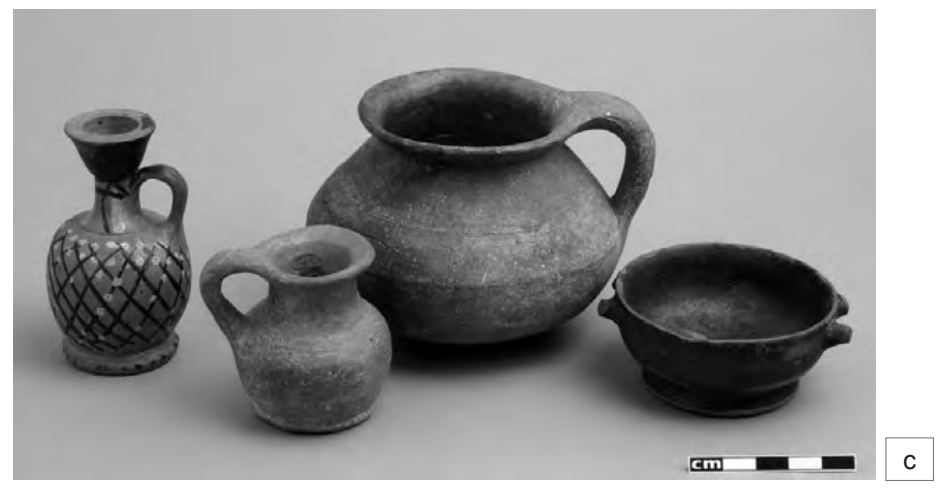


Planche 55

DP 8

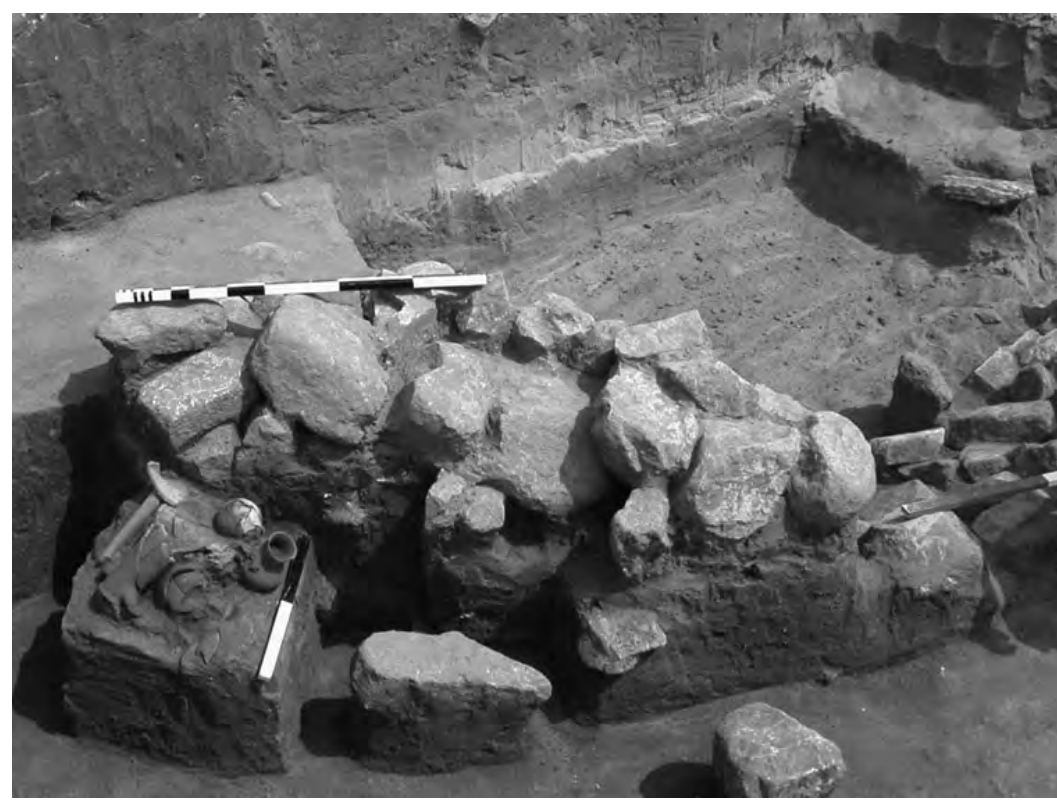

DP 9

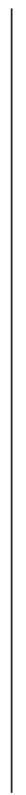

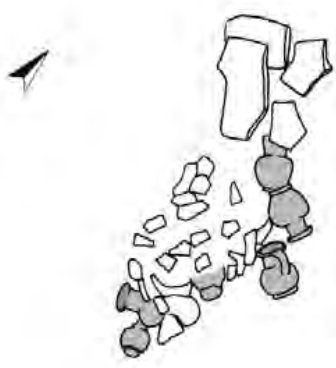

b

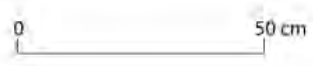

a

DP 12

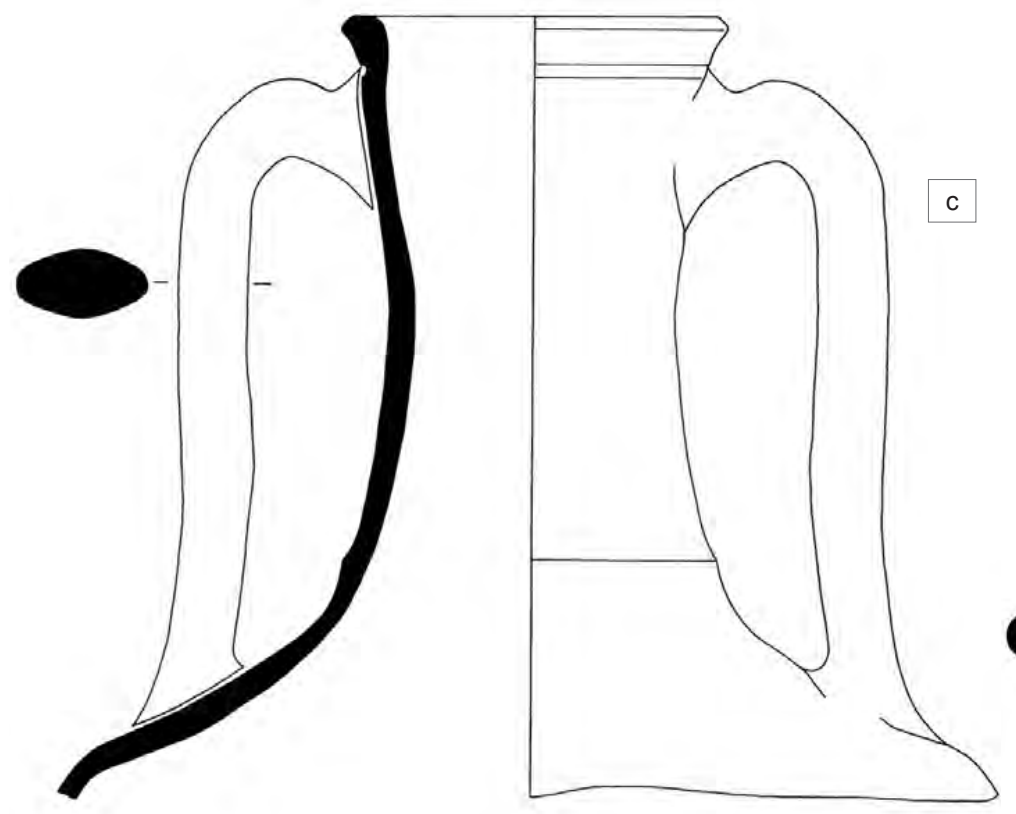

d
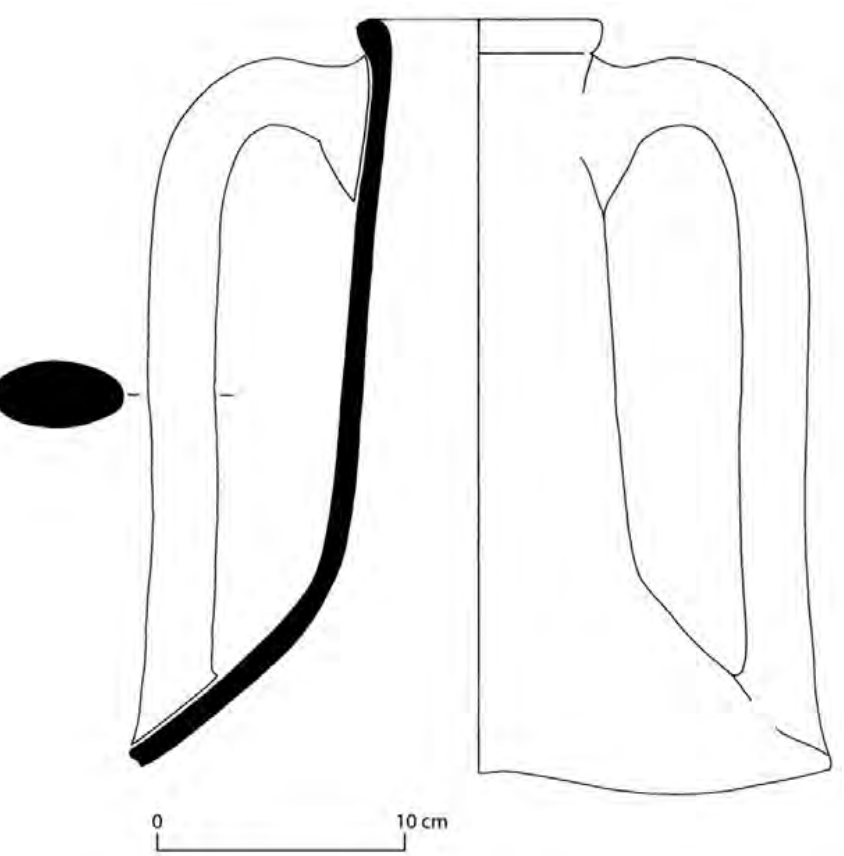
Planche 56

DP 13
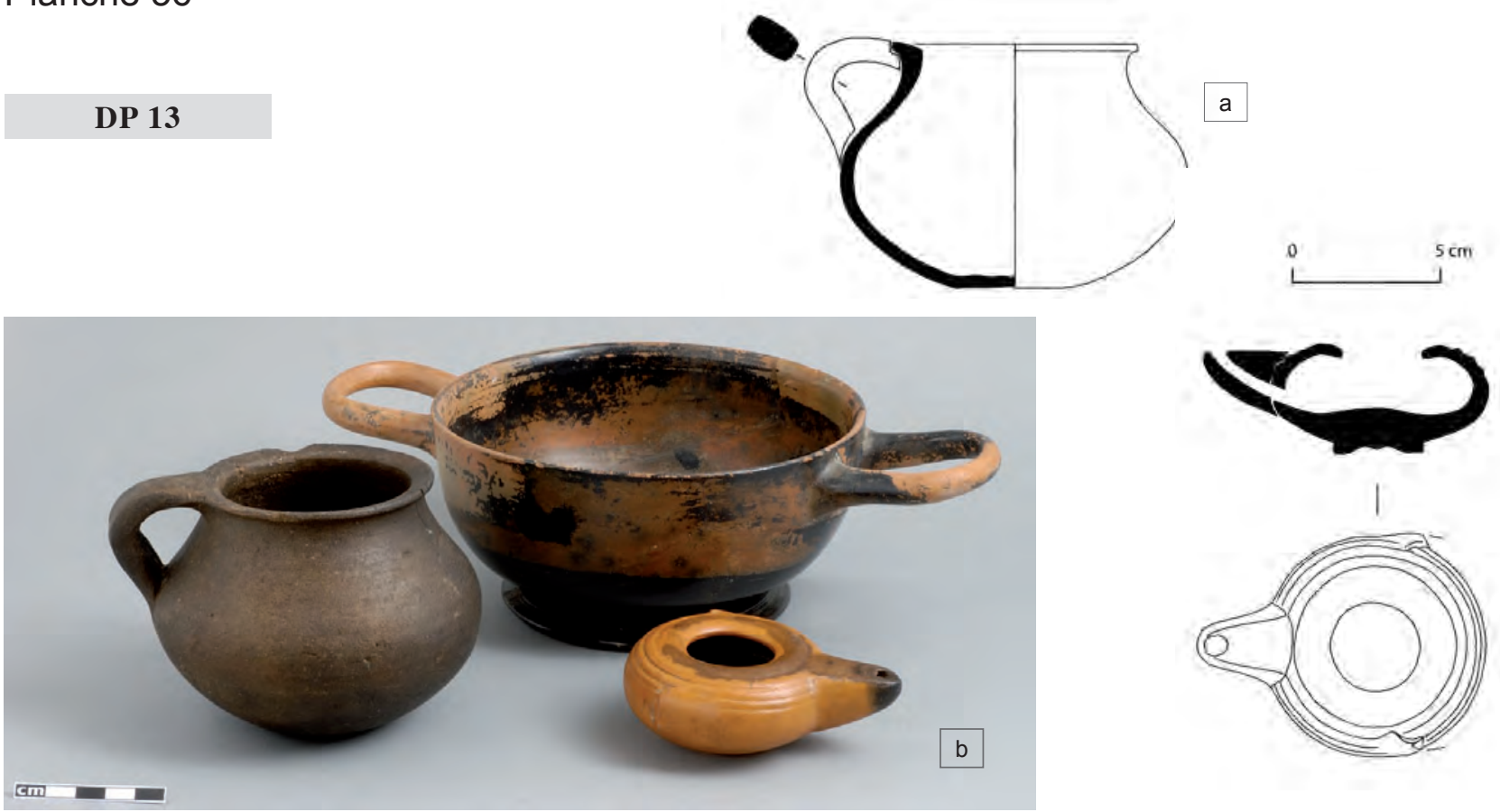

c

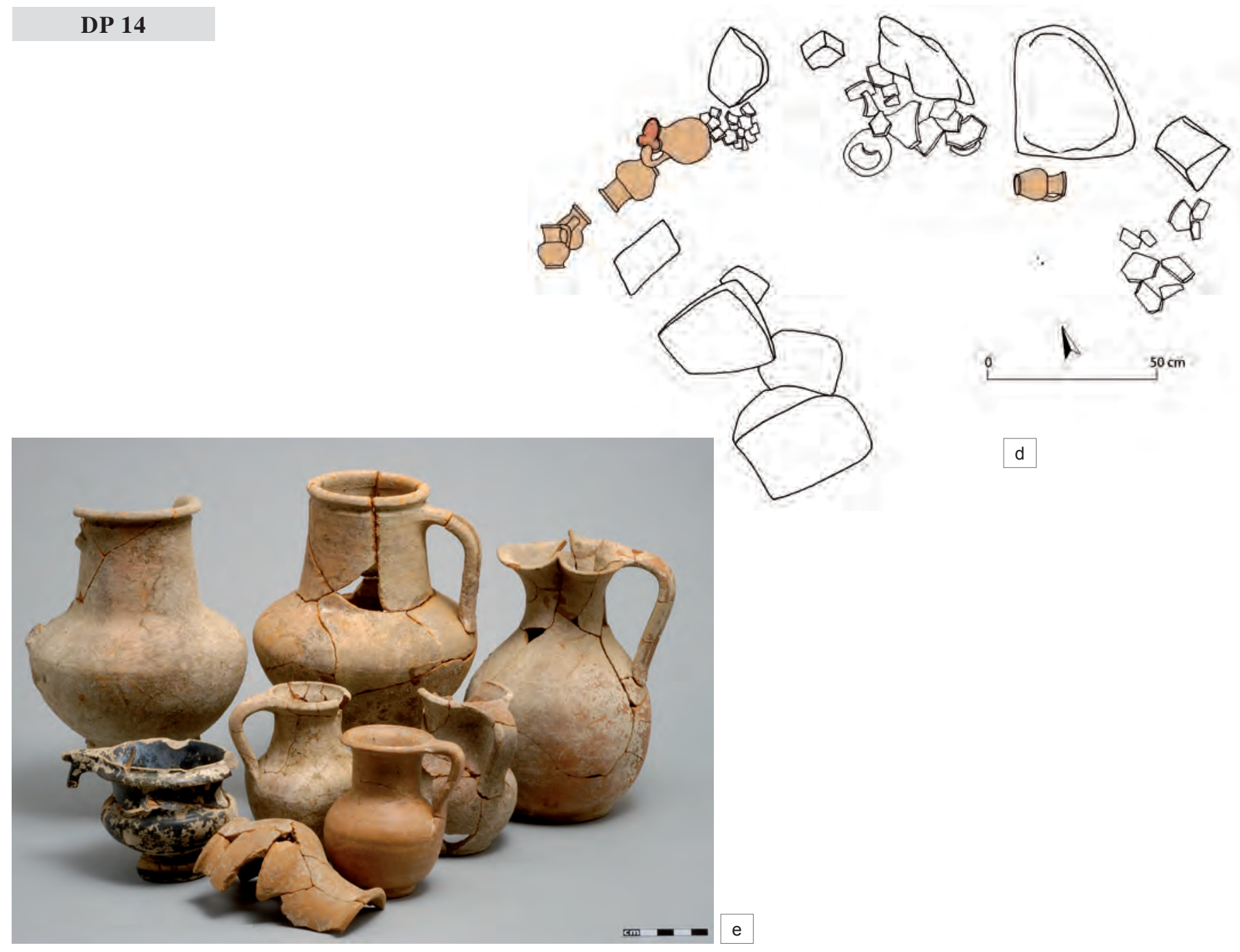


Planche 57

DP 15

a
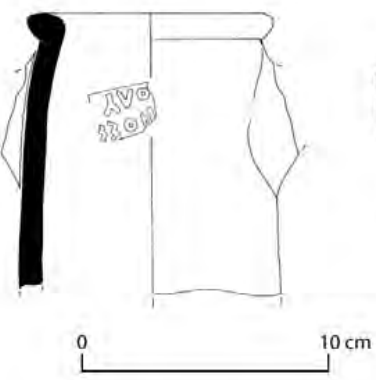
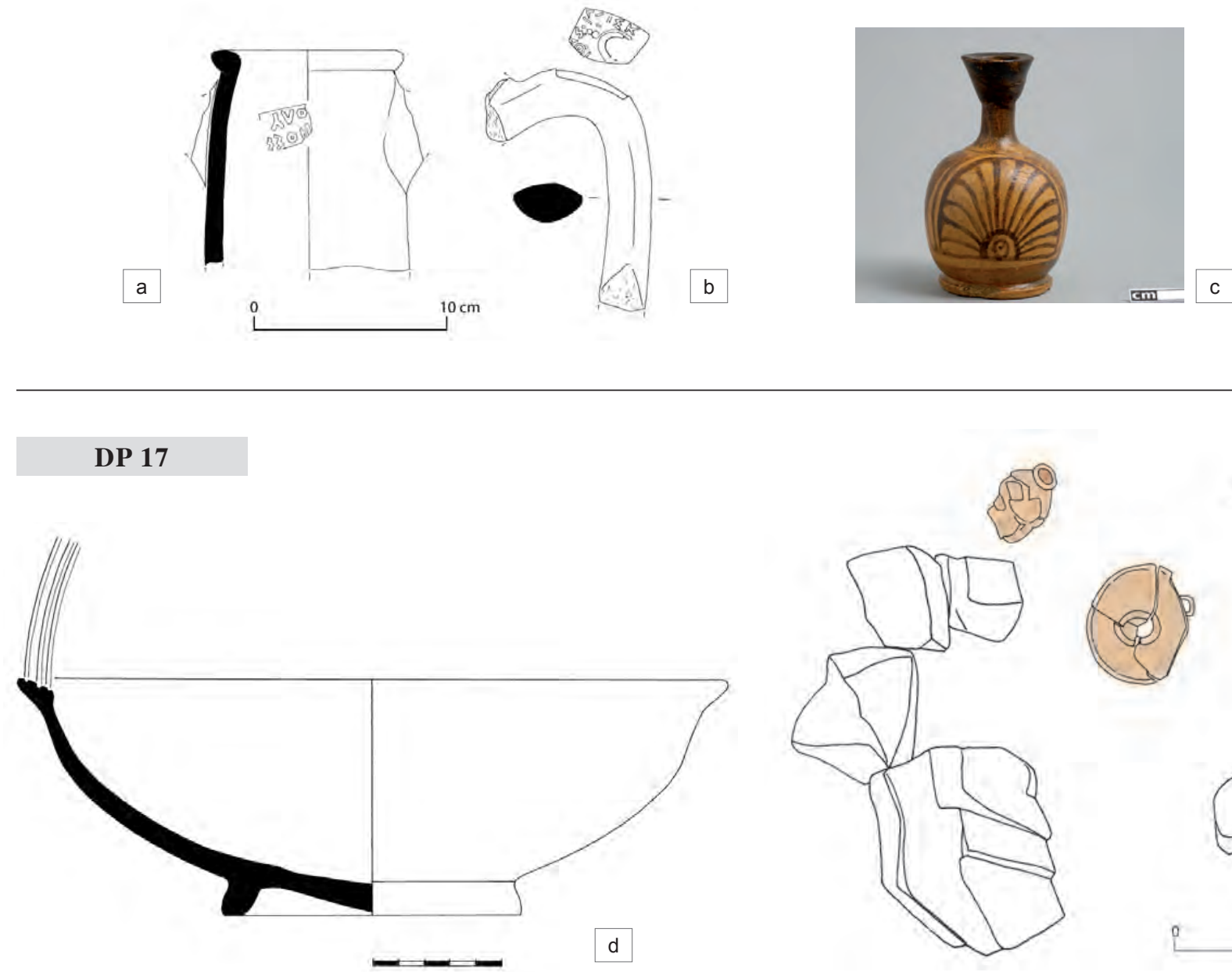

1
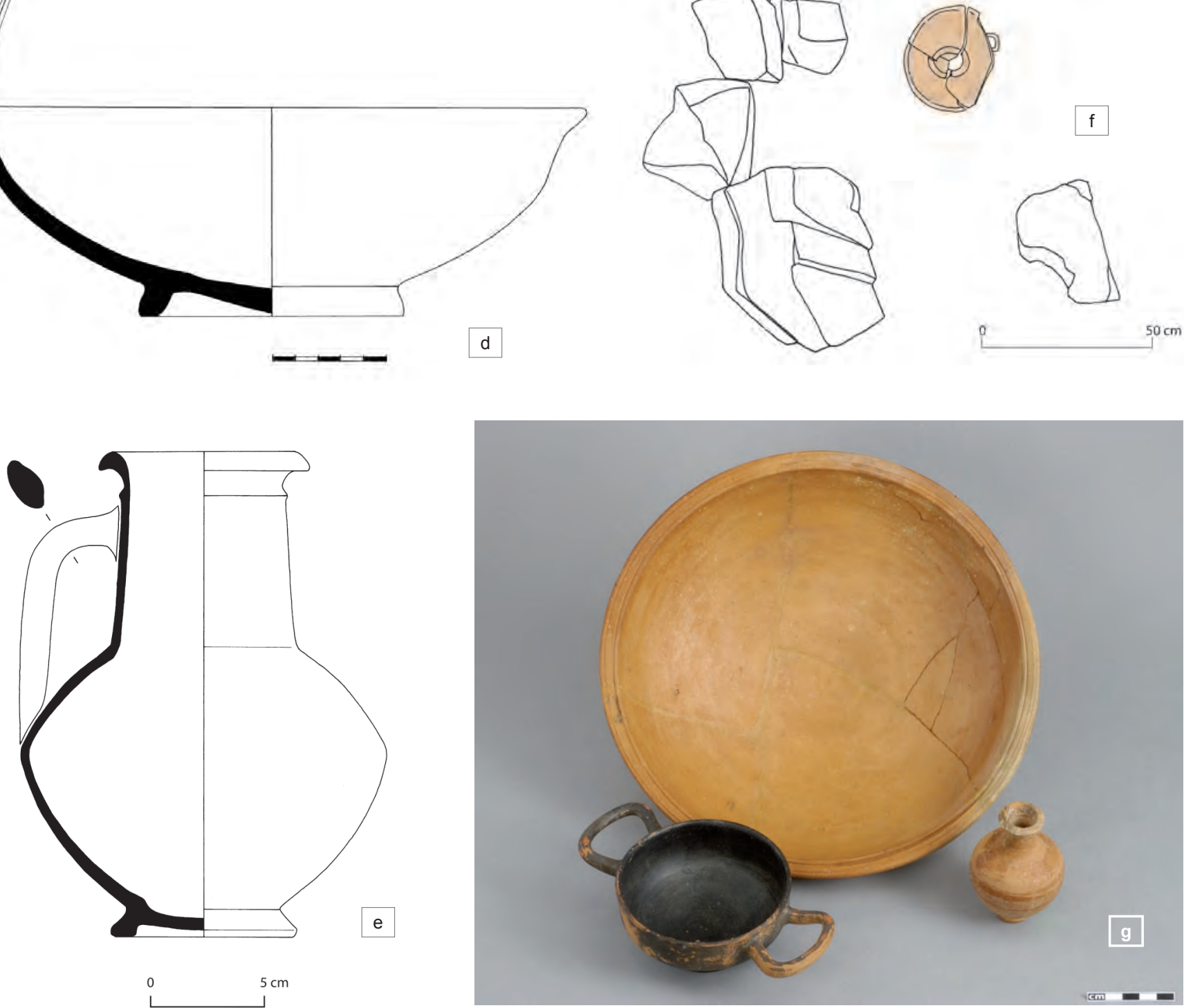
Planche 58

DP 18

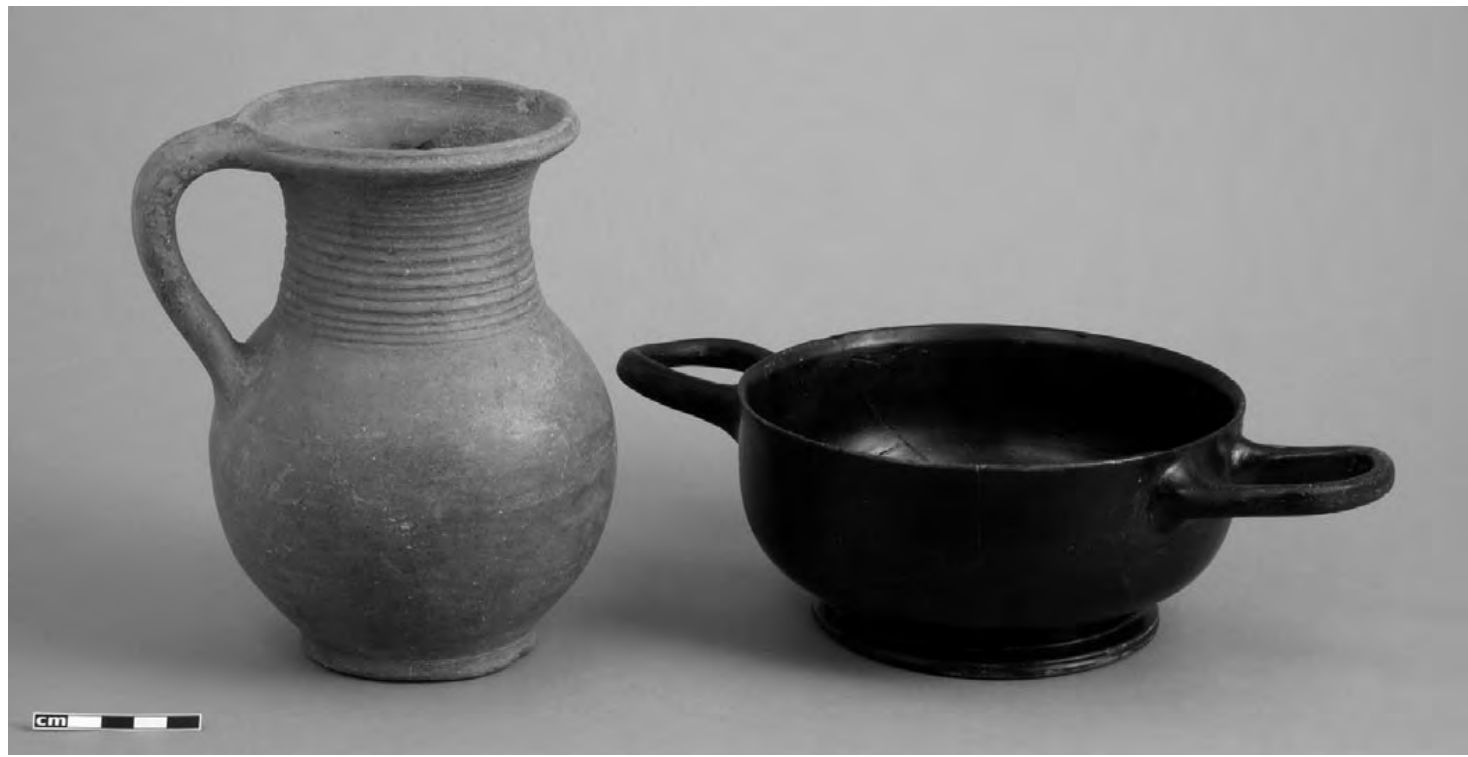

DP 21

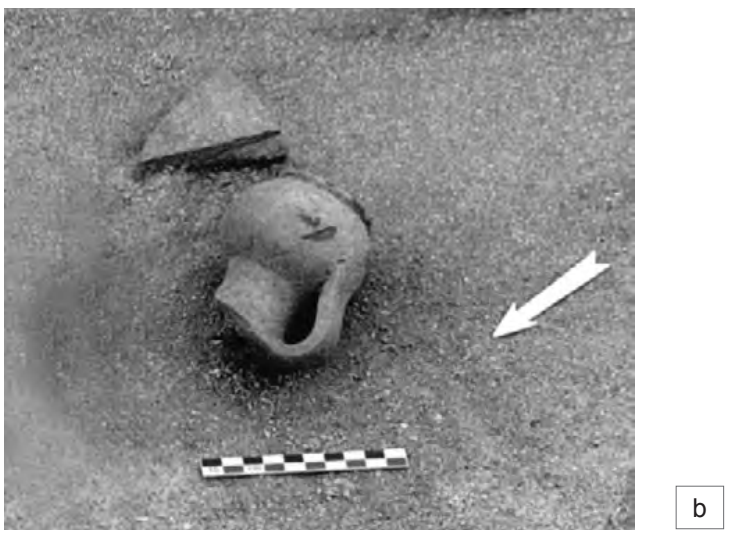

DP 22

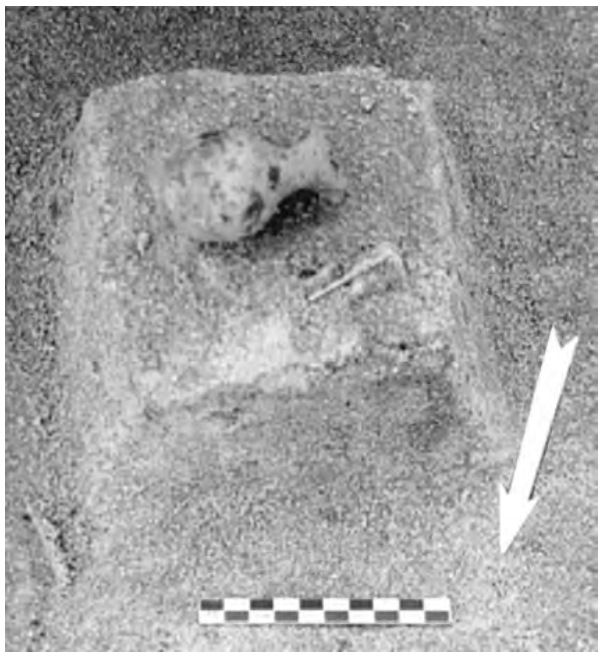

c

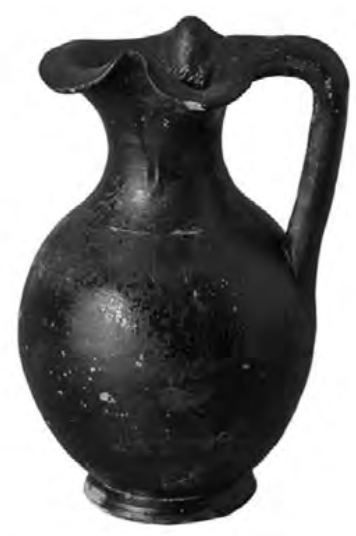


Planche 59
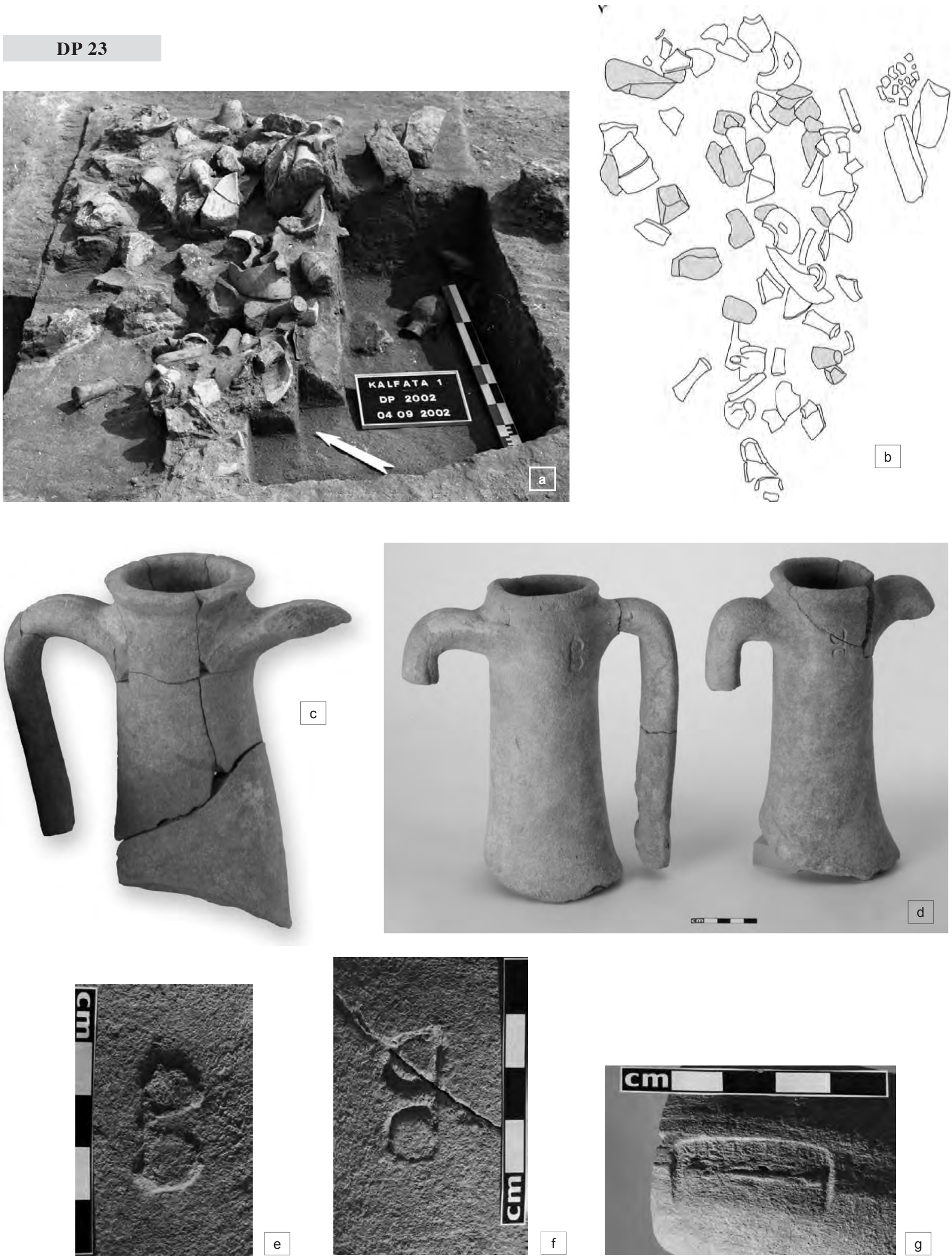
Planche 60

DP 23
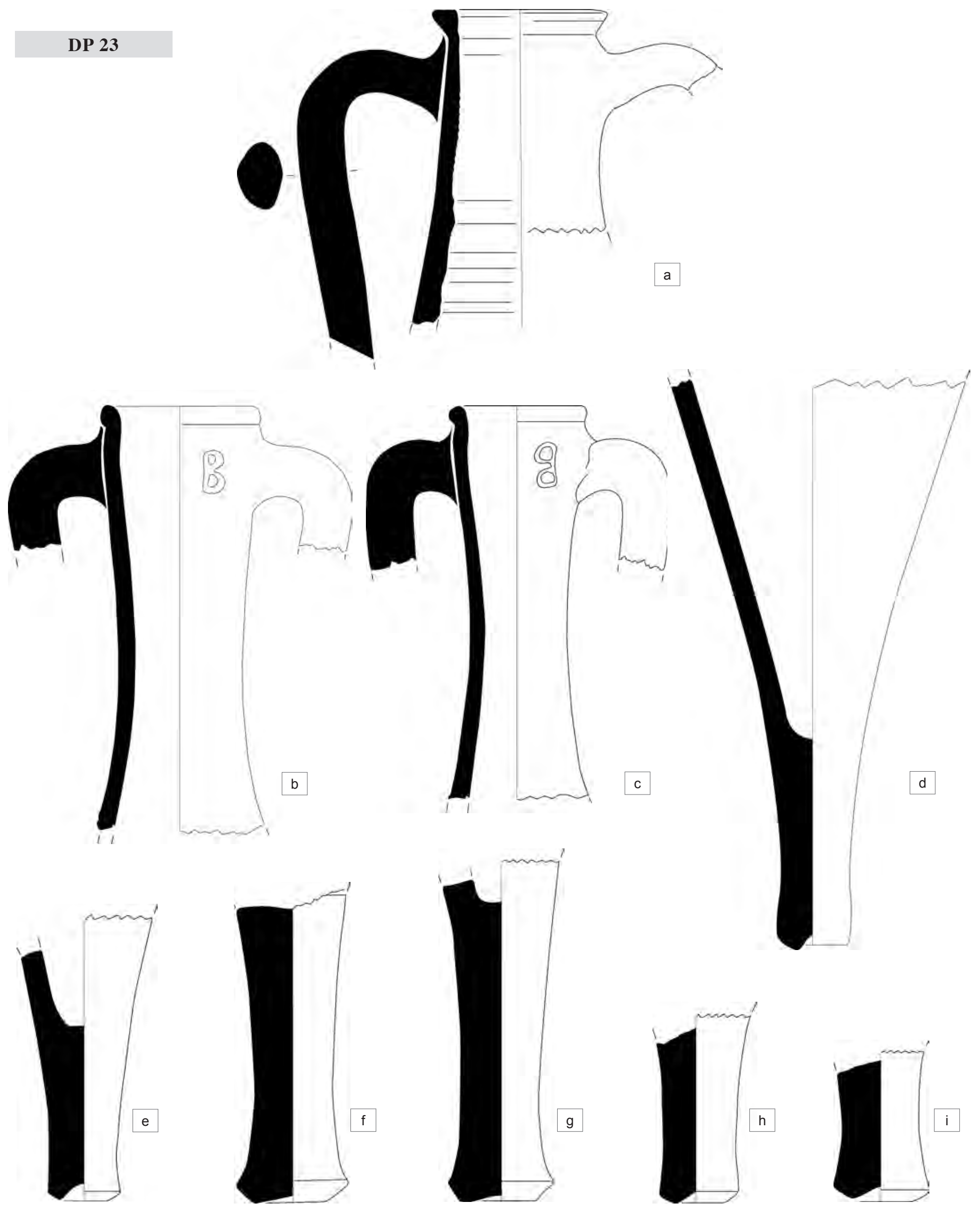

Échelle $1: 3$ 
Planche 61

DP 24
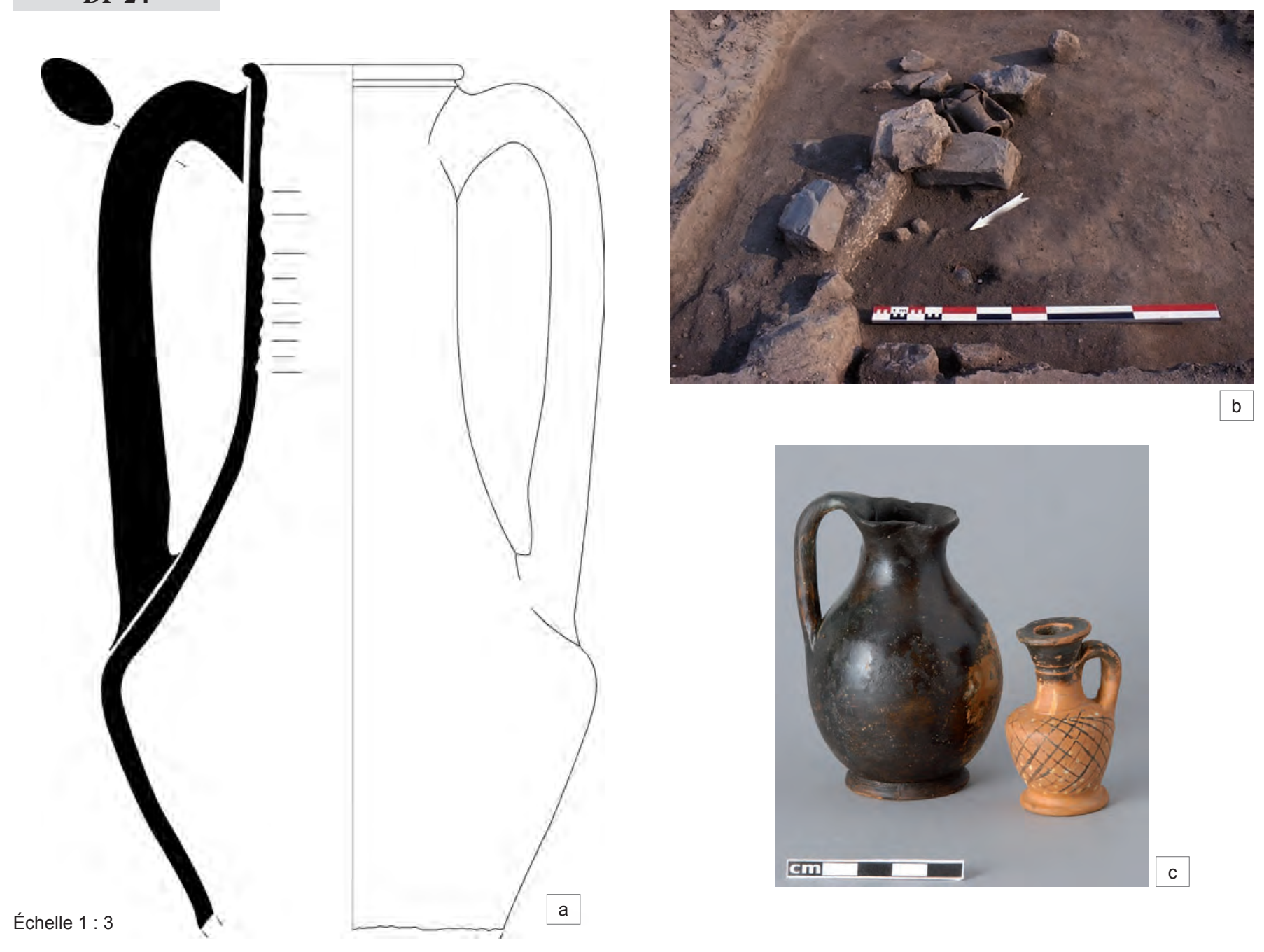

DP 25
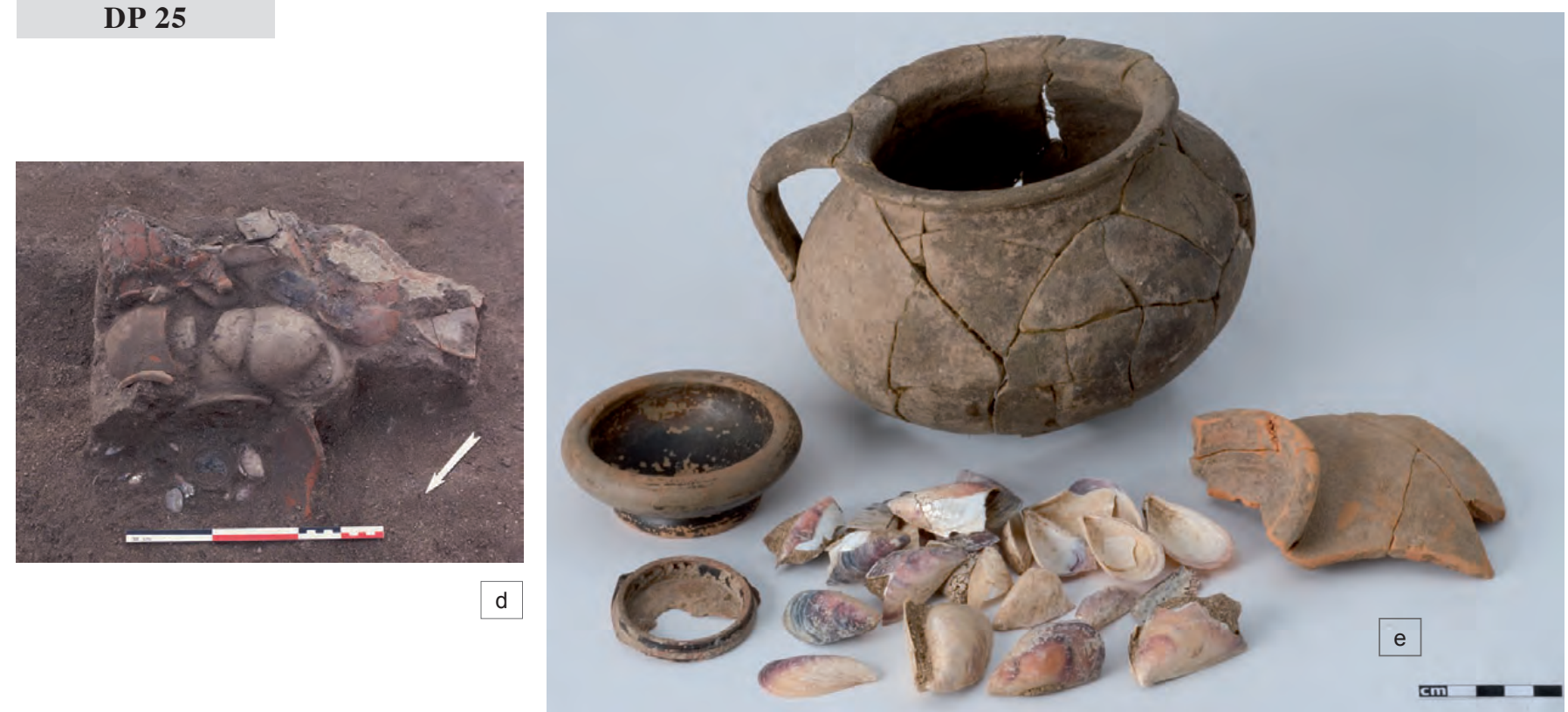
Planche 62

DP 26
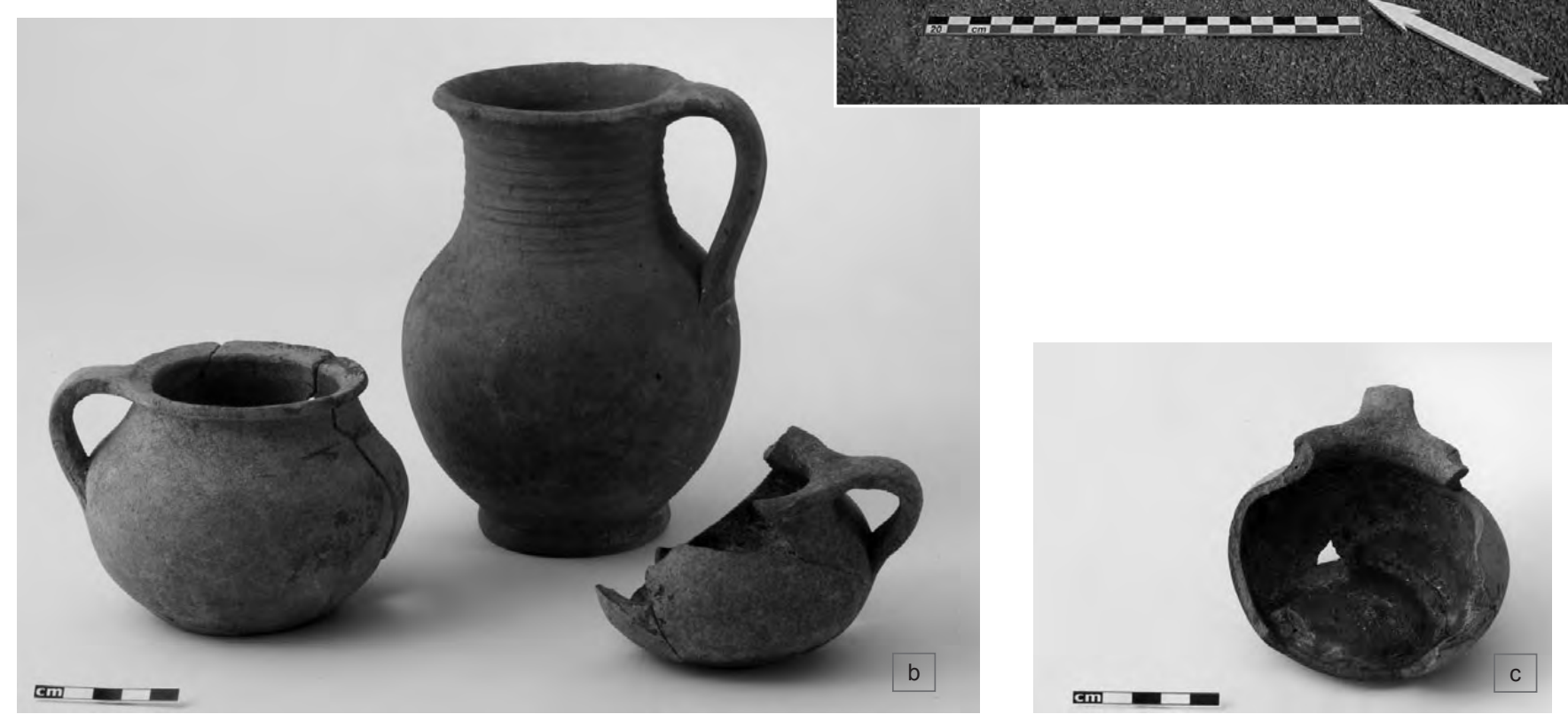

DP 27

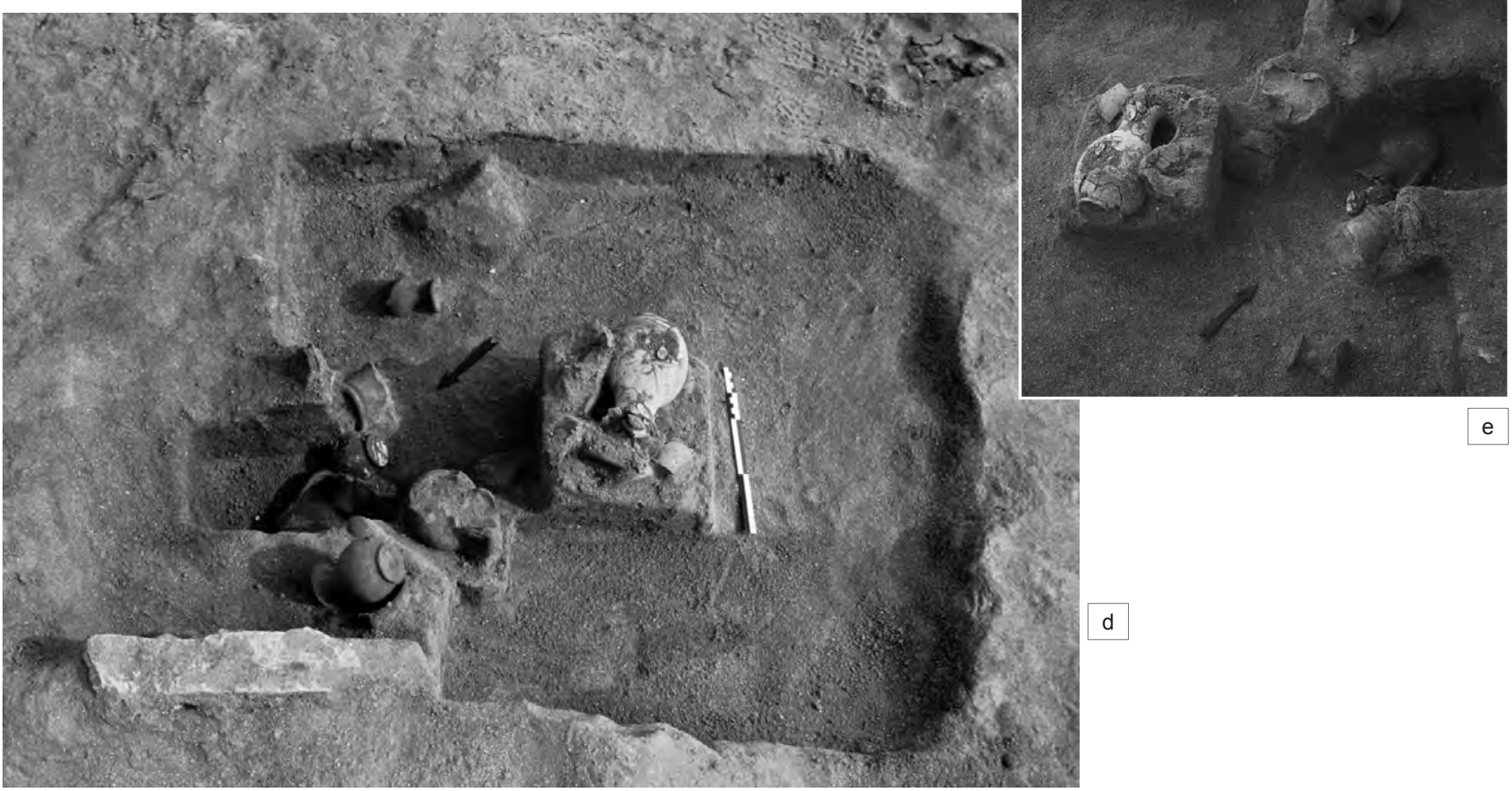


Planche 63

DP 27
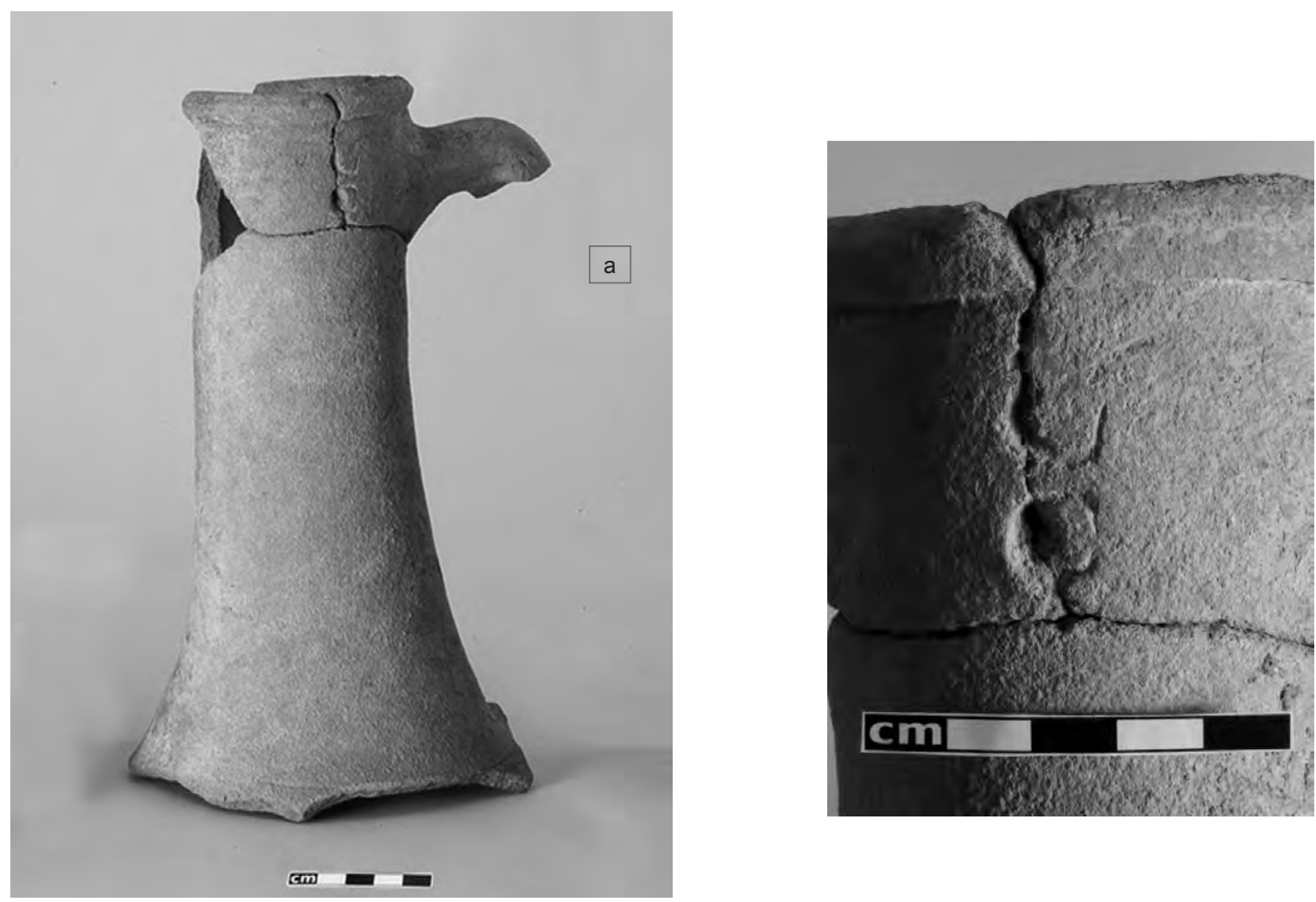

$\mathrm{b}$

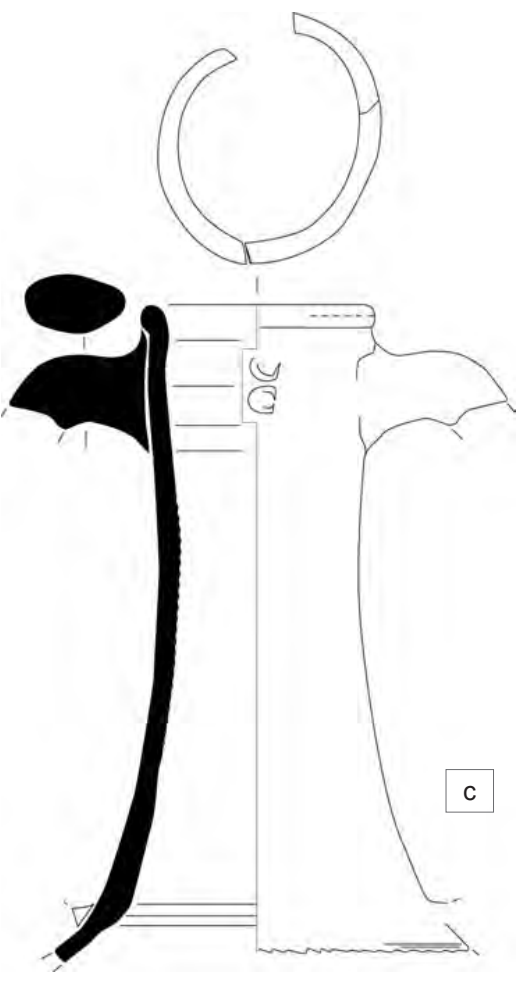

Échelle 1:4

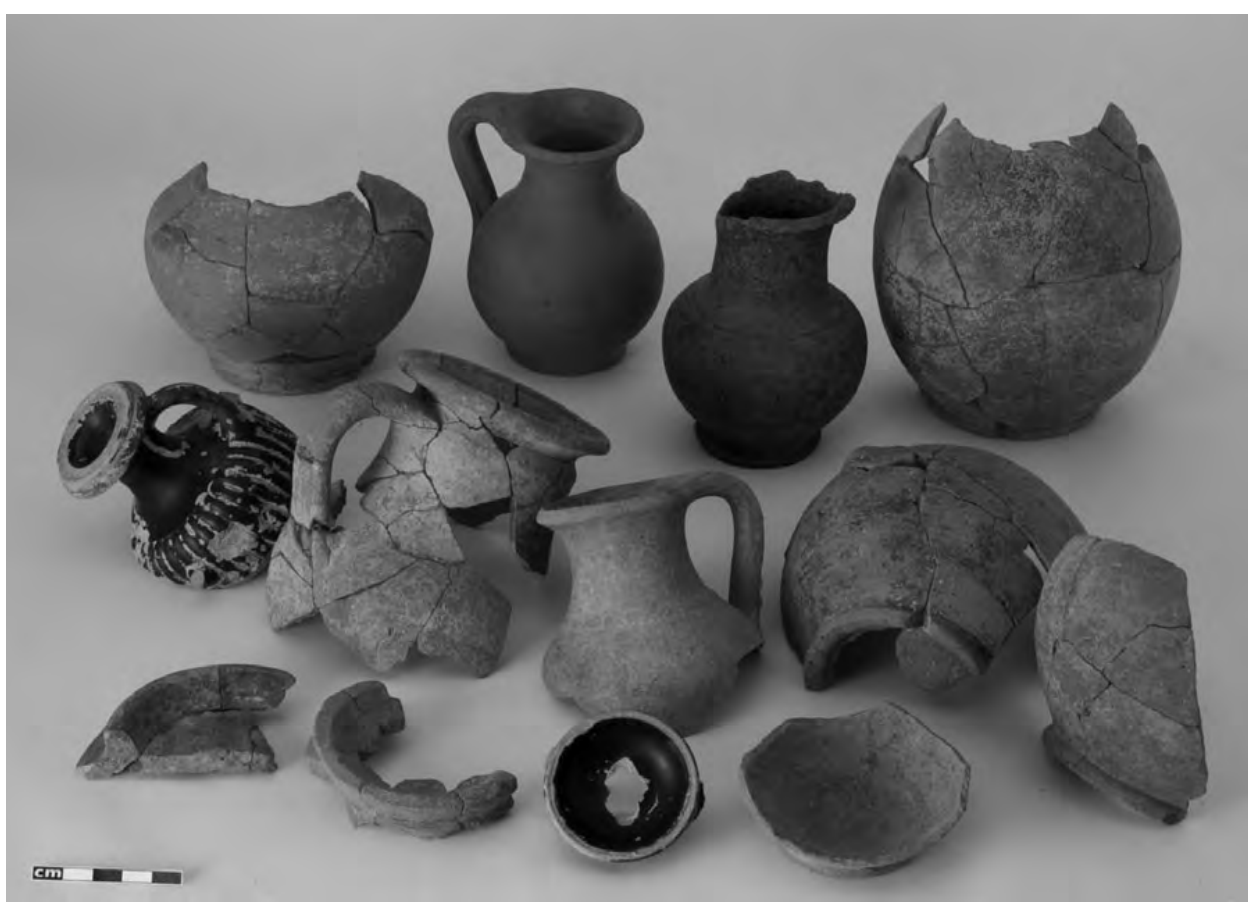


Planche 64

DP 28

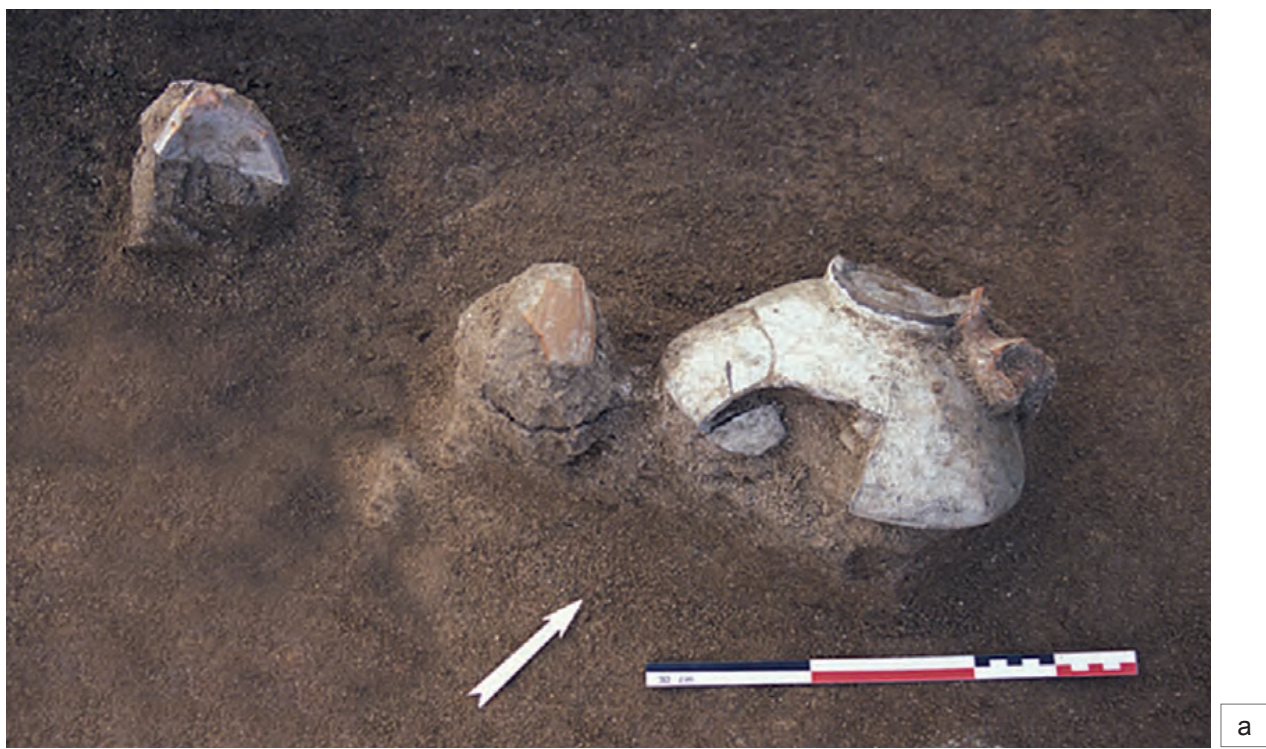

DP 29
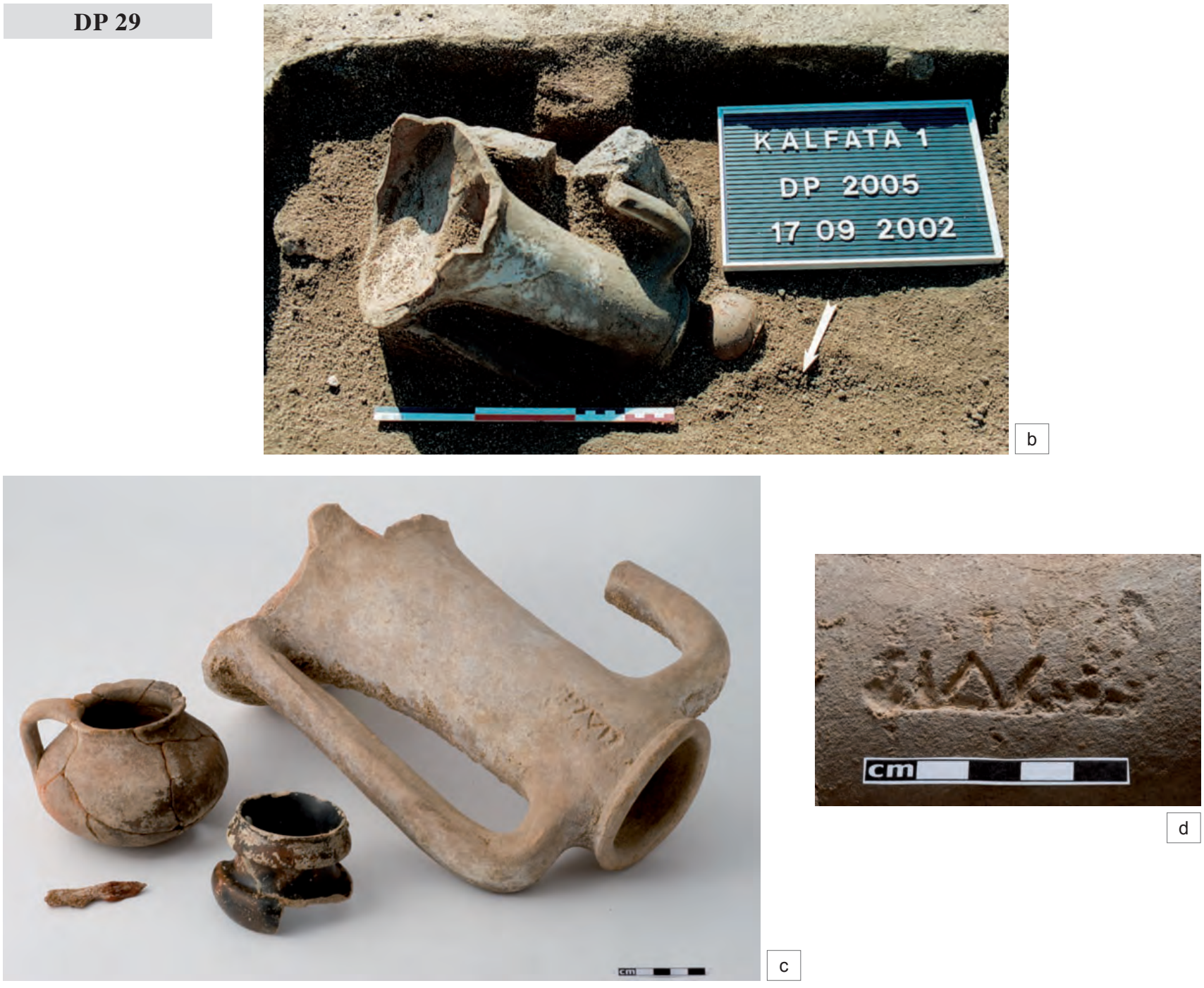
Planche 65

DP 29
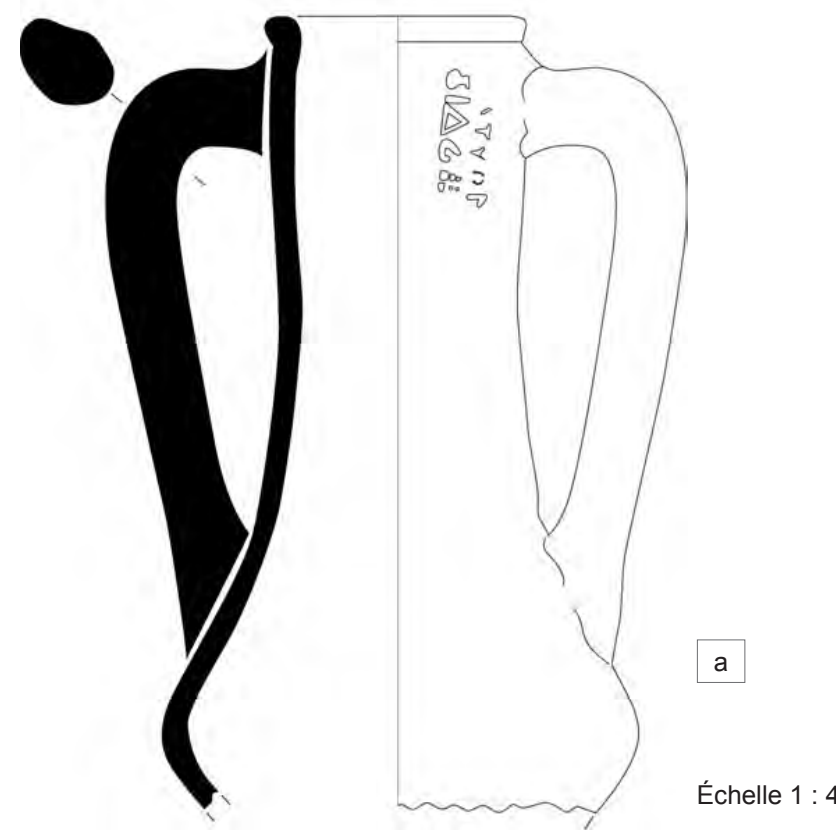

DP 30-31
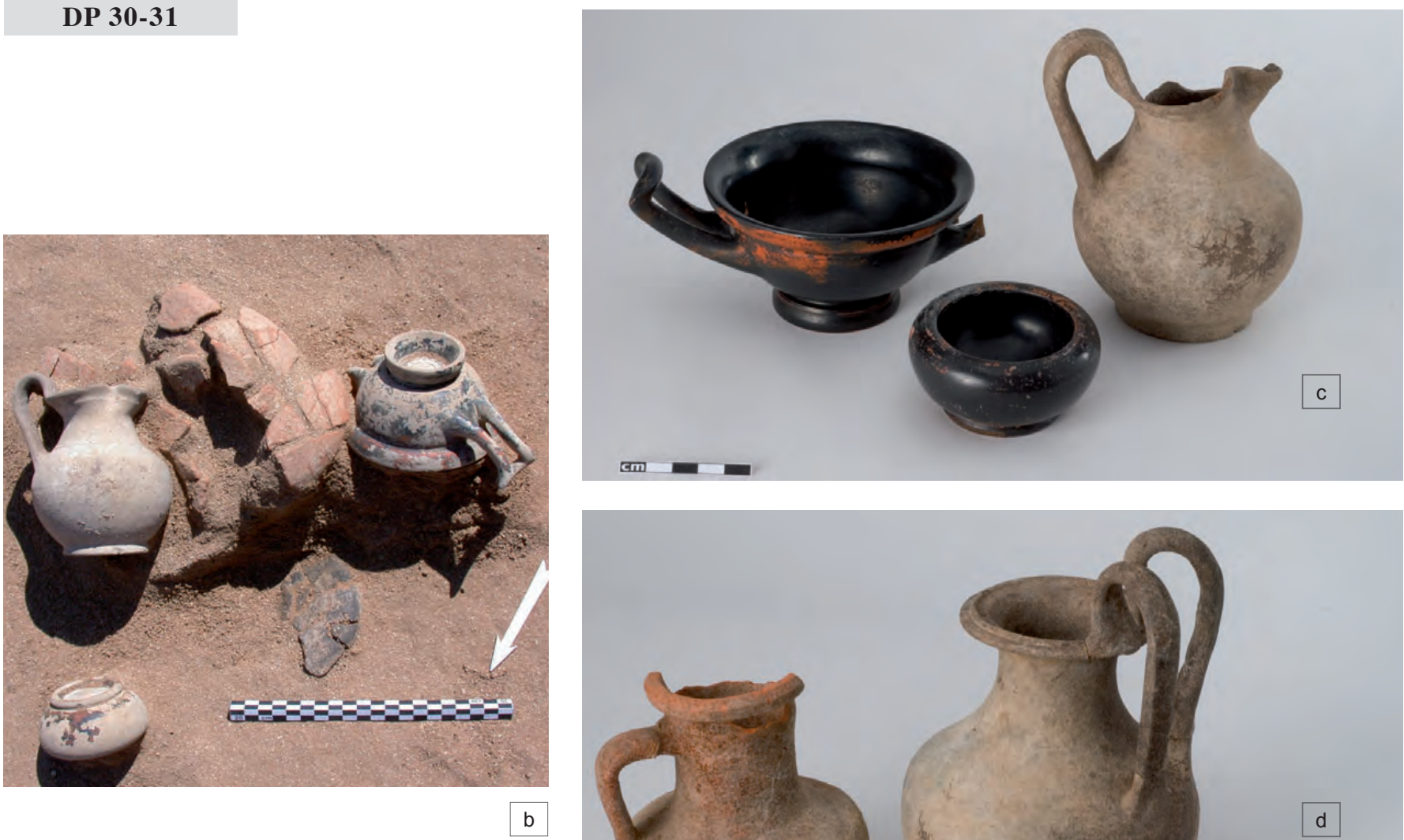

Ce vase n'appartient pas au dépôt

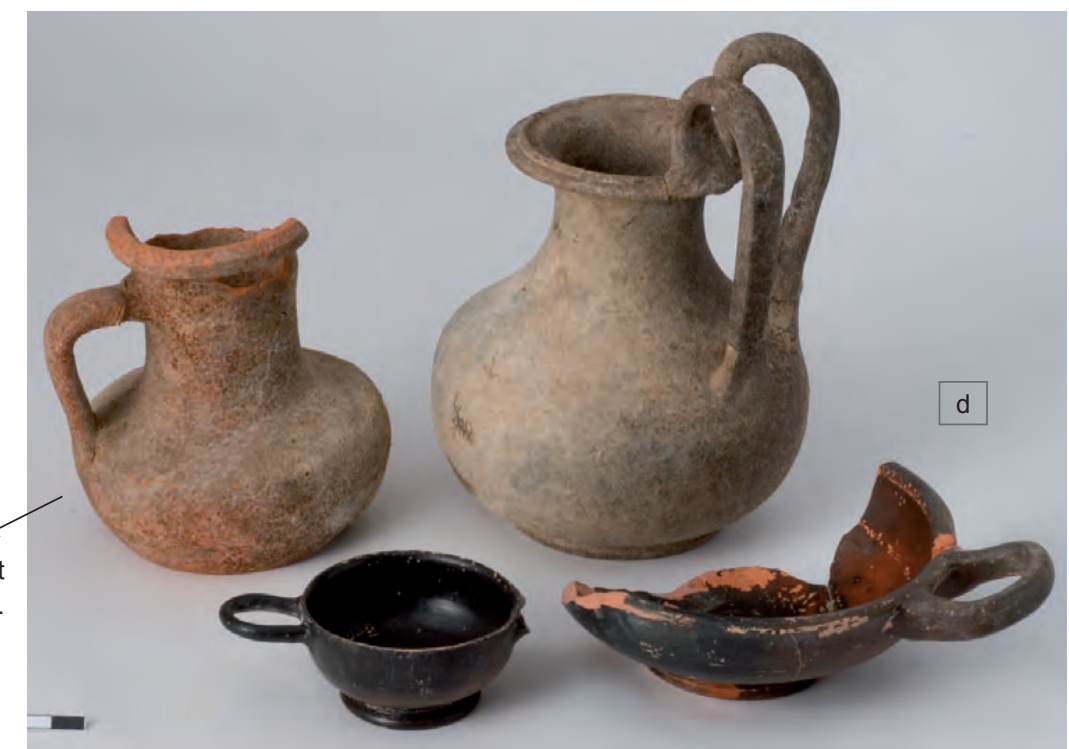


Planche 66

DP 32
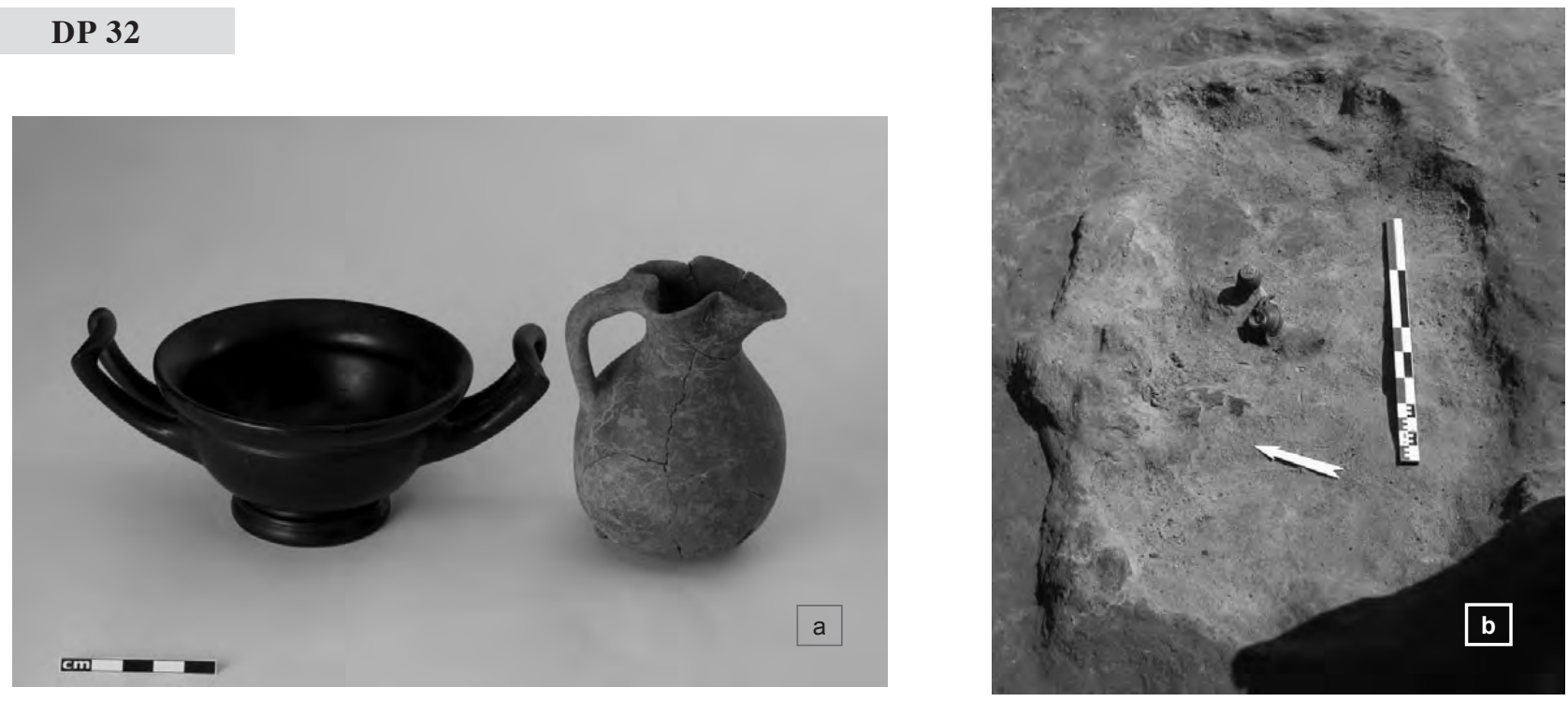

DP 33
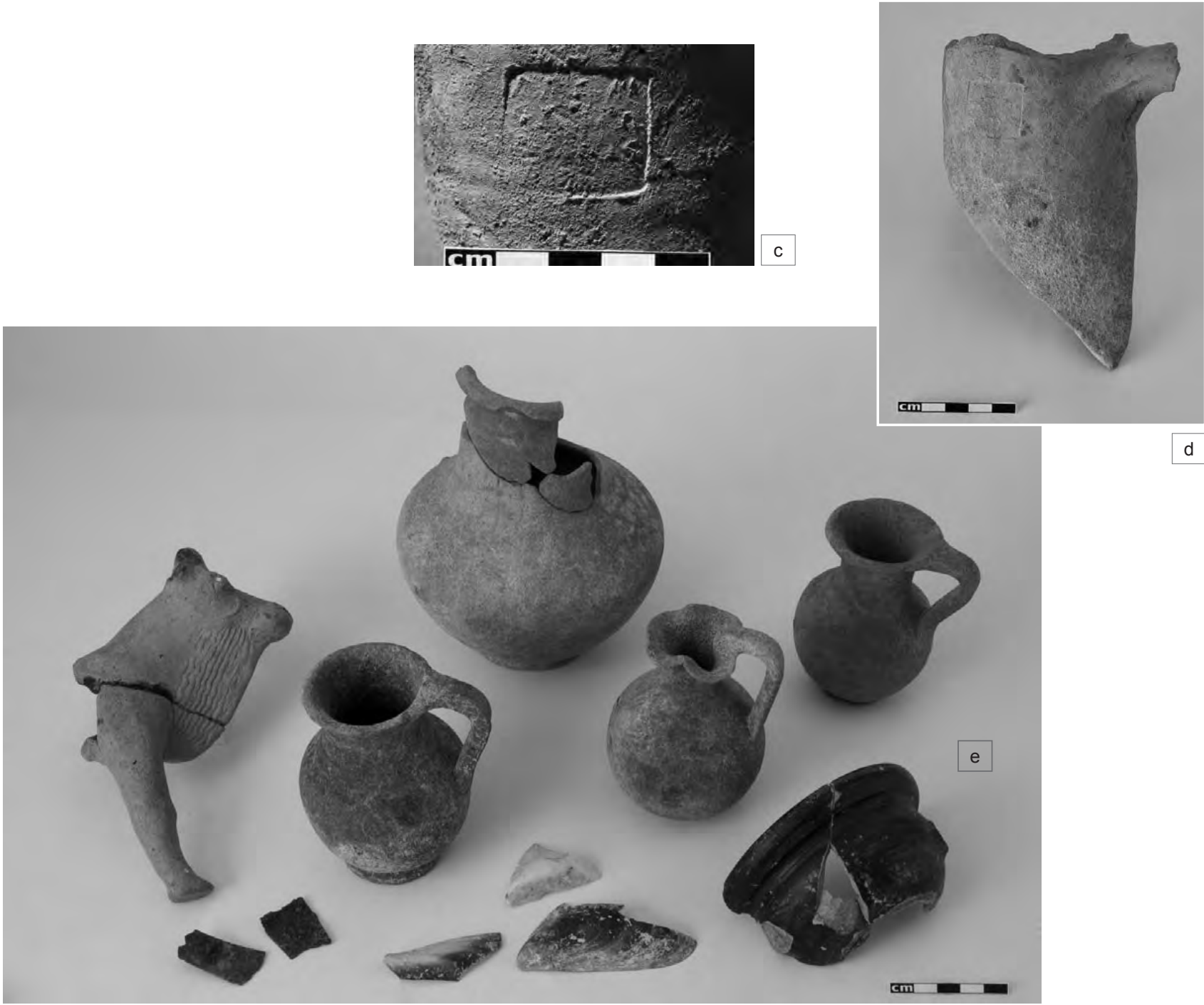

d 
Planche 67

DP 33
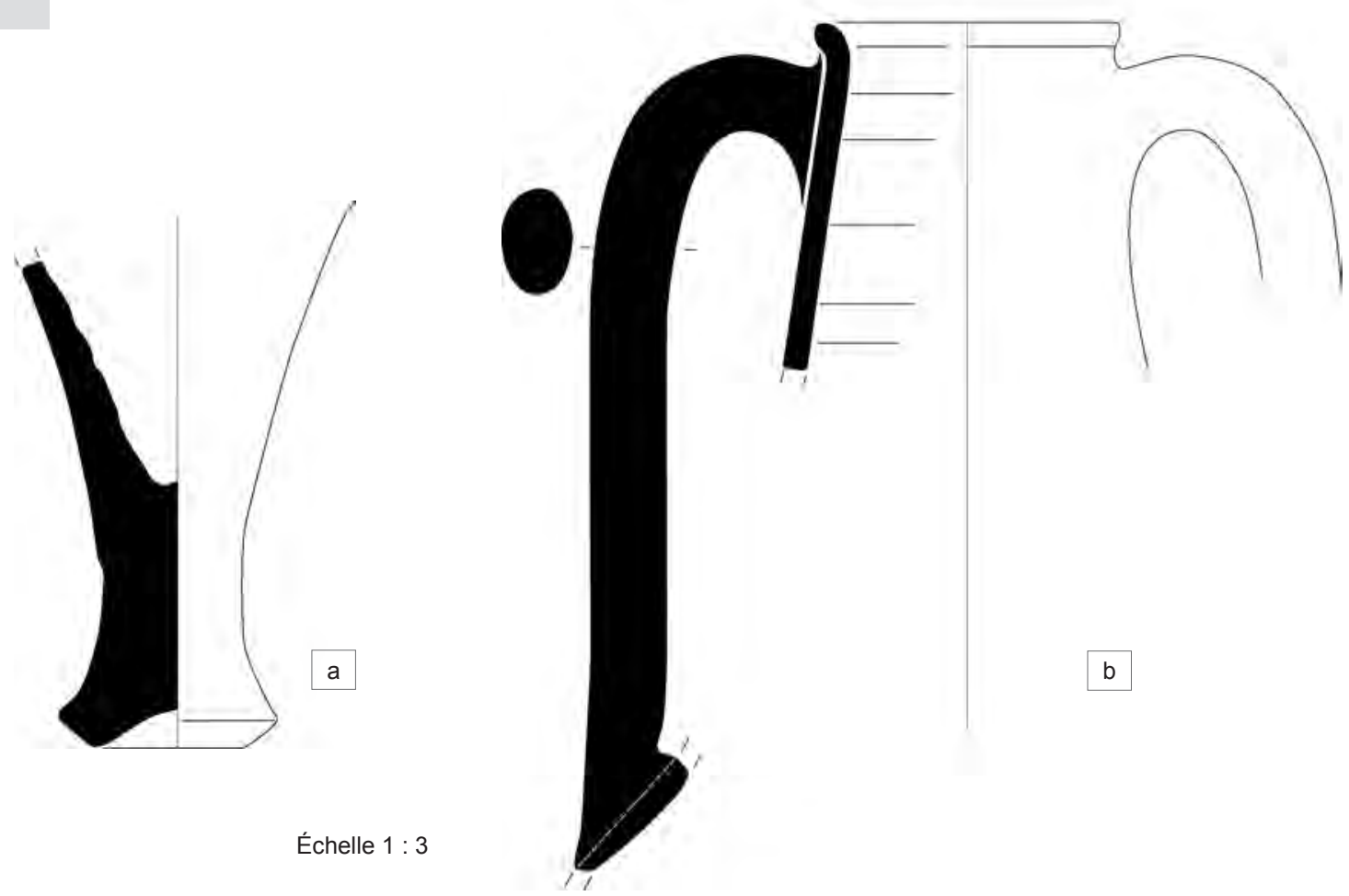

DP 34

Échelle $1: 3$

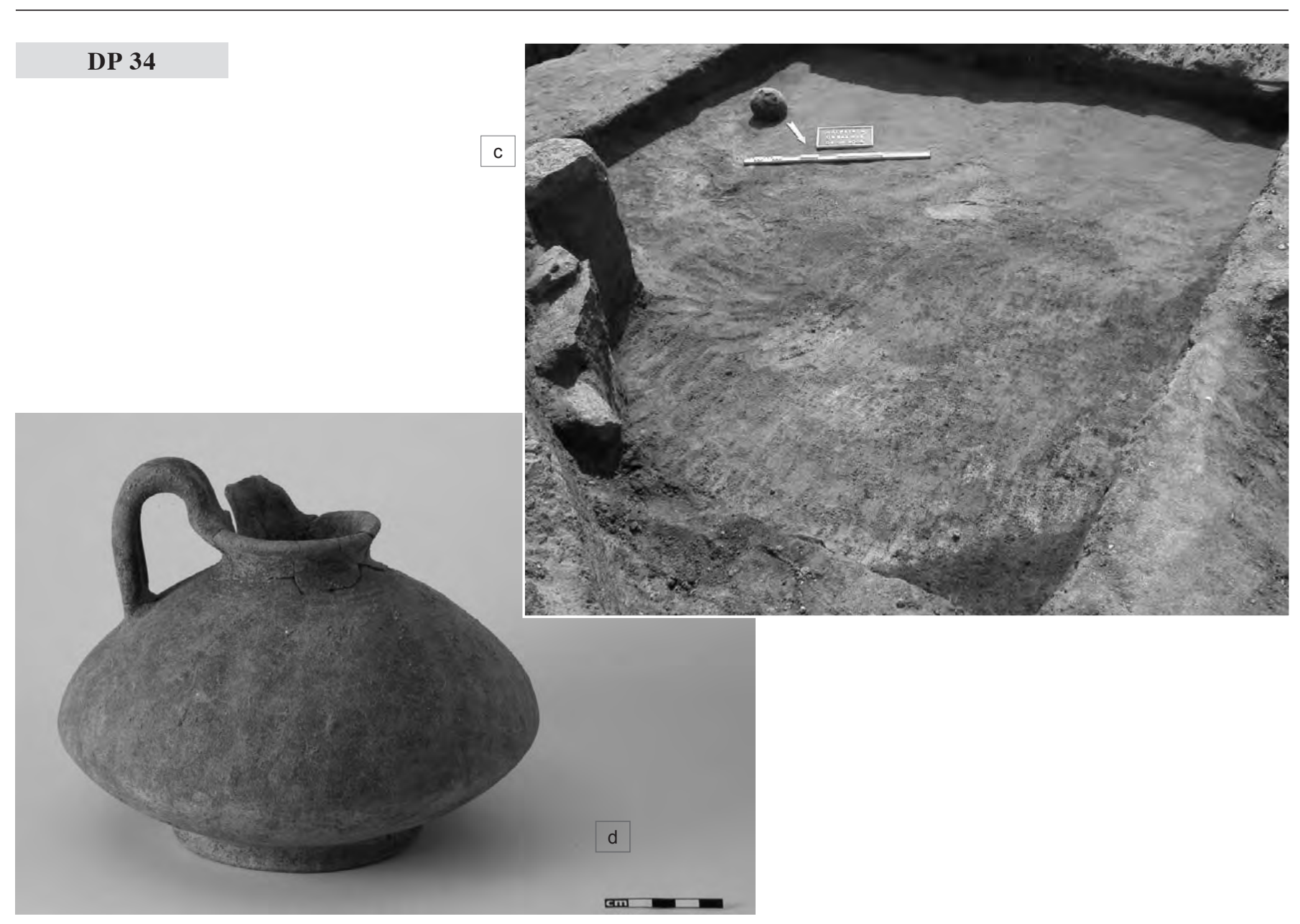


Planche 68

F 1

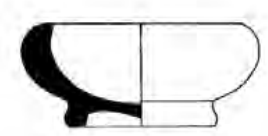

a

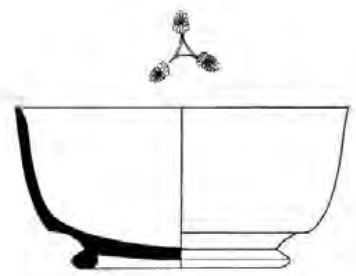

d
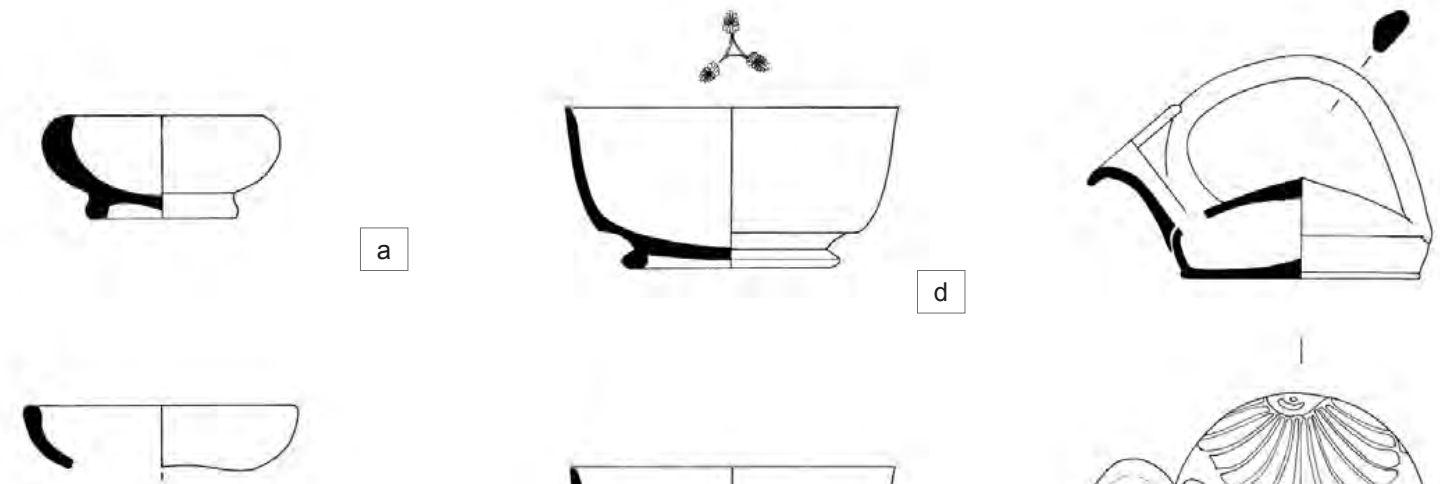

$\mathrm{b}$

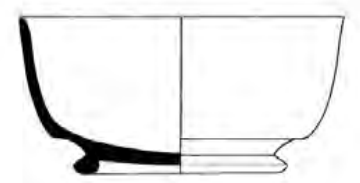

e
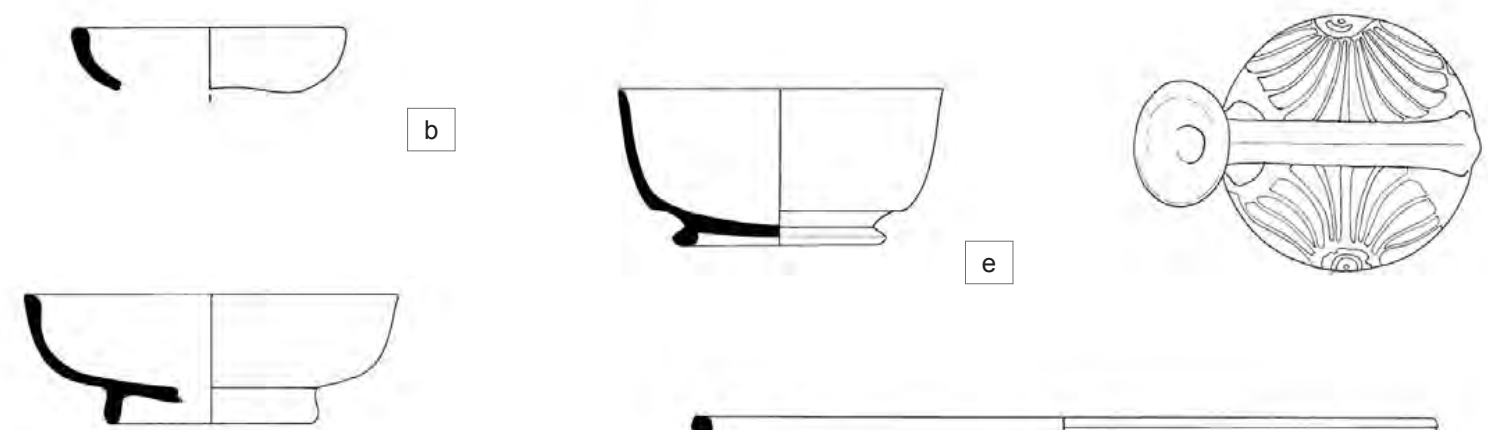

Échelle $1: 3$
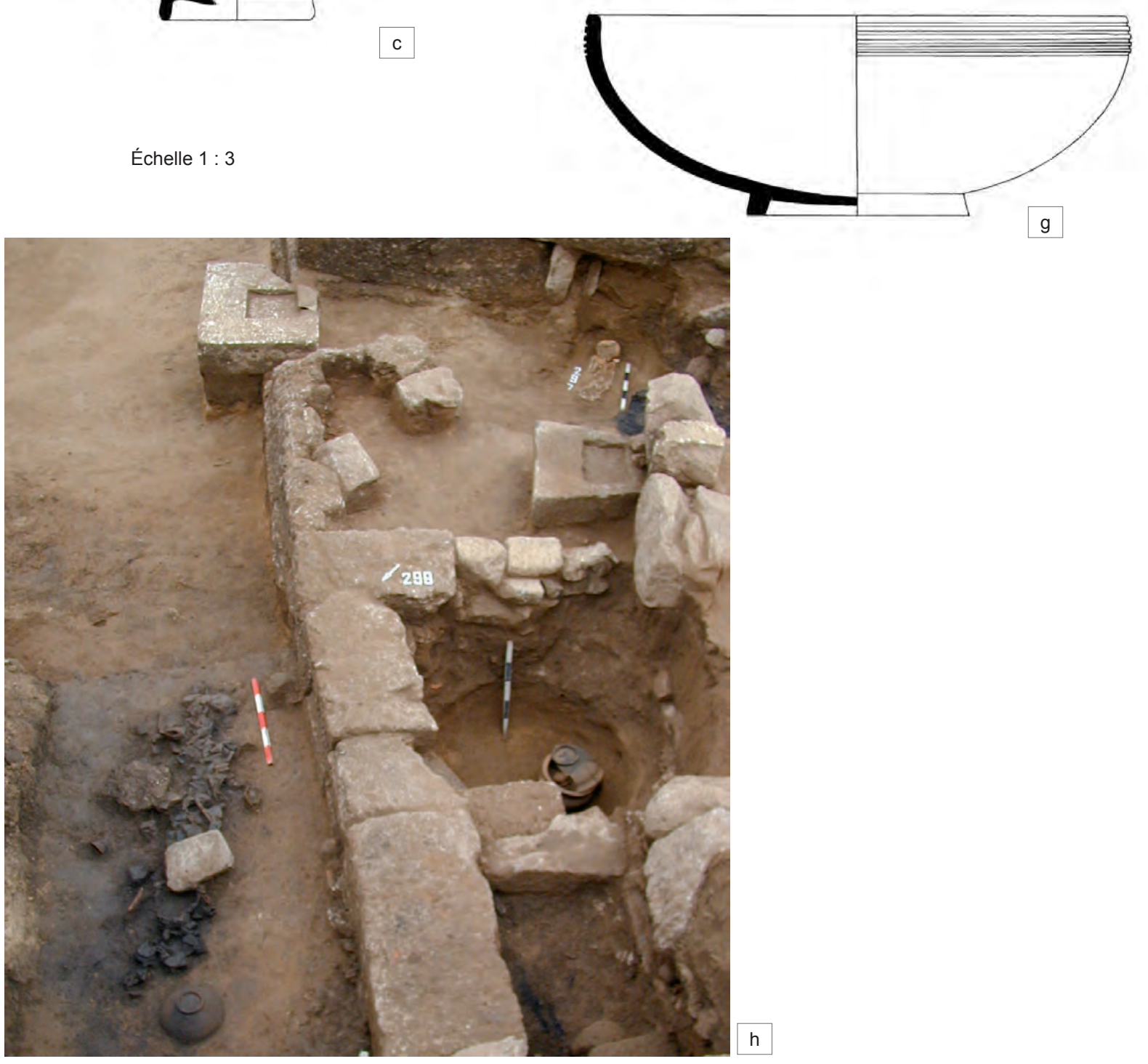
Planche 69

F 2
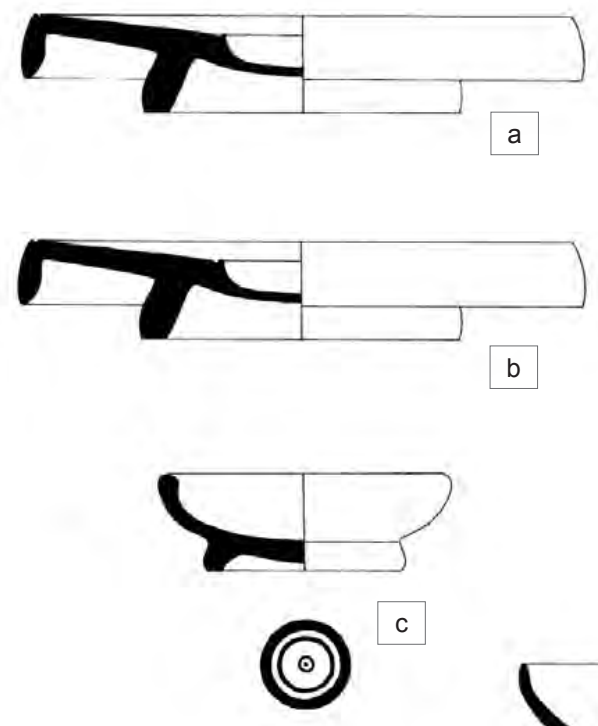

Échelle $1: 3$
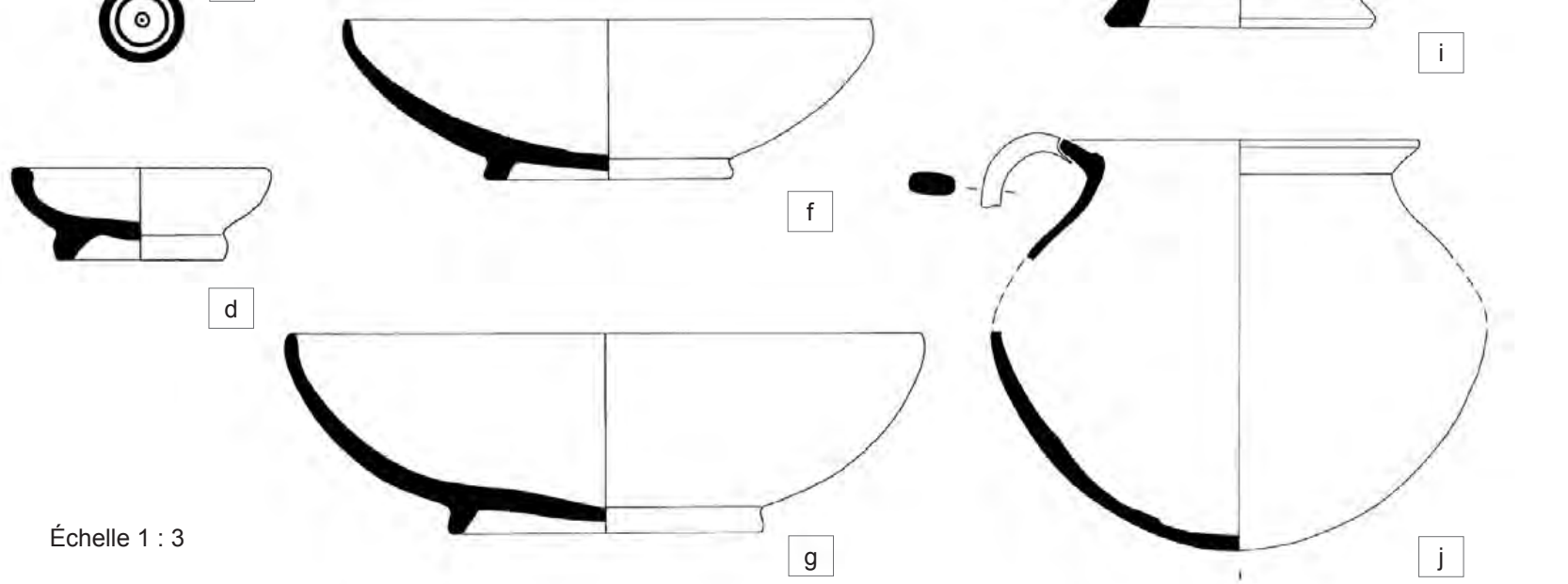

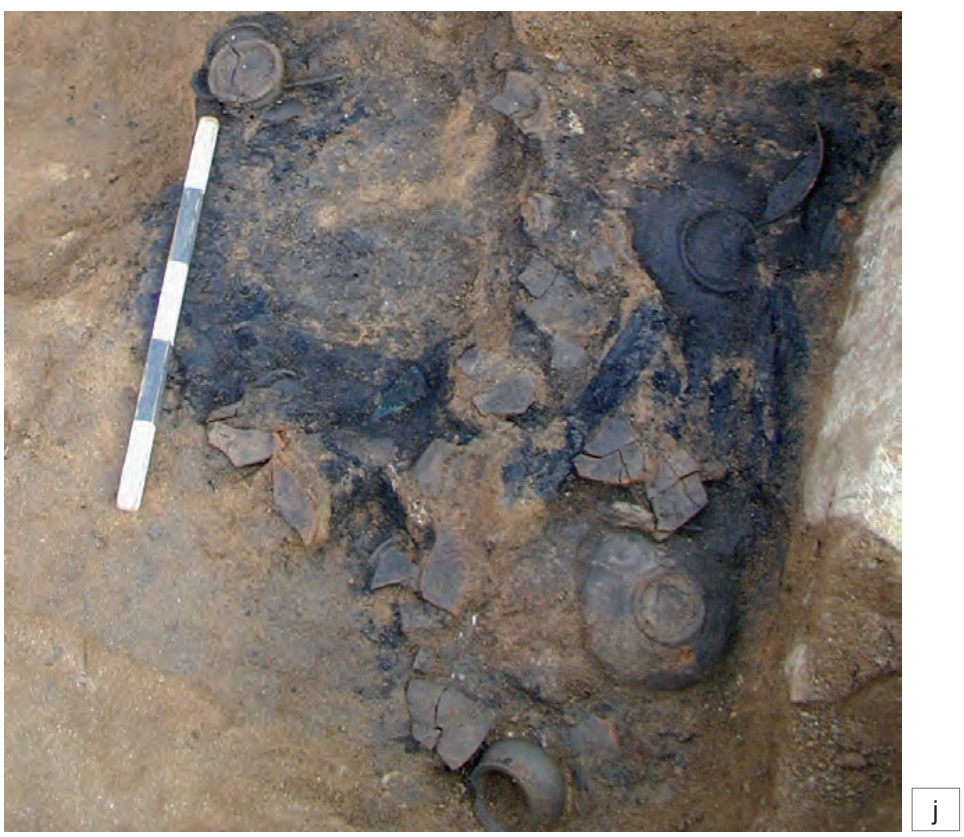


Planche 70

F 4
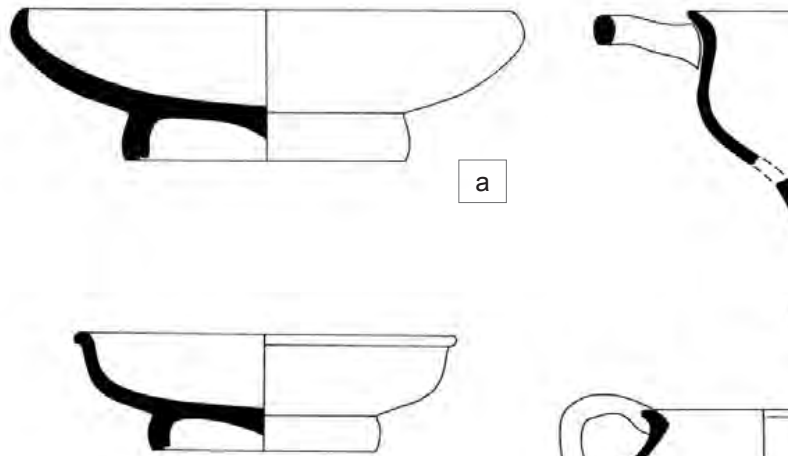

a

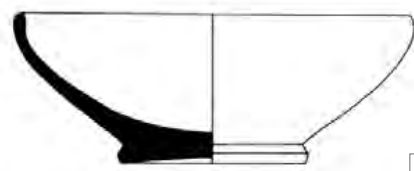

b
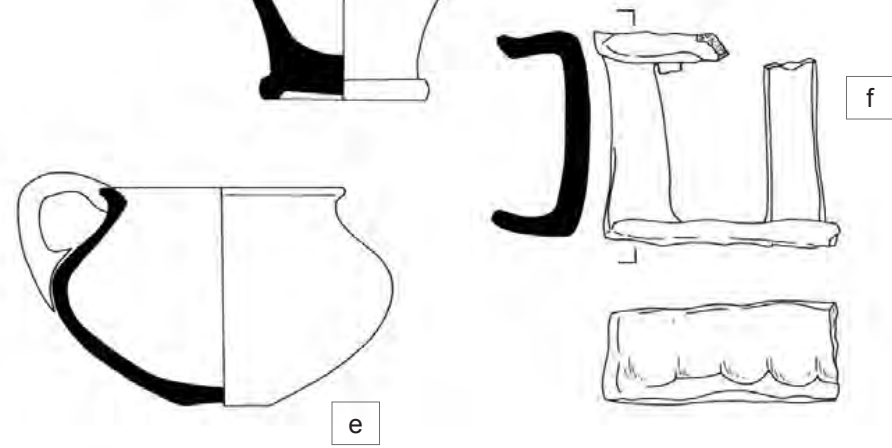

c

Échelle $1: 3$
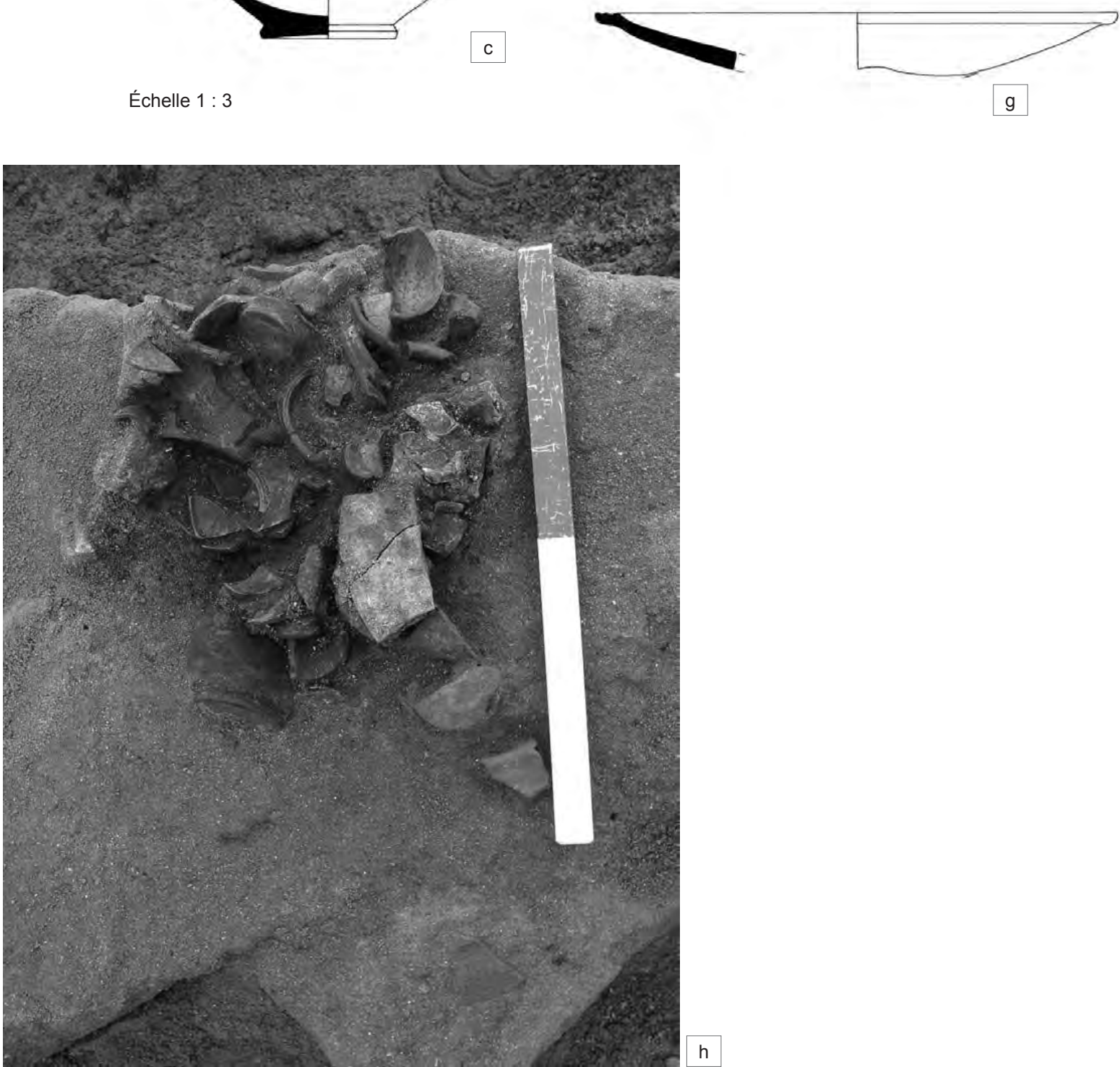
Planche 71

F 5
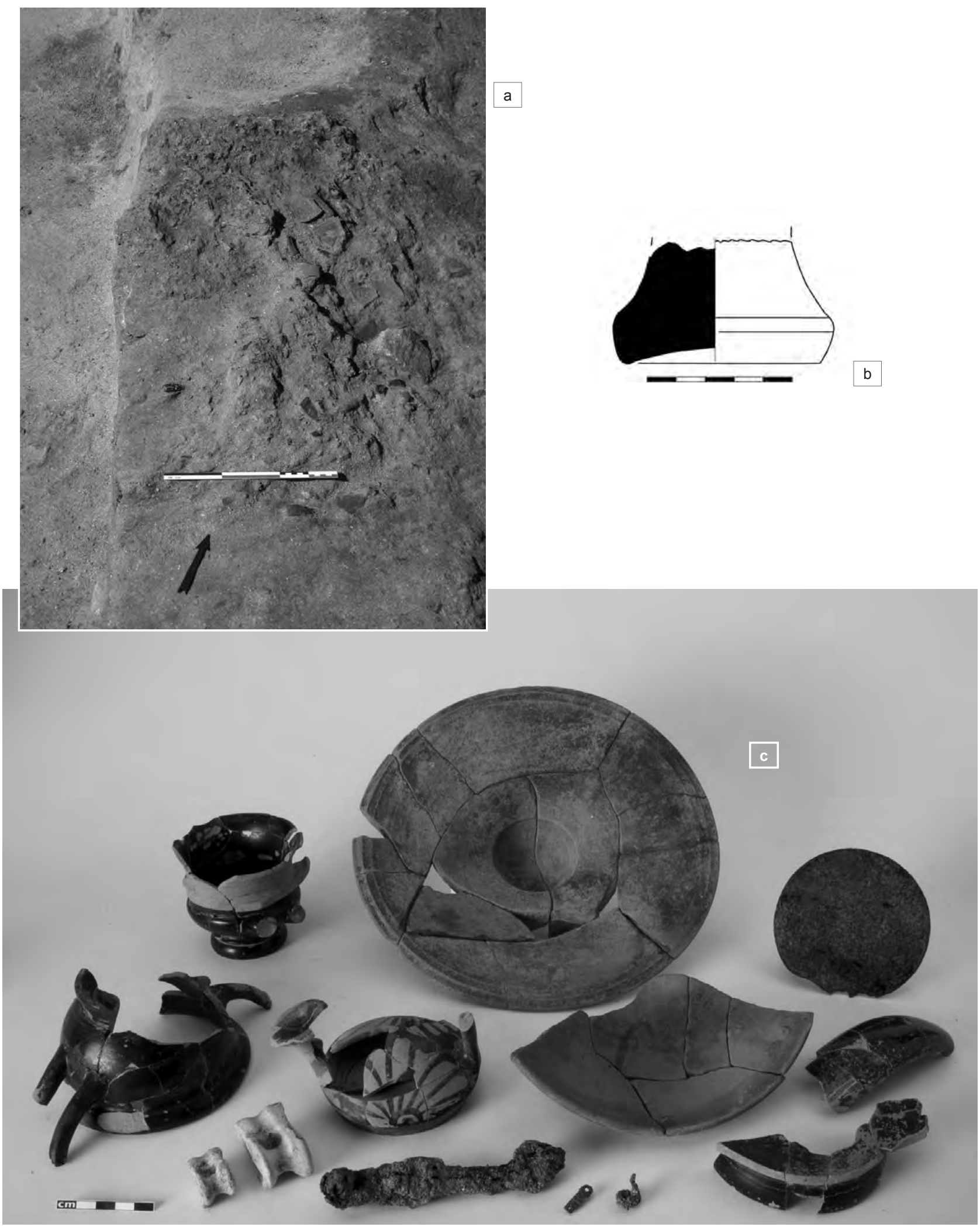
Planche 72

F 6

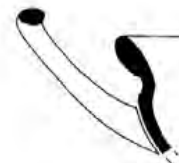

I
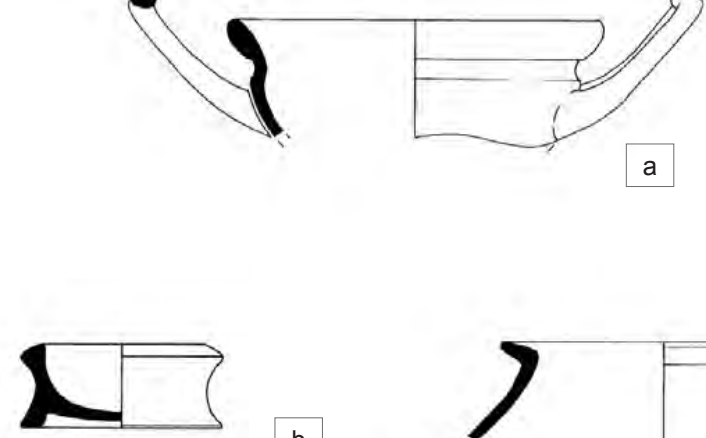

b

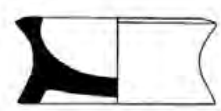

c
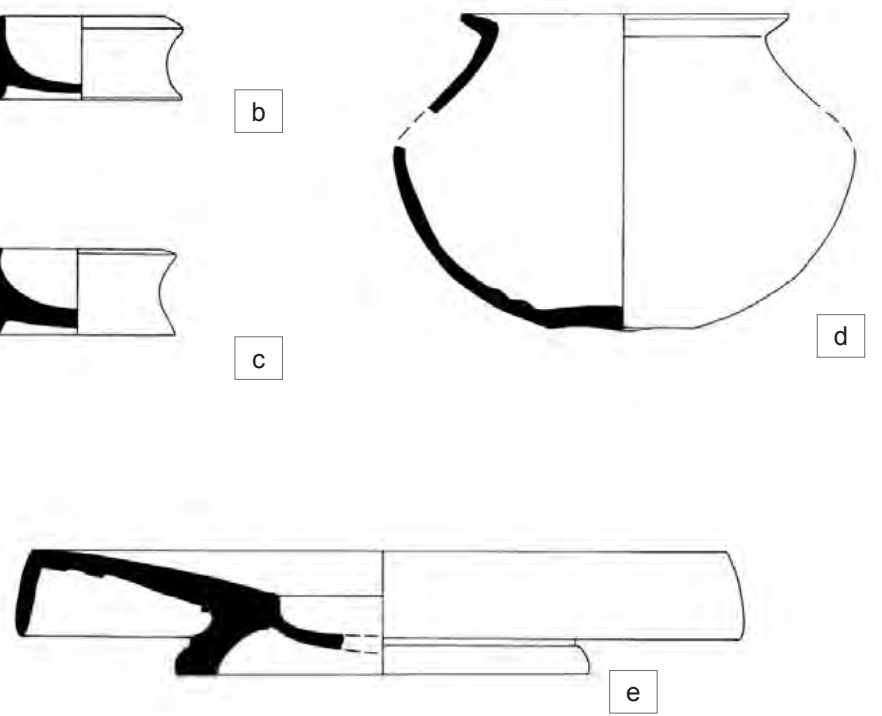

Échelle 1:3

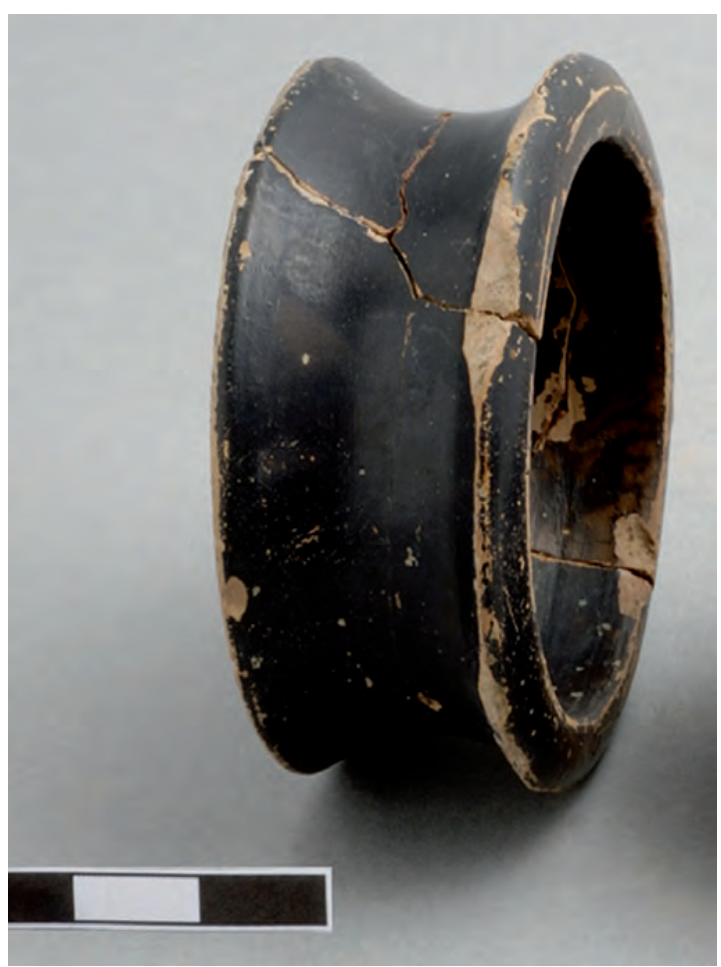

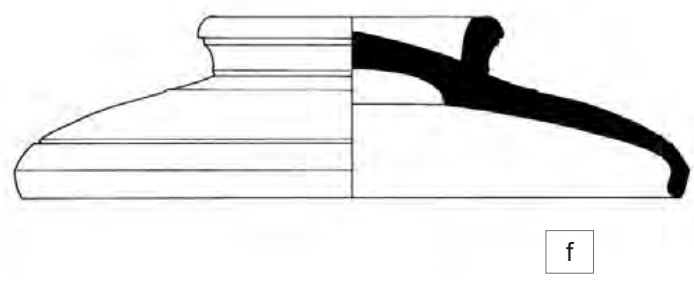

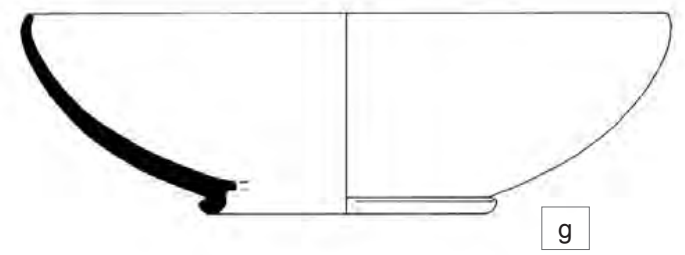


Planche 73

F 7
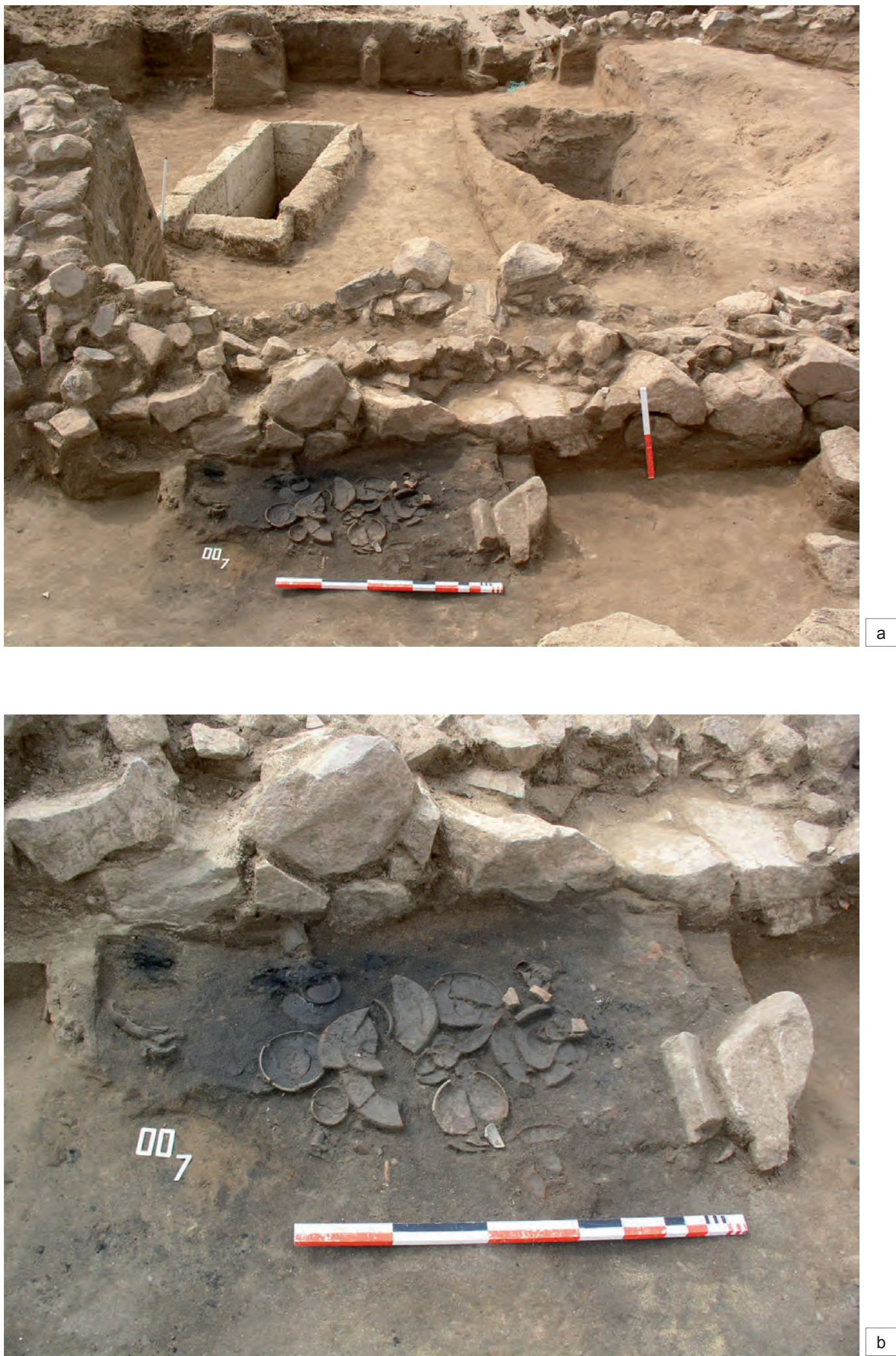
Planche 74

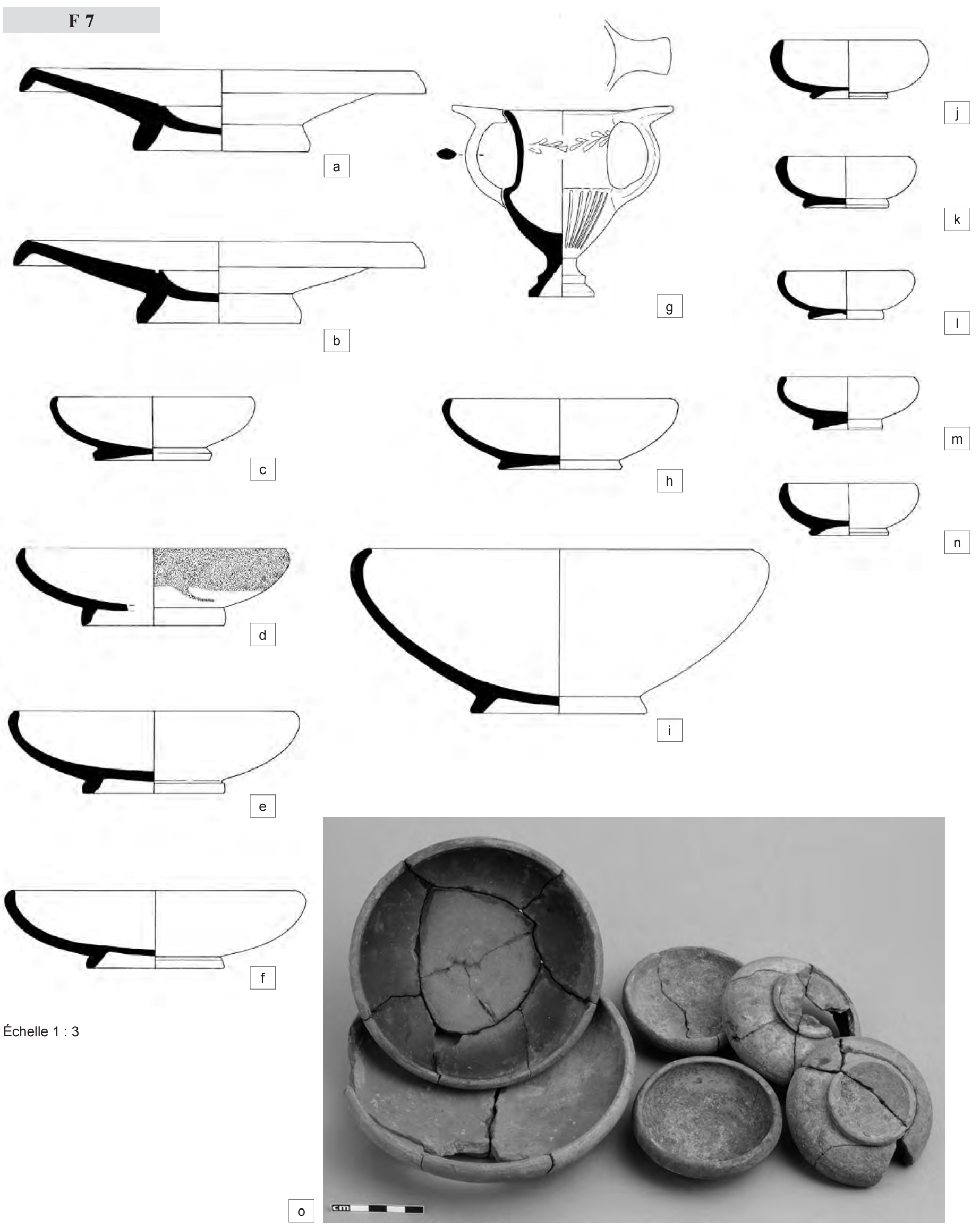




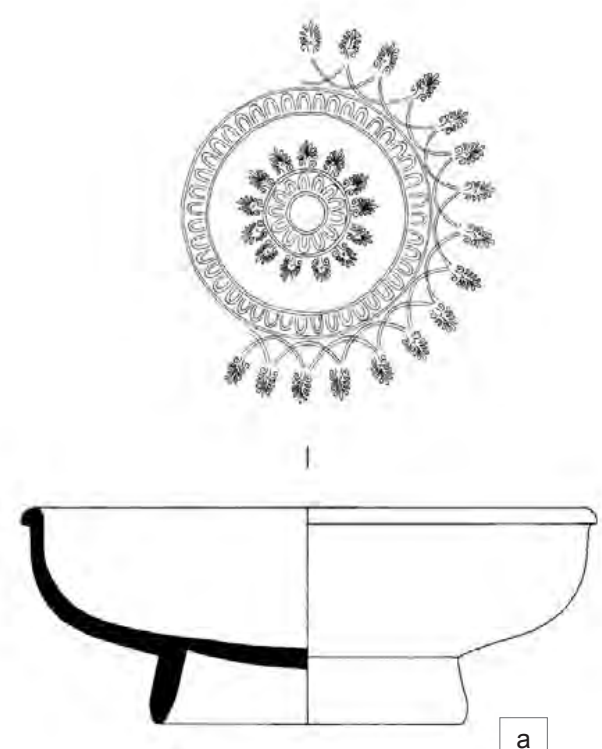

a
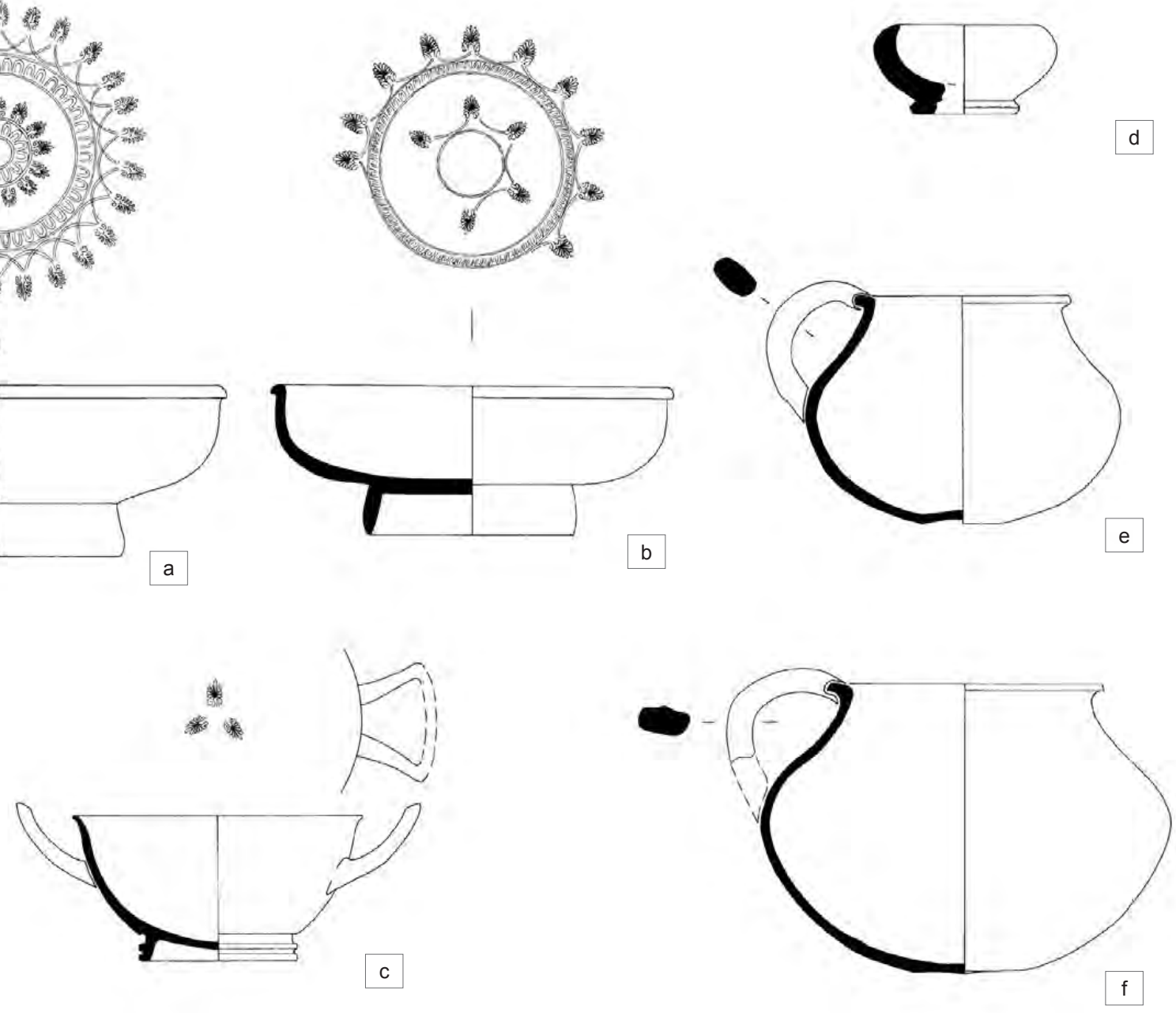

Échelle $1: 3$
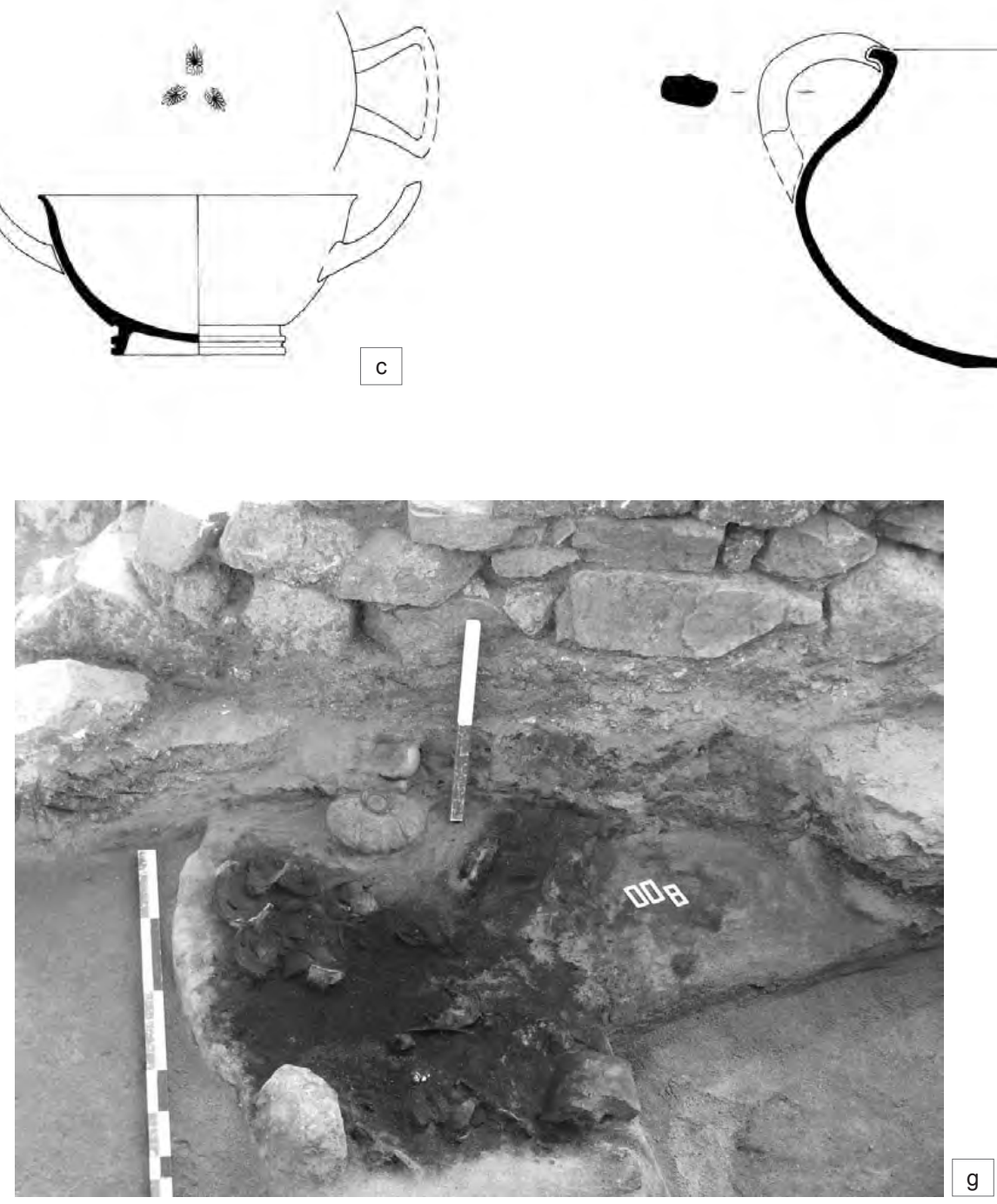
Planche 76

F 9
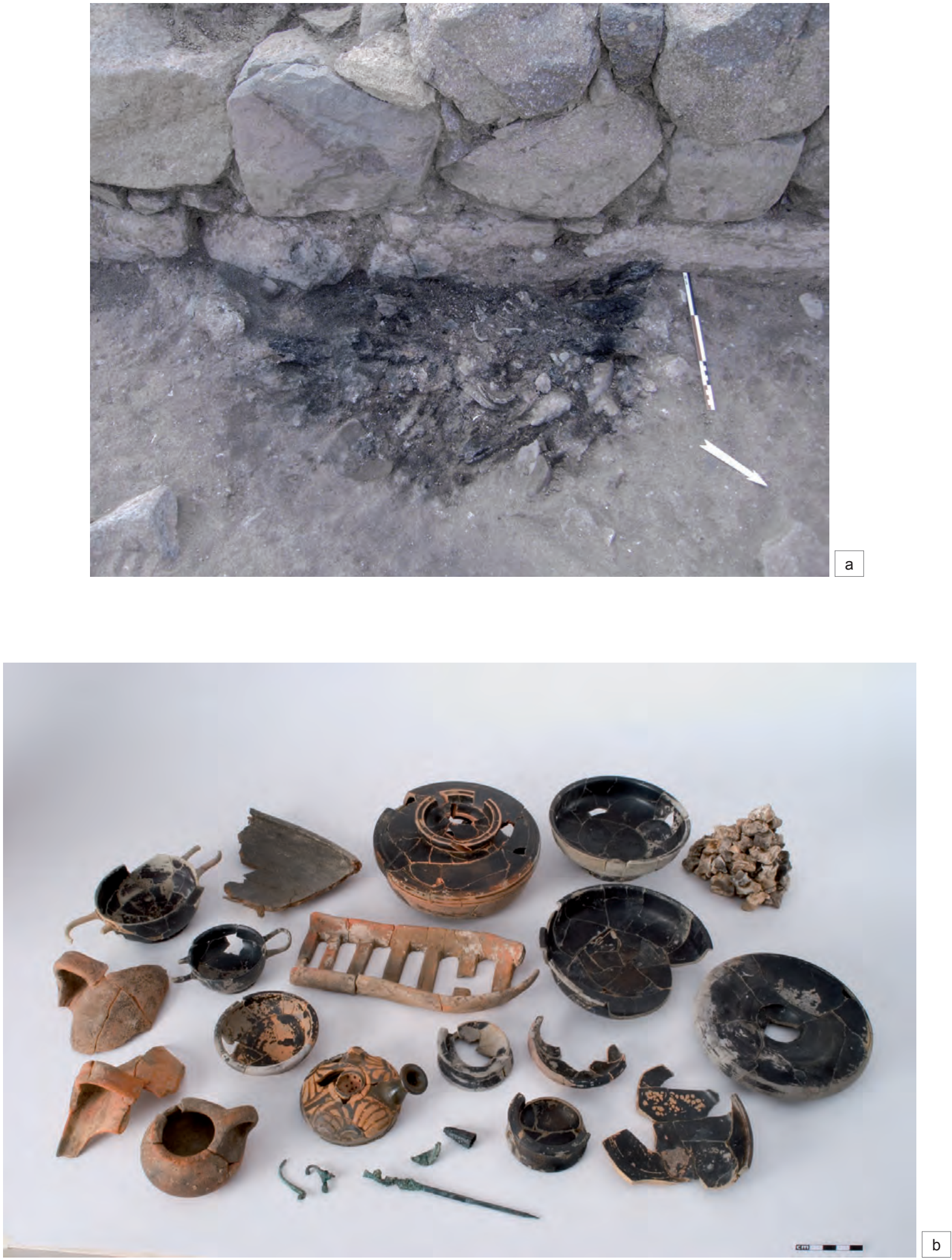
F 10

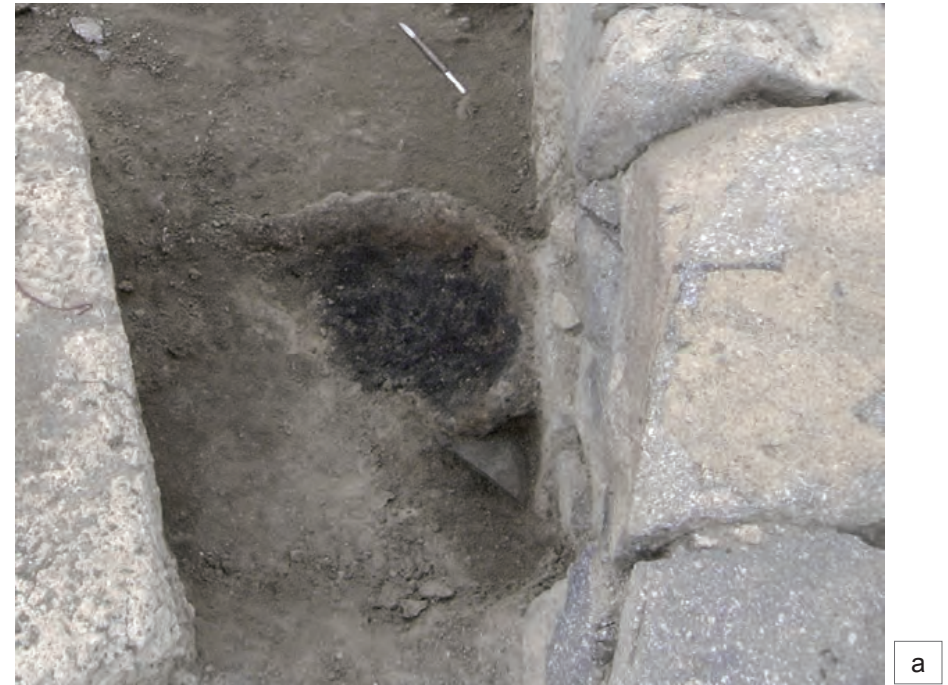

F 11

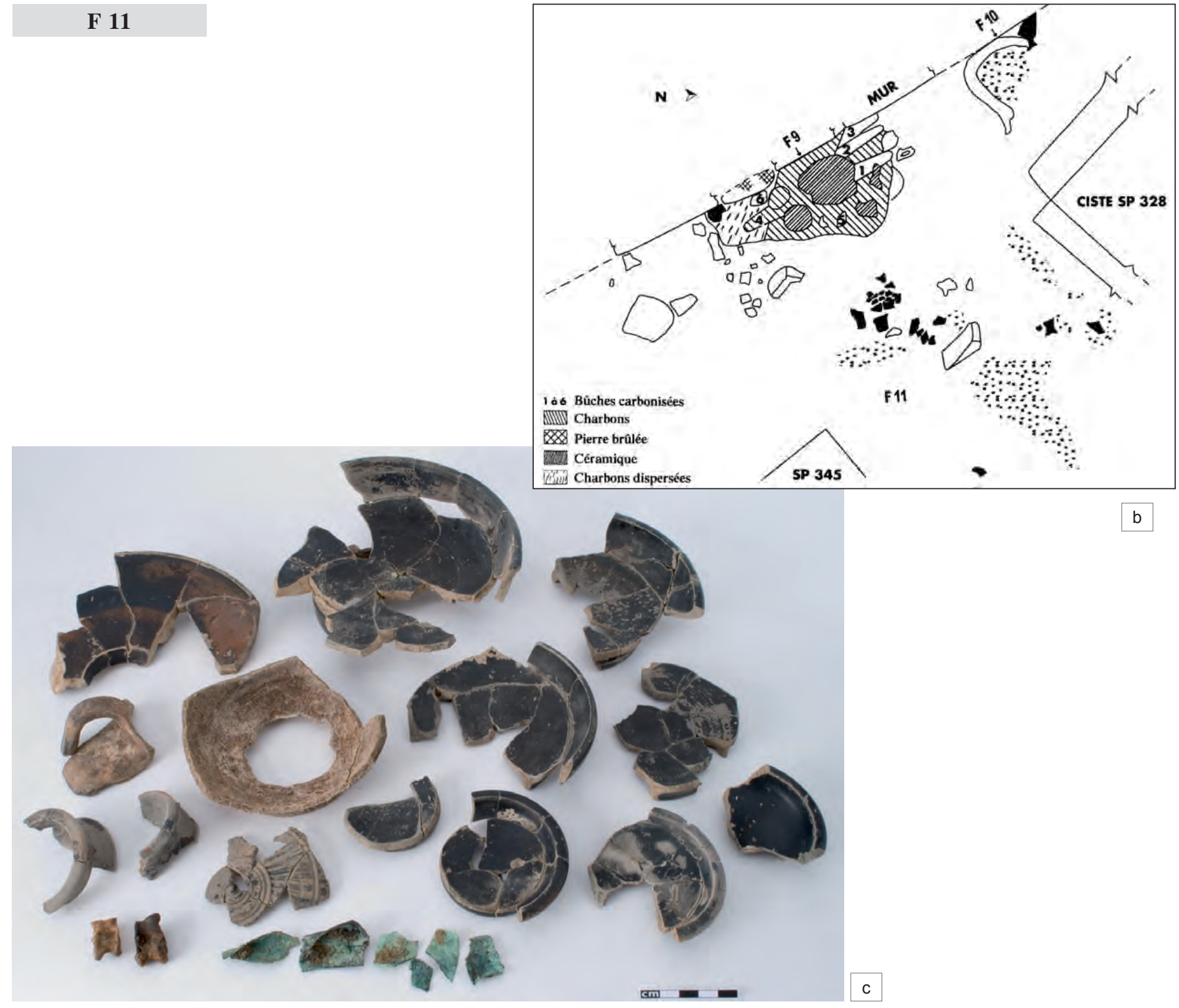


Planche 78

CP 2-6

Échelle $1: 3$
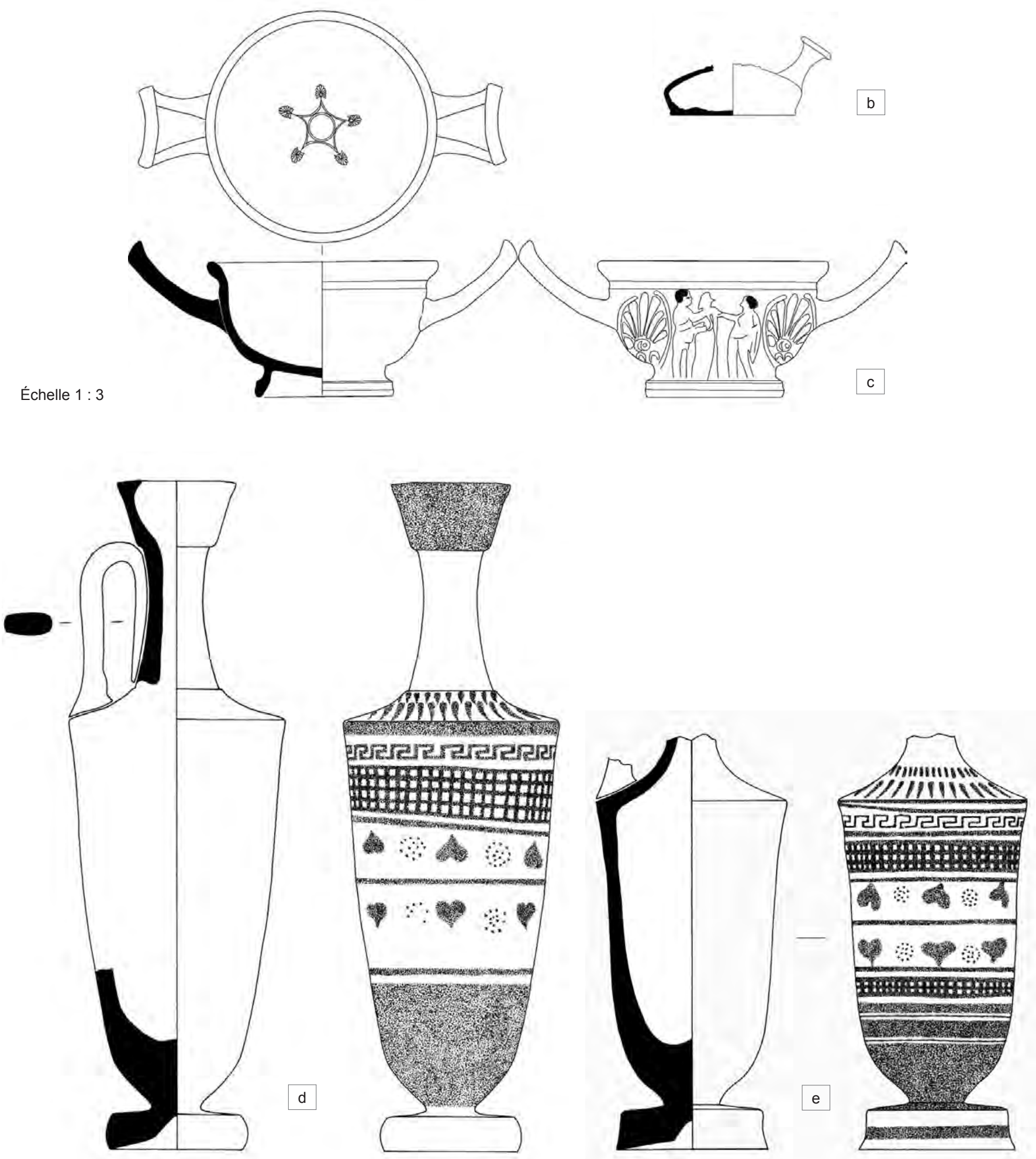


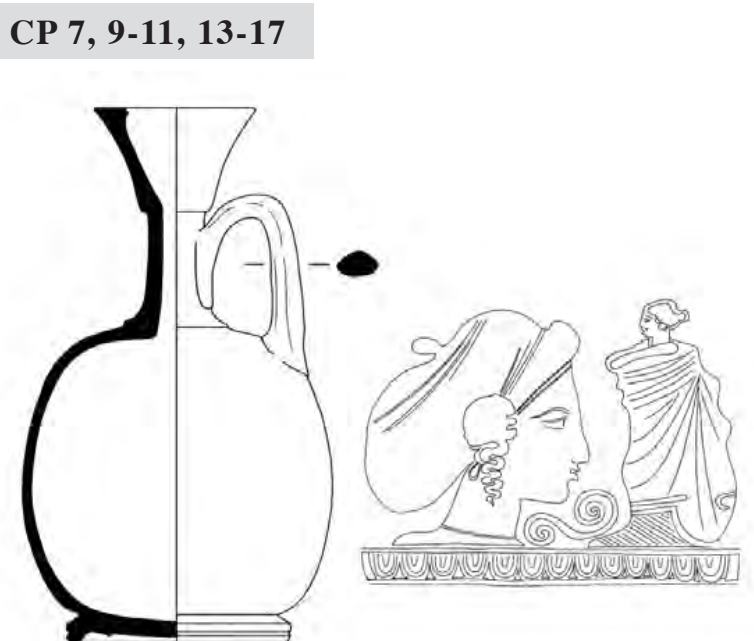

a
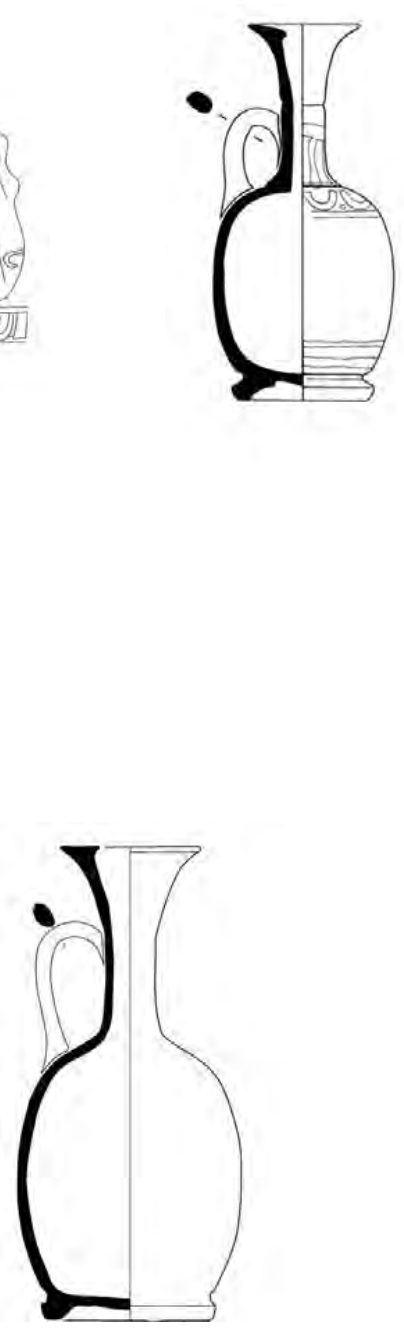

d

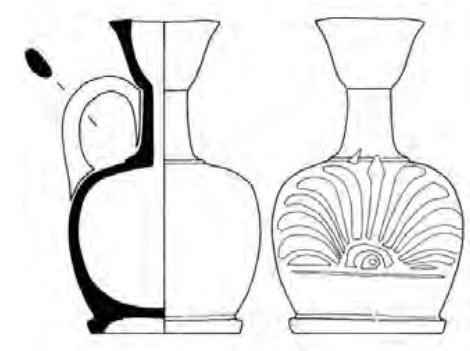

$\mathrm{g}$

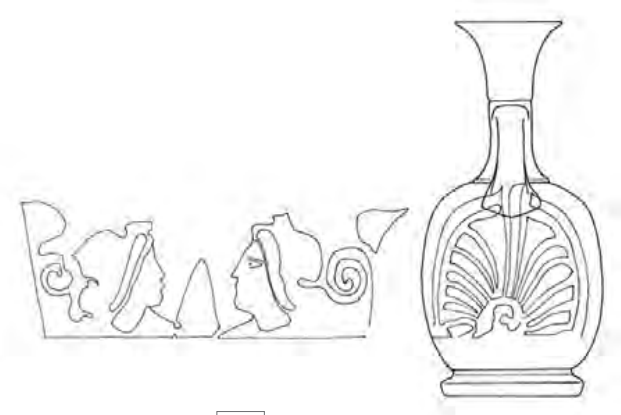

$\mathrm{b}$

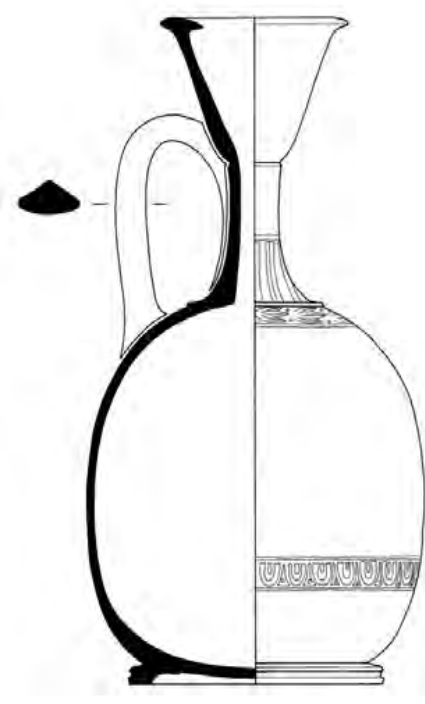

e

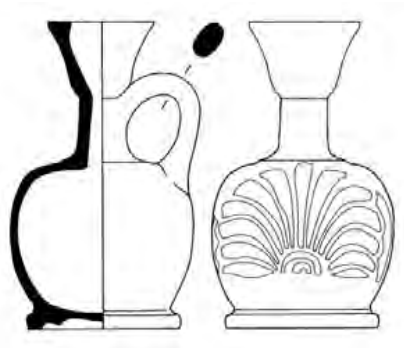

$\mathrm{h}$

Échelle $1: 3$ 
Planche 80

CP 18, 22, 23, 25

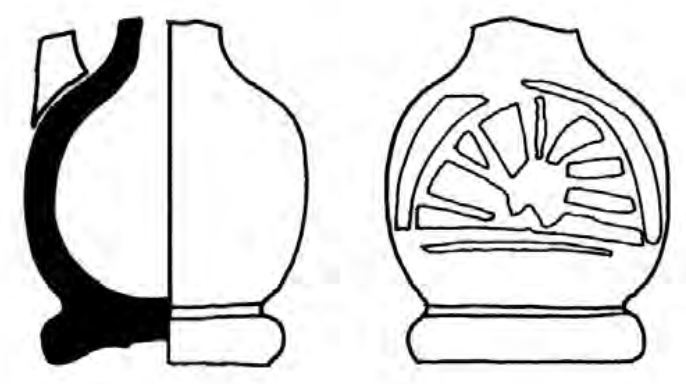

Échelle $1: 1$

a
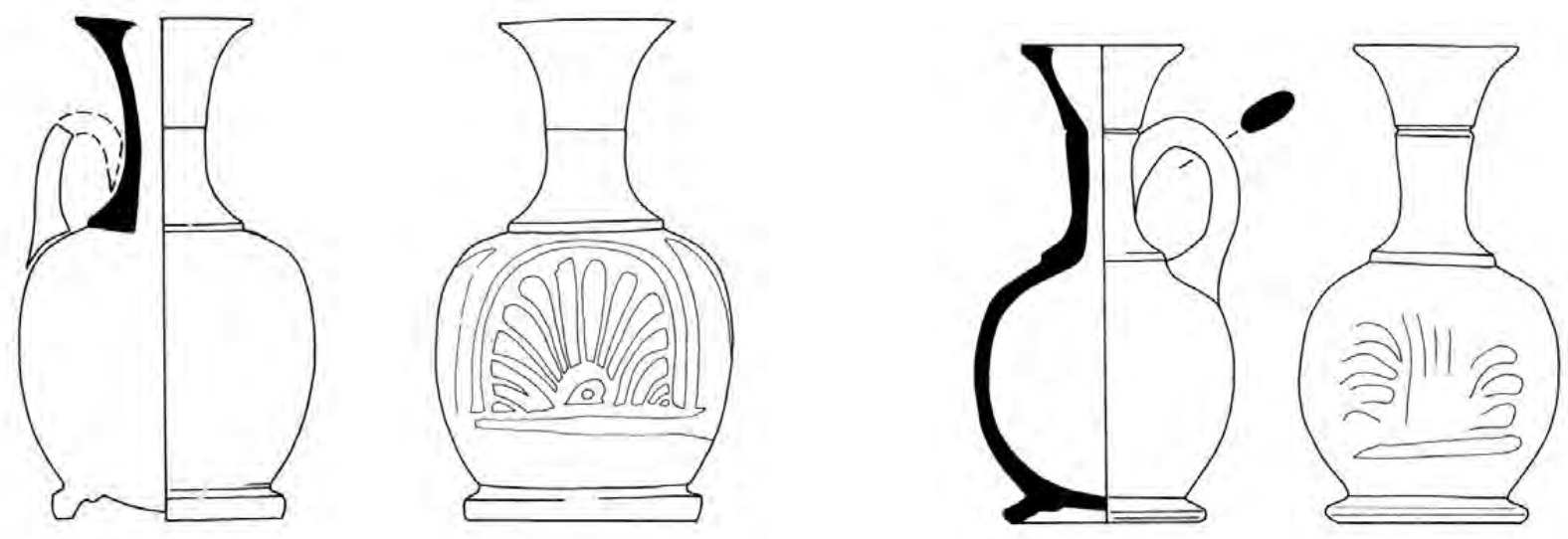

$\mathrm{b}$

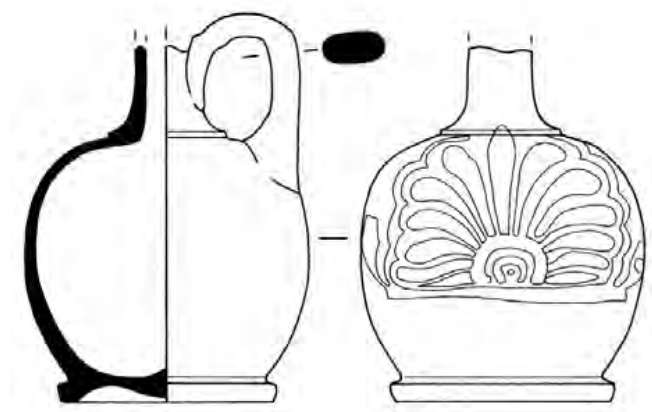


Planche 81

CP 28, 30, 32-35, 39, 40

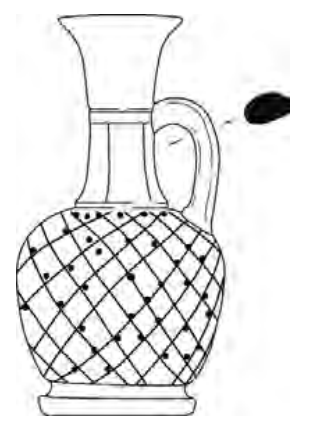

a

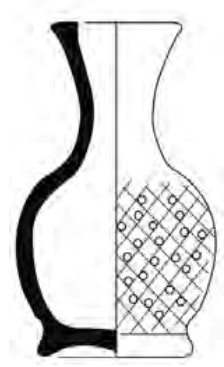

b

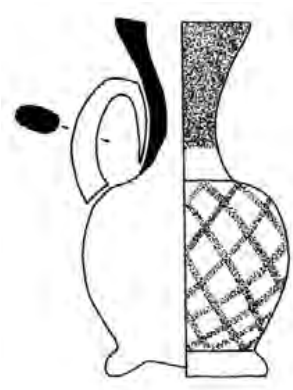

C

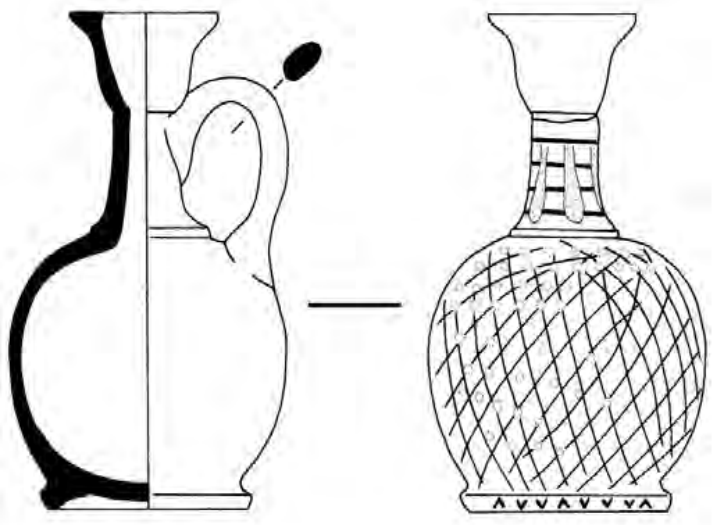

d

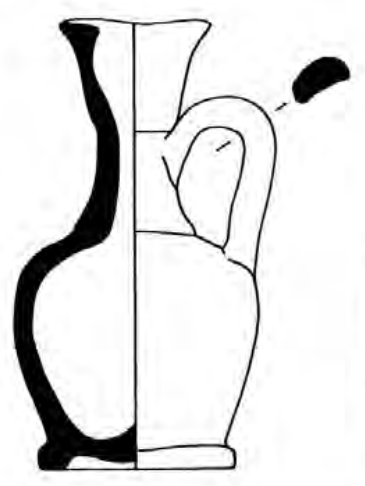

e
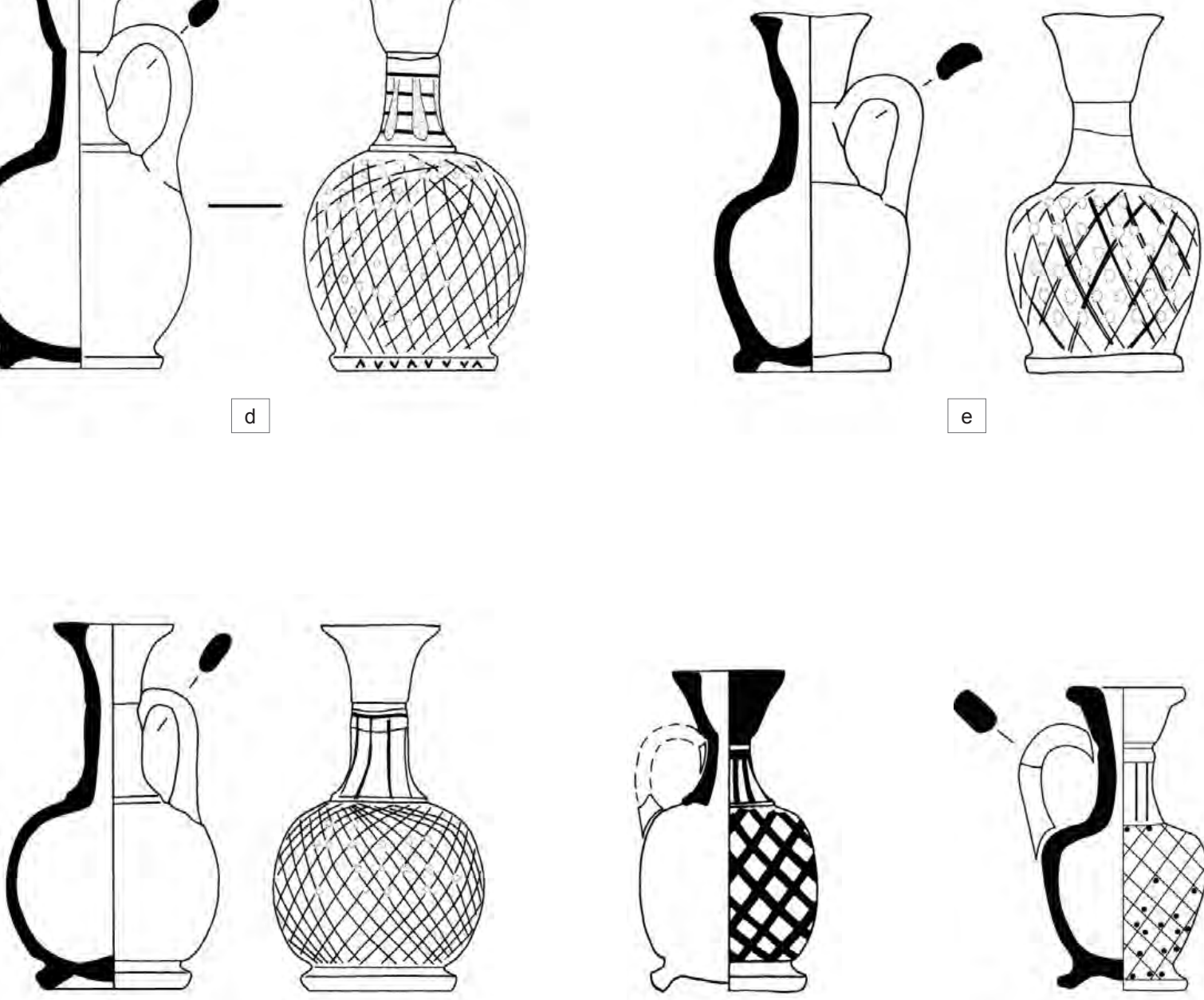

f

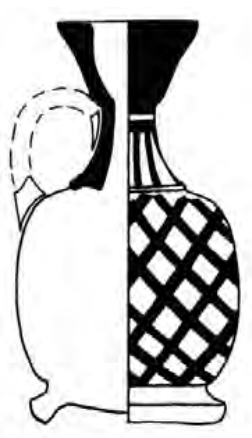

g

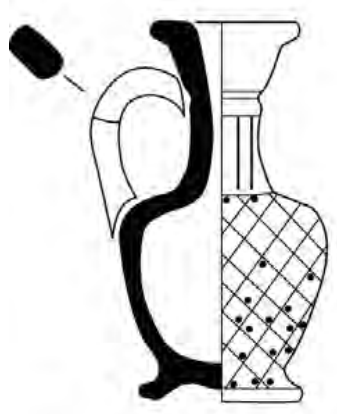

$\mathrm{h}$ 
Planche 82

CP 41, 42, 44-46
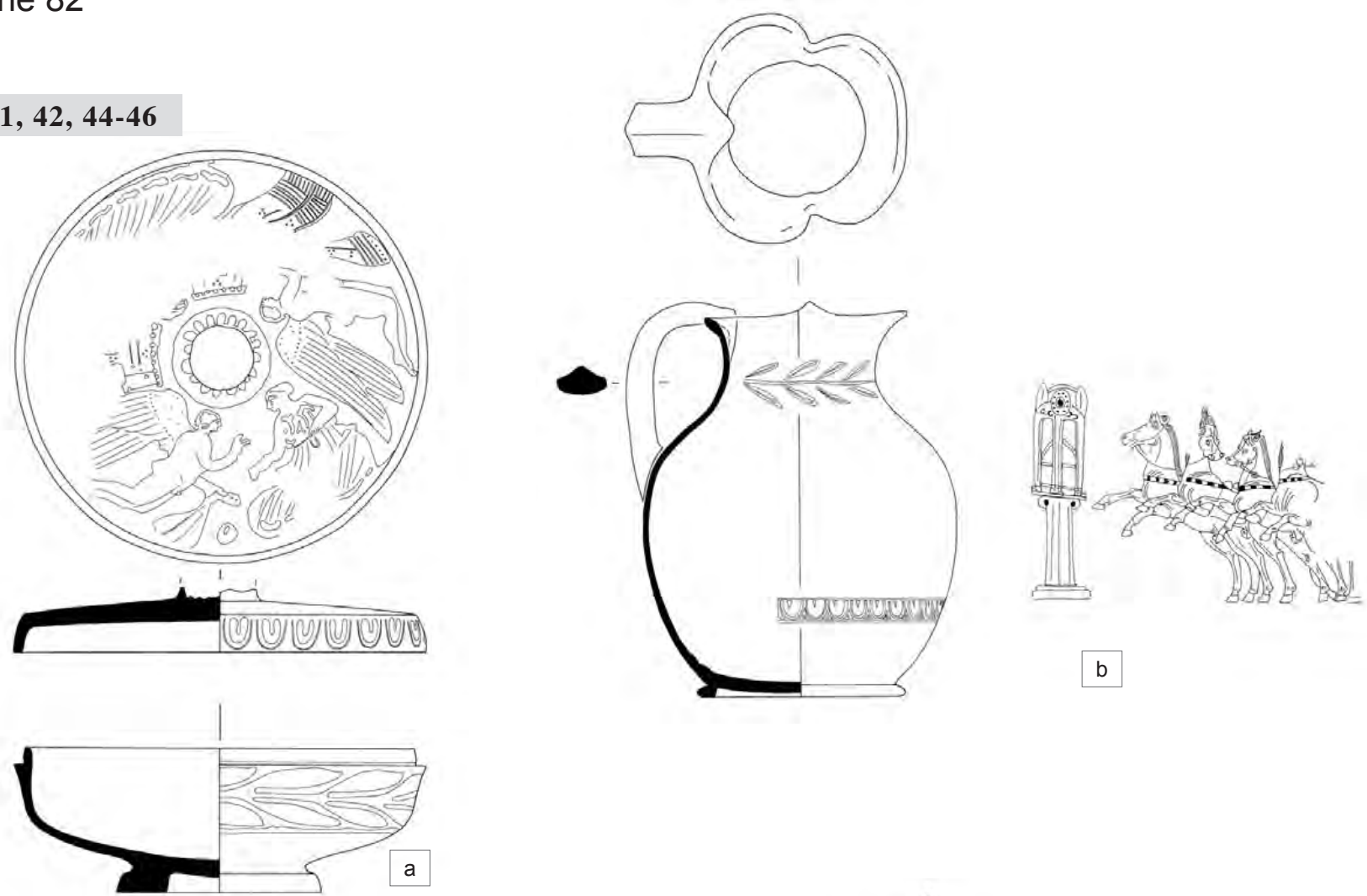

b
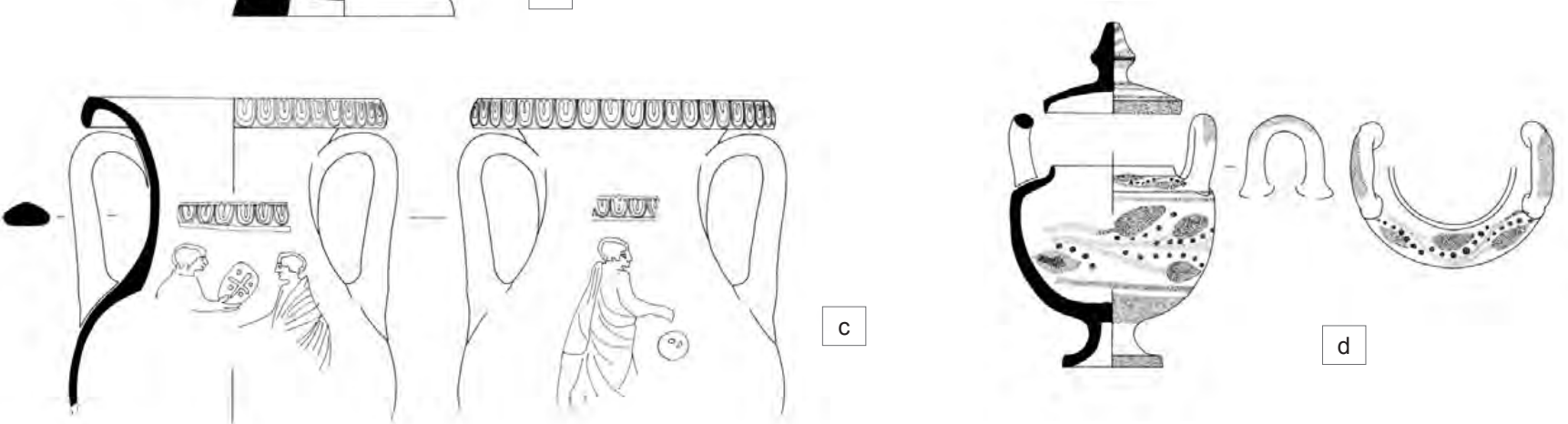

Échelle $1: 4$
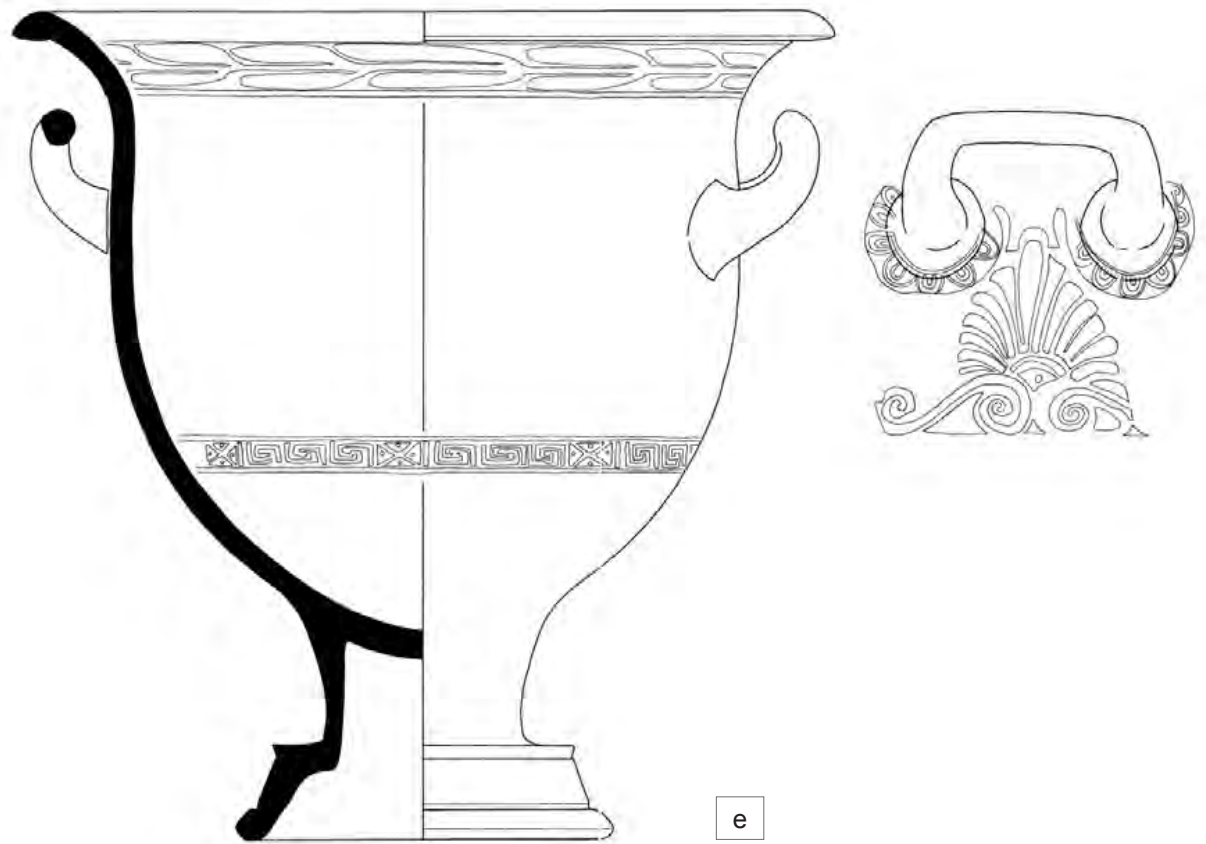

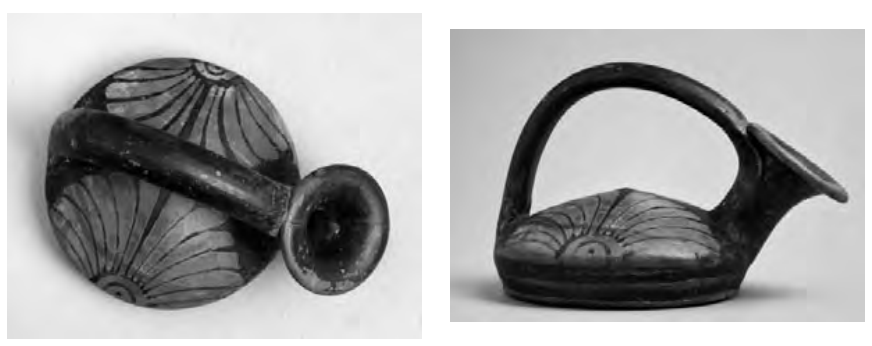

a-1

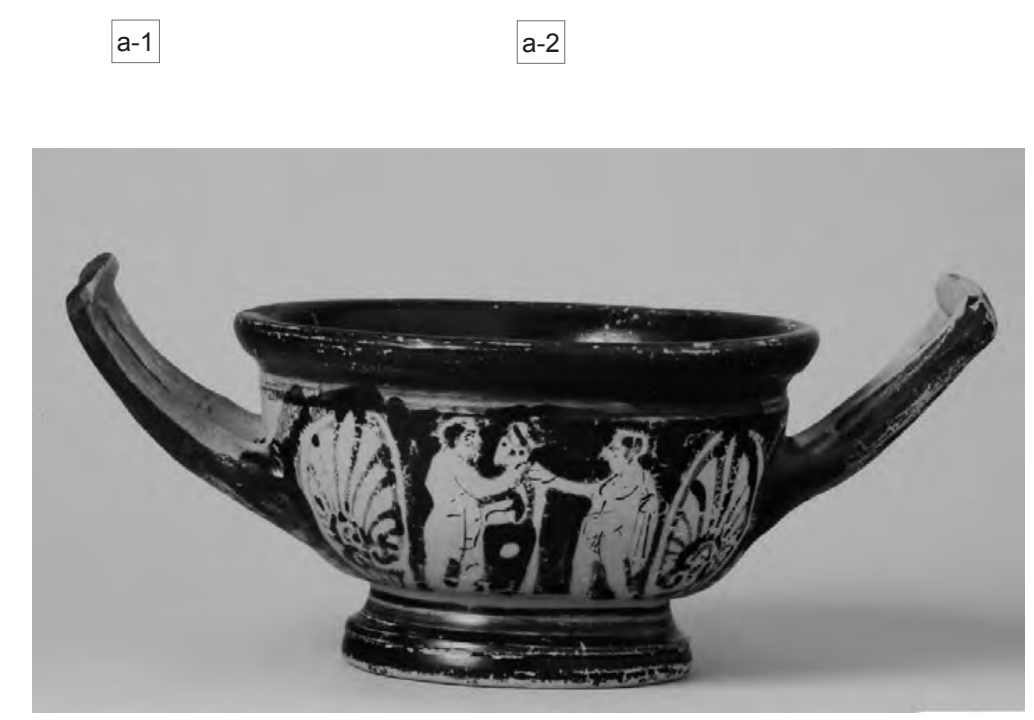

d

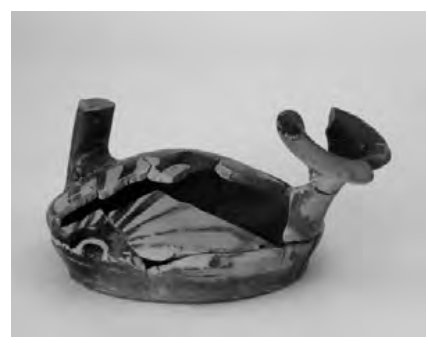

$b$

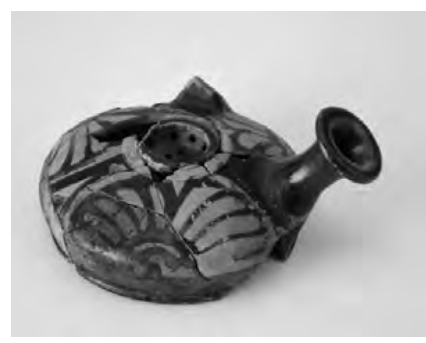

C

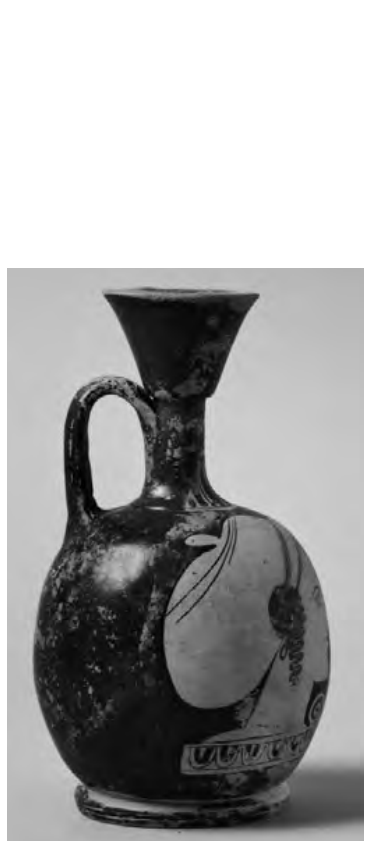

f-1

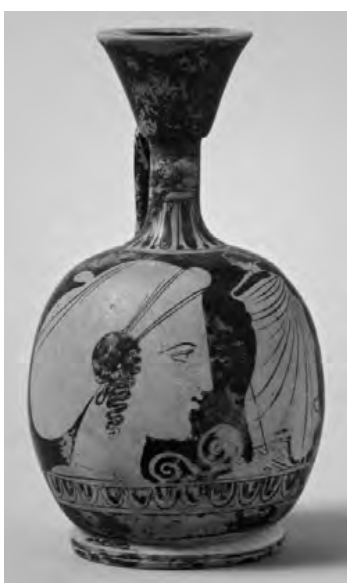

f-2

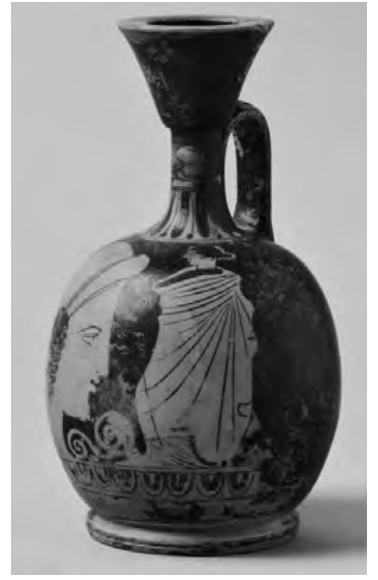

f-3

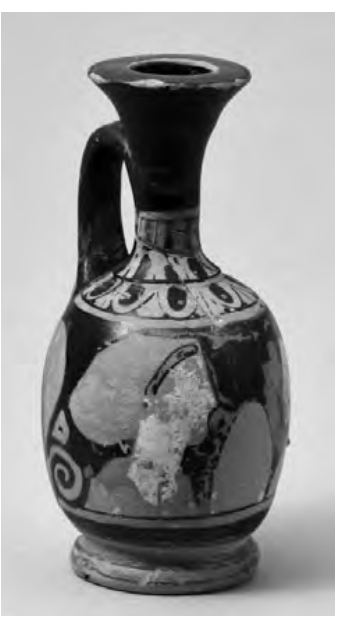

$\mathrm{g}$

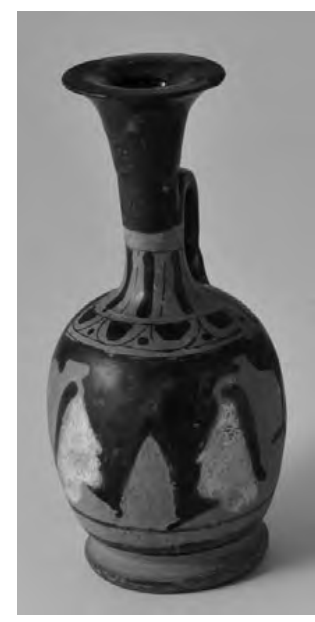

$\mathrm{h}$ 
Planche 84

CP 10-11

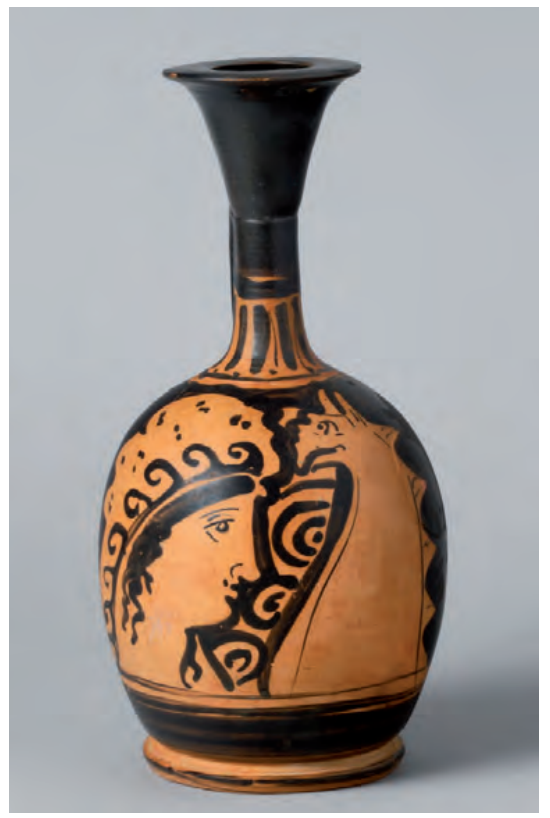

a-1

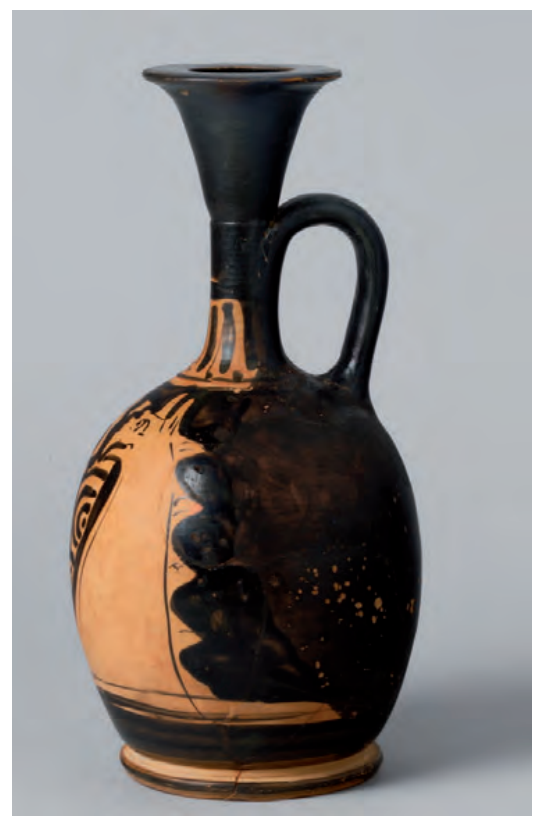

a-2

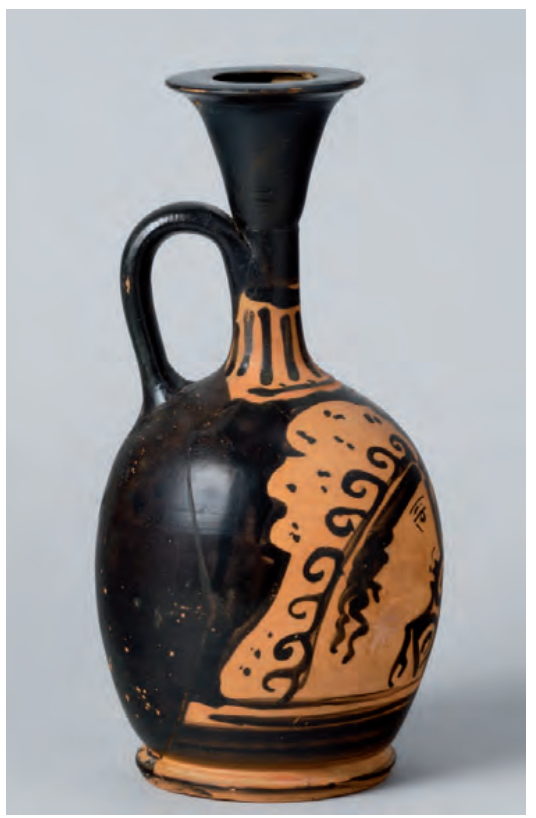

a-3

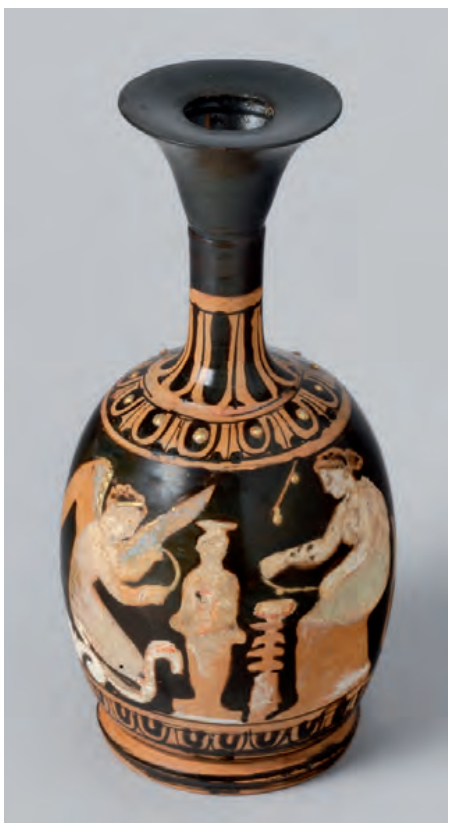

b-1

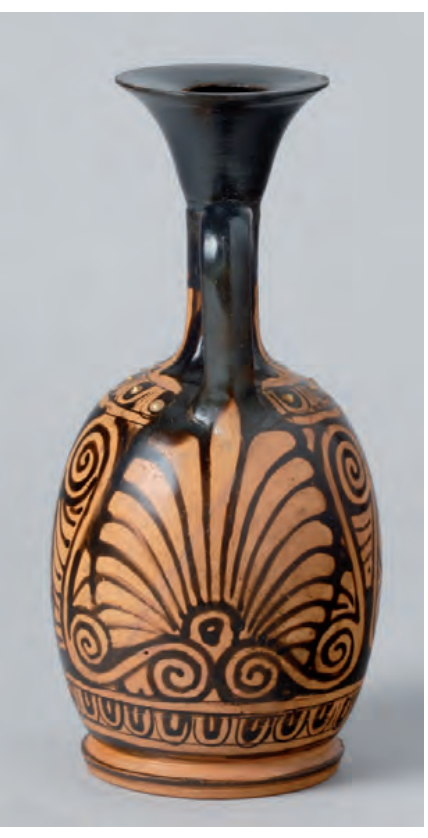

b-2

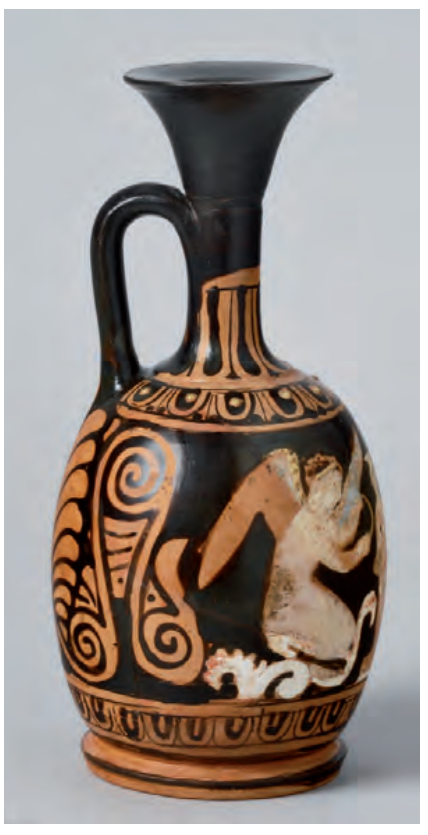

b-3

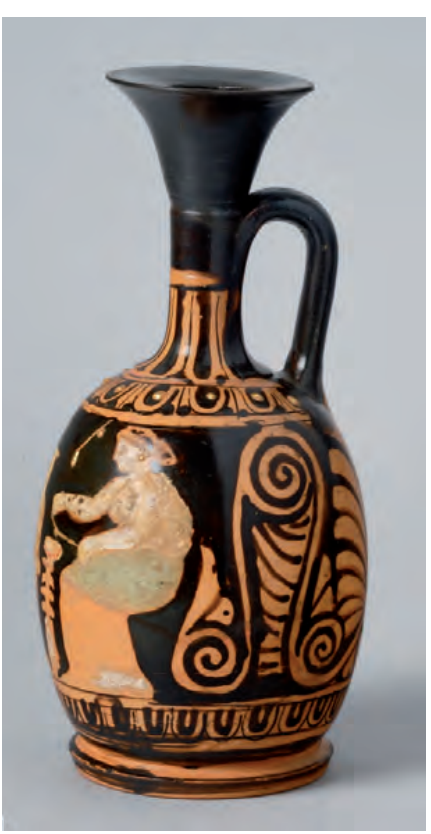


Planche 85

CP 14

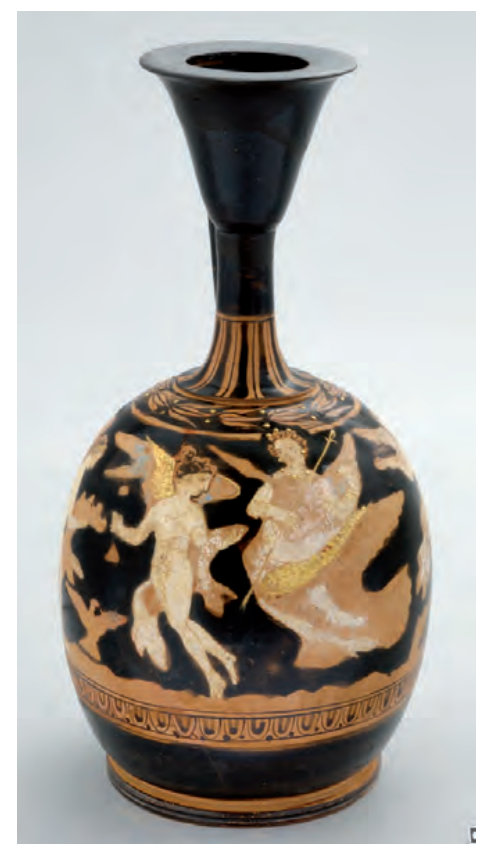

a-1

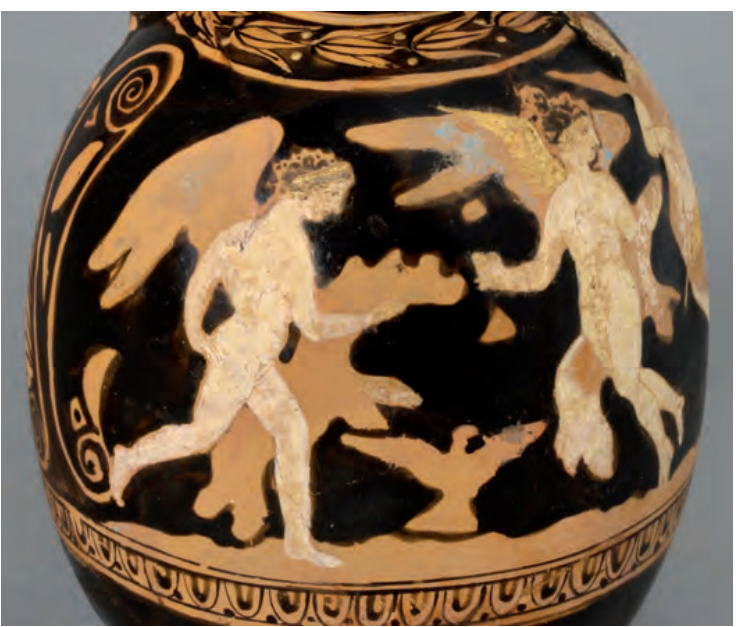

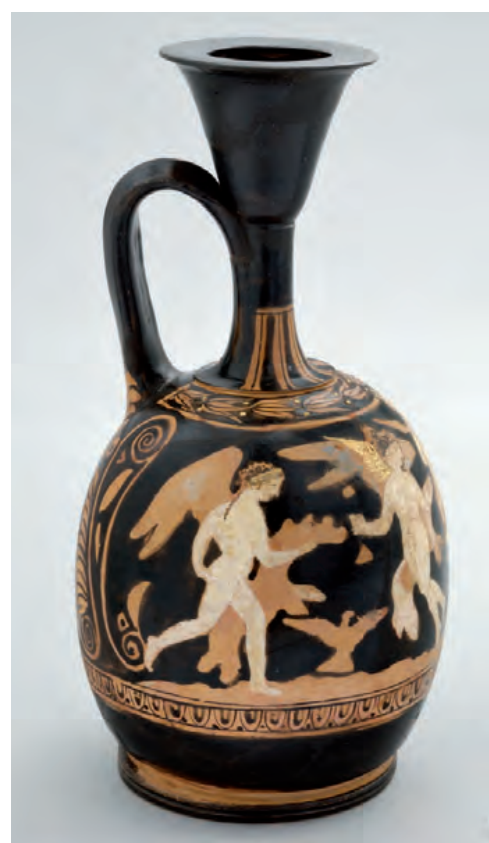

a-2

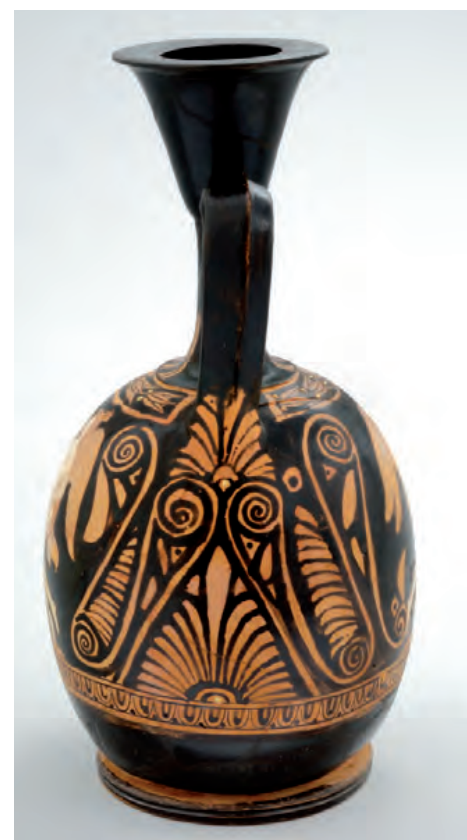

a-3

b-1

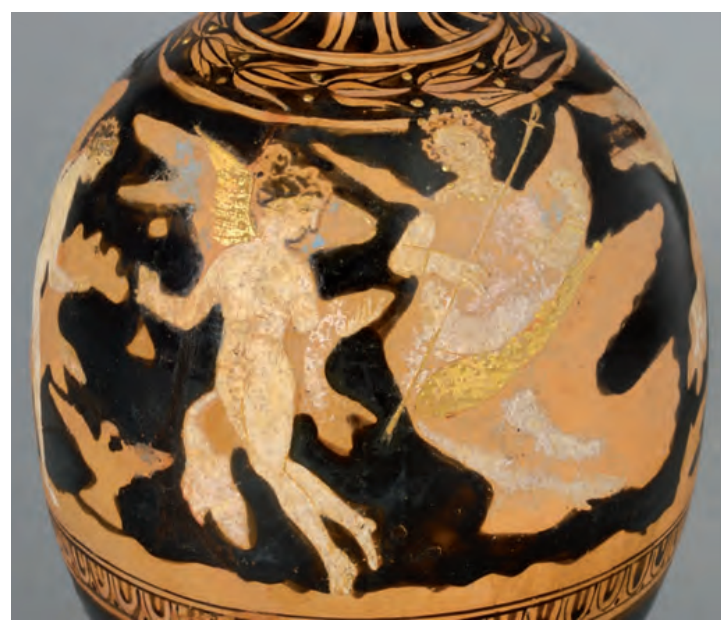

b-2

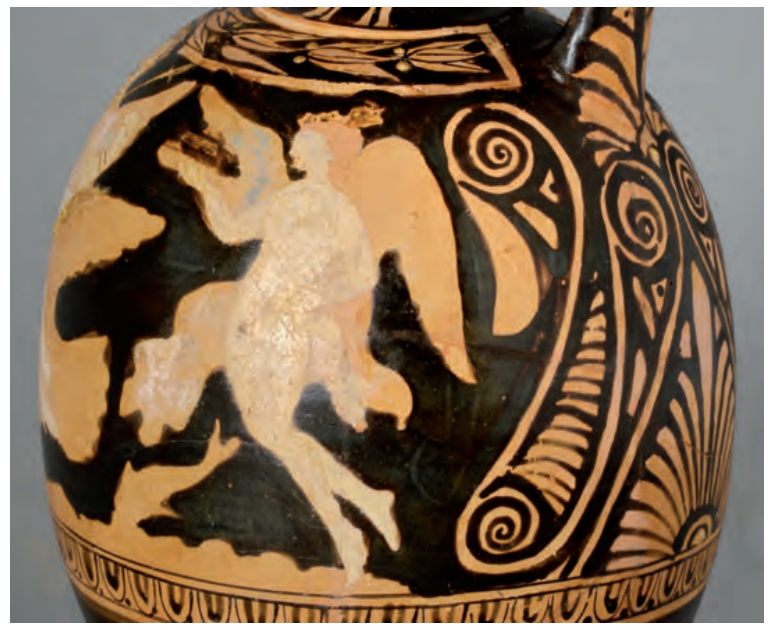


Planche 86

CP 16-18, 21, 22, 24

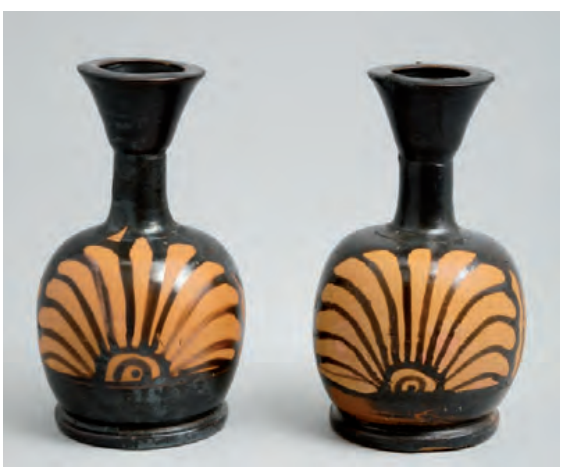

a-1

b-1

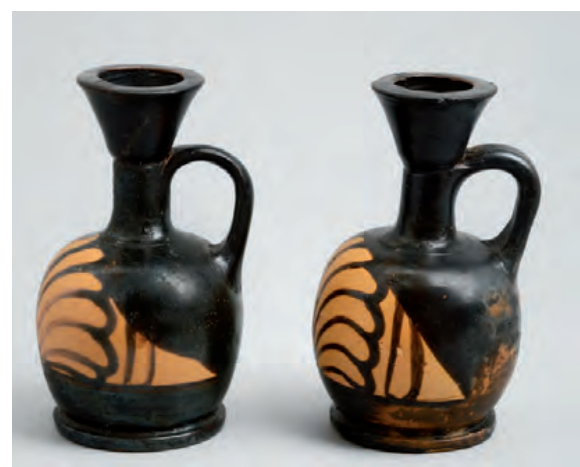

a-2 b-2

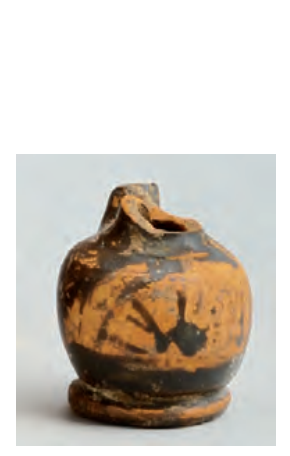

c

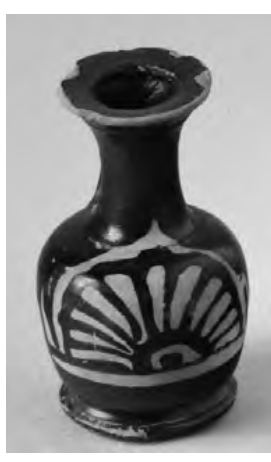

d
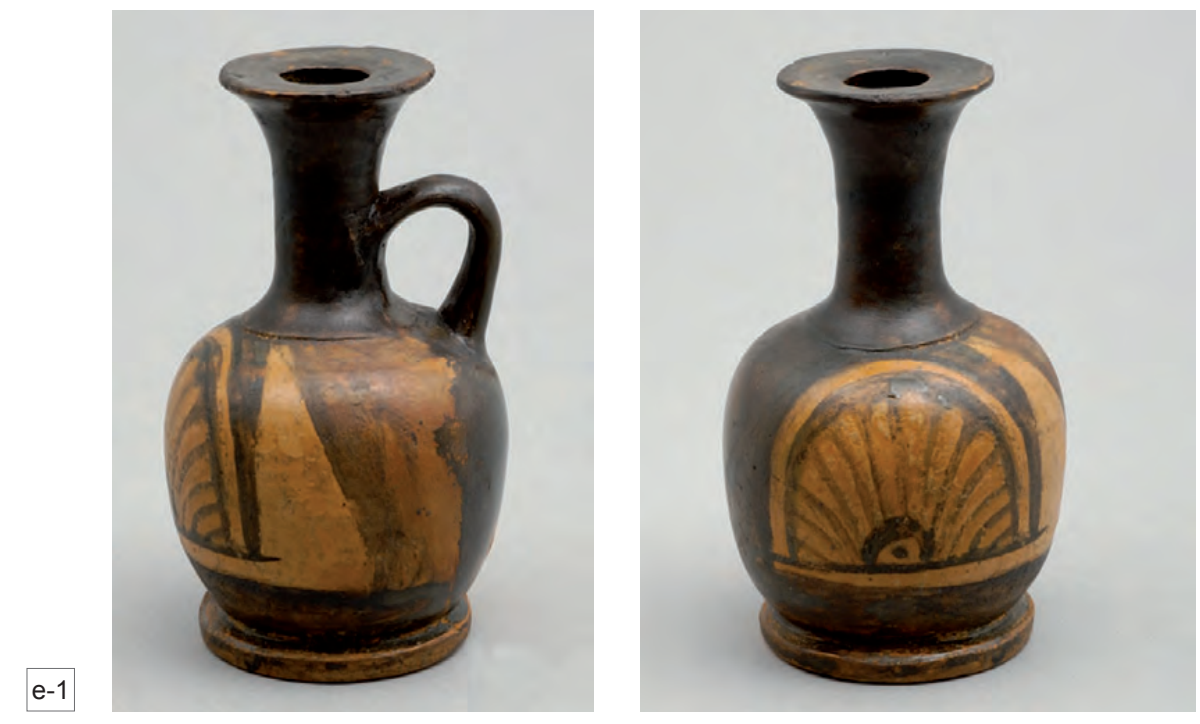

e-2

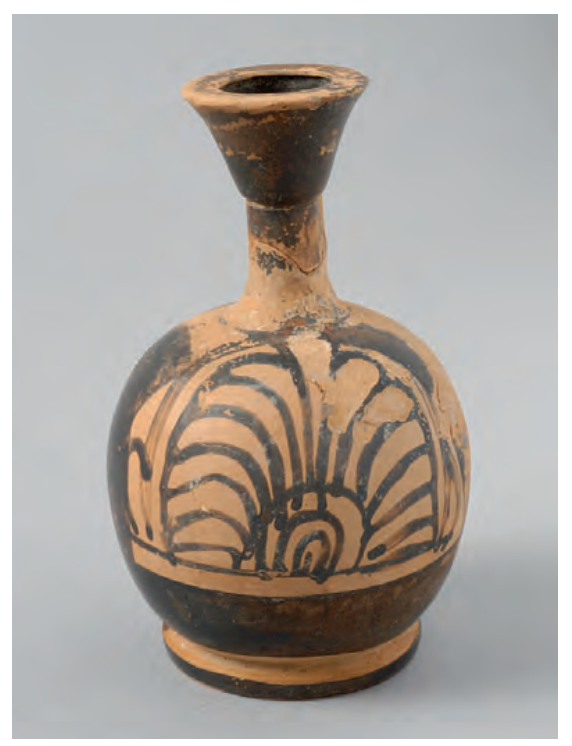

f-1

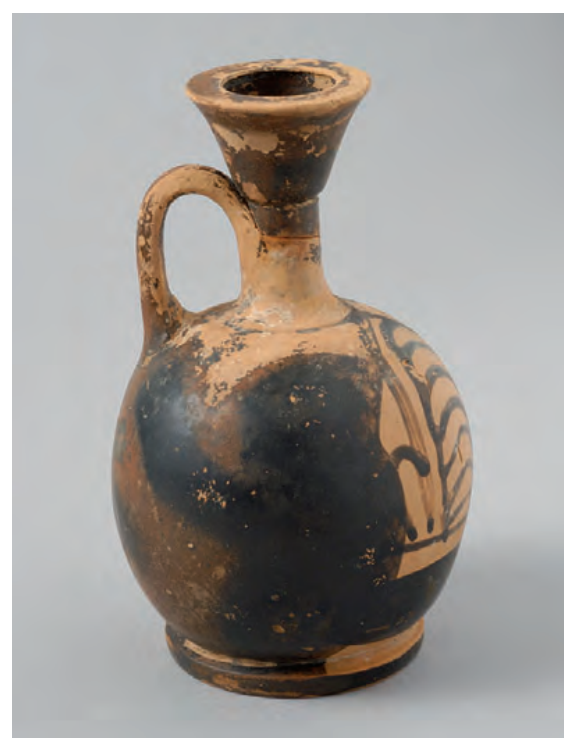

$f-2$ 
CP 25, 26, 33, 37, 39

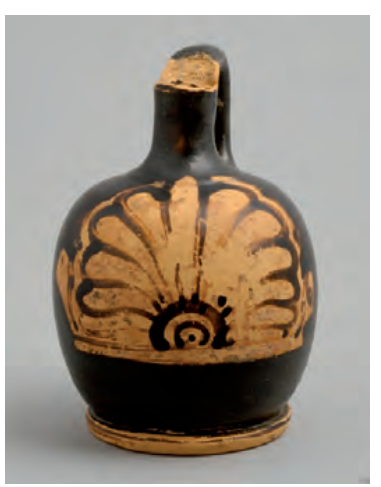

a-1

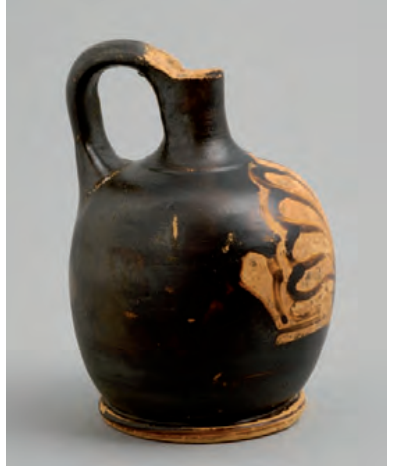

a-2

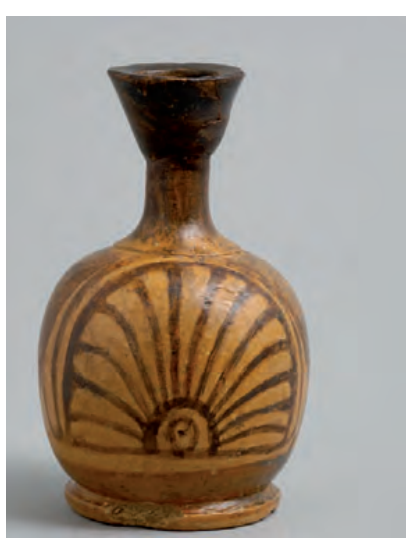

b-1

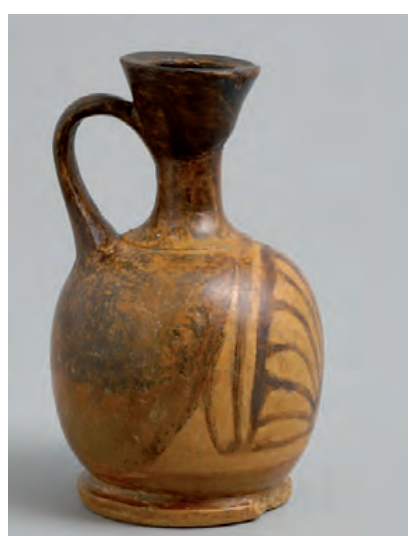

b-2
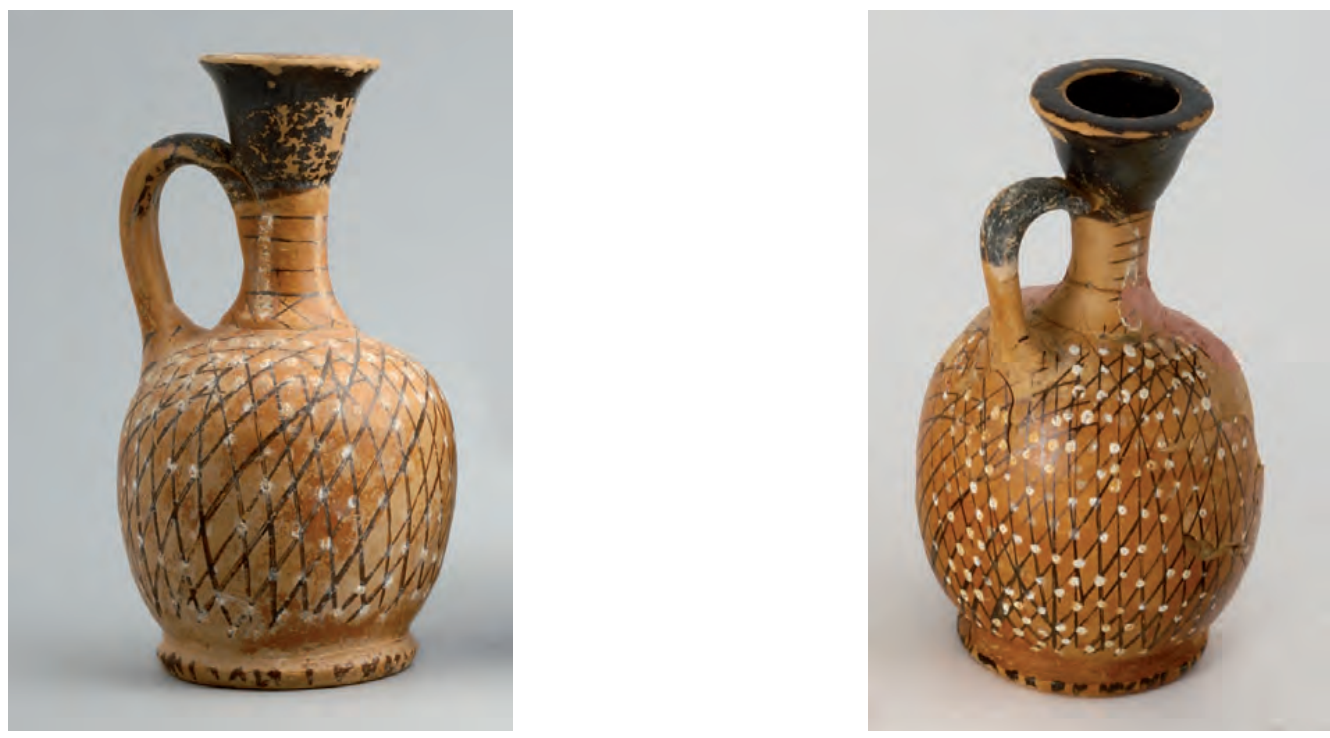

C

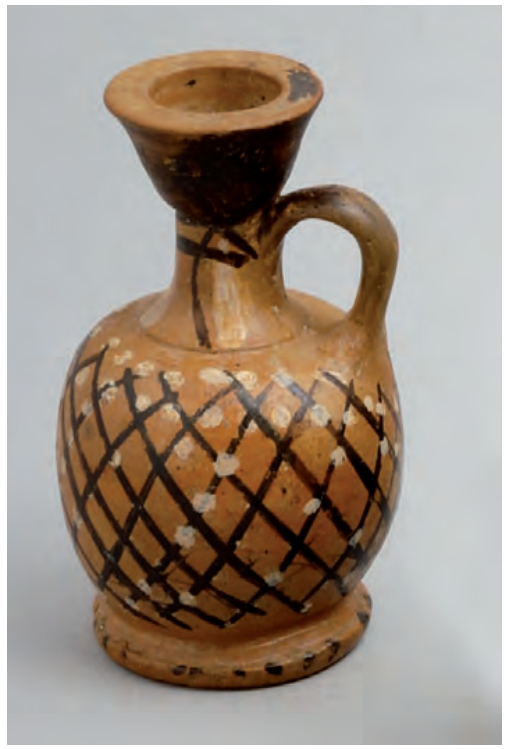

d 
Planche 88

CP 41, 42
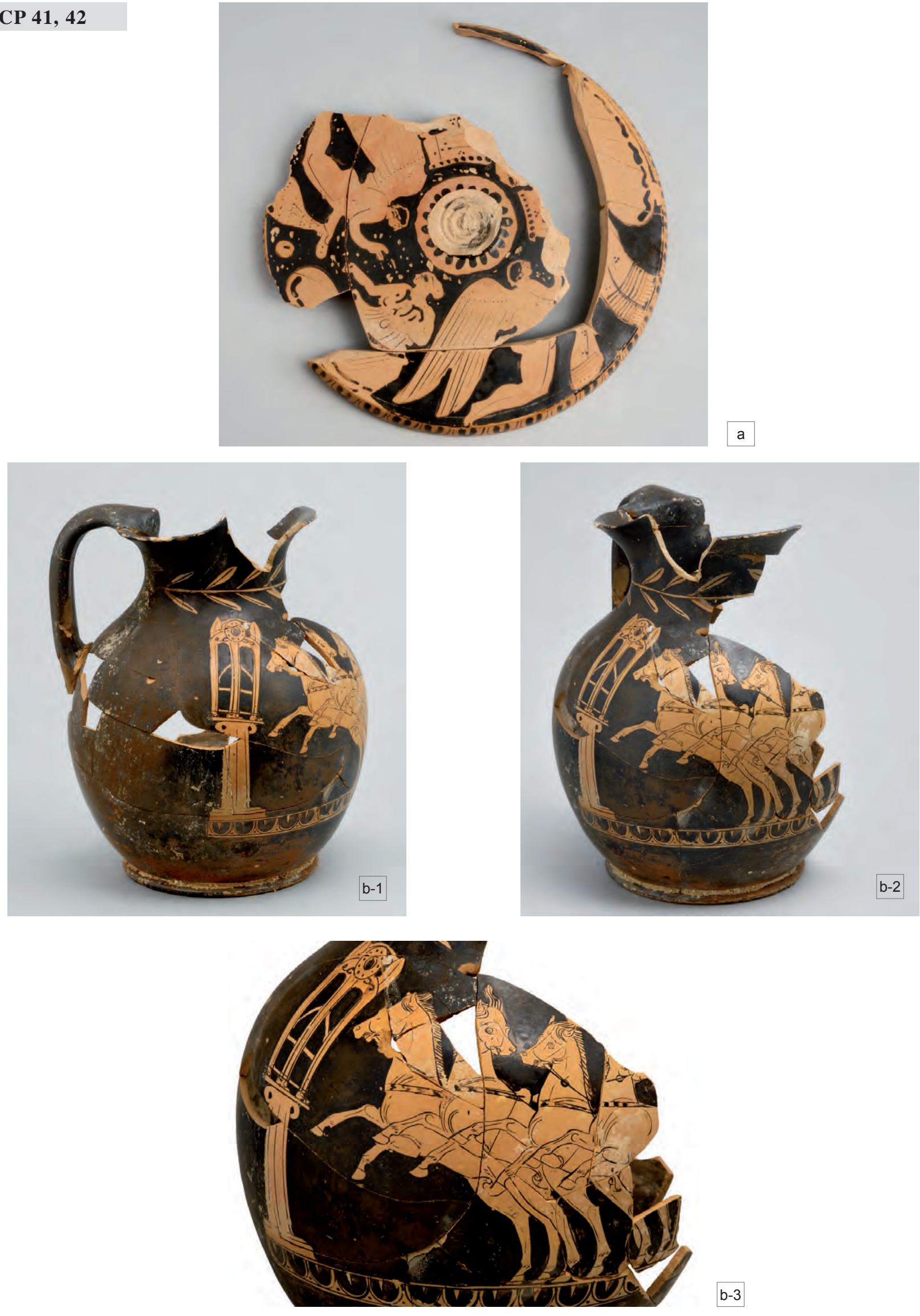
CP 44, 45

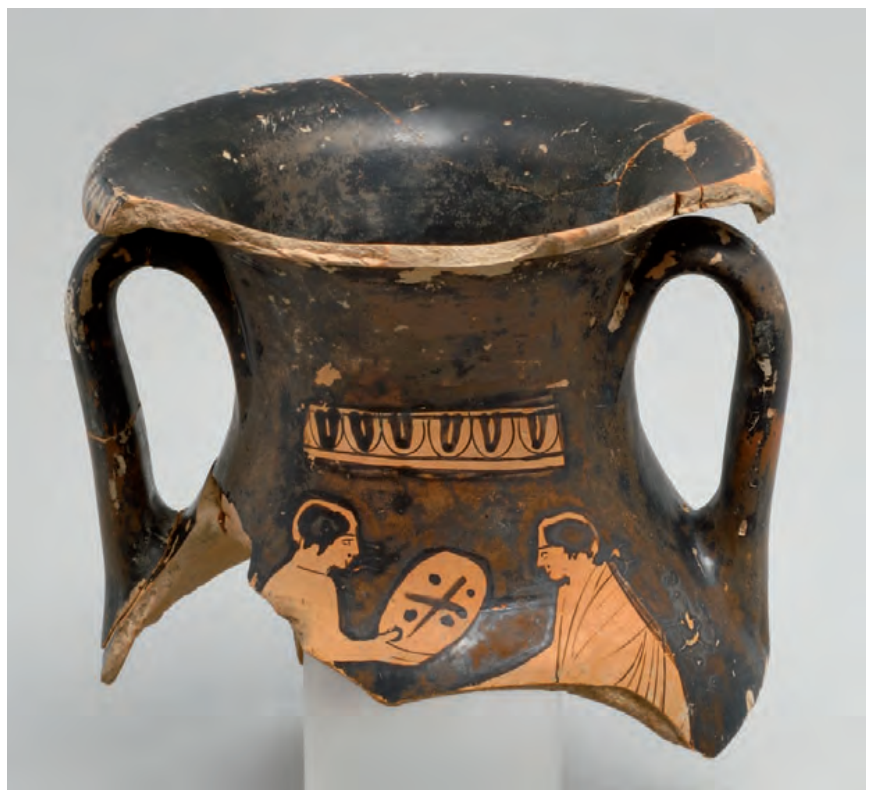

a-1

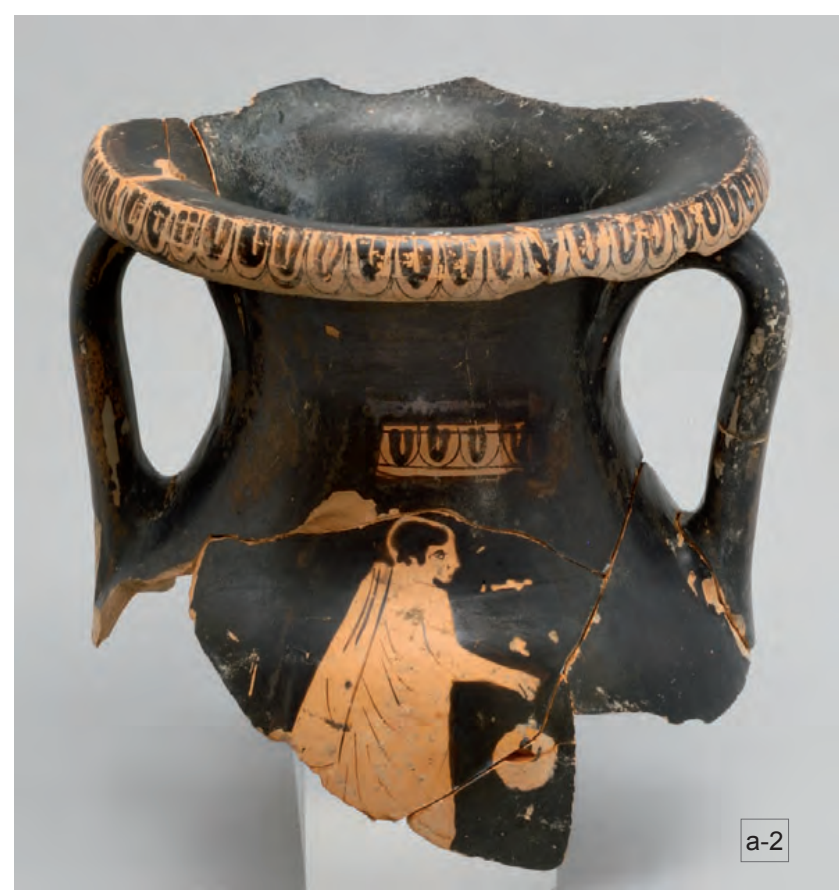

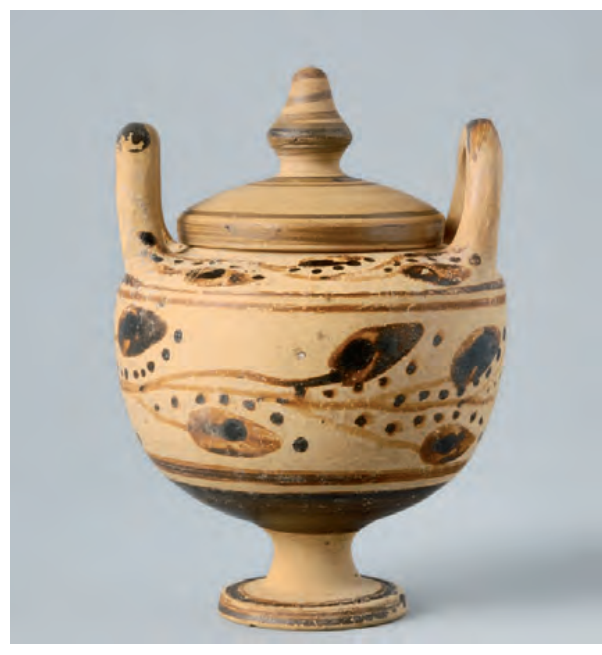

b-1

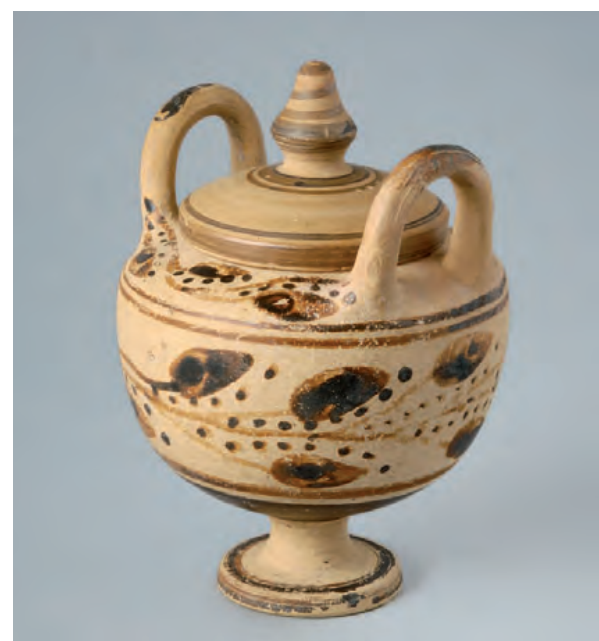

b-2

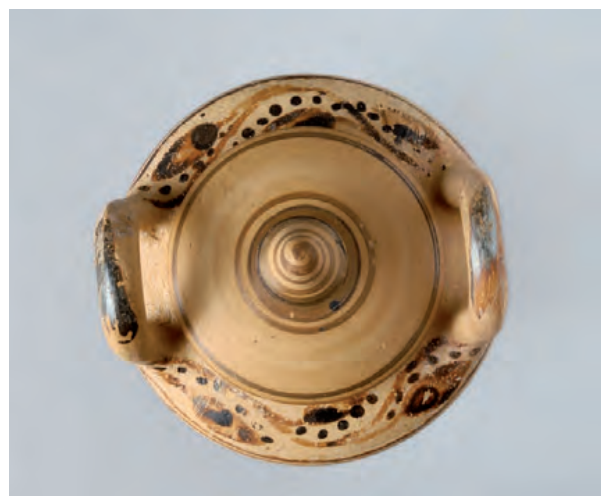


Planche 90

\section{CP 46}

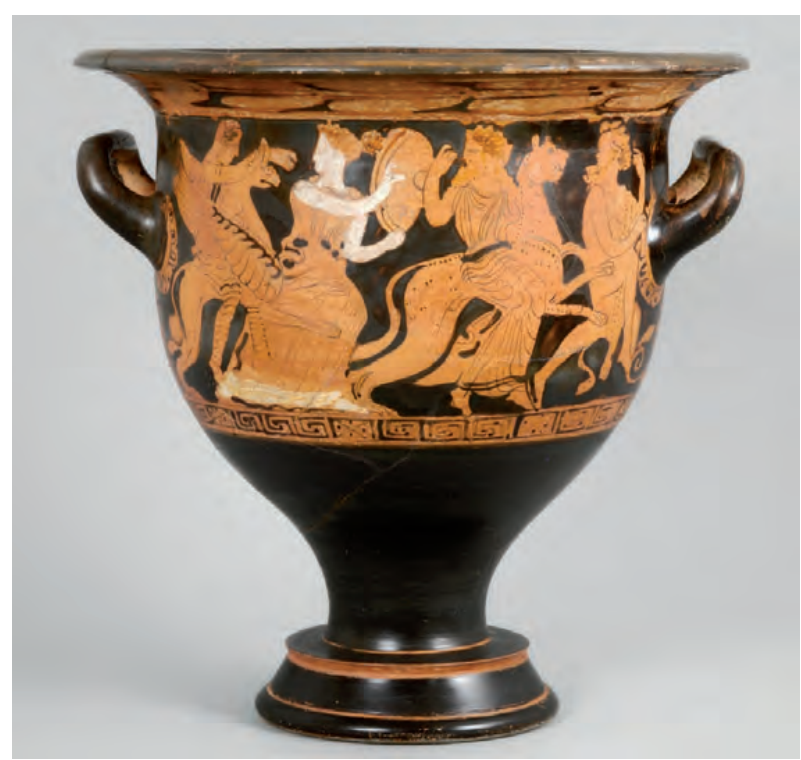

a-1

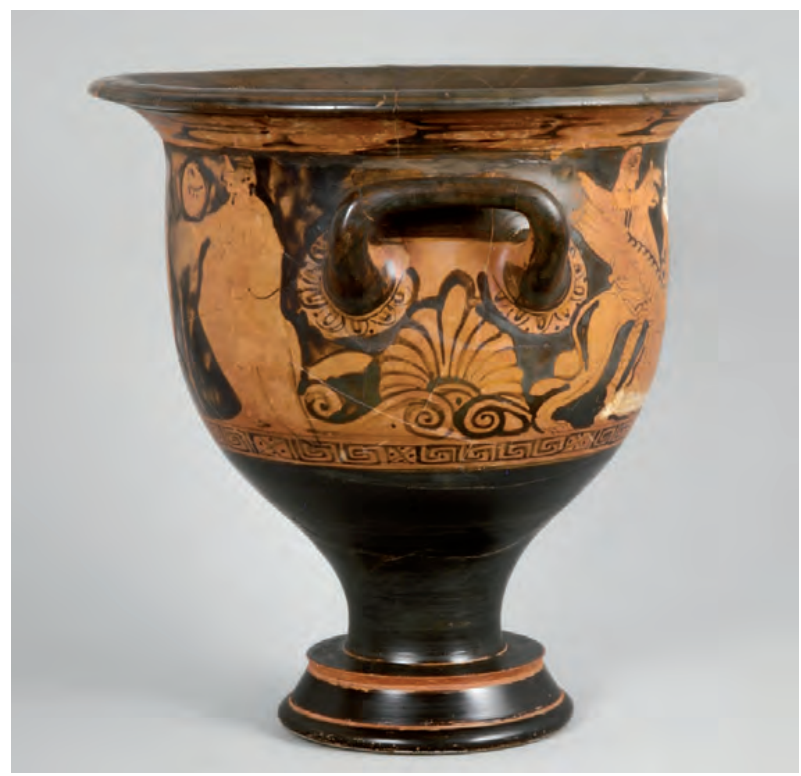

a-3

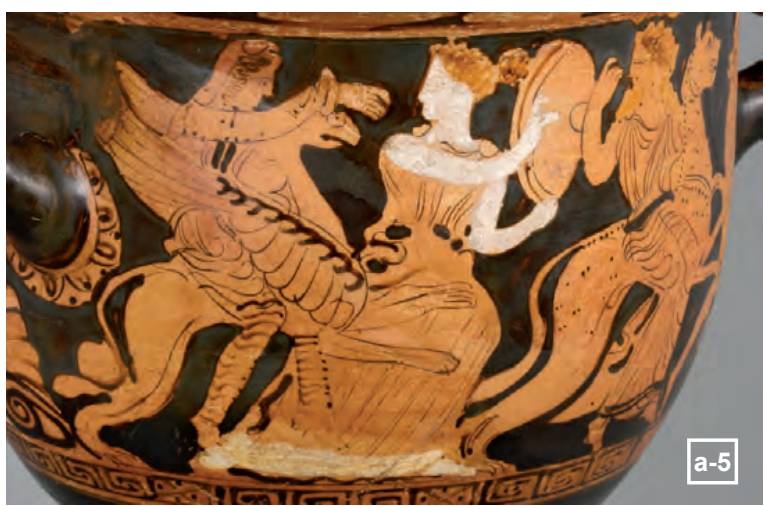

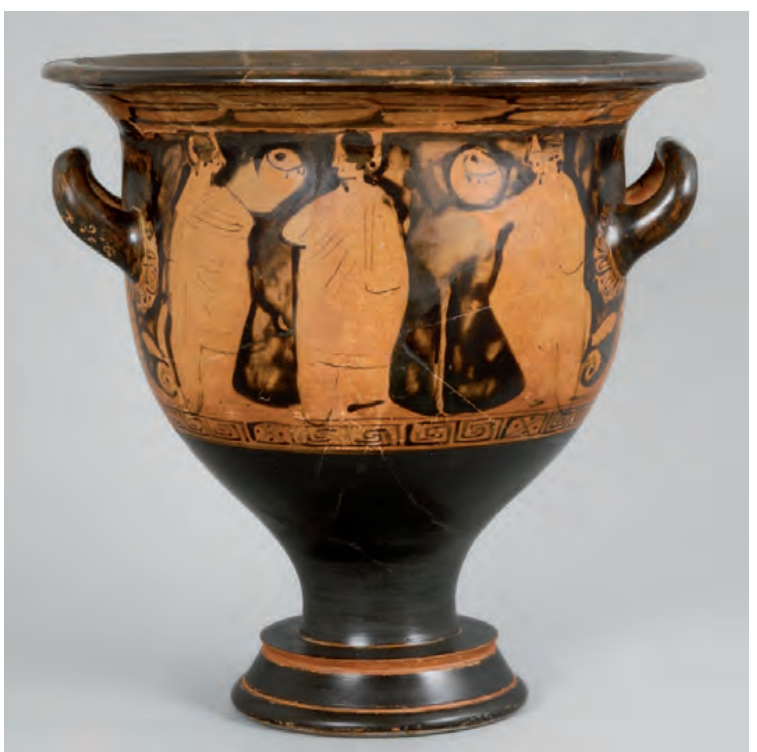

a-2

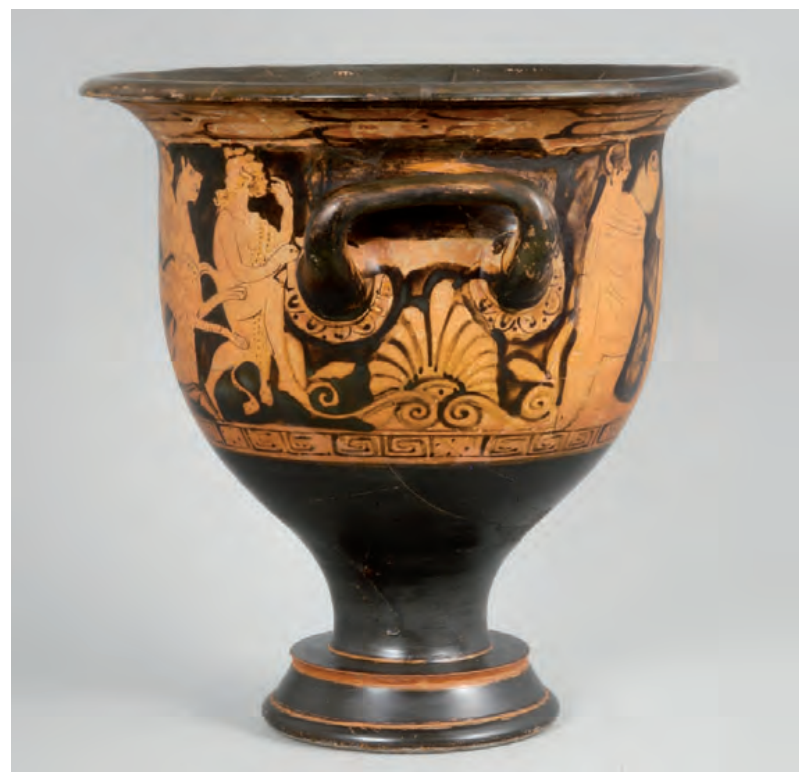

a-4

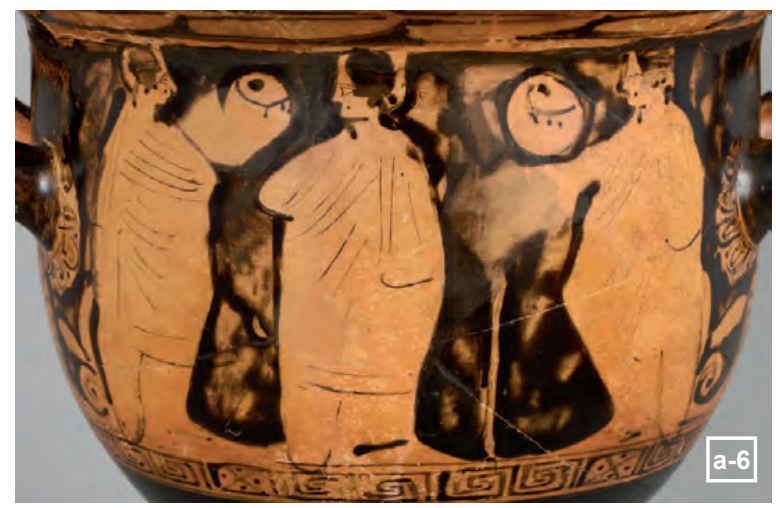


CP 47

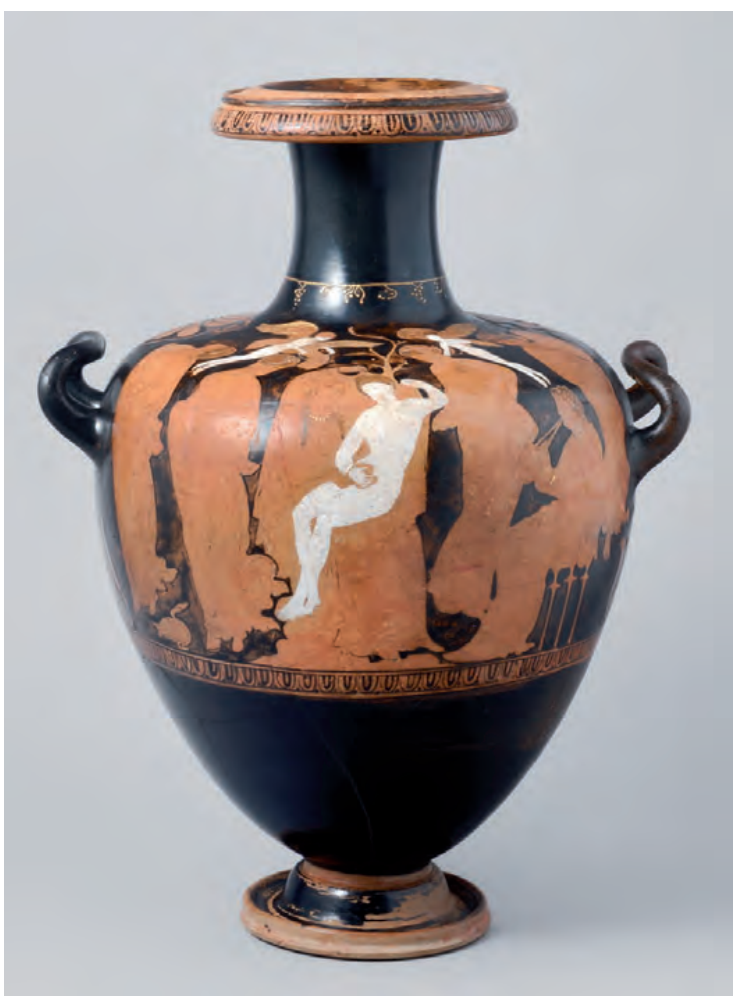

a-1

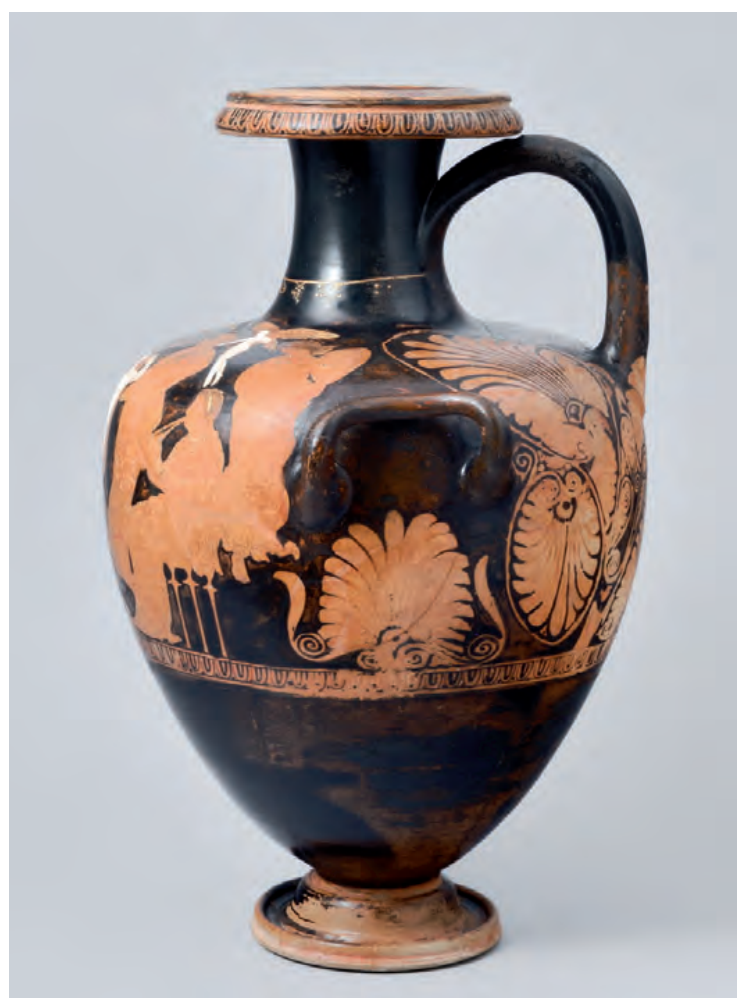

a-3

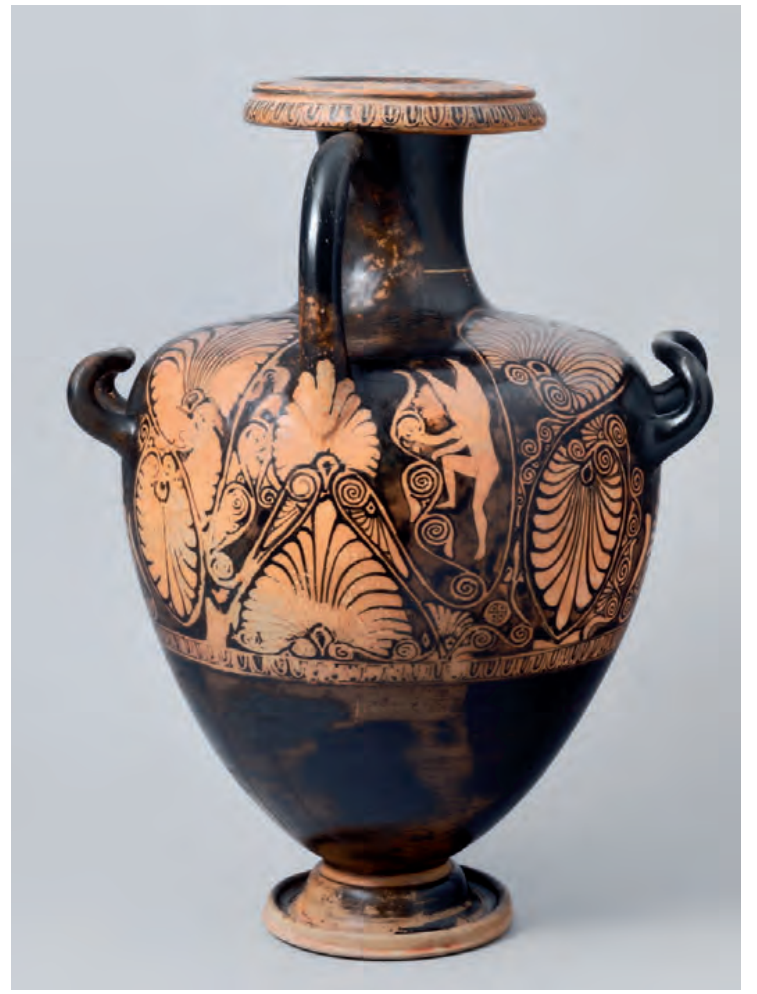

a-2

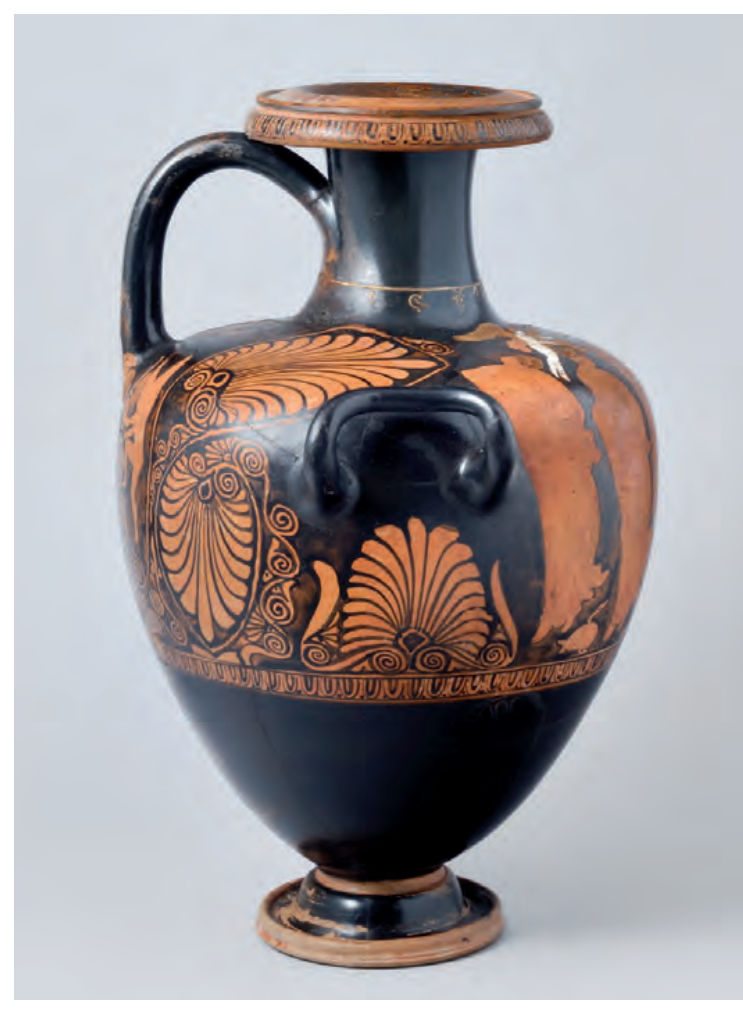

a-4 
Planche 92
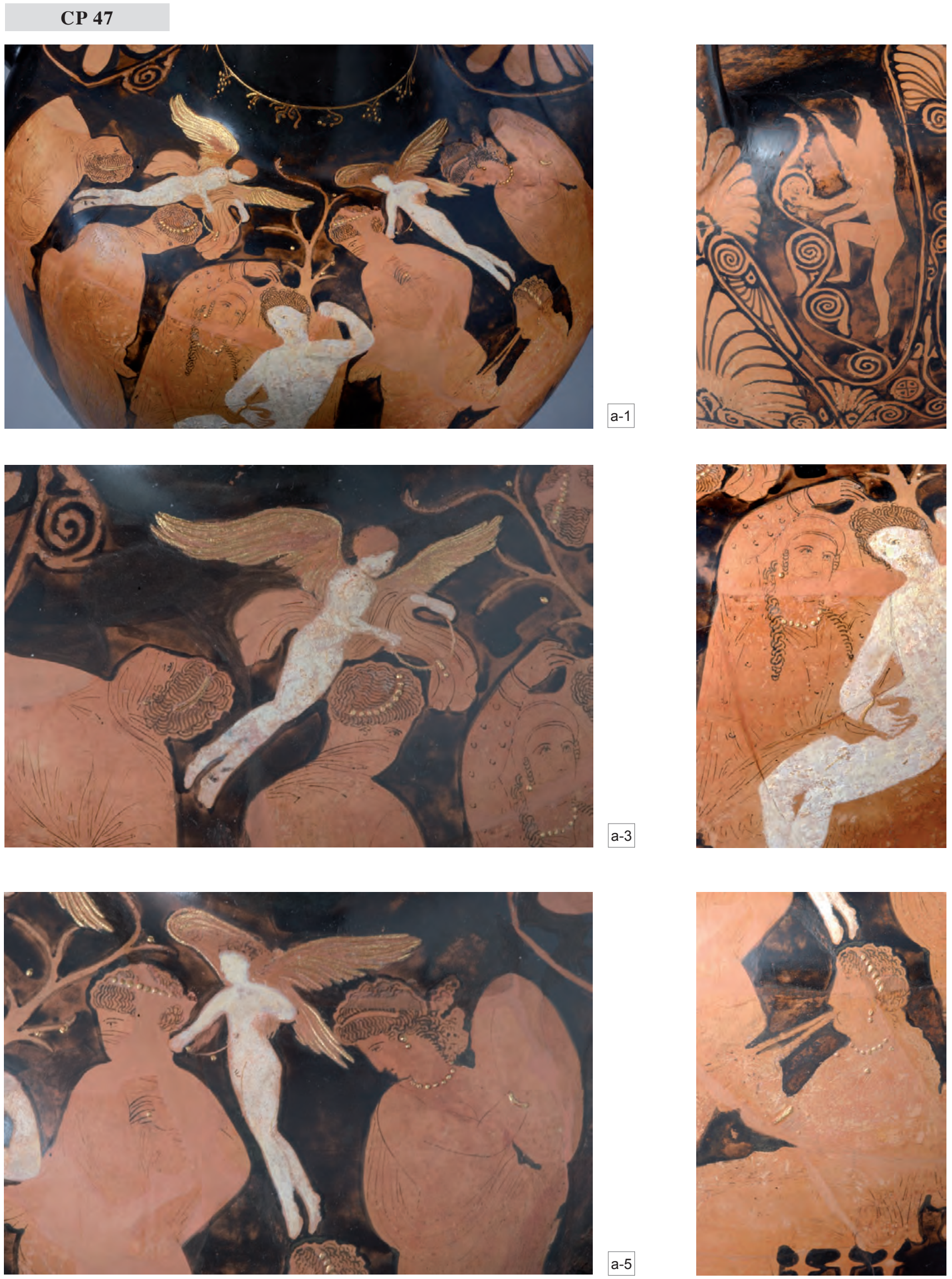
VN 1, 3-5, 8-10, 13

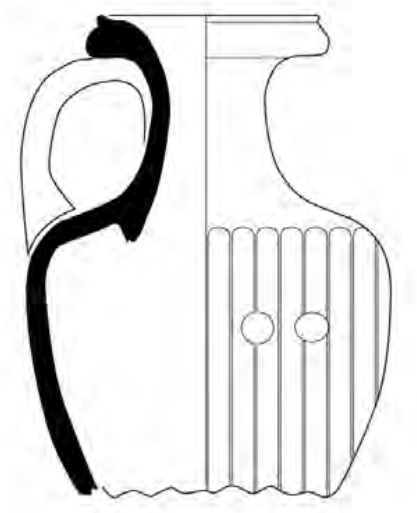

$\mathrm{a}$
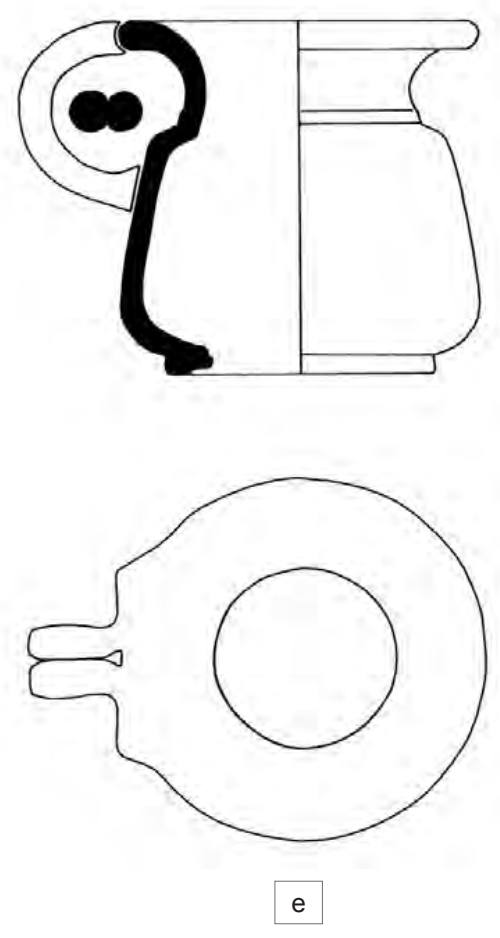

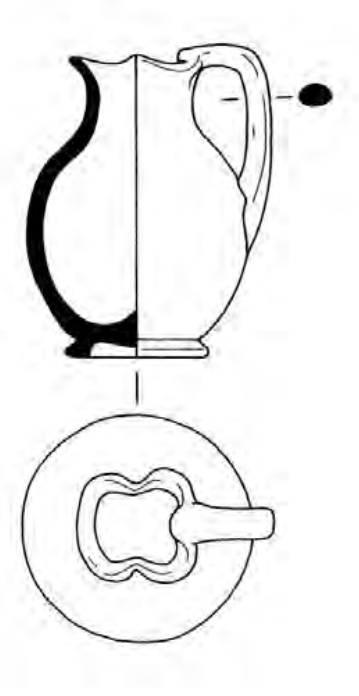

$\mathrm{b}$

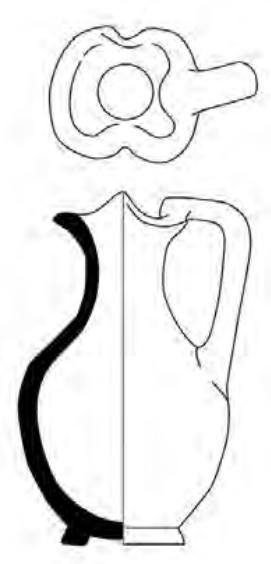

C

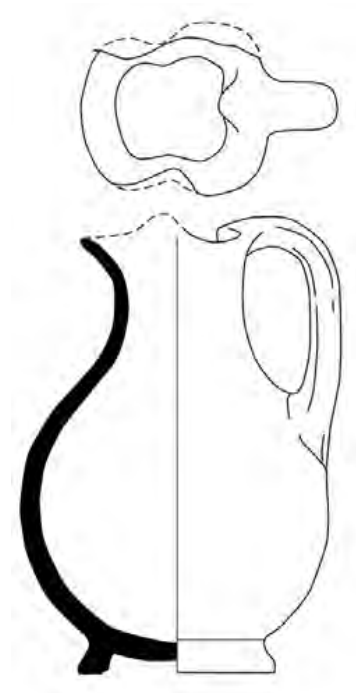

$d$

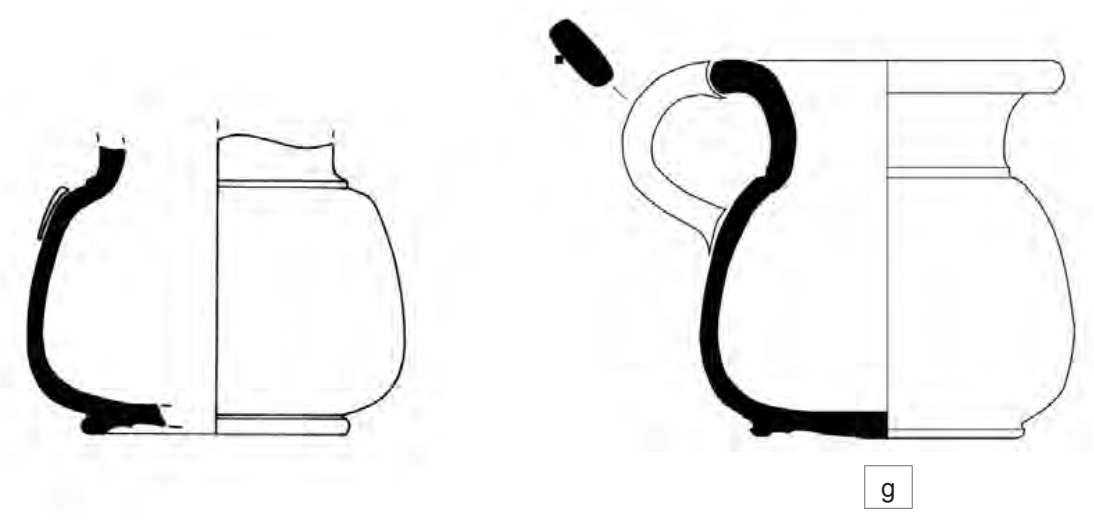

$\mathrm{f}$
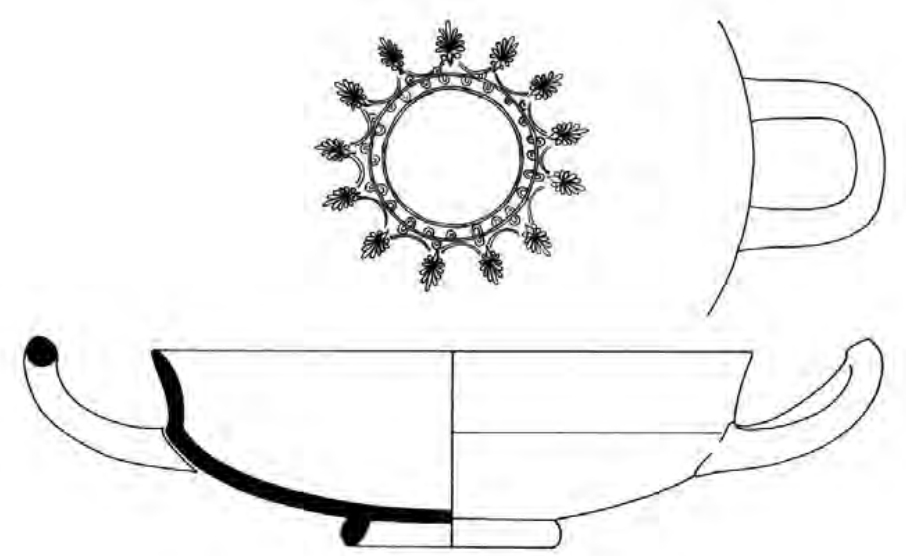

Échelle $1: 2$ 
Planche 94

VN 14, 17-21
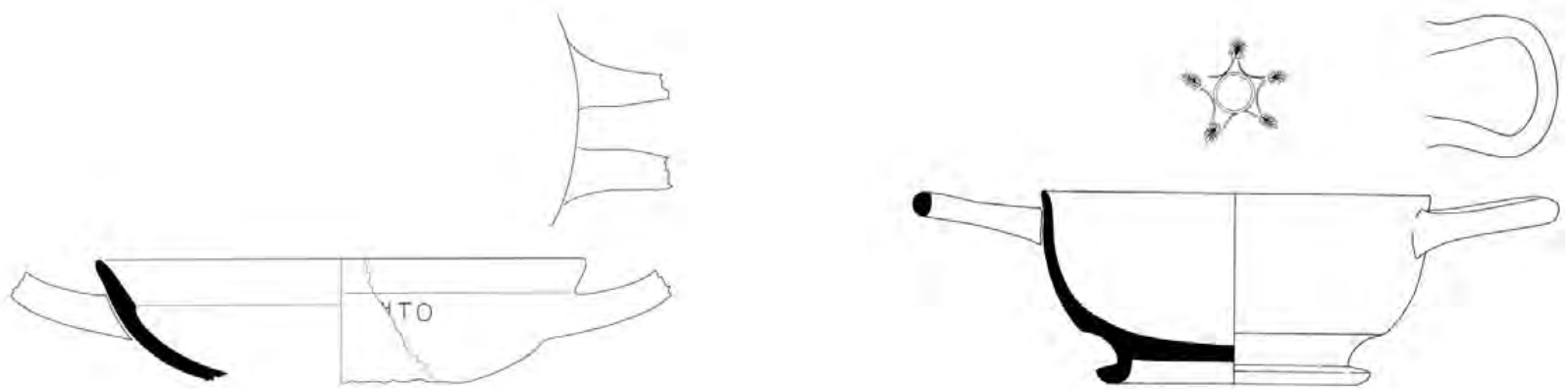

Échelle $1: 4$

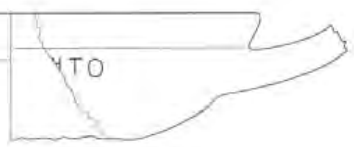

a

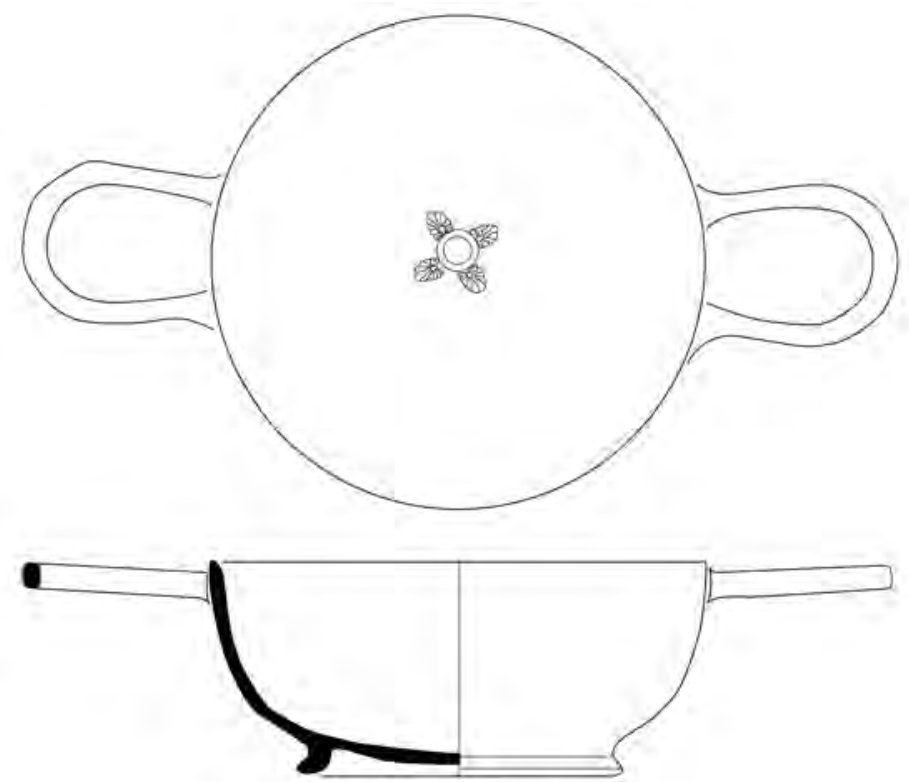

$\mathrm{b}$

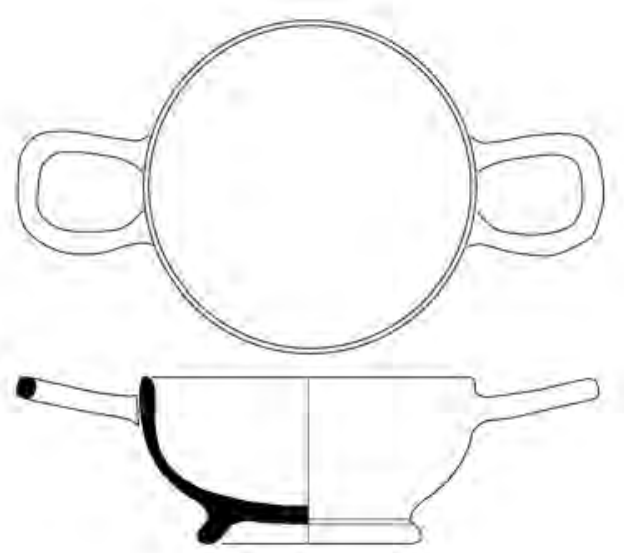

Échelle $1: 2$

d

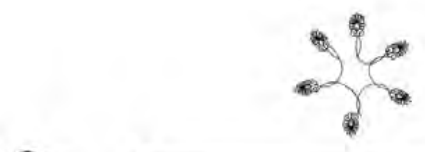

1

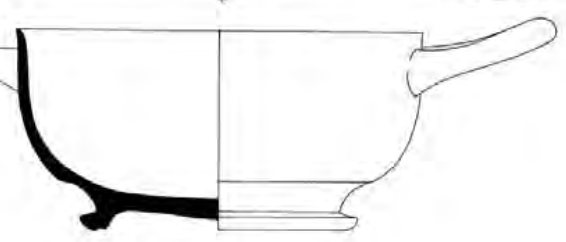

Échelle 1: 4 e
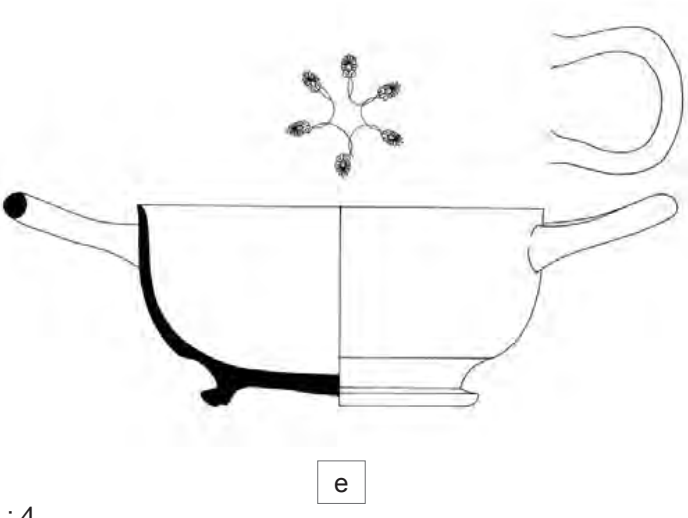

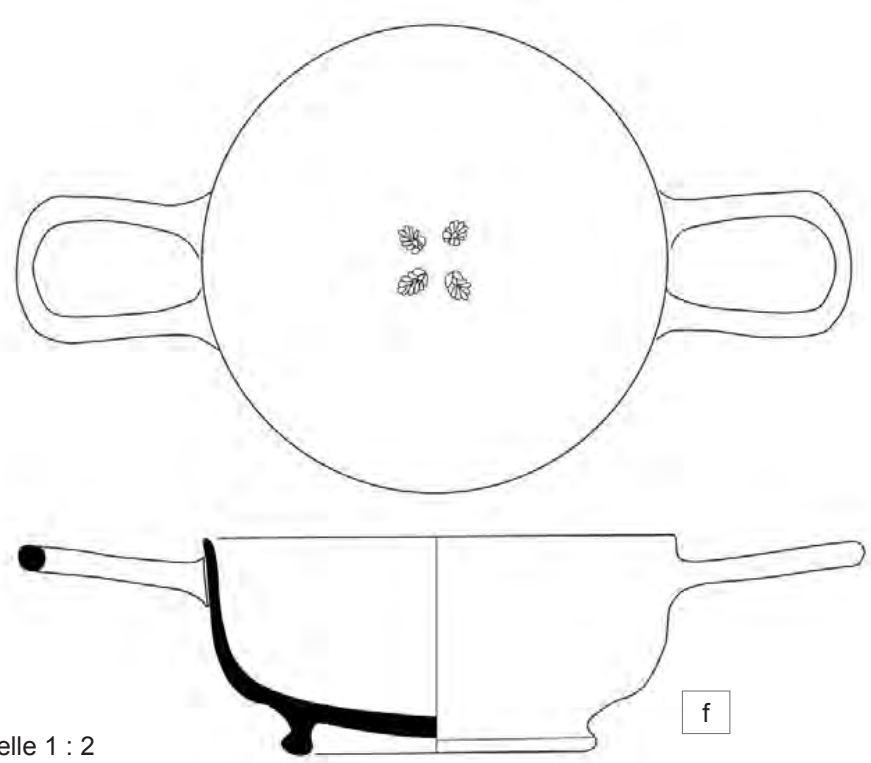

Échelle $1: 2$ 
Planche 95

VN 22, 26-28, 31, 32
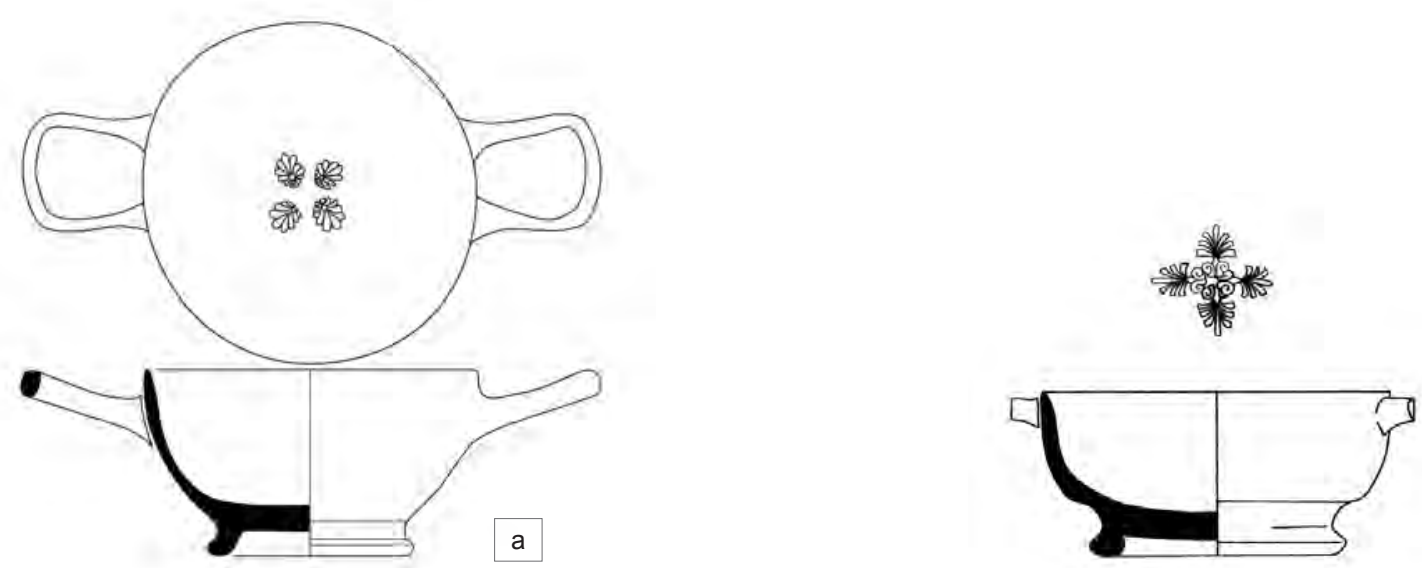

Échelle $1: 2$
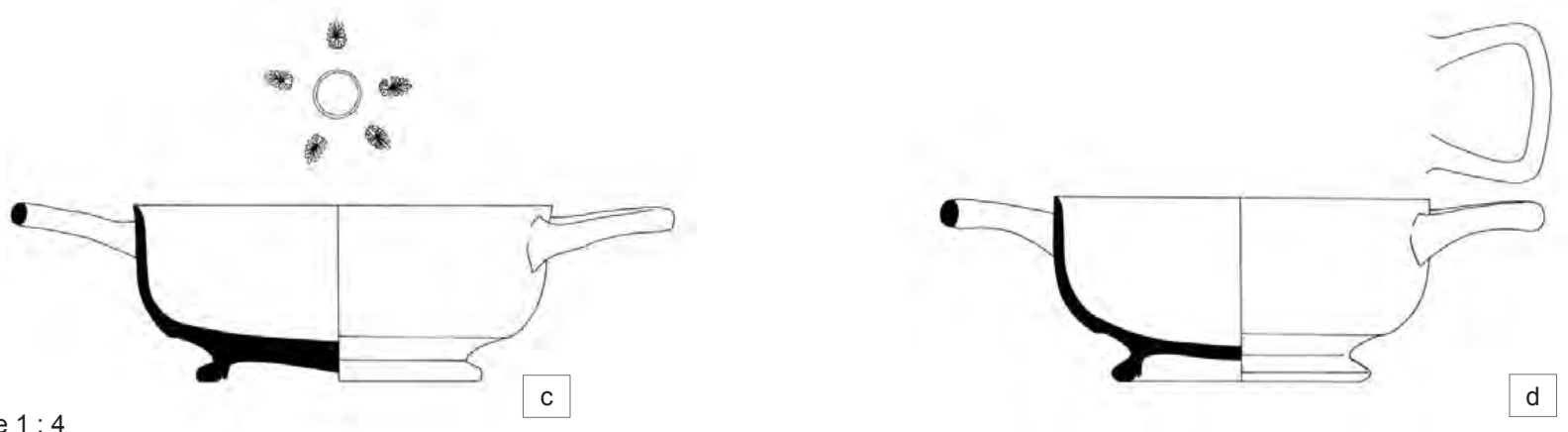

Échelle $1: 4$
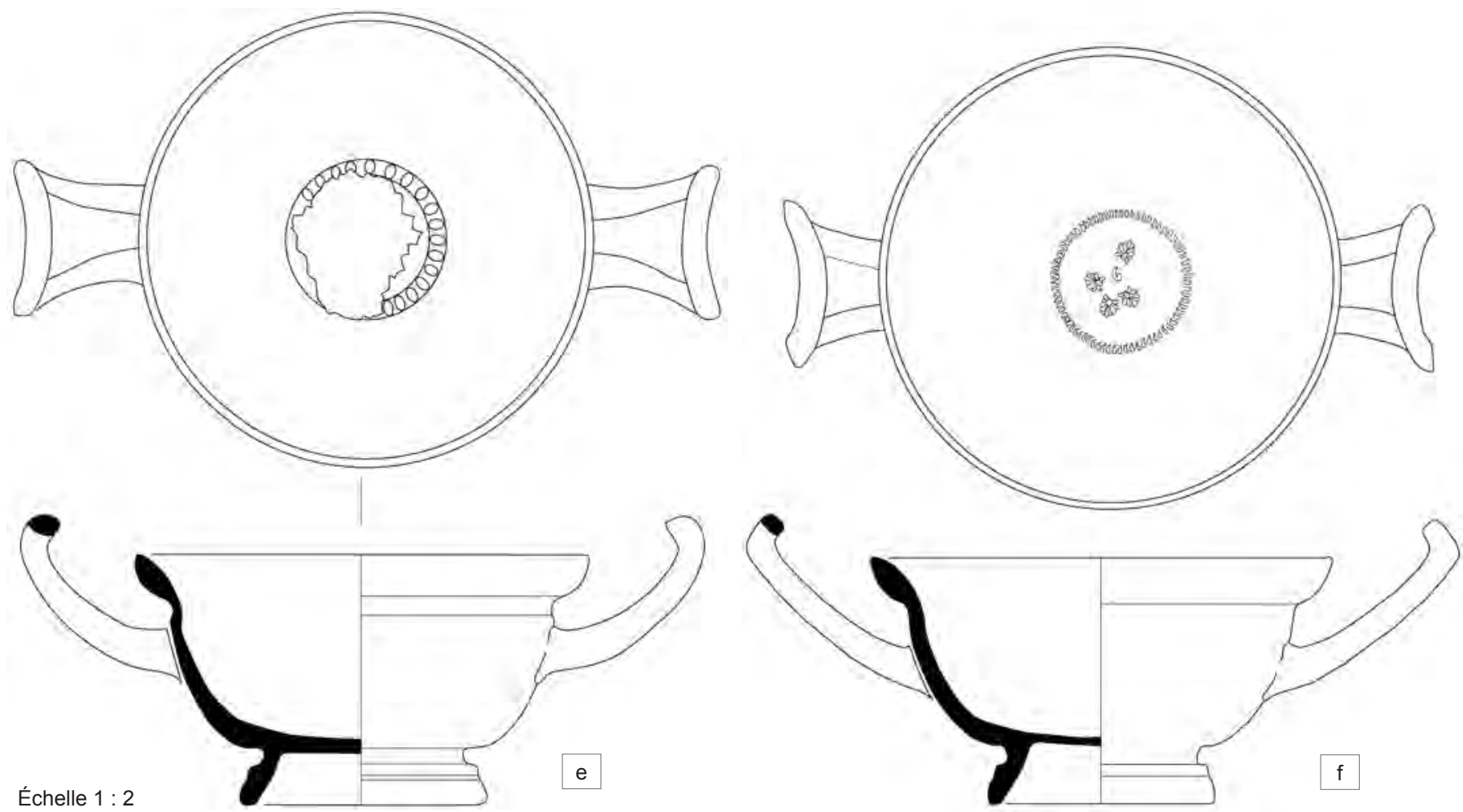
Planche 96

VN 33-35, 37-39
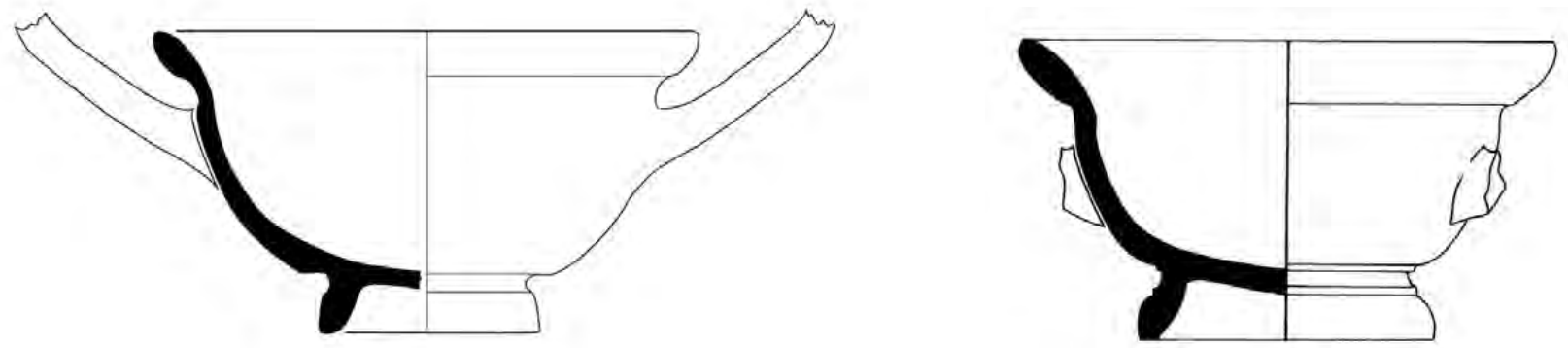

a
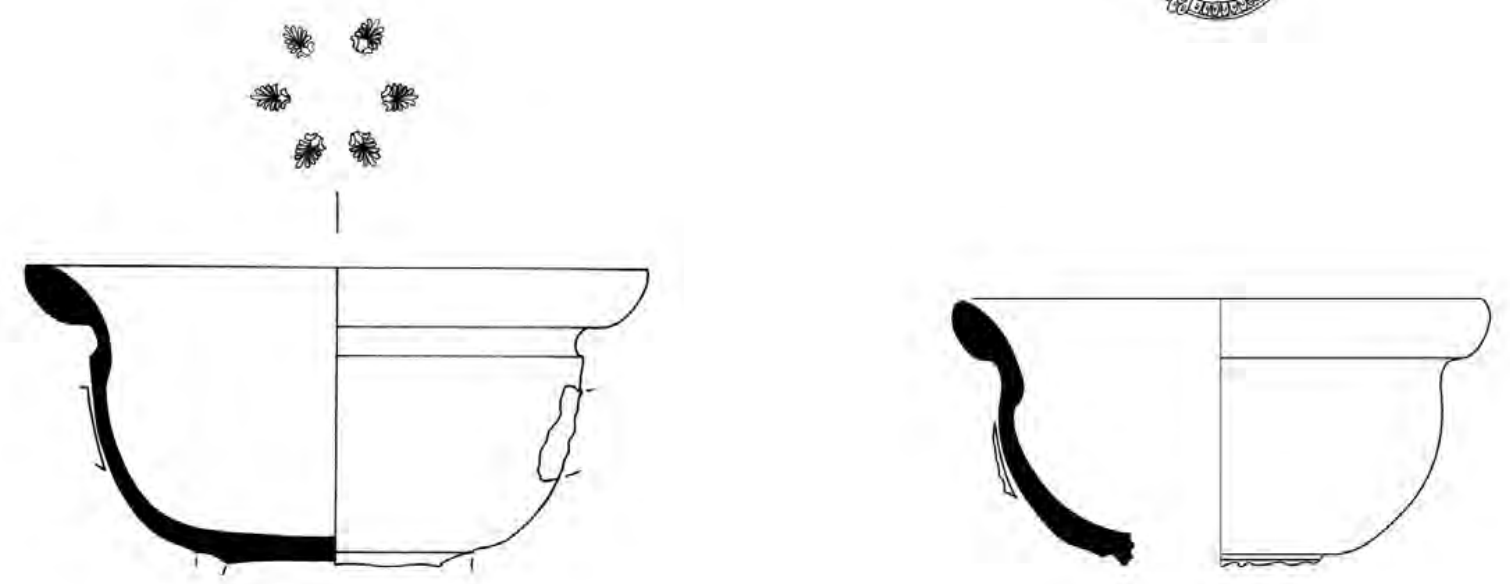

c

d
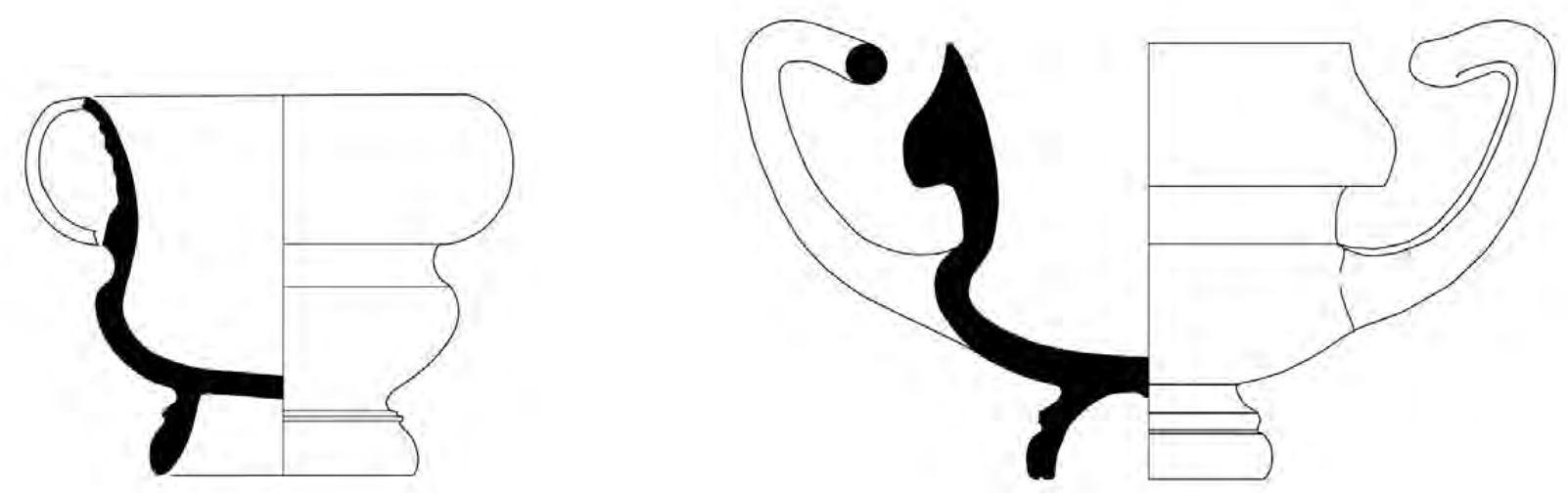

Échelle $1: 2$

e

$\mathrm{f}$ 
Planche 97

VN 40, 42-47
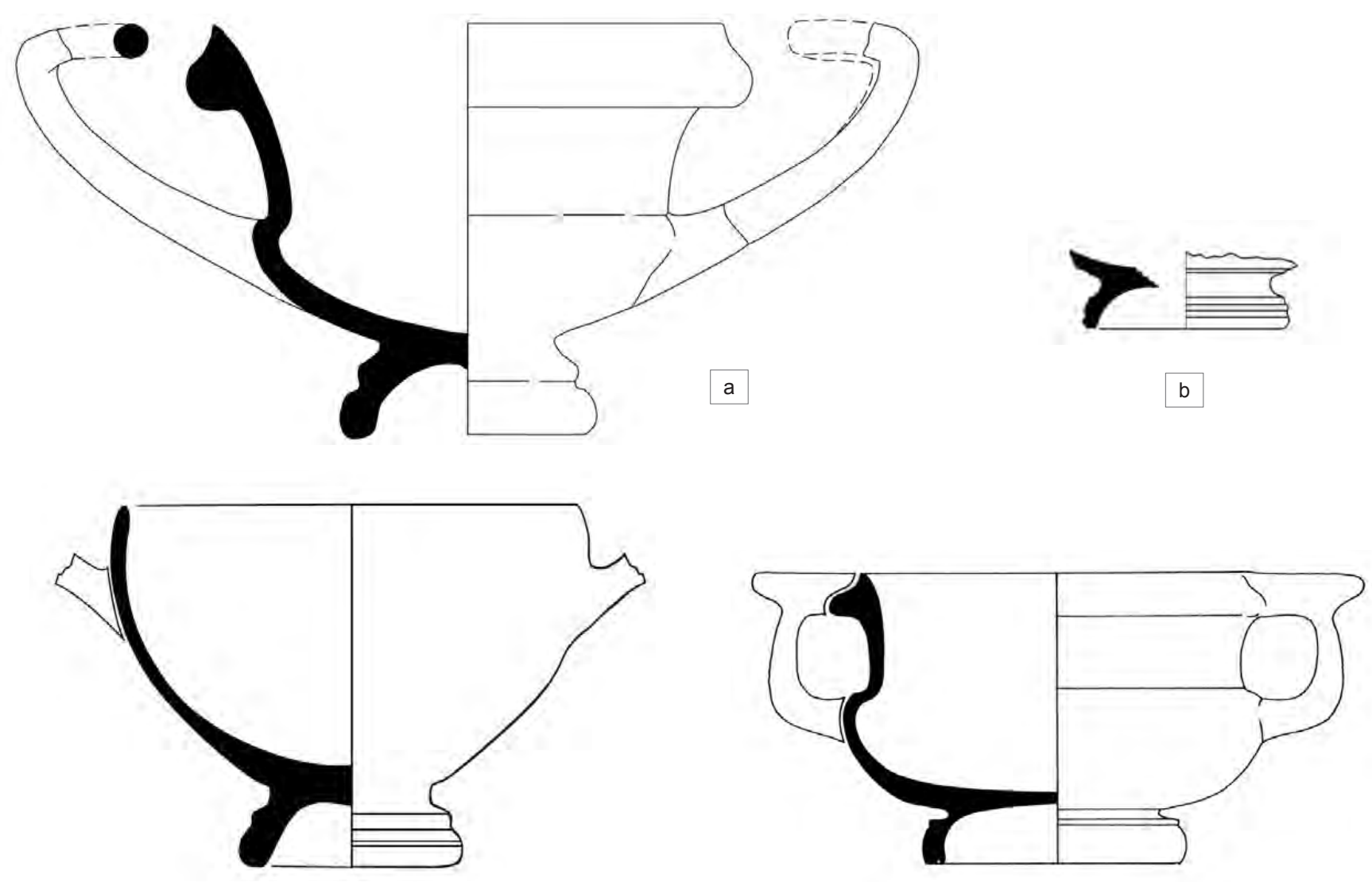

C

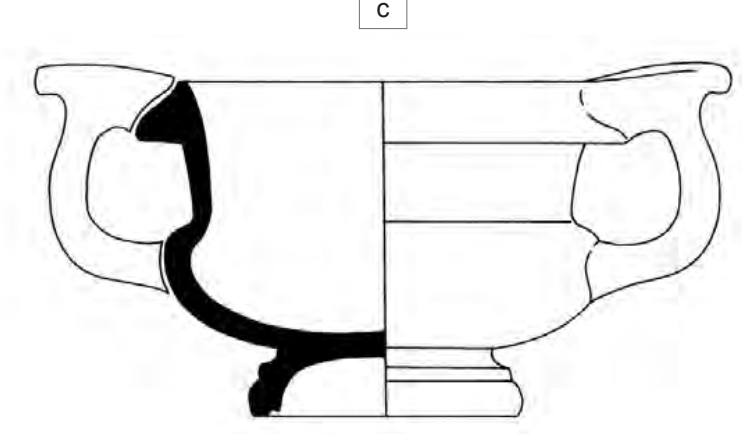

d
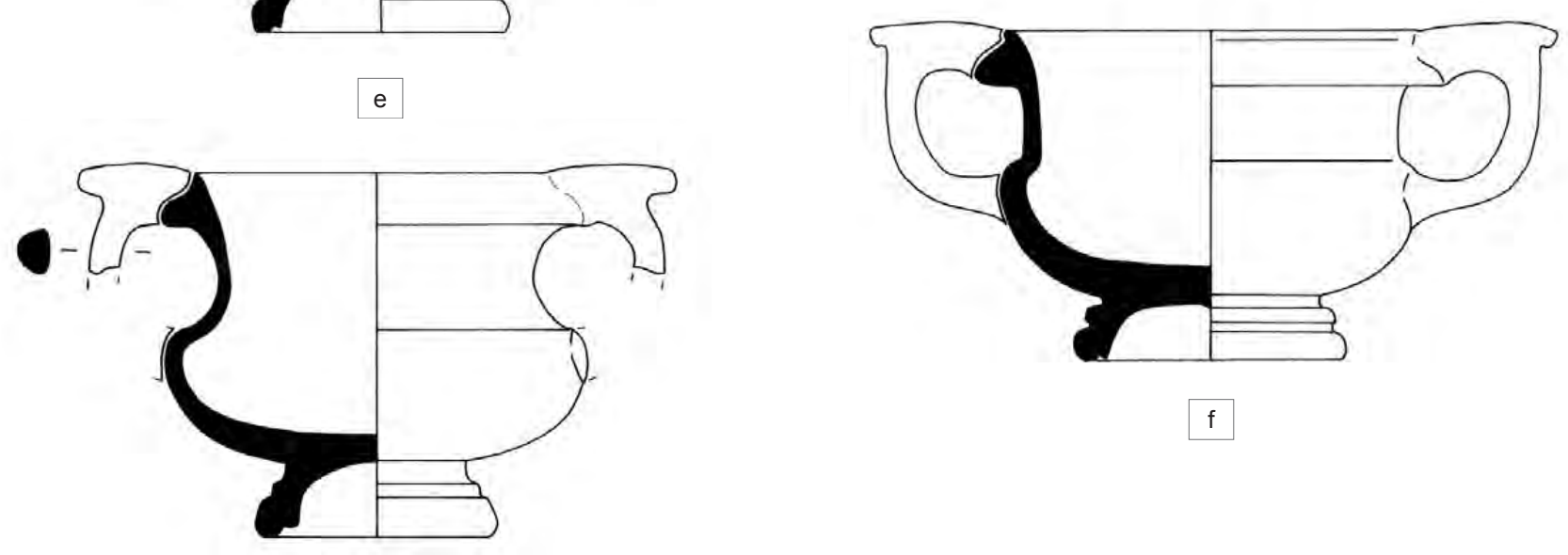

Échelle $1: 2$

$\mathrm{g}$ 
Planche 98

VN 48, 49, 51-53, 56

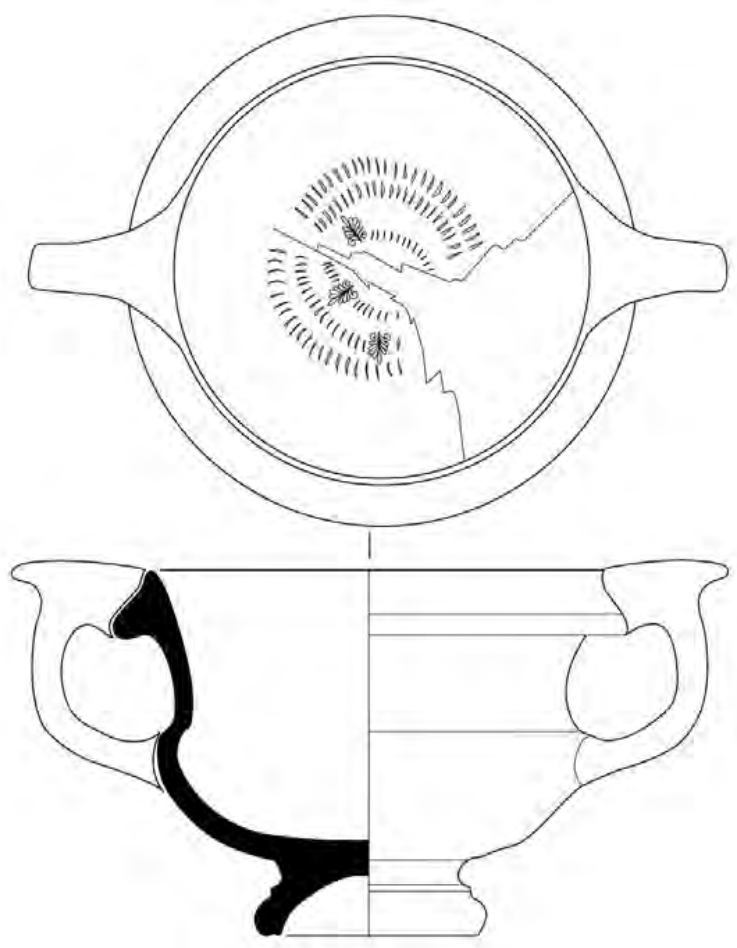

$a$
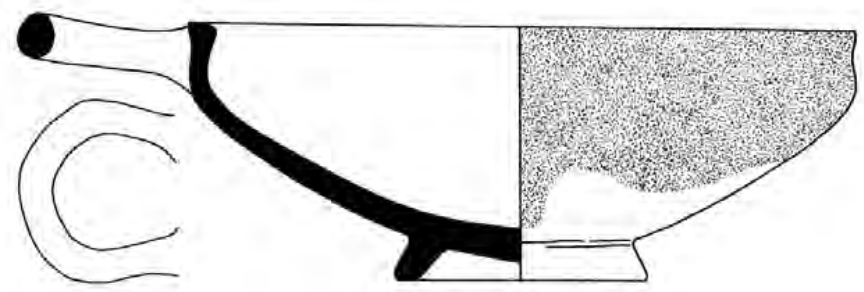

d
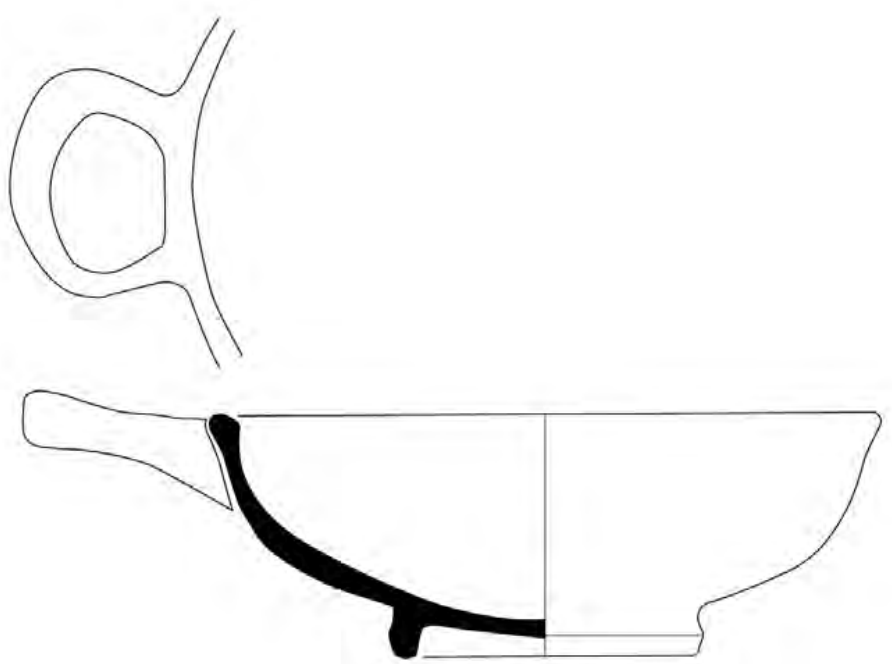

Échelle $1: 2$
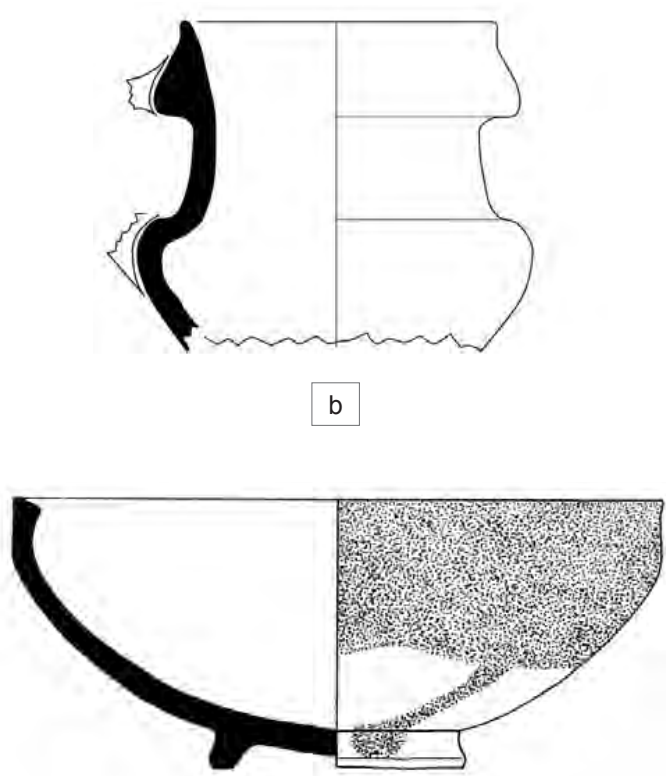

c
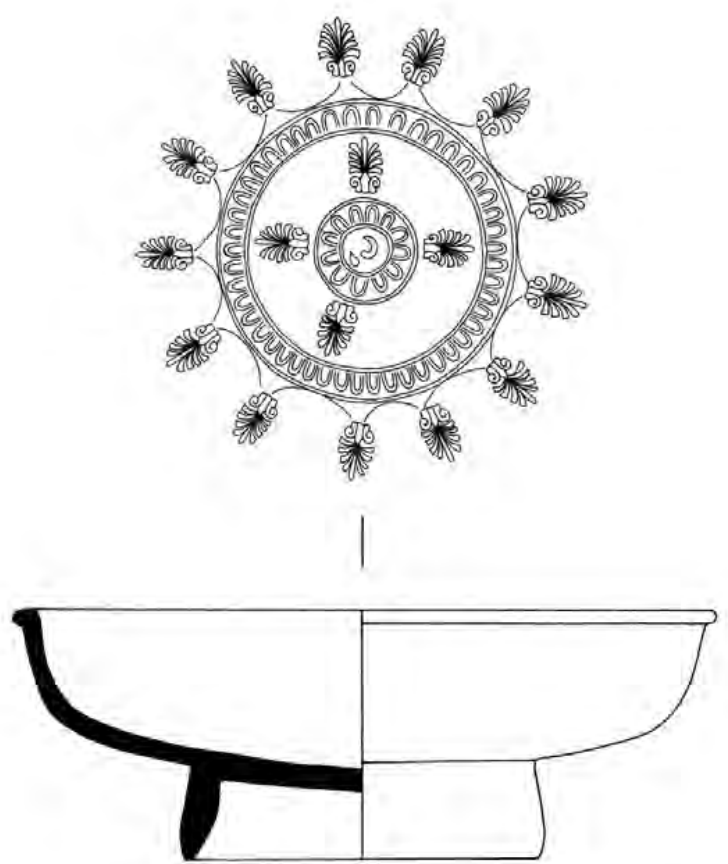


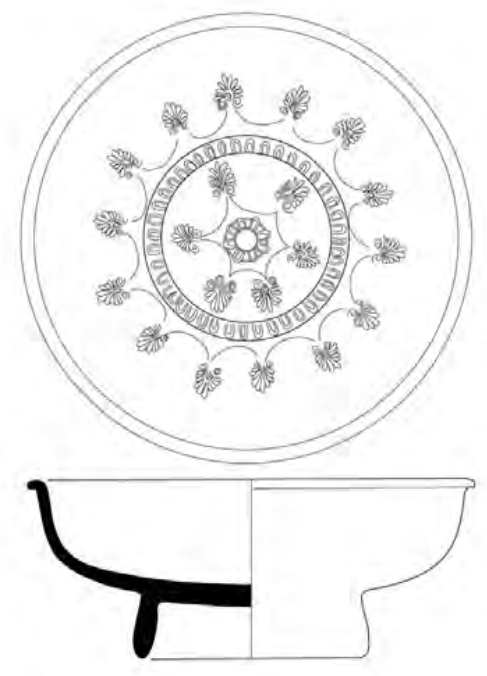

a
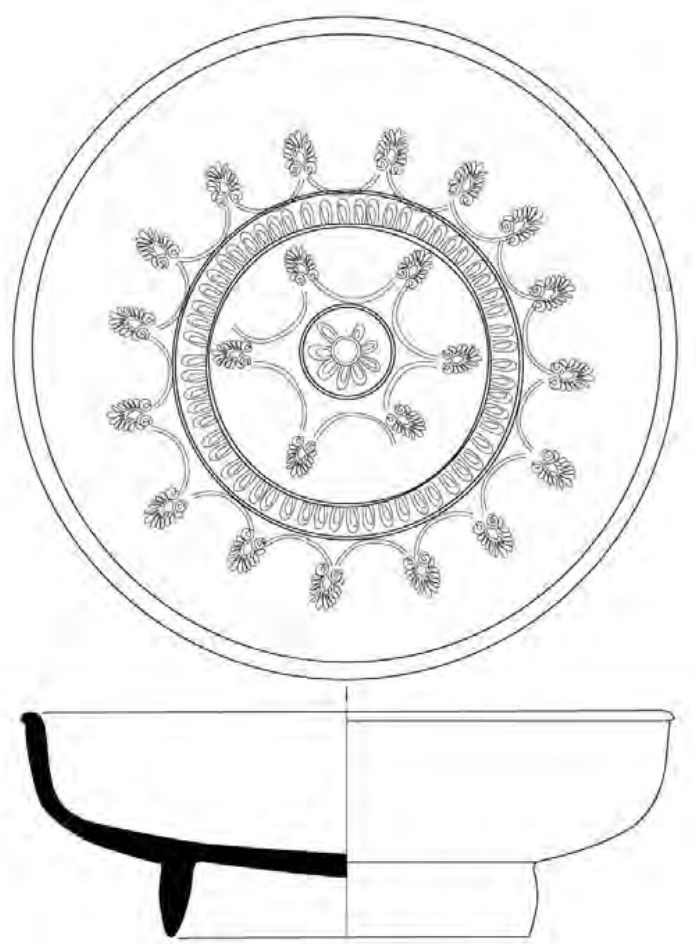

Échelle $1: 3$

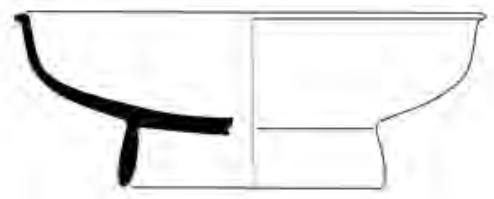

c
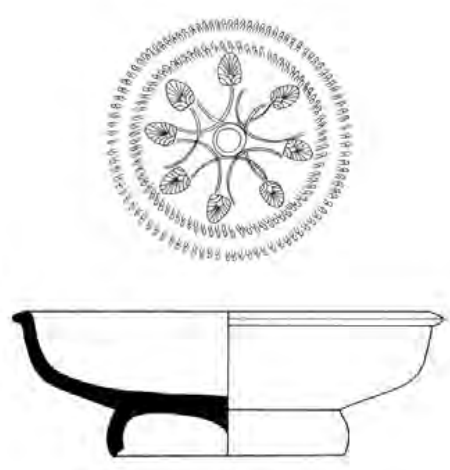

e

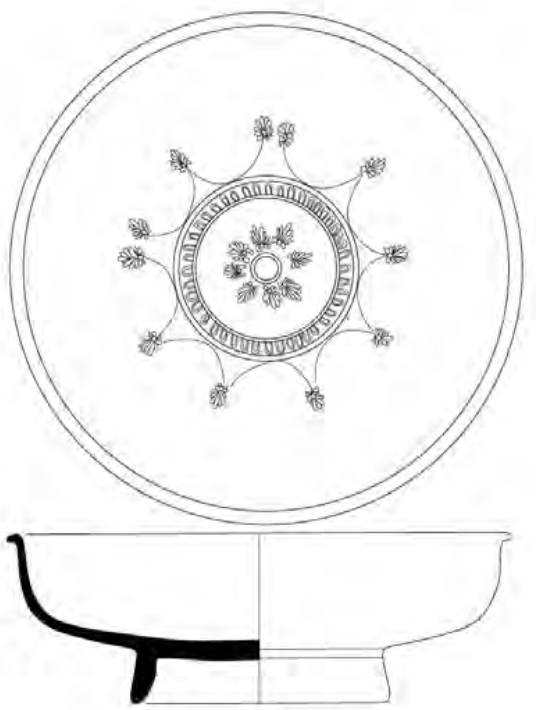

b
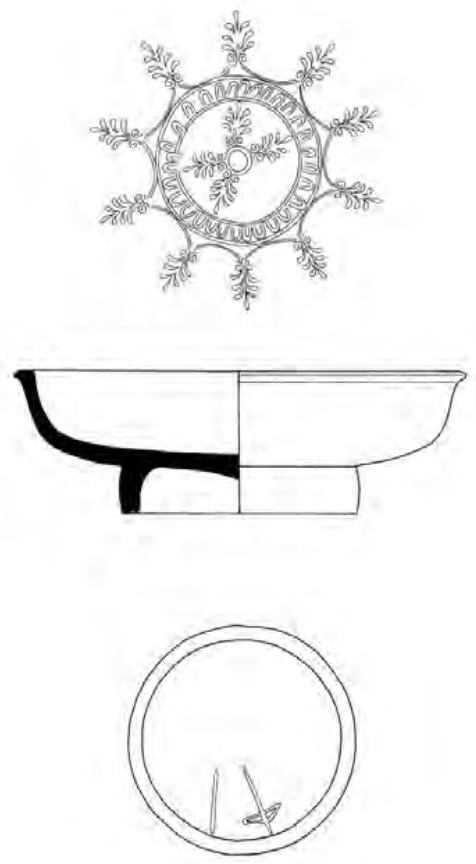

f 
Planche 100

VN 69, 71, 73, 74a et b
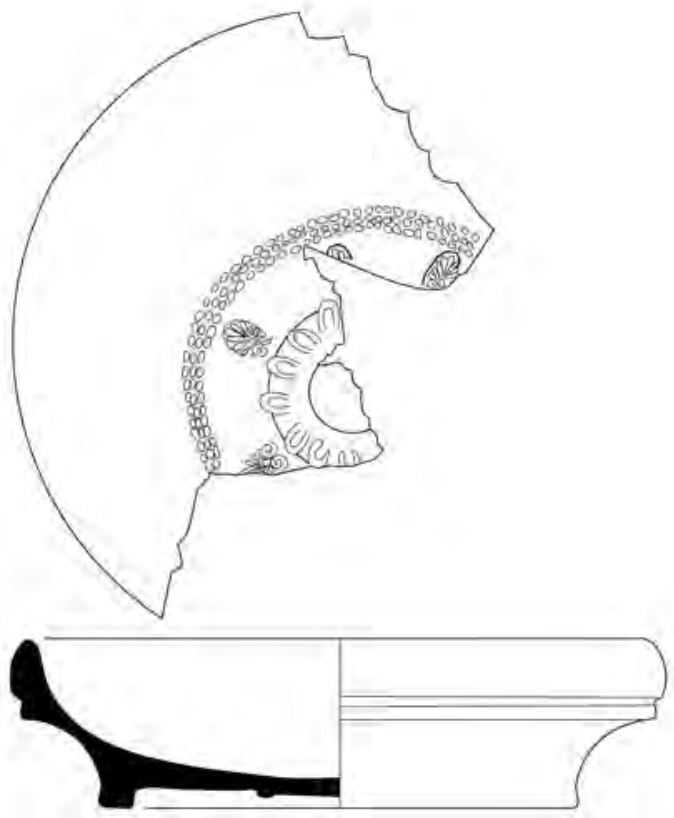

a
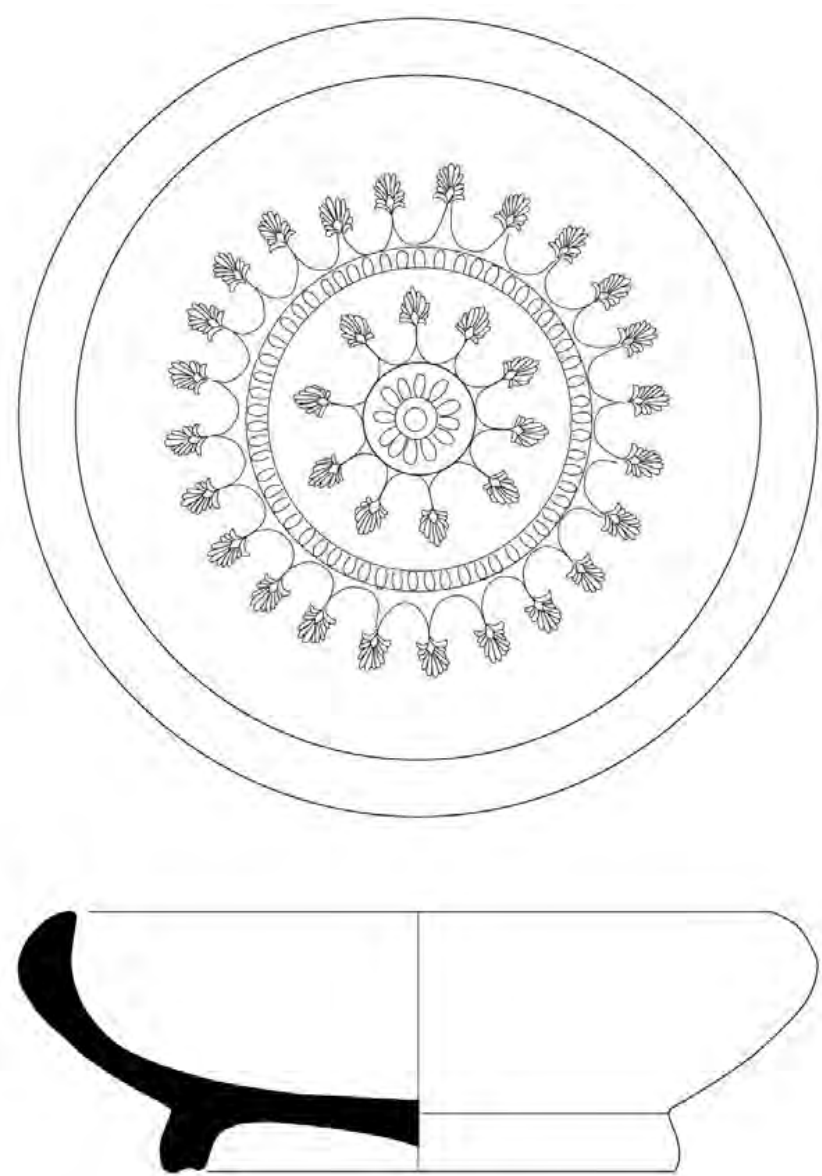

Échelle 1:2

d
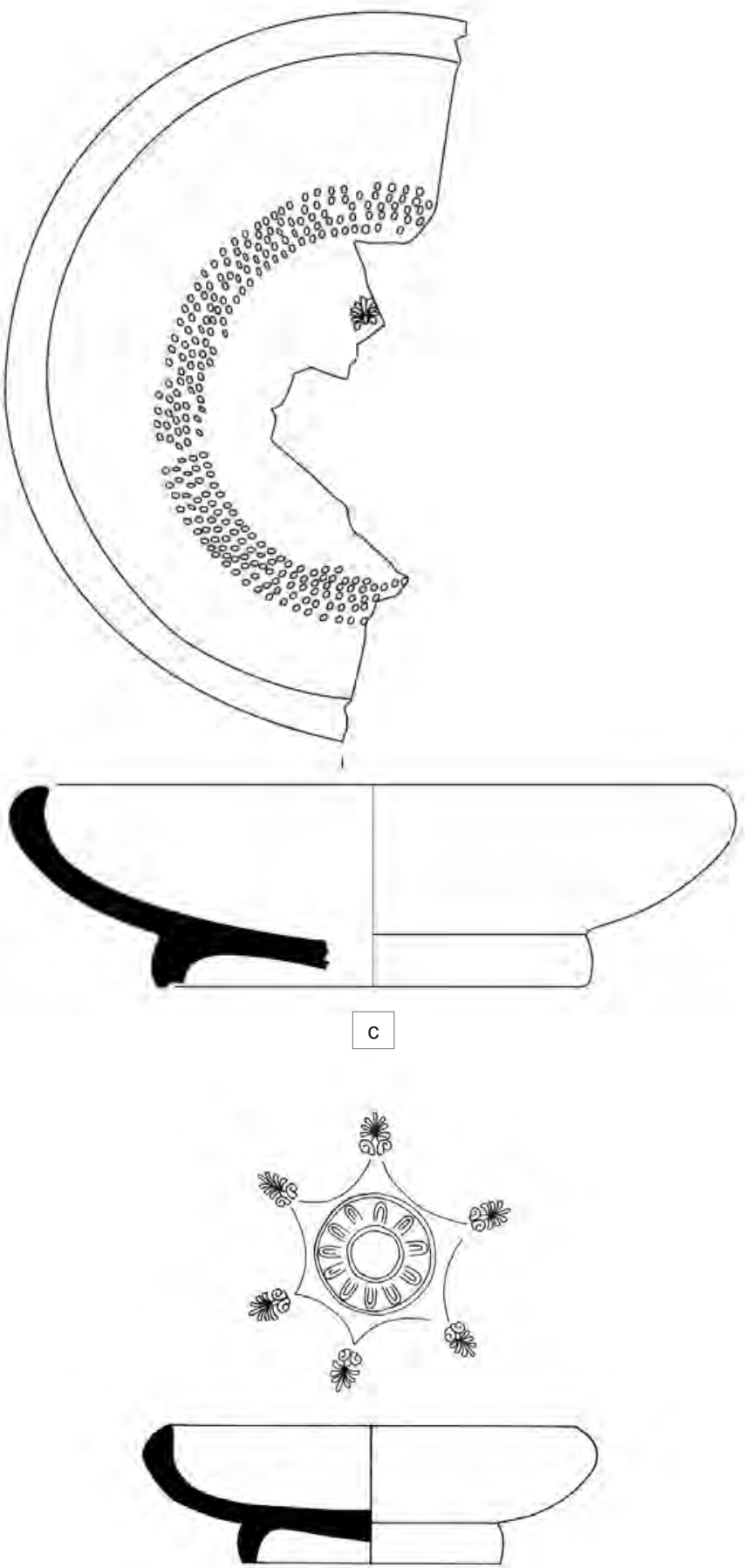

e 
VN 80, 81, 83, 84, 88, 89, 91
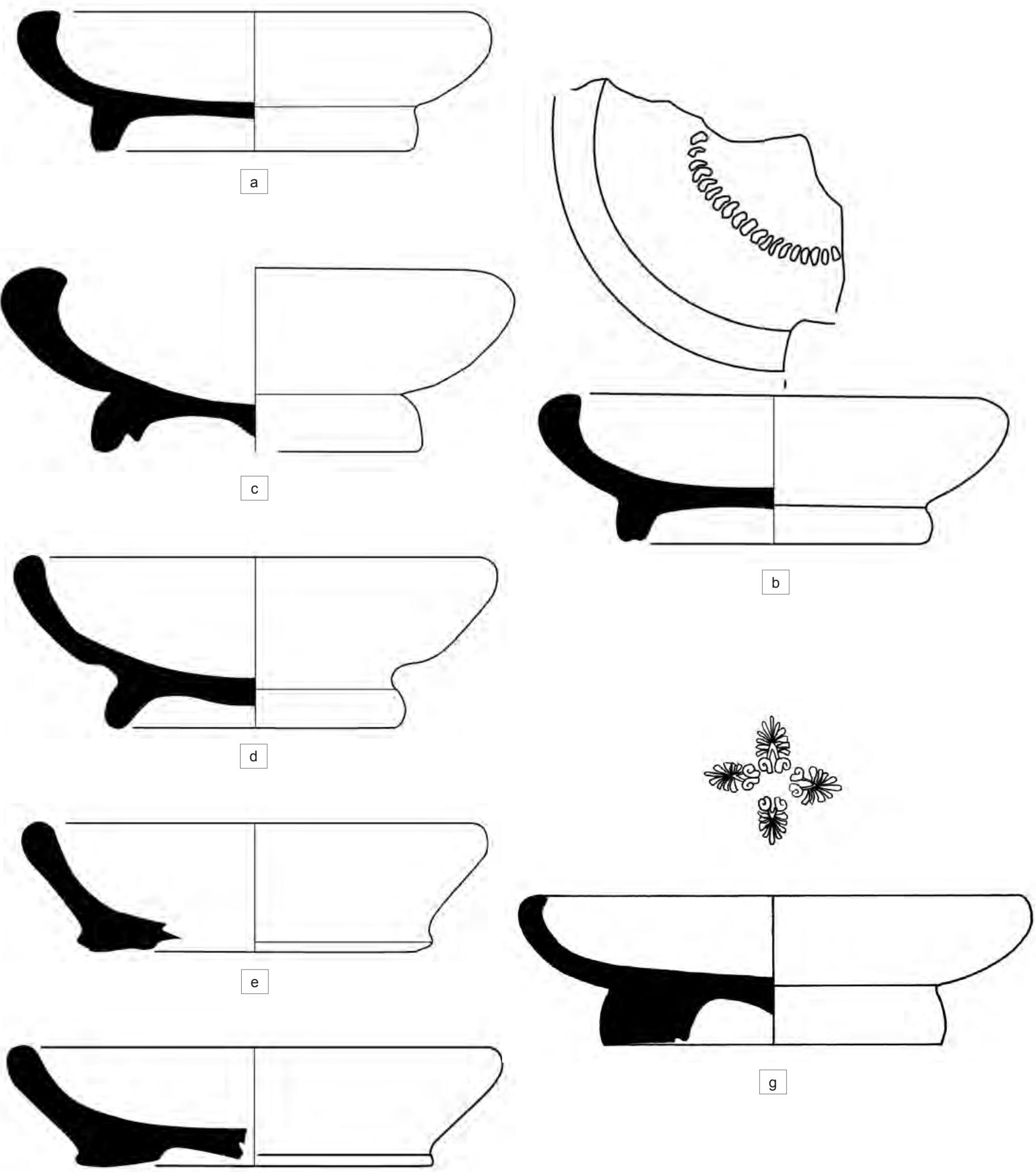

Échelle $1: 1$

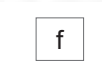


Planche 102

VN 94-97, 100, 102, 105
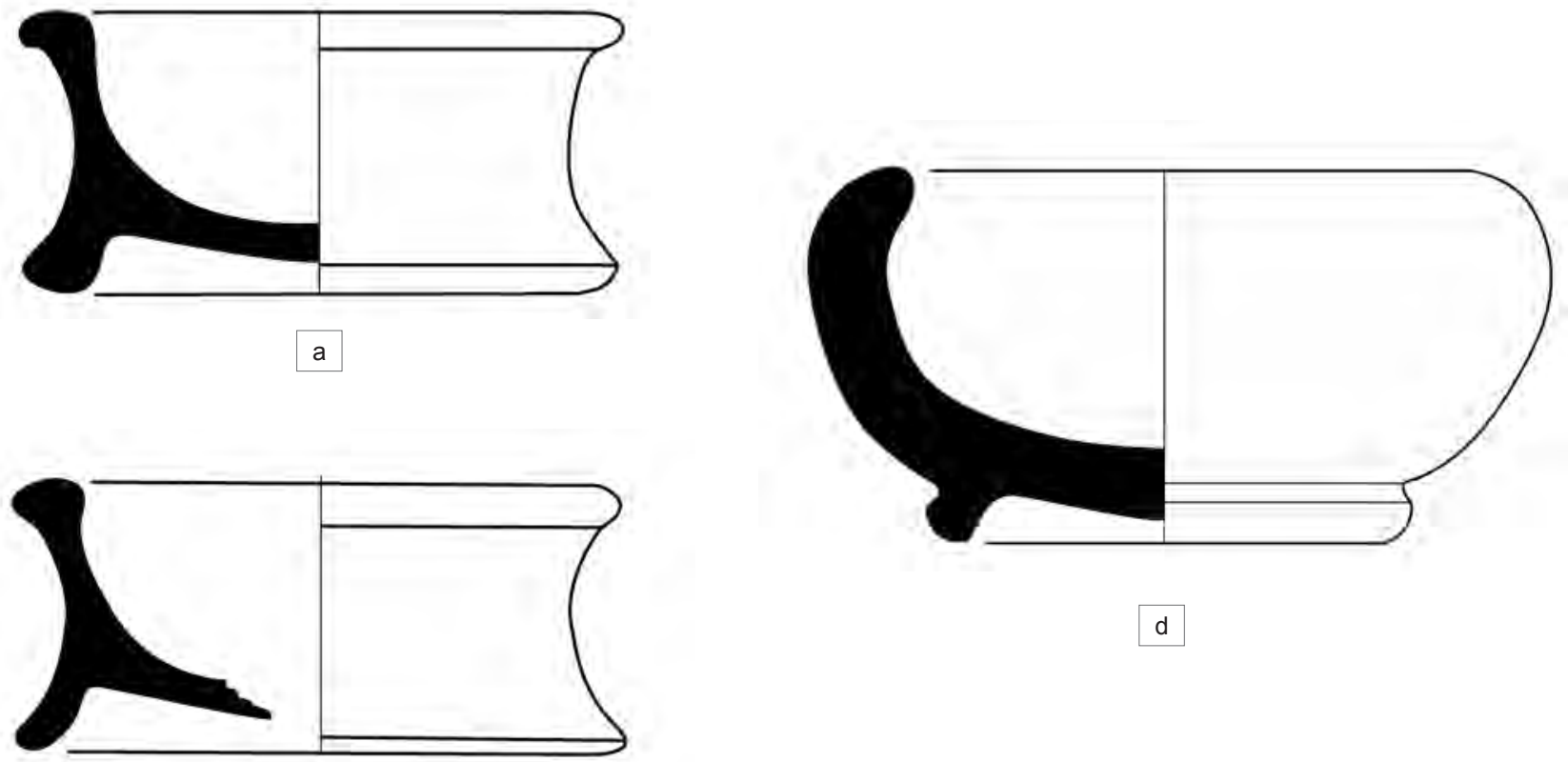

d

$\mathrm{b}$
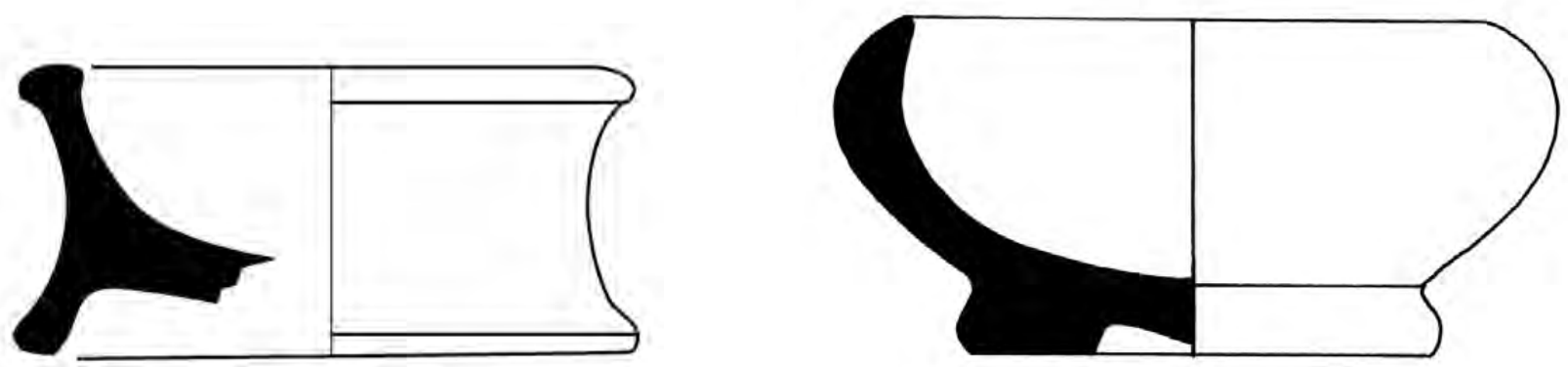

c

Échelle $1: 1$

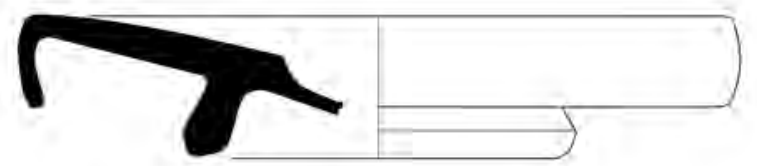

f

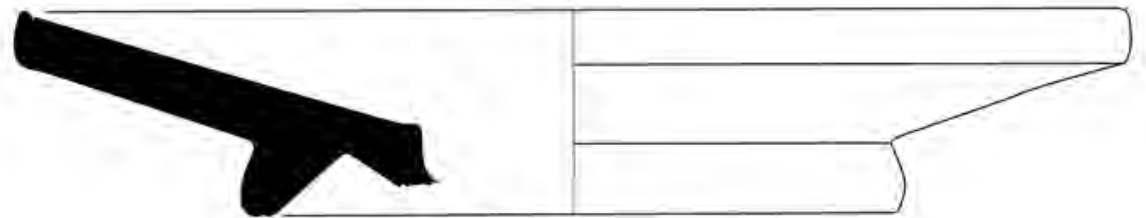


VN 109a et b, 111
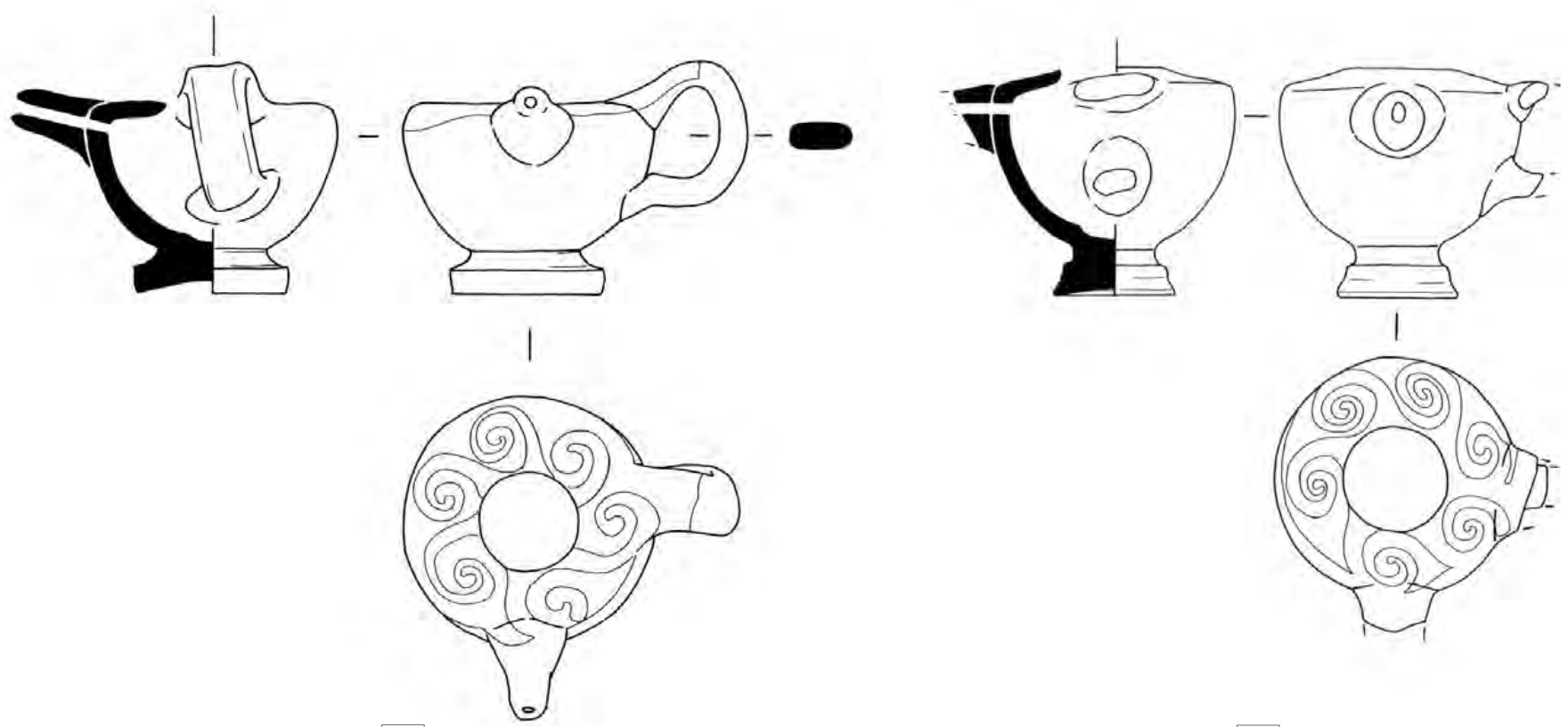

a

Échelle $1: 2$
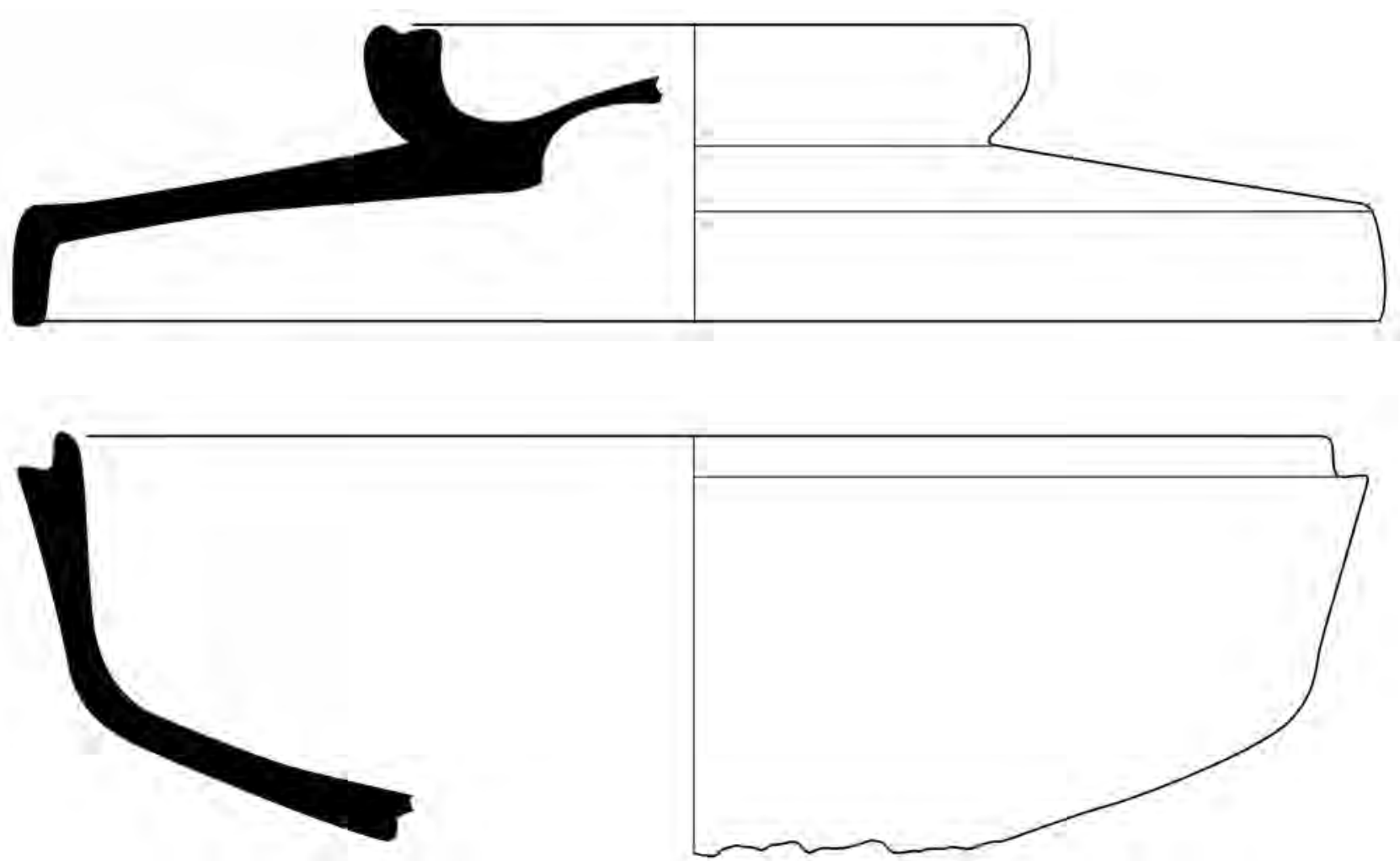


$$
\begin{array}{cc}
2 & 2 \\
2 & 2 \\
2 & 2
\end{array}
$$




$$
\begin{aligned}
& < \\
& -?)
\end{aligned}
$$


Planche 106

CC 28, 29, 31-33
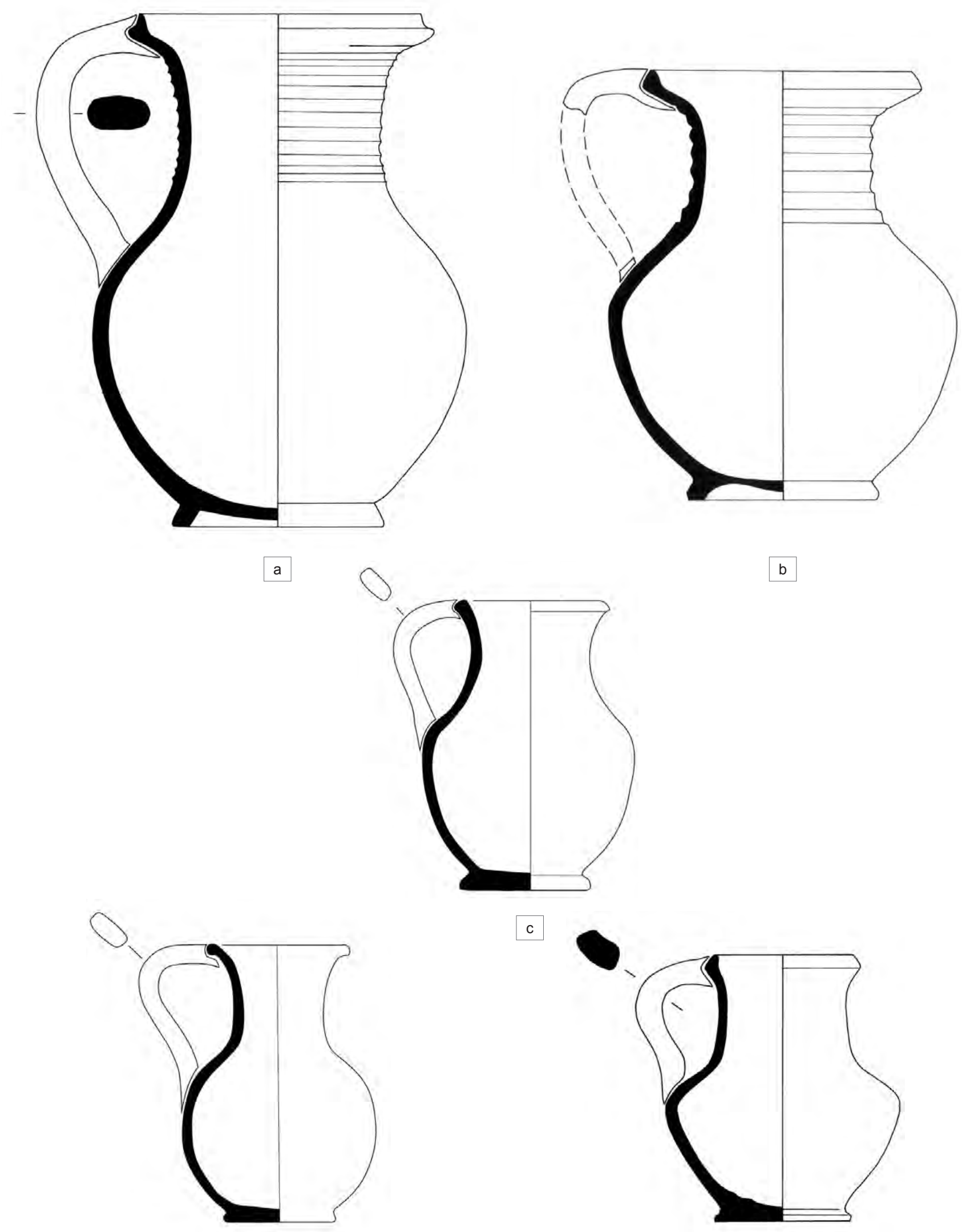

$\mathrm{b}$

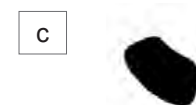

Échelle $1: 2$

d

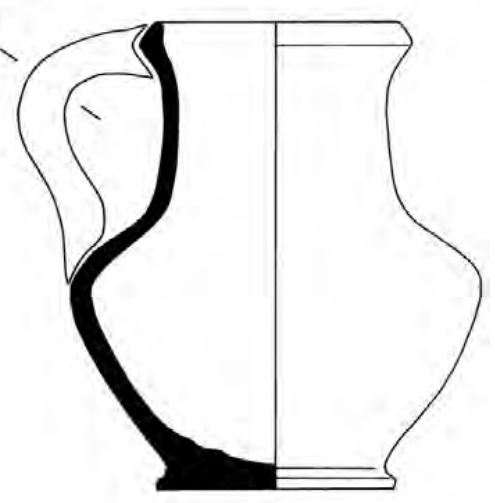

e 
CC 34, 36, 39-42, 45
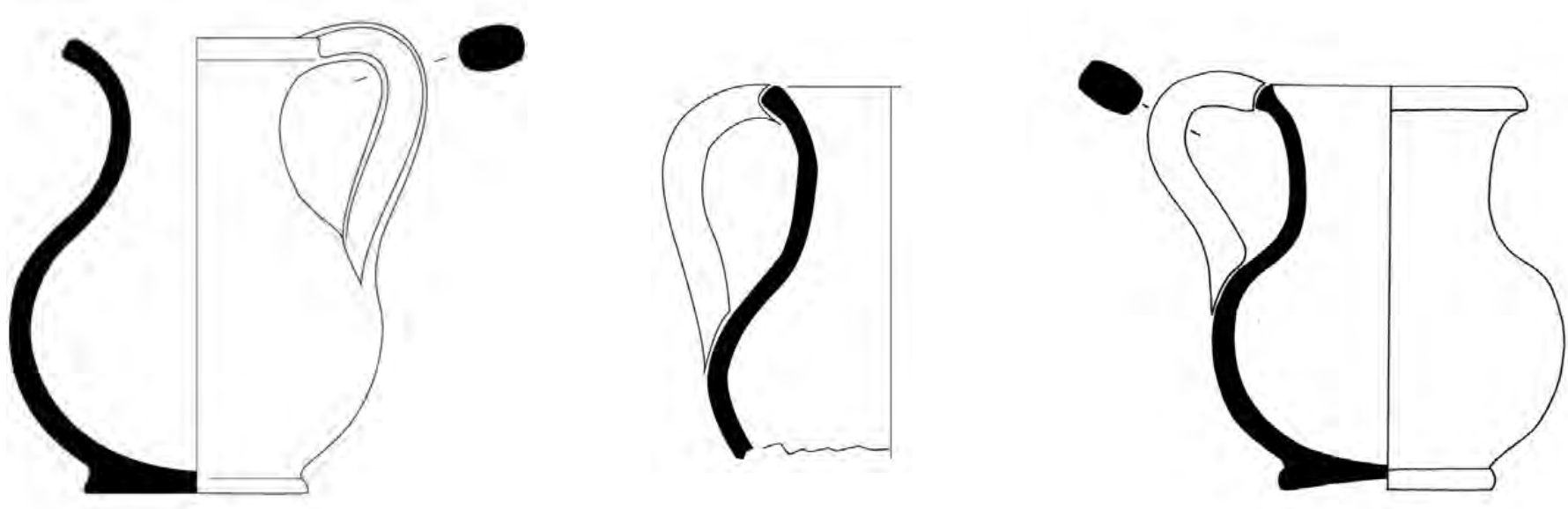

a

b

c

0

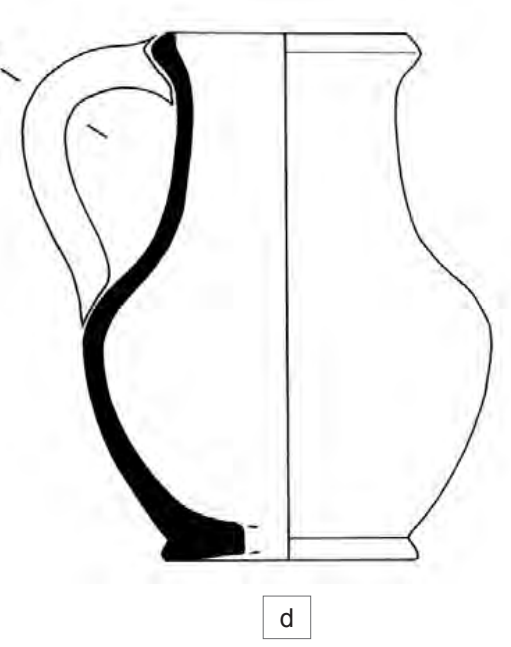

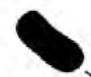

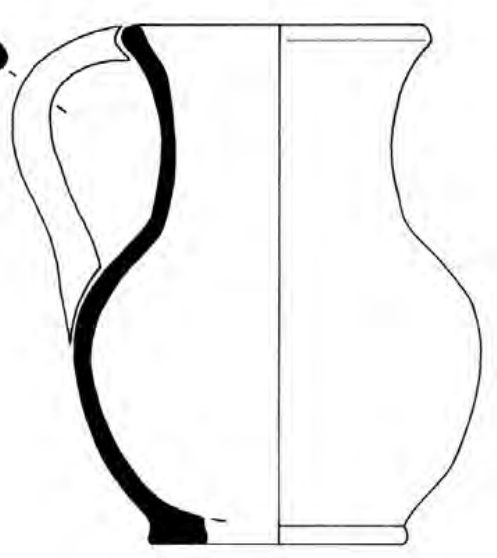

$\mathrm{f}$
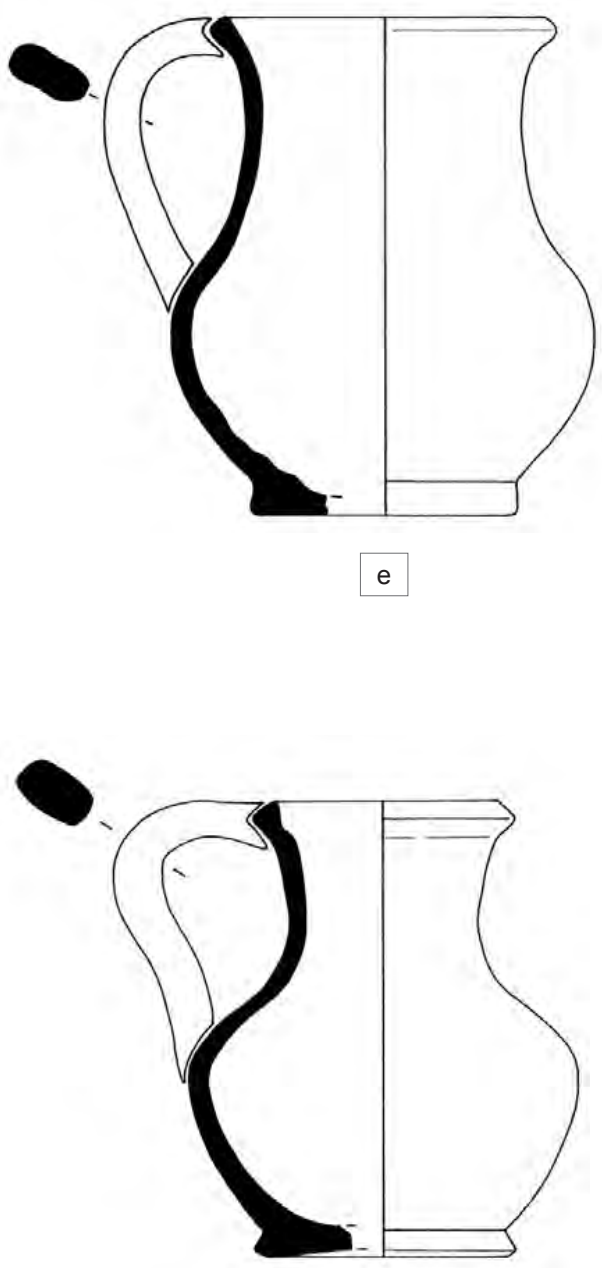

g 


$$
?
$$




$$
\begin{gathered}
2 \\
2 \\
-2 ?
\end{gathered}
$$




$$
\frac{j}{j}<
$$




$$
\begin{aligned}
& 2 x^{2} \\
& 2<2
\end{aligned}
$$


Planche 112

CC 106-109
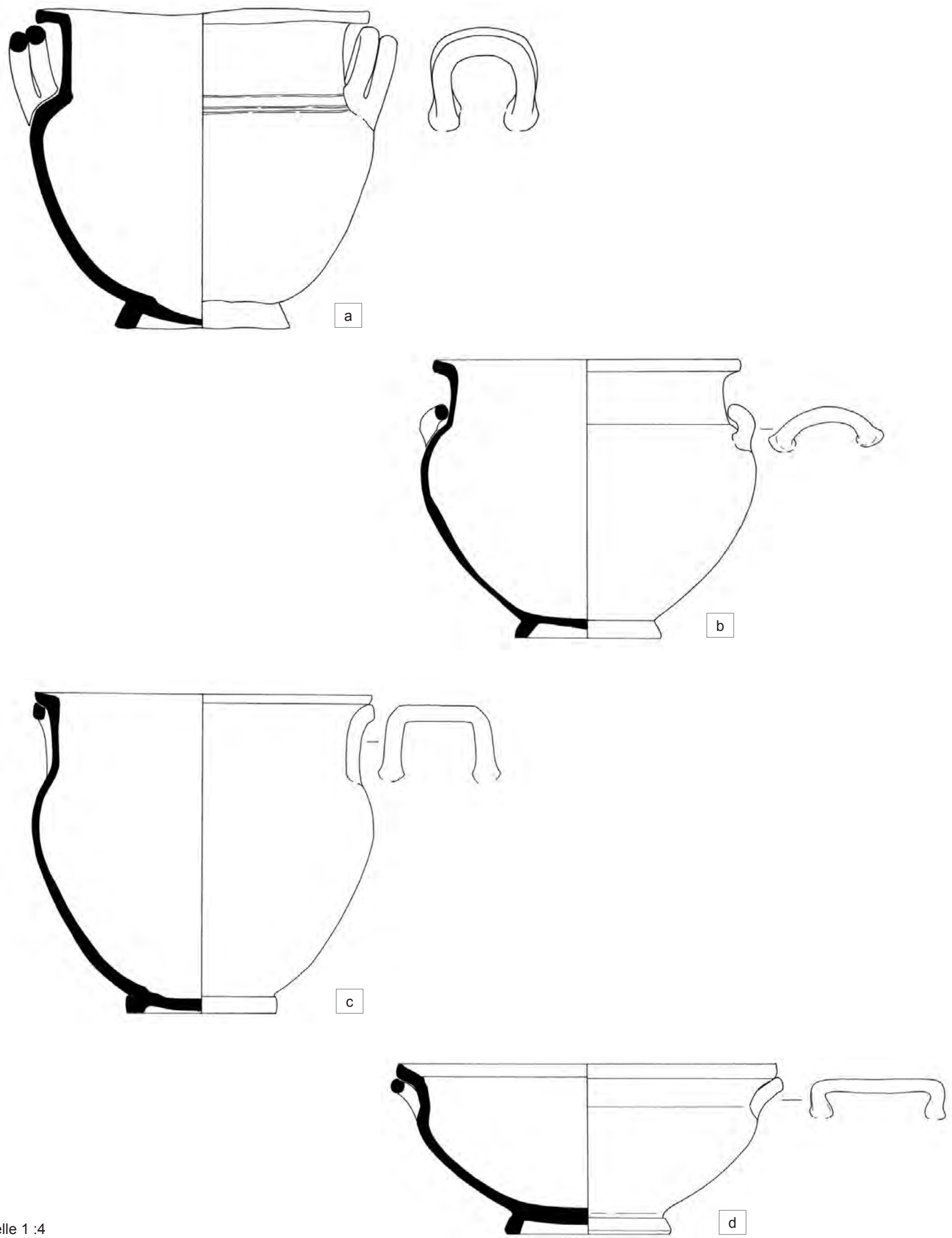
Planche 113

CC 110, 119, 120, 127, 128

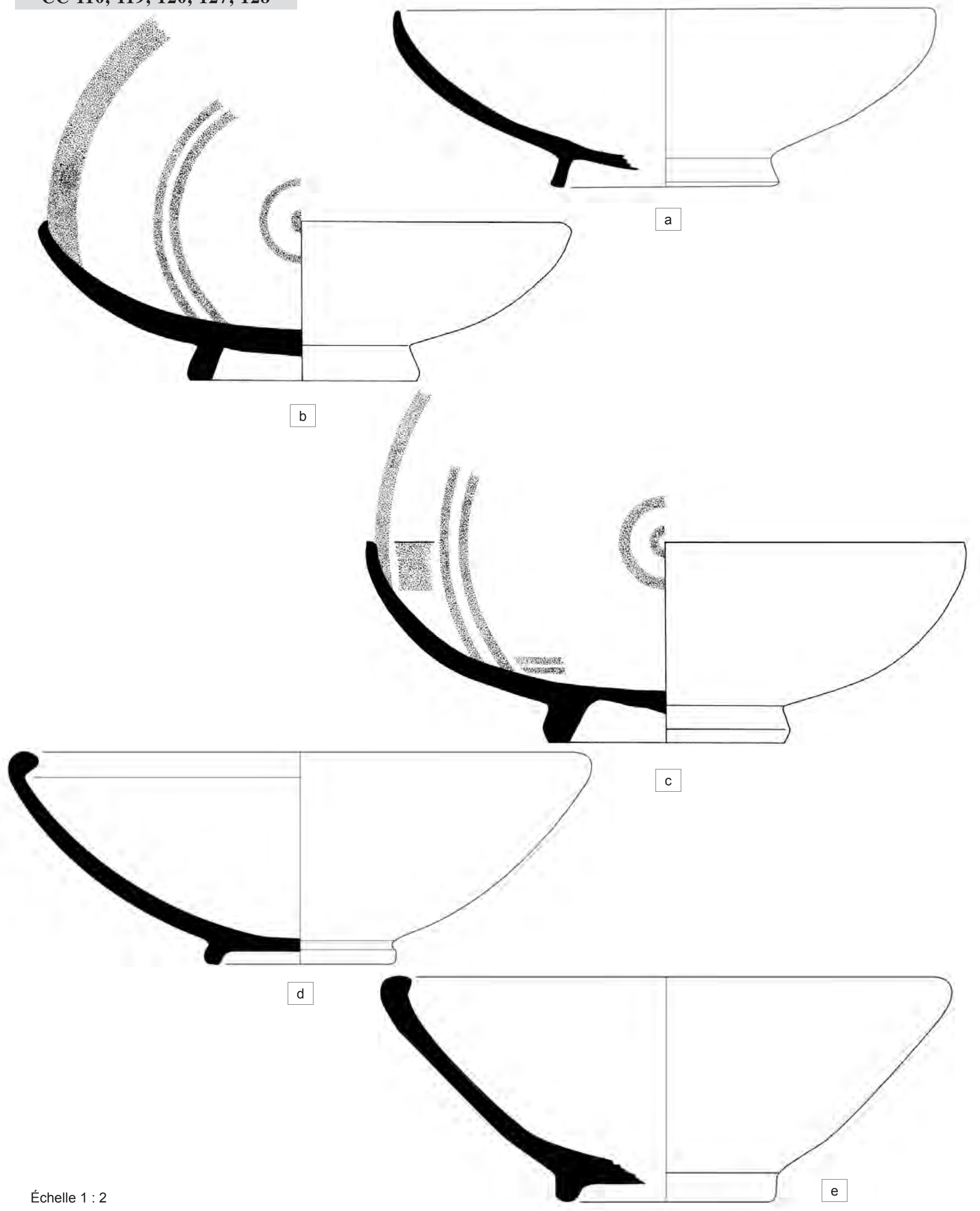


Planche 114

CC 129, 138-140, 149

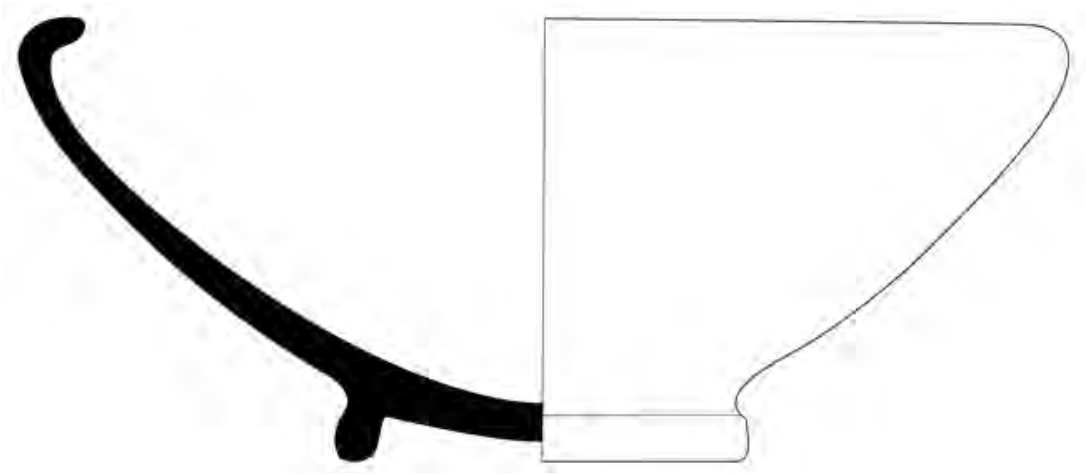

a
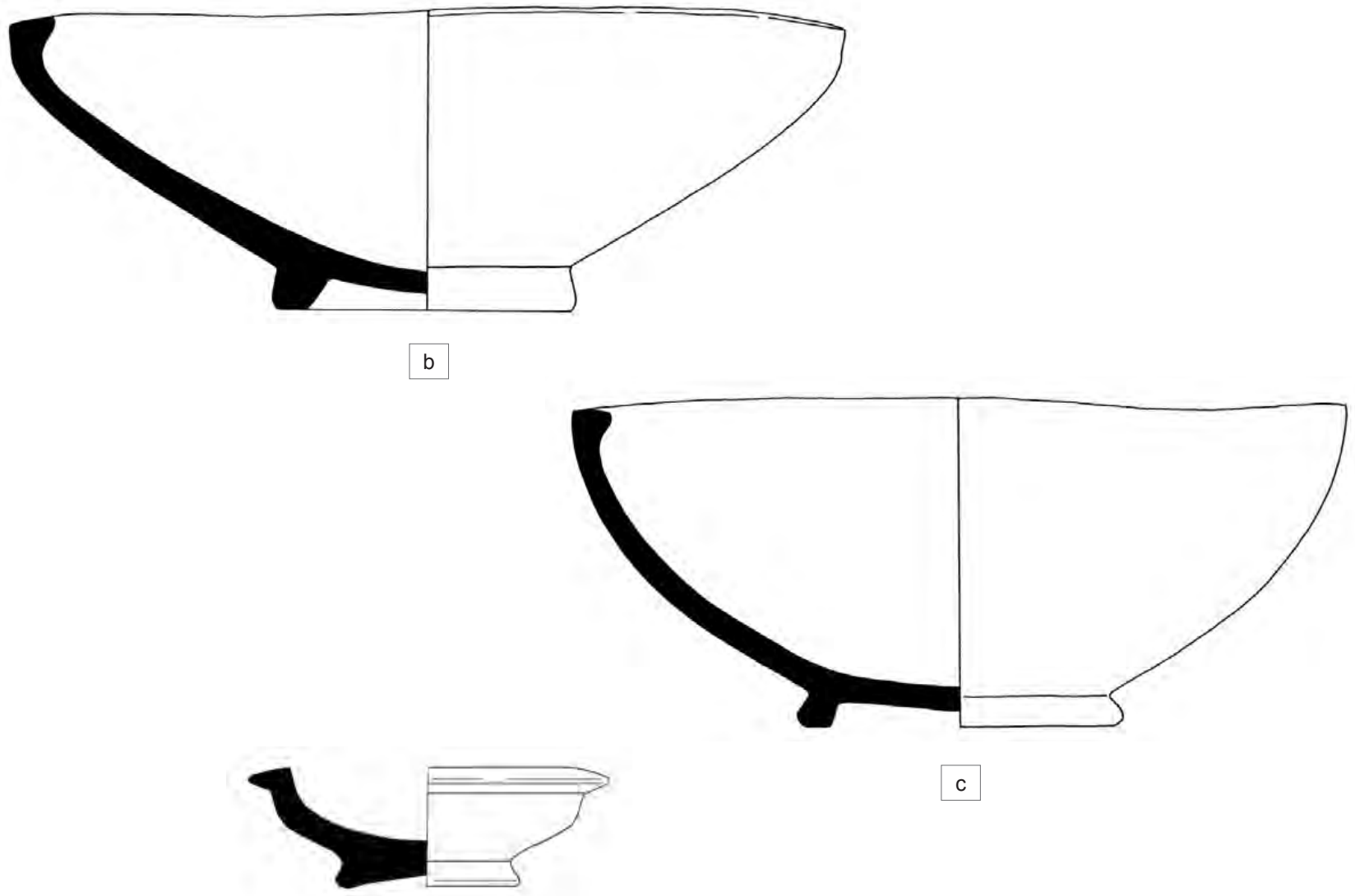

C

d

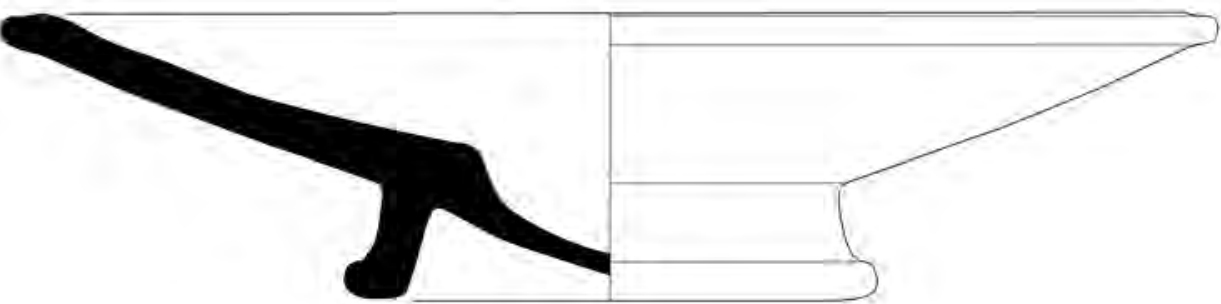

e 
Planche 115

CC 150, 152-156, 158

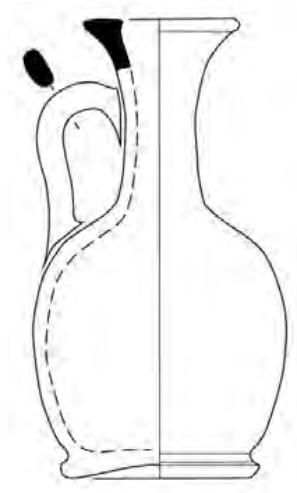

a

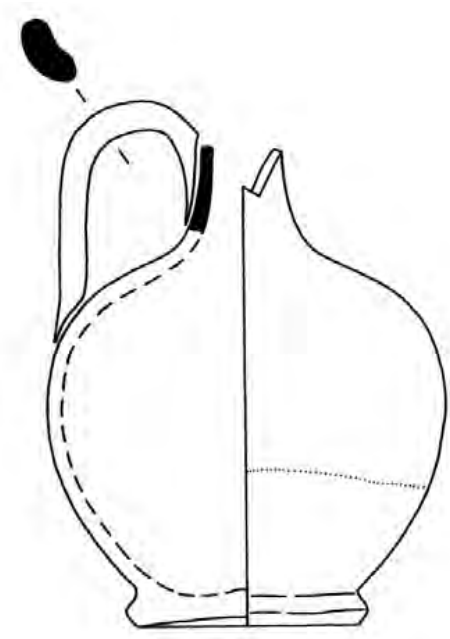

c

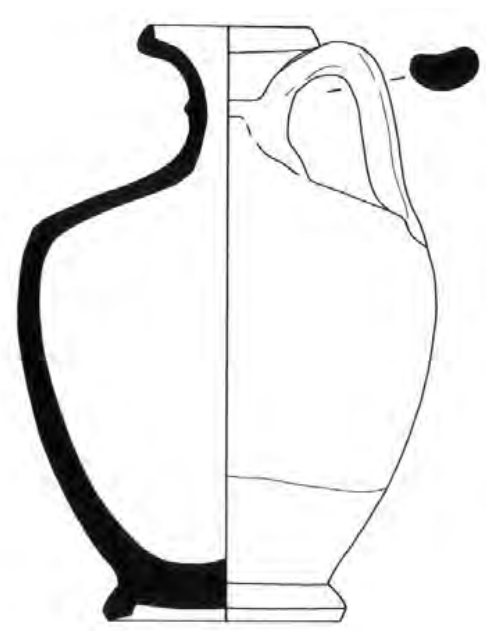

Échelle $1: 2$

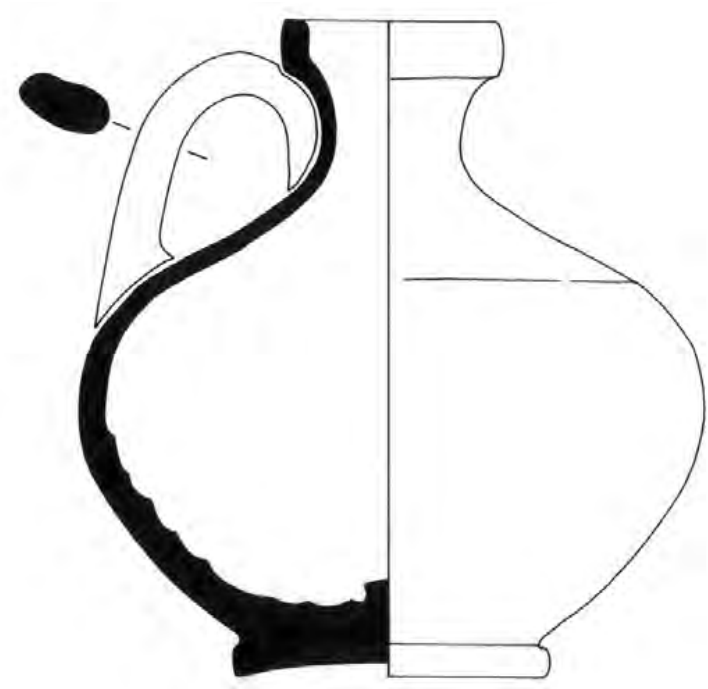

b

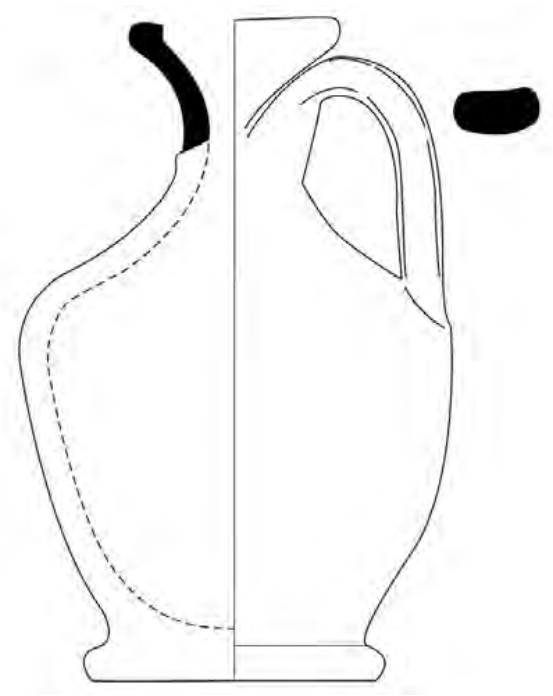

d

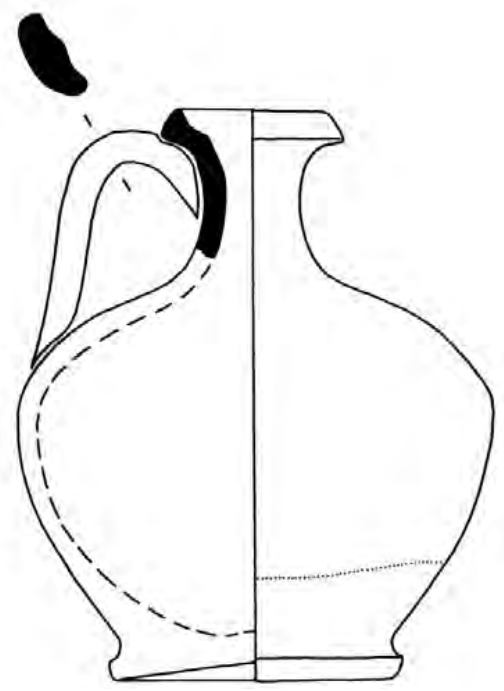

f

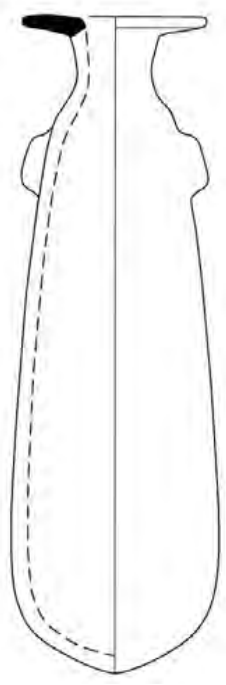

g 
Planche 116

CC 159-163, 165, 167, 174, 176, 177

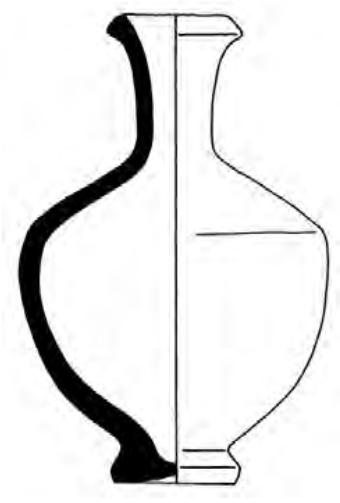

a

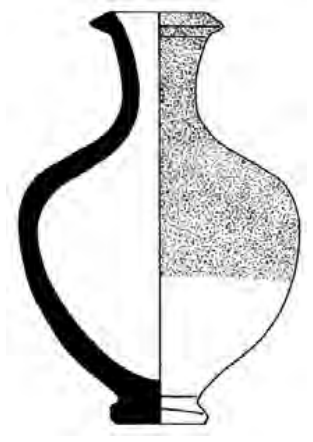

b

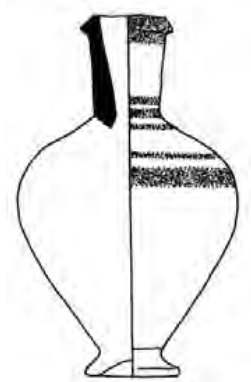

c

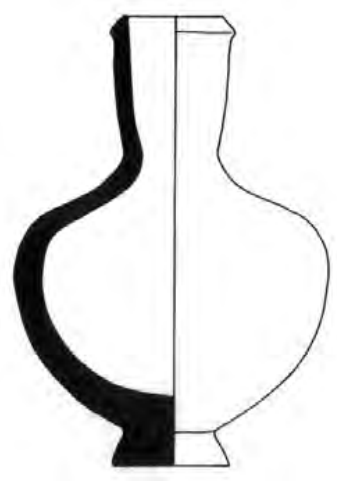

d

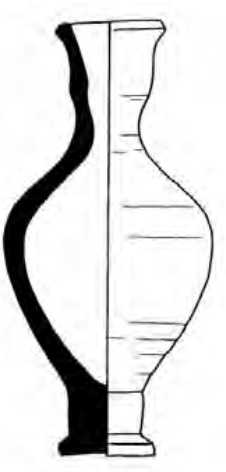

e
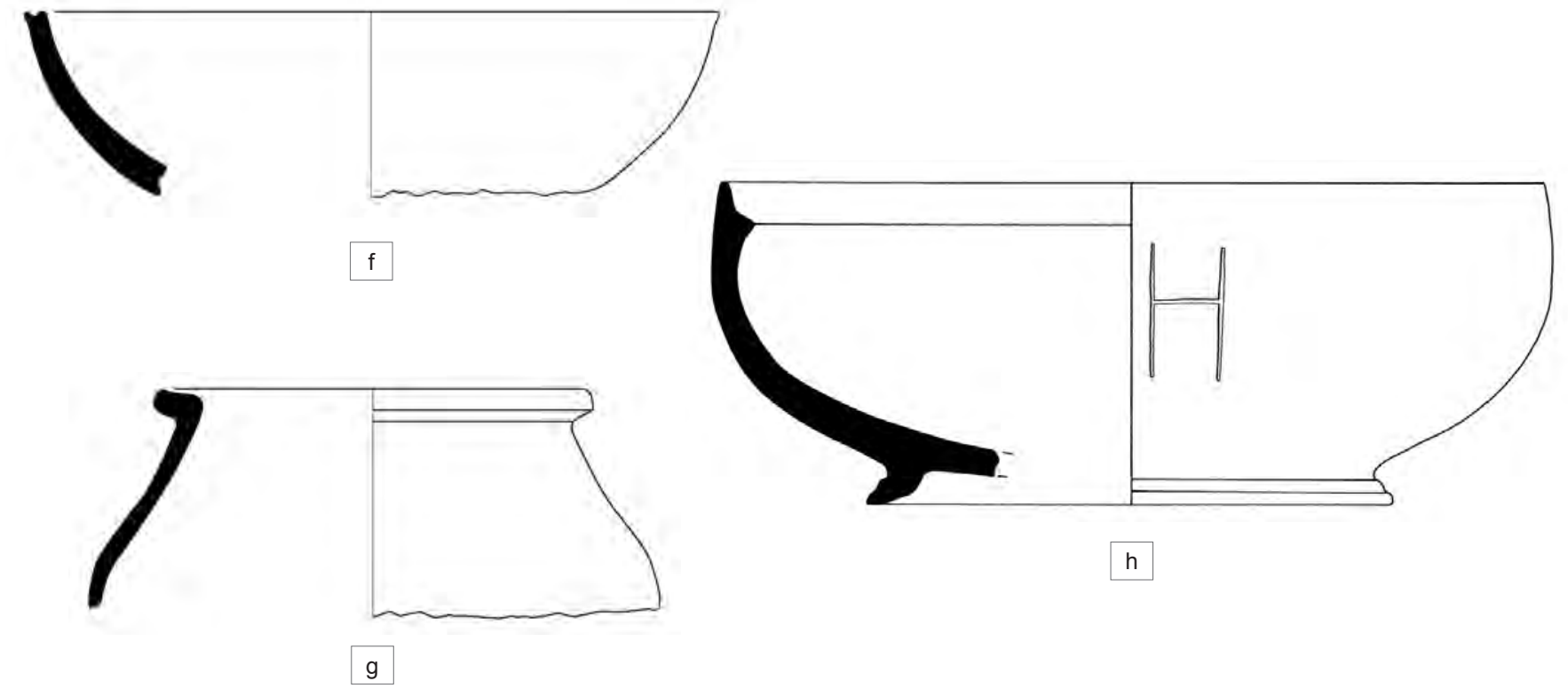

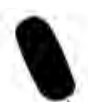
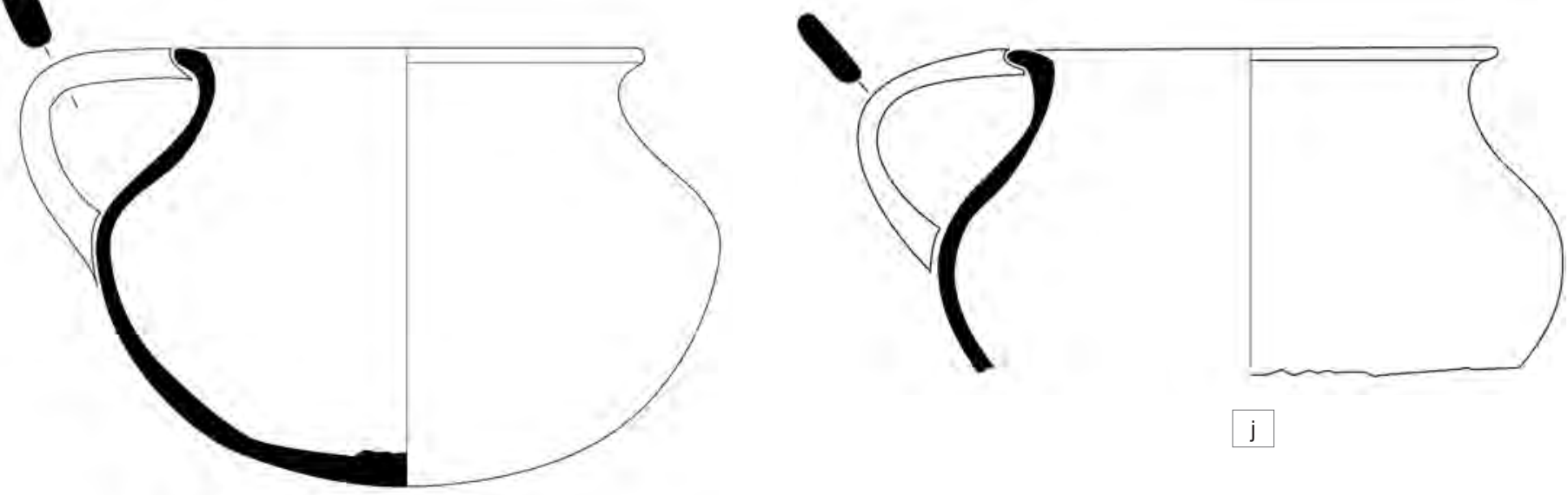

Échelle $1: 2$ 


$$
\begin{array}{ll}
\overline{2} & 2 \\
1 & 2 \\
2 & 2
\end{array}
$$




$$
\begin{array}{ll}
2 & 2 \\
2 & 2 \\
-2 & 2 \\
2 & 2
\end{array}
$$


Planche 119

CC 199-201, 203-207
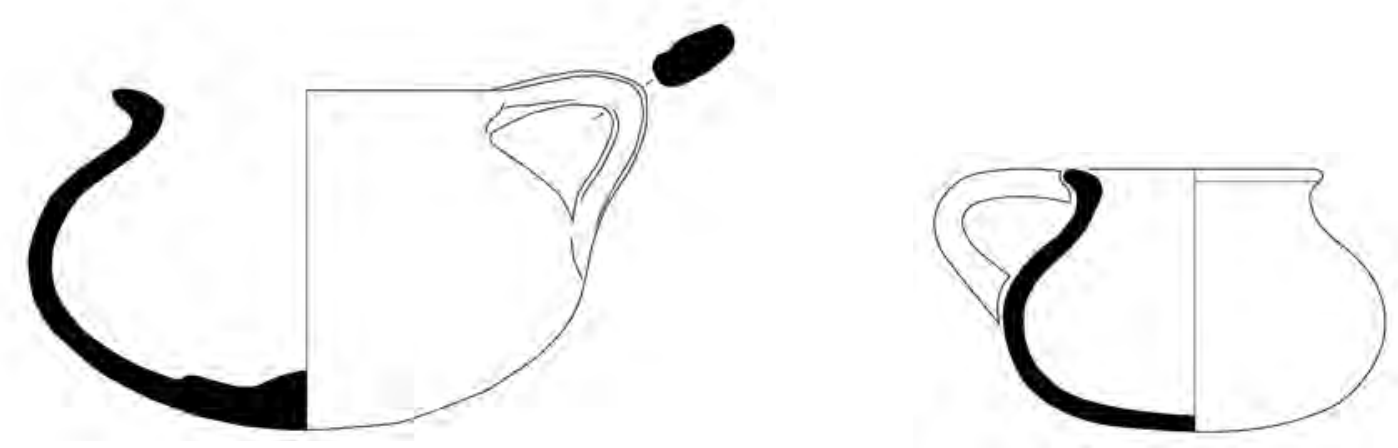

a
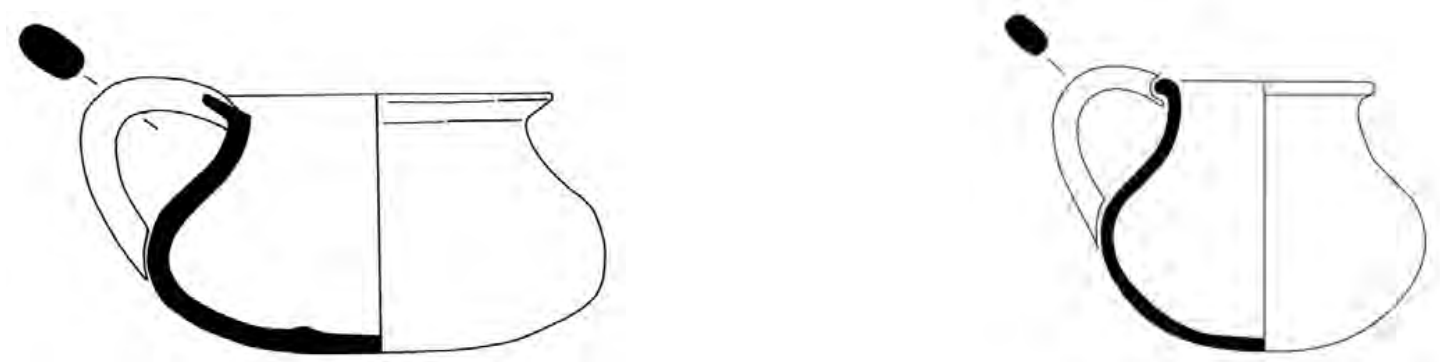

C

-

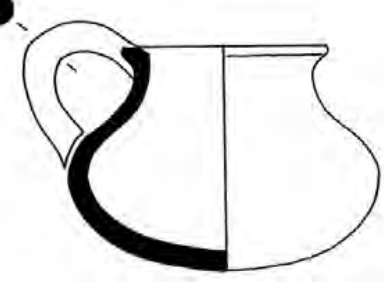

e

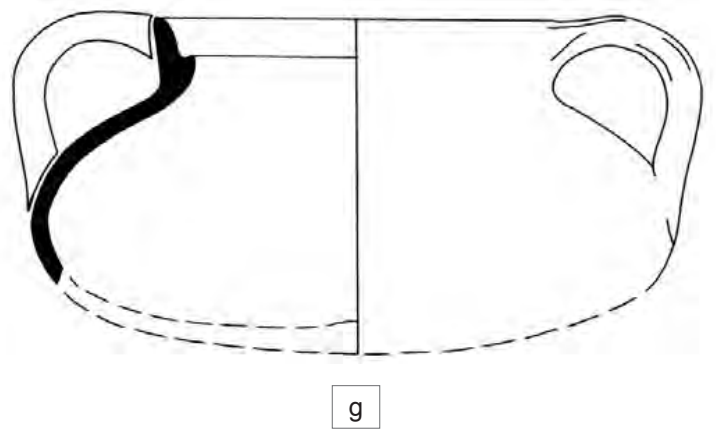

$\checkmark$

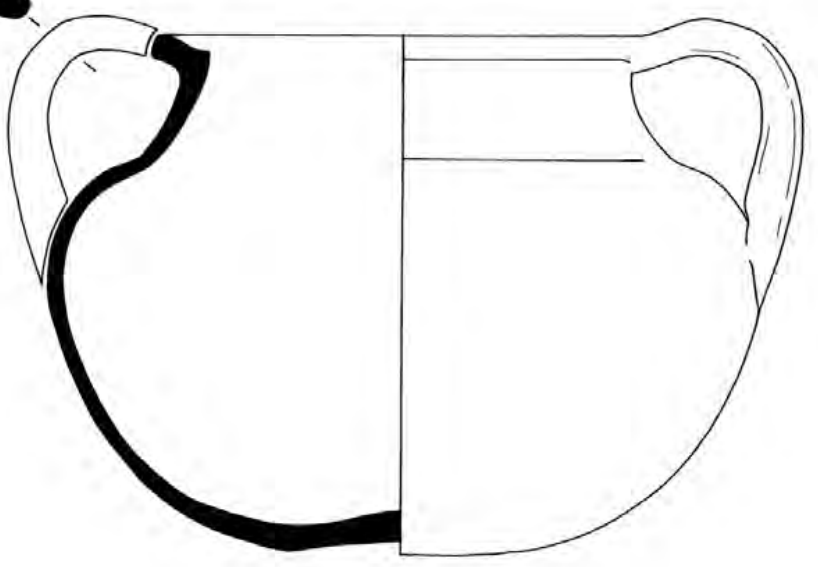

f

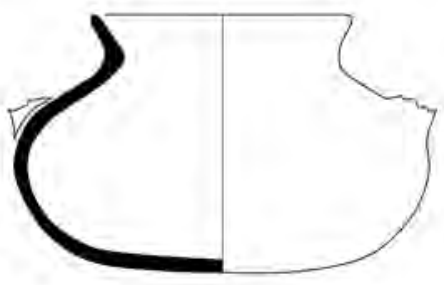

Échelle $1: 2$ 
Planche 120

TC 3-7

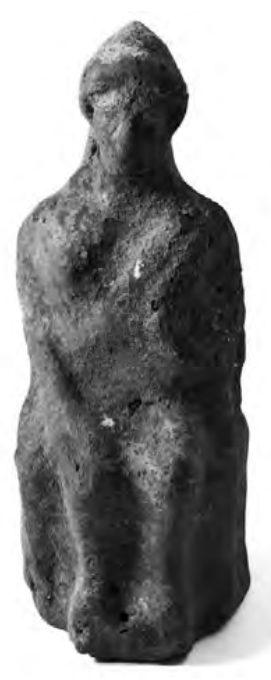

a-1

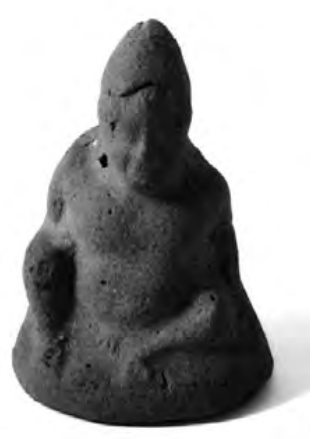

C

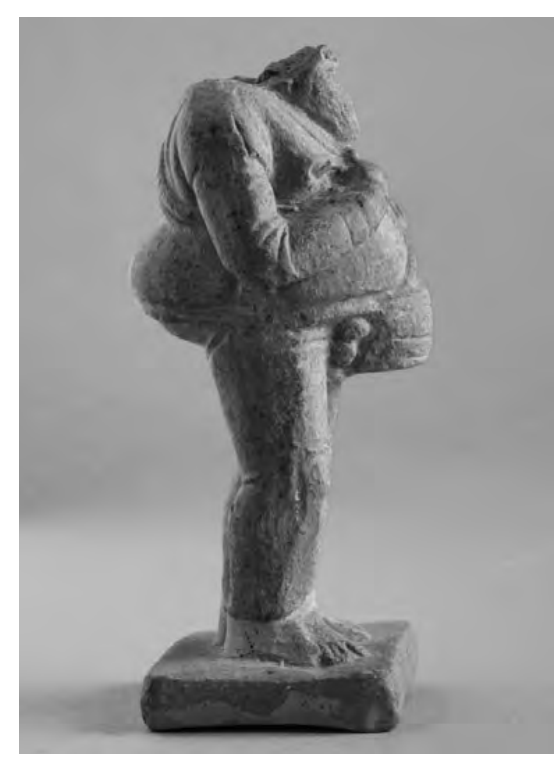

e-1

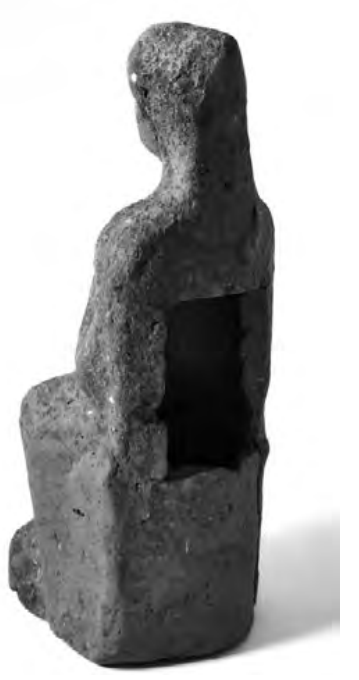

a-2

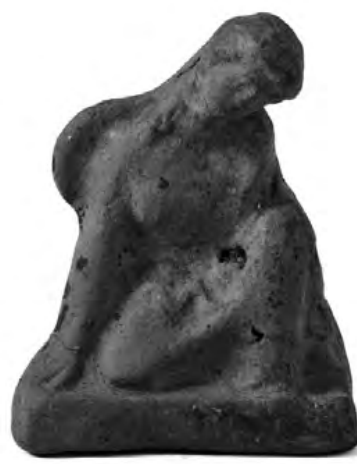

b

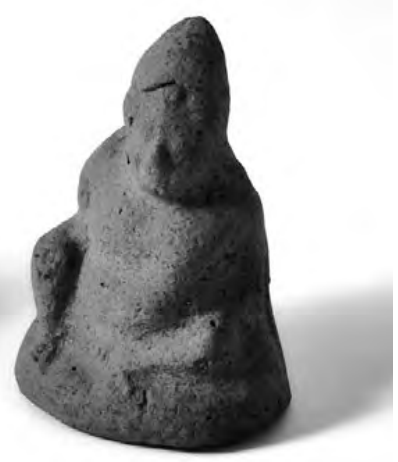

d-2

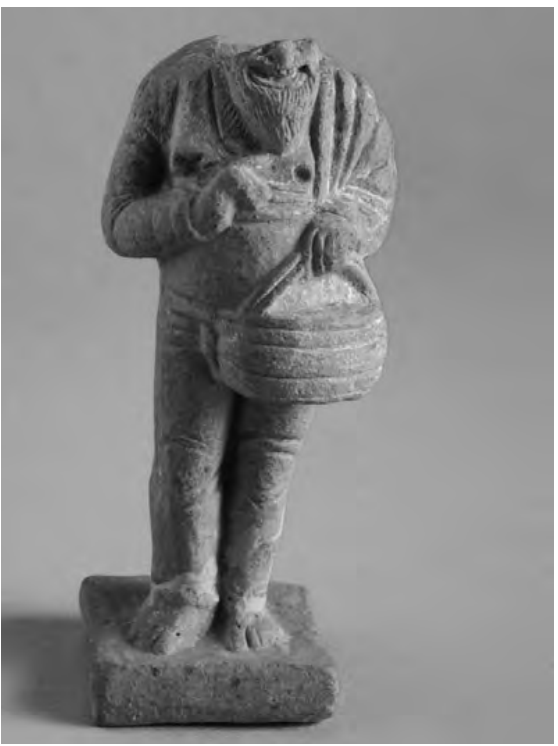

e-2

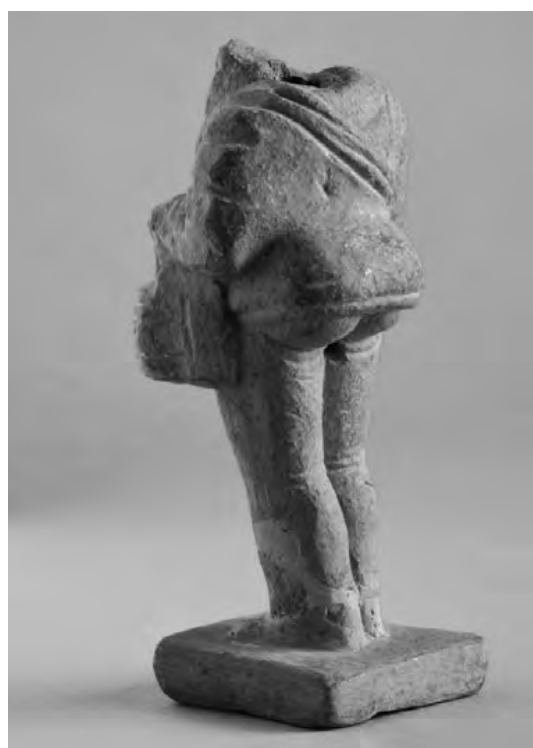

e-3 
TC 8-12

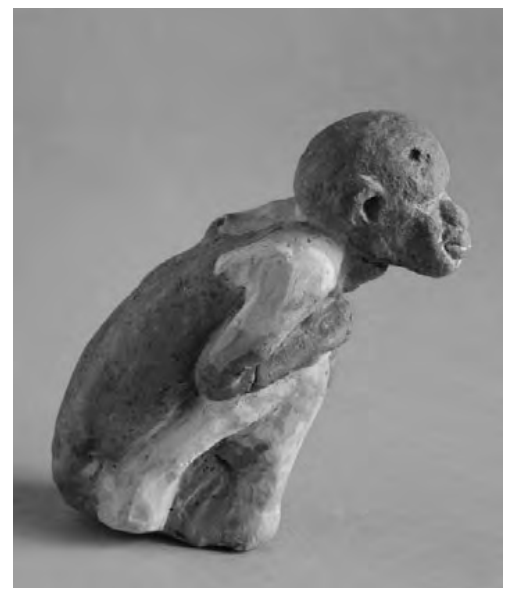

a

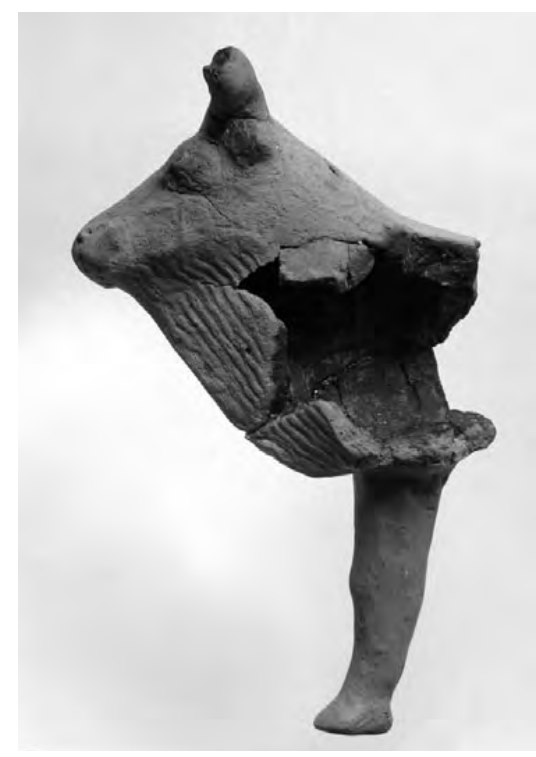

c-1

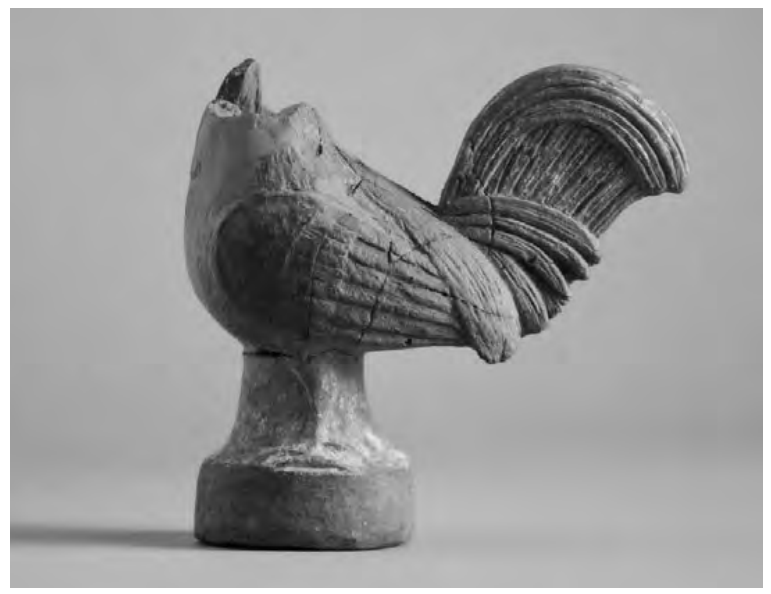

b

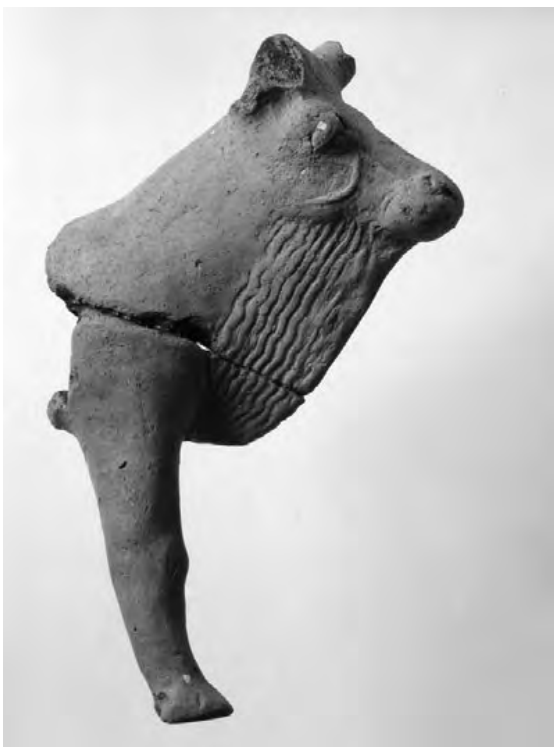

c-2

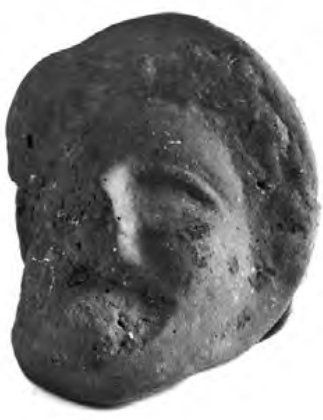

d

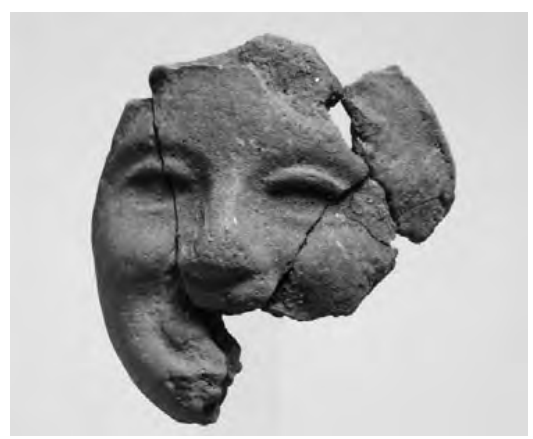

e-1

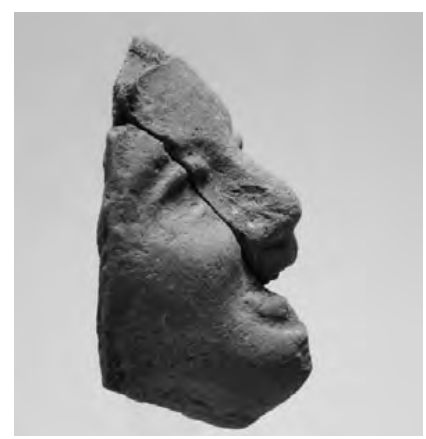

e-2 
Planche 122

TC 13, 14, 20

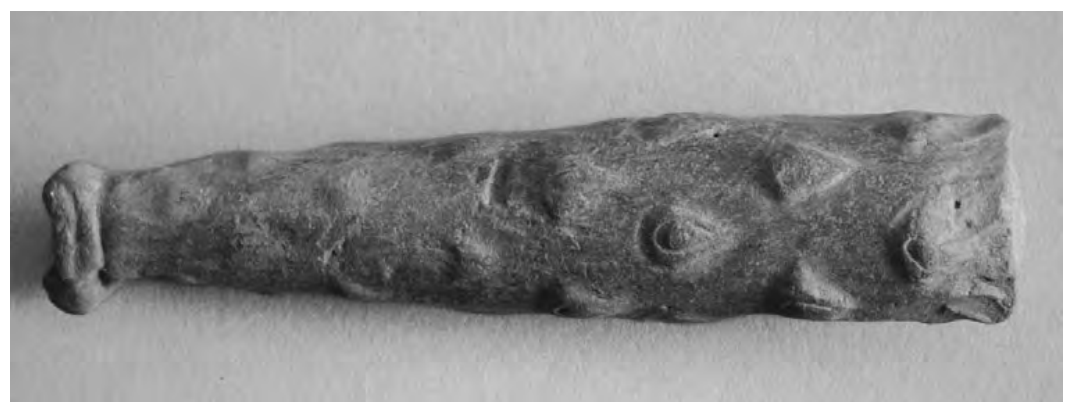

a

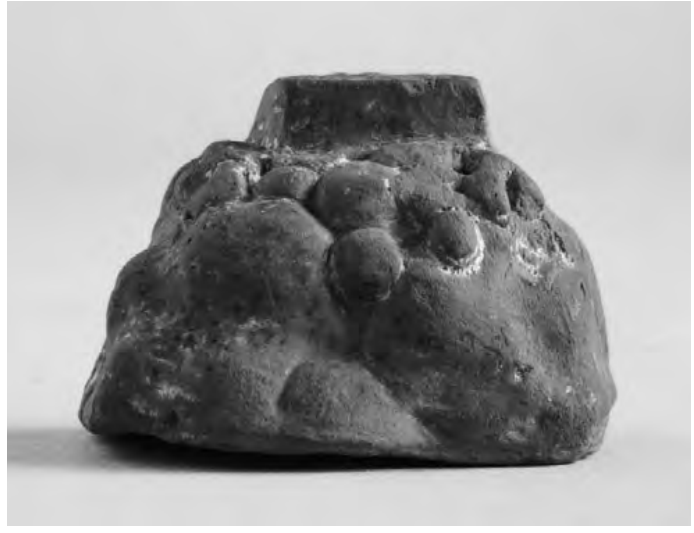

b-1

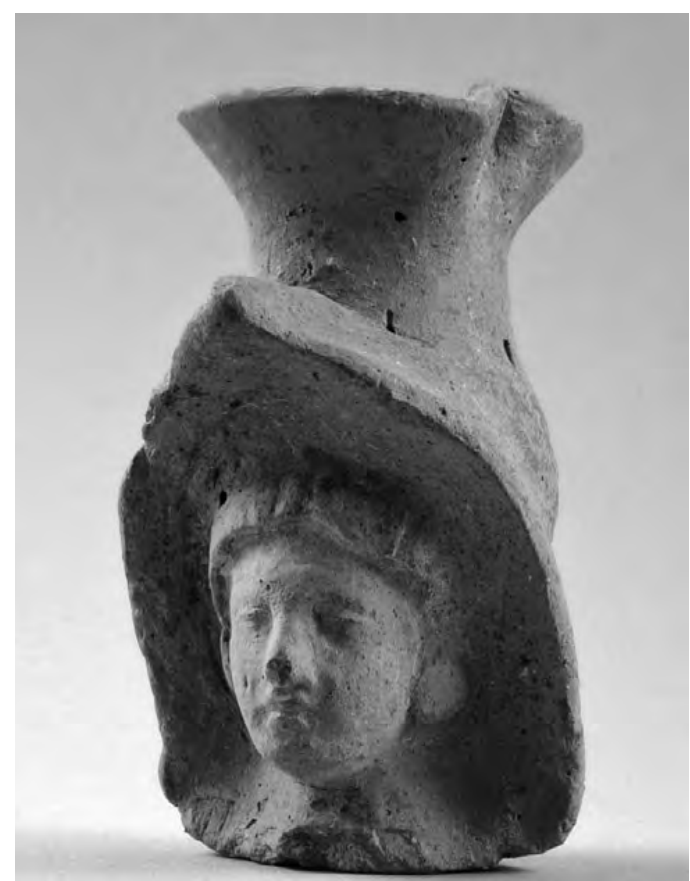

c-1

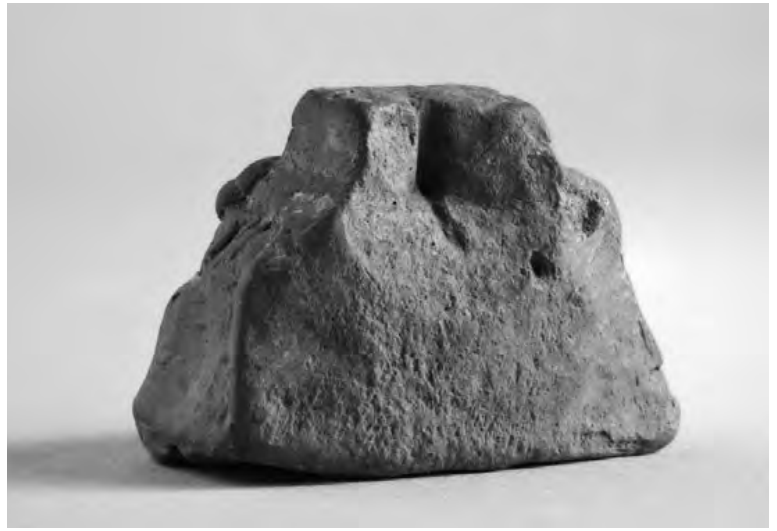

b-2

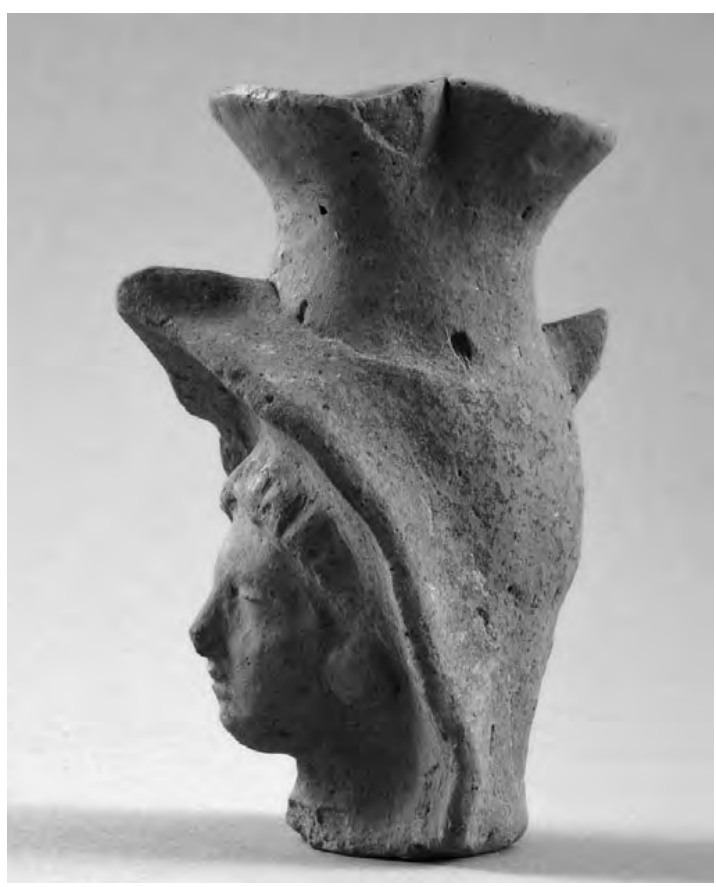

c-2 
Planche 123

TC 21, 27
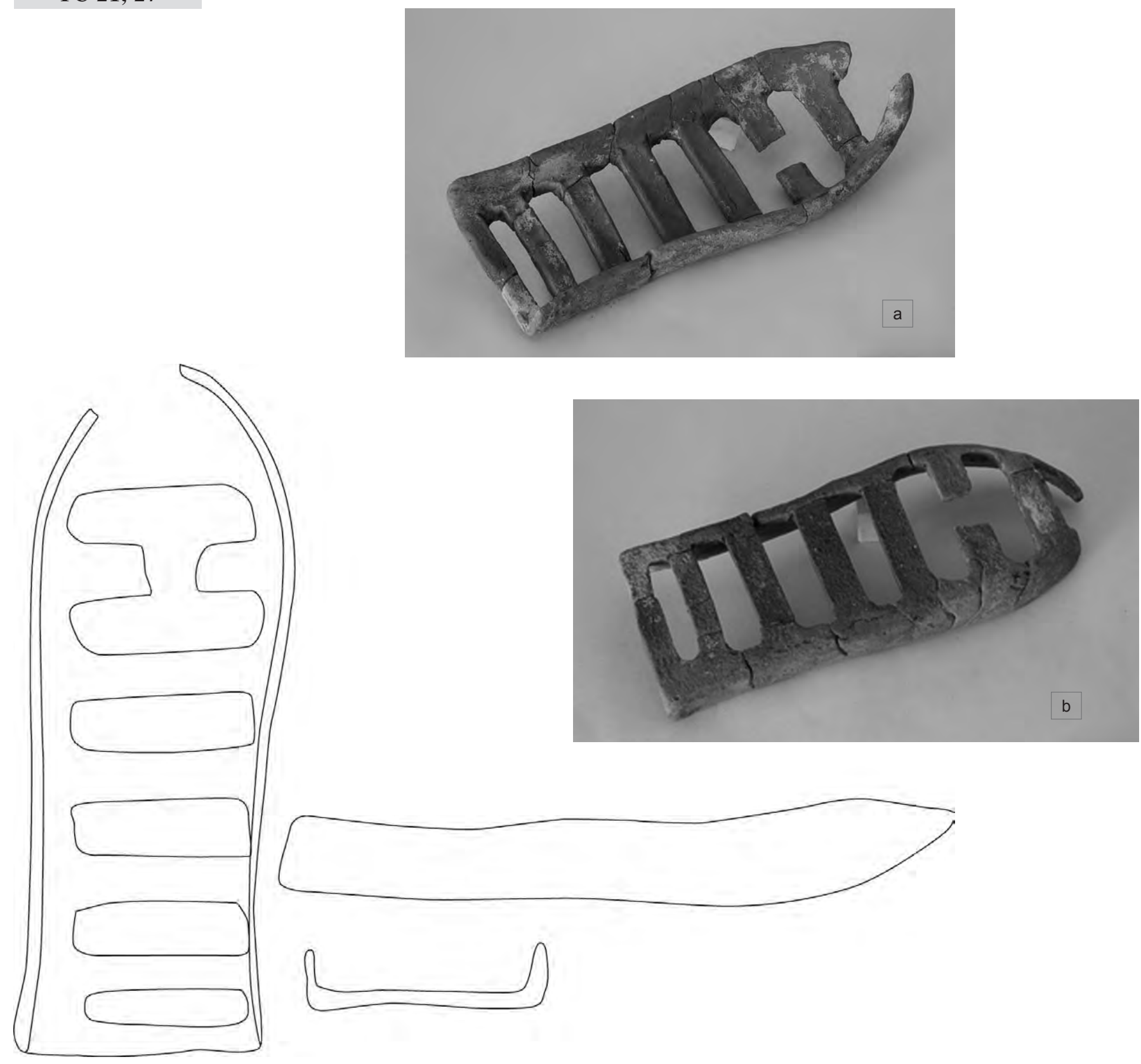

c

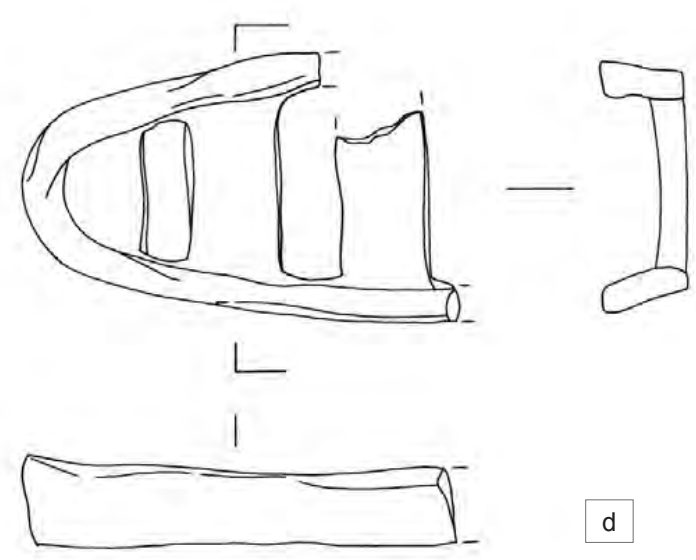


Planche 124

TT $7,4,8$

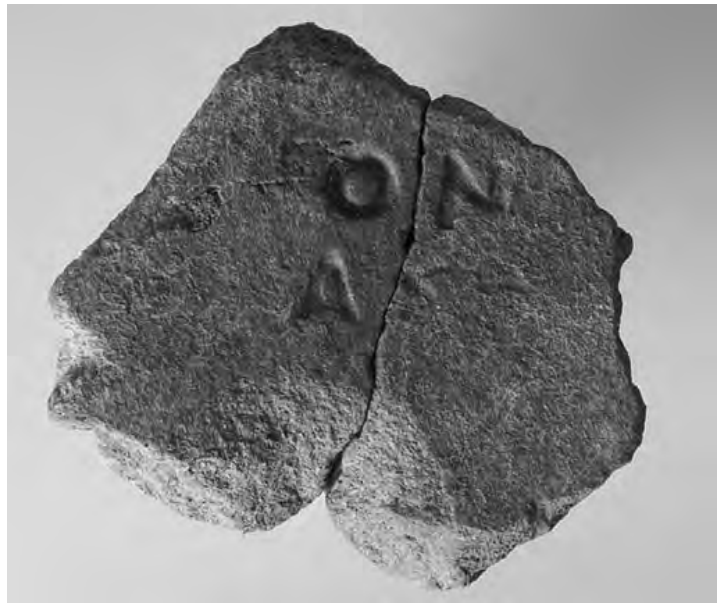

a

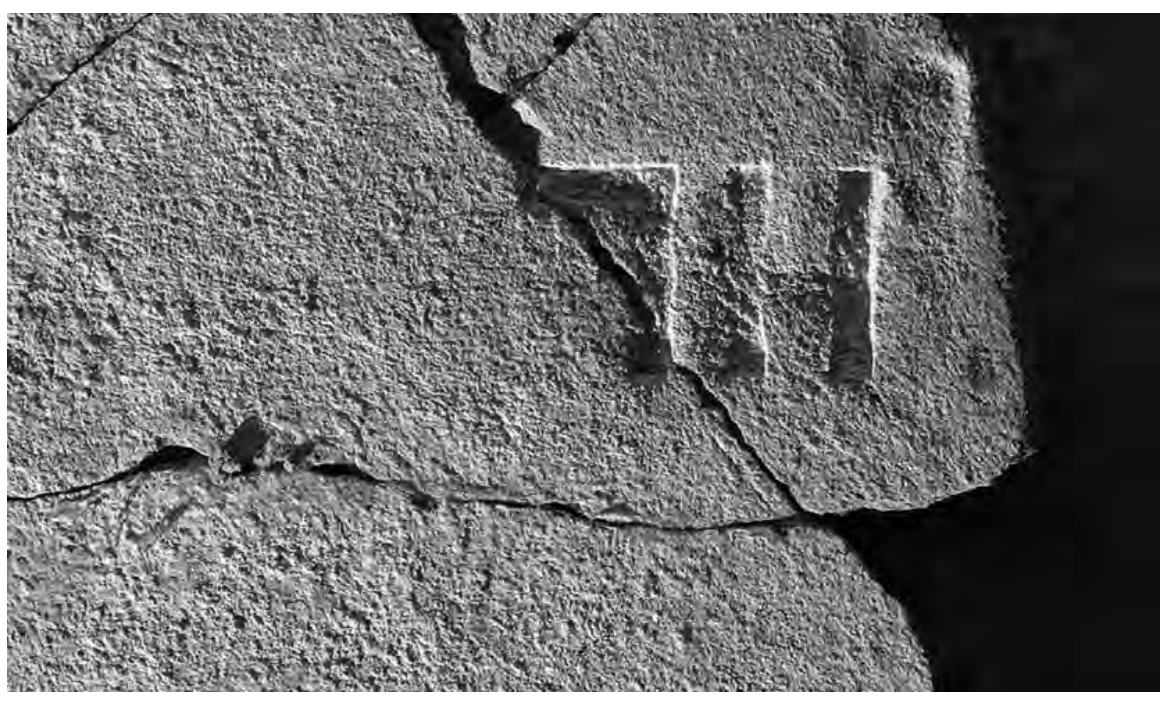

b

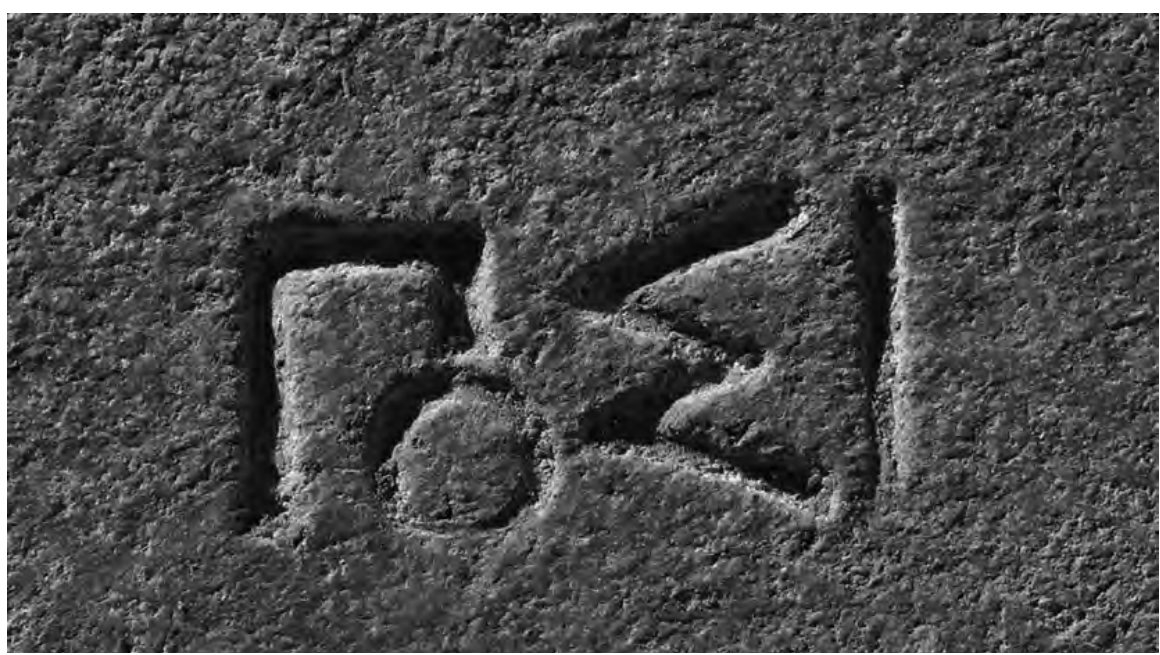


M 2, 4, 12, 13, 58, 59, 60

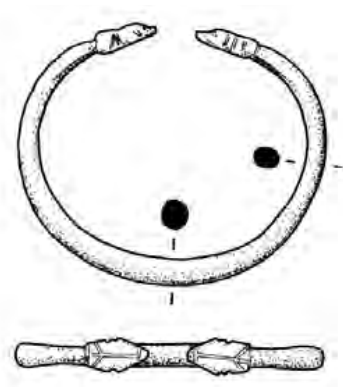

a
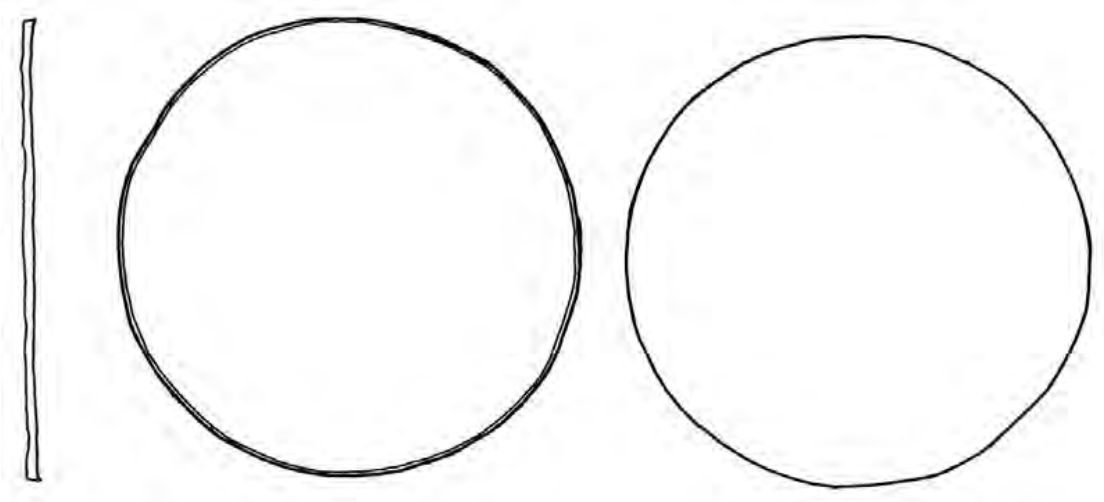

C

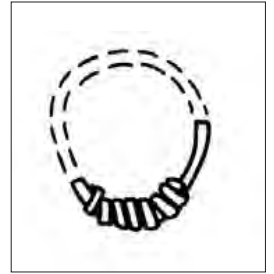

b

Échelle $1: 1$

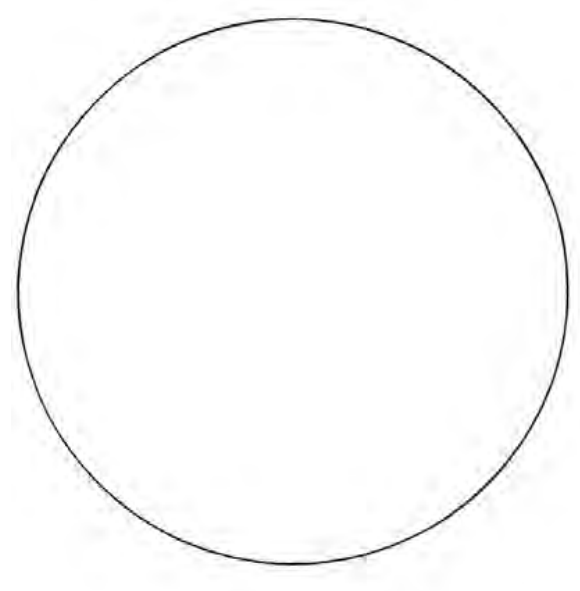

$\mathrm{d}$
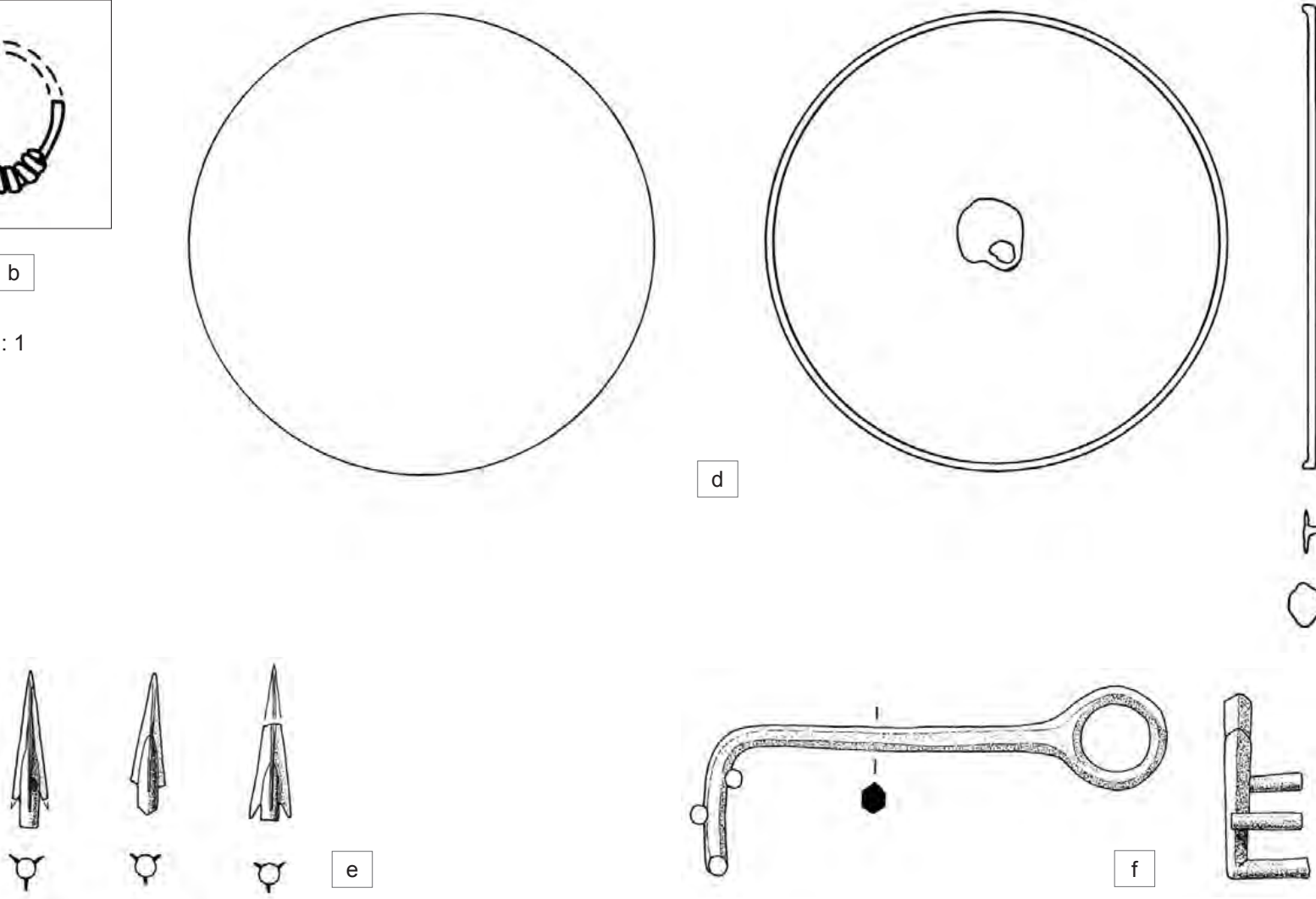

Échelle $1: 2$
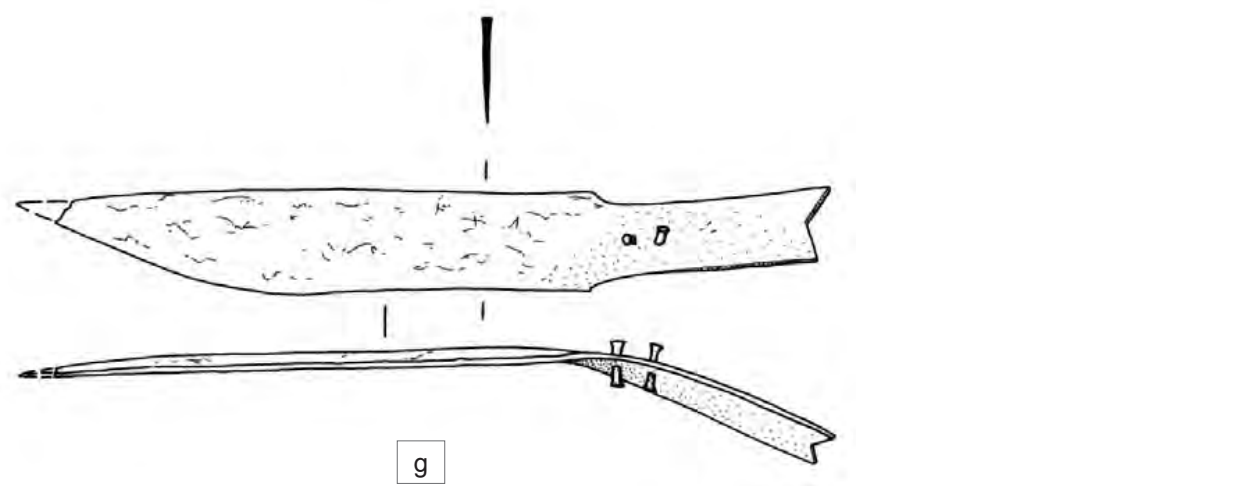
Planche 126

M $1,2,5,7,8$

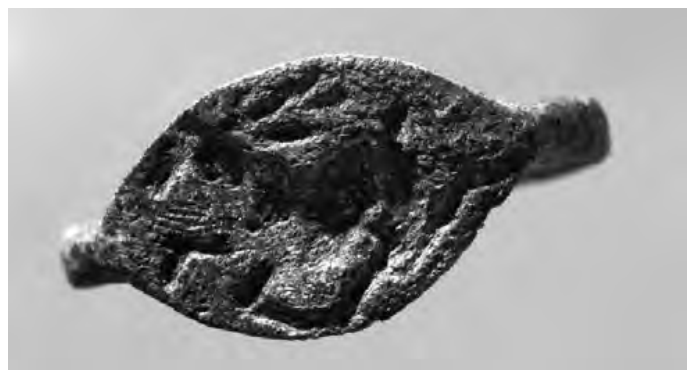

a-1

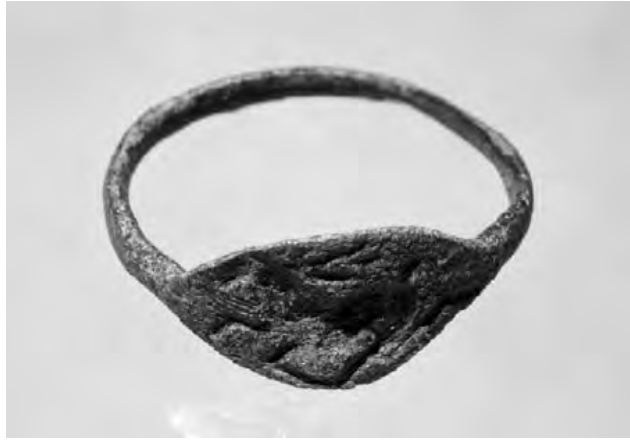

a-2

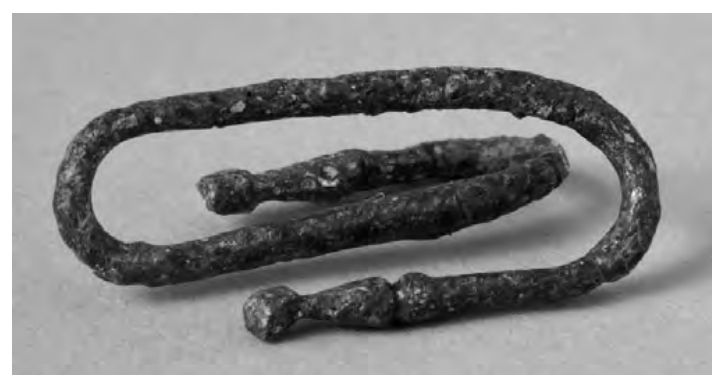

b

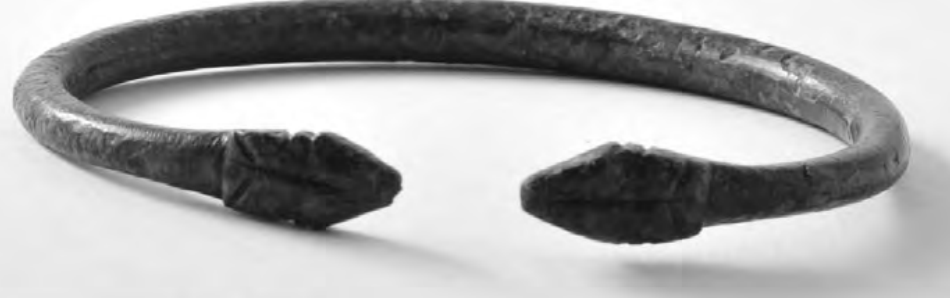

C

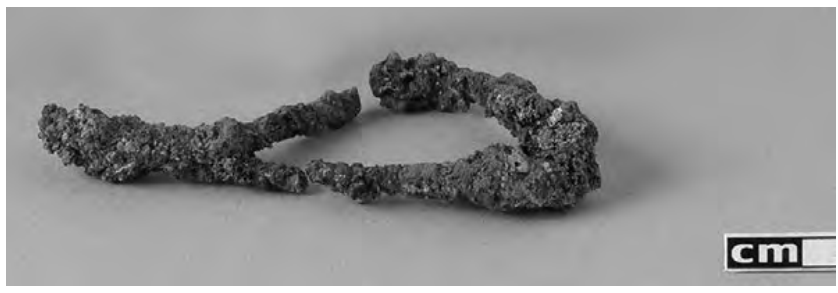

d

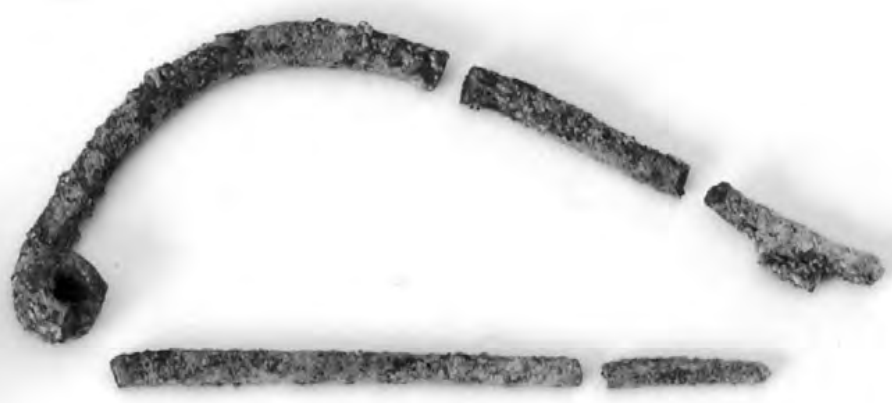


M 11-14

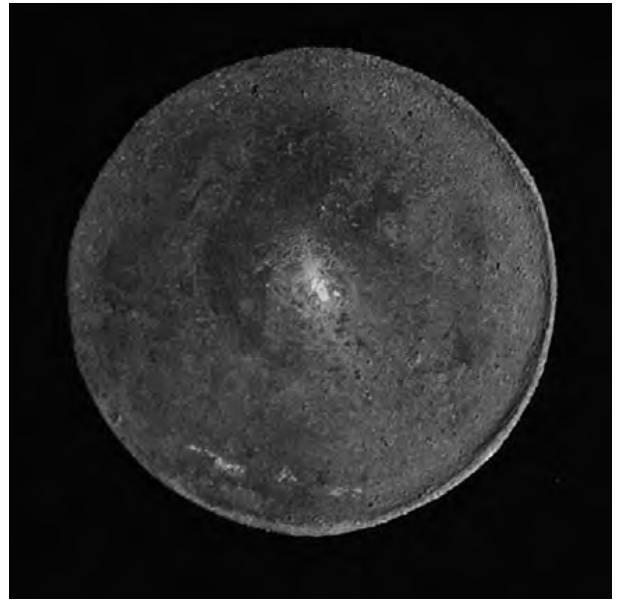

a

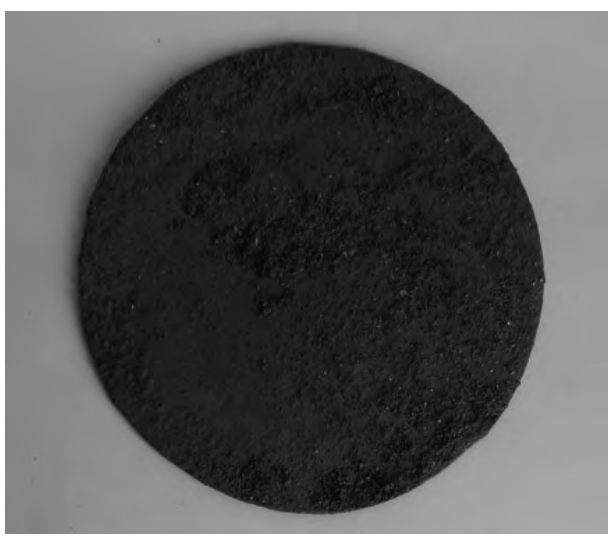

c-1

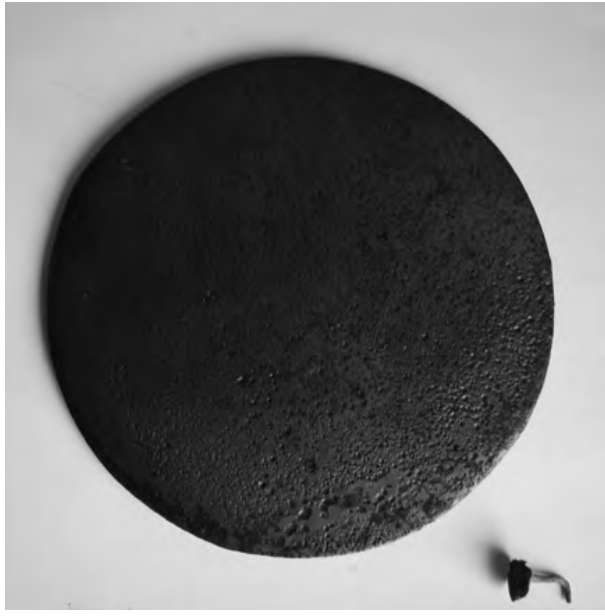

d-1

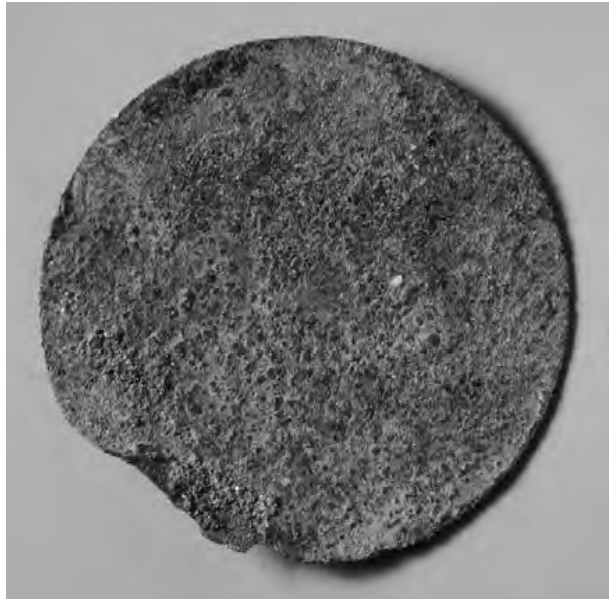

b

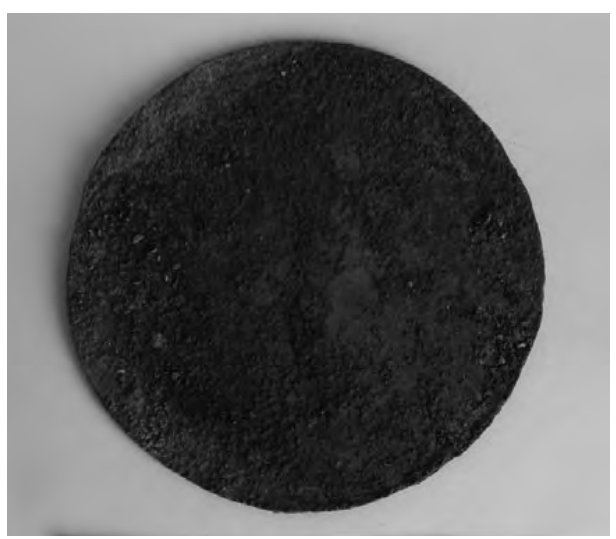

c-2

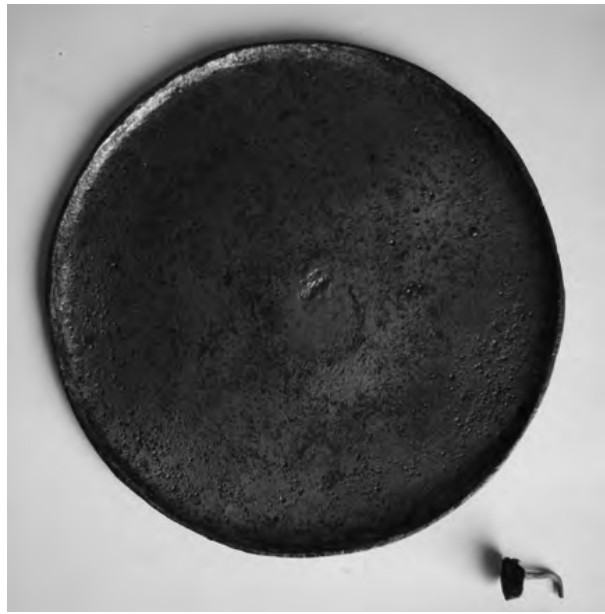

d-2 
Planche 128

M 15, 23, 29, 33, 34

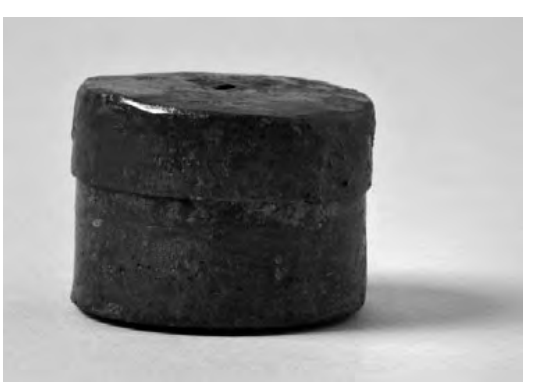

a
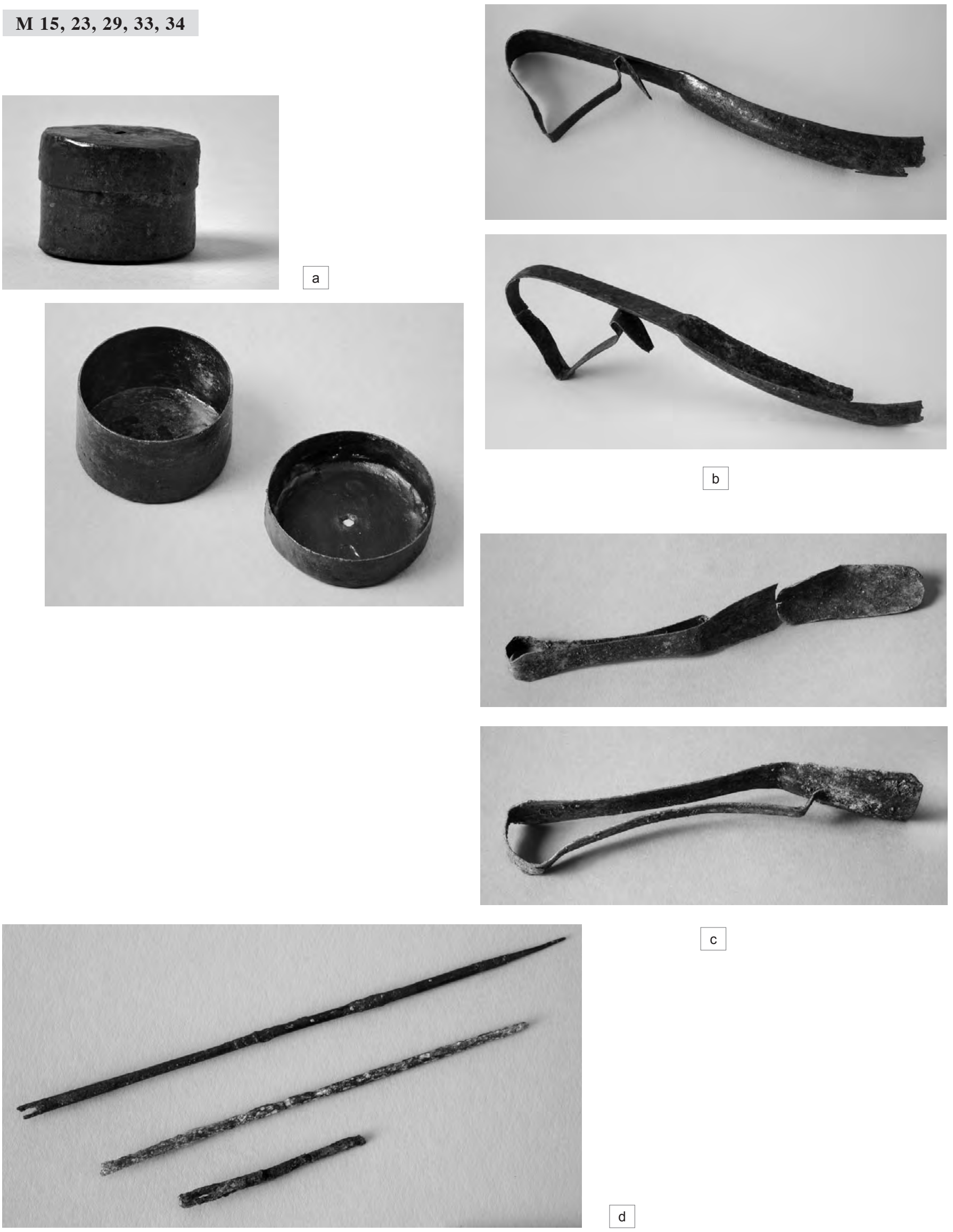

c 
M 37, 57, 68, 69

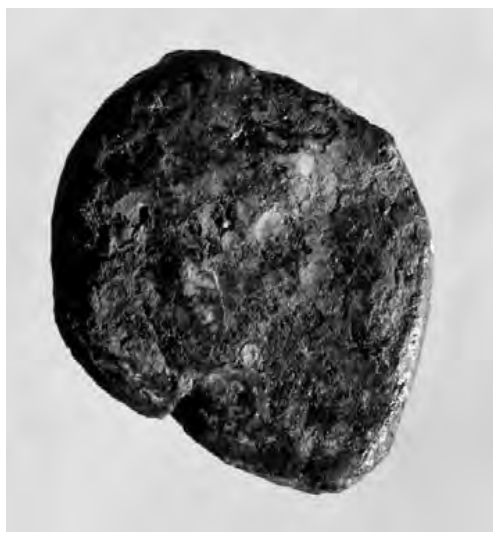

a
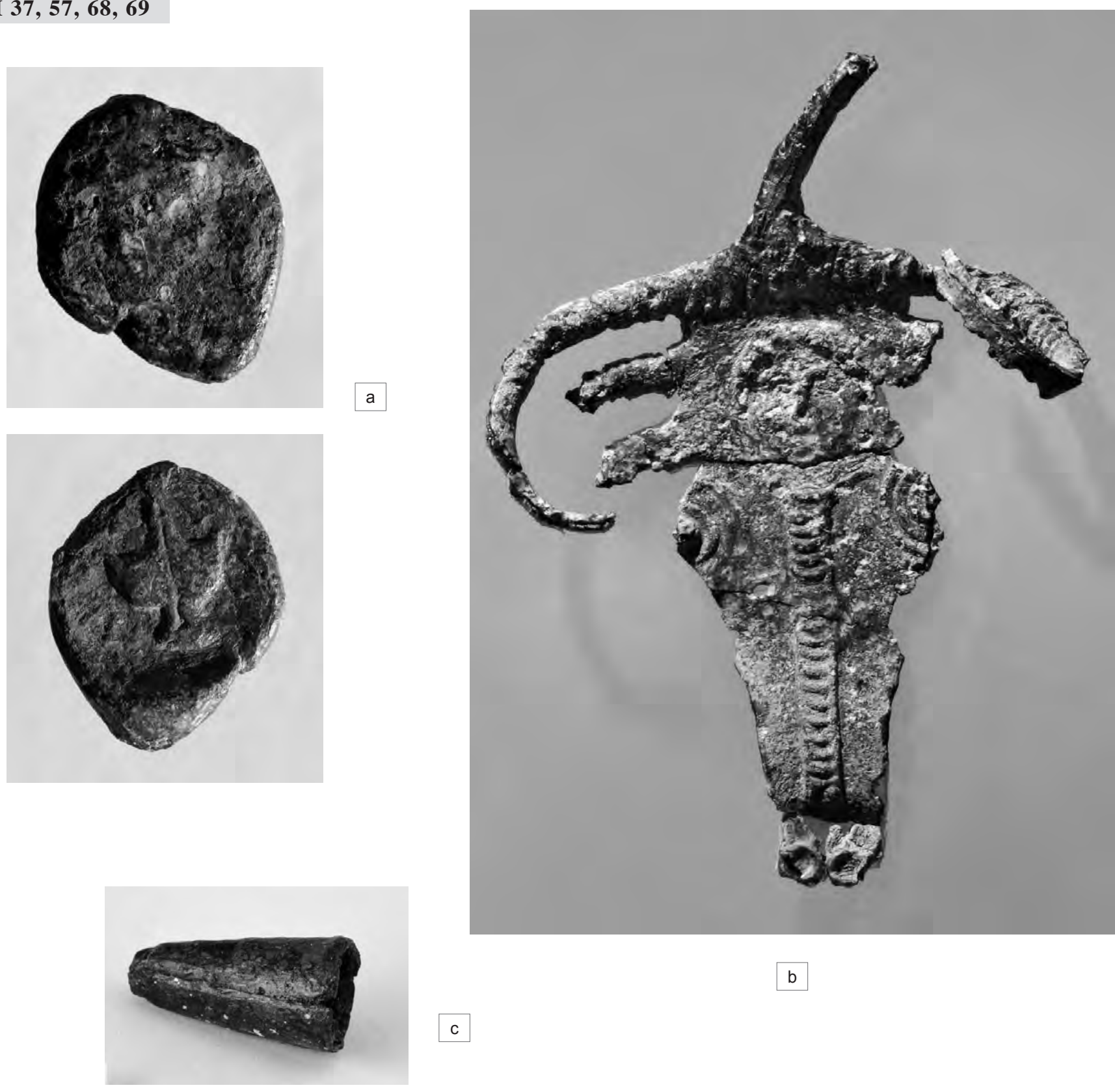

b

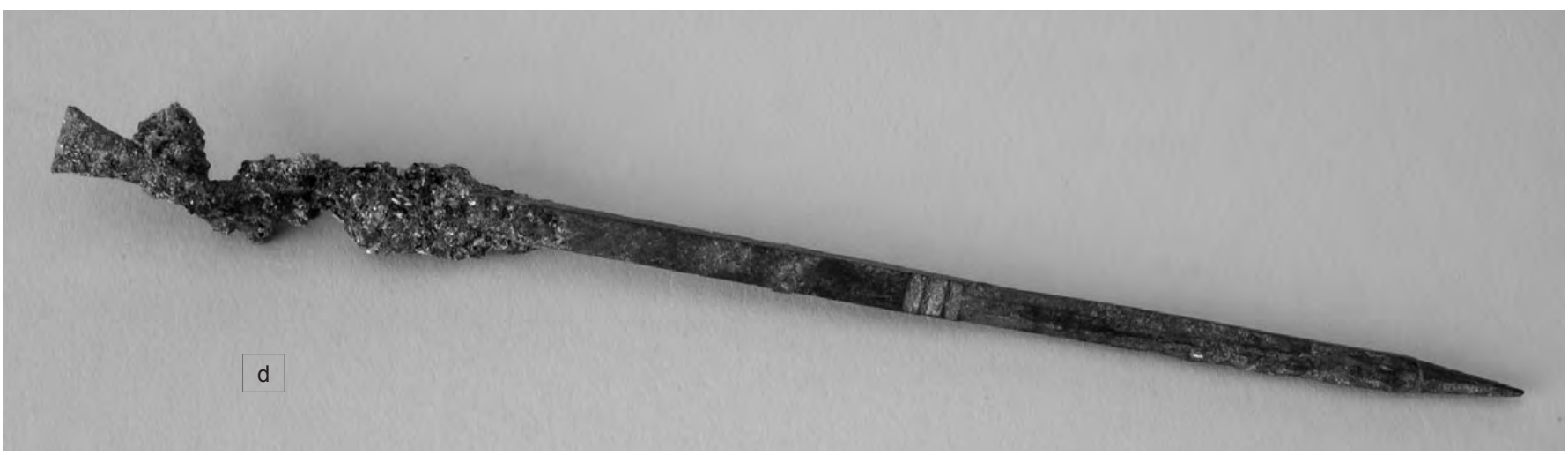




\section{PUBLICATIONS \\ DU CENTRE CAMILLE JULLIAN}

BIBLIOTHÈQUE D'ARCHÉOLOGIE MÉDITERRANÉENNE ET AFRICAINE (BIAMA)

Editions Errance, 7 rue Jean-du-Bellay, 75004 Paris.

http://www.librairie-epona.fr/

La BiAMA prend la suite des Travaux du Centre Camille Jullian

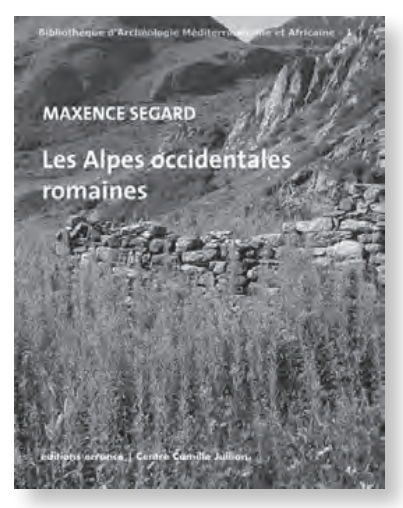

1. M. Segard, Les Alpes Occidentales à l'époque romaine, Développement urbain et exploitation des ressources des régions de montagne (Gaule Narbonnaise, Italie, provinces alpines), Paris 2009, $288 \mathrm{p}$.

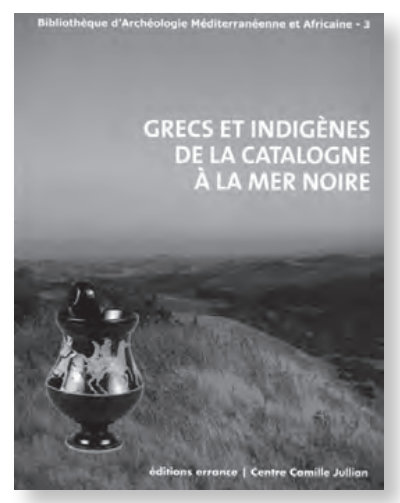

3. Grecs et indigènes de la Catalogne à la mer Noire, actes des rencontres du programme européen Ramses (2006-2008), édités par H. Tréziny, Paris 2010, 716 p.

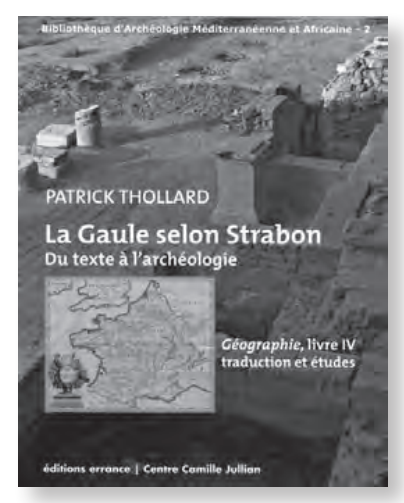

2. Patrick Thollard, La Gaule selon Strabon : du texte à l'archéologie (Géographie livre IV). Traduction et études, Paris 2009, 265 p.

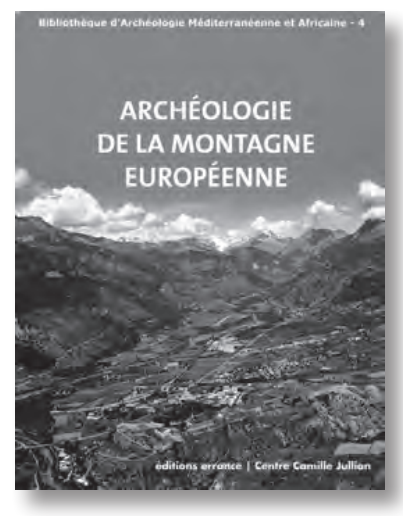

4. Archéologie de la montagne européenne. Actes de la table ronde internationale de Gap (29 septembre-1er octobre 2008), textes réunis par Stéfan Tzortzis et Xavier Delestre, avec la collaboration de Jennifer Greck, Paris 2010, 333 p.

6. L. Rivet, Recherches archéologiques au coeur de Forum Iulii - Les fouilles dans le groupe épiscopal de Fréjus et à ses abords (1979-1989), Paris 2010, 420 p. 


\section{COLLECTION ÉTUDES MASSALIÈTES (EtMassa)}

1. Le territoire de Marseille grecque, actes de la table ronde d'Aix-en-Provence, 1985, édités par M. Bats et H. Tréziny, Université de Provence, Aix-en-Provence, 1986.

2. Les amphores de Marseille grecque, actes de la table ronde de Lattes, 1988, édités par M. Bats, Université de Provence/ADAM éditions, Aix-en-Provence/Lattes, 1990.

3. Marseille grecque et la Gaule, actes des colloques de Marseille et Aix-en-Provence, 1990, édités par M. Bats, G. Bertucchi, G. Congès, H. Tréziny, Université de Provence / ADAM éditions, Aix-enProvence / Lattes, 1992.

4. Sur les pas des Grecs en Occident. Hommages à André Nickels, édités par P. Arcelin, M. Bats, G. Marchand, M. Schwaller, éditions Errance / ADAM éditions, Paris-Lattes 1995.

5. Fouilles à Marseille. Les mobiliers ( ${ }^{e r}$ - VII ${ }^{e}$ S. ap. J.-C.), vol. collectif sous la direction de M. Bonifay, M.-Br. Carre et Y. Rigoir, éditions Errance / ADAM éditions, Paris-Lattes 1998.

6. Les cultes des cités phocéennes, actes du coll. d'Aix-en-Provencel Marseille, juin 1999, édités par A. Hermary et H. Tréziny, Édisud/Centre C. Jullian, Aix-en-Provence, 2000.

7. Marseille. Trames et paysages urbains de Gyptis au Roi René, Actes du colloque international d'archéologie, Marseille, 3-5 novembre1999, textes réunis et édités par M. Bouiron et H. Tréziny, B. Bizot, A. Guilcher, J. Guyon et M. Pagni, Édisud/Centre C. Jullian, Aix-en-Provence, 2001.

8. La nécropole de Sainte-Barbe à Marseille (IV s. av. J.-C. - II e s. ap. J.-C.), vol. collectif sous la direction de M. Moliner, Édisud/Centre C. Jullian, Aix-en-Provence, 2003.

9. Olbia de Provence à l'époque romaine, vol. collectif sous la direction de Michel Bats, Édisud/Centre C. Jullian, Aix-en-Provence, 2007.

REVUE ANTIQUITÉS AFRICAINES,

CNRS Editions, 15 rue Malebranche, 75005 Paris - http://www.cnrseditions.fr

Dernier volume paru, t. 44, 2008 [2010]

\section{COLLECTION}

ÉTUDES D'ANTIQUITÉS AFRICAINES

CNRS Editions, 15 rue Malebranche, 75005 Paris - http://www.cnrseditions.fr

Derniers volumes parus :

Liliane Ennabli, La basilique de Carthagenna et le locus des sept moines de Gafsa. Nouveaux édifices chrétiens de Carthage, 2000.

François Baratte, Janet Lang, Catherine Metzger et Susan La Niece, Le trésor de Carthage : contribution à l'étude de l'orfèvrerie de l'Antiquité tardive, 2002.

Nadine Labory, Inscriptions antiques du Maroc, 2. Inscriptions latines - Supplément, 2003.

Hédi Slim, Pol Trousset, Roland Paskoff et Ameur Oueslati, avec la collaboration de Michel Bonifay et Jean Lenne, Le littoral de la Tunisie. Étude géoarchéologique et historique, 2004.

Sabah Ferdi, Corpus des mosaïques de Cherchel, 2005.

Lieux de cultes : aires votives, temples, églises, mosquées. IXe Colloque international sur l'histoire et l'archéologie de l'Afrique du Nord antique et médiévale (Tripoli, 19-25 février 2005), 2008.

Jean-Marie Lassère, Maisons de Clupea. Exemples de l'architecture domestique dans un port de l'Afrique proconsulaire. Les maisons de l'Ecole de pêche, avec une étude de la céramique par Jean Piton (sous presse). 


\section{COLLECTION}

ARCHAEONAUTICA

CNRS Editions, 15 rue Malebranche, 75005 Paris - http://www.cnrseditions.fr

Derniers volumes parus :

14-1998, P. Pomey, E. Rieth (dir.) - Construction navale, maritime et fluviale. Approches archéologiques, historique et ethnologique Actes du Septième Colloque International d'Archéologie Navale - Proceedings of the Seventh International Symposium on Boat and ship Archaeology, Ile Tatihou 1994 (Saint-Vaastla-Hougue). 335 p. - ISBN 2-271-05640-3

15 - 2008, L'archéologie maritime et navale de la Préhistoire à l'époque contemporaine, Paris 2009.

\section{TRAVAUX DU CENTRE CAMILLE JULLIAN}

Derniers volumes parus :

24. B. Sabattini, dir. La céramique attique du IVe siècle en Méditerranée occidentale, Actes du Colloque International d'Arles (7-9 décembre 1995), Naples, Centre Jean Bérard, 2000 (= Collection du Centre Jean Bérard, 19).

25. J.-P Morel, C. Rondi-Costanzo et D. Ugolini, éd., Corallo di ieri, corallo di oggi, Actes du Colloque International du Centre Universitaire Européen pour les Biens Culturels, Ravello, Italie (13-15 décembre 1996), Bari, Edipuglia, 2000 (= CUEBC, Scienze e materiali del patrimonio culturale, 5).

26. P. Leveau et J.-P. Saquet, éd., Milieu et sociétés dans la Vallée des Baux. Études présentées au colloque de Mouriès. Montpellier, 2000 (= Suppl. 31 à la R.A.N.).

27. L. Rivet, D. Brentchaloff, S. Roucole, S. Saulnier, Atlas topographique des villes de Gaule méridionale 2. Fréjus, Montpellier, 2000 (= Suppl. 32 à la R.A.N.).

28. P. Lévêque et J.-P. Morel, dir., Céramiques hellénistiques et romaines. III, Paris, 2001.

29. Ph. Columeau, Alimentation carnée en Gaule du Sud: VII ${ }^{e}$ s. av. J.-C.-XIVE s., éditions Université de Provence, Aix-en-Provence 2002.

30. J.-P. Brun et Ph. Jockey, éd., TECHNAI. Techniques et sociétés en Méditerranée, Hommage à M.-Cl. Amouretti, Paris, Maisonneuve et Larose, 2001 (MMSH, coll. L'atelier méditerranéen), Aix-enProvence 2001.

Achevé d'imprimer en octobre 2010 par Corlet Imprimeur

à Condé-sur-Noireau

Dépôt légal : novembre 2010

$\mathrm{N}$ imprimeur :

Imprimé en France 